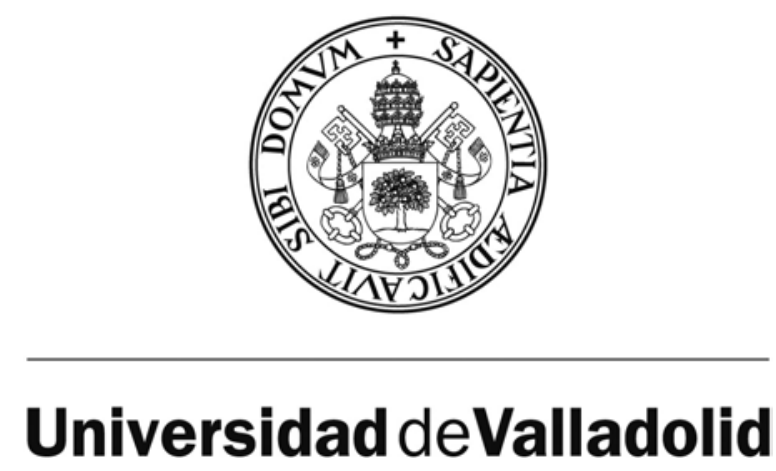

ESCUELA TÉCNICA SUPERIOR DE INGENIERÍAS AGRARIAS

DEPARTAMENTO DE INGENIERÍA AGRÍCOLA Y FORESTAL

TESIS DOCTORAL:

\title{
OPTIMIZACIÓN DEL RENDIMIENTO EN LOS SISTEMAS SOLARES TÉRMICOS MEDIANTE MODELOS NEURALES
}

Presentada por D. Francisco Javier Diez Morante para optar al grado de

doctor por la Universidad de Valladolid

Dirigida por:

Dr. Luis Manuel Navas Gracia

Dr. Andrés Martínez Rodríguez 



\section{RESUMEN}

Las energías renovables son inagotables y no contaminantes, distribuidas por amplias zonas, pudiéndose utilizar descentralizadamente, contribuyendo al autoabastecimiento e independencia energética, estimulan el desarrollo empresarial y empleo. Las energías convencionales se caracterizan por todo lo contrario son muy costosas ambiental, social y económicamente, además de bastante complejas técnicamente. La energía solar utiliza tecnologías de conversión muy flexibles y su desarrollo se puede realizar en distintas escalas, evitando su distribución y transporte.

En esta Tesis Doctoral se pretende conseguir una optimización en el rendimiento energético de los sistemas solares térmicos, respecto al obtenido mediante los métodos de diseño utilizados habitualmente.

El objetivo de esta Tesis Doctoral es desarrollar un modelo de simulación que, de manera general, permita reproducir el funcionamiento en pequeños intervalos y durante largos periodos de tiempo, de los componentes principales del sistema solar térmico, fundamentándose en la teoría del modelado de la predicción de las series de tiempo, formadas por datos procedentes de las medidas registradas durante su operación de la irradiancia solar y las temperaturas acaecidas en la instalación solar particular. Aplicada con la técnica de las redes neuronales artificiales, perteneciente al área de conocimiento de la inteligencia computacional. Y con un bajo coste en la obtención de los datos, así como de su tratamiento por personal no especialista en la materia.

El modelo propuesto simula la dinámica del funcionamiento de un sistema solar térmico en base a cuatro variables:

- La irradiancia solar que incide en el captador solar, estimada respecto el valor que se registra o se predice sobre la horizontal.

- La temperatura ambiente en el entorno del captador solar, que se registra o se predice para el día de mañana.

- El caudal de agua caliente solar de consumo que se estima para cada intervalo de tiempo en la simulación.

- La temperatura del agua de red que entra en el depósito acumulador, que se estima respecto a mediciones durante el año.

Los resultados de la simulación se comparan con el método f-chart, usado como referencia, en sus mismas condiciones de aplicación y teniendo en cuenta el efecto de la estratificación térmica en el depósito acumulador del cual se consigue una importante optimización del rendimiento en el sistema solar térmico.

Además se consigue identificar matemáticamente la evolución de las temperaturas de estratificación estática mediante la suma de dos curvas exponenciales. Se estudia y agrupa la metodología para la estimación de la irradiación solar incidente sobre el captador solar a partir de la recibida en la horizontal. Se desarrollan nuevos modelos de predicción de las variables ambientales a corto plazo. Y se encuentra un fallo en la aplicación actual del método f-chart, al utilizar los coeficientes de la ecuación característica del captador solar ensayado con un caudal del fluido portador distinto al especificado por el método, lo que ocasiona variaciones importantes en la cobertura solar resultante. 



\section{ABSTRACT}

Renewable energies are inexhaustible and non-polluting, distributed over wide areas and can be used in a decentralized, contributing to self-sufficiency and energy independence, stimulate business development and employment. Conventional energy sources are characterized by the opposite are costly environmentally, socially and economically as well as technically quite complex. Solar energy conversion technologies used very flexible and their development can be performed on different scales, avoiding their distribution and transport.

This Doctoral Thesis aims to achieve energy efficiency optimization of solar thermal systems, compared to that obtained by the methods commonly used design.

The aim of this Doctoral Thesis is to develop a simulation model that, in general, to reproduce the operation in small intervals and for long periods of time, the main components of solar thermal system, building on the theory of prediction modeling time series, consisting of data from the measurements recorded during operation of solar irradiance and temperatures in the solar system occurred particular. Applied with the technique of artificial neural networks, belonging to the area of computational intelligence knowledge. And with low cost in obtaining the data, and their treatment by non-specialist in the subject.

The proposed model simulates the dynamics of the operation of a solar thermal system based on four variables:

- The solar irradiance incident on the solar collector, estimated on the value that is recorded or is predicted above the horizontal.

- The environmental temperature of the solar collector, which is recorded or is predicted for tomorrow.

- The flow of solar hot water consumption is estimated for each time interval in the simulation.

- The mains water temperature entering the storage tank, estimated about measurements during the year.

The simulation results are compared with f-chart method, used as a reference in its conditions of application, taking into account the effect of thermal stratification in the accumulator tank which achieves significant performance optimization in the solar thermal system.

Identifying mathematically also achieving the evolution of the static temperature stratification by the sum of two exponential curves. And groups studied methodology for estimating the solar radiation incident on the solar collector received from the horizontal. You develop new models to predict the short-term environmental variables. And there is a bug in the current implementation of the f-chart method, using the coefficients of the characteristic equation tested solar collector with a flow rate of the carrier fluid not specified by the method, which causes significant variations in the resulting solar coverage. 

Hay personas que transforman el Sol en una simple mancha amarilla, pero hay también quien hace de una simple mancha amarilla el propio Sol. - Pablo Picasso 



\section{JUSTIFICACIÓN}

Los métodos de cálculo y simulación del funcionamiento de los sistemas solares térmicos, pueden obtener resultados más o menos precisos y detallados, en función de su complejidad, lo que repercute en su coste. Conseguir una metodología para la modelización de un sistema solar térmico, solamente a partir de los datos medidos durante su actividad de los valores de la irradiancia solar y las temperaturas. Resulta muy interesante, debido a su bajo coste y además de que se obtiene un informe actualizado de las condiciones específicas de cada instalación solar.

Con una simulación detallada se puede estimar de una forma más precisa el rendimiento del sistema solar térmico, ya sea con datos medidos y registrados de su funcionamiento, o generados por otros métodos para cada componente, pudiéndose utilizar para el diseño.

Al variar la cantidad de agua caliente solar consumida en función de unas predicciones climatológicas para el día de mañana, puede lograrse una optimización del rendimiento del sistema solar térmico, además de tener en cuenta el efecto de la estratificación térmica del agua caliente solar en el depósito acumulador.

Esta metodología puede aplicarse a otros sistemas de energías renovables como los eólicos o fotovoltaicos. Además de reforzar las investigaciones llevadas a cabo para el modelado neural de los componentes de otros tipos de sistemas.

Los beneficios de esta investigación pueden llegar a cualquier técnico o ingeniero que con una muestra de datos representativos del funcionamiento en un sistema solar térmico, pueden crear modelos neuronales de los componentes y simular el rendimiento del sistema completo, buscando las condiciones más idóneas para cada caso. 

Si tuviese que elegir una religión, el Sol como fuente universal de vida sería mi dios.- Napoleón 



\section{ÍNDICE}

\begin{tabular}{|c|c|c|}
\hline \multicolumn{2}{|r|}{ Capítulo 1 INTRODUCCIÓN, OBJETIVOS, ESTRUCTURA Y CONTENIDO DE LA TESIS DOCTORAL } & 1:1 \\
\hline 1.1 & 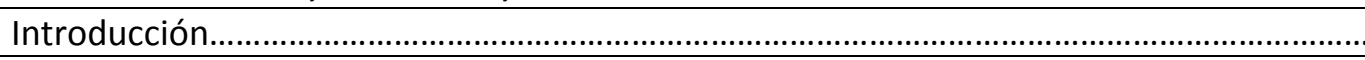 & $.1: 2$ \\
\hline 1.2 & Objetivos de la Tesis Doctoral...................... & \\
\hline 1.3 & Estructura y contenido de la Tesis Doctoral. & $.1: 6$ \\
\hline
\end{tabular}

Capítulo 2 ESTADO DEL ARTE $\quad 2: 1$

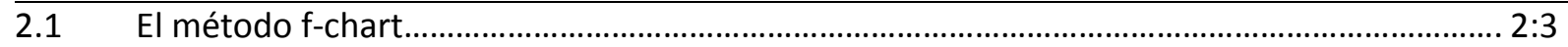

2.1.1 Modelado y simulación de los sistemas solares térmicos............................................. 2:5

2.2 Predicción de las variables ambientales: irradiación solar y temperatura ambiente.............. 2:8

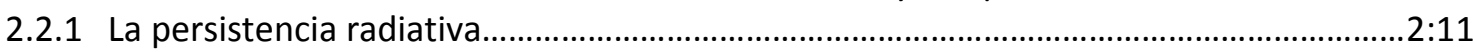

2.2.2 Validación y rendimiento de los modelos.................................................................. 2:13

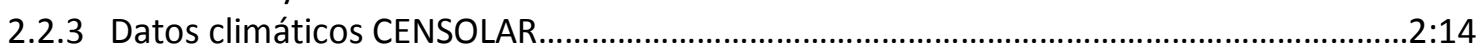

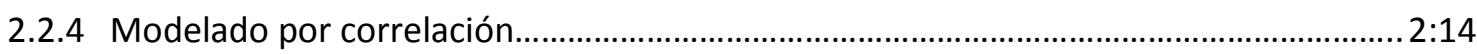

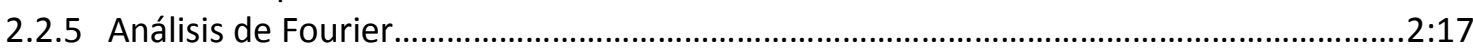

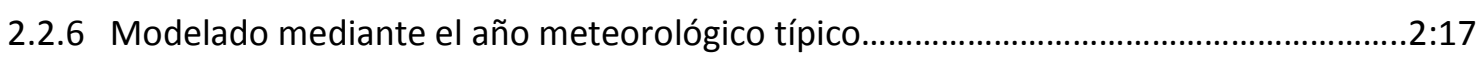

2.2.7 Modelado por satélites artificiales............................................................................... 2:21

2.2.8 La estimación y la predicción de la irradiación solar mediante la inteligencia

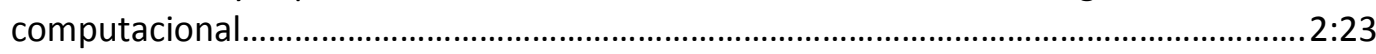

2.2.9 La predicción de la irradiación solar global diaria a partir de la temperatura diaria.... 2:31

$2.3 \quad$ Estimación de la irradiación solar incidente sobre un plano inclinado y orientado..................2:34

2.3.1 La irradiación solar difusa horizontal............................................................................. 2:37

2.3.2 Los componentes de la irradiación solar sobre un plano inclinado................................. 2:40

2.3.3 La irradiación solar global incidente sobre un plano inclinado....................................... 2:44

$2.4 \quad$ Modelado de los componentes de un sistema solar térmico....................................................2:45

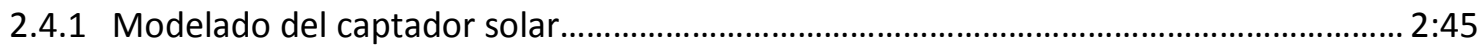

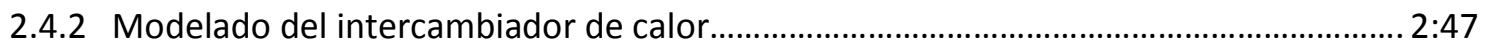

2.4.3 Modelado de la estratificación térmica en el depósito....................................................2:50

2.5 Las series de tiempo en la inteligencia computacional. Marco teórico...................................... 2:63

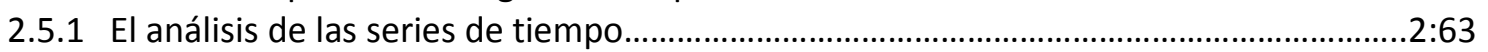

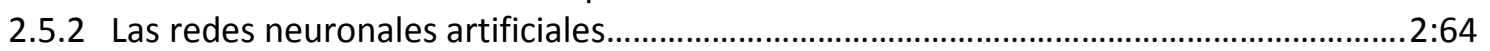

2.5.3 La inteligencia computacional en el modelado....................................................... 2:76

\begin{tabular}{|c|c|c|}
\hline Capí & o 3 MATERIALES Y METODOLOGÍA & $3: 1$ \\
\hline 3.1 & Descripción técnica de la planta pilo & $3: 3$ \\
\hline
\end{tabular}

3.2.1 Modelado de los componentes del circuito primario del sistema solar térmico en el método f-chart............................................................................................................. 3:10

3.2.2 El método f-chart para sistemas solares térmicos con fluido portador líquido..............3:16 
3.2.3 Resultados en la aplicación del método f-chart.............................................................2:22

$3.3 \quad$ Herramienta para la implementación de las redes neuronales artificiales............................... 3:24

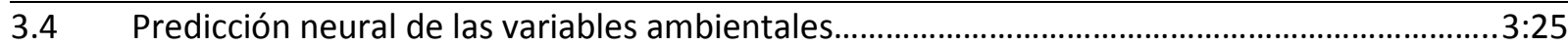

3.4.1 La predicción de la irradiación solar global diaria del día de mañana mediante redes neuronales artificiales.

3.4.2 La predicción de la irradiación solar global diaria del día de mañana a partir de la temperatura ambiente mediante redes neuronales artificiales.

3.4.3 La predicción de las temperaturas media, máxima y mínima diaria del día de mañana mediante redes neuronales artificiales.

3.4.4 Estimación de la irradiancia solar horaria media a partir de la irradiación solar global diaria mediante redes neuronales artificiales

3.4.5 Estimación de la temperatura media horaria a partir de las temperaturas media, máxima y mínima diaria mediante redes neuronales artificiales.................................. 3:39

3.5 Estimación de la irradiación solar sobre el plano inclinado y orientado.......................................42

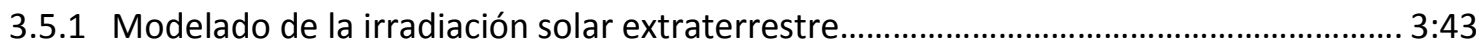

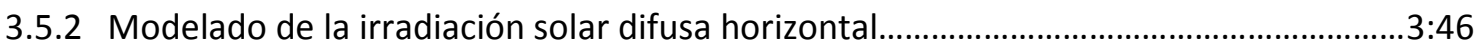

3.5.3 Modelado de la altura solar y el ángulo zenit............................................................... 3:46

3.5.4 Modelado del ángulo de incidencia de la irradiación solar sobre el captador................3:46

3.6 Modelado neural de los componentes del sistema solar térmico............................................ 3:48

3.6.1 Modelado del captador solar con redes neuronales artificiales.................................... 3:48

3.6.2 Modelado del intercambiador de calor con redes neuronales artificiales..................... 3:49

3.6.3 Modelado de la estratificación térmica del agua caliente solar en el depósito acumulador con redes neuronales artificiales................................................................. $3: 51$

$3.7 \quad$ Simulación neural del sistema solar térmico.......................................................................... 3:56

3.8 Optimización del rendimiento en el sistema solar térmico........................................................ 3:62

Capítulo 4 RESULTADOS Y PRESENTACIÓN DE LOS DATOS $\quad$ 4:1

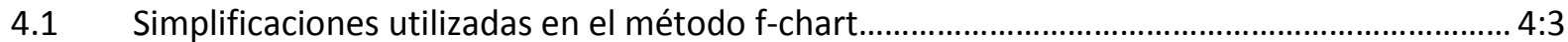

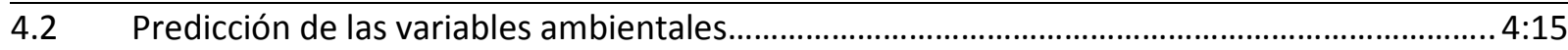

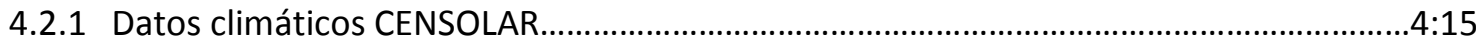

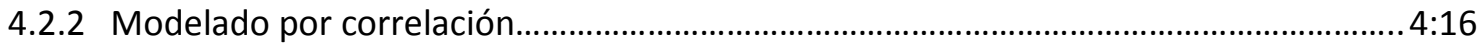

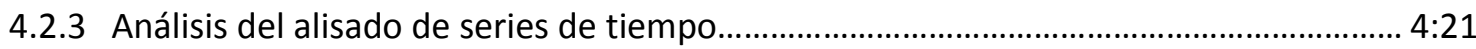

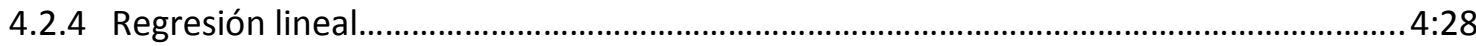

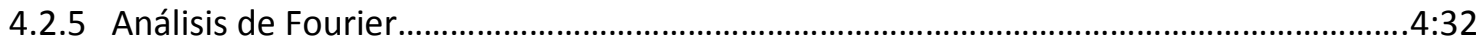

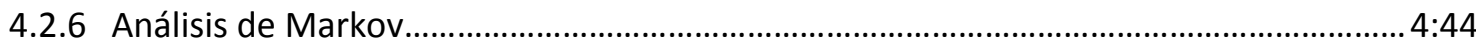

4.2.7 Estimación de la temperatura media horaria con el método ASHRAE.............................4:48

$4.3 \quad$ Modelado de los componentes del circuito primario.............................................................4:49

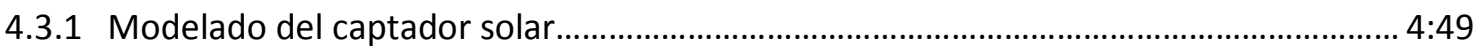

4.3.2 Modelado del intercambiador de calor................................................................................. 4:55

4.4 Predicción neural de las variables ambientales...........................................................................4:60

4.4.1 Resultados de la predicción de la irradiación solar global diaria.................................... 4:61

4.4.2 La predicción de la irradiación solar global diaria del día de mañana a partir de la temperatura ambiente mediante redes neuronales artificiales..................................... 4:73

4.4.3 La predicción de las temperaturas media, máxima y mínima diaria del día de mañana mediante redes neuronales artificiales............................................................. 4:80

4.4.4 Resultado de la estimación de la irradiancia solar horaria media a partir de la irradiación solar global diaria mediante redes neuronales artificiales.

4.4.5 Resultados de la estimación de la temperatura media horaria a partir de las temperaturas media, máxima y mínima mediante redes neuronales artificiales......... 4:86

4.5 Estimación de la irradiación solar sobre el plano inclinado y orientado..................................... 4:89

4.5.1 Resultado del modelado de la irradiación solar extraterrestre........................................4:89 
4.5.2 Resultado del modelado de la irradiación solar difusa horizontal.

4.5.3 Resultado del cálculo de la altura solar horaria en la latitud $42^{\circ}$ Norte y la longitud $5,6^{\circ}$ Oeste.

4.5.4 Resultado del cálculo del ángulo de incidencia horario sobre un captador inclinado $45^{\circ}$ en la latitud $42^{\circ}$ y longitud $5,6^{\circ}$ Oeste.

4.5.5 Resultados obtenidos de la irradiación solar sobre el captador solar.............................4:97

4.6 Modelado neural de los componentes del sistema solar térmico........................................... 4:100

4.6.1 Resultado del modelado del captador solar con redes neuronales artificiales.............. 4:100

4.6.2 Resultado del modelado del intercambiador de calor con redes neuronales artificiales.

4.6.3 Resultado del modelado de la estratificación térmica del depósito acumulador de agua caliente con redes neuronales artificiales.............................................................106

$4.7 \quad$ Simulación neural del sistema solar térmico................................................................................ 4:113

4.7.1 Resultado de la simulación del sistema solar térmico el día 10-10-2011 en León......... 4:114

4.7.2 Resultado de la simulación del sistema solar térmico el día 28-11-2011 en León......... 4:116

4.7.3 Resultado de la simulación del sistema solar térmico mensualmente durante diez años en León.

$4: 118$

$4.8 \quad$ Optimización del rendimiento en los sistemas solares térmicos................................................. 4:133

\begin{tabular}{|c|c|}
\hline apít & 5 ANÁLISIS Y DISCUSIÓN DE LOS RESULTADOS \\
\hline .1 & 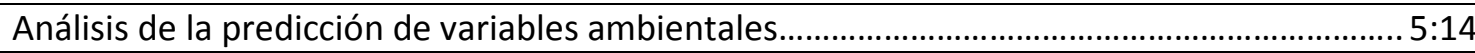 \\
\hline .2 & Análisis de la estimación de irradiación solar sobre el plano inclinado......................................26 \\
\hline 5.3 & omponentes del sistema solar térmico.......................... 5:29 \\
\hline 4 & Análisis sobre la simulación neural del sistema solar térmico............................................... 5:35 \\
\hline & $\begin{array}{l}\text { Análisis de la optimización del rendimiento mediante la distribución del consumo } \\
\text { respecto a la energía solar disponible............................................................ } 5: 41\end{array}$ \\
\hline
\end{tabular}

Capítulo 6 CONCLUSIONES

A.1.1 Estación meteorológica SIAR en Mansilla Mayor (León).............................................................1:2

A.1.2 Datos de irradiación solar SIAR en Mansilla Mayor (León)..........................................................1:5

A.1.3 Datos de temperatura ambiente SIAR en Mansilla Mayor (León)............................................. A.1:11

A.1.4 Datos de irradiación solar CENSOLAR en León............................................................................. A.1:17

A.1.5 Datos de temperatura ambiente CENSOLAR en León..................................................................1:17

Anexo 2 DATOS DE LOS ENSAYOS EN LA PLANTA PILOTO A.2:1

A.2.1 Datos del ensayo en la planta piloto del día: 1-7-2011..................................................... A.2:2

A.2.2 Datos del ensayo en la planta piloto del día: 4-7-2011............................................................. A.2:3

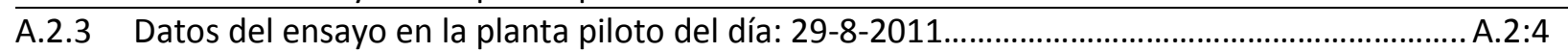

A.2.4 Datos del ensayo en la planta piloto del día: 7-9-2011 ............................................................ A.2:5

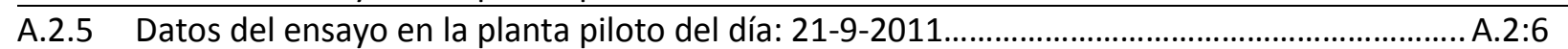

A.2.6 Datos del ensayo en la planta piloto del día: 4-10-2011 .................................................... A.2:7

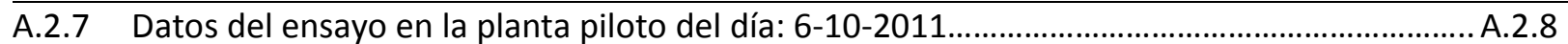

A.2.8 Datos del ensayo en la planta piloto del día: 10-10-2011.................................................. A.2:9

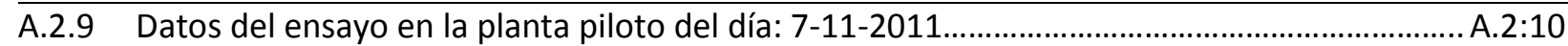

A.2.10 Datos del ensayo en la planta piloto del día: 28-11-2011 .................................................. A.2:11

A.2.11 Datos del ensayo en la planta piloto del día: 9-3-2012 ....................................................... A.2:12 


\section{ÍNDICE DE FIGURAS}

(Fig. Capítulo/Anexo.Apartado.Número)

(Capítulo/Anexo:Página)

\section{Capítulo 2}

Fig. 2.5.1 Número de neuronas en la entrada para la predicción de un paso por delante (Palit

y Popovic, 2005).................................................................................................... 2:68

\section{Capítulo 3}

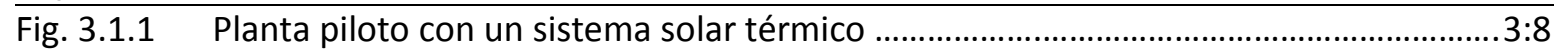

Fig. 3.1.2 Esquema de conexionado del sistema solar térmico de la planta piloto.......................3:9

Fig. 3.2.1 Ecuación característica del captador solar de la planta piloto resultado de los datos del ensayo en el día 4-7-2011: $\eta=0,64-5,4\left(\frac{T_{e}-T_{a}}{i}\right)$.......

Fig. 3.2.2 Sistema solar térmico con fluido portador líquido y el depósito mezclado (Duffie y Beckman, 2006).................................................................................................................18

Fig. 3.2.3 Las curvas-f para sistemas solares térmicos con fluido portador líquido y el depósito mezclado (Duffie y Beckman, 2006).............................................................. 3:19

Fig. 3.2.4 Resultados de la aplicación del método f-chart en distintas condiciones.................... 3:23

Fig. 3.4.1 Modelo de predicción de la irradiancia solar horaria sobre la horizontal para el día de mañana, a partir de la irradiación solar global diaria del día de hoy y el día del año sobre el que se realiza la predicción.

Fig. 3.4.2 Red neuronal artificial utilizada para la predicción de la irradiación solar global diaria del día de mañana respecto al valor del día anterior.

Fig. 3.4.3 Red neuronal artificial utilizada para la predicción de la irradiación solar global diaria del día de mañana respecto al valor de los dos días anteriores.

Fig. 3.4.4 Red neuronal artificial utilizada para la predicción de la irradiación solar global diaria del día de mañana respecto al valor de los tres días anteriores.

Fig. 3.4.5 Red neuronal artificial utilizada para la predicción de la irradiación solar global diaria del día de mañana respecto al valor del día anterior y el día del año

Fig. 3.4.6 Red neuronal artificial utilizada para la predicción de la irradiación solar global diaria del día de mañana respecto al valor de los dos días anteriores y el día del año.

Fig. 3.4.7 Red neuronal artificial utilizada para la predicción de la irradiación solar global diaria del día de mañana respecto al valor de los tres días anteriores y el día del año.

Fig. 3.4.8 Red neuronal artificial utilizada para la predicción de la irradiación solar global diaria del día de mañana respecto al valor del día anterior y el índice de claridad.

Fig. 3.4.9 Red neuronal artificial utilizada para la predicción de la irradiación solar global diaria del día de mañana respecto al valor del día anterior, su índice de claridad y el día del año. 
Fig. 3.4.10 Red neuronal artificial utilizada para la predicción de la irradiación solar global diaria del día de mañana respecto al valor de la temperatura media diaria del día anterior.

Fig. 3.4.11 Red neuronal artificial utilizada para la predicción de la irradiación solar global diaria del día de mañana respecto al valor de la temperatura máxima y mínima diaria del día anterior.

Fig. 3.4.12 Red neuronal artificial utilizada para la predicción de la irradiación solar global diaria del día de mañana respecto al valor de la temperatura media, máxima y mínima diaria del día anterior.

Fig. 3.4.13 Red neuronal artificial utilizada para la predicción de la irradiación solar global diaria del día de mañana respecto al valor de la temperatura media diaria y el día del año anterior

Fig. 3.4.14 Red neuronal artificial utilizada para la predicción de la irradiación solar global diaria del día de mañana respecto al valor de la temperatura máxima y mínima diaria y el día del año anterior.

Fig. 3.4.15 Red neuronal artificial utilizada para la predicción de la irradiación solar global diaria del día de mañana respecto al valor de la temperatura media, máxima y mínima diaria y el día del año anterior...

Fig. 3.4.16 Red neuronal artificial para la predicción de las temperaturas media, máxima y mínima diaria del día de mañana respecto a los valores del día anterior.

Fig. 3.4.17 Red neuronal artificial para la predicción de las temperaturas media, máxima y mínima diaria del día de mañana respecto a los valores del día anterior y del día del año.

Fig. 3.4.18 Red neuronal artificial utilizada para la estimación de la irradiancia solar horaria respecto a la irradiación solar global diaria del mismo día.....

Fig. 3.4.19 Red neuronal artificial utilizada para la estimación de la irradiancia solar horaria respecto a la irradiación solar global diaria y el día del año del mismo día.

Fig. 3.4.20 Red neuronal artificial utilizada para la estimación de la temperatura media horaria respecto a las temperaturas media, máxima y mínima diaria del mismo día. 3:40

Fig. 3.4.21 Red neuronal artificial utilizada para la estimación de la temperatura media horaria respecto a las temperaturas media, máxima y mínima diaria y el día del año del mismo día.

Fig. 3.5.1 Módulo para la conversión de los valores medidos de irradiación global sobre una superficie horizontal a los calculados que recibe un plano inclinado........................... 3:43

Fig. 3.6.1 Estructura de la red neuronal artificial diseñada para la predicción de la temperatura de ida del captador solar, respecto de la irradiancia solar incidente, la temperatura ambiente, la temperatura y caudal del fluido portador de retorno al captador solar.

Fig. 3.6.2 Estructura de la red neuronal artificial diseñada para la predicción de la temperatura de retorno al captador solar, respecto de las temperaturas de estratificación del depósito, la temperatura y caudal del fluido portador de ida del captador solar.

Fig. 3.6.3 Estructura de la red neural artificial diseñada para la predicción de las temperaturas de la estratificación del depósito, respecto a la temperatura de ida y el caudal del fluido portador en el circuito primario y las temperaturas de estratificación en el lapso de tiempo anterior.

Fig. 3.6.4 Estructura de la red neuronal artificial diseñada para la predicción de las temperaturas de la estratificación del depósito, respecto a la temperatura de ida y el caudal del fluido portador en el circuito primario, las temperaturas de estratificación, el caudal de agua caliente solar consumida y la temperatura del agua de red en el lapso de tiempo anterior... 
Fig. 3.6.5 Estructura de la red neural artificial diseñada para la predicción de las temperaturas de la estratificación del depósito, respecto a las temperaturas de estratificación en el lapso de tiempo anterior.

Fig. 3.6.6 Estructura de la red neuronal artificial diseñada para la predicción de las temperaturas de la estratificación del depósito, respecto a las temperaturas de estratificación, el caudal de agua caliente solar consumida y la temperatura del agua de red en el lapso de tiempo anterior...

Fig. 3.7.1 Modelado de la planta piloto desarrollado en Simulink con los modelos de redes neuronales artificiales.

Fig. 3.7.2 Bloque consigna irradiancia solar.............................................................................. 3:58

Fig. 3.7.3 Bloque estado inicial, realimentación estratificación depósito.......................................3:58

Fig. 3.7.4 Módulo de predicción de la estratificación en el estado NOCHE, con una RNA entrenada para lapsos de tiempo de 10 minutos y realiza una interpolación del resultado a un lapso de tiempo de un minuto.

\section{Capítulo 4}

Fig. 4.1.1 Resultados del método f-chart aplicado a la planta piloto para un consumo de 75 $\mathrm{l} / \mathrm{d}$ a $50^{\circ} \mathrm{C}$, con datos de irradiación solar y temperatura ambiente diarios medios mensuales de CENSOLAR y la base de datos SIAR en Mansilla Mayor (León) para cada año.

Fig. 4.1.2 Datos del ensayo realizado al captador solar de la planta piloto el día 1-7-2011 y la ecuación característica cuadrática: $\eta=0,71-6,4\left(\frac{T_{m}-T_{a}}{i}\right)+8,6\left(\frac{T_{m}-T_{a}}{i}\right)^{2}$.

Fig. 4.1.3.a Ecuación característica respecto a la temperatura de entrada al captador resultado del ensayo en el día 29-8-2011: $\eta=0,66-7,7\left(\frac{T_{e}-T_{a}}{i}\right)$.

Fig. 4.1.3.b Ecuación característica respecto a la temperatura media del captador resultado del ensayo en el día 29-8-2011: $\eta=0,69-7,8\left(\frac{\mathrm{T}_{\mathrm{m}}-\mathrm{T}_{\mathrm{a}}}{\mathrm{i}}\right)$.

Fig. 4.1.3.c Ecuación característica respecto a la temperatura de salida del captador resultado del ensayo en el día 29-8-2011: $\eta=0,72-8,1\left(\frac{T_{s}-T_{a}}{i}\right)$.

Fig. 4.1.4 Ensayos realizados con el captador solar de la planta piloto al variar el caudal en 1, 1,6 y $2 \mathrm{l} / \mathrm{min}$ y ecuación característica del captador resultante: $\eta=0,46-2,6\left(\frac{\mathrm{T}_{\mathrm{e}}-\mathrm{T}_{\mathrm{T}}}{\mathrm{I}}\right) \ldots . . .4: 10$

Fig. 4.1.5.a Ecuación característica resultante de los ensayos realizados con la planta piloto a un caudal de $2 \mathrm{l} / \mathrm{min}: \eta=0,61-4,2\left(\frac{T_{e}-T_{a}}{i}\right)$

Fig. 4.1.5.b Ecuación característica resultante de los ensayos realizados con la planta piloto a un caudal de 1,6 I/min: $\eta=0,46-2,3\left(\frac{T_{e}-T_{a}}{\dot{I}}\right)$.

Fig. 4.1.5.c Ecuación característica resultante de los ensayos realizados con la planta piloto a

Fig. 4.1.6.a Ecuación característica del captador resulta

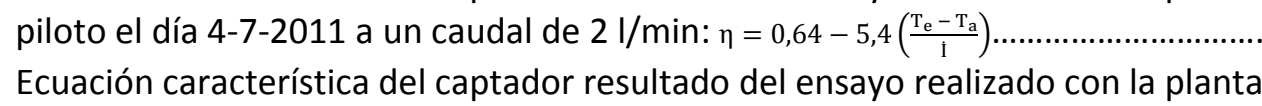

Fig. 4.1.6.a Ecuación característica del captador resultado del ensayo realizado con la planta

Fig. 4.1.6.b Ecuación característica del captador resultado del ensayo realizado con la planta piloto el día 1-7-2011 a un caudal de 1,6 $\mathrm{l} / \mathrm{min}: \eta=0,5-3,5\left(\frac{\mathrm{T}_{e}-\mathrm{T}_{a}}{\mathrm{i}}\right)$.

Ecuación característica del captador resultado del ensayo realizado con la planta

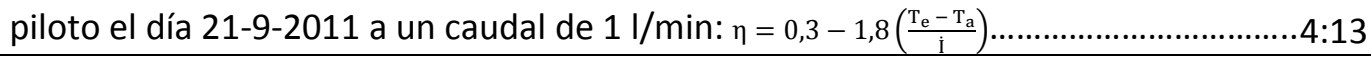

Fig. 4.2.1 Datos de irradiación solar global diaria SIAR en Mansilla Mayor (León), valores recomendados para la provincia de León por CENSOLAR y el error producido...

Fig. 4.2.2 Datos de temperatura ambiente media diaria SIAR en Mansilla Mayor (León), valores recomendados para la provincia de León por CENSOLAR y el error producido.

Fig. 4.2.3 Coeficientes de autocorrelación parcial de la serie de datos de irradiación solar global diaria para retardos de tiempo de 1 a 20 días, SIAR en Mansilla Mayor (León)...... 
Fig. 4.2.4 Coeficientes de autocorrelación parcial de la serie de datos de temperatura media diaria para retardos de tiempo de 1 a 20 días, SIAR en Mansilla Mayor (León)

Fig. 4.2.5 Coeficientes de autocorrelación parcial de la serie de datos de temperatura máxima diaria para retardos de tiempo de 1 a 20 días, SIAR en Mansilla Mayor (León).

Fig. 4.2.6 Coeficientes de autocorrelación parcial de la serie de datos de temperatura mínima diaria para retardos de tiempo de 1 a 20 días, SIAR en Mansilla Mayor (León).

Fig. 4.2.7 Datos de la irradiación solar global del año 2011 SIAR en Mansilla Mayor (León), valores resultado de la predicción realizada con la media móvil ponderada de 2 días de retardo y el error producido para cada día del año...

Fig. 4.2.8 Datos de la irradiación solar global del año 2011 SIAR en Mansilla Mayor (León), valores resultado de la predicción realizada con la media móvil ponderada de 11 días de retardo y el error producido para cada día del año.

Fig. 4.2.9 RMSE del error producido por la media móvil ponderada de 2 a 20 días de retardo, en la predicción de la serie de los datos de la irradiación solar global diaria, para el año 2011 SIAR en Mansilla Mayor (León).

Fig. 4.2.10 Datos de la temperatura media diaria del año 2011 SIAR en Mansilla Mayor (León), valores resultado de la predicción realizada con la media móvil ponderada de 2 días de retardo y el error producido para cada día del año.

Fig. 4.2.11 Datos de la temperatura media diaria del año 2011 SIAR en Mansilla Mayor (León), valores resultado de la predicción realizada con la media móvil ponderada de 5 días de retardo y el error producido para cada día del año.

Fig. 4.2.12 Datos de la temperatura máxima diaria del año 2011 SIAR en Mansilla Mayor (León), valores resultado de la predicción realizada con la media móvil ponderada de 2 días de retardo y el error producido para cada día del año.

Fig. 4.2.13 Datos de la temperatura máxima diaria del año 2011 SIAR en Mansilla Mayor (León), valores resultado de la predicción realizada con la media móvil ponderada de 5 días de retardo y el error producido para cada día del año.

Fig. 4.2.14 Datos de la temperatura mínima diaria del año 2011 SIAR en Mansilla Mayor (León), valores resultado de la predicción realizada con la media móvil ponderada de 2 días de retardo y el error producido para cada día del año.

Fig. 4.2.15 Datos de la temperatura mínima diaria del año 2011 SIAR en Mansilla Mayor (León), valores resultado de la predicción realizada con la media móvil ponderada de 5 días de retardo y el error producido para cada día del año.

Fig. 4.2.16 RMSE del error producido por la media móvil ponderada de 2 a 20 días de retardo, en la predicción de la serie de los datos de las temperaturas media, máxima y mínima diaria, para el año 2011 SIAR en Mansilla Mayor (León).

Fig. 4.2.17 Ecuación de la regresión lineal con un día de retardo, resultado de los datos de la irradiación solar global diaria de los años 2004-2010 SIAR en Mansilla Mayor (León)4:28

Fig. 4.2.18 Datos de la irradiación solar global diaria del año 2011 SIAR en Mansilla Mayor (León), valores resultado de la predicción realizada con la regresión lineal de un día de retardo y el error producido para cada día del año.

Fig. 4.2.19 Ecuación de la regresión lineal con un día de retardo, resultado de los datos de la temperatura media diaria de los años 2004-2010 SIAR en Mansilla Mayor (León)..... 4:30

Fig. 4.2.20 Datos de la temperatura media diaria del año 2011 SIAR en Mansilla Mayor (León), valores resultado de la predicción realizada con la regresión lineal de un día de retardo y el error producido para cada día del año.

Fig. 4.2.21 Datos de la irradiación solar global diaria del año 2004 al 2010 SIAR en Mansilla Mayor (León), función anual típica del primer armónico y error producido 4:33 
Fig. 4.2.22 Datos de la irradiación solar global diaria del año 2011 SIAR en Mansilla Mayor (León), función anual típica del primer al octavo armónico y error producido para cada día del año.

Fig. 4.2.23 Datos de la temperatura media diaria del año 2004 al 2010 SIAR en Mansilla Mayor (León), función anual típica del primer armónico y error producido..

Fig. 4.2.24 Datos de la temperatura media diaria del año 2011 SIAR en Mansilla Mayor (León), función anual típica del primer al octavo armónico y error producido para cada día del año.

Fig. 4.2.25 Datos de la temperatura máxima diaria del año 2004 al 2010 SIAR en Mansilla Mayor (León), función anual típica del primer armónico y error producido

Fig. 4.2.26 Datos de la temperatura máxima diaria del año 2011 SIAR en Mansilla Mayor (León), función anual típica del primer al octavo armónico y error producido para cada día del año.

Fig. 4.2.27 Datos de la temperatura mínima diaria del año 2004 al 2010 SIAR en Mansilla Mayor (León), función anual típica del primer armónico y error producido

Fig. 4.2.28 Datos de la temperatura mínima diaria del año 2011 SIAR en Mansilla Mayor (León), función anual típica del primer al octavo armónico y error producido para cada día del año.

Fig. 4.2.29 Datos de la irradiación solar global diaria del año 2011 SIAR en Mansilla Mayor (León), valores resultado de la predicción realizada con la matriz de transición de Markov y el error producido para cada día del año.

Fig. 4.2.30 Datos de la temperatura media horaria SIAR en Mansilla Mayor (León) y valor resultado de la estimación realizada con el método ASHRAE para los días 10, 11,

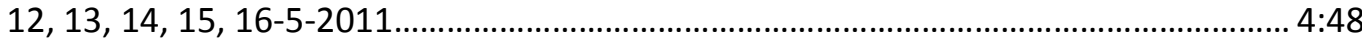

Fig. 4.3.1 Modelado del captador solar según EN 12975, resultados obtenidos con los datos registrados cada minuto en los ensayos de la planta piloto y curva CENER a 800 $\mathrm{W} / \mathrm{m}^{2}$ de irradiancia solar media...

Fig. 4.3.2 Modelado del captador solar según EN 12975, resultados obtenidos con los datos registrados cada minuto en el ensayo de la planta piloto del día 1-7-2011 y curva CENER a $800 \mathrm{~W} / \mathrm{m}^{2}$ de irradiancia solar media.

Fig. 4.3.3 Modelado del captador solar según EN 12975, resultados obtenidos con los datos registrados cada minuto en el ensayo de la planta piloto del día 7-11-2011 y curva CENER a $800 \mathrm{~W} / \mathrm{m}^{2}$ de irradiancia solar media.

Fig. 4.3.4.a Modelado del captador con los datos registrados cada minuto en el ensayo de la planta piloto del día 7-9-2011 (Fig. A.2.4) con un caudal de 2 l/min, resultados obtenidos del balance energético y resultados de la ecuación CENER a $800 \mathrm{~W} / \mathrm{m}^{2}$ de irradiancia solar media.

Fig. 4.3.4.b Modelado del captador con los datos registrados cada minuto en el ensayo de la planta piloto del día 1-7-2011 (Fig. A.2.1) con un caudal de 1,6 I/min, resultados obtenidos del balance energético y resultados de la ecuación CENER a $800 \mathrm{~W} / \mathrm{m}^{2}$ de irradiancia solar media.

Fig. 4.3.4.c Modelado del captador con los datos registrados cada minuto en el ensayo de la planta piloto del día 21-9-2011 (Fig. A.2.5) con un caudal de $1 \mathrm{l} / \mathrm{min}$, resultados obtenidos del balance energético y resultados de la ecuación CENER a $800 \mathrm{~W} / \mathrm{m}^{2}$ de irradiancia solar media.....

Fig. 4.3.5.a Modelado del intercambiador con los datos registrados cada minuto en el ensayo de la planta piloto del día 7-9-2011 (Fig. A.2.4) con un caudal de $2 \mathrm{l} / \mathrm{min}$.

Fig. 4.3.5.b Eficiencia energética del intercambiador con los datos registrados cada minuto en el ensayo de la planta piloto del día 7-9-2011 (Fig. A.2.4) con un caudal de 2 l/min...4:57

Fig. 4.3.6.a Modelado del intercambiador con los datos registrados cada minuto en el ensayo de la planta piloto del día 1-7-2011 (Fig. A.2.1) con un caudal de 1,6 I/min. $. .4: 58$ 
Fig. 4.3.6.b Eficiencia energética del intercambiador con los datos registrados cada minuto en el ensayo de la planta piloto del día 1-7-2011 (Fig. A.2.1) con un caudal de 1,6 $\mathrm{I} / \mathrm{min}$

Fig. 4.3.7.a Modelado del intercambiador con los datos registrados cada minuto en el ensayo de la planta piloto del día 21-9-2011 (Fig. A.2.5) con un caudal de $1 \mathrm{l} / \mathrm{min}$

Fig. 4.3.7.b Eficiencia energética del intercambiador con los datos registrados cada minuto en el ensayo de la planta piloto del día 21-9-2011 (Fig. A.2.5) con un caudal de 1 $\mathrm{l} / \mathrm{min}$......

Fig. 4.4.1 Datos de la irradiación solar global diaria SIAR en Mansilla Mayor (León), valores resultado de la predicción realizada con una red neuronal artificial de una entrada del valor del día anterior y el error producido para cada día del año.

Fig. 4.4.2 Datos de la irradiación solar global diaria SIAR en Mansilla Mayor (León), valores resultado de la predicción realizada con una red neuronal artificial de dos entradas del valor de los días anteriores y el error producido para cada día del año

Fig. 4.4.3 Datos de la irradiación solar global diaria SIAR en Mansilla Mayor (León), valores resultado de la predicción realizada con una red neuronal artificial de tres entradas del valor de los días anteriores y el error producido para cada día del año.

Fig. 4.4.4 RMSE del error producido por las redes neuronales artificiales con una, dos y tres entradas de los días de retardo y con diferente número de neuronas ocultas, en la predicción de la serie de los datos de la irradiación solar global diaria, para el año 2011 SIAR en Mansilla Mayor (León).

Fig. 4.4.5 Datos de la irradiación solar global diaria SIAR en Mansilla Mayor (León), valores resultado de la predicción realizada con una red neuronal artificial con dos entradas del valor del día anterior $\mathrm{H}(\mathrm{t})$ y $\mathrm{J}(\mathrm{t})$, y el error producido para cada día del año

Fig. 4.4.6 Datos de la irradiación solar global diaria SIAR en Mansilla Mayor (León), valores resultado de la predicción realizada con una red neuronal artificial con tres entradas del valor del día anterior $\mathrm{H}(\mathrm{t}-1), \mathrm{H}(\mathrm{t})$ y J(t), y el error producido para cada día del año.

Fig. 4.4.7 Datos de la irradiación solar global diaria SIAR en Mansilla Mayor (León), valores resultado de la predicción realizada con una red neuronal artificial con cuatro entradas del valor del día anterior $\mathrm{H}(\mathrm{t}-2), \mathrm{H}(\mathrm{t}-1), \mathrm{H}(\mathrm{t})$ y $\mathrm{J}(\mathrm{t})$, y el error producido para cada día del año.

Fig. 4.4.8 RMSE del error producido por las redes neuronales artificiales con una, dos y tres entradas de los días de retardo y el día del año, y con diferente número de neuronas ocultas, en la predicción de la serie de los datos de la irradiación solar global diaria, para el año 2011 SIAR en Mansilla Mayor (León).

Fig. 4.4.9 Datos de la irradiación solar global diaria SIAR en Mansilla Mayor (León), valores resultado de la predicción realizada con una red neuronal artificial con dos entradas del valor del día anterior $\mathrm{H}(\mathrm{t})$ y $\mathrm{K}_{\mathrm{t}}(\mathrm{t})$, y el error producido para cada día del año.

Fig. 4.4.10 Datos de la irradiación solar global diaria SIAR en Mansilla Mayor (León), valores resultado de la predicción realizada con una red neuronal artificial con tres entradas del valor del día anterior $\mathrm{H}(\mathrm{t}), \mathrm{K}_{\mathrm{t}}(\mathrm{t})$ y $\mathrm{J}(\mathrm{t})$, y el error producido para cada día del año.

Fig. 4.4.11 RMSE del error producido por las redes neuronales artificiales con dos y tres entradas, para un día de retardo, el índice de claridad y/o el día del año, y con diferente número de neuronas ocultas, en la predicción de la serie de los datos de la irradiación solar global diaria, para el año 2011 SIAR en Mansilla Mayor (León).... 4:72 
Fig. 4.4.12 Datos de la irradiación solar global diaria SIAR en Mansilla Mayor (León), valores resultado de la predicción realizada con una red neuronal artificial con una entrada del valor del día anterior de temperatura media diaria y el error producido para cada día del año.

Fig. 4.4.13 Datos de la irradiación solar global diaria SIAR en Mansilla Mayor (León), valores resultado de la predicción realizada con una red neuronal artificial con dos entradas del valor del día anterior $\mathrm{T}_{\max }(\mathrm{t})$ y $\mathrm{T}_{\min }(\mathrm{t})$, y el error producido para cada día del año.

Fig. 4.4.14 Datos de la irradiación solar global diaria SIAR en Mansilla Mayor (León), valores resultado de la predicción realizada con una red neuronal artificial con tres entradas del valor del día anterior $T_{\operatorname{med}}(t), T_{\max }(t)$ y $T_{\min }(t)$, y el error producido para cada día del año.

Fig. 4.4.15 Datos de la irradiación solar global diaria en SIAR Mansilla Mayor (León), valores resultado de la predicción realizada con una red neuronal artificial con dos entradas del valor del día anterior $T_{\text {med }}(t)$ y $J(t)$, y el error producido para cada día del año...

Fig. 4.4.16 Datos de la irradiación solar global diaria SIAR en Mansilla Mayor (León), valores resultado de la predicción realizada con una red neuronal artificial con tres entradas del valor del día anterior $T_{\max }(t), T_{\min }(t)$ y $\mathrm{J}(\mathrm{t})$, y el error producido para cada día del año.......

Fig. 4.4.17 Datos de la irradiación solar global diaria SIAR en Mansilla Mayor (León), valores resultado de la predicción realizada con una red neuronal artificial con cuatro entradas del valor del día anterior $T_{\operatorname{med}}(t), T_{\max }(t), T_{\min }(t)$ y $\mathrm{J}(\mathrm{t})$, y el error producido para cada día del año.

Fig. 4.4.18 RMSE del error producido por las redes neuronales artificiales con tres entradas, para un día de retardo y con diferente número de neuronas ocultas, en la predicción de la serie de datos de las temperaturas media, máxima y mínima diaria, para el año 2011 SIAR en Mansilla Mayor (León).....

Fig. 4.4.19 RMSE del error producido por las redes neuronales artificiales con cuatro entradas, para un día de retardo y el día del año y con diferente número de neuronas ocultas, en la predicción de la serie de datos de las temperaturas media, máxima y mínima diaria, para el año 2011 SIAR en Mansilla Mayor (León)...

Fig. 4.4.20 Datos de la irradiancia solar horaria SIAR en Mansilla Mayor (León) y valores resultado de la estimación realizada con una red neuronal artificial con una entrada del valor de la irradiación solar global del mismo día..

Fig. 4.4.21 Datos de la irradiancia solar horaria SIAR en Mansilla Mayor (León) y valores resultado de la estimación realizada con una red neuronal artificial con dos entradas del valor de la irradiación solar global y el día del año del mismo día.....

Fig. 4.4.22 Datos de la temperatura media horaria SIAR en Mansilla Mayor (León) y valores resultado de la estimación realizada con una red neuronal artificial con tres entradas del valor de las temperaturas media, máxima y mínima diaria del mismo día......

Fig. 4.4.23 Datos de la temperatura media horaria SIAR en Mansilla Mayor (León) y valores resultado de la estimación realizada con una red neuronal artificial con cuatro entradas del valor de las temperaturas media, máxima y mínima diaria y el día del año del mismo día.......................................................................................................... 4:88

Fig. 4.5.1 Irradiación solar extraterrestre diaria calculada en la latitud $42^{\circ}$ Norte para cada día del año.

Fig. 4.5.2 Irradiación solar extraterrestre horaria calculada en la latitud $42^{\circ}$ Norte y la longitud $5,6^{\circ}$ Oeste para cada día 15 del mes de enero a junio...

Fig. 4.5.3 Irradiación solar extraterrestre horaria calculada en la latitud $42^{\circ}$ Norte y la longitud $5,6^{\circ}$ Oeste para cada día 15 del mes de julio a diciembre. 
Fig. 4.5.4 Muestra distintas correlaciones de irradiación solar difusa sobre la horizontal propuestas en la literatura...

Fig. 4.5.5 Datos resultantes de la fracción difusa horaria respecto al índice de claridad horario de las ocho horas centrales del día del año 2011, registrados por AEMET en la estación de La Virgen del Camino (León) y el modelo propuesto de estimación de la irradiación solar difusa horizontal.

Fig. 4.5.6 Altura solar horaria calculada en la latitud $42^{\circ}$ Norte y la longitud 5, $6^{\circ}$ Oeste, para cada día 15 del mes de enero a junio

Fig. 4.5.7 Altura solar horaria calculada en la latitud $42^{\circ}$ Norte y la longitud 5, $6^{\circ}$ Oeste, para cada día 15 del mes de julio a diciembre.

Fig. 4.5.8 Altura solar al mediodía solar calculada en la latitud $42^{\circ}$ Norte y la longitud $5,6^{\circ}$ Oeste, para todos los días del año

Fig. 4.5.9 Ángulo de incidencia horario calculado en la latitud $42^{\circ}$ Norte y la longitud $5,6^{\circ}$ Oeste, para cada día 15 del mes de enero a junio.

Fig. 4.5.10 Ángulo de incidencia horario calculado en la latitud $42^{\circ}$ Norte y la longitud $5,6^{\circ}$ Oeste, para cada día 15 del mes de julio a diciembre.

Fig. 4.5.11 Ángulo de incidencia al mediodía solar calculado en la latitud $42^{\circ}$ Norte y la longitud $5,6^{\circ}$ Oeste, para todos los días del año...

Fig. 4.5.12 Comparación de los valores diarios de irradiación solar global medidos sobre la horizontal y estimados sobre el plano inclinado a $45^{\circ}$ y orientado hacia el ecuador con cuatro modelos.

Fig. 4.5.13 Comparación de los valores horarios de irradiancia solar medidos sobre la horizontal SIAR en Mansilla Mayor (León), estimados sobre el plano inclinado a $45^{\circ}$ y orientación al ecuador, con cinco modelos y los registrados en la planta piloto para el día 11-4-2011.

Fig. 4.5.14 Comparación de los valores horarios de irradiancia solar medidos sobre la horizontal SIAR en Mansilla Mayor (León), estimados sobre el plano inclinado a $45^{\circ}$ y orientación al ecuador, con cinco modelos y los registrados en la planta piloto para el día 11-10-2011................................................................................................ 4:99

Fig. 4.6.1 Valores de RMSE obtenidos de la salida de las redes neuronales artificiales probadas con distintos números de neuronas en la capa oculta para el modelado del captador solar.

Fig. 4.6.2 Modelado RNA captador, datos medidos en el ensayo de la planta piloto el día 7-92011 y resultado de las predicciones.

Fig. 4.6.3 Modelado RNA captador, datos medidos en el ensayo de la planta piloto el día 1-72011 y resultado de las predicciones.

Fig. 4.6.4 Modelado RNA captador, datos medidos en el ensayo de la planta piloto el día 410-2011 y resultado de las predicciones

Fig. 4.6.5 Valores de RMSE obtenidos de la salida de las redes neuronales artificiales probadas con distintos números de neuronas en la capa oculta para el modelado del intercambiador de calor

Fig. 4.6.6 Modelado RNA del intercambiador, datos medidos en el ensayo de la planta piloto el día 7-9-2011 con un caudal del fluido portador de $2 \mathrm{l} / \mathrm{min}$ y resultado de las predicciones.

Fig. 4.6.7 Modelado RNA del intercambiador, datos medidos en el ensayo de la planta piloto el día 1-7-2011 con un caudal del fluido portador de 1,6 l/min y resultado de las predicciones.

Fig. 4.6.8 Modelado RNA del intercambiador, datos medidos en el ensayo de la planta piloto el día 21-9-2011 con un caudal del fluido portador de $1 \mathrm{l} / \mathrm{min}$ y resultado de las predicciones. 
Fig. 4.6.9 Modelado RNA estratificación durante el periodo de insolación sin consumo de agua caliente solar, datos medidos en el ensayo de la planta piloto el día 6-10-2011 y resultado de las predicciones

Fig. 4.6.10 Modelado RNA estratificación durante el periodo de insolación con consumo de agua caliente solar, datos medidos en el ensayo de la planta piloto el día 6-10-2011 y resultado de las predicciones...

Fig. 4.6.11 Modelado RNA estratificación durante el periodo de noche o cielo nubado sin consumo de agua caliente solar, datos medidos en el ensayo de la planta piloto los días $6,7,8,9$ y 10-10-2011 y resultado de las predicciones.

Fig. 4.6.12 Ensayo realizado en el interior del laboratorio del día 4 al 5-7-2011, se representan los datos registrados cada 10 minutos de la temperatura de estratificación del depósito, junto con la aproximación de una curva exponencial doble.

Fig. 4.6.13 Modelado RNA estratificación durante el periodo de noche o cielo nublado con consumo de agua caliente solar, datos medidos en el ensayo de la planta piloto el día 9-3-2012 y resultado de las predicciones................................................................4:112

Fig. 4.7.1 Modelado RNA planta piloto con el caudal del circuito primario $1 \mathrm{l} / \mathrm{min}$, datos medidos en el ensayo del día 10-10-2011 y resultado de la simulación realizada........4:114

Fig. 4.7.2 Modelado RNA planta piloto durante el periodo de noche o cielo nubado sin consumo de agua caliente, datos medidos en el ensayo de la planta piloto los días 10 y 11-10-2011 y resultado de la simulación realizada.

Fig. 4.7.3 Modelado RNA planta piloto con el caudal del circuito primario $1,6 \mathrm{l} / \mathrm{min}$, datos medidos en el ensayo del día 28-11-2011 y resultado de la simulación realizada........4:116

Fig. 4.7.4 Modelado RNA planta piloto durante el periodo de noche o cielo nubado sin consumo de agua caliente, datos medidos en el ensayo de la planta piloto los días 28 y 29-11-2011 y resultado de la simulación realizada...

Fig. 4.7.5 Temperaturas de estratificación de la simulación con el modelo RNA de la planta piloto para el mes de enero-2012..

Fig. 4.7.6 Temperaturas de estratificación de la simulación con el modelo RNA de la planta piloto para el mes de febrero-2012..

Fig. 4.7.7 Temperaturas de estratificación de la simulación con el modelo RNA de la planta piloto para el mes de marzo-2012..

Fig. 4.7.8 Temperaturas de estratificación de la simulación con el modelo RNA de la planta piloto para el mes de abril-2012.

Fig. 4.7.9 Temperaturas de estratificación de la simulación con el modelo RNA de la planta piloto para el mes de mayo-2012.

Fig. 4.7.10 Temperaturas de estratificación de la simulación con el modelo RNA de la planta piloto para el mes de junio-2012.

Fig. 4.7.11 Temperaturas de estratificación de la simulación con el modelo RNA de la planta piloto para el mes de julio-2012.

Fig. 4.7.12 Temperaturas de estratificación de la simulación con el modelo RNA de la planta piloto para el mes de agosto-2012..

Fig. 4.7.13 Temperaturas de estratificación de la simulación con el modelo RNA de la planta piloto para el mes de septiembre-2012.

Fig. 4.7.14 Temperaturas de estratificación de la simulación con el modelo RNA de la planta piloto para el mes de octubre-2012...

Fig. 4.7.15 Temperaturas de estratificación de la simulación con el modelo RNA de la planta piloto para el mes de noviembre-2012.

Fig. 4.7.16 Temperaturas de estratificación de la simulación con el modelo RNA de la planta piloto para el mes de diciembre-2012.

Fig. 4.7.17 Rendimiento anual de la planta piloto simulado con el modelo RNA y con el método f-chart. 
Fig. 4.8.1 Rendimiento mensual y anual en el año 2012, obtenido de la simulación neural en la planta piloto para distintas distribuciones horarias de la carga ACS demandada de $75 \mathrm{l} / \mathrm{d}$ a $50^{\circ} \mathrm{C}$.

Fig. 4.8.2 Rendimiento mensual y anual del año 2012, obtenido de la simulación neural en la planta piloto para distintas distribuciones diarias de la carga ACS demandada a 50 ${ }^{\circ} \mathrm{C}$, según el nivel de irradiación solar...

\section{Anexo 1}

Fig. A.1.1 Situación de la red de estaciones meteorológicas del proyecto SIAR en Castilla y León.

Fig. A.1.2 Imagen de la estación meteorológica SIAR situada en Mansilla Mayor (León). Hora Local GMT-21,725555...

Fig. A.1.3 Datos de la irradiación solar global diaria horizontal de la estación SIAR en Mansilla Mayor (León) del año 2002.

Fig. A.1.4 Datos de la irradiación solar global diaria horizontal de la estación SIAR en Mansilla Mayor (León) del año 2004

Fig. A.1.5 Datos de la irradiación solar global diaria horizontal de la estación SIAR en Mansilla Mayor (León) del año 2005.

Fig. A.1.6 Datos de la irradiación solar global diaria horizontal de la estación SIAR en Mansilla Mayor (León) del año 2006.

Fig. A.1.7 Datos de la irradiación solar global diaria horizontal de la estación SIAR en Mansilla Mayor (León) del año 2007.

Fig. A.1.8 Datos de la irradiación solar global diaria horizontal de la estación SIAR en Mansilla Mayor (León) del año 2008.

Fig. A.1.9 Datos de la irradiación solar global diaria horizontal de la estación SIAR en Mansilla Mayor (León) del año 2009.

Fig. A.1.10 Datos de la irradiación solar global diaria horizontal de la estación SIAR en Mansilla Mayor (León) del año 2010.

Fig. A.1.11 Datos de la irradiación solar global diaria horizontal de la estación SIAR en Mansilla Mayor (León) del año 2011

Fig. A.1.12 Datos de la irradiación solar global diaria horizontal de la estación SIAR en Mansilla Mayor (León) del año 2012.

Fig. A.1.13 Datos de la irradiancia solar horizontal de la estación SIAR en Mansilla Mayor (León) del día 26-6-2011.

Fig. A.1.14 Datos de la temperatura máxima, media y mínima diaria de la estación SIAR en Mansilla Mayor (León) del año 2002

Fig. A.1.15 Datos de la temperatura máxima, media y mínima diaria de la estación SIAR en Mansilla Mayor (León) del año 2004.

Fig. A.1.16 Datos de la temperatura máxima, media y mínima diaria de la estación SIAR en Mansilla Mayor (León) del año 2005.

Fig. A.1.17 Datos de la temperatura máxima, media y mínima diaria de la estación SIAR en Mansilla Mayor (León) del año 2006.

Fig. A.1.18 Datos de la temperatura máxima, media y mínima diaria de la estación SIAR en Mansilla Mayor (León) del año 2007.

Fig. A.1.19 Datos de la temperatura máxima, media y mínima diaria de la estación SIAR en Mansilla Mayor (León) del año 2008.

Fig. A.1.20 Datos de la temperatura máxima, media y mínima diaria de la estación SIAR en Mansilla Mayor (León) del año 2009.

Fig. A.1.21 Datos de la temperatura máxima, media y mínima diaria de la estación SIAR en Mansilla Mayor (León) del año 2010. 
Fig. A.1.22 Datos de la temperatura máxima, media y mínima diaria de la estación SIAR en Mansilla Mayor (León) del año 2011.

Fig. A.1.23 Datos de la temperatura máxima, media y mínima diaria de la estación SIAR en Mansilla Mayor (León) del año 2012.

Fig. A.1.24 Datos de la temperatura ambiente media de la estación SIAR en Mansilla Mayor (León) del día 26-6-2011.

Fig. A.1.25 Datos de la irradiación solar global diaria horizontal CENSOLAR en la provincia de León.

Fig. A.1.26 Datos de la temperatura ambiente media durante las horas de sol CENSOLAR en la provincia de León.

Anexo 2

Fig. A.2.1 Datos registrados de la irradiancia solar, la temperatura ambiente, la temperatura de ida, la temperatura de retorno y las temperaturas de estratificación, el caudal del agua de red, la temperatura del agua caliente solar y el caudal del circuito primario en el ensayo de la planta piloto realizado el día 1-7-2011.

Fig. A.2.2 Datos registrados de la irradiancia solar, la temperatura ambiente, la temperatura de ida, la temperatura de retorno y las temperaturas de estratificación, el caudal del agua de red, la temperatura del agua caliente solar y el caudal del circuito primario en el ensayo de la planta piloto realizado el día 4-7-2011

Fig. A.2.3 Datos registrados de la irradiancia solar, la temperatura ambiente, la temperatura de ida, la temperatura de retorno y las temperaturas de estratificación, el caudal del agua de red, la temperatura del agua caliente solar y el caudal del circuito primario en el ensayo de la planta piloto realizado el día 29-8-2011.

Fig. A.2.4 Datos registrados de la irradiancia solar, la temperatura ambiente, la temperatura de ida, la temperatura de retorno y las temperaturas de estratificación, el caudal del agua de red, la temperatura del agua caliente solar y el caudal del circuito primario en el ensayo de la planta piloto realizado el día 7-9-2011.

Fig. A.2.5 Datos registrados de la irradiancia solar, la temperatura ambiente, la temperatura de ida, la temperatura de retorno y las temperaturas de estratificación, el caudal del agua de red, la temperatura del agua caliente solar y el caudal del circuito primario en el ensayo de la planta piloto realizado el día 21-9-2011

Fig. A.2.6 Datos registrados de la irradiancia solar, la temperatura ambiente, la temperatura de ida, la temperatura de retorno y las temperaturas de estratificación, el caudal del agua de red, la temperatura del agua caliente solar y el caudal del circuito primario en el ensayo de la planta piloto realizado el día 4-10-2011.

Fig. A.2.7 Datos registrados de la irradiancia solar, la temperatura ambiente, la temperatura de ida, la temperatura de retorno y las temperaturas de estratificación, el caudal del agua de red, la temperatura del agua caliente solar y el caudal del circuito primario en el ensayo de la planta piloto realizado el día 6-10-2011...

Fig. A.2.8 Datos registrados de la irradiancia solar, la temperatura ambiente, la temperatura de ida, la temperatura de retorno y las temperaturas de estratificación, el caudal del agua de red, la temperatura del agua caliente solar y el caudal del circuito primario en el ensayo de la planta piloto realizado el día 10-10-2011.

Fig. A.2.9 Datos registrados de la irradiancia solar, la temperatura ambiente, la temperatura de ida, la temperatura de retorno y las temperaturas de estratificación, el caudal del agua de red, la temperatura del agua caliente solar y el caudal del circuito primario en el ensayo de la planta piloto realizado el día 7-11-2011.

Fig. A.2.10 Datos registrados de la irradiancia solar, la temperatura ambiente, la temperatura de ida, la temperatura de retorno y las temperaturas de estratificación, el caudal del agua de red, la temperatura del agua caliente solar y el caudal del circuito primario en el ensayo de la planta piloto realizado el día 28-11-2011. 
Fig. A.2.11 Datos registrados de la irradiancia solar, la temperatura ambiente, la temperatura de ida, la temperatura de retorno y las temperaturas de estratificación, el caudal del agua de red, la temperatura del agua caliente solar y el caudal del circuito primario en el ensayo de la planta piloto realizado el día 9-3-2012. 


\section{ÍNDICE DE TABLAS}

(Tabla Capítulo/Anexo.Apartado.Número)

(Capítulo/Anexo:Página)

\section{Capítulo 4}

Tabla 4.2.1 Coeficientes de autocorrelación parcial de la serie de datos de irradiación solar global diaria para retardos de tiempo de 1 a 20 días, SIAR en Mansilla Mayor (León).

Tabla 4.2.2 Coeficientes de autocorrelación parcial de la serie de datos de temperatura media diaria para retardos de tiempo de 1 a 20 días, SIAR en Mansilla Mayor (León).

Tabla 4.2.3 Coeficientes de autocorrelación parcial de la serie de datos de temperatura máxima diaria para retardos de tiempo de 1 a 20 días, SIAR en Mansilla Mayor (León).

Tabla 4.2.4 Coeficientes de autocorrelación parcial de la serie de datos de temperatura mínima diaria para retardos de tiempo de 1 a 20 días, SIAR en Mansilla Mayor (León).

Tabla 4.2.5 Funciones anuales típicas de Fourier de los datos de la irradiación solar global diaria en Mansilla Mayor (León), del primer al octavo armónico y el error producido.

Tabla 4.2.6 Funciones anuales típicas de Fourier de los datos de la temperatura media diaria SIAR en Mansilla Mayor (León), del primer al octavo armónico y el error producido.

Tabla 4.2.7 Funciones anuales típicas de Fourier de los datos de la temperatura máxima diaria SIAR en Mansilla Mayor (León), del primer al octavo armónico y el error producido.

Tabla 4.2.8 Funciones anuales típicas de Fourier de los datos de la temperatura mínima diaria SIAR en Mansilla Mayor (León), del primer al octavo armónico y el error producido.

Tabla 4.2.9 Función de Matlab para crear la matriz de probabilidades.

Tabla 4.2.10 Matriz de transición de Markov resultado de los datos de la irradiación solar global diaria del año 2004 al 2010 SIAR en Mansilla Mayor (León), para 33 estados.

Tabla 4.2.11 Matriz de transición de Markov normalizada resultado de los datos de la irradiación solar global diaria del año 2004 al 2010 SIAR en Mansilla Mayor (León), para 33 estados.

Tabla 4.2.12 Función de Matlab para realizar la predicción del próximo día, multiplicando el vector de estado del día de hoy con la matriz de transición de Markov normalizada.

Tabla 4.2.13 Factor horario ASHRAE de la temperatura ambiente del aire.

Tabla 4.5.1 Función de aproximación de Fourier a la irradiación solar extraterrestre diaria en la latitud $42^{\circ}$ Norte, con el $1^{\circ}, 2^{\circ}$ y $3^{\circ}$ armónico y el error producido. $4: 90$ 
Tabla 4.5.2 Función de aproximación de funciones senos a la irradiación solar extraterrestre diaria en la latitud $42^{\circ}$ Norte, con 2, 3 y 4 senos y el error producido....................... 4:90

Tabla 4.6.1 Ensayo realizado en el interior del laboratorio del día 4 al 5-7-2011, se representa la ecuación para cada capa del depósito................................................................... 4:111

Tabla 4.7.1 Rendimientos anuales y mensuales de la planta piloto simulados con RNA a un caudal de $2 \mathrm{l} / \mathrm{min}$

Tabla 4.7.2 Rendimientos anuales y mensuales de la planta piloto simulados con RNA a un caudal de $1,6 \mathrm{l} / \mathrm{min}$.

Tabla 4.7.3 Rendimientos anuales y mensuales de la planta piloto simulados con RNA a un caudal de $1 \mathrm{l} / \mathrm{min}$

Tabla 4.7.4 Rendimiento anual y mensual de la planta piloto simulado con el método f-chart y el captador solar ensayado a $2 \mathrm{l} / \mathrm{min}$

Tabla 4.7.5 Rendimiento anual y mensual de la planta piloto simulado con el método f-chart y el captador solar ensayado a $1,6 \mathrm{l} / \mathrm{min}$.....

Tabla 4.7.6 Rendimiento anual y mensual de la planta piloto simulado con el método $f$-chart

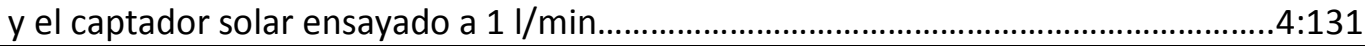

Tabla 4.8.1 Rendimiento mensual y anual en el año 2012, obtenido de la simulación neural en la planta piloto para distintas distribuciones horarias de la carga ACS demandada de $75 \mathrm{l} / \mathrm{d}$ a $50{ }^{\circ} \mathrm{C}$.

Tabla 4.8.2 Rendimiento mensual y anual del año 2012, obtenido de la simulación neural en la planta piloto para distintas distribuciones diarias de la carga ACS demandada a $50{ }^{\circ} \mathrm{C}$, según el nivel de irradiación solar....................................................................... 4:134

\section{Capítulo 5}

Tabla 5.1.1 Efectividad de las tablas de irradiación solar CENSOLAR respecto a los datos de SIAR en Mansilla Mayor (León) para el año 2011.

Tabla 5.1.2 Efectividad de las tablas de temperatura ambiente diurna CENSOLAR respecto a los datos de SIAR en Mansilla Mayor (León) para el año 2011.

Tabla 5.1.3 Efectividad de la predicción media móvil ponderada con los coeficientes de autocorrelación parcial de irradiación solar respecto a los datos de SIAR en Mansilla Mayor (León) para el año 2011.

Tabla 5.1.4 Efectividad de la predicción media móvil ponderada con los coeficientes de autocorrelación parcial de temperatura media, máxima y mínima respecto a los datos de SIAR en Mansilla Mayor (León) para el año 2011

Tabla 5.1.5 Efectividad de la predicción regresión lineal de irradiación solar respecto a los datos de SIAR en Mansilla Mayor (León) para el año $2011 . .$.

Tabla 5.1.6 Efectividad de la predicción regresión lineal de temperatura media diaria respecto a los datos de SIAR en Mansilla Mayor (León) para el año 2011

Tabla 5.1.7 Efectividad de la predicción de la función anual típica de Fourier del $1^{\circ}$ al $8^{\circ}$ armónico de irradiación solar respecto a los datos de SIAR en Mansilla Mayor (León) para el año 2011.

Tabla 5.1.8 Efectividad de la predicción de la función anual típica de Fourier del $1^{\circ}$ al $8^{\circ}$ armónico de temperatura media respecto a los datos de SIAR en Mansilla Mayor (León) para el año 2011.

Tabla 5.1.9 Efectividad de la predicción de la función anual típica de Fourier del $1^{\circ}$ al $8^{\circ}$ armónico de temperatura máxima respecto a los datos de SIAR en Mansilla Mayor (León) para el año 2011

Tabla 5.1.10 Efectividad de la predicción de la función anual típica de Fourier del $1^{\circ}$ al $8^{\circ}$ armónico de temperatura mínima respecto a los datos de SIAR en Mansilla Mayor (León) para el año 2011 
Tabla 5.1.11 Efectividad de la predicción del análisis de Markov con una matriz de transición de 33 estados de irradiación solar respecto a los datos de SIAR en Mansilla Mayor (León) para el año 2011.

Tabla 5.1.12 Efectividad de la estimación de la temperatura media horaria con el método ASHRAE respecto a los datos de SIAR en Mansilla Mayor (León) de los días 10 al 16-5-2011.

Tabla 5.1.13 Efectividad de la predicción neural de irradiación solar mediante $\mathrm{H}(\mathrm{t}-2), \mathrm{H}(\mathrm{t}-1)$, $\mathrm{H}(\mathrm{t})$ respecto a los datos de SIAR en Mansilla Mayor (León) para el año 2011..........5:21

Tabla 5.1.14 Efectividad de la predicción neural de irradiación solar mediante $\mathrm{H}(\mathrm{t}-\mathrm{2}), \mathrm{H}(\mathrm{t}-1)$, $\mathrm{H}(\mathrm{t}), \mathrm{J}(\mathrm{t})$ respecto a los datos de SIAR en Mansilla Mayor (León) para el año 2011.. 5:21

Tabla 5.1.15 Efectividad de la predicción neural de irradiación solar mediante $\mathrm{H}(\mathrm{t}), \mathrm{K}_{\mathrm{t}}(\mathrm{t}), \mathrm{J}(\mathrm{t})$ respecto a los datos de SIAR en Mansilla Mayor (León) para el año 2011

Tabla 5.1.16 Efectividad de la predicción neural de irradiación solar mediante $T_{\operatorname{med}}(t), T_{\max }(t)$, $\mathrm{T}_{\min }(\mathrm{t})$ respecto a los datos de SIAR en Mansilla Mayor (León) para el año 2011...... 5:22

Tabla 5.1.17 Efectividad de la predicción neural de irradiación solar mediante $T_{\operatorname{med}}(t), T_{\max }(t)$, $T_{\min }(t), J(t)$ respecto a los datos de SIAR en Mansilla Mayor (León) para el año 2011.

Tabla 5.1.18 Efectividad de la predicción neural de temperatura diaria mediante $T_{\operatorname{med}}(\mathrm{t})$, $T_{\max }(t), T_{\min }(t), \mathrm{J}(\mathrm{t})$ respecto a los datos de SIAR en Mansilla Mayor (León) para el año 2011.

Tabla 5.1.19 Efectividad de la predicción neural de irradiancia horaria mediante $\mathrm{H}(\mathrm{t}), \mathrm{J}(\mathrm{t})$ respecto a los datos de SIAR en Mansilla Mayor (León) para el año 2011

Tabla 5.1.20 Efectividad de la predicción neural de temperatura horaria mediante $T_{\operatorname{med}}(\mathrm{t})$, $T_{\max }(t), T_{\min }(t), J(t)$ respecto a los datos de SIAR en Mansilla Mayor (León) para el año 2011

Tabla 5.3.1 Efectividad del modelo neural del captador solar durante tres días de funcionamiento con distintos caudales del fluido portador.

Tabla 5.3.2 Efectividad del modelo neural del intercambiador de calor durante tres días de funcionamiento con distintos caudales del fluido portador.

Tabla 5.3.3 Efectividad del modelo neural de la estratificación térmica durante el estado SOL durante el ensayo del día 6-10-2011.

Tabla 5.3.4 Efectividad del modelo neural de la estratificación térmica durante el estado SOL

+ ACS durante el ensayo del día 6-10-2011

Tabla 5.3.5 Efectividad del modelo neural de la estratificación térmica durante el estado NOCHE durante el ensayo de los días 6...10-10-2011....

Tabla 5.3.6 Efectividad del modelo neural de la estratificación térmica durante el estado NOCHE + ACS durante el ensayo del día 9-3-2012.

Tabla 5.3.7 Efectividad de la identificación de la estratificación térmica ESTÁTICA durante el ensayo del día 4 al 5-7-2011...................................................................................... 5:34

Tabla 5.4.1 Efectividad de la simulación neural en la estratificación térmica durante el estado SOL y SOL + ACS en el ensayo del día 10-10-2011.

Tabla 5.4.2 Efectividad de la simulación neural en la estratificación térmica durante el estado NOCHE en el ensayo del día 10 al 11-10-2011.

Tabla 5.4.3 Efectividad de la simulación neural en la estratificación térmica durante el estado SOL y SOL + ACS en el ensayo del día 28-11-2011.................................................... 5:38

Tabla 5.4.4 Efectividad de la simulación neural en la estratificación térmica durante el estado NOCHE en el ensayo del día 28 al 29-10-2011......................................................... 5:38

\section{Anexo 1}

Tabla A.1.1 Datos absolutos diarios registrados en la estación SIAR de Mansilla Mayor (León). A.1:3 Tabla A.1.2 Datos calculados en base diaria en la estación SIAR de Mansilla Mayor (León).........A.1:3 


\section{ACRÓNIMOS}

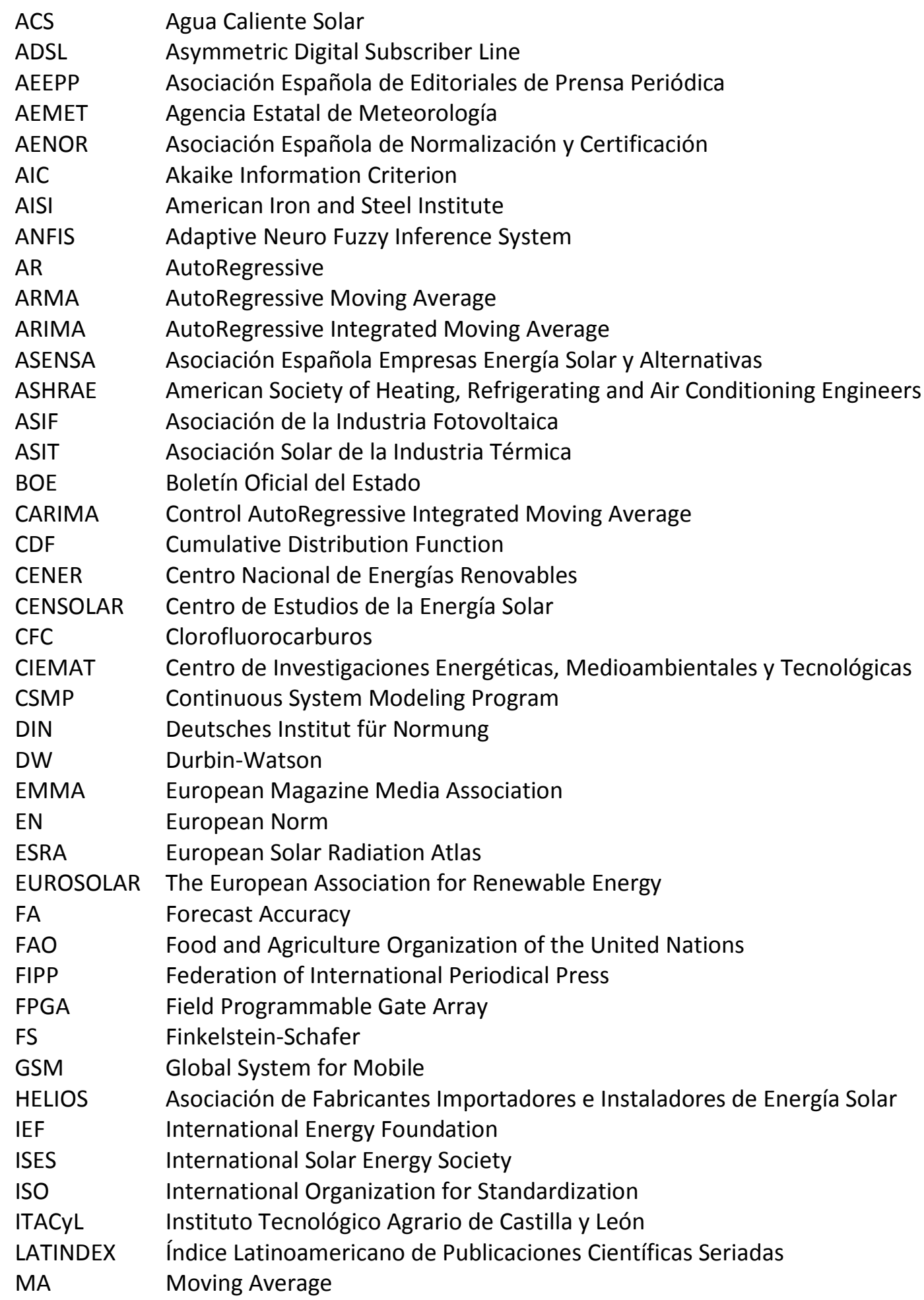


MAPA Ministerio de Agricultura, Pesca y Alimentación

MBE Mean Bias Error

MLP MultiLayer Perceptron

MPE Mean Percentage Error

MSE Mean Squared Error

NARX Nonlinear AutoRegressive with eXogenous inputs

NASA-SSE National Aeronautics and Space Administration-Surface Meteorology and Solar Energy

NIC Network Information Criterion

NNARX Neural Network AutoRegressive with eXogenous inputs

NREL National Renewable Energy Laboratory

ONU Organización de las Naciones Unidas

PA Poliamida

PIR Poliisocianurato

PU Poliuretano

PVC PolyVinylChloride

PVGIS Photovoltaic Geographical Information System

RAL Reichsausschuß für Lieferbedingungen

RBF Radial Basis Function

RMSE Root Mean Square Error

RNA Red Neuronal Artificial

$\mathrm{R}^{2} \quad$ Coeficiente de Determinación

SEI Solar Energy International

SIAR Sistema de Información Agroclimática para el Regadío

SIG Sistema de Información Geográfica

SLR Solar Load Ratio

SoDa Solar radiation Data (Solar Energy Services for Professionals)

SWERA Solar and Wind Energy Resource Assessment

TMY Typical Meteorological Year

TRNSYS TRaNsient SYstems Simulation

TRY Test Reference Year

UNE Una Norma Española

UNEF Unión Española Fotovoltaica

UTC Coordinated Universal Time

WCRE World Council for Renewable Energy

WMO World Meteorological Organization

WRR World Radiometric Reference

WYEC Weather Year for Energy Calculations 


\section{NOMENCLATURA}

$a_{1} \quad$ Coeficiente de pérdidas térmicas del captador solar

$\mathrm{a}_{2}$

A

Coeficiente de pérdidas térmicas dependiente de la temperatura del captador solar

Amperio

$\mathrm{A}_{c} \quad$ Área del captador solar

$\mathrm{A}_{\mathrm{g}} \quad$ Área total del terreno visto por el plano inclinado

ACS Agua Caliente Solar

$\alpha \quad$ Altura solar y Absortancia del captador solar

$\beta$

Ángulo de inclinación del captador solar desde la posición horizontal

$\mathrm{C}_{\mathrm{e}} \quad$ Calor específico del fluido portador

$\mathrm{C}_{\min } \quad$ La menor capacidad térmica del fluido en el intercambiador de calor

C Caudal del fluido portador

${ }^{\circ} \mathrm{C} \quad$ Grado centígrado

$\mathrm{cm} \quad$ Centímetro

$\mathrm{Cu} \quad$ Cobre

d Día

$\delta \quad$ Declinación solar

$\Delta \quad$ Incremento y Azimut de la superficie inclinada con respecto al del Sol, este ángulo se reduce a $\omega$ para superficies inclinadas hacia el ecuador

$\Delta \mathrm{t} \quad$ Número total de segundos del mes

$\Delta U \quad$ Intercambio de energía en el depósito acumulador

E Energía auxiliar requerida durante un mes

$\mathrm{E}_{0} \quad$ Factor de corrección de la excentricidad de la Tierra

Eficiencia del intercambiador de calor y Emisividad del captador solar

$\varepsilon_{\mathrm{L}} \quad$ Efectividad del intercambiador de calor agua-aire de la carga

$\eta \quad$ Eficiencia del captador solar

$\eta_{0} \quad$ Eficiencia óptica del captador solar

Fracción total mensual de la demanda térmica suministrada por la energía solar Fracción de la demanda térmica anual suministrada por la energía solar Factor de eficiencia de extracción de calor del captador solar Factor de corrección captador-intercambiador Latitud geográfica y diámetro

$\mathrm{H} \quad$ Irradiación solar global diaria incidente sobre una superficie horizontal

$\overline{\mathrm{H}} \quad$ Irradiación solar diaria media mensual sobre la horizontal

$\overline{\mathrm{H}}_{\beta \gamma} \quad$ Irradiación solar diaria media mensual sobre el plano inclinado y orientado

$\mathrm{H}_{0} \quad$ Irradiación solar extraterrestre diaria incidente sobre una superficie horizontal

I Irradiación solar global horaria incidente sobre una superficie horizontal

i Irradiancia solar

$\mathrm{I}_{0} \quad$ Irradiación solar extraterrestre horaria incidente sobre una superficie horizontal

$\mathrm{I}_{\mathrm{O}} \quad$ Irradiación solar extraterrestre horaria incidente sobre una superficie inclinada y orientada hacia el ecuador 
loßv Irradiación solar extraterrestre horaria incidente sobre una superficie inclinada y orientada en cualquier dirección

$I_{\beta \gamma} \quad$ Irradiación solar global horaria incidente sobre un plano inclinado y orientado en cualquier dirección

$i_{\beta \gamma} \quad$ Irradiancia solar incidente sobre un plano inclinado y orientado en cualquier dirección

$\mathrm{I}_{\mathrm{b}} \quad$ Irradiación solar directa horaria incidente sobre una superficie horizontal

$\mathrm{I}_{\mathrm{b} \beta \mathrm{V}} \quad$ Irradiación solar directa horaria incidente sobre un plano inclinado y orientado en cualquier dirección

$I_{d} \quad$ Irradiación solar difusa horaria incidente sobre una superficie horizontal

$\mathrm{I}_{\mathrm{d} \beta} \quad$ Irradiación solar difusa horaria incidente sobre un plano inclinado y orientado en cualquier dirección

Ir Irradiación solar difusa horaria reflejada por la tierra incidente sobre un plano inclinado

$\mathrm{I}_{\mathrm{s}} \quad$ Irradiación solar difusa del cielo horaria incidente sobre un plano inclinado

$\dot{i}_{\mathrm{sc}} \quad$ Constante solar

J Número de día del año

K Grado Kelvin

$\mathrm{k}_{\mathrm{d}} \quad$ Índice de la fracción difusa horaria

$\mathrm{k}_{\mathrm{t}} \quad$ Índice de claridad horario

$\mathrm{K}_{\mathrm{t}} \quad$ Índice de claridad diario

$\mathrm{K}_{1} \quad$ Factor de corrección por almacenamiento

$\mathrm{K}_{2} \quad$ Factor de corrección, para ACS, que relaciona la temperatura mínima de ACS, la del agua de red y la media mensual ambiente

kg Kilogramo

kJ Kilojulio

km Kilómetro

kW Kilovatio

kWh Kilovatio hora

I Litro

L Demanda energética mensual

$\mathrm{L}_{\mathrm{m}} \quad$ Longitud geográfica de la zona de medición

$\mathrm{L}_{z} \quad$ Longitud geográfica del centro de la zona de tiempo local

m Metro

$\mathrm{mA} \quad$ Miliamperio

min Minuto

$\mathrm{mm} \quad$ Milímetro

$\mathrm{mV} \quad$ Milivoltio

M Capacidad de almacenamiento del depósito respecto a la superficie de captador solar

MJ Megajulio

Mg Magnesio

MWh Megavatio hora

N Número de días del mes

N1...8 Capa 1 ...8 del depósito acumulador

$\mathrm{nm} \quad$ Nanómetro

$\omega \quad$ Ángulo horario solar en el momento en que ocurre el punto medio del periodo considerado

$\omega_{1} \quad$ Ángulo horario solar al inicio del periodo

$\omega_{2} \quad$ Ángulo horario solar al final del periodo

$\omega_{\mathrm{s}} \quad$ Ángulo horario a la puesta del Sol

$\Omega \quad$ Ohmio

$\psi \quad$ Azimut solar

$\mathrm{Q}_{u} \quad$ Energía útil que recoge el captador solar

$Q_{T} \quad$ Energía solar útil entregada durante un mes

$r \quad$ Distancia actual Sol-Tierra 
rad

rpm

Distancia media Sol-Tierra

Ratio de la irradiación solar sobre un plano inclinado y sobre la superficie horizontal en ausencia de la atmósfera terrestre

$$
\text { Radian }
$$

Revolución por minuto

Relación entre la irradiación solar sobre el plano inclinado y la horizontal

\section{Albedo}

Albedo del suelo debido a la irradiación solar directa

Albedo de las nubes

Albedo del suelo debido a la irradiación solar difusa

Albedo de la Tierra

\section{Segundo}

Corrección estacional para el tiempo solar

\section{Silicio}

Hora estándar en el punto medio del periodo considerado y lapso de tiempo

Duración del periodo considerado

Temperatura ambiente

Temperatura ambiente diaria media mensual

Temperatura mínima aceptable del agua caliente solar

Temperatura caliente

Temperatura de entrada del fluido portador en el captador solar

Temperatura del fluido portador en la entrada del circuito primario del intercambiador de calor

Temperatura del agua caliente solar en la entrada del circuito secundario del intercambiador de calor

\section{Temperatura fría}

Temperatura del fluido portador en la tubería de ida del circuito primario

Temperatura media del fluido portador en el captador solar

Temperatura ambiente máxima

Temperatura ambiente media

Temperatura media o mezcla del agua acumulada en el depósito

Temperatura ambiente mínima

Temperatura del agua de red

Temperatura de referencia en el método f-chart

Temperatura del fluido portador en la tubería de retorno del circuito primario

Temperatura de salida del fluido portador en el captador solar

Temperatura del fluido portador en la salida del circuito primario del intercambiador de calor Temperatura del agua caliente solar en la salida del circuito secundario del intercambiador de calor

$$
\text { Transmitancia solar de la cubierta transparente del captador solar }
$$

Producto transmitancia-absortancia media mensual

Producto transmitancia-absortancia con incidencia normal de la irradiancia

Ángulo de incidencia para una superficie inclinada y orientada arbitrariamente

Ángulo de incidencia para una superficie inclinada y orientada hacia el ecuador

Ángulo zenit

Coeficiente global de pérdidas de energía del captador solar

Unidad astronómica

Producto área-coeficiente de pérdidas totales del edificio

Vatio

Proporción de las pérdidas energéticas del captador solar respecto a la demanda térmica mensual 
Y Proporción de la energía solar absorbida por la superficie del captador solar respecto a la demanda térmica mensual 


\section{Capítulo 1}

\section{INTRODUCCIÓN, OBJETIVOS, ESTRUCTURA Y CONTENIDO DE LA TESIS DOCTORAL}

\subsection{Introducción}

1.2 Objetivos de la Tesis Doctoral

1.3 Estructura y contenido de la Tesis Doctoral

El primer capítulo presenta un acercamiento a los sistemas solares térmicos destinados a la producción de agua caliente, enunciando los objetivos planteados para la realización de la Tesis Doctoral, y se indican de forma sintética los contenidos de los demás capítulos. 


\subsection{Introducción}

La energía solar es el origen y la continuación de la vida en la Tierra. El Sol se formó hace 5000 millones de años y se estima que siga brillando otros tantos años. La irradiación solar que llega a la superficie terrestre es captada por las hojas de las plantas, para utilizarla en el proceso de la fotosíntesis, en el que la materia inorgánica se convierte en materia orgánica. Los sistemas solares térmicos captan la irradiación solar mediante los captadores solares para calentar el agua que circula por su interior.

La irradiación solar extraterrestre diaria varía su valor de energía estacionalmente a lo largo del año de manera continua y en forma senoidal, estando afectada por la interposición de las nubes del cielo en su trayectoria hacia el suelo de una forma aleatoria, además de por los componentes de la atmósfera terrestre. Los sistemas solares térmicos pueden almacenar la energía solar captada, transformada en energía calorífica y utilizarla durante los días nublados o durante la noche.

El Sol es una fuente energética eterna para el hombre, pudiéndose aprovechar, por su abundancia y disponibilidad, de forma natural o artificial, siendo un invariante en la organización agrícola, urbana, industrial,... de la sociedad. El aprovechamiento de la energía solar en forma directa se puede realizar mediante su captación con sistemas térmicos o fotovoltaicos, en esta Tesis Doctoral se centra en la energía solar térmica activa a baja temperatura para el calentamiento de agua.

La invención del captador solar, que es el principal componente de los sistemas solares térmicos, se atribuye a Sanssure durante la segunda mitad del siglo XVIII, y otros investigadores, como Herschel en 1837 y Tellier en 1885, que ensayaron captadores solares muy semejantes a los que se utilizan en nuestros días. Pero fue Kemp, un industrial de Maryland USA, quien en 1892, fabricó por primera vez un captador solar de agua para su venta.

Para la optimización de los sistemas solares térmicos se dispone de una energía recibida del Sol, de manera gratuita, se tiene unas necesidades energéticas que cubrir, en este caso de agua caliente, se desarrollan unos sistemas que captan la energía llegada desde el Sol y se transforma en energía calorífica utilizable en las viviendas o en la industria. Estos sistemas alcanzan un rendimiento que relaciona estas dos energías, el cual se convierte en un ahorro económico, al no tener que utilizar fuentes de energía, caras y contaminantes del medio ambiente, para cubrir las necesidades particulares.

Investigar cómo aumentar este rendimiento es el objetivo, pudiéndose realizar desde varias posiciones: prediciendo la cantidad de energía solar que se va a disponer a lo largo de cada día del año y en cada lugar concreto, conociendo anticipadamente cuales van a ser las necesidades energéticas caloríficas, diseñando el sistema solar térmico más adecuado para cada caso, fabricando componentes para el sistema solar térmico de gran calidad, instalando adecuadamente los sistemas solares térmicos para evitar pérdidas y manteniendo las instalaciones solares en el punto para el que fueron ideadas en su correcto funcionamiento.

Se ha discutido si el Sol emite un flujo de energía constante. Algunos estudios indican variaciones de la emisión de energía mínimos a lo largo de un ciclo solar. Sin embargo, para los temas que en esta Tesis Doctoral se tratan lo consideramos constante, estando el recurso solar más influido por las variaciones estacionales debidas a la posición Tierra-Sol y a las variaciones meteorológicas de la atmósfera que 
rodea a la superficie terrestre, además de por el fenómeno de oscurecimiento solar ocasionado por la contaminación atmosférica, más que a las propias variaciones solares.

El Sol emite radiación en toda la gama del espectro electromagnético, sin embargo, para los fines de estos sistemas de aprovechamiento de la energía, solo es importante la llamada radiación térmica, que incluye la radiación ultravioleta, la visible y la infrarroja fundamentalmente. 


\subsection{Objetivos de la Tesis Doctoral}

En el desarrollo de los estudios de investigación, cuyos resultados se reúnen en esta Tesis Doctoral, el objetivo principal buscado ha sido el de:

\section{"Optimizar el rendimiento de los sistemas solares térmicos activos de producción de agua caliente a baja temperatura, ya instalados, mediante modelos neurales, respecto al rendimiento obtenido por el habitual y conocido procedimiento de diseño, método f-chart".}

El método f-chart formulado por Klein en 1976, fue el resultado de las correlaciones de un gran número de simulaciones realizadas con el programa TRNSYS, dando lugar a un método sencillo, práctico y ampliamente aceptado para el dimensionamiento de los sistemas solares térmicos. Excluye del modelado de los componentes, justificando las simplificaciones, aspectos que le suponen un efecto pequeño sobre el rendimiento del sistema solar térmico a largo plazo. Identificadas estas simplificaciones, el objetivo de optimización se centró en cuatro líneas que conjuntamente aplicadas, espera conseguir un aumento significativo en el rendimiento de los sistemas solares térmicos respecto al calculado por el método f-chart utilizado como referencia, que en un principio se le considera un método capaz, pero que realiza unos cálculos conservadores que dan lugar a un sobredimensionamiento de la superficie de captadores solares requerida para las necesidades energéticas a cubrir.

La primera línea de actuación son los datos climatológicos utilizados por el método de cálculo para la simulación de un año entero en la estimación de su rendimiento. Las bases de datos de la irradiación solar horizontal y la temperatura ambiente diurna en una resolución temporal diaria media mensual y una resolución espacial de tipo provincial, procedentes de tablas son utilizadas habitualmente entre los técnicos e ingenieros solares.

En esta Tesis Doctoral se propone la utilización de métodos de predicción a corto plazo de las variables ambientales, que principalmente afectan al funcionamiento operacional del sistema solar térmico, como la irradiancia solar y la temperatura ambiente. Para ello se revisan y proponen nuevos modelos que realizan las predicciones a corto plazo de la evolución de un día para otro del nivel de irradiación solar y temperatura ambiente, generando perfiles diarios de la irradiancia solar y la temperatura ambiente en periodos de tiempo de un minuto, que se utilizan como datos de entrada del modelo neural en la simulación del sistema solar térmico.

La segunda línea de actuación es el estudio de la evolución de las temperaturas de estratificación térmica en el depósito acumulador de agua caliente solar, durante todos sus estados de operación que combinan la carga y/o descarga de agua caliente. Un modelo de mezcla total del agua en el depósito proporciona una estimación mesurada del rendimiento obtenido por el sistema solar térmico, el modelo de depósito completamente mezclado ha sido utilizado en los estudios de diseño generalizados por el método f-chart. 
En esta Tesis Doctoral se revisan los modelos de estratificación térmica del agua caliente en el depósito acumulador y se propone la utilización de un nuevo modelo para determinar la evolución de las temperaturas de la estratificación del agua en el depósito durante todos sus estados de operación.

La tercera línea de actuación es el modelado de los componentes del sistema solar térmico, mediante una técnica común, que sea fácilmente exportable a todas las instalaciones e implementable por personal que no necesite una gran especialización y consiguiendo muy buenos resultados.

En esta Tesis Doctoral la técnica escogida fue las redes neuronales artificiales, que son utilizadas en el modelado de los componentes. De esta forma, se ofrece una verdadera alternativa para evaluar el rendimiento de un sistema solar térmico mediante una simulación dinámica, aplicando los modelos neurales obtenidos de los componentes. Las redes neuronales artificiales también se utilizan para implementar las otras dos líneas de actuación anteriores, la predicción de las variables ambientales y la estratificación térmica.

La cuarta línea de actuación se centra en la revisión de los métodos para la estimación de la irradiación solar incidente sobre una superficie inclinada con distintas orientaciones hacia el ecuador, en las que el captador solar de los sistemas solares térmicos puede ser instalado, respecto a la recibida en la horizontal. Los datos de la irradiación solar medidos y registrados en las estaciones meteorológicas, habitualmente están referidos a la superficie horizontal. La estimación de su valor sobre el captador solar se realiza muchas veces mediante unos simples coeficientes, ya que los métodos expuestos en la literatura suelen ser complicados y difíciles de aplicar sino es por un experto.

En esta Tesis Doctoral se hace una revisión y se intenta hacer más fácil la utilización de los métodos de estimación de la irradiación solar sobre el plano inclinado, para obtener unos valores más precisos que los producidos por los coeficientes, que suelen ser moderados, resultando valores ligeramente menores de los reales.

Los objetivos específicos de los estudios de investigación organizados en esta Tesis Doctoral, son:

- Crear nuevos modelos para la predicción de la evolución a corto plazo de las variables ambientales, diarias.

- Crear un nuevo modelo para la predicción de la evolución de la estratificación térmica del agua caliente solar almacenada en el depósito acumulador.

- Crear nuevos modelos para los componentes del sistema solar térmico.

- Desarrollar un sistema dinámico que ofrezca una verdadera alternativa para evaluar el rendimiento de los sistemas solares térmicos.

- Revisar el modelado para la estimación de la irradiación solar que incide sobre los captadores solares, a partir de la que recibe la superficie horizontal. 


\subsection{Estructura y contenido de la Tesis Doctoral}

Esta Tesis Doctoral está compuesta de siete capítulos, tres anexos complementarios y de la bibliografía analizada.

En el capítulo primero, se ha realizado un preámbulo a los sistemas solares térmicos, además de introducir al documento completo, delimitando los objetivos de salida en la realización de los estudios efectuados, cuyos resultados se recogen en los demás capítulos y anexos. Enunciando el objetivo principal de los estudios de investigación llevados a cabo y se exponen los objetivos específicos con los que se pretende conseguir el principal.

En el capítulo segundo, se presenta el estado del arte, donde se recogen los antecedentes científicos anteriores y los estudios previos a esta Tesis Doctoral. Se tratan los diferentes modelos descritos en artículos publicados de la literatura internacional, detallando las peculiaridades más significativas, los resultados y limitaciones que consiguen en cada caso. Este capítulo ha sido muy laborioso en su confección al tener que revisar distintos temas que afectan a los sistemas solares térmicos.

- La primera parte, revisa el modelado y simulación de los sistemas solares térmicos, con especial atención al tradicional y extendido método f-chart utilizado como referencia en esta Tesis Doctoral.

- La segunda parte, revisa las técnicas de modelado y predicción de las variables ambientales, en concreto la irradiación solar y la temperatura ambiente, más influyentes en el funcionamiento de los sistemas solares térmicos.

- La tercera parte, revisa los modelos de estimación de la irradiación solar incidente sobre una superficie inclinada y orientada arbitrariamente respecto de la recibida en la horizontal, que conlleva el modelado de la irradiación solar extraterrestre, la irradiación solar difusa horizontal, la altura solar y el ángulo de incidencia de la irradiación solar sobre la superficie del captador solar. La irradiación solar sobre una superficie inclinada se descompone para su cálculo en la irradiación directa del sol, la irradiación reflejada por la tierra y la irradiación difusa del cielo que inciden las tres sobre una superficie inclinada, constituyendo la irradiación solar global incidente sobre el captador solar.

- La cuarta parte, revisa el modelado del funcionamiento de los componentes principales de un sistema solar térmico como son el captador solar de placa plana, el intercambiador de calor y la estratificación térmica del agua caliente en el depósito acumulador.

- La quinta parte, revisa el marco teórico en el que se basan las metodologías desarrolladas en esta Tesis Doctoral, mediante la técnica de las redes neuronales artificiales de la inteligencia computacional, aplicadas a la resolución del problema de las series de tiempo, constituidas por los datos medidos y registrados en el proceso de funcionamiento de los sistemas solares térmicos.

En el capítulo tercero, se presenta la metodología propuesta en esta Tesis Doctoral, basada en el conocimiento de un área concreta (redes neuronales artificiales de la inteligencia computacional), para resolver un problema que pertenece a otra área de conocimiento distinta (modelado y optimización del rendimiento de los sistemas solares térmicos). 
- La primera parte, presenta la descripción técnica de la planta piloto con un sistema solar térmico que se ha construido, en el cual se desarrollan los ensayos y se validan las simulaciones de los modelos obtenidos en esta Tesis Doctoral.

- La segunda parte, presenta un estudio en profundidad de la forma en que el método f-chart modela los componentes del sistema solar térmico, la descripción detallada del método y las simplificaciones que han sido utilizadas en su desarrollo, con el fin de detectar debilidades que puedan utilizarse para mejorar el rendimiento del sistema solar térmico.

- La tercera parte, presenta la herramienta informática utilizada en esta Tesis Doctoral para el proceso de implementación de las redes neuronales artificiales.

- La cuarta parte, presenta la metodología que se aplica en el desarrollo de los modelos neurales para la predicción de la irradiación solar y la temperatura ambiente en esta Tesis Doctoral.

- La quinta parte, presenta la metodología para la estimación del valor de la irradiación solar global que incide en los captadores solares, a partir de la irradiación solar global sobre la superficie horizontal.

- La sexta parte, presenta la metodología aplicada en el desarrollo de los modelos neurales que representan a los componentes principales del sistema solar térmico en esta Tesis Doctoral.

- La séptima parte, presenta la metodología aplicada en el desarrollo del modelado para el funcionamiento de un sistema solar térmico particular ideado en esta Tesis Doctoral, exportable a cualquier otro, con la que se puede realizar la simulación neural de su comportamiento.

- La octava parte, presenta la metodología aplicada en esta Tesis Doctoral para la optimización del rendimiento de los sistemas solares térmicos, que puede aplicarse a cualquier instalación solar doméstica de una forma fácil y sencilla.

En el capítulo cuarto, se presentan los resultados obtenidos al aplicar las metodologías desarrolladas en esta Tesis Doctoral, utilizando las gráficas para comparar los resultados obtenidos con los valores medidos y registrados, representando el error cometido en cada intervalo de tiempo. También se calculó el estadístico RMSE para su posterior comparación y análisis.

- La primera parte, expone los datos resultados de las simplificaciones que utiliza en su desarrollo el método f-chart usado como referencia en esta Tesis Doctoral.

- La segunda parte, expone los resultados obtenidos al aplicar varios modelos de predicción de las variables ambientales, irradiación solar y temperatura ambiente, revisados en la literatura: los datos CENSOLAR, la autocorrelación parcial, la media móvil ponderada, la regresión lineal, el análisis de Fourier, las matrices de Markov y el método ASHRAE, utilizando la base de datos climatológicos para su validación.

- La tercera parte, expone los resultados obtenidos al aplicar varias metodologías de la literatura para modelar el funcionamiento de los componentes del circuito primario de un sistema solar térmico, el captador solar de placa plana y el intercambiador de calor con los ensayos en la planta piloto, para su estudio y la validación en distintas situaciones de funcionamiento. También se comprueba el efecto que produce en el rendimiento la variación de las distintas variables, como por ejemplo el caudal del fluido portador.

- La cuarta parte, expone los resultados obtenidos en las predicciones de la irradiación solar y la temperatura ambiente con las metodologías neurales desarrolladas en esta Tesis Doctoral. 
- La quinta parte, expone los resultados obtenidos en la estimación del valor de la irradiación solar global incidente sobre el plano del captador solar, a partir del valor de la irradiación solar global de la superficie horizontal.

- La sexta parte, expone los resultados obtenidos en el modelado neural de los componentes del sistema solar térmico, captador solar, intercambiador de calor y la estratificación térmica en el depósito acumulador, desarrollados en esta Tesis Doctoral.

- La séptima parte, expone los resultados obtenidos en la simulación neural del funcionamiento de un sistema solar térmico completo, durante 10 años en León, realizada en esta Tesis Doctoral, utilizando como entrada a la simulación los valores de la irradiancia solar, la temperatura ambiente, el caudal y la temperatura del agua de red en intervalos de tiempo de un minuto. Además, se muestran los resultados obtenidos por el método f-chart para la validación respecto a este método ampliamente aceptado en sus mismas condiciones, y comprobar la optimización que puede conseguirse al contemplar la estratificación térmica y los datos climatológicos reales.

- La octava parte, expone los datos resultados de la metodología planteada en esta Tesis Doctoral para la optimización del rendimiento de los sistemas solares térmicos, utilizando la filosofía de desplazar los consumos más importantes de agua caliente solar a las horas de mayor irradiación solar.

En el capítulo quinto, se realiza el análisis y discusión de los datos y resultados obtenidos por el método desarrollado y propuesto en esta Tesis Doctoral, para optimizar el rendimiento de los sistemas solares térmicos, mediante la predicción a corto plazo de la evolución de las variables ambientales que más influyen en su funcionamiento, la utilización de un depósito acumulador de agua caliente solar estratificada y la estimación del valor de la irradiación solar incidente sobre los captadores solares con modelos más precisos que los utilizados habitualmente. Se disertan las relaciones y las generalizaciones que los resultados de las metodologías revelan y los aspectos no resueltos, se muestra la relación con los resultados de otros estudios anteriormente publicados, se exponen las consecuencias teóricas y prácticas de los estudios de investigación, se dan recomendaciones para la aplicación de la metodología propuesta, se formulan las conclusiones y se resumen las pruebas que respaldan cada conclusión.

- La primera parte, analiza y discute los resultados de los modelos de predicción de las variables ambientales, irradiación solar y temperatura ambiente, recopilados de la literatura y los modelos neurales desarrollados en esta Tesis Doctoral.

- La segunda parte, analiza y discute los resultados de la estimación de irradiación solar que incide sobre el plano inclinado del captador solar a partir de datos de la irradiación solar global horizontal.

- La tercera parte, analiza y discute los resultados del modelado neural de los componentes principales del sistema solar térmico, captador solar, intercambiador de calor y depósito acumulador estratificado térmicamente, desarrollados en esta Tesis Doctoral.

- La cuarta parte, analiza y discute los resultados de la simulación neural del sistema solar térmico construido, con la metodología desarrollada en esta Tesis Doctoral.

- La quinta parte, analiza y discute los resultados de la optimización horaria y diaria en el sistema solar térmico, propuestas en esta Tesis Doctoral. 
En el capítulo sexto, se exponen las conclusiones a las que se ha llegado en esta Tesis Doctoral, después del análisis y discusión de los resultados obtenidos, resaltando las aportaciones más interesantes relacionadas con los objetivos.

En el capítulo séptimo, se proponen las líneas futuras para nuevos estudios de investigación y sobre las cuestiones sin resolver en esta Tesis Doctoral.

En el anexo primero, se realiza la presentación de la estación meteorológica y la representación gráfica de los datos climatológicos, utilizados en las metodologías de predicción de las variables ambientales y en la simulación del sistema solar térmico, procedentes de la base de datos SIAR de la irradiación solar global diaria horizontal y la temperatura ambiente en Mansilla Mayor (León).

En el anexo segundo, se realiza la representación gráfica de las variables ambientales y operacionales, medidas y registradas, de 11 ensayos realizados con el sistema solar térmico construido, de los numerosos realizados en dos años de experimentos, durante el día y la noche, con y sin descargas de agua caliente solar, donde se puede observar la evolución de cada variable del sistema solar térmico en las distintas situaciones a las que está expuesto.

En el anexo tercero, se recogen dos artículos escritos por el autor de esta Tesis Doctoral, resultado de los estudios llevados a cabo.

- Sistemas solares térmicos. Modelado del captador mediante redes neuronales artificiales (I) y (II), es el título del artículo publicado en la revista técnica Era Solar $n^{\circ} 176$ (Septiembre/Octubre 2013) páginas 26-34 y n¹77 (Noviembre/Diciembre 2013) páginas 42-54 del año XXXI, fundada en el año 1983, está dedicada exclusivamente a la energía solar, se publican artículos escritos por académicos, investigadores y profesionales de prestigio, sujetos a selección supervisada por un Comité Técnico. La revista está recogida en la base de datos internacional de ingeniería, International Development Abstracts, Índice Latinoamericano de Publicaciones Científicas Seriadas LATINDEX. Se la considera como una referencia de calidad en el campo de la energía solar con edición latinoamericana. Portavoz de varias asociaciones nacionales, europeas e internacionales, como: Unión Española Fotovoltaica UNEF, Asociación Solar de la Industria Térmica ASIT, Asociación Española Empresas Energía Solar y Alternativas ASENSA, Asociación de la Industria Fotovoltaica ASIF, Centro de Estudios de la Energía Solar CENSOLAR, The European Association for Renewable Energy EUROSOLAR, Asociación de Fabricantes Importadores e Instaladores de Energía Solar HELIOS, Solar Energy International SEI, Asociación Española de la Industria Solar Termoeléctrica PROTERMOSOLAR, World Council for Renewable Energy WCRE, International Energy Foundation IEF. Y miembro de: Asociación Española de Editoriales de Prensa Periódica AEEPP, Federation of International Periodical Press FIPP, European Magazine Media Association EMMA.

- Prediction and identification of the evolution of solar-heated hot water temperature in a stratified tank in static mode using artificial neural networks, es el título del artículo que actualmente se encuentra en fase de publicación.

En la bibliografía, se enumeran las referencias bibliográficas utilizadas y consultadas durante los estudios de investigación llevados a cabo en esta Tesis Doctoral. 



\section{Capítulo 2}

\section{ESTADO DEL ARTE}

\subsection{El método f-chart}

2.2 Predicción de las variables ambientales: irradiación solar y temperatura ambiente

2.3 Estimación de la irradiación solar incidente sobre un plano inclinado y orientado

\subsection{Modelado de los componentes de un sistema solar térmico}

2.5 Las series de tiempo en la inteligencia computacional. Marco teórico

En este capítulo se despliegan los antecedentes y estudios previos de los modelos publicados en la literatura científica, y el marco teórico en el que se sustentan las investigaciones y los modelos propuestos en esta Tesis Doctoral. Para cada uno de ellos se detallan las particularidades más significativas y sus limitaciones.

La primera parte revisa el método f-chart buscando sus orígenes y la bibliografía publicada, así como del modelado y simulación de los sistemas solares térmicos.

La segunda parte realiza una presentación y clasificación de las técnicas de predicción aplicadas a las variables ambientales, en el caso de esta Tesis Doctoral: la irradiación solar y la temperatura ambiente. Se repasa la propiedad denominada persistencia radiativa. La forma de validación y rendimiento de los modelos de predicción. Y se realiza una recopilación de la literatura sobre los datos climáticos medios, el modelado por correlación, el análisis de las series de Fourier, el análisis de Markov, el modelado mediante el año meteorológico típico, el modelado con satélites artificiales, la aplicación de las técnicas de la inteligencia artificial, que se utilizan en la predicción de la irradiación solar.

La tercera parte revisa la métodos presentados en la literatura para la estimación de la irradiación solar incidente sobre un plano inclinado y orientado, para lo cual es necesario conocer los métodos de la estimación de la irradiación solar difusa horizontal a partir de los datos disponibles de la irradiación solar global horizontal, con el estudio por separado de los tres componentes que forman la irradiación solar global sobre un plano inclinado que son la directa del sol, la reflejada del suelo y la difusa del cielo.

La cuarta parte revisa los modelos existentes en la literatura para el modelado del funcionamiento de los principales componentes del circuito primario de un sistema solar térmico como son el captador solar de placa plana, el intercambiador de calor y el depósito acumulador. 
La quinta parte presenta el marco teórico de las series de tiempo en el que se apoyan las investigaciones y modelos propuestos en esta Tesis Doctoral. Para el análisis y predicción de las series de tiempo formadas con los datos medidos y registrados en los procesos. Se revisan los métodos tradicionales estadísticos y en especial los que utilizan las técnicas más actuales de la inteligencia computacional empleados para la predicción y el modelado. 


\subsection{El método f-chart}

El método f-chart es un análisis útil para el diseño de sistemas solares térmicos, especialmente para la selección del tamaño y tipo de captadores solares, destinados al suministro de agua caliente y calefacción en los edificios residenciales. Originalmente fue desarrollado como parte del doctorado de Sanford Alan Klein, que realizó la Tesis Doctoral titulada "A design procedure for solar heating systems" (Klein, 1976), el método se describe en dos de sus artículos publicados en la revista Solar Energy, uno para los sistemas con fluido portador líquido (Klein et al., 1976) y el otro para los sistemas con fluido portador aire (Klein et al., 1977).

El método f-chart resulta de las correlaciones de un gran número de simulaciones realizadas con el programa informático TRaNsient SYstems Simulation TRNSYS (Klein et al., 1975), con una estructura modular en la que el usuario especifica los componentes que constituyen el sistema y la forma en que están conectados, la biblioteca TRNSYS incluye los componentes y los algoritmos comúnmente utilizados para controlar la entrada de datos meteorológicos. Su naturaleza modular facilita la adición de modelos matemáticos no incluidos en la librería estándar, siendo apropiado para el análisis detallado de cualquier sistema cuyo comportamiento depende del tiempo.

La primera publicación sobre el método f-chart se realiza un año después del doctorado de Klein, con el libro (Beckman et al., 1977). Una revisión de este libro la realiza (Kreith, 1978) de la cual se ha considerado interesante extraer lo siguiente:

Este libro resume los resultados de la investigación financiada por el gobierno USA, llevada a cabo en la Universidad de Wisconsin, para predecir la cantidad económicamente óptima de calor que deben suministrar a un edificio, los sistemas solares térmicos activos que utilizan agua o aire como fluido portador.

Los autores eliminan el gasto y la complejidad de los programas de simulación dinámica y presentan un método sencillo y práctico para dimensionar los sistemas solares térmicos destinados a calefacción y producción de agua caliente.

Este libro, y por tanto el método, está destinado a personas que sin desear profundizar en el tema, quieran respuestas rápidas a preguntas como ¿Qué superficie de captadores necesito en mi casa? o ¿Cuánto costará la energía solar que me aporte? Cada paso se ilustra con ejemplos sencillos, que hacen del diseño de sistemas solares térmicos, se vea casi como un libro de recetas de cocina más que un arte.

Los autores presentan un modelo en el que todas las pérdidas de calor en el depósito acumulador van a producir energía útil y que el almacenamiento a largo plazo no es una alternativa realista, es decir, solo los sistemas que utilizan energía auxiliar capaz de suministrar una gran fracción de las necesidades totales de energía pueden ser económicos.

Los autores proponen un procedimiento para extender el método f-chart a los sistemas solares térmicos, que solo prestan servicio de agua caliente, pero no de calefacción a un edificio.

En vista del hecho de que ciertos organismos del gobierno USA, requieren predicciones de la fracción solar basadas en el método f-chart en las solicitudes de financiación, sería importante validar el modelo 
de diseño f-chart experimentalmente, bajo condiciones de carga controlada para una variedad de estrategias de control y condiciones meteorológicas.

En resumen, este método trata una aplicación simplificada, que proporciona al lector una metodología sencilla y directa para el dimensionamiento de los sistemas solares térmicos que siguen los supuestos indicados a su comienzo. Al mismo tiempo se advierte que no debe sobre extenderse la metodología a sistemas solares térmicos que difieran de lo descrito por los autores.

(Haberl y Cho, 2004) muestra un recorrido de la historia del método f-chart y una comparativa respecto a mediciones experimentales, al programa TRNSYS y otros métodos.

El método f-chart es una correlación que se basa en miles de simulaciones realizadas con una versión simplificada del programa TRNSYS. Por lo tanto, una evaluación de la exactitud del método f-chart debe incluir una evaluación de la exactitud del programa TRNSYS. Desde el momento de su desarrollo, se reconoce que la diferencia entre la complejidad de los modelos detallados de simulación como TRNSYS y el método de correlación f-chart es considerable y numerosos intentos se han realizado para desarrollar métodos simplificados con un nivel intermedio de complejidad (Tsilingiris, 1996).

TRNSYS es un modelo de simulación ampliamente reconocido como la herramienta de diseño solar más completa y precisa, después de su lanzamiento, el código se ha visto enriquecido y refinado, se considera el mejor modelo actualmente disponible, sobre todo útil como herramienta de análisis y de investigación. Sin embargo, su uso generalizado se descarta por el coste, y porque el usuario debe de tener gran experiencia y conocimiento para aprovechar las capacidades del modelo, además de necesitar datos meteorológicos relativamente complejos.

El método de las áreas relativas para el cálculo directo, sin iteración, de la superficie aproximada de captación solar que minimiza el coste del sistema solar térmico, está basado en una relación empírica entre el porcentaje anual de exposición solar y el área relativa de captación. Esta relación se determina mediante la correlación de los datos generados por el programa f-chart (Barley y Winn, 1978), además relaciona diversas restricciones de uso del método f-chart.

La metodología para estimar el rendimiento de los sistemas solares térmicos pasivos llamado Solar Load Ratio SLR, propuesto por (Balcomb y McFarland, 1978), se compara con el método f-chart para sistemas solares activos en (Drew y Selvage, 1979). Las ecuaciones describen un sistema solar pasivo con una pared de agua y un muro Trombe. Señala la correspondencia entre los resultados obtenidos mediante el método SLR y los que resultan del método f-chart de la estimación del rendimiento solar.

Una correlación matemática entre el área de captadores solares y la energía auxiliar utilizada en un sistema solar térmico para el calentamiento de agua se obtiene mediante el programa TRNSYS en (Chang y Minardi, 1980). A partir de esta correlación, el área de captador solar óptimo es directamente relacionado tanto con factores económicos, como con los parámetros del sistema, obteniendo un criterio de viabilidad.

Un método para predecir el rendimiento a largo plazo de los sistemas solares térmicos se presenta en (Sfeir, 1980), el método utiliza un enfoque estocástico y se basa en algunas propiedades estadísticas de la irradiación solar mensual media y la temperatura ambiente. La irradiación solar diaria media consiste en fluctuaciones diarias superpuestas sobre el cambio estacional debido a la variación de la declinación solar. Las fluctuaciones diarias tienen una distribución normal alrededor de la media para intervalos de 
duración que no exceden de un mes. Estos hechos pueden ser aproximadamente ciertos (Brinkworth, 1977). Las fluctuaciones de la temperatura ambiente diaria promedio, para una duración del intervalo de un mes, también tienen una distribución normal alrededor de la media. Las dos variables irradiación solar y temperatura se supone que cumplen la hipótesis ergódica. Esto implica que sus promedios conjuntos son similares a los promedios en otro intervalo de tiempo.

El método R-chart realiza de manera directa un cálculo del ratio entre el área de la superficie actual de captadores del sistema solar térmico y el área ideal para cualquier valor que se prescriba de la fracción solar de la carga anual. La construcción de la tabla que utiliza se basa en la correlación de los datos generados por el método f-chart (Hawas y Abou-Zeid, 1983).

(Ajona y Gordon, 1987) presenta un modelo analítico para la predicción del comportamiento mensual y anual de los sistemas solares térmicos de calentamiento de aire. En el método se tiene en cuenta, explícitamente, los efectos de la estratificación térmica del lecho, derivando una expresión para el cálculo de la fracción solar mensual en función de las variables que caracterizan al sistema y al clima.

Un modelo informático de simulación sencillo para el diseño de sistemas solares térmicos se desarrolla por (Tsilingiris, 1996). En comparación con los actuales métodos simplificados de correlación, este modelo permite una notable expansión de su aplicabilidad a fin de incorporar perfiles de demanda horaria, la configuración del sistema solar térmico y las pérdidas de calor de algunos componentes del sistema. Además de poder eliminar algunas restricciones en los parámetros de diseño como el modificador del ángulo de incidencia y el tratamiento por separado de la irradiación solar directa y difusa.

Un procedimiento aplicable a cualquier parte del mundo (Cuadros et al., 2007), a partir de datos disponibles de la base de datos Climwat de la FAO, como son los valores de la irradiación solar diarios medios mensuales, temperaturas máxima y mínima, y número de horas de sol. Se utilizan para comparar la eficiencia de diversos captadores solares en distintas instalaciones. El porcentaje de cobertura del sistema solar térmico se obtiene de la relación entre la irradiación solar horizontal diaria con las necesidades energéticas diarias y la eficiencia del captador solar para cada día del año. Se aplican unos coeficientes correctores para el ángulo de inclinación, acumulación de la suciedad en la cubierta del captador solar y la disminución de la irradiación solar en los momentos del día cuando el Sol está muy bajo en el cielo. La validación del método se lleva a cabo mediante una comparación con otros métodos conocidos y aceptados en todo el mundo: ISOFOTÓN, CENSOLAR, f-CHART y TRNSYS.

Un sistema solar térmico para el suministro de agua caliente a una temperatura adecuada en una unidad de acuicultura es presentado (Atia et al., 2010), la optimización se realiza utilizando un algoritmo genético, la cual es una técnica moderna de optimización de naturaleza evolutiva, que puede mejorar cualquier tipo de función objetivo y restricciones. El diseño óptimo de la superficie de captador solar utiliza algoritmos genéticos para optimizar la función objetivo, teniendo en cuenta las limitaciones necesarias para la unidad.

\subsubsection{Modelado y simulación de los sistemas solares térmicos}

Los métodos sencillos que se utilizan para diseñar sistemas solares térmicos como f-chart o Utilizability han demostrado ser lo suficientemente precisos, pero la manera más exacta para estimar el 
rendimiento de los sistemas solares térmicos es con una simulación detallada (Kalogirou, 2009). El dimensionado de los componentes de los sistemas solares térmicos es un problema complejo que incluye tanto elementos predecibles como impredecibles. El paso inicial en el modelado de un sistema es plantear una estructura general que represente el sistema. La posibilidad de utilizar estructuras alternativas del sistema se debe dejar abierta mientras se selecciona el método de modelado a realizar. La estructura que representa el sistema no debe ser confundida con el sistema real. La estructura es siempre una copia imperfecta de la realidad. Sin embargo, el acto de desarrollar una estructura del sistema y la estructura misma promueve la comprensión del sistema real.

Los métodos de análisis simplificado tienen las ventajas de una necesidad de cálculo baja y facilidad de uso. Las desventajas incluyen la flexibilidad limitada para la optimización del diseño, la falta de control de los supuestos y una selección limitada de los sistemas que pueden ser analizados. Por lo que, si la aplicación del sistema, configuración o características de la carga en cuestión no son estándares, una simulación por ordenador detallada puede ser necesaria para lograr resultados precisos.

La modelización de los sistemas solares térmicos con ordenador tienen las ventajas siguientes (Kalogirou, 2009):

- Se eliminan los gastos de construcción del prototipo.

- Los sistemas complejos se organizan de una forma más comprensible.

- Proporcionan más conocimiento sobre el funcionamiento.

- Facilita la posibilidad de optimizar los componentes.

- Estiman la energía suministrada por el sistema.

- Facilitan las variaciones de temperatura del sistema.

- Estiman los cambios de las variables del sistema respecto a las condiciones climáticas.

Las simulaciones pueden proporcionar información sobre el rendimiento a largo plazo de los sistemas solares térmicos y la dinámica del sistema. Esto incluye las variaciones de la temperatura.

A lo largo de los años se han desarrollado una serie de programas destinados a la modelización y simulación de los sistemas solares térmicos, los más populares se comentarán a continuación. Además de las técnicas de la inteligencia computacional utilizadas recientemente para el modelado y evaluación del rendimiento de los componentes que forman los sistemas solares térmicos, en concreto las redes neuronales artificiales que son las utilizadas en esta Tesis Doctoral.

TRNSYS, este programa se encuentra en la versión 17 (TRNSYS, 2013), consta de subrutinas para muchos componentes, sus modelos matemáticos se dan en términos de ecuaciones. Se pueden interconectar los componentes del sistema en la forma deseada y resolver las ecuaciones, el problema de la simulación del sistema se reduce a un problema de identificar los componentes de cada sistema particular.

WATSUN, este programa fue desarrollado en la Universidad de Waterloo (WATSUN, 1996), a nivel de usuario se sitúa entre las herramientas más simples basadas en hojas de cálculo utilizadas para una evaluación rápida y los programas de simulación completa, que proporcionan más flexibilidad, pero son más difíciles de utilizar.

POLYSUN, este programa proporciona simulaciones dinámicas anuales de los sistemas solares térmicos y ayuda a optimizar los mismos (POLYSUN, 2008). El programa es fácil de utilizar, la simulación se basa en modelos físicos que trabajan sin términos de correlaciones empíricas. El programa POLYSUN fue 
validado en (Gantner, 2000) encontrando una precisión 5-10 \%.

CENSOLAR, TRANSOL, ACSOL, T-SOL, ISOFOTÓN, son otros programas utilizados para el modelado de sistemas solares térmicos. 


\subsection{Predicción de las variables ambientales: irradiación solar y temperatura ambiente}

Las técnicas de predicción constituyen el instrumento para llevar a cabo el proceso de predicción. El objetivo es muy sencillo: Pronosticar valores futuros de variables con objeto de reducir la incertidumbre que produce el futuro. La predicción es un instrumento que ayuda a la toma de decisiones, atenúa la dependencia con el azar y hace que se observe el entorno como más controlable, aunque no directamente manejable. La predicción es una herramienta que proporciona información sobre el futuro.

Existen multitud de técnicas, pero no se puede decir que exista una técnica que garantice las mejores predicciones, dependerá del comportamiento de la variable en el pasado y de la información que se disponga de ella, el conocimiento de otras variables que influyan en el comportamiento de la variable en estudio, el horizonte de predicción, los medios o cualificación que tenga el personal encargado del análisis e incluso la confianza que se tenga en la disciplina de la predicción.

La predicción de las variables ambientales en esta Tesis Doctoral se realiza a la irradiación solar global sobre una superficie horizontal y a la temperatura ambiente, las cuales se consideran las variables ambientales más influyentes en el funcionamiento de un sistema solar térmico.

La irradiación solar que llega al tope de la atmósfera de la Tierra es una cantidad conocida en el tiempo. Sin embargo, la irradiación solar que llega a un cierto punto de la superficie terrestre tiene una componente aleatoria, debida a los gases, nubes y polvo en la atmósfera, que absorbe y/o dispersa una parte de la irradiación solar en diferentes longitudes de onda.

La obtención de datos fiables de irradiación solar a nivel del suelo requiere de mediciones sistemáticas. Sin embargo, en la mayoría de los países la densidad espacial de las estaciones actinométricas es insuficiente. Esta situación lleva al desarrollo de procedimientos, para obtener estimaciones de la irradiación solar, en los lugares donde las mediciones no se realizan y en los lugares donde hay lagunas de los registros de medición.

Las estimaciones de la irradiación solar para un tiempo histórico se pueden obtener mediante la predicción usando un modelo de irradiación específico para el lugar o mediante un modelo de predicción mecanicista.

Un modelo específico para el lugar se basa en relaciones empíricas de la irradiación solar con las variables climatológicas que se registran en la estación. A pesar, de que una ecuación específica para el lugar requiere un conjunto de datos reales de la irradiación solar para la determinación de los coeficientes adecuados, este enfoque suele ser más fácil de calcular y puede ser más preciso que complicados modelos mecanicistas. Estas ecuaciones simples, propias del lugar, también pueden ser interesantes para sitios cercanos a donde estos modelos se desarrollan.

Estas técnicas aplicadas al modelado de la irradiación solar que estiman el valor de la cantidad de irradiación solar a partir de otras variables ambientales y geográficas son las escogidas en esta Tesis Doctoral, utilizándose para la predicción del valor de la irradiación solar y la temperatura ambiente del 
día de mañana. En la elección del tipo de modelo se tiene presente la disponibilidad de los datos utilizados como entrada al modelo, la precisión de los resultados requerida y la complejidad práctica del método desarrollado.

Los tipos de datos de la irradiación solar requeridos dependen de la aplicación y su uso. Los datos medios mensuales o diarios se requieren para estudios climatológicos o de viabilidad de los sistemas de energía solar. Los datos horarios o en periodos más cortos son necesarios para simular el rendimiento de los componentes de los sistemas solares, como por ejemplo durante los ensayos del captador solar.

Con la proliferación de los ordenadores personales de altas prestaciones, se puede cubrir una necesidad creciente de datos horarios o más cortos que se utilizan en la simulación de los procesos, diseño y dimensionamiento óptimo de los sistemas solares térmicos.

La irradiación solar global es una medida del total de la energía solar incidente sobre la superficie de la tierra. La predicción de la irradiación solar global es esencial para el correcto diseño de los edificios y los sistemas solares térmicos. La estimación de la irradiación solar global y de sus componentes (irradiación solar directa, difusa y albedo) es necesaria para dimensionarlos.

Numerosos modelos para predecir la irradiación solar global están presentados en la literatura. Se pueden agrupar en varias categorías: los métodos empíricos, incluyen modelos que se obtienen por medios estadísticos con los datos de irradiación solar medidos, y los modelos físicos que se basan en ecuaciones de principios básicos.

Otra distribución es entre modelos que predicen la distribución temporal de la irradiación solar global en condiciones de cielo claro y los que tienen en cuenta el impacto de la presencia de nubes, su tipo y la cobertura nubosa total.

También, hay muchos modelos que tratan de definir los componentes de la irradiación solar global, a saber, irradiación directa, irradiación difusa e irradiación de albedo, esta última representa solo un pequeño porcentaje de la irradiación solar global y depende de la morfología del terreno. Estos modelos se conocen como modelos de descomposición.

Sucesivas revisiones y comparaciones de la confiabilidad entre los diferentes modelos se han realizado en diversas publicaciones, mientras que modelos representativos de las categorías anteriores se pueden encontrar en la literatura. Estos modelos son validados globalmente, pero requieren de un número extenso de condiciones atmosféricas como entradas.

Los diferentes modelos desarrollados a lo largo de la historia sirven para proporcionar predicciones de la irradiación solar cuando o donde no se mide adecuadamente o en absoluto, también son utilizados para calibrar instrumentos de medida. Una tipología aceptada de modelos de irradiación solar no existe en la actualidad. Está claro que los modelos de irradiación solar se pueden clasificar de diferentes maneras, a partir de una revisión exhaustiva de la literatura (Gueymard y Myers, 2008) identifica nueve criterios de clasificación, como siguen:

- Criterio 1. Tipo de datos de salida: que suelen ser la irradiación directa, difusa y global, pero con frecuencia solo una se utiliza, por ejemplo, la irradiación solar global sobre un plano inclinado, otros modelos intentan derivar la componente directa y/o difusa de la irradiación global que se utiliza como entrada. 
- Criterio 2. Tipo de datos de entrada: pueden ser variables meteorológicas, datos climatológicos, o componentes de la irradiación solar. Estas entradas pueden ser tomadas en lugares de la superficie terrestre, o de la teledetección con sensores aéreos o vehículos espaciales.

- Criterio 3. Resolución espacial: unos modelos proporcionan predicciones para un lugar concreto del que utilizan los datos, otros dan resultados reticulados cuando se utilizan entradas de satélites. Los primeros tienen mayor resolución espacial, mientras que los últimos tienen mayor cobertura espacial.

- Criterio 4. Tiempo de resolución: la irradiancia solar de la salida puede ser de resolución alta cada minuto utilizado en concentradores solares, de resolución estándar cada hora para simulaciones de sistemas solares, de resolución media para días en meteorología agrícola, de resolución baja para promedios horarios o diarios de un mes en el diseño de sistemas solares y climatológicos para promedios a largo plazo de varios años tales como de 10 a 30 años. Algunos modelos convierten los datos de promedios diarios de irradiación en datos promedios horarios.

- Criterio 5. Resolución espectral: la mayoría de los modelos evalúan la irradiación solar de onda corta de 300-4000 nm. Algunos modelos, sin embargo consideran dos o más bandas para una mayor resolución, por ejemplo, hay modelos que se limitan a la luz ultravioleta, otros a la banda fotosintética $400-700 \mathrm{~nm}$. Estos modelos son necesarios para aplicaciones específicas, tales como la física de la atmósfera, teledetección, sistemas fotovoltaicos y acristalamientos revestidos.

- Criterio 6. Tipo de metodología: puede ser determinista o estocástica. Un algoritmo determinista intenta determinar la irradiancia solar durante un tiempo específico, pasado, presente o futuro. Un algoritmo estocástico predice el valor de la irradiación solar respetando las propiedades estadísticas de las series de tiempo de la irradiancia solar, como la varianza, la distribución de frecuencia acumulada, la persistencia,... Otros modelos combinan las características deterministas y estocásticas.

- Criterio 7. Tipo de algoritmo: entre modelos físicos derivados de los principios físicos y los modelos empíricos basados en los datos de irradiancia solar medidos en un lugar y periodo específico para predecir la irradiancia en otros lugares y/o periodos.

- Criterio 8. Geometría de la superficie: los datos de irradiación solar pueden ser necesarios para superficies horizontales, inclinadas o con seguimiento solar que se dirigen siempre hacia el Sol. Como son las aplicaciones solares en los edificios que son fijos o tienen seguimiento del Sol y las aplicaciones ecológicas que implican el modelado de la irradiación solar sobre la topografía del terreno montañoso. La irradiación solar sobre las superficies inclinadas se obtienen a partir de los datos de irradiación solar horizontal mediante el uso de los llamados métodos de transposición.

- Criterio 9. Tipos de cielo: el efecto de las nubes es de primordial importancia, aunque en la aplicación de las cargas térmicas de los edificios la predicción de la irradiancia solar se limita a cielos despejados. 
Los resultados finales pueden requerir del uso de varios modelos sucesivamente cuyos resultados están vinculados, por ejemplo, si se pretende evaluar la irradiancia solar promedio mensual sobre una pared vertical y solo se dispone de las horas de insolación, se utilizará un primer modelo para derivar la irradiación solar global horizontal, un segundo modelo para separar la irradiación solar directa y difusa, y un tercer modelo para predecir la irradiación solar global inclinada de estos dos componentes.

Las técnicas de la inteligencia computacional utilizadas en esta Tesis Doctoral, tienen varios métodos para la predicción de la irradiancia solar en diferentes escalas de tiempo, basados en las redes neuronales artificiales, la lógica borrosa y los sistemas híbridos como ANFIS, las redes neuronales artificiales con wavelet y las redes neuronales artificiales con los algoritmos genéticos (Camacho et al., 2012). Estos enfoques se pueden clasificar en tres tipos diferentes:

El primero de ellos puede estimar la irradiancia solar, en diferentes escalas de tiempo, basados en algunos parámetros meteorológicos, como la temperatura del aire, la humedad relativa, la velocidad del viento, la nubosidad, la duración de la insolación, el índice de claridad, la presión y las coordenadas geográficas como la latitud y la longitud. El segundo enfoque permite la predicción de la irradiancia solar futura, en escalas de tiempo diferentes, sobre la base de los últimos datos observados. El tercer enfoque combina los dos anteriores.

Ejemplos de la aplicación de estas técnicas se tratan en la revisión de la literatura realizada en esta Tesis Doctoral. La utilización de las redes neuronales artificiales es un factor de motivación en el desarrollo de nuevas clases de modelos combinando las redes neuronales artificiales con otras técnicas. Otra tendencia que se observa en la literatura publicada es combinar las redes neuronales artificiales con wavelets, regresiones y otras redes neuronales artificiales. Típicamente, en estos modelos híbridos, se estima inicialmente con una regresión y los resultados se procesan utilizando una red neuronal artificial.

\subsubsection{La persistencia radiativa}

La irradiación solar tiene una propiedad que recibe el nombre de persistencia radiativa, la cual se utiliza en (Hontoria, 2001) para la generación de series sintéticas de irradiación solar combinando herramientas estadísticas y redes neuronales, basada en que de un día para otro los cambios climáticos no son bruscos, sino que son graduales, por lo que la influencia de cómo haya sido un día sobre cómo será el siguiente es importante. Por ejemplo, si un día ha sido muy nublado, este hecho incrementa la probabilidad de que el siguiente también lo sea, o que sea algo nuboso, pero decrementa la probabilidad de que sea totalmente despejado. Y al contrario ocurrirá algo similar, si un día es muy claro y despejado de nubes, muy probablemente el día siguiente será similar, y si se pasa a nublado es presumible que lo haga de forma gradual. En esta propiedad se basan principalmente los métodos clásicos para generar secuencias temporales de irradiación solar a escala diaria.

(Mora y Sidrach, 1997) y (Mora y Sidrach, 1998) para caracterizar las series de exposición horaria de irradiación solar global utilizando un número mínimo de parámetros y (Mora, 1994) para la caracterización y generación de series de exposición horaria de irradiación global. Encuentran dos propiedades fundamentales, que sirven para determinar el modelo con el que se pueden identificar. Estas dos características son el valor de la exposición para una hora está muy relacionado con el valor que se dio la hora anterior, y la perturbación que se produce en una hora del día está relacionada con la 
que se produjo el día anterior a esa misma hora. Con estas dos propiedades se encuentra un método que permite generar series de estos valores utilizando, solamente, datos normalmente disponibles.

El estado del tiempo atmosférico en un momento concreto de temperatura, humedad, precipitación, viento, presión, insolación, nubosidad,... Se encuentra relacionado con las condiciones climatológicas registradas en el pasado más inmediato. Esta dependencia disminuye a medida que aumenta el tiempo transcurrido. En relación con ello, se entiende por inercia la capacidad que tiene un cuerpo a persistir o, lo que es lo mismo, la resistencia que opone éste a cambiar de un estado a otro. Esta propiedad resulta, en mayor o menor medida, inherente a todas las variables climatológicas (Martín, 2003), y depende directamente de la continuidad, por vía de ejemplo. La temperatura del aire presenta un carácter de persistencia mayor en comparación a la precipitación, al tratarse de una variable física continua, frente a la segunda que no lo es, de cada variable ambiental.

La persistencia es una característica posible de una serie climatológica. Se trata de una tendencia a que las condiciones en un periodo de continuar como antes. Es debido a un retraso en el cambio de un tipo de clima a otro, lo que lleva a la concentración de las ocasiones con el mismo clima, es decir, tiempo estable (Linacre, 1992). Modelos que han seguido idéntico enfoque han sido desarrollados desde mediados del siglo pasado, destacando la aplicación de técnicas probabilísticas markovianas, modelo estocástico de las cadenas de Markov, método de las rachas con la longitud media de las rachas, y los coeficientes de persistencia como por ejemplo la probabilidad de lluvia.

(Wilks, 2006) presenta la persistencia como una probabilidad condicional en las variables ambientales que a menudo presentan dependencia estadística con sus propios valores pasados o futuros. En la terminología de las ciencias de la atmósfera, esta dependencia a través del tiempo es generalmente conocida como persistencia.

La persistencia se puede definir como la existencia de dependencia positiva estadística entre los valores sucesivos de la misma variable, o entre las apariciones sucesivas de un evento determinado. La dependencia positiva significa que los valores grandes de la variable tienden a ser seguidos por los valores relativamente grandes y los valores pequeños de la variable tienden a ser seguidos por los valores relativamente pequeños. Por lo general, el caso de la dependencia estadística de las variables meteorológicas en el tiempo es positiva. Por ejemplo, la probabilidad de una temperatura superior a la media mañana es más alta si la temperatura de hoy ha sido superior a la media. Por lo tanto, otro nombre para la persistencia es la dependencia serial positiva.

La persistencia meteorológica, o la tendencia del clima en periodos sucesivos a ser similares, se ponen de manifiesto en términos de probabilidades condicionales, por ejemplo, para los dos eventos discretos, precipitación y no precipitación.

Para las variables continuas, por ejemplo, la temperatura, la persistencia típicamente se caracteriza en términos de la correlación serial, o autocorrelación temporal. El prefijo auto en autocorrelación denota la correlación de una variable consigo misma, por lo que la autocorrelación temporal indica la correlación de una variable con su propio futuro y los valores del pasado. Algunas veces tales correlaciones se conocen como correlaciones retardadas. Las autocorrelaciones se suelen calcular como coeficientes de correlación de Pearson momento-producto. 
Para el análisis de los datos climatológicos diarios en esta Tesis Doctoral, se ha utilizado la autocorrelación parcial la cual hace referencia a la dependencia del valor de una determinada variable $\mathrm{x}$ estadística para un tiempo $\mathrm{t}$, con valores de esa misma variable precedentes en el tiempo. Si la autocorrelación es nula, indica que no existe ninguna relación entre el valor de la variable $\mathrm{x}$ en un instante $\mathrm{t} y$ los valores previos en el tiempo. El otro caso extremo es cuando el valor de la autocorrelación es 1 , lo que indicaría una dependencia total.

La función de autocorrelación parcial, calcula el coeficiente de autocorrelación parcial de orden k, se calcula la correlación entre parejas de valores separados esa distancia pero eliminando el efecto debido a la correlación producida por retardos anteriores a k. Mide la correlación entre los valores de la serie distanciados un lapso de tiempo k. Proporciona el coeficiente de correlación consigo misma, para distintos retardos. Los intervalos de confianza ayudan a detectar los valores significativos. Si están dentro de las bandas se considera no significativo, en general. Esto indica que la observación no influye excesivamente sobre los que están alejados de ella en esa cantidad de periodos.

En esta Tesis Doctoral se analizaron los valores de la irradiación solar global, las temperaturas media, máxima y mínima diarios de una base de datos, mostrando, analizando y aplicando los resultados.

\subsubsection{Validación y rendimiento de los modelos}

Un modelo perfecto no existe y aunque existiera, sería imposible determinarlo debido a que la verdadera irradiancia solar no puede determinarse teóricamente o medirse experimentalmente con certeza (Gueymard y Myers, 2007). Las fuentes de incertidumbre en la medición de la irradiación solar experimental deberían estar presentes al evaluar el desempeño de cualquier modelo con los datos medidos. Al proponerse un nuevo modelo, éste tiene que ponerse a prueba para asegurar su validez al ser utilizado por otros usuarios. Por otra parte los modelos desarrollados empíricamente a partir de datos medidos en un lugar concreto, su universalidad debe de comprobarse mediante pruebas contra datos de una variedad de lugares. Todo esto requiere tiempo, por lo que es difícil recomendar un modelo nuevo para su aplicación generalizada. También hay que tener en cuenta que los cambios de calibración y procedimientos de medición pueden alterar el rendimiento del modelo.

La comparación entre las predicciones de un modelo de irradiancia solar y las mediciones correspondientes, es la diferencia que debería haber sido lograda para la validación de los resultados, esta es la forma habitual de evaluar su validez y rendimiento. Otra forma consiste en la comparación de las predicciones contra las predicciones de otro modelo validado y más sofisticado que el propuesto, (Gueymard, 2003ab) demuestra que esta forma tiene la ventaja de no estar limitado por las condiciones particulares de un lugar, o por la calidad de sus datos. Finalmente, cuando los datos experimentales de calidad excepcional, con incertidumbre bien caracterizada y documentada están disponibles, pueden ser agrupados en un conjunto de datos de referencia (Gueymard, 2008) y (Gueymard y Myers, 2008), contra el cual varios modelos pueden ser probados con confianza.

El rendimiento de los modelos se puede comprobar con varios índices estadísticos: el coeficiente de determinación $\mathrm{R}^{2}$, el sesgo medio del error $\mathrm{MBE}$, la raíz del error cuadrático medio RMSE,... Por un lado MBE ofrece información sobre el rendimiento a largo plazo de los modelos estudiados, es una medida de los errores sistemáticos o de sesgo. Por otra parte RMSE (Ec. 2.2.1) proporciona información sobre 
los resultados a corto plazo de los modelos, es principalmente una medida de los errores aleatorios, ya que permite una comparación término a término de la desviación real entre el valor calculado y el valor medido. Cuando el investigador está interesado en el rendimiento de los modelos predictivos de la cantidad total de energía durante un periodo largo de tiempo, entonces el modelo con un bajo MBE debe ser considerado para obtener mejores resultados. Cuando la investigación se lleva a cabo con el fin de seleccionar un modelo más sensible a las desviaciones de los valores calculados (predicciones) respecto de las medidas (datos), entonces el modelo con bajo RMSE debe ser preferido (Tymvios et al., 2005).

$$
\text { RMSE }=\sqrt{\text { MSE }}=\sqrt{\frac{\sum_{\mathrm{i}=1}^{\mathrm{n}}\left(\mathrm{X}_{\text {datos }}-\widehat{\mathrm{X}}_{\text {predicciones }}\right)^{2}}{\mathrm{n}}}
$$

\subsubsection{Datos climáticos CENSOLAR}

EL Pliego de Condiciones Técnicas de Instalaciones de Baja Temperatura Instalaciones Solares Térmicas (IDAE, 2009) recomienda unos valores de irradiación solar global diaria sobre la superficie horizontal y la temperatura ambiente media durante las horas de sol medios diarios para cada mes del año y para cada provincia de España, para el uso en el diseño y cálculo de sistemas solares térmicos. Estos datos a pesar de dar una buena aproximación tienen el inconveniente de no contemplar las variaciones diarias y anuales que se producen en los distintos meses y años.

\subsubsection{Modelado por correlación}

El modelado por correlación cuando es utilizado para la estimación de la irradiación solar, involucra las relaciones empíricas entre la irradiación solar y los parámetros climatológicos y geográficos más fácilmente disponibles como las horas de sol, la humedad, la temperatura, la latitud,... Sin embargo, estos modelos dependen de los datos espaciales del lugar de interés, es decir, aplicar estos modelos a condiciones distintas de las condiciones de observación es cuestionable.

Algunos parámetros que afectan a la irradiación solar pueden resumirse como (Ertekin y Yaldiz, 1999) por factores astronómicos como la constante solar, la distancia Tierra-Sol, la declinación solar y el ángulo horario, por factores geográficos como la latitud, la longitud y la altura del lugar, por factores geométricos como la orientación, la inclinación, la altura solar y el azimut solar, por factores físicos como la dispersión de las moléculas del aire, el contenido de vapor de agua, la dispersión del polvo y otros componentes atmosféricos como el $\mathrm{O}_{2}, \mathrm{~N}_{2}, \mathrm{CO}_{2}, \mathrm{O}_{3}, \ldots$ y factores meteorológicos como los efectos de la nubosidad y el reflejo de los alrededores.

La primera correlación empírica para estimar la irradiación solar global incidente sobre la superficie horizontal está propuesta por (Ångström, 1924) que correlaciona la irradiación solar global y el ratio de la duración de las horas de sol, posteriormente fue modificada por (Prescott, 1940) y (Page, 1964).

(Dincer et al., 1996) propone un método para estimar la irradiancia solar horaria global y difusa, haciendo uso de la temperatura ambiente, los datos experimentales utilizados son de los años 1990- 
1992 en Gebze, Turquía, se encuentra una fuerte correlación entre la temperatura ambiente y la irradiancia solar, obteniendo coeficientes de regresión alrededor de 0,95 y que el modelo es capaz de estimar la irradiación solar horaria global y difusa en el futuro. Esta correlación se representa en forma gráfica y mediante ecuación polinomial de orden quinto para cada mes del año.

(Skeiker, 2006) en este estudio investiga la correlación entre los parámetros geográficos y los meteorológicos con la irradiación solar global diaria media mensual para la provincia de Damasco, Siria, utilizando siete variables diferentes de media diaria como son la intensidad de la irradiación solar extraterrestre, el ratio de la duración de la insolación, la humedad relativa, la temperatura máxima del aire, la temperatura máxima de bulbo seco, la presión atmosférica y el seno del ángulo de la declinación solar. El resultado es una relación de regresión múltiple para dar estimaciones precisas de la irradiación solar global diaria media mensual sobre la horizontal con un coeficiente de correlación de 0,9915, y para el caso de utilizar una relación de dos variables se obtiene un coeficiente de correlación 0,9853. Además de ofrecer una amplia relación de este tipo de estudios realizados por todo el mundo.

(Brinkworth, 1977) estudia la característica de la variación secuencial de la irradiación solar diaria que puede ser representada en términos simplemente numéricos, deducidos de funciones de autocorrelación de un modelo estocástico directo. Pudiendo ser generadas secuencias sintéticas, que relacionan las características de largo plazo de la irradiación solar respecto a sus propiedades secuenciales, como la tendencia estacional y la variación de las fluctuaciones.

(Mustacchi et al., 1979) realiza la simulación estocástica de la irradiación solar global horaria mediante el modelo autorregresivo media móvil ARMA, técnicas de análisis factorial y el modelo de Markov con una matriz de transición de la transmitancia atmosférica. También prueba el tensor de transición y el mapa gausiano.

(Exell, 1981) realiza modelos para la simulación de la irradiación solar global diaria y los flujos de la irradiación solar horaria basados en estudios de los datos de irradiación solar en Tailandia, pudiéndose extender su uso a toda la región, fórmulas empíricas de la distribución binomial se encuentran para la aproximación de las distribuciones de probabilidad, mediante matrices de probabilidad del índice de claridad diario.

(Engels et al., 1981) estudia el comportamiento estadístico de la irradiación solar global horizontal de la cual indica que su distribución de probabilidad es no gaussiana, por lo que, la media y la varianza reportados en los resúmenes estadísticos no pueden ser los estadísticos más apropiados ni útiles, en particular, son de dudoso valor en el diseño de sistemas de conversión de la energía solar.

(Sfeir, 1981) analiza los datos de dos lugares en Líbano uno en la costa y otro en el interior del país, mediante la correlaciones del tipo de Ångström diarias y mensuales, calcula las funciones de densidad de probabilidad para los valores de irradiación solar global diaria para cada mes y las compara con los resultados de (Liu y Jordan, 1960). También aplica otros modelos para predecir la irradiación solar global media mensual.

(Biga y Rosa, 1981) estudia el comportamiento de la distribución estadística de la media móvil con la irradiación solar sobre días consecutivos en Lisboa, Portugal, en función del número de días y el índice de claridad. La disponibilidad de la irradiación solar a lo largo de días consecutivos es un factor importante a considerar en el diseño de sistemas solares térmicos con sistemas de almacenamiento. 
(Skaggs et al., 1982) analiza 17 años de mediciones de la irradiación solar global diaria de una localidad en Minnesota, USA, con el objetivo de determinar el grado de persistencia en los datos y demostrar el efecto de la persistencia en el análisis estadístico de los datos. Encuentra que la persistencia varía a lo largo del año y que el tiempo característico entre los rangos de las observaciones independientes está entre un día y poco más de tres días.

(Boileau, 1983) utiliza modelos simples estadísticos adaptados para el cálculo de las previsiones con pocas medidas, media móvil MA, y otro con series más largas, autorregresivo AR, de la irradiación solar global diaria de los datos medidos en tres lugares diferentes uno de clima templado en Trappes y otro clima mediterráneo en Carpentras, Francia y una zona ecuatorial a gran altura de Huallao, Perú.

(Ma y lqbal, 1984) compara estadísticamente varias correlaciones de la irradiación solar global diaria media mensual y otros modelos existentes para la irradiación solar difusa sobre la horizontal y recomienda las que mejor se ajustan a los datos de una serie de lugares en América del Norte y Europa, y más sencillos de utilizar.

(Vergara-Domínguez et al., 1985) presenta un nuevo modelo automático para la simulación de series de irradiación solar global diaria el cual es producto de dos factores, un componente estacional de baja frecuencia debido al movimiento periódico del sol, con un carácter determinista y periódico de un año, y otro componente aleatorio debido a las rápidas fluctuaciones del ambiente atmosférico, debido a la dispersión, absorción y reflexión.

(Amato et al., 1986) analiza estadísticamente series de datos de la irradiación solar global diaria de 20 años 1958-1977 de cuatro localidades en Italia, mediante la serie de Fourier con pocos coeficientes y un modelo de primer orden de Markov. También comenta que la capacidad del depósito de almacenamiento de los sistemas solares térmicos depende de las características estadísticas de las secuencias de irradiación solar diaria, es decir, sobre la probabilidad de la persistencia en las condiciones de cielo despejado.

(Gordon y Reddy, 1988a) analiza las series de tiempo de la irradiación solar global diaria sobre la horizontal, aplicando una base mensual, de lugares con distintas condiciones climáticas y geográficas en Australia, India, Israel y Tailandia. De entre los aspectos estudiados está el análisis del comportamiento secuencial, que consiste en el cálculo de los componentes estocásticos mediante los coeficientes de autocorrelación para determinar los tiempos de persistencia del día a día de la irradiación solar global diaria, recopilando los estudios realizados al respecto.

(Gordon y Reddy, 1988b) continua el estudio con la irradiación solar global horaria y con respecto a las propiedades secuenciales muestra que los coeficientes de autocorrelación parcial, son una buena aproximación, independiente de la hora del día, encontrando unas correlaciones muy fuertes en los tiempos de retardo de una hora.

Las técnicas de alisado son de fácil aplicación y se suelen utilizar en el campo de la predicción a corto plazo, ya que los cambios estructurales se detectan antes que con otros métodos. Se realimentan a medida que se generan nuevos datos, lo que facilita enormemente la predicción, que se realiza con fórmulas recurrentes. Cuando la estructura de los datos se muestra más inestable los métodos de alisado dan mejores resultados, ya que tratan de combinar en cada momento las observaciones pasadas con el fin de descubrir la estructura del fenómeno. En este sentido se dice que son modelos de validez 
local. Los resultados son más satisfactorios, incluso cuando se dispone de un número limitado de observaciones (Rodríguez, 2000).

\subsubsection{Análisis de Fourier}

En el diseño y simulación de los sistemas solares térmicos es necesario conocer la irradiación solar global y la temperatura ambiente del aire. El objetivo de este modelo de predicción consiste en el desarrollo de una función típica de tiempo anual, que permita el uso y análisis de las variables climatológicas como la irradiación solar global diaria y la temperatura ambiente del aire que muestran frecuencias significativas y que cuentan con series climatológicas suficientes a través del análisis de Fourier.

En general, las variables climatológicas, como la irradiación solar, pueden dividirse en un componente determinista y un componente aleatorio, ambos dependientes del tiempo. El componente determinista puede expresarse por la suma de un componente de tendencia, constante en el tiempo que será el valor medio de las observaciones y un componente de frecuencia, oscilatorio.

El análisis de Fourier de series temporales, que presentan frecuencias o armónicos importantes, se basa en la hipótesis de que esta serie está formada por un conjunto de ondas senoidales y cosenoidales de frecuencias diferentes. El componente de frecuencia puede expresarse como una suma de armónicos. El componente aleatorio corresponde al ruido de las fuentes presentes en las observaciones.

La función anual típica se obtiene mediante la técnica de mínimos cuadrados para un sistema no lineal, aplicada al conjunto de ecuaciones representativas de los diferentes años analizados. Para la realización del Atlas de Radiación Solar de Cataluña, donde se utiliza esta técnica, se considera solamente el armónico fundamental (Baldasano et al., 1988), (Coronas y Baldasano, 1984) y (Santabárbara et al., 1996).

\subsubsection{Modelado mediante el año meteorológico típico}

Para modelar a medio y largo plazo el rendimiento de los sistemas solares, es necesario simular el comportamiento del sistema utilizando muchos años de datos meteorológicos reales o como alternativa se utiliza un año de datos meteorológicos típico. El primer método debe dar resultados más exactos, pero la simulación requiere mucho más tiempo. El segundo método permite obtener resultados mucho más rápidos, pero hay que seleccionar un año adecuado.

Los conjuntos de datos meteorológicos de varios años, son un conjunto fundamental que incluye una gran cantidad de información. También existen, los días representativos que son los datos de unos días o semanas desarrollados para representar las condiciones típicas del clima, resultan más económicos para el análisis a pequeña escala y se encuentran a menudo en simulaciones simplificadas y en herramientas de diseño (Carter, 1994).

En los últimos años, los estudios de eficiencia energética en los edificios, así como el diseño de sistemas solar no se realizan usando promedios a largo plazo de datos meteorológicos como entradas, son 
preferidos un conjunto de datos representativos de la climatología característica del lugar concreto en el que se van a realizar estos estudios. Estos conjuntos de datos son Test Reference Year TRY, Typical Meteorological Year TMY y Weather Year for Energy Calculations WYEC.

El ensayo de referencia anual TRY, representa todo un año de datos meteorológicos reales. El año escogido para los datos TRY se selecciona entre los registros climáticos anuales disponibles. El proceso de selección elimina años con meses con muy altos o extremadamente bajos datos medidos. El proceso de eliminación continúa hasta que solo un año, TRY queda. Los datos TRY representan una forma de media del clima en el sentido, de que los datos extremos se han eliminado.

Sin embargo, todavía, se compone de los datos de un año del calendario actual, y un año solo no es una estadística promedio real de las condiciones climáticas que ocurren durante un periodo largo de tiempo. Por esta razón, los datos TRY no se consideran suficientemente típicos para ser utilizados como base al obtener las estimaciones de energía requerida a lo largo de varios años.

Los datos TRY pueden ser utilizados efectivamente cuando se comparan opciones de diseño, pero no se recomienda para la predicción del rendimiento a largo plazo de las instalaciones de un edificio. Sin embargo, si no hay alternativas a los datos TRY para un lugar, entonces su uso es preferible a los datos seleccionados con todavía menos rigor.

El año meteorológico típico TMY, representa también un año de datos climatológicos, pero se construyen, con meses medios o típicos de un largo número de años. Está considerado como más representativo de las condiciones meteorológicas medias que el formato TRY. Los meses que forman TMY, se escogen individualmente por búsqueda a través de todos los datos disponibles del clima para un lugar determinado y selecciona el mes que mejor representa el plazo promedio de las condiciones a lo largo de ese mes. Con este procedimiento TMY se genera a partir de meses de diferentes años.

Lo que cabe señalar, es que el método TMY produce saltos en el valor de los datos del final y comienzo de meses adyacentes, porque estos meses no son del mismo año. Esto se resuelve mediante el uso de técnicas de ajuste de curvas, que facilitan datos en cada par de meses cuando se unen.

En el año climático para cálculos energéticos WYEC, los datos representan también un año de datos meteorológicos, pero se construye utilizando el mes representativo del histórico con mayor representatividad a 30 años. Se considera que los registros de una base de datos de 30 años son estables y que son muy pocos los cambios que se dan en periodos de 10 años con nuevos periodos de 10 años (Said y Kadry, 1994).

Así, en lugar de tratar un año completo, lo que se hace es buscar un mes típico completo para enero, un mes típico para febrero,... hasta completar un año, los meses individuales pueden ser de diferentes años y una vez seleccionados los doce meses del año se concatenan para formar un año completo, porque los meses adyacentes son generalmente seleccionados de diferentes años, las discontinuidades se producen al unir los meses. Estas pueden ser suavizadas si es necesario usando una interpolación lineal simple o una técnica de ajuste de curvas.

Para realizar la selección del mes típico de entre varios años, se suele utilizar el estadístico FS (Finkelstein y Schafer, 1971), este método es sencillo de aplicar y selecciona meses con las propiedades deseadas, no existe evidencia que utilizando métodos más complejos produzcan mejores selecciones de los meses. 
(Hall et al., 1978) propone el uso del método Finkelstein-Schafer FS para comparar la distribución de frecuencia acumulada CDF, como medida de similitud de dos distribuciones. Para la selección de un mes típico se compara la distribución de frecuencia acumulada de todos los datos de un mes concreto de todos los años disponibles con la distribución de frecuencia acumulada de un solo mes de un año. Si el estadístico FS para el mes concreto de un año es pequeño, entonces los datos reales tendrán una similar media, mediana, moda, desviación estándar, percentiles y otros estadísticos que los datos a largo plazo de ese mes.

El procedimiento para la selección de datos mediante el método FS es el siguiente: las funciones de distribución acumulada se calculan para cada parámetro meteorológico, para cada mes individual de cada año y para los datos combinados de cada mes, la función de distribución acumulada consiste en una tabla de valores del porcentaje de frecuencia acumulada vs. los valores del parámetro. El estadístico FS se calcula para cada parámetro meteorológico para cada mes individual del año, comparando su CDF con el CDF de los datos combinados de todos los registros de ese mes (Ec. 2.2.2). Los estadísticos FS de cada variable ambiental se multiplican por los factores de ponderación, si fuera necesario.

$$
\mathrm{FS}_{\mathrm{x}}=\left(\frac{1}{\mathrm{n}}\right) \sum_{\mathrm{i}=1}^{\mathrm{n}}\left|\mathrm{CDF}_{\mathrm{m}}\left(\mathrm{x}_{\mathrm{i}}\right)-\mathrm{CDF}_{\mathrm{y}, \mathrm{m}}\left(\mathrm{x}_{\mathrm{i}}\right)\right|
$$

(Rahman y Dewsbury, 2007) describe los métodos de selección de los datos meteorológicos típicos y la selección del año meteorológico típico en Subang, Malasia. El año meteorológico típico es seleccionado mediante el estadístico FS, de 19 años de datos meteorológicos registrados durante el periodo 19801998, aplicando una ponderación a las diferentes variables meteorológicas como son la temperatura ambiente, la irradiación solar, la humedad relativa y la velocidad del viento, pero tuvo poco efecto en la selección, por lo que se recomienda que debe utilizarse la ponderación a menos de que existan razones especiales.

(Skeiker, 2004) realiza la generación de un año meteorológico típico para la zona de Damasco, Siria, utilizando el método estadístico FS, con los datos meteorológicos horarios registrados durante el periodo 1981-1990 que incluyen los datos de irradiación solar global y otros 10 parámetros meteorológicos. (Skeiker, 2007) compara diferentes metodologías para seleccionar TMY con criterios basados en la irradiación solar, junto con otras variables meteorológicas: método Laboratorio Sandia que resultó ser el mejor, método Danish, método Festa-Ratto, método Crow, método Miguel-Bilbao, método Gazela-Mathioulakis y el año meteorológico promedio. (Skeiker y Ghani, 2008) y (Skeiker y Ghani, 2009) presenta un programa informático destinado a la creación de un año meteorológico típico para cualquier lugar de interés.

(Chan et al., 2006) revisa una serie de enfoques diferentes para derivar un año meteorológico típico y genera el correspondiente a Hong Kong, China, utilizando datos meteorológicos de 25 años de 19792003 de las variables ambientales: temperatura de bulbo seco, temperatura del punto de rocío, velocidad del viento e irradiación solar.

(Yang et al., 2007) realiza el año meteorológico típico para 60 ciudades en China de cinco zonas climáticas diferentes: frío intenso, frío, verano caliente e invierno frío, verano caliente e invierno templado, y suave. Con datos medidos en el periodo de 1971-2000 de las variables ambientales temperatura de bulbo seco, temperatura de punto de rocío, velocidad del viento e irradiación solar. Un total de siete índices climáticos se utilizan para seleccionar los doce meses típicos meteorológicos que 
componen el año meteorológico típico para cada ciudad. Resultando que las funciones de distribución acumulada de los meses meteorológicos típicos seleccionados tienden a seguir a sus homólogos de largo plazo muy bien. (Yang et al., 2008) realiza una simulación detallada horaria para edificios en las zonas climáticas anteriores, comparando la simulación energética realizada con TMY y las medidas a largo plazo.

(Ebrahimpour y Maerefat, 2010) aplica el método Sandia basado en el criterio de persistencia de (Hall et al., 1978) para el año meteorológico típico de un periodo de datos de 14 años 1992-2005 en Bardarash, Irán, y se compara con los resultados de dos programas informáticos: Meteonorm y Weather Generator.

(Bulut, 2003) realiza el año de referencia típico diario para los datos de la irradiación solar global de 19 años en Estambul, Turquía, y también lo expresa con una ecuación trigonométrica. (Bulut, 2004) presenta el año típico de la irradiación solar en forma de tabla para siete provincias de la región de Anatolia, Turquía, a partir de datos de la irradiación solar global diaria durante 14 años.

(Bilbao et al., 2004) y (Miguel y Bilbao, 2005) realiza el año meteorológico típico con un nuevo método y evalúa otros métodos con datos de 10 años 1991-2000 en Valladolid y 24 años 1975-1998 en Madrid, España.

(Ferrante et al., 2008) compara el resultado obtenido del método Belga y el método Sandia con datos de ocho años 1999-2006 en Palermo, Italia.

(Mosalam y Tadros, 1994) realiza el año típico de irradiación solar de Egipto generado mediante el uso de los datos diarios de la irradiación solar global obtenida por las mediciones en 10 estaciones durante largos periodos, además los valores horarios para el mediodía de los diferentes componentes de la irradiación solar, directa, difusa y global sobre las estaciones, se estiman para cada mes mediante modelos empíricos y usando datos meteorológicos.

(Kalogirou, 2003) presenta la generación del año meteorológico típico TMY-2 a partir de simples TMY creados con datos horarios, 8760 datos al año, del periodo 1986-1992 en Nicosia, Chipre. (Feuermann et al., 1985) analiza el rendimiento de un sistema solar térmico con datos de un día meteorológico típico. (Pissimanis et al., 1988) genera un conjunto de datos representativos en la ciudad de Atenas, Grecia. (Festa y Ratto, 1993) presenta un procedimiento para crear un año de referencia, consistente en 8760 datos horarios. (Gansler et al., 1994) evalúa los datos meteorológicos generados para su uso en simulaciones de sistemas de energía solar.

(Argiriou et al., 1999) utiliza para generar 17 TMY con varias metodologías a las que aplica 20 años de mediciones de datos meteorológicos horarios en Atenas, Grecia, que cubren el periodo de 1977-1996, aplicándose los resultados a simulaciones de sistemas solares térmicos y fotovoltaicos. (Gazela y Mathioulakis, 2001) propone un método para la determinación de un año meteorológico típico, que se compara con otros métodos y se utiliza para la evaluación del rendimiento a largo plazo de los sistemas solares térmicos. (Chow et al., 2006) estudia y compara el año meteorológico típico realizado con datos en las ciudades de Hong Kong y Macao, China.

(Ruíz, 2004) para el control de las mermas de vino, analiza la persistencia de la irradiación solar y la temperatura ambiente media para aplicar el año meteorológico típico en La Rioja, España, para la caracterización térmica de las naves de crianza climatizadas. (Mandurino, 2009) estudia los datos meteorológicos mediante el año meteorológico típico para su aplicación energética y ambiental. 


\subsubsection{Modelado por satélites artificiales}

El conocimiento preciso de la irradiación solar sobre la superficie de la tierra, se realiza de forma más precisa con los datos obtenidos sobre el terreno para caracterizar el recurso solar en un lugar determinado.

Sin embargo, a pesar de que las redes de estaciones de medida están creciendo, su densidad espacial suele ser muy baja. Por lo que, los datos estimados de la irradiación solar derivados de las imágenes de satélite son una herramienta interesante para cuantificar la irradiación solar a nivel del suelo en un área determinada. Con la que se pueden derivar los valores horarios con una exactitud tan buena como la interpolación entre estaciones de tierra a una distancia de $25 \mathrm{~km}$ (Zelenka et al., 1999). (Perez et al., 1997) compara la exactitud de la irradiancia solar horaria derivada de los datos satelitales en un tiempo y lugar específico, con las obtenidas a través de la extrapolación y/o interpolación de las mediciones en las estaciones de tierra.

Los satélites artificiales para la observación de la Tierra se pueden clasificar, de acuerdo a su órbita en polares y geoestacionarios. Los satélites polares con una órbita de $800 \mathrm{~km}$ tienen una alta resolución espacial, pero una cobertura temporal limitada. La mayoría de los métodos para derivar la irradiación solar a partir de información satelital hacen uso de los satélites geoestacionarios, con una órbita de $36000 \mathrm{~km}$ girando alrededor del eje de la Tierra a su misma velocidad, proporcionan una resolución espacial de hasta $1 \mathrm{~km}$ y temporal de 15 minutos. Meteosat para Europa situado sobre el golfo de Guinea, GOES para América, INSAT para India, GMS para extremo Oriente, Elektro para Rusia y FY-2 para China, son algunos de ellos.

La información que reciben los sensores de los satélites artificiales para la observación de la Tierra es la reflejada por el suelo y la dispersada por la atmósfera. Teniendo en cuenta la conservación de la energía para el sistema tierra-atmósfera se puede decir que la irradiación solar extraterrestre es igual a la reflejada por la tierra y la atmósfera, más la absorbida por la tierra y la atmósfera (Polo, 2008). Con lo que la irradiación solar absorbida por la superficie de la tierra se puede expresar en función del albedo y la irradiación incidente en la superficie. Y está queda representada por el albedo, la extraterrestre, la reflejada por la tierra y la atmosfera, y la absorbida por la atmósfera.

Las imágenes de satélites artificiales utilizadas en la recuperación de la irradiación solar es una medida de la irradiación de la tierra en el canal visible en un momento determinado y sobre unas ventanas espaciales. Los valores de irradiación solar registrados por el radiómetro del satélite artificial varían según el estado de la atmósfera, de las situaciones de cielo despejado a completamente cubierto y dependiendo también de la reflectancia de la superficie del suelo. Se normaliza el parámetro llamado, índice de nubosidad, por (Cano et al., 1986) y (Diabaté et al., 1989), como una relación de reflectancias y albedos de la tierra y de la atmósfera, de las medidas por el sensor del satélite (Ec. 2.2.3).

$$
\mathrm{n}=\frac{\rho-\rho_{\mathrm{g}}}{\rho_{\mathrm{c}}-\rho_{\mathrm{g}}}
$$

Donde,

$\mathrm{n}$ : Índice de nubosidad.

$\rho$ : Reflectancia vista por el radiómetro del satélite por albedo planetario instantáneo.

$\rho_{c}$ : Reflectancia de las nubes por albedo de las nubes. 
$\rho_{\mathrm{g}}:$ Reflectancia de la tierra por albedo de la tierra.

Este concepto de índice de nubosidad, que da información de la cubierta de nubes, se relaciona con la irradiancia solar que llega a la superficie de la tierra. Con lo que, las metodologías estadísticas para estimar la irradiación solar a partir de imágenes de satélites se basan en la hipótesis de la relación lineal entre la transmitancia atmosférica y el índice de nubosidad (Diabaté et al., 1988), (Schmetz, 1989), (Noia et al., 1993ab) ofrece una visión general con ejemplos de la precisión de las técnicas, (Ineichen y Perez, 1999), (Rigollier et al., 2004) y (Zarzalejo, 2005) aplica las técnicas de la inteligencia artificial.

Para la obtención de datos de irradiancia solar desde la información de las imágenes satelitales, se desarrollan diversas rutinas (Tarpley, 1979), (Gautier et al., 1980), (Moser y Rachke, 1983), (Haar et al., 1973), (Exell, 1984), (Moser y Rachke 1984), (Zelenka, 1986), (Cano et al., 1986), (Dedieu et al., 1987), (Sorapipatana et al., 1988), (Sorapipatana y Exell, 1989), (Diabaté et al., 1989), (Perez et al., 1990), (Czeplak et al., 1991), (Nunez, 1993), (Pinker y Laszlo 1995), (Beyer et al., 1996), (Hirunlabh et al., 1997), (Zelenka et al., 1999), (Ineichen y Perez 1999), (Hammer et al., 1999), (Wyser et al., 2002), (Schillings et al., 2004b), (Perez et al., 2004), (Janjai et al., 2005), (Vignola et al., 2007) y (Martins et al., 2007).

Varios modelos computacionales se han desarrollado, evolucionando con mejoras, hacia un modelo híbrido entre la estadística y la física.

El modelo Heliosat, propuesto por (Cano et al., 1986) y modificado por (Diabaté et al., 1988), (Diabaté et al., 1989) y (Beyer et al., 1996) utilizado con imágenes del satélite Meteosat. Se basa en los siguientes supuestos, por lo general, el albedo de la superficie de la tierra o el océano es menor que el albedo de una atmósfera nebulosa. Así, el aumento del albedo da una medida de la cubierta de nubes.

El modelo Heliosat 1, consiste básicamente en una relación lineal entre el índice de nubosidad y el índice de claridad.

El modelo Heliosat 2, se refiere a la atmósfera y la extinción de nubes por separado. La radiación con cielo despejado se calcula utilizando el modelo ESRA (Rigollier et al., 2000), con el factor de turbidez Linke como parámetro para la composición de la atmósfera. El flujo de los rayos solares hacia la tierra y hacia arriba con transmitancias (Happ et al., 1989) de cielo claro, se utilizan para corregir la estimación de la reflectancia de la tierra y de las nubes. (Lefèvre et al., 2007) utiliza un conjunto reducido de datos de los satélites Meteosat y el método Heliosat 2, para evaluar la irradiación solar media diaria en la superficie de cualquier lugar geográfico en Europa y África.

(Guemene et al., 2010) compara las mediciones sobre el terreno de 10 lugares de Camerún durante el año 1984, con las estimaciones basadas en las imágenes de satélite, aplicando el método Heliosat 2, sobre la herramienta web Helioclim del proyecto SoDa. Las curvas de correlaciones se construyen entre las estimaciones de la irradiación diaria de datos de satélites y de las mediciones.

El modelo Heliosat 3, evoluciona hacia un sistema más físico, utilizando un nuevo tipo de esquema de cálculo SOLIS (Mueller et al., 2004).

El modelo Perez, es una evolución del modelo (Cano et al., 1986), que se ha desarrollado en la Universidad de Albany y se aplica a las imágenes del satélite GOES (Perez et al., 2002). El modelo propone estimar la irradiancia global horaria desde el índice de nubosidad, basado en el modelo Kasten (Ineichen y Perez, 2002). El modelo BRASIL-SR, es una evolución del modelo físico (Moser y Raschke, 
1983), ofrece mapas de irradiación, utilizando imágenes de GOES (Pereira et al., 2000) y (Martins et al., 2007). El modelo DLR-SOLEMI, para irradiancia directa normal, desde imágenes de Meteosat (Schillings et al., 2004a), se basa en el modelo de cielo claro (Bird y Huldstrom, 1983).

Varios estudios evalúan las necesidades del usuario para los datos de irradiación solar (ESRA, 2000). Estas necesidades consisten generalmente en la irradiación global horaria o diaria y las cantidades derivadas para distintas partes del mundo. Las condiciones de uso requieren que los datos deben presentar un acceso conveniente y de bajo coste, y deberían estar disponibles en alta resolución espacial y con un error relativo bajo. Los datos de irradiación solar estimados desde imágenes de satélite en forma de mapas o bases de datos los podemos encontrar en:

- Satel-Light, uno de los primeros, resultado de un proyecto de la Unión Europea 1996-1998, se basa en la metodología Heliosat que cubre Europa y el norte de África.

- SoDa, es un instrumento para consolidar diferentes bases de datos (Wald et al., 2002) y (Wald et al., 2004).

- SWERA, es un proyecto de la Organización de las Naciones Unidas ONU, que ofrece mapas de irradiación solar de varias regiones, África, América del Sur y Asia Oriental, incluye la metodología BRASIL-SR y Heliosat.

- PVGIS, integra datos de irradiación solar estimada de satélite con un SIG para Europa, África y Asia, incluyendo los efectos de la inclinación, orientación y sombras.

- NASA Surface Meteorology and Solar Energy, es un archivo a nivel mundial con una resolución de $1^{\circ} \times 1^{\circ}$.

- Australian Bureau of Meteorology, estima la irradiación solar desde el satélite MTSAT-1R y ofrece datos y mapas de Australia.

\subsubsection{La estimación y la predicción de la irradiación solar mediante la inteligencia computacional}

En este apartado se revisa la literatura publicada referente a la predicción de la irradiación solar utilizando las técnicas de la inteligencia computacional utilizada en esta Tesis Doctoral.

(Gardner y Dorling, 1998) presenta una discusión de las aplicaciones de las redes neuronales artificiales del tipo MultiLayer Perceptron MLP en las ciencias atmosféricas, con una revisión de numerosos artículos que sirve de guía a través de la literatura, describiendo las ventajas que las redes neuronales artificiales ofrecen en comparación con los modelos de técnicas estadísticas más tradicionales. Como por ejemplo en la predicción de contaminación del aire y eventos poco frecuentes que son a menudo de gran importancia como las tormentas.

(Aitkenhead et al., 2003) expone que en muchos casos, las situaciones ambientales de interés son lo suficientemente complejas y no lineales, lo que hace a estos modelos de utilidad por su dinámica, que solo se pueden obtener a través de datos empíricos, no a través de ecuaciones analíticas. El análisis estadístico de las series de datos ambientales puede ser difícil cuando se enfrentan a sistemas en los que grandes cantidades de datos se generan, por ejemplo, a través de los registradores de datos. Debido a que la potencia de cálculo de los ordenadores ha aumentado, hace que sea posible la aplicación de las teorías de la inteligencia artificial. (Lek y Guégan, 1999) muestran que las redes 
neuronales artificiales son adecuadas en situaciones donde las relaciones subyacentes son poco conocidas. (Oliveira et al., 2000) investiga la estructura óptima para redes neuronales artificiales utilizadas en la predicción de series de tiempo, de las cuales los datos ambientales son un buen ejemplo.

(Dorvlo et al., 2002) elabora modelos basados en redes neuronales artificiales para la estimación de la irradiación solar en lugares de Omán que no cuentan con instrumentos de medida. Los modelos de redes neuronales artificiales que se analizan estiman la irradiación solar por una primera estimación del índice de claridad, las redes neuronales artificiales del tipo MultiLayer Perceptron MLP y funciones de base radial RBF fueron entrenadas con los datos de seis estaciones y validadas con los datos de otras dos estaciones. Los modelos obtenidos se pueden utilizar para estimar la irradiación solar en Omán en función de su latitud, longitud, horas de sol y el mes del año.

(Mellit et al., 2006) usa la arquitectura adaptativa de la red wavelet para encontrar un modelo de predicción de la irradiación solar global diaria, a tal efecto, se utilizan los datos de la irradiación solar global diaria que se han registrado durante el periodo que va desde el año 1981 al 2001 por una estación meteorológica en Argelia. El modelo de red wavelet es entrenado utilizando los datos de 19 años o de un año, en ambos casos los datos del año 2001 se utilizan para validar el modelo. Además, los resultados del modelo se comparan con diferentes estructuras de redes neuronales artificiales wavelet, MultiLayer Perceptron MLP, funciones de base radial RBF, y modelos clásicos como autorregresivos AR, autorregresivos media móvil ARMA y matrices de transición de Markov. El modelo puede ser utilizado para completar los datos faltantes en las bases de datos meteorológicos. Además, el modelo propuesto puede ser generalizado y utilizado en diferentes lugares y por otros datos meteorológicos tales como la duración de la insolación solar y la temperatura ambiente. La predicción de las secuencias futuras de los datos de irradiación solar se lleva a cabo de una manera muy sencilla. Este modelo puede predecir el valor futuro de la irradiación solar global diaria $\mathrm{H}(\mathrm{t})$ en base de los valores anteriores $\mathrm{H}(\mathrm{t}-1), \mathrm{H}(\mathrm{t}-2), \ldots$

(Shah et al., 2009) desarrolla modelos utilizando redes neuronales artificiales para la estimación de la irradiación solar difusa diaria y horaria media mensual, sobre datos de 10 estaciones en la India, bajo diferentes condiciones climáticas. El algoritmo backpropagation feedforward se utiliza en el análisis. Demostrando que son más precisas y versátiles en comparación con otros modelos para predecir la irradiación solar difusa diaria y horaria. Las neuronas de la capa de entrada reciben nueve entradas como son la latitud, la longitud, la altura, el mes del año, la temperatura del aire, la humedad relativa, la precipitación, la velocidad del viento y la longitud de onda larga, la neurona de la capa de salida representa la irradiación solar difusa mediante el índice de la fracción difusa.

(Mellit, 2008) realiza una revisión del estado actual de las técnicas de la inteligencia artificial para el modelado y la predicción de datos de la irradiación solar, como son los sistemas expertos, las redes neuronales artificiales, los algoritmos genéticos y la lógica borrosa, además de los sistemas híbridos que son combinaciones de dos o más de las técnicas mencionadas anteriormente. Además propone una nueva metodología basada en Field Programming Gate Array FPGA, para implementar estimaciones de la irradiación solar en un lugar aislado.

(Cao y Cao, 2005) combina las redes neuronales artificiales recurrentes con el análisis wavelet para la predicción de la irradiación solar, la secuencia de los datos de la irradiación solar se muestra en un primer mapeado en los dominios tiempo-frecuencia, y entonces una red neuronal artificial recurrente se establece para cada dominio. La predicción de la irradiación solar es la suma de las predicciones 
realizadas por las dos redes en cada dominio. Un ejemplo de la predicción de la irradiación solar del día a día se presenta, sobre los registros históricos en el periodo 1995-2000 de Shanghái, China.

(López et al., 2005) utiliza el llamado método bayesano de la determinación automática de relevancia para evaluar la importancia relativa de un gran conjunto de variables atmosféricas y radiométricas utilizadas para aplicar como entradas a un modelo de redes neuronales artificiales, resultando el índice de claridad y la masa relativa del aire en la estimación de la irradiación solar directa horaria. También muestra que esta metodología, se puede utilizar en condiciones desfavorables con términos de cantidad limitada de datos disponibles. Los datos utilizados están entre los años 1998-1999 en Desert Rock, USA.

(Cao y Cao, 2006) con el fin de obtener una mayor precisión en la predicción ha combina las redes neuronales artificiales y el análisis wavelet para desarrollar un método para la predicción de la irradiación solar. La precisión de un modelo de predicción puede mejorarse notablemente si se preprocesan los datos de la muestra correctamente. El flujo de la irradiación solar sobre la superficie de la tierra en un amplio espectro del infrarrojo al ultravioleta se ve afectado por muchos factores como la masa de aire, las nubes y otras condiciones de entorno de la tierra. La influencia es variada de acuerdo a diferentes frecuencias de la luz solar. Los componentes de la irradiación solar correspondientes a dominios distintos de tiempo-frecuencia se pueden obtener mediante el análisis wavelet, y luego transformar de nuevo los componentes a dominios de frecuencia diferentes. Se aplica a un ejemplo de predicción con datos del día a día entre 1995-2000 en Shanghái, China.

(Elminir et al., 2007) desarrolla un modelo de predicción de la fracción difusa diaria y horaria, utilizando redes neuronales artificiales. Una comparación entre los resultados del modelo de redes neuronales artificiales con los de dos modelos de regresión lineal se informa. Un intento se hace también para describir las salidas de las redes neuronales artificiales en términos de polinomios de primer orden de la fracción difusa en función del índice de claridad y la fracción de horas de sol, que pueden generalizar y transferirse a otros lugares. Se utilizan datos de entre los años 1999-2001 y se verificaron los modelos con datos del año 2002 en tres zonas de Egipto. Se concluye que las redes neuronales artificiales son más adecuadas para predecir la fracción difusa que los modelos de regresión.

(Cao y Lin, 2008a) mejora las predicciones de la irradiación solar horaria y la capacidad de generalización de los modelos con redes neuronales artificiales, mediante una red neuronal wavelet recurrente diagonal y aplicando la lógica borrosa a los datos históricos de la cubierta de nubes en Shanghái, China.

(Cao y Lin, 2008b) mejora las predicciones de la irradiación solar global diaria y horaria de los modelos que utilizan redes neuronales artificiales, con la combinación de las propiedades dinámicas de una red neuronal wavelet recurrente diagonal, con datos en Shanghái, China.

(Reddy y Ranjan, 2003) presenta modelos basados en redes neuronales artificiales para la estimación de los valores de la irradiación solar global diaria y horaria media mensual. Los datos de un año en seis estaciones meteorológicas en el sur de la India y de cinco en el norte del país se utilizaron para el entrenamiento de las redes neuronales artificiales y los datos de otras dos estaciones una en el norte y otra en el sur fueron utilizados para validar el modelo. Los resultados indican que el modelo de redes neuronales artificiales presenta mejores posibilidades para evaluar la irradiación solar global, en comparación con otros modelos de correlación. 
(Sözen et al., 2004) estudia el potencial de la energía solar en Turquía usando redes neuronales artificiales y también busca el mejor algoritmo de entrenamiento para cada estación meteorológica. Para el entrenamiento de las redes neuronales artificiales se utilizan datos de los años 2000-2002 de 11 estaciones y para la validación de los resultados datos de seis estaciones. Las entradas a los modelos fueron los datos meteorológicos y geográficos: latitud, longitud, altitud, mes del año, duración media de la insolación solar y temperatura media, los resultados de la salida de la irradiación solar son los valores de las previsiones del potencial solar que se presentan en forma de mapas mensuales para Turquía.

(Pattanasethanon et al., 2008) presenta los resultados de un estudio sobre todos los tipos de cielo de la disponibilidad de la iluminación e irradiación solar global horizontal para un clima tropical, con datos de una estación meteorológica en Mahasarakham, Tailandia. Se desarrolla un modelo senoidal que consta de funciones polinómicas o exponenciales y se valida. Además, una red neuronal artificial se propone como modelo alternativo.

(Azadeh et al., 2009) presenta un modelo de redes neuronales artificiales para predecir la irradiación solar global en función de las variables climatológicas: temperatura máxima media, temperatura mínima media, humedad relativa media, presión de vapor media, precipitación total, velocidad del viento media y duración de la insolación media. Utiliza datos mensuales registrados durante seis años 1995-2000 en seis ciudades de Irán, con un modelo independiente para cada ciudad. Los resultados obtenidos mejoran considerablemente, comparados con el modelo clásico de Ångström. Concluye que los modelos con redes neuronales artificiales pueden ser muy beneficiosos en los lugares remotos que no existen instrumentos de medición solar.

(Benghanem et al., 2009) desarrolla seis modelos de estimación de la irradiación solar global diaria con redes neuronales artificiales, utilizando diferentes combinaciones de entrada de la temperatura del aire, la humedad relativa, la duración de la insolación y el día del año, para cada modelo la salida es la irradiación solar global diaria. Los datos utilizados son de los años 1998-2002 disponibles en el sitio web National Renewable Energy Laboratory NREL, se manejan cuatro años para el entrenamiento y uno para la validación, en la ciudad de Al-Medina, Arabia Saudí. Se encuentra que el modelo que utiliza como entradas la duración de la insolación y la temperatura del aire dio los mejores resultados. También se comparan los resultados con los métodos clásicos de las ecuaciones de correlación.

(Mellit et al., 2010) describe y ensaya varios modelos adaptativos con redes neuronales artificiales para predecir la irradiancia solar horaria global, directa y difusa para la hora siguiente. La base de datos utilizada de los años 1998-2002 en la localidad de Jeddah, Arabia Saudí, se encuentra en el sitio web National Renewable Energy Laboratory NREL, incluye datos de la irradiancia global, difusa, directa, la temperatura del aire y la humedad relativa, todos estos datos recogidos cada cinco minutos. Además, se ha calculado la duración de la insolación, horas de sol, que se define por la Organización Meteorológica Mundial WMO, como el intervalo de tiempo cuando la irradiancia solar directa supera los $120 \mathrm{~W} / \mathrm{m}^{2}$. La ventaja de los modelos adaptativos desarrollados permite una fácil aplicación y flexibilidad, se puede añadir o quitar algunos parámetros, especialmente si estas variables no están disponibles. Además, se puede aplicar estos modelos para predecir otros parámetros climáticos, tales como la temperatura, la humedad relativa, la velocidad del viento, la dirección del viento, la precipitación o la presión.

(Iqdour y Zeroual, 2007) aplica las redes neuronales artificiales MultiLayer Perceptron MLP para la predicción de los datos diarios de la irradiación solar. Utiliza como entradas a las redes neuronales artificiales la irradiación solar global diaria de los días anteriores hasta el quinto día, al que se realiza la 
predicción en la salida del modelo. Los resultados se comparan con los obtenidos de los modelos ARMA. La base de datos utilizada es de la localidad de Dakhla, Marruecos, con dos años para el entrenamiento y un año para la validación de los modelos.

(Ruffing, 2009) utiliza la red neuronal recurrente echo state, elegida para superar dificultades en el entrenamiento, y para realizar predicciones a corto y medio plazo de la irradiación solar a 30, 60,..., 270 minutos. En este estudio, se asume que hay instrumentación disponible en el lugar donde se realizan las predicciones. Los datos utilizados para el entrenamiento y validación fueron tomados por National Renewable Energy Laboratory NREL en Golden, Colorado, USA.

(Seme et al., 2009) plantea la forma de estimar el potencial solar en Eslovenia, con datos de 22 estaciones. Con el fin de predecir la irradiación solar global cada media hora se aplican redes neuronales artificiales. Las cinco entradas del modelo son la irradiación solar extraterrestre sobre la superficie horizontal, el ángulo cenital solar, el día del año, la temperatura y la presión atmosférica relativa, dados en intervalos de media hora, la salida del modelo se aplica para predecir la distribución diaria de la irradiación solar global. La comparación de la distribución en la medición y la estimación por las redes neuronales artificiales de la irradiación solar global diaria muestra muy buen acuerdo para los días claros.

(Moghaddamnia et al., 2009) expone que a pesar de la aplicación generalizada de los modelos matemáticos no lineales, los estudios comparativos de los distintos modelos son todavía una enorme tarea para los modelistas. En este estudio presenta un enfoque de la eficiencia mediante la prueba Gamma para seleccionar las variables de entrada y la longitud de los datos de entrenamiento. Esta técnica ayuda a los modelistas para determinar las mejores combinaciones de entrada al modelo para alcanzar un objetivo particular a la salida. La metodología es probada con datos en Brue, UK. Se han desarrollado varios modelos no lineales, incluyendo una regresión lineal local, MultiLayer Perceptron MLP, redes Elman, redes auto-regresivas con entradas exógenas NNARX y una red adaptativa de un sistema de inferencia neuro-difuso ANFIS. Evaluando su rendimiento para estimar los valores de irradiación solar global diaria.

(Al-Alawi y Al-Hinai, 1998) presenta modelos con redes neuronales artificiales para el análisis de la relación de la irradiación solar global mensual y las variables climatológicas, y para predecir los recursos de irradiación solar global de lugares no cubiertos por los datos de entrenamiento del modelo. Las previsiones de los valores de irradiación solar global para diferentes lugares y meses, se comparan con los valores reales. Los datos climatológicos de seis estaciones de los años 1987-1992 en Omán, que cubren todas las regiones y se detallan en informes mensuales. Los modelos en la capa de entrada reciben ocho entradas: localización, mes, presión media, temperatura media, presión de vapor media, humedad relativa media, velocidad del viento media y duración de la insolación media.

(Mohandes et al., 1998) utiliza la técnica de las redes neuronales artificiales para el modelado espacial de la irradiación solar en Arabia Saudí. Los datos de 31 lugares se utilizan para el entrenamiento y los datos de otras 10 localidades se utilizan para la validación, recopilados desde el año 1971. Este estudio utiliza para modelar los valores de irradiación solar global diaria media mensual sobre la superficie horizontal, usando como entradas la latitud, la longitud, la altitud y la duración de la insolación solar. Los resultados indican un buen acuerdo entre los valores propuestos y los observados. 
(Mellit et al., 2008) presenta un sistema de inferencia neuro-difuso adaptativo ANFIS para la estimación de las secuencias del índice de claridad media mensual y la irradiación solar global en lugares aislados sobre la base de las coordenadas geográficas. El modelo ANFIS es entrenado utilizando las redes neuronales artificiales MultiLayer Perceptron MLP sobre la base de la lógica borrosa. Las entradas del modelo ANFIS propuesto son la latitud, la longitud y la altitud, mientras que la salida son los 12 valores del índice de claridad medio mensual. Los datos están recopilados de 60 localizaciones en Argelia. También puede ser utilizado para la estimación de otros parámetros meteorológicos. Posteriormente el método de las matrices de Markov se utiliza para generar las secuencias de datos de irradiación solar global diaria a partir del índice de claridad medio mensual. Con esta metodología se genera la serie de datos de irradiación solar global diaria propuesta durante 10 años, que se utilizarán en este caso para el dimensionamiento de un sistema solar fotovoltaico autónomo. La metodología se puede generalizar para ser utilizada en otras partes del mundo, ya que la técnica propuesta no depende de las propiedades intrínsecas de las secuencias. Se propone generalizarlo para cualquier lugar de África.

(Zervas et al., 2008) desarrolla un modelo de predicción de la distribución de la irradiancia solar global utilizando las redes neuronales artificiales y aplicado a una base de datos climatológicos en Atenas, Grecia. Se introduce una función de Gauss para predecir la distribución diaria de la irradiancia solar global, junto con una red neuronal artificial para predecir la amplitud de la función de Gauss en relación al estado del tiempo, con seis estados de nubosidad diferentes y el número de periodos de 10 minutos de tiempo desde el que se realiza la predicción y el mediodía solar.

(Mubiru, 2008) estudia el desarrollo de un modelo con redes neuronales artificiales para predecir la irradiación solar global diaria media mensual para ubicaciones en Uganda sobre la base de datos geográficos y meteorológicos: latitud, longitud, altitud, duración de la insolación, humedad relativa y temperatura máxima.

(Siqueira et al., 2010) propone la utilización de las redes neuronales artificiales como una alternativa para la generación de series sintéticas de la irradiación solar global diaria. Las secuencias fueron generadas para el uso de series de tiempo diarias con variables meteorológicas que se midieron simultáneamente, entre los años 1998-2006 en dos localidades Sao Paulo y Río Grande del Sur, Brasil.

(Sen, 1998) diseña un algoritmo de lógica borrosa para la estimación de la irradiación solar a partir de mediciones de duración de la insolación solar. De este modo la clásica ecuación de regresión de Ångström se remplaza por un conjunto de reglas borrosas. La estrategia de aproximación se aplica para tres sitios con la irradiación solar global diaria media mensual en la parte occidental de Turquía.

(Kemmoku et al., 1999) desarrolla una red neuronal artificial en varias etapas para reducir el error al predecir la insolación del día siguiente. La red neuronal artificial de la primera etapa realiza la previsión de la presión atmosférica media del día siguiente a partir de los datos de la presión atmosférica del día anterior. La red neuronal artificial de la segunda etapa prevé el nivel de insolación del próximo día a partir de la presión atmosférica media y los datos meteorológicos del día anterior. La red neuronal artificial de la tercera etapa predice la insolación del próximo día a partir del nivel de insolación y los datos meteorológicos del día anterior. Los datos meteorológicos utilizados son de los años 1988-1994 en Omaezaki, Japón.

(Sfetsos y Coonick, 2000) realiza la predicción de un solo paso por delante de la irradiancia solar horaria media recibida sobre la superficie horizontal. Los métodos tradicionales lineales ARMA y varias técnicas 
de la inteligencia artificial son estudiados, feedforward, recurrentes Elman, funciones de base radial y un sistema adaptativo de inferencia neuro-difuso ANFIS. El problema se examina inicialmente para el caso univariante y se extiende para incluir otros parámetros en el proceso de estimación del modelo óptimo. Los resultados indican que los modelos de la inteligencia artificial son más eficaces para predecir la serie de datos de la irradiancia solar. La capacidad de predicción de los modelos se puede mejorar con el uso de otros parámetros meteorológicos. Los datos utilizados son de la primavera-verano del año 1996 en la isla de Córcega, Francia.

(Mohandes et al., 2000) utiliza las redes neuronales artificiales de base radial para la estimación de los valores de la irradiación solar global diaria media mensual y compara su desempeño con la red MultiLayer Perceptron MLP y también con un modelo de regresión clásico. Se utilizan datos de un año de la irradiación solar de 41 estaciones en Arabia Saudí. Las entradas a los modelos son la latitud, la longitud, la altura y la duración de la insolación.

(Hontoria et al., 2002) presenta una metodología consistente en la generación de series sintéticas de irradiación solar horaria, el modelo se basa en las redes neuronales artificiales MultiLayer Perceptron MLP. Un estudio comparativo con otros métodos para comprobar su validez se realiza. Las entradas del modelo son la distancia en días entre el valor que se genera y el día con un valor máximo del índice de claridad horario, la hora del día, el índice de claridad diario y el índice de claridad horario de las tres horas previas, la salida de la red neuronal artificial es el índice de claridad horario de la próxima hora.

(Mellit et al., 2005) propone desarrollar un modelo hibrido que se utiliza para predecir los datos de la irradiación solar global diaria mediante una combinación entre una red neuronal artificial y las matrices de transición de Markov. El modelo desarrollado puede generar una secuencia de datos de la irradiación solar global diaria con un mínimo de datos de entrada como la latitud, la longitud y la altitud, especialmente para lugares aislados. La base de datos utilizada de la irradiación solar global diaria proviene de 60 estaciones meteorológicas durante el periodo de los años 1991-2000 en Argelia. Los resultados se compararon con modelos tradicionales AR, ARMA, cadena de Markov, matrices de transición de Markov y los datos medidos.

(Hontoria et al., 2005) presenta la aplicación de una metodología para obtener mapas de la irradiación solar, basada en redes neuronales artificiales. Por lo general, la calidad de los datos y su densidad espacial no es tan buena como debería ser para la mayoría de los propósitos. Este problema se ha resuelto y los mapas de irradiación solar se han obtenido para la provincia de Jaén, España.

(Tymvios et al., 2005) desarrolla una variedad de modelos para la estimación de la irradiación solar sobre una superficie horizontal. Mediante dos metodologías diferentes, la primera metodología se refiere a la tradicional con el modelo de Ångström que se basa en la medición de la duración de la insolación solar, la segunda metodología se refiere a los modelos basados en redes neuronales artificiales. Tres modelos de Ångström y siete modelos con redes neuronales artificiales se presentan. Todos estos modelos se verifican con datos independientes y se comparan. Los datos utilizados se tomaron en Athalassa, Chipre.

(Hocaoğlu et al., 2008) utiliza y estudia los datos horarios de irradiancia solar registrados en el periodo del día 1-8-2005 al 30-7-2006 en Eskisehir, Turquía. Un modelo de representación 2D de los datos de irradiancia solar horaria se propone. El modelo da una visualización única y compacta de los datos para la inspección, y permite su predicción por los métodos de procesamiento de la imagen. El modelo que se 
forma en la imagen por filas y columnas representan los días del año y las horas del día, respectivamente. Las correlaciones entre los días a una misma hora las proporcionan las correlaciones verticales en la imagen. La representación en 2D permite la visualización y la búsqueda de dependencias entre los días y a lo largo de la misma hora del día. Se prueban nueve filtros lineales con distintas configuraciones. Se prueba también la capacidad predictiva de las redes neuronales artificiales, encontrando que las redes neuronales artificiales debido a su capacidad de representar el comportamiento no lineal, logran mejores predicciones que los filtros de imágenes. Por ejemplo, se puede examinar el estado en la hora anterior en el mismo día y el día pasado y el estado en la misma hora del día pasado.

(Mellit y Pavan, 2010) da un método práctico para la predicción de la irradiancia solar usando redes neuronales artificiales Multilayer Perceptron MLP que permite predecir la irradiancia solar en una base de 24 horas, para cada hora del día de mañana, usando valores actuales del día de hoy de la irradiación diaria y la temperatura del aire diaria media. La base de datos experimentales utilizados son del día 1-72008 al 23-5-2009 y del día 23-11-2009 al 24-1-2010 en Triestre, Italia. Se comprueba que el modelo funciona satisfactoriamente para días soleados y baja ligeramente su rendimiento en los días nublados. El modelo se utiliza para realizar la previsión de energía producida por un sistema solar fotovoltaico conectado a la red eléctrica.

(Paoli et al., 2010) utiliza redes neuronales artificiales MultiLayer Perceptron MLP y un tratamiento previo de la serie de tiempo para desarrollar una metodología para la predicción de la irradiación solar global diaria del día de mañana. Los datos utilizados son 19 años de Ajaccio en Córcega, Francia. Se ha demostrado que un tratamiento previo como una normalización sobre los datos de irradiación solar respecto a los datos de irradiación solar extraterrestre mejora la correlación entre las mediciones y los datos predichos. Compara dos estrategias de pre-tratamiento: el primero basado en el índice de claridad y el segundo en el índice de cielo despejado. Identificados en la literatura los métodos de predicción por series de tiempo: ARIMA, inferencia bayesana, cadenas de Markov y los predictores vecinos más cercanos. Se comparan con el método de redes neuronales artificiales que utiliza de una a 15 entradas de los valores diarios anteriores, como la arquitectura básica para la predicción de la serie de tiempo de datos de la irradiación solar diaria durante la fase de entrenamiento.

Una de las características más interesantes de las redes neuronales artificiales es su capacidad de aprender y modelar un fenómeno. Para establecer la predicción, un número fijo $\mathrm{p}$ de los valores anteriores se establece como entradas de la red MLP, la salida es la predicción del valor futuro de la serie de tiempo. Este método llamado técnica de ventana deslizante, utiliza una ventana de tiempo en movimiento para seleccionar $n$ veces, $p$ entradas de datos para el entrenamiento. El modelo se aplica a un sistema solar fotovoltaico.

(Martín et al., 2010) presenta una comparación de modelos estadísticos basados en series de tiempo aplicado a la predicción de los valores de la irradiación solar global diaria con un horizonte temporal de tres días. Utiliza el valor mitad diario que para un día son dos valores: el primero es el valor de la irradiación solar global acumulada desde el amanecer hasta el mediodía solar y el segundo es el valor de la irradiación desde el mediodía solar hasta el anochecer, el cual facilita un detalle de las características dinámicas de la irradiación solar diaria. Utiliza datos de las estaciones en Madrid, Lleida, Albacete y Murcia, España. Debido al comportamiento no estacionario de la irradiación solar global las series de tiempo se transforman en dos variables: el índice de claridad y el componente perdido definido como la 
diferencia entre la irradiación solar extraterrestre y la irradiación solar sobre la superficie de la tierra. Utiliza el modelo autorregresivo AR, el modelo de redes neuronales artificiales en diversas configuraciones, el sistema neuro-borroso de inferencia adaptativa ANFIS. El modelo básico elegido para la comparación es el modelo de persistencia, ya que es el modelo más extendido a diferencia de los nuevos modelos propuestos. La persistencia se basa en el supuesto de que el valor del paso temporal al siguiente es el mismo que el valor actual $\hat{\mathrm{x}}_{\mathrm{t}+\mathrm{k}}=\mathrm{x}_{\mathrm{t}}$. Busca la aplicación de estas predicciones a una estrategia de optimización de un sistema solar.

(Behrang et al., 2010) plantea como objetivo del estudio el de predecir la irradiación solar global diaria sobre la superficie horizontal, sobre la base de variables meteorológicas, utilizando redes neuronales artificiales. Utilizando la temperatura diaria media del aire, la humedad relativa, las horas de insolación, la evaporación y la velocidad del viento entre los años 2002-2006 para la ciudad de Dehful, Irán. Con el fin de considerar el efecto de cada variable en la predicción de la irradiación solar global diaria, se consideran seis combinaciones de variables de entrada y se aplican a redes neuronales artificiales MultiLayer Perceptron MLP y de función de base radial RBF. Los resultados de los modelos con redes neuronales artificiales se comparan con modelos clásicos basados en las horas de insolación y la humedad.

(Mihalakakou et al., 2000) utiliza las redes neuronales artificiales para modelar y hacer predicciones a corto plazo sobre la serie de tiempo de irradiación solar global. Los valores futuros de la irradiación solar global horaria se predicen mediante la extracción de conocimiento a partir de sus valores pasados, utilizando redes neuronales artificiales backpropagation feedforward. La predicción del próximo valor se realiza usando los cinco a diez anteriores, encontrándose que de cinco a ocho valores aumenta la eficiencia y que con más de nueve se mantiene. Por otra parte, un modelo autorregresivo AR es desarrollado por el análisis y representación de la serie de tiempo de irradiación solar global. Los datos utilizados son de los años 1984-1995 en Atenas, Grecia. Se encuentra que las redes neuronales artificiales conducen a mejores predicciones que el modelo autorregresivo AR. Las predicciones se realizaron a un paso y a varios pasos de tiempo.

\subsubsection{La predicción de la irradiación solar global diaria a partir de la temperatura diaria}

La temperatura del aire es una variable registrada por todas las estaciones meteorológicas de todo el mundo, pero no es un parámetro común para el cálculo de la irradiación solar. Sin embargo, la temperatura máxima, mínima, media o la amplitud, se han incluido en el modelado de la irradiación solar desarrollado recientemente para usos agrícolas. Debido a que las mediciones de la temperatura son simples y robustas, es una razón para que tales modelos se adapten para estimar la irradiación solar diaria con una precisión razonable en las aplicaciones de los sistemas solares térmicos.

La disminución de la irradiación solar, debido a las nubes es más importante que la debida a cualquiera de los otros constituyentes atmosféricos. La mayoría de los modelos de irradiación solar tienen en cuenta la disminución de la irradiación solar en relación con la cobertura de nubes a través de la ecuación de (Ångström, 1924) y (Prescott, 1940) que conduce a tomar la duración de la insolación relativa como parámetro natural en este tipo de correlaciones. 
Con el fin de aumentar la precisión, esta ecuación se fue modificando, con otros parámetros meteorológicos superficiales, como la cantidad de nubosidad. En el modelado se incluye las temperaturas extremas del aire, la temperatura máxima, la temperatura mínima, y la nubosidad diaria media en la estimación empírica de la irradiación solar. Tomar la temperatura del aire y la nubosidad está motivado por la disponibilidad habitual de ambos parámetros meteorológicos.

La temperatura del aire se añade a los modelos para aumentar la calidad de la predicción, porque se conoce que con el aumento de la nubosidad la precisión disminuye. El inconveniente de incluir la temperatura del aire es que conduce a una conexión más cercana del modelo con la ubicación geográfica.

La ecuación de (Supit y van Kappel, 1998) es un modelo típico que relaciona linealmente la irradiación solar global a nivel del suelo y su valor extraterrestre, combinando la amplitud de la temperatura máxima y mínima (Hargreaves et al., 1985) y una dependencia no lineal con la nubosidad o turbidez atmosférica (Kasten y Czeplak, 1980) los coeficientes se proporcionan para 95 localizaciones en Europa desde Finlandia hasta España. (El-Metwally, 2004) deriva otras expresiones para el norte de África.

(Paulescu, 2008) calcula los coeficientes de regresión para dos polinomios de segundo orden con datos en Timisoara, Rumanía, uno con la nubosidad y el otro añadiendo la diferencia entre la temperatura máxima y mínima, demostrando que el hecho de añadir la diferencia de las temperaturas mejora el modelo. Es lógico, si tenemos en cuenta que la amplitud de la temperatura del aire es menor en los días nublados que en los días soleados.

Un modelado en dos etapas para incluir la temperatura del aire en los modelos de irradiación solar global, en primer lugar, un modelo empírico de irradiancia solar con la temperatura del aire, además de la nubosidad y altura solar, posteriormente la irradiación solar global diaria se calcula por integración del modelo de irradiancia entre el amanecer y el atardecer con el ángulo horario.

En la evaluación del potencial productivo de la agricultura es donde más popularidad están teniendo los modelos que utilizan solo la temperatura del aire máxima y mínima como parámetros de entrada. (Bristow y Campbell, 1984) establecen un ecuación empírica para la irradiación solar global diaria con la amplitud de la temperatura del aire, donde sus coeficientes se dan para distintos lugares, pudiéndose calibrarse con una base de datos local. Este modelo se ha utilizado como núcleo para muchos otros modelos.

Fórmulas sencillas se pueden utilizar para calcular la irradiación solar global diaria basadas en los datos de la temperatura del aire. Estos modelos ya sea utilizando la temperatura del aire como parámetro adicional a la nubosidad o usando solo la temperatura del aire son alternativas viables a las ecuaciones clásicas basadas en la duración de la insolación. Estas ecuaciones pueden ser útiles en muchos lugares donde las mediciones de duración de la insolación faltan pero las mediciones de temperatura del aire están disponibles en bases de datos de muchos años. Por lo tanto, el número de lugares donde se pueden realizar la estimación es mucho mayor.

(Rahimikhoob, 2010) prueba las redes neuronales artificiales para estimar la irradiación solar global diaria en función de los datos de la temperatura del aire. Las redes neuronales artificiales fueron entrenadas para estimar la irradiación solar global en función de la temperatura máxima, la temperatura mínima y la irradiación solar extraterrestre. Los datos de entrenamiento son de los años 1994-2001 en 
Ahwaz, Irán. También se compara los resultados del modelo de redes neuronales artificiales con la ecuación empírica de (Hargreaves y Samani, 1982), obteniendo un mejor rendimiento el modelo neural.

El método ASHRAE ofrece un valor para la temperatura de cada hora del día, en función del valor máximo y mínimo, y de un factor para cada hora del día (ASHRAE, 1997). 


\subsection{Estimación de la irradiación solar incidente sobre un plano inclinado y orientado}

Los modelos utilizados para el cálculo de la irradiación solar que recibe un plano inclinado con un cierto ángulo respecto a la horizontal y orientado hacia el ecuador o con una desviación hacia el este u oeste de un ángulo azimutal formado entre la proyección de la normal del plano inclinado y el meridiano local, respecto a la irradiación solar que llega a la superficie horizontal, que es la habitualmente medida y registrada en las estaciones meteorológicas, necesitan de diversas variables y parámetros.

Además, como su conversión se realiza tratando por separado a sus tres componentes, la directa recibida en la dirección del sol, la difusa del cielo llegada desde las restantes direcciones de la bóveda celeste y cuando se eleva el plano con una inclinación sobre la horizontal, aparece un tercer componente conocido como el albedo, que es la irradiación solar reflejada desde los alrededores de la superficie de la tierra.

Los datos de irradiación solar medidos sobre el plano inclinado suelen ser escasos. Sin embargo, estos datos son a menudo necesarios para el diseño arquitectónico de los edificios, la optimización de las cubiertas y la orientación de las paredes, el diseño de los sistemas solares térmicos y la evaluación de los captadores solares de placa plana.

(Oladiran, 1994) estudia la irradiación solar incidente sobre una superficie inclinada en Nigeria, a partir de modelos teóricos, para tres zonas climáticas representativas del país. Resultando que la insolación depende fuertemente de los factores climatológicos como la nubosidad del cielo y que la atenuación de la irradiación solar extraterrestre por la atmósfera depende de la latitud. El rendimiento del captador solar depende de su inclinación y puede variar hasta el $35 \%$ dependiendo de la situación geográfica y la época del año, apareciendo un óptimo para una inclinación de $\pm 10^{\circ}$ de la latitud del lugar.

(El-Sebaii et al., 2010) estudia la irradiación solar global, directa y difusa sobre la horizontal y sobre el plano inclinado en Jeddah, Arabia Saudí. Los datos se dividieron en dos grupos el primero de los años 1996-2004 se emplea para desarrollar correlaciones empíricas de la fracción de irradiación solar global diaria media mensual $\mathrm{H} / \mathrm{H}_{0}$ respecto de otras variables ambientales, el subconjunto de datos de los años 2005-2007 se utiliza para evaluar las correlaciones derivadas. También compara los resultados con las estimaciones de los datos disponibles en el sitio web Atmospheric Science Data Center NASA Surface Meteorology and Solar Energy NASA-SSE. Se encuentra que para este lugar los captadores solares de placa plana orientados hacia el ecuador, tienen el mejor rendimiento con la inclinación igual a la latitud.

(Skeiker, 2009) utiliza un modelo matemático para estimar la irradiación solar sobre un plano inclinado y determinar la inclinación y la orientación óptima del captador solar en varias zonas de Siria, sobre una base diaria y para un periodo de tiempo específico. Se calcula el ángulo óptimo mediante la búsqueda de los valores para los cuales la irradiación solar en la superficie inclinada es un máximo para un día concreto o periodo de tiempo. Resulta que un cambio de la inclinación cada mes, o sea utilizando la inclinación óptima mensual, mantiene aproximadamente la cantidad de irradiación solar cerca del máximo que se encuentra cambiando el ángulo de inclinación diariamente a su valor óptimo. Esto logra una ganancia anual de irradiación solar de aproximadamente un $30 \%$ más que en el caso de un captador solar fijado sobre la superficie horizontal. 
En tiempos pasados (Kondratyev y Manolova, 1960) expone que el problema del balance de irradiación solar, tiene una solución pobre y unilateral, porque solo la irradiación solar directa incidente en las superficies inclinadas con distintas orientaciones se ha estudiado de cerca desde distintos experimentos, numerosos cálculos, tablas y nomogramas por diversos autores. La naturaleza de los flujos de la irradiación solar dispersa y reflejada sobre los planos inclinados es bastante complicada debido a que los flujos son considerablemente no isotrópicos. Propone que los flujos de la irradiación solar difusa y reflejada en los planos inclinados y su irradiación efectiva puede ser determinado con exactitud, ya sea por la medición de los mismos en cada plano inclinado, o mediante el cálculo del flujo de irradiación en los planos inclinados de acuerdo a la distribución dada de la intensidad de irradiación angular.

(Norris, 1966) para predecir la cantidad de energía solar que incide sobre las superficies inclinadas estudia y prueba varias fórmulas basadas en las horas de sol, la nubosidad, la irradiación solar global y la irradiación solar difusa sobre la horizontal respecto a los valores de las mediciones de la energía solar en una superficie inclinada.

(Heywood, 1966) propone un método para realizar el cálculo de la irradiación solar global incidente sobre una superficie inclinada con cualquier inclinación y orientación a partir de la irradiación recibida sobre la horizontal y de ciertos parámetros determinados para el lugar concreto.

(Klein, 1977) presenta un método verificado con mediciones experimentales que permite el cálculo de la irradiación solar diaria media mensual sobre superficies inclinadas y con cualquier orientación, a partir del método (Liu y Jordan, 1962) que solo considera las orientadas hacia el ecuador.

(Temps y Coulson, 1977) evalúa el modelo de flujo solar (Robinson, 1966) mejorando el modelo y logrando un mejor acuerdo con las mediciones de la irradiación solar sobre el plano inclinado y orientado.

(Bugler, 1977) usa las mediciones de valores horarios de la irradiación solar global en una superficie horizontal, para desarrollar un método que calcula los valores correspondientes horarios de insolación sobre una superficie inclinada en cualquier ángulo y orientada en cualquier dirección. El método emplea un modelo en el cual la componente difusa es calculada desde la global horizontal usando tres relaciones diferentes acordes con el valor de la relación con la insolación global horaria medida para condiciones de cielo claro. El método se comprueba usando valores horarios medidos durante cinco años en Melbourne, Australia, sobre superficies horizontales, y a $38^{\circ}$ de inclinación respecto a la horizontal y orientado hacia el ecuador.

(Iqbal, 1978b) calcula la irradiación solar global sobre el plano inclinado orientado hacia el sur, utilizando valores horarios de la irradiación solar global y difusa obtenidos experimentalmente en Montreal, Toronto y Goose Bay, Canadá, y se compara con el método (Liu y Jordan, 1962) para la obtención de la irradiación solar diaria sobre superficies inclinadas hacia el ecuador, observando pequeñas diferencias debidas a que la formulación teórica original se realiza para periodos diarios, el método horario tiene en cuenta las asimetrías de la irradiación solar global y difusa alrededor del mediodía solar mientras que el método diario asume la simetría, además que el método para periodos diarios asume la transmisividad atmosférica constante durante el día y el método horario solo durante una hora.

(Hay, 1979) presenta un método que utiliza datos diarios en lugar de los intervalos de tiempo horario para el cálculo de los valores mensuales medios de la irradiación solar sobre la horizontal y el plano 
inclinado de nueve localidades en Canadá. Este objetivo fue deseado para reducir el esfuerzo de cálculo y al haber una disponibilidad mayor de datos diarios. Las entradas al modelo son las horas de sol y el albedo de la superficie.

(Klucher, 1979) estudia la validez de diferentes modelos de irradiación solar que emplean la isotropía o una aproximación a la distribución anisotrópica de la luz del cielo para predecir la irradiación solar sobre las superficies inclinadas en un periodo de seis meses de enero-junio de 1977 en Cleveland, USA.

(Jiménez y Castro, 1982) comprueba la validez del modelo (Liu y Jordan, 1963) con la hipótesis de distribución isotrópica de la irradiación difusa, para el cálculo de la irradiación solar diaria sobre superficies inclinadas con datos tomados en Granada, España.

(Ma y lqbal, 1983) compara estadísticamente tres modelos para estimar la irradiación solar global sobre planos inclinados, considerando condiciones de cielo arbitrarias y suponiendo que son aplicables en cualquier parte del mundo.

(Reindl et al., 1990b) evalúa varios modelos de irradiación solar horaria sobre el plano inclinado uno isotrópico (Hottel y Woertz, 1942) y cuatro anisotrópicos (Hay y Davies, 1980), (Perez et al., 1987) y (Perez et al., 1988), además de uno nuevo. Se observan las diferencias entre la energía solar aprovechable medida y la energía solar utilizable predicha para varias inclinaciones y orientaciones del plano y niveles críticos de irradiación solar, utilizando datos de varias localidades, USA.

(Feuermann y Zemel, 1992) estima la precisión de tres modelos de irradiación solar sobre planos inclinados comparados con las mediciones tomadas con cuatro instrumentos en diferentes inclinaciones y orientaciones en Sede Boqer, Israel.

(Remund et al., 1998) propone un método para calcular los valores de irradiación solar global horarios sobre planos inclinados en cualquier lugar deseado. A partir de una serie de datos de 10 años de la irradiación solar y temperatura de 64 estaciones meteorológicas en Suiza. Se interpolan los valores de irradiación solar global horizontal mensuales medios para cualquier lugar escogido y se incorporan a las superficies inclinadas.

(Gómez y Casanovas, 2003) propone un modelo de irradiación solar sobre superficies inclinadas y arbitrariamente orientadas en base a procedimientos de lógica difusa, requiere un número limitado de clases y parámetros ajustables, el modelo considera clases superpuestas permitiendo una mejor descripción de las situaciones de cielo en las zonas de transición entre categorías contiguas. Se comprueba con datos de los años 1990-1995 en Valencia, España.

(Loutzenhiser et al., 2007) valida siete modelos de irradiación solar global sobre el plano inclinado (Hottel y Woertz, 1942), (Klucher, 1979), (Hay y Davies, 1980), (Reindl et al., 1990b), (Muneer et al., 2004), (Perez et al., 1987) y (Perez et al., 1990) que se implementan en los programas de simulación para edificios, Energy Plus, DOE-2.1E, TRNSYS-TUD y ESP-r, en este caso sobre una fachada acristalada en Duebendorf, Suiza.

(Evseev y Kudish, 2009) valida 11 modelos de irradiación solar global sobre un plano inclinado a $40^{\circ}$ sobre la horizontal y orientado hacia el ecuador, en función de cuatro condiciones de cielo diferentes, utilizando datos en Beer Sheva, Israel. 
(Padovan y Del Col, 2010) presenta datos experimentales de la irradiación solar horaria global y difusa en Padua, Italia, para investigar la modelización de la irradiación solar horizontal y sobre planos inclinados a $20^{\circ}$ y $30^{\circ}$ sobre la horizontal y en orientaciones hacia el ecuador y a $45^{\circ}$ y $65^{\circ}$ hacia el este.

\subsubsection{La irradiación solar difusa horizontal}

Para la modelización de las aplicaciones de la energía solar, es necesario conocer la cantidad de irradiación solar sobre un plano inclinado. Puesto que solo la componente directa de la irradiación solar incidente sobre un plano inclinado puede calcularse trigonométricamente, es necesario conocer la componente difusa de la irradiación solar disponible sobre la horizontal. En algunos lugares se mide la irradiación solar global y difusa. Sin embargo, por lo general, solo son medidos los datos globales o inferidos del satélite.

Teniendo en cuenta que las mediciones de la irradiación solar global sobre una superficie horizontal son los datos más ampliamente disponibles de la energía solar. Modelos para estimar la irradiación solar difusa sobre la horizontal a partir de la irradiación solar global horizontal están desarrollados. El pionero en la literatura (Liu y Jordan, 1960), tras él surgieron numerosos modelos basados en su método, los cuales proporcionan una relación entre la irradiación solar difusa diaria y la irradiación solar global sobre una superficie horizontal.

Estos modelos generalmente se expresan en términos de polinomios de primer a cuarto grado relacionando la fracción difusa $k_{d}$ que es la proporción entre la irradiación solar difusa y la global, con el índice de claridad k que es la proporción entre la irradiación solar global y la extraterrestre.

lo: Irradiación solar extraterrestre horaria incidente sobre una superficie horizontal.

I: Irradiación solar global horaria incidente sobre una superficie horizontal.

$I_{d}$ : Irradiación solar difusa horaria incidente sobre una superficie horizontal.

$\mathrm{k}_{\mathrm{t}}$ : Índice de claridad horario $\left(\mathrm{I} / \mathrm{I}_{0}\right)$.

$k_{d}$ : Índice de la fracción difusa horaria $\left(I_{d} / I\right)$.

En estos estudios se discute su validez general, para ser aplicados en lugares diferentes de los que se han utilizado los datos para su desarrollo y que tienen distintas condiciones climáticas $u$ otras latitudes geográficas.

La correlación original fue desarrollada para valores diarios, pero en esta Tesis Doctoral se ha utilizado para el cálculo la fracción difusa horaria en función del índice de claridad horario. Al ser la irradiación solar horaria incidente en la superficie del captador solar, una entrada fundamental requerida en la simulación de un diseño exhaustivo del sistema solar térmico.

Debido a la escasez de series de datos de la irradiación solar medida en una superficie inclinada, varios modelos se utilizan para estimar la irradiación solar incidente sobre la superficie del captador solar, a partir de la medición de la irradiación global sobre una superficie horizontal.

Esta estimación requiere de un conocimiento a priori de las componentes directa y difusa de la irradiación global horizontal. Dado que no se registran a menudo en las estaciones de medición, la búsqueda de estos componentes se hace generalmente a través de modelos de estimación. En el caso 
de la irradiación difusa, los modelos o correlaciones más utilizados son los que se refieren a la fracción difusa $k_{d} y$ al índice de claridad $k_{t}$ sobre una base horaria, diaria o media mensual.

Para el caso de las fracciones horarias de las relaciones $k_{d} y k_{t}$, los modelos que se han ido presentando por los autores pueden clasificarse como de primer orden, al modelo (Orgill y Hollands, 1977) que usa datos de la ubicación en Toronto, Canadá, (Ec. 2.3.1), comparando los resultados obtenidos con el modelo (Liu y Jordan, 1960).

$$
\mathrm{k}_{\mathrm{d}}= \begin{cases}1-0,249 \mathrm{k}_{\mathrm{t}} & \mathrm{k}_{\mathrm{t}}<0,35 \\ 1,557-1,84 \mathrm{k}_{\mathrm{t}} \text { para } & 0,35 \leq \mathrm{k}_{\mathrm{t}} \leq 0,75 \\ 0,177 & 0,75<\mathrm{k}_{\mathrm{t}}\end{cases}
$$

El modelo (Reindl et al., 1990a) que estudia la influencia de las variables climáticas y geométricas de la fracción difusa horaria basándose en datos de cinco estaciones en Europa y USA (Ec. 2.3.2).

$$
\mathrm{k}_{\mathrm{d}}=\left\{\begin{array}{lc}
1,02-0,248 \mathrm{k}_{\mathrm{t}} & \mathrm{k}_{\mathrm{t}}<0,3 \\
1,45-1,67 \mathrm{k}_{\mathrm{t}} & \text { para } 0,3 \leq \mathrm{k}_{\mathrm{t}} \leq 0,78 \\
0,147 & 0,78<\mathrm{k}_{\mathrm{t}}
\end{array}\right.
$$

El modelo (Boland et al., 2001) que usa datos de la localidad de Victoria, Australia, con los que construye una correlación simple exponencial (Ec. 2.3.3).

$$
\mathrm{k}_{\mathrm{d}}=\frac{1}{1+\mathrm{e}^{7,997\left(\mathrm{k}_{\mathrm{t}}-0,586\right)}}
$$

Los modelos de segundo orden, al modelo (Hawlader, 1984) que utiliza datos de una zona tropical en Singapur (Ec. 2.3.4).

$$
\mathrm{k}_{\mathrm{d}}=\left\{\begin{array}{lc}
0,915 & \mathrm{k}_{\mathrm{t}}<0,225 \\
1,135-0,9422 \mathrm{k}_{\mathrm{t}}-0,3878 \mathrm{k}_{\mathrm{t}}^{2} \text { para } 0,225<\mathrm{k}_{\mathrm{t}}<0,775 \\
1,215 & 0,775 \leq \mathrm{k}_{\mathrm{t}}
\end{array}\right.
$$

Los modelos de tercer orden, al modelo (Miguel et al., 2001) que utiliza datos de varios países de la zona norte del Mediterráneo (Ec. 2.3.5).

$$
\mathrm{k}_{\mathrm{d}}=\left\{\begin{array}{lc}
0,995-0,081 \mathrm{k}_{\mathrm{t}} & \mathrm{k}_{\mathrm{t}} \leq 0,21 \\
0,724+2,738 \mathrm{k}_{\mathrm{t}}-8,32 \mathrm{k}_{\mathrm{t}}^{2}+4,967 \mathrm{k}_{\mathrm{t}}^{3} & \text { para } 0,21<\mathrm{k}_{\mathrm{t}} \leq 0,76 \\
0,18 & 0,76<\mathrm{k}_{\mathrm{t}}
\end{array}\right.
$$

El modelo (Karatasou et al., 2003) basado en datos tomados en Atenas, Grecia (Ec. 2.3.6).

$$
\mathrm{k}_{\mathrm{d}}= \begin{cases}0,9995-0,05 \mathrm{k}_{\mathrm{t}}-2,4156 \mathrm{k}_{\mathrm{t}}^{2}+1,426 \mathrm{k}_{\mathrm{t}}^{3} & \text { para } \begin{array}{l}
0<\mathrm{k}_{\mathrm{t}} \leq 0,78 \\
0,2
\end{array} \\
0,78<\mathrm{k}_{\mathrm{t}}\end{cases}
$$

Los modelos de cuarto orden, al modelo (Erbs et al., 1982) que utiliza datos de cuatro estaciones, USA (Ec. 2.3.7).

$$
\mathrm{k}_{\mathrm{d}}=\left\{\begin{array}{lc}
1-0,09 \mathrm{k}_{\mathrm{t}} & \mathrm{k}_{\mathrm{t}} \leq 0,22 \\
0,9511-0,1604 \mathrm{k}_{\mathrm{t}}+4,388 \mathrm{k}_{\mathrm{t}}^{2}-16,638 \mathrm{k}_{\mathrm{t}}^{3}+12,336 \mathrm{k}_{\mathrm{t}}^{4} \text { para } 0,22<\mathrm{k}_{\mathrm{t}} \leq 0,80 \\
0,165 & 0,80<\mathrm{k}_{\mathrm{t}}
\end{array}\right.
$$

El modelo (Chandrasekaran y Kumar, 1994) desde una zona tropical en Madrás, India (Ec. 2.3.8).

$$
\mathrm{k}_{\mathrm{d}}=\left\{\begin{array}{lc}
1,0086-0,178 \mathrm{k}_{\mathrm{t}} & \mathrm{k}_{\mathrm{t}} \leq 0,24 \\
0,9686+0,1325 \mathrm{k}_{\mathrm{t}}+1,4183 \mathrm{k}_{\mathrm{t}}^{2}-10,1862 \mathrm{k}_{\mathrm{t}}^{3}+8,3733 \mathrm{k}_{\mathrm{t}}^{4} \text { para } 0,24<\mathrm{k}_{\mathrm{t}} \leq 0,80 & 0,80<\mathrm{k}_{\mathrm{t}}
\end{array}\right.
$$


El modelo (Oliveira et al., 2002) que utiliza datos de una zona tropical en Sao Paolo, Brasil (Ec. 2.3.9).

$$
\mathrm{k}_{\mathrm{d}}= \begin{cases}1 & \mathrm{k}_{\mathrm{t}} \leq 0,17 \\ 0,97+0,8 \mathrm{k}_{\mathrm{t}}-3 \mathrm{k}_{\mathrm{t}}^{2}-3,1 \mathrm{k}_{\mathrm{t}}^{3}+5,2 \mathrm{k}_{\mathrm{t}}^{4} \text { para } 0,17<\mathrm{k}_{\mathrm{t}} \leq 0,75 \\ 0,17 & 0,75<\mathrm{k}_{\mathrm{t}}\end{cases}
$$

Y basado en los mismos datos el modelo (Soares et al., 2004) que establece otra correlación con un polinomio de cuarto orden por medio de una técnica de redes neuronales (Ec. 2.3.10).

$$
\mathrm{k}_{\mathrm{d}}= \begin{cases}1 & \mathrm{k}_{\mathrm{t}} \leq 0,17 \\ 0,9+1,1 \mathrm{k}_{\mathrm{t}}-4,5 \mathrm{k}_{\mathrm{t}}^{2}+0,01 \mathrm{k}_{\mathrm{t}}^{3}+3,14 \mathrm{k}_{\mathrm{t}}^{4} \text { para } 0,17<\mathrm{k}_{\mathrm{t}} \leq 0,75 \\ 0,17 & 0,75<\mathrm{k}_{\mathrm{t}}\end{cases}
$$

Estas correlaciones propuestas en la literatura son comparadas (Jacovides et al., 2006) usando datos horarios de los años 1998-2002 tomados en Athalassa, Chipre, mediante indicadores estadísticos como: la raíz del error cuadrático medio RMSE, el sesgo medio del error MBE y el test $t$, resultando que son independientes de la ubicación y que también pueden aplicarse a otros lugares con las mismas características geográficas y climáticas. Además, teniendo en cuenta que Chipre tiene dos estaciones, húmeda y seca, regresiones polinomiales se derivaron para la temporada de lluvias de noviembre a marzo y para la estación seca de abril a octubre.

Otros autores que contribuyen tanto con correlaciones como con revisiones (Batlles et al., 2000) y (Wong y Chow, 2001). Más recientemente (Muneer y Munawwar, 2006) contando con una amplia red de estaciones en Europa y Asia, demuestra que el modelo convencional $k_{d}-k_{t}$ para la irradiación solar difusa produce una dispersión alta y por tanto no satisfactoria.

(Boland et al., 2008) detalla nuevos avances en el desarrollo de un marco teórico para el uso de la función logística en vez de funciones lineales a trozos o simples no lineales, además de ser el primer paso para identificar los medios para el desarrollo de un modelo genérico que estima la irradiación difusa desde la irradiación global y otros predictores.

(Ridley et al., 2010) desarrolla un modelo de predicción múltiple, utilizando como predictores el índice de claridad horario y diario, la altura solar, el tiempo solar aparente y una medida de la persistencia del nivel de irradiación solar global. Los resultados para la localidad de Adelaida, Australia, se muestran, sugiriendo que se puede utilizar como modelo universal.

(Posadillo y López, 2009) optimiza el cálculo de la componente difusa horaria de la irradiación solar desde la irradiación solar global de la superficie horizontal en Córdoba, España, estudiando la dependencia de $k_{d} y$ del índice de claridad difuso horario respecto a la altura solar, pudiéndose generalizar a otros lugares.

(Posadillo y López, 2010) concluye también que $k_{t}$ no es una variable suficiente para parametrizar el efecto de las nubes sobre la irradiación difusa. Sobre los datos medidos en Córdoba, España. Además de la inclusión del seno de la altura solar, propone otros parámetros relacionados con la variabilidad en el índice de claridad horario y con las fluctuaciones presentadas por la serie de tiempo de los valores instantáneos de este índice. También presenta la aplicación de un algoritmo que permite tanto la determinación de la irradiación solar difusa horaria, como la discriminación entre las condiciones del cielo en las diferentes situaciones conocidas por la denominación de cielo parcialmente nublado. En función del índice de claridad horario, el seno de la altura solar media en cada hora y una función móvil asociada al índice de claridad horario. 
Otros estudios experimentales relativos a la irradiación solar difusa sobre la horizontal se pueden consultar: (Al-Hamdani et al., 1989) en Bagdag, Iraq. (Alnaser, 1989), (Al-Sadah et al., 1990) y (Ragab y Som, 1991) en Bahrein. (Bendt et al., 1981) con la distribución en frecuencia de los valores diarios de 90 estaciones USA. (Benson et al., 1984) con la insolación en Atlanta, USA. (Bruno, 1978) en Hamburgo, Alemania. (Camps y Soler, 1992) para días nublados en Barcelona, España. (Choudhury, 1963) en Nueva Delhi, India. (Collares-Pereira y Rabl, 1979) USA. (Elminir, 2007) en El Cairo, Egipto. (Gopinathan, 1989) en Sudáfrica. (Hay, 1976) en Canadá. (Hottel, 1976) con la transmitancia en días claros de la atmósfera. (Iqbal, 1978a), (Iqbal, 1979a), (Iqbal, 1979b) y (Iqbal, 1980) con datos de tres estaciones en Canadá y dos en Francia. (Jiménez et al., 1977) en Barcelona, España. (Moriarty, 1991) con 15 estaciones en Australia. (Ruíz-Arias et al., 2010) con datos de 21 estaciones en Europa y USA. (Srivastava et al., 1995) en Lucknow, India. (Stanhill, 1966) en Gilat, Israel. (Torres et al., 2010) en Pamplona, España. (Tuller, 1976) con cuatro estaciones en Canadá. (Alam et al., 2009) con datos de 10 estaciones en la India demuestra que el modelo de redes neuronales artificiales es más preciso y versátil, en comparación con otros modelos para predecir la irradiación solar difusa horaria y diaria.

\subsubsection{Los componentes de la irradiación solar sobre un plano inclinado}

La evaluación de la irradiación solar que llega a un plano inclinado es muy importante, ya que habitualmente solo se dispone de datos de irradiación solar registrados sobre la superficie horizontal.

En los análisis de los captadores solares de placa plana, las cantidades de irradiación solar directa y difusa que reciben deben ser determinadas con valores durante un periodo mínimo de una hora, y es necesario que se establezcan procedimientos.

A continuación se describen métodos de la literatura para calcular cada componente de la irradiación solar que incide sobre el captador solar: directa del sol, reflejada del suelo y difusa del cielo, por separado.

\section{1) La irradiación directa del sol incidente sobre un plano inclinado}

La irradiación solar directa incidente sobre un plano inclinado resulta de una relación entre la irradiación solar directa, extraterrestre, horizontal e inclinada (Iqbal, 1983), donde se asume que la relación entre la irradiación directa sobre una superficie inclinada vs. una superficie horizontal es la misma en la superficie de la tierra como en la parte superior de la atmósfera (Ec. 2.3.11).

$$
\mathrm{I}_{\mathrm{b} \beta \gamma}=\mathrm{I}_{\mathrm{b}} \frac{\mathrm{I}_{0 \beta \gamma}}{\mathrm{I}_{0}}
$$

Pudiéndose escribir también como (Ec. 2.3.12).

$$
\mathrm{I}_{\mathrm{b} \beta \gamma}=\mathrm{I}_{\mathrm{b}} \frac{\cos \theta}{\cos \theta_{\mathrm{z}}}=\mathrm{I}_{\mathrm{b}} \mathrm{r}_{\mathrm{b}}
$$

Donde,

$\mathrm{I}_{\mathrm{b}}$ : Irradiación directa horaria incidente sobre una superficie horizontal. 
$\mathrm{I}_{\mathrm{b} \beta \gamma}$ : Irradiación directa horaria incidente sobre un plano inclinado y orientado.

$r_{b}$ : Ratio de la irradiación sobre un plano inclinado y sobre la superficie horizontal en ausencia de la atmósfera terrestre $\left(\frac{I_{0 \beta}}{I_{0}} \approx \frac{\cos \theta_{0}}{\cos \theta_{z}}\right)$.

\section{2) La irradiación reflejada por la tierra incidente sobre un plano inclinado}

La irradiación solar que llega al suelo se compone de dos, la directa y la difusa, la palabra tierra aquí significa un compuesto de toda la superficie de la tierra que el plano inclinado ve. Dependiendo del tipo de cubierta de la tierra, el albedo de la irradiación solar directa y difusa, no es el mismo, con lo que la irradiación total reflejada por el suelo puede ser descrita como (Iqbal, 1983) por (Ec. 2.3.13).

$$
I_{r}=\left(I_{b} \rho_{b}+I_{d} \rho_{d}\right) A_{g}
$$

Donde,

Ir: Irradiación difusa horaria reflejada por la tierra incidente sobre un plano inclinado.

$\mathrm{I}_{\mathrm{d}}$ I Irradiación difusa horaria incidente sobre una superficie horizontal.

$\rho_{b}$ : Albedo del suelo debido a la irradiación directa.

$\rho_{d}$ : Albedo del suelo debido a la irradiación difusa.

$A_{g}$ : Área total del terreno visto por el plano inclinado.

Pudiéndose dar dos casos de reflexión la isotrópica y la anisotrópica, que se presentan a continuación.

\section{El albedo con reflexión isotrópica}

El albedo con reflexión isotrópica designa a la reflexión perfectamente difusa. Ocurre cuando la irradiación solar global se compone principalmente de la irradiación difusa y/o cuando la cobertura del suelo es un reflector perfectamente difuso, como un piso de concreto. Utilizando el ratio de la irradiación solar sobre un plano inclinado y una superficie horizontal resulta un factor de configuración desde el suelo al plano inclinado como (Iqbal, 1983) por (Ec. 2.3.14).

$$
\mathrm{I}_{\mathrm{r}}=\frac{1}{2} \mathrm{I} \rho(1-\cos \beta)
$$

Donde,

$\rho:$ Albedo del suelo (Irradiación reflejada desde el suelo/Irradiación incidente sobre el suelo).

\section{El albedo con reflexión anisotrópica}

El albedo con reflexión anisotrópica designa a la reflexión difusa imperfecta. Bajo un cielo limpio y despejado, la irradiación solar global se compone principalmente de irradiación directa. Cuando el suelo esta mojado o hay superficies brillantes, la reflexión de la irradiación es anisotrópica. Entonces el modelo isotrópico se corrige con los siguientes factores como (Iqbal, 1983) por (Ec. 2.3.15). 


$$
I_{r}=\frac{1}{2} I \rho(1-\cos \beta)\left[1+\operatorname{sen}^{2}\left(\frac{\theta_{z}}{2}\right)\right](|\cos \Delta|)
$$

Donde,

$\Delta$ : Azimut de la superficie inclinada con respecto al del Sol, este ángulo se reduce a $\omega$ para superficies inclinadas hacia el ecuador.

\section{3) La irradiación difusa del cielo incidente sobre un plano inclinado}

Las formulaciones empíricas para la irradiación solar difusa del cielo incidente sobre una superficie inclinada se encuentran en la literatura para cada categoría de cielo: claros, nublados y parcialmente nublados.

\section{Modelo circumsolar}

El modelo circumsolar se aplica a cielos limpios y despejados. Se supone que toda la irradiación solar que llega a la superficie horizontal parece provenir de la dirección del sol (Iqbal, 1983), por lo tanto, puede ser tratada de la misma manera que la irradiación directa por (Ec. 2.3.16).

$$
\mathrm{I}_{\mathrm{s}}=\mathrm{I}_{\mathrm{d}} \mathrm{r}_{\mathrm{b}}
$$

Donde,

$\mathrm{I}_{s}$ : Irradiación difusa del cielo horaria incidente sobre un plano inclinado.

Este modelo sobrestima la irradiación difusa.

\section{Modelo isotrópico}

En el modelo isotrópico la intensidad de la irradiación solar difusa del cielo se supone uniforme en toda la bóveda celeste. Se aproxima a la condición de cielo nublado. La irradiación difusa del cielo incidente sobre un plano inclinado está dada (Liu y Jordan, 1963) en el tratamiento de la componente difusa asume que se trata de isotrópico como una aproximación justa y proponen que la relación de la irradiación solar difusa incidente en planos inclinados vs. la irradiación solar difusa incidente en una superficie horizontal está dado por la expresión (Ec. 2.3.17).

$$
I_{s}=\frac{1}{2} I_{d}(1+\cos \beta)
$$

Este modelo subestima la irradiación difusa del cielo en la vertiente opuesta de la superficie inclinada, y en condiciones de cielo claro y parcialmente nuboso.

\section{Modelos anisotrópicos}


Se ha demostrado que la luz del cielo es anisotrópica en muchos casos y que el supuesto de una distribución isotrópica puede introducir un error en el cálculo sobre la superficie inclinada. Aquí se tratan los modelos en las condiciones de los cielos parcialmente nublados, esta condición puede variar desde un cielo despejado en un extremo hasta los cielos nublados en el otro extremo. A continuación se presentan tres modelos al efecto.

\section{Modelo de Temps y Coulson}

El modelo de Temps y Coulson de distribución anisotrópica para cielo claro (Temps y Coulson, 1977) proporciona una buena predicción con cielos despejados, pero sobrestima la irradiación solar cuando se usa para los días nublados (Ec. 2.3.18).

$$
I_{s}=\frac{1}{2} I_{d}(1+\cos \beta)\left[1+\operatorname{sen}^{3}\left(\frac{\beta}{2}\right)\right]\left(1+\cos ^{2} \theta \operatorname{sen}^{3} \theta_{z}\right)
$$

Combina tres factores de corrección con el término de irradiación difusa isotrópica para tener en cuenta cada una de las tres regiones de la anisotropía en el campo de la irradiación difusa.

Un factor $\left[1+\operatorname{sen}^{3}\left(\frac{\beta}{2}\right)\right]$ explica el aumento de la luz del cielo observada cerca del horizonte en los días claros.

El brillo del cielo cerca del Sol se aproxima por el factor $\left(1+\cos ^{2} \theta \operatorname{sen}^{3} \theta_{z}\right)$.

Un tercer factor que representa la mejora de la reflexión de la superficie, no se tiene en cuenta.

\section{Modelo de Klucher}

El modelo de Klucher de distribución anisotrópica para todo tipo de cielo (Klucher, 1979), modifica la formulación de Temps y Coulson como se indica a continuación (Ec. 2.3.19).

$$
I_{s}=\frac{1}{2} I_{d}(1+\cos \beta)\left[1+F \operatorname{sen}^{3}\left(\frac{\beta}{2}\right)\right]\left(1+F \cos ^{2} \theta \operatorname{sen}^{3} \theta_{z}\right)
$$

Donde,

$$
\mathrm{F}=1-\left(\frac{\mathrm{I}_{\mathrm{d}}}{\mathrm{I}}\right)^{2}
$$

Cuando el cielo está completamente nublado $\mathrm{F}=0$ con lo que vuelve al modelo isotrópico y cuando los cielos están despejados $\mathrm{F}=1$ se tiene el modelo de Temps y Coulson, con lo que mejora las estimaciones en todo tipo de cielo.

\section{Modelo de Hay}

El modelo de Hay se describe como (Ec. 2.3.20): 


$$
I_{s}=I_{d}\left\{\frac{I-I_{d}}{I_{0}} r_{b}+\frac{1}{2}(1+\cos \beta)\left[1-\frac{I-I_{d}}{I_{0}}\right]\right\}
$$

Se basa en un componente circunsolar que viene directamente de la dirección del sol, y otro componente de irradiación difusa que se distribuye isotrópicamente del resto de la bóveda celeste. Estos dos componentes se ponderan de acuerdo a un índice de isotropía. Este índice es esencialmente una relación de la irradiación solar directa de la superficie horizontal sobre la tierra y la irradiación solar extraterrestre sobre una superficie horizontal (Hay, 1976) y (Hay, 1979).

\subsubsection{La irradiación solar global incidente sobre un plano inclinado}

La cantidad total de irradiación solar que incide sobre un plano inclinado se compone de tres componentes: directa, reflejada del suelo y difusa del cielo. Una vez conocidos por separado hay que unirlos (Iqbal, 1983). En los lugares donde se conoce la irradiación solar horaria global y difusa sobre superficies horizontales o puede ser estimada esta última, la irradiación global sobre un plano inclinado se puede escribir como (Ec. 2.3.21).

$$
I_{\beta \gamma}=\left(I-I_{d}\right) r_{b}+I_{r}+I_{s}
$$

O también (Ec. 2.3.22).

$$
\mathrm{I}_{\beta \gamma}=\mathrm{I}_{\mathrm{b} \beta \gamma}+\mathrm{I}_{\mathrm{d} \beta}
$$

Donde,

$I_{\beta \gamma}$ : Irradiación global horaria incidente sobre un plano inclinado y orientado.

$\mathrm{I}_{\mathrm{b} \beta \gamma}$ : Irradiación directa horaria incidente sobre un plano inclinado y orientado.

$I_{\mathrm{d} \beta}$ : Irradiación difusa horaria incidente sobre un plano inclinado y orientado $\left(\mathrm{I}_{\mathrm{r}}+\mathrm{I}_{\mathrm{s}}\right)$.

Esta ecuación se utiliza ampliamente en la investigación y desarrollo de métodos de simulación, donde la utilización de los valores por separado de la componente directa y difusa en los planos inclinados se hace obligatoria. Con los valores medidos o estimados de la irradiación solar global horaria I y la irradiación solar difusa horaria $I_{d}$, el análisis del sistema solar térmico puede llevarse a cabo de hora en hora durante todo el año. Tal análisis conduce a procedimientos de diseño adecuados, que los ingenieros y arquitectos pueden emplear directamente. 


\subsection{Modelado de los componentes de un sistema solar térmico}

En este apartado se realiza una revisión de los modelos presentados en la literatura del funcionamiento de los principales componentes de un sistema solar térmico, como son el captador solar de placa plana que es el más característico, el intercambiador de calor y la estratificación térmica en el depósito acumulador.

\subsubsection{Modelado del captador solar}

El primer modelo matemático de captador solar plano de tubos paralelos fue publicado por (Hottel y Whillier, 1955). Se trata de un modelo unidimensional de aleta y tubo, con tratamiento de la radiación en dos bandas, onda corta y onda larga. Aunque se han propuesto modelos más detallados, este modelo es el que con mayor sencillez contempla las variables que determinan la eficiencia del captador solar, lo que le ha convertido en un clásico. En general el rendimiento de un captador se ha modelado mediante la ecuación de Hottel-Whillier-Bliss en estado estacionario.

La eficiencia de un captador solar es un factor clave para el desempeño de los sistemas solares térmicos. Como las condiciones climáticas varían continuamente durante el día, el rendimiento instantáneo del captador solar no solo depende de los componentes empleados en su construcción, sino también de las condiciones reales del medio ambiente, la temperatura del fluido portador y el envejecimiento (Rodríguez-Hidalgo, 2011ab).

La irradiación solar se transforma en el interior del captador solar en energía térmica útil, y este proceso da como resultado un aumento de la temperatura del fluido portador en el interior. La eficiencia de la conversión energética depende de las pérdidas ópticas y térmicas del captador solar. Estas pérdidas se deben a los procesos de transferencia del calor por conducción, convección y radiación al medio ambiente, también a las condiciones locales de irradiación solar y las propiedades ópticas del captador solar (Duffie y Beckman, 2006).

Para caracterizar el rendimiento de los captadores solares, hay diferentes estándares de ensayo en condiciones específicas de funcionamiento, tales como ASHRAE 93 y EN 12975, que se aplican en USA y Europa, respectivamente. (Rojas, 2008) compara experimentalmente los dos estándares y llega a la conclusión de que resultan valores similares de la curva de eficiencia en un captador solar de placa plana.

(Kalogirou, 2004) realiza un extenso estudio sobre los captadores solares térmicos: tipos, historia, análisis, rendimiento, modelado de sistemas solares térmicos, economía y aplicaciones.

El modelado de los captadores solares se realiza mediante ensayos experimentales y validando los modelos resultantes. En el diseño del modelo es necesario conocer las características del captador solar, también hay que tener claro el grado de complejidad que va a alcanzar y la precisión de los resultados. Los métodos unidimensionales logran una gran precisión en sus resultados, que es aumentada por los bidimensionales (Kazeminejad, 2002). Pero es necesario un acuerdo entre la simplicidad del modelo y su 
precisión. Los parámetros que repercuten en el rendimiento del captador solar se pueden clasificar como de diseño, operacionales y ambientales.

(Klein, 1978) utiliza el método Utilizability desarrollado por (Whillier, 1953) y difundido por (Liu y Jordan, 1963). (Whillier, 1964) estudia la resistencia térmica de la unión entre los tubos de la parrilla y la placa del absorbedor.

Aunque los efectos transitorios no se tienen en cuenta en los modelos estacionarios, respecto al tiempo de duración en un periodo diario su influencia es muy pequeña. También hay que tener en consideración que la resolución temporal de los datos ambientales usualmente no supera una hora, por lo que un modelado muy complejo no tiene mucha utilidad. Por otra parte, la identificación experimental de las características ópticas y térmicas de un captador solar es importante para la normalización y certificación de captadores solares.

(Frid, 1990) realiza una revisión de los modelos y ensayos de los captadores solares, además de una formulación para dos y tres nodos del captador solar. (Amer et al., 1997) plantea otra revisión y clasificación de los métodos de ensayo de los captadores solares que se encuentran en la literatura.

(El-Adawi, 2002) utiliza la técnica de la transformada de Fourier para resolver la difusión del calor en el absorbedor y estimar el rendimiento del captador solar.

(Matuska et al., 2009) para la modelización de los captadores de placa plana, también existe software de diseño como la herramienta Kolektor útil para la creación de prototipos virtuales y análisis de los parámetros que influyen en el rendimiento de los captadores solares utilizados en la edificación.

Los modelos de ensayos para los captadores solares se pueden clasificar en modelos de estado estacionario y modelos de prueba dinámicos.

El enfoque dinámico es más preciso para el cálculo del rendimiento y diseño de los captadores solares de placa plana. (Arinze et al., 1993) presenta el modelo dinámico que describe las temperaturas en el fluido portador, absorbedor y cubierta del captador solar con tres ecuaciones diferenciales, resolubles mediante series de Taylor y el método Runge-Kutta.

Para citar algunos más están, (Hou et al., 2004), (Wang, 2008) y (Xu, 2009) con el método de la función de transferencia que se utiliza para obtener la temperatura de salida en el captador solar en condiciones estacionarias y dinámicas, (Kong et al., 2012) lo mejora estimando los parámetros de los captadores solares como el coeficiente de pérdida cero y el coeficiente de pérdida de calor. (Emery y Rogers, 1984) con el método de la función respuesta que se utiliza para ensayar captadores solares en modo transitorio. (Cruz-Peragon et al., 2012) presenta una metodología para validar un modelo de captador solar con una complejidad indeterminada caracterizada por coeficientes físicos y optimizar un modelo de diferencias finitas con caudal bajo.

(Farkas y Géczy-Víg, 2003) utiliza para modelar los captadores solares un modelo basado en redes neuronales artificiales, se ofrece su utilidad cuando otros modelos presentan dificultades en su aplicación. Las variables de entrada son la irradiancia solar, la temperatura de entrada del fluido portador al captador solar y la temperatura del ambiente, la salida resulta ser la temperatura de salida del fluido portador del captador solar. El entrenamiento de la red neuronal artificial se realiza con datos 
medidos para las entradas del modelo y/o con simulados por el modelo Hottel-Whillier-Bliss para la salida.

(Kalogirou, 2006) muestra cómo utilizar los datos experimentales de los ensayos de rendimiento en los captadores solares, mediante redes neuronales artificiales para realizar la predicción de los parámetros del rendimiento, evitando ensayos prolongados.

(Sözen, 2008) crea una ecuación cuyos coeficientes se calculan mediante una red neuronal artificial, para la determinación del rendimiento de un captador solar, a partir de los datos experimentales, utilizando como variables de entrada a la red neuronal artificial la fecha, la hora, la temperatura de la superficie, la irradiancia solar y los ángulos de declinación, el azimut y la inclinación.

(Fischer et al., 2012) propone utilizar las redes neuronales artificiales como alternativa al método de la norma europea EN 12975-2 para el modelado de otros tipos de captadores solares diferentes al de placa plana, que no pueden realizarse con la misma precisión. El modelo de red neuronal artificial es de tipo no lineal autorregresivo con entradas exógenas NARX, tiene como variables de entrada la irradiancia solar directa y difusa, la diferencia de temperatura entre el fluido portador en la entrada del captador solar y el ambiente, y el caudal másico del fluido portador en el captador solar, la salida es la energía calorífica del fluido portador en la propia salida del captador solar.

\subsubsection{Modelado del intercambiador de calor}

Los intercambiadores de calor son componentes utilizados comúnmente para la transferencia de calor entre distintos fluidos, muy complejos, debido a su comportamiento no lineal y la complicación causada por muchos fenómenos tales como las pérdidas, la fricción, la dependencia de las propiedades del fluido con la temperatura, la resistencia de contacto, propiedades desconocidas de los fluidos,... para los cuales la predicción de su funcionamiento a partir de los principios básicos se hace muy difícil.

Hay un gran número de fenómenos asociados con el flujo y la transferencia de calor, que son tal vez fácil de resolver por separado, pero el resultado cuando se combinan en un sistema es imposible de calcular. Algunos de estos se comentan a continuación: geometrías complicadas en el flujo de los fluidos y calor, turbulencias en el flujo, zonas en las entradas del fluido y calor, no uniformes localmente en la temperatura del fluido y la velocidad de transferencia de calor, flujos secundarios en las curvas de los tubos, vórtices en las uniones de las aletas con el tubo, flujos en el lado del aire desarrollados en los conductos de las aletas, conducción de calor a lo largo de las paredes del tubo, convección natural dentro de los tubos y entre las aletas, y la dependencia de las propiedades del fluido con la temperatura (Sen y Yang, 2000).

Así en estado estacionario las predicciones no son fáciles de hacer a partir de un análisis de los principios básicos, pero las predicciones dinámicas son más difíciles todavía. La mayoría de modelos, con el fin de hacer el problema más fácil de manejar, se basan en supuestos y simplificaciones que no son totalmente realistas. Los resultados por lo tanto son más cualitativos que cuantitativamente exactos. Algunas de las suposiciones más comunes son las siguientes: agrupar las condiciones térmicas, propiedades constantes en el fluido, coeficientes de transferencia de calor constantes, velocidades de flujo constantes, mezcla completa transversal en el flujo, conducción de calor despreciable por la pared, 
conducción de calor insignificante a través de las aletas y capacidad calorífica despreciable de la pared (Roetzel y Xuan, 1999).

Los modelos que incluyen más física son por lo general en derivadas parciales y con soluciones dependientes del tiempo, con alto nivel de cómputo y no son adecuadas para el control en tiempo real. Otra dificultad es que el rendimiento típico de un intercambiador de calor cambia lentamente con el tiempo debido a factores como la suciedad que modifica las características de transferencia de calor de las superficies. Como resultado en la práctica, la mayoría de las predicciones se basan en correlaciones que se han derivado de experimentos llevados a cabo en un intercambiador de calor específico (Kays y London, 1984). Las medidas son por lo general de los caudales y las temperaturas de entrada y salida de los fluidos. A partir de estos la transferencia de calor se puede determinar. Los datos experimentales se utilizan para obtener correlaciones adimensionales sobre la eficiencia del intercambiador de calor, los resultados de las correlaciones en los ensayos pueden ser utilizados por el usuario para predecir la transferencia de calor del mismo, bajo diferentes condiciones de funcionamiento de los fluidos.

Las redes neuronales artificiales se han utilizado en los últimos años para evitar problemas asociados con los enfoques deterministas, y también para aproximar funciones no lineales hasta cualquier nivel de precisión deseado (Hecht-Nielsen, 1987). Las redes neuronales artificiales son menos sensibles al ruido y la información incompleta que otros métodos como los modelos y las correlaciones empíricas. Las ventajas de utilizar redes neuronales artificiales para simular procesos térmicos, son que, después de haber sido entrenadas, representan una forma rápida y fiable de predecir su funcionamiento. Por lo tanto, si se aplica esta técnica al problema de simulación de los intercambiadores de calor, entonces se obtiene una predicción precisa en un corto periodo de tiempo computacional para la simulación. Estudios previos han demostrado la utilidad de la técnica de las redes neuronales artificiales para la predicción del comportamiento de los intercambiadores de calor.

(Díaz et al., 2001) y (Díaz, 2000) emplean la técnica de las redes neuronales para la simulación del comportamiento de un intercambiador de calor y se utiliza para controlar la temperatura del aire que pasa por él.

(Vasičkaninová et al., 2011) utiliza las redes neuronales artificiales como un modelo de proceso no lineal, para predecir el comportamiento futuro del intercambiador de calor, como un sistema con parámetros distribuidos.

(Islamoglu, 2003) aplica el enfoque de redes neuronales artificiales para predecir la velocidad de transferencia de calor en un intercambiador de calor del tipo tubo sobre alambre, que es el condensador más utilizado en pequeños sistemas de refrigeración. Los resultados indican que el enfoque de las redes neuronales artificiales es adecuado para su uso en la estimación de la velocidad de transferencia de calor. Además, concluye que las redes neuronales artificiales pueden ser entrenadas para simular sistemas similares para el análisis térmico, siendo una herramienta de modelado sencilla para los ingenieros térmicos.

(Xie et al., 2007) analiza la transferencia de calor en los intercambiadores de calor del tipo carcasa y tubo, con datos experimentales en redes neuronales artificiales. La comparación de las predicciones con correlaciones, muestra una superioridad de las redes neuronales artificiales. Recomienda las redes neuronales artificiales para ser usadas en la predicción del rendimiento de los sistemas térmicos en 
aplicaciones de la ingeniería, tales como el modelado de los intercambiadores de calor para el análisis de la transferencia de calor.

(Peng y Ling, 2008) propone la aplicación de un algoritmo genético combinado con las redes neuronales artificiales para el diseño óptimo de un intercambiador de calor del tipo placa y aleta. Este método de optimización es universal y puede ser utilizado para diferentes intercambiadores de calor.

(Peng y Ling, 2009) ofrece una nueva forma de simular sistemas complejos no lineales, inciertos, o desconocidos sin necesidad de ningún conocimiento explicito acerca de la relación entrada/salida. Se recomienda el modelo de predicción de redes neuronales artificiales por su alta fiabilidad para la simulación de sistemas térmicos, especialmente para los fabricantes o diseñadores para modelar los intercambiadores de calor en aplicaciones de ingeniería complejas con escasos datos experimentales.

(Tan et al., 2009) presenta el uso de modelos con redes neuronales artificiales para simular el rendimiento térmico de un intercambiador compacto del tipo tubo y aleta con aire-agua mezcla de anticongelante etilenglicol como fluido portador. Las predicciones del modelo se comparan con los datos experimentales en un amplio rango de velocidades del flujo, temperaturas de entrada y con diversas concentraciones de etilenglicol. Las redes neuronales artificiales fueron capaces de predecir la velocidad de transferencia de calor en el intercambiador de calor, con un alto grado de precisión y se encuentra que es superior a los modelos convencionales de regresión no lineal en la captura subyacente de las no linealidades en los datos. Los resultados indican que las redes neuronales artificiales debidamente entrenadas pueden simular tanto las características generales, como las particulares de un intercambiador de calor compacto.

(Lecoeuche et al., 2005) concreta los pasos para crear un modelo elemental con redes neuronales artificiales. Siendo necesario encontrar la arquitectura óptima, estudiando simultáneamente la influencia del número de entradas, del número de salidas, del número de neuronas y su función de activación en la capa oculta. La calidad de los resultados se estima mediante el cálculo del error cuadrático medio entre las salidas reales y las salidas estimadas. Demostrando que las redes neuronales artificiales son herramientas potentes para modelar el estado transitorio de un intercambiador de calor.

(Radhakrishnan et al., 2007) estudia el tren de precalentamiento del crudo en una refinería de petróleo que se compone de un conjunto de intercambiadores de calor de gran tamaño de los cuales se recupera el calor residual para precalentar el crudo petrolífero. En estos intercambiadores de calor el coeficiente global de transferencia de calor se reduce significativamente debido al ensuciamiento. La velocidad de ensuciamiento es altamente dependiente de las propiedades de las mezclas de crudo, así como de la temperatura de funcionamiento y las condiciones del flujo. Este estudio desarrolla un modelo de redes neuronales artificiales sobre el ensuciamiento del intercambiador de calor, basado en los datos históricos de operación de la planta. También ilustra la metodología mediante la cual el modelo predictivo puede ser utilizado para desarrollar una herramienta de programación del mantenimiento predictivo, destinada a mejorar el rendimiento global de los sistemas, prediciendo la disminución de la eficiencia del intercambiador de calor.

(Lalot y Pálsson, 2010) presenta un método para la detección de las incrustaciones en un intercambiador de calor del tipo de flujo cruzado mediante redes neuronales artificiales. La gama de sectores industriales afectados por la suciedad en los intercambiadores de calor es bastante amplia. 
(Ferreiro, 2012) tiene el objetivo de la supervisión en la vigilancia de las incrustaciones en los intercambiadores de calor utilizando redes neuronales artificiales. El ensuciamiento de los intercambiadores de calor en las plantas de proceso da como resultado un impacto de costo significativo en términos de pérdida de producción, eficiencia energética y costes de mantenimiento. Encuentra en esta metodología dos inconvenientes como es el esfuerzo que tiene que llevarse a cabo en la fase de adquisición de conocimiento, para formar una base de datos consistente y el requerimiento de conocimiento real con diferentes condiciones de funcionamiento nominales del intercambiador de calor que se llevan a cabo.

(Dudzik, 2011) presenta un análisis de los resultados de la simulación realizada con un algoritmo para el cálculo del consumo de la energía calorífica, utilizando las redes neuronales artificiales entrenadas con datos procedentes de mediciones con termografías infrarrojas.

(Pacheco-Vega et al., 2003) y (Pacheco-Vega, 2002) proponen un método de reducción de datos que mejora las predicciones de las correlaciones obtenidas a partir de mediciones en el intercambiador de calor, estas correlaciones pueden predecir la transferencia de calor del mismo intercambiador de calor bajo diferentes condiciones de funcionamiento.

\subsubsection{Modelado de la estratificación térmica en el depósito}

Hasta principios de los años 70, los sistemas solares térmicos con caudales altos en el circuito primario y depósitos no estratificados fueron el estado de la técnica. La razón de esto es que, según la ecuación Hottel-Whillier-Bliss grandes caudales conducen a rendimientos más grandes del captador solar. Esto se creía que llevaba, erróneamente, a mayores eficiencias en todo el sistema solar térmico, cuando el comportamiento del sistema se pasa por alto. Los caudales grandes en el circuito primario dan lugar a temperaturas más bajas en el depósito, lo cual tiene una utilidad limitada para el uso en la calefacción o el agua caliente.

Actualmente se acepta que la estratificación térmica aumenta el rendimiento del sistema solar térmico, principalmente por dos factores. El primero es que si el depósito de mezcla completa utiliza la energía auxiliar, el agua se recircula hacia el captador solar con la temperatura alta, con lo que resulta un rendimiento bajo del captador solar. Un depósito estratificado tiene una temperatura más baja en las capas inferiores, lo que aumenta la eficacia del captador solar. En segundo lugar una temperatura alta en la parte superior del depósito necesita menos o ningún calentamiento auxiliar para alcanzar el nivel de temperatura requerido para el agua caliente o calefacción.

(Fischer et al., 1975) identifica la estratificación térmica como un medio para aumentar la eficiencia del almacenamiento de la energía térmica. Sin lugar a dudas la estratificación térmica ha estado presente en los depósitos antes, sin embargo, su potencial para aumentar la eficiencia de los sistemas solares térmicos no estaba reconocido.

El almacenamiento térmico mediante calor sensible en agua es utilizado como una herramienta efectiva para extender el uso de la energía solar durante todo el día, debido al desfase entre la oferta y demanda de la energía solar, el medio de almacenamiento más utilizado es el agua debido a su alta capacidad calorífica volumétrica y bajo coste. Además, el agua es el fluido utilizado en el circuito primario y secundario en la mayoría de los sistemas solares térmicos. 
El rendimiento de los sistemas solares térmicos que utilizan almacenamiento térmico sensible en agua, depende en gran medida del mantenimiento de la separación del agua más caliente de la más fría en el depósito durante todo el ciclo de funcionamiento. Es importante que el agua caliente y fría almacenada se mezcle lo mínimo durante el proceso de carga y descarga. Este es un factor clave para mantener la disponibilidad termodinámica de la energía almacenada, así como garantizar un alto rendimiento de los captadores solares. Un alto grado de estratificación térmica aumenta el rendimiento térmico de los sistemas solares térmicos de agua caliente porque la temperatura de retorno al captador solar es más baja, con una temperatura de retorno al captador solar inferior se incrementa el rendimiento del captador solar y por lo tanto, la disminución de los períodos de funcionamiento de la fuente de energía auxiliar de apoyo. Numerosos estudios demuestran que la estratificación térmica en el interior del depósito tiene un efecto positivo a largo plazo en el rendimiento de los sistemas solares térmicos.

La utilización de varios depósitos es una forma obvia de lograr esta separación, pero no es la mejor opción en cuanto a la sencillez, la viabilidad económica y la utilización del espacio. Existen otros esquemas diseñados e implementados, por ejemplo, un depósito con un diafragma montado en posición horizontal o vertical, depósitos de laberinto en los que se obliga a que el agua fluya por él, y el depósito estratificado en el que se hace uso del proceso natural de la estratificación, que permite al agua caliente flotar por encima del agua fría. Un único depósito estratificado es la mejor opción debido a su simplicidad y bajo costo. Por otra parte, el rendimiento del depósito estratificado es comparable con los otros tipos. Este tipo de almacenamiento térmico ha sido objeto de muchas investigaciones, tanto analíticas como experimentales.

El rendimiento térmico de un depósito estratificado depende de la termoclina, definida por la zona de gradiente térmico más alto en todo el interior del depósito, de que se pueda mantener su espesor, lo que depende de varios factores, como:

- La velocidad de pérdida de calor al exterior.

- La flotabilidad de los líquidos.

- La conducción de calor por las paredes del depósito.

- Los chorros en las entradas del depósito.

El objetivo es mantener la región del termoclina lo más fina posible.

En la literatura son numerosos y diferentes los modelos teóricos de almacenamiento de la energía térmica en los depósitos, así como estudios experimentales. La mayoría de ellos se refieren a su funcionamiento dinámico cuando se utiliza la energía térmica del agua en el depósito, es decir, cuando tienen lugar los procesos de carga y/o descarga. Para una revisión completa y clasificación de estos modelos puede consultarse (Dinçer y Rosen, 2011).

La estratificación térmica en el depósito de un sistema solar térmico se puede lograr por varios métodos (Shah, 1999) como son el calentamiento de las paredes verticales que se traduce en la creación de capas límite térmicas que llevan el agua caliente a la parte superior del depósito, el intercambio de calor entre el agua contenida en el depósito y el que circula por el intercambiador de calor colocado dentro o fuera del depósito y la entrada directa en el depósito de agua caliente a la altura adecuada.

El principio de funcionamiento de los depósitos de almacenamiento estratificado se basa en el proceso natural de la estratificación. Cuando un depósito de agua caliente sin flujo externo está sujeto a la 
temperatura ambiente, una estratificación térmica del agua se forma en el curso del proceso de enfriamiento. El agua fría se acumula en el fondo, mientras que el agua caliente sube a la parte superior del depósito. Este fenómeno se produce aun cuando inicialmente la totalidad del agua en el depósito se encuentra a una temperatura uniforme. Se origina en el hecho de que, antes de la liberación de calor al ambiente, la pared del depósito enfría una capa delgada vertical de agua a lo largo de la pared del depósito. Parte de este calor se transfiere por difusión hacia el centro del tanque. El agua de la capa vertical se vuelve más densa que su alrededor y entonces se desliza hacia el fondo del depósito creando la estratificación.

El efecto contrario a esta circulación es el creado al actuar el serpentín interior del depósito, este suministra calor a la capa vertical que se vuelve menos densa que su alrededor y entonces se eleva hacia la parte superior del depósito. El agua en la zona central que está más fría circula hacia la parte inferior del depósito.

Los depósitos utilizados en los sistemas solares térmicos, en el caso de utilizar intercambiador exterior, el agua fría se retira de la parte inferior y se lleva para su calentamiento por los captadores solares, recirculándose a la parte superior del tanque a una temperatura relativamente alta. Como resultado, una diferencia de temperatura entre la parte superior y la parte inferior del depósito se presenta con la consiguiente variación de la densidad en el medio. En la zona de entrada aparece una región de mezcla de aguas que es empujada abajo, poco a poco, a medida que el agua entra en el depósito. Como consecuencia, una región con un fuerte gradiente se forma, lo que se conoce como la región de la termoclina. Una vez que la termoclina se desarrolla, en el proceso de carga, limita la mezcla entre las zonas caliente (superior) y fría (inferior).

El espesor de la termoclina se utiliza como un medio para cuantificar la eficacia de la estratificación en un depósito acumulador. Cuanto mayor sea la mezcla en la entrada, más grande es la zona de termoclina. El espesor de la termoclina indica el grado de mezcla que se produce debido a las corrientes de flujo de entrada durante los ciclos. Este factor influye en la degradación de la estratificación, junto a las pérdidas de transferencia de calor desde el depósito.

La estratificación térmica se caracteriza por su extrema debilidad. Hay varios factores asociados con la pérdida de la estratificación térmica en los depósitos de almacenamiento térmico de agua. Los factores más importantes de la desestratificación están en los mecanismos principales para la transmisión de calor y el intercambio de energía que en un depósito son los siguientes:

- Caudal del agua de entrada y salida al depósito.

- Pérdidas de calor por convección al ambiente a través de la pared del depósito.

- Conducción a través del agua por la termoclina dentro del depósito.

- Convección natural por mezcla del agua en el depósito.

- Mezcla turbulenta del agua debida a los efectos del caudal.

- Conducción de las capas del fluido caliente a las capas del fluido frío a través de la pared conductora del depósito.

La precisión de los modelos de estratificación térmica depende fuertemente de cómo estos factores se describen en especial la mezcla introducida durante los ciclos de carga y/o descarga, que generalmente se considera la causa principal del deterioro de la estratificación. 
La temperatura media del agua en el depósito es la temperatura con la que sale el agua del depósito, suponiendo que el depósito está totalmente mezclado. Esta hipótesis ha sido ampliamente utilizada. La estratificación del depósito es una mejora significativa en el rendimiento del sistema. El modelo de mezcla del depósito puede ser demasiado conservador (Phillips y Dave, 1982).

Debido al insuficiente conocimiento teórico, las directrices de diseño para depósitos estratificados térmicamente a corto plazo son en su mayor parte de base empírica (Berkel, 1996).

En la actualidad, no existen normas válidas y ampliamente aceptadas, para la comparación del rendimiento de los sistemas de almacenamiento térmico estratificado (Rosen et al., 2004), los métodos utilizados actualmente para caracterizar un depósito de energía térmica pueden clasificarse y basarse como sigue:

- Los números generales adimensionales de transferencia de calor y la dinámica de fluidos.

- La primera ley de la termodinámica, caracterizaciones fundadas en la energía.

- La segunda ley de la termodinámica, caracterizaciones fundadas en la entropía y la exergía.

Los modelos del movimiento del fluido existentes se pueden clasificar en tres, dos y una dimensión.

Los modelos tridimensionales describen el movimiento del fluido con tres ecuaciones que lo gobiernan: conservación de la masa o continuidad, conservación del momento y conservación de la energía. Mediante las ecuaciones de estado y los límites apropiados de condiciones de espacio y tiempo, se obtiene el modelo general que describe el movimiento de las partículas en el fluido.

Los modelos matemáticos bidimensionales de movimiento de fluidos en los depósitos suelen tener en cuenta las siguientes hipótesis: incomprensibles y de flujo laminar, comportamiento newtoniano, propiedades físicas constantes, con excepción de las variaciones de densidad que se tratan asumiendo la aproximación de Boussinesq, relevante en cuanto a la flotabilidad de la ecuación de momento, disipación viscosa en la ecuación de energía insignificante y no participa como medio radiante. Bajo estas hipótesis, es posible cubrir una amplia gama de condiciones de funcionamiento en los depósitos de agua caliente de los sistemas solares térmicos.

Los modelos unidimensionales suponen que el flujo dentro del depósito es de una dimensión, siendo válidos solo en el caso de que la entrada del depósito tenga un difusor bien diseñado, y si el gradiente de temperatura en la dirección radial es pequeño, las corrientes por convección debidas a la conducción con la pared del depósito pueden ser descuidadas. Varios modelos unidimensionales se proponen en la literatura y se implementan en TRNSYS. Modelos multi-nodos y multi-puertos, modelo de flujo pistón, modelo de arrastre de pluma y modelo zonal para el depósito de manto.

Los modelos de dos y tres dimensiones consiguen muy buena descripción de la estratificación térmica, utilizándose en el diseño de componentes. Se caracterizan por llevar un largo tiempo de cálculo, no son adecuados para la simulación de sistemas y tienen un alto coste computacional.

Los modelos de una dimensión se consiguen con un rápido tiempo de cálculo, llevando una representación relativamente buena de la estratificación térmica y obteniendo una buena simulación global del sistema. La información empírica necesaria como los coeficientes de transferencia de calor en la convección,... son necesarios. Estos parámetros empíricos están basados en el análisis experimental, 
por lo que, la validez de estos resultados depende de la precisión de los coeficientes de experimentación y su idoneidad para los modelos.

El método de mezcla del depósito necesita un tiempo de cálculo muy corto, no da una descripción de la estratificación térmica, pero pueden servir para un estudio previo de aproximación.

A continuación se hace un recorrido por las numerosas investigaciones experimentales realizadas en los últimos 40 años entorno a la estratificación térmica de los depósitos.

(Bloisi et al., 1980) presenta un método sencillo para evaluar el efecto de la unidad de almacenamiento de calor situada entre el captador solar y las cargas térmicas del edificio.

(Oppel et al., 1986) crea un modelo unidimensional de diferencias finitas para un solo depósito que ha sido desarrollado y comprobado con datos experimentales. El modelo se aplica a través de condiciones de carga o descarga, la conducción y la mezcla turbulenta del agua.

(Zurigat et al., 1988) realiza la predicción del desarrollo de la termoclina en los depósitos de almacenamiento térmico estratificado, mediante la cuantificación de la mezcla en flujo turbulento en la zona de entrada, mediante la introducción de la difusividad efectiva en un modelo de flujo unidimensional.

(Ghaddar et al., 1989) presenta un modelo numérico unidimensional de la estratificación en el depósito de almacenamiento térmico, pudiendo ser utilizado para simular la carga y descarga del depósito.

(Kandari, 1990) realiza un modelo experimental a escala 1:25 del construido para estudiar el efecto del uso de un distribuidor y una malla para reducir la zona de amortiguación.

(Knudsen y Furbo, 2004) estudia como se ve afectada la estratificación térmica por las diferentes posiciones de las entradas de un intercambiador de calor de manto vertical, con aplicación a un sistema solar térmico doméstico para agua caliente.

(Adams y Davidson, 1993) determina el nivel de estratificación del depósito que puede tener un sistema solar térmico con velocidades convencionales del fluido y un intercambiador flexible y poroso.

(Nelson et al., 1999ab) realiza el análisis de la estratificación en los depósitos de agua fría, utilizados para climatización, con un modelo unidimensional transitorio de la transferencia de calor que tiene en cuenta los efectos de la conducción axial, las propiedades físicas de la pared del depósito, la difusión térmica, la transferencia de calor con el ambiente, sus dimensiones y los efectos de la mezcla debidos a la entrada y salida del agua. Este modelo se utiliza para predecir las temperaturas del agua y la pared del depósito en modo estático y dinámico de funcionamiento.

(Shin et al., 2004) determina el mecanismo de la estratificación térmica de un depósito de almacenamiento y por lo tanto determina el diseño óptimo y las condiciones de funcionamiento. Los principales parámetros que considera son el tamaño del depósito, el caudal de carga del agua caliente, la diferencia de temperatura entre el agua caliente y fría, las variables geométricas del depósito como la entrada de agua caliente y la forma del difusor.

(Bahnfleth y Song, 2005) registra y analiza la distribución de la temperatura en un depósito de gran tamaño estratificado de agua fría con difusores de anillo de doble tubería ranurada. 
(Altuntop et al., 2005) analiza numéricamente el efecto del uso de diferentes obstáculos en la estratificación térmica de un depósito cilíndrico de agua caliente. Se obtiene las distribuciones de las temperaturas en el depósito para 12 obstáculos diferentes. Los resultados indican que colocar un obstáculo en el depósito proporciona una mejor estratificación térmica en comparación con el uso de ningún obstáculo. Los tipos de obstáculos que tienen hueco en el centro parecen conseguir mejor estratificación térmica que tener el hueco cerca de la pared del depósito. Pudiendo suministrar agua caliente a temperaturas más altas. Tan pronto como el agua caliente se extrae del depósito, el agua fría fluye hacia el depósito mezclándose con el agua caliente restante y por lo tanto reduce la temperatura del agua en el depósito, se trata de un resultado no deseado. Considera diseños de depósitos de almacenamiento de energía solar con diversos obstáculos para reducir al mínimo la mezcla del agua fría y caliente, para que pueda suministrar agua a altas temperaturas.

(Fernández-Seara et al., 2007a) determina el comportamiento térmico de un depósito en su calentamiento y enfriamiento estático para caracterizar su rendimiento. El modo estático de funcionamiento se refiere a su comportamiento térmico cuando el agua del depósito no se utiliza, es decir, cuando no hay agua que fluye hacia o desde el depósito. El funcionamiento en modo estático de un depósito es un tema muy importante y también se debe investigar ya que representa el estado más frecuente del depósito. Los resultados experimentales muestran que el proceso de enfriamiento está influenciado por la temperatura ambiente. La presión en el depósito influye poco en los procesos de enfriamiento. El análisis de la estratificación revela que depende principalmente del perfil inicial de la temperatura del agua. Por lo tanto, el proceso de enfriamiento depende del estado de calentamiento inicial. En el proceso de calentamiento la potencia térmica aportada al depósito tiene influencia sobre el tiempo de calentamiento y en los perfiles transitorios de la temperatura del agua.

(Fernández-Seara et al., 2007b) modela el funcionamiento de un depósito en modo dinámico cuando la energía térmica del depósito se utiliza, por ejemplo, cuando tiene lugar el proceso de carga y/o descarga. El depósito tiene tres entradas y dos salidas usando tres caudales distintos, se estudian seis combinaciones diferentes, identificando la mejor. El análisis se basa en las distribuciones transitorias de la temperatura del flujo del agua de entrada y salida y en los perfiles medidos de temperatura transitoria del agua dentro del depósito. Durante el funcionamiento dinámico, se produce la estratificación térmica del agua dentro del depósito. Tal estratificación separa el agua caliente de baja densidad que flota en la parte superior del depósito, del agua fría de mayor densidad que se hunde en el fondo, con una capa de mezcla entre las dos. La termoclina se desplaza desde la parte inferior a la parte superior del depósito durante la operación descarga, y viceversa durante la carga, además de que se comporta como una barrera natural dinámica que mantiene la capa caliente separada de la fría.

En el enfriamiento dinámico, la distribución de temperaturas a lo largo de la altura del depósito es desigual debido a la estratificación térmica. La temperatura normalmente disminuye desde la parte superior a la parte inferior del depósito. El mayor cambio de temperatura se produce en la termoclina. En consecuencia se distinguen tres zonas en el depósito:

- La zona de agua caliente con alta temperatura y bajo gradiente en la parte superior.

- La zona de agua fría con baja temperatura y bajo gradiente en la parte inferior.

- La capa termoclina con diferencias de temperaturas altas y alto gradiente entre la zona caliente y fría. 
La estratificación térmica de un depósito depende de la geometría del depósito, el diseño de la entrada y salida, y las condiciones de funcionamiento. Existen tres mecanismos de mezcla, que contribuyen a la degradación de la estratificación del agua y, en consecuencia, al aumento del espesor de la zona termoclina, se trata de: la transferencia del calor a los alrededores del ambiente a través de la envolvente del depósito, la difusión del calor en el agua y la conducción axial del calor. Sin embargo, en el modo dinámico de funcionamiento, la transferencia de calor debido a la mezcla del agua en las entradas y salidas es el más importante, dependen principalmente del diseño de la entrada y salida por lo que es un asunto clave para garantizar su formación eficaz y el mantenimiento de la estratificación durante el funcionamiento dinámico para mejorar su rendimiento.

Por otra parte, una revisión de la literatura indica que el diseño del puerto de entrada tiene mayor influencia en el logro de la estratificación natural en el funcionamiento dinámico del depósito, que el diseño del puerto de salida. En la literatura, hay numerosos estudios relacionados con el diseño y los ensayos con diferentes geometrías y configuraciones de entradas y salidas, así como una gama de difusores. La mayoría de estos estudios están relacionados con depósitos de sistemas solares térmicos, que generalmente operan con una temperatura de entrada variable, que aumenta considerablemente los efectos de las mezclas. Recientemente, algunos autores han considerado insertar distintos elementos para promover la estratificación, que también se aplican a depósitos solares.

(Kenjo et al., 2007) expone que la simulación dinámica durante largos periodos de tiempo es necesaria. Desarrolla un modelo para el depósito de manto utilizando un enfoque zonal, la ventaja que aporta es de ser mucho más rápido que los modelos de dinámica fluido computacional, con los que es difícil estudiar el comportamiento de los sistemas solares térmicos durante un largo periodo de tiempo como un año.

(Jack y Wrobel, 2009) combina el análisis de exergía con el modelado dinámico para determinar los parámetros óptimos de diseño. El modelo puede tratar toda la gama de estratificación desde un depósito totalmente mezclado hasta la estratificación perfecta. Se demuestra que la estratificación aumenta la eficacia y acorta el tiempo de carga óptima termodinámica.

(Wolf et al., 1984) desarrolla un programa informático para la simulación de una central solar térmica de agua caliente y validado por comparación con los datos de rendimiento obtenidos. Con el lenguaje de programación CSMP, para la solución de las ecuaciones diferenciales que describen el sistema. La gestión del consumo, puede mejorar tanto la calidad y cantidad del rendimiento térmico de un sistema solar térmico.

(Hariharan et al., 1991) estudia experimentalmente los efectos de las condiciones de funcionamiento de la termoclina y la eficiencia de la extracción, variando los siguientes parámetros: temperatura del agua fría, temperatura del agua caliente, caudal del agua y la esbeltez como relación de la longitud por diámetro del depósito. Se observa que la estratificación mejora con el aumento de la diferencia de temperatura entre la salida y la entrada. Se encuentra que la esbeltez óptima está entre 3 y 4 . La eficiencia de la extracción se correlaciona con una expresión analítica.

(Ismail et al., 1997) presenta resultados de un estudio comparativo de depósitos estratificados térmicamente. Emplea un modelo bidimensional del que se obtiene una solución. El modelo se simplifica para el caso de conducción pura. Los resultados de los dos modelos se comparan entre si y con los resultados experimentales. Concluye que el modelo de conducción pura es solo aceptable 
durante los primeros momentos. Con el inicio de las corrientes de convección, las diferencias aumentan continuamente.

(Abdoly y Rapp, 1982) efectúa un cálculo teórico de la degradación de calor en la termoclina basado en un modelo de conducción. Como descuida los otros mecanismos de degradación, proporciona un límite superior para el desempeño del depósito. Utiliza el cálculo teórico de la degradación de la termoclina basado en el modelo de conducción y las medidas experimentales de la degradación estática y dinámica de la termoclina.

(Oliveski et al., 2003) analiza experimental y numéricamente el campo de velocidad y temperatura dentro del depósito sometido a convección natural. Un modelo bidimensional en coordenadas cilíndricas se utiliza para un tiempo de enfriamiento de 45 a 60 horas. Los investigadores dividen su atención entre los modelos numéricos que tienen que ver con la conservación de la masa, el momento, junto a las ecuaciones de la energía, y los modelos menos genéricos que normalmente solo utilizan una ecuación de balance de energía única para determinar el perfil de temperatura dentro del depósito.

(Al-Marafie, 1987) estudia el comportamiento de la estratificación en un depósito de agua fría. Satisface las cargas de aire acondicionado, fuera de las horas pico de alta demanda de consumo de la energía eléctrica. El uso de depósitos estratificados de agua fría puede compensar los picos de demanda. El almacenamiento térmico de agua fría se utiliza para el propósito de trasladar la demanda de energía eléctrica de la planta de aire acondicionado hasta el periodo de poca actividad.

(Cristofari et al., 2003) evalúa con un modelo térmico en diferencias finitas el rendimiento de un captador solar de placa plana fabricado en material copolímero, con lo que se reduce su peso un $50 \%$, lo que implica una instalación más fácil. La influencia del caudal y la estratificación es analizada.

(Han et al., 2009) presenta un estudio de los diversos tipos de depósitos estratificados térmicamente, los métodos de investigación y los beneficios de la estratificación térmica.

(Bouhdjar y Harhad, 2002) expone que la estratificación debe promoverse mucho más con el fin de mejorar la eficiencia del sistema termodinámico. En este ámbito, presenta un estudio numérico de la mezcla convectiva transitoria. Investigando el uso de diferentes fluidos. Desarrollando un modelo bidimensional considerando el efecto de ciertos parámetros físicos y geométricos sobre el comportamiento dinámico y térmico del líquido en la cavidad cilíndrica de almacenamiento con el eje vertical.

(Lavan y Thompson, 1977) pionero en el estudio experimental de las temperaturas de estratificación en los depósitos de agua caliente, enfatizando en los altos estados de extracción. Los datos son extraídos de varias relaciones de esbeltez, diferentes temperaturas de entrada y salida, y caudales. Los datos fueron correlacionados empíricamente para obtener relaciones útiles para el diseño. Concluye que la estratificación mejora con el aumento de la esbeltez del depósito, el aumento de la diferencia de la temperatura entre la entrada y salida, y disminuye con el aumento del caudal.

(Cabelli, 1977) realiza el estudio numérico de un modelo bidimensional del movimiento que tiene lugar en los depósitos usados en los sistemas solares térmicos de agua caliente con entradas verticales y horizontales. Se examina el efecto del número de Reynolds de entrada y la contribución a la flotabilidad en la promoción de la estratificación. Además, se compara con una aproximación simple unidimensional. El movimiento combina el efecto de la convección forzada y natural. Los gradientes 
horizontales que se forman en las entradas calientes son acompañados por cambios de densidad, impulsando el movimiento por flotabilidad que se lleva a cabo.

(Phillips, 1981) presenta un modelo teórico que predice los efectos de la estratificación en el depósito de lecho de rocas de un sistema solar térmico de aire caliente. Los resultados se presentan en forma de términos de un coeficiente de estratificación que se define como la proporción de la ganancia útil real respecto la ganancia que se lograría si el lecho se mantuviera a una temperatura uniforme. La disminución de la temperatura en la superficie inicialmente se acompaña con un aumento en la temperatura de las capas inferiores, seguido de una disminución de la temperatura en todo el cuerpo en etapas posteriores.

(Jaluria y Gupta, 1982) realiza el estudio experimental de la decadencia de las temperaturas en un depósito estratificado. Los perfiles de temperatura dependientes del tiempo se miden para varias distribuciones de temperaturas iniciales y condiciones ambientales. Un depósito inicialmente isotérmico se estratifica térmicamente por medio de las descargas que se le realizan y también mediante la adicción de agua caliente en la parte superior. La decadencia de la estratificación con el tiempo debido a la transferencia de calor al medio ambiente y en el volumen de agua se estudia experimentalmente para diversas situaciones iniciales y de pérdidas de calor. La distribución de la temperatura inicial resulta ser muy importante en la posterior descomposición de la estratificación.

(Phillips y Dave, 1982) presenta un modelo simplificado, útil para predecir el efecto de la estratificación en depósitos de pequeños sistemas solares térmicos domésticos.

(Lund, 1988) observa el efecto del comportamiento térmico del depósito en un sistema solar térmico estacional. Compara el sistema solar térmico con un depósito estratificado y otro completamente mezclado. Se incorporan un conjunto de factores que cambian el rendimiento del captador solar, pérdidas en el depósito y la fracción solar según el modo de almacenamiento.

(Fanney y Klein, 1988) expone que el rendimiento del sistema solar térmico de agua caliente está influenciado por el caudal de los fluidos que transfieren el calor dentro del sistema en el que se distribuyen.

(Hollands y Lightstone, 1989) el caudal relativamente alto en el captador solar se utilizaba tradicionalmente en los sistemas solares térmicos de circulación forzada, tal vez porque los captadores solares con un caudal alto mejoran su curva de rendimiento mediante la mejora del factor de eliminación del calor $F_{R}$. Pero si todo el sistema se considera, el beneficio que un tanque estratificado puede obtener con caudales bajos puede compensar la disminución correspondiente en la curva de rendimiento del captador solar, al mover el punto de funcionamiento en la curva de rendimiento a los valores más favorables. Además de reducir el coste de tuberías y bomba.

(Jaluria y O'Mara, 1989) estudia experimentalmente el campo térmico en un depósito debido a una descarga horizontal del chorro de agua caliente. Se observa un transitorio rápido, seguido de una variación gradual de la temperatura en el estado estacionario. Reseña el campo térmico en el diseño, en particular, sobre la ubicación de las entradas y salidas. Además de la penetración de la corriente del chorro.

(Murthy, 1992) se refiere a los efectos en el depósito de la conductividad térmica y espesor de la pared sobre la degradación de la energía térmica en un sistema dinámico. La mayoría de las investigaciones se 
limitan a las operaciones de descarga, pero aquí, cubre también la carga y descarga simultánea. Propone un forro interior aislante para el depósito.

(Csordas et al., 1992) trata los efectos del arrastre de pluma en el depósito de los sistemas solares térmicos de agua caliente que emplean estrategias de control de caudal variable. El arrastre de pluma se produce cuando el agua fría se inserta en la parte superior del depósito que contiene agua caliente, provocando la mezcla, convirtiéndose en un mecanismo de destrucción de la estratificación.

(Kleinbach et al., 1993) estudia el rendimiento de modelos unidimensionales para depósitos estratificados, utiliza dos enfoques para modelar la distribución de las temperaturas en los depósitos de los sistemas solares térmicos. El enfoque multinodo, que divide el depósito en varios nodos, con un balance energético para cada nodo, da como resultado un conjunto de ecuaciones diferenciales, que pueden ser resueltas para las temperaturas de los nodos en función del tiempo. El enfoque de flujo de pistón, son segmentos de líquido a diferentes temperaturas y tamaños, que se supone se mueven a través del depósito en forma de flujo de pistón. Cada vez que el líquido entrante de la fuente de calor es más frío que el líquido en la parte superior del depósito, se produce el arrastre de pluma.

(Yoo y Pak, 1993) estudia un modelo teórico del proceso de carga con el fin de proporcionar un límite superior del rendimiento de la estratificación en el depósito. A medida que aumenta el caudal, se intensifica la mezcla. Por lo tanto, disminuye la eficiencia del almacenamiento.

(Mavros et al., 1994) investiga la estratificación de varios depósitos de sistemas solares térmicos.

(Berkel, 1996) trata dos aspectos importantes a corto plazo en los depósitos de energía térmica estratificada, la mezcla y el espesor del termoclina se estudian analíticamente, de forma experimental y numérica.

(Morrison et al., 1998) presenta un modelo experimental de un intercambiador de manto horizontal que se utiliza para evaluar los patrones de flujo y la transferencia de calor en el depósito.

(Dahm et al., 1998) evalúa las configuraciones del depósito con intercambiadores de calor internos en un sistema solar térmico. Se experimentan cuatro configuraciones diferentes durante una secuencia de seis días de prueba.

(Hahne y Chen, 1998) estudia numéricamente las características de la transferencia del calor y flujo en un tanque cilíndrico de agua caliente durante el proceso de carga, bajo condiciones térmicas de límite adiabático.

(Alizadeh, 1999) realiza un estudio experimental y numérico de la estratificación térmica en depósitos cilíndricos horizontales de los sistemas solares térmicos. Cuatro conjuntos de experimentos se llevan a cabo, donde se inyecta agua fría en la parte inferior del depósito con tres campos térmicos iniciales. El primero con una temperatura inicial del depósito inferior a la temperatura de afluencia, el segundo que resultó ser el mejor cuando el depósito tiene una temperatura mayor, el tercero es isotérmico, y el cuarto igual que el primero pero cambia la inclinación y forma de la tubería de entrada.

(Yoo et al., 1999) realiza una aproximación de las soluciones analíticas de la estratificación del depósito en condiciones de temperatura de admisión variable, con un modelo unidimensional que describe el proceso de carga de los depósitos, así como el momento inducido por la mezcla. 
(Berkel et al., 1999) estudia un proceso de almacenamiento estratificado de dos capas de forma analítica, numérica y experimental, entendiendo que el mecanismo predominante de mezcla es inducido por el arrastre de líquido de la termoclina. Aunque en la práctica de la estratificación en los depósitos de los sistemas solares térmicos la energía solar está continuamente variando, aquí la atención se centra en dos capas que almacenan el agua caliente y fría, debido a su menor complejidad y mayor relevancia en los depósitos térmicos.

(Jordan y Vajen, 2001) estudia la influencia de los perfiles del agua caliente sanitaria sobre la fracción de energía de un sistema solar térmico con una demanda total de calor anual constante. Un perfil de la demanda de agua caliente sanitaria para un periodo se ha generado. A fin de tener en cuenta las condiciones más realistas, un intervalo de tiempo de un minuto es elegido.

(Yee y Lai, 2001) estudia el efecto de un intercambiador poroso sobre la estratificación de un depósito, elimina el impulso del líquido entrante e inhibe la mezcla, mientras que las fuerzas de flotabilidad colocan el líquido al nivel apropiado en el depósito. En lugar de utilizar el tubo con agujeros (Loehrke et al., 1979).

(Rosen, 2001) realiza el análisis de energía y exergía de los sistemas solares térmicos con estratificación, junto con los conocimientos y beneficios resultantes. Seis modelos de distribución de la temperatura en el depósito estratificado se consideran: lineal, escalonado, en tres zonas,... El análisis de exergía reconoce las diferencias de temperatura de almacenamiento, incluso para cuando el depósito contiene una cantidad equivalente de energía.

(Mather et al., 2002) investiga experimental y analíticamente un multi-depósito de un sistema solar térmico de baja temperatura. La motivación es la ventaja económica percibida sobre un solo depósito, cuando el volumen total requerido de agua caliente es bastante grande. Así como un efecto de diodo térmico, termodinámicamente favorable.

(Cruickshank, 2009) evalúa experimental y numéricamente un nuevo método de almacenamiento de energía térmica multi-depósito para aplicaciones en los sistemas solares térmicos, interconectando tres depósitos para el almacenamiento de agua caliente solar por un bucle de carga de flujo único de termosifón y un intercambiador de calor exterior por convección natural.

(Shah y Furbo, 2003) realiza el análisis teórico y experimental con los chorros de agua que entran al depósito de un sistema solar térmico. Cálculos mediante la dinámica de fluidos computacional de tres diseños de entradas con diferentes caudales, se llevan a cabo para ilustrar el comportamiento variable de las condiciones térmicas en el depósito. Los resultados muestran el impacto del diseño de la entrada en los patrones de flujo en el depósito y por tanto, cómo la calidad de la energía en el depósito de agua caliente se mejora con diseños eficientes en la entrada.

(Cònsul et al., 2004) crea prototipos virtuales de depósitos por medio de la dinámica de fluidos computacional tridimensional y simulaciones numéricas de transferencia de calor, lo que parece ser una herramienta alternativa. Un buen rendimiento de los dispositivos de almacenamiento puede significar un aumento considerable en la eficiencia general de los sistemas solares térmicos. Sin embargo, las simulaciones numéricas de los depósitos pueden ser difíciles debido a su enorme costo computacional, como las simulaciones transitorias tridimensionales. Aunque el aumento en potencia de cálculo y la mejora de los métodos numéricos ha sido notable, y que muchos ingenieros han comenzado a utilizar la 
dinámica de fluidos computacional en sus ordenadores de escritorio, la resolución numérica de los problemas transitorios tridimensional utilizando equipos estándar sigue siendo computacionalmente muy costosa.

(Johannes et al., 2005) analiza el campo de temperaturas dentro del depósito de un sistema solar térmico. Este estudio propone verificar la capacidad de los modelos tipo 60 y 140 de TRNSYS para reproducir el campo de temperaturas en el depósito y analizar el movimiento del fluido por medio de simulaciones con la dinámica de fluidos computacional. Para probar la exactitud de los modelos se realizan experimentos en un depósito para los casos de carga y descarga.

(Jordan y Furbo, 2005) estudia el efecto de la extracción en la estratificación térmica en depósitos de pequeños sistemas solares térmicos, compara depósitos de sistemas solares térmicos para agua caliente con diferentes dispositivos de entrada de agua fría. Investiga el impacto del dispositivo de la entrada de agua fría en la estratificación y evalúa la mejora en el rendimiento anual. Dos diseños diferentes se comparan, uno conectado a una pequeña placa curva colocado por encima del tubo de la entrada, y el otro con una placa mucho más grande. El agua entra en el depósito en dirección vertical desde la parte inferior.

(Madhlopa et al., 2006) estudia el efecto de la geometría y la interconexión de dos tanques horizontales sobre la temperatura de la estratificación en un sistema solar térmico integrado captador-depósitos de agua caliente.

(Panthalookaran et al., 2007) caracteriza la estratificación del depósito con un método que integra la primera y segunda ley de la termodinámica. La información sobre la evolución del campo de temperaturas del sistema en el tiempo es requisito del método. Se puede obtener a partir de experimentos o simulaciones numéricas con la dinámica de fluidos computacional.

(Andersen et al., 2007) utiliza tubos de estratificación de varias capas de tela para depósitos de sistemas solares térmicos. Cuanto mayor es el grado de estratificación térmica, mayor será el rendimiento térmico de los sistemas solares térmicos. La estratificación térmica en el depósito se puede conseguir, por ejemplo, con el uso de tubos estratificadores junto con caudales bajos en el circuito primario del sistema. Investigando con tubos estratificadores textiles y se compara con los tubos estratificados no flexibles con válvulas antiretorno.

(Arahal et al., 2008) crea un modelo grey-box del depósito estratificado térmicamente para el control de la planta solar de Almería. El enfoque grey-box (Ljung, 1987) se deriva del hecho de que lo mejor es aprovechar el conocimiento a priori de un sistema. Este conocimiento se expresa habitualmente en términos de un conjunto de ecuaciones obtenidas a partir de principios básicos. Para algunos sistemas no son completamente conocidos y los datos tienen que ser utilizados para rellenar el vacío a través de un proceso de identificación. En la mayoría de los casos los modelos grey-box tienen mejores características de generalización que los black-box y requieren menos cantidad de datos para la fase de identificación.

(Haller et al., 2009) revisa los diferentes métodos que se han propuesto en la literatura para caracterizar la estratificación térmica de los depósitos desde un punto de vista teórico. En concreto, se centra en los métodos que se pueden utilizar para determinar la capacidad de un depósito para promover y mantener la estratificación durante la carga, el almacenamiento y la descarga, y representar esta capacidad con un 
solo valor numérico en términos de eficiencia de la estratificación para un experimento dado o bajo ciertas condiciones de contorno.

(Haller et al., 2010) presenta un método para el cálculo de la eficiencia en la estratificación de los depósitos basado en la segunda ley de la termodinámica. Se estudia la influencia de las pérdidas de calor teórica y experimentalmente.

(Géczy-Víg, 2010) introduce un modelo de redes neuronales artificiales para la modelización de las temperaturas de las capas del depósito de un sistema solar térmico. El modelo se basa en los datos medidos de un sistema solar térmico de agua caliente. La distribución de las temperaturas en el depósito se divide en ocho partes iguales en dirección vertical. Se calculan cada cinco minutos, usando datos medidos de cada minuto y promediados cada cinco minutos de la irradiación solar global, la temperatura ambiente, el caudal másico del circuito primario, la demanda de agua caliente y las temperaturas de las capas del depósito en el intervalo de tiempo anterior. El modelo de redes neuronales artificiales consta de dos partes que describen los periodos con y sin demanda de agua caliente. Los modelos identificados dan resultados aceptables dentro del intervalo de formación, con una variación media de $0,22{ }^{\circ} \mathrm{C}$ durante el entrenamiento y de $0,24{ }^{\circ} \mathrm{C}$ durante la validación. 


\subsection{Las series de tiempo en la inteligencia computacional. Marco teórico}

El análisis y la predicción de las series de tiempo tienen una gran utilidad para los ingenieros y científicos. Un tema específico son los procesos industriales, para los cuales resulta interesante la predicción de las series de tiempo, basándose en datos registrados, con el objetivo de predecir los valores que tomarán en el futuro las variables que intervienen.

Una serie temporal es una sucesión ordenada de valores observados de una variable, realizada en intervalos de tiempo equidistantes $\Delta t$, representado como un conjunto de valores discretos $x_{1}, x_{2}, \ldots, x_{n}$. En la industria, la secuencia de valores se obtiene de los sensores por muestreo de las señales continuas afectadas. En esta Tesis Doctoral las variables ambientales estudiadas son la irradiación solar, la temperatura ambiente y en el sistema solar térmico las temperaturas de ida y retorno al captador solar, el caudal del fluido portador en el circuito primario y las temperaturas de la estratificación térmica en el depósito acumulador.

Al estar basado en los valores medidos, que están influidos por el ruido, las series de tiempo habitualmente contienen un componente determinista y otro componente estocástico que representa el ruido que origina fluctuaciones alrededor del determinista.

El análisis de una serie de tiempo está dirigido a estudiar su estructura interna, para conseguir un mejor conocimiento del proceso dinámico por el cual los datos de la serie de tiempo se generan. En el control de procesos, la predicción del valor de los datos en la serie de tiempo ayuda a la hora de decidir sobre las acciones de control que deben tomarse. El análisis de series de tiempo abarca actividades como la definición, clasificación, descripción, construcción del modelo utilizando los datos registrados de la serie de tiempo y la predicción de los valores futuros.

Para la predicción de los valores futuros de una serie de tiempo existen diversos métodos en la literatura, en la clasificación tradicional está el suavizado exponencial, el análisis de regresión y los modelos que detectan las características en el funcionamiento del sistema dinámico, el enfoque moderno de análisis y predicción utiliza métodos y herramientas de la inteligencia artificial.

\subsubsection{El análisis de las series de tiempo}

El análisis de las series de tiempo se define como una rama de la estadística, que se ocupa de las dependencias estructurales entre los datos observados de los fenómenos y los parámetros afectados. Los fenómenos son indexados por el tiempo como el único parámetro, por ello, se utiliza el nombre de serie de tiempo para su denominación.

Las características principales de la serie de tiempo son la estacionariedad, la linealidad, la tendencia y la estacionalidad. La series de tiempo se clasifican en lineales, no lineales, caóticas, univariadas y multivariadas estas últimas se generan mediante la observación simultánea de dos o más variables del proceso. Los valores observados y registrados se presentan como vectores. Este tipo de observaciones 
son muy comunes en la ingeniería, donde dos o más variables físicas: temperatura, presión, caudal,... tienen que ser muestreadas simultáneamente para la construcción del modelo de un sistema dinámico.

El principal objetivo es la construcción de modelos entrada-salida (black box), que representan la función de transferencia equivalente a los procesos, que están detrás de la serie de tiempo. Para realizar la predicción de los valores de la serie de tiempo en el futuro desde los valores del pasado.

En la ingeniería, la modelización de los fenómenos dinámicos ha sido siempre tenida como una herramienta de ayuda muy valiosa para tener un conocimiento más completo de la estructura y el comportamiento de los sistemas dinámicos.

La estadística tiene dos modelos básicos para las series de tiempo: los modelos deterministas, matemáticamente vistos como modelos analíticos representados por relaciones deterministas $\mathrm{x}_{\mathrm{t}}=\mathrm{f}(\mathrm{t})$ o ecuaciones recurrentes $\mathrm{x}_{\mathrm{t}}=\mathrm{f}\left(\mathrm{x}_{\mathrm{t}-1}, \mathrm{x}_{\mathrm{t}-2}, \ldots\right)$ y los modelos estocásticos, estadísticamente vistos como funciones de variables aleatorias.

Distintas técnicas para construir modelos que representen las series de tiempo se encuentran en la literatura. Los modelos regresivos se construyen utilizando el análisis de regresión, que es una colección de métodos para el estudio de las relaciones entre las variables y para la estimación y la predicción de los valores de una variable utilizando los valores de otras variables incorporadas en un conjunto de series de tiempo. Los modelos de regresión más utilizados son la autorregresión AR, la media móvil MA, ARMA, ARIMA Y CARIMA.

Cuando el modelo predictivo de las series de tiempo más adecuado para cada caso se ha construido, entonces puede ser empleado. La predicción de los valores futuros de una serie de tiempo se puede definir de dos formas: la primera dado un conjunto de valores observados $\mathrm{x}_{1}, \mathrm{x}_{2}, \ldots, \mathrm{x}_{\mathrm{n}}$ de una serie de tiempo, el valor futuro $x_{n+1}, x_{n+2}, \ldots$ debe ser estimado, la segunda es la predicción de $n$-pasos por delante $x_{n+q} \circ \hat{x}_{n}(q)$, calculado en el punto $n y$ donde $q$ es el lapso de tiempo de la estimación. Las predicciones pueden ser objetivas en base a una información subjetiva de la intuición, univariadas basadas en el modelo unidimensional de los datos registrados y multivariadas basadas en la observación de dos o más variables.

\subsubsection{Las redes neuronales artificiales}

Las redes neuronales artificiales se caracterizan por ser masivamente paralelas, estos sistemas de procesamiento distribuido representan una tecnología de computación basada en la analogía con el sistema de procesamiento humano de la información. Las redes neuronales artificiales son una evolución desde la idea inicial de (Hebb, 1949) sobre la estructura y el comportamiento de un sistema neuronal biológico. Las bases fueron establecidas por (McCulloch y Pitts, 1943) que, utilizando la lógica formal, modelan redes neuronales usando las neuronas como dispositivos binarios con umbrales fijos conectados entre sí por sinapsis. (Rosenblatt, 1958) extiende la idea de la computación neuronal al perceptron como elemento de una red computacional autoorganizada capaz de aprender por la realimentación y por la adaptación estructural. (Widrow y Hoff, 1960) crea e implementa los dispositivos electrónicos analógicos conocidos como Adaline y Madaline. 
Los investigadores recurren a variantes de la red como posibles alternativas. (Amari y Maginu, 1988) con redes autoorganizadas. (Grossberg, 1987) redes neuronales de resonancia. (Werbos, 1974) redes feedforward. (Kohonen, 1989) redes de memoria asociativa. (Hecht-Nielsen, 1987) redes counterpropagation. (Elman, 1990) redes recurrentes. (Broomhead y Lowe, 1988) redes de función de base radial. (Specht, 1988) redes probabilísticas. Las redes neuronales artificiales más utilizadas en la ingeniería son las redes MultiLayer Perceptron MLP y las redes de base radial RBF.

Debido a sus capacidades de aprendizaje y generalización a partir de datos de las observaciones, las redes neuronales artificiales han sido ampliamente aceptadas por los ingenieros e investigadores como una técnica para el procesamiento de los datos experimentales.

El uso práctico de las redes neuronales artificiales ha sido reconocido por características tan distinguidas como en los procesos de asignación no lineal entre un subconjunto de valores pasados de la serie de tiempo y los valores futuros de la serie de tiempo, la capacidad de capturar relaciones funcionales esenciales entre los datos, lo que es valioso cuando las relaciones no son a priori conocidas o son muy difíciles de describir matemáticamente y/o cuando los datos de la observación están dañados por el ruido, la capacidad de aproximación a una función universal que permite el modelado de funciones continuas arbitrarias no lineales en cualquier grado de exactitud, y la capacidad de aprendizaje y generalización de los ejemplos con el manejo de datos de una forma autoadaptable (Palit y Popovic, 2005).

\section{1) Las redes neuronales artificiales utilizadas en la predicción}

(Hu, 1964) es el primero en demostrar, con un ejemplo de predicción meteorológica práctica, la capacidad de predicción general de las redes neuronales artificiales. (Werbos, 1974) experimenta con las redes neuronales artificiales como herramienta para la predicción de las series de tiempo, sobre la base de datos de observación. (Werbos, 1989) y (Werbos, 1990) experimenta con redes backpropagation, concluyendo que las redes neuronales artificiales superan a los métodos de predicción estadísticos, tales como el análisis de regresión y el método de predicción Box-Jenkins. (Lapedes y Farber, 1988) también utiliza redes para la modelización y predicción de las series de tiempo no lineales. Las redes neuronales artificiales típicas utilizadas con fines de predicción son MultiLayer Perceptron MLP principalmente, función de base radial RBF, recurrentes, counterpropagation y probabilísticas.

\section{2) El entrenamiento de las redes neuronales artificiales}

Los algoritmos de entrenamiento supervisados son los más utilizados en aplicaciones prácticas, como el algoritmo de entrenamiento backpropagation, también conocido como regla delta generalizada, desarrollado inicialmente por (Werbos, 1974), redescubierto por (Parker, 1985) y generalizado por (Rumelhart y McClelland, 1986).

Las redes perceptron multicapa a partir del entrenamiento con ejemplos o patrones de entrada-salida implementa el mapeo no lineal de las funciones. En el proceso de entrenamiento, la red aprende a través de la adaptación de los pesos sinápticos, de tal forma que la discrepancia entre el patrón dado y el patrón correspondiente a la salida de la red se minimiza. Debido a que la adaptación sináptica sigue la 
ley del gradiente descendente de ajuste de parámetros, el algoritmo de entrenamiento backpropagation es considerado como el algoritmo de búsqueda de la minimización sin restricciones de una función de error adecuadamente construida en la salida de la red.

El objetivo del algoritmo de entrenamiento es reducir al mínimo la función de error al cuadrado de salida instantáneo en la red, definido como el cuadrado de la diferencia entre la señal de salida deseada y la señal de salida real en la red, mediante la modificación de los pesos sinápticos.

El proceso de minimización en pasos de ajuste de parámetros se basa en la regla de gradiente descendiente más pronunciado, en la que se determina la velocidad de convergencia hasta llegar al mínimo. Los pesos sinápticos se suelen cambiar de forma incremental y la neurona converge gradualmente a un conjunto de pesos que resuelven el problema específico.

El algoritmo backpropagation generalmente sufre de una convergencia relativamente lenta y con la posibilidad de quedar atrapado en un mínimo local, o también de la posible oscilación entorno a un valor mínimo local, lo que puede limitar su aplicación práctica en algunos casos.

Para evitar dicho inconveniente, la velocidad de convergencia del algoritmo puede ser acelerada, por ejemplo, por la selección de los pesos iniciales en lugar de tomarlos al azar. A través del preprocesado de los datos de entrenamiento, por ejemplo, mediante el empleo de algoritmos de extracción de características. $\mathrm{O}$ mejorando el algoritmo de optimización utilizado, por ejemplo, como la adaptación de la tasa de aprendizaje, o utilizando el término impulso, de estas formas el tiempo de entrenamiento se puede reducir considerablemente.

\section{3) Metodología de predicción con redes neuronales artificiales}

La metodología de la predicción se entiende como un conjunto de métodos y técnicas desde el registro de datos de las series de tiempo, que se utilizarán para la predicción de valores futuros de la serie de tiempo, basado en los valores del pasado. La metodología de la predicción incluye los pasos siguientes:

1. Preparación de los datos para la predicción, es decir, la adquisición, el preprocesamiento, la normalización y la estructuración de datos, la determinación del conjunto de datos para el entrenamiento y la prueba.

2. Determinación de la arquitectura de red, es decir, la selección del tipo de red que se utilizará para la predicción, la determinación del número de entradas y salidas de la red, el número de capas, el número de neuronas en las capas, la determinación de las interconexiones entre las neuronas, la selección de las funciones de activación de las neuronas,...

3. Diseño de la estrategia de entrenamiento de la red, es decir, la selección del algoritmo de entrenamiento, el índice de rendimiento y el tipo de control del entrenamiento.

4. Evaluación global de los resultados de las predicciones utilizando datos de las observaciones de nuevas series de tiempo. 


\section{Preparación de los datos para la predicción con redes neuronales artificiales}

Los datos utilizados para el análisis y la predicción de las series de tiempo son registrados normalmente por observaciones o mediciones. En la ingeniería, el análisis de los datos obtenidos mediante el muestreo de señales provenientes de los sensores y la predicción del comportamiento futuro son de gran interés. Por lo que la aplicación en esta Tesis Doctoral, se centra en los datos experimentales tomados de los elementos sensores colocados en los sistemas solares térmicos.

En este caso, en función de la naturaleza de las señales proporcionadas por los sensores, hay dos cuestiones fundamentales: la primera es el número de datos necesarios para la caracterización representativa de la señal observada en vista de su linealidad, estacionariedad,... la segunda es el periodo de muestreo necesario para registrar la frecuencia de la señal muestreada.

El preprocesamiento de los datos obtenidos, debido a la presencia de ruido, derivas y las imprecisiones del sensor, se presenta como un procedimiento de ensayo y error.

La normalización de los datos es un proceso de preparación de los datos finales para su uso directo en el entrenamiento de la red. Que incluye la normalización de los datos del preprocesado desde su rango natural al rango de operación de la red neuronal artificial, de modo que los datos normalizados son planteados para responder a las exigencias de las neuronas de la capa de entrada de la red y se adaptan a las no linealidades, por lo que sus resultados no deben pasar los límites de la saturación.

La estructuración de los datos se realiza mediante la preparación de los pares de datos, para la entrada relacionada con la salida, que van a ser utilizados en el aprendizaje supervisado y/o en la preparación de datos multivariantes. En el caso del entrenamiento de las redes con fines de predicción, el siguiente valor $x_{t+1}$ de la serie de tiempo univariada se relaciona con los valores pasados de la serie de tiempo hasta el valor actual de $x_{t}$. En el paso siguiente del entrenamiento el valor $x_{t+2}$ se relaciona con los valores pasados hasta el valor $\mathrm{x}_{\mathrm{t}+1}, \ldots$

Antes de la estructuración de los datos de una serie de tiempo multivariada para la formación de una red predictora, se debe recordar el hecho, que este tipo de serie de tiempo es un conjunto de series de tiempo múltiples simultáneamente construidas con los valores de cada serie de tiempo individuales estando relacionadas con los valores correspondientes de otras series de tiempo. Esto se debe a que la serie de tiempo multivariada se construye mediante la observación simultánea de dos o más procesos, de modo que la observación resultante a través de todas las muestras individuales en un momento determinado construye un vector de observación $\mathrm{x}_{\mathrm{i}}=\left[\mathrm{x}_{\mathrm{i} 1}, \mathrm{x}_{\mathrm{i} 2}, \ldots, \mathrm{x}_{\mathrm{in}}\right]$. Por lo tanto, la serie de tiempo múltiple resultante, representa un conjunto de vectores de observación $x_{i}$, donde $i=1,2, \ldots, m$ para la construcción de la matriz de observación (Ec. 2.5.1). En la cual, las series de tiempo de los procesos individuales están representadas por las columnas de la matriz correspondiente.

$$
\mathrm{X}=\left[\begin{array}{cccc}
\mathrm{x}_{11} & \mathrm{x}_{12} & \cdots & \mathrm{x}_{1 \mathrm{n}} \\
\mathrm{x}_{21} & \mathrm{x}_{22} & \cdots & \mathrm{x}_{2 \mathrm{n}} \\
\vdots & \vdots & \ddots & \vdots \\
\mathrm{x}_{\mathrm{m} 1} & \mathrm{x}_{\mathrm{m} 2} & \cdots & \mathrm{x}_{\mathrm{mn}}
\end{array}\right]
$$

Un conjunto de datos llamados de entrenamiento se utiliza para enseñar a la red a comportarse como un predictor, y otro conjunto de datos llamados de prueba se utiliza después del entrenamiento, para 
poner a prueba su capacidad de predicción. Ambos conjuntos de datos van a ser construidos a partir de todo el conjunto de datos registrados.

Lo que no hay es una pauta de selección para dividir los datos preparados en estos dos conjuntos. Las recomendaciones van de un ratio del 90-10 \%, hasta una proporción del 50-50 \%. Sin embargo, cualquiera que sea el ratio seleccionado, se debe prestar atención para asegurar que el conjunto de datos de entrenamiento es lo suficientemente grande como para cubrir todas las características dominantes necesarias para el entrenamiento fiable de la red como predictor.

El conjunto restante de datos puede ser utilizado para probar la red entrenada con las muestras de datos no utilizados en el entrenamiento. Por esta razón, se recomienda que el conjunto de datos de no entrenamiento debe ser lo suficientemente grande para permitir la construcción no solo del conjunto de prueba, sino también el conjunto de datos de validación usado para ser utilizado en la evaluación global de la red.

\section{Determinación de la arquitectura de las redes neuronales artificiales}

La determinación de la arquitectura es la tarea principal en la construcción de la estructura de la red neuronal artificial respecto a la problemática específica que la red debe resolver de forma óptima. En este caso es el predictor óptimo. Esta tarea es la más difícil de ejecutar, ya que requiere de la habilidad y la experiencia práctica del diseñador. Ya que al ser una tarea no trivial con una multiplicidad de soluciones posibles, hay opiniones que dicen que es más una especie de arte que la rutina de un experto. Las cuestiones que se tratan a continuación presentan las actividades que se llevan a cabo en el desarrollo de la arquitectura de red. Éstas incluyen la determinación de las entradas y salidas requeridas, selección del número de capas ocultas y de sus neuronas, determinación de la estructura de interconexión entre neuronas y selección de la función de activación de las neuronas.

La determinación de la cantidad necesaria de nodos de entrada es una tarea relativamente fácil, ya que depende principalmente del número de variables independientes que se presentan en el conjunto de datos preparados. Como regla general, cada variable independiente debe ser representada por su propio nodo de entrada. En el caso de los datos de entrada preparados para la predicción, el número de nodos de entrada está directamente determinado por el número de valores de retardo que se utilizarán en la predicción del siguiente valor $x(t+1)=f(x(t), x(t-1), x(t-2), \ldots, x(t-n))$ como se representa (Fig. 2.5.1).

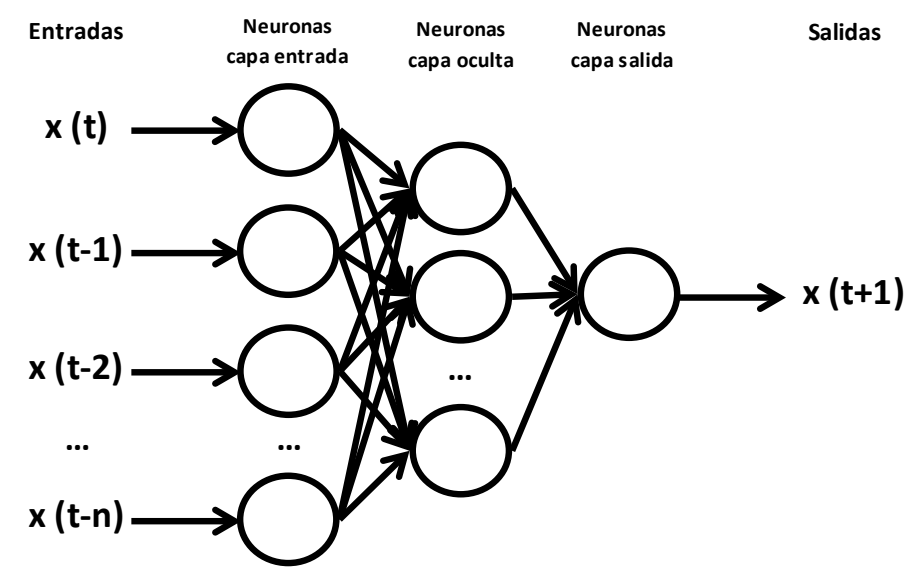

Fig. 2.5.1 Número de neuronas en la entrada para la predicción de un paso por delante (Palit y Popovic, 2005) 
En la práctica, el predictor de un solo paso por delante es seleccionado con más frecuencia debido a que es relativamente simple y garantiza los resultados de las predicciones más precisas. De lo contrario, cuando se construye un predictor de varios pasos, la determinación de la cantidad necesaria de nodos de entrada es un proceso de compensación en el sentido de que, siguiendo la tendencia general, este número debe seleccionarse lo más pequeño posible, pero que siga garantizando buenos resultados en las predicciones, y tan grande como sea necesario para la extracción de todas las características relevantes de la estructura de autocorrelación incrustada en los datos de entrenamiento. Para resolver este problema de forma óptima, realizar algunas pruebas experimentales es de gran utilidad.

El número de nodos de salida, de nuevo, es también una tarea orientada al problema a resolver. En la predicción de un paso por delante, es evidente que solo un nodo de salida es suficiente como nodo de predicción. En consecuencia, en el caso de la predicción para varios pasos por delante, el número de nodos de salida debe corresponder al horizonte de predicción, es decir, el número de las previsiones que se presentan simultáneamente en la salida de la red. Por otra parte, un único nodo de salida se puede utilizar y todas las previsiones futuras requeridas determinadas en pasos iterativos.

En la mayoría de las aplicaciones de la predicción, solo una capa oculta se usa. La suficiencia de una sola capa oculta está cubierta por el teorema de Kolmogorov, (Hecht-Nielsen, 1987) lo aplica y confirma, que una capa oculta en la red es suficiente para revelar todos los rasgos característicos presentes en los nodos de entrada de la red. Introducir nuevas capas ocultas aumenta la capacidad de extracción de características de la red a costa de extender significativamente el entrenamiento y el tiempo de operación del predictor.

(Lippmann, 1987) expone que el perceptron de tres capas puede formar regiones de decisión arbitrariamente complejas y separar las clases, lo que significa que no más de tres capas en la red son necesarias. Esto es especialmente válido para las redes con una salida, como se requiere para predicciones de un paso por delante. (Cybenko, 1989) destaca que no se necesitan más de dos capas ocultas en redes para resolver problemas complejos. Además, la investigación de las capacidades de la red neuronal relacionada con la estructura interna ha demostrado que las redes con más de dos capas ocultas son más propensas a decaer en mínimos locales malos. (Villiers y Barnard, 1992) señala que ambas redes de una o dos capas ocultas funcionan de manera similar en todos los demás aspectos. Esto se puede entender a partir de la comparación del grado de complejidad de las dos redes investigadas y medidas por la dimensión de Vapmik-Chervonenkis como ha hecho (Baum y Hausler, 1989).

Para simplificar los casos, en todos los experimentos con neuropredictores, las redes con una capa oculta y las redes sin capa oculta se utilizan como alternativa. Los resultados experimentales muestran que una capa oculta en la red tiene una capacidad de predicción mejor.

Se pasa ahora al problema del número de neuronas ocultas colocadas dentro de la capa oculta. Para determinar el número óptimo de neuronas ocultas no existe una metodología sencilla, pero algunas sugerencias de cómo hacer esto se han propuesto. Por ejemplo, en una red de una sola capa oculta, se recomienda tomar como número de neuronas de la capa oculta el $75 \%$ del número de entradas de red, o entre 0,5 y 3 veces el número de entradas de la red. La regla de la pirámide geométrica, por otra parte, sugiere la asignación de $\mathrm{N}_{h}=\alpha \sqrt{\mathrm{N}_{\mathrm{i}} \mathrm{N}_{\mathrm{o}}}$ donde $\alpha$ es el valor de un factor que depende de la complejidad del problema a resolver entre un rango de $0,5<\alpha<2$. 
De todos modos el número óptimo de neuronas en la capa oculta implica experimentos de ensayo y error. A partir de un número de neuronas en la capa se decide, basándose en la precisión final de cada proceso de aprendizaje, para aumentar o disminuir el número de neuronas ocultas e iniciar un nuevo proceso de aprendizaje. De esta manera se pueden añadir o quitar neuronas ocultas necesarias para un desempeño óptimo de la capa. Se parte de un número relativamente pequeño de neuronas, porque si se parte de un gran número de neuronas tiene el riesgo de producirse un tiempo largo de cálculo y de quedar atrapado en mínimos locales.

(Khorasani y Weng, 1994) presentan un enfoque para la adaptación estructural de la red neuronal artificial feedforward por la poda neuronal, es decir, mediante la adición y la eliminación de neuronas ocultas basada en el estado de la actividad de las neuronas individuales en el aprendizaje, medido por la variación de la señal en la neurona y por la fuerza de la retropropagación del error. Esta es una indicación adecuada de la actividad neuronal que ayuda a decidir que neurona de baja actividad y redundante se va a eliminar.

También existe un método fiable para determinar el número de neuronas ocultas utilizando el Criterio de Información Akaike AIC, este criterio estadístico evalúa la bondad de un modelo mediante la combinación del error cuadrático medio para los datos de entrenamiento y el número de parámetros a estimar. Visto de otra manera, el AIC combina una medida de la forma y el término de penalización para dar cuenta de la complejidad del modelo. Su aplicación para la creación de modelos de redes neuronales artificiales es reconocido por (Kurita, 1990) y (Fogel, 1991) que reformula el criterio. Para facilitar su aplicación directa se crea el Criterio de Información de Red NIC por (Stone, 1977).

Lo que a las interconexiones de los nodos de la red se refiere, la interconexión completa se recomienda para la configuración inicial de la red, en la salida de cada neurona de una capa está conectada con la entrada de cada neurona de la capa siguiente. Sin embargo, en algunas aplicaciones, las desviaciones de la plena conexión también tienen éxito.

Para la selección de la función de activación generalmente la función sigmoide y la tangente hiperbólica tienen éxito en la predicción de las series de tiempo. La función de paso y rampa, son alternativas más favorables para el procesamiento de variables binarias. Para evitar la destrucción funcional de la neurona, la función seleccionada debe limitarse a su salida, por lo general entre los valores -1 y +1. Aunque hay pautas para la selección de las funciones de activación en las capas individuales de la red y su distribución dentro de las capas, sigue siendo la mejor manera la de crear capas homogéneas individuales y para las neuronas ocultas, posiblemente, usar la función de activación sigmoide. Pero aun así, algunos investigadores han utilizado con éxito la función tangente hiperbólica como función de activación de las neuronas de la capa oculta.

Muy rara vez las capas de red heterogéneas han sido utilizadas. Para la predicción de series de tiempo, la experiencia general demuestra que las neuronas de salida de las funciones de activación lineal ofrecen los mejores resultados. Algunas pruebas teóricas de esto han sido dadas por (Rumelhart y McClelland, 1986).

\section{Estrategia de entrenamiento de las redes neuronales artificiales}


El entrenamiento de la red neuronal artificial es un proceso en el que la red aprende a reconocer patrones inherentes a los datos utilizados. En el entrenamiento de la red para predecir series de tiempo, todas las características importantes incorporadas en los datos de entrenamiento aparecen en la estructura de autocorrelación de las series de tiempo, que deben ser descubiertas y aprendidas.

El entrenamiento se lleva a cabo en el modo fuera de línea utilizando un algoritmo de minimización no lineal sin restricciones, como el método del gradiente descendiente, para el ajuste de los pesos de interconexión de la red. El objetivo es conseguir el comportamiento óptimo de la red a través del conjunto de entrenamiento.

El entrenamiento de la red se puede ejecutar en modo supervisado, modelo Hopfield, o en modo no supervisado, modelo Kohonen. Mediante el aprendizaje supervisado la red se entrena por medio de ejemplos de datos que incluyen la salida deseada. Mediante el aprendizaje no supervisado los valores de salida deseados no son necesarios porque la red encuentra los valores de salida adecuados ella misma.

El objetivo del entrenamiento es encontrar el conjunto de los valores más adecuados para los pesos de interconexión a través de su ajuste durante el entrenamiento de la red. Al hacerlo, la red todavía debe alcanzar el atributo de generalización más alto.

Con la precaución de no caer en un mínimo local en vez del mínimo global, mediante algunas consideraciones en la elaboración del diseño del experimento para el entrenamiento de la red. Como la inicialización de la red para el entrenamiento, la selección del algoritmo de entrenamiento apropiado, el seguimiento del proceso de entrenamiento mediante un índice de desempeño adecuado, la formulación de los criterios de parada,...

La inicialización de la red es una decisión que se toma antes de que el proceso para el ajuste de comienzo. Esta es una decisión difícil, ya que la velocidad y el tiempo de entrenamiento se ven fuertemente influidos. Con el fin de evitar la saturación de las neuronas y otros fenómenos se aconseja dar pequeños valores distribuidos de forma aleatoria, evitando dar el mismo valor a los pesos inicialmente.

El entrenamiento se lleva a cabo fuera de línea, porque en la práctica, una gran cantidad de datos disponibles tienen que ser procesados antes de su aplicación para el entrenamiento. Además para los fines de predicción los pares de datos de entrada-salida relacionados también tienen que ser construidos y transformados.

\section{Entrenamiento, parada y evaluación de las redes neuronales artificiales}

En principio, se acepta que la red neuronal artificial debe ser entrenada hasta que aprenda su tarea. Aunque no existe un proceso directo de cómo hacer esto. En general, se dice que un número alto de iteraciones, o de pasos de entrenamiento, es bastante bueno, en el sentido de que la red ha aprendido lo suficiente como para ser un experto cualificado en un dominio específico, por ejemplo en la predicción, no se sostiene.

Hasta ahora, al menos teóricamente, alcanzando un mínimo global de la función objetivo es aceptado como un entrenamiento eficiente, de manera que al acercarse a este mínimo la función error disminuye 
constantemente hasta que el mínimo ha sido alcanzado. Descubrir que no hay una disminución adicional de la función error sería entonces una indicación para detener el proceso de entrenamiento.

En la práctica, para encontrar el mínimo global, el entrenamiento de la red puede requerir un número de ensayos de entrenamiento repetidos con diferentes valores de pesos iniciales. Después de cada entrenamiento, al ejecutar los resultados, estos tienen que ser evaluados y comparados con los resultados de las pruebas anteriores, con el fin de seleccionar la mejor racha.

Algunos investigadores centran aquí el problema de una determinación a priori de un número máximo de ensayos de entrenamiento requeridos para el entrenamiento, dentro de un nivel de confianza. Sin embargo, incluso cuando se utiliza el número predeterminado de pasos de entrenamiento, generalmente no habrá ninguna garantía de que los parámetros de red se ajustan adecuadamente. La estrategia de parada óptima es dejar de entrenar después de que la red ha aprendido todo sobre la clase de problema que tiene que resolver. Esto ocurre cuando la interrupción del entrenamiento se efectúa en el punto donde la red ha llegado a la generalización máxima.

Para el experto, esto significa que la interrupción se debe activar exactamente en el punto en que el error de salida de la red ha alcanzado su valor mínimo esto se conoce como detección temprana. Si el entrenamiento se continúa más allá de este punto, el resultado podría ser el sobreentrenamiento de la red o sobreajuste (overfitting) de la red.

Pero aun así el dilema sigue siendo: determinar el fin del entrenamiento ¿cómo nos damos cuenta de que la red ha aprendido todos los conocimientos requeridos de los datos de entrenamiento y ha alcanzado su generalización máxima?

Desde la teoría del entrenamiento, se conoce que después de alcanzar el punto máximo de generalización, la red, aunque se entrene más y más, comenzará a menos cavar el rendimiento de la prueba debido a su sobreentrenamiento. Para evitar esto el método de la detención temprana con validación cruzada ha sido sugerido.

La validación cruzada es un procedimiento tradicional para la división estadística aleatoria de los datos recogidos en un conjunto de entrenamiento y un conjunto de prueba. Con diferentes criterios de parada, tanto el problema de sobreentrenamiento (overfitting) como el problema opuesto infraentrenamiento (underfitting), surgen como consecuencia de una parada del entrenamiento inadecuado.

Por ejemplo, si una red neuronal artificial que va a ser entrenada es menos compleja que la tarea que tiene que aprender, entonces la red, después de ser entrenada, puede sufrir underfitting, y puede, por lo tanto, identificar mal las características dentro de un gran conjunto de datos para entrenamiento. Por el contrario, una red neuronal artificial muy compleja puede, después de haberse entrenado, sufrir overfitting, y puede, por lo tanto, extraer las características dentro del conjunto de entrenamiento junto con el ruido superpuesto. Como consecuencia una red compleja puede producir predicciones que no son aceptables.

La complejidad de la red neuronal artificial está principalmente relacionada con el número de pesos. El término se utiliza en relación con la selección del modelo de predicción en el sentido de que la precisión de la predicción de una red determina su complejidad. 
Este es el punto de partida de la selección del modelo de red: ¿Cuántos y de qué tamaño son los pesos, y el número de neuronas ocultas? ¿Debe tener el modelo para la optimización la exactitud deseada, sin o al menos el mínimo overfitting?

Desde el punto de vista estadístico, el underfitting y el overfitting están relacionados con el sesgo y la varianza estadística que producen. Ellos influyen en la capacidad de generalización de la red neuronal artificial entrenada como sigue. El sesgo estadístico se relaciona con el grado de ajuste de la salida y las restricciones de la complejidad de la red, pero no se preocupa por la generalización de la red entrenada. La varianza estadística, es la desviación de la eficiencia de la red neuronal artificial entrenada dentro del conjunto de datos de entrenamiento, se preocupa por la generalización de la red entrenada. Por ejemplo, el underfitting produce un sesgo muy alto en las salidas de la red, mientras que el overfitting produce una gran varianza.

La dificultad de su reducción simultánea o su equilibrio en el proceso de aprendizaje, es esencial para lograr el grado de generalización más alto posible, que se conoce como el dilema sesgo-varianza. El dilema se debe entender como sigue: el sesgo de una red neuronal con un alto rendimiento a través del ajuste del conjunto de entrenamiento dado de datos es muy bajo, pero su varianza es muy alta. Mediante la reducción de la varianza el rendimiento de la red en el conjunto de datos se reducirá. Como consecuencia de ello, una solución de compromiso entre el sesgo bajo y la baja varianza es necesario.

Si el tamaño de la red neuronal artificial seleccionada es demasiado pequeño, entonces la red no será capaz de ajustar los datos de manera óptima y el ajuste de los datos será acompañado por un error de sesgo que disminuirá gradualmente con el aumento de tamaño de la red hasta que el error de la red alcanza su valor mínimo. El aumento del tamaño de la red más allá de este punto, producirá que la red también comenzará a aprender del ruido presente en los datos de entrenamiento, ya que habrá más parámetros internos que son necesarios para ajustarse a los datos. Con esto, también la varianza del error de la red se incrementará.

El punto de cruce de la curva del sesgo y la varianza del error garantizará el menor sesgo y la menor varianza del error, más baja para el ajuste del conjunto de datos dado. En este punto, el entrenamiento de la red debe ser detenido, lo que se conoce como principio de parada o parada con validación cruzada. La red entrenada de esta forma garantiza la mejor generalización.

En resumen, el tamaño óptimo de la red neuronal artificial es esencial para la óptima resolución del problema porque una red relativamente pequeña no será capaz de ajustarse a los datos dados con precisión y por tanto no será capaz de aprender las características más importantes incorporadas en los datos. Por esta razón, el tamaño de la red debería ser aumentado. Por otro lado debido a que una red de gran tamaño tiende a aprender no solo los rasgos característicos de los datos dados, sino también del ruido de acompañamiento y otros componentes no relevantes de su idiosincrasia, ocultos en los datos, su tamaño debe ser reducido. En ambos casos, una reducción del tamaño de la red y/o un aumento en el tamaño óptimo de la red se debería encontrar que asegura el rendimiento óptimo de la red.

En la práctica esto se consigue normalmente equilibrando una red creciente y/o por poda de red. El crecimiento de la red es un proceso de adición sucesiva de nuevas neuronas y sus interconexiones relacionadas con la red inicial de tamaño pequeño hasta que el rendimiento óptimo de la red se alcanza. La poda de red, es un proceso de eliminación sucesiva de interconexiones correspondientes entre neuronas dentro de una red de gran tamaño, esencialmente empeorando el rendimiento de la red. 
Para mejorar la capacidad de generalización de la red, se utiliza el método de análisis de componentes principales, esta es una valiosa herramienta matemática para reducir la dimensionalidad de un sistema mediante la eliminación de las variables redundantes. Para detectar las variables que tienen una baja influencia en la función de error.

En la práctica con una red entrenada, existe una recomendación fundamental, es decir, cuando varias redes entrenadas tienen aproximadamente los mismos rendimientos finales, la red más sencilla estructuralmente debe ser seleccionada como la mejor generalización. Esta recomendación refleja la filosofía de la navaja de Occam, que recomienda que un modelo científico deba favorecer la simplicidad.

Hay que lograr un compromiso entre la intención de que la red entrenada debe ser capaz de aprender un amplio espectro de categorías de problemas similares, lo que requeriría una red de gran tamaño, y el requisito de que la red debe ser lo más simple posible, con el fin de evitar el overtraining.

\section{4) Predicción usando las redes neuronales artificiales}

A diferencia de los métodos estadísticos tradicionales de análisis y predicción de las series de tiempo, las redes neuronales artificiales necesitan una cantidad reducida de información para predecir los datos futuros. Sobre la base de datos registrados de las series de tiempo disponibles, los parámetros internos de la red neuronal artificial se ajustan usando un algoritmo apropiado. Esto puede, si es necesario, también incluir la modificación de la arquitectura de la red neuronal artificial elegida inicialmente para adaptarse mejor al problema en cuestión.

A continuación se compara la predicción de las series de tiempo con métodos tradicionales y utilizando redes neuronales artificiales. Indicando las ventajas de la predicción mediante el uso conjunto de los dos tipos de enfoques y por la construcción de una combinación lineal de las predicciones. Por último, algunas características relacionadas con la predicción de las series de tiempo multivariante mediante redes neuronales artificiales se comentan.

\section{Redes neuronales artificiales vs. Predicción estadística tradicional}

La comparación de la capacidad predictiva de los métodos estadísticos tradicionales respecto de los predictores neurales, mantiene la atención de los investigadores desde la década de los años 90 . Sus informes se basan en investigaciones experimentales utilizando diferentes configuraciones de red y diferentes tipos de datos de las series de tiempo. Resultando, que la predicción de datos lineales utilizando redes neuronales artificiales no puede mejorar los resultados de la predicción usando algoritmos estadísticos lineales. Otro caso, cuando se trata de datos de las series de tiempo no lineales, la predicción usando redes neuronales artificiales ofrece mejores resultados que los algoritmos tradicionales. En consecuencia cuando se trata de datos registrados de las series de tiempo con una mezcla lineal/no lineal, una combinación de lo tradicional y el enfoque neural podría ser óptima.

(Lapedes y Farber, 1988) son los primeros en estudiar que simples redes neuronales artificiales pueden superar a los métodos estadísticos tradicionales hasta en muchos órdenes de magnitud. (Sharda y Patil, 1990) investiga sobre un conjunto de 75 series diferentes con el objetivo de comparar la exactitud de las 
previsiones del método Box-Jenkins y de un predictor neural. (Tang et al., 1991) utiliza 14 series de tiempo para el análisis comparativo, determinando que las redes neuronales artificiales obtienen mejores resultados de predicción que los enfoques tradicionales.

Se encuentra que por medio de experimentos, en general, las series de tiempo con memoria larga para ambos enfoques ofrecen resultados similares, que para las series de tiempo con memoria corta las redes neuronales artificiales superan al método tradicional de Box-Jenkins y que para series de tiempo de diversa complejidad los modelos neurales se adaptan óptimamente obteniendo una mayor eficiencia que los métodos tradicionales.

(Hill et al., 1996) compara seis métodos tradicionales con un predictor neural para 111 series de tiempo diferentes y encuentra que los predictores neurales son significativamente mejores que los métodos estadísticos tomados en consideración.

\section{Combinación de redes neuronales artificiales y métodos tradicionales}

La aplicación de híbridos, es decir, combinar las redes neuronales artificiales y los métodos tradicionales, en las predicciones de las series de tiempo es un intento para aumentar la precisión de las predicciones más allá de los límites que cualquiera de los dos métodos utilizados por si solos son capaces de alcanzar.

\section{Combinación no lineal de las predicciones usando redes neuronales artificiales}

Debido a que un gran número de métodos de predicción de las series de tiempo están disponibles, se vuelve interesante combinar un grupo de métodos de predicción y examinar la precisión de las predicciones de su combinación.

Se ha llegado a que los mejores resultados de predicción se pueden lograr cuando la combinación de métodos de predicción tradicional es no lineal. Y se propone en la literatura, la combinación de diversas técnicas, examinando el uso de diferentes tecnologías inteligentes.

En la práctica de la ingeniería, la elección del mejor método de predicción es elegir un método que sea el mejor en las circunstancias dadas. (McNees, 1985) ningún modelo de predicción conserva su precisión para todos los valores de las variables durante todo el tiempo. Asimismo, se comprueba que, si mediante un método de predicción a corto plazo es bueno, entonces no hay garantía de que a la larga también será bueno. Por lo tanto, vale la pena buscar una combinación adecuada para cada situación de la aplicación. Esto se debe a que la combinación de métodos incorpora capacidades diferentes de cognición y puede, en un caso concreto, producir mejores predicciones que cualquiera de los métodos dentro de la misma combinación.

Además, las investigaciones experimentales lo confirma como (Winkler y Markridakis, 1983) que la precisión resultante del aumento de predictores combinados con el aumento en el número de métodos de predicción en cuestión. (Mahmoud, 1984) también llega a una conclusión similar, que la precisión de la predicción combinada mejora a medida que más métodos se incluyen en la combinación. (Bates y 
Grauger, 1969) expone que no es aconsejable preferir un método de predicción frente a otro, porque no hay solo un método de predicción que produzca en todas las situaciones las predicciones con la misma precisión. Lo más recomendable es tomar una combinación de las predicciones generadas por diferentes métodos.

(Shi y Liu, 1993) y (Harald y Kamastra, 1997) ofrecen una serie de métodos avanzados para la combinación no lineal de las predicciones usando redes neuronales artificiales. El problema se define a partir de la disponibilidad de $k$ diferentes predicciones $f_{1}, f_{2}, \ldots, f_{k}$ de alguna variable aleatoria $z$, que deben ser combinados en una única predicción $f_{c}$. El paso directo sería formar una combinación lineal de predicciones $\mathrm{f}_{\mathrm{c}}(\mathrm{z})=\sum \omega_{\mathrm{i}} \mathrm{f}_{\mathrm{i}}(\mathrm{z})$ donde $\omega_{\mathrm{i}}$ es el peso asignado a $\mathrm{f}_{\mathrm{i}}$ de la predicción i. Una combinación no lineal es mejor que las predicciones individuales.

\section{Las predicciones de series de tiempo multivariadas}

Investigaciones experimentales sobre la predicción de series de tiempo multivariadas (Chakraborty et al., 1992) centran su atención en la afirmación de que en el caso de importantes correlaciones cruzadas de variables individuales de datos en las series de tiempo multivariadas, la precisión de la predicciones de cada variable puede ser mejorada cuando simultáneamente cambian los valores de otras variables dentro de la serie de tiempo que se toma en cuenta.

Esto se ha observado en el análisis estadístico multivariado, sobre la base de datos registrados, la identificación de las interdependencias de las variables que intervienen en un sistema multivariable. Para probar esto, (Chakraborty et al., 1992) analiza el comportamiento de la predicción a un paso y multipaso de una serie de tiempo trivariada $\mathrm{x}_{\mathrm{t}}=\left[\mathrm{x}_{1 \mathrm{t}}, \mathrm{x}_{2 \mathrm{t}}, \mathrm{x}_{3 \mathrm{t}}\right]$ en el intervalo de $\mathrm{t}=1 . . .100$ muestreos usados. El modelado separado de cada componente de la serie de tiempo multivariada, interpretando cada serie de tiempo univariada como independientes entre sí, el modelado combinado, por la consideración simultánea de las tres variables, y el modelado estadístico son aplicados. El análisis de las series por separado se lleva a cabo utilizando alternativamente redes neuronales artificiales con distinto número de neuronas en las capas de entrada, oculta y salida, y la evaluación de los resultados de cada componente de la serie de tiempo, usando el estadístico RMSE como indicador del rendimiento. El análisis demuestra que un método de modelado multivariado es superior a los modelos separados, y que ambos son superiores a los modelos estadísticos.

\subsubsection{La inteligencia computacional en el modelado}

Las redes neuronales artificiales pertenecen a la clase de métodos basados en datos, en lugar de métodos basados en modelos, para el análisis y los resultados dependen de los datos disponibles (Chakraborty et al., 1992). Las relaciones entre las variables de los modelos, leyes y predicciones se construyen después de construir una máquina que simula los datos considerados. El proceso de construcción de una máquina basada en los datos disponibles es dirigido por algoritmos como el perceptron (Rosenblat, 1962) o el backpropagation (Chauvin y Rumelhart, 1994). Las redes neuronales artificiales tienen la capacidad de extraer conocimiento a partir de los datos disponibles, es decir, la 
capacidad de aprender de los ejemplos, que los sistemas de lógica difusa no tienen. Esta capacidad se conoce como paradigma de aprendizaje conexionista.

El proceso de aprendizaje puede tener lugar en modo supervisado, cuando las redes backpropagation son usadas, o en modo no supervisado, cuando las redes recurrentes Kohonen son utilizadas. Esto se debe a la computación neuronal o el perceptron, con la base teórica elaborada (Minsky y Papert, 1969). La configuración del perceptron multicapa es capaz de emular el comportamiento del cerebro humano en el aprendizaje y la cognición. La capacidad de aprendizaje del perceptron multicapa, según lo expuesto (Werbos, 1974) se debe obtener a través de un proceso de entrenamiento adaptativo con ejemplos.

Dentro de la inteligencia artificial la inteligencia computacional es ampliamente entendida como un conjunto de metodologías, que ayudan a solucionar problemas de la ciencia y la tecnología, los cuales no encuentran, al menos fácilmente, soluciones mediante el uso de los métodos matemáticos convencionales.

En el término inteligencia computacional definido (Bezdek, 1992) se dice que se ocupa de los datos numéricos proporcionados por los sensores y no se ocupa de los conocimientos. Esto es diferente de la inteligencia artificial, que trata principalmente con el conocimiento no numérico del sistema. Clasifica los dos tipos de inteligencia, teniendo a la inteligencia artificial como un nivel medio de computación en el estilo de la mente, mientras que la inteligencia computacional es el cómputo de bajo nivel en el estilo de la mente.

(Marks, 1993) sobre la Inteligencia: Artificial vs. Computacional, indica que a pesar de la búsqueda de objetivos similares, la inteligencia computacional se ha convertido en un campo soberano, cuya investigación es virtualmente distinta de la inteligencia artificial. Esto indica que hay dos tecnologías inteligentes alternativas, lo artificial y lo computacional. El concepto de adaptabilidad es introducido en la definición de la inteligencia computacional (Eberhard et al., 1995) y (Fogel, 1995).

Una evolución paralela de dos corrientes de cómputo, el soft computing y la inteligencia computacional, ha tenido lugar, ambas basadas en los métodos y herramientas de la inteligencia artificial, predominantemente en las redes neuronales, la lógica difusa y la computación evolutiva (Popovic y Bhatkar, 1994). Pero hoy en día, tanto el soft computing y la inteligencia computacional han integrado un gran número de metodologías y es difícil establecer una clara distinción entre ellos. 



\section{Capítulo 3}

\section{MATERIALES Y METODOLOGÍA}

\subsection{Descripción técnica de la planta piloto}

\subsection{El método f-chart}

3.3 Herramienta para la implementación de las redes neuronales artificiales

3.4 Predicción neural de las variables ambientales

3.5 Estimación de la irradiación solar sobre el plano inclinado y orientado

3.6 Modelado neural de los componentes del sistema solar térmico

3.7 Simulación neural del sistema solar térmico

3.8 Optimización del rendimiento en el sistema solar térmico

La primera parte presenta la planta piloto que se ha construido con un sistema solar térmico de fluido portador líquido, en la que se desarrollan los ensayos y se validan los modelos y las simulaciones realizadas. De ella se obtienen medidas de temperaturas, caudal e irradiancia solar, la cual está formada por un captador de placa plana, un depósito acumulador, una bomba, un vaso de expansión, una válvula de seguridad, una válvula de compensación, un purgador de aire, aislante térmico para tubería, sondas de temperatura y un piranómetro.

La segunda parte estudia en profundidad la forma en que el método f-chart modela los componentes del sistema solar térmico y la descripción detallada del método, utilizado como referencia en esta Tesis Doctoral.

La tercera parte presenta la herramienta manejada para la implementación de las redes neuronales artificiales, escogida por la gran difusión que ha alcanzado entre los técnicos e ingenieros, Neural Network Toolbox de Matlab, describiendo el proceso de creación, entrenamiento y simulación.

En los apartados siguientes de este capítulo se presenta la metodología utilizada en esta Tesis Doctoral, ubicándola en una corriente de conocimiento concreta como es la inteligencia computacional aplicada con la técnica de las redes neuronales artificiales a las series de tiempo formadas por los datos del proceso de funcionamiento del sistema solar térmico para su simulación y optimización.

La cuarta parte presenta la metodología aplicada en el desarrollo de los modelos neurales de predicción de la irradiación solar y la temperatura ambiente, utilizando la base de datos climatológicos de la red SIAR en la estación de Mansilla Mayor, situada a $20 \mathrm{~km}$ al sur de la ciudad de León. Estos datos se representan gráficamente en el (Anexo 1 Datos climatológicos). 
La quinta parte presenta la metodología para la estimación del valor de la irradiación solar global incidente sobre el plano inclinado del captador solar, a partir de la irradiación solar global que recibe la superficie horizontal, que es la habitualmente registrada en las estaciones meteorológicas. Se presenta la metodología a seguir, la cual necesita de diversas variables y procedimientos, que se detallan claramente para facilitar su cálculo.

La sexta parte presenta la metodología aplicada en el desarrollo de los modelos neurales que representan los componentes principales del sistema solar térmico, como son el captador solar, el intercambiador de calor y el depósito acumulador de agua caliente solar. Estos modelos se realizan con datos registrados en el sistema solar térmico de la planta piloto que se describe en el (Apartado 3.1) y se representan gráficamente en el (Anexo 2 Datos de los ensayos en la planta piloto).

La técnica escogida para el desarrollo de las metodologías desarrolladas en la cuarta y sexta parte es las redes neuronales artificiales de la inteligencia computacional aplicadas a la base teórica de las series de tiempo, que se describió como marco teórico de esta Tesis Doctoral en el (Apartado 2.5). La metodología de la quinta parte se desarrolla con modelos de la literatura presentados en el (Apartado 2.3), lo que se ofrece aquí es una exposición clara, que se echa en falta para su correcta aplicación. Pero también se propone en capítulos siguientes aplicar la misma metodología para ser resuelto el problema planteado con la técnica utilizada en los apartados cuarto y sexto.

La séptima parte presenta la metodología aplicada en el desarrollo del modelado conjunto de todo el sistema solar térmico, que se utiliza para la realización de la simulación de su funcionamiento, usando como entradas los datos de las predicciones que se realizan de la irradiación solar y la temperatura ambiente o los propios datos reales medidos y registrados en las estaciones meteorológicas, el caudal de agua caliente solar consumido y la temperatura del agua de red.

La octava parte presenta la metodología aplicada para la optimización del rendimiento de los sistemas solares térmicos, que puede aplicarse a cualquier instalación solar doméstica de una forma fácil y sencilla, según la filosofía de aumentar el consumo los días de alta irradiación solar y reduciendo el consumo los días con previsiones de baja irradiación solar. 


\subsection{Descripción técnica de la planta piloto}

Se realiza la descripción técnica de los componentes utilizados para la construcción de la planta piloto utilizada en esta Tesis Doctoral, su conexionado para formar el sistema solar térmico y los sensores instalados para la medida de las temperaturas e irradiancia solar.

\section{1) El captador de placa plana}

Un captador de placa plana dentro del cual se calienta el fluido portador por medio de la irradiación solar, transfiriéndose el calor a través del circuito primario del sistema, de la marca Takama y modelo T3-Inox, está instalado a $45^{\circ}$ sobre el plano horizontal.

La superficie de absorción está sometida a un proceso de estampación en el que se embuten 8266 semiesferas consiguiendo una estructura tridimensional, esto ya de por si es una mejora ya que aumenta la superficie de captación efectiva. Esta estructura tridimensional trae consigo las siguientes ventajas:

La superficie de absorción se amplía de $2 \mathrm{~m}^{2}$ a 2,593 $\mathrm{m}^{2}$, dentro de las mismas medidas externas del captador de $2 \mathrm{~m}$ de largo $\times 1 \mathrm{~m}$ de ancho. Debido a que durante todo el día hay planos de la superficie de absorción en los que la irradiación solar incide perpendicularmente, el rendimiento por día es más elevado, un 72,3 \% de la energía solar que incide en la placa a lo largo de todo el día es captada por el captador, según su fabricante (Takama, 2006).

Estas características tienen como resultado, el que son necesarios menos captadores para obtener la misma cantidad de agua caliente, con lo que el coste total de la instalación disminuye considerablemente y además constituye un factor importante en las instalaciones donde la superficie disponible para la colocación de los captadores es limitado (Takama, 2006).

\section{Características técnicas del captador solar térmico marca Takama modelo T3-Inox}

La carcasa tiene unas dimensiones totales de $2000 \times 1000 \times 72 \mathrm{~mm}$, lo que da un área total de $2 \mathrm{~m}^{2}$ y unas dimensiones de apertura de $1940 \times 942 \mathrm{~mm}$, con un área de apertura de 1,83 $\mathrm{m}^{2}$, es una caja de acero inoxidable AISI 304L de 0,6 mm de espesor soldada y sellada con silicona termoresistente para su total estanqueidad. Lleva incorporados cuatro anclajes para su fijación a la estructura con tolerancia suficiente para absorber las posibles dilataciones. La caja lleva incorporados dos evaporadores anticondensación.

La cubierta es de vidrio templado Dura Solar prismático de $4 \mathrm{~mm}$ de espesor y bajo contenido en hierro.

El captador es una parrilla de ocho tubos verticales tipo Flat Pipe de cobre de $\varnothing 10 \mathrm{~mm}$ soldados con cobre a dos tubos horizontales de cobre de $\varnothing 18 \mathrm{~mm}$.

La superficie absorbedora tiene unas dimensiones de $1950 \times 950 \times 0,3 \mathrm{~mm}$, lo que da un área de absorbedor de $1,85 \mathrm{~m}^{2}$, es de chapa de aluminio con ocho canales planos y 8266 semiesferas embutidas que aumentan la superficie útil de absorción hasta 2,593 $\mathrm{m}^{2}$. Este aumento de superficie se ve reflejado en un aumento del rendimiento del captador. En los canales planos van encajados los tubos Flat Pipe en contacto con pasta termoconductora formando un solo cuerpo soldados mediante resistencia eléctrica. 
La superficie absorbedora lleva un recubrimiento selectivo de alto rendimiento y eficacia sin cromo, a base de óxido de Cu negro, $\mathrm{Mg}$ y $\mathrm{Si}$, con una absortividad $\alpha=0,94$ y una emisividad $\varepsilon=0,29$.

Las conexiones son cuatro salidas desnudas de tubo $\varnothing 18 \mathrm{~mm}$ con racords de unión rectos sin soldadura a prueba de dilatación.

El aislamiento térmico es espuma de poliisocianurato PIR de $20 \mathrm{~mm}$, revestida por ambas caras con aluminio gofrado.

Las limitaciones de funcionamiento son de $150^{\circ} \mathrm{C}$ de máxima temperatura de operación, 7 bar de máxima presión de operación y de $25^{\circ}$ a $60^{\circ}$ de mínimo y máximo ángulo de inclinación.

El peso del captador en vacío es de 39,3 kg, pudiendo contener 1,2 I de fluido portador (CENER-CIEMAT, 2006).

El tipo citado de captador solar ha sido certificado con contraseña de certificación GPS-8130 (BOE, 2007).

\section{2) El depósito acumulador}

Un depósito acumulador de agua caliente solar ACS, cumpliendo la función de almacén que permite independizar el suministro de calor solar del consumo, porque el perfil temporal de la entrada de energía no suele corresponder con el de consumo energético, de la marca Lapesa y modelo CV-150-M1S, instalado en posición vertical, dotado de serpentín interno como sistema de intercambio térmico.

\section{Características técnicas del depósito acumulador marca Lapesa modelo CV-150-M1S}

El depósito acumulador está fabricado en acero vitrificado, según la norma DIN 4753.

La capacidad del depósito acumulador es de 150 I de ACS, con un diámetro exterior de $560 \mathrm{~mm}$ y una longitud total de $1265 \mathrm{~mm}$.

La superficie de intercambio del serpentín es de $0,6 \mathrm{~m}^{2}$, con $40 \mathrm{~kW}$ de potencia para $3 \mathrm{~m}^{3} / \mathrm{h}$ de caudal primario y de $44 \mathrm{~kW}$ para $5 \mathrm{~m}^{3} / \mathrm{h}$ cuando alcanza $90{ }^{\circ} \mathrm{C}$ la temperatura del primario y de $10{ }^{\circ} \mathrm{C}$ a $45^{\circ} \mathrm{C}$ el incremento de temperatura del secundario.

El aislamiento térmico está realizado con espuma poliuretano PU inyectado en molde, libre de clorofluorocarburos CFC y acabado exterior con forro acolchado desmontable en blanco RAL 9016 y cubiertas de PVC.

Las limitaciones de funcionamiento son de $90{ }^{\circ} \mathrm{C}$ de máxima temperatura y de 8 bar de máxima presión en el depósito del ACS, de $200^{\circ} \mathrm{C}$ de máxima temperatura y de 25 bar de máxima presión en el circuito de calentamiento.

El peso del depósito acumulador en vacío es de 60 kg, incorpora un ánodo de magnesio para su protección catódica.

Las conexiones son de $3 / 4$ " en la entrada de agua fría y salida de ACS, y de 1/2" en el avance y el retorno del circuito primario (Lapesa, 2006). 


\section{3) La bomba}

Una bomba o electrocirculador para producir la circulación del fluido portador en el circuito primario, de la marca Wilo y modelo RS 25/4-3, instalada con el eje en posición horizontal, en el retorno del circuito primario donde las temperaturas de funcionamiento son mínimas.

\section{Características técnicas de la bomba marca Wilo modelo RS 25/4-3}

La bomba roscada está fabricada con un rodete de polipropileno y un cojinete de grafito, es de 1" de diámetro nominal de tubería.

Las limitaciones de funcionamiento son de $4 \mathrm{~m}$ de máxima altura de impulsión, de 10 bar de máxima presión admisible, de entre $-10{ }^{\circ} \mathrm{C} y+110{ }^{\circ} \mathrm{C}$ de mínima y máxima temperatura de trabajo, de $40{ }^{\circ} \mathrm{C}$ de máxima temperatura ambiente, la presión mínima de entrada a $50^{\circ} \mathrm{C}$ es de 0,05 bar, a $95^{\circ} \mathrm{C}$ es de 0,3 bar y a $110^{\circ} \mathrm{C}$ de 1 bar.

A una velocidad de $2050 \mathrm{rpm}$ circula una corriente de $0,28 \mathrm{~A}$ y el consumo es de $65 \mathrm{~W}$, a una velocidad de $1650 \mathrm{rpm}$ tiene 0,20 A y $45 \mathrm{~W}$ y a una velocidad de $1300 \mathrm{rpm}$ tiene 0,13 A y $30 \mathrm{~W}$. El índice de protección es IP44 (Wilo, 2006).

\section{4) El vaso de expansión}

Un vaso de expansión para compensar los cambios del volumen del fluido de trabajo ocasionados por la dilatación térmica, sin él sería imposible evitar el escape del fluido por la válvula de seguridad, de la marca Ibaiondo, se instala en la parte baja del circuito primario y hacia abajo la parte de gas para evitar que en la membrana se queden burbujas de aire.

\section{Características técnicas del vaso de expansión marca lbaiondo}

El vaso de expansión de membrana fija, tiene 5 I de capacidad y un diámetro exterior de $200 \mathrm{~mm}$ y una longitud total de $240 \mathrm{~mm}$ de color blanco $5 \mathrm{SMF}$, la conexión de agua es de 3/4".

Las limitaciones de funcionamiento son de $-10{ }^{\circ} \mathrm{C} \mathrm{a}+130^{\circ} \mathrm{C}$ de mínima y máxima temperatura de servicio, de 2,5 bar a 10 bar de mínima y máxima presión, de 15 bar de presión de test y de un $50 \%$ de resistencia al etilenglicol para la adición de anticongelante (Ibaiondo, 2006).

\section{5) La válvula de seguridad}

Una válvula de seguridad que garantiza la seguridad de operación y previene los daños en la instalación y ofrece seguridad al operario, de la marca Watts Industries y modelo SVW.

\section{Características técnicas de la válvula de seguridad marca Watts Industries modelo SVW}

La válvula de seguridad de membrana está tarada a 6 bar de presión, con conexión de 1/2", con un rango de $-10{ }^{\circ} \mathrm{C}$ a $+110{ }^{\circ} \mathrm{C}$ de temperatura de trabajo, conforme a la Directiva PED 97/23/CE (Watts, 2006). 


\section{6) La válvula de compensación}

Una válvula de compensación que lleva un caudalímetro de muelle de 2 a $16 \mathrm{l} / \mathrm{min}$, en la misma carcasa. El volumen de paso se va indicando constantemente, es decir que el ajuste de la válvula se puede realizar inmediatamente en el indicador de paso.

\section{7) El purgador de aire}

Un purgador automático de aire que libera al exterior el aire del circuito primario, de la marca Caleffi Solar, se instala en la parte alta del circuito donde acaban llegando las burbujas.

\section{Características técnicas del purgador automático marca Caleffi Solar}

El purgador automático de aire está fabricado en cuerpo de latón y cromado, tiene $3 / 8$ " de diámetro, de 10 bar de máxima presión de entrada, de 5 bar de máxima presión de salida, con un rango de $-30{ }^{\circ} \mathrm{C}$ a +200 ${ }^{\circ} \mathrm{C}$ de temperatura de funcionamiento y de un $50 \%$ de resistencia al etilenglicol para la adición de anticongelante (Caleffi, 2006).

\section{8) El aislante térmico para tubería}

El aislante térmico de la tubería que evita las pérdidas de calor del fluido de trabajo, es de la marca Armaflex y modelo S HT, se instala en las tuberías de cobre de las conducciones del circuito primario.

\section{Características técnicas del aislante térmico marca Armaflex modelo S HT}

El aislante térmico de la tubería es de espuma elastomérica flexible, un aislamiento de célula cerrada que actúa como una eficaz barrera de vapor y reduce el riesgo de condensación e incorpora un recubrimiento de copolímero de poliolefina de color blanco resistente al ultravioleta, de entre $-50{ }^{\circ} \mathrm{C} \mathrm{a}+150{ }^{\circ} \mathrm{C}$ es el campo de temperaturas que puede resistir con unos picos de $+175^{\circ} \mathrm{C}$, con $0,040 \mathrm{~W} /(\mathrm{m} \mathrm{K})$ de conductividad térmica del aislamiento a $20^{\circ} \mathrm{C}$, de $10 \mathrm{~W} /\left(\mathrm{m}^{2} \mathrm{~K}\right)$ de coeficiente superficial de transmisión de calor y tubería de $18 \mathrm{~mm}$ de cobre, con $32,6^{\circ} \mathrm{C}$ de temperatura superficial (Armacell, 2006).

\section{9) Las sondas de temperatura}

Dos sondas de temperatura para la ida y retorno con las que se muestrea la temperatura del fluido portador de ida y retorno en el circuito primario, de la marca Danfoss y modelo ESMU-100.

\section{Características técnicas de la sonda de temperatura marca Danfoss modelo ESMU-100}

La sonda de temperatura tiene un sensor básico con base de platino Pt-1000 a $0{ }^{\circ} \mathrm{C}$ lineal que cumple con la norma EN 60751 Sonda de inmersión, de entre $0{ }^{\circ} \mathrm{C}$ a $140{ }^{\circ} \mathrm{C}$ de rango de temperaturas, el índice de protección es IP54, con $2 \mathrm{~s}$ de constante de tiempo en agua y de $7 \mathrm{~s}$ en aire, la sonda de $100 \mathrm{~mm}$ de longitud va en tubo de cobre y cuerpo de latón, con la cabeza de poliamida PA, la vaina es AISI 316, la 
conexión eléctrica en bloque de terminales para dos cables en cabeza de entrada PG 9, el montaje de la vaina es $\mathrm{G} 1 / 2 \mathrm{~A}$ (Danfoss, 2006).

Una sonda de temperatura ambiente con una resistencia de platino Pt-100, protegida de la insolación y del viento mediante un forro plástico y hoja de aluminio.

Una sonda de temperatura para la estratificación en el depósito construida especialmente con ocho resistencias de platino Pt-100, pegadas con silicona a una placa de aluminio, junto a un alambre para darla rigidez y dentro de una funda termoretráctil plana de PVC, colocados a una distancia que cubra las ocho capas en las que se dividió el depósito para el estudio de la estratificación térmica. Esta sonda se introduce por la parte alta del depósito mediante una conexión $\mathrm{T}$.

\section{0) El piranómetro}

Un piranómetro para la medida de la irradiancia solar global (directa + difusa), de la marca Delta Ohm y modelo LP PYRA 02 AC, instalado en el mismo plano que el captador solar para medir la irradiancia solar que le llega a éste.

\section{Características técnicas del piranómetro marca Delta Ohm modelo LP PYRA 02}

El piranómetro es de 1a clase, está fabricado de acuerdo con la norma ISO 9060 y siguiendo las recomendaciones de World Meteorological Organization WMO, mide la irradiancia global pudiéndose colocar un anillo de sombra para la componente directa y así medir la componente difusa de la radiación solar por separado, no necesita alimentación externa, genera una tensión de $10 \mathrm{mV} /\left(\mathrm{kW} \mathrm{m}^{2}\right)$ y una señal de corriente de $4 \mathrm{~mA}$ con $0 \mathrm{~W} / \mathrm{m}^{2}$ y de $20 \mathrm{~mA}$ con $2000 \mathrm{~W} / \mathrm{m}^{2}$.

Cada piranómetro está calibrado individualmente usando como referencia el World Radiometric Reference WRR, tiene de $33 \Omega$ a $45 \Omega$ de impedancia, de $0 \mathrm{~W} / \mathrm{m}^{2}$ a $2000 \mathrm{~W} / \mathrm{m}^{2}$ de rango de medida, $2 \pi \mathrm{sr}$ de rango de visión, de $-40{ }^{\circ} \mathrm{C}$ a $+80^{\circ} \mathrm{C}$ de temperatura de trabajo y un campo espectral de 305 a $2800 \mathrm{~nm}$

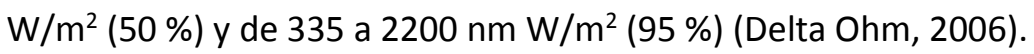

\section{1) La planta piloto}

Todos estos componentes están acoplados con tubería de cobre y montado todo ello en una estructura de perfiles de acero, sobre ruedas con el objeto de que sea fácil su transporte, como se puede ver en la fotografía (Fig. 3.1.1) y el esquema (Fig. 3.1.2).

Este sistema solar térmico una vez puesto en funcionamiento recoge los valores de las variables mediante los sensores colocados en él y quedan registrados en un ordenador, los datos de las temperaturas, caudal e irradiancia solar mediante una tarjeta de adquisición de datos y las temperaturas de la estratificación del depósito en un registrador de datos de la marca Fourier Systems y modelo DaqPRO 5300 (Fourier, 2006). 
Fig. 3.1.1 Planta piloto con un sistema solar térmico 


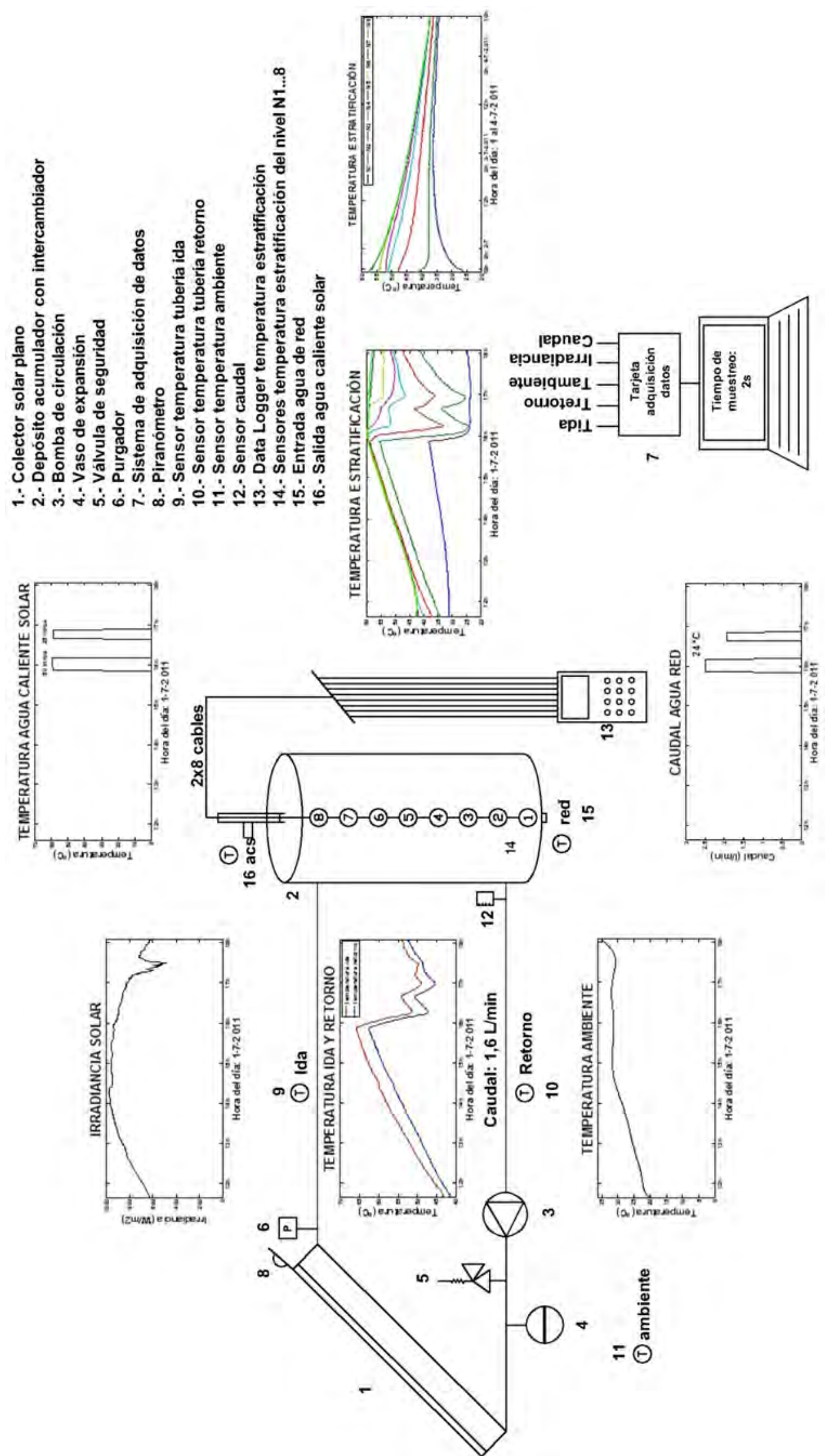

Fig. 3.1.2 Esquema de conexionado del sistema solar térmico de la planta piloto 


\subsection{El método f-chart}

Se realiza la descripción del modelado de los componentes en el circuito primario del sistema solar térmico utilizado en el método f-chart y se describe la metodología a seguir para su aplicación en sistemas de fluido portador líquido, empleado como referencia en esta Tesis Doctoral.

\subsubsection{Modelado de los componentes del circuito primario del sistema solar térmico en el método f-chart}

El captador solar de placa plana es el componente principal que se utiliza en los sistemas solares térmicos instalados en los edificios, su funcionamiento es en teoría sencillo. La mayor parte de la energía solar que incide sobre el captador solar es absorbida, parte de la energía absorbida se transfiere al fluido portador, mientras que el resto se pierde hacia los alrededores. El calor transportado por el fluido portador, es la energía útil ganada por el captador solar, la cual se almacena o se utiliza directamente. Los captadores solares de placa plana proporcionan calor a baja temperatura, que es la forma de energía necesaria para la calefacción y el agua caliente destinada a usos domésticos.

\section{1) Teoría del captador solar de placa plana}

El captador solar tiene dos tipos de rendimientos, el instantáneo, que es el rendimiento del captador solar en un momento determinado, función de la climatología y las condiciones de funcionamiento que concurren en ese momento y el rendimiento a largo plazo, en funcionamiento práctico sobre un amplio rango de condiciones durante todo el año, en caliente, con baja eficiencia y en frío, con alta eficiencia en otras ocasiones. Para determinar cómo funciona el captador solar en el rango de variación de las condiciones de funcionamiento, es necesario comprender el rendimiento instantáneo en las condiciones climatológicas y de funcionamiento.

El rendimiento del captador solar se determina a partir de la energía absorbida y la perdida, que se determinan de los ensayos realizados a los captadores solares, en los que se mide la eficiencia instantánea del captador solar en un intervalo apropiado de condiciones (Hottel y Woertz, 1942), (Hottel y Whillier, 1955), (Bliss, 1959) y (Duffie y Beckman, 2006). La ganancia de energía útil del captador solar en un momento dado es la diferencia entre la cantidad de energía solar absorbida y la perdida hacia los alrededores (Ec. 3.2.1).

$$
Q_{u}=F_{R} A_{c}\left[\dot{I}(\tau \alpha)-U_{L}\left(T_{e}-T_{a}\right)\right]
$$

Donde,

$\mathrm{Q}_{u}$ : Energía útil que recoge el captador solar.

$F_{R}$ : Factor de eficiencia de extracción de calor del captador solar.

$A_{c}$ : Área del captador solar.

i: Irradiancia solar que incide sobre el captador solar.

$\tau$ : Transmitancia solar de la cubierta transparente del captador solar. 
$\alpha$ : Absortancia del captador solar.

$\mathrm{U}_{\mathrm{L}}$ : Coeficiente global de pérdidas de energía del captador solar.

$T_{e}$ : Temperatura de entrada al captador solar.

$\mathrm{T}_{\mathrm{a}}$ : Temperatura ambiente.

La irradiación solar incidente sobre un captador solar en un intervalo de tiempo, incluye tres componentes: la directa, la difusa y el albedo, que son función de la inclinación del captador solar y el tipo de superficie que lo rodea. Cuando el captador solar se ensaya, la irradiancia solar se mide con un piranómetro instalado en el mismo plano que el captador solar, como se describe en el (Apartado 3.1).

La velocidad con que la energía solar es absorbida por la placa del captador en un intervalo de tiempo es el producto de la irradiancia solar incidente İ, la fracción transmitida por la cubierta del captador $\tau$, y la fracción absorbida por la placa del captador $\alpha$. Tanto $\tau$ y $\alpha$ son función de los materiales y el ángulo de la irradiación incidente, o sea, el ángulo entre la normal al captador solar y la dirección de la irradiación solar. Las componentes de la irradiación solar directa, difusa y albedo que inciden sobre el captador solar lo hacen con distintos ángulos. Con lo que, la transmitancia y absortancia se calcula como una media ponderada de estas componentes.

Las pérdidas energéticas que se producen en el captador solar son por varios mecanismos. El calor se pierde desde la placa del captador solar por radiación y convección y desde la cubierta al aire exterior también por radiación y convección, pero en diferentes proporciones. Las pérdidas de calor a través de la parte posterior del aislamiento y los laterales del captador solar se producen por conducción. Los captadores solares, por lo tanto, deben estar diseñados de manera que todas estas pérdidas sean tan pequeñas como sea posible.

El producto del coeficiente global de pérdidas de energía del captador $U_{L}$ y la diferencia de temperaturas del fluido portador en la entrada al captador solar y el ambiente $\left(T_{e}-T_{a}\right)$ representa las pérdidas de energía de la placa del captador solar. La placa del captador solar estará a una temperatura superior que la temperatura de entrada del fluido portador cuando la energía útil está siendo captada. Esto es necesario para que el calor se transfiera desde la placa al fluido. Como resultado, las pérdidas de energía reales de los captadores solares son más altas que el producto $U_{L}\left(T_{e}-T_{a}\right)$. La diferencia se explica por el factor de eficiencia de extracción térmica $F_{R}$.

El coeficiente global de pérdidas de energía del captador solar $U_{L}$ es la suma de los coeficientes de pérdidas correspondientes a la parte superior, inferior y laterales del captador solar. Para un captador solar bien diseñado están entre $0,5-0,75 \mathrm{~W} /\left({ }^{\circ} \mathrm{C} \mathrm{m}^{2}\right)$.

El coeficiente de pérdidas máximo es una función de la temperatura de la placa absorbedora, el número de cubiertas transparentes, el material de las cubiertas, la emitancia térmica infrarroja del absorbedor, la temperatura ambiente y la velocidad del viento.

El análisis de la ganancia de la energía útil en los sistemas solares térmicos es conveniente realizarlo respecto a la temperatura de entrada. Sin embargo, las pérdidas de energía que se producen en el captador solar ocurren respecto de la temperatura media de la placa, la cual siempre es mayor que la temperatura de entrada del fluido portador, cuando se está captando energía útil. 
El efecto del factor de eficiencia de extracción térmica del captador solar $F_{R}$ se calcula para reducir la ganancia de energía a partir de la que sería útil, si fuera la temperatura de entrada al captador solar, la que realmente es, como un fluido el cual aumenta la temperatura al atravesar el captador solar.

$F_{R}$ es casi independiente de la intensidad de la irradiancia solar y la temperatura ambiente, pero es función del caudal del fluido portador y el diseño de la placa absorbedora, espesor, material, distancia entre los tubos,...

Los productos $F_{R}(\tau \alpha)_{n}$ y $F_{R} U_{L}$ se determinan mediante los ensayos del captador solar.

\section{2) Ensayo del captador solar de placa plana}

El procedimiento de ensayo de los captadores solares necesita de un banco de pruebas bajo condiciones estacionarias, es decir, la irradiancia solar, la velocidad del viento, la temperatura ambiente y la temperatura de entrada del fluido al captador solar tienen que ser esencialmente constantes para un intervalo de tiempo, tal que la temperatura de salida del fluido y la ganancia de temperatura útil no cambien apreciablemente con el tiempo.

Las condiciones en el ensayo deben de ser representativas de las condiciones en las que se utiliza el captador solar. Las mediciones que se realizan son de la irradiancia solar incidente, el caudal y la temperatura del fluido portador en el captador solar, y la temperatura del ambiente.

La ganancia de energía útil está dada por la ecuación (Ec. 3.2.2).

$$
\mathrm{Q}_{\mathrm{u}}=\mathrm{A}_{\mathrm{c}} \mathrm{C} \mathrm{c}_{\mathrm{e}}\left(\mathrm{T}_{\mathrm{s}}-\mathrm{T}_{\mathrm{e}}\right)
$$

Donde,

C: Caudal del fluido portador.

$\mathrm{C}_{\mathrm{e}}$ : Calor específico del fluido portador.

$\mathrm{T}_{\mathrm{s}}$ : Temperatura de salida del captador solar.

Los resultados de los ensayos del captador solar están normalmente dados en términos de eficiencia del captador solar $\eta$ definida como la ecuación (Ec. 3.2.3).

$$
\eta=\frac{Q_{u}}{\dot{I} A_{c}}
$$

Donde,

i: Irradiancia solar medida sobre el plano del captador solar por unidad de área.

Los ensayos de los captadores solares se realizan al aire libre en días claros cerca del mediodía solar, o en interiores utilizando un simulador solar. En cualquier caso la componente difusa de la irradiación solar es pequeña y la irradiación que incide sobre la superficie del captador solar es casi en incidencia normal. Como resultado el producto de transmitancia-absortancia resultante de los ensayos del captador solar corresponde a la irradiación solar directa en incidencia normal. Esta incidencia normal del producto transmitancia-absortancia se escribe como $(\tau \alpha)_{n}$. 
Los resultados de los ensayos de las pruebas del captador solar son presentados en un diagrama de eficiencia instantánea vs. $\left(T_{e}-T_{a}\right) / i$. La base teórica para presentar los ensayos del captador solar resultantes de esta manera pueden ser divididos a ambos lados de la ecuación (Ec. 3.2.1) por i $A_{c}$. La eficiencia instantánea del captador solar entonces se puede expresar como la ecuación (Ec. 3.2.4).

$$
\eta=\frac{Q_{u}}{\dot{I} A_{c}}=F_{R}(\tau \alpha)_{n}-F_{R} U_{L}\left(\frac{T_{e}-T_{a}}{\dot{I}}\right)
$$

Si $U_{L}$ se asume que es constante, la gráfica de la eficiencia del captador solar vs. $\left(T_{e}-T_{a}\right) / i$ resulta una línea recta con una intersección con el eje vertical en $F_{R}(\tau \alpha)_{n}$ y una pendiente igual a $-F_{R} U_{L}$. Esto es lo más conveniente, ya que los valores $F_{R}(\tau \alpha)_{n}$ y $F_{R} U_{L}$ se necesitan en el método f-chart para estimar el rendimiento a largo plazo del sistema solar térmico.

Los ensayos de los captadores solares se suelen presentar de esta manera. Generalmente, los datos del ensayo tienen una dispersión sobre la recta. La dispersión está causada por variaciones de $\mathrm{U}_{\mathrm{L}}$ con la velocidad del viento y por la temperatura, así como por los errores en las mediciones. Para los tipos de captador solar normalmente empleados en los sistemas solares térmicos y para los fines del método de diseño f-chart, los resultados del ensayo pueden ser adecuadamente presentados por una sola línea recta, lo que implica que $U_{\llcorner}$puede ser considerado relativamente constante.

Las características del captador solar que afectan a la pendiente y la intersección de la gráfica de la eficacia vs. $\left(T_{e}-T_{a}\right) / i$ son el número de cubiertas y el material de la superficie de la placa del captador solar, placa negra o superficie selectiva. Las eficiencias relativas varían, dependiendo de la gama de temperaturas de operación del captador solar. Pero no es posible decir que un captador solar funciona mejor que otro, hasta que el método f-chart se haya aplicado. Los datos de los ensayos se deben utilizar para caracterizar un captador solar particular siempre que sea posible.

La ecuación característica del captador solar de la planta piloto descrita en el (Apartado 3.1), resultado del ensayo realizado en el día 4-7-2011 recogido en la (Fig. A.2.2), resulta la ecuación característica: $\eta=$ $0,64-5,4\left(T_{e}-T_{a}\right) / i$ que se representa en la (Fig. 3.2.1) junto a los datos registrados ese día.

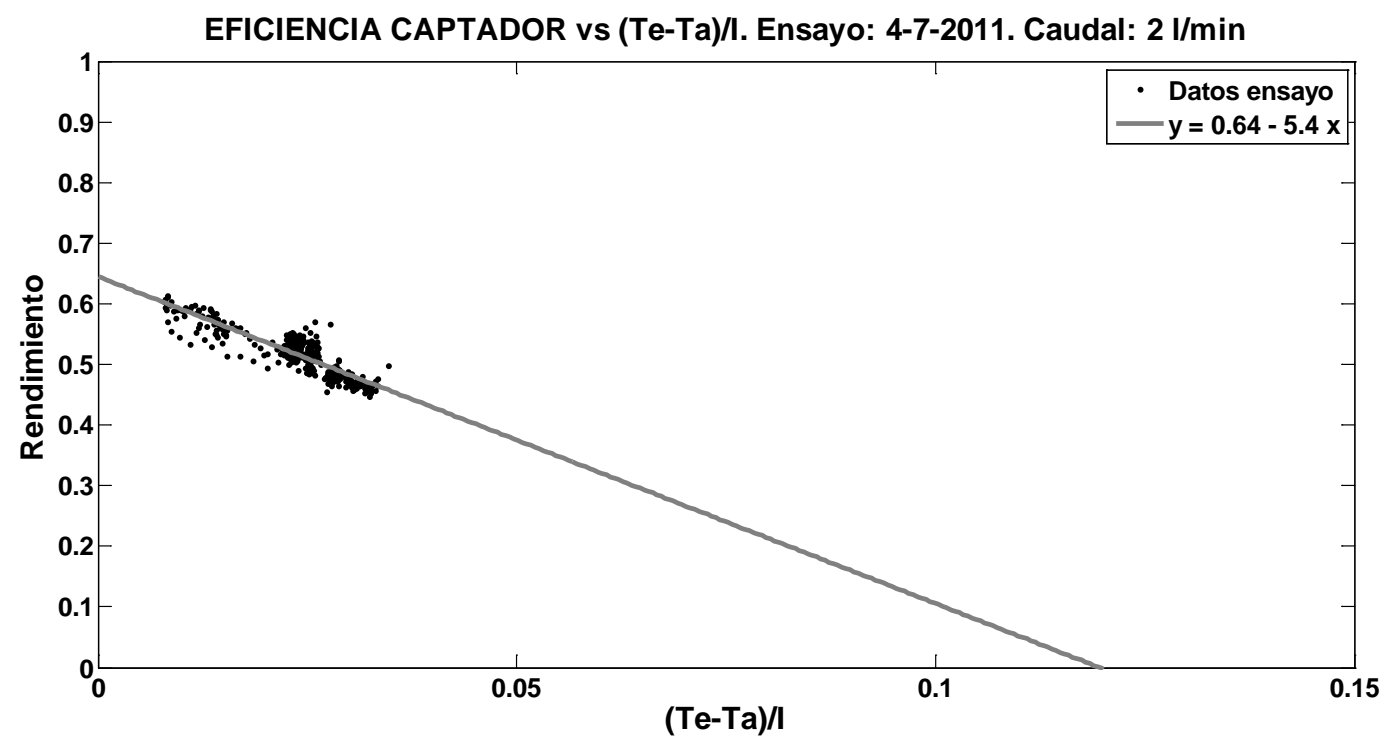

Fig. 3.2.1 Ecuación característica del captador solar de la planta piloto resultado de los datos del ensayo en el día 4-7-2011: $\eta=0,64-5,4\left(\frac{T_{e}-T_{a}}{i}\right)$ 
La eficiencia del captador solar a veces se representa vs. $\left(T_{m}-T_{a}\right) / i$ o $\left(T_{s}-T_{a}\right) / i$.

Donde,

$T_{m}$ : Temperatura media del captador solar.

Las gráficas de esta forma son muy similares a la gráfica de la eficiencia del captador vs. $\left(T_{e}-T_{a}\right) / i$.

Sin embargo, la pendiente y la intersección de las gráficas tienen una interpretación diferente. Si el caudal másico del fluido que circula a través del captador solar durante el ensayo es conocido, entonces los valores de $F_{R} U_{L}$ y $F_{R}(\tau \alpha)_{n}$ se pueden determinar a partir de la pendiente y la intersección de estos resultados del ensayo. Esto se realiza mediante un factor $\mathrm{K}$ tanto a la pendiente como a la intersección, ecuación (Ec. 3.2.5).

$$
\left.K=\left\{\begin{array}{cc}
\frac{C c_{e}}{C c_{e}-\frac{p e n d i e n t e}{2}} & \text { para } \eta \text { vs. }\left(\frac{T_{m}-T_{a}}{\dot{I}}\right) \\
\frac{C C_{e}}{C c_{e}-\text { pendiente }} & \text { para } \eta \text { vs. }\left(\frac{T_{s}-T_{a}}{\grave{I}}\right)
\end{array}\right\} \text { entonces } \begin{array}{c}
F_{R} U_{L}=-K \text { pendiente } \\
F_{R}(\tau \alpha)_{n}=K \text { intersección }
\end{array}\right\}
$$

\section{3) Factor de eficiencia captador-intercambiador de calor}

En los lugares donde hay heladas, un intercambiador de calor se utiliza en los sistemas solares térmicos con fluido líquido entre el captador solar y el depósito acumulador, con una solución de anticongelante y agua en el circuito del captador solar. Si bien este intercambiador de calor no es una parte del captador solar, se define para su utilización en el método $f$-chart un factor de eficiencia adicional $F_{R}^{\prime}$ que puede ser añadido en la ecuación (Ec. 3.2.1) para calcular el rendimiento combinado del captador solar e intercambiador de calor.

La relación $\mathrm{F}_{\mathrm{R}}^{\prime} / \mathrm{F}_{\mathrm{R}}$ denominada factor de corrección captador-intercambiador, es un índice que oscila entre 0-1, y que indica la penalización sobre la captación de energía útil impuesto por el uso de un intercambiador de calor con un circuito de doble flujo. El valor de $\mathrm{F}_{\mathrm{R}}^{\prime} / \mathrm{F}_{\mathrm{R}}$ se determina con la ecuación (Ec. 3.2.6) como una función de parámetros del captador solar, los caudales del intercambiador de calor y la efectividad del intercambiador (Winter, 1975).

$$
\frac{\mathrm{F}_{\mathrm{R}}^{\prime}}{\mathrm{F}_{\mathrm{R}}}=\left[1+\left(\frac{\mathrm{F}_{\mathrm{R}} \mathrm{U}_{\mathrm{L}}}{\mathrm{C} \mathrm{C}_{\mathrm{e}}}\right)\left(\frac{\mathrm{A} \mathrm{C} \mathrm{C}_{\mathrm{e}}}{\varepsilon_{\mathrm{c}} \mathrm{C}_{\min }}-1\right)\right]^{-1}
$$

Donde,

$\varepsilon_{\mathrm{c}}$ : Eficiencia del intercambiador de calor.

$\mathrm{C}_{\min }$ : El menor de las dos capacidades térmicas del fluido (caudal másico por el calor específico) en el intercambiador de calor.

(Duffie y Beckman, 2006) ofrece gráficas de $F_{R}^{\prime} / F_{R}$ en función de $\left(F_{R} U_{L}\right) /\left(C c_{e}\right)$ y $\left(\varepsilon_{c} C_{\min }\right) /\left(A C C_{e}\right)$. 


\section{4) Efectividad del intercambiador de calor}

El rendimiento del sistema solar térmico se ve afectado por el rendimiento de los intercambiadores de calor utilizados, el cual se expresa en términos de la eficacia del intercambiador $\varepsilon$, y la capacidad térmica mínima $\mathrm{C}_{\min }$, es decir, la menor de las dos capacidades térmicas del intercambiador, del caudal másico por el calor especifico, en el intercambiador de calor. Cuando el caudal másico es igual en los dos lados del intercambiador $\mathrm{C}_{\min }$ es el del lado del captador solar ya que la solución con anticongelante tiene un calor específico menor que el agua pura. La eficacia del intercambiador de calor se determina desde los datos de rendimiento suministrados normalmente por el fabricante.

La eficacia del intercambiador de calor $\varepsilon$, es la relación entre la tasa de transferencia de calor real y la tasa de transferencia de calor máximo posible de la ecuación (Ec. 3.2.7) y tiene un valor entre 0-1.

$$
\varepsilon=\frac{\text { Tasa de transferencia de calor actual }}{\text { Tasa de transferencia de calor máxima }}
$$

En un intercambiador de calor particulae, tanto la tasa de transferencia de calor máxima y la real varían con la temperatura de los fluidos en el intercambiador de calor.

La ventaja del concepto es que la relación de las tasas de transferencia de calor real y máximo es casi constante, independientemente de las variaciones de temperatura, si los caudales del fluido en el intercambiador de calor son constantes.

La tasa de transferencia de calor máxima es el producto de la capacidad térmica mínima $C_{\min }$ y la diferencia entre las temperaturas de los fluidos que entran caliente $T_{c} y$ frío $T_{f}$ en la ecuación (Ec. 3.2.8).

$$
\text { Tasa de transferencia de calor máxima }=\mathrm{C}_{\min }\left(\mathrm{T}_{\mathrm{c}}-\mathrm{T}_{\mathrm{f}}\right)
$$

La tasa de transferencia de calor real es función del tamaño y diseño del intercambiador de calor, la capacidad térmica y la temperatura de los fluidos. Los cambios de temperatura de los fluidos en un intercambiador de calor específico en condiciones conocidas están normalmente disponibles a partir de tablas o gráficos suministrados por el fabricante.

\section{5) Efecto de la orientación sobre la transmitancia y la absortancia}

La transmitancia de la cubierta transparente $\tau$ y la absortancia de la placa $\alpha$ del captador solar del sistema solar térmico, dependen del ángulo en el que la irradiación solar incide sobre la superficie del captador solar.

En el ensayo del captador solar es el producto de $F_{R}, \tau$ y $\alpha$ el que se determina, no pueden conocerse sus valores por separado. Esto, sin embargo, no es un problema ya que es el valor de su producto el que se necesita para estimar el rendimiento del sistema solar térmico en el método f-chart.

Un problema que surge en los ensayos del captador solar, se debe a que la irradiación solar incidente suele ser en direcciones casi perpendiculares sobre el captador solar. Así el producto de $F_{R}, \tau$ y $\alpha$ determinado desde el ensayo del captador solar corresponde a los valores de la transmitancia y absortancia para una irradiación solar incidente normal $F_{R}(\tau \alpha)_{n}$. Dependiendo de la orientación del 
captador solar y la época del año, los valores medios mensuales de la transmitancia y absortancia pueden ser significativamente más bajos que los valores para la irradiación incidente normal.

Un método simplificado para determinar el producto transmitancia-absortancia media mensual $(\overline{\tau \alpha})$, el cual es útil en las situaciones más comunes, es como sigue. Cuando un captador solar tiene una inclinación igual a la latitud $\pm 15^{\circ}$ y cuando el captador solar está orientado hacia el sur $\pm 15^{\circ}$, la relación $(\overline{\tau \alpha}) /(\tau \alpha)_{\mathrm{n}}$ es aproximadamente 0,96 para un captador solar con una cubierta y 0,94 para un captador solar con dos cubiertas. Para todos los meses durante las épocas de calentamiento solar.

Otro método detallado para determinar la relación $(\overline{\tau \alpha}) /(\tau \alpha)_{\mathrm{n}}$ para captadores solares inclinados a más de $15^{\circ}$ respecto de la latitud, debe ser usado. La irradiación solar incidente sobre el captador solar tiene tres componentes: directa, difusa y reflejada. Como consecuencia la relación $(\overline{\tau \alpha}) /(\tau \alpha)_{n}$ puede ser calculada como una función de una media ponderada para cada componente de la irradiación solar incidente (Duffie y Beckman, 2006). Además en varias gráficas para distintos captadores solares se puede observar la relación $\tau / \tau_{n}$ vs. ángulo de incidencia y $\alpha / \alpha_{n}$ vs. ángulo de incidencia. Con esta información, solo es necesario especificar los ángulos de incidencia medios mensuales para la irradiación solar directa, difusa y reflejada para determinar $(\overline{\tau \alpha}) /(\tau \alpha)_{n}$.

El valor de $F_{\mathrm{R}}(\overline{\tau \alpha})$, es necesario para estimar el rendimiento a largo plazo de los sistemas solares térmicos utilizando el método $f$-chart, el cual es determinado por la multiplicación del valor $F_{R}(\tau \alpha)_{n}$ obtenido en el ensayo del captador solar y el valor de $(\overline{\tau \alpha}) /(\tau \alpha)_{n}$.

\subsubsection{El método f-chart para sistemas solares térmicos con fluido portador líquido}

El uso de simulaciones con ordenador ha ayudado en el diseño de los sistemas solares térmicos, pero no es una solución satisfactoria para los arquitectos e ingenieros interesados en el diseño de instalaciones en edificaciones y que no disponen de sistemas de simulación.

Las simulaciones seguirán siendo una importante herramienta de diseño para los grandes sistemas y también para instalaciones singulares, pero el uso generalizado de los sistemas solares térmicos requiere un procedimiento de diseño simplificado, para las instalaciones típicas de los sistemas, donde el coste de una simulación detallada no puede ser justificado. Por esas razones el método f-chart fue desarrollado y se describe aquí.

El enfoque que se propone en el método $f$-chart es identificar las variables adimensionales importantes de los sistemas solares térmicos y utilizar detalladas simulaciones informáticas para establecer la correlación entre estas variables y el rendimiento a largo plazo de los sistemas solares térmicos.

Las correlaciones desarrolladas para los sistemas solares térmicos con fluido portador aire o líquido destinadas a calefacción y agua caliente de los edificios están representadas en forma de ecuación y en forma de gráfica a las cuales se las denomina curvas-f.

El método f-chart de estimación del rendimiento de los sistemas solares térmicos fue comparado con los pocos métodos de cálculo del rendimiento a largo plazo de los sistemas disponibles en su época, y con detalladas simulaciones informáticas como describe (Klein, 1976). 
El resultado es un método simple que requiere solo de datos climatológicos medios mensuales, que puede ser utilizado para estimar el rendimiento a largo plazo de los sistemas solares térmicos, como una función de los parámetros de diseño del sistema más importantes. El método f-chart proporciona un procedimiento con el que los arquitectos e ingenieros pueden determinar fácilmente el rendimiento del sistema solar térmico, y así optimizar el diseño de los sistemas solares térmicos en función de los costes.

\section{1) Identificación de las variables adimensionales del sistema solar térmico}

Un balance energético total en un sistema solar térmico durante un periodo de un mes, puede escribirse como la ecuación (Ec. 3.2.9).

$$
\Delta \mathrm{U}=\mathrm{Q}_{\mathrm{T}}-\mathrm{L}+\mathrm{E}
$$

Donde,

$\Delta \mathrm{U}$ : Intercambio de energía en el depósito acumulador.

$Q_{T}$ : Energía solar útil entregada durante un mes.

L: Energía demandada para calefacción y agua caliente durante un mes.

E: Energía auxiliar requerida durante un mes.

El método f-chart considera que para los volúmenes de almacenamiento de uso común en los sistemas solares térmicos, $\Delta U$ para un mes es pequeño con respecto a $Q_{T}, L$ y $E$, pudiéndose ser considerada igual a cero. Entonces la ecuación (Ec. 3.2.9) puede ser reordenada como la ecuación (Ec. 3.2.10).

$$
f=\frac{L-E}{L}=\frac{Q_{T}}{L}
$$

Donde,

f: Fracción total mensual de la demanda térmica suministrada por la energía solar.

Esta ecuación (Ec. 3.2.10) no puede ser usada para calcular $f$ directamente ya que $Q_{T}$ es una función complicada dependiente de la irradiación solar incidente, la temperatura ambiente y la demanda térmica. Sin embargo, considerando los parámetros de los que $Q_{T}$ depende, que han sido discutidos en (Duffie y Beckman, 2006), esta ecuación sugiere que $f$ puede ser empíricamente relacionada a los dos grupos adimensionales siguientes con las ecuaciones (Ec. 3.2.11) y (Ec. 3.2.12).

$$
\begin{gathered}
X=\frac{A_{c} F_{R}^{\prime} U_{L}\left(T_{r e f}-\bar{T}_{a}\right) \Delta t}{L} \\
Y=\frac{A_{c} F_{R}^{\prime}(\bar{\tau} \alpha) \bar{H}_{\beta \gamma} N}{L}
\end{gathered}
$$

Estos grupos adimensionales tienen un significado físico. $\mathrm{X}$ está relacionado con la proporción de las pérdidas energéticas del captador solar respecto a la demanda térmica mensual e, $Y$ está relacionado con la proporción de la energía solar absorbida por la superficie del captador solar respecto a la demanda térmica mensual. Las ecuaciones (Ec. 3.2.11) y (Ec. 3.2.12) para X e Y pueden ser rescritas modificando ligeramente su forma por la conveniencia para los cálculos, como las ecuaciones (Ec. 3.2.13) y (Ec. 3.2.14). 


$$
\begin{gathered}
X=F_{R} U_{L} \frac{F_{R}^{\prime}}{F_{R}}\left(T_{r e f}-\bar{T}_{a}\right) \Delta t \frac{A_{c}}{L} \\
Y=F_{R}(\tau \alpha)_{n} \frac{F_{R}^{\prime}}{F_{R}} \frac{(\overline{\tau \alpha})}{(\tau \alpha)_{n}} \bar{H}_{\beta \gamma} N \frac{A_{c}}{L}
\end{gathered}
$$

Hay que tener en cuenta que $F_{R} U_{L}$ y $F_{R}(\tau \alpha)_{n}$ se obtienen de los resultados del ensayo realizado al captador solar por el método indicado en el (Apartado 3.2.1), $\mathrm{F}_{\mathrm{R}}^{\prime} / \mathrm{F}_{\mathrm{R}}$ por el método del (Apartado 3.2.1), $(\overline{\tau \alpha}) /(\tau \alpha)_{\mathrm{n}}$ por uno de los dos métodos del (Apartado 3.2.1), la temperatura ambiente diaria diurna media mensual $\overline{\mathrm{T}}_{\mathrm{a}}$ de los datos climatológicos para cada mes del año y el lugar concreto, la irradiación solar diaria media mensual sobre el plano inclinado y orientado $\overline{\mathrm{H}}_{\beta \gamma}$ se encuentra a partir de la irradiación solar diaria media mensual sobre la horizontal $\overline{\mathrm{H}}$ y la relación entre la irradiación en el plano inclinado y la horizontal es $\overline{\mathrm{R}}$ por el método dado en (Duffie y Beckman, 2006), la demanda energética mensual L está determinada por el método de grados-día, el valor de $A_{c}$ es el de la superficie de captador solar seleccionado. Así todos los términos en estas dos ecuaciones están fácilmente determinados de la información disponible.

\section{2) El sistema solar térmico con fluido portador líquido para calefacción y agua caliente}

La fracción de la demanda total mensual f suministrada por el sistema térmico solar con fluido portador líquido destinado a calefacción y agua caliente que se muestra (Fig. 3.2.2), se da como una función de las variables adimensionales $X$ e $Y$ definidas en las ecuaciones (Ec. 3.2.13) y (Ec. 3.2.14) y en las curvas-f (Fig. 3.2.3).

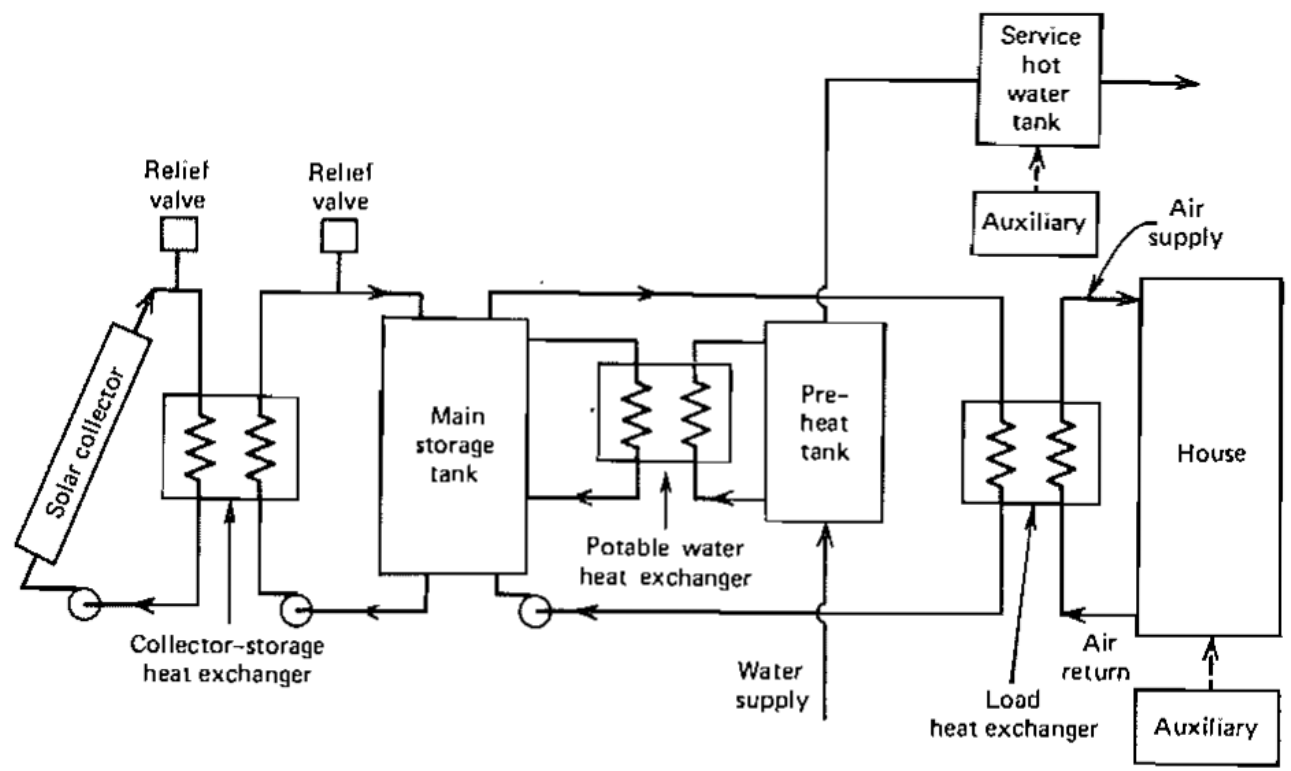

Fig. 3.2.2 Sistema solar térmico con fluido portador líquido y el depósito mezclado (Duffie y Beckman, 2006)

Esta correlación ha sido desarrollada desde los resultados que se obtuvieron de miles de simulaciones informáticas para varios lugares y para una amplia gama de variables de diseño de los sistemas solares térmicos. 


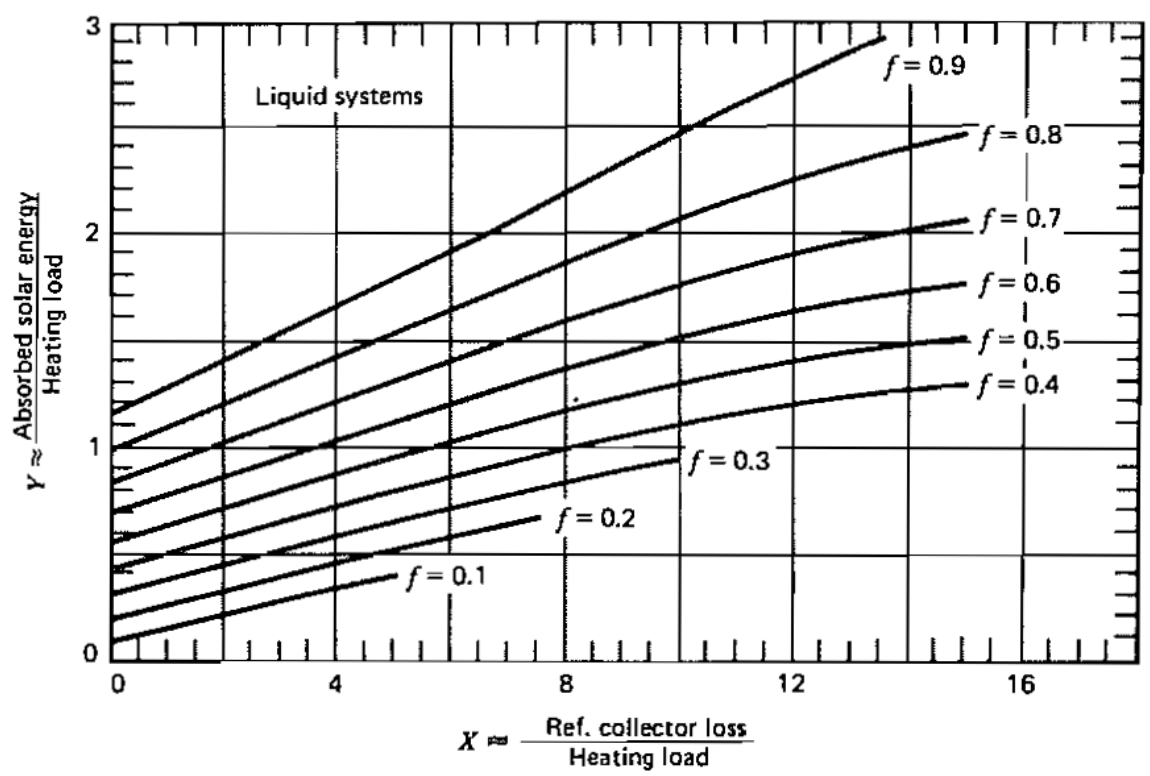

Fig. 3.2.3 Las curvas-f para sistemas solares térmicos con fluido portador líquido y el depósito mezclado (Duffie y Beckman, 2006)

Los resultados (Fig. 3.2.3) se refieren al método f-chart para sistemas solares térmicos con fluido portador líquido para calefacción y agua caliente. Para determinar f la fracción de la demanda térmica suministrada por la energía solar durante un mes, con los valores de $\mathrm{X}$ e $\mathrm{Y}$ calculados para un modelo de captador solar y de demanda térmica específica. El valor de f está determinado en la intersección de X e Y sobre la curva. Esto se hace para cada mes del año. La contribución de energía solar para el mes es el producto de f y la demanda térmica total $L$ para el mes. La fracción de la demanda térmica anual suministrada por la energía solar $F$, es entonces la suma de la contribución de la energía solar mensualmente dividida por la demanda anual. La relación entre $X, Y$ y $f$ que se da en la (Fig. 3.2.3) puede también ser expresada en forma de ecuación (Ec. 3.2.15).

$$
f=1,029 \mathrm{Y}-0,065 \mathrm{X}-0,245 \mathrm{Y}^{2}+0,0018 \mathrm{X}^{2}+0,0215 \mathrm{Y}^{3} \text { para }\left\{\begin{array}{c}
0 \leq \mathrm{X} \leq 18 \\
0 \leq \mathrm{Y} \leq 3
\end{array}\right.
$$

\section{3) Parámetros de diseño del sistema fijados en el método f-chart}

Hay tres parámetros de diseño del sistema solar térmico que quedan fijados cuando se genera el método f-chart, estos son:

- El caudal del fluido portador por unidad de superficie de captador solar instalado.

- La capacidad de almacenamiento del depósito por unidad de superficie de captador solar.

- El tamaño del intercambiador de calor de la carga.

Los efectos de los cambios en estos parámetros de diseño se consideran a continuación. 


\section{Caudal del fluido portador líquido en el captador solar}

El caudal del fluido portador óptimo en el captador solar, es el caudal en el que la energía captada es máxima, que es infinitamente grande. Sin embargo, la dependencia del rendimiento del sistema respecto al caudal del captador solar es asintótica, con solo un pequeño aumento en el factor de eficiencia de la evacuación de calor en el captador $F_{R}$ y por lo tanto solo un pequeño aumento en la captación de energía. Es posible si la capacidad térmica (caudal másico por calor especifico) del fluido en el captador solar se incrementa más allá de $50 \mathrm{~W} /\left({ }^{\circ} \mathrm{C} \mathrm{m}^{2}\right)$ de captador solar que corresponde a un caudal de flujo en solución anticongelante de $0,015 \mathrm{l} /\left(\mathrm{s} \mathrm{m}^{2}\right)$.

Los caudales bajos en el captador pueden reducir la captación de energía de manera significativa al reducir el valor de $F_{R} O$ de $F_{R}^{\prime}$. Además, si el caudal es bajo, el fluido puede alcanzar el punto de ebullición y la energía se pierde a través de la válvula de seguridad.

Los resultados de la simulación y correlaciones que se realizaron en el desarrollo del método f-chart se obtuvieron utilizando un caudal del fluido de solución anticongelante en el captador de $0,015 \mathrm{l} /\left(\mathrm{s} \mathrm{m}^{2}\right)=$ $0,9 \mathrm{l} /\left(\operatorname{min~}^{2}\right)$. Sin embargo, ya que un cambio en el caudal del fluido portador, normalmente solo produce un efecto pequeño sobre el rendimiento del sistema, que se refleja en el valor de $F_{R}$ y por lo tanto en los grupos adimensionales $\mathrm{X}$ e $\mathrm{Y}$. Las correlaciones presentadas para sistemas líquidos son aplicables para prácticamente todos los caudales del fluido portador líquido.

\section{Capacidad de acumulación del depósito}

Las simulaciones realizadas para crear el método $f$-chart se realizaron para evaluar el efecto de la capacidad de almacenamiento en el rendimiento del sistema solar térmico a largo plazo. Se encontró que si la capacidad de almacenamiento es superior a $50 \mathrm{l} / \mathrm{m}^{2}$ solo pequeñas mejoras en los resultados del rendimiento anual se obtienen con una capacidad de almacenamiento adicional. Cuando se consideran los costes parece que hay un óptimo resultado en el intervalo de $50-100 \mathrm{l} / \mathrm{m}^{2}$ de captador solar.

El método f-chart se generó para una capacidad de almacenamiento de $75 \mathrm{l} / \mathrm{m}^{2}$ de captador solar. El método f-chart puede ser usado para estimar el rendimiento de los sistemas con otras capacidades de almacenamiento mediante la modificación del grupo adimensional $X$ con el factor de corrección dado en forma de ecuación (Ec. 3.2.16) y de gráfica en (Duffie y Beckman, 2006).

$$
\frac{\mathrm{X}_{\mathrm{c}}}{\mathrm{X}}=\left(\frac{\mathrm{M}}{75}\right)^{-0,25} \text { para } 37,5<\mathrm{M}<300
$$

Donde,

M: Capacidad de almacenamiento del depósito respecto a la superficie de captador solar $\left(\mathrm{l} / \mathrm{m}^{2}\right)$.

\section{Tamaño del intercambiador de calor de la carga}

El tamaño del intercambiador de calor de la carga puede afectar significativamente al rendimiento del sistema solar térmico. Cuando el intercambiador de calor utilizado para calentar el aire del edificio se reduce su tamaño, la temperatura de almacenamiento debe ser aumentada para suministrar la misma 
cantidad de calor. Esto da como resultado mayores temperaturas en la entrada del captador solar. El tamaño necesario del intercambiador de calor para un edificio concreto es proporcionado por el parámetro adimensional $\left(\varepsilon_{\llcorner} C_{\min } / U A\right)$. Donde $\varepsilon_{\llcorner}$es la efectividad del intercambiador de calor agua-aire de la carga, $C_{\min }$ es la capacidad térmica mínima (caudal másico por calor específico), que para este caso suele ser el del lado del aire y UA es el producto área-coeficiente de pérdidas totales del edificio.

El valor óptimo de este parámetro es infinitamente grande. Sin embargo, el rendimiento del sistema es asintóticamente dependiente del valor de este parámetro. Para valores de $\left(\varepsilon_{\llcorner} C_{\min } / U A\right)>10$, el rendimiento del sistema será casi el mismo que para el valor infinitamente grande. La reducción del rendimiento del sistema debido a un cambio de carga de calor demasiado pequeña será apreciable para valores de $\left(\varepsilon_{\llcorner} C_{\min } / U A\right)<1$. Valores prácticos son $1<\left(\varepsilon_{\llcorner} C_{\min } / U A\right)<3$ cuando el coste del intercambiador se considera. El método f-chart utilizó en su desarrollo el valor de $\left(\varepsilon_{\mathrm{L}} \mathrm{C}_{\min } / \mathrm{UA}\right)=2$.

El rendimiento de los sistemas solares térmicos que tienen otros valores de $\left(\varepsilon_{\mathrm{L}} \mathrm{C}_{\min } / \mathrm{UA}\right)$ pueden ser calculados con el método f-chart pero modificando el grupo adimensional $\mathrm{Y}$, como indica la ecuación (Ec. 3.2.17) y la figura del factor de corrección para el intercambiador de carga en (Duffie y Beckman, 2006).

$$
\frac{Y_{c}}{Y}=0,39+0,65 e^{-\frac{0,139}{\left(\frac{\varepsilon_{L} C_{\min }}{U A}\right)}} \text { para } 0,5<\frac{\varepsilon_{\mathrm{L}} C_{\min }}{U A}<50
$$

\section{4) El sistema solar térmico para agua caliente}

Las curvas- $f$ se utilizan para el diseño de sistemas solares térmicos destinados a calefacción y agua caliente de los edificios destinados a viviendas, se supone que la carga térmica destinada a agua caliente es una pequeña parte, menos de un $20 \%$ que la carga térmica para calefacción.

El método para la estimación del rendimiento de los sistemas solares térmicos, cuando la carga térmica mayoritariamente o totalmente debida a agua caliente se describe a continuación.

La temperatura del agua de red $T_{\text {red }}$ y la temperatura mínima aceptable del agua caliente $T_{\text {ac }}$ afectan ambas al rendimiento de los sistemas solares térmicos para agua caliente. Como $T_{\text {red }}$ y $T_{a c}$ afectan al nivel de la temperatura media de funcionamiento, y por lo tanto a las pérdidas del captador solar, es razonable esperar que el parámetro adimensional $X$ cuyo significado físico relaciona las pérdidas energéticas del captador solar, puede ser redefinido a fin de incluir los efectos de $T_{\text {red }}$ y $T_{a c}$. Si los valores mensuales de $X$ son multiplicados por el factor de corrección de la ecuación (Ec. 3.2.18) en los sistemas solares térmicos para agua caliente (Duffie y Beckman, 2006).

$$
\frac{X_{c}}{X}=\frac{11,6+1,18 \bar{T}_{a c}+3,86 \bar{T}_{\text {red }}-2,32 \overline{\mathrm{T}}_{\mathrm{a}}}{100-\overline{\mathrm{T}}_{\mathrm{a}}}
$$

El método f-chart para sistemas solares térmicos con fluido portador líquido destinados a calefacción y agua caliente de la ecuación (Ec. 3.2.15) y (Fig. 3.2.3), puede ser utilizado para estimar los valores mensuales de $\mathrm{f}$ en los sistemas solares térmicos destinados al agua caliente.

Los sistemas solares térmicos para uso de agua caliente considerados aquí tienen una capacidad de almacenamiento de $75 \mathrm{l} / \mathrm{m}^{2}$. La distribución de agua caliente demanda asumida a lo largo del día se 
muestra en (Duffie y Beckman, 2006) por (Mutch, 1974). Estas son condiciones en las que el método fchart está basado.

La distribución de la carga térmica durante el día no tiene un efecto fuerte sobre el rendimiento del sistema solar térmico con esta capacidad de almacenamiento. Sin embargo, la distribución real de la carga térmica de agua caliente puede variar en gran medida de la distribución media utilizada en el método fchart. Si la mayor parte del uso diario se produce normalmente dentro de un corto intervalo de tiempo cada día, la fracción de carga suministrada por la energía solar puede ser más baja que la estimada con el método f-chart de la manera recomendada. En este caso, un incremento en la capacidad de almacenamiento incrementaría el rendimiento del sistema solar térmico más de lo que se sugiere por su modificación correspondiente.

También, la presente corrección asume que el agua calentada por encima de la temperatura mínima aceptable $T_{\text {ac }}$ no es más útil que calentar agua a una temperatura de $T_{\text {ac. }}$. A veces, la temperatura del agua almacenada será superior a $\mathrm{T}_{\mathrm{ac}}$. El método f-chart supone que la energía solar que calienta el agua por encima de $\mathrm{T}_{\mathrm{ac}}$ se desperdicia y esta energía no se considera parte de la carga de calentamiento del agua.

\subsubsection{Resultados en la aplicación del método f-chart}

El método f-chart se ha aplicado en distintas situaciones, variando el número de captadores solares de uno a cuatro, el volumen de acumulación del depósito en 150 I y 300 I, la temperatura mínima aceptable $\mathrm{T}_{\text {ac }}$ de $30^{\circ} \mathrm{C}$ a $90^{\circ} \mathrm{C}$ y su volumen diario de consumo de $50 \mathrm{l} / \mathrm{d}$ a $600 \mathrm{l} / \mathrm{d}$. Representándose gráficamente en la (Fig. 3.2.4) los diferentes resultados de la cobertura solar anual F.

Sobre las correlaciones del método f-chart, se comprueba que al doblar el número de captadores solares y el volumen del depósito, se consigue el doble de agua caliente solar a la misma temperatura con la misma cobertura solar. Por ejemplo, dos captadores solares con un depósito de 300 I para la misma temperatura mínima aceptable $\left(T_{a c}=50^{\circ} \mathrm{C}\right)$ y cobertura anual solar $(F=80 \%)$, consigue producir el doble de volumen de agua caliente solar $(100 \mathrm{l} / \mathrm{d})$, que un captador solar y un depósito de $150 \mathrm{I}$ que produce $(50 \mathrm{l} / \mathrm{d})$ de agua caliente solar. Lo mismo ocurre, con cuatro captadores solares y un depósito de $300 \mathrm{I}$ para la misma temperatura mínima aceptable $\left(\mathrm{T}_{\mathrm{ac}}=60^{\circ} \mathrm{C}\right)$ y cobertura anual solar $(\mathrm{F}=43 \%)$, consigue producir el doble de volumen de agua caliente solar ( $400 \mathrm{l} /$ día), respecto a dos captadores solares y un depósito de 150 I que produce (200 I/día) de agua caliente solar. 

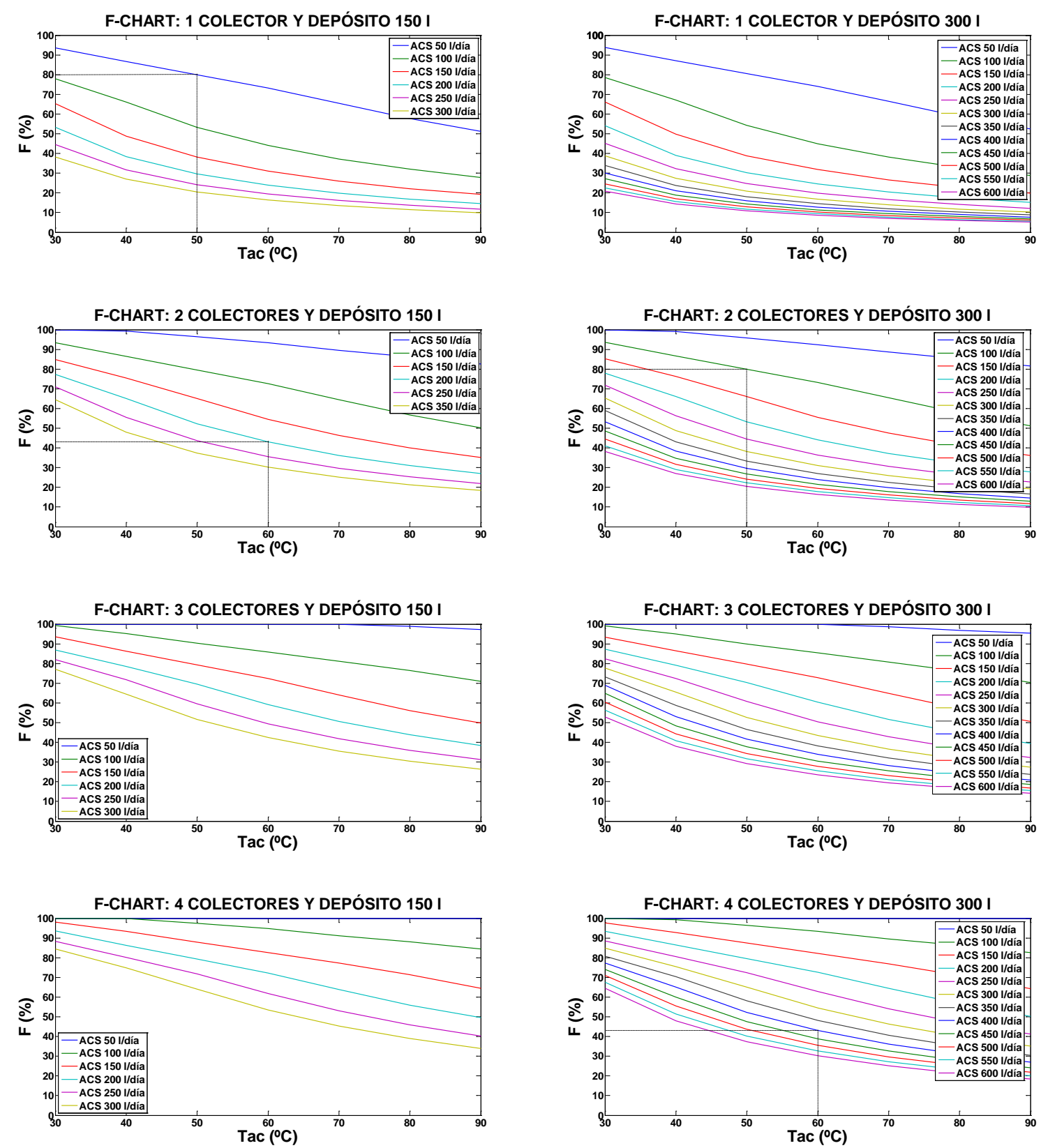

Fig. 3.2.4 Resultados de la aplicación del método f-chart en distintas condiciones

También se comprueba que al doblar el número de captadores, dejando fijo el volumen del depósito acumulador, se consigue el doble de volumen de agua caliente solar a la misma temperatura con un porcentaje ligeramente inferior de cobertura. Con lo que aumentar el volumen del depósito no afecta significativamente al porcentaje de cobertura solar anual. 


\subsection{Herramienta para la implementación de las redes neuronales artificiales}

Para la implementación de las redes neuronales artificiales en esta Tesis Doctoral se ha utilizado Neural Network Toolbox de Matlab 'nntool', pudiéndose realizar directamente desde el Command Window con la siguiente secuencia de funciones (Demuth et al., 2010).

1) Para la creación de la red neuronal se hace uso de la función 'newff' de la siguiente forma

>> net=newff(x,y,h);

Donde 'net' es la red feedforward backpropagation que resulta con la matriz de vectores de datos de entrada ' $x$ ', la matriz de vectores de datos de salida ' $y$ ', el número escogido de neuronas de la capa oculta ' $h$ '. De esta forma queda determinado el tamaño de la capa de salida por la matriz ' $y$ ', las funciones de transferencia de las neuronas en la capa oculta como tangente sigmoidal hiperbólica 'tansig' y las neuronas de la capa de salida como lineal 'purelin', la función de entrenamiento de la red backpropagation Levenberg-Marquardt 'trainlm', la función de aprendizaje del sesgo y el momento del peso con gradiente descendente 'learngdm', la función de rendimiento error medio cuadrado normalizado 'mse', las funciones de procesamiento de los elementos de la matriz de entrada como el procesado de datos para hacer las filas con datos desconocidos 'fixunknowns', 'remconstantrows', el procesado de matrices para hacer las filas con valores mínimos y máximos de [-1 1] 'mapminmax', las funciones de procesamiento de los elementos de la matriz de salida 'removeconstantrows', 'mapminmax'. Esta función 'newff' devuelve una red feedforward backpropagation de n-capas.

2) Para el entrenamiento de la red neuronal se hace uso de la función 'train' de la siguiente forma > net=train(net, $x, y)$;

Donde 'net' es la red feedforward backpropagation que previamente ha sido creada, con la matriz de vectores de datos de entrada ' $x$ ', la matriz de vectores de datos de salida ' $y$ ', pudiéndose fijar las condiciones iniciales. Esta función retorna la red entrenada, graba el proceso de entrenamiento (epoch y rendimiento), dando las salidas de la red, los errores y el estado final.

3) Para la simulación de la red neuronal se hace uso de la función 'sim' de la siguiente forma

$>\mathrm{ts}=\operatorname{sim}($ net, tx $)$;

Donde 'ts' es el resultado de la simulación con la matriz de vectores de datos de entrada ' $t x$ ' en la red 'net' feedforward backpropagation previamente entrenada, pudiéndose fijar las condiciones iniciales. Esta función retorna las salidas de la red.

Los resultados del entrenamiento y la simulación de las redes neuronales artificiales se pueden seguir a través del interface gráfico, donde se muestra la arquitectura de la red neuronal artificial escogida, los algoritmos de entrenamiento, rendimiento, como se han realizado los conjuntos de datos, la evolución de la progresión en el entrenamiento y la validación. 


\subsection{Predicción neural de las variables ambientales}

Varios modelos para la predicción de la irradiación solar global sobre la superficie horizontal y de la temperatura ambiente del aire se han desarrollado en esta Tesis Doctoral. La metodología escogida está basada en la técnica de las redes neuronales artificiales de la inteligencia computacional sobre una base teórica de las series de tiempo, presentada en el capítulo dedicado al Estado del Arte, y se aplicaron a la base de datos climatológicos de la red SIAR, los datos utilizados se han representado gráficamente (Anexo 1 Datos climatológicos). La investigación de la autocorrelación entre los valores diarios de la irradiación solar y la temperatura ambiente tiene un papel esencial en el desarrollo de los modelos que fueron calculados (Apartado 4.2.2).

La información de entrada al modelo escogido de los propuestos es por una parte el valor de la irradiación solar global de un día concreto y por otra el día del año, 1 para el 1 de enero y 365 para el 31 de diciembre. La variable de salida del modelo es el valor de la irradiación solar global para el día siguiente al utilizado en la entrada, resultando un valor de la predicción para el día de mañana.

En esta Tesis Doctoral se han desarrollado varios modelos empíricos de predicción de la irradiación solar global, de modo que la información de entrada sea mínima. En particular se presentan varios modelos fiables que pueden predecir la distribución de la irradiancia solar global y la temperatura ambiente a lo largo de un día, para su utilización en la simulación del funcionamiento de un sistema solar térmico en tramos de tiempo de un minuto, en función del valor registrado el día anterior de estas variables ambientales y el día del año referido.

Un enfoque simple y práctico para predecir la distribución de la irradiancia solar global mediante dos redes neuronales artificiales se introdujo por primera vez, como a continuación se describe.

Las entradas necesarias al modelo son los valores diarios de la irradiación solar global y el día del año. La primera red neuronal artificial del modelo tiene como salida el valor diario que resulta de la predicción para el día siguiente. Este valor resultante de la predicción para el día de mañana, con el día del año correspondiente es la entrada de la segunda red neuronal artificial entrenada para generar a su salida un perfil horario correspondiente a su valor global. Esta red neuronal artificial tiene 24 salidas en las que se asigna un valor de irradiancia solar medio a cada hora del día, su arquitectura se representa en la (Fig. 3.4.1).

Estos valores horarios de irradiancia solar global que proporciona el modelo propuesto a su salida, transformados en unidades energéticas de megajulios MJ son la entrada al siguiente bloque, que se plantea en esta Tesis Doctoral destinado a estimar su valor sobre el plano inclinado de la superficie de captación del sistema solar térmico. 


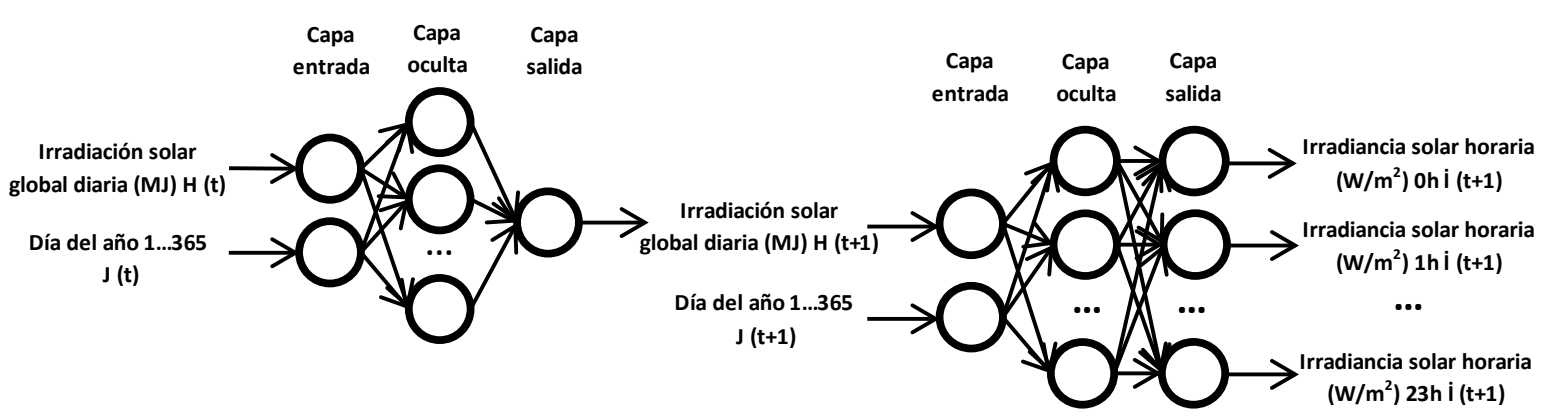

Fig. 3.4.1 Modelo de predicción de la irradiancia solar horaria sobre la horizontal para el día de mañana, a partir de la irradiación solar global diaria del día de hoy y el día del año sobre el que se realiza la predicción

\subsubsection{La predicción de la irradiación solar global diaria del día de mañana mediante redes neuronales artificiales}

La predicción de la cantidad de irradiación solar global que recibirá la superficie horizontal el día de mañana, se realizó utilizando redes neuronales artificiales, procurando el mínimo número de entradas para facilitar su uso.

Se probaron los modelos más sencillos posibles, para que su utilización sea práctica en cualquier lugar, donde se disponga de una serie de datos de irradiación solar global diaria, ya sea medida en el propio lugar o estimada de otras variables ambientales.

En las predicciones realizadas se utilizaron los datos de irradiación solar global del día anterior, de dos días y de tres días de retardo, el entrenamiento de la red neuronal artificial se realizó con datos de los años 2004-2010, comparando los resultados de los modelos en la simulación realizada con la base de datos de la red SIAR en Mansilla Mayor (León) del año 2011 en el capítulo cuatro para su validación.

1) La primera combinación realizada de entradas a la red neuronal artificial fue de la irradiación solar global diaria, del día anterior sobre el que se hace la predicción.

2) La segunda combinación realizada de entradas a la red neuronal artificial fue de la irradiación solar global diaria, de dos días anteriores sobre el que se hace la predicción.

3) La tercera combinación realizada de entradas a la red neuronal artificial fue de la irradiación solar global diaria, de tres días anteriores sobre el que se hace la predicción.

4) La cuarta combinación realizada de entradas a la red neuronal artificial fue de la irradiación solar global diaria del día anterior sobre el que se hace la predicción y el día del año.

5) La quinta combinación realizada de entradas a la red neuronal artificial fue de la irradiación solar global diaria de dos días anteriores sobre el que se hace la predicción y el día del año.

6) La sexta combinación realizada de entradas a la red neuronal artificial fue de la irradiación solar global diaria de tres días anteriores sobre el que se hace la predicción y el día del año.

7) La séptima combinación realizada de entradas a la red neuronal artificial fue de la irradiación solar global diaria del día anterior sobre el que se hace la predicción y el índice de claridad.

8) La octava combinación realizada de entradas a la red neuronal artificial fue de la irradiación solar global diaria, el índice de claridad y el día del año, del día anterior sobre el que se hace la predicción. 


\section{1) Predicción de la irradiación solar global diaria con un día de retardo}

La predicción de la irradiación solar global diaria del día de mañana $\mathrm{H}(\mathrm{t}+1)$ se realiza con varias redes neuronales artificiales, se utiliza una entrada con el valor de la irradiación solar global diaria del día anterior $\mathrm{H}(\mathrm{t})$, sobre el que se realiza la predicción $\mathrm{H}(\mathrm{t}+1)$, (Fig. 3.4.2) el modelo de arquitectura utilizado.

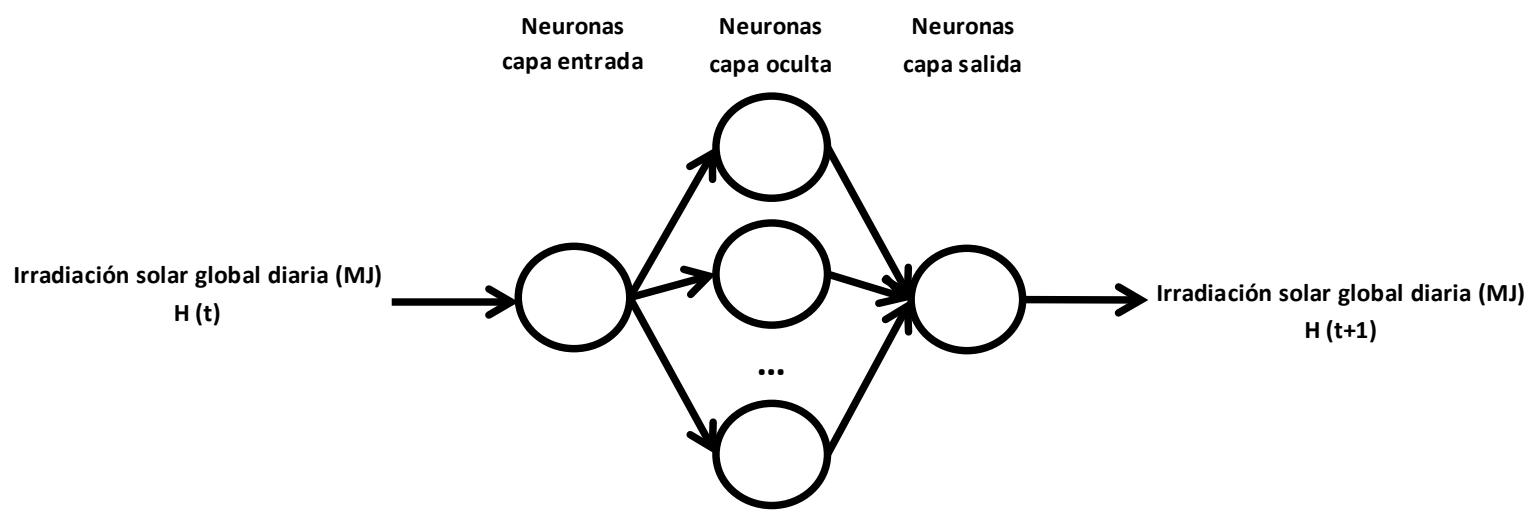

Fig. 3.4.2 Red neuronal artificial utilizada para la predicción de la irradiación solar global diaria del día de mañana respecto al valor del día anterior

\section{2) Predicción de la irradiación solar global diaria con dos días de retardo}

La predicción de la irradiación solar global diaria del día de mañana $\mathrm{H}(\mathrm{t}+1)$ se realiza con varias redes neuronales artificiales, se utilizan dos entradas con el valor de la irradiación solar global diaria de los días anteriores $\mathrm{H}(\mathrm{t}-1)$ y $\mathrm{H}(\mathrm{t})$, sobre el que se realiza la predicción $\mathrm{H}(\mathrm{t}+1)$, (Fig. 3.4.3) el modelo de arquitectura utilizado.

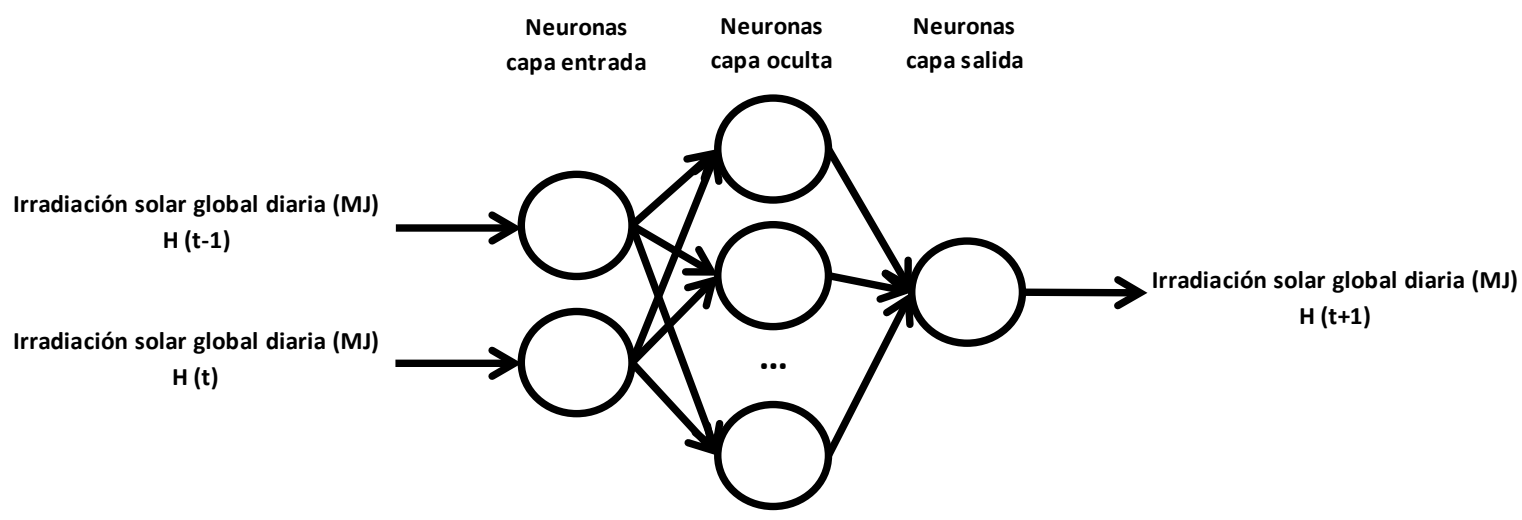

Fig. 3.4.3 Red neuronal artificial utilizada para la predicción de la irradiación solar global diaria del día de mañana respecto al valor de los dos días anteriores 


\section{3) Predicción de la irradiación solar global diaria con tres días de retardo}

La predicción de la irradiación solar global diaria del día de mañana $H(t+1)$ se realiza con varias redes neuronales artificiales, se utilizan tres entradas con el valor de la irradiación solar global diaria de los días anteriores $\mathrm{H}(\mathrm{t}-2), \mathrm{H}(\mathrm{t}-1)$ y $\mathrm{H}(\mathrm{t})$, sobre el que se realiza la predicción $\mathrm{H}(\mathrm{t}+1)$, (Fig. 3.4.4) el modelo de arquitectura utilizado.

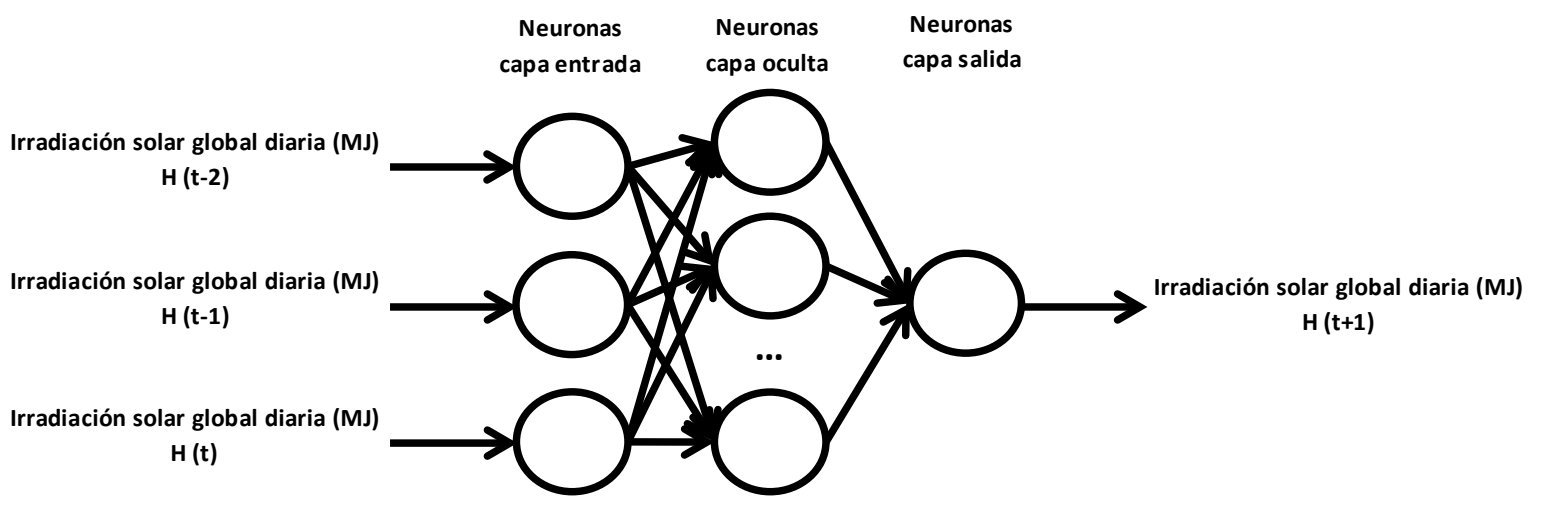

Fig. 3.4.4 Red neuronal artificial utilizada para la predicción de la irradiación solar global diaria del día de mañana respecto al valor de los tres días anteriores

\section{4) Predicción de la irradiación solar global diaria con un día de retardo + el día del año}

La predicción de la irradiación solar global diaria del día de mañana $\mathrm{H}(\mathrm{t}+1)$ se realiza con varias redes neuronales artificiales, se utilizan dos entradas con el valor de la irradiación solar global diaria del día anterior $\mathrm{H}(\mathrm{t})$ y el día del año $\mathrm{J}(\mathrm{t})$, sobre el que se realiza la predicción $\mathrm{H}(\mathrm{t}+1)$, (Fig. 3.4.5) el modelo de arquitectura utilizado.

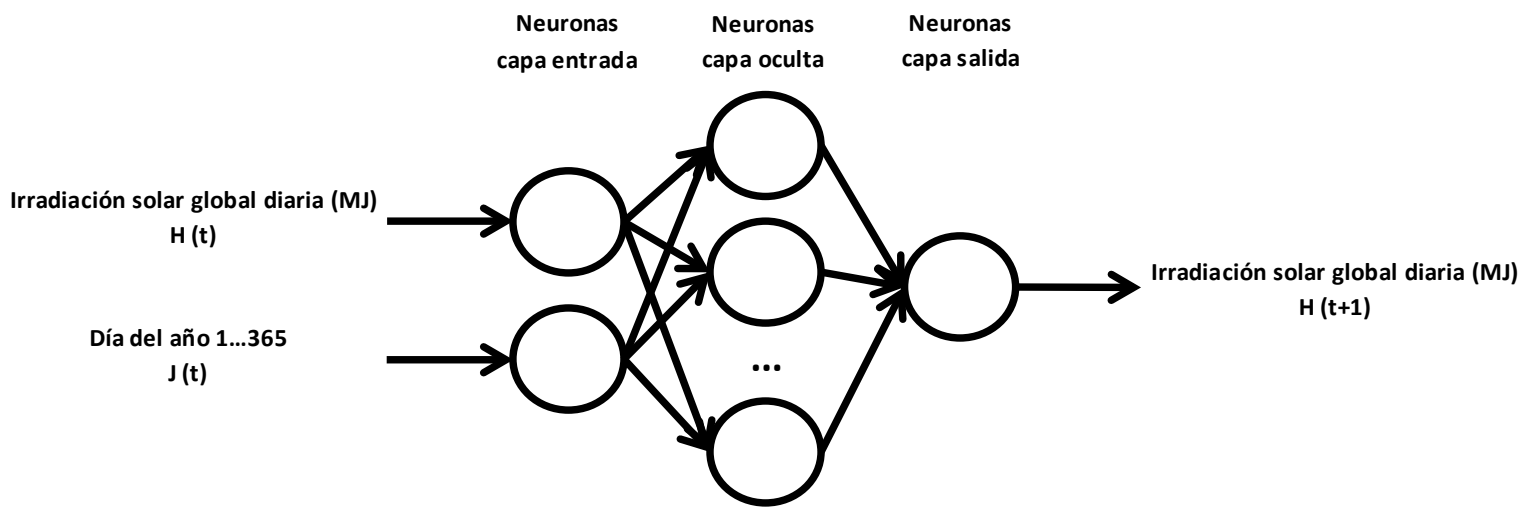

Fig. 3.4.5 Red neuronal artificial utilizada para la predicción de la irradiación solar global diaria del día de mañana respecto al valor del día anterior y el día del año 


\section{5) Predicción de la irradiación solar global diaria con dos días de retardo + el día del año}

La predicción de la irradiación solar global diaria del día de mañana $H(t+1)$ se realiza con varias redes neuronales artificiales, se utilizan tres entradas con el valor de la irradiación solar global diaria de los dos días anteriores $\mathrm{H}(\mathrm{t}-1)$ y $\mathrm{H}(\mathrm{t})$ y el día del año $\mathrm{J}(\mathrm{t})$, sobre el que se realiza la predicción $\mathrm{H}(\mathrm{t}+1)$, (Fig. 3.4.6) el modelo de arquitectura utilizado.

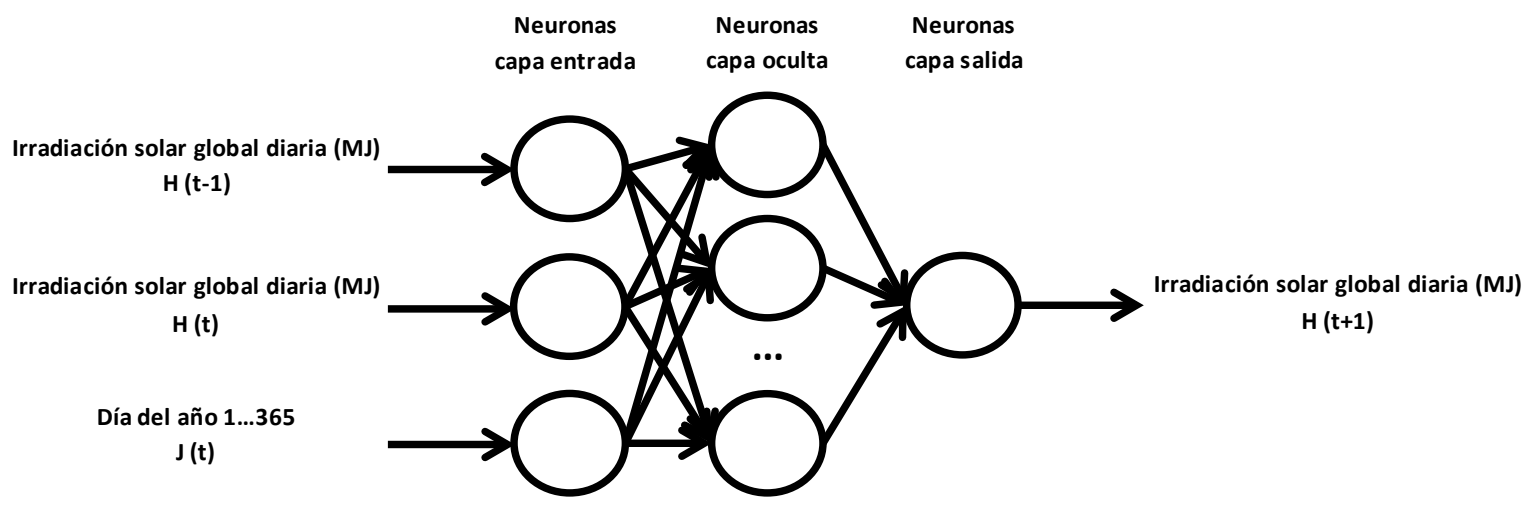

Fig. 3.4.6 Red neuronal artificial utilizada para la predicción de la irradiación solar global diaria del día de mañana respecto al valor de los dos días anteriores y el día del año

\section{6) Predicción de la irradiación solar global diaria con tres días de retardo + el día del año}

La predicción de la irradiación solar global diaria del día de mañana $\mathrm{H}(\mathrm{t}+1)$ se realiza con varias redes neuronales artificiales, se utilizan cuatro entradas con el valor de la irradiación solar global diaria de los tres días anteriores $\mathrm{H}(\mathrm{t}-2), \mathrm{H}(\mathrm{t}-1)$ y $\mathrm{H}(\mathrm{t})$ y el día del año $\mathrm{J}(\mathrm{t})$, sobre el que se realiza la predicción $\mathrm{H}(\mathrm{t}+1)$, (Fig. 3.4.7) el modelo de arquitectura utilizado.

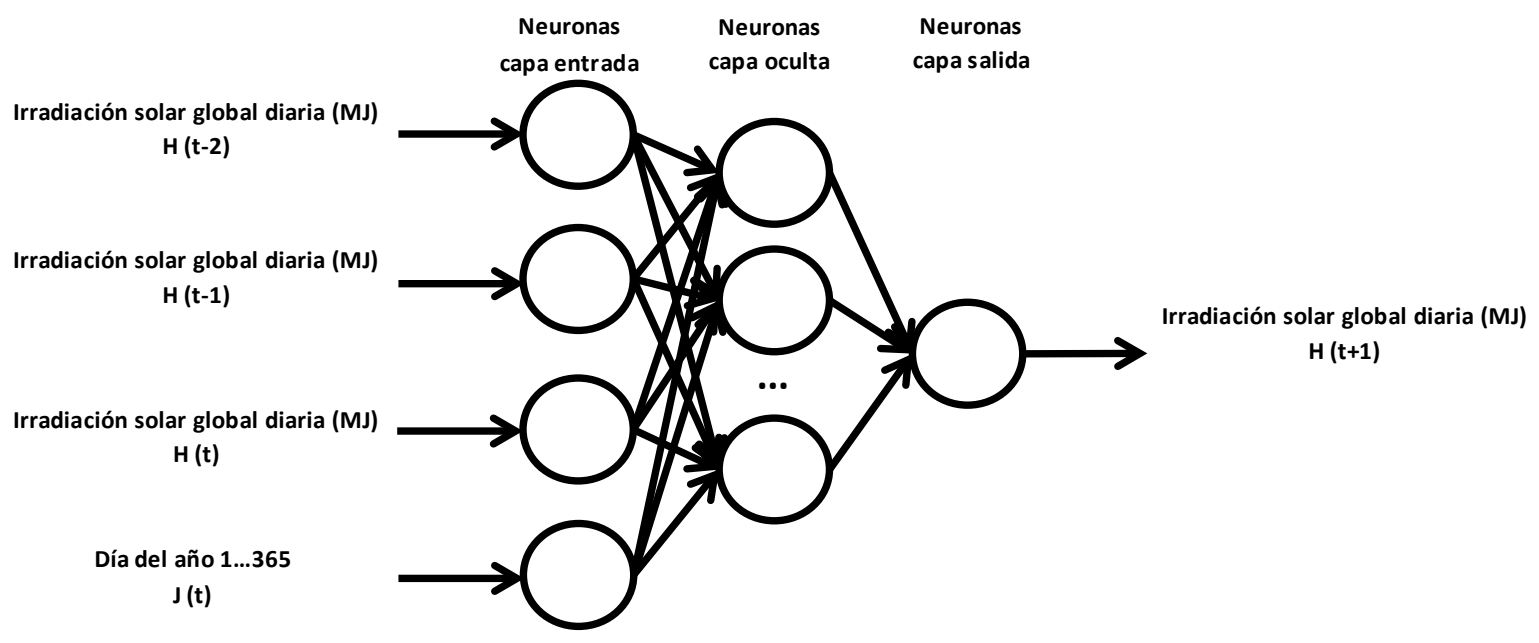

Fig. 3.4.7 Red neuronal artificial utilizada para la predicción de la irradiación solar global diaria del día de mañana respecto al valor de los tres días anteriores y el día del año 


\section{7) Predicción de la irradiación solar global diaria con un día de retardo + el índice de claridad}

La predicción de la irradiación solar global diaria del día de mañana $\mathrm{H}(\mathrm{t}+1)$ se realiza con varias redes neuronales artificiales, se utilizan dos entradas con el valor de la irradiación solar global diaria del día anterior $\mathrm{H}(\mathrm{t})$ y el índice de claridad $\mathrm{K}_{\mathrm{t}}(\mathrm{t})$, sobre el que se realiza la predicción $\mathrm{H}(\mathrm{t}+1)$, (Fig. 3.4.8) el modelo de arquitectura utilizado.

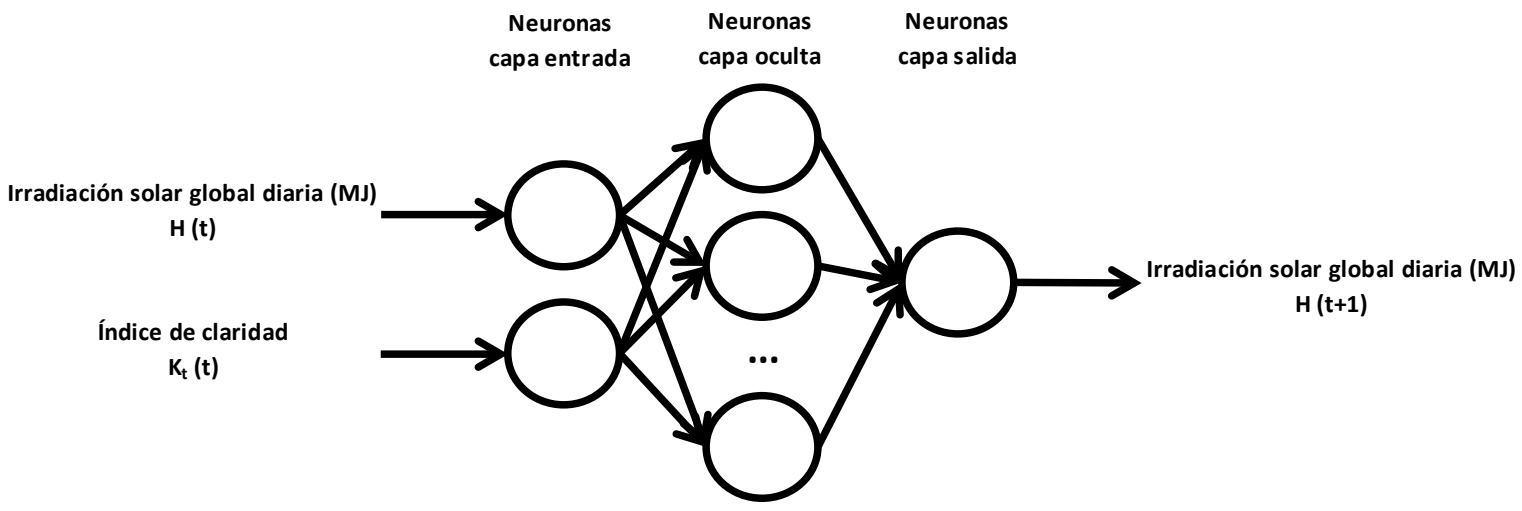

Fig. 3.4.8 Red neuronal artificial utilizada para la predicción de la irradiación solar global diaria del día de mañana respecto al valor del día anterior y el índice de claridad

\section{8) Predicción de la irradiación solar global diaria con un día de retardo + el índice de claridad + el día del año}

La predicción de la irradiación solar global diaria del día de mañana $\mathrm{H}(\mathrm{t}+1)$ se realiza con varias redes neuronales artificiales, se utilizan tres entradas con el valor de la irradiación solar global diaria del día anterior $\mathrm{H}(\mathrm{t})$, el índice de claridad $\mathrm{K}_{\mathrm{t}}(\mathrm{t})$ y el día del año $\mathrm{J}(\mathrm{t})$, sobre el que se realiza la predicción $\mathrm{H}(\mathrm{t}+1)$, (Fig. 3.4.9) el modelo de arquitectura utilizado.

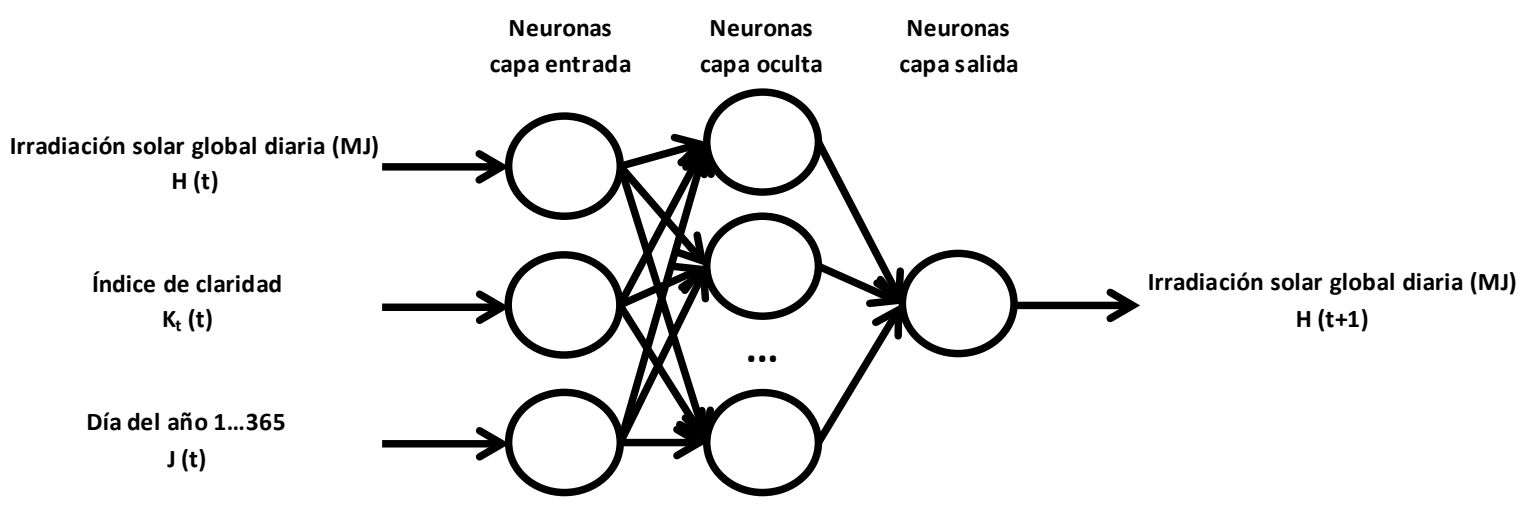

Fig. 3.4.9 Red neuronal artificial utilizada para la predicción de la irradiación solar global diaria del día de mañana respecto al valor del día anterior, su índice de claridad y el día del año 


\subsubsection{La predicción de la irradiación solar global diaria del día de mañana a partir de la temperatura ambiente mediante redes neuronales artificiales}

La predicción de la cantidad de la irradiación solar global que recibirá la superficie horizontal el día de mañana, se realizó utilizando redes neuronales artificiales, a partir de la temperatura ambiente, al ser esta una variable ambiental que se registra en todas las estaciones meteorológicas.

Se probaron varias combinaciones de entradas hasta encontrar la que resultó con un error menor. En las predicciones realizadas se utilizaron los datos del día anterior sobre el que se realiza la predicción, el entrenamiento de la red neuronal artificial se realizó con datos de los años 2004-2010, comparando los resultados de los modelos en la simulación realizada con la base de datos de SIAR en Masilla Mayor (León) del año 2011 en el capítulo cuatro para su validación.

1) La primera combinación realizada de entradas a la red neuronal artificial fue de la temperatura media diaria, del día anterior sobre el que se hace la predicción del valor de la irradiación solar global diaria.

2) La segunda combinación realizada de entradas a la red neuronal artificial fue de las temperaturas máxima y mínima diaria, del día anterior sobre el que se hace la predicción del valor de la irradiación solar global diaria.

3) La tercera combinación realizada de entradas a la red neuronal artificial fue de las temperaturas media, máxima y mínima diaria, del día anterior sobre el que se hace la predicción del valor de la irradiación solar global diaria.

4) La cuarta combinación realizada de entradas a la red neuronal artificial fue de la temperatura media diaria del día anterior sobre el que se hace la predicción del valor de la irradiación solar global diaria y el día del año.

5) La quinta combinación realizada de entradas a la red neuronal artificial fue de las temperaturas máxima y mínima diaria del día anterior sobre el que se hace la predicción del valor de la irradiación solar global diaria y el día del año.

6) La sexta combinación realizada de entradas a la red neuronal artificial fue de las temperaturas media, máxima y mínima diaria del día anterior sobre el que se hace la predicción del valor de la irradiación solar global diaria y el día del año. 


\section{1) Predicción de la irradiación solar global diaria a partir de la temperatura media diaria con un día de retardo}

La predicción de la irradiación solar global diaria del día de mañana $\mathrm{H}(\mathrm{t}+1)$ se realiza con varias redes neuronales artificiales, se utiliza una entrada con el valor de la temperatura media diaria del día anterior $T_{\text {med }}(t)$, sobre el que se realiza la predicción $H(t+1)$, (Fig. 3.4.10) el modelo de arquitectura utilizado.

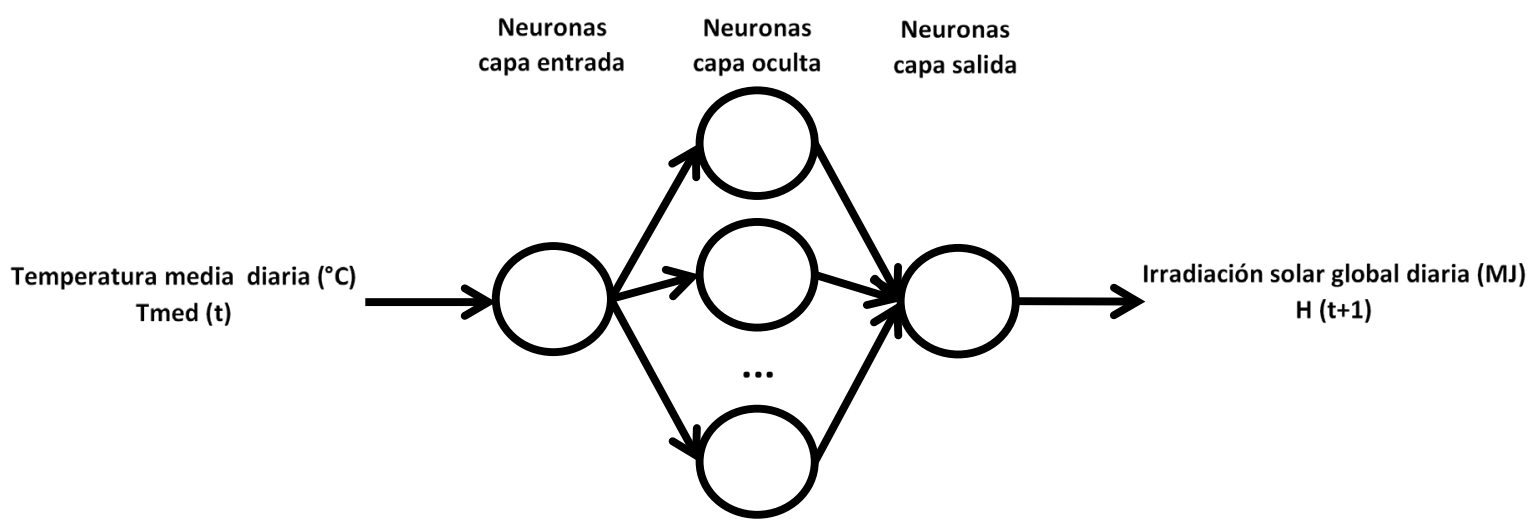

Fig. 3.4.10 Red neuronal artificial utilizada para la predicción de la irradiación solar global diaria del día de mañana respecto al valor de la temperatura media diaria del día anterior

\section{2) Predicción de la irradiación solar global diaria a partir de la temperatura máxima y mínima diaria con un día de retardo}

La predicción de la irradiación solar global diaria del día de mañana $\mathrm{H}(\mathrm{t}+1)$ se realiza con varias redes neuronales artificiales, se utilizan dos entradas con el valor de la temperatura máxima y mínima diaria del día anterior $T_{\max }(t)$ y $T_{\min }(t)$, sobre el que se realiza la predicción $H(t+1)$, (Fig. 3.4.11) el modelo de arquitectura utilizado.

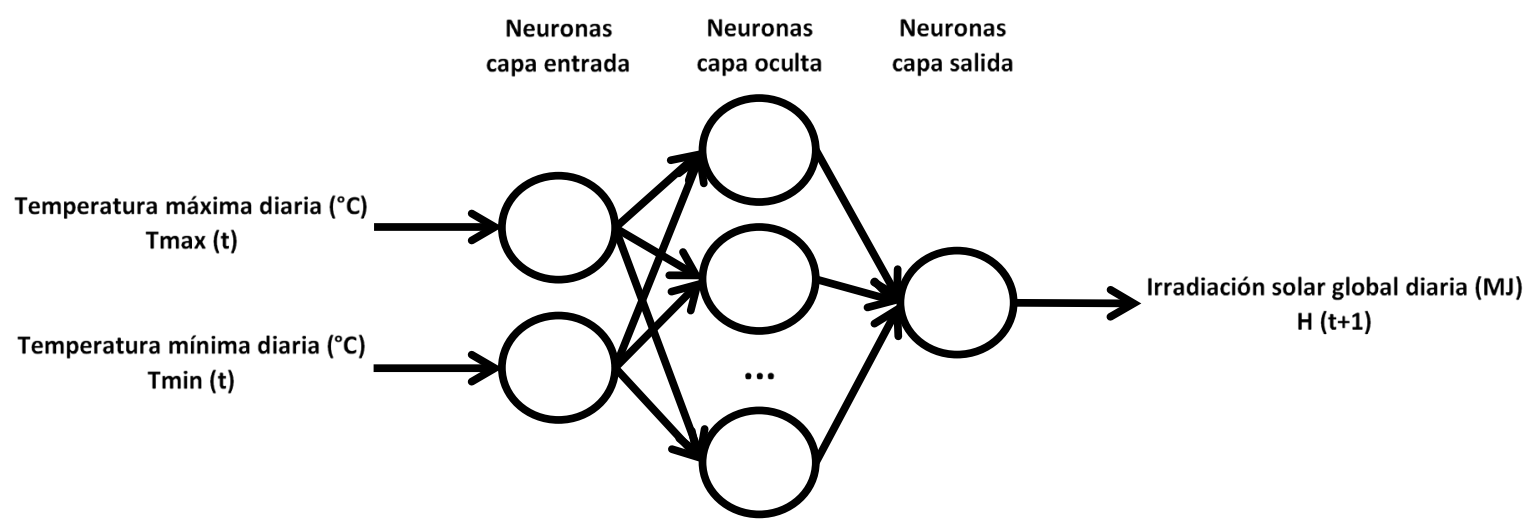

Fig. 3.4.11 Red neuronal artificial utilizada para la predicción de la irradiación solar global diaria del día de mañana respecto al valor de la temperatura máxima y mínima diaria del día anterior 


\section{3) Predicción de la irradiación solar global diaria a partir de la temperatura media, máxima y mínima diaria con un día de retardo}

La predicción de la irradiación solar global diaria del día de mañana $H(t+1)$ se realiza con varias redes neuronales artificiales, se utilizan tres entradas con el valor de la temperatura media, máxima y mínima diaria del día anterior $T_{\operatorname{med}}(t), T_{\max }(t)$ y $T_{\min }(t)$, sobre el que se realiza la predicción $H(t+1)$, (Fig. 3.4.12) el modelo de arquitectura utilizado.

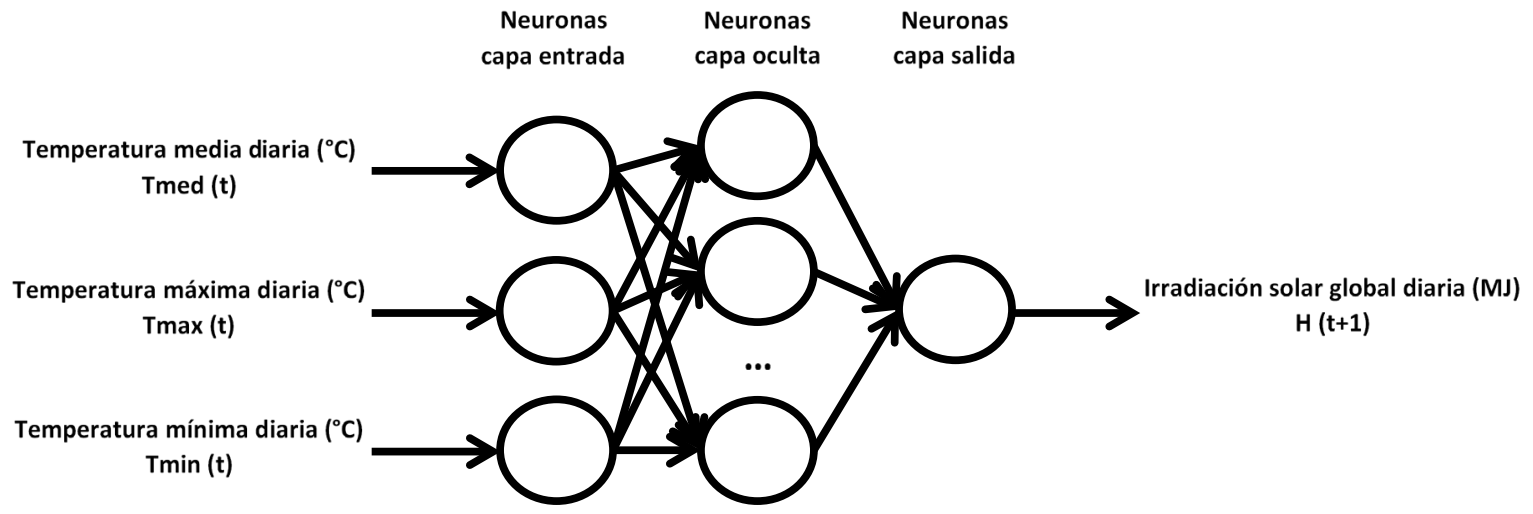

Fig. 3.4.12 Red neuronal artificial utilizada para la predicción de la irradiación solar global diaria del día de mañana respecto al valor de la temperatura media, máxima y mínima diaria del día anterior

\section{4) Predicción de la irradiación solar global diaria a partir de la temperatura media diaria con un día de retardo + el día del año}

La predicción de la irradiación solar global diaria del día de mañana $\mathrm{H}(\mathrm{t}+1)$ se realiza con varias redes neuronales artificiales, se utilizan dos entradas con el valor de la temperatura media diaria del día anterior $\mathrm{T}_{\text {med }}(\mathrm{t})$ y el día del año $\mathrm{J}(\mathrm{t})$, sobre el que se realiza la predicción $\mathrm{H}(\mathrm{t}+1)$, (Fig. 3.4.13) el modelo de arquitectura utilizado.

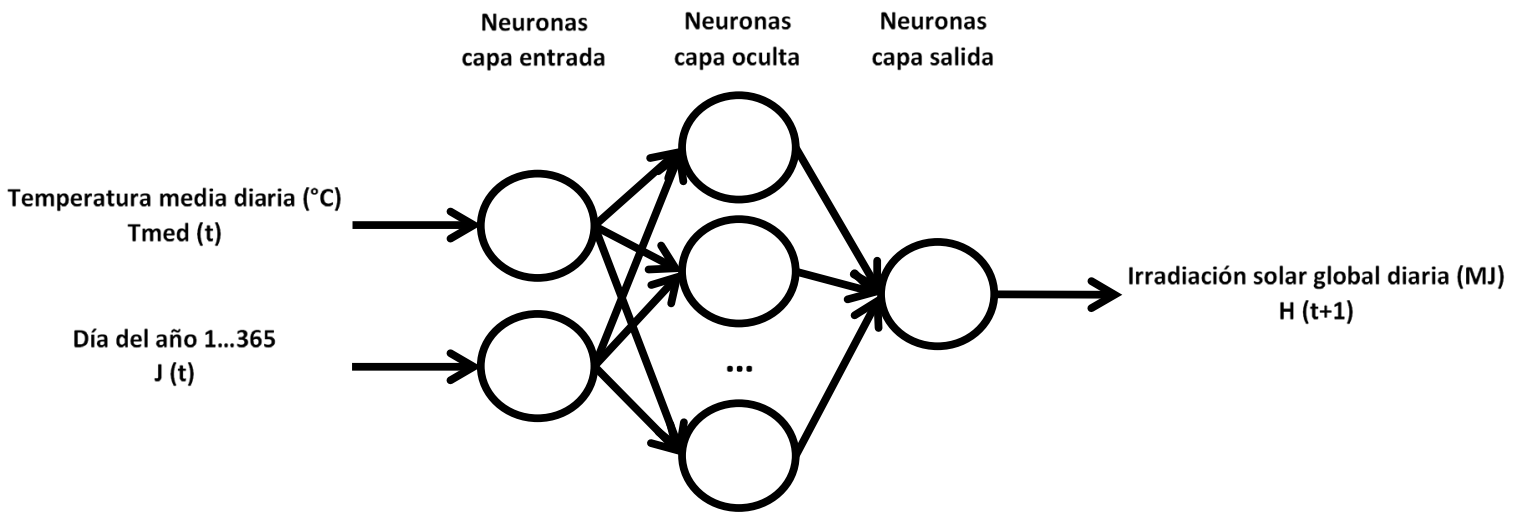

Fig. 3.4.13 Red neuronal artificial utilizada para la predicción de la irradiación solar global diaria del día de mañana respecto al valor de la temperatura media diaria y el día del año anterior 


\section{5) Predicción de la irradiación solar global diaria a partir de la temperatura máxima y mínima diaria con un día de retardo + el día del año}

La predicción de la irradiación solar global diaria del día de mañana $\mathrm{H}(\mathrm{t}+1)$ se realiza con varias redes neuronales artificiales, se utilizan tres entradas con el valor de la temperatura máxima y mínima diaria del día anterior $T_{\max }(t)$ y $T_{\min }(t)$ y el día del año $\mathrm{J}(\mathrm{t})$, sobre el que se realiza la predicción $H(t+1)$, (Fig. 3.4.14) el modelo de arquitectura utilizado.

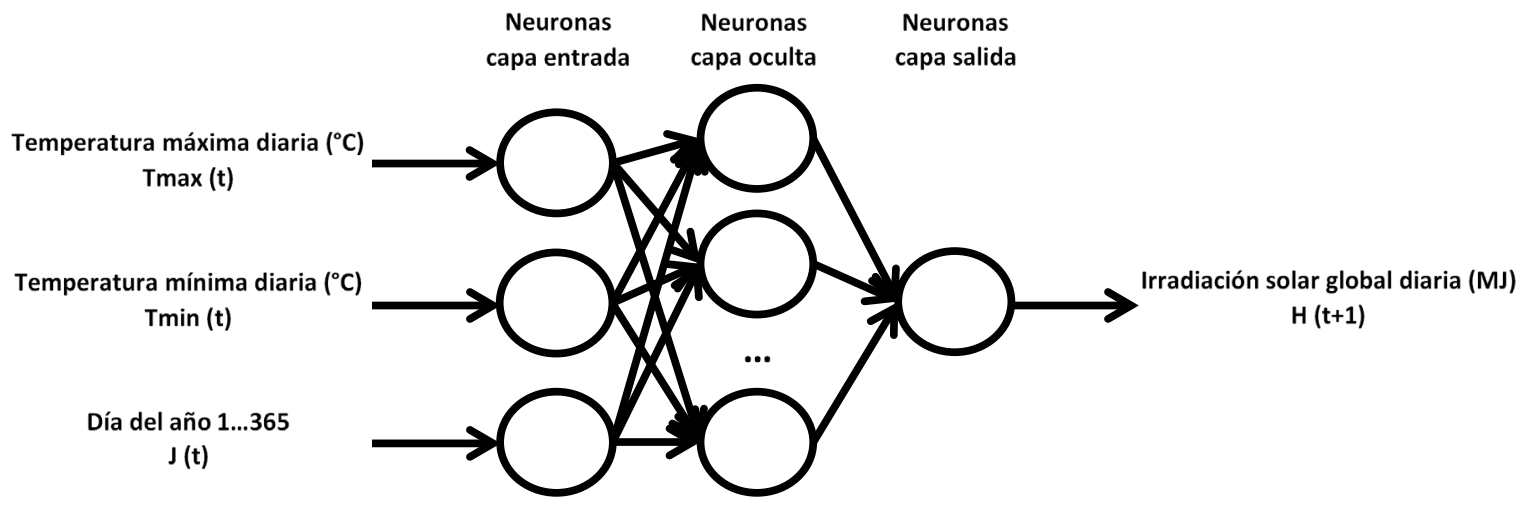

Fig. 3.4.14 Red neuronal artificial utilizada para la predicción de la irradiación solar global diaria del día de mañana respecto al valor de la temperatura máxima y mínima diaria y el día del año anterior

\section{6) Predicción de la irradiación solar global diaria a partir de la temperatura media, máxima y mínima diaria con un día de retardo + el día del año}

La predicción de la irradiación solar global diaria del día de mañana $\mathrm{H}(\mathrm{t}+1)$ se realiza con varias redes neuronales artificiales, se utilizan cuatro entradas con el valor de la temperatura media, máxima y mínima diaria del día anterior $T_{\operatorname{med}}(t), T_{\max }(t)$ y $T_{\min }(t)$ y el día del año $\mathrm{J}(\mathrm{t})$, sobre el que se realiza la predicción $\mathrm{H}(\mathrm{t}+1)$, (Fig. 3.4.15) el modelo de arquitectura utilizado.

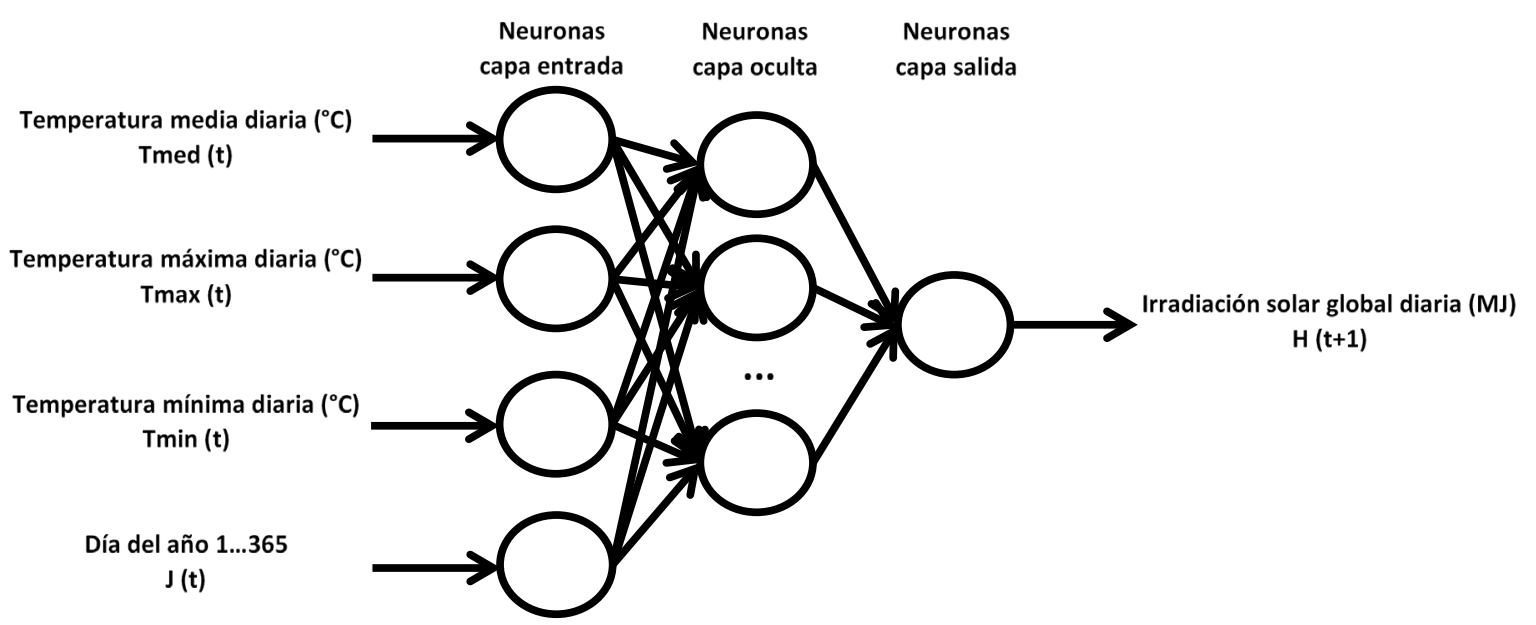

Fig. 3.4.15 Red neuronal artificial utilizada para la predicción de la irradiación solar global diaria del día de mañana respecto al valor de la temperatura media, máxima y mínima diaria y el día del año anterior 


\subsubsection{La predicción de las temperaturas media, máxima y mínima diaria del día de mañana mediante redes neuronales artificiales}

La predicción de la temperatura ambiente del día de mañana, se realizó utilizando redes neuronales artificiales, a partir de la temperatura ambiente del día anterior respecto del que se realiza la predicción.

Se probaron dos combinaciones de entradas. En las predicciones realizadas se utilizan los datos del día anterior sobre el que se realiza la predicción, el entrenamiento de la red neuronal artificial se realiza con datos de los años 2004-2010, comparando los resultados de los modelos en la simulación realizada con la base de datos de SIAR en Masilla Mayor (León) del año 2011 en el capítulo cuatro para su validación.

1) La primera combinación de entradas a la red neuronal artificial fue de las temperaturas media, máxima y mínima diaria del día anterior sobre el que se hace la predicción del valor de las temperaturas media, máxima y mínima futuras.

2) La segunda combinación de entradas a la red neuronal artificial fue de las temperaturas media, máxima y mínima y el día del año anterior sobre el que se hace la predicción del valor de las temperaturas media, máxima y mínima futuras. 


\section{1) Predicción de las temperaturas media, máxima y mínima diaria con un día de retardo}

La predicción de la temperatura media, máxima y mínima diaria $T_{\operatorname{med}}(t+1), T_{\max }(t+1)$ y $T_{\min }(t+1)$, se realizó con varias redes neuronales artificiales, se utilizan tres entradas con el valor de la temperatura media, máxima y mínima diaria del día anterior $T_{\operatorname{med}}(t), T_{\max }(t)$ y $T_{\min }(t)$, sobre el que se realiza la predicción $T_{\text {med }}(t+1), T_{\max }(t+1)$ y $T_{\min }(t+1)$, (Fig. 3.4.16) el modelo de arquitectura utilizado.

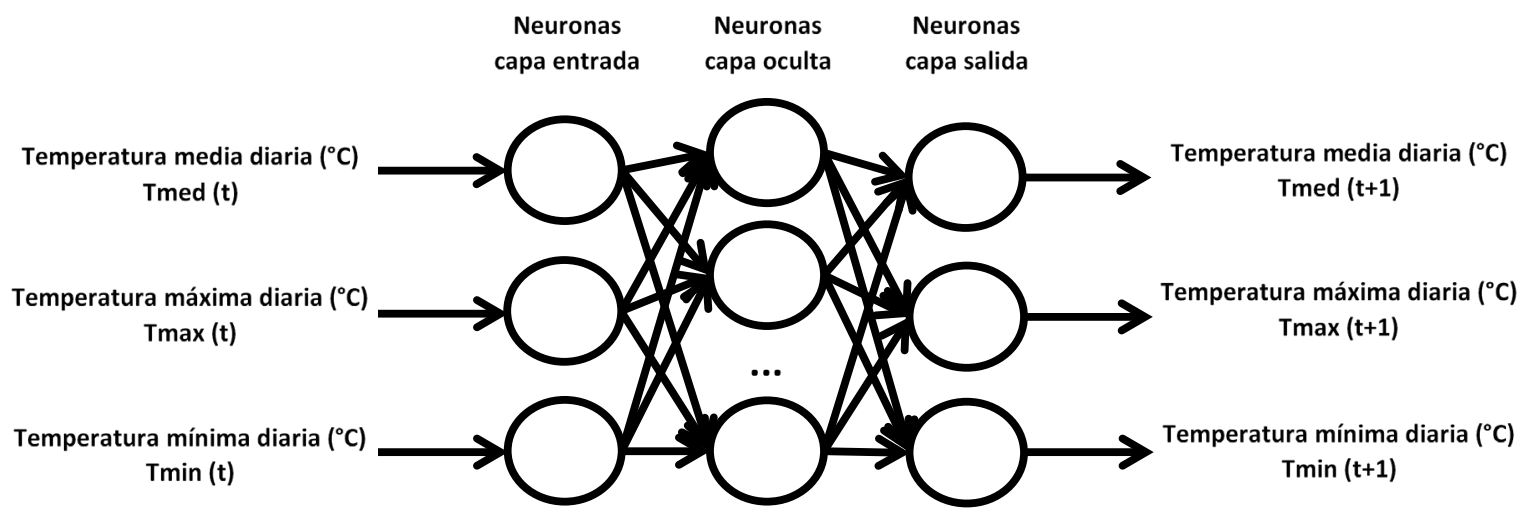

Fig. 3.4.16 Red neuronal artificial para la predicción de las temperaturas media, máxima y mínima diaria del día de mañana respecto a los valores del día anterior

\section{2) Predicción de las temperaturas media, máxima y mínima diaria con un día de retardo + el día del año}

La predicción de la temperatura media, máxima y mínima diaria $T_{\operatorname{med}}(t+1), T_{\max }(t+1)$ y $T_{\min }(t+1)$, se realizó con varias redes neuronales artificiales, se utilizan cuatro entradas con el valor de la temperatura media, máxima y mínima diaria del día anterior $T_{\operatorname{med}}(t), T_{\max }(t)$ y $T_{\min }(t)$ y el día del año $\mathrm{J}(\mathrm{t})$, sobre el que se realiza la predicción $T_{\operatorname{med}}(t+1)$, $T_{\max }(t+1)$ y $T_{\min }(t+1)$, (Fig. 3.4.17) el modelo de arquitectura utilizado.

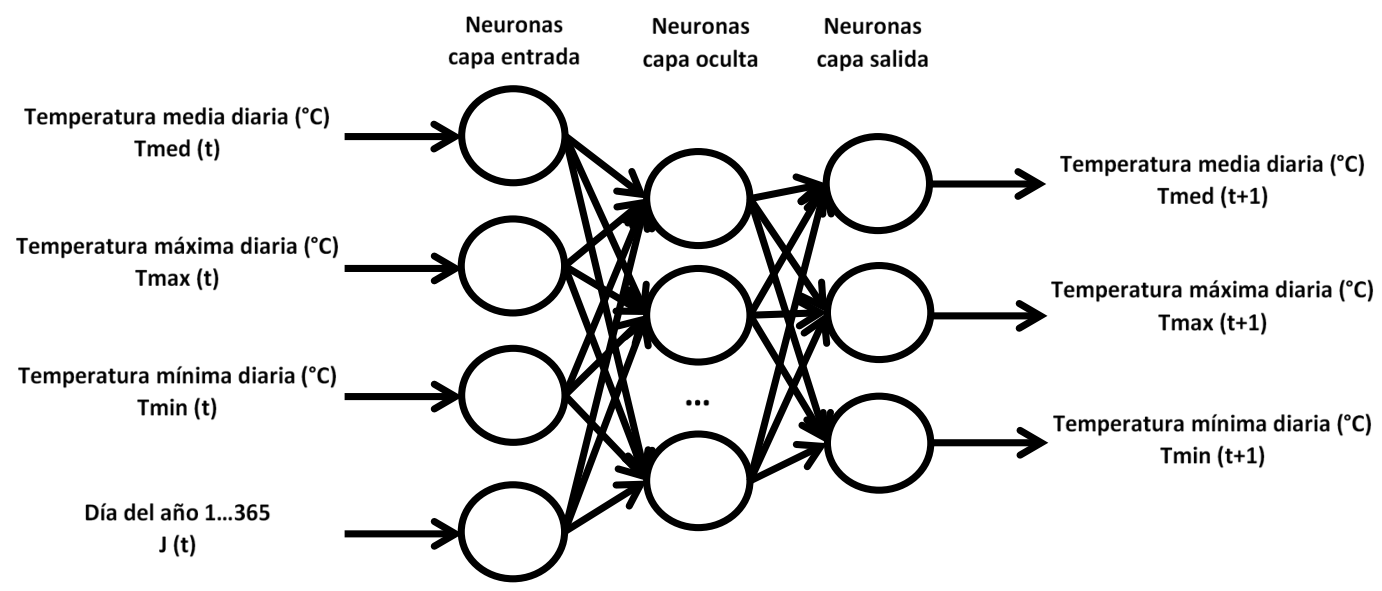

Fig. 3.4.17 Red neuronal artificial para la predicción de las temperaturas media, máxima y mínima diaria del día de mañana respecto a los valores del día anterior y del día del año 


\subsubsection{Estimación de la irradiancia solar horaria media a partir de la irradiación solar global diaria mediante redes neuronales artificiales}

La estimación de la irradiancia solar horaria media, término de potencia, se realizó utilizando redes neuronales artificiales, a partir de la irradiación solar global diaria, término de energía, del mismo día respecto del que se realiza la estimación.

Se probaron dos combinaciones de entradas. En las estimaciones realizadas se utilizan los datos de un día sobre el que se realiza la estimación, el entrenamiento de la red neuronal artificial se realiza con datos de los años 2004-2010, comparando los resultados de los modelos en la simulación realizada con la base de datos de SIAR en Mansilla Mayor (León) del año 2011 en el capítulo cuatro para su validación.

1) La primera combinación de entradas a la red neuronal artificial fue de la irradiación solar global diaria del día sobre el que se realiza la estimación de la irradiancia solar horaria media de cada hora del día, obtenida en 24 salidas en la red neuronal artificial correspondientes a las 24 horas del día.

2) La segunda combinación de entradas a la red neuronal artificial fue de la irradiación solar global diaria y el día del año sobre el que se realiza la estimación de la irradiancia solar horaria media de cada hora del día, obtenida en 24 salidas en la red neuronal artificial, correspondientes a las 24 horas del día. 


\section{1) Estimación de la irradiancia solar horaria con la irradiación solar global diaria}

La estimación de la irradiancia solar horaria $\dot{I}_{0 h}(t) \ldots \dot{I}_{23 h}(t)$, se realizó con varias redes neuronales artificiales, se utiliza una entrada con el valor de la irradiación solar global diaria $\mathrm{H}(\mathrm{t})$ en el que se realiza la estimación y 24 salidas para el valor de la irradiancia solar horaria del mismo día $\dot{I}_{\text {oh }}(\mathrm{t})$... $\mathrm{I}_{23 \mathrm{~h}}(\mathrm{t})$ ) (Fig. 3.4.18) el modelo de arquitectura utilizado.

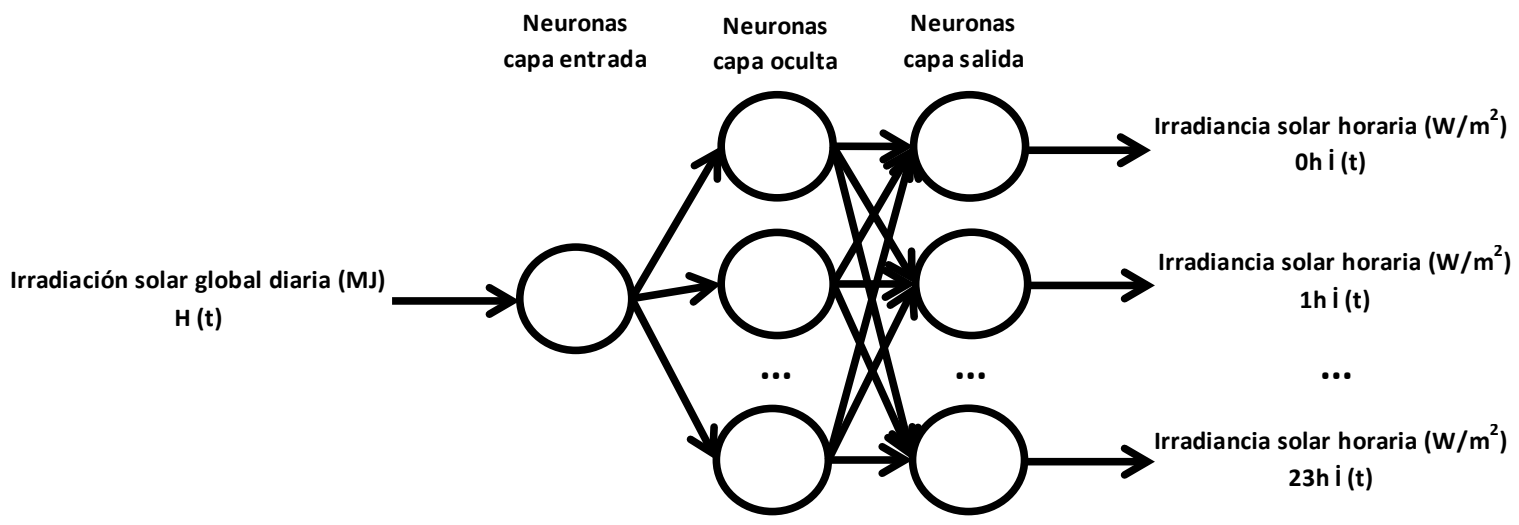

Fig. 3.4.18 Red neuronal artificial utilizada para la estimación de la irradiancia solar horaria respecto a la irradiación solar global diaria del mismo día

\section{2) Estimación de la irradiancia solar horaria con la irradiación solar global horaria + el día del año}

La estimación de la irradiancia solar horaria $\dot{I}_{0 h}(t) \ldots \dot{I}_{23 h}(t)$, se realizó con varias redes neuronales artificiales, se utilizan dos entradas con el valor de la irradiación solar global diaria $\mathrm{H}(\mathrm{t})$ y el día del año $\mathrm{J}(\mathrm{t})$ en el que se realiza la estimación y 24 salidas para el valor de la irradiancia solar horaria del mismo día $\dot{I}_{\text {oh }}(\mathrm{t})$... $\dot{I}_{23 \mathrm{~h}}(\mathrm{t})$, (Fig. 3.4.19) el modelo de arquitectura utilizado.

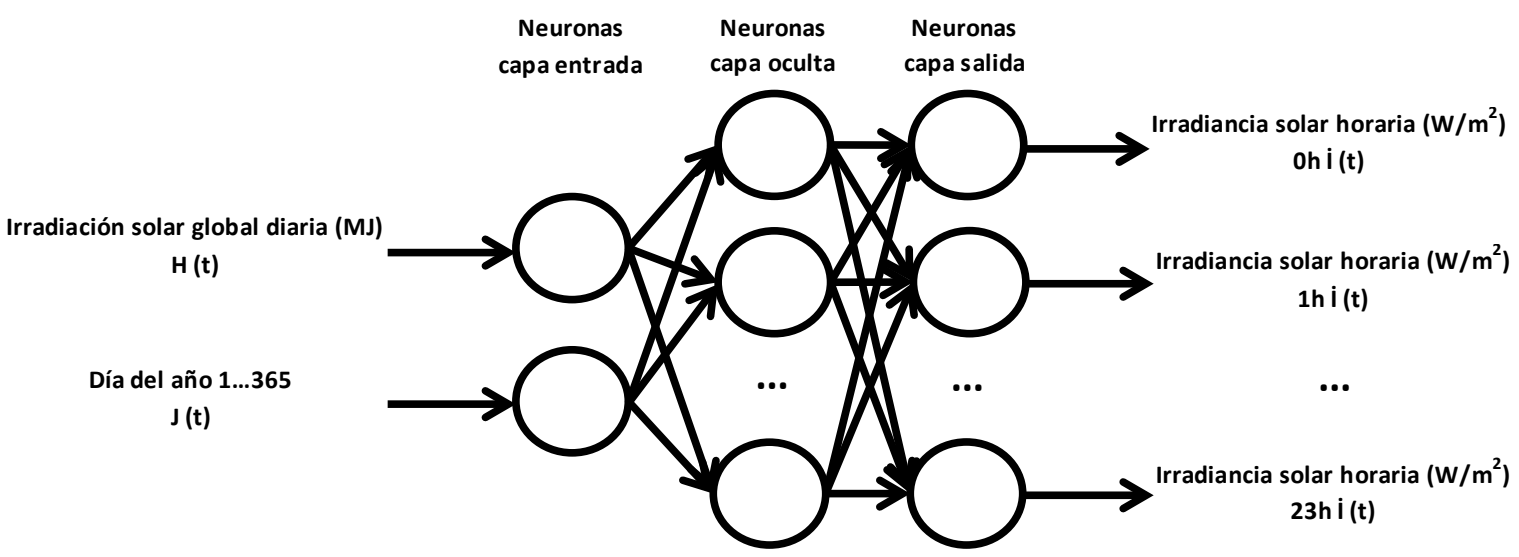

Fig. 3.4.19 Red neuronal artificial utilizada para la estimación de la irradiancia solar horaria respecto a la irradiación solar global diaria y el día del año del mismo día 


\subsubsection{Estimación de la temperatura media horaria a partir de las temperaturas media, máxima y mínima diaria mediante redes neuronales artificiales}

La estimación de la temperatura media horaria, se realizó utilizando redes neuronales artificiales, a partir de las temperaturas media, máxima y mínima diaria del mismo día respecto del que se realiza la estimación.

Se probaron dos combinaciones de entradas. En las estimaciones realizadas se utilizan los datos de un día sobre el que se realiza la estimación, el entrenamiento de la red neuronal artificial se realiza con datos de los años 2004-2010, comparando los resultados de los modelos en la simulación realizada con la base de datos de SIAR en Mansilla Mayor (León) del año 2011 en el capítulo cuatro para su validación.

1) La primera combinación de entradas a la red neuronal artificial fue de las temperaturas media, máxima y mínima diaria del día sobre el que se realiza la estimación de la temperatura media horaria de cada hora del día, obtenida en 24 salidas en la red neuronal artificial, correspondientes a las 24 horas del día.

2) La segunda combinación de entradas a la red neuronal artificial fue de las temperaturas media, máxima y mínima diaria y el día del año sobre el que se realiza la estimación de la temperatura media horaria de cada hora del día, obtenida en 24 salidas en la red neuronal artificial, correspondientes a las 24 horas del día. 


\section{1) Estimación de la temperatura media horaria con las temperaturas media, máxima y mínima diaria}

La estimación de la temperatura media horaria $T_{\text {med } 0 h}(t) \ldots T_{\text {med } 23 h}(t)$, se realizó con varias redes neuronales artificiales, se utilizan tres entradas con el valor de las temperaturas media, máxima y mínima diaria $T_{\text {med }}(t), T_{\max }(t)$ y $T_{\min }(t)$ en el que se realiza la estimación y 24 salidas para el valor de la temperatura media horaria del mismo día $\mathrm{T}_{\text {med oh }}(\mathrm{t})$... $\mathrm{T}_{\text {med 23h }}(\mathrm{t})$, (Fig. 3.4.20) el modelo de arquitectura utilizado.

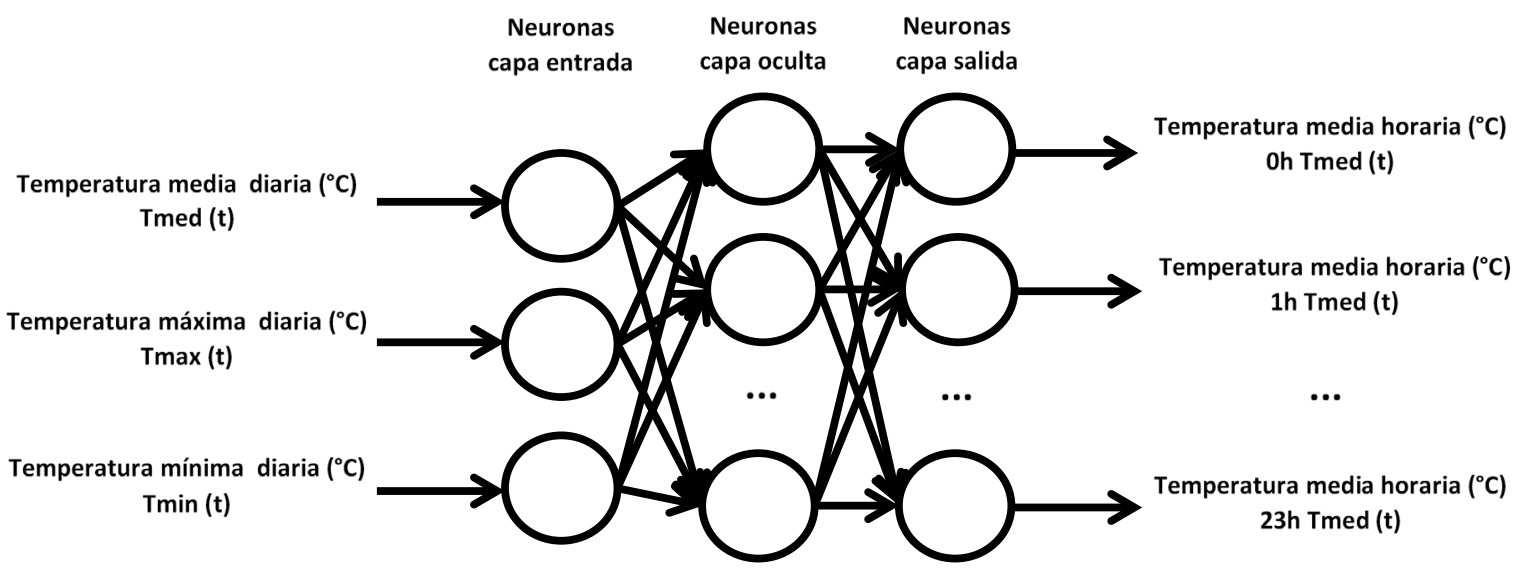

Fig. 3.4.20 Red neuronal artificial utilizada para la estimación de la temperatura media horaria respecto a las temperaturas media, máxima y mínima diaria del mismo día 


\section{2) Estimación de la temperatura media horaria con las temperaturas media, máxima y mínima diaria + el día del año}

La estimación de la temperatura media horaria $T_{\text {med oh }}(t) \ldots T_{\text {med 23h }}(t)$, se realizó con varias redes neuronales artificiales, se utilizan cuatro entradas con el valor de las temperaturas media, máxima y mínima diaria $\operatorname{Tmed}(\mathrm{t}), \operatorname{Tmax}(\mathrm{t})$ y $\operatorname{Tmin}(\mathrm{t})$ y el día del año J(t) en el que se realiza la estimación y 24 salidas para el valor de la temperatura media horaria del mismo día $\mathrm{T}_{\text {med } 0 \mathrm{~h}}(\mathrm{t})$... $\mathrm{T}_{\text {med } 23 \mathrm{~h}}(\mathrm{t})$, (Fig. 3.4.21) el modelo de arquitectura utilizado.

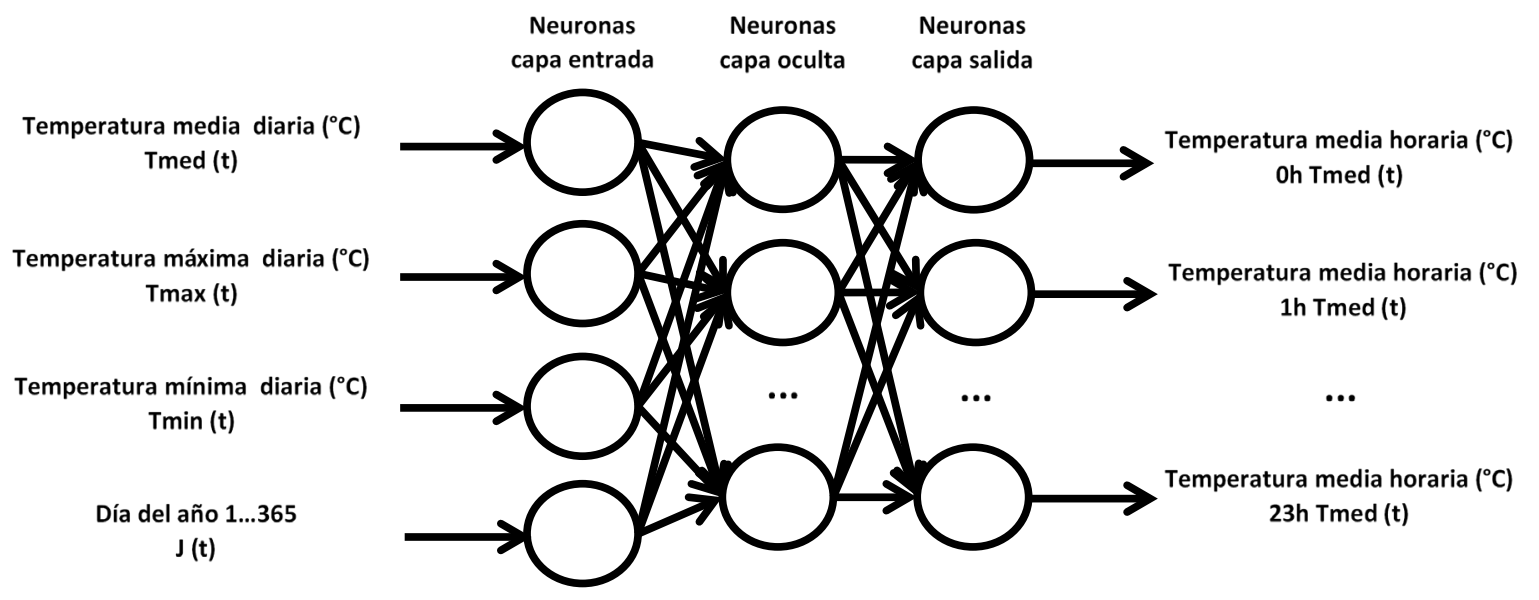

Fig. 3.4.21 Red neuronal artificial utilizada para la estimación de la temperatura media horaria respecto a las temperaturas media, máxima y mínima diaria y el día del año del mismo día 


\subsection{Estimación de la irradiación solar sobre el plano inclinado y orientado}

Los modelos existentes en la literatura para el cálculo de la irradiación solar sobre una superficie inclinada y orientada, necesitan como variables de entrada de la irradiación solar global horizontal, la irradiación solar difusa horizontal, la altura solar y el ángulo de incidencia, ya sean medidos o estimados sus valores. Cuando son calculados a través de otros modelos se proporciona el valor de la irradiación solar extraterrestre mediante los valores de los parámetros de la constante solar, un factor de corrección de la excentricidad de la Tierra, el día del año, la declinación solar, el ángulo horario solar y otros parámetros de la situación del sistema solar térmico como su latitud y longitud geográfica, la inclinación y orientación del captador solar.

Para ello se ha incluido este apartado, en el que se desarrolla una metodología con modelos de diferentes autores, aceptados en la literatura, facilitando su uso. Se escogió la plataforma Simulink del programa Matlab, para su programación con objetos visuales por su facilidad de utilización. El carácter modular con el que sea ha diseñado, da la posibilidad de que en cada caso de estudio se puedan utilizar distintos modelos existentes, que sean más adecuados para cada caso o que se puedan crear para la obtención de las diversas variables a utilizar.

El modelo global utilizado en esta Tesis Doctoral, con el que se obtiene el valor de la irradiación solar global, en este caso horaria, sobre un plano inclinado, según el esquema planteado (Fig. 3.5.1), consta de:

- Un modelo para el cálculo de la irradiación solar extraterrestre horaria sobre la horizontal Io.

- Un modelo para el cálculo de la altura solar $\alpha$ en cada hora del día.

- Un modelo para el cálculo del ángulo de incidencia $\Theta$ de los rayos solares sobre el plano inclinado y orientado.

- Un modelo para la estimación de la irradiación solar difusa del cielo horaria sobre la horizontal $I_{d}$.

- El propio modelo del paso a los valores sobre el plano inclinado.

Este modelo global recibe como parámetros de entrada:

- El día del año J, 1 para el 1 de enero, 365 para el 31 de diciembre.

- El valor medio del intervalo horario a estudiar t, la hora del día +0,5.

- La irradiación solar global horaria medida sobre la superficie horizontal I.

El resto de parámetros para la evaluación de cada sistema solar térmico concreto quedan fijados en el interior de cada modelo, como son:

- La inclinación del captador solar $\beta$.

- La orientación del captador solar $\gamma$.

- La constante solar $\mathrm{I}_{\mathrm{sc}}$.

- El albedo $\rho$.

- La latitud $\phi$.

- La longitud geográfica del lugar. 
Por último, se realiza una conversión del valor energético de la irradiación solar global horaria obtenido para el plano inclinado y orientado, al valor de potencia de irradiancia solar media horaria correspondiente, para su utilización como valores de entrada a la simulación del modelo de un sistema solar térmico. Estos valores horarios a través de una interpolación se utilizarán para crear una base de datos, con un intervalo de tiempo de un minuto para realizar una simulación más detallada del funcionamiento del sistema solar térmico a estudiar.

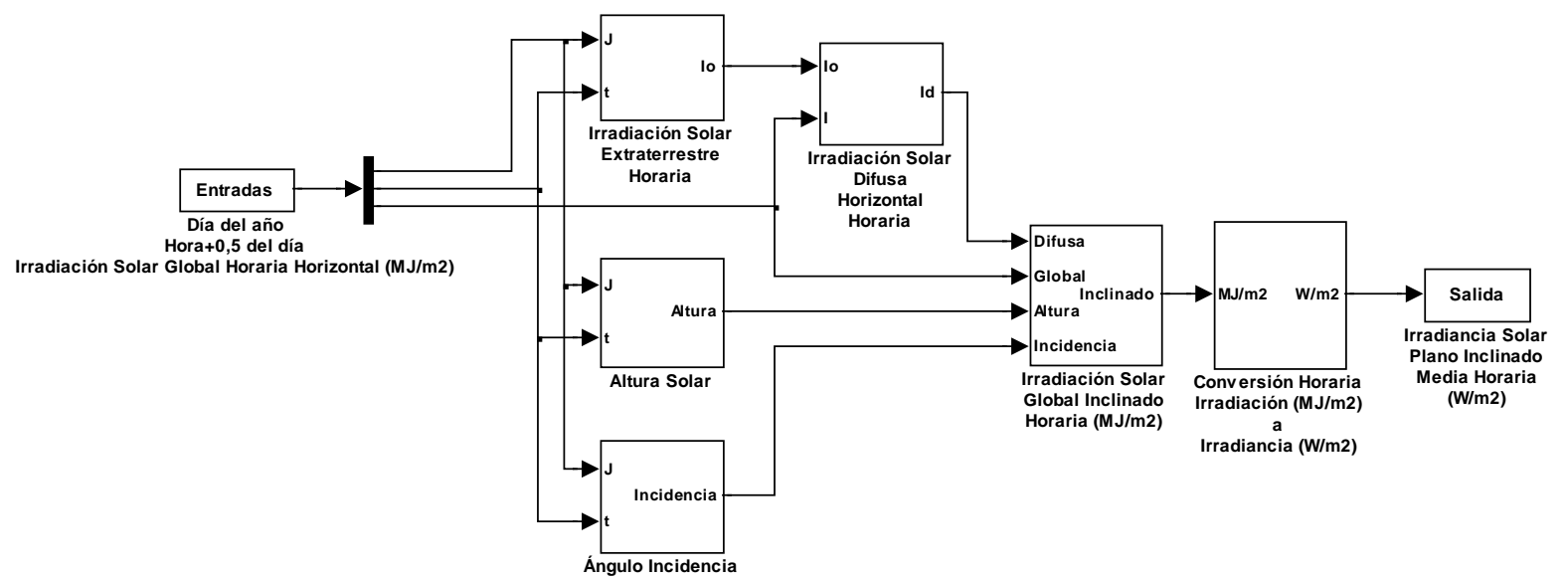

Fig. 3.5.1 Módulo para la conversión de los valores medidos de irradiación global sobre una superficie horizontal a los calculados que recibe un plano inclinado

En los apartados siguientes se detalla la implementación de cada parte de que consta el modulo con los procedimientos utilizados en esta Tesis Doctoral.

\subsubsection{Modelado de la irradiación solar extraterrestre}

El Sol emite un flujo de energía que lo consideramos casi constante, a excepción de pequeñas variaciones debidas al origen de las manchas solares, esta energía solar cuando llega al tope de la atmósfera, recibe la denominación de irradiación solar extraterrestre, es la irradiación solar que llegaría a un punto determinado de la Tierra en el supuesto de que en nuestro planeta no existiera la atmósfera que la protege.

Este valor puede ser calculado mediante el procedimiento que, por ejemplo, se expone y se detalla en (Allen, 2006) recomendado por la FAO para el desarrollo de los cálculos de la evapotranspiración de los cultivos. Se puede realizar su estimación para periodos de tiempo diarios y horarios (Duffie y Beckman, 2006) y (Kalogirou, 2009).

A continuación se detalla su proceso de cálculo para el periodo diario y horario. 


\section{1) Metodología de cálculo de la irradiación solar extraterrestre diaria}

La irradiación solar extraterrestre diaria $\mathrm{H}_{0}$, es la irradiación solar recibida en los límites de la atmósfera terrestre, para cada día del año y para diversas latitudes se puede estimar a partir de la constante solar, la declinación solar y la época del año (Allen, 2006), (Duffie y Beckman, 2006) y (Kalogirou, 2009) mediante la ecuación (Ec. 3.5.1).

$$
\mathrm{H}_{0}=\left(\frac{24 \cdot 60}{\pi}\right) \mathrm{I}_{\mathrm{sc}} \mathrm{E}_{0}\left[\omega_{\mathrm{s}} \operatorname{sen} \phi \operatorname{sen} \delta+\cos \phi \cos \delta \operatorname{sen} \omega_{\mathrm{s}}\right]
$$

Donde,

$\mathrm{H}_{0}$ : Irradiación solar extraterrestre diaria incidente sobre una superficie horizontal ( $\mathrm{MJ} / \mathrm{m}^{2} / \mathrm{d}$ ).

Isc $_{\text {sc }}$ Constante solar $1367 \mathrm{~W} / \mathrm{m}^{2}$. Definida como valor medio de la energía solar por unidad de superficie y de tiempo, que a lo largo de un año llega a un plano perpendicular a los rayos del Sol: $4,921 \mathrm{MJ} / \mathrm{m}^{2} / \mathrm{h}=0,082 \mathrm{MJ} / \mathrm{m}^{2} / \mathrm{min}$.

$E_{0}$ : Factor de corrección de la excentricidad de la Tierra $\left(r_{0} / r\right)^{2}$ en la ecuación (Ec. 3.5.2).

$r_{0}$ : Distancia media Sol-Tierra, 1 ua.

r: Distancia actual Sol-Tierra (ua).

ua: Unidad astronómica $=1,49610^{8} \mathrm{~km}$.

$$
\mathrm{E}_{0}=1+0,033 \cos \frac{2 \pi \mathrm{J}}{365}
$$

J: Número de día del año, 1 para el 1 de enero, 365 para el 31 de diciembre.

$\omega_{s}$ : Ángulo horario a la puesta del Sol (rad) en la ecuación (Ec. 3.5.3). Definido como el desplazamiento angular del Sol al este o al oeste del meridiano local debido a la rotación de la Tierra sobre su eje, a $15^{\circ}$ por hora, por la mañana (-), al mediodía (0) y por la tarde (+).

$$
\omega_{\mathrm{s}}=\cos ^{-1}[-\operatorname{tg} \phi \operatorname{tg} \delta]
$$

$\phi$ : Latitud geográfica ( $\mathrm{rad})$, al norte $(+)$ y al sur $(-):-90^{\circ} \leq \phi \leq 90^{\circ} .(\mathrm{rad})=\pi / 180\left({ }^{\circ}\right.$ decimales $)$.

$\delta$ : Declinación solar (rad) en la ecuación (Ec. 3.5.4). Definida como la posición angular del Sol al mediodía solar, es decir, cuando el Sol está en el meridiano local, con respecto al plano del ecuador de la Tierra, al norte (+) y al sur (-): $-23,45^{\circ} \leq \delta \leq 23,45^{\circ}$.

$$
\delta=0,409 \operatorname{sen}\left(\frac{2 \pi \mathrm{J}}{365}-1,39\right)
$$

Estos valores se desvían levemente de los valores en los Cuadros Smithsonianos. Para los meses invernales en las latitudes norte o sur mayores a $55^{\circ}$, la ecuación (Ec. 3.5.1) tiene validez limitada. Se debe comparar con los valores presentados en los Cuadros Smithsonianos para evaluar posibles desviaciones. 


\section{2) Metodología de cálculo de la irradiación solar extraterrestre horaria}

La irradiación solar extraterrestre es la irradiación solar recibida en los límites de la atmósfera terrestre, para diversas latitudes se puede estimar a partir de la constante solar, la declinación solar y la época del año, para periodos horarios o menores para ello debe ser tenido en cuenta el ángulo solar al principio y al final del periodo considerado (Allen, 2006), (Duffie y Beckman, 2006) y (Kalogirou, 2009) mediante la ecuación (Ec. 3.5.5).

$$
I_{0}=\left(\frac{12 \cdot 60}{\pi}\right) I_{s c} E_{0}\left[\left(\omega_{2}-\omega_{1}\right) \operatorname{sen} \phi \operatorname{sen} \delta+\cos \phi \cos \delta\left(\operatorname{sen} \omega_{2}-\operatorname{sen} \omega_{1}\right)\right]
$$

Donde,

$\mathrm{I}_{0}$ : Irradiación solar extraterrestre horaria incidente sobre una superficie horizontal $\left(\mathrm{MJ} / \mathrm{m}^{2} / \mathrm{h}\right)$.

$\mathrm{I}_{\mathrm{sc}}$ : Constante solar $0,082 \mathrm{MJ} / \mathrm{m}^{2} / \mathrm{min}$.

$\omega_{1}$ : Ángulo horario solar al inicio del periodo (rad) en la ecuación (Ec. 3.5.6).

$$
\omega_{1}=\omega-\frac{\pi t_{1}}{24}
$$

$\omega$ : Ángulo horario solar en el momento en que ocurre el punto medio del periodo considerado (rad) en la ecuación (Ec. 3.2.7).

$t_{1}$ : Duración del periodo considerado (horas), 1 para periodos horarios, 0,5 para periodos de 30 minutos.

$$
\omega=\frac{\pi}{12}\left[\left(t+0,06667\left(L_{z}-L_{m}\right)+S_{c}\right)-12\right]
$$

t: Hora estándar en el punto medio del periodo considerado $(\mathrm{h})$, para un periodo entre las $14 \mathrm{~h} 00$ y las $15 \mathrm{~h} 00, \mathrm{t}=14,5$.

$\mathrm{L}_{2}$ : Longitud geográfica del centro de la zona de tiempo local (grados Oeste de Greenwich): $75^{\circ}$ Este, $90^{\circ}$ Central, $105^{\circ}$ Rocky Mountain, $120^{\circ}$ Pacífico USA, $0^{\circ}$ Greenwich, $330^{\circ}$ El Cairo, $255^{\circ}$ Bangkok, $345^{\circ}$ España Península Ibérica.

$L_{m}$ : Longitud geográfica de la zona de medición (grados Oeste de Greenwich).

$\mathrm{S}_{c}$ : Corrección estacional para el tiempo solar (horas) en las ecuaciones (Ec. 3.5.8) y (Ec. 3.5.9).

$$
\begin{gathered}
S_{c}=0,1645 \operatorname{sen} 2 b-0,1255 \cos b-0,025 \operatorname{sen} b \\
b=\frac{2 \pi(J-81)}{364}
\end{gathered}
$$

$\omega_{2}$ : Ángulo horario solar al final del periodo (rad) en la ecuación (Ec. 3.5.10).

$$
\omega_{2}=\omega+\frac{\pi t_{1}}{24}
$$

Por la mañana $\omega<-\omega_{\mathrm{s}}$ ó por la tarde $\omega>\omega_{\mathrm{s}}$ indica que el Sol está bajo el horizonte de manera que $I_{0}=0$.

Es necesario tener también en cuenta el adelanto horario de la hora del reloj sobre la hora oficial: UTC+1 horario de invierno a partir del último domingo de octubre y UTC+2 horario de verano a partir del último domingo de marzo. 


\subsubsection{Modelado de la irradiación solar difusa horizontal}

El modelado de la irradiación solar difusa horizontal a partir del índice de claridad horario $\left(\mathrm{k}_{\mathrm{t}}=\mathrm{l} / \mathrm{l}_{0}\right)$ y el índice de la fracción difusa horaria $\left(k_{d}=l_{d} / l\right)$, se lleva a cabo con el modelo de tercer orden (Miguel et al., 2001) que utiliza datos de varios países de la zona norte del Mediterráneo para su realización resultando (Ec. 3.5.11).

$$
\mathrm{k}_{\mathrm{d}}=\left\{\begin{array}{lc}
0,995-0,081 \mathrm{k}_{\mathrm{t}} & \mathrm{k}_{\mathrm{t}} \leq 0,21 \\
0,724+2,738 \mathrm{k}_{\mathrm{t}}-8,32 \mathrm{k}_{\mathrm{t}}^{2}+4,967 \mathrm{k}_{\mathrm{t}}^{3} \text { para } 0,21<\mathrm{k}_{\mathrm{t}} \leq 0,76 \\
0,18 & 0,76<\mathrm{k}_{\mathrm{t}}
\end{array}\right.
$$

\subsubsection{Modelado de la altura solar y el ángulo zenit}

La altura solar, también llamada elevación solar, es la altura angular del Sol sobre el horizonte celeste del observador, es un ángulo de entre $0^{\circ}$ y $90^{\circ}$.

El ángulo zenit, también llamado distancia cenital, es el ángulo entre el zenit local y la línea que une al observador y el Sol, es un ángulo de entre $0^{\circ}$ y $90^{\circ}$.

La altura solar es el complemento del ángulo zenit. Para una posición geográfica dada, en ausencia de la refracción atmosférica de la tierra, la relación trigonométrica entre el Sol y una superficie horizontal es la ecuación (Ec. 3.5.12), (Iqbal, 1983).

$$
\cos \theta_{z}=\operatorname{sen} \delta \operatorname{sen} \phi+\cos \delta \cos \phi \cos \omega=\operatorname{sen} \alpha
$$

Donde,

$\alpha$ : Altura solar. Ángulo de elevación del Sol por encima del horizonte verdadero.

$\theta_{z}$ : Ángulo zenit. Posición angular del Sol con respecto a la vertical local, $\theta_{z}=90^{\circ}-\alpha$.

\subsubsection{Modelado del ángulo de incidencia de la irradiación solar sobre el captador}

El ángulo de incidencia es el ángulo formado entre la normal al plano inclinado y el vector Sol-Tierra. Pueden darse dos casos:

1) El plano inclinado está orientado hacia el ecuador.

2) El plano inclinado tiene una orientación arbitraria hacia el este o al oeste.

\section{1) Metodología de cálculo del ángulo de incidencia de un captador inclinado y orientado hacia el ecuador}

El ángulo de incidencia para una superficie inclinada y orientada hacia el ecuador puede describirse como la ecuación (Ec. 3.5.13), (Liu y Jordan, 1961). 


$$
\cos \theta_{0}=\operatorname{sen} \delta \operatorname{sen}(\phi-\beta)+\cos \delta \cos (\phi-\beta) \cos \omega
$$

Donde,

$\theta_{0}$ : Ángulo de incidencia para una superficie inclinada y orientada hacia el ecuador.

$\beta$ : Inclinación de la superficie respecto a la posición horizontal.

\section{2) Metodología de cálculo del ángulo de incidencia en un captador inclinado y orientado arbitrariamente}

El ángulo de incidencia para una superficie inclinada y orientada en cualquier dirección con respecto al meridiano local, sigue una relación trigonométrica (Berod y Bock, 1934), (Kondratyev, 1969) y (Coffari, 1977), para el cálculo del ángulo de incidencia se puede describir en las dos formas siguientes (Ec. 3.5.14).

$$
\begin{gathered}
\cos \theta=(\operatorname{sen} \phi \cos \beta-\cos \phi \operatorname{sen} \beta \cos \gamma) \operatorname{sen} \delta+(\cos \phi \cos \beta+\operatorname{sen} \phi \operatorname{sen} \beta \cos \gamma) \cos \delta \cos \omega \\
+\cos \delta \operatorname{sen} \beta \operatorname{sen} \gamma \operatorname{sen} \omega
\end{gathered}
$$

Donde,

$\theta$ : Ángulo de incidencia para una superficie inclinada y orientada arbitrariamente.

O también con (Ec. 3.5.15).

$$
\cos \theta=\cos \beta \cos \theta_{\mathrm{z}}+\operatorname{sen} \beta \cos \theta_{\mathrm{z}} \cos (\psi-\gamma)
$$

Donde,

$\gamma$ : Ángulo azimut de superficie, orientación. Definida como la desviación de la normal a la superficie del captador solar con respecto al meridiano local, oeste (-), sur (0) y este (+). $\psi$ : Azimut solar (Ec. 3.2.16). Ángulo en el zenit local entre el plano del meridiano del observador y el plano de un gran círculo que pasa por el zenit y el Sol, oeste (-), sur (0) y este $(+):-180^{\circ} \leq 0^{\circ} \leq$ $+180^{\circ}$.

$$
\begin{aligned}
& \cos \psi=\frac{(\operatorname{sen} \alpha \operatorname{sen} \phi-\operatorname{sen} \delta)}{\cos \alpha \cos \phi} \\
& 0^{\circ} \leq \psi \leq 90^{\circ}, \quad \cos \psi \geq 0 \\
& 90^{\circ} \leq \psi \leq 180^{\circ}, \quad \cos \psi \leq 0
\end{aligned}
$$

\section{3) Medida del ángulo de incidencia de la irradiación solar directa}

La medida del ángulo de incidencia de la irradiación solar directa se puede realizar construyendo un dispositivo simple, mediante el montaje de un puntero normal a una superficie plana, en la cual se marcan circunferencias concéntricas graduadas. Se puede medir la longitud de la sombra proyectada por el puntero utilizando las circunferencias concéntricas y usarla para determinar el ángulo de incidencia. El dispositivo debe ubicarse en el plano y a un lado del captador solar, UNE-EN 12975-2 (AENOR, 2006). 


\subsection{Modelado neural de los componentes del sistema solar térmico}

El éxito en la simulación de los sistemas solares térmicos depende en gran medida de la disponibilidad de modelos para la simulación eficiente de los componentes que forman el sistema solar térmico. El captador solar, el depósito acumulador y su intercambiador de calor son los componentes esenciales que contribuyen a optimizar el rendimiento de los sistemas solares térmicos de agua caliente. La técnica escogida para ello en esta Tesis Doctoral son las redes neuronales artificiales aplicadas a la teoría de las series de tiempo constituidas por los datos del proceso de funcionamiento del sistema (Apartado 2.5) capítulo Estado del Arte, que han sido tomados en el sistema solar térmico (Anexo 2 Datos de los ensayos en la planta piloto).

Con los datos medidos y registrados del funcionamiento de cada componente en el sistema solar térmico se entrenan las redes neuronales artificiales, construyendo los modelos que caracterizan a los componentes, para los que no existe un modelo preciso de análisis debido a la complejidad de la física involucrada y que a la vez sean fácilmente aplicables.

En esta Tesis Doctoral, la tecnología de redes neuronales artificiales se utiliza para el modelado de los componentes de un sistema solar térmico. Las redes neuronales artificiales son modelos computacionales que pueden considerarse como un intento de simular de manera más sencilla la estructura y funciones del cerebro humano.

\subsubsection{Modelado del captador solar con redes neuronales artificiales}

En esta Tesis Doctoral para el modelado del captador solar se utiliza un modelo black box, con tecnología de redes neuronales artificiales, se utilizan cuatro entradas al modelo:

- La irradiancia solar incidente sobre el captador solar.

- La temperatura ambiente del entorno al captador solar.

- La temperatura del fluido portador de entrada al captador solar.

- El caudal del fluido portador en el captador dado por la bomba del circuito primario.

Y una salida para:

- La temperatura del fluido portador de salida del captador solar.

Esto sería para un solo captador solar, caso de la planta piloto utilizada para los ensayos realizados en el laboratorio, en los sistemas solares térmicos se entiende por captador solar, el campo de captación completo, siendo las temperaturas de ida y de retorno, las temperaturas de salida y de entrada del fluido portador al campo de captadores, con lo que así se modela todos los captadores en su funcionamiento conjunto.

La arquitectura de la red neuronal artificial diseñada para el modelado del comportamiento del captador solar se muestra (Fig. 3.6.1), con la capa de entrada para cuatro neuronas correspondientes a: 
- La irradiancia solar $\left(\mathrm{W} / \mathrm{m}^{2}\right)$.

- La temperatura ambiente $\left({ }^{\circ} \mathrm{C}\right)$.

- La temperatura de retorno $\left({ }^{\circ} \mathrm{C}\right)$.

- El caudal en el captador solar ( $\mathrm{l} / \mathrm{min})$.

La capa de salida tiene una neurona, correspondiente a:

- La temperatura de ida del captador solar $\left({ }^{\circ} \mathrm{C}\right)$.

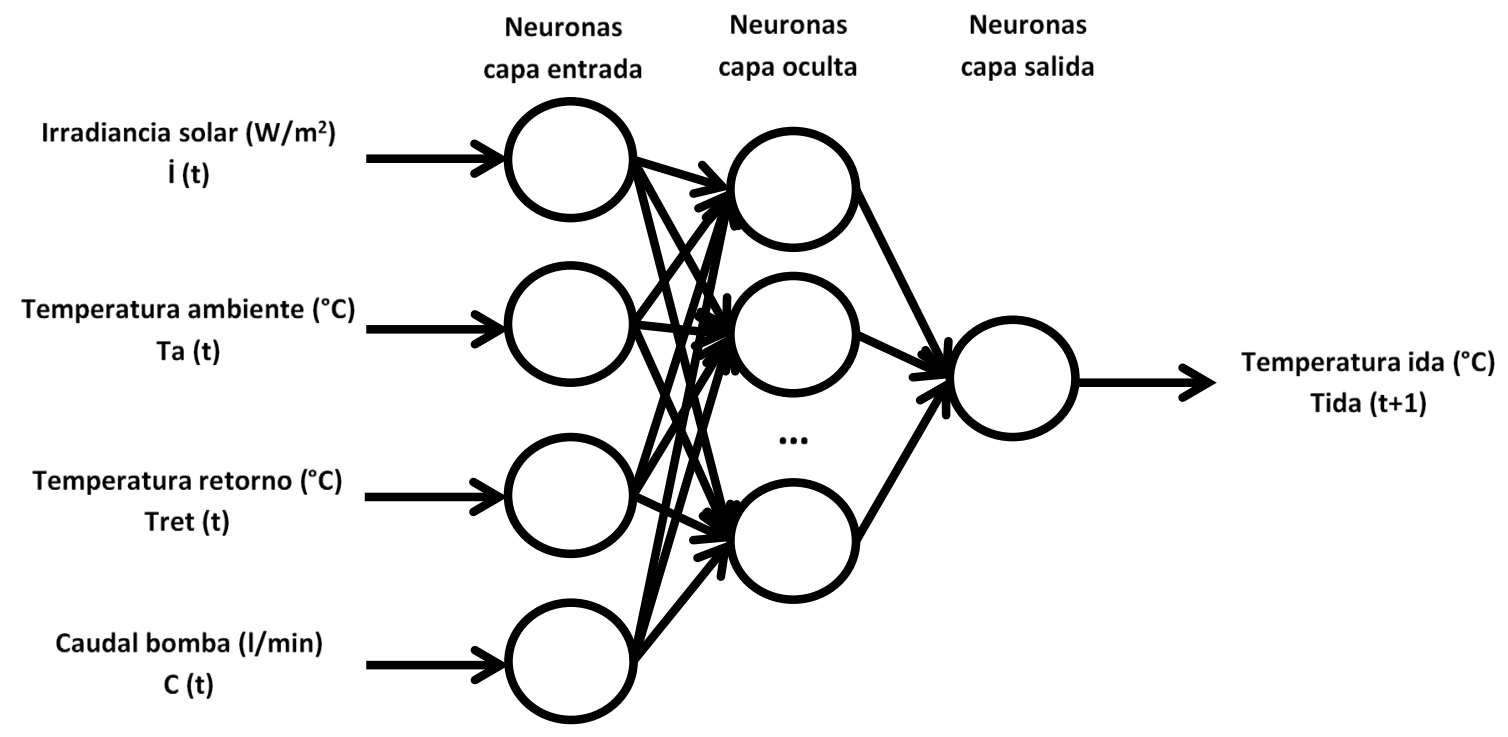

Fig. 3.6.1 Estructura de la red neuronal artificial diseñada para la predicción de la temperatura de ida del captador solar, respecto de la irradiancia solar incidente, la temperatura ambiente, la temperatura y caudal del fluido portador de retorno al captador solar

\subsubsection{Modelado del intercambiador de calor con redes neuronales artificiales}

En esta Tesis Doctoral para el modelado del intercambiador de calor se utiliza un modelo black box, con tecnología de redes neuronales artificiales, se utilizan diez entradas al modelo:

- La temperatura del fluido portador en la entrada del intercambiador de calor.

- Las temperaturas de estratificación en las 8 capas del depósito acumulador.

- El caudal del fluido portador en el intercambiador de calor.

Y una salida para:

- La temperatura del fluido portador en la salida del intercambiador.

Las temperaturas de estratificación de las capas en las que no está sumergido el intercambiador de calor, pueden ser eliminadas, como entradas de la red neuronal artificial al no tener un efecto directo a corto plazo sobre la velocidad de transferencia de calor del intercambiador, siempre y cuando sea conocida la disposición interna del intercambiador de calor dentro del depósito acumulador.

Las pérdidas térmicas de las tuberías que unen el captador solar y el intercambiador de calor, en el caso de la planta piloto no se han tenido en cuenta al tratarse de tramos muy cortos de tubería y estar aisladas térmicamente, se despreció su valor al considerarse muy pequeño. En el caso de instalaciones en las que 
si deba tenerse en cuenta su valor, debido por ejemplo a su largo recorrido, se modelaría su funcionamiento con otra red neuronal artificial en la que se utilizarían los valores de las temperaturas de entrada y salida del fluido portador al tramo de la tubería en estudio, su caudal y la temperatura ambiente que le rodea, considerándose otro componente del sistema solar térmico.

En los sistemas solares térmicos que utilizan un intercambiador de calor externo, las variables utilizadas en la red neuronal artificial serían las temperaturas y caudales de los dos fluidos que circulan por el intercambiador de calor, pudiéndose añadir además la temperatura ambiente que rodea al intercambiador de calor que influye sobre sus pérdidas. En el caso de utilizar un intercambiador externo las temperaturas de la estratificación térmica del depósito no se tendrían que tener en cuenta al modelar el intercambiador de calor externo.

La arquitectura de la red neuronal artificial diseñada para el modelado del comportamiento del intercambiador de calor sumergido en el depósito de la planta piloto se muestra (Fig. 3.6.2), con la capa de entrada para diez neuronas correspondientes a:

- La temperatura de ida al captador solar $\left({ }^{\circ} \mathrm{C}\right)$.

- Las temperaturas de las 8 capas del depósito acumulador $\left({ }^{\circ} \mathrm{C}\right)$.

- El caudal en el intercambiador de calor ( $1 / \mathrm{min})$.

La capa de salida tiene una neurona, correspondiente a:

- La temperatura de retorno al captador solar $\left({ }^{\circ} \mathrm{C}\right)$.

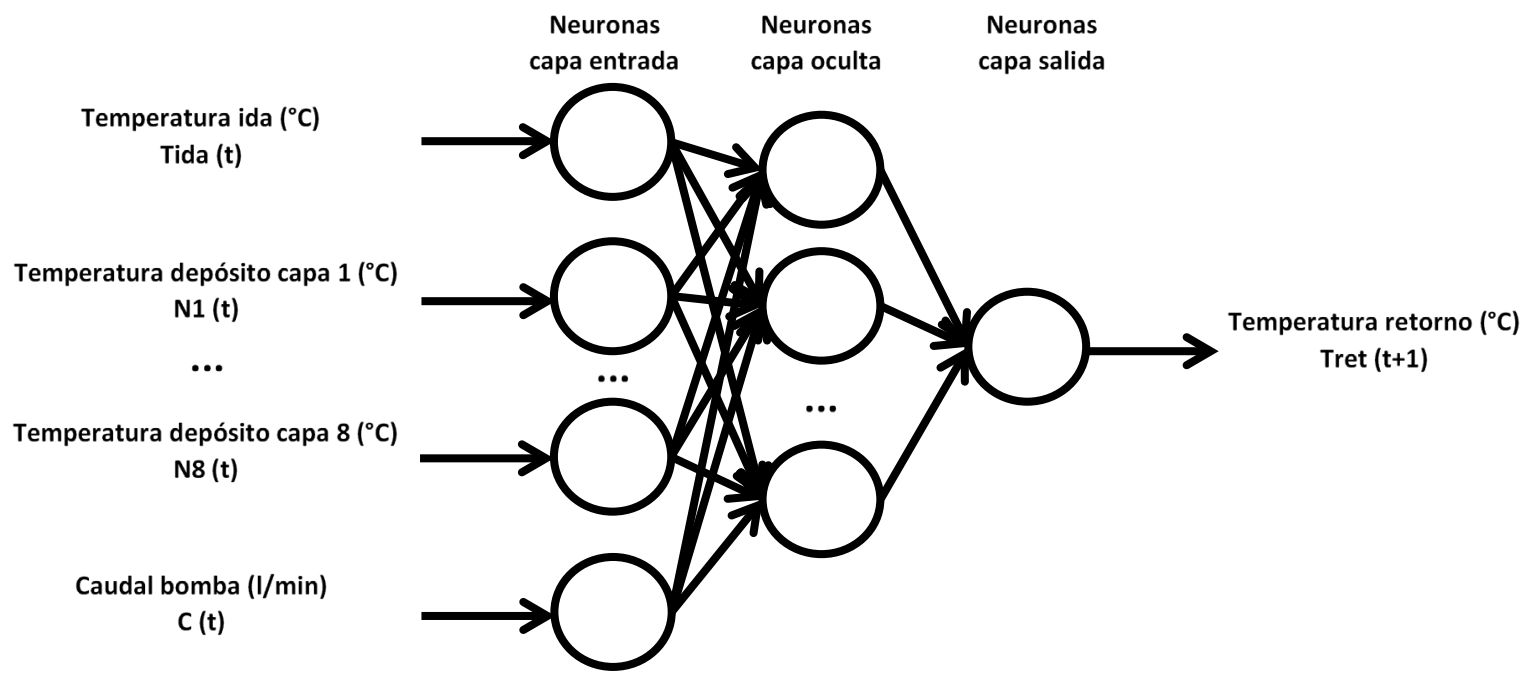

Fig. 3.6.2 Estructura de la red neuronal artificial diseñada para la predicción de la temperatura de retorno al captador solar, respecto de las temperaturas de estratificación del depósito, la temperatura y caudal del fluido portador de ida del captador solar 


\subsubsection{Modelado de la estratificación térmica del agua caliente solar en el depósito acumulador con redes neuronales artificiales}

En el modelado de la estratificación térmica del agua caliente solar en el depósito acumulador del sistema solar térmico, sean identificado cuatro posibles estados o situaciones de funcionamiento que se traducen en cuatro modelos, que predicen la evolución de las temperaturas de la estratificación, en el siguiente lapso de tiempo, para cada estado del sistema solar térmico, que se exponen a continuación:

1) El modelado de las temperaturas de la estratificación térmica en condiciones de insolación, denominado estado SOL, en el cual la bomba del circuito primario está en funcionamiento, aportando energía solar al depósito, carga.

2) El modelado de las temperaturas de la estratificación térmica en condiciones de insolación y de consumo de agua caliente solar, denominado estado SOL + ACS, en el cual la bomba del circuito primario está en funcionamiento, aportando energía solar al depósito acumulador y además se está descargando del depósito agua caliente solar para el consumo, carga y descarga. Suele ser de corta duración respecto al estado SOL.

3) El modelado de las temperaturas de la estratificación térmica en condiciones de baja o nula insolación, denominado estado NOCHE, en el cual la bomba del circuito primario no está funcionando, por lo que no se aporta energía solar al depósito acumulador, sin carga y sin descarga. Este estado se da por la noche y los días nublados con una baja irradiancia solar.

4) El modelado de las temperaturas de la estratificación en condiciones de baja o nula insolación y de consumo de agua caliente solar, denominado estado NOCHE + ACS, en el cual la bomba del circuito primario no está funcionando, por lo que no se aporta energía solar al depósito y además se está descargando del depósito agua caliente solar para el consumo, sin carga y con descarga. Suele ser de corta duración respecto al estado NOCHE.

La temperatura ambiente que rodea al depósito acumulador es una variable que influye en las pérdidas del depósito acumulador y por lo tanto en la evolución de la estratificación térmica, pero en el modelado de la estratificación térmica del depósito acumulador de la planta piloto (Apartado 3.1) no se consideró, ya que se observó que la temperatura del laboratorio era lo suficientemente constante a lo largo del tiempo, por lo que su efecto ya queda incrustado en los datos medidos y registrados para el entrenamiento de las redes neuronales artificiales, pudiéndose tener en cuenta en otros sistemas solares térmicos en el que la ubicación del depósito así lo aconseje por sus cambios de temperatura ambiente. 


\section{1) Modelado de la estratificación térmica en el estado: SOL}

En esta Tesis Doctoral para el modelado de la estratificación térmica del depósito acumulador en el estado SOL en condiciones de insolación, se utiliza un modelo black box, con tecnología de redes neuronales artificiales, se utilizan diez entradas al modelo:

- La temperatura del fluido portador en la entrada del intercambiador de calor.

- Las temperaturas de estratificación en las 8 capas del depósito acumulador.

- El caudal del fluido portador en el intercambiador de calor.

Y ocho salidas para:

- Las temperaturas de estratificación las 8 capas del depósito acumulador.

La arquitectura de la red neuronal artificial diseñada para el modelado del comportamiento de la estratificación térmica en el depósito acumulador de la planta piloto en el estado SOL, se muestra (Fig. 3.6.3), con la capa de entrada para diez neuronas correspondientes a:

- La temperatura de ida al captador solar $\left({ }^{\circ} \mathrm{C}\right)$.

- Las temperaturas de las 8 capas del depósito acumulador $\left({ }^{\circ} \mathrm{C}\right)$.

- El caudal en el intercambiador de calor (I/min).

La capa de salida tiene ocho neuronas, correspondientes a:

- Las temperaturas de las 8 capas del depósito acumulador $\left({ }^{\circ} \mathrm{C}\right)$.

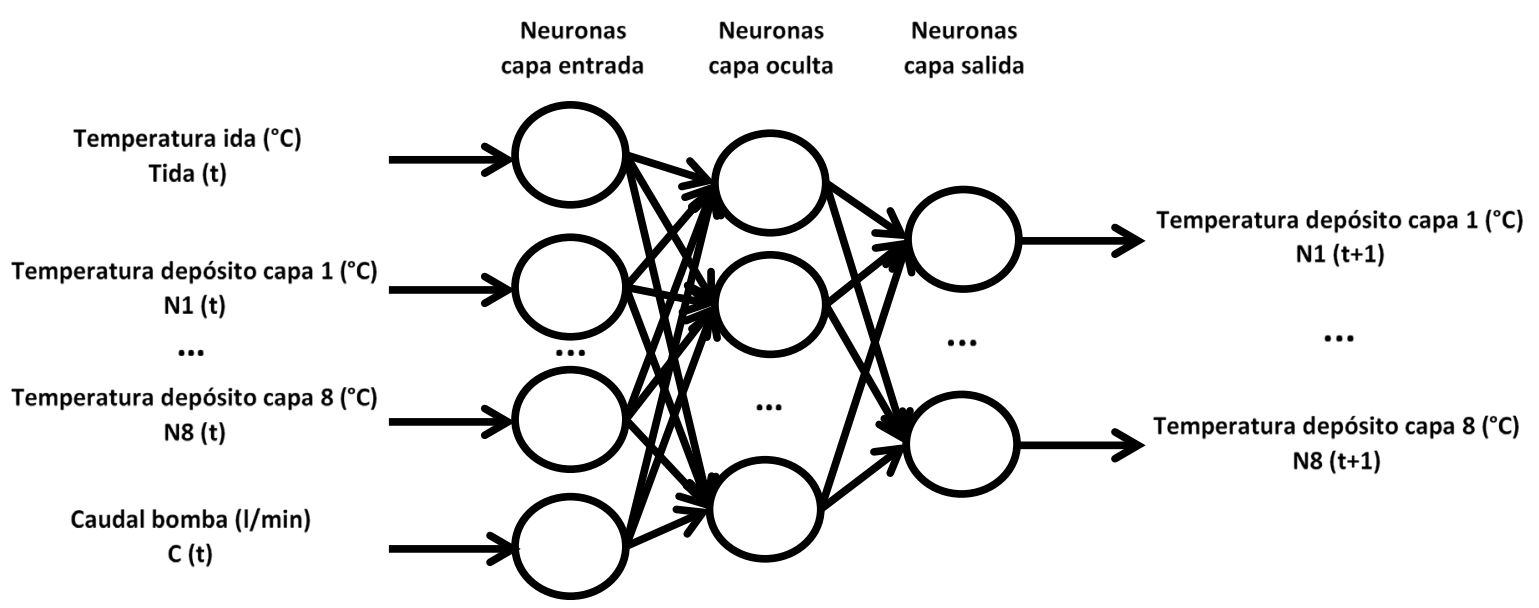

Fig. 3.6.3 Estructura de la red neural artificial diseñada para la predicción de las temperaturas de la estratificación del depósito, respecto a la temperatura de ida y el caudal del fluido portador en el circuito primario y las temperaturas de estratificación en el lapso de tiempo anterior

\section{2) Modelado de la estratificación térmica en el estado: SOL + ACS}

En esta Tesis Doctoral para el modelado de la estratificación térmica del depósito acumulador en el estado $\mathrm{SOL}+\mathrm{ACS}$ en condiciones de insolación y de descarga de agua caliente solar, se utiliza un modelo black box, con tecnología de redes neuronales artificiales, se utilizan doce entradas al modelo: 
- La temperatura de ida del fluido portador en la entrada del intercambiador de calor.

- Las temperaturas de estratificación en las 8 capas del depósito acumulador.

- El caudal de agua caliente solar consumido.

- La temperatura del agua de red en la entrada del depósito acumulador.

- El caudal del fluido portador en el intercambiador de calor.

Y ocho salidas para:

- Las temperaturas de estratificación en las 8 capas del depósito acumulador.

La arquitectura de la red neuronal artificial diseñada para el modelado del comportamiento de la estratificación térmica en el depósito acumulador de la planta piloto en el estado SOL + ACS, se muestra (Fig. 3.6.4), con la capa de entrada para doce neuronas correspondientes a:

- La temperatura de ida al captador solar $\left({ }^{\circ} \mathrm{C}\right)$.

- Las temperaturas de las 8 capas del depósito acumulador $\left({ }^{\circ} \mathrm{C}\right)$.

- El caudal de descarga en agua caliente solar consumido (I/min).

- La temperatura del agua de red $\left({ }^{\circ} \mathrm{C}\right)$.

- El caudal en el intercambiador de calor ( $/ / \mathrm{min})$.

La capa de salida tiene ocho neuronas, correspondientes a:

- Las temperaturas de las 8 capas del depósito acumulador $\left({ }^{\circ} \mathrm{C}\right)$.

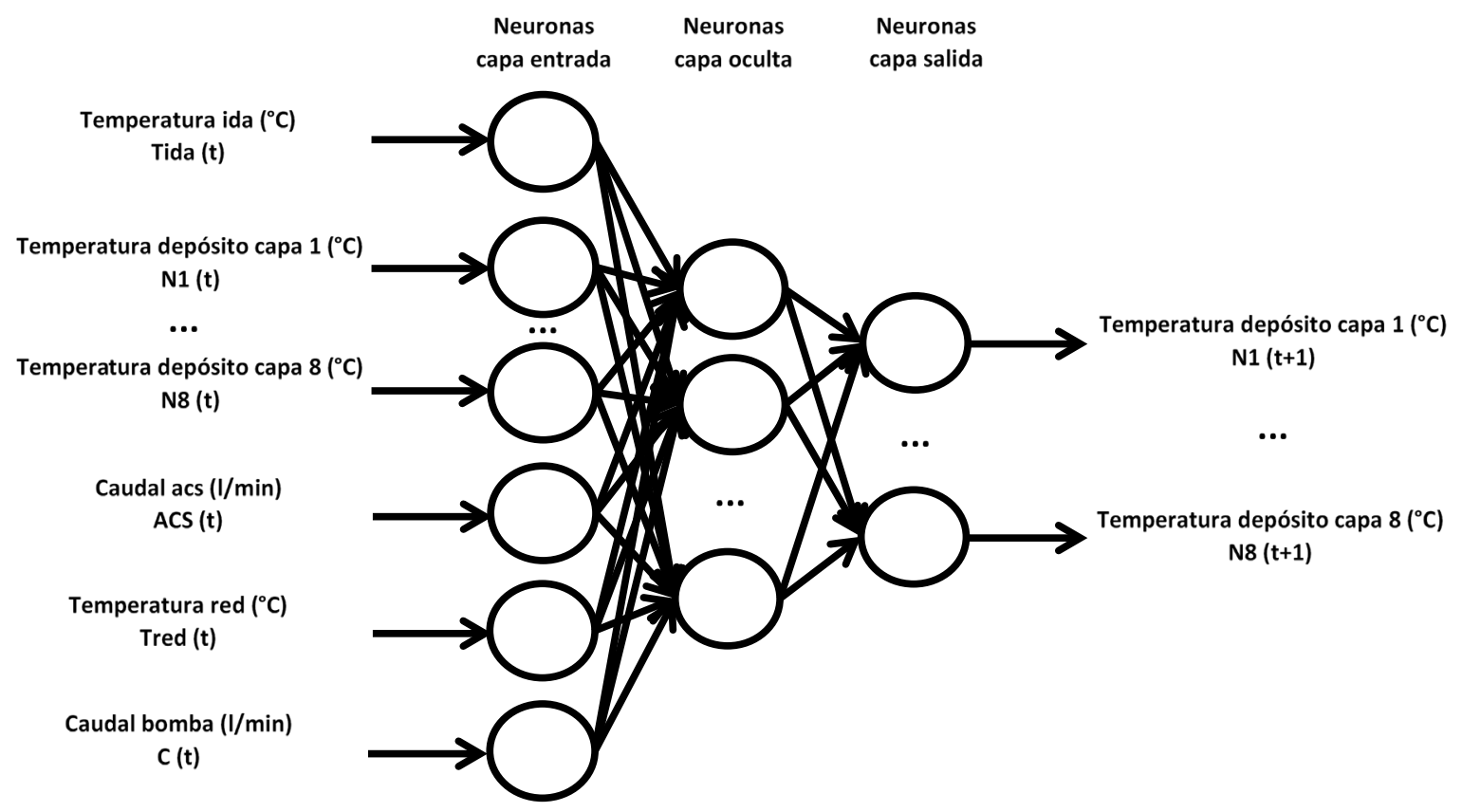

Fig. 3.6.4 Estructura de la red neuronal artificial diseñada para la predicción de las temperaturas de la estratificación del depósito, respecto a la temperatura de ida y el caudal del fluido portador en el circuito primario, las temperaturas de estratificación, el caudal de agua caliente solar consumida y la temperatura del agua de red en el lapso de tiempo anterior 


\section{3) Modelado de la estratificación térmica en el estado: NOCHE}

En esta Tesis Doctoral para el modelado de la estratificación térmica del depósito acumulador en el estado NOCHE durante la noche o con el cielo nublado en condiciones de baja insolación se utiliza un modelo black box, con tecnología de redes neuronales artificiales, se utilizan ocho entradas al modelo:

- Las temperaturas de estratificación en las 8 capas del depósito acumulador.

Y ocho salidas para:

- Las temperaturas de estratificación en las 8 capas del depósito acumulador.

La arquitectura de la red neuronal artificial diseñada para el modelado del comportamiento de la estratificación térmica en el depósito acumulador de la planta piloto en el estado NOCHE, se muestra (Fig. 3.6.5), con la capa de entrada para ocho neuronas correspondientes a:

- Las temperaturas de las 8 capas del depósito acumulador $\left({ }^{\circ} \mathrm{C}\right)$.

La capa de salida tiene ocho neuronas, correspondientes a:

- Las temperaturas de las 8 capas del depósito acumulador $\left({ }^{\circ} \mathrm{C}\right)$.

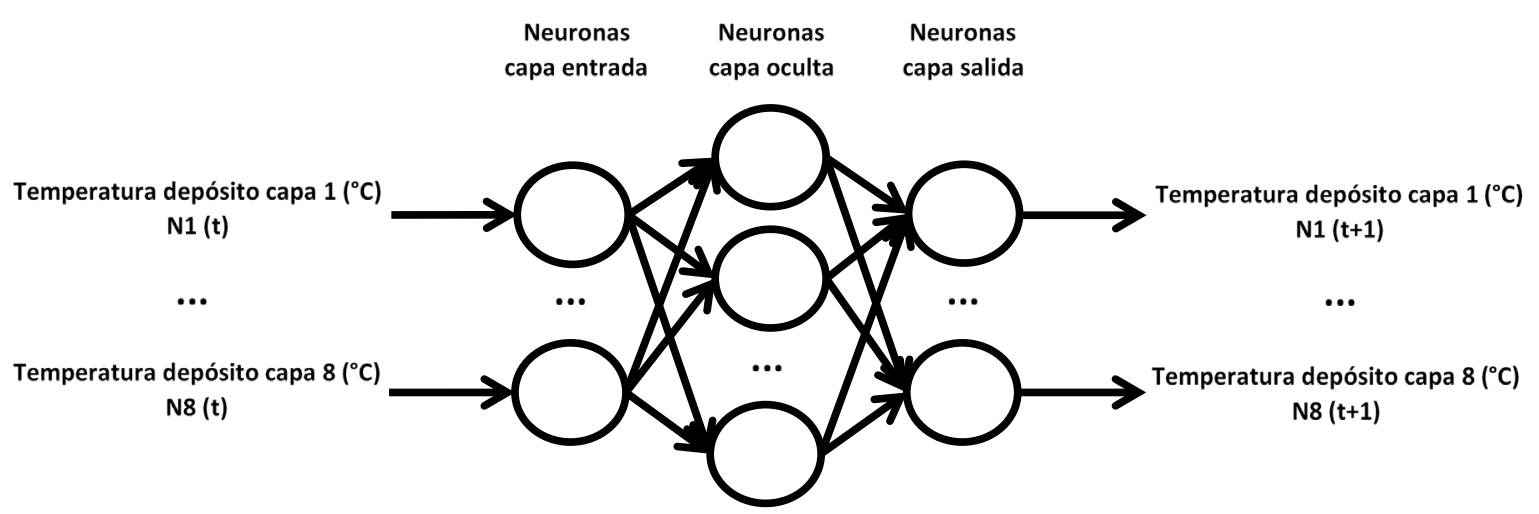

Fig. 3.6.5 Estructura de la red neural artificial diseñada para la predicción de las temperaturas de la estratificación del depósito, respecto a las temperaturas de estratificación en el lapso de tiempo anterior 


\section{4) Modelado de la estratificación térmica en el estado: NOCHE + ACS}

En esta Tesis Doctoral para el modelado de la estratificación térmica del depósito acumulador en el estado NOCHE + ACS durante la noche o con el cielo nublado y efectuando la descarga de agua caliente solar, se utiliza un modelo black box, con tecnología de redes neuronales artificiales, se utilizan diez entradas al modelo:

- Las temperaturas de estratificación en las 8 capas del depósito acumulador.

- El caudal de agua caliente solar consumido.

- La temperatura del agua de red en la entrada del depósito acumulador.

Y ocho salidas para:

- Las temperaturas de estratificación en las 8 capas del depósito acumulador.

La arquitectura de la red neuronal artificial diseñada para el modelado del comportamiento de la estratificación térmica en el depósito acumulador de la planta piloto en el estado NOCHE + ACS, se muestra (Fig. 3.6.6), con la capa de entrada para diez neuronas correspondientes a:

- Las temperaturas de las 8 capas del depósito acumulador $\left({ }^{\circ} \mathrm{C}\right)$.

- El caudal de descarga en agua caliente solar consumido ( $/ / \mathrm{min})$.

- La temperatura del agua de red $\left({ }^{\circ} \mathrm{C}\right)$.

La capa de salida tiene ocho neuronas, correspondientes a:

- Las temperaturas de las 8 capas del depósito acumulador $\left({ }^{\circ} \mathrm{C}\right)$.

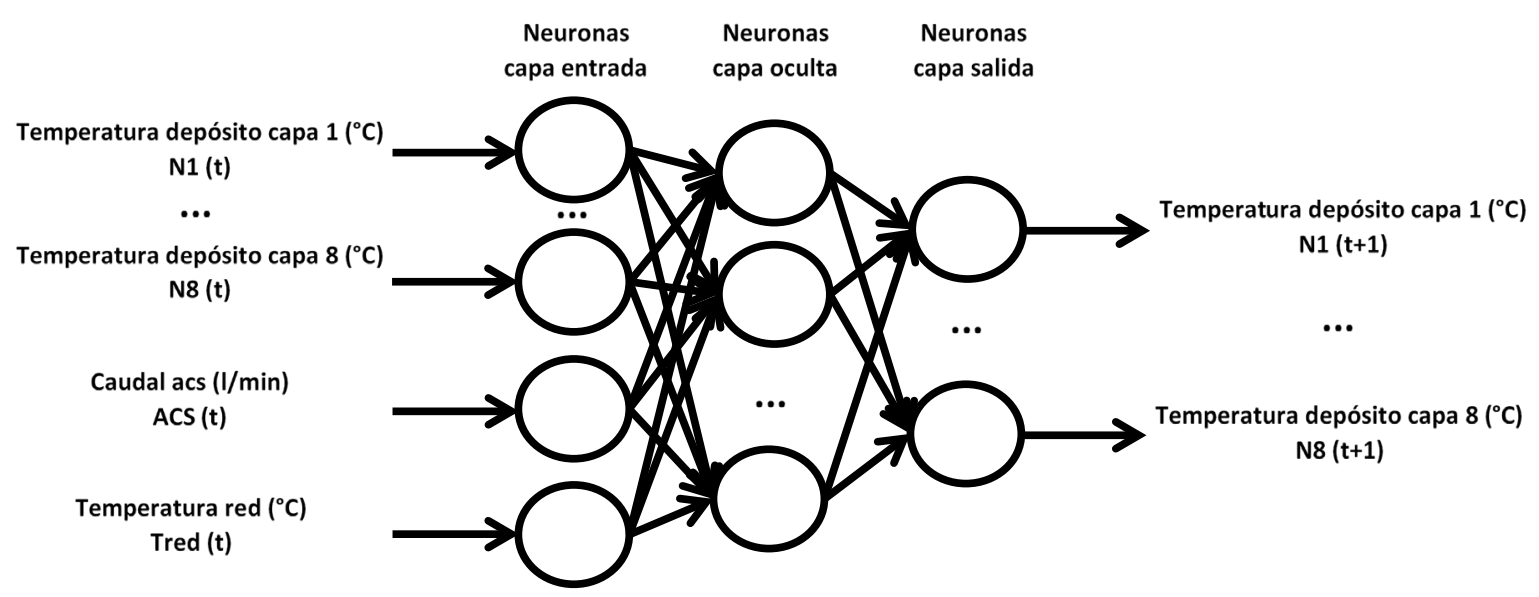

Fig. 3.6.6 Estructura de la red neuronal artificial diseñada para la predicción de las temperaturas de la estratificación del depósito, respecto a las temperaturas de estratificación, el caudal de agua caliente solar consumida y la temperatura del agua de red en el lapso de tiempo anterior 


\subsection{Simulación neural del sistema solar térmico}

El modelado de un sistema solar térmico como el construido (Apartado 3.1), se realizó en esta Tesis Doctoral conectando los modelos implementados con redes neuronales artificiales para cada componente de la instalación solar:

- El captador solar (Apartado 3.6.1).

- El intercambiador de calor (Apartado 3.6.2).

- El depósito acumulador estratificado (Apartado 3.6.3) este último con cuatro modelos para cada estado posible de funcionamiento.

o SOL: Solo con carga.

o SOL + ACS: Con carga y descarga.

o NOCHE: Sin carga ni descarga.

o NOCHE + ACS: Solo descarga.

Se utilizó para su desarrollo, un entorno de programación visual como la herramienta de simulación de modelos o sistemas Simulink de Matlab. Los modelos desarrollados con redes neuronales artificiales a partir de los datos registrados en el sistema solar térmico de la planta piloto, se convierten en bloques funcionales del programa Simulink mediante la función 'gensim' (Demuth et al., 2010).

>> gensim(net);

La función 'gensim' genera un bloque que representa la red neuronal artificial 'net' para que pueda ser usado en la simulación con Simulink. El tiempo de muestreo queda ajustado en este caso a un minuto a fin de tener en cuenta las condiciones más realistas de funcionamiento del sistema solar térmico, pudiendo ajustarse otro intervalo de tiempo, según se hayan entrenado los modelos neurales correspondientes a los componentes del sistema solar térmico.

El modelo del sistema solar térmico de la planta piloto se forma como se muestra en el esquema (Fig. 3.7.1). Las entradas que recibe el modelado de la planta piloto son las siguientes:

- La irradiancia solar $\left(\mathrm{W} / \mathrm{m}^{2}\right)$.

- La temperatura ambiente $\left({ }^{\circ} \mathrm{C}\right)$.

- El caudal de agua caliente solar consumido ( $/ / \mathrm{min})$.

- La temperatura del agua de la red $\left({ }^{\circ} \mathrm{C}\right)$.

Estas variables de entrada se introducen con los valores que toman cada minuto, durante el periodo de tiempo en que se realiza la simulación del funcionamiento de la planta piloto.

Antes del comienzo de la simulación se ajustan los siguientes parámetros del sistema solar térmico de la planta piloto:

- Se fija el caudal de funcionamiento de la bomba de impulsión.

- Se fija el valor de la irradiancia solar de consigna, para el cual la bomba se para, en el bloque de consigna de la irradiancia solar (Fig. 3.7.2). 
- Se fijan los valores de la temperatura en las ocho capas del depósito acumulador, con las que comienza la simulación, en el bloque estado inicial de la estratificación (Fig. 3.7.3).

- Los valores de la temperatura en las tuberías de ida y retorno, iniciales a la simulación también pueden ser fijados, para los que se observó su rápido posicionamiento a valores reales.

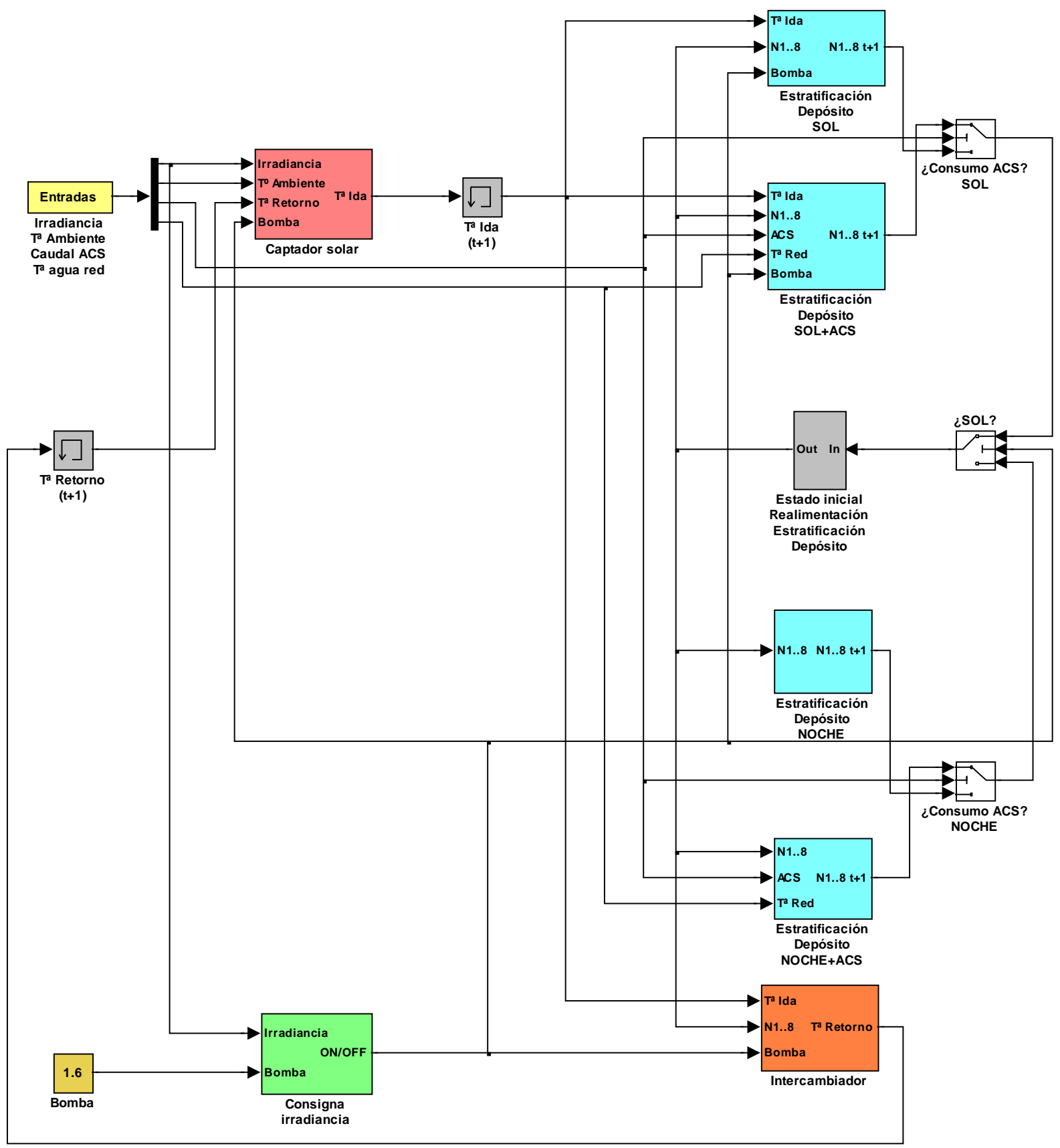

Fig. 3.7.1 Modelado de la planta piloto desarrollado en Simulink con los modelos de redes neuronales artificiales 


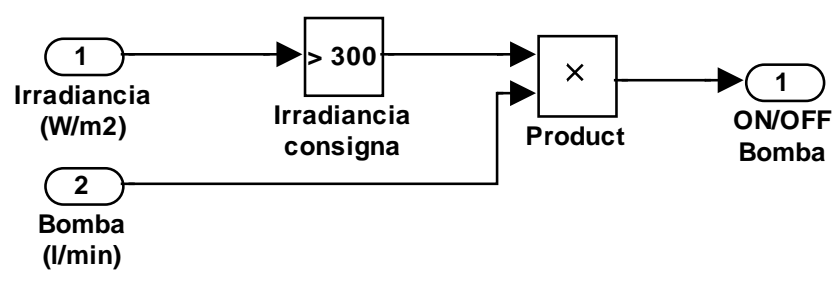

Fig. 3.7.2 Bloque consigna irradiancia solar

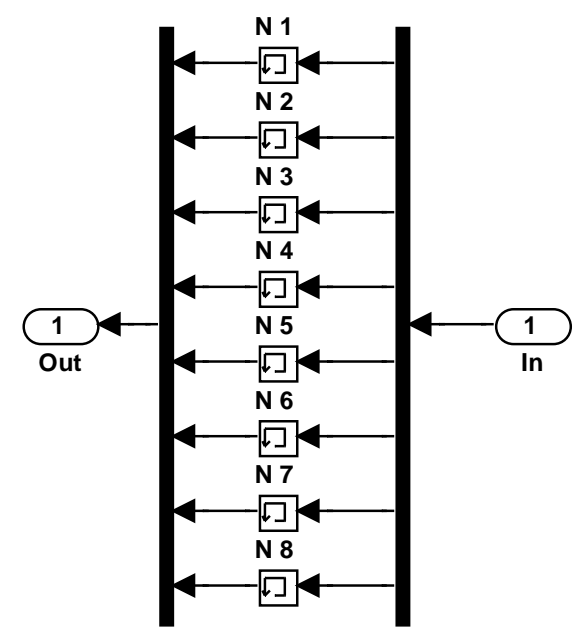

Fig. 3.7.3 Bloque estado inicial, realimentación estratificación depósito

La simulación se desarrolla variando a cada paso de tiempo de muestreo de un minuto, los valores de las variables a su estado pronosticado por cada bloque.

El bloque que representa al captador solar produce una predicción del valor de la temperatura en la tubería de ida del fluido portador en el circuito primario para el siguiente paso de tiempo.

El bloque del intercambiador de calor produce una predicción del valor de la temperatura en la tubería de retorno del fluido portador en el circuito primario para el siguiente paso de tiempo.

El modelado del depósito acumulador produce una predicción del valor de la temperatura de sus 8 capas para el siguiente paso de tiempo. El cuál está formado por cuatro modelos correspondientes a los cuatro estados posibles de funcionamiento, sobre los que se hace conmutar, para utilizar como salida el modelo que proporciona el estado correspondiente a la situación en la que se encuentra en cada paso de tiempo, según la combinación de carga y descarga del depósito, dado por la marcha/paro de la bomba de circulación y el caudal del agua caliente solar consumida. Los conmutadores cambian su posición según sea el estado de funcionamiento: dos conmutadores para controlar el caso de que haya extracción de agua caliente solar del depósito y otro conmutador en serie que se activa cuando incide irradiación solar suficiente en el captador solar para que la bomba de circulación funcione.

El modelo del depósito acumulador para el estado NOCHE de funcionamiento sin irradiación solar y sin consumo de agua caliente solar, con redes neuronales artificiales fue entrenado con datos muestreados cada 10 minutos, con lo que en la salida resultará la predicción de la evolución de la estratificación para ese lapso de tiempo. Para obtener la predicción a un lapso de tiempo de un minuto, se realiza una 
interpolación de la salida, dividiendo entre diez la diferencia entre la entrada y la salida y restando el resultado a la entrada, (Fig. 3.7.4) el esquema implementado.

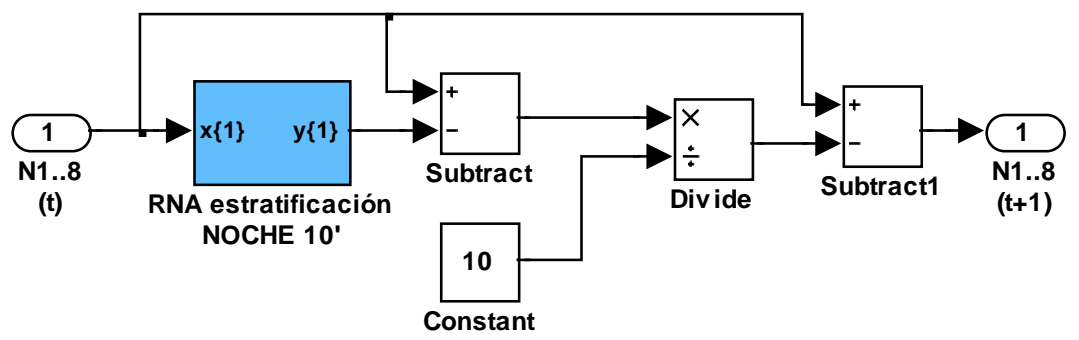

Fig. 3.7.4 Módulo de predicción de la estratificación en el estado NOCHE, con una RNA entrenada para lapsos de tiempo de 10 minutos y realiza una interpolación del resultado a un lapso de tiempo de un minuto

La salida del sistema para el agua caliente solar ACS de consumo es el valor de la capa número 8, la situada en la parte superior del depósito N8, que es donde se encuentra la salida de agua caliente solar en el depósito acumulador de la planta piloto.

La energía almacenada en el depósito se puede calcular mediante la ecuación (Ec. 3.7.1) en (German Solar Energy Society, 2010).

$$
\mathbf{Q}(\mathrm{Wh})=\mathbf{m}(\mathrm{kg}) \mathbf{1}, \mathbf{1 6}\left(\frac{\mathrm{Wh}}{\mathrm{kg}^{\circ} \mathrm{C}}\right) \Delta \mathbf{T}\left({ }^{\circ} \mathrm{C}\right)
$$

Que teniendo en cuenta el efecto de la estratificación térmica para las 8 capas en las que se ha dividido el depósito, queda como la ecuación (Ec. 3.7.2).

$$
\mathbf{Q}(\mathrm{Wh})=\sum_{\mathrm{i}=1}^{8} \mathbf{m}_{\mathrm{Ni}}(\mathrm{kg}) \mathbf{1}, \mathbf{1 6}\left(\frac{\mathrm{Wh}}{\mathrm{kg}^{\circ} \mathrm{C}}\right)\left(\mathbf{T}_{\mathbf{N i}}-\mathbf{T}_{\text {red }}\right)\left({ }^{\circ} \mathrm{C}\right)
$$

La temperatura mezcla del depósito acumulador se puede calcular a partir de la energía almacenada como la ecuación (Ec. 3.7.3).

$$
\mathbf{T}_{\text {mez }}\left({ }^{\circ} \mathrm{C}\right)=\frac{\mathbf{Q}(\mathrm{Wh})}{\mathbf{m}(\mathrm{kg}) \mathbf{1}, \mathbf{1 6}\left(\frac{\mathrm{Wh}}{\mathrm{kg}^{\circ} \mathrm{C}}\right)}+\mathbf{T}_{\text {red }}\left({ }^{\circ} \mathrm{C}\right)
$$

O en base a la media de las temperaturas de cada capa del depósito como la ecuación (Ec. 3.7.4).

$$
\mathbf{T}_{\mathbf{m e z}}\left({ }^{\circ} \mathrm{C}\right)=\frac{\sum_{\mathrm{i}=1}^{\mathbf{8}}\left(\mathbf{m}_{\mathrm{Ni}}(\mathrm{kg}) \mathbf{T}_{\mathrm{Ni}}\left({ }^{\circ} \mathrm{C}\right)\right)}{\sum_{\mathrm{i}=1}^{8} \mathbf{m}_{\mathrm{Ni}}(\mathrm{kg})}
$$

Que al ser las capas del mismo volumen, se puede considerar que la temperatura del depósito mezclado homogéneamente sea la ecuación (Ec. 3.4.5).

$$
\mathbf{T}_{\text {mez }}\left({ }^{\circ} \mathrm{C}\right)=\frac{\sum_{\mathrm{i}=1}^{8} \mathbf{T}_{\mathrm{Ni}}\left({ }^{\circ} \mathrm{C}\right)}{8}
$$

Donde,

$\mathrm{T}_{\mathrm{mez}}$ : Temperatura media o mezcla del agua acumulada en el depósito.

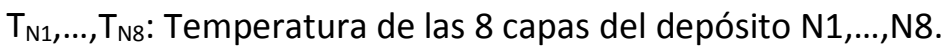


Con esta energía se consigue un volumen de agua caliente a la temperatura de preparación, por ejemplo de $50{ }^{\circ} \mathrm{C}$ en este caso, mezclando el agua caliente solar en la salida del depósito con el agua de red mediante la relación de la ecuación (Ec. 3.7.6) en (Whitten y Gailey, 1987) y (German Solar Energy Society, 2010) se obtiene el volumen de agua caliente a la temperatura de preparación que el sistema solar térmico puede suministrar a la demanda del consumo.

$$
\mathrm{V}_{\mathrm{T}_{2}}=\frac{\mathrm{T}_{1}-\mathrm{T}_{\text {fría }}}{\mathrm{T}_{2}-\mathrm{T}_{\text {fría }}} \mathrm{V}_{\mathrm{T}_{1}}
$$

En el caso del depósito estratificado con la ecuación (Ec. 3.7.7).

$$
\mathrm{V}_{50{ }^{\circ} \mathrm{C}}=\frac{\mathrm{T}_{\mathrm{N} 8}-\mathrm{T}_{\text {red }}}{\mathrm{T}_{50{ }^{\circ} \mathrm{C}}-\mathrm{T}_{\mathrm{red}}} \mathrm{V}_{\mathrm{T}_{\mathrm{N} 8}}
$$

Y en el caso del depósito mezclado con la ecuación (Ec. 3.7.8).

$$
\mathrm{V}_{500^{\circ} \mathrm{C}}=\frac{\mathrm{T}_{\mathrm{mez}}-\mathrm{T}_{\mathrm{red}}}{\mathrm{T}_{50{ }^{\circ} \mathrm{C}}-\mathrm{T}_{\mathrm{red}}} \mathrm{V}_{\mathrm{T}_{\mathrm{mez}}}
$$

Donde,

$\mathrm{V}_{\mathrm{T} 2}=\mathrm{V}_{50}{ }^{\circ} \mathrm{c}$ : Volumen de agua caliente que se obtiene mediante mezcla a la temperatura de preparación de $T_{2}$.

$\mathrm{V}_{\mathrm{T} 1}=\mathrm{V}_{\mathrm{TN} 8}$ : Volumen de agua caliente solar de salida del depósito a la temperatura considerada $\mathrm{T}_{\mathrm{N} 8 .}$. $\mathrm{T}_{1}=\mathrm{T}_{\mathrm{N} 8}$ : Temperatura considerada del agua caliente solar de salida del depósito estratificado.

$\mathrm{T}_{1}=\mathrm{T}_{\text {mez }}$ : Temperatura considerada del agua caliente solar de salida del depósito mezclado.

$\mathrm{T}_{2}=\mathrm{T}_{50}{ }^{\circ} \mathrm{C}$ : Temperatura de preparación, en este caso $50^{\circ} \mathrm{C}$.

$T_{\text {fría }}=T_{\text {red}}:$ Temperatura del agua fría de red que entra en la válvula mezcladora.

Este volumen de agua caliente a la temperatura de preparación de $50{ }^{\circ} \mathrm{C}$ variará según la irradiación solar aprovechada por el sistema solar térmico, unas veces cubrirá el volumen demandado y otras no llegará a ser suficiente, ocasión en la que tendrá que ponerse en funcionamiento un sistema auxiliar de energía convencional.

El rendimiento del sistema solar térmico, se obtiene del porcentaje cubierto por el agua caliente solar almacenada en el depósito acumulador con la temperatura de preparación, deseada para cada paso de la simulación, teniendo en cuenta el efecto de la estratificación y para el caso de utilizar un depósito mezclado, para poder comparar sus efectos posteriormente.

También se puede obtener el rendimiento con valores energéticos de la ecuación (Ec. 3.7.1), utilizando la ecuación (Ec. 3.7.9) para calcular el valor energético producido en exceso o defecto, en cada lapso de tiempo de la simulación, en este caso de un minuto.

$$
\mathbf{Q}(\mathrm{Wh})=\left(\mathbf{m}_{50}{ }^{\circ} \mathrm{C}-\mathbf{m}_{\mathrm{acs}}\right)(\mathrm{kg}) \mathbf{1}, \mathbf{1 6}\left(\frac{\mathrm{Wh}}{\mathrm{kg}{ }^{\circ} \mathrm{C}}\right)\left(\mathbf{T}_{50}{ }^{\circ} \mathrm{C}-\mathbf{T}_{\text {red }}\right)\left({ }^{\circ} \mathrm{C}\right)
$$

Donde,

$m_{\text {acs: }}$ Masa de agua caliente demandada a la temperatura de preparación.

$m_{50}{ }^{\circ} \mathrm{c}$ : Masa de agua caliente obtenida a la temperatura de preparación. 
Para realizar la simulación del funcionamiento del sistema solar térmico, por ejemplo de un mes, se crea una base de datos con las entradas al modelo de la planta piloto:

1) La primera columna se sitúa el número de minuto del mes.

2) La segunda columna son los valores de la irradiancia solar sobre el captador solar resultado de la predicción realizada o de datos reales registrados, estimando su valor sobre la superficie inclinada y por último se realiza una interpolación entre los valores horarios para obtener el valor que se aplica a cada minuto de cada hora.

3) La tercera columna contiene los valores de la temperatura ambiente del entorno del captador solar resultado de la predicción realizada o de datos reales registrados, y de una interpolación realizada entre los valores horarios para obtener el valor que se aplica a cada minuto de cada hora.

4) La cuarta columna contiene el valor del caudal consumido de agua caliente solar en cada minuto de la simulación.

5) La quinta columna contiene al valor correspondiente a la temperatura del agua de red que entra en el depósito, de medidas realizadas durante todos los meses del año.

La interpolación de datos horarios para obtener su valor en un lapso de tiempo de un minuto, se realizó utilizando un bloque paramétrico, Matlab Fcn: interp1q((1:24)',u,(1:0.01598:24)') con una dimensión de

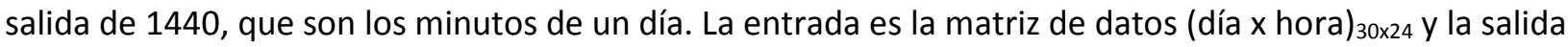
obtenida por la función es una matriz de los datos interpolados para un minuto de todo el mes (día $\mathrm{x}$ minuto) $)_{30 \times 1440}$, esta matriz se traspone y se forma una matriz columna con los datos de todo el mes alineados consecutivamente, mediante la función: reshape $(a, 43200,[])$ que devuelve una matriz (minuto $x$ mes) $43200 \times 1$.

De esta forma se realiza la simulación del funcionamiento del sistema solar térmico de la planta piloto para cada mes del año, con el modelo propuesto en esta Tesis Doctoral, a partir del modelado de los componentes del sistema solar térmico mediante redes neuronales artificiales. 


\subsection{Optimización del rendimiento en el sistema solar térmico}

Para la optimización del rendimiento de los sistemas solares térmicos se propone en esta Tesis Doctoral, priorizar su uso durante los periodos en que la energía solar y la energía calorífica almacenada en el depósito están disponibles, en lugar de plantear, como se realiza hasta ahora en el método f-chart, una demanda diaria fija del consumo para cada día del mes y un perfil horario fijo de consumo para todos los días del año.

Se proponen dos alternativas en esta Tesis Doctoral, una optimización horaria y otra diaria en las que se adaptan los consumos de agua caliente solar a la energía disponible.

1) La optimización horaria. La metodología que aquí se propone, consiste en realizar un consumo inteligente del agua caliente solar durante las horas del día, cuando la temperatura del depósito acumulador es más alta, desplazando a esos periodos los consumos más importantes, que se pueden realizar en una vivienda como el uso de los electrodomésticos, lavadora y lavavajillas, y los baños.

2) La optimización diaria. La metodología que aquí se propone, consiste en realizar un consumo inteligente del agua caliente solar durante los días en que la irradiación solar es más alta, desplazando a esos días los consumos más importantes, que se pueden realizar en una vivienda como el uso de la lavadora, piscina y climatización (frío solar). 


\section{Capítulo 4}

\section{RESULTADOS Y PRESENTACIÓN DE LOS DATOS}

\subsection{Simplificaciones utilizadas en el método f-chart}

4.2 Predicción de las variables ambientales

4.3 Modelado de los componentes del circuito primario

4.4 Predicción neural de las variables ambientales

4.5 Estimación de la irradiación solar sobre el plano inclinado y orientado

4.6 Modelado neural de los componentes del sistema solar térmico

4.7 Simulación neural del sistema solar térmico

4.8 Optimización del rendimiento en los sistemas solares térmicos

En este capítulo se presentan los datos resultados de las metodologías desarrolladas en el capítulo anterior de esta Tesis Doctoral, los modelos revisados de predicción de las variables ambientales en la literatura y las simplificaciones que se aplican en el método f-chart.

La primera parte presenta los datos resultados de las simplificaciones que utiliza en su desarrollo el método f-chart usado como referencia en esta Tesis Doctoral.

La segunda parte presenta los resultados obtenidos al aplicar varios modelos de predicción de las variables ambientales revisados en la literatura, como son: los datos climatológicos diarios medios mensuales con alcance provincial de CENSOLAR, la autocorrelación parcial, la media móvil ponderada, la regresión lineal, el análisis de Fourier, las matrices de Markov y el método ASHRAE.

La tercera parte presenta los resultados obtenidos al aplicar varios modelos para caracterizar el captador solar y el intercambiador de calor revisados en la literatura, que fueron simulados y validados respecto a los ensayos realizados con la planta piloto, y se observan diversos aspectos en las distintas condiciones de funcionamiento.

La cuarta parte presenta los datos resultados de las metodologías neurales desarrolladas para la predicción de la irradiación solar y la temperatura ambiente, utilizando la base de datos climatológicos de la red SIAR en la estación de Mansilla Mayor, situada a 20 km al sur de la ciudad de León. Esta base de datos se describe y se representa gráficamente en el (Anexo 1 Datos climatológicos).

La quinta parte presenta los datos resultados de las metodologías desarrolladas para la estimación del valor de la irradiación solar global sobre el plano inclinado del captador solar, a partir de la irradiación solar global sobre la superficie horizontal, que es la habitualmente registrada en las estaciones 
meteorológicas. Se representan los resultados obtenidos de las diversas variables necesarias y una comparativa entre las diversas metodologías en base de tiempo diaria y anual.

La sexta parte presenta los datos resultados de las metodologías neurales desarrolladas para el modelado de los componentes principales del sistema solar térmico, como son el captador solar, el intercambiador de calor y el depósito acumulador de agua caliente solar, utilizando los datos registrados en la planta piloto del (Apartado 3.1) que se representan gráficamente en el (Anexo 2 Datos de la planta piloto).

La séptima parte presenta los datos resultados de la metodología neural desarrollada para el modelado de todo el sistema solar térmico de la planta piloto, utilizando como entradas los datos reales medidos y registrados o de las predicciones de la irradiancia solar, la temperatura ambiente, y las estimaciones de consumo del caudal agua caliente solar y la temperatura del agua de red que entra en el depósito acumulador. Se presentan los resultados de la simulación del funcionamiento en distintos estados, en base de tiempo diaria, mensual y anual. Además, de los resultados obtenidos para el mismo sistema solar térmico con el método f-chart utilizado como referencia para la validación de la metodología neural propuesta en esta Tesis Doctoral.

La octava parte presenta los datos resultados de la metodología desarrollada para la optimización del rendimiento de los sistemas solares térmicos, utilizando la filosofía planteada (Apartado 3.8) desplazando los consumos más importantes de agua caliente solar a las horas del mediodía solar y la tarde, y a los días de alta irradiación solar. 


\subsection{Simplificaciones utilizadas en el método f-chart}

El método f-chart excluye del modelado de los componentes, justificando las simplificaciones, aspectos que le suponen un efecto pequeño sobre el rendimiento del sistema solar térmico a largo plazo (Klein et al., 1976). Que a continuación se exponen junto con los resultados obtenidos en esta Tesis Doctoral.

\section{1) Datos climatológicos}

El uso de un alisamiento en la distribución media de la irradiación solar por hora, siempre da como resultado una estimación conservadora del rendimiento del sistema a largo plazo. La estimación es más conservadora para diseños de sistemas que proporcionan una gran fracción de la carga total de calor y en un clima que normalmente tiene grandes fluctuaciones en la intensidad de la irradiación solar a lo largo del día.

Se realizó para su comprobación, la aplicación del método f-chart en la planta piloto para un consumo de agua caliente de $75 \mathrm{l} / \mathrm{d}$ a $50{ }^{\circ} \mathrm{C}$, utilizando la base de datos de la irradiación solar horizontal y la temperatura ambiente diurna diaria media mensual de las tablas CENSOLAR (IDAE, 2009). Resultando una cobertura solar anual $F=65,48 \%$.

Se realizó el mismo análisis utilizando los datos reales de la irradiación solar y la temperatura ambiente de la base de datos SIAR en la estación de Mansilla Mayor (León) descrita en el (Apartado A.1.1). Resultando una cobertura mayor en todos los años: de $+8,1 \%$ en 2012 , de $+6,8 \%$ en 2011 , de $+5,8 \%$ en 2010, de $+9,1 \%$ en 2009 , de $+6,2 \%$ en 2008 , de $+7,5 \%$ en 2007 , de $+5,9 \%$ en 2006 , de $+8,6 \%$ en 2005 , de $+5,7 \%$ en 2004 , y de $+1,2 \%$ en 2002 . Se representa la fracción solar mensual para cada mes del año, obtenida aplicando el método f-chart con datos climatológicos diarios medios mensuales estimados CENSOLAR y con los datos medidos y registrados durante cada año de la base de datos SIAR (Fig. 4.1.1).

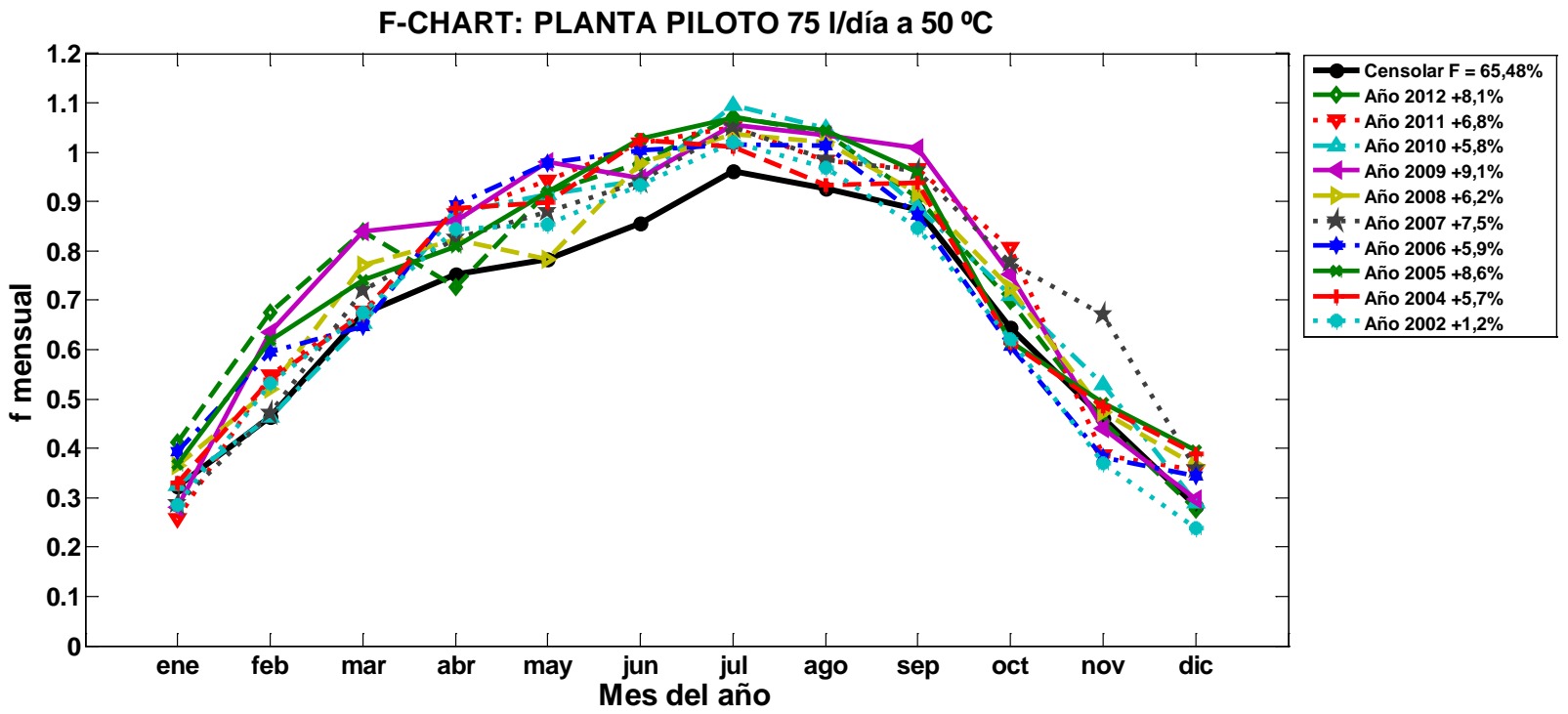

Fig. 4.1.1 Resultados del método f-chart aplicado a la planta piloto para un consumo de $75 \mathrm{l} / \mathrm{d}$ a $50{ }^{\circ} \mathrm{C}$, con datos de irradiación solar y temperatura ambiente diarios medios mensuales de CENSOLAR y la base de datos SIAR en Mansilla Mayor (León) para cada año 
La ecuación característica utilizada para el captador solar resultado de varios días de ensayos con la planta piloto es la ecuación (Ec. 4.1.1) obtenida a un caudal de 1,6 l/min del fluido portador (Fig. 4.1.5.b).

$$
\eta=\frac{Q_{u}}{\dot{\mathrm{I} A}}=0,46-2,3\left(\frac{\mathrm{T}_{\mathrm{e}}-\mathrm{T}_{\mathrm{a}}}{\dot{\mathrm{I}}}\right)
$$

\section{2) Configuración del sistema solar térmico}

Las curvas-f han sido desarrolladas para tres configuraciones estándar de sistemas solares térmicos que se encuentran en (Duffie y Beckman, 2006):

- Con fluido portador líquido para calefacción y agua caliente.

- Con fluido portador aire para calefacción y agua caliente.

- Con fluido portador líquido o aire para agua caliente.

\section{3) Captador solar}

El rendimiento del captador solar se caracteriza por la relación entre el calor útil producido por el captador solar y la irradiación solar disponible sobre su área de apertura, y se expresa en función de los parámetros de ensayo obtenidos en el laboratorio, que son la eficacia óptica $\eta_{0}$ y el coeficiente de pérdidas $U_{L}$ dependiente del diferencial de temperatura. El rendimiento instantáneo $\eta$ se expresa en función de la irradiación solar sobre el área de apertura y la dependencia entre la temperatura media del fluido y la temperatura ambiente.

El modelo de captador solar utilizado es el de Hottel-Whillier-Bliss (Hottel y Whillier, 1955). Los parámetros característicos del rendimiento del captador solar a introducir en el método f-chart son los referidos a la temperatura de entrada. Introducir los referentes a la temperatura media es un error que sobrestima la producción solar.

Actualmente los laboratorios proporcionan el ensayo cuadrático del captador solar, es decir, aproximan a una curva los puntos obtenidos en el ensayo experimental del rendimiento en función de la temperatura media del fluido, la temperatura ambiente y la irradiancia solar. En la (Fig. 4.1.2) se muestran los datos del ensayo realizado con la planta piloto el día 1-7-2011 (Fig. A.2.1) y la ecuación característica cuadrática resultante para el captador solar (Ec. 4.1.2).

$$
\eta=0,71-6,4\left(\frac{\mathrm{T}_{\mathrm{m}}-\mathrm{T}_{\mathrm{a}}}{\dot{\mathrm{I}}}\right)+8,6\left(\frac{\mathrm{T}_{\mathrm{m}}-\mathrm{T}_{\mathrm{a}}}{\dot{\mathrm{I}}}\right)^{2}
$$

Sin embargo, si se requiere la ecuación característica del captador solar para ser utilizada con el método f-chart se necesita aplicar la aproximación lineal, es decir, la ecuación lineal del rendimiento del captador solar en función de la temperatura de entrada al captador solar, para ello, o bien se solicita al laboratorio correspondiente dicha aproximación, o se hace una estimación calculando los parámetros correspondientes a la ecuación lineal en función de los parámetros de la ecuación cuadrática dada por el ensayo (Wagner, 2009). 


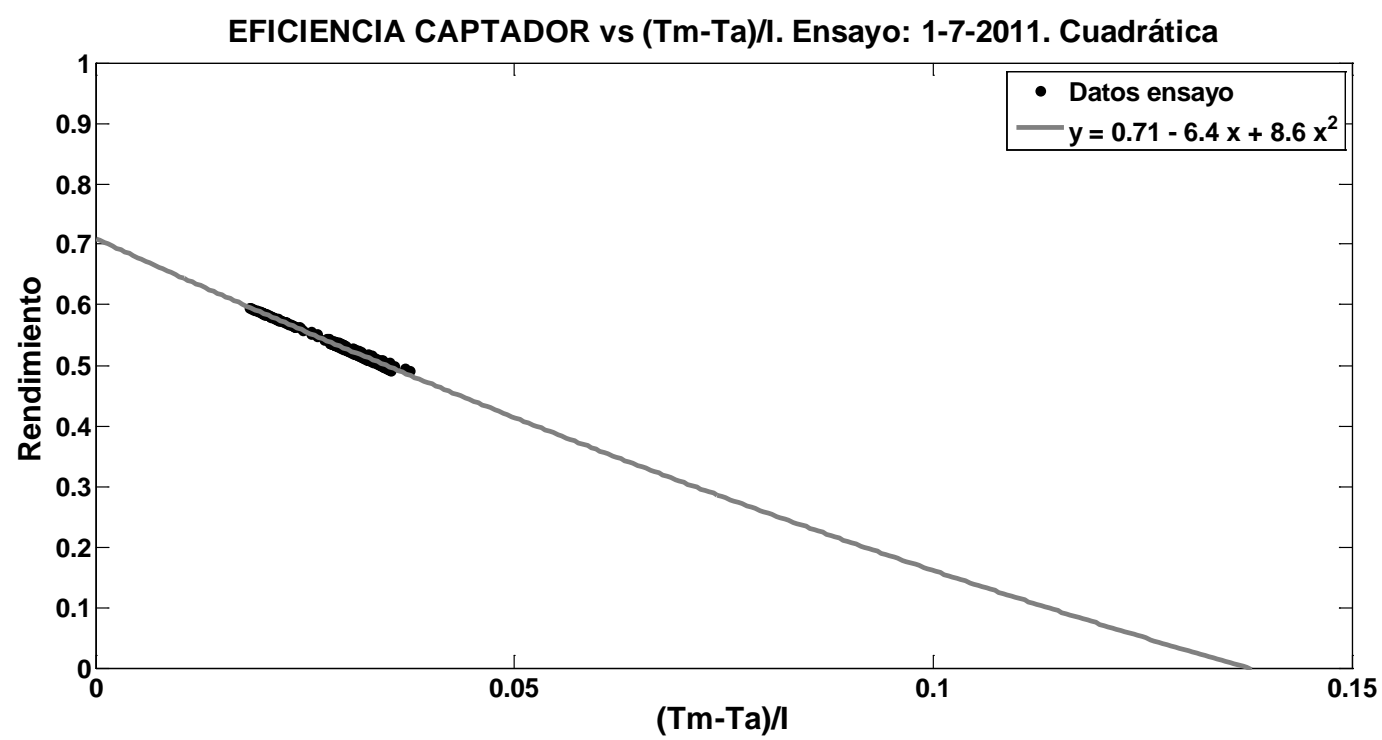

Fig. 4.1.2 Datos del ensayo realizado al captador solar de la planta piloto el día 1-7-2011 y la ecuación característica cuadrática: $\eta=0,71-6,4\left(\frac{T_{m}-T_{a}}{i}\right)+8,6\left(\frac{T_{m}-T_{a}}{i}\right)^{2}$

Además, las correlaciones del método f-chart se realizaron para los captadores solares que tienen dos cubiertas transparentes, aunque el método puede ser aplicado para los captadores con una cubierta con un pequeño error adicional.

Se calculó la ecuación característica para el captador solar de la planta piloto respecto a las temperaturas de entrada, media y salida, que se representan en las gráficas (Fig. 4.1.3.a), (Fig. 4.1.3.b) y (Fig. 4.1.3.c) con los datos registrados en el ensayo del día 29-8-2011 (Fig. A.2.3).

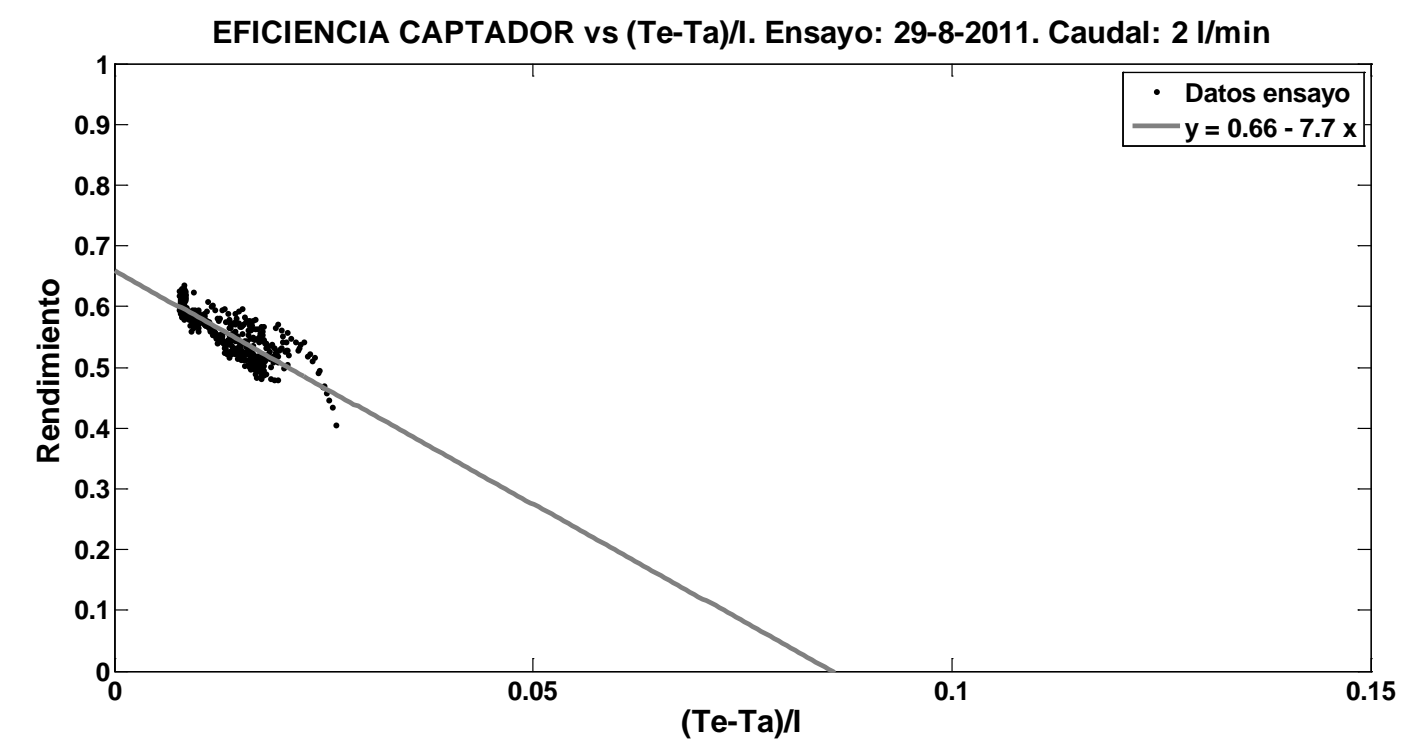

Fig. 4.1.3.a Ecuación característica respecto a la temperatura de entrada al captador resultado del ensayo en el día 29-8-2011: $\eta=0,66-7,7\left(\frac{T_{e}-T_{a}}{i}\right)$ 


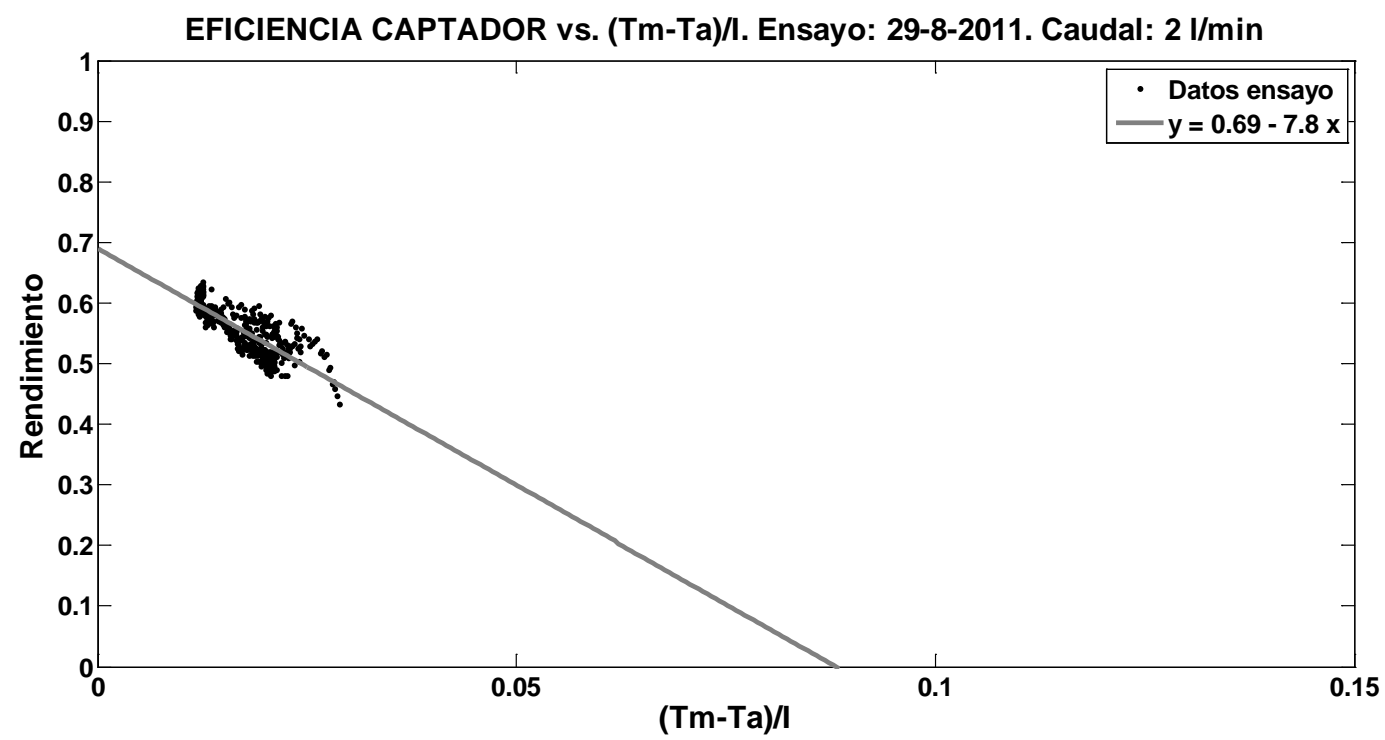

Fig. 4.1.3.b Ecuación característica respecto a la temperatura media del captador resultado del ensayo en el día 29-8-2011: $\eta=0,69-7,8\left(\frac{T_{m}-T_{a}}{\dot{I}}\right)$

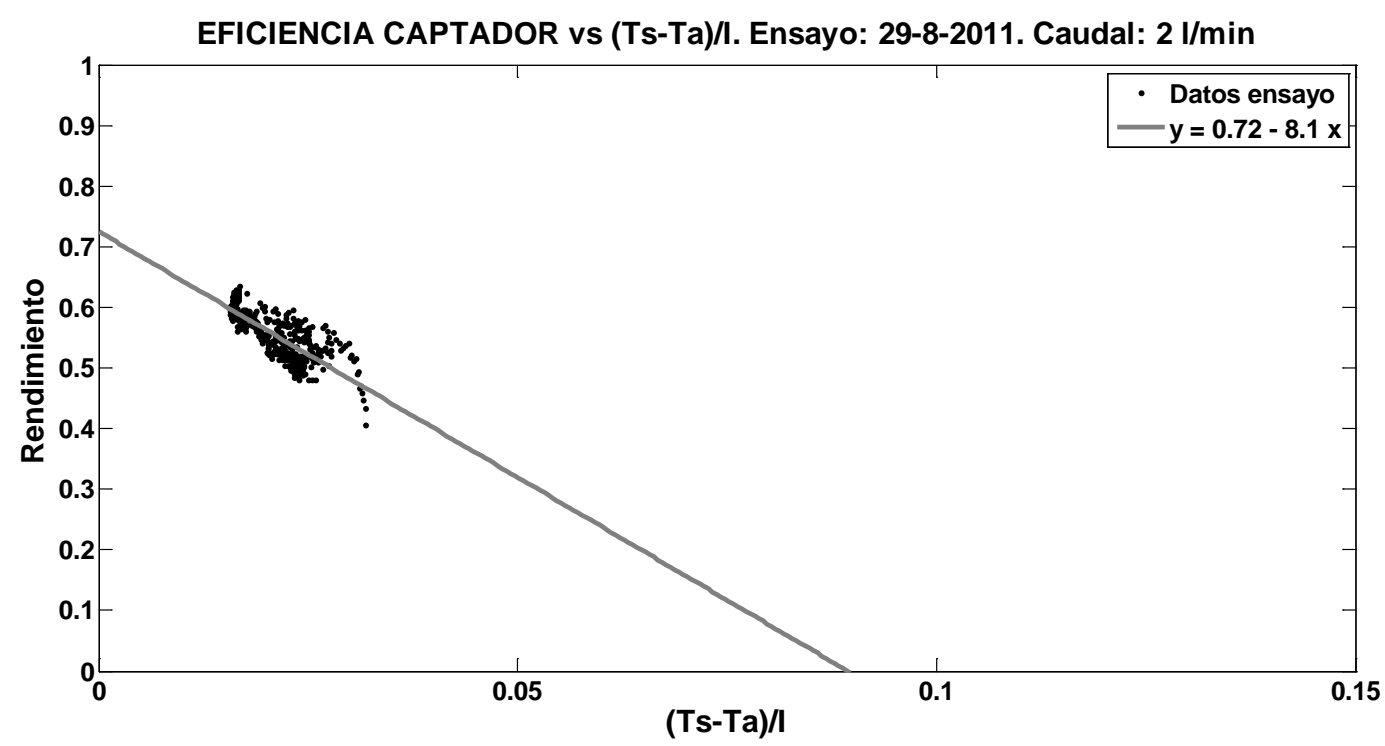

Fig. 4.1.3.c Ecuación característica respecto a la temperatura de salida del captador resultado del ensayo en el día 29-8-2011: $\eta=0,72-8,1\left(\frac{\mathrm{T}_{\mathrm{s}}-\mathrm{T}_{\mathrm{a}}}{\dot{\mathrm{I}}}\right)$

De lo que se observa que los coeficientes de la recta que representa la ecuación característica del captador solar aumentan al utilizar la temperatura de entrada, media y salida al captador solar, respectivamente.

\section{4) Coeficiente de pérdidas energéticas totales del captador solar: $U_{L}$}

El modelo de captador solar utilizado es el de Hottel-Whillier-Bliss con un coeficiente de pérdidas de calor constante $\mathrm{U}_{\mathrm{L}}$. Despreciando la dependencia de $\mathrm{U}_{\mathrm{L}}$ en condiciones de funcionamiento, proporciona un medio para simplificar el modelo de simulación. 
Un examen de las gráficas de $U_{L}$ respecto la temperatura y la velocidad del viento, indica que la dependencia funcional de $U_{L}$ sobre las condiciones de operación no es muy fuerte, en particular para los captadores solares con dos o más cubiertas transparentes y/o con placas de superficies selectivas (Duffie y Beckman, 2006).

El efecto de $U_{L}$ en el rendimiento a largo plazo de un sistema solar térmico del tipo analizado en el método f-chart, fue examinado por (Klein et al., 1976) para una variedad de diseños de sistemas y condiciones de operación. Encontró que, para un captador solar con dos cubiertas de vidrio y una superficie selectiva, el error en el porcentaje de la carga de calor total suministrado por la energía solar, causada por dejar de lado la dependencia de $U_{L}$ sobre las condiciones de operación es por lo general no más del $5 \%$.

Siempre que el valor de $U_{\mathrm{L}}$ se evalúa en las condiciones medias normales de funcionamiento estimado de captación, el error puede ser muy pequeño. Por lo que, la dependencia de $U_{\llcorner}$respecto de las condiciones de operación fluctuantes se ha descuidado en los estudios de diseño generalizados que se describen en el método f-chart.

\section{5) Pérdidas térmicas en las tuberías}

En el sistema solar térmico del tipo analizado en el método f-chart, la temperatura del fluido que entra en el captador solar es la temperatura del fluido en la salida del intercambiador de calor, despreciando las pérdidas térmicas en las tuberías captador-intercambiador (Klein et al., 1976). (Domínguez et al., 2008) expone como una de las principales limitaciones del método f-chart es no considerar explícitamente las redes de distribución y recirculación, que en el caso de instalaciones comunitarias puede tener un efecto significativo sobre la contribución solar.

\section{6) Intercambiadores captador-depósito y depósito-consumo}

La eficacia del intercambiador de calor captador-depósito se estima respecto las temperaturas de salida y entrada del captador solar y la temperatura en la parte baja del depósito, se recomienda $\left(\mathrm{F}_{\mathrm{R}}^{\prime} / \mathrm{F}_{\mathrm{R}}\right)>$ 0,9 .

El tamaño del intercambiador de calor depósito-consumo corresponde y se recomienda un valor de entre $1>\left(\left(\varepsilon_{\mathrm{c}} \mathrm{C}_{\mathrm{min}}\right) / \mathrm{UA}\right)>5$ utilizando el valor de 2 en las simulaciones del método $\mathrm{f}$-chart.

El intercambiador de calor agua-aire entre el depósito de almacenamiento y el consumo de calefacción debe ser dimensionado de manera que no penalice el rendimiento del sistema solar térmico. Si este intercambiador de calor es demasiado pequeño, la temperatura media de almacenamiento será mayor de lo necesario y la salida del captador solar será correspondientemente menor. 


\section{7) Control bomba}

(Close, 1967) explica que la mayor captación de energía en un sistema solar térmico, tiene como estrategia de control de funcionamiento de la bomba, el que se consigue mediante el uso de un control marcha-paro por diferencial de temperaturas, entre la temperatura de la parte baja del depósito y la temperatura de salida del captador solar, que es el utilizado en el método f-chart.

\section{8) Volumen de acumulación}

El rendimiento térmico de los sistemas solares térmicos es bastante insensible a la capacidad de almacenamiento, siempre que sea mayor de $50 \mathrm{l} / \mathrm{m}^{2}$ del área de captador solar instalado. El volumen de almacenamiento por tanto, no es un factor crítico de diseño. El método f-chart recomienda una capacidad de almacenamiento de 50 a $100 \mathrm{l} / \mathrm{m}^{2}$ de captador solar. La capacidad de almacenamiento del precalentador de agua doméstica en el método f-chart será de 1,5 a 2 veces la capacidad de un calentador de agua convencional.

\section{9) Estratificación depósito acumulador}

Las relaciones básicas de transferencia de calor y masa que rigen el comportamiento del depósito de almacenamiento son complicadas. Según (Close, 1967) el almacenamiento térmico estratificado puede ser modelado considerando un depósito con $\mathrm{N}$ capas mezcladas completamente. El modelo de estratificación supone que el fluido que entra en el depósito busca el segmento del tanque al que está más cercano a su densidad y por lo tanto a la temperatura. Esta suposición es razonable cuando el fluido fluye hacia dentro y fuera del tanque con velocidades muy bajas, una condición que minimiza la mezcla.

En (Klein et al., 1976) se dice que la estratificación térmica aumenta la fracción de la carga de calor total suministrado por la energía solar en solo un 1-3 \%. Los sistemas de suministro de una fracción mayor de consumo total de calor fueron capaces de beneficiarse más de los efectos de la estratificación térmica, que los sistemas con el suministro de pequeñas fracciones, ya que las temperaturas fueron más altas para estos diseños de sistemas.

Dado que los efectos de la estratificación térmica son relativamente pequeños y un modelo de mezcla total del depósito proporciona una estimación conservadora del rendimiento del sistema, un modelo de depósito completamente mezclado ha sido utilizado en los estudios de diseño generalizados en el método f-chart. La capacidad de almacenamiento es de $315 \mathrm{~kJ} /\left({ }^{\circ} \mathrm{C} \mathrm{m}\right)$ para líquido, que se supone óptimo en el método f-chart.

\section{0) Demanda térmica de agua caliente}

El método f-chart asume que la demanda de agua caliente es una pequeña fracción, menor que un $20 \%$ de la demanda de calefacción. Un método de estimación del rendimiento de los sistemas solares térmicos cuando la demanda térmica es principalmente o totalmente debida al agua caliente se describe 
en el método f-chart (Duffie y Beckman, 2006). El método $f$-chart para sistemas solares térmicos con fluido portador líquido, destinado al calentamiento de espacios y de agua, puede ser usado para estimar los valores mensuales de $\mathrm{f}$ para sistemas solares térmicos de agua caliente.

Los sistemas solares térmicos para uso de agua caliente considerados en el método f-chart, tienen una capacidad de almacenamiento de $75 \mathrm{l} / \mathrm{m}^{2}$ de área de captador solar. La distribución de agua demandada diariamente que se asume está dada por (Mutch, 1974), que se muestra en (Duffie y Beckman, 2006). El método supone que la distribución de consumo térmico durante el día no tiene un efecto fuerte sobre el rendimiento del sistema solar térmico con esta capacidad de almacenamiento (Duffie y Beckman, 2006), sin embargo variaciones de un día para el siguiente en la demanda pueden tener efectos substanciales sobre el rendimiento (Buckles y Klein, 1980).

Falta de flexibilidad para cubrir cualquier demanda de consumo de agua caliente por hora. La distribución real del consumo térmico de agua caliente puede variar en gran medida de la distribución media de (Mutch, 1974). Si la mayor parte del uso diario se produce normalmente dentro de un corto intervalo de tiempo cada día, la fracción de consumo suministrada por la energía solar puede ser más baja que la estimada con el método f-chart de la manera en que se recomienda. En este caso, un incremento en la capacidad de almacenamiento incrementaría el rendimiento del sistema más de lo que se sugiere por la modificación en el volumen del depósito.

También, la presente corrección asume que el agua que se calienta por encima de la temperatura mínima aceptable $T_{a c}$ no es más útil para calentar agua a una temperatura de $T_{a c}$. Se supone que la energía solar que calienta el agua por encima de $T_{a c}$ se desperdicia y esta energía no se considera parte del calentamiento del agua de consumo.

El factor de corrección para agua caliente del método f-chart está basado en la hipótesis de un buen aislamiento del depósito de precalentamiento solar y las pérdidas del depósito auxiliar no están incluidas en las correlaciones en el f-chart.

\section{1) Caudal del fluido portador en el captador solar}

El caudal recomendado por el método f-chart en el captador solar para una mezcla (50-50, etilenglicolagua) es de $0,015 \mathrm{l} /\left(\mathrm{s} \mathrm{m}^{2}\right)=0,9 \mathrm{l} /\left(\mathrm{min} \mathrm{m}^{2}\right)$ que en la planta piloto con una superficie de $1,85 \mathrm{~m}^{2}$ de captador solar corresponde a 1,665 l/min. El método f-chart solo tiene en cuenta el efecto del caudal a partir de la variación de $F_{R}$ (Wagner, 2009).

Se realizaron distintos ensayos en el captador solar de la planta piloto a lo largo de un año, utilizando tres caudales en el fluido portador de 1, 1,6 y $2 \mathrm{l} / \mathrm{min}$ el resultado se muestra en la gráfica (Fig. 4.1.4) sobre la eficiencia del captador solar respecto de $\left(T_{e}-T_{a}\right) / i$ donde se pueden apreciar tres zonas distintas de funcionamiento del captador solar. 


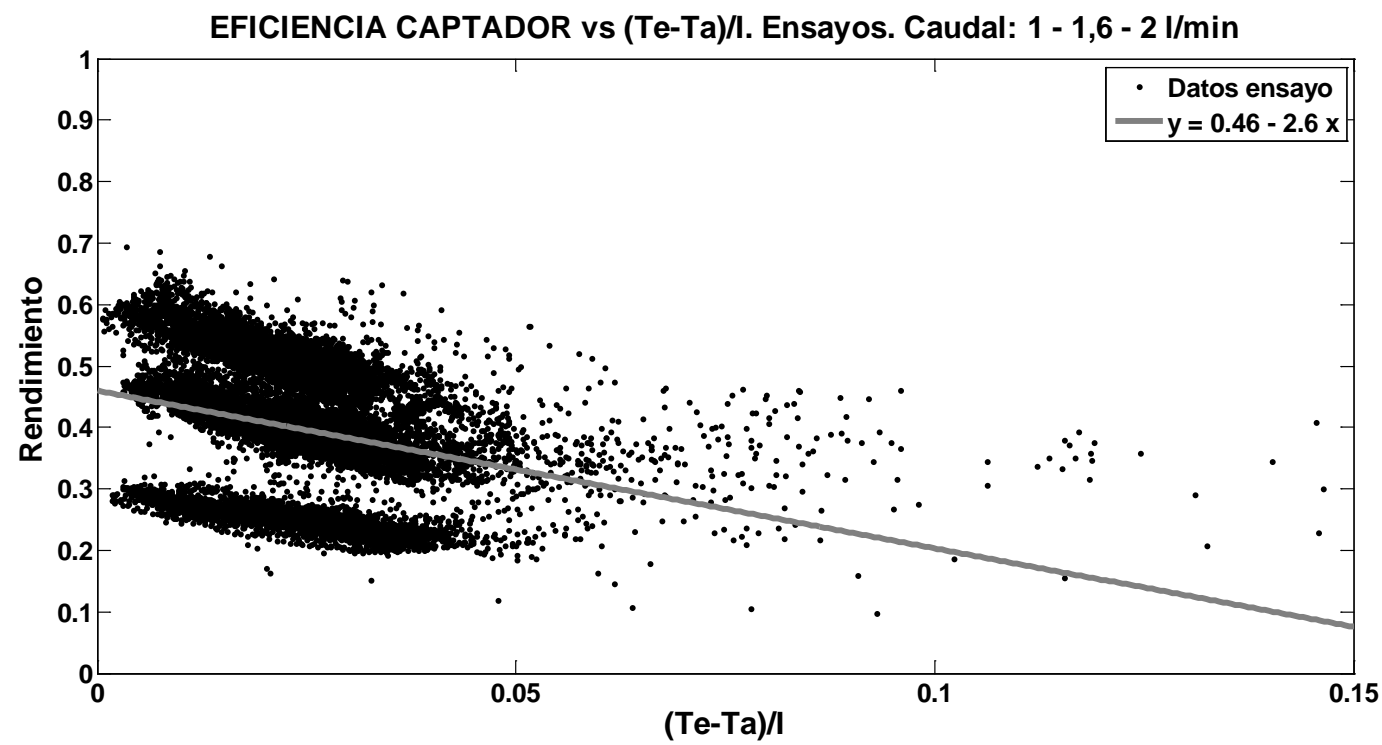

Fig. 4.1.4 Ensayos realizados con el captador solar de la planta piloto al variar el caudal en 1, 1,6 y 2 l/min y ecuación característica del captador resultante: $\eta=0,46-2,6\left(\frac{T_{e}-T_{a}}{\dot{I}}\right)$

Estas tres zonas que se crean en el funcionamiento del captador solar, con una concentración en la zona alta, otra intermedia y otra en la zona baja del total, se atribuye su distribución a los distintos caudales de circulación del fluido portador, ya que al utilizar un caudal mayor conlleva un aumento del rendimiento del captador solar al aumentar la velocidad de extracción de energía útil de la placa del captador solar. Para comprobar esto, se separaron los ensayos realizados con el captador solar de la planta piloto en tres grupos, correspondientes a los tres caudales de ensayo utilizados. Los resultados se muestran en las gráficas (Fig. 4.1.5.a), (Fig. 4.1.5.b) y (Fig. 4.1.5.c) con los datos de los ensayos de varios días.

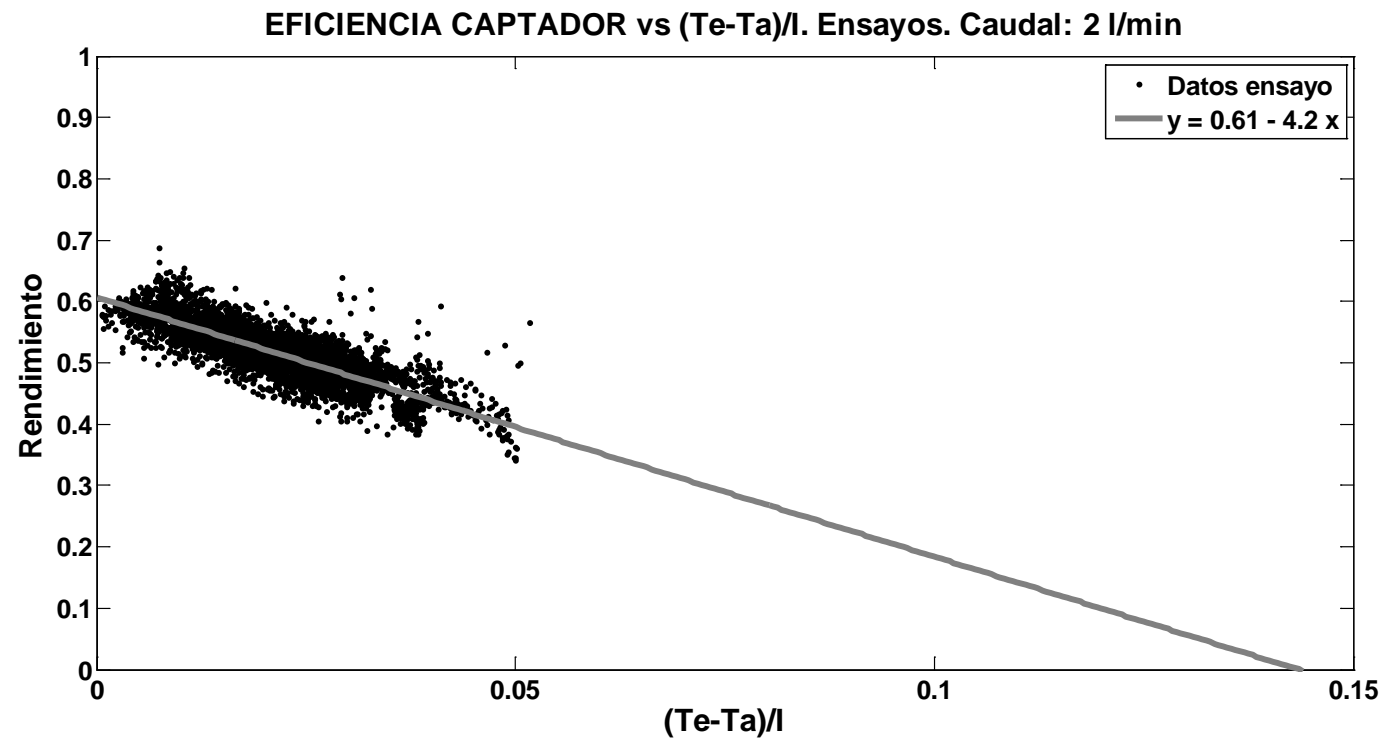

Fig. 4.1.5.a Ecuación característica resultante de los ensayos realizados con la planta piloto a un caudal de $2 \mathrm{l} / \mathrm{min}: \eta=0,61-4,2\left(\frac{\mathrm{T}_{\mathrm{e}}-\mathrm{T}_{\mathrm{a}}}{\mathrm{I}}\right)$ 


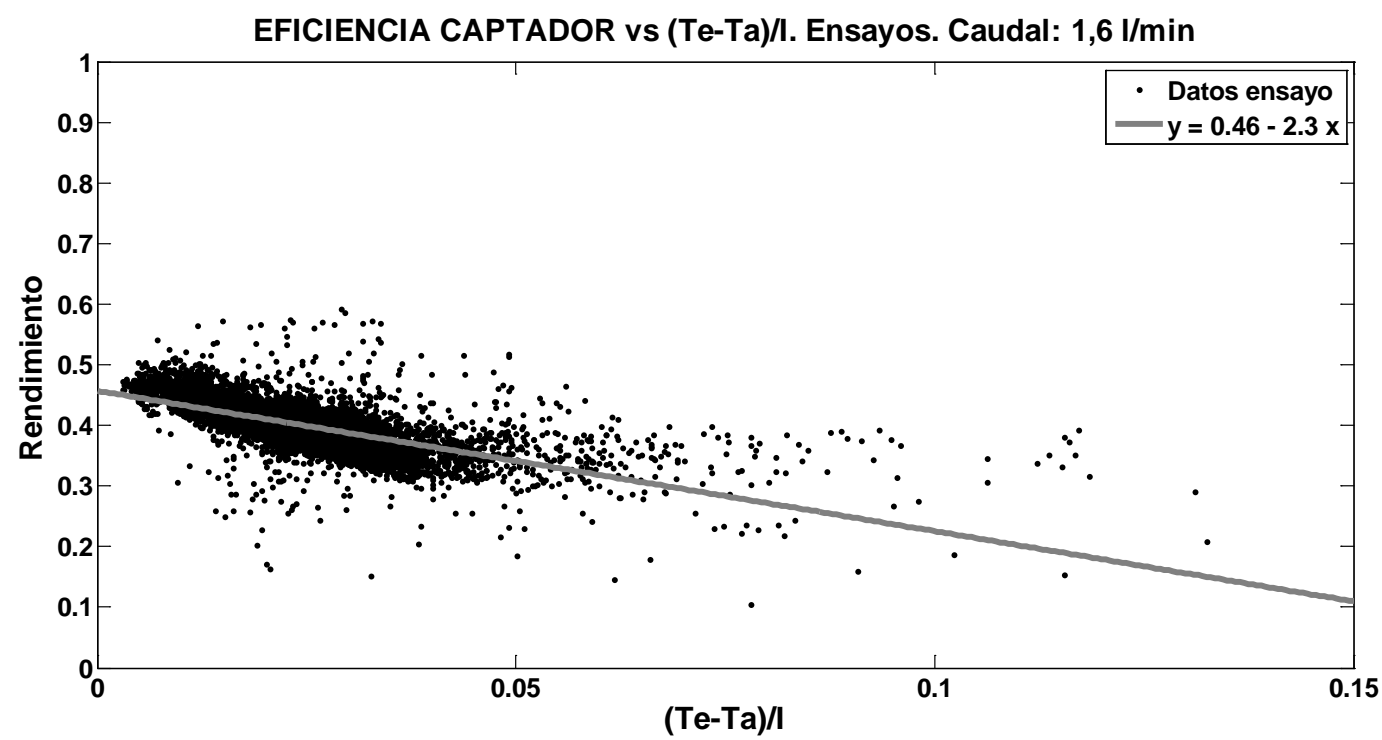

Fig. 4.1.5.b Ecuación característica resultante de los ensayos realizados con la planta piloto a un caudal de 1,6 I/min: $\eta=0,46-2,3\left(\frac{T_{e}-T_{a}}{i}\right)$

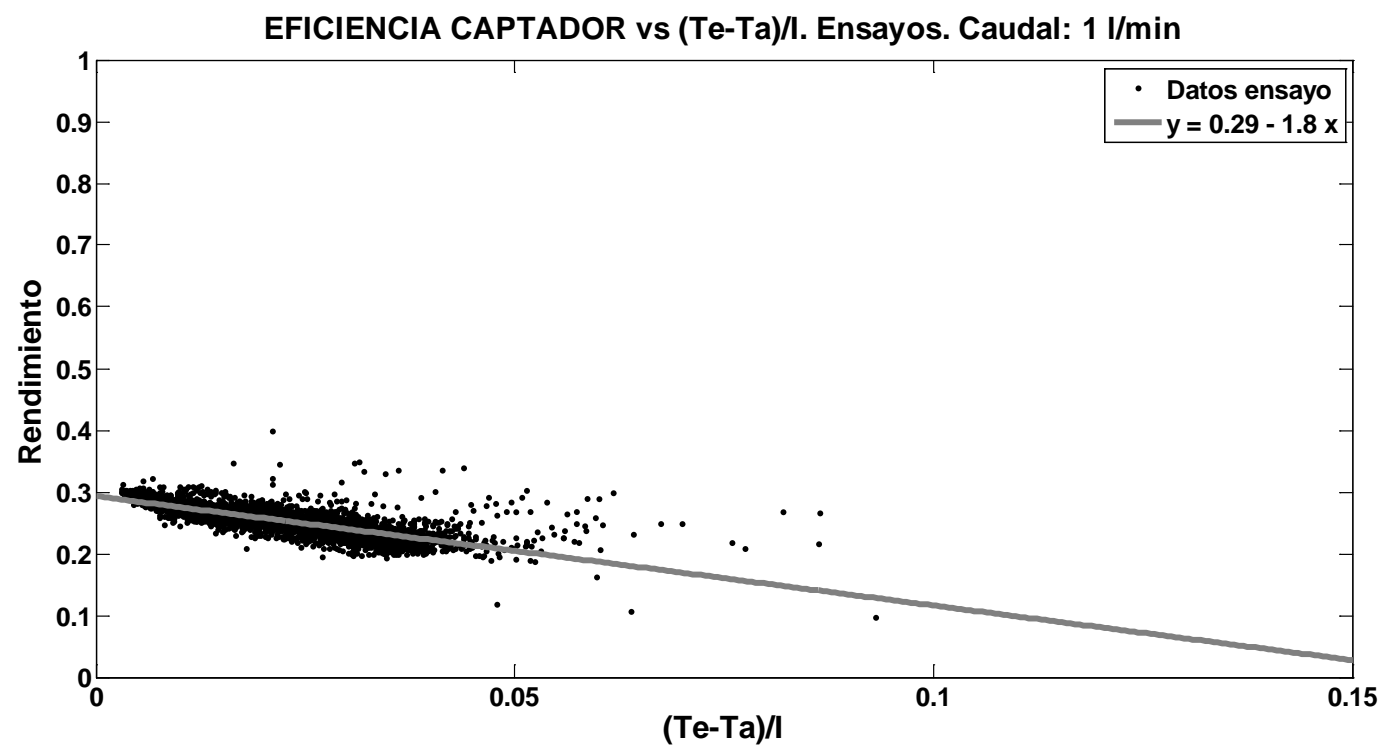

Fig. 4.1.5.c Ecuación característica resultante de los ensayos realizados con la planta piloto a un caudal de $1 \mathrm{l} / \mathrm{min}: \eta=0,29-1,8\left(\frac{\mathrm{T}_{\mathrm{e}}-\mathrm{T}_{\mathrm{a}}}{\mathrm{I}}\right)$ 
En estos ensayos se comprueba que cada caudal lleva al captador solar a una zona de funcionamiento determinada, con un rendimiento mayor con el caudal del fluido portador más alto. En las gráficas (Fig. 4.1.6.a), (Fig. 4.1.6.b) y (Fig. 4.1.6.c) se representa el ensayo para un solo día con distintos caudales del fluido portador por el captador solar.

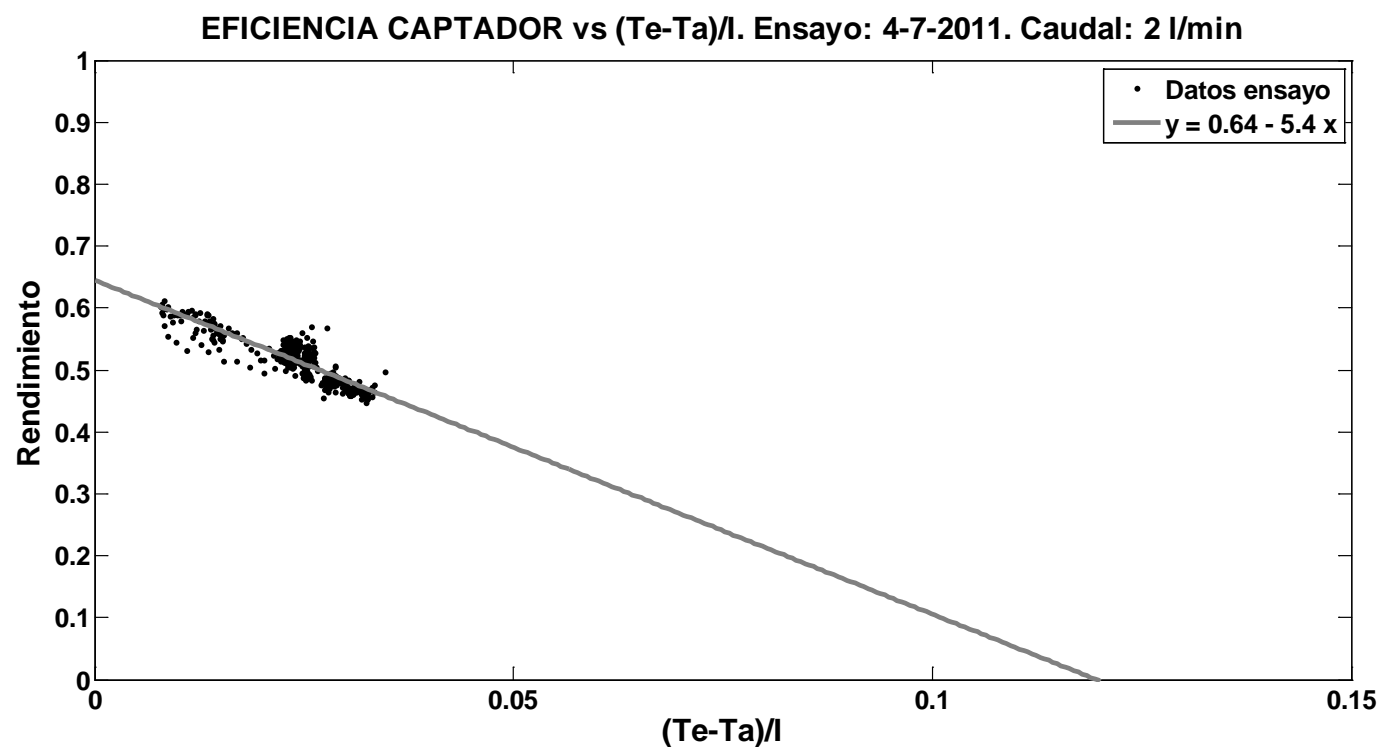

Fig. 4.1.6.a Ecuación característica del captador resultado del ensayo realizado con la planta piloto el día 4-7-2011 a un caudal de 2 l/min: $\eta=0,64-5,4\left(\frac{T_{e}-T_{a}}{\dot{I}}\right)$

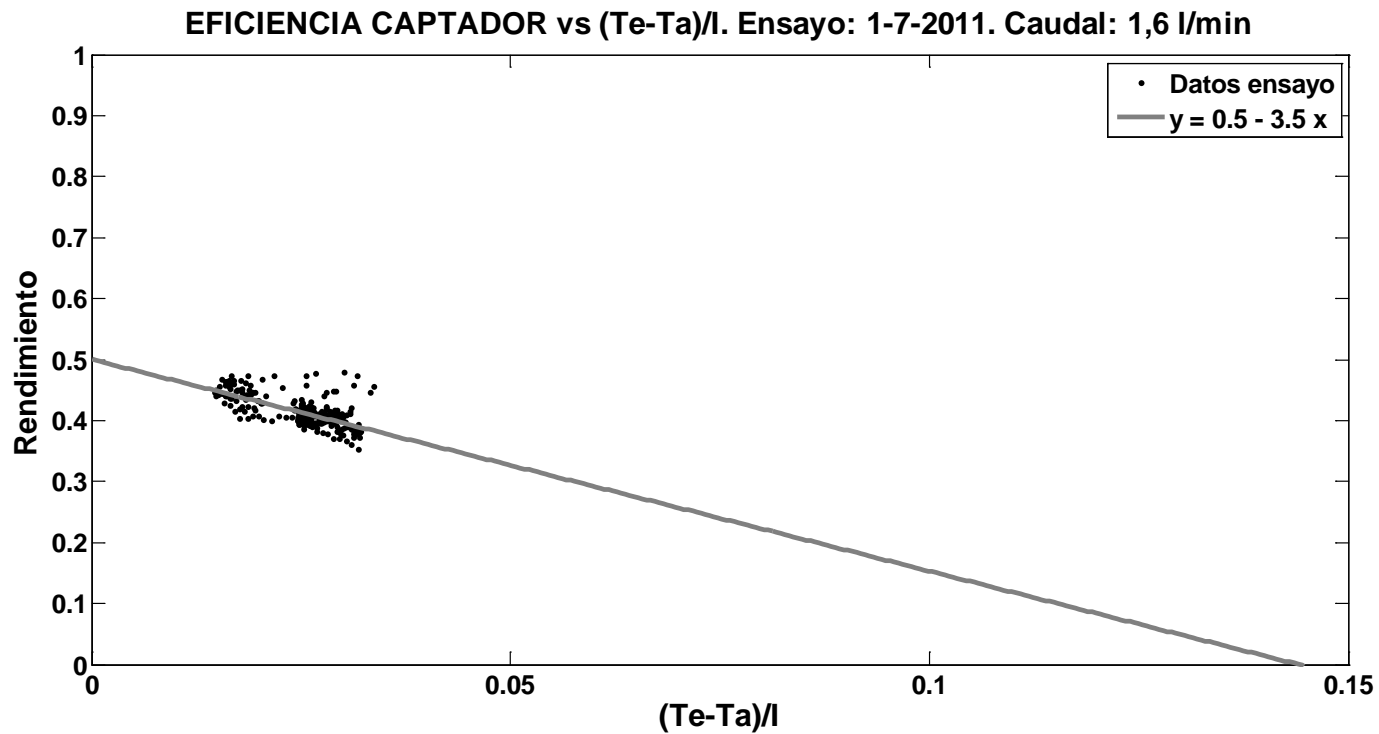

Fig. 4.1.6.b Ecuación característica del captador resultado del ensayo realizado con la planta piloto el día 1-7-2011 a un caudal de 1,6 I/min: $\eta=0,5-3,5\left(\frac{\mathrm{T}_{\mathrm{e}}-\mathrm{T}_{\mathrm{a}}}{\dot{\mathrm{I}}}\right)$ 


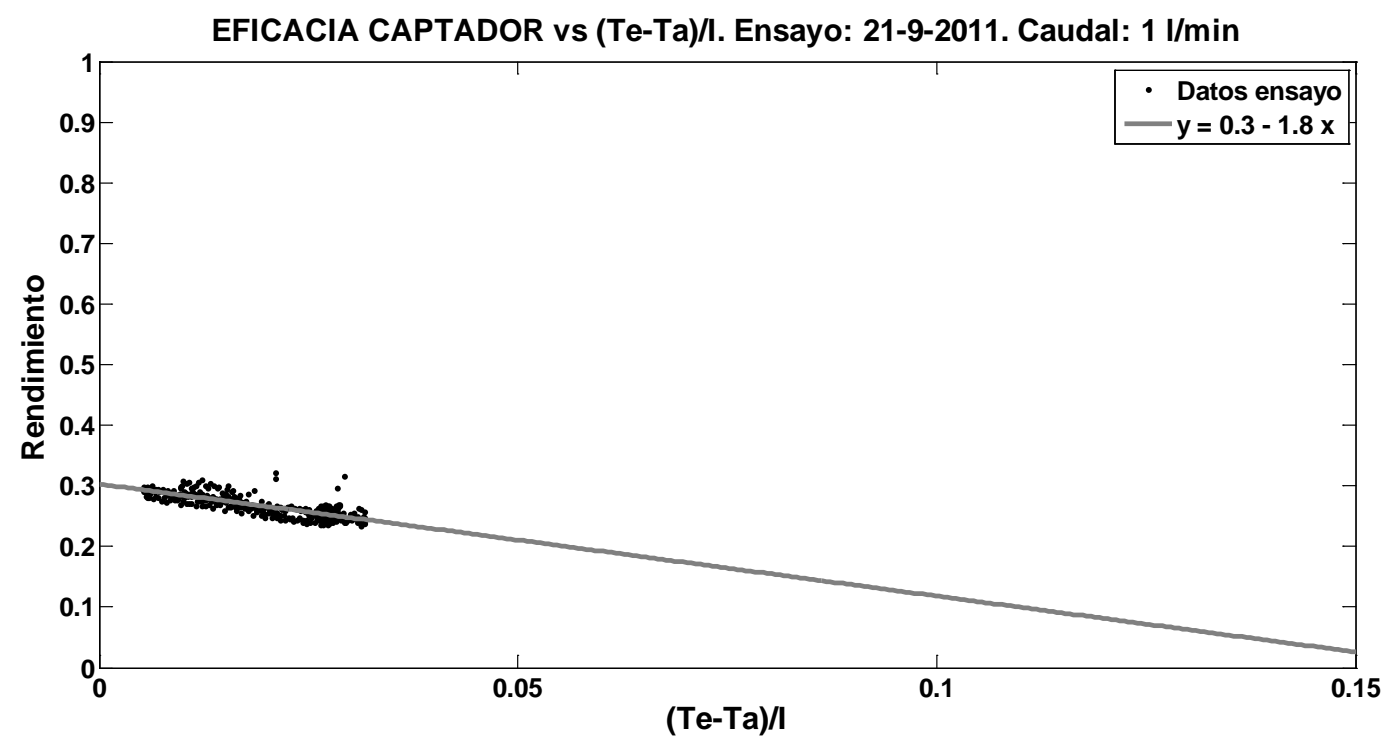

Fig. 4.1.6.c Ecuación característica del captador resultado del ensayo realizado con la planta piloto el día 21-9-2011 a un caudal de 1 l/min: $\eta=0,3-1,8\left(\frac{T_{e}-T_{a}}{i}\right)$

De los ensayos con el captador solar de la planta piloto se observa que el caudal de fluido portador que circula, influye de la siguiente manera en los valores de los coeficientes $F_{R}(\tau \alpha)_{n}$ y $F_{R} U_{L}$ que corresponden con la intersección con el eje vertical y la pendiente respectivamente de la ecuación característica del captador solar.

El valor de $F_{R}(\tau \alpha)_{n}$ y el valor de $F_{R} U_{L}$ aumentan con el caudal del fluido portador en el captador solar.

\section{2) Cálculo de los consumos de calefacción}

El método f-chart usa el modelo grados-día para la estimación de los consumos energéticos de calefacción (Duffie y Beckman, 2006).

\section{3) Inclinación de los captadores solares}

La inclinación de los captadores solares admisible en el método f-chart es igual a los grados de la latitud del lugar en que se sitúa el sistema solar térmico en el caso de estar destinado al calentamiento de agua. Si el uso de la instalación es el de calefacción o combinado con agua caliente, la inclinación será de la latitud del lugar más $10^{\circ}$. El método se considera aplicable para inclinaciones con una tolerancia de $\pm 15^{\circ}$ (Duffie y Beckman, 2006).

\section{4) Orientación de los captadores solares}

La orientación de los captadores solares en el método f-chart se considera con un azimut igual a $0^{\circ}$ frente al ecuador. El método se considera aplicable para azimuts con una tolerancia de $\pm 15^{\circ}$ (Duffie y Beckman, 2006). 


\section{5) Rangos limitados para otros parámetros de diseño}

Los rangos de parámetros de diseño utilizados en el desarrollo de las curvas-f, para sistemas solares térmicos con fluido portador líquido (Duffie y Beckman, 2006).

$0,6 \leq(\tau \alpha)_{n} \leq 0,9$ : Producto de la transmisividad por la absortividad del captador solar con ángulo normal.

$2,1 \leq U_{\mathrm{L}} \leq 8,3$ : Coeficiente global de pérdidas del captador solar $\left(\mathrm{W} /\left({ }^{\circ} \mathrm{C} \mathrm{m}^{2}\right)\right)$.

$5 \leq F_{R}^{\prime} A_{c} \leq 120$ : Producto factor de eficiencia por el área total de captación ( $\left.m^{2}\right)$.

$30^{\circ} \leq \beta \leq 90^{\circ}$ : Inclinación de los captadores solares con respecto a la horizontal.

$83 \leq(\mathrm{UA})_{\mathrm{h}} \leq 667$ : Producto coeficiente de pérdidas de calor por área del edificio $\left(\mathrm{W} /{ }^{\circ} \mathrm{C}\right)$.

\section{6) Fracciones solares elevadas}

El método f-chart y su idoneidad como procedimiento de cálculo frente a otro que utiliza el rendimiento instantáneo del captador solar se analiza en (Guerrero, 2006). Este análisis es consecuencia de conocer la existencia de instalaciones sobredimensionadas y por tanto más caras y menos eficientes. Demuestra que el método f-chart provoca un sobredimensionamiento de las instalaciones cuando se pretende conseguir fracciones solares mayores del $40 \%$ y esta desviación aumenta más cuanto mayor sea la cobertura solar que se quiera tener en la instalación. 


\subsection{Predicción de las variables ambientales}

En este apartado se presentan los resultados de aplicar diferentes modelos de predicción a las variables ambientales, expuestos en la literatura: datos climáticos CENSOLAR, autocorrelación parcial, media móvil ponderada, regresión lineal, análisis de Fourier, Markov y método ASHRAE. Utilizando la base de datos climatológicos SIAR en Mansilla Mayor (León).

\subsubsection{Datos climáticos CENSOLAR}

Se presentan los datos de las variables climatológicas de las tablas CENSOLAR junto con la base de datos SIAR en Mansilla Mayor (León).

\section{1) Datos de irradiación solar global diaria horizontal CENSOLAR}

Se representa los valores de la irradiación solar global diaria horizontal recomendados para la provincia de León en las tablas CENSOLAR (IDAE, 2009), junto a los datos de la irradiación solar global diaria del año 2011 en Mansilla Mayor (León) de la base de datos SIAR y el error producido para cada día del año, $\mathrm{RMSE}=5,18 \mathrm{MJ} / \mathrm{m}^{2} / \mathrm{d}$ (Fig. 4.2.1).

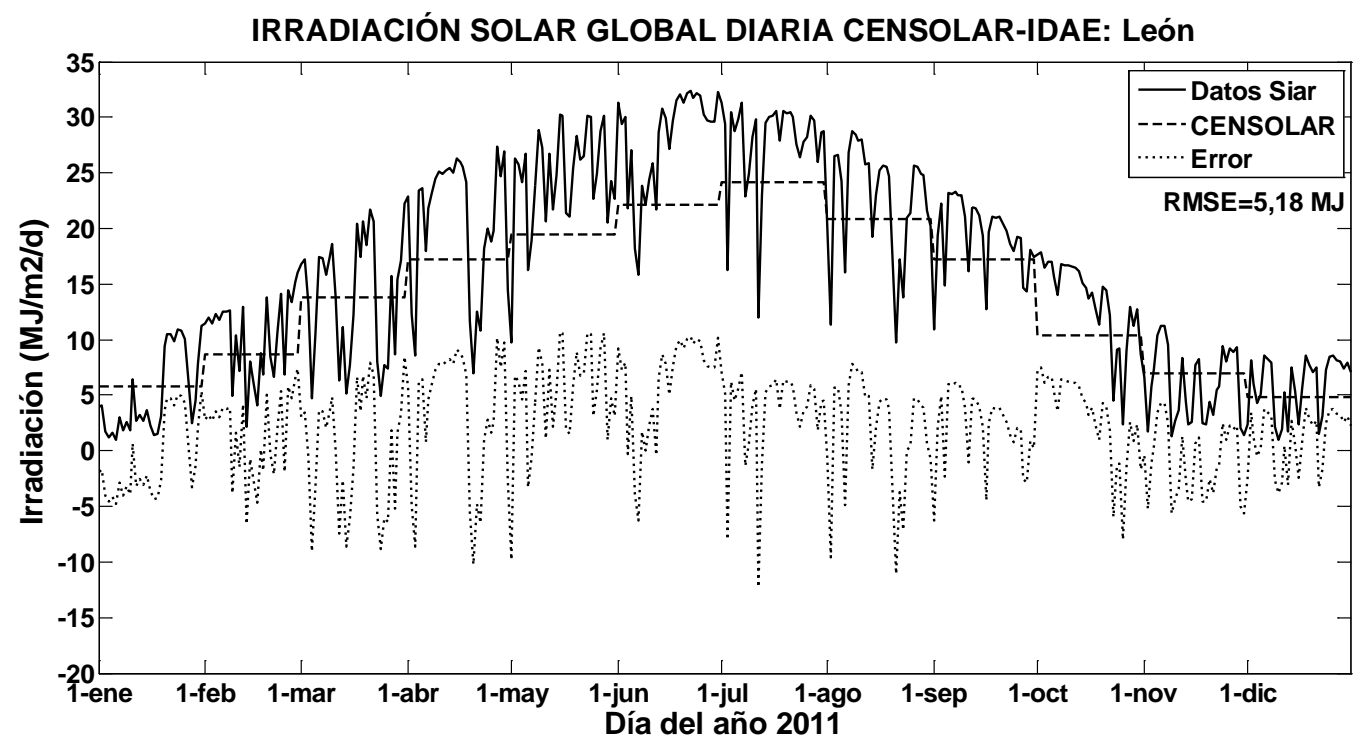

Fig. 4.2.1 Datos de irradiación solar global diaria SIAR en Mansilla Mayor (León), valores recomendados para la provincia de León por CENSOLAR y el error producido 


\section{2) Datos de temperatura ambiente media diaria diurna CENSOLAR}

Se representa los valores de la temperatura ambiente media diaria durante las horas de sol recomendados para la provincia de León en las tablas CENSOLAR (IDAE, 2009), junto a los datos de temperatura media diurna diaria del año 2011 en Mansilla Mayor (León) de la base de datos SIAR y el error producido para cada día del año, RMSE $=3,64^{\circ} \mathrm{C} / \mathrm{d}$ (Fig. 4.2.2).

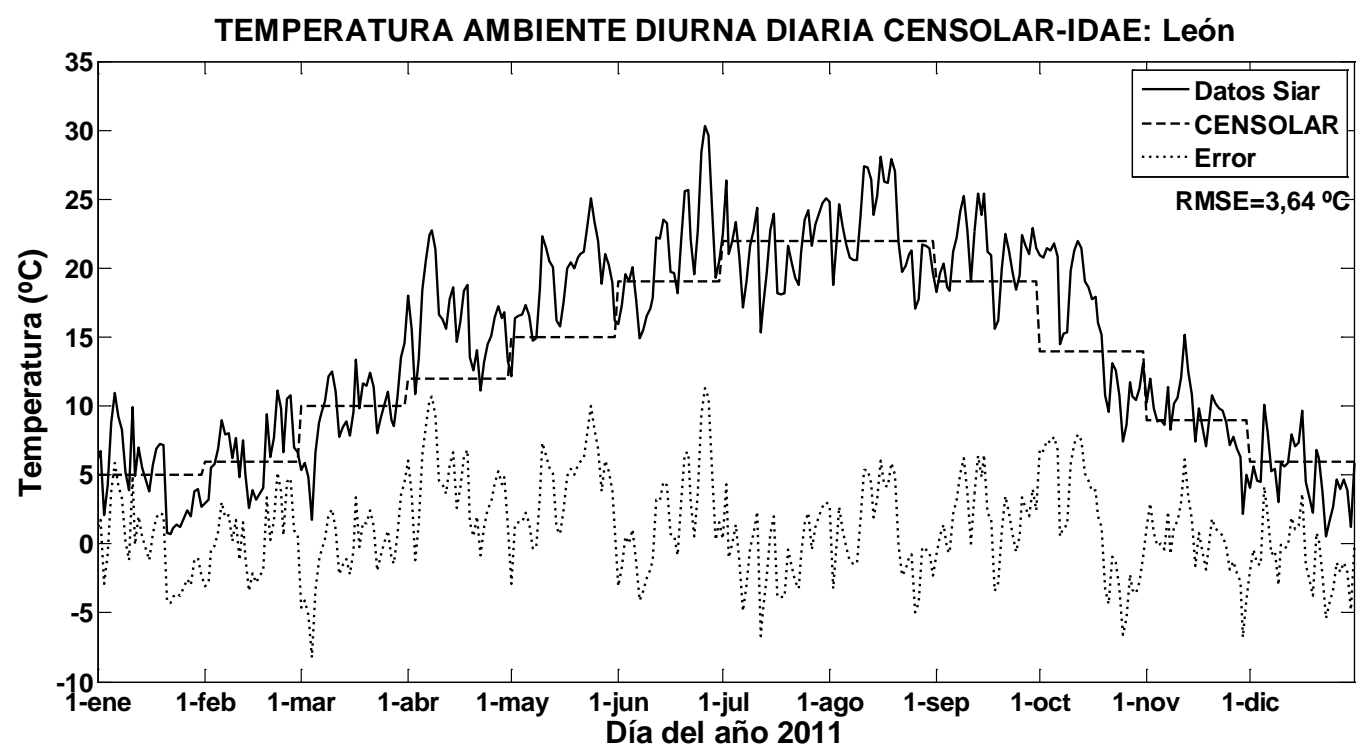

Fig. 4.2.2 Datos de temperatura ambiente media diaria SIAR en Mansilla Mayor (León), valores recomendados para la provincia de León por CENSOLAR y el error producido

\subsubsection{Modelado por correlación}

La autocorrelación hace referencia a la dependencia del valor de una determinada variable $\mathrm{x}$ estadística para un tiempo, con valores de esa misma variable x precedentes en el tiempo. Si la autocorrelación es nula, indica que no existe ninguna relación entre el valor de la variable $x$ en un instante $t y$ los valores previos en el tiempo. El otro caso extremo es cuando el valor de la autocorrelación es 1, lo que indicaría una dependencia total.

Los datos de la irradiación solar global diaria, las temperaturas ambiente media, máxima y mínima diarias de los datos en la estación situada en Mansilla Mayor (León) del proyecto SIAR, registrados durante los años 2004-2010, se analizaron calculando la autocorrelación parcial de cada serie de datos, utilizando la función 'parcorr' de Matlab.

Se presentan los resultados de la autocorrelación parcial para retardos de tiempo de 1 a 20 días de las variables climatológicas de la base de datos SIAR en Mansilla Mayor (León). 


\section{1) La autocorrelación parcial de la irradiación solar global diaria}

Se realizó el cálculo de la autocorrelación parcial a los datos de irradiación solar global diaria horizontal para retardos de tiempo de 1 a 20 días, resultando los coeficientes que se muestran en (Tabla 4.2.1) y (Fig. 4.2.3). Se comprobó que la dependencia de la irradiación solar global diaria en un determinado día es máxima con la del día anterior, disminuyendo esa dependencia rápidamente con la irradiación solar recibida en días anteriores.

Tabla 4.2.1 Coeficientes de autocorrelación parcial de la serie de datos de irradiación solar global diaria para retardos de tiempo de 1 a 20 días, SIAR en Mansilla Mayor (León)

Datos de irradiación solar global diaria (MJ/m2/d) SIAR-MAPA Mansilla Mayor 2004-2010

\begin{tabular}{|c|c|}
\hline Días de retardo & Autocorrelación parcial \\
\hline 1 & 0,8747 \\
\hline 2 & 0,2622 \\
\hline 3 & 0,1777 \\
\hline 4 & 0,0843 \\
\hline 5 & 0,1158 \\
\hline 6 & 0,1123 \\
\hline 8 & 0,0888 \\
\hline 9 & 0,0585 \\
\hline 10 & 0,0570 \\
\hline 11 & 0,1018 \\
\hline 12 & 0,0309 \\
\hline 13 & 0,0370 \\
\hline 14 & 0,0976 \\
\hline 15 & 0,0334 \\
\hline 16 & 0,0556 \\
\hline 17 & 0,0335 \\
\hline 18 & 0,0161 \\
\hline 19 & 0,0193 \\
\hline 20 & 0,0242 \\
\hline & 0,0156 \\
\hline
\end{tabular}

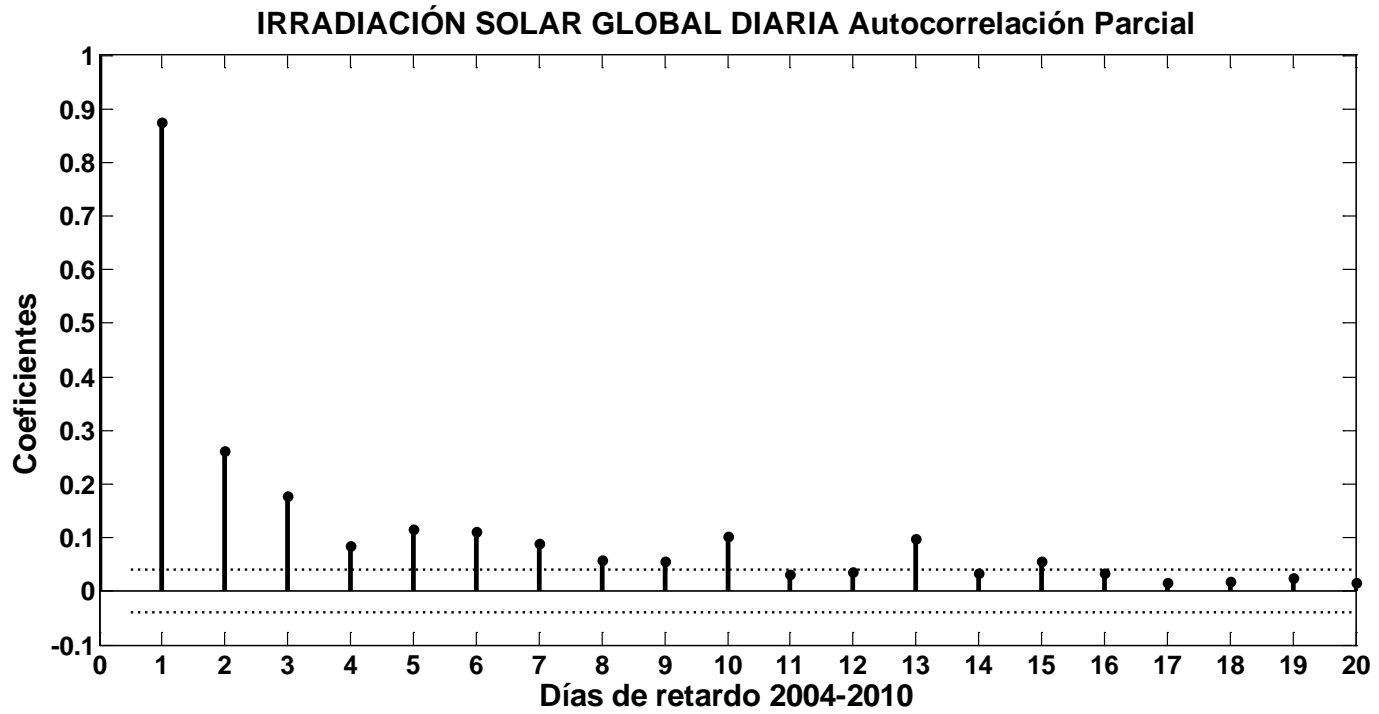

Fig. 4.2.3 Coeficientes de autocorrelación parcial de la serie de datos de irradiación solar global diaria para retardos de tiempo de 1 a 20 días, SIAR en Mansilla Mayor (León) 


\section{2) La autocorrelación parcial de la temperatura media diaria}

Se realizó el cálculo de la autocorrelación parcial a los datos de temperatura ambiente media diaria para retardos de tiempo de 1 a 20 días, resultando los coeficientes que se muestran en (Tabla 4.2.2) y (Fig. 4.2.4). Se comprobó que la dependencia de la temperatura media diaria en un determinado día es máxima con la del día anterior, desapareciendo esa dependencia con la temperatura en días anteriores. Esta dependencia en el caso de la temperatura es mayor que en el caso de la irradiación global diaria, al ser la temperatura una variable continua.

Tabla 4.2.2 Coeficientes de autocorrelación parcial de la serie de datos de temperatura media diaria para retardos de tiempo de 1 a 20 días, SIAR en Mansilla Mayor (León)

\begin{tabular}{|c|c|}
\hline Datos de temperatura media diaria ( ${ }^{\circ} \mathbf{C}$ ) SIAR-MAPA Mansilla Mayor 2004-2010 \\
\hline Días de retardo & Autocorrelación parcial \\
\hline 1 & 0,9579 \\
\hline 2 & $-0,0863$ \\
\hline 3 & 0,1626 \\
\hline 4 & 0,1057 \\
\hline 5 & 0,0757 \\
\hline 6 & 0,0855 \\
\hline 7 & 0,0679 \\
\hline 8 & 0,0105 \\
\hline 9 & 0,0468 \\
\hline 10 & 0,0689 \\
\hline 11 & 0,0332 \\
\hline 12 & 0,0568 \\
\hline 13 & 0,0024 \\
\hline 14 & 0,0254 \\
\hline 15 & 0,0545 \\
\hline 16 & 0,0204 \\
\hline 17 & 0,0289 \\
\hline 18 & 0,0320 \\
\hline 19 & 0,0454 \\
\hline 20 & $-0,0049$ \\
\hline
\end{tabular}

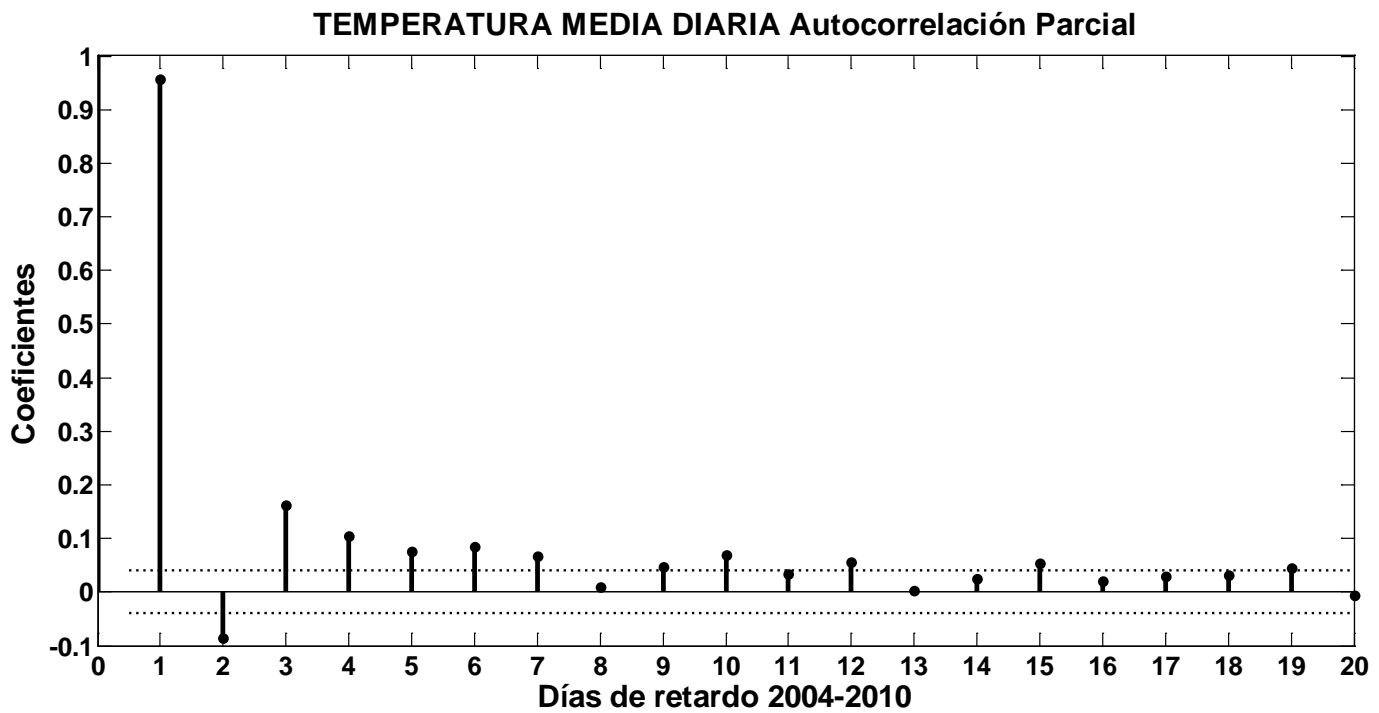

Fig. 4.2.4 Coeficientes de autocorrelación parcial de la serie de datos de temperatura media diaria para retardos de tiempo de 1 a 20 días, SIAR en Mansilla Mayor (León) 


\section{3) La autocorrelación parcial de la temperatura máxima diaria}

Se realizó el cálculo de la autocorrelación parcial a los datos de temperatura ambiente máxima diaria para retardos de tiempo de 1 a 20 días, resultando los coeficientes que se muestran en (Tabla 4.2.3) y (Fig. 4.2.5). Se comprobó que la dependencia de la temperatura máxima diaria en un determinado día es máxima con la del día anterior, desapareciendo esa dependencia con la temperatura en días anteriores.

Tabla 4.2.3 Coeficientes de autocorrelación parcial de la serie de datos de temperatura máxima diaria para retardos de tiempo de 1 a 20 días, SIAR en Mansilla Mayor (León)

\begin{tabular}{|c|c|}
\hline \multicolumn{2}{|c|}{ Datos de temperatura máxima diaria $\left({ }^{\circ} \mathbf{C}\right)$ SIAR-MAPA Mansilla Mayor 2004-2010 } \\
\hline Días de retardo & Autocorrelación parcial \\
\hline 1 & 0,9326 \\
\hline 2 & 0,0817 \\
\hline 3 & 0,1006 \\
\hline 4 & 0,0988 \\
\hline 5 & 0,0816 \\
\hline 7 & 0,0734 \\
\hline 8 & 0,1014 \\
\hline 9 & 0,0248 \\
\hline 10 & 0,0600 \\
\hline 11 & 0,0490 \\
\hline 12 & 0,0462 \\
\hline 13 & 0,0255 \\
\hline 14 & 0,0384 \\
\hline 15 & 0,0448 \\
\hline 16 & 0,0225 \\
\hline 17 & 0,0249 \\
\hline 18 & 0,0085 \\
\hline 20 & 0,0540 \\
\hline & 0,0406 \\
\hline
\end{tabular}

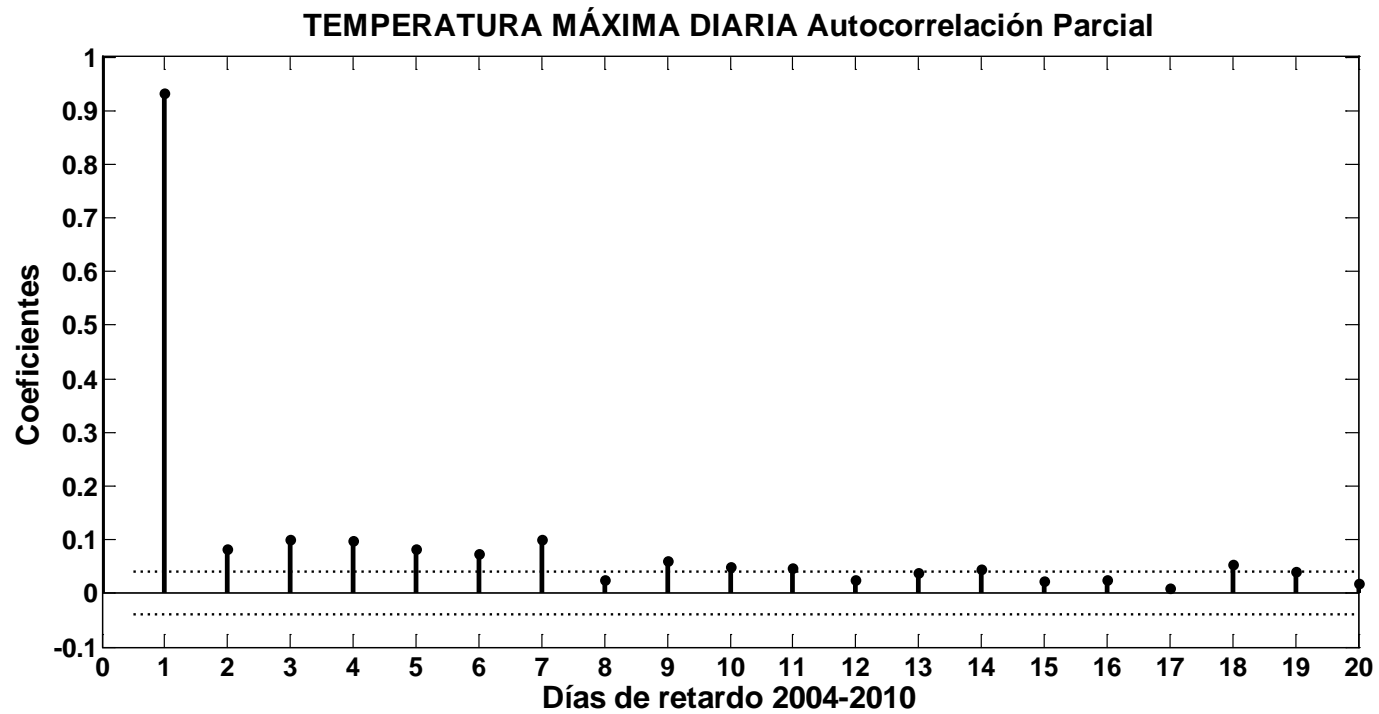

Fig. 4.2.5 Coeficientes de autocorrelación parcial de la serie de datos de temperatura máxima diaria para retardos de tiempo de 1 a 20 días, SIAR en Mansilla Mayor (León) 


\section{4) La autocorrelación parcial de la temperatura mínima diaria}

Se realizó el cálculo de la autocorrelación parcial a los datos de temperatura ambiente mínima diaria para retardos de tiempo de 1 a 20 días, resultando los coeficientes que se muestran en (Tabla 4.2.4) y (Fig. 4.2.6). Se comprobó que la dependencia de la temperatura mínima diaria en un determinado día es máxima con la del día anterior, desapareciendo esa dependencia con la temperatura en días anteriores.

Tabla 4.2.4 Coeficientes de autocorrelación parcial de la serie de datos de temperatura mínima diaria para retardos de tiempo de 1 a 20 días, SIAR en Mansilla Mayor (León)

\begin{tabular}{|c|c|}
\hline Datos de temperatura mínima diaria $\left({ }^{\circ} \mathbf{C}\right)$ SIAR-MAPA Mansilla Mayor 2004-2010 \\
\hline Días de retardo & Autocorrelación parcial \\
\hline 1 & 0,8961 \\
\hline 2 & 0,0331 \\
\hline 3 & 0,1239 \\
\hline 4 & 0,1303 \\
\hline 6 & 0,0994 \\
\hline 7 & 0,0904 \\
\hline 8 & 0,0357 \\
\hline 9 & 0,0222 \\
\hline 10 & 0,0459 \\
\hline 11 & 0,0593 \\
\hline 12 & 0,0598 \\
\hline 13 & 0,0397 \\
\hline 14 & 0,0637 \\
\hline 15 & 0,0170 \\
\hline 16 & 0,0354 \\
\hline 17 & 0,0286 \\
\hline 19 & 0,0578 \\
\hline 20 & 0,0246 \\
\hline & 0,0257 \\
\hline & 0,0160 \\
\hline
\end{tabular}

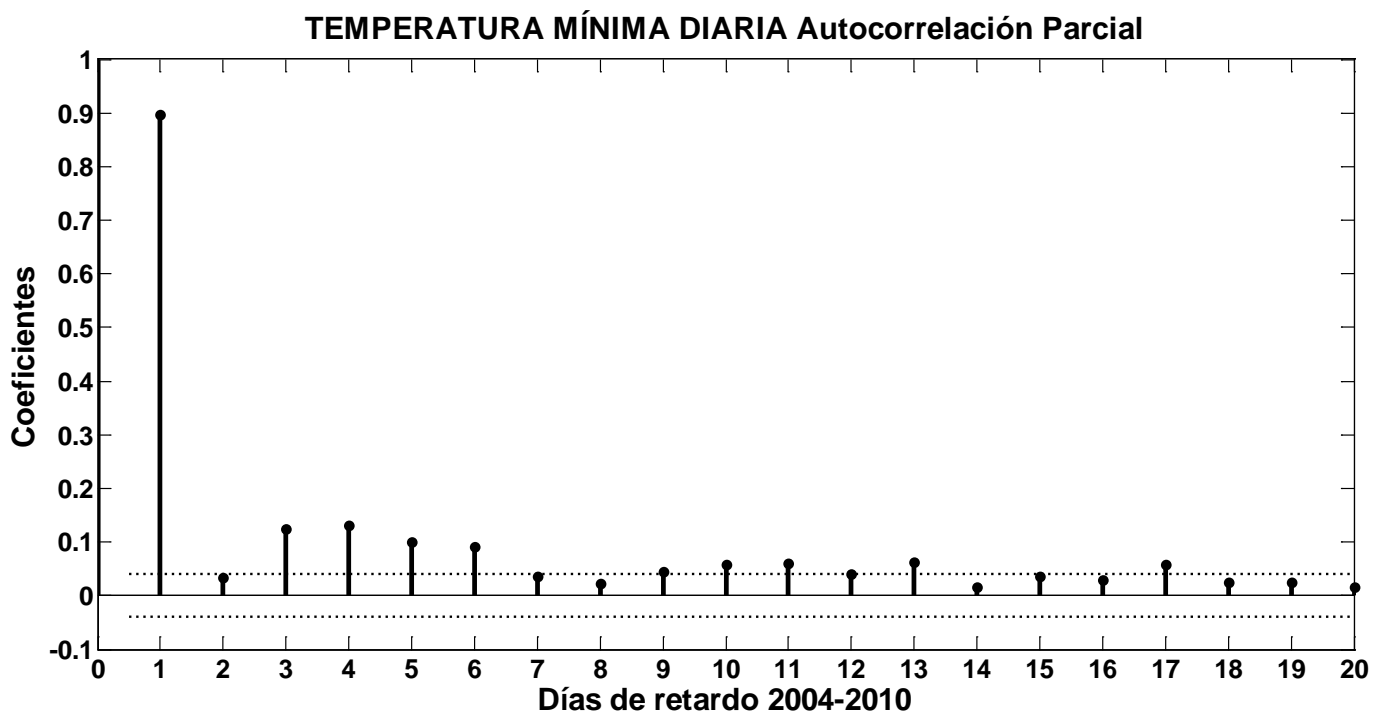

Fig. 4.2.6 Coeficientes de autocorrelación parcial de la serie de datos de temperatura mínima diaria para retardos de tiempo de 1 a 20 días, SIAR en Mansilla Mayor (León) 


\subsubsection{Análisis del alisado de series de tiempo}

La media móvil MA ponderada se utiliza dando más peso a los días más próximos y menos a los más alejados intentando que la media se comporte de forma más ágil en relación a una media móvil simple. La media móvil ponderada reacciona más rápidamente a los cambios que la media móvil simple.

Aquí se utilizaron los coeficientes de autocorrelación parcial de orden k, calculados anteriormente para la irradiación solar global y las temperaturas medias, máximas y mínimas diarias, y se aplican a los datos registrados en el año 2011 del siguiente modo. Para obtener la media móvil ponderada de un período determinado se multiplican los coeficientes de autocorrelación parcial por el valor correspondiente a su día de retardo, se realiza el sumatorio de sus productos y se divide por el sumatorio de los pesos asignados por los coeficientes de autocorrelación parcial de orden k utilizados. Como puede apreciarse la importancia que se les da a los valores más próximos es mucho mayor que a la de los valores más alejados.

Un valor k de retardo grande proporciona una serie más alisada que un valor pequeño. Si las variaciones de la serie se deben a la influencia del elemento aleatorio, un $\mathrm{k}$ grande sería más conveniente. Por el contrario, si es el nivel medido es la causa principal de variación en la serie se debe recurrir a un valor de $\mathrm{k}$ pequeño, precisamente para no infravalorar el cambio del nivel medido, ya que, en este caso, las predicciones son más sensibles a los valores recientes de la serie.

Se presentan los resultados de la media móvil ponderada por los coeficientes de autocorrelación parcial para retardos de tiempo de 1 a 20 días de las variables climatológicas de la base de datos SIAR en Mansilla Mayor (León). 


\section{1) Media móvil ponderada de la irradiación solar global diaria}

Se representan los valores obtenidos de la predicción de la irradiación solar global diaria horizontal para el año 2011, utilizando los datos de 2 días de retardo mediante la ecuación (Ec. 4.2.1) en la gráfica (Fig. 4.2.7) con un valor de RMSE $=4,26 \mathrm{MJ} / \mathrm{m}^{2} / \mathrm{d}$ y con 11 días de retardo mediante la ecuación (Ec. 4.2.2) en la gráfica (Fig. 4.2.8) con un valor de RMSE $=3,98 \mathrm{MJ} / \mathrm{m}^{2} / \mathrm{d}$. Se puede observar que al aumentar el número de días de retardo la gráfica de la predicción se suaviza.

$$
\widehat{\mathrm{Y}}_{\mathrm{t}+1}=\frac{0,8747 \mathrm{Y}_{\mathrm{t}}+0,2622 \mathrm{Y}_{\mathrm{t}-1}}{0,8747+0,2622}
$$

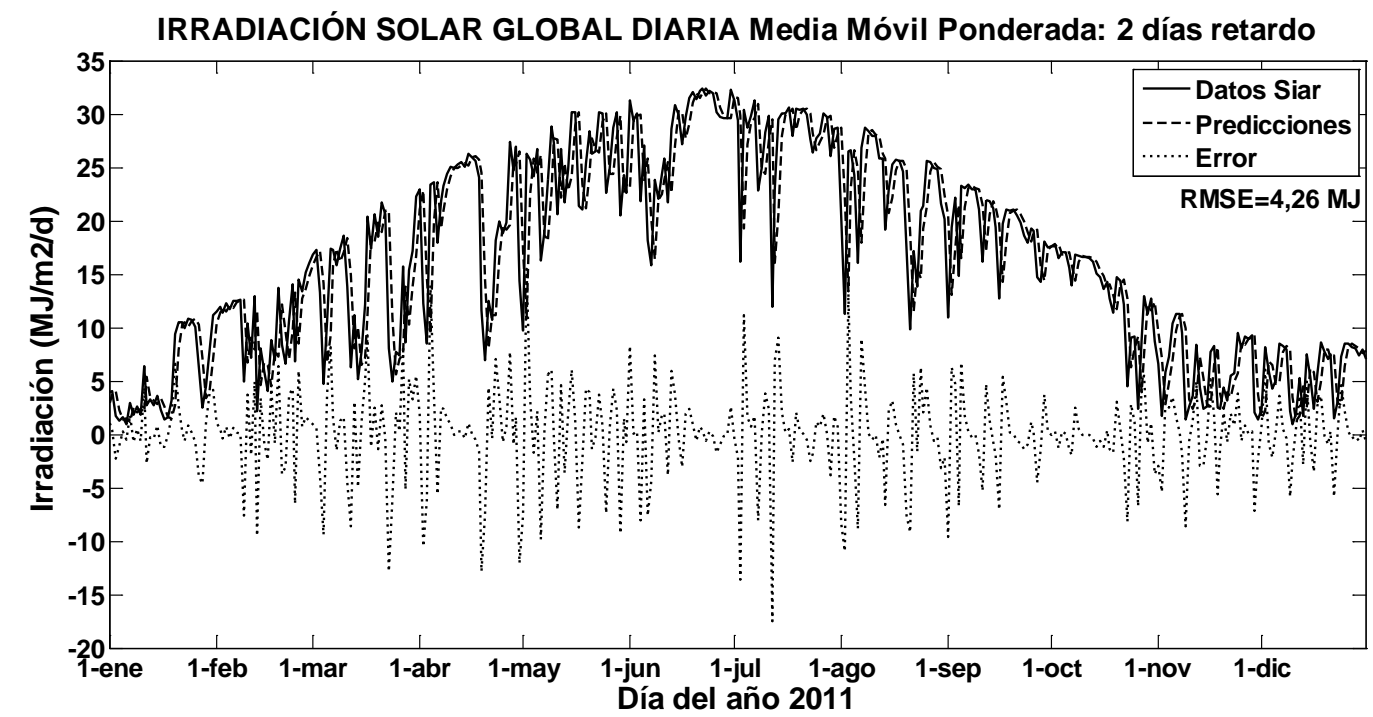

Fig. 4.2.7 Datos de la irradiación solar global del año 2011 SIAR en Mansilla Mayor (León), valores resultado de la predicción realizada con la media móvil ponderada de 2 días de retardo y el error producido para cada día del año

$\widehat{Y}_{t+1}=\frac{0,8747 Y_{t}+0,2622 Y_{t-1}+0,1777 Y_{t-2}+0,0843 Y_{t-3}+0,1158 Y_{t-4}+0,1123 Y_{t-5}+0,0888 Y_{t-6}+0,0585 Y_{t-7}+0,0570 Y_{t-8}+0,1018 Y_{t-9}+0,0309 Y_{t-10}}{0,8747+0,2622+0,1777+0,0843+0,1158+0,1123+0,0888+0,0585+0,0570+0,1018+0,0309}$

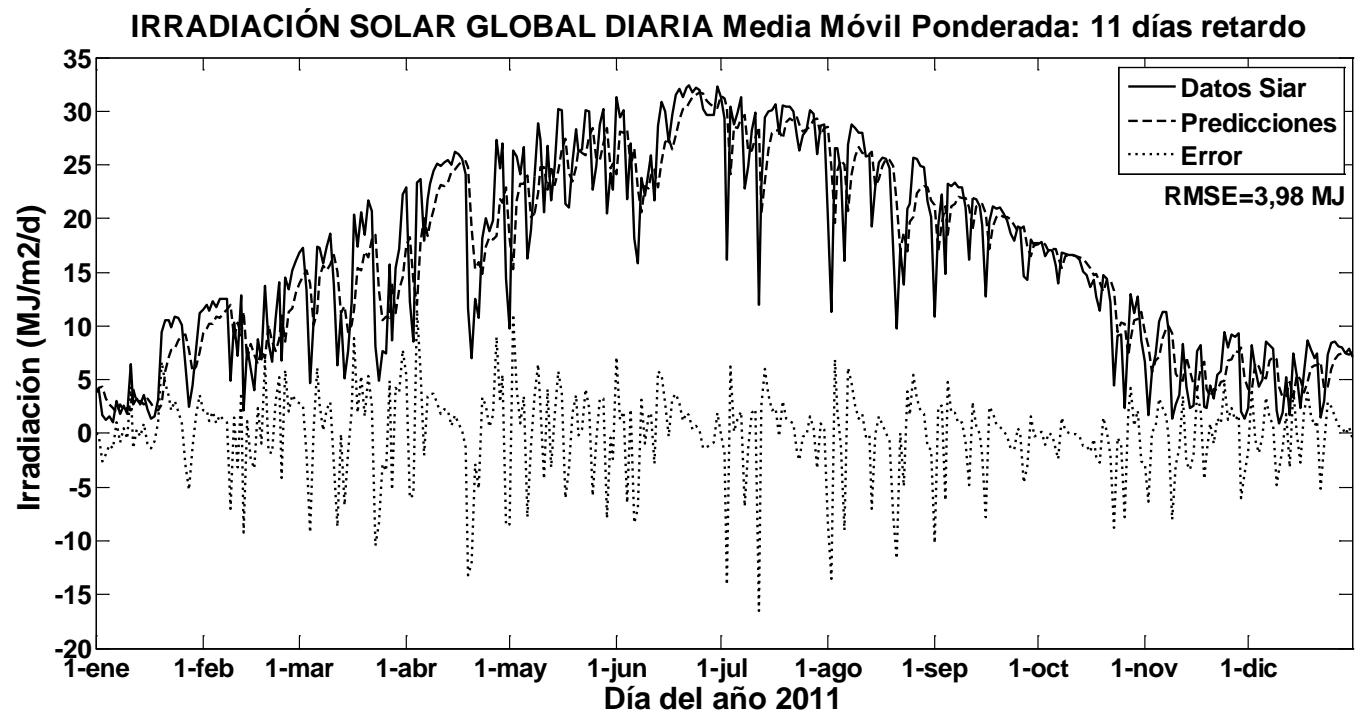

Fig. 4.2.8 Datos de la irradiación solar global del año 2011 SIAR en Mansilla Mayor (León), valores resultado de la predicción realizada con la media móvil ponderada de 11 días de retardo y el error producido para cada día del año 
El cálculo de la predicción de la irradiación solar global diaria para el año 2011 se realizó, utilizando la media móvil ponderada con los coeficientes de autocorrelación parcial de 2 a 20 días de retraso y se comparan los resultados mediante el estadístico RMSE en la gráfica (Fig. 4.2.9). Obteniéndose el mejor resultado para 11 días de retardo con un valor de RMSE $=3,98 \mathrm{MJ} / \mathrm{m}^{2} / \mathrm{d}$.

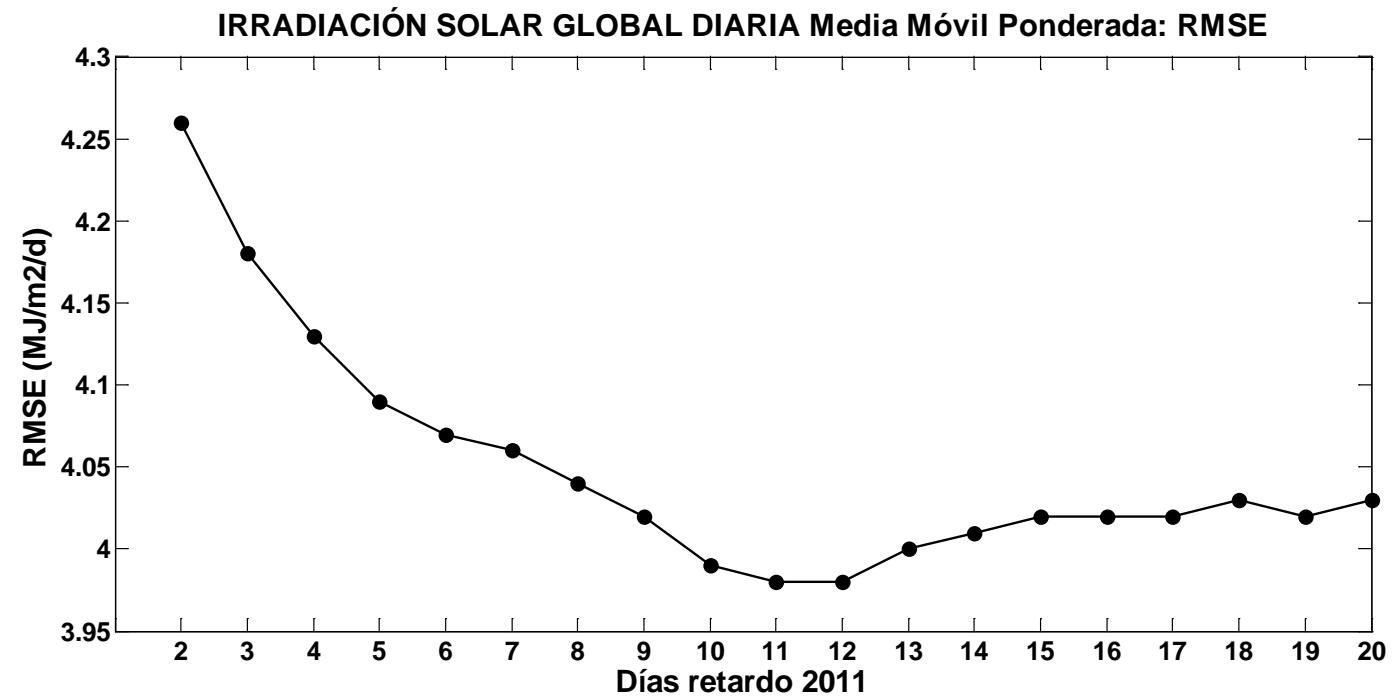

Fig. 4.2.9 RMSE del error producido por la media móvil ponderada de 2 a 20 días de retardo, en la predicción de la serie de los datos de la irradiación solar global diaria, para el año 2011 SIAR en Mansilla Mayor (León) 


\section{2) Media móvil ponderada de la temperatura media diaria}

Se representan los valores obtenidos de la predicción de la temperatura ambiente media diaria para el año 2011, utilizando los datos de 2 días de retardo mediante la ecuación (Ec. 4.2.3) en la gráfica (Fig. 4.2.10) con un valor de $\mathrm{RMSE}=1,86^{\circ} \mathrm{C} / \mathrm{d}$ y con 5 días de retardo mediante la ecuación (Ec. 4.2.4) en la gráfica (Fig. 4.2.11) con un valor de RMSE $=1,81^{\circ} \mathrm{C} / \mathrm{d}$. Se puede observar que al aumentar el número de días de retardo la gráfica de la predicción se suaviza.

$$
\widehat{\mathrm{Y}}_{\mathrm{t}+1}=\frac{0,9579 \mathrm{Y}_{\mathrm{t}}+0,0863 \mathrm{Y}_{\mathrm{t}-1}}{0,9579+0,0863}
$$

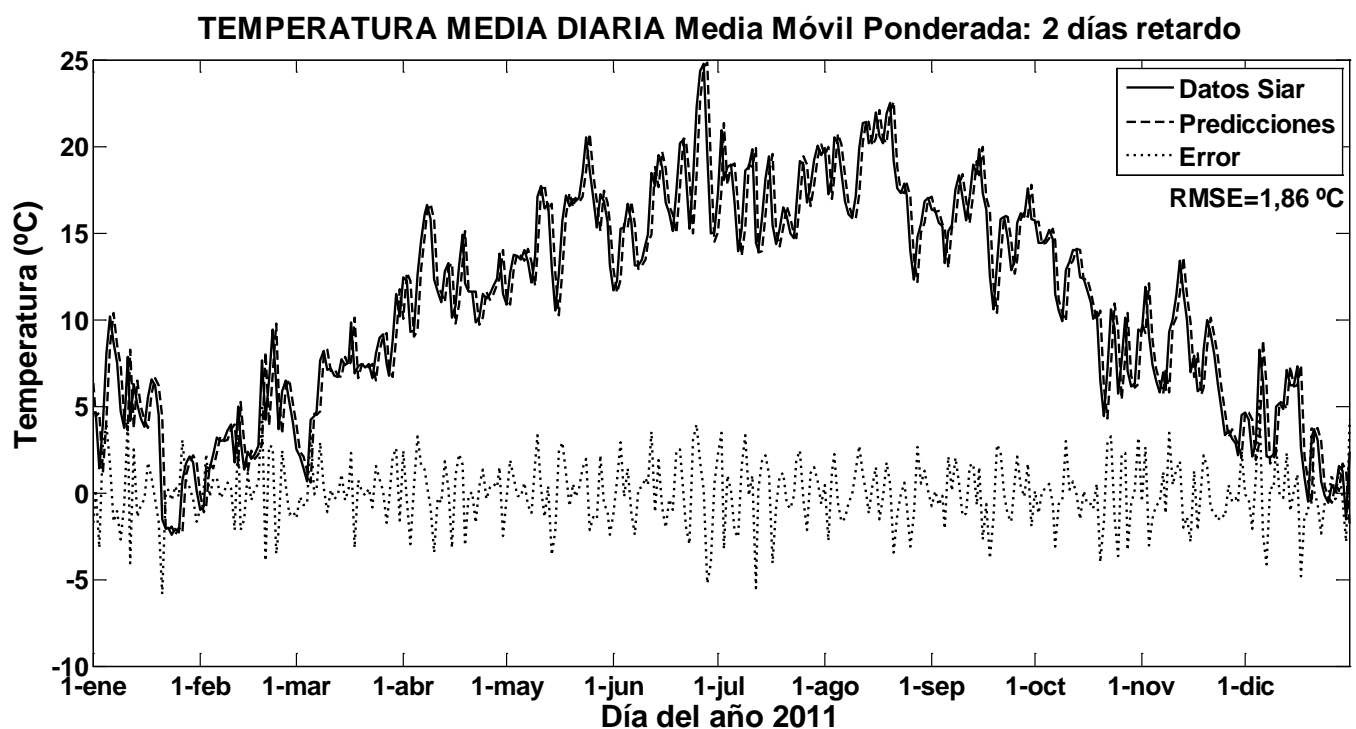

Fig. 4.2.10 Datos de la temperatura media diaria del año 2011 SIAR en Mansilla Mayor (León), valores resultado de la predicción realizada con la media móvil ponderada de 2 días de retardo y el error producido para cada día del año

$$
\widehat{\mathrm{Y}}_{\mathrm{t}+1}=\frac{0,9579 \mathrm{Y}_{\mathrm{t}}+0,0863 \mathrm{Y}_{\mathrm{t}-1}+0,1620 \mathrm{Y}_{\mathrm{t}-2}+0,1057 \mathrm{Y}_{\mathrm{t}-3}+0,0757 \mathrm{Y}_{\mathrm{t}-4}}{0,9579+0,0863+0,1620+0,1057+0,0757}
$$

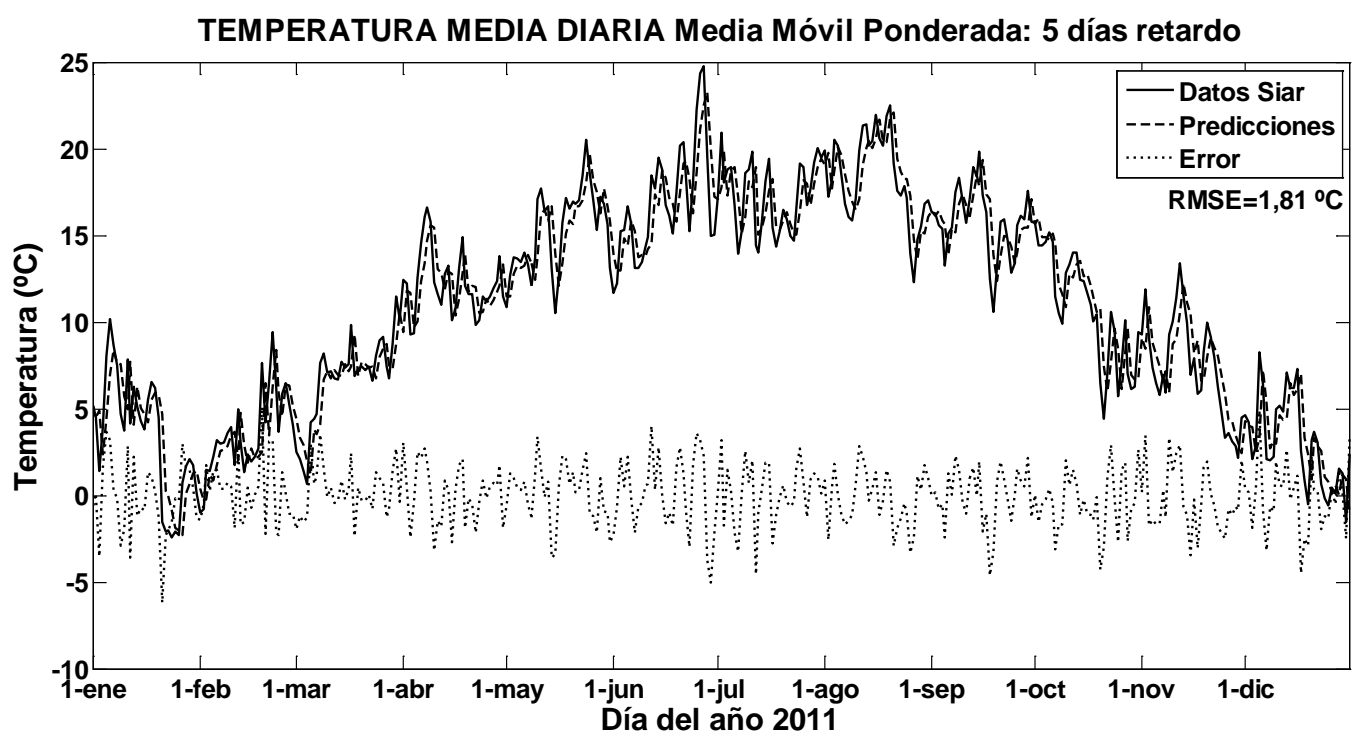

Fig. 4.2.11 Datos de la temperatura media diaria del año 2011 SIAR en Mansilla Mayor (León), valores resultado de la predicción realizada con la media móvil ponderada de 5 días de retardo y el error producido para cada día del año 


\section{3) Media móvil ponderada de la temperatura máxima diaria}

Se representan los valores obtenidos de la predicción de la temperatura ambiente máxima diaria para el año 2011, utilizando los datos de 2 días de retardo mediante la ecuación (Ec. 4.2.5) en la gráfica (Fig. 4.2.12) con un valor de RMSE $=2,86^{\circ} \mathrm{C} / \mathrm{d}$ y con 5 días de retardo mediante la ecuación (Ec. 4.2.6) en la gráfica (Fig. 4.2.13) con un valor de RMSE $=2,76^{\circ} \mathrm{C} / \mathrm{d}$. Se puede observar que al aumentar el número de días de retardo la gráfica de la predicción se suaviza.

$$
\widehat{\mathrm{Y}}_{\mathrm{t}+1}=\frac{0,9326 \mathrm{Y}_{\mathrm{t}}+0,0817 \mathrm{Y}_{\mathrm{t}-1}}{0,9326+0,0817}
$$

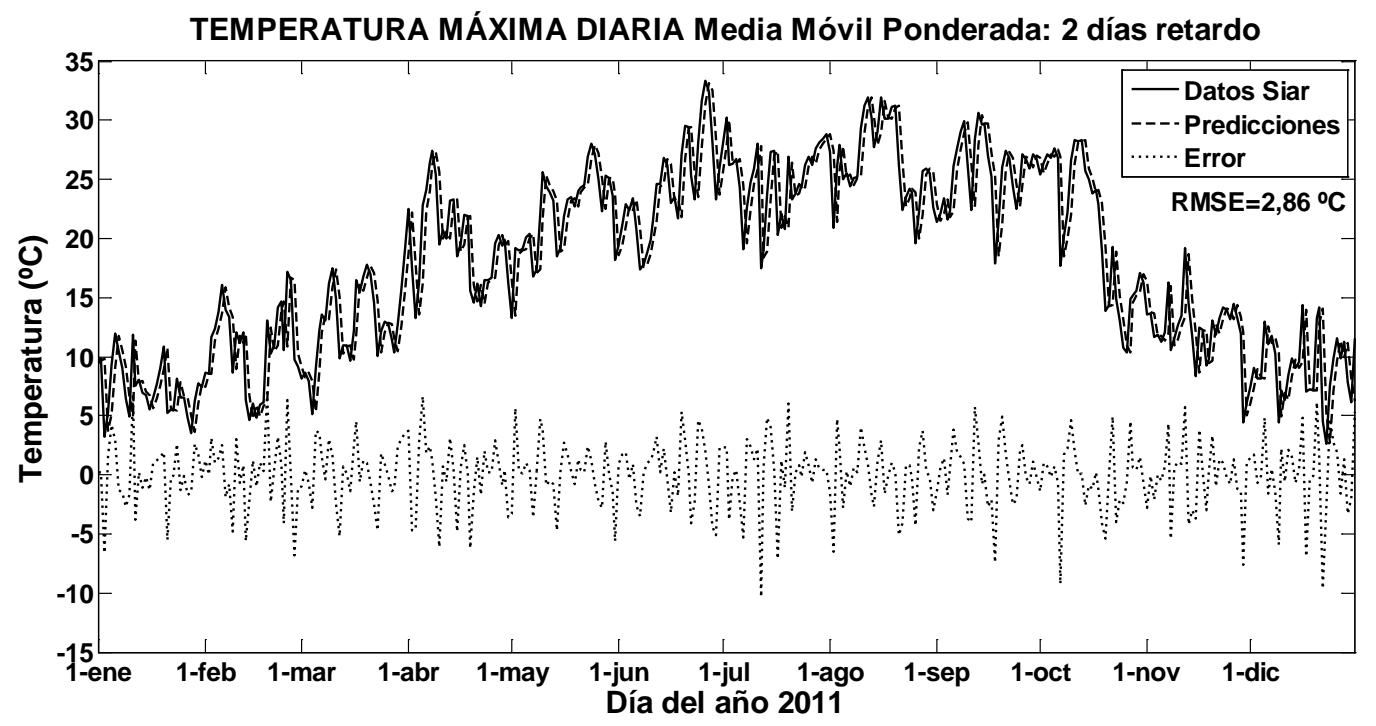

Fig. 4.2.12 Datos de la temperatura máxima diaria del año 2011 SIAR en Mansilla Mayor (León), valores resultado de la predicción realizada con la media móvil ponderada de 2 días de retardo y el error producido para cada día del año

$$
\widehat{\mathrm{Y}}_{\mathrm{t}+1}=\frac{0,9326 \mathrm{Y}_{\mathrm{t}}+0,0817 \mathrm{Y}_{\mathrm{t}-1}+0,1006 \mathrm{Y}_{\mathrm{t}-2}+0,0988 \mathrm{Y}_{\mathrm{t}-3}+0,0816 \mathrm{Y}_{\mathrm{t}-4}}{0,9326+0,0817+0,1006+0,0988+0,0816}
$$

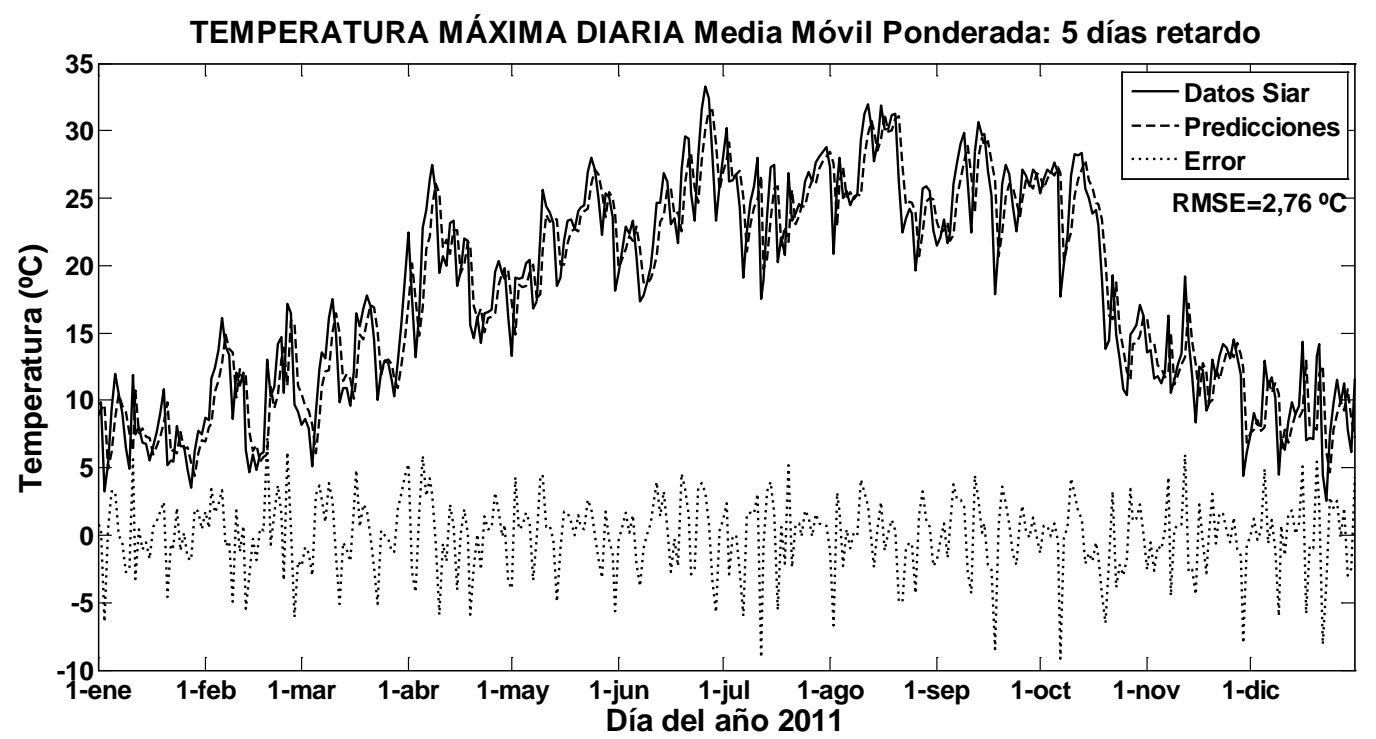

Fig. 4.2.13 Datos de la temperatura máxima diaria del año 2011 SIAR en Mansilla Mayor (León), valores resultado de la predicción realizada con la media móvil ponderada de 5 días de retardo y el error producido para cada día del año 


\section{4) Media móvil ponderada de la temperatura mínima diaria}

Se representan los valores obtenidos de la predicción de la temperatura ambiente mínima diaria para el año 2011, utilizando los datos de 2 días de retardo mediante la ecuación (Ec. 4.2.7) en la gráfica (Fig. 4.2.14) con un valor de $\mathrm{RMSE}=2,52{ }^{\circ} \mathrm{C} / \mathrm{d}$ y con 5 días de retardo mediante la ecuación (Ec. 4.2.8) en la gráfica (Fig. 4.2.15) con un valor de RMSE $=2,53^{\circ} \mathrm{C} / \mathrm{d}$. Se puede observar que al aumentar el número de días de retardo la gráfica de la predicción se suaviza.

$$
\widehat{\mathrm{Y}}_{\mathrm{t}+1}=\frac{0,8961 \mathrm{Y}_{\mathrm{t}}+0,0331 \mathrm{Y}_{\mathrm{t}-1}}{0,8961+0,0331}
$$

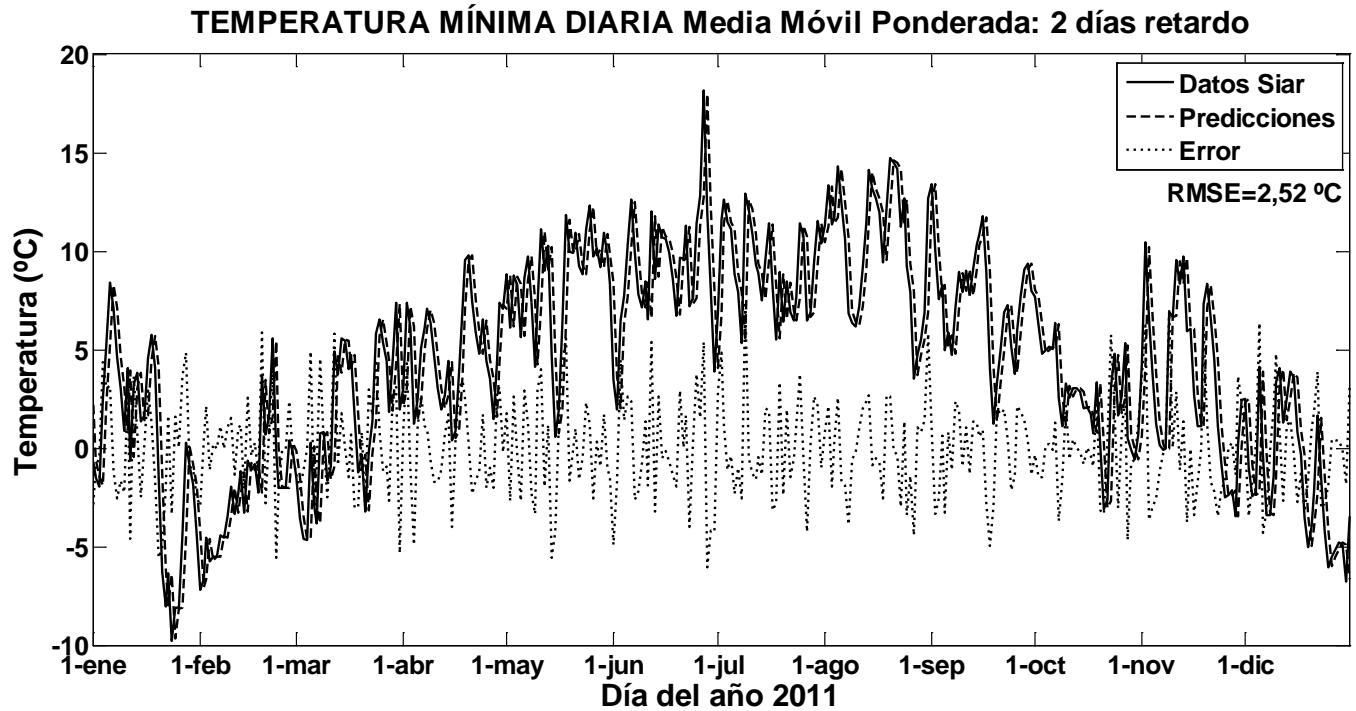

Fig. 4.2.14 Datos de la temperatura mínima diaria del año 2011 SIAR en Mansilla Mayor (León), valores resultado de la predicción realizada con la media móvil ponderada de 2 días de retardo y el error producido para cada día del año

$$
\widehat{Y}_{t+1}=\frac{0,8961 Y_{t}+0,0331 Y_{t-1}+0,1239 Y_{t-2}+0,1303 Y_{t-3}+0,0994 Y_{t-4}}{0,8961+0,0331+0,1239+0,1303+0,0994}
$$

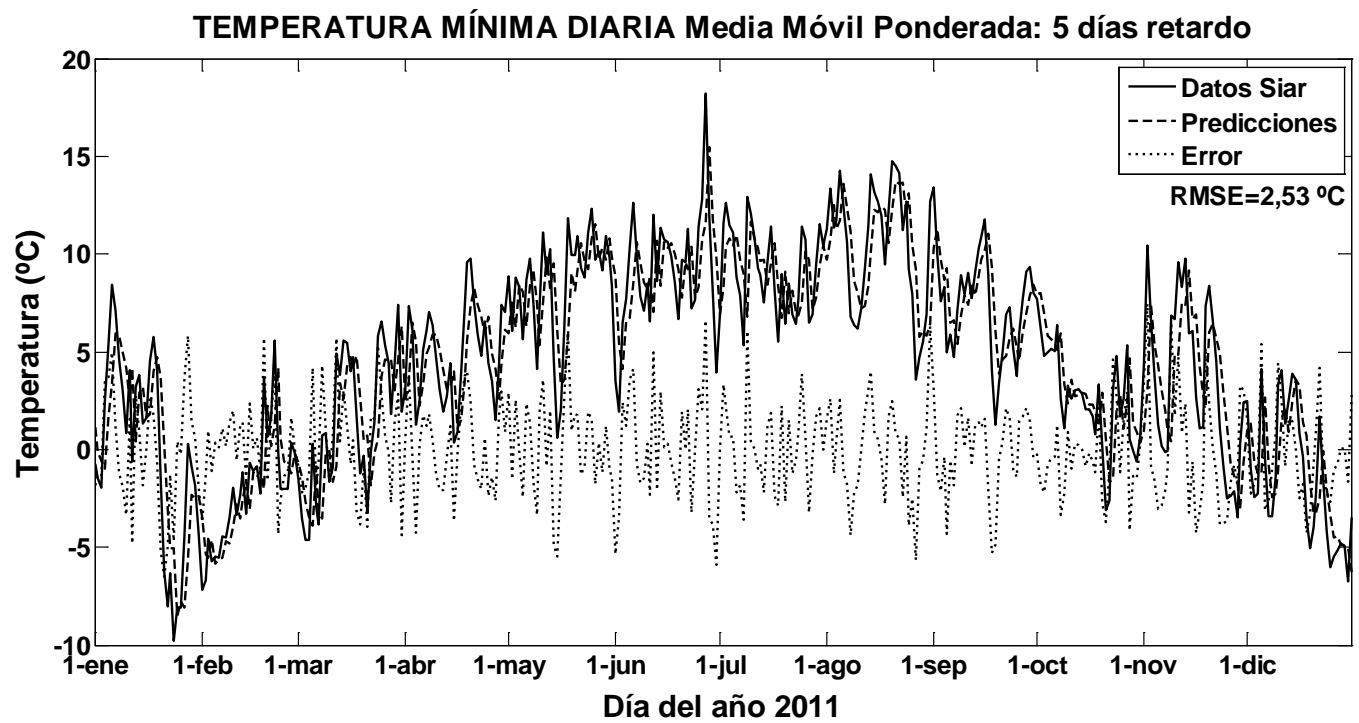

Fig. 4.2.15 Datos de la temperatura mínima diaria del año 2011 SIAR en Mansilla Mayor (León), valores resultado de la predicción realizada con la media móvil ponderada de 5 días de retardo y el error producido para cada día del año 


\section{5) Error producido por la media móvil ponderada de la temperatura media, máxima y mínima diaria}

El cálculo de la predicción de las temperaturas ambiente media, máxima y mínima diaria para el año 2011 se realizó, utilizando la media móvil ponderada y los coeficientes de autocorrelación de 2 a 20 días de retardo y se compararon los resultados mediante el estadístico RMSE en la gráfica (Fig. 4.2.16). Obteniéndose:

- El valor mínimo para 5 días de retardo con un $\mathrm{RMSE}=1,81^{\circ} \mathrm{C} / \mathrm{d}$ para la temperatura media diaria.

- El valor mínimo para 6 días de retardo con un $\mathrm{RMSE}=2,75^{\circ} \mathrm{C} / \mathrm{d}$ para la temperatura máxima diaria.

- El valor mínimo para 10 días de retardo con un $\mathrm{RMSE}=2,50^{\circ} \mathrm{C} / \mathrm{d}$ para la temperatura mínima diaria.

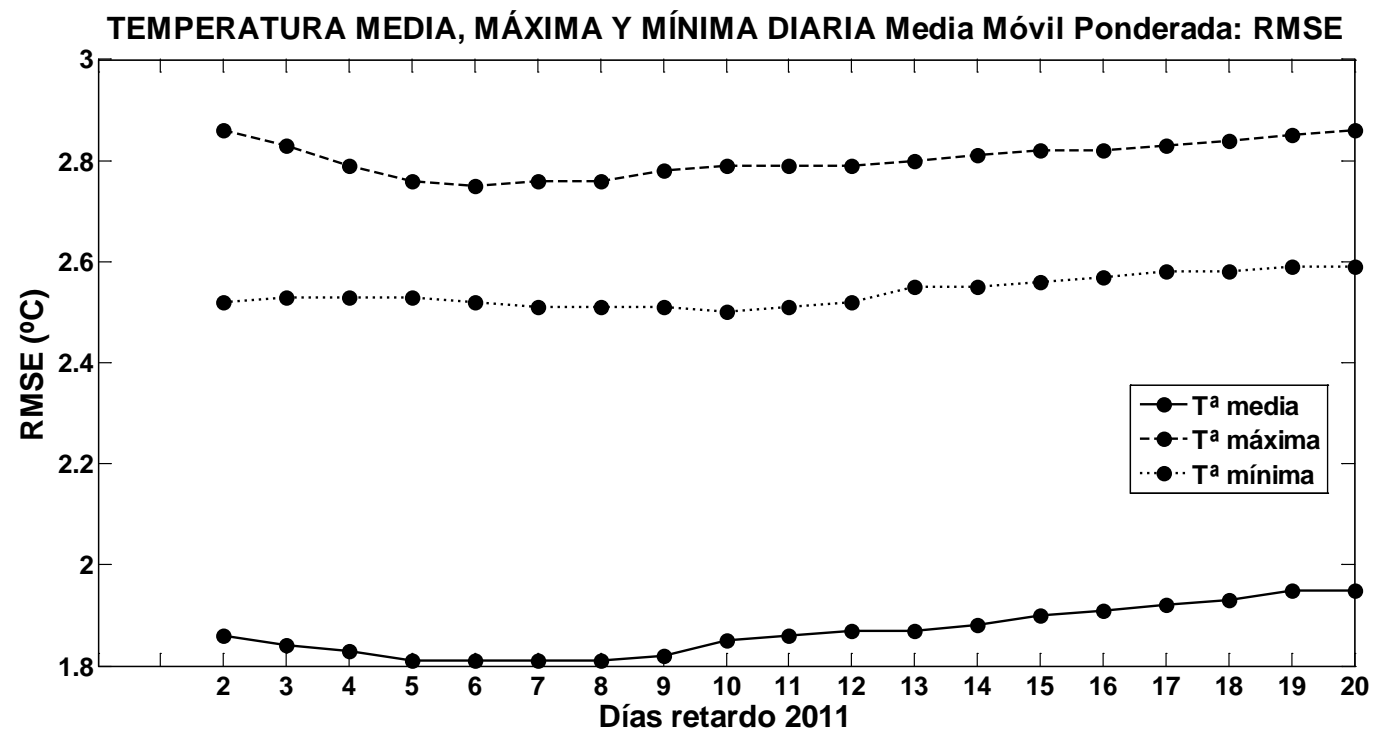

Fig. 4.2.16 RMSE del error producido por la media móvil ponderada de 2 a 20 días de retardo, en la predicción de la serie de los datos de las temperaturas media, máxima y mínima diaria, para el año 2011 SIAR en Mansilla Mayor (León) 


\subsubsection{Regresión lineal}

Se presentan los resultados de la regresión lineal respecto a un día de retardo de las variables climatológicas de la base de datos SIAR en Mansilla Mayor (León).

\section{1) Regresión lineal de la irradiación solar global diaria}

La predicción de la irradiación solar global diaria del día de mañana se realizó con la regresión lineal o ajuste lineal, que es un método matemático que modela la relación entre una variable dependiente en este caso el valor de la irradiación solar global del día de mañana $\mathrm{H}(\mathrm{t}+1)$, las variables independientes en este caso el valor de la irradiación solar global del día de hoy $\mathrm{H}(\mathrm{t})$ y un término aleatorio. Este modelo puede ser expresado como la ecuación (Ec. 4.2.9):

$$
H(t+1)=0,8748 \mathrm{H}(\mathrm{t})+2,048
$$

Obtenido de los datos de la irradiación solar global de los años 2004-2010 SIAR en Mansilla Mayor (León), con un RMSE = 4,32 MJ/m²/d, que se muestra en la gráfica (Fig. 4.2.17).

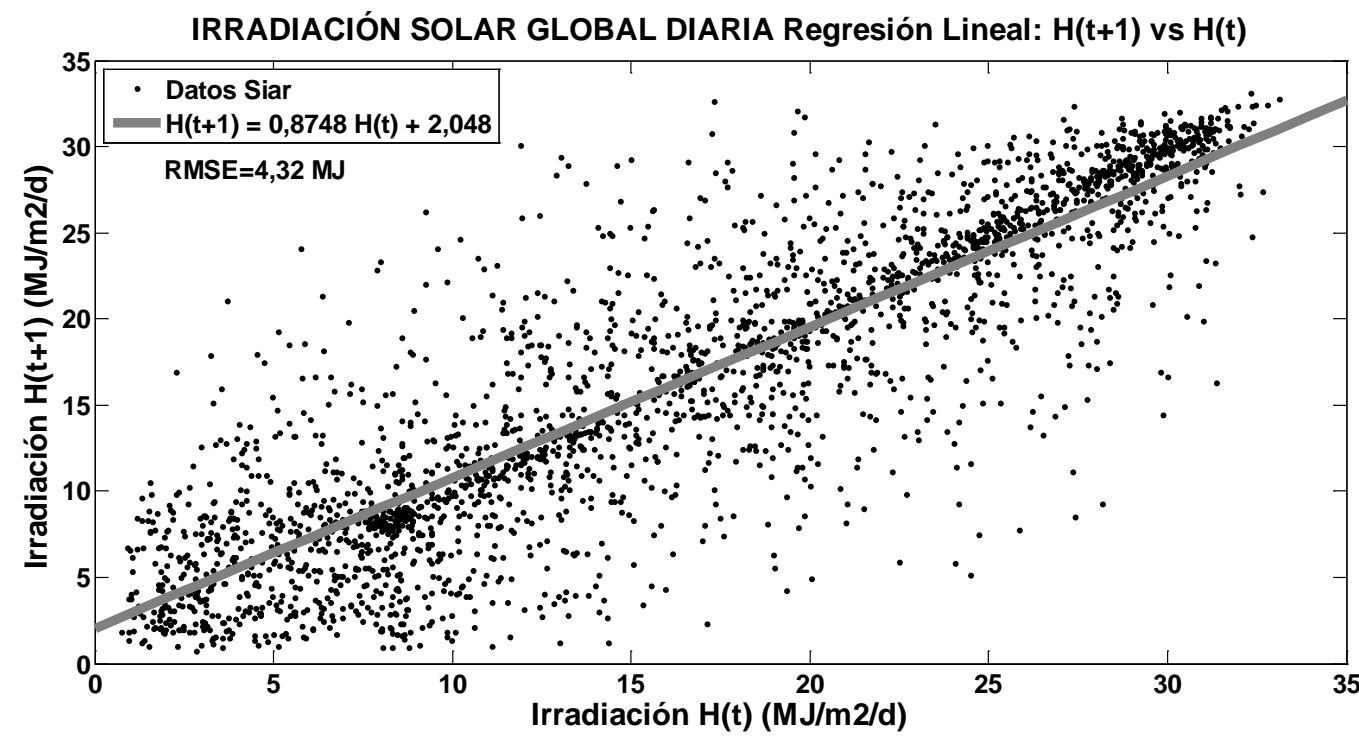

Fig. 4.2.17 Ecuación de la regresión lineal con un día de retardo, resultado de los datos de la irradiación solar global diaria de los años 20042010 SIAR en Mansilla Mayor (León) 
Se representa la simulación realizada para el año 2011 con la ecuación de regresión lineal obtenida (Ec. 4.2.9), junto con los datos y el error producido para cada día del año, RMSE $=4,24 \mathrm{MJ} / \mathrm{m}^{2} / \mathrm{d}$, en la gráfica (Fig. 4.2.18).

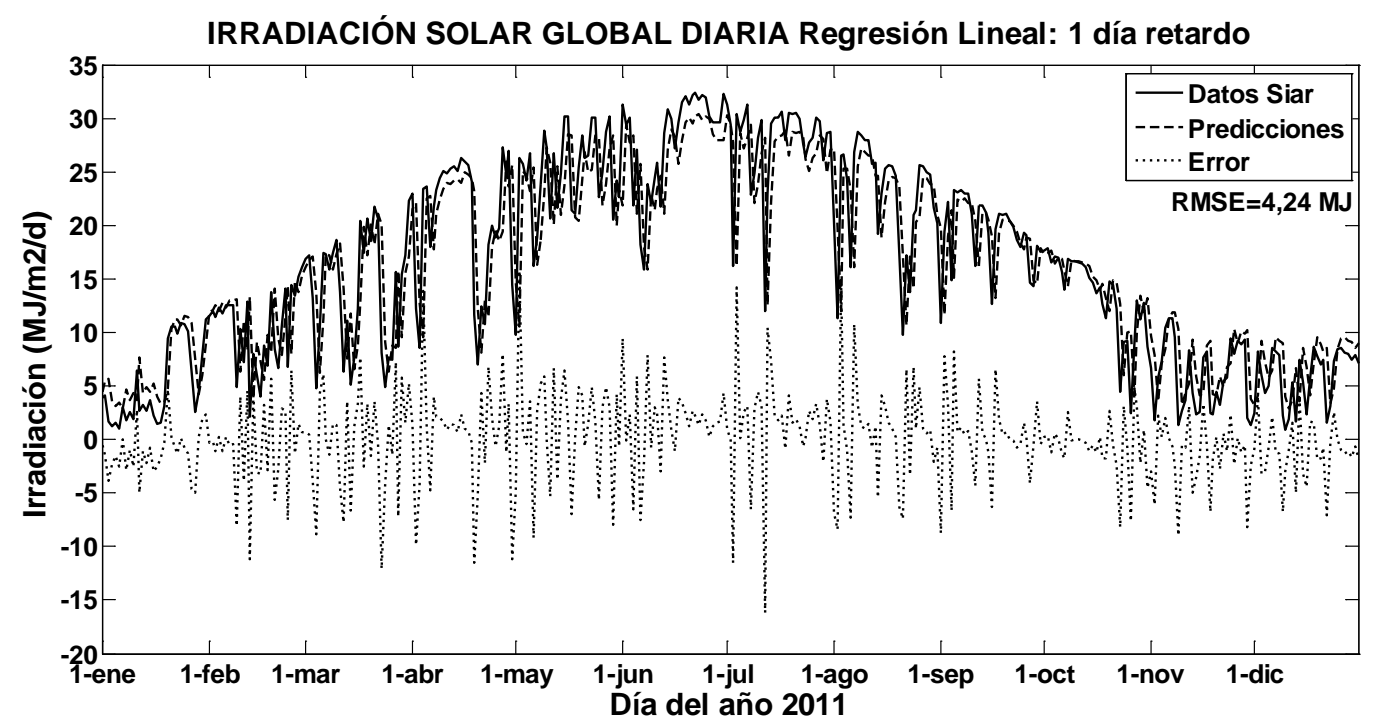

Fig. 4.2.18 Datos de la irradiación solar global diaria del año 2011 SIAR en Mansilla Mayor (León), valores resultado de la predicción realizada con la regresión lineal de un día de retardo y el error producido para cada día del año 


\section{2) Regresión lineal de la temperatura media diaria}

La predicción de la temperatura media diaria del día de mañana se realizó con la regresión lineal o ajuste lineal, que es un método matemático que modela la relación entre una variable dependiente en este caso el valor de la temperatura media diaria del día de mañana $T_{\text {med }}(t+1)$, las variables independientes en este caso el valor de la temperatura media diaria del día de hoy $T_{\text {med }}(t)$ y un término aleatorio. Este modelo puede ser expresado como la ecuación (Ec. 4.2.10):

$$
\mathrm{T}_{\text {med }}(\mathrm{t}+1)=0,9576 \mathrm{~T}_{\text {med }}(\mathrm{t})+0,4357
$$

Obtenido de los datos de la temperatura media diaria de los años 2004-2010 SIAR en Mansilla Mayor (León), con un RMSE $=1,96^{\circ} \mathrm{C} / \mathrm{d}$, que se muestra en la gráfica (Fig. 4.2.19).

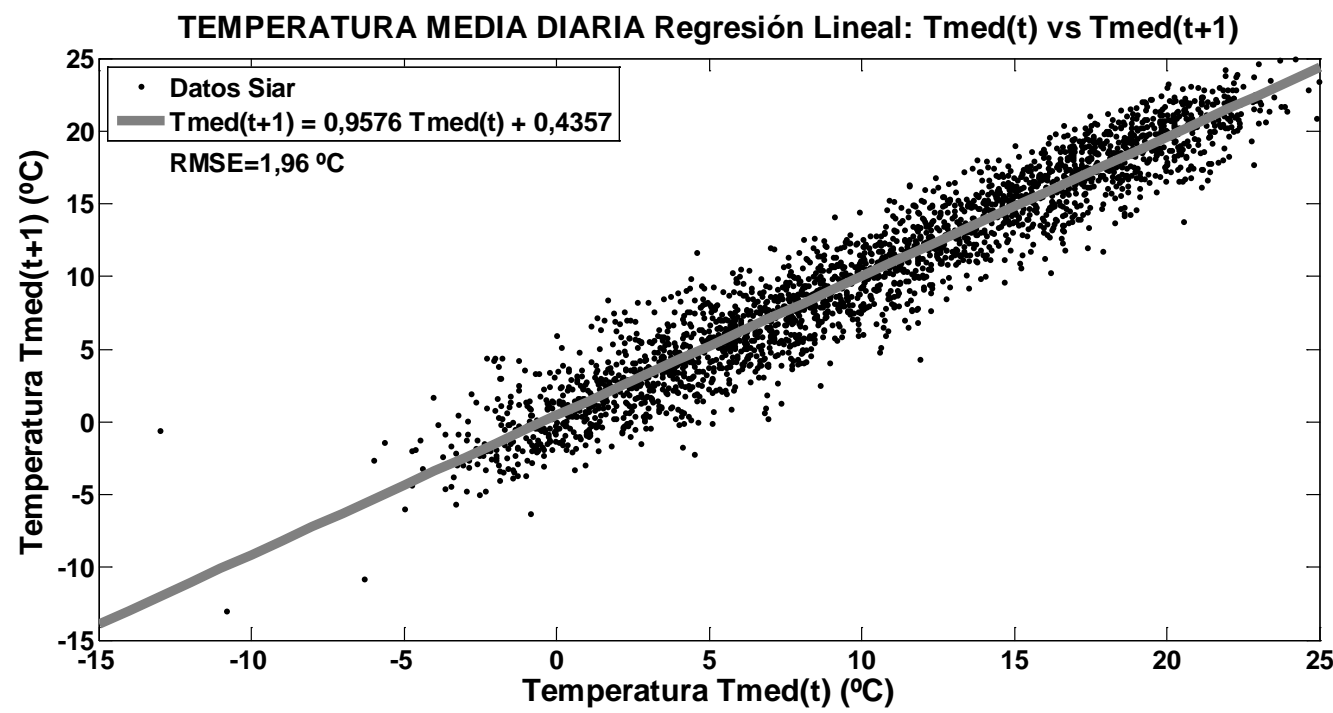

Fig. 4.2.19 Ecuación de la regresión lineal con un día de retardo, resultado de los datos de la temperatura media diaria de los años 2004-2010 SIAR en Mansilla Mayor (León) 
Se representa la simulación realizada para el año 2011 con la ecuación de regresión lineal obtenida (Ec. 4.2.10), junto con los datos y el error producido para cada día del año, $R M S E=1,85^{\circ} \mathrm{C} / \mathrm{d}$, en la gráfica (Fig. 4.2.20).

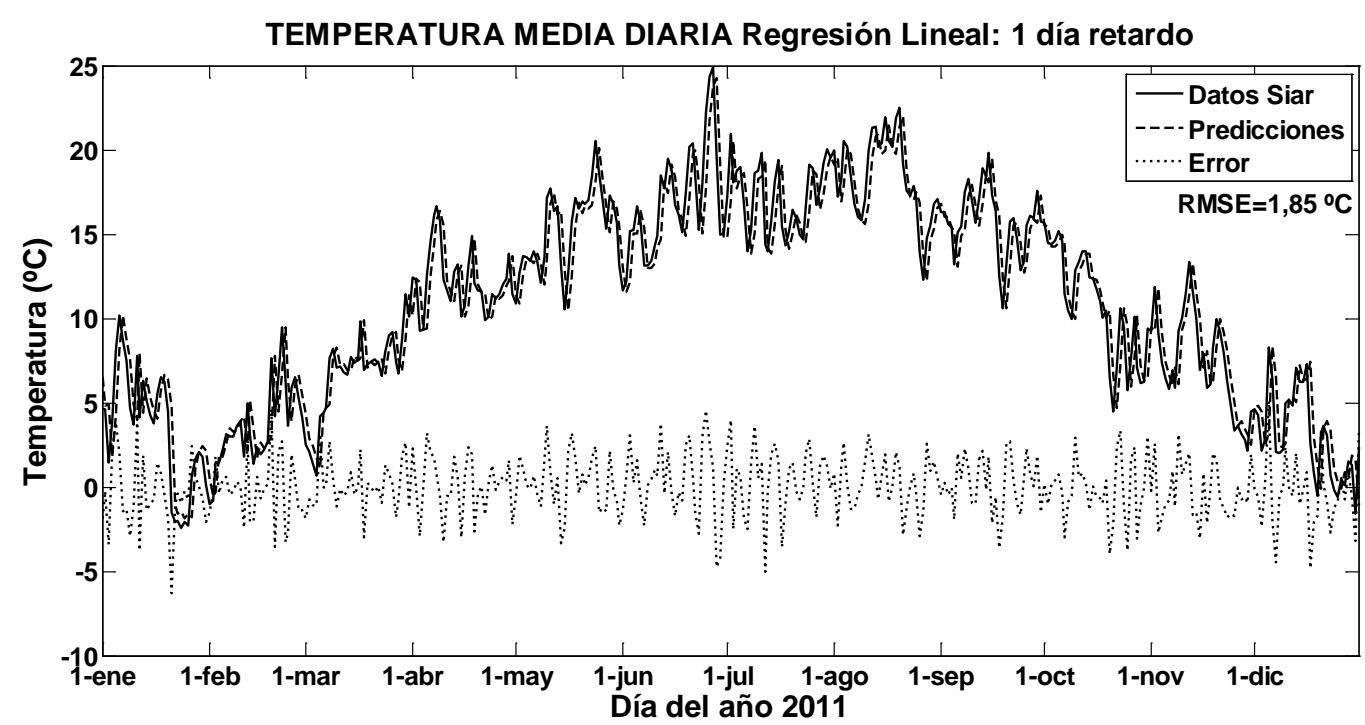

Fig. 4.2.20 Datos de la temperatura media diaria del año 2011 SIAR en Mansilla Mayor (León), valores resultado de la predicción realizada con la regresión lineal de un día de retardo y el error producido para cada día del año 


\subsubsection{Análisis de Fourier}

El método de cálculo se puede aplicar a las variables climatológicas que muestran frecuencias significativas como es el caso de la irradiación solar global diaria y las temperaturas ambiente media, máxima y mínima diaria y que cuentan con series climatológicas suficientes. Se llevó a cabo un análisis de Fourier de la totalidad de la serie anual de la variable analizada, que permite eliminar los fenómenos aleatorios, la ecuación representativa del año se obtiene de los armónicos utilizados.

En esta Tesis Doctoral para el cálculo de los coeficientes del análisis de Fourier se aplicó a todo el conjunto de datos tanto de irradiación solar global como de las temperaturas media, máxima y mínima diarias del año 2004 al 2010, obteniendo resultados similares que los derivados año por año, se utilizó para ello la Curve Fitting Toolbox de Matlab 'cftool' con la cual se puede realizar el análisis de Fourier para los ocho primeros armónicos.

Se presentan los resultados del análisis de Fourier del primer al octavo armónico de las variables climatológicas de la base de datos SIAR en Mansilla Mayor (León).

\section{1) Análisis de Fourier de la irradiación solar global diaria}

Se efectuó el cálculo de los coeficientes del análisis de Fourier de los datos de la irradiación solar global diaria del año 2004 al 2010 SIAR en Mansilla Mayor (León), obteniéndose las funciones anuales típicas de Fourier que se muestran en la (Tabla 4.2.5), desde el primer al octavo armónico y con el error producido para cada función.

Tabla 4.2.5 Funciones anuales típicas de Fourier de los datos de la irradiación solar global diaria en Mansilla Mayor (León), del primer al octavo armónico y el error producido

\begin{tabular}{|c|c|c|}
\hline \multicolumn{3}{|c|}{ Datos de irradiación solar global diaria (MJ/m²/d) SIAR Mansilla Mayor 2004-2010 } \\
\hline $\begin{array}{c}\mathbf{N}^{\circ} \text { de } \\
\text { armónicos }\end{array}$ & Función anual típica de Fourier & RMSE \\
\hline 1 & $H(t)=16,31-10,9 \cos (0,01712 t)+1,383 \operatorname{sen}(0,01712 t)$ & 4,417 \\
\hline 2 & $\begin{array}{l}\mathrm{H}(\mathrm{t})=16,79-10,75 \cos (0,01792 \mathrm{t})-0,1918 \operatorname{sen}(0,01792 \mathrm{t})-0,4302 \cos (2 \cdot 0,01792 \mathrm{t})+0,9119 \operatorname{sen}(2 \cdot \\
0,01792 \mathrm{t})\end{array}$ & 4,372 \\
\hline 3 & $\begin{array}{l}\mathrm{H}(\mathrm{t})=16,82-10,72 \cos (0,01795 \mathrm{t})-0,2652 \operatorname{sen}(0,01795 \mathrm{t})-0,4444 \cos (2 \cdot 0,01795 \mathrm{t})+0,9129 \operatorname{sen}(2 \cdot \\
0,01795 \mathrm{t})-0,1614 \cos (3 \cdot 0,01795 \mathrm{t})-0,2203 \operatorname{sen}(3 \cdot 0,01795 \mathrm{t})\end{array}$ & 4,370 \\
\hline 4 & $\begin{array}{l}\mathrm{H}(\mathrm{t})=14-8,82 \cos (0,01374 \mathrm{t})+7,663 \operatorname{sen}(0,01374 \mathrm{t})+0,4119 \cdot \cos (2 \cdot 0,01374 \mathrm{t})-1,859 \operatorname{sen}(2 \\
0,01374 \mathrm{t})-1,071 \cos (3 \cdot 0,01374 \mathrm{t})+0,2203 \operatorname{sen}(3 \cdot 0,01374 \mathrm{t})-0,1655 \cos (4 \cdot 0,01374 \mathrm{t})+ \\
0,1346 \operatorname{sen}(4 \cdot 0,01374 \mathrm{t})\end{array}$ & 4,365 \\
\hline 5 & $\begin{array}{l}\mathrm{H}(\mathrm{t})=15,95-10,9 \cos (0,01659 \mathrm{t})+2,442 \operatorname{sen}(0,01659 \mathrm{t})+0,4894 \cos (2 \cdot 0,01659 \mathrm{t})+0,62 \operatorname{sen}(2 \cdot \\
0,01659 \mathrm{t})-0,2298 \cos (3 \cdot 0,01659 \mathrm{t})-0,438 \operatorname{sen}(3 \cdot 0,01659 \mathrm{t})-0,08166 \cos (4 \cdot 0,01659 \mathrm{t})- \\
0,2479 \operatorname{sen}(4 \cdot 0,01659 \mathrm{t})-0,4204 \cos (5 \cdot 0,01659 \mathrm{t})-0,1472 \operatorname{sen}(5 \cdot 0,01659 \mathrm{t})\end{array}$ & 4,360 \\
\hline 6 & $\begin{array}{l}H(t)=15,59-10,71 \cos (0,01601 t)+3,58 \operatorname{sen}(0,01601 t)+0,8222 \cos (2 \cdot 0,01601 t)+0,2469 \operatorname{sen}(2 \cdot \\
0,01601 t)-0,3552 \cos (3 \cdot 0,01601 t)-0,5187 \operatorname{sen}(3 \cdot 0,01601 t)-0,1731 \cos (4 \cdot 0,01601 t)- \\
0,2608 \operatorname{sen}(4 \cdot 0,01601 t)-0,3646 \cos (5 \cdot 0,01601 t)+0,01903 \operatorname{sen}(5 \cdot 0,01601 t)+0,1542 \cos (6 \\
0,01601 t)-0,2483 \operatorname{sen}(6 \cdot 0,01601 t)\end{array}$ & 4,358 \\
\hline 7 & $\begin{array}{l}H(t)=15,62-10,77 \cos (0,01608 t)+3,439 \operatorname{sen}(0,01608 t)+0,7548 \cos (2 \cdot 0,01608 t)+0,3084 \cdot \\
\operatorname{sen}(2 \cdot 0,01608 t)-0,3652 \cos (3 \cdot 0,01608 t)-0,502 \cdot \operatorname{sen}(3 \cdot 0,01608 t)-0,1898 \cos (4 \cdot 0,01608 t)- \\
0,2505 \operatorname{sen}(4 \cdot 0,01608 t)-0,4033 \cos (5 \cdot 0,01608 t)+0,0155 \operatorname{sen}(5 \cdot 0,01608 t)+0,1429 \cos (6 \cdot \\
0,01608 t)-0,2134 \operatorname{sen}(6 \cdot 0,01608 t)-0,2898 \cos (7 \cdot 0,01608 t)+0,05327 \operatorname{sen}(7 \cdot 0,01608 t)\end{array}$ & 4,355 \\
\hline 8 & $\begin{array}{l}\mathrm{H}(\mathrm{t})=15,9-10,88 \cos (0,01608 \mathrm{t})+2,604 \operatorname{sen}(0,01608 \mathrm{t})+0,5436 \cos (2 \cdot 0,01608 \mathrm{t})+0,5728 \operatorname{sen}(2 \cdot \\
0,01608 \mathrm{t})-0,243 \cos (3 \cdot 0,01608 \mathrm{t})-0,4557 \operatorname{sen}(3 \cdot 0,01608 \mathrm{t})-0,09469 \cos (4 \cdot 0,01608 \mathrm{t})- \\
0,2583 \operatorname{sen}(4 \cdot 0,01608 \mathrm{t})-0,4202 \cos (5 \cdot 0,01608 \mathrm{t})-0,1266 \operatorname{sen}(5 \cdot 0,01608 \mathrm{t})+0,2067 \cos (6 \\
0,01608 \mathrm{t})-0,1177 \operatorname{sen}(6 \cdot 0,01608 \mathrm{t})-0,2595 \cos (7 \cdot 0,01608 \mathrm{t})-0,1288 \operatorname{sen}(7 \cdot 0,01608 \mathrm{t})- \\
0,1798 \cos (8 \cdot 0,01608 \mathrm{t})-0,04178 \operatorname{sen}(8 \cdot 0,01608 \mathrm{t})\end{array}$ & 4,355 \\
\hline
\end{tabular}


Se representa la función anual típica de Fourier para el primer armónico obtenida junto a los datos de irradiación solar global diaria del año 2004 al 2010 utilizados para su cálculo en la gráfica (Fig. 4.2.21), con un valor de $\mathrm{RMSE}=4,41 \mathrm{MJ} / \mathrm{m}^{2} / \mathrm{d}$.

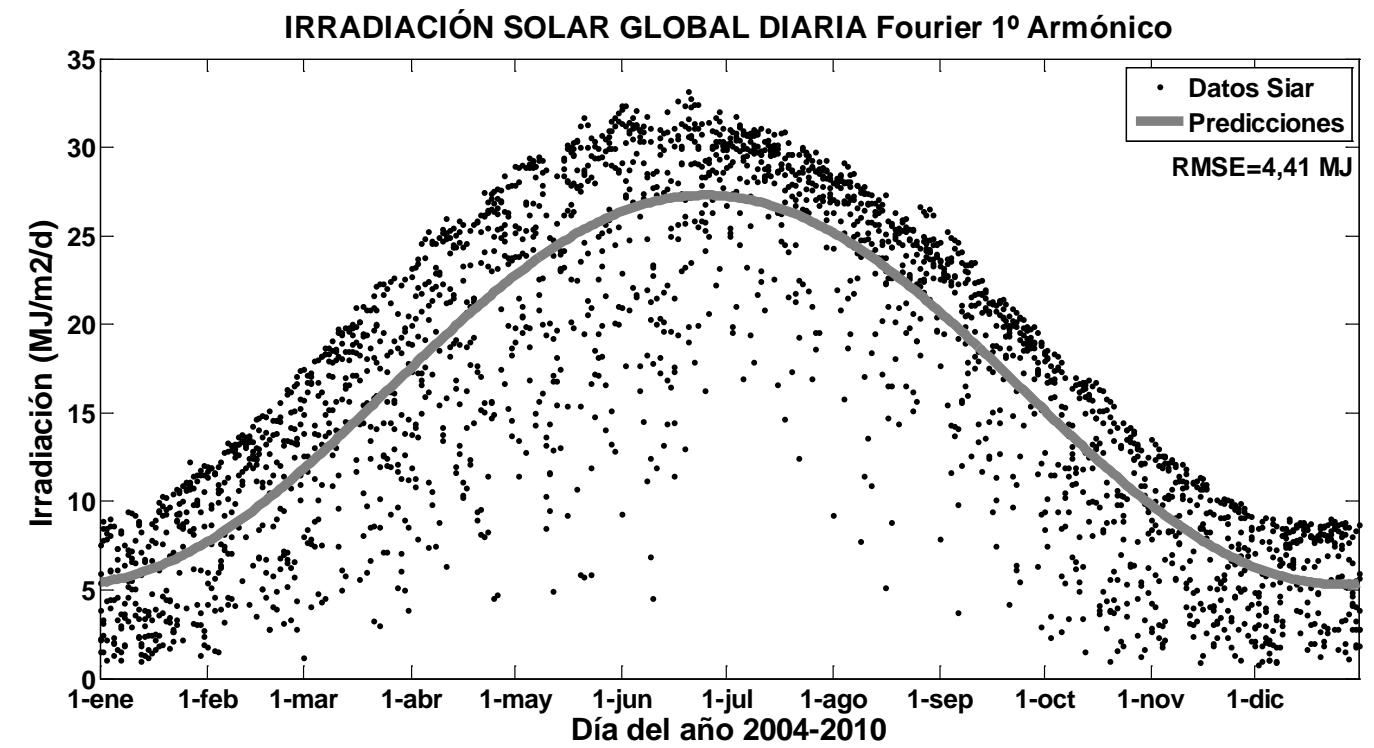

Fig. 4.2.21 Datos de la irradiación solar global diaria del año 2004 al 2010 SIAR en Mansilla Mayor (León), función anual típica del primer armónico y error producido 
Se representa la función anual típica de Fourier del primer al octavo armónico obtenidas de los datos de la irradiación solar global diaria del año 2004 al 2010 utilizados para su cálculo, junto a los datos de irradiación solar global diaria del año 2011 y el error producido para cada día del año en las gráficas (Fig. 4.2.22).

Fourier $1^{\circ}$ armónico: RMSE $=4,27 \mathrm{MJ} / \mathrm{m}^{2} / \mathrm{d}$

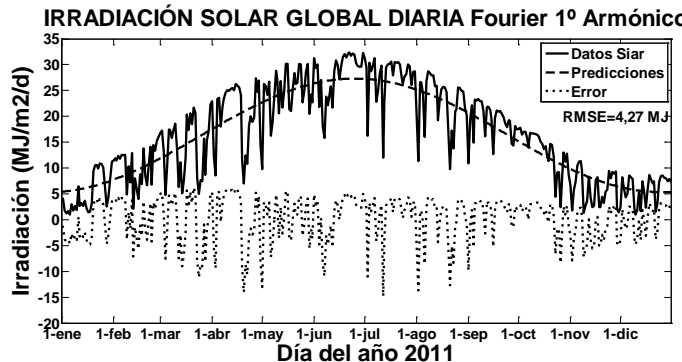

Fourier $3^{\circ}$ armónico: RMSE $=4,26 \mathrm{MJ} / \mathrm{m}^{2} / \mathrm{d}$

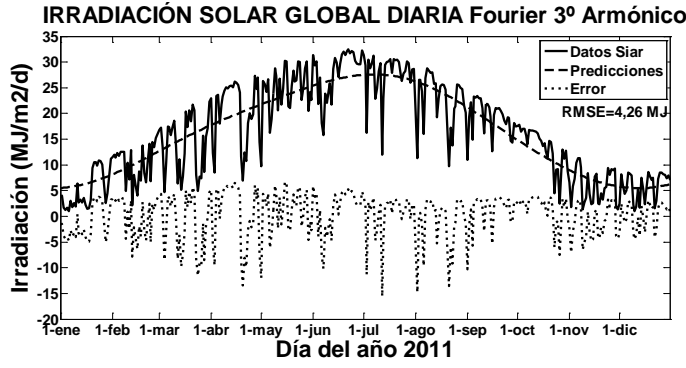

Fourier $5^{\circ}$ armónico: RMSE = 4,24 MJ $/ \mathrm{m}^{2} / \mathrm{d}$

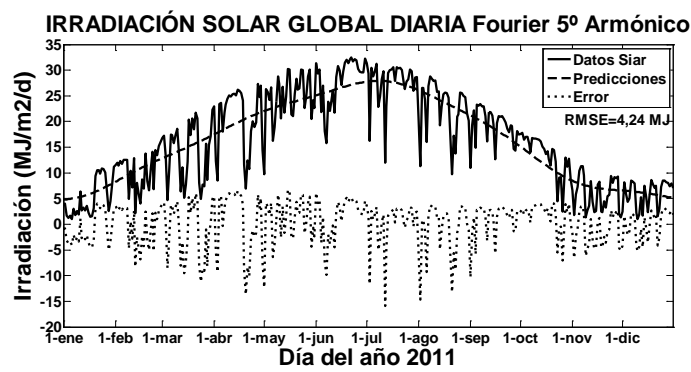

Fourier $7^{\circ}$ armónico: RMSE $=4,25 \mathrm{MJ} / \mathrm{m}^{2} / \mathrm{d}$

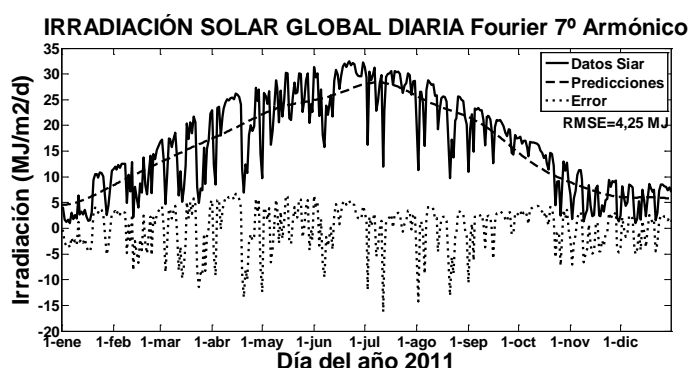

Fourier $2^{\circ}$ armónico: $\mathrm{RMSE}=4,26 \mathrm{MJ} / \mathrm{m}^{2} / \mathrm{d}$

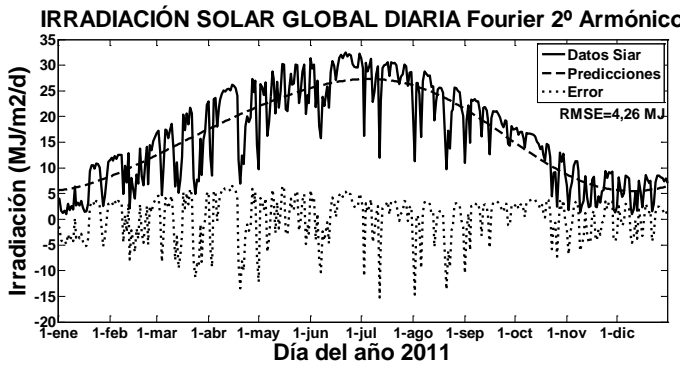

Fourier $4^{\circ}$ armónico: $\mathrm{RMSE}=4,26 \mathrm{MJ} / \mathrm{m}^{2} / \mathrm{d}$

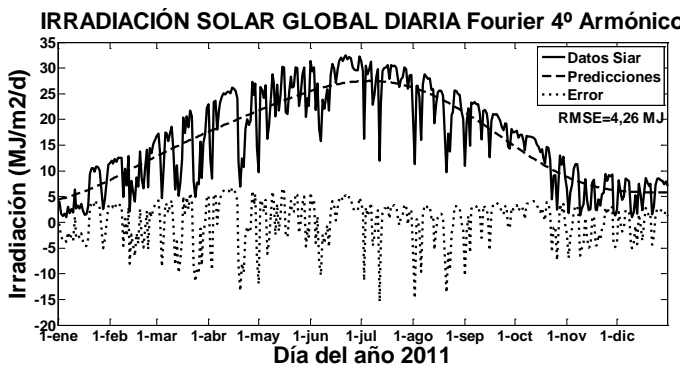

Fourier $6^{\circ}$ armónico: $\mathrm{RMSE}=4,25 \mathrm{MJ} / \mathrm{m}^{2} / \mathrm{d}$

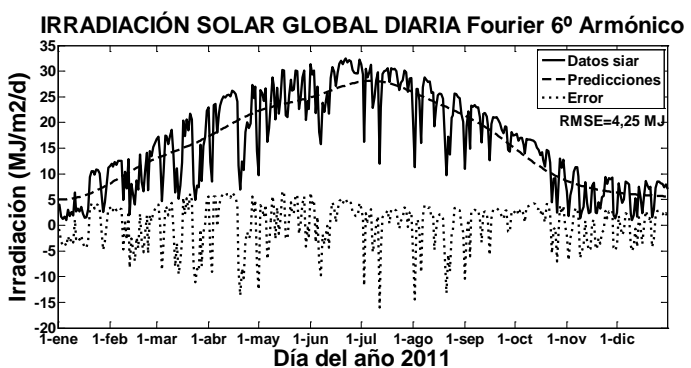

Fourier $8^{\circ}$ armónico: $\mathrm{RMSE}=4,25 \mathrm{MJ} / \mathrm{m}^{2} / \mathrm{d}$

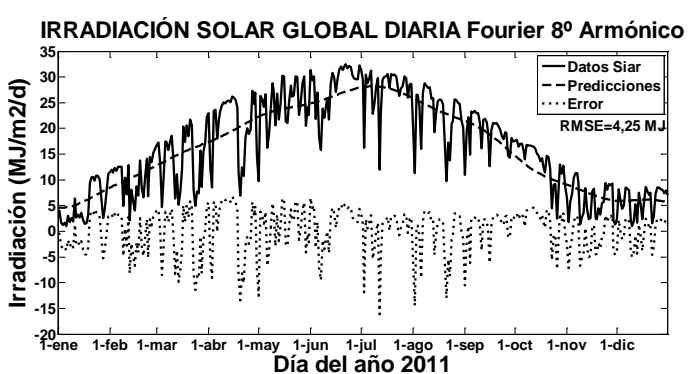

Fig. 4.2.22 Datos de la irradiación solar global diaria del año 2011 SIAR en Mansilla Mayor (León), función anual típica del primer al octavo armónico y error producido para cada día del año 


\section{2) Análisis de Fourier de la temperatura media diaria}

Se efectuó el cálculo de los coeficientes del análisis de Fourier de los datos de la temperatura media diaria del año 2004 al 2010 SIAR en Mansilla Mayor (León), obteniéndose las funciones anuales típicas de Fourier que se muestran en la (Tabla 4.2.6), desde el primer al octavo armónico y con el error producido para cada función.

Tabla 4.2.6 Funciones anuales típicas de Fourier de los datos de la temperatura media diaria SIAR en Mansilla Mayor (León), del primer al octavo armónico y el error producido

\begin{tabular}{|c|c|c|}
\hline \multicolumn{3}{|c|}{ Datos de temperatura media diaria $\left({ }^{\circ} \mathrm{C}\right)$ SIAR Mansilla Mayor 2004-2010 } \\
\hline $\begin{array}{c}\mathrm{N}^{\circ} \text { de } \\
\text { armónicos }\end{array}$ & Función anual típica de Fourier & RMSE \\
\hline 1 & $\operatorname{Tmed}(t)=10,59-7,77 \cos (0,01791 \mathrm{t})-3,511 \operatorname{sen}(0,01791 \mathrm{t})$ & 3,032 \\
\hline 2 & $\begin{array}{l}\text { Tmed }(\mathrm{t})=7,033-4,591 \cos (0,01111 \mathrm{t})+7,348 \operatorname{sen}(0,01111 \mathrm{t})-0,157 \cos (2 \cdot 0,01111 \mathrm{t})-3,559 \operatorname{sen}(2 \cdot \\
0,01111 \mathrm{t})\end{array}$ & 2,995 \\
\hline 3 & $\begin{array}{l}\text { Tmed }(t)=10,83-7,264 \cos (0,01837 t)-4,176 \operatorname{sen}(0,01837 t)-0,4432 \cos (2 \cdot 0,01837 t)+ \\
0,1391 \operatorname{sen}(2 \cdot 0,01837 t)-0,5165 \cos (3 \cdot 0,01837 t)-0,1922 \operatorname{sen}(3 \cdot 0,01837 t)\end{array}$ & 2,992 \\
\hline 4 & $\begin{array}{l}\text { Tmed }(t)=9,063-4,886 \cos (0,01227 t)+4,095 \operatorname{sen}(0,01227 t)+0,7542 \cos (2 \cdot 0,01227 t)-4,555 \operatorname{sen}(2 \cdot \\
0,01227 t)-1,292 \cos (3 \cdot 0,01227 t)-0,7837 \operatorname{sen}(3 \cdot 0,01227 t)-0,7717 \cos (4 \cdot 0,01227 t)+ \\
0,3988 \operatorname{sen}(4 \cdot 0,01227 t)\end{array}$ & 2,987 \\
\hline 5 & $\begin{array}{l}\text { Tmed }(t)=9,727-8,823 \cos (0,0161 t)-0,4606 \operatorname{sen}(0,0161 t)+0,6361 \cos (2 \cdot 0,0161 t)+0,6803 \operatorname{sen}(2 \cdot \\
0,0161 t)+0,0942 \cos (3 \cdot 0,0161 t)+0,3764 \operatorname{sen}(3 \cdot 0,0161 t)+0,2968 \cos (4 \cdot 0,0161 t)-0,09827 \operatorname{sen}(4 \\
0,0161 t)+0,3474 \cos (5 \cdot 0,0161 t)+0,06249 \operatorname{sen}(5 \cdot 0,0161 t)\end{array}$ & 2,983 \\
\hline 6 & $\begin{array}{l}\text { Tmed }(t)=9,946-8,676 \cos (0,01654 t)-1,251 \operatorname{sen}(0,01654 t)+0,3369 \cos (2 \cdot 0,01654 t)+ \\
0,7051 \operatorname{sen}(2 \cdot 0,01654 t)-0,08379 \cos (3 \cdot 0,01654 t)+0,3957 \operatorname{sen}(3 \cdot 0,01654 t)+0,2522 \cos (4 \\
0,01654 t)+0,01242 \operatorname{sen}(4 \cdot 0,01654 t)+0,3075 \cos (5 \cdot 0,01654 t)+0,2099 \operatorname{sen}(5 \cdot 0,01654 t)+ \\
0,1048 \cos (6 \cdot 0,01654 t)+0,007583 \operatorname{sen}(6 \cdot 0,01654 t)\end{array}$ & 2,983 \\
\hline 7 & $\begin{array}{l}\text { Tmed }(t)=9,874-8,751 \cos (0,01643 t)-1,041 \operatorname{sen}(0,01643 t)+0,3864 \cos (2 \cdot 0,01643 t)+0,714 \operatorname{sen}(2 \cdot \\
0,01643 t)-0,06148 \cos (3 \cdot 0,01643 t)+0,4084 \operatorname{sen}(3 \cdot 0,01643 t)+0,246 \cos (4 \cdot 0,01643 t)+ \\
0,00087 \operatorname{sen}(4 \cdot 0,01643 t)+0,3057 \cos (5 \cdot 0,01643 t)+0,1888 \operatorname{sen}(5 \cdot 0,01643 t)+0,0705 \cos (6 \\
0,01643 t)+0,009187 \operatorname{sen}(6 \cdot 0,01643 t)-0,1137 \cos (7 \cdot 0,01643 t)+0,1537 \operatorname{sen}(7 \cdot 0,01643 t)\end{array}$ & 2,982 \\
\hline 8 & $\begin{array}{l}\text { Tmed }(t)=10,47-7,99 \cos (0,0176 t)-3,034 \operatorname{sen}(0,0176 t)-0,224 \cos (2 \cdot 0,0176 t)+0,4723 \operatorname{sen}(2 \\
0,0176 t)-0,4428 \cos (3 \cdot 0,0176 t)+0,1546 \operatorname{sen}(3 \cdot 0,0176 t)+0,04217 \cos (4 \cdot 0,0176 t)+0,04157 \operatorname{sen}(4 \\
0,0176 t)-0,03351 \cos (5 \cdot 0,0176 t)+0,3185 \operatorname{sen}(5 \cdot 0,0176 t)+0,06229 \cos (6 \cdot 0,0176 t)+0,191 \operatorname{sen}(6 \\
0,0176 t)-0,1071 \cos (7 \cdot 0,0176 t)-0,02178 \operatorname{sen}(7 \cdot 0,0176 t)-0,2866 \cos (8 \cdot 0,0176 t)-0,1989 \operatorname{sen}(8 \\
0,0176 t)\end{array}$ & 2,977 \\
\hline
\end{tabular}


Se representa la función anual típica de Fourier para el primer armónico obtenida junto a los datos de temperatura media diaria del año 2004 al 2010 utilizados para su cálculo en la gráfica (Fig. 4.2.23), con un valor de $\mathrm{RMSE}=3,03^{\circ} \mathrm{C}$.

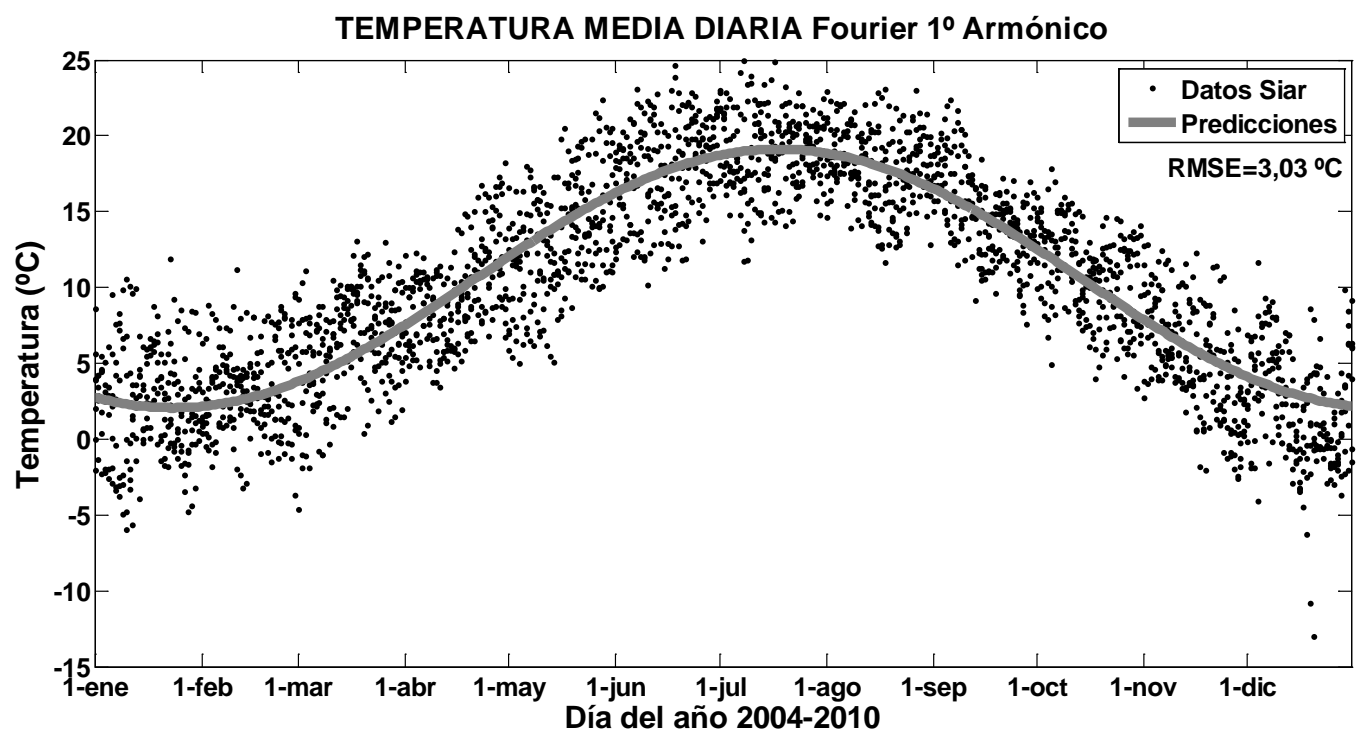

Fig. 4.2.23 Datos de la temperatura media diaria del año 2004 al 2010 SIAR en Mansilla Mayor (León), función anual típica del primer armónico y error producido 
Se representa la función anual típica de Fourier del primer al octavo armónico obtenidas de los datos de la temperatura media diaria del año 2004 al 2010 utilizados para su cálculo, junto a los datos de temperatura media diaria del año 2011 y el error producido para cada día del año en las gráficas (Fig. 4.2.24).

Fourier $1^{\circ}$ armónico: $\mathrm{RMSE}=2,66^{\circ} \mathrm{C}$

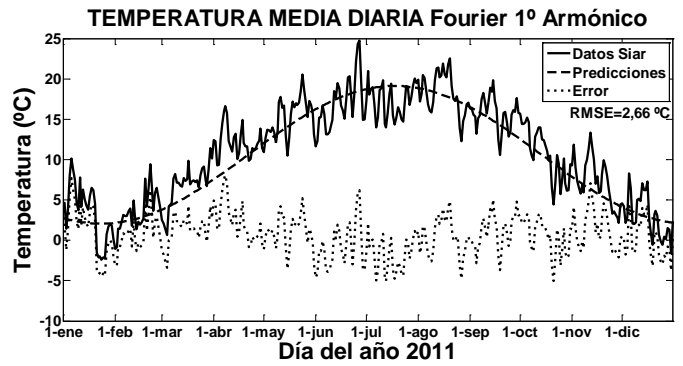

Fourier $3^{\circ}$ armónico: $\operatorname{RMSE}=2,70^{\circ} \mathrm{C}$

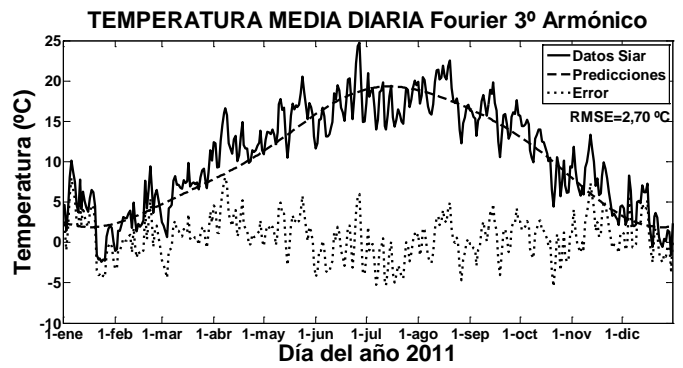

Fourier $5^{\circ}$ armónico: $\operatorname{RMSE}=2,69^{\circ} \mathrm{C}$

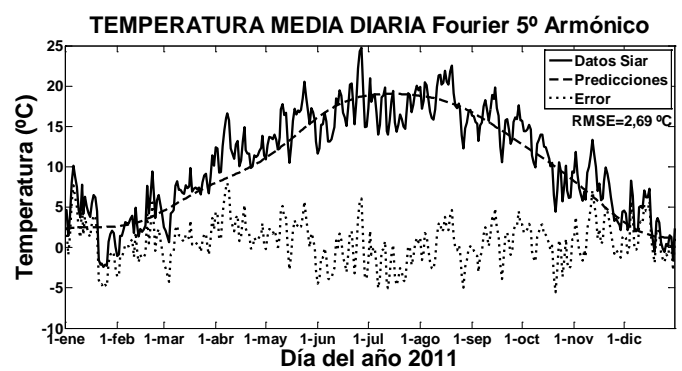

Fourier $7^{\circ}$ armónico: $\operatorname{RMSE}=2,71^{\circ} \mathrm{C}$

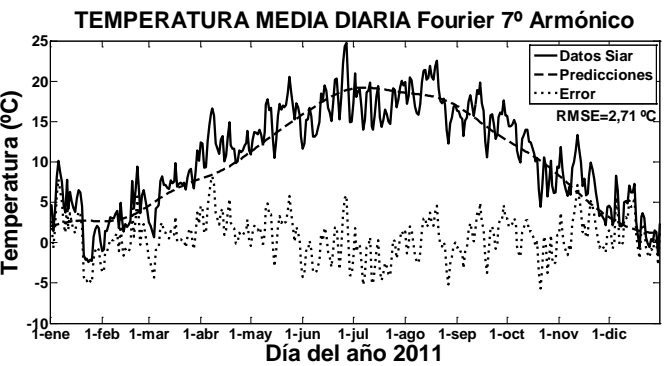

Fourier $2^{\circ}$ armónico: $\mathrm{RMSE}=2,67^{\circ} \mathrm{C}$

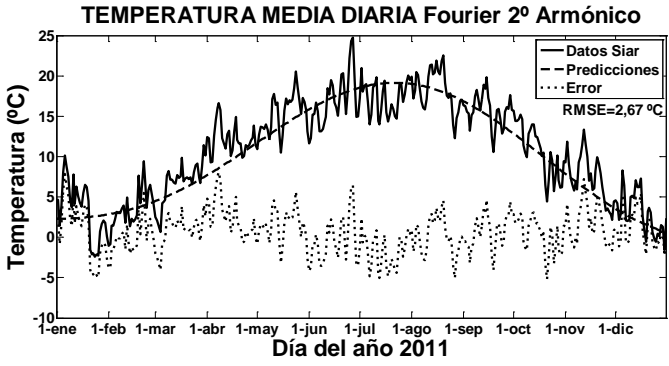

Fourier $4^{\circ}$ armónico: $\mathrm{RMSE}=2,70^{\circ} \mathrm{C}$

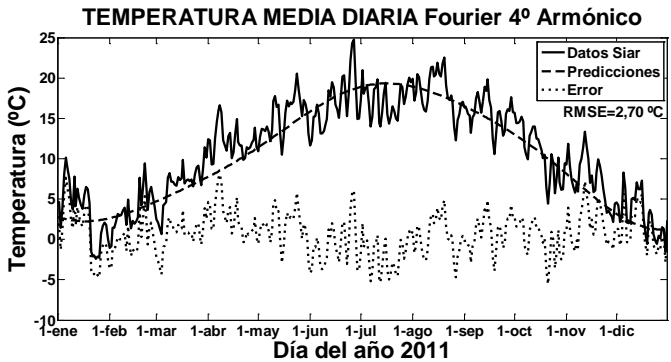

Fourier $6^{\circ}$ armónico: $\mathrm{RMSE}=2,70^{\circ} \mathrm{C}$

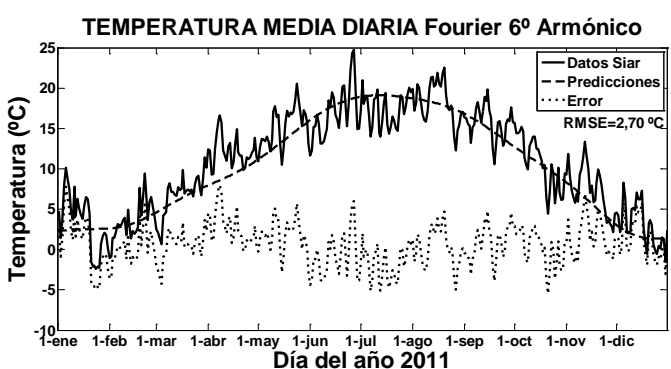

Fourier $8^{\circ}$ armónico: $\mathrm{RMSE}=2,82^{\circ} \mathrm{C}$

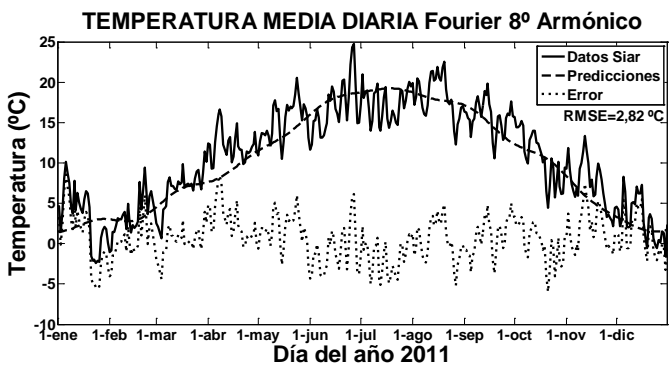

Fig. 4.2.24 Datos de la temperatura media diaria del año 2011 SIAR en Mansilla Mayor (León), función anual típica del primer al octavo armónico y error producido para cada día del año 


\section{3) Análisis de Fourier de la temperatura máxima diaria}

Se efectuó el cálculo de los coeficientes del análisis de Fourier de los datos de la temperatura máxima diaria del año 2004 al 2010 SIAR en Mansilla Mayor (León), obteniéndose las funciones anuales típicas de Fourier que se muestran en la (Tabla 4.2.7), desde el primer al octavo armónico y con el error producido para cada función.

Tabla 4.2.7 Funciones anuales típicas de Fourier de los datos de la temperatura máxima diaria SIAR en Mansilla Mayor (León), del primer al octavo armónico y el error producido

\begin{tabular}{|c|c|c|}
\hline \multicolumn{3}{|c|}{ Datos de temperatura máxima diaria $\left({ }^{\circ} \mathrm{C}\right)$ SIAR Mansilla Mayor 2004-2010 } \\
\hline $\begin{array}{c}\mathbf{N}^{\circ} \text { de } \\
\text { armónicos }\end{array}$ & Función anual típica de Fourier & RMSE \\
\hline 1 & $\operatorname{Tmax}(t)=17,38-9,237 \cos (0,01742 t)-3,553 \operatorname{sen}(0,01742 t)$ & 4,015 \\
\hline 2 & $\begin{array}{l}\operatorname{Tmax}(t)=16,34-10,4 \cos (0,01574 t)-0,112 \operatorname{sen}(0,01574 t)+0,7262 \cos (2 \cdot 0,01574 t)+1,319 \operatorname{sen}(2 \cdot \\
0,01574 t)\end{array}$ & 3,902 \\
\hline 3 & $\begin{array}{l}\operatorname{Tmax}(t)=17,73-8,947 \cos (0,01766 t)-3,991 \operatorname{sen}(0,01766 t)-0,8181 \cos (2 \cdot 0,01766 t)+ \\
0,9866 \operatorname{sen}(2 \cdot 0,01766 t)-0,5532 \cos (3 \cdot 0,01766 t)+0,1289 \operatorname{sen}(3 \cdot 0,01766 t)\end{array}$ & 3,894 \\
\hline 4 & $\begin{array}{l}\operatorname{Tmax}(\mathrm{t})=17,47-9,061 \cos (0,01756 \mathrm{t})-3,808 \operatorname{sen}(0,01756 \mathrm{t})-0,757 \cos (2 \cdot 0,01756 \mathrm{t})+1,043 \operatorname{sen}(2 \cdot \\
0,01756 \mathrm{t})-0,5232 \cos (3 \cdot 0,01756 \mathrm{t})+0,1571 \operatorname{sen}(3 \cdot 0,01756 \mathrm{t})+0,03129 \cos (4 \cdot 0,01756 \mathrm{t})- \\
0,09783 \operatorname{sen}(4 \cdot 0,01756 \mathrm{t})\end{array}$ & 3,895 \\
\hline 5 & $\begin{array}{l}\operatorname{Tmax}(t)=15,76-10,03 \cos (0,01446 t)+2,507 \operatorname{sen}(0,01446 t)+1,986 \cos (2 \cdot 0,01446 t)+ \\
0,08989 \operatorname{sen}(2 \cdot 0,01446 t)-0,1587 \cos (3 \cdot 0,01446 t)-0,4054 \operatorname{sen}(3 \cdot 0,01446 t)-0,5053 \cos (4 \\
0,01446 t)-0,3611 \operatorname{sen}(4 \cdot 0,01446 t)-0,07432 \cos (5 \cdot 0,01446 t)-0,1128 \operatorname{sen}(5 \cdot 0,01446 t)\end{array}$ & 4,100 \\
\hline 6 & $\begin{array}{l}\operatorname{Tmax}(t)=17,84-8,27 \cos (0,01822 \mathrm{t})-4,927 \operatorname{sen}(0,01822 \mathrm{t})-1,08 \cos (2 \cdot 0,01822 \mathrm{t})+0,6339 \operatorname{sen}(2 \cdot \\
0,01822 \mathrm{t})-0,6738 \cos (3 \cdot 0,01822 \mathrm{t})-0,07937 \operatorname{sen}(3 \cdot 0,01822 \mathrm{t})-0,04703 \cos (4 \cdot 0,01822 \mathrm{t})- \\
0,1428 \operatorname{sen}(4 \cdot 0,01822 \mathrm{t})-0,1463 \cos (5 \cdot 0,01822 \mathrm{t})+0,02918 \operatorname{sen}(5 \cdot 0,01822 \mathrm{t})-0,1591 \cos (6 \\
0,01822 \mathrm{t})+0,1942 \operatorname{sen}(6 \cdot 0,01822 \mathrm{t})\end{array}$ & 3,894 \\
\hline 7 & $\begin{array}{l}\operatorname{Tmax}(t)=401600-241900 \cos (0,006293 t)-680000 \operatorname{sen}(0,006293 t)-404100 \cos (2 \cdot 0,006293 t)+ \\
329300 \operatorname{sen}(2 \cdot 0,006293 t)+255000 \cos (3 \cdot 0,006293 t)+154500 \operatorname{sen}(3 \cdot 0,006293 t)+26280 \cos (4 \cdot \\
0,006293 t)-128400 \operatorname{sen}(4 \cdot 0,006293 t)-41560 \cos (5 \cdot 0,006293 t)+5917 \operatorname{sen}(5 \cdot 0,006293 t)+ \\
4092 \cos (6 \cdot 0,006293 t)+7779 \operatorname{sen}(6 \cdot 0,006293 t)+618,7 \cos (7 \cdot 0,006293 t)-669,5 \operatorname{sen}(7 \cdot 0,006293 t)\end{array}$ & 3,893 \\
\hline 8 & $\begin{array}{l}\operatorname{Tmax}(\mathrm{t})=17,26-9,431 \cos (0,01721 \mathrm{t})-3,149 \operatorname{sen}(0,01721 \mathrm{t})-0,5215 \cos (2 \cdot 0,01721 \mathrm{t})+1,209 \operatorname{sen}(2 \cdot \\
0,01721 \mathrm{t})-0,4128 \cos (3 \cdot 0,01721 \mathrm{t})+0,2276 \operatorname{sen}(3 \cdot 0,01721 \mathrm{t})+0,0707 \cos (4 \cdot 0,01721 \mathrm{t})- \\
0,1249 \operatorname{sen}(4 \cdot 0,01721 \mathrm{t})+0,06714 \cos (5 \cdot 0,01721 \mathrm{t})+0,08861 \operatorname{sen}(5 \cdot 0,01721 \mathrm{t})+0,1252 \cos (6 \\
0,01721 \mathrm{t})+0,03636 \operatorname{sen}(6 \cdot 0,01721 \mathrm{t})-0,07931 \cos (7 \cdot 0,01721 \mathrm{t})-0,2324 \operatorname{sen}(7 \cdot 0,01721 \mathrm{t})- \\
0,2771 \cos (8 \cdot 0,01721 \mathrm{t})-0,3641 \operatorname{sen}(8 \cdot 0,01721 \mathrm{t})\end{array}$ & 3,882 \\
\hline
\end{tabular}


Se representa la función anual típica de Fourier para el primer armónico obtenida junto a los datos de temperatura máxima diaria del año 2004 al 2010 utilizados para su cálculo en la gráfica (Fig. 4.2.25), con un valor de $\mathrm{RMSE}=4,01^{\circ} \mathrm{C}$.

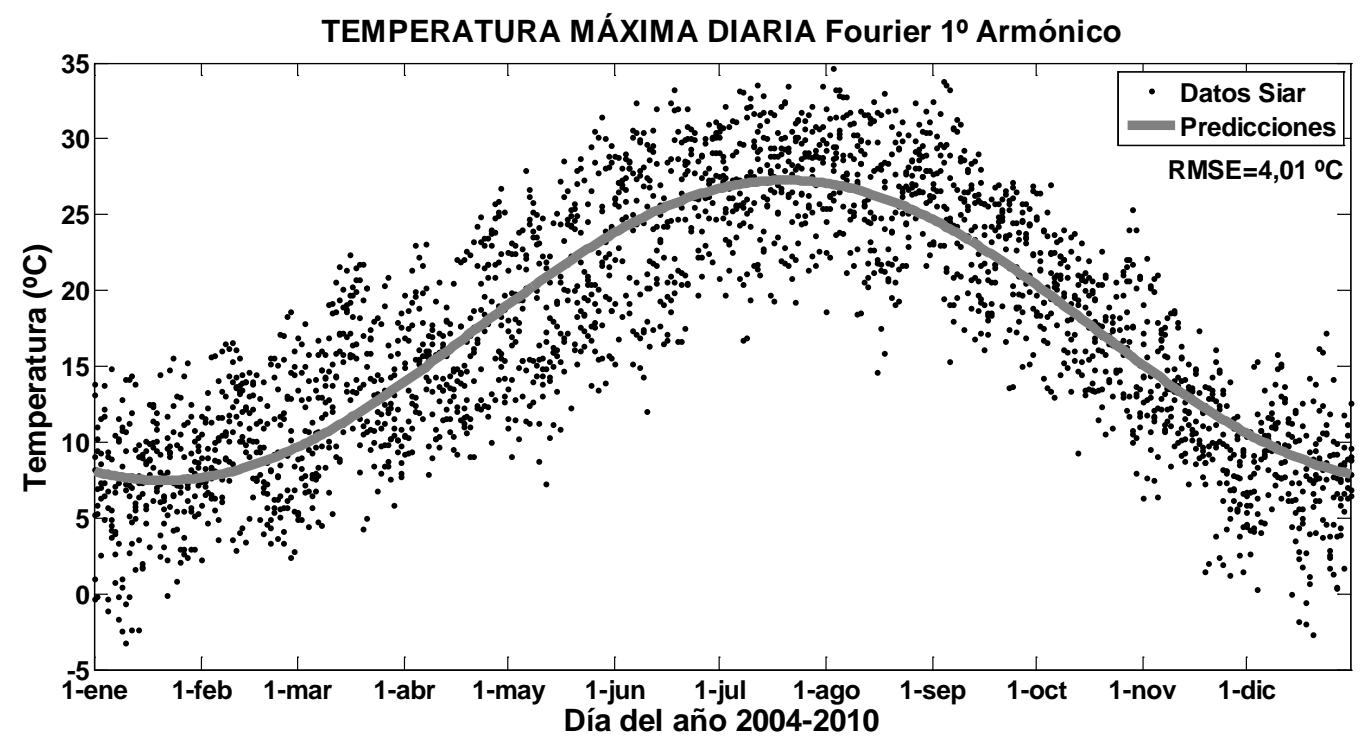

Fig. 4.2.25 Datos de la temperatura máxima diaria del año 2004 al 2010 SIAR en Mansilla Mayor (León), función anual típica del primer armónico y error producido 
Se representa la función anual típica de Fourier del primer al octavo armónico obtenidas de los datos de la temperatura máxima diaria del año 2004 al 2010 utilizados para su cálculo, junto a los datos de temperatura máxima diaria del año 2011 y el error producido para cada día del año en las gráficas (Fig. 4.2.26).

Fourier $1^{\circ}$ armónico: RMSE $=3,83^{\circ} \mathrm{C}$

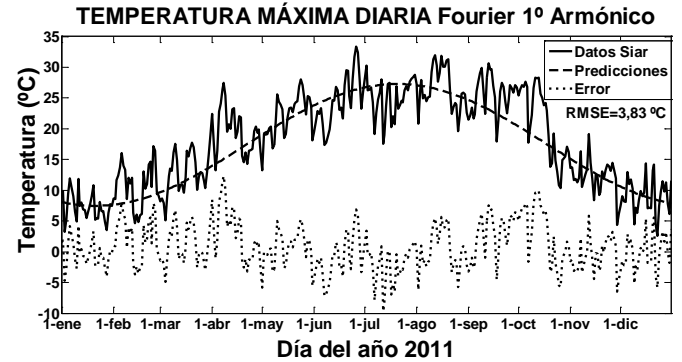

Fourier $3^{\circ}$ armónico: RMSE $=3,74{ }^{\circ} \mathrm{C}$

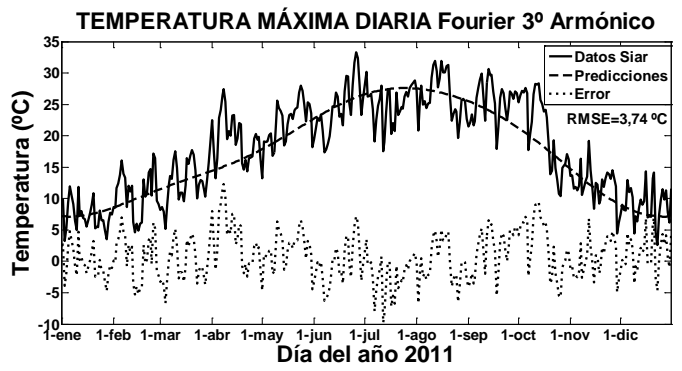

Fourier $5^{\circ}$ armónico: $\mathrm{RMSE}=3,75^{\circ} \mathrm{C}$

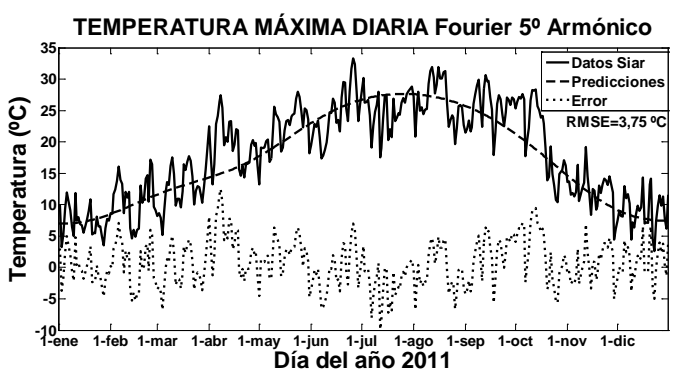

Fourier $7^{\circ}$ armónico: RMSE $=3,76^{\circ} \mathrm{C}$

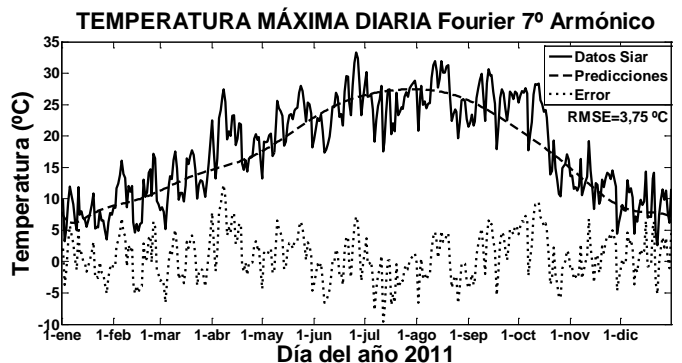

Fourier $2^{\circ}$ armónico: $\mathrm{RMSE}=3,75^{\circ} \mathrm{C}$

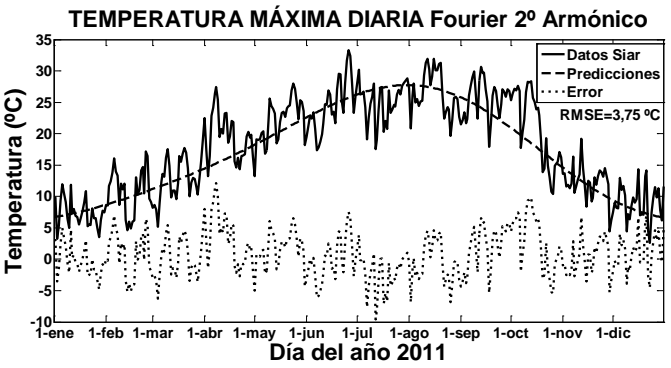

Fourier $4^{\circ}$ armónico: RMSE $=3,74^{\circ} \mathrm{C}$

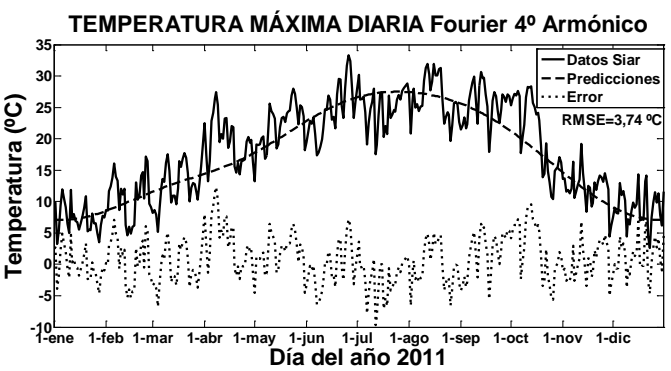

Fourier $6^{\circ}$ armónico: RMSE $=3,79^{\circ} \mathrm{C}$

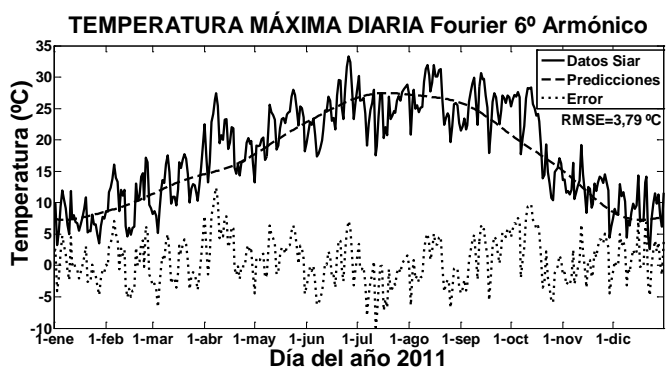

Fourier $8^{\circ}$ armónico: $\mathrm{RMSE}=3,84{ }^{\circ} \mathrm{C}$

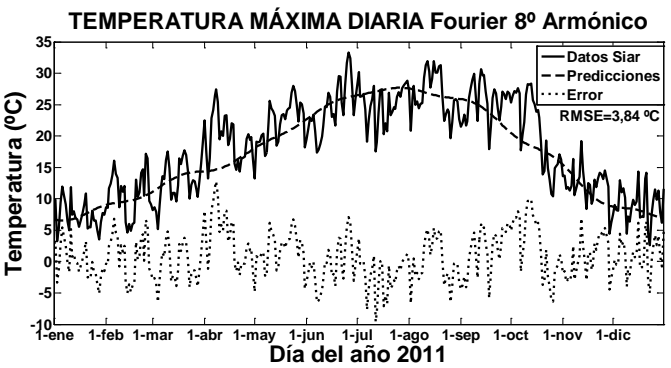

Fig. 4.2.26 Datos de la temperatura máxima diaria del año 2011 SIAR en Mansilla Mayor (León), función anual típica del primer al octavo armónico y error producido para cada día del año 


\section{4) Análisis de Fourier de la temperatura mínima diaria}

Se efectuó el cálculo de los coeficientes del análisis de Fourier de los datos de la temperatura mínima diaria del año 2004 al 2010 SIAR en Mansilla Mayor (León), obteniéndose las funciones anuales típicas de Fourier que se muestran en la (Tabla 4.2.8), desde el primer al octavo armónico y con el error producido para cada función.

Tabla 4.2.8 Funciones anuales típicas de Fourier de los datos de la temperatura mínima diaria SIAR en Mansilla Mayor (León), del primer al octavo armónico y el error producido

\begin{tabular}{|c|c|c|}
\hline \multicolumn{3}{|c|}{ Datos de temperatura mínima diaria $\left({ }^{\circ} \mathrm{C}\right)$ SIAR Mansilla Mayor 2004-2010 } \\
\hline $\begin{array}{c}\mathrm{N}^{\circ} \text { de } \\
\text { armónicos }\end{array}$ & Función anual típica de Fourier & RMSE \\
\hline 1 & $\operatorname{Tmin}(t)=4,232-5,568 \cos (0,01853 t)-3,642 \operatorname{sen}(0,01853 t)$ & 3,564 \\
\hline 2 & $\begin{array}{l}\operatorname{Tmin}(t)=34,26-13,72 \cos (0,006226 t)-47,1 \operatorname{sen}(0,006226 t)-21,07 \cos (2 \cdot 0,006226 t)+ \\
14,31 \operatorname{sen}(2 \cdot 0,006226 t)\end{array}$ & 3,555 \\
\hline 3 & $\begin{array}{l}\operatorname{Tmin}(t)=1,642-4,772 \cdot \cos (0,01208 \cdot t)+5,076 \cdot \operatorname{sen}(0,01208 \cdot t)+1,262 \cdot \cos (2 \cdot 0,01208 \cdot t)-2,271 \cdot \\
\operatorname{sen}(2 \cdot 0,01208 \cdot t)+0,5186 \cdot \cos (3 \cdot 0,01208 \cdot t)-0,6906 \cdot \operatorname{sen}(3 \cdot 0,01208 \cdot t)\end{array}$ & 3,544 \\
\hline 4 & $\begin{array}{l}\operatorname{Tmin}(t)=12810000000-2,0310000000 \cos (0,0008166 t)+2,886000000 \operatorname{sen}(0,0008166 t)+ \\
9,878000000 \cos (2 \cdot 0,0008166 t)-2,865000000 \operatorname{sen}(2 \cdot 0,0008166 t)-2,691000000 \cos (3 \cdot \\
0,0008166 t)+1,213000000 \operatorname{sen}(3 \cdot 0,0008166 t)+3,13700000 \cos (4 \cdot 0,0008166 t)-1,98600000 \operatorname{sen}(4 \cdot \\
0,0008166 t)\end{array}$ & 3,540 \\
\hline 5 & $\begin{array}{l}\operatorname{Tmin}(t)=3,31-6,84 \cos (0,01585 t)-0,2011 \operatorname{sen}(0,01585 t)+0,8658 \cos (2 \cdot 0,01585 t)+0,1112 \operatorname{sen}(2 \cdot \\
0,01585 t)+0,3911 \cos (3 \cdot 0,01585 t)+0,5454 \operatorname{sen}(3 \cdot 0,01585 t)+0,4313 \cos (4 \cdot 0,01585 t)- \\
0,03046 \operatorname{sen}(4 \cdot 0,01585 t)+0,4672 \cos (5 \cdot 0,01585 t)+0,02904 \operatorname{sen}(5 \cdot 0,01585 t)\end{array}$ & 3,534 \\
\hline 6 & $\begin{array}{l}\operatorname{Tmin}(t)=3,156-6,85 \cos (0,01544 t)+0,3841 \operatorname{sen}(0,01544 t)+1,047 \cos (2 \cdot 0,01544 t)+ \\
0,01405 \operatorname{sen}(2 \cdot 0,01544 t)+0,563 \cos (3 \cdot 0,01544 t)+0,4533 \operatorname{sen}(3 \cdot 0,01544 t)+0,4101 \cos (4 \\
0,01544 t)-0,165 \operatorname{sen}(4 \cdot 0,01544 t)+0,3898 \cos (5 \cdot 0,01544 t)-0,1011 \operatorname{sen}(5 \cdot 0,01544 t)- \\
0,06743 \cos (6 \cdot 0,01544 t)+0,0967 \operatorname{sen}(6 \cdot 0,01544 t)\end{array}$ & 3,535 \\
\hline 7 & $\begin{array}{l}\operatorname{Tmin}(t)=3,35-6,901 \cos (0,01608 t)-0,5126 \operatorname{sen}(0,01608 t)+0,6787 \cos (2 \cdot 0,01608 t)+0,181 \operatorname{sen}(2 \cdot \\
0,01608 t)+0,21 \cos (3 \cdot 0,01608 t)+0,6252 \operatorname{sen}(3 \cdot 0,01608 t)+0,3578 \cos (4 \cdot 0,01608 t)+0,1079 \operatorname{sen}(4 \cdot \\
0,01608 t)+0,4412 \cos (5 \cdot 0,01608 t)+0,1948 \operatorname{sen}(5 \cdot 0,01608 t)-0,02654 \cos (6 \cdot 0,01608 t)+ \\
0,02654 \operatorname{sen}(6 \cdot 0,01608 t)+0,1169 \cos (7 \cdot 0,01608 t)+0,2493 \operatorname{sen}(7 \cdot 0,01608 t)\end{array}$ & 3,532 \\
\hline 8 & $\begin{array}{l}\operatorname{Tmin}(t)=3,573-6,732 \cos (0,01666 t)-1,332 \operatorname{sen}(0,01666 t)+0,4493 \cos (2 \cdot 0,01666 t)+ \\
0,1722 \operatorname{sen}(2 \cdot 0,01666 t)-0,06693 \cos (3 \cdot 0,01666 t)+0,574 \operatorname{sen}(3 \cdot 0,01666 t)+0,2302 \cos (4 \\
0,01666 t)+0,2102 \operatorname{sen}(4 \cdot 0,01666 t)+0,3272 \cos (5 \cdot 0,01666 t)+0,4028 \operatorname{sen}(5 \cdot 0,01666 t)+ \\
0,01972 \cos (6 \cdot 0,01666 t)+0,06246 \operatorname{sen}(6 \cdot 0,01666 t)-0,07979 \cos (7 \cdot 0,01666 t)+0,2817 \operatorname{sen}(7 \\
0,01666 t)+0,05128 \cos (8 \cdot 0,01666 t)+0,3089 \operatorname{sen}(8 \cdot 0,01666 t)\end{array}$ & 3,528 \\
\hline
\end{tabular}


Se representa la función anual típica de Fourier para el primer armónico obtenida junto a los datos de temperatura mínima diaria del año 2004 al 2010 utilizados para su cálculo en la gráfica (Fig. 4.2.27), con un valor de $\mathrm{RMSE}=3,56^{\circ} \mathrm{C}$.

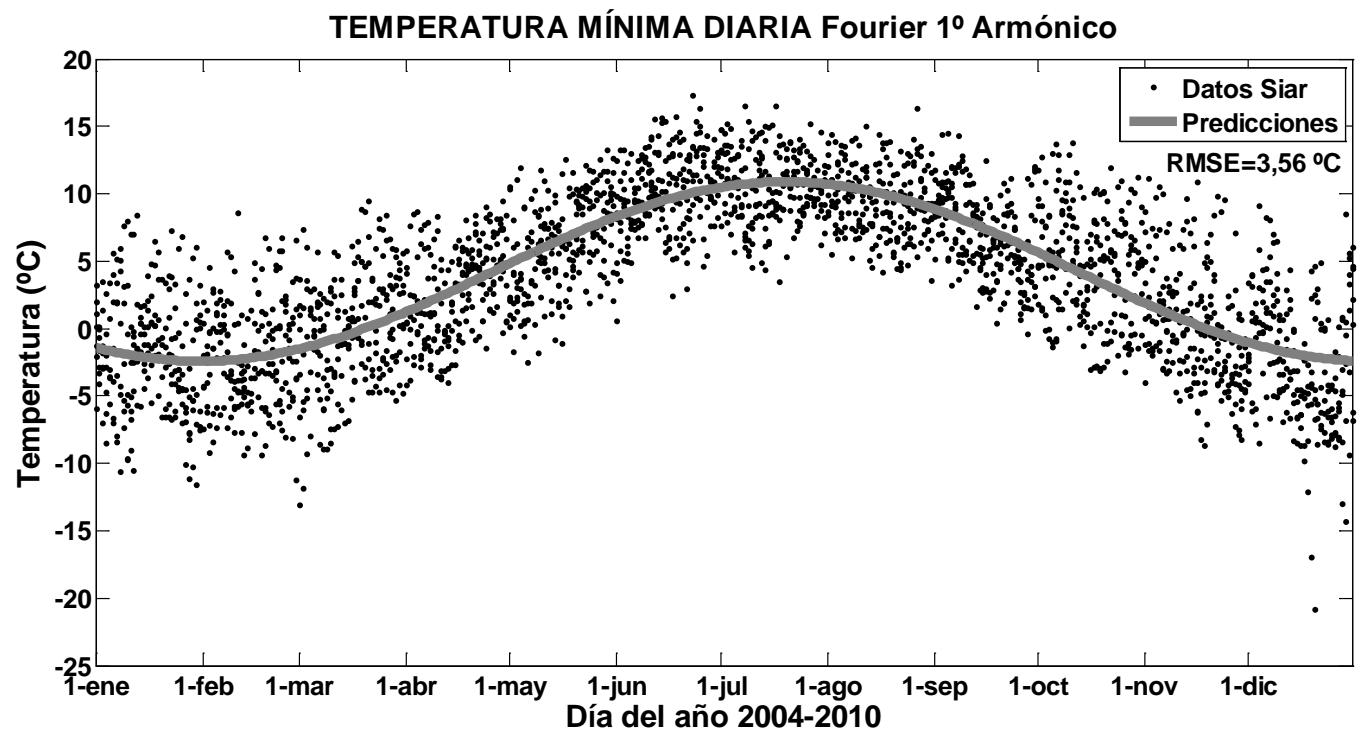

Fig. 4.2.27 Datos de la temperatura mínima diaria del año 2004 al 2010 SIAR en Mansilla Mayor (León), función anual típica del primer armónico y error producido 
Se representa la función anual típica de Fourier del primer al octavo armónico obtenidas de los datos de la temperatura mínima diaria del año 2004 al 2010 utilizados para su cálculo, junto a los datos de temperatura mínima diaria del año 2011 y el error producido para cada día del año en las gráficas (Fig. 4.2.28).

Fourier $1^{\circ}$ armónico: $\operatorname{RMSE}=3,37^{\circ} \mathrm{C}$

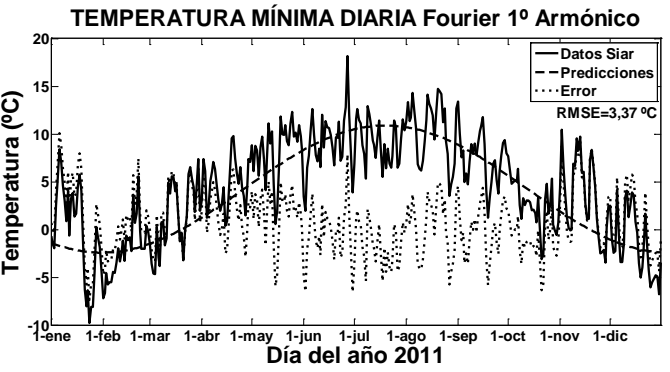

Fourier $3^{\circ}$ armónico: $\operatorname{RMSE}=3,37^{\circ} \mathrm{C}$

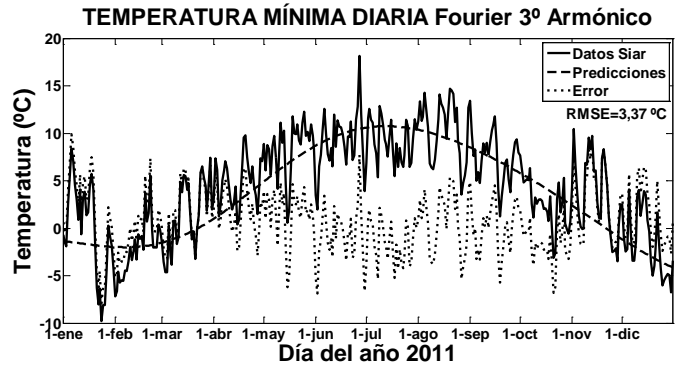

Fourier $5^{\circ}$ armónico: $\operatorname{RMSE}=3,36^{\circ} \mathrm{C}$

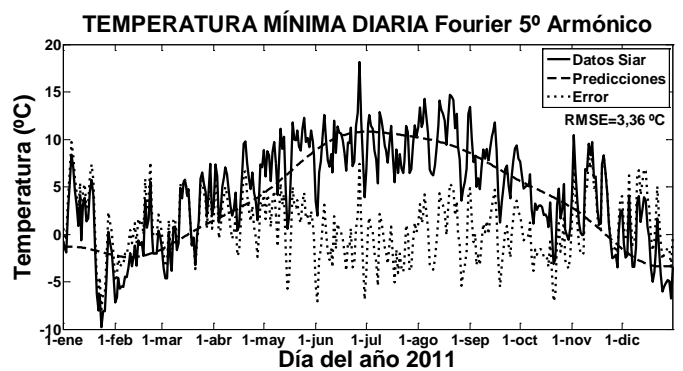

Fourier $7^{\circ}$ armónico: $\operatorname{RMSE}=3,37^{\circ} \mathrm{C}$

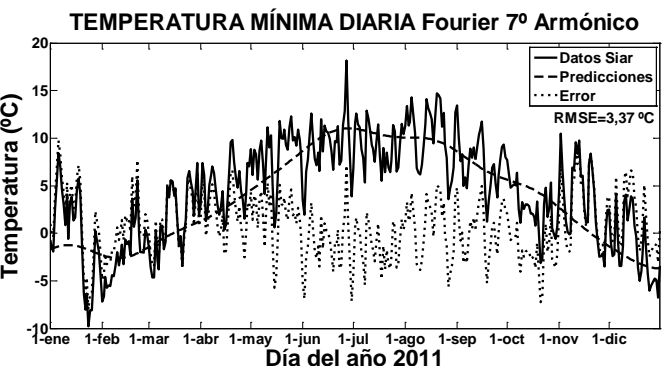

Fourier $2^{\circ}$ armónico: $\mathrm{RMSE}=3,34^{\circ} \mathrm{C}$

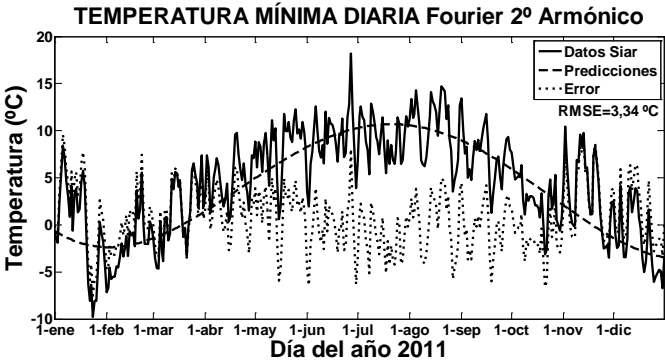

Fourier $4^{\circ}$ armónico: $\mathrm{RMSE}=3,39^{\circ} \mathrm{C}$

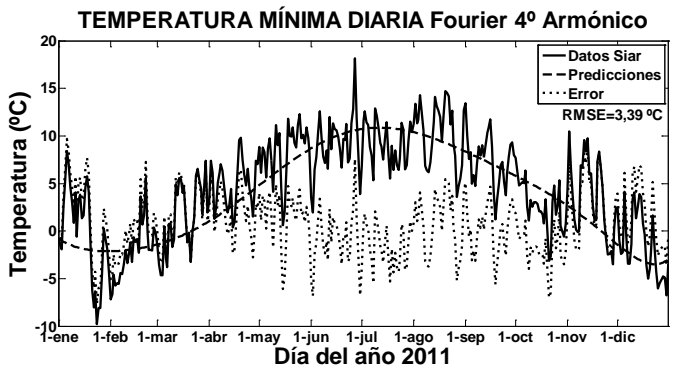

Fourier $6^{\circ}$ armónico: $\mathrm{RMSE}=3,36^{\circ} \mathrm{C}$

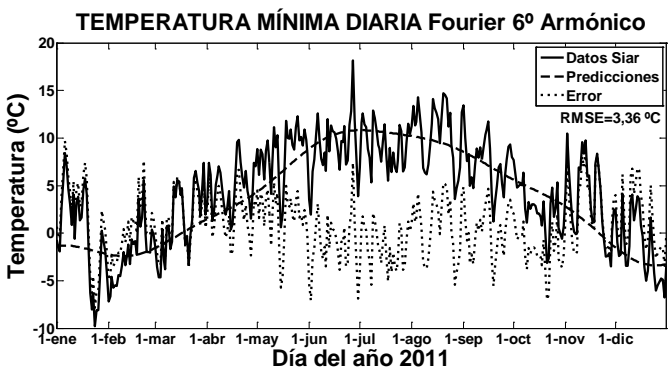

Fourier $8^{\circ}$ armónico: $\mathrm{RMSE}=3,40{ }^{\circ} \mathrm{C}$

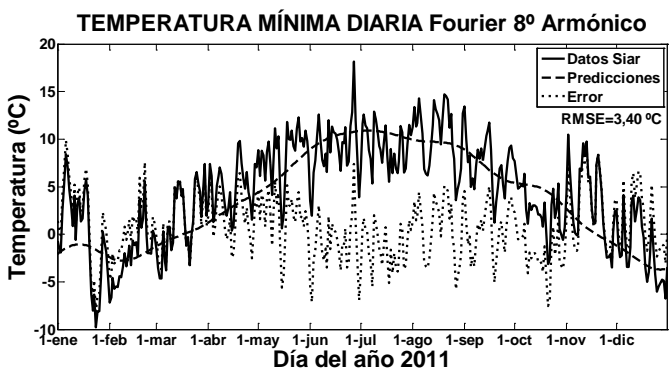

Fig. 4.2.28 Datos de la temperatura mínima diaria del año 2011 SIAR en Mansilla Mayor (León), función anual típica del primer al octavo armónico y error producido para cada día del año 


\subsubsection{Análisis de Markov}

En un proceso aleatorio en el que se produce un cambio de estado entre ciertos estados en el tiempo, se supone que hay un número finito de estados posibles. Surge así una sucesión o cadena de situaciones, en la que cada una es igual a uno de los estados. Este proceso se llama cadena de Markov si las probabilidades condicionas que expresan este cambio de situaciones satisfacen la propiedad de Markov, para todos los instantes de tiempo, todos los estados y todas las posibles sucesiones de estados previos.

Esta propiedad traduce la condición de que las cadenas de Markov no guardan su historia pasada en la memoria; en cada momento, la evolución al estado siguiente hace tabla rasa de lo anterior y empieza de nuevo.

Se definieron los estados, uno por cada valor entero de la irradiación solar global diaria en los valores enteros de la unidad en megajulios MJ posibles, para ello se redondeó todos los valores y se les asignó ese estado resultando 33 estados posibles, para ello se utilizó la función 'round' de MATLAB.

Se buscó el valor máximo y mínimo de la serie de datos de la irradiación solar global diaria, con las funciones 'max' y 'min' de Matlab.

Se creó una matriz con las transiciones habidas en la base de datos, una para cada fila de la matriz b (Ec. 4.2.11).

$$
\mathrm{b}=\left[\begin{array}{cc}
\mathrm{x}_{1} & \mathrm{x}_{2} \\
\mathrm{x}_{2} & \mathrm{x}_{3} \\
\cdots & \cdots \\
\mathrm{x}_{\mathrm{n}-1} & \mathrm{x}_{\mathrm{n}}
\end{array}\right]
$$

Se creó una matriz de probabilidades, matriz de transiciones de Markov MTM, con el número de transiciones para cada estado en la base de datos (Ec. 4.2.12).

$$
\operatorname{MTM}=\left[\begin{array}{cccccc}
1 \rightarrow 1 & 1 & \rightarrow 2 & \cdots & 1 \rightarrow 33 \\
2 \rightarrow 1 & 2 \rightarrow 2 & \cdots & 2 \rightarrow 33 \\
\vdots & \vdots & \ddots & \vdots \\
33 \rightarrow 1 & 33 \rightarrow 2 & \cdots & 33 \rightarrow 33
\end{array}\right]
$$

Con la función de Matlab (Tabla 4.2.9) que recorre los cambios de estado de la base de datos y actualiza la matriz de transición de Markov.

Tabla 4.2.9 Función de Matlab para crear la matriz de probabilidades

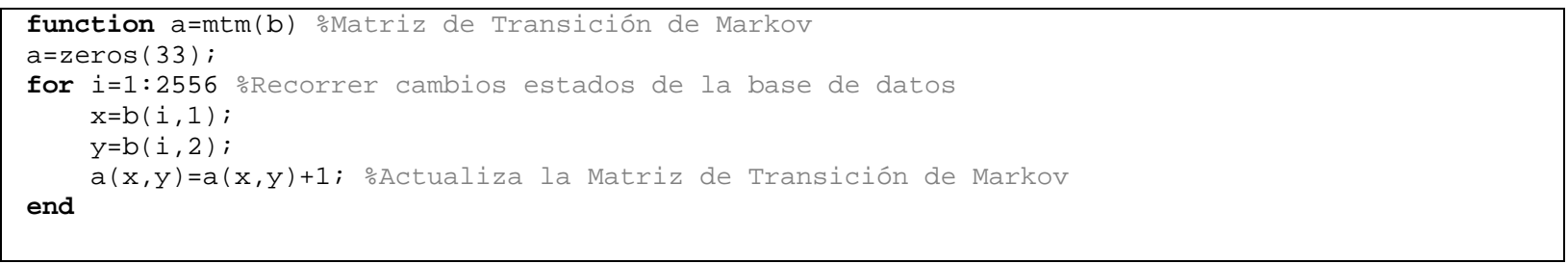


Resultando la matriz de transición de Markov que se muestra (Tabla 4.2.10). Cada elemento de la matriz tiene el número de cambios habidos en la base de datos entre el estado representado por el número de la fila hacia el estado representado por el número de la columna.

Tabla 4.2.10 Matriz de transición de Markov resultado de los datos de la irradiación solar global diaria del año 2004 al 2010 SIAR en Mansilla Mayor (León), para 33 estados

\begin{tabular}{|c|c|c|c|c|c|c|c|c|c|c|c|c|c|c|c|c|c|c|c|c|c|c|c|c|c|c|c|c|c|c|c|c|}
\hline 3 & 4 & 6 & 4 & 1 & 1 & 4 & 3 & 0 & 1 & 0 & 0 & 0 & 0 & 0 & 0 & 0 & 0 & 0 & 0 & 0 & 0 & 0 & 0 & 0 & 0 & 0 & 0 & 0 & 0 & 0 & 0 & 0 \\
\hline 2 & 16 & 13 & 8 & 7 & 5 & 4 & 8 & 5 & 4 & 0 & 0 & 0 & 0 & 0 & 0 & 1 & 0 & 0 & 0 & 0 & 0 & 0 & 0 & 0 & 0 & 0 & 0 & 0 & 0 & 0 & 0 & 0 \\
\hline 5 & 11 & 7 & 17 & 6 & 8 & 9 & 6 & 7 & 2 & 1 & 0 & 2 & 0 & 1 & 0 & 0 & 1 & 0 & 0 & 0 & 0 & 0 & 0 & 0 & 0 & 0 & 0 & 0 & 0 & 0 & 0 & 0 \\
\hline 4 & 7 & 9 & 3 & 9 & 12 & 7 & 9 & 6 & 2 & 2 & 4 & 4 & 2 & 0 & 1 & 0 & 0 & 0 & 0 & 1 & 0 & 0 & 0 & 0 & 0 & 0 & 0 & 0 & 0 & 0 & 0 & 0 \\
\hline 3 & 5 & 10 & 5 & 3 & 10 & 5 & 10 & 4 & 3 & 3 & 2 & 3 & 1 & 2 & 0 & 1 & 1 & 2 & 0 & 0 & 0 & 0 & 0 & 0 & 0 & 0 & 0 & 0 & 0 & 0 & 0 & 0 \\
\hline 1 & 5 & 9 & 5 & 8 & 3 & 11 & 7 & 10 & 3 & 4 & 1 & 5 & 1 & 1 & 0 & 2 & 1 & 1 & 0 & 1 & 0 & 0 & 1 & 0 & 0 & 0 & 0 & 0 & 0 & 0 & 0 & 0 \\
\hline 0 & 3 & 8 & 7 & 11 & 5 & 11 & 12 & 7 & 3 & 6 & 1 & 1 & 0 & 2 & 4 & 1 & 0 & 0 & 1 & 0 & 0 & 0 & 0 & 0 & 0 & 0 & 0 & 0 & 0 & 0 & 0 & 0 \\
\hline 2 & 8 & 8 & 7 & 9 & 8 & 9 & 35 & 22 & 5 & 5 & 4 & 1 & 1 & 1 & 2 & 1 & 0 & 0 & 0 & 0 & 0 & 2 & 0 & 0 & 0 & 0 & 0 & 0 & 0 & 0 & 0 & 0 \\
\hline 3 & 8 & 4 & 6 & 4 & 5 & 10 & 15 & 29 & 10 & 8 & 3 & 5 & 4 & 2 & 0 & 0 & 3 & 1 & 0 & 1 & 1 & 0 & 0 & 0 & 1 & 0 & 0 & 0 & 0 & 0 & 0 & 0 \\
\hline 1 & 3 & 2 & 8 & 4 & 5 & 2 & 3 & 9 & 15 & 6 & 5 & 8 & 3 & 0 & 2 & 0 & 0 & 0 & 1 & 0 & 1 & 0 & 1 & 1 & 0 & 0 & 0 & 0 & 0 & 0 & 0 & 0 \\
\hline 1 & 1 & 1 & 1 & 5 & 4 & 1 & 7 & 5 & 11 & 20 & 6 & 5 & 5 & 3 & 2 & 0 & 0 & 4 & 0 & 3 & 0 & 2 & 1 & 0 & 0 & 0 & 0 & 0 & 0 & 0 & 0 & 0 \\
\hline 0 & 1 & 2 & 1 & 1 & 1 & 2 & 5 & 3 & 2 & 9 & 23 & 6 & 6 & 1 & 1 & 5 & 6 & 5 & 3 & 1 & 1 & 0 & 0 & 0 & 2 & 0 & 0 & 0 & 1 & 0 & 0 & 0 \\
\hline 1 & 0 & 2 & 6 & 0 & 4 & 3 & 1 & 2 & 6 & 7 & 12 & 17 & 9 & 1 & 3 & 6 & 3 & 2 & 2 & 2 & 2 & 0 & 0 & 0 & 0 & 0 & 1 & 2 & 0 & 0 & 0 & 0 \\
\hline 1 & 0 & 2 & 2 & 2 & 2 & 1 & 0 & 3 & 2 & 4 & 5 & 12 & 10 & 2 & 6 & 6 & 2 & 5 & 1 & 4 & 0 & 1 & 0 & 4 & 0 & 0 & 1 & 0 & 0 & 0 & 0 & 0 \\
\hline 0 & 0 & 1 & 0 & 0 & 1 & 0 & 1 & 4 & 1 & 3 & 2 & 8 & 6 & 11 & 2 & 0 & 4 & 4 & 3 & 0 & 1 & 3 & 0 & 3 & 0 & 1 & 0 & 2 & 0 & 0 & 0 & 0 \\
\hline 0 & 0 & 0 & 1 & 1 & 1 & 1 & 1 & 0 & 5 & 0 & 4 & 2 & 4 & 5 & 9 & 8 & 5 & 5 & 1 & 4 & 1 & 0 & 0 & 0 & 2 & 0 & 0 & 0 & 0 & 0 & 0 & 0 \\
\hline 0 & 1 & 0 & 0 & 0 & 0 & 1 & 2 & 1 & 1 & 1 & 3 & 2 & 7 & 5 & 8 & 13 & 11 & 5 & 7 & 1 & 0 & 4 & 3 & 1 & 1 & 2 & 1 & 1 & 0 & 1 & 0 & 1 \\
\hline 0 & 0 & 0 & 0 & 0 & 0 & 1 & 0 & 1 & 0 & 0 & 4 & 2 & 4 & 7 & 4 & 5 & 11 & 5 & 10 & 2 & 5 & 2 & 0 & 3 & 2 & 0 & 2 & 2 & 0 & 0 & 0 & 0 \\
\hline 0 & 0 & 0 & 1 & 0 & 2 & 0 & 1 & 0 & 1 & 1 & 4 & 2 & 5 & 4 & 3 & 11 & 10 & 10 & 4 & 4 & 4 & 4 & 4 & 1 & 1 & 2 & 0 & 0 & 0 & 0 & 0 & 0 \\
\hline 0 & 0 & 0 & 0 & 1 & 0 & 0 & 1 & 1 & 1 & 4 & 2 & 3 & 3 & 2 & 4 & 1 & 6 & 13 & 16 & 4 & 4 & 6 & 3 & 4 & 2 & 2 & 2 & 1 & 1 & 1 & 2 & 0 \\
\hline 0 & 0 & 0 & 0 & 0 & 0 & 0 & 1 & 2 & 1 & 1 & 1 & 0 & 0 & 1 & 3 & 6 & 3 & 5 & 11 & 14 & 5 & 4 & 3 & 3 & 1 & 4 & 0 & 2 & 0 & 0 & 0 & 0 \\
\hline 0 & 0 & 0 & 0 & 0 & 0 & 0 & 0 & 0 & 0 & 1 & 1 & 0 & 2 & 0 & 3 & 5 & 2 & 2 & 2 & 8 & 15 & 8 & 3 & 2 & 2 & 0 & 4 & 1 & 3 & 0 & 0 & 0 \\
\hline 0 & 0 & 0 & 0 & 0 & 1 & 0 & 0 & 0 & 1 & 0 & 0 & 3 & 1 & 4 & 0 & 3 & 0 & 2 & 7 & 4 & 8 & 12 & 9 & 8 & 3 & 8 & 1 & 1 & 1 & 0 & 0 & 0 \\
\hline 0 & 0 & 0 & 0 & 0 & 1 & 0 & 0 & 1 & 0 & 1 & 1 & 2 & 1 & 1 & 1 & 1 & 0 & 1 & 5 & 3 & 1 & 11 & 14 & 11 & 4 & 3 & 4 & 1 & 1 & 1 & 0 & 0 \\
\hline 0 & 0 & 0 & 0 & 1 & 0 & 1 & 0 & 0 & 0 & 0 & 0 & 0 & 0 & 2 & 0 & 2 & 1 & 3 & 7 & 3 & 5 & 7 & 17 & 30 & 11 & 6 & 3 & 5 & 2 & 0 & 0 & 0 \\
\hline 0 & 0 & 0 & 0 & 0 & 0 & 0 & 1 & 0 & 0 & 0 & 0 & 0 & 1 & 1 & 1 & 0 & 1 & 1 & 2 & 2 & 2 & 4 & 5 & 14 & 16 & 9 & 5 & 6 & 4 & 2 & 0 & 0 \\
\hline 0 & 0 & 0 & 0 & 0 & 0 & 0 & 1 & 0 & 0 & 1 & 0 & 1 & 1 & 1 & 0 & 1 & 1 & 0 & 2 & 3 & 4 & 2 & 1 & 6 & 11 & 16 & 9 & 9 & 4 & 4 & 2 & 0 \\
\hline 0 & 0 & 0 & 0 & 0 & 0 & 0 & 0 & 1 & 0 & 0 & 0 & 0 & 0 & 1 & 0 & 3 & 0 & 3 & 3 & 3 & 1 & 2 & 2 & 6 & 3 & 9 & 35 & 11 & 7 & 1 & 0 & 0 \\
\hline 0 & 0 & 0 & 0 & 0 & 0 & 0 & 0 & 0 & 0 & 0 & 0 & 0 & 0 & 0 & 0 & 0 & 0 & 0 & 0 & 2 & 1 & 0 & 3 & 3 & 10 & 10 & 12 & 31 & 14 & 11 & 1 & 0 \\
\hline 0 & 0 & 0 & 0 & 0 & 0 & 0 & 0 & 0 & 0 & 0 & 0 & 0 & 1 & 0 & 0 & 2 & 0 & 0 & 0 & 1 & 1 & 1 & 0 & 4 & 3 & 4 & 8 & 16 & 39 & 19 & 2 & 0 \\
\hline 0 & 0 & 0 & 0 & 0 & 0 & 0 & 0 & 0 & 0 & 0 & 0 & 0 & 0 & 0 & 1 & 0 & 0 & 0 & 2 & 0 & 1 & 2 & 0 & 1 & 2 & 2 & 2 & 7 & 23 & 24 & 4 & 0 \\
\hline 0 & 0 & 0 & 0 & 0 & 0 & 0 & 0 & 0 & 0 & 0 & 0 & 0 & 0 & 0 & 0 & 0 & 0 & 0 & 0 & 0 & 0 & 0 & 0 & 1 & 0 & 1 & 1 & 0 & 1 & 7 & 7 & 1 \\
\hline 0 & 0 & 0 & 0 & 0 & 0 & 0 & 0 & 0 & 0 & 0 & 0 & 0 & 0 & 0 & 0 & 0 & 0 & 0 & 0 & 0 & 0 & 0 & 0 & 0 & 0 & 1 & 0 & 0 & 0 & 0 & 1 & 1 \\
\hline
\end{tabular}


La matriz de transición de Markov resultante se normaliza para cada fila, se divide cada elemento de la fila por el valor de la suma de todos sus elementos. La matriz resultante tendrá como suma de los elementos en todas las filas el valor 1 , que se muestra (Tabla 4.2.11).

Tabla 4.2.11 Matriz de transición de Markov normalizada resultado de los datos de la irradiación solar global diaria del año 2004 al 2010 SIAR en Mansilla Mayor (León), para 33 estados

\begin{tabular}{|c|c|c|c|c|c|c|c|c|c|c|c|c|c|c|c|c|c|c|c|c|c|c|c|c|c|c|c|c|c|c|c|c|}
\hline 0,11 & 0,15 & 0,22 & 0,15 & 0,04 & 0,04 & 0,15 & 0,11 & 0,00 & 0,04 & 0,00 & 0,00 & 0,00 & 0,00 & 0,00 & 0,00 & 0,00 & 0,00 & 0,00 & 0,00 & 0,00 & 0,00 & 0,00 & 0,00 & 0,00 & 0,00 & 0,00 & 0,00 & 0,00 & 0,00 & 0,00 & 0,00 & 0,00 \\
\hline 0,03 & 0,22 & 0,18 & 0,11 & 0,10 & 0,07 & 0,05 & 0,11 & 0,07 & 0,05 & 0,00 & 0,00 & 0,00 & 0,00 & 0,00 & 0,00 & 0,01 & 0,00 & 0,00 & 0,00 & 0,00 & 0,00 & 0,00 & 0,00 & 0,00 & 0,00 & 0,00 & 0,00 & 0,00 & 0,00 & 0,00 & 0,00 & 0,00 \\
\hline 0,06 & 0,13 & 0,08 & 0,20 & 0,07 & 0,10 & 0,11 & 0,07 & 0,08 & 0,02 & 0,01 & 0,00 & 0,02 & 0,00 & 0,01 & 0,00 & 0,00 & 0,01 & 0,00 & 0,00 & 0,00 & 0,00 & 0,00 & 0,00 & 0,00 & 0,00 & 0,00 & 0,00 & 0,00 & 0,00 & 0,00 & 0,00 & 0,00 \\
\hline 0,05 & 0,09 & 0,11 & 0,04 & 0,11 & 0,15 & 0,09 & 0,11 & 0,07 & 0,02 & 0,02 & 0,05 & 0,05 & 0,02 & 0,00 & 0,01 & 0,00 & 0,00 & 0,00 & 0,00 & 0,01 & 0,00 & 0,00 & 0,00 & 0,00 & 0,00 & 0,00 & 0,00 & 0,00 & 0,00 & 0,00 & 0,00 & 0,00 \\
\hline 0,04 & 0,07 & 0,14 & 0,07 & 0,04 & 0,14 & 0,07 & 0,14 & 0,05 & 0,04 & 0,04 & 0,03 & 0,04 & 0,01 & 0,03 & 0,00 & 0,01 & 0,01 & 0,03 & 0,00 & 0,00 & 0,00 & 0,00 & 0,00 & 0,00 & 0,00 & 0,00 & 0,00 & 0,00 & 0,00 & 0,00 & 0,00 & 0,00 \\
\hline 0,01 & 0,06 & 0,11 & 0,06 & 0,10 & 0,04 & 0,14 & 0,09 & 0,13 & 0,04 & 0,05 & 0,01 & 0,06 & 0,01 & 0,01 & 0,00 & 0,03 & 0,01 & 0,01 & 0,00 & 0,01 & 0,00 & 0,00 & 0,01 & 0,00 & 0,00 & 0,00 & 0,00 & 0,00 & 0,00 & 0,00 & 0,00 & 0,00 \\
\hline 0,00 & 0,04 & 0,10 & 0,08 & 0,13 & 0,06 & 0,13 & 0,14 & 0,08 & 0,04 & 0,07 & 0,01 & 0,01 & 0,00 & 0,02 & 0,05 & 0,01 & 0,00 & 0,00 & 0,01 & 0,00 & 0,00 & 0,00 & 0,00 & 0,00 & 0,00 & 0,00 & 0,00 & 0,00 & 0,00 & 0,00 & 0,00 & 0,00 \\
\hline 0,02 & 0,06 & 0,06 & 0,05 & 0,07 & 0,06 & 0,07 & 0,27 & 0,17 & 0,04 & 0,04 & 0,03 & 0,01 & 0,01 & 0,01 & 0,02 & 0,01 & 0,00 & 0,00 & 0,00 & 0,00 & 0,00 & 0,02 & 0,00 & 0,00 & 0,00 & 0,00 & 0,00 & 0,00 & 0,00 & 0,00 & 0,00 & 0,00 \\
\hline 0,02 & 0,07 & 0,03 & 0,05 & 0,03 & 0,04 & 0,08 & 0,12 & 0,24 & 0,08 & 0,07 & 0,02 & 0,04 & 0,03 & 0,02 & 0,00 & 0,00 & 0,02 & 0,01 & 0,00 & 0,01 & 0,01 & 0,00 & 0,00 & 0,00 & 0,01 & 0,00 & 0,00 & 0,00 & 0,00 & 0,00 & 0,00 & 0,00 \\
\hline 0,01 & 0,04 & 0,03 & 0,10 & 0,05 & 0,06 & 0,03 & 0,04 & 0,11 & 0,19 & 0,08 & 0,06 & 0,10 & 0,04 & 0,00 & 0,03 & 0,00 & 0,00 & 0,00 & 0,01 & 0,00 & 0,01 & 0,00 & 0,01 & 0,01 & 0,00 & 0,00 & 0,00 & 0,00 & 0,00 & 0,00 & 0,00 & 0,00 \\
\hline 0,01 & 0,01 & 0,01 & 0,01 & 0,06 & 0,05 & 0,01 & 0,08 & 0,06 & 0,13 & 0,23 & 0,07 & 0,06 & 0,06 & 0,03 & 0,02 & 0,00 & 0,00 & 0,05 & 0,00 & 0,03 & 0,00 & 0,02 & 0,01 & 0,00 & 0,00 & 0,00 & 0,00 & 0,00 & 0,00 & 0,00 & 0,00 & 0,00 \\
\hline 0,00 & 0,01 & 0,02 & 0,01 & 0,01 & 0,01 & 0,02 & 0,06 & 0,03 & 0,02 & 0,10 & 0,26 & 0,07 & 0,07 & 0,01 & 0,01 & 0,06 & 0,07 & 0,06 & 0,03 & 0,01 & 0,01 & 0,00 & 0,00 & 0,00 & 0,02 & 0,00 & 0,00 & 0,00 & 0,01 & 0,00 & 0,00 & 0,00 \\
\hline 0,01 & 0,00 & 0,02 & 0,06 & 0,00 & 0,04 & 0,03 & 0,01 & 0,02 & 0,06 & 0,07 & 0,13 & 0,18 & 0,10 & 0,01 & 0,03 & 0,06 & 0,03 & 0,02 & 0,02 & 0,02 & 0,02 & 0,00 & 0,00 & 0,00 & 0,00 & 0,00 & 0,01 & 0,02 & 0,00 & 0,00 & 0,00 & 0,00 \\
\hline 0,01 & 0,00 & 0,03 & 0,03 & 0,03 & 0,03 & 0,01 & 0,00 & 0,04 & 0,03 & 0,05 & 0,06 & 0,15 & 0,13 & 0,03 & 0,08 & 0,08 & 0,03 & 0,06 & 0,01 & 0,05 & 0,00 & 0,01 & 0,00 & 0,05 & 0,00 & 0,00 & 0,01 & 0,00 & 0,00 & 0,00 & 0,00 & 0,00 \\
\hline 0,00 & 0,00 & 0,02 & 0,00 & 0,00 & 0,02 & 0,00 & 0,02 & 0,07 & 0,02 & 0,05 & 0,03 & 0,13 & 0,10 & 0,18 & 0,03 & 0,00 & 0,07 & 0,07 & 0,05 & 0,00 & 0,02 & 0,05 & 0,00 & 0,05 & 0,00 & 0,02 & 0,00 & 0,03 & 0,00 & 0,00 & 0,00 & 0,00 \\
\hline 0,00 & 0,00 & 0,00 & 0,02 & 0,02 & 0,02 & 0,02 & 0,02 & 0,00 & 0,08 & 0,00 & 0,07 & 0,03 & 0,07 & 0,08 & 0,15 & 0,13 & 0,08 & 0,08 & 0,02 & 0,07 & 0,02 & 0,00 & 0,00 & 0,00 & 0,03 & 0,00 & 0,00 & 0,00 & 0,00 & 0,00 & 0,00 & 0,00 \\
\hline 0,00 & 0,01 & 0,00 & 0,00 & 0,00 & 0,00 & 0,01 & 0,02 & 0,01 & 0,01 & 0,01 & 0,04 & 0,02 & 0,08 & 0,06 & 0,10 & 0,15 & 0,13 & 0,06 & 0,08 & 0,01 & 0,00 & 0,05 & 0,04 & 0,01 & 0,01 & 0,02 & 0,01 & 0,01 & 0,00 & 0,01 & 0,00 & 0,01 \\
\hline 0,00 & 0,00 & 0,00 & 0,00 & 0,00 & 0,00 & 0,01 & 0,00 & 0,01 & 0,00 & 0,00 & 0,06 & 0,03 & 0,06 & 0,10 & 0,06 & 0,07 & 0,15 & 0,07 & 0,14 & 0,03 & 0,07 & 0,03 & 0,00 & 0,04 & 0,03 & 0,00 & 0,03 & 0,03 & 0,00 & 0,00 & 0,00 & 0,00 \\
\hline 0,00 & 0,00 & 0,00 & 0,01 & 0,00 & 0,03 & 0,00 & 0,01 & 0,00 & 0,01 & 0,01 & 0,05 & 0,03 & 0,06 & 0,05 & 0,04 & 0,14 & 0,13 & 0,13 & 0,05 & 0,05 & 0,05 & 0,05 & 0,05 & 0,01 & 0,01 & 0,03 & 0,00 & 0,00 & 0,00 & 0,00 & 0,00 & 0,00 \\
\hline 0,00 & 0,00 & 0,00 & 0,00 & 0,01 & 0,00 & 0,00 & 0,01 & 0,01 & 0,01 & 0,04 & 0,02 & 0,03 & 0,03 & 0,02 & 0,04 & 0,01 & 0,07 & 0,14 & 0,18 & 0,04 & 0,04 & 0,07 & 0,03 & 0,04 & 0,02 & 0,02 & 0,02 & 0,01 & 0,01 & 0,01 & 0,02 & 0,00 \\
\hline 0,00 & 0,00 & 0,00 & 0,00 & 0,00 & 0,00 & 0,00 & 0,01 & 0,03 & 0,01 & 0,01 & 0,01 & 0,00 & 0,00 & 0,01 & 0,04 & 0,08 & 0,04 & 0,07 & 0,15 & 0,20 & 0,07 & 0,06 & 0,04 & 0,04 & 0,01 & 0,06 & 0,00 & 0,03 & 0,00 & 0,00 & 0,00 & 0,00 \\
\hline 0,00 & 0,00 & 0,00 & 0,00 & 0,00 & 0,00 & 0,00 & 0,00 & 0,00 & 0,00 & 0,02 & 0,02 & 0,00 & 0,03 & 0,00 & 0,05 & 0,08 & 0,03 & 0,03 & 0,03 & 0,13 & 0,23 & 0,13 & 0,05 & 0,03 & 0,03 & 0,00 & 0,06 & 0,02 & 0,05 & 0,00 & 0,00 & 0,00 \\
\hline 0,00 & 0,00 & 0,00 & 0,00 & 0,00 & 0,01 & 0,00 & 0,00 & 0,00 & 0,01 & 0,00 & 0,00 & 0,04 & 0,01 & 0,05 & 0,00 & 0,04 & 0,00 & 0,03 & 0,09 & 0,05 & 0,10 & 0,16 & 0,12 & 0,10 & 0,04 & 0,10 & 0,01 & 0,01 & 0,01 & 0,00 & 0,00 & 0,00 \\
\hline 0,00 & 0,00 & 0,00 & 0,00 & 0,00 & 0,01 & 0,00 & 0,00 & 0,01 & 0,00 & 0,01 & 0,01 & 0,03 & 0,01 & 0,01 & 0,01 & 0,01 & 0,00 & 0,01 & 0,07 & 0,04 & 0,01 & 0,16 & 0,20 & 0,16 & 0,06 & 0,04 & 0,06 & 0,01 & 0,01 & 0,01 & 0,00 & 0,00 \\
\hline 0,00 & 0,00 & 0,00 & 0,00 & 0,01 & 0,00 & 0,01 & 0,00 & 0,00 & 0,00 & 0,00 & 0,00 & 0,00 & 0,00 & 0,02 & 0,00 & 0,02 & 0,01 & 0,03 & 0,07 & 0,03 & 0,05 & 0,07 & 0,16 & 0,28 & 0,10 & 0,06 & 0,03 & 0,05 & 0,02 & 0,00 & 0,00 & 0,00 \\
\hline 0,00 & 0,00 & 0,00 & 0,00 & 0,00 & 0,00 & 0,00 & 0,01 & 0,00 & 0,00 & 0,00 & 0,00 & 0,00 & 0,01 & 0,01 & 0,01 & 0,00 & 0,01 & 0,01 & 0,03 & 0,03 & 0,03 & 0,05 & 0,06 & 0,18 & 0,21 & 0,12 & 0,06 & 0,08 & 0,05 & 0,03 & 0,00 & 0,00 \\
\hline 0,00 & 0,00 & 0,00 & 0,00 & 0,00 & 0,00 & 0,00 & 0,01 & 0,00 & 0,00 & 0,01 & 0,00 & 0,01 & 0,01 & 0,01 & 0,00 & 0,01 & 0,01 & 0,00 & 0,03 & 0,04 & 0,05 & 0,03 & 0,01 & 0,08 & 0,14 & 0,20 & 0,11 & 0,11 & 0,05 & 0,05 & 0,03 & 0,00 \\
\hline 0,00 & 0,00 & 0,00 & 0,00 & 0,00 & 0,00 & 0,00 & 0,00 & 0,01 & 0,00 & 0,00 & 0,00 & 0,00 & 0,00 & 0,01 & 0,00 & 0,03 & 0,00 & 0,03 & 0,03 & 0,03 & 0,01 & 0,02 & 0,02 & 0,07 & 0,03 & 0,10 & 0,38 & 0,12 & 0,08 & 0,01 & 0,00 & 0,00 \\
\hline 0,00 & 0,00 & 0,00 & 0,00 & 0,00 & 0,00 & 0,00 & 0,00 & 0,00 & 0,00 & 0,00 & 0,00 & 0,00 & 0,00 & 0,00 & 0,00 & 0,00 & 0,00 & 0,00 & 0,00 & 0,02 & 0,01 & 0,00 & 0,03 & 0,03 & 0,10 & 0,10 & 0,12 & 0,32 & 0,14 & 0,11 & 0,01 & 0,00 \\
\hline 0,00 & 0,00 & 0,00 & 0,00 & 0,00 & 0,00 & 0,00 & 0,00 & 0,00 & 0,00 & 0,00 & 0,00 & 0,00 & 0,01 & 0,00 & 0,00 & 0,02 & 0,00 & 0,00 & 0,00 & 0,01 & 0,01 & 0,01 & 0,00 & 0,04 & 0,03 & 0,04 & 0,08 & 0,16 & 0,39 & 0,19 & 0,02 & 0,00 \\
\hline 0,00 & 0,00 & 0,00 & 0,00 & 0,00 & 0,00 & 0,00 & 0,00 & 0,00 & 0,00 & 0,00 & 0,00 & 0,00 & 0,00 & 0,00 & 0,01 & 0,00 & 0,00 & 0,00 & 0,03 & 0,00 & 0,01 & 0,03 & 0,00 & 0,01 & 0,03 & 0,03 & 0,03 & 0,10 & 0,32 & 0,34 & 0,06 & 0,00 \\
\hline 0,00 & 0,00 & 0,00 & 0,00 & 0,00 & 0,00 & 0,00 & 0,00 & 0,00 & 0,00 & 0,00 & 0,00 & 0,00 & 0,00 & 0,00 & 0,00 & 0,00 & 0,00 & 0,00 & 0,00 & 0,00 & 0,00 & 0,00 & 0,00 & 0,05 & 0,00 & 0,05 & 0,05 & 0,00 & 0,05 & 0,37 & 0,37 & 0,05 \\
\hline 0,00 & 0,00 & 0,00 & 0,00 & 0,00 & 0,00 & 0,00 & 0,00 & 0,00 & 0,00 & 0,00 & 0,00 & 0,00 & 0,00 & 0,00 & 0,00 & 0,00 & 0,00 & 0,00 & 0,00 & 0,00 & 0,00 & 0,00 & 0,00 & 0,00 & 0,00 & 0,33 & 0,00 & 0,00 & 0,00 & 0,00 & 0,33 & 0,33 \\
\hline
\end{tabular}


Ahora con la matriz de transición de Markov normalizada ya se puede calcular la probabilidad de cambio de estado para el día de mañana a partir del estado de hoy, multiplicando el vector del estado inicial de hoy con la matriz normalizada, resulta un vector en el que la posición en que se encuentre el valor más alto será el estado que tenga más probabilidad de suceder mañana, mediante la función de Matlab (Tabla 4.2.12).

Tabla 4.2.12 Función de Matlab para realizar la predicción del próximo día, multiplicando el vector de estado del día de hoy con la matriz de transición de Markov normalizada

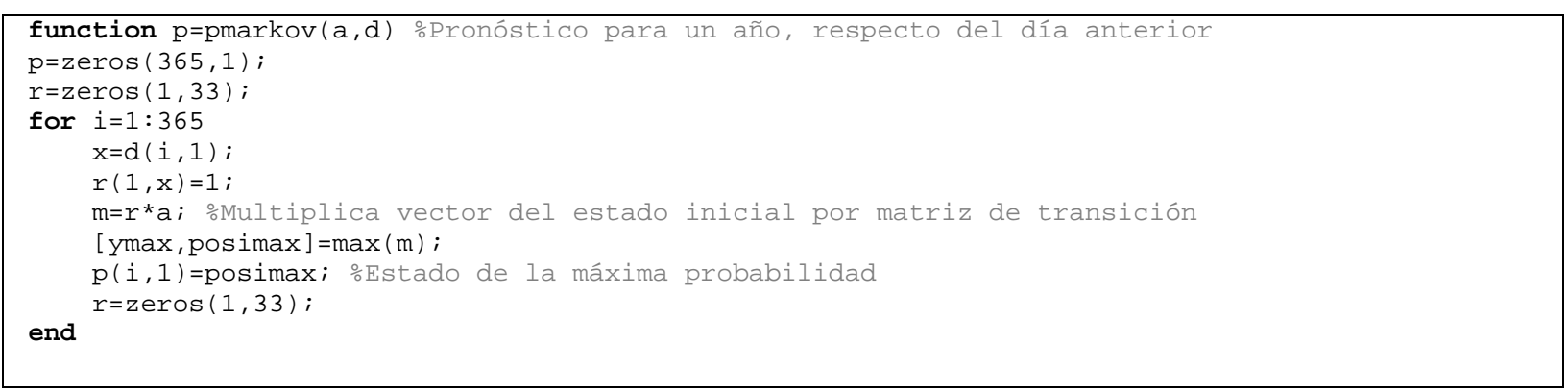

Se representa el resultado obtenido del análisis de Markov, junto a los datos de irradiación solar global diaria del año 2011 y el error producido para cada día del año, RMSE $=4,37 \mathrm{MJ} / \mathrm{m}^{2} / \mathrm{d}$, en la gráfica (Fig. 4.2.29).

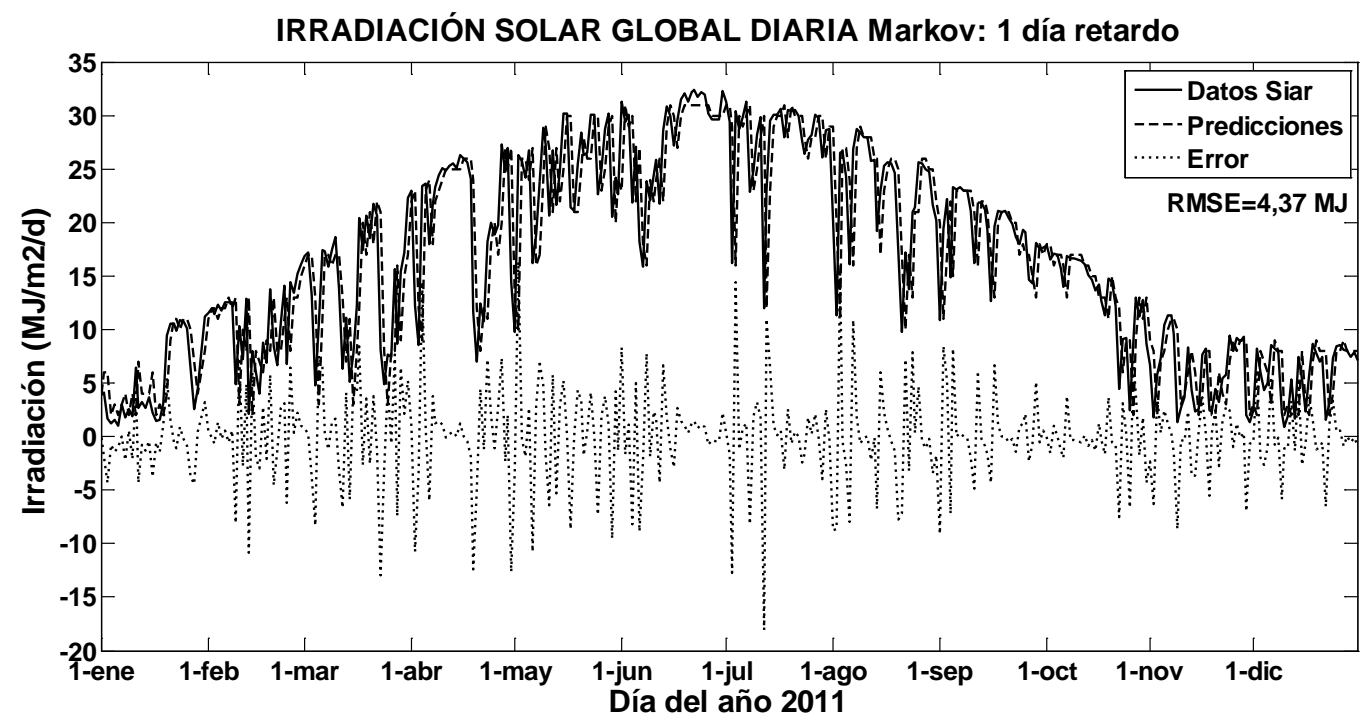

Fig. 4.2.29 Datos de la irradiación solar global diaria del año 2011 SIAR en Mansilla Mayor (León), valores resultado de la predicción realizada con la matriz de transición de Markov y el error producido para cada día del año 


\subsubsection{Estimación de la temperatura media horaria con el método ASHRAE}

El ciclo de la irradiación solar diaria condiciona que las temperaturas mínimas suelen acontecer poco antes del amanecer, y las temperaturas máximas entre una y cuatro horas después del mediodía solar. La curva diaria de temperaturas se divide en dos periodos, uno de calentamiento por la mañana y otro de enfriamiento por la tarde, mostrado en los datos (Fig. A.1.24).

El método ASHRAE ofrece un valor para la temperatura de cada hora del día TASHRAE, en función del valor diario máximo $T_{\max }$ y mínimo $T_{\min }$ y de un factor para cada hora del día $f_{\text {hora, }}$ (ASHRAE, 1997) que se muestran (Tabla 4.2.13), para ser aplicados en la ecuación (Ec. 4.2.13).

$$
\mathrm{T}_{\text {ASHRAE }}=\mathrm{T}_{\max }-\left[\mathrm{f}_{\text {hora }}\left(\mathrm{T}_{\max }-\mathrm{T}_{\min }\right)\right]
$$

Tabla 4.2.13 Factor horario ASHRAE de la temperatura ambiente del aire

\section{Factor horario ASHRAE: Temperatura Ambiente del Aire}

\begin{tabular}{|c|c|c|c|c|c|c|c|c|c|c|c|c|c|c|c|c|c|c|c|c|c|c|c|}
\hline $0 \mathrm{~h}$ & $1 \mathrm{~h}$ & $2 \mathrm{~h}$ & $3 \mathrm{~h}$ & $4 \mathrm{~h}$ & $5 \mathrm{~h}$ & $6 \mathrm{~h}$ & $\mathbf{7 h}$ & $8 \mathrm{~h}$ & $9 \mathrm{~h}$ & $10 \mathrm{~h}$ & $11 \mathrm{~h}$ & $12 \mathrm{~h}$ & $13 \mathrm{~h}$ & $14 \mathrm{~h}$ & $15 \mathrm{~h}$ & $16 \mathrm{~h}$ & $17 \mathrm{~h}$ & $18 \mathrm{~h}$ & $19 \mathrm{~h}$ & $20 \mathrm{~h}$ & $21 \mathrm{~h}$ & $22 \mathrm{~h}$ & $23 \mathrm{~h}$ \\
\hline
\end{tabular}

\begin{tabular}{|l|l|l|l|l|l|l|l|l|l|l|l|l|l|l|l|l|l|l|l|l|l|l|l|l|l|l|l|l|l}
\hline 0,87 & 0,91 & 0,94 & 0,97 & 0,99 & 1,00 & 0,94 & 0,82 & 0,65 & 0,44 & 0,27 & 0,15 & 0,07 & 0,02 & 0,00 & 0,01 & 0,07 & 0,18 & 0,31 & 0,45 & 0,58 & 0,70 & 0,79 & 0,85 \\
\hline
\end{tabular}

Se representa la temperatura media horaria durante una semana junto con las estimaciones realizadas en la gráfica (Fig. 4.2.30), de la simulación realizada con el método ASHRAE para el año 2011 resulta un RMSE $=1,85^{\circ} \mathrm{C} / \mathrm{h}$.

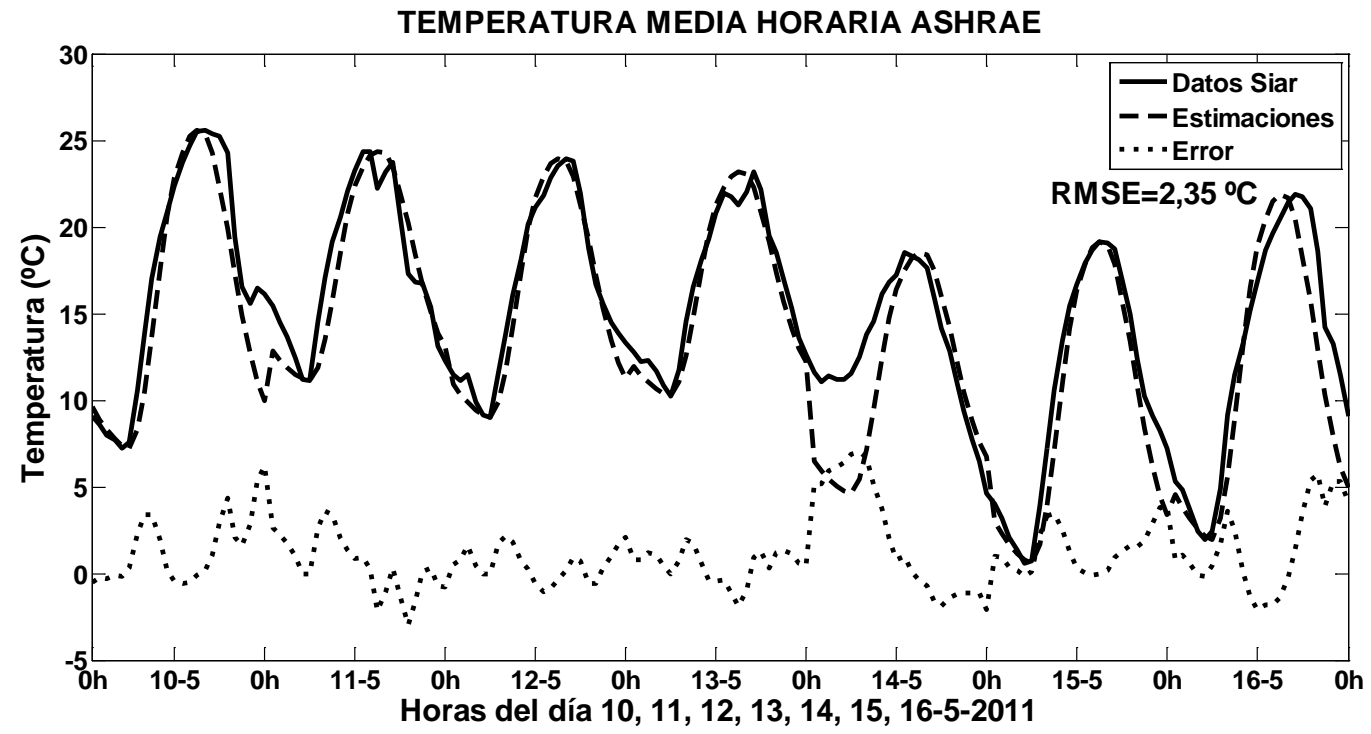

Fig. 4.2.30 Datos de la temperatura media horaria SIAR en Mansilla Mayor (León) y valor resultado de la estimación realizada con el método ASHRAE para los días 10, 11, 12, 13, 14, 15, 16-5-2011

Esta distribución se da en días despejados, cuando aparecen las nubes se suele producir el efecto de una temperatura constante a lo largo de esas horas, cuando hay tormentas o lluvias repentinas la temperatura desciende más súbitamente. Pero, ¿qué es lo que ocurre en el sistema solar térmico en esos periodos? Que la irradiación solar no llega al mínimo para que la bomba se accione, con lo que no estamos recogiendo energía del captador solar, por lo que, aunque el modelo no se ajuste a la realidad, no tiene importancia ya que no se está aplicando en esa situación. 


\subsection{Modelado de los componentes del circuito primario}

En este apartado se presentan los resultados obtenidos al modelar el captador solar e intercambiador de calor mediante metodologías revisadas en la literatura.

\subsubsection{Modelado del captador solar}

Se realizó el modelado del captador solar mediante la norma EN 12975 y el balance energético.

\section{1) Modelado del captador solar EN 12975}

La eficiencia instantánea del captador solar $\eta$, basada en el área de absorbedor/apertura según la norma EN 12975-2 (AENOR, 2006), con referencia a la diferencia de temperatura reducida $\left(T_{m}-T_{a}\right) / i_{\beta \gamma}$, tiene como ecuación para la eficiencia instantánea del captador (Ec. 4.3.1).

$$
\eta=\eta_{0}-a_{1}\left(\frac{T_{m}-T_{a}}{\dot{I}_{\beta \gamma}}\right)-a_{2} \dot{\mathrm{I}}_{\beta \gamma}\left(\frac{\mathrm{T}_{\mathrm{m}}-\mathrm{T}_{\mathrm{a}}}{\dot{\mathrm{I}}_{\beta \gamma}}\right)^{2}
$$

Donde,

$\eta_{0}$ : Eficiencia óptica del captador solar, $\eta \mathrm{a}\left(\mathrm{T}_{\mathrm{m}}-\mathrm{T}_{\mathrm{a}}\right) / \mathrm{i}_{\beta \gamma}=0$.

$a_{1}$ : Coeficiente de pérdidas térmicas a $T_{m}-T_{a}=0\left(W / m^{2} K\right)$.

$a_{2}$ : Coeficiente de pérdidas térmicas dependiente de la temperatura $\left(\mathrm{W} / \mathrm{m}^{2} \mathrm{~K}^{2}\right)$.

$\mathrm{T}_{\mathrm{m}}$ : Temperatura media del fluido portador $\left({ }^{\circ} \mathrm{C}\right)$.

$\mathrm{T}_{\mathrm{a}}$ : Temperatura del aire ambiente circundante $\left({ }^{\circ} \mathrm{C}\right)$.

$\dot{I}_{\beta \gamma}$ : Irradiancia solar sobre el plano del captador solar $\left(\mathrm{W} / \mathrm{m}^{2}\right)$.

La curva de eficiencia basada en el área del absorbedor y la temperatura media, con $800 \mathrm{~W} / \mathrm{m}^{2} \mathrm{de}$ irradiancia solar media, y $0,018 \mathrm{~kg} /\left(\mathrm{s}^{2}\right)$ de caudal del agua como fluido portador en el circuito primario, en el captador solar instalado en la planta piloto, según el laboratorio de ensayos CENER, siguiendo el método de ensayo descrito en la norma EN 12975, resulta una ecuación característica (Ec. 4.3.2).

$$
\eta=0,693-4,972\left(\frac{\mathrm{T}_{\mathrm{m}}-\mathrm{T}_{\mathrm{a}}}{\dot{\mathrm{I}}_{\beta \gamma}}\right)-0,022 \dot{\mathrm{I}}_{\beta \gamma}\left(\frac{\mathrm{T}_{\mathrm{m}}-\mathrm{T}_{\mathrm{a}}}{\dot{\mathrm{I}}_{\beta \gamma}}\right)^{2}
$$

En la (Fig. 4.3.1) se representan los valores obtenidos en cada intervalo de tiempo de un minuto, con los datos registrados en todos los ensayos realizados en el captador solar de la planta piloto, junto con la curva CENER de eficiencia a $800 \mathrm{~W} / \mathrm{m}^{2}$. 


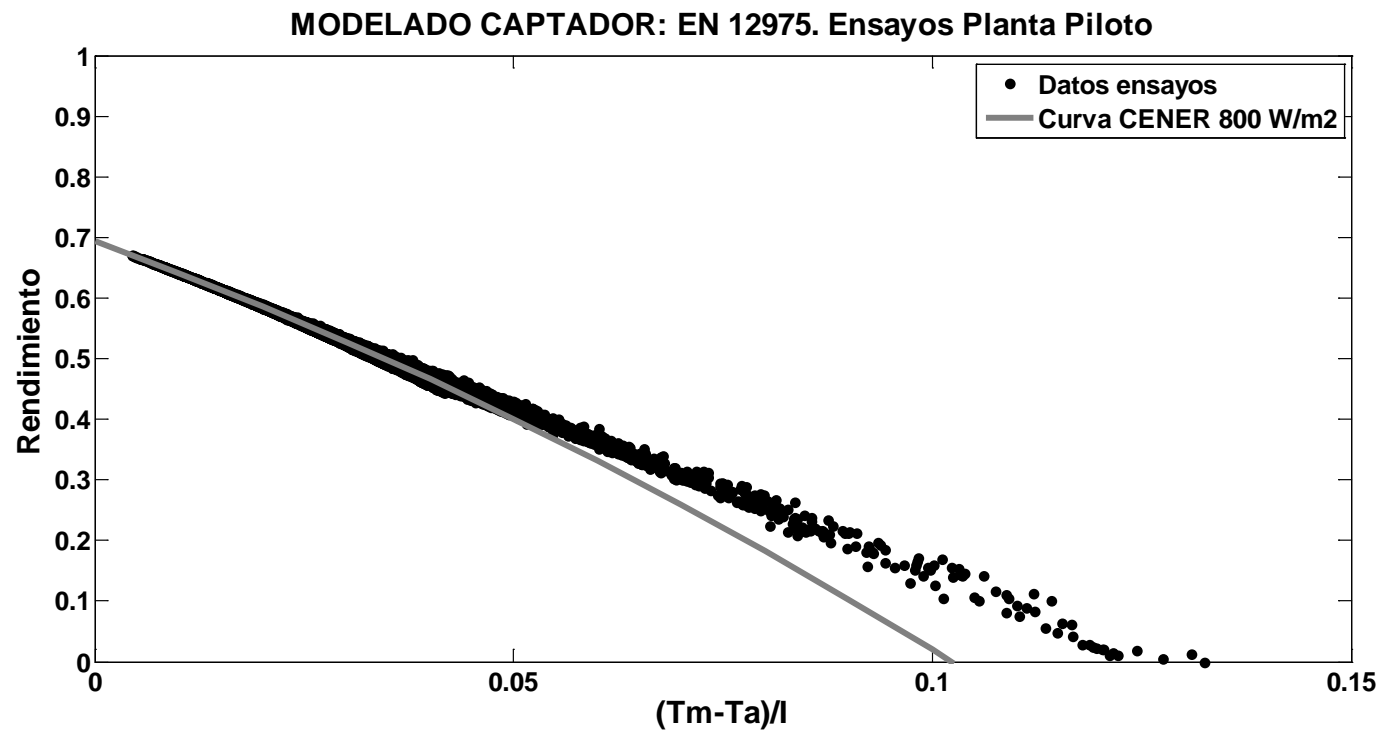

Fig. 4.3.1 Modelado del captador solar según EN 12975, resultados obtenidos con los datos registrados cada minuto en los ensayos de la planta piloto y curva CENER a $800 \mathrm{~W} / \mathrm{m}^{2}$ de irradiancia solar media

Se observan desviaciones en la segunda mitad de la gráfica, debido a que en esos momentos la irradiancia solar está más alejada del valor de la irradiancia solar media con la que fue ensayada la curva por el laboratorio CENER, cuando la irradiancia solar en el plano de apertura del captador siempre es mayor de $650 \mathrm{~W} / \mathrm{m}^{2}$. También son debidos a que los ensayos se realizaron con tres caudales distintos del fluido portador en el captador solar y como se ha comprobado (Apartado 4.1), el rendimiento del captador solar disminuye al reducir el caudal del fluido portador por el captador solar. La curva CENER se obtiene para un caudal de agua de $0,018 \mathrm{~kg} /\left(\mathrm{s} \mathrm{m}^{2}\right)$ que en el captador solar de la planta piloto equivale a un caudal de agua de $2 \mathrm{l} / \mathrm{min}$.

El ensayo realizado el día 1-7-2011 (Fig. A.2.1), soleado y despejado, en el que los valores de irradiancia solar registrados estuvieron en torno a $800 \mathrm{~W} / \mathrm{m}^{2}$, fue más ajustado a la curva CENER, como se muestra en la gráfica (Fig. 4.3.2).

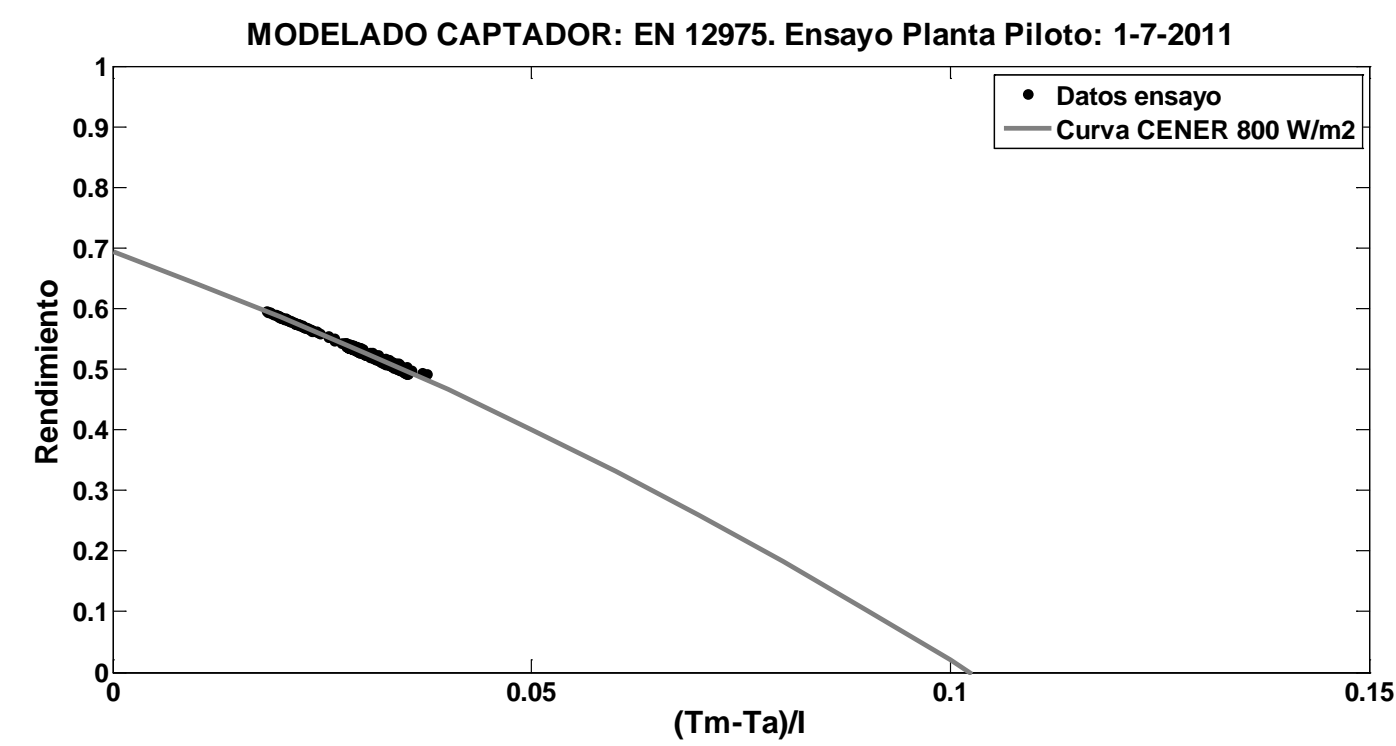

Fig. 4.3.2 Modelado del captador solar según EN 12975, resultados obtenidos con los datos registrados cada minuto en el ensayo de la planta piloto del día 1-7-2011 y curva CENER a $800 \mathrm{~W} / \mathrm{m}^{2}$ de irradiancia solar media 
El ensayo realizado el día 7-11-2011 (Apartado A.2.9), soleado y casi despejado, en el que los valores registrados en las horas centrales del día estaban en torno a $800 \mathrm{~W} / \mathrm{m}^{2}$ de irradiancia solar son los valores más ajustados a la curva, pero que a primeras horas de la mañana y por la tarde la irradiancia solar fue menor de $700 \mathrm{~W} / \mathrm{m}^{2}$ con lo que se desvía de la curva CENER, como se muestra en la gráfica (Fig. 4.3.3).

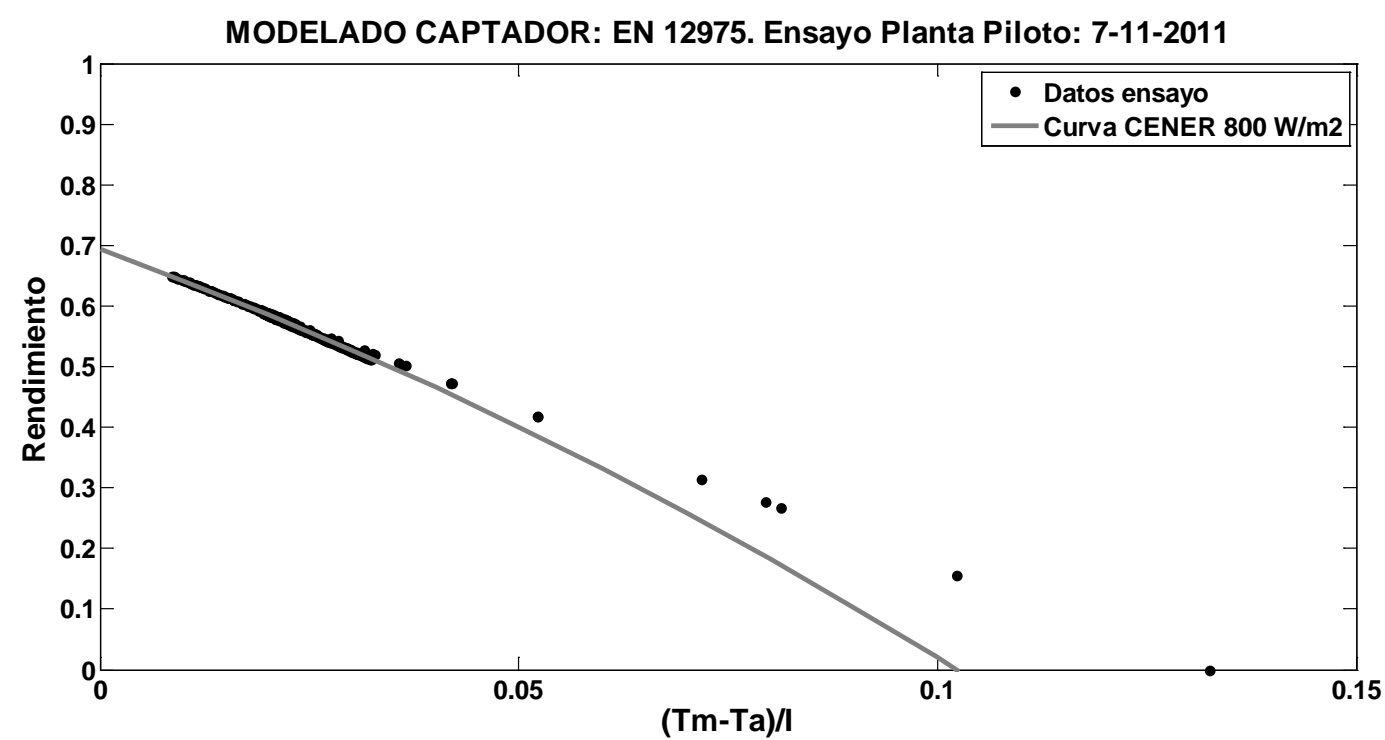

Fig. 4.3.3 Modelado del captador solar según EN 12975, resultados obtenidos con los datos registrados cada minuto en el ensayo de la planta piloto del día 7-11-2011 y curva CENER a $800 \mathrm{~W} / \mathrm{m}^{2}$ de irradiancia solar media 


\section{2) Modelado del captador solar por balance energético}

La curva de eficiencia $\eta$, basada en el área del absorbedor y la temperatura se define como la relación de la energía que el captador solar ha conseguido absorber y la energía solar que incide sobre su superficie y recibe en el mismo intervalo de tiempo (Ec. 4.3.3).

Donde,

$$
\eta=\frac{Q_{u}}{\dot{\mathrm{I}}_{\beta \gamma} \mathrm{A}_{\mathrm{c}}}
$$

$\mathrm{Q}_{u}$ : Energía útil que recoge el captador solar.

$\mathrm{i}_{\beta \gamma}:$ Irradiancia solar que incide sobre el captador solar por unidad de área.

$A_{c}$ : Área del captador solar plano.

Para el caso de los ensayos realizados en la planta piloto durante intervalos de tiempo de un minuto y teniendo en cuenta la equivalencia de $1 \mathrm{~kJ}=1000 \mathrm{~W}$ s, resulta para su cálculo la ecuación (Ec. 4.3.4).

$$
\eta=\frac{\text { Caudal }\left(\frac{\mathrm{kg}}{\mathrm{min}}\right) 4,18\left(\frac{\mathrm{kJ}}{\mathrm{kg}^{\circ} \mathrm{C}}\right)\left(\mathbf{T}_{\mathrm{s}}-\mathbf{T}_{\mathbf{e}}\right)\left({ }^{\circ} \mathrm{C}\right)}{\dot{\mathbf{I}}_{\beta \gamma}\left(\frac{\mathrm{W}}{\mathrm{m}^{2}}\right) 1,85\left(\mathrm{~m}^{2}\right) 60(\mathrm{~s}) / 1000\left(\frac{\mathrm{W} \mathrm{s}}{\mathrm{kJ}}\right)}
$$

Se compararon los resultados obtenidos mediante el balance energético realizado al captador solar en función del diferencial de la temperatura entre el fluido de la salida y la entrada del captador solar $\left(T_{s}\right.$ $T_{e}$ ), junto con los valores obtenidos con el método de ensayo descrito en la norma EN 12975 función de la temperatura media del fluido en el captador solar, en las gráficas (Fig. 4.3.4.a), (Fig. 4.3.4.b) y (Fig. 4.3.4.c). Cada uno de los tres ensayos se realizó a un caudal del fluido portador distinto de 2, 1,6 y 1 $\mathrm{I} / \mathrm{min}$ respectivamente.

Se observa la disminución del rendimiento del captador solar respecto a la reducción de caudal del fluido portador en el captador solar. La ecuación CENER a $800 \mathrm{~W} / \mathrm{m}^{2}$ está diseñada para un caudal de 2 $\mathrm{I} / \mathrm{min}$, cuando se reduce el caudal en los ensayos este modelo no tiene en cuenta su efecto, de un $10 \%$ al utilizar el caudal de $1,6 \mathrm{l} / \mathrm{min}$ y de un $25 \%$ al utilizar el caudal de $1 \mathrm{l} / \mathrm{min}$.

También se observa una variación en el rendimiento al variar las temperaturas de ida y de retorno al captador solar del fluido portador, coincidiendo con los consumos de agua caliente solar desde el depósito acumulador y la correspondiente entrada de agua fría proveniente de la red. Esta bajada en la temperatura del fluido portador se transforma en un aumento en el rendimiento del captador. 


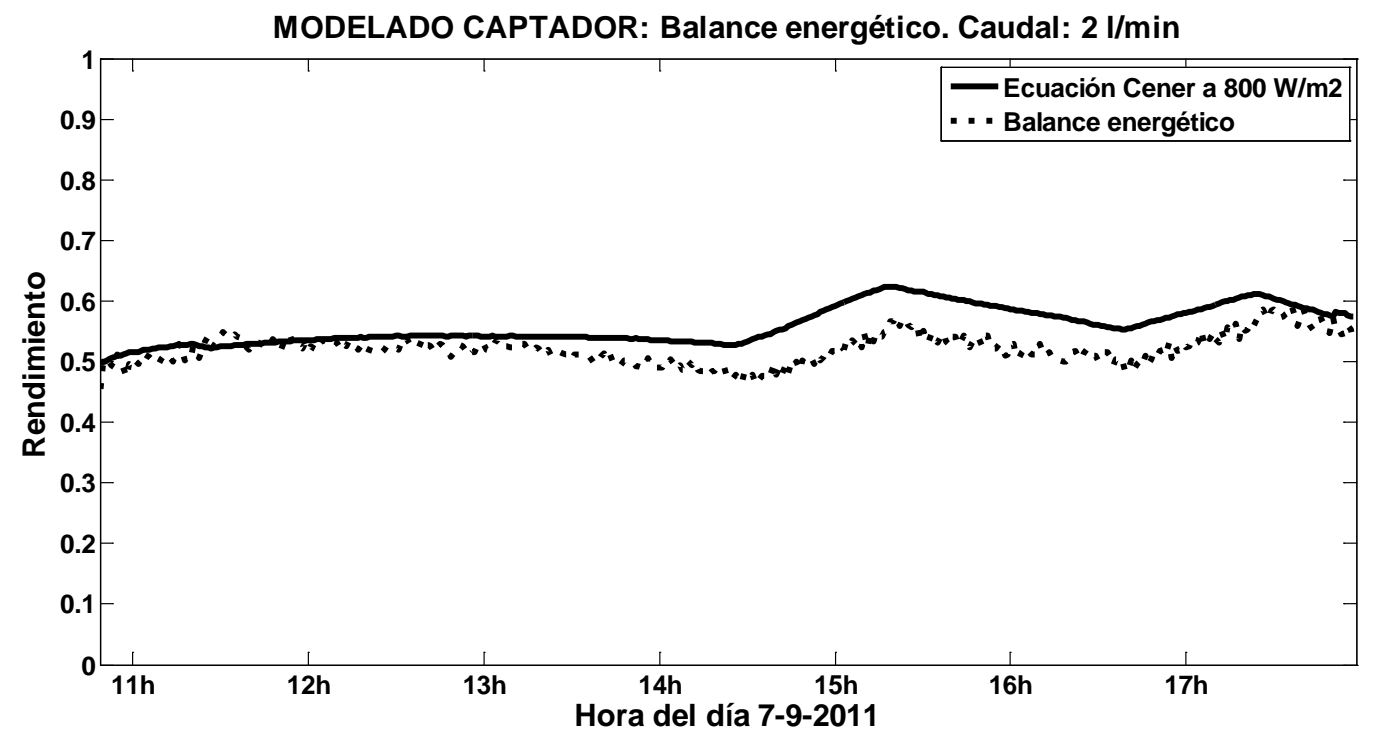

Fig. 4.3.4.a Modelado del captador con los datos registrados cada minuto en el ensayo de la planta piloto del día 7-9-2011 (Fig. A.2.4) con un caudal de $2 \mathrm{l} / \mathrm{min}$, resultados obtenidos del balance energético y resultados de la ecuación CENER a $800 \mathrm{~W} / \mathrm{m}^{2}$ de irradiancia solar media

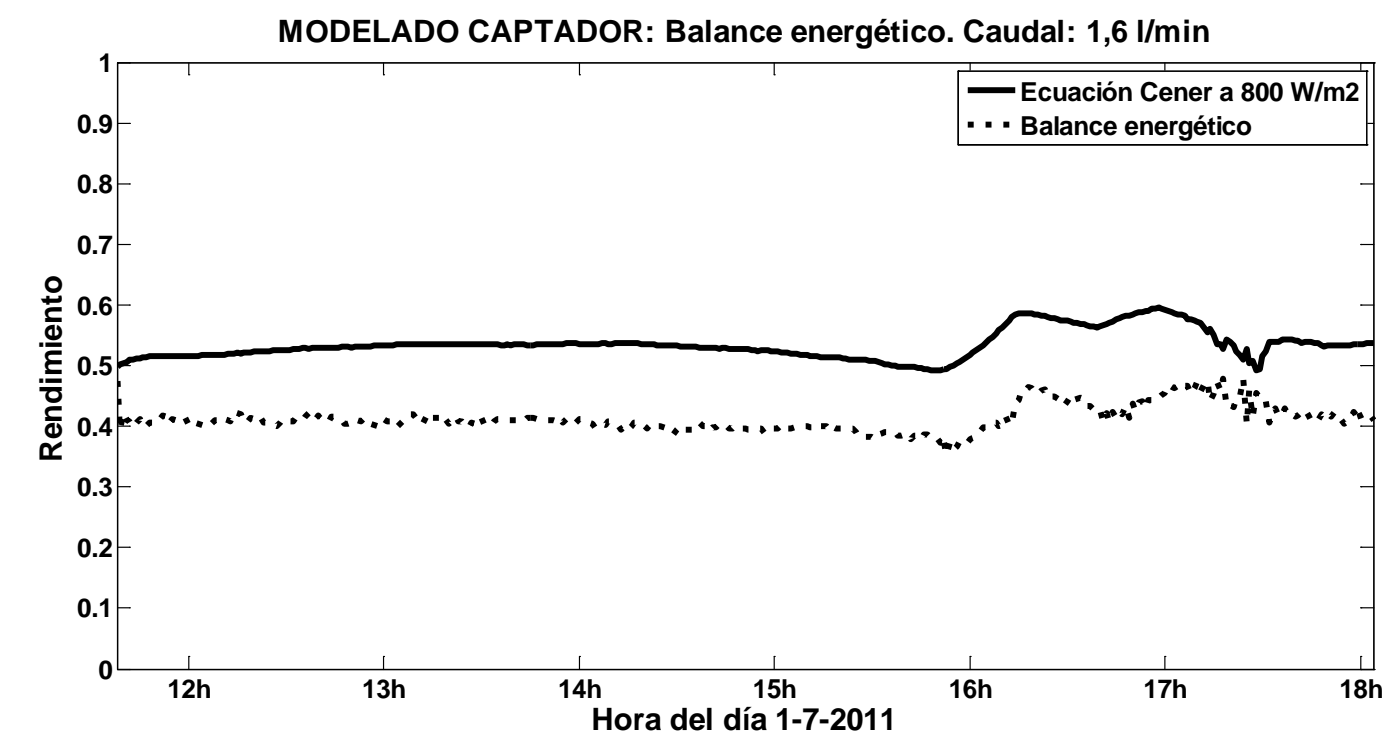

Fig. 4.3.4.b Modelado del captador con los datos registrados cada minuto en el ensayo de la planta piloto del día 1-7-2011 (Fig. A.2.1) con un caudal de 1,6 l/min, resultados obtenidos del balance energético y resultados de la ecuación CENER a $800 \mathrm{~W} / \mathrm{m}^{2}$ de irradiancia solar media 


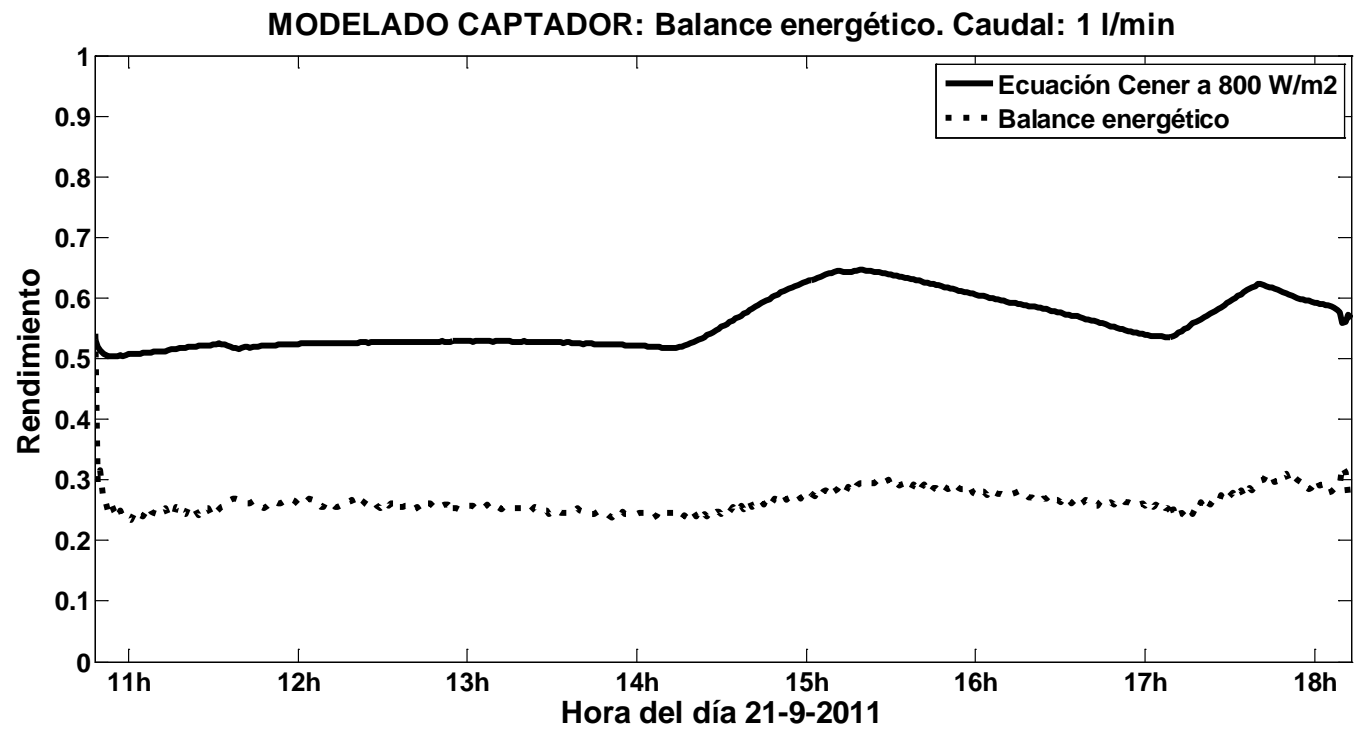

Fig. 4.3.4.c Modelado del captador con los datos registrados cada minuto en el ensayo de la planta piloto del día 21-9-2011 (Fig. A.2.5) con un caudal de $1 \mathrm{l} / \mathrm{min}$, resultados obtenidos del balance energético y resultados de la ecuación CENER a $800 \mathrm{~W} / \mathrm{m}^{2}$ de irradiancia solar media 


\subsubsection{Modelado del intercambiador de calor}

Los intercambiadores de calor ubicados en el interior del depósito, la eficiencia $\varepsilon$, es resultado de la relación entre la energía que sea intercambiado, dada por el salto térmico entre la temperatura de la entrada y la salida del intercambiador de calor, y la energía que se podía haber intercambiado, dada por el salto térmico entre la temperatura de entrada y la temperatura del agua en el depósito más próxima al intercambiador de calor (Ibáñez et al., 2005). En el caso del intercambiador de calor en la planta piloto, la temperatura del agua más próxima es la situada en las capas N2, N3, N4 y N5, según la ecuación (Ec. 4.3.5).

$$
\varepsilon=\frac{\mathrm{T}_{\text {ida }}-\mathrm{T}_{\mathrm{ret}}}{\mathrm{T}_{\mathrm{ida}}-\mathrm{T}_{\mathrm{N} 2 . .5}} 100
$$

Donde,

$T_{\text {ida: }}$ : Temperatura de ida del circuito primario es la temperatura de entrada del fluido portador en el intercambiador de calor.

$T_{\text {ret: }}$ Temperatura de retorno del circuito primario es la temperatura de salida del fluido portador en el intercambiador de calor.

$\mathrm{T}_{\mathrm{N} 2 . .5}$ : Temperatura media de las capas de agua del depósito que rodean al intercambiador de calor es la temperatura del agua en el depósito más próxima al intercambiador de calor.

Los intercambiadores de calor situados en el exterior del depósito, la eficiencia $\varepsilon$, es resultado de la relación entre la energía que sea intercambiado, dada por el salto térmico entre la temperatura de la entrada y la salida del lado del circuito primario, y la energía que se podía haber intercambiado, dada por el salto térmico entre las temperaturas de entrada al circuito primario y secundario (Ibáñez et al., 2005), siendo la capacidad de intercambio térmico mínima la del fluido del circuito primario, según la ecuación (Ec. 4.3.6).

$$
\varepsilon=\frac{\mathrm{T}_{\mathrm{e} 1}-\mathrm{T}_{\mathrm{s} 1}}{\mathrm{~T}_{\mathrm{e} 1}-\mathrm{T}_{\mathrm{e} 2}} 100
$$

Donde,

$\mathrm{T}_{\mathrm{e} 1}$ : Temperatura del fluido portador en la entrada del circuito primario del intercambiador de calor.

$\mathrm{T}_{\mathrm{s} 1}$ : Temperatura del fluido portador en la salida del circuito primario del intercambiador de calor.

$\mathrm{T}_{\mathrm{e} 2}$ : Temperatura del agua caliente solar en la entrada del circuito secundario del intercambiador de calor.

Y para el caso de la capacidad de intercambio térmico mínima del fluido del circuito secundario, según la ecuación (Ec. 4.3.7).

$$
\varepsilon=\frac{\mathrm{T}_{\mathrm{s} 2}-\mathrm{T}_{\mathrm{e} 2}}{\mathrm{~T}_{\mathrm{e} 1}-\mathrm{T}_{\mathrm{e} 2}} 100
$$

Donde,

$\mathrm{T}_{\mathrm{s} 2}$ : Temperatura del agua caliente solar en la salida del circuito secundario del intercambiador de calor. 
$T_{\mathrm{e} 2}:$ Temperatura del agua caliente solar en la entrada del circuito secundario del intercambiador de calor.

$\mathrm{T}_{\mathrm{e} 1}$ : Temperatura del fluido portador en la entrada del circuito primario del intercambiador de calor.

Para el caso de la planta piloto que utiliza un intercambiador de calor interno en el depósito acumulador, la eficiencia $\varepsilon$ según el primer modelo de la ecuación (Ec. 4.3.5), que es función de la diferencia de temperaturas del fluido portador entre la entrada y la salida del intercambiador de calor ( $T_{\text {ida }}-T_{\text {ret }}$ y también de la diferencia de temperaturas entre la entrada del intercambiador de calor y la temperatura del agua del depósito más próxima al intercambiador de calor $\left(\mathrm{T}_{\mathrm{ida}}-\mathrm{T}_{\mathrm{N} 2 . .5}\right)$.

A continuación de estudian las variaciones en el ensayo de un día, durante los periodos de insolación, carga, y con intervalos de consumo de agua caliente solar, descarga, en la planta piloto. Se representan las variaciones de los saltos térmicos $\left(T_{\text {ida }}-T_{\text {ret }}\right)$ y $\left(T_{i d a}-T_{N 2 . .5}\right)$ y la variación de la eficiencia del intercambiador de calor según el modelo de la ecuación (Ec. 4.3.5) durante los ensayos realizados el día 7-9-2011 (Fig. A.2.4), el día 1-7-2011 (Fig. A.2.1) y el día 21-9-2011 (Fig. A.2.5).

Durante las primeras horas del ensayo las diferencias $\left(T_{\text {ida }}-T_{\text {ret }}\right)$ y $\left(T_{\text {ida }}-T_{N 2 . .5}\right)$ van en aumento, debido al aumento de irradiancia solar durante la mañana, pero la eficiencia va en un ligero descenso debido a que ( $\left.T_{\text {ida }}-T_{N 2.5}\right)$ aumenta más rápidamente que ( $T_{\text {ida }}-T_{\text {ret }}$ ), ya que $T_{N 2 . .5}$ tiene una temperatura baja, al situarse el calor en las capas más altas del depósito, esto hace que el modelo dé una eficiencia peor.

Al llegar el mediodía y las temperaturas en las capas medias y superiores del depósito llegan a la misma temperatura, y la $T_{N 2 . .5}$ ha aumentado su valor con lo que $\left(T_{\text {ida }}-T_{N 2 . .5}\right)$ ya no crece y la $\left(T_{\text {ida }}-T_{\text {ret }}\right)$ también se estabiliza, la eficiencia tiene un ligero aumento, ya que $T_{\mathrm{N} 2 . .5}$ tiene una temperatura más alta y el modelo da una eficiencia mejor, al poder esperar ceder una menor energía. La relación de la eficiencia entre la energía que ha cedido y la que podía haber cedido, aumenta, al haber disminuido esta última.

Llegado el momento del consumo de agua caliente solar, con la correspondiente entrada de agua fría proveniente de la red, que rodea al intercambiador de calor, esto hace que ( $\left.T_{\text {ida }}-T_{\text {ret }}\right)$ aumente al estar cediendo calor más rápidamente a un elemento más frío que antes, la $\left(T_{\text {ida }}-T_{N 2 . .5}\right)$ también aumenta, al estar $\mathrm{T}_{\mathrm{N} 2 . .5}$ más fría que antes.

Pero la relación de la eficiencia entre la energía que ha cedido, que ahora es mayor y la que podía haber cedido, disminuye en contra de lo que podía haberse esperado, esto se debe a que esta última ha aumentado más rápidamente que la energía cedida, al tener $T_{N 2 . .5}$ una temperatura mucho más baja, con lo que en el modelo resulta una eficiencia menor.

Aunque la energía cedida es mayor en este caso y se esperaría un aumento de la eficiencia, al mismo tiempo la energía que se podía haber cedido ha aumentado, respecto a la anterior situación, al rodear el intercambiador el agua de red mucho más fría. El aumento de la energía cedida $\left(T_{\text {ida }}-T_{\text {ret }}\right)$ se está comparando respecto a $\left(T_{\text {ida }}-T_{\mathrm{N} 2 . .5}\right)$ que ha variado mucho más rápido.

Otro efecto que se observa al variar el caudal del fluido portador es que en las situaciones de consumo de agua caliente solar, la eficiencia sube más con caudales bajos, este efecto es debido a que al aumentar ( $T_{\mathrm{ida}}-\mathrm{T}_{\mathrm{N} 2 . .5}$ ) considerablemente con la entrada de agua fría de la red, la capacidad de intercambio de calor ( $T_{\text {ida }}-T_{\text {ret }}$ ) aumenta y al circular el fluido más lentamente tiene más tiempo para enfriarse y ceder más energía al depósito. 
Se representan los resultados de la eficiencia obtenidos en el intercambiador de calor de la planta piloto, durante el ensayo de un día para cada minuto, con un caudal del fluido portador de $2 \mathrm{l} / \mathrm{min}$ (Fig. 4.3.5.a) y (Fig. 4.3.5.b), con un caudal de $1,6 \mathrm{l} / \mathrm{min}$ (Fig. 4.3.6.a) y (Fig. 4.3.6.b), y con un caudal de 1 I/min (Fig. 4.3.7.a) y (Fig. 4.3.7.b). Las temperaturas de entrada y salida del fluido portador en el intercambiador y las temperaturas de estratificación de cada ensayo se muestran en (Anexo 2 Datos de los ensayos en la planta piloto) realizado el día 7-9-2011 (Fig. A.2.4), el día 1-7-2011 (Fig. A.2.1) y el día 21-9-2011 (Fig. A.2.5).

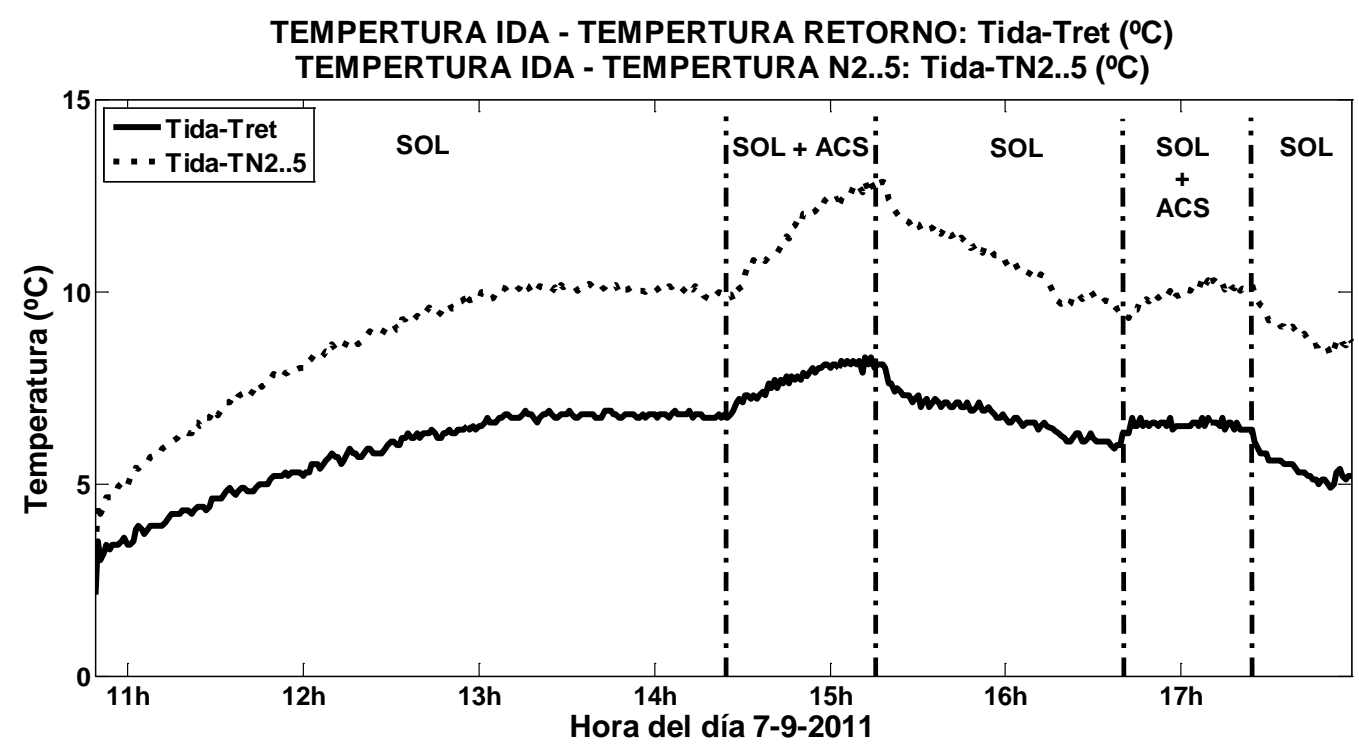

Fig. 4.3.5.a Modelado del intercambiador con los datos registrados cada minuto en el ensayo de la planta piloto del día 7-9-2011 (Fig. A.2.4) con un caudal de $2 \mathrm{l} / \mathrm{min}$

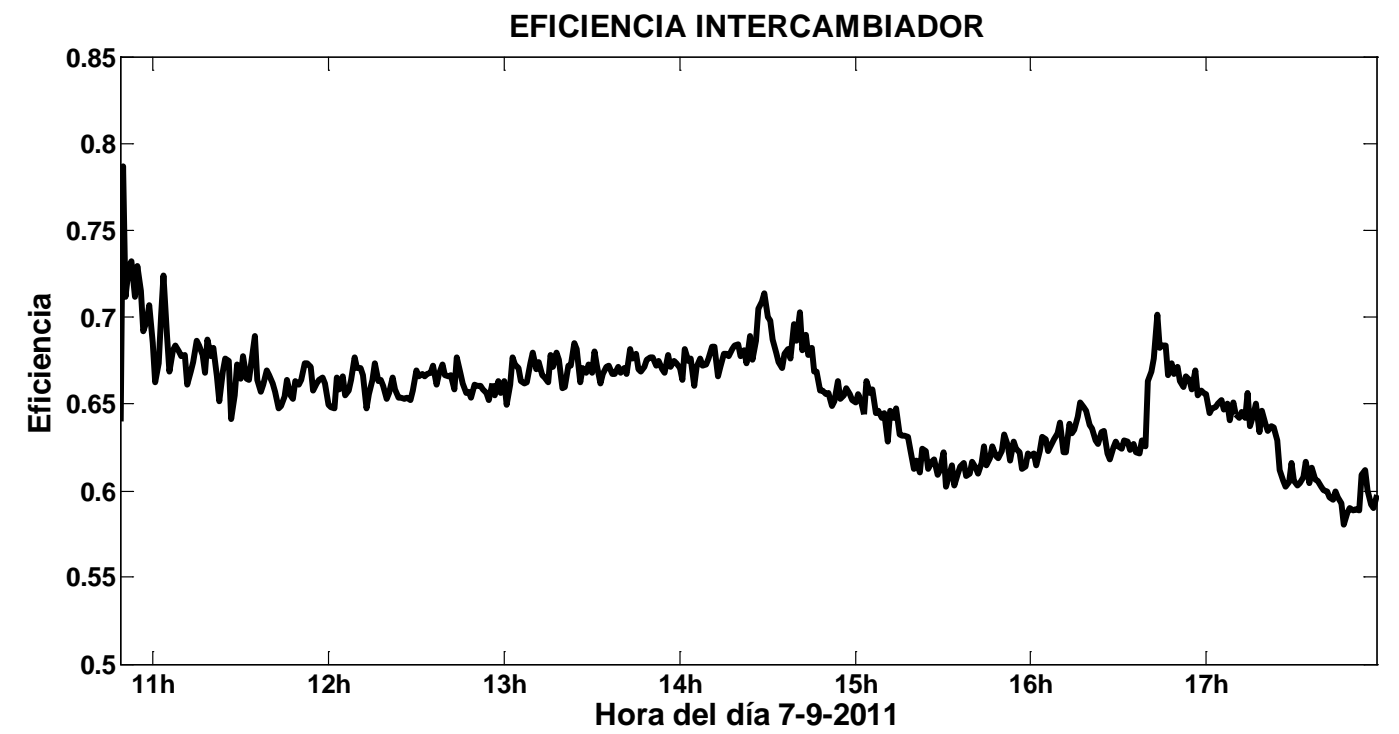

Fig. 4.3.5.b Eficiencia energética del intercambiador con los datos registrados cada minuto en el ensayo de la planta piloto del día 7-9-2011 (Fig. A.2.4) con un caudal de $2 \mathrm{l} / \mathrm{min}$ 


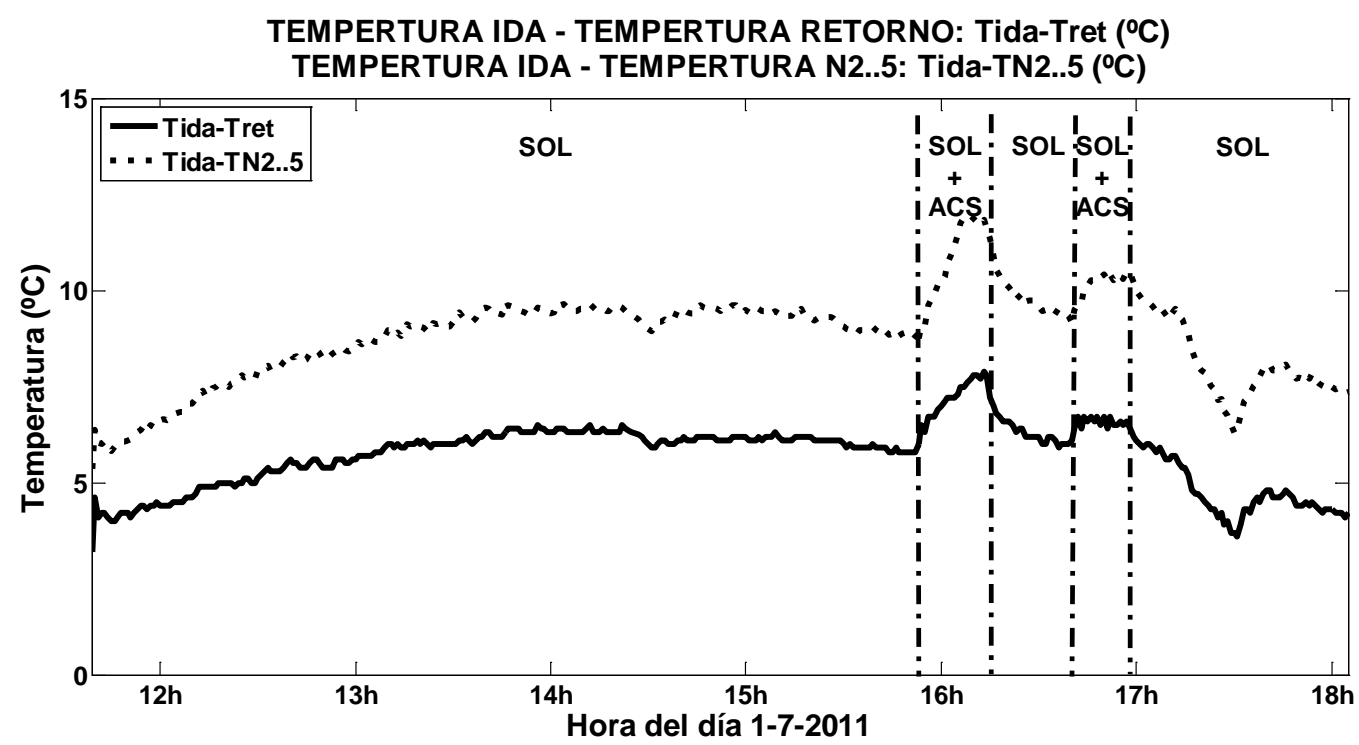

Fig. 4.3.6.a Modelado del intercambiador con los datos registrados cada minuto en el ensayo de la planta piloto del día 1-7-2011 (Fig. A.2.1) con un caudal de $1,6 \mathrm{l} / \mathrm{min}$

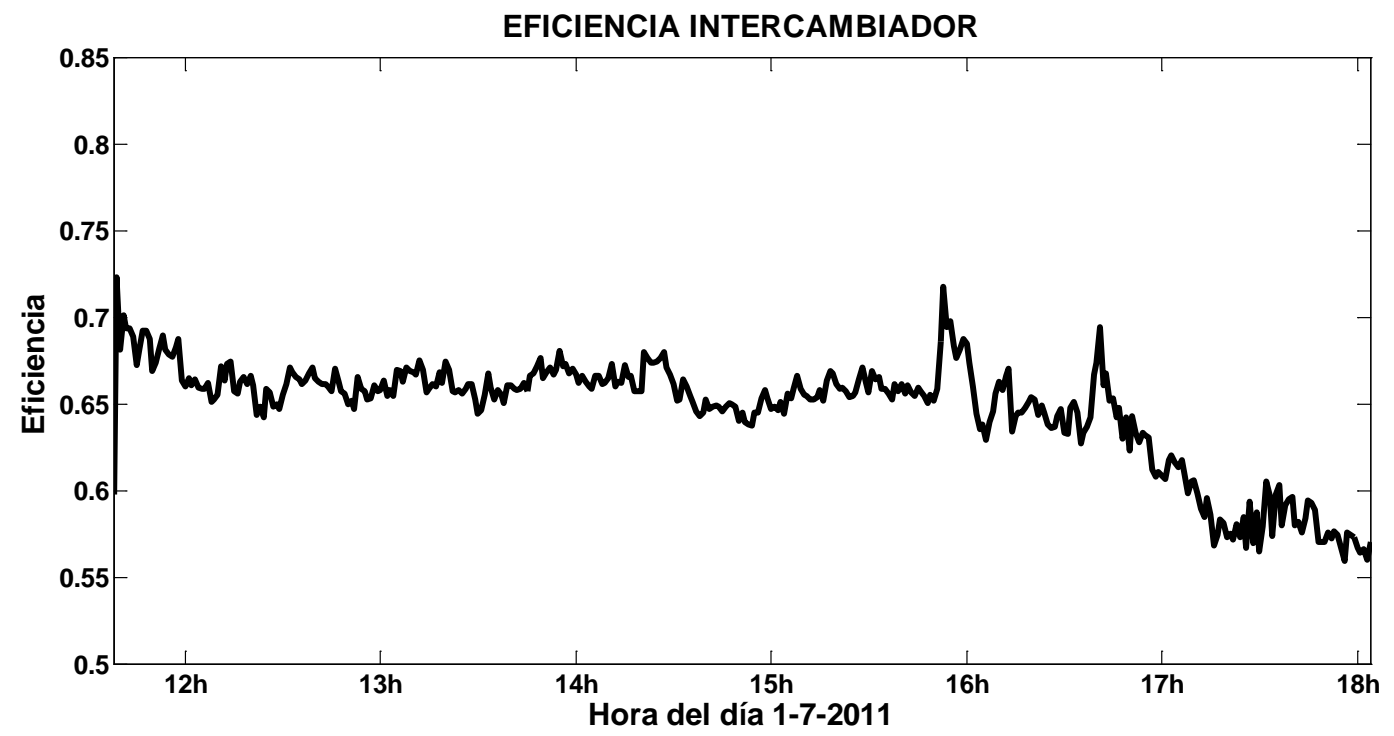

Fig. 4.3.6.b Eficiencia energética del intercambiador con los datos registrados cada minuto en el ensayo de la planta piloto del día 1-7-2011 (Fig. A.2.1) con un caudal de $1,6 \mathrm{l} / \mathrm{min}$ 


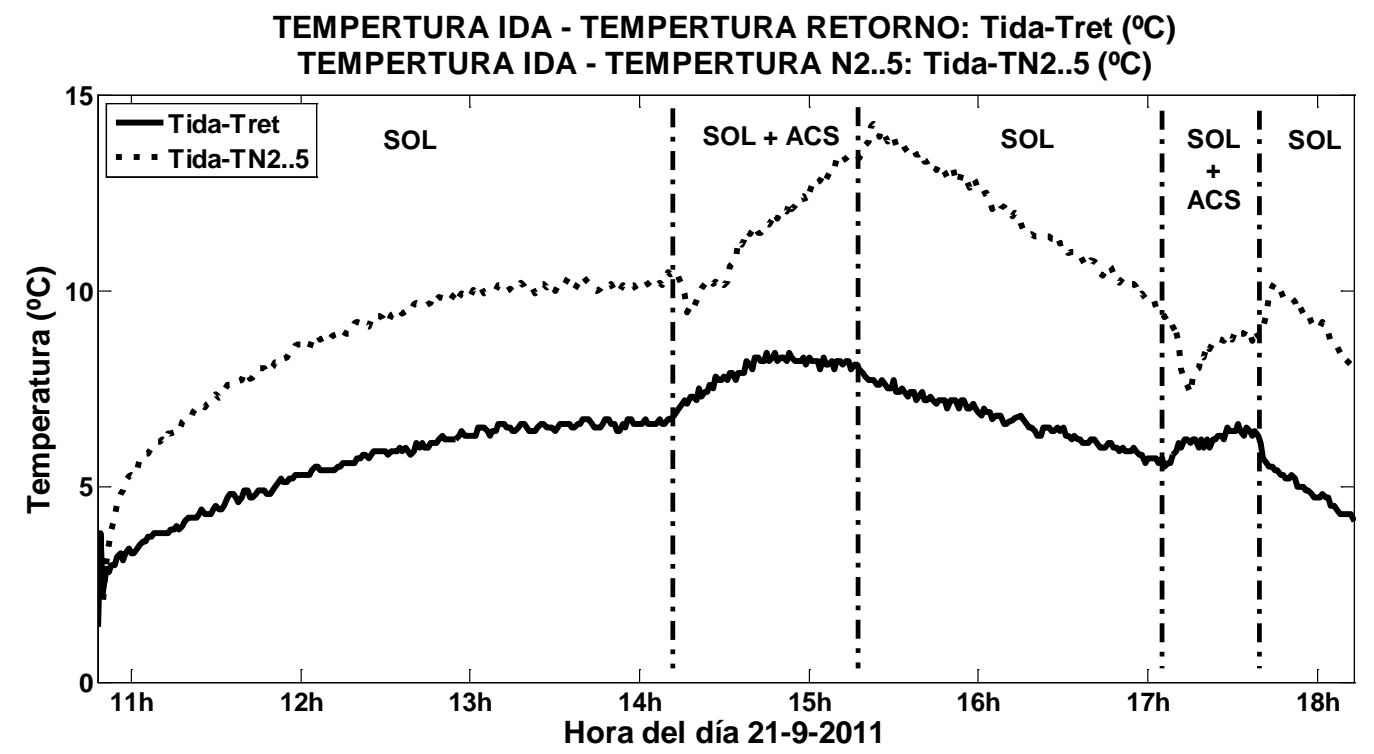

Fig. 4.3.7.a Modelado del intercambiador con los datos registrados cada minuto en el ensayo de la planta piloto del día 21-9-2011 (Fig. A.2.5) con un caudal de $1 \mathrm{l} / \mathrm{min}$

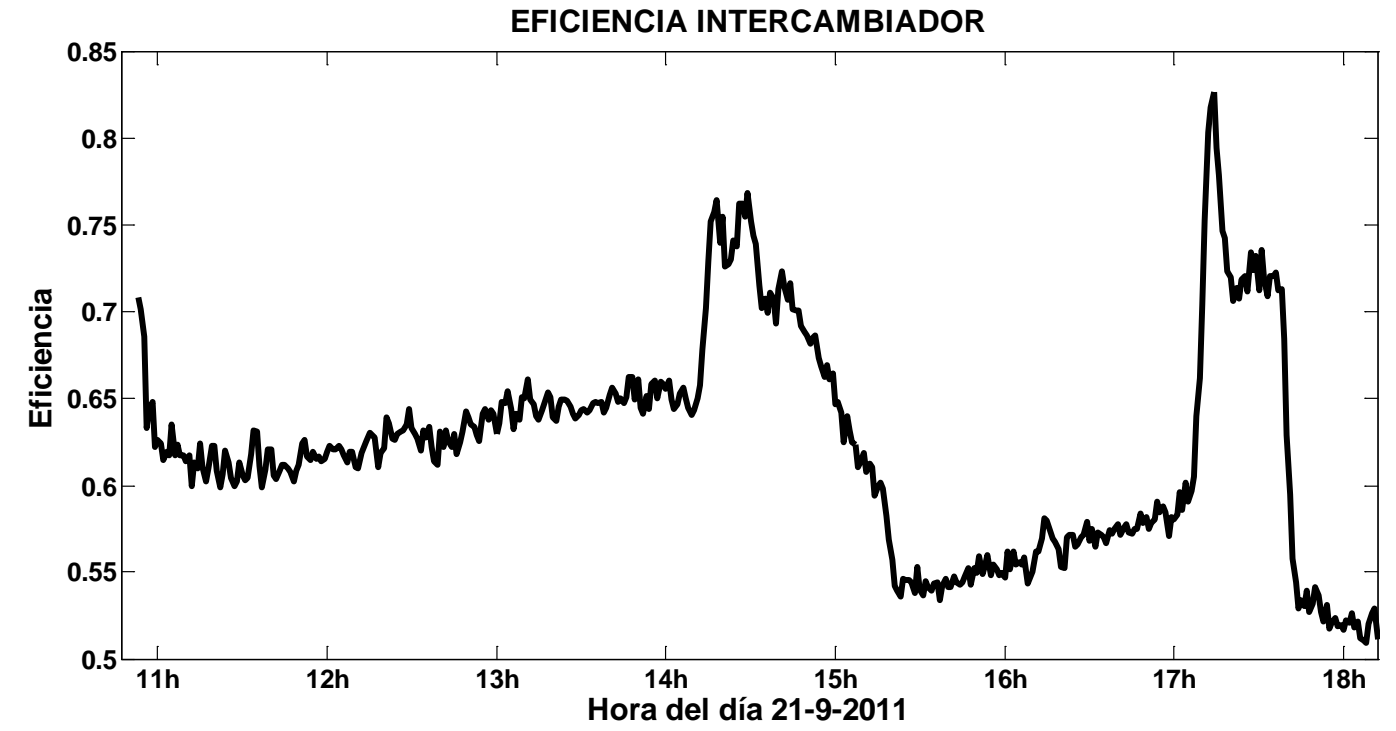

Fig. 4.3.7.b Eficiencia energética del intercambiador con los datos registrados cada minuto en el ensayo de la planta piloto del día 21-9-2011 (Fig. A.2.5) con un caudal de $1 \mathrm{l} / \mathrm{min}$ 


\subsection{Predicción neural de las variables ambientales}

En este apartado se aplican las metodologías desarrolladas en esta Tesis Doctoral, propuestas para la predicción de las variables ambientales de la irradiación solar y la temperatura ambiente, que se consideran más influyentes en el funcionamiento de los sistemas solares térmicos. La técnica utilizada son las redes neuronales artificiales de la inteligencia computacional aplicadas a la base teórica de las series de tiempo, la cual se desarrolló sobre las series de tiempo construidas con datos reales en el capítulo segundo dedicado al Estado del Arte. Los resultados de las metodologías de predicción se aplican y validan con la base de datos de la red SIAR en la estación de Mansilla Mayor (León). 


\subsubsection{Resultados de la predicción de la irradiación solar global diaria}

Se presentan los resultados de la metodología para la predicción de la irradiación solar global diaria mediante redes neuronales artificiales, a partir de los datos de la irradiación solar global diaria con uno, dos o tres días de retardo, el día del año y el índice de claridad aplicando las metodologías del (Apartado 3.4.1). El entrenamiento de la red neuronal artificial se realizó con datos de los años 2004-2010, y se validan comparando los resultados de los modelos en la simulación realizada con la base de datos de SIAR en Masilla Mayor (León) del año 2011, gráficamente y con el valor del estadístico RMSE.

Se probaron varias combinaciones de entradas hasta encontrar la que resultó con un error menor. En las predicciones realizadas se utilizaron los datos de los tres días anteriores sobre el que se realiza la predicción, el día del año y el índice de claridad.

1) La primera combinación realizada de entradas a la red neuronal artificial fue de la irradiación solar global diaria, del día anterior sobre el que se hace la predicción del valor de la irradiación solar global diaria.

2) La segunda combinación realizada de entradas a la red neuronal artificial fue de la irradiación solar global diaria, de los dos días anteriores sobre el que se hace la predicción del valor de la irradiación solar global diaria.

3) La tercera combinación realizada de entradas a la red neuronal artificial fue de la irradiación solar global diaria, de los tres días anteriores sobre el que se hace la predicción del valor de la irradiación solar global diaria.

4) La cuarta combinación realizada de entradas a la red neuronal artificial fue de la irradiación solar global diaria y el día del año, del día anterior sobre el que se hace la predicción del valor de la irradiación solar global diaria.

5) La quinta combinación realizada de entradas a la red neuronal artificial fue de la irradiación solar global diaria y el día del año, de los dos días anteriores sobre el que se hace la predicción del valor de la irradiación solar global diaria.

6) La sexta combinación realizada de entradas a la red neuronal artificial fue de la irradiación solar global diaria y el día del año, de los tres días anteriores sobre el que se hace la predicción del valor de la irradiación solar global diaria.

7) La séptima combinación realizada de entradas a la red neuronal artificial fue de la irradiación solar global diaria y el índice de claridad, del día anterior sobre el que se hace la predicción del valor de la irradiación solar global diaria.

8) La octava combinación realizada de entradas a la red neuronal artificial fue de la irradiación solar global diaria, el índice de claridad y el día del año, del día anterior sobre el que se hace la predicción del valor de la irradiación solar global diaria. 


\section{1) Resultados de la predicción de la irradiación solar global diaria con un día de retardo}

Se representa la predicción realizada del modelo (Fig. 3.4.2), con una red neuronal artificial de una neurona en la capa oculta para el año 2011, junto con los datos y el error producido para cada día del año, $\mathrm{RMSE}=4,26 \mathrm{MJ} / \mathrm{m}^{2} / \mathrm{d}$, en la gráfica (Fig. 4.4.1).

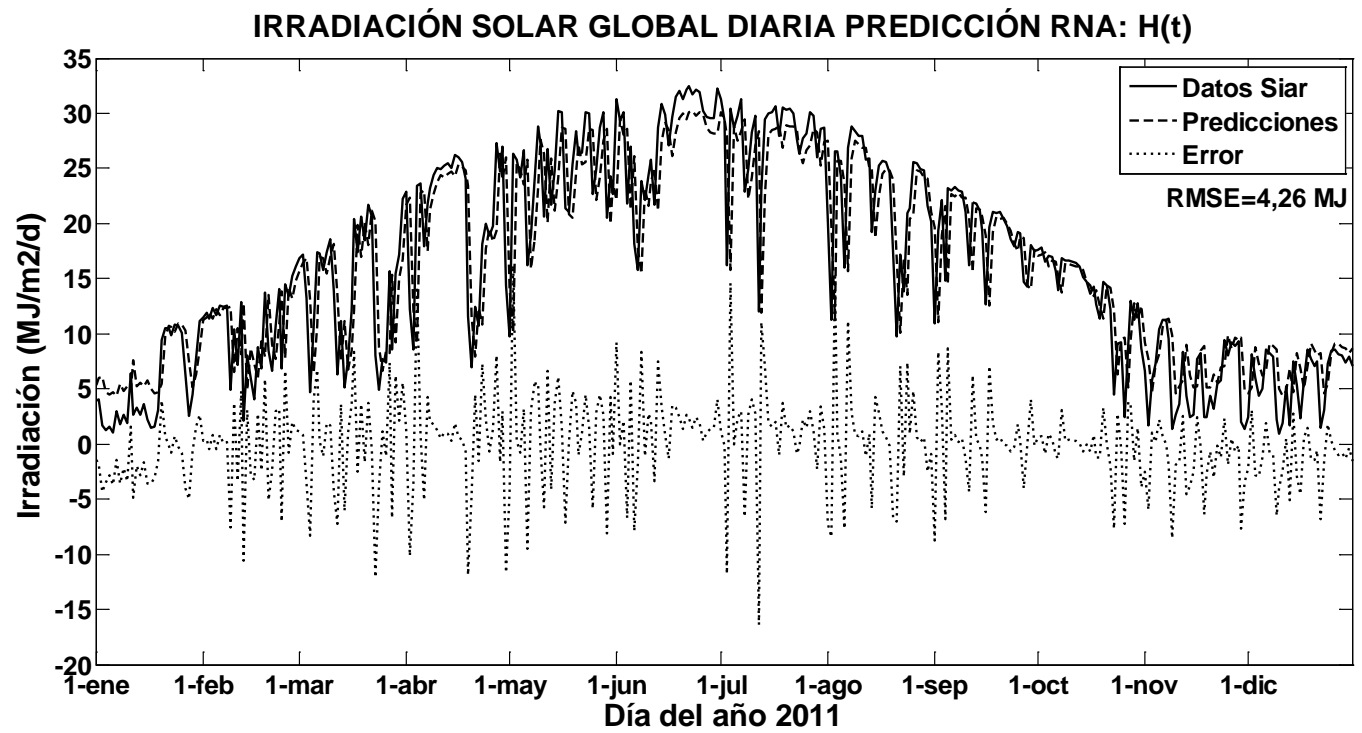

Fig. 4.4.1 Datos de la irradiación solar global diaria SIAR en Mansilla Mayor (León), valores resultado de la predicción realizada con una red neuronal artificial de una entrada del valor del día anterior y el error producido para cada día del año 


\section{2) Resultados de la predicción de la irradiación solar global diaria con dos días de retardo}

Se representa la predicción realizada del modelo (Fig. 3.4.3), con una red neuronal artificial de seis neuronas en la capa oculta para el año 2011, junto con los datos y el error producido para cada día del año, RMSE = 4,13 MJ/m²/d, en la gráfica (Fig. 4.4.2).

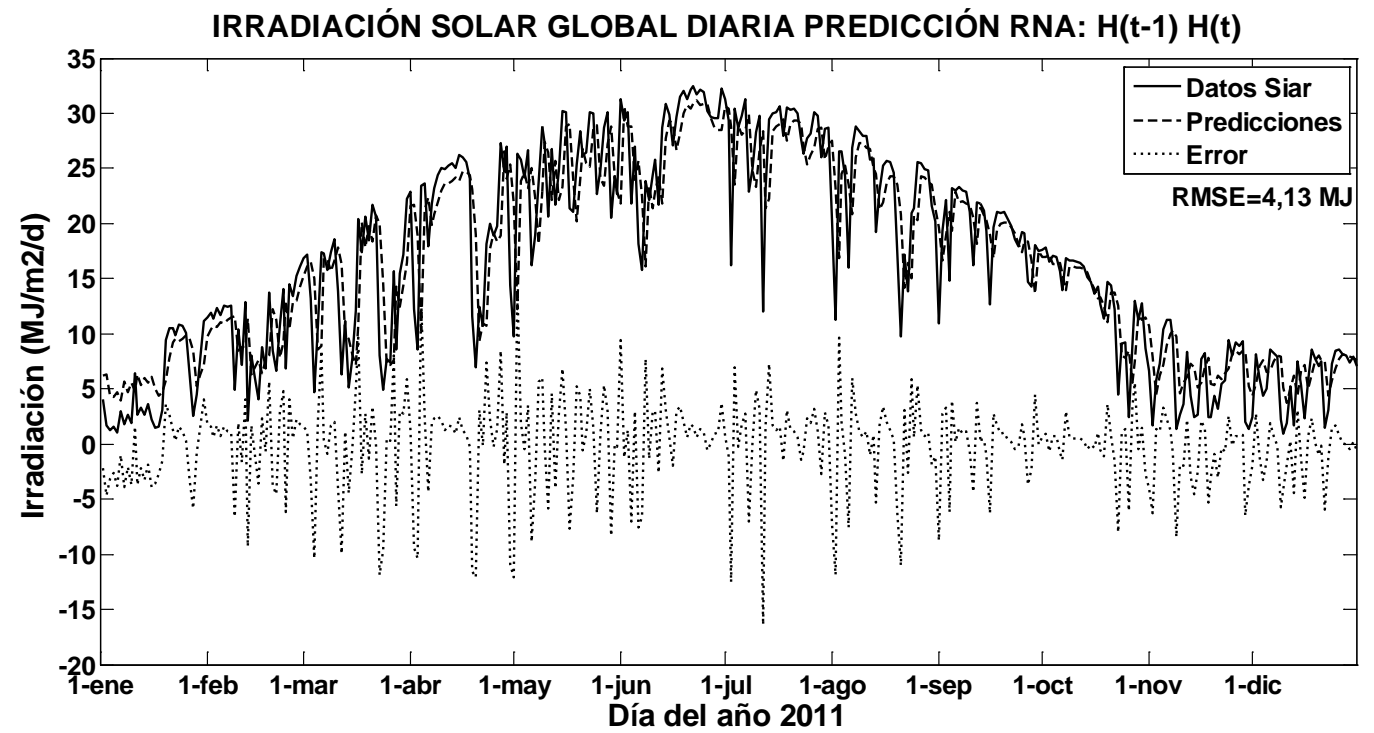

Fig. 4.4.2 Datos de la irradiación solar global diaria SIAR en Mansilla Mayor (León), valores resultado de la predicción realizada con una red neuronal artificial de dos entradas del valor de los días anteriores y el error producido para cada día del año 


\section{3) Resultado de la predicción de la irradiación solar global diaria con tres días de retardo}

Se representa la predicción realizada del modelo (Fig. 3.4.4), con una red neuronal artificial de ocho neuronas en la capa oculta para el año 2011, junto con los datos y el error producido para cada día del año, $\operatorname{RMSE}=4,02 \mathrm{MJ} / \mathrm{m}^{2} / \mathrm{d}$, en la gráfica (Fig. 4.4.3).

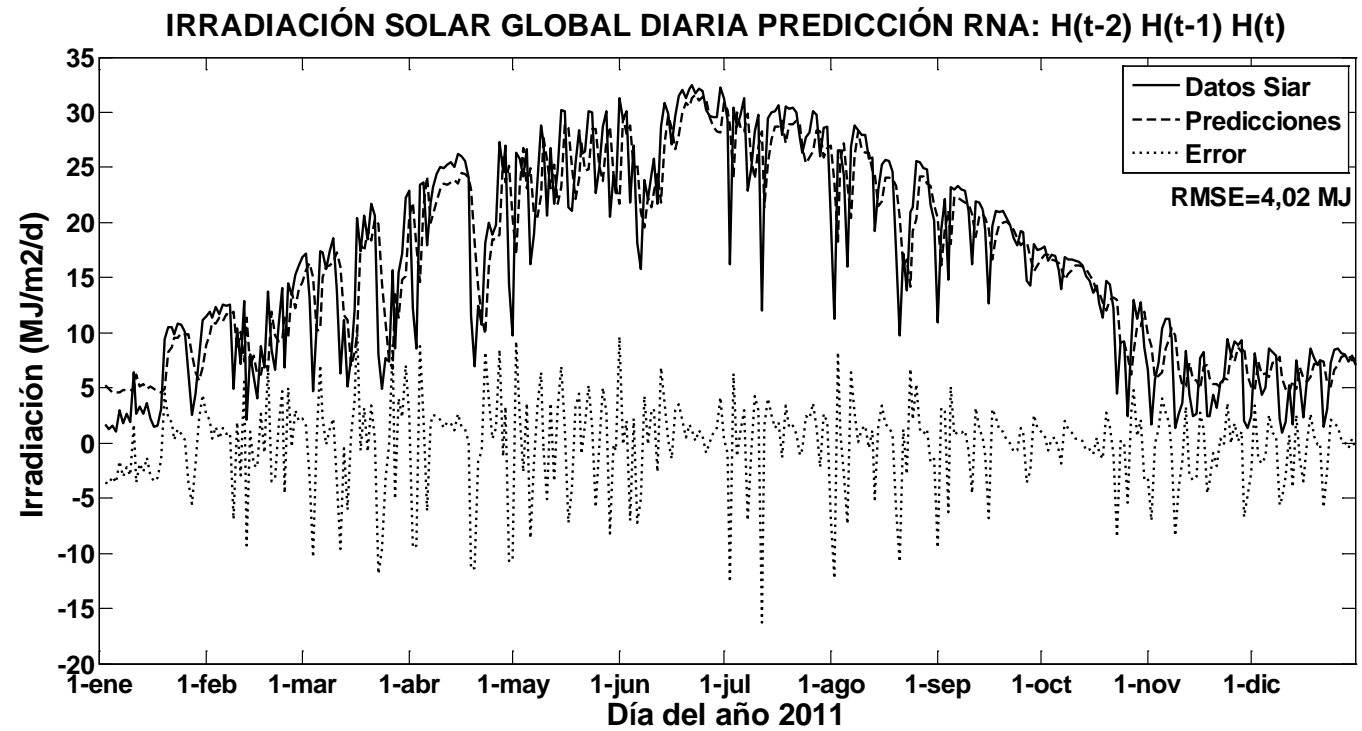

Fig. 4.4.3 Datos de la irradiación solar global diaria SIAR en Mansilla Mayor (León), valores resultado de la predicción realizada con una red neuronal artificial de tres entradas del valor de los días anteriores y el error producido para cada día del año 


\section{Error producido en la predicción de la irradiación solar global diaria del día de mañana con uno, dos y tres días de retardo}

El error producido en la predicción de los modelos (Fig. 3.4.2), (Fig. 3.4.3) y (Fig. 3.4.4), con distintas entradas, se representa con el valor del estadístico RMSE obtenido con todas las redes neuronales artificiales implementadas con distinto número de neuronas ocultas, para predecir la irradiación solar global diaria para el caso de un, dos y tres días de retardo, en la gráfica (Fig. 4.4.4).

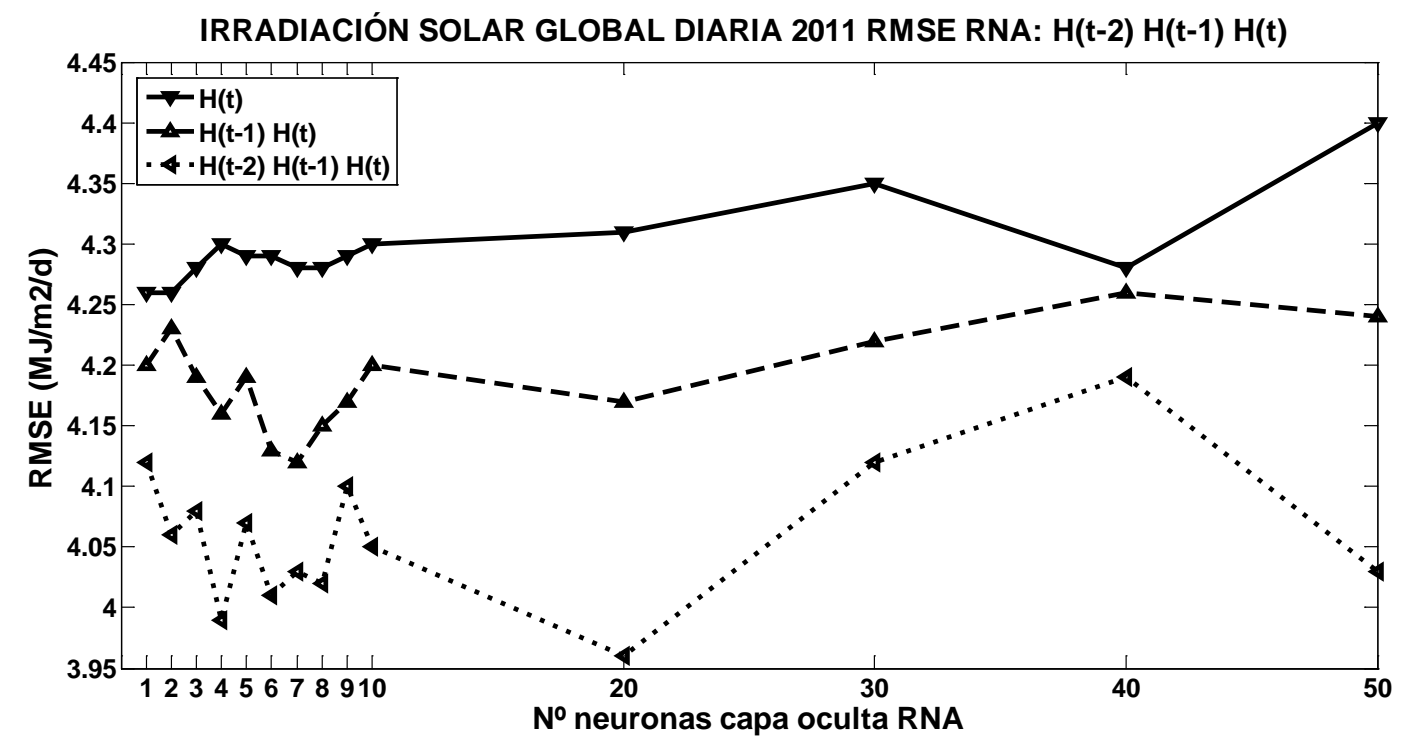

Fig. 4.4.4 RMSE del error producido por las redes neuronales artificiales con una, dos y tres entradas de los días de retardo y con diferente número de neuronas ocultas, en la predicción de la serie de los datos de la irradiación solar global diaria, para el año 2011 SIAR en Mansilla Mayor (León)

Se observa que el rendimiento de los modelos aumenta, al considerar la irradiación solar global diaria de más días de retardo. 


\section{4) Resultado de la predicción de la irradiación solar global diaria con un día de retardo + el día del año}

Se representa la predicción realizada del modelo (Fig. 3.4.5), con una red neuronal artificial de cinco neuronas en la capa oculta para el año 2011, junto con los datos y el error producido para cada día del año, $\operatorname{RMSE}=3,80 \mathrm{MJ} / \mathrm{m}^{2} / \mathrm{d}$, en la gráfica (Fig. 4.4.5).

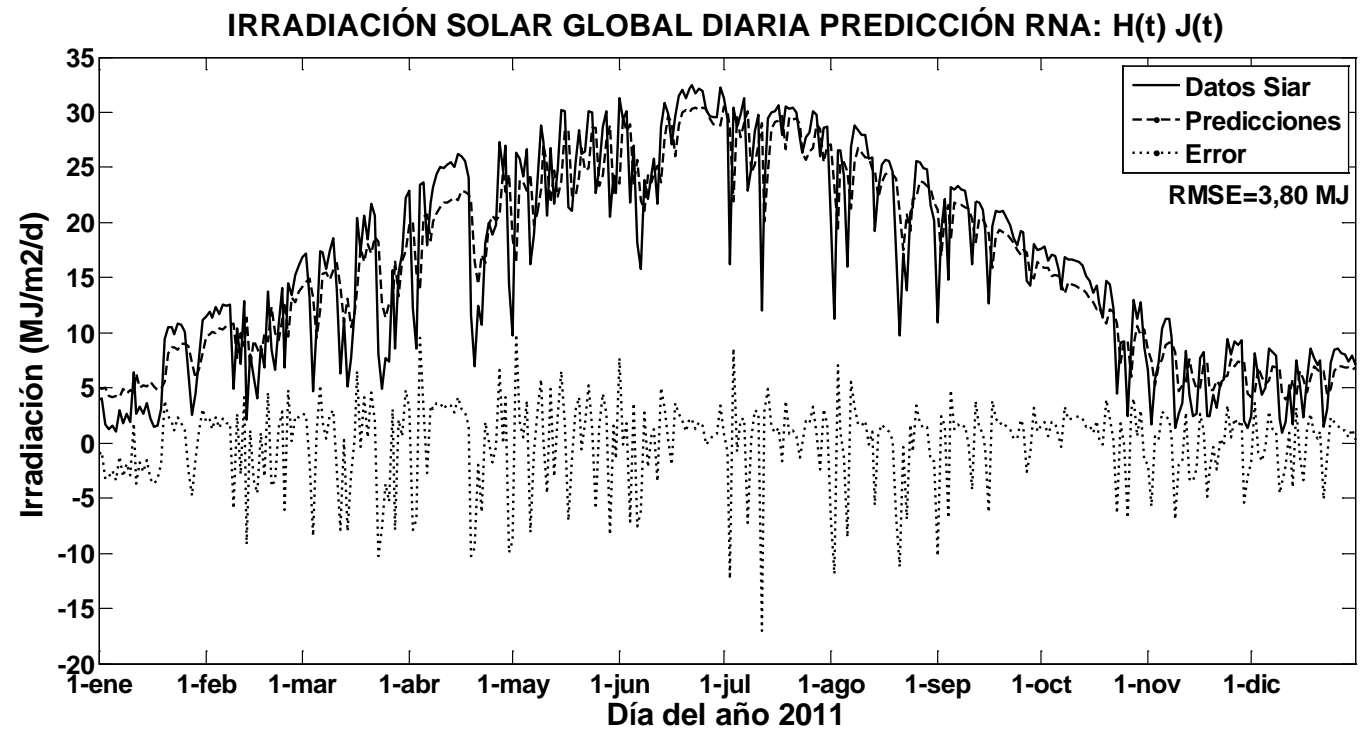

Fig. 4.4.5 Datos de la irradiación solar global diaria SIAR en Mansilla Mayor (León), valores resultado de la predicción realizada con una red neuronal artificial con dos entradas del valor del día anterior $\mathrm{H}(\mathrm{t})$ y J(t), y el error producido para cada día del año 


\section{5) Resultado de la predicción de la irradiación solar global diaria con dos días de retardo + el día del año}

Se representa la predicción realizada del modelo (Fig. 3.4.6), con una red neuronal artificial de 10 neuronas en la capa oculta para el año 2011, junto con los datos y el error producido para cada día del año, $\mathrm{RMSE}=3,85 \mathrm{MJ} / \mathrm{m}^{2} / \mathrm{d}$, en la gráfica (Fig. 4.4.6).

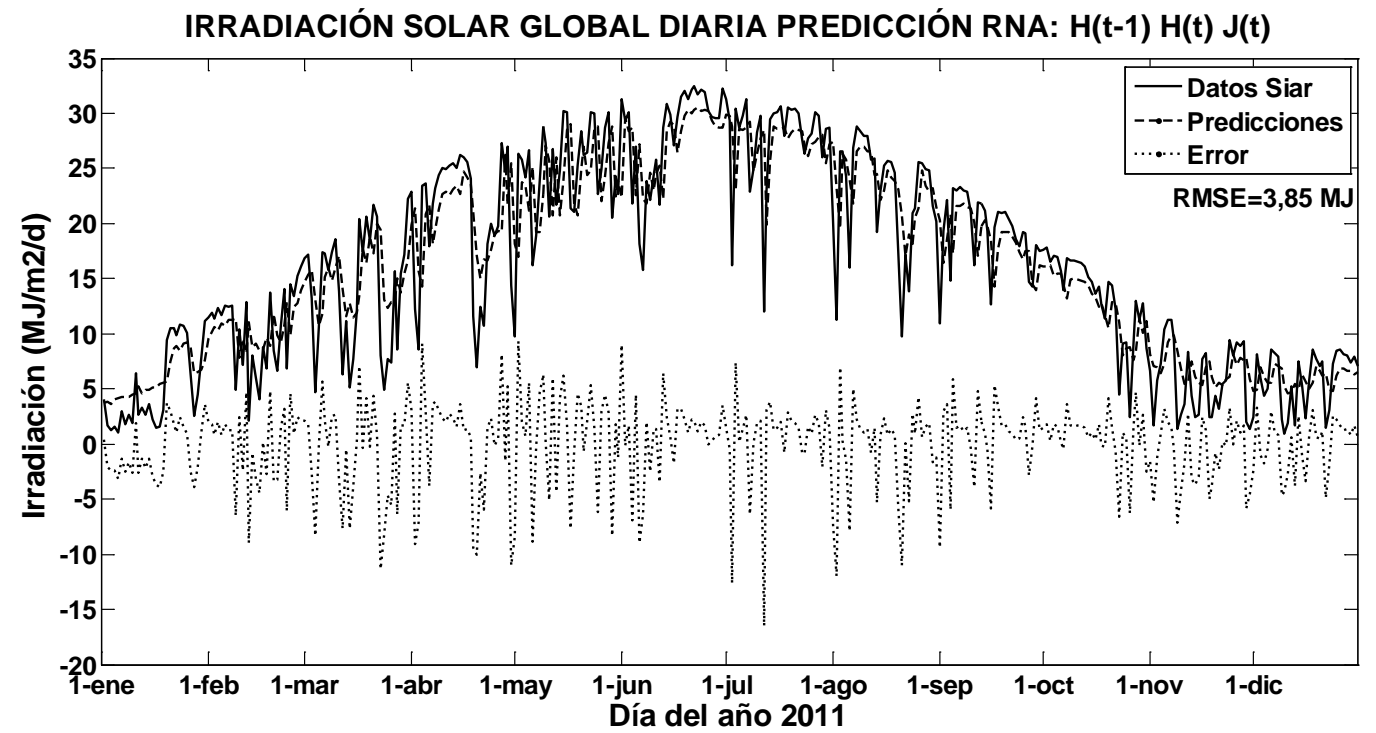

Fig. 4.4.6 Datos de la irradiación solar global diaria SIAR en Mansilla Mayor (León), valores resultado de la predicción realizada con una red neuronal artificial con tres entradas del valor del día anterior $\mathrm{H}(\mathrm{t}-1), \mathrm{H}(\mathrm{t})$ y $\mathrm{J}(\mathrm{t})$, y el error producido para cada día del año 


\section{6) Resultado de la predicción de la irradiación solar global diaria con tres días de retardo + el día del año}

Se representa la predicción realizada del modelo (Fig. 3.4.7), con una red neuronal artificial de siete neuronas en la capa oculta para el año 2011, junto con los datos y el error producido para cada día del año, $\operatorname{RMSE}=3,84 \mathrm{MJ} / \mathrm{m}^{2} / \mathrm{d}$, en la gráfica (Fig. 4.4.7).

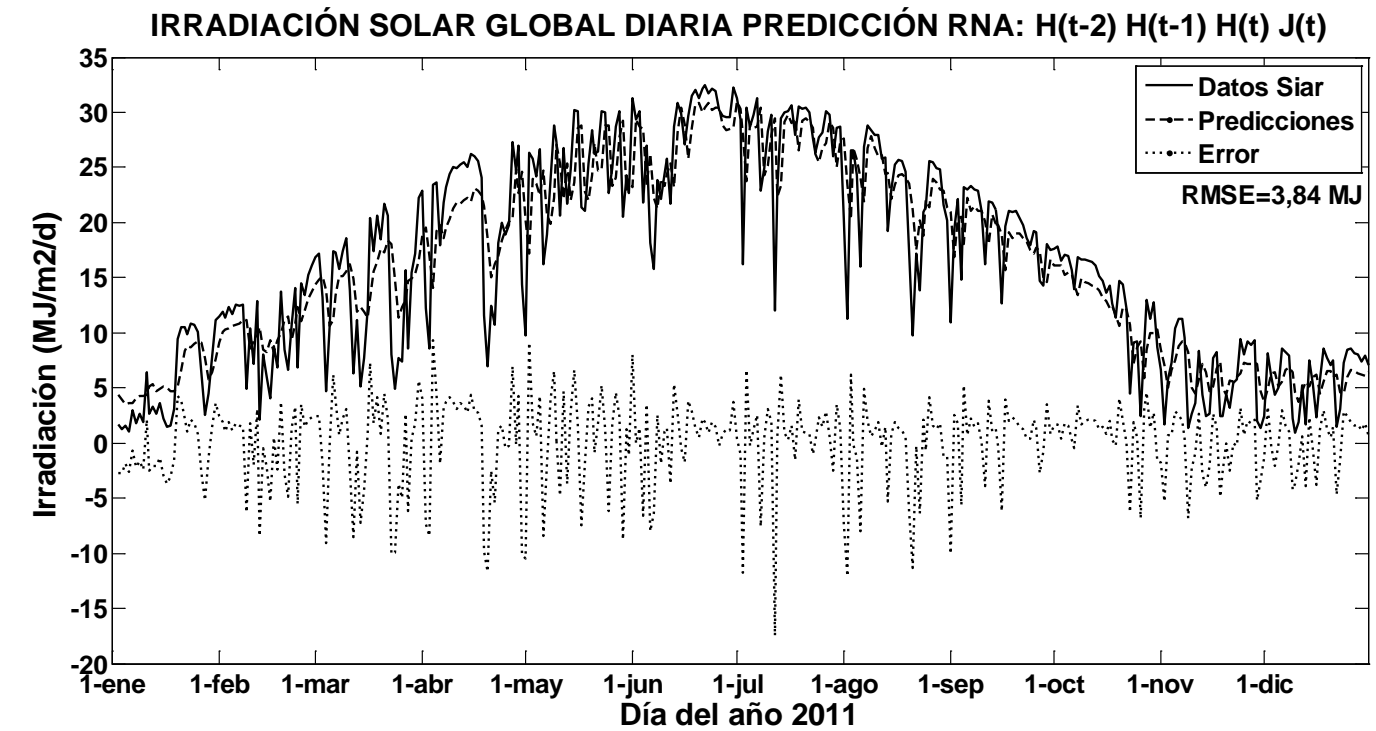

Fig. 4.4.7 Datos de la irradiación solar global diaria SIAR en Mansilla Mayor (León), valores resultado de la predicción realizada con una red neuronal artificial con cuatro entradas del valor del día anterior $\mathrm{H}(\mathrm{t}-2), \mathrm{H}(\mathrm{t}-1), \mathrm{H}(\mathrm{t})$ y $\mathrm{J}(\mathrm{t})$, y el error producido para cada día del año 


\section{Error producido en la predicción de la irradiación solar global diaria del día de mañana con uno, dos y tres días de retardo + el día del año}

El error producido en la predicción de los modelos (Fig. 3.4.5), (Fig. 3.4.6) y (Fig. 3.4.7), con distintas entradas, se representa con el valor del estadístico RMSE obtenido con todas las redes neuronales artificiales implementadas con distinto número de neuronas ocultas, para predecir la irradiación solar global diaria para el caso de uno, dos y tres días de retardo y el día del año en que se realiza la predicción, en la gráfica (Fig. 4.4.8).

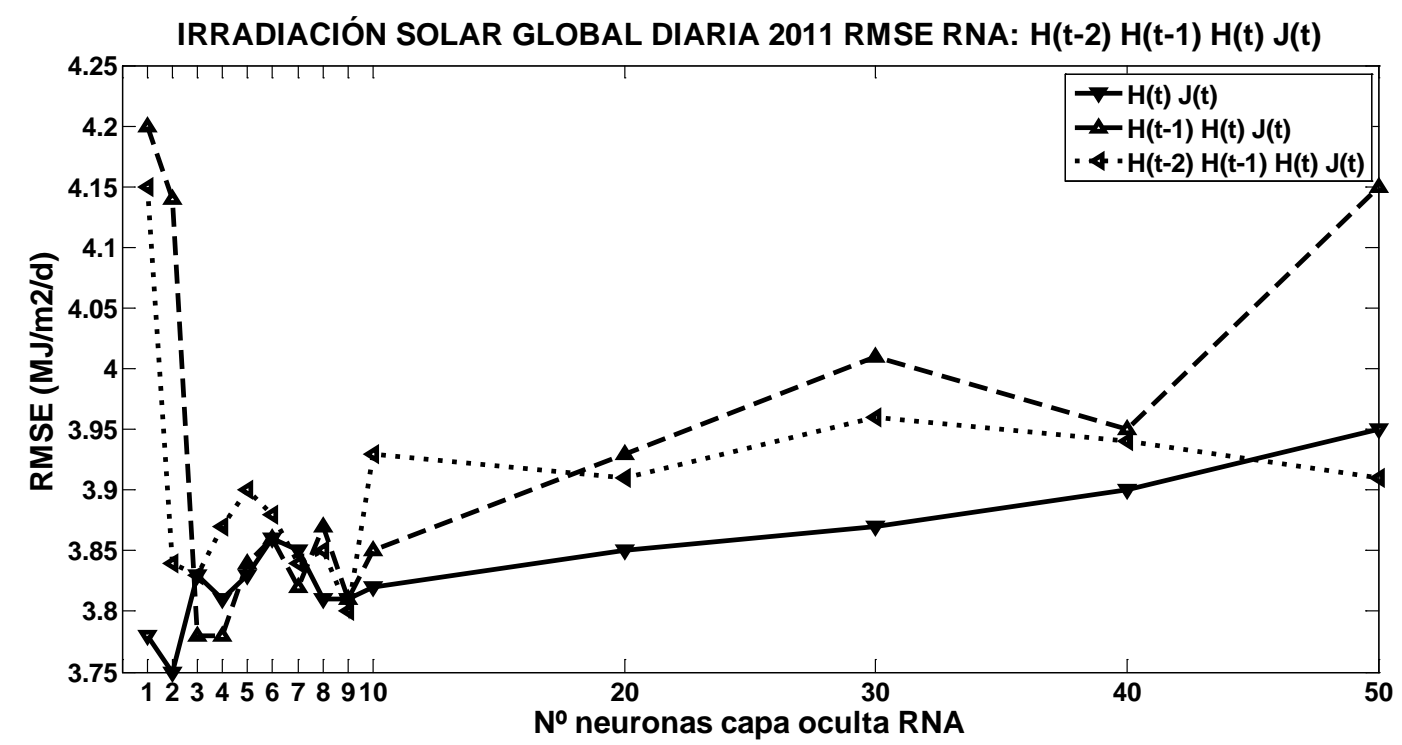

Fig. 4.4.8 RMSE del error producido por las redes neuronales artificiales con una, dos y tres entradas de los días de retardo y el día del año, y con diferente número de neuronas ocultas, en la predicción de la serie de los datos de la irradiación solar global diaria, para el año 2011 SIAR en Mansilla Mayor (León)

Se observa que el rendimiento de los modelos no varía significativamente, al considerar la irradiación solar global diaria de más días de retardo.

También se observa que el utilizar el día del año como predictor mejora el rendimiento del modelo, ya que se introduce un parámetro que indica la época o estación del año en que se realiza la predicción. 


\section{7) Resultado de la predicción de la irradiación solar global diaria con un día de retardo + el índice de claridad}

Se representa la predicción realizada del modelo (Fig. 3.4.8), con una red neuronal artificial de seis neuronas en la capa oculta para el año 2011, junto con los datos y el error producido para cada día del año, $\operatorname{RMSE}=3,77 \mathrm{MJ} / \mathrm{m}^{2} / \mathrm{d}$, en la gráfica (Fig. 4.4.9).

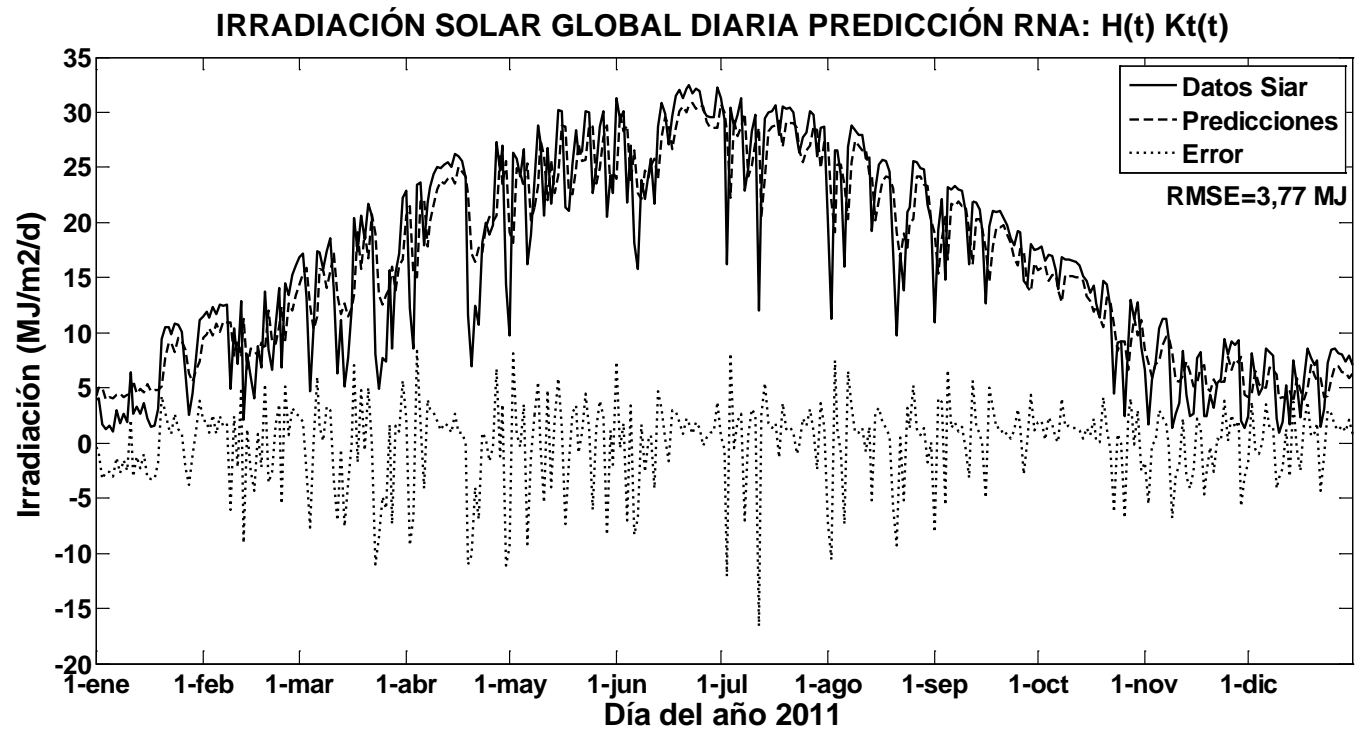

Fig. 4.4.9 Datos de la irradiación solar global diaria SIAR en Mansilla Mayor (León), valores resultado de la predicción realizada con una red neuronal artificial con dos entradas del valor del día anterior $\mathrm{H}(\mathrm{t})$ y $\mathrm{K}_{\mathrm{t}}(\mathrm{t})$, y el error producido para cada día del año 


\section{8) Resultado de la predicción de la irradiación solar global diaria con un día de retardo + el índice de claridad + el día del año}

Se representa la predicción realizada del modelo (Fig. 3.4.9), con una red neuronal artificial de siete neuronas en la capa oculta para el año 2011, junto con los datos y el error producido para cada día del año, $\mathrm{RMSE}=3,80 \mathrm{MJ} / \mathrm{m}^{2} / \mathrm{d}$, en la gráfica (Fig. 4.4.10).

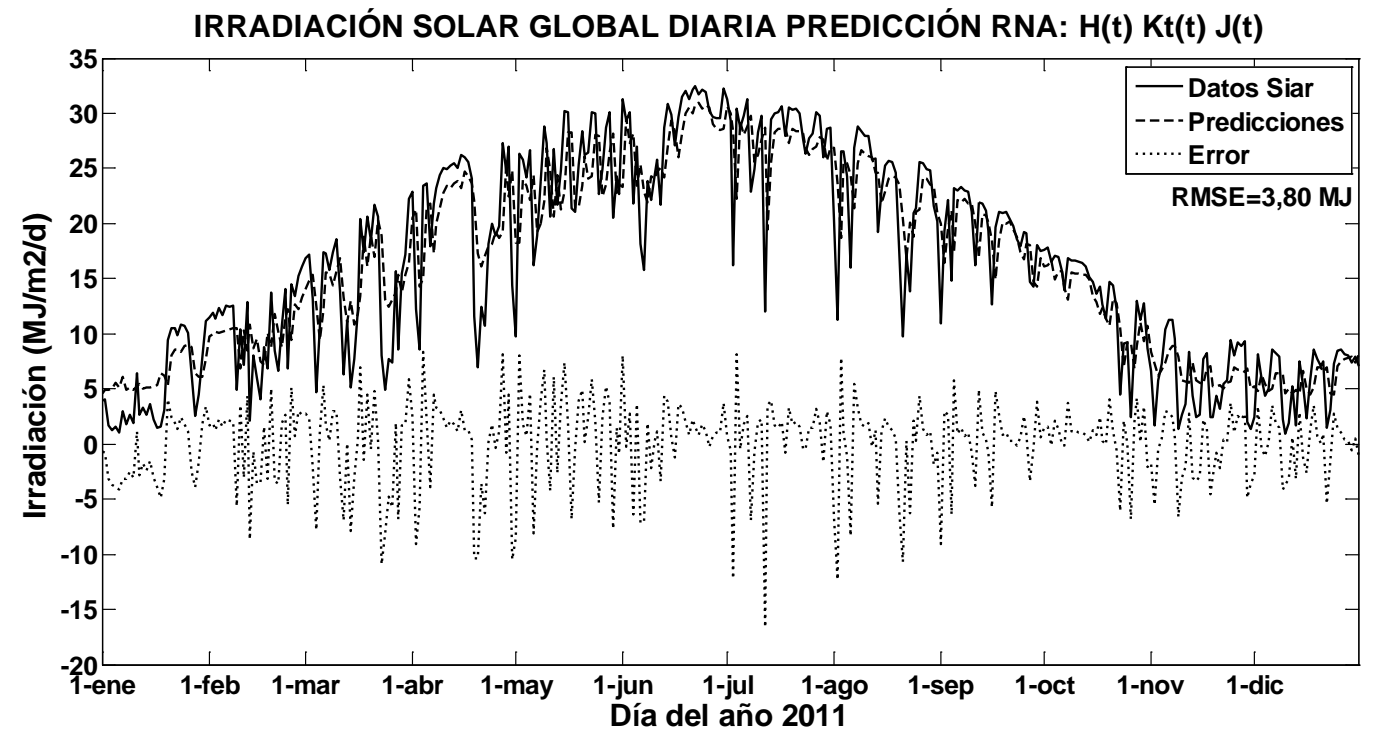

Fig. 4.4.10 Datos de la irradiación solar global diaria SIAR en Mansilla Mayor (León), valores resultado de la predicción realizada con una red neuronal artificial con tres entradas del valor del día anterior $\mathrm{H}(\mathrm{t}), \mathrm{K}_{\mathrm{t}}(\mathrm{t})$ y $\mathrm{J}(\mathrm{t})$, y el error producido para cada día del año 


\section{Error producido en la predicción de la irradiación solar global diaria del día de mañana con un retardo + el índice de claridad y/o el día del año}

El error producido en la predicción de los modelos (Fig. 3.4.8) y (Fig. 3.4.9), con distintas entradas, se representa con el valor del estadístico RMSE obtenido con todas las redes neuronales artificiales implementadas con distinto número de neuronas ocultas, para predecir la irradiación solar global diaria para el caso de un día de retardo, su índice de claridad y/o el día del año en que se realiza la predicción, en la gráfica (Fig. 4.4.11).

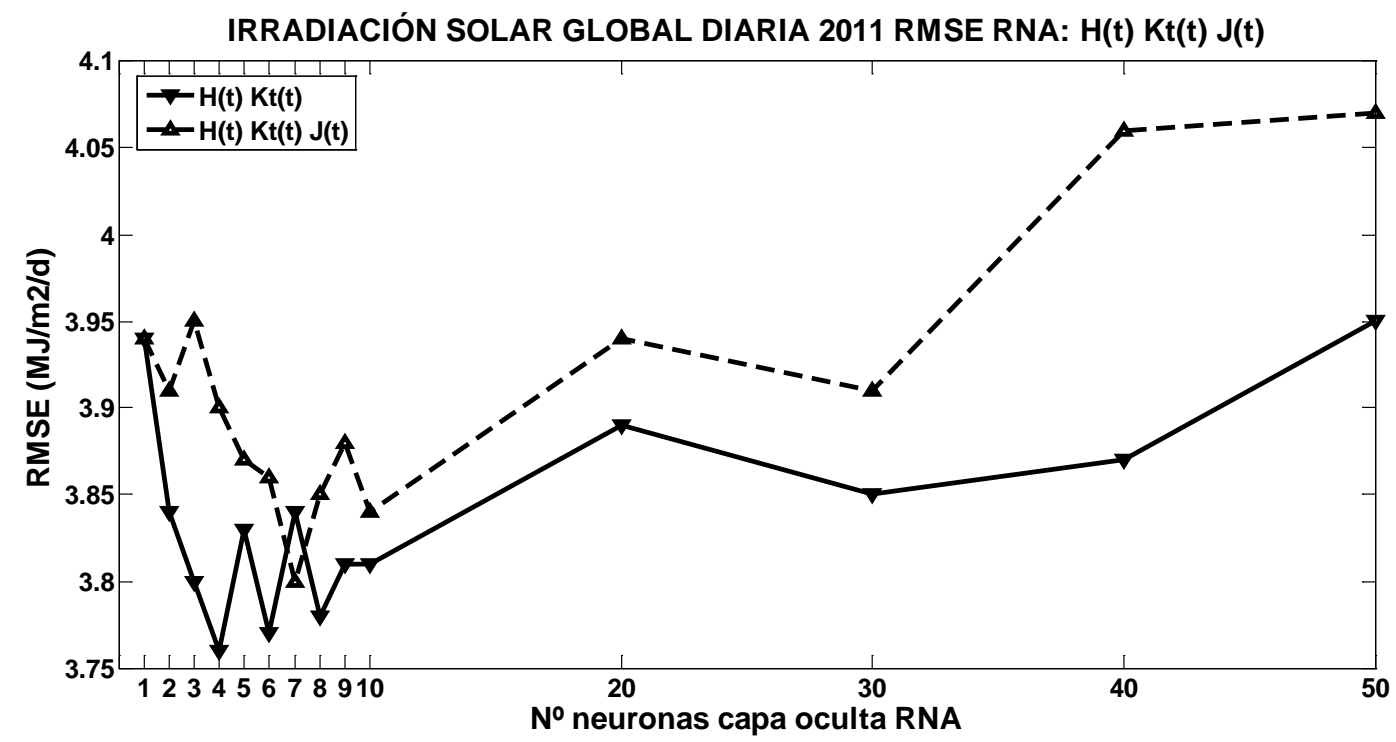

Fig. 4.4.11 RMSE del error producido por las redes neuronales artificiales con dos y tres entradas, para un día de retardo, el índice de claridad y/o el día del año, y con diferente número de neuronas ocultas, en la predicción de la serie de los datos de la irradiación solar global diaria, para el año 2011 SIAR en Mansilla Mayor (León)

Se observa que el rendimiento de los modelos mejora, al considerar su índice de claridad.

También se observa que el utilizar el día del año o el índice de claridad como predictor tiene el mismo peso al valorar el rendimiento del modelo, con lo que se decide por utilizar el día del año al ser un valor más sencillo de utilizar que el índice de claridad y producir rendimientos similares. 


\subsubsection{La predicción de la irradiación solar global diaria del día de mañana a partir de la temperatura ambiente mediante redes neuronales artificiales}

La predicción de la cantidad de irradiación solar global que recibirá la superficie horizontal el día de mañana, se realizó utilizando redes neuronales artificiales, a partir de la temperatura ambiente, al ser esta una variable ambiental que se registra en todas las estaciones meteorológicas.

Se probaron varias combinaciones de entradas hasta encontrar la que resultó con un error menor de las metodologías (Apartado 3.4.2). En las predicciones realizadas se utilizaron los datos del día anterior sobre el que se realiza la predicción, el entrenamiento de la red neuronal artificial se realizó con datos de los años 2004-2010, comparando los resultados de los modelos en la simulación realizada con la base de datos de SIAR en Masilla Mayor (León) del año 2011.

1) La primera combinación realizada de entradas a la red neuronal artificial fue de la temperatura media diaria, del día anterior sobre el que se hace la predicción del valor de la irradiación solar global diaria.

2) La segunda combinación realizada de entradas a la red neuronal artificial fue de las temperaturas máxima y mínima diaria, del día anterior sobre el que se hace la predicción del valor de la irradiación solar global diaria.

3) La tercera combinación realizada de entradas a la red neuronal artificial fue de las temperaturas media, máxima y mínima diaria, del día anterior sobre el que se hace la predicción del valor de la irradiación solar global diaria.

4) La cuarta combinación realizada de entradas a la red neuronal artificial fue de la temperatura media diaria y el día del año, del día anterior sobre el que se hace la predicción del valor de la irradiación solar global diaria.

5) La quinta combinación realizada de entradas a la red neuronal artificial fue de las temperaturas máxima y mínima diaria y el día del año, del día anterior sobre el que se hace la predicción del valor de la irradiación solar global diaria.

6) La sexta combinación realizada de entradas a la red neuronal artificial fue de las temperaturas media, máxima y mínima diaria y el día del año, del día anterior sobre el que se hace la predicción del valor de la irradiación solar global diaria. 


\section{1) Predicción de la irradiación solar global diaria a partir de la temperatura media diaria con un día de retardo}

Se representa la predicción realizada del modelo (Fig. 3.4.10) con una red neuronal artificial de nueve neuronas en la capa oculta para el año 2011, junto con los datos y el error producido para cada día del año, RMSE = 6,13 MJ/m²/d, en la gráfica (Fig. 4.4.12).

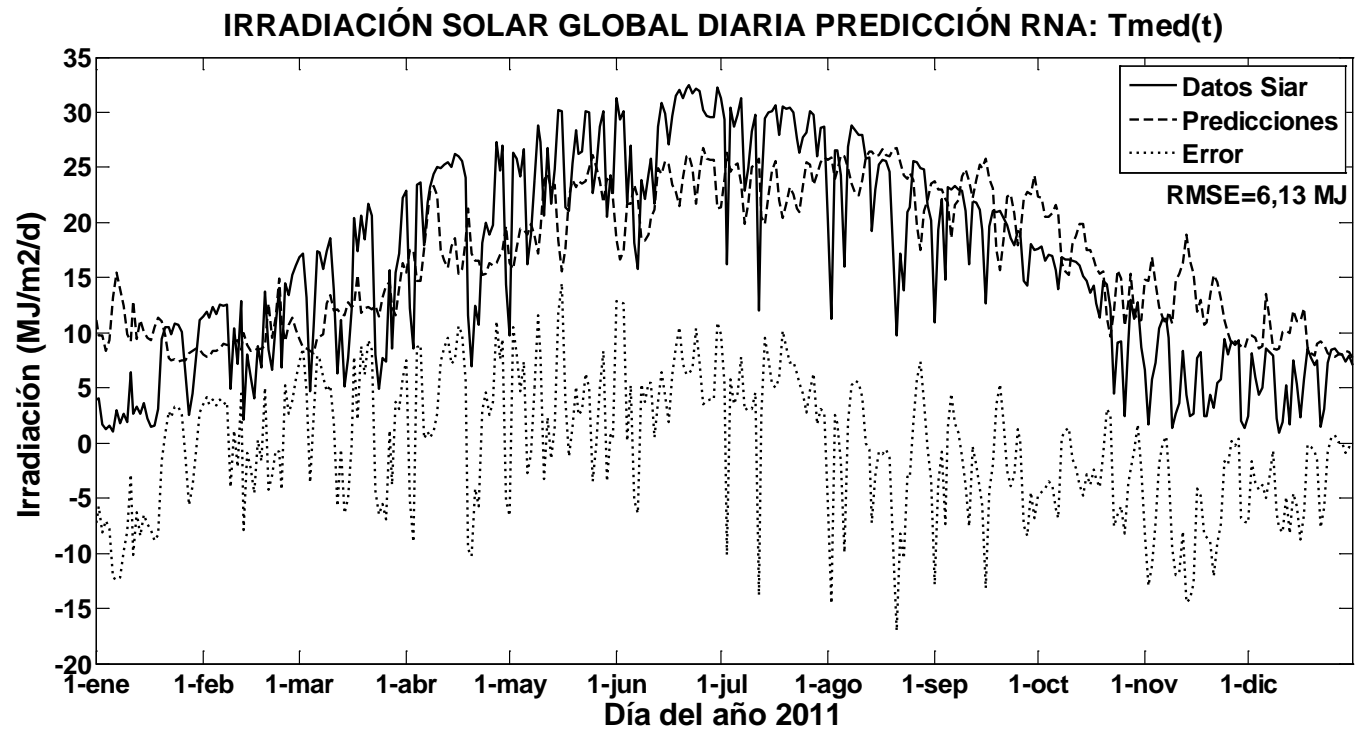

Fig. 4.4.12 Datos de la irradiación solar global diaria SIAR en Mansilla Mayor (León), valores resultado de la predicción realizada con una red neuronal artificial con una entrada del valor del día anterior de temperatura media diaria y el error producido para cada día del año 


\section{2) Predicción de la irradiación solar global diaria a partir de la temperatura máxima y mínima diaria con un día de retardo}

Se representa la predicción realizada del modelo (Fig. 3.4.11) con una red neuronal artificial de ocho neuronas en la capa oculta para el año 2011, junto con los datos y el error producido para cada día del año, $\mathrm{RMSE}=5,68 \mathrm{MJ} / \mathrm{m}^{2} / \mathrm{d}$, en la gráfica (Fig. 4.4.13).

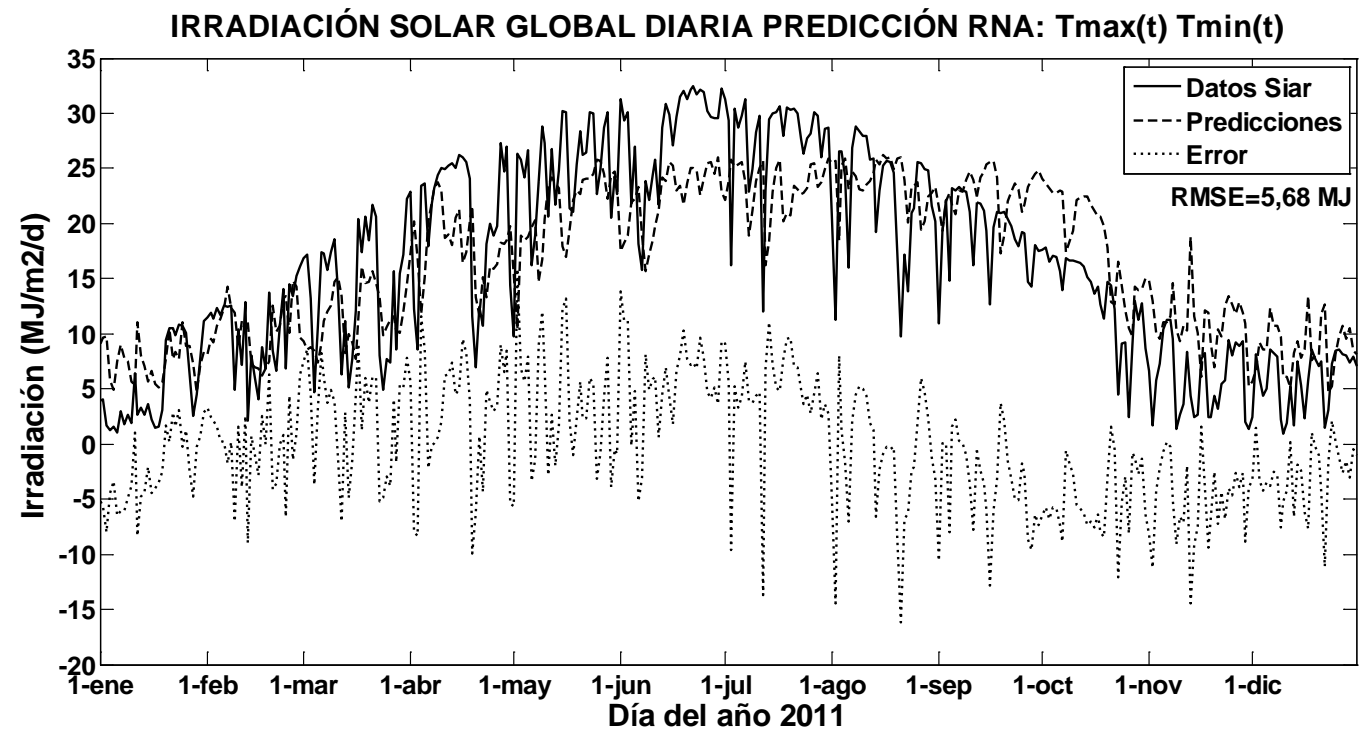

Fig. 4.4.13 Datos de la irradiación solar global diaria SIAR en Mansilla Mayor (León), valores resultado de la predicción realizada con una red neuronal artificial con dos entradas del valor del día anterior $\operatorname{Tmax}(\mathrm{t})$ y $\operatorname{Tm} \min (\mathrm{t})$, y el error producido para cada día del año 


\section{3) Predicción de la irradiación solar global diaria a partir de la temperatura media, máxima y mínima diaria con un día de retardo}

Se representa la predicción realizada del modelo (Fig. 3.4.12) con una red neuronal artificial de ocho neuronas en la capa oculta para el año 2011, junto con los datos y el error producido para cada día del año, RMSE = 5,40 MJ/m²/d, en la gráfica (Fig. 4.4.14).

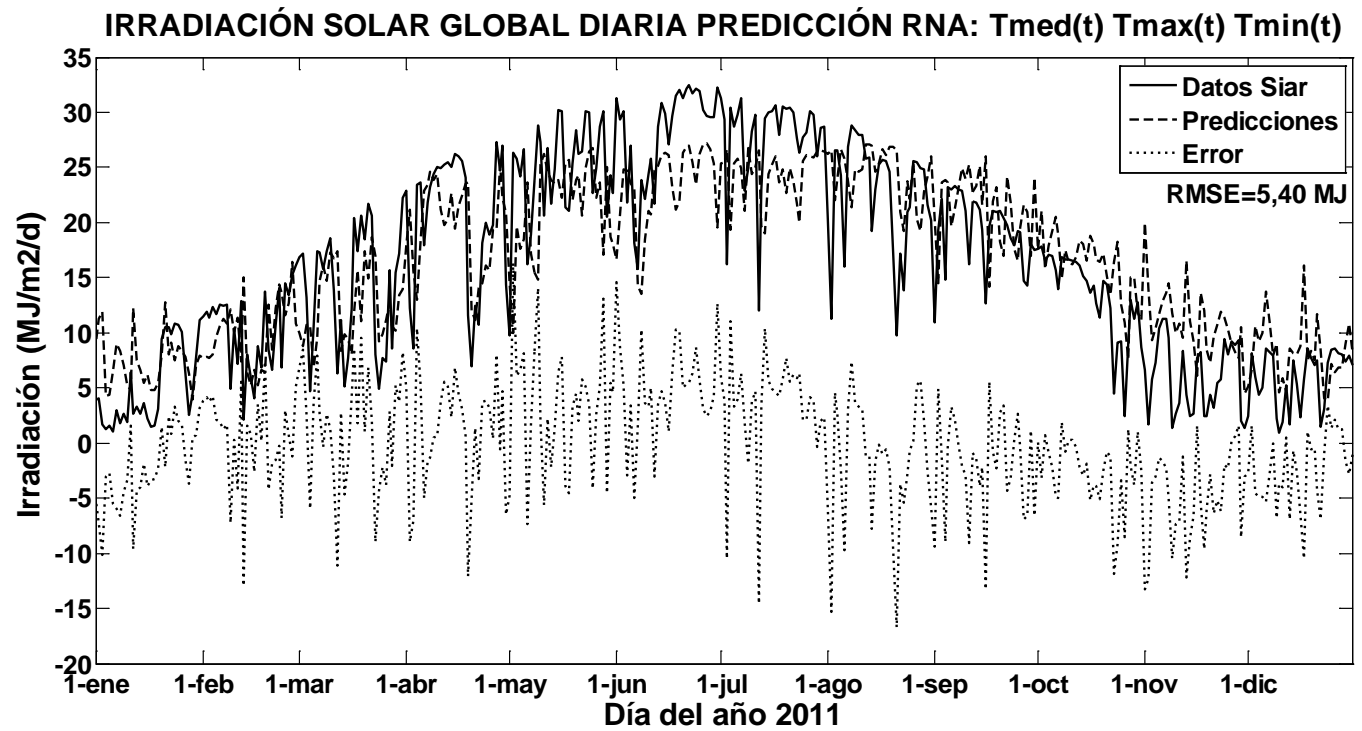

Fig. 4.4.14 Datos de la irradiación solar global diaria SIAR en Mansilla Mayor (León), valores resultado de la predicción realizada con una red neuronal artificial con tres entradas del valor del día anterior $\operatorname{Tmed}(\mathrm{t}), \operatorname{Tmax}(\mathrm{t})$ y $\operatorname{Tmin}(\mathrm{t})$, y el error producido para cada día del año 


\section{4) Predicción de la irradiación solar global diaria a partir de la temperatura media diaria con un día de retardo + el día del año}

Se representa la predicción realizada del modelo (Fig. 3.4.13) con una red neuronal artificial de siete neuronas en la capa oculta para el año 2011, junto con los datos y el error producido para cada día del año, $\mathrm{RMSE}=4,28 \mathrm{MJ} / \mathrm{m}^{2} / \mathrm{d}$, en la gráfica (Fig. 4.4.15).

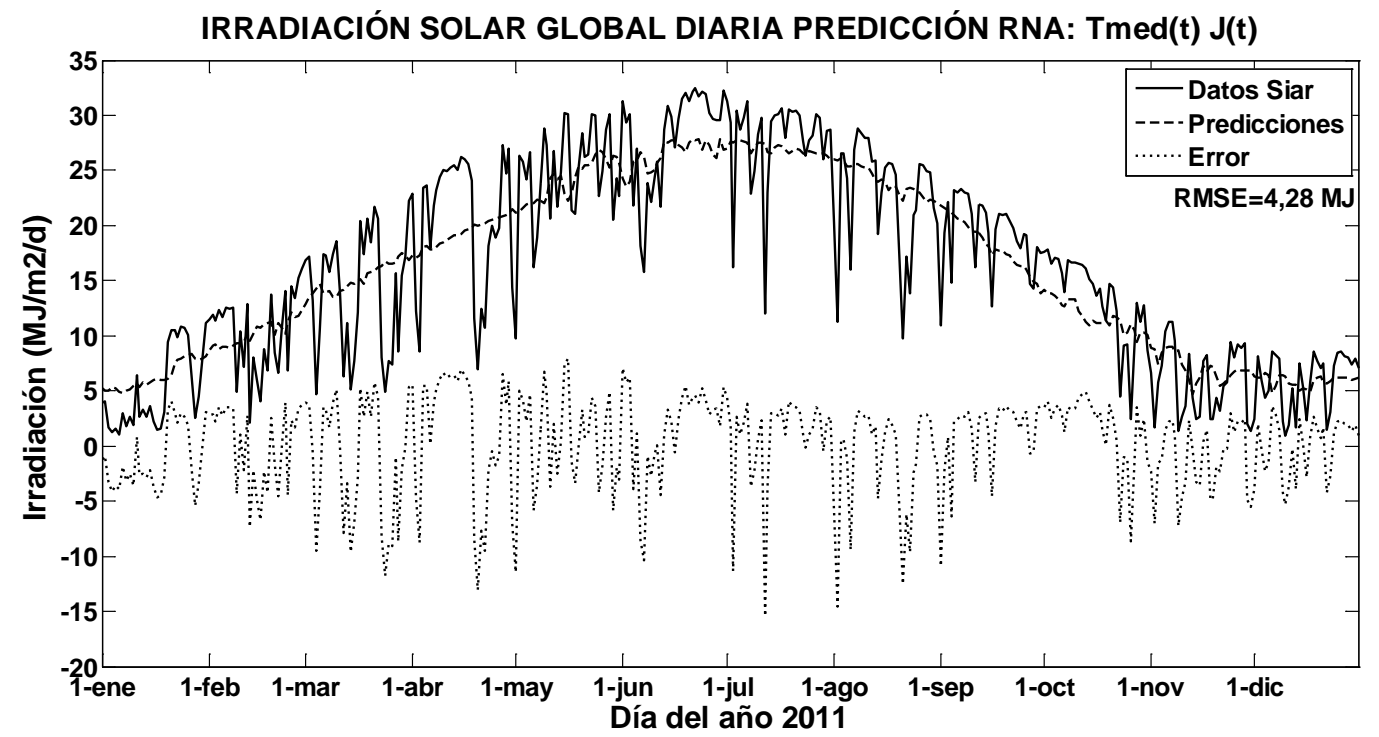

Fig. 4.4.15 Datos de la irradiación solar global diaria en SIAR Mansilla Mayor (León), valores resultado de la predicción realizada con una red neuronal artificial con dos entradas del valor del día anterior $\operatorname{Tmed}(\mathrm{t})$ y J(t), y el error producido para cada día del año 


\section{5) Predicción de la irradiación solar global diaria a partir de la temperatura máxima y mínima diaria con un día de retardo + el día del año}

Se representa la predicción realizada del modelo (Fig. 3.4.14) con una red neuronal artificial de 10 neuronas en la capa oculta para el año 2011, junto con los datos y el error producido para cada día del año, RMSE = 3,92 MJ/m²/d, en la gráfica (Fig. 4.4.16).

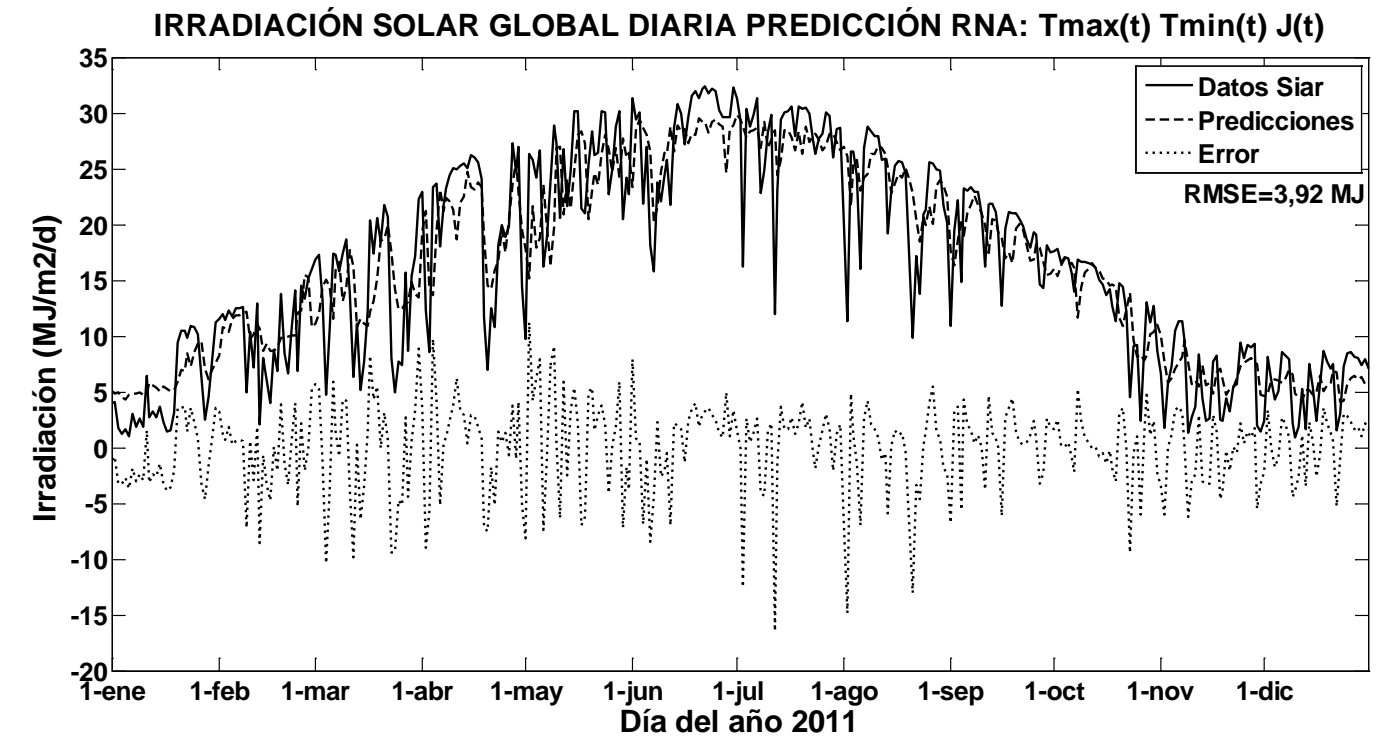

Fig. 4.4.16 Datos de la irradiación solar global diaria SIAR en Mansilla Mayor (León), valores resultado de la predicción realizada con una red neuronal artificial con tres entradas del valor del día anterior $\operatorname{Tmax}(\mathrm{t}), \operatorname{Tm} \operatorname{in}(\mathrm{t})$ y J(t), y el error producido para cada día del año 


\section{6) Predicción de la irradiación solar global diaria a partir de la temperatura media, máxima y mínima diaria con un día de retardo + el día del año}

Se representa la predicción realizada del modelo (Fig. 3.4.15) con una red neuronal artificial de seis neuronas en la capa oculta para el año 2011, junto con los datos y el error producido para cada día del año, $\mathrm{RMSE}=3,84 \mathrm{MJ} / \mathrm{m}^{2} / \mathrm{d}$, en la gráfica (Fig. 4.4.17).

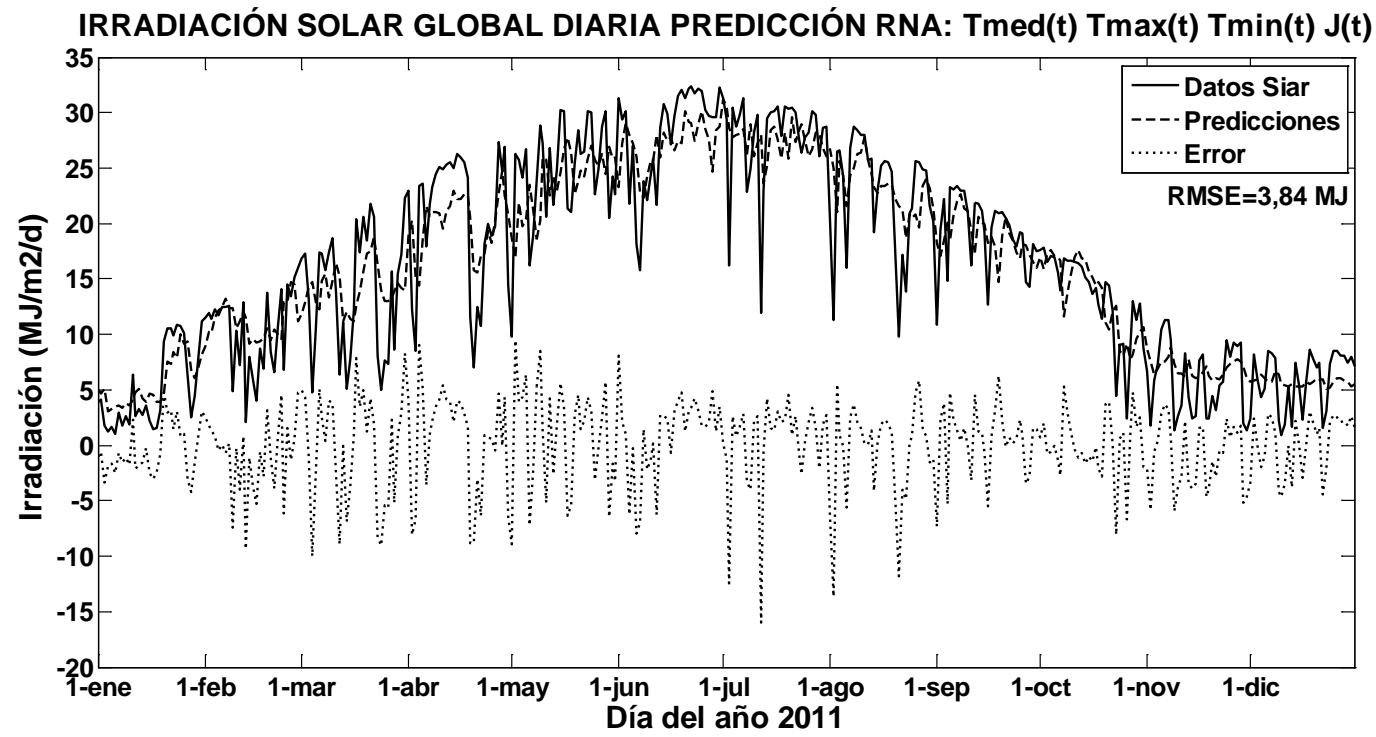

Fig. 4.4.17 Datos de la irradiación solar global diaria SIAR en Mansilla Mayor (León), valores resultado de la predicción realizada con una red neuronal artificial con cuatro entradas del valor del día anterior $\operatorname{Tmed}(\mathrm{t})$, $\operatorname{Tmax}(\mathrm{t}), \operatorname{Tm} \min (\mathrm{t})$ y J(t), y el error producido para cada día del año 


\subsubsection{La predicción de las temperaturas media, máxima y mínima diaria del día de mañana mediante redes neuronales artificiales}

La predicción de la temperatura ambiente del día de mañana, se realizó utilizando redes neuronales artificiales, a partir de la temperatura ambiente del día anterior respecto del que se realiza la predicción.

Se probaron dos combinaciones de entradas con las metodologías (Apartado 3.4.3). En las predicciones realizadas se utilizaron los datos del día anterior sobre el que se realiza la predicción, el entrenamiento de la red neuronal artificial se realizó con datos de los años 2004-2010, comparando los resultados de los modelos en la simulación realizada con la base de datos de SIAR en Masilla Mayor (León) del año 2011.

1) La primera combinación de entradas a la red neuronal artificial fue de las temperaturas media, máxima y mínima diaria del día anterior sobre el que se hace la predicción del valor de las temperaturas media, máxima y mínima.

2) La segunda combinación de entradas a la red neuronal artificial fue de las temperaturas media, máxima y mínima y el día del año anterior sobre el que se hace la predicción del valor de las temperaturas media, máxima y mínima. 


\section{1) Predicción de las temperaturas media, máxima y mínima diaria con un día de retardo}

Se representa el valor RMSE obtenido con todas las redes neuronales artificiales probadas con distinto número de neuronas en la capa oculta realizada del modelo (Fig. 3.4.16), para predecir la temperatura media, máxima y mínima diaria para el caso de un día de retardo, en la gráfica (Fig. 4.4.18).

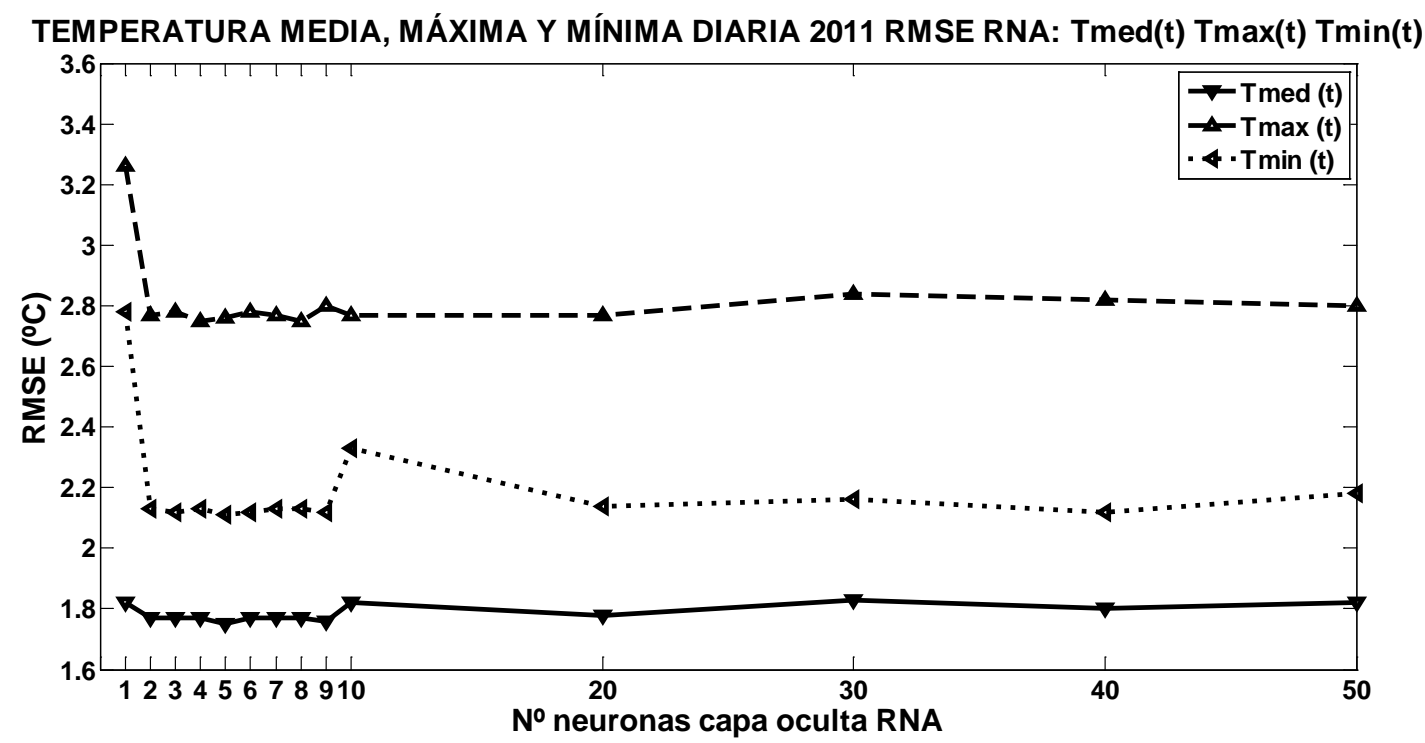

Fig. 4.4.18 RMSE del error producido por las redes neuronales artificiales con tres entradas, para un día de retardo y con diferente número de neuronas ocultas, en la predicción de la serie de datos de las temperaturas media, máxima y mínima diaria, para el año 2011 SIAR en Mansilla Mayor (León)

Se observa que el error de la predicción es mucho menor para la temperatura media diaria con un RMSE $=1,8{ }^{\circ} \mathrm{C}$, que para la temperatura mínima diaria que se obtiene un RMSE $=2,2^{\circ} \mathrm{C}$ y para la temperatura máxima diaria que se consigue un $\mathrm{RMSE}=2,8^{\circ} \mathrm{C}$. 


\section{2) Predicción de las temperaturas media, máxima y mínima diaria con un día de retardo + el día del año}

Se representa el valor RMSE obtenido con todas las redes neuronales artificiales probadas con distinto número de neuronas en la capa oculta realizada del modelo (Fig. 3.4.17), para predecir la temperatura media, máxima y mínima diaria para el caso de un día de retardo y el día del año en que se realiza la predicción, en la gráfica (Fig. 4.4.19).

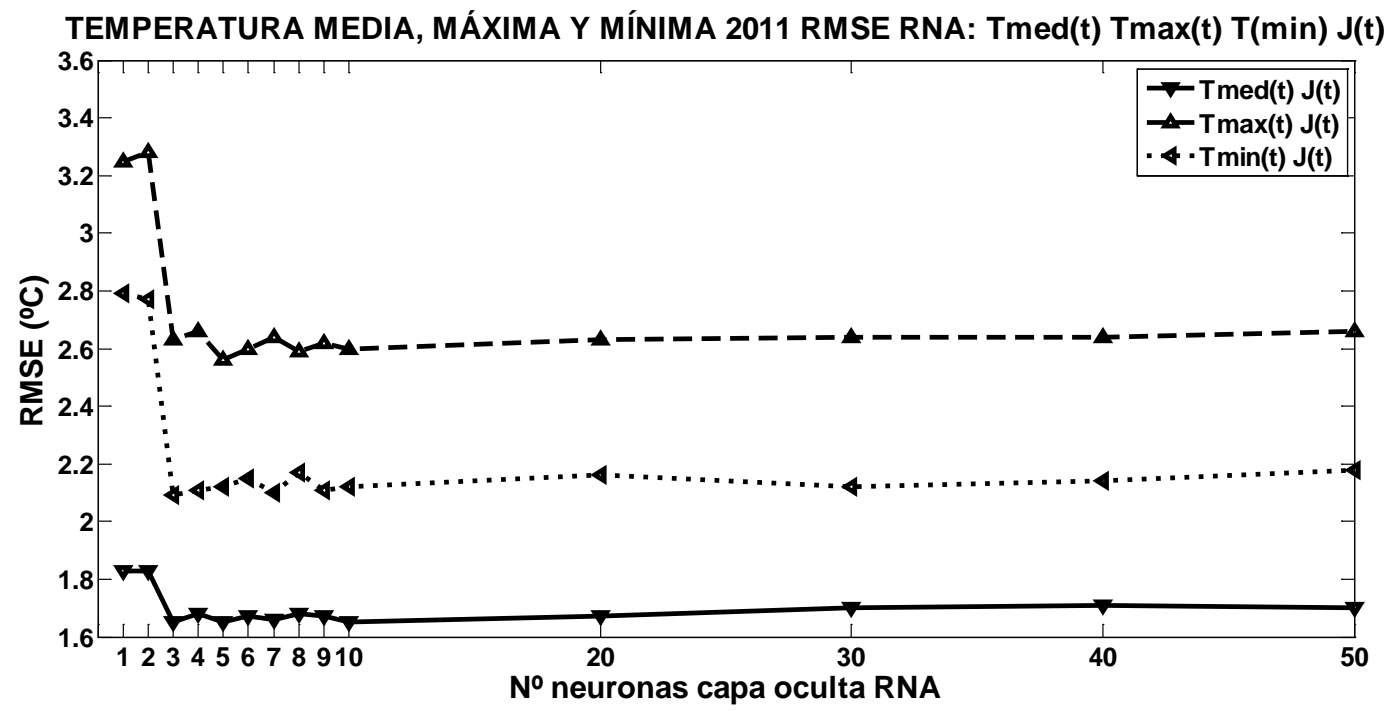

Fig. 4.4.19 RMSE del error producido por las redes neuronales artificiales con cuatro entradas, para un día de retardo y el día del año y con diferente número de neuronas ocultas, en la predicción de la serie de datos de las temperaturas media, máxima y mínima diaria, para el año 2011 SIAR en Mansilla Mayor (León)

Se observa que el error de la predicción es ligeramente inferior cuando se añade la entrada del día del año para las tres temperaturas, siendo mucho menor para la temperatura media diaria con un RMSE = $1,7^{\circ} \mathrm{C}$, que para la temperatura mínima diaria que se obtiene un $\mathrm{RMSE}=2,1^{\circ} \mathrm{C}$ y para la temperatura máxima diaria que se consigue un $\mathrm{RMSE}=2,6^{\circ} \mathrm{C}$. 


\subsubsection{Resultado de la estimación de la irradiancia solar horaria media a partir de la irradiación solar global diaria mediante redes neuronales artificiales}

La estimación de la irradiancia solar horaria media en el mismo día, se realizó utilizando redes neuronales artificiales, a partir de la irradiación solar global diaria del mismo día respecto del que se realiza la estimación.

Se probaron dos combinaciones de entradas con las dos metodologías (Apartado 3.4.4). En las estimaciones se utilizaron los datos del mismo día sobre el que se hace la estimación, el entrenamiento de la red neuronal artificial se realizó con datos de los años 2004-2010, comparando los resultados de los modelos en la simulación realizada con la base de datos de SIAR en Mansilla Mayor (León) del año 2011.

1) La primera combinación de entradas a la red neuronal artificial fue de la irradiación solar global diaria del mismo día sobre el que se hace la estimación del valor de la irradiancia solar horaria media.

2) La segunda combinación de entradas a la red neuronal artificial fue de la irradiación solar global diaria y el día del año del mismo día sobre el que se hace la estimación del valor de la irradiancia solar horaria media. 


\section{1) Estimación de la irradiancia solar horaria con la irradiación solar global diaria}

Se representa la irradiancia solar horaria durante una semana de la estimación realizada con el modelo (Fig. 3.4.18), con una red neuronal artificial de 40 neuronas en la capa oculta para el año 2011, junto con los datos, en la gráfica (Fig. 4.4.20), de los resultados de todos los valores horarios del año resulta un $\mathrm{RMSE}=87 \mathrm{~W} / \mathrm{m}^{2} / \mathrm{h}$.

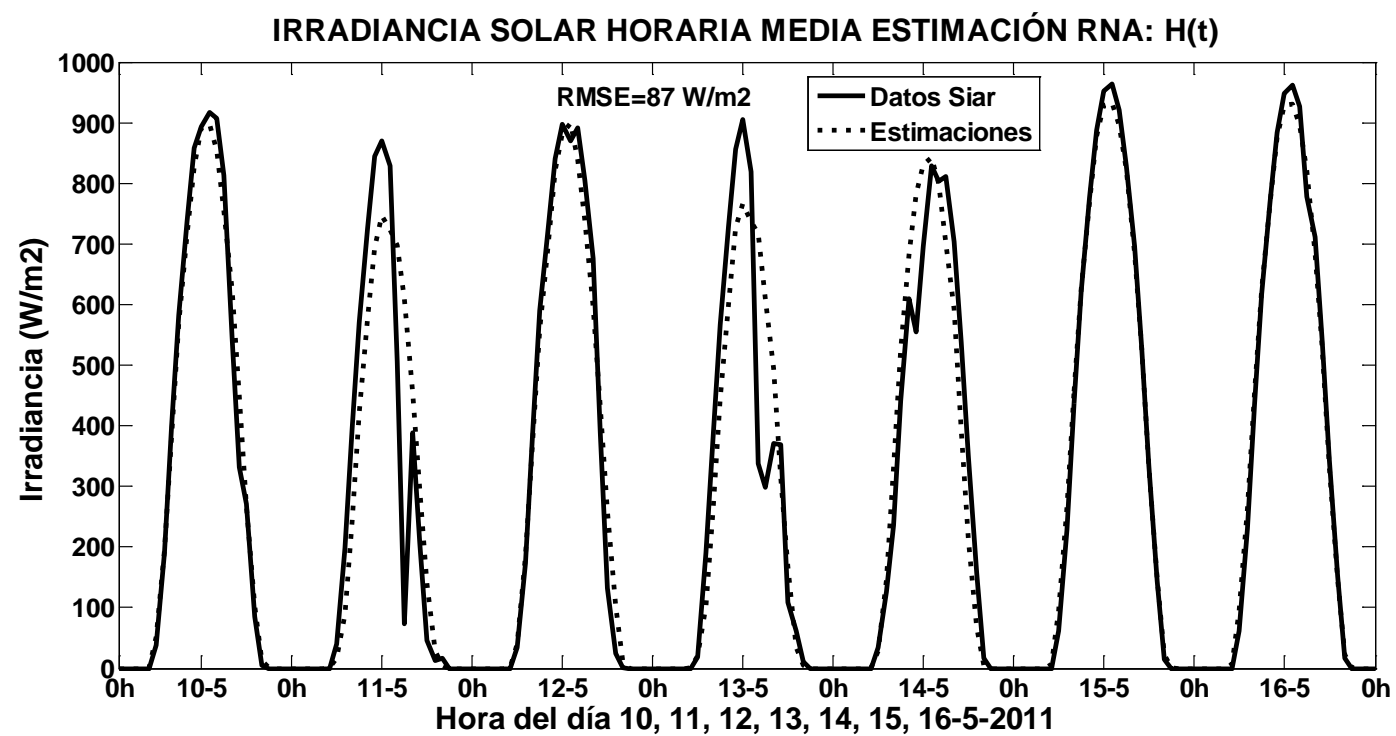

Fig. 4.4.20 Datos de la irradiancia solar horaria SIAR en Mansilla Mayor (León) y valores resultado de la estimación realizada con una red neuronal artificial con una entrada del valor de la irradiación solar global del mismo día 


\section{2) Resultado de la estimación de la irradiancia solar horaria con la irradiación solar global diaria + el día del año}

Se representa la irradiancia solar horaria durante una semana de la estimación realizada con el modelo (Fig. 3.4.19), con una red neuronal artificial de 34 neuronas en la capa oculta para el año 2011, junto con los datos, en la gráfica (Fig. 4.4.21), de los resultados de todos los valores horarios del año resulta un RMSE $=51 \mathrm{~W} / \mathrm{m}^{2} / \mathrm{h}$.

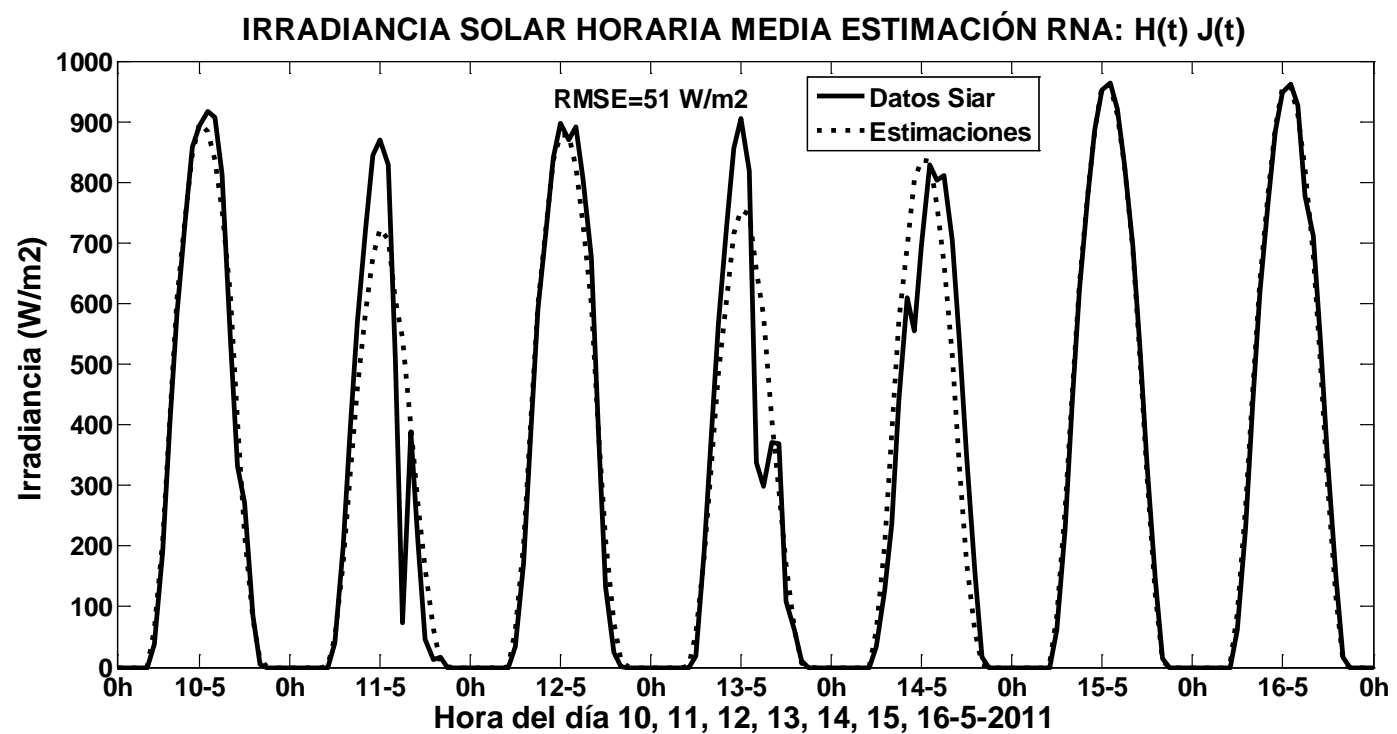

Fig. 4.4.21 Datos de la irradiancia solar horaria SIAR en Mansilla Mayor (León) y valores resultado de la estimación realizada con una red neuronal artificial con dos entradas del valor de la irradiación solar global y el día del año del mismo día 


\subsubsection{Resultados de la estimación de la temperatura media horaria a partir de las temperaturas media, máxima y mínima mediante redes neuronales artificiales}

Los resultados de la metodología para la estimación de la temperatura media horaria mediante redes neuronales artificiales, a partir de los datos de las temperaturas media, máxima y mínima diaria, se realizó con la metodología (Apartado 3.4.5), y se validan con los datos del año 2011 de la red SIAR en la estación de Mansilla Mayor (León), gráficamente y con el valor del estadístico RMSE.

La estimación de la temperatura media horaria en el mismo día, se realizó utilizando redes neuronales artificiales, a partir de la temperatura media, máxima y mínima diaria del mismo día respecto del que se realiza la estimación.

Se probaron dos combinaciones de entradas con las dos metodologías (Apartado 3.4.5). En las estimaciones se utilizaron los datos del mismo día sobre el que se hace la estimación, el entrenamiento de la red neuronal artificial se realizó con datos de los años 2004-2010, comparando los resultados de los modelos en la simulación realizada con la base de datos de SIAR en Mansilla Mayor (León) del año 2011.

1) La primera combinación de entradas a la red neuronal artificial fue de la temperatura media, máxima y mínima diaria del mismo día sobre el que se hace la estimación del valor de la temperatura media horaria.

2) La segunda combinación de entradas a la red neuronal artificial fue de la temperatura media, máxima y mínima diaria y el día del año del mismo día sobre el que se hace la estimación del valor de la temperatura media horaria. 


\section{1) Resultados de la estimación de la temperatura media horaria con las temperaturas media, máxima y mínima diaria}

Se representa la temperatura media horaria durante una semana de la estimación realizada con el modelo (Fig. 3.4.20), con una red neuronal artificial de 28 neuronas en la capa oculta para el año 2011, junto con los datos, en la gráfica (Fig. 4.4.22), de los resultados de todos los valores horarios del año resulta un $\mathrm{RMSE}=1,27^{\circ} \mathrm{C} / \mathrm{h}$.

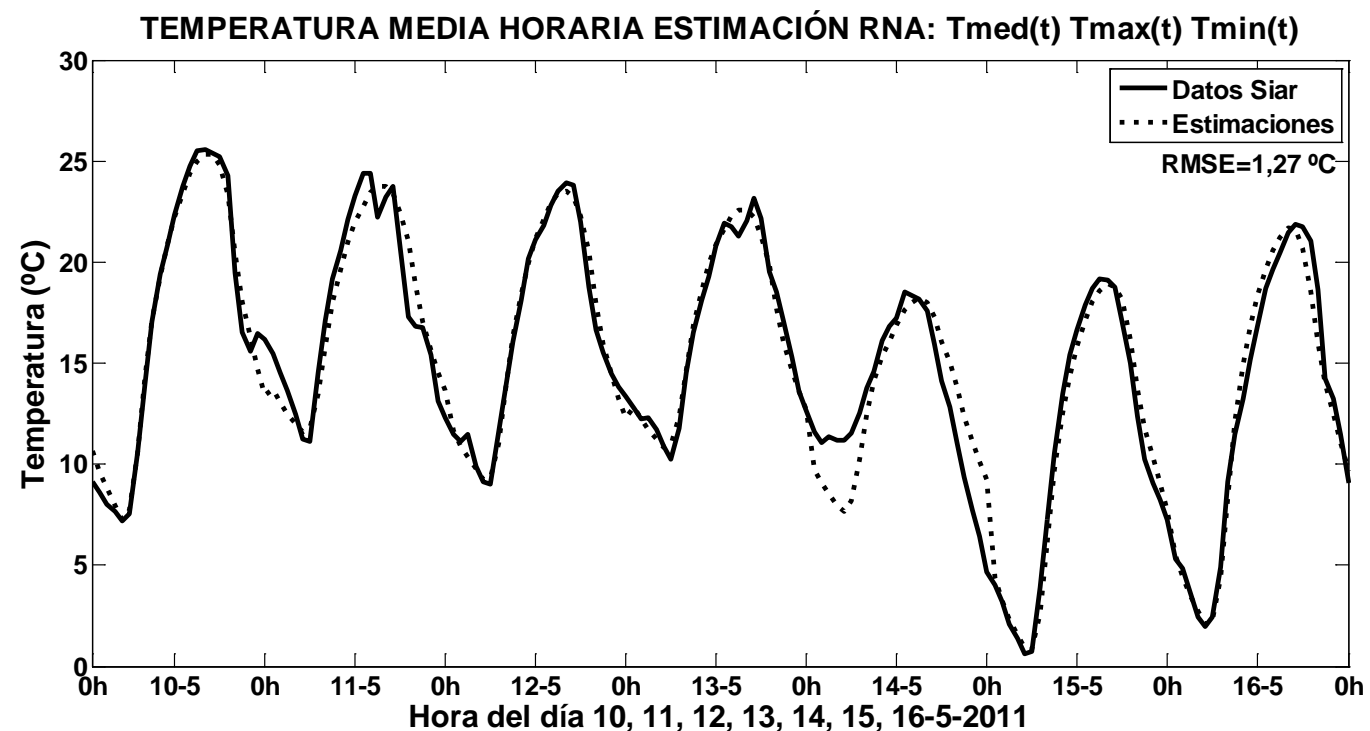

Fig. 4.4.22 Datos de la temperatura media horaria SIAR en Mansilla Mayor (León) y valores resultado de la estimación realizada con una red neuronal artificial con tres entradas del valor de las temperaturas media, máxima y mínima diaria del mismo día 


\section{2) Resultado de la estimación de la temperatura media horaria con las temperatura media, máxima y mínima diaria + el día del año}

Se representa la temperatura media horaria durante una semana de la estimación realizada con el modelo (Fig. 3.4.21), con una red neuronal artificial de 26 neuronas en la capa oculta para el año 2011, junto con los datos, en la gráfica (Fig. 4.4.23), de los resultados de todos los valores horarios del año resulta un de $\mathrm{RMSE}=1,24^{\circ} \mathrm{C} / \mathrm{h}$.

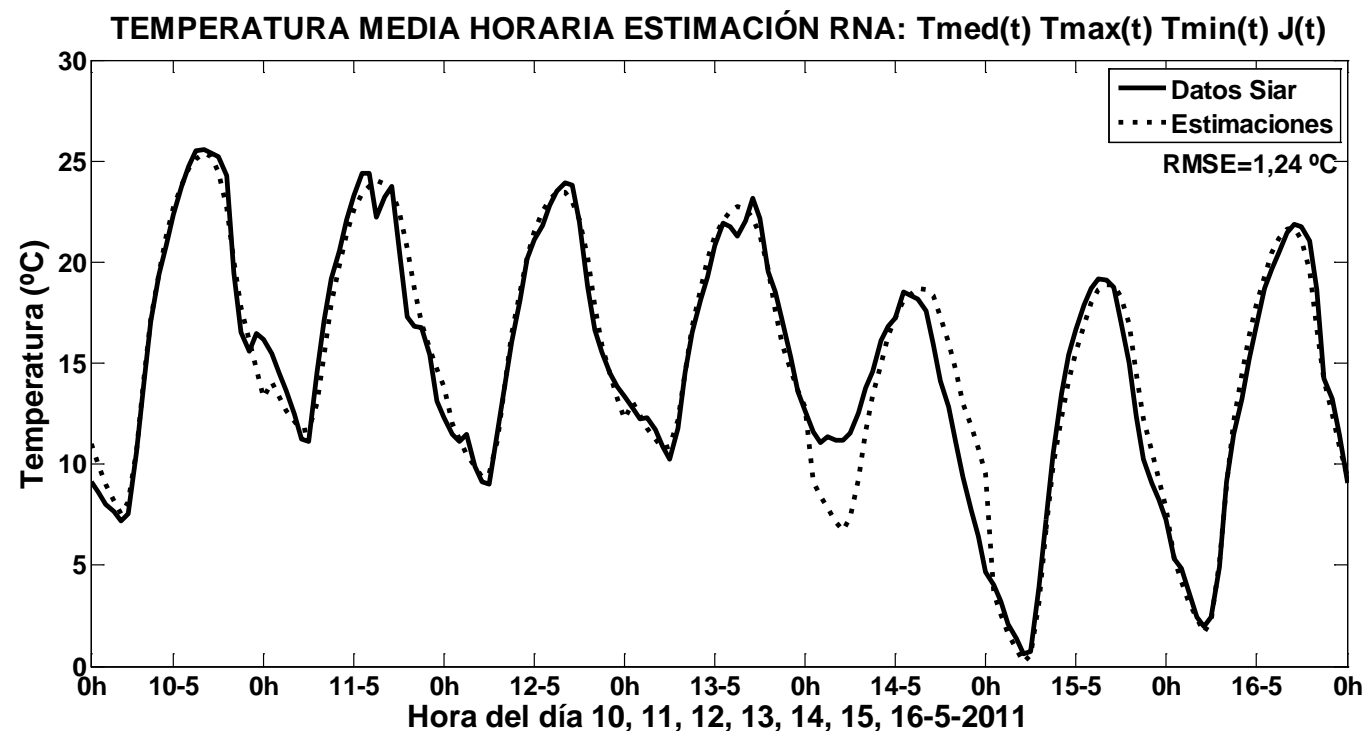

Fig. 4.4.23 Datos de la temperatura media horaria SIAR en Mansilla Mayor (León) y valores resultado de la estimación realizada con una red neuronal artificial con cuatro entradas del valor de las temperaturas media, máxima y mínima diaria y el día del año del mismo día 


\subsection{Estimación de la irradiación solar sobre el plano inclinado y orientado}

Los resultados de la metodología para la estimación de la irradiación solar sobre el plano inclinado del captador solar, a partir de la irradiación solar incidente sobre la superficie horizontal, que es la habitualmente disponible en las estaciones meteorológicas.

Se presentan los resultados obtenidos de las variables necesarias para su cálculo:

- La irradiación solar extraterrestre.

- La irradiación solar difusa horizontal.

- La altura solar.

- El ángulo de incidencia sobre el plano inclinado.

También se realiza una comparativa entre las diversas metodologías para la estimación de la irradiación solar global sobre el plano inclinado en base de tiempo diaria y anual.

\subsubsection{Resultado del modelado de la irradiación solar extraterrestre}

El modelado de la irradiación solar extraterrestre se aplica para el caso de la latitud de $42^{\circ}$ Norte, durante todo un año en periodos diarios y para el día 15 de cada mes del año en periodos horarios. Así se puede conocer la evolución temporal de la irradiación solar extraterrestre en el tope de la atmósfera, que llegaría a un punto determinado de la Tierra, teniendo en cuenta que no se consideran los efectos de atenuación y dispersión, que la atmósfera produce al paso de los rayos solares.

\section{1) Resultado del cálculo de la irradiación solar extraterrestre diaria en la latitud $42^{\circ}$ Norte}

Los resultados de la metodología presentada para el cálculo de la irradiación solar extraterrestre diaria (Apartado 3.5.1), obtenidos para los 365 días del año en la latitud $42^{\circ}$ Norte, se muestran en la gráfica (Fig. 4.5.1), donde se puede apreciar un máximo de irradiación solar extraterrestre diaria en la última quincena del mes de junio y un mínimo de irradiación durante la última quincena del mes de diciembre. La irradiación solar extraterrestre diaria varía durante el año desde el valor mínimo de $12,28 \mathrm{MJ} / \mathrm{m}^{2} / \mathrm{d}$ hasta el valor máximo de $41,91 \mathrm{MJ} / \mathrm{m}^{2} / \mathrm{d}$. Los resultados se validaron por comparación con los tabulados en la literatura (Allen, 2006) resultando un buen ajuste, sin considerar la aplicación de más estadísticos. 


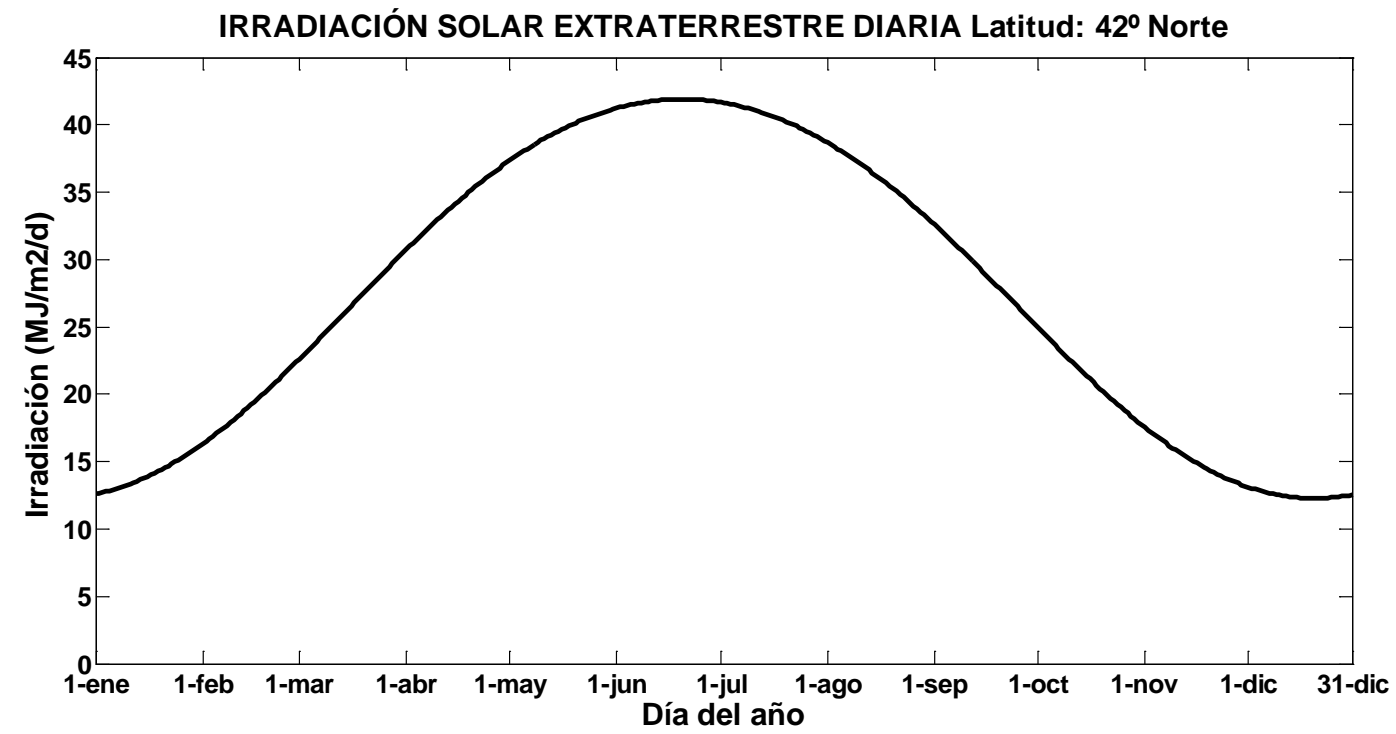

Fig. 4.5.1 Irradiación solar extraterrestre diaria calculada en la latitud $42^{\circ}$ Norte para cada día del año

Esta metodología propuesta en la literatura tiene el inconveniente de ser complicada para su aplicación a no ser por un experto. Aquí se propone la utilización de funciones de aproximación, calculadas con una serie de Fourier (Tabla 4.5.1), o mediante la suma de funciones seno (Tabla 4.5.2). En esta Tesis Doctoral se calcularon para la latitud $42^{\circ}$ Norte objeto de estudio. Estas funciones de aproximación pueden facilitar su uso y programación en aplicaciones particulares.

Tabla 4.5.1 Función de aproximación de Fourier a la irradiación solar extraterrestre diaria en la latitud $42^{\circ}$ Norte, con el $1^{\circ}, 2^{\circ}$ y $3^{\circ}$ armónico y el error producido

\begin{tabular}{|c|l|c|}
\hline \multicolumn{3}{|c|}{ Irradiación solar extraterrestre diaria $\left(\mathbf{M J} / \mathbf{m}^{\mathbf{2}} / \mathbf{d}\right)$ Latitud $\mathbf{4 2}^{\circ} \mathbf{~ N o r t e ~}$} \\
\hline $\begin{array}{c}|c| \\
\mathbf{N}^{\circ} \text { de } \\
\text { armónicos }\end{array}$ & \multicolumn{1}{|c|}{ Función de aproximación de Fourier } & RMSE \\
\hline 1 & $\mathrm{H}_{0}(\mathrm{t})=16,31-14,58 \cos (0,01675 \mathrm{t})+4,057 \operatorname{sen}(0,01675 \mathrm{t})$ & 0,210 \\
\hline 2 & $\begin{array}{l}\mathrm{H}_{0}(\mathrm{t})=27,68-14,65 \cos (0,01743 \mathrm{t})+2,296 \operatorname{sen}(0,01743 \mathrm{t})-0,5386 \cos (2 \cdot 0,01743 \mathrm{t})+0,1106 \operatorname{sen}(2 \cdot \\
0,01743 \mathrm{t})\end{array}$ & 0,048 \\
\hline 3 & $\begin{array}{l}\mathrm{H}_{0}(\mathrm{t})=27,53-14,65 \cos (0,01725 \mathrm{t})+2,741 \operatorname{sen}(0,01725 \mathrm{t})-0,433 \cos (2 \cdot 0,01725 \mathrm{t})+0,1068 \operatorname{sen}(2 \cdot \\
0,01725 \mathrm{t})+0,08373 \cos (3 \cdot 0,01725 \mathrm{t})-0,04929 \operatorname{sen}(3 \cdot 0,01725 \mathrm{t})\end{array}$ & 0,009 \\
\hline
\end{tabular}

Tabla 4.5.2 Función de aproximación de funciones senos a la irradiación solar extraterrestre diaria en la latitud $42^{\circ}$ Norte, con 2 , 3 y 4 senos y el error producido

\begin{tabular}{|c|c|c|c|}
\hline \multicolumn{3}{|c|}{ Irradiación solar extraterrestre diaria $\left(\mathbf{M J} / \mathbf{m}^{\mathbf{2}} / \mathbf{d}\right)$ Latitud $\mathbf{4 2}^{\circ}$ Norte } \\
\hline $\mathbf{N}^{\circ}$ de senos & Función de aproximación con suma de funciones senos & RMSE \\
\hline 2 & $\mathrm{H}_{0}(\mathrm{t})=30,13 \operatorname{sen}(0,0001206 \mathrm{t}+1,088)+15,24 \operatorname{sen}(0,01665 \mathrm{t}+5,013)$ & 0,193 \\
\hline 3 & $\mathrm{H}_{0}(\mathrm{t})=29,93 \operatorname{sen}(0,003287 \mathrm{t}+1,004)+0,4265 \operatorname{sen}(0,04049 \mathrm{t}-2,329)+12,41 \operatorname{sen}(0,01812 \mathrm{t}-1,53)$ & 0,006 \\
\hline 4 & $\begin{array}{c}\mathrm{H}_{0}(\mathrm{t})=29,56 \operatorname{sen}(0,002815 \mathrm{t}+1,094)+1,189 \operatorname{sen}(0,02655 \mathrm{t}+0,06927)+13,76 \operatorname{sen}(0,01857 \mathrm{t}-1,619) \\
+0,2333 \operatorname{sen}(0,04441 \mathrm{t}+3,321)\end{array}$ & 0,004 \\
\hline
\end{tabular}




\section{2) Resultado del cálculo de la irradiación solar extraterrestre horaria en la latitud $42^{\circ}$ Norte y la longitud $5,6^{\circ}$ Oeste}

Los resultados de la metodología presentada para el cálculo de irradiación solar extraterrestre horaria (Apartado 3.5.1), obtenidos para el día 15 de todos los meses del año en la latitud $42^{\circ}$ Norte y la longitud $5,6^{\circ}$ Oeste, se muestran en las gráficas (Fig. 4.5.2) y (Fig. 4.5.3), donde se puede apreciar la irradiación solar extraterrestre para cada hora del día, del día 15 de todos los meses del año, se observa la simetría de la irradiación solar extraterrestre a lo largo del día respecto al mediodía solar y el progresivo aumento de irradiación solar desde el mes de diciembre hasta el mes de junio y el descenso de la irradiación solar desde el mes de junio hasta el mes de diciembre. Los resultados se validaron por comparación de la suma de los valores horarios de cada día con los tabulados en la literatura (Allen, 2006) resultando un buen ajuste, sin considerar la aplicación de más estadísticos.

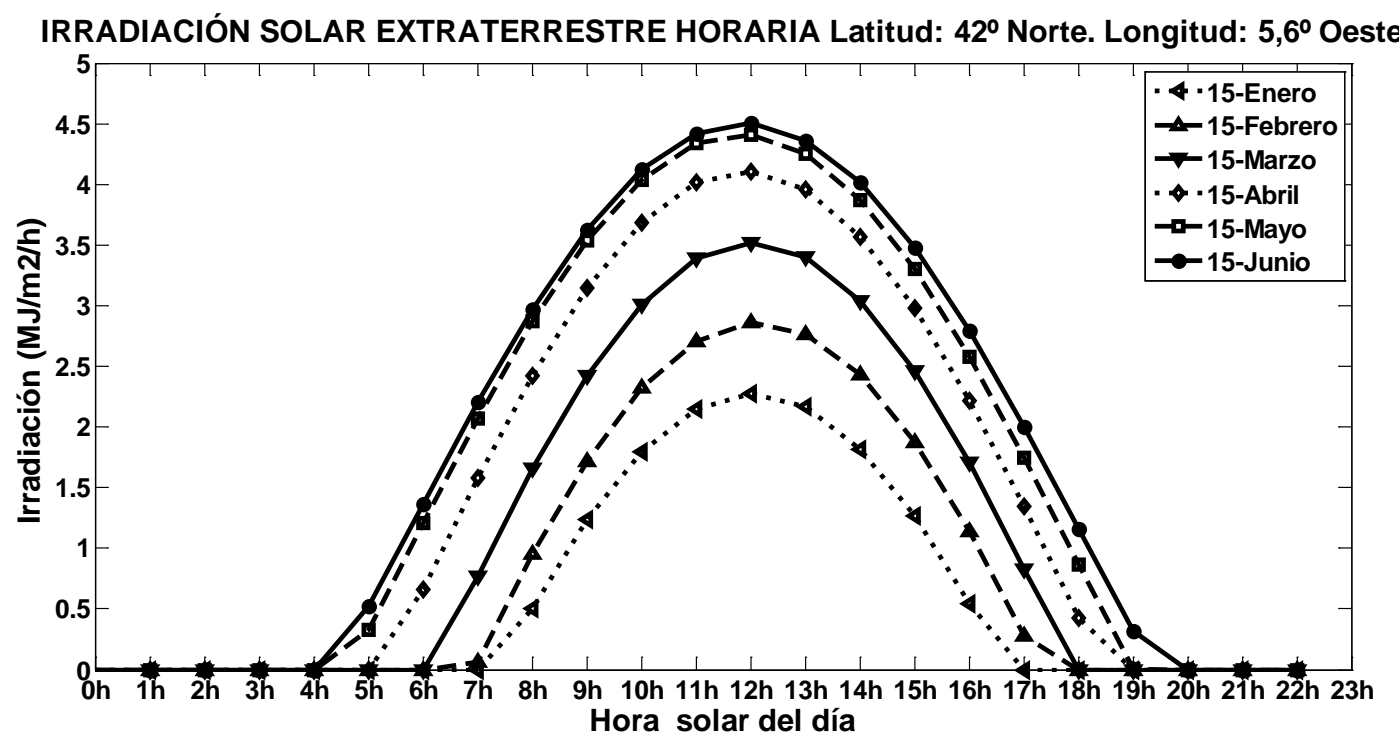

Fig. 4.5.2 Irradiación solar extraterrestre horaria calculada en la latitud $42^{\circ}$ Norte y la longitud 5, $6^{\circ}$ Oeste para cada día 15 del mes de enero a junio

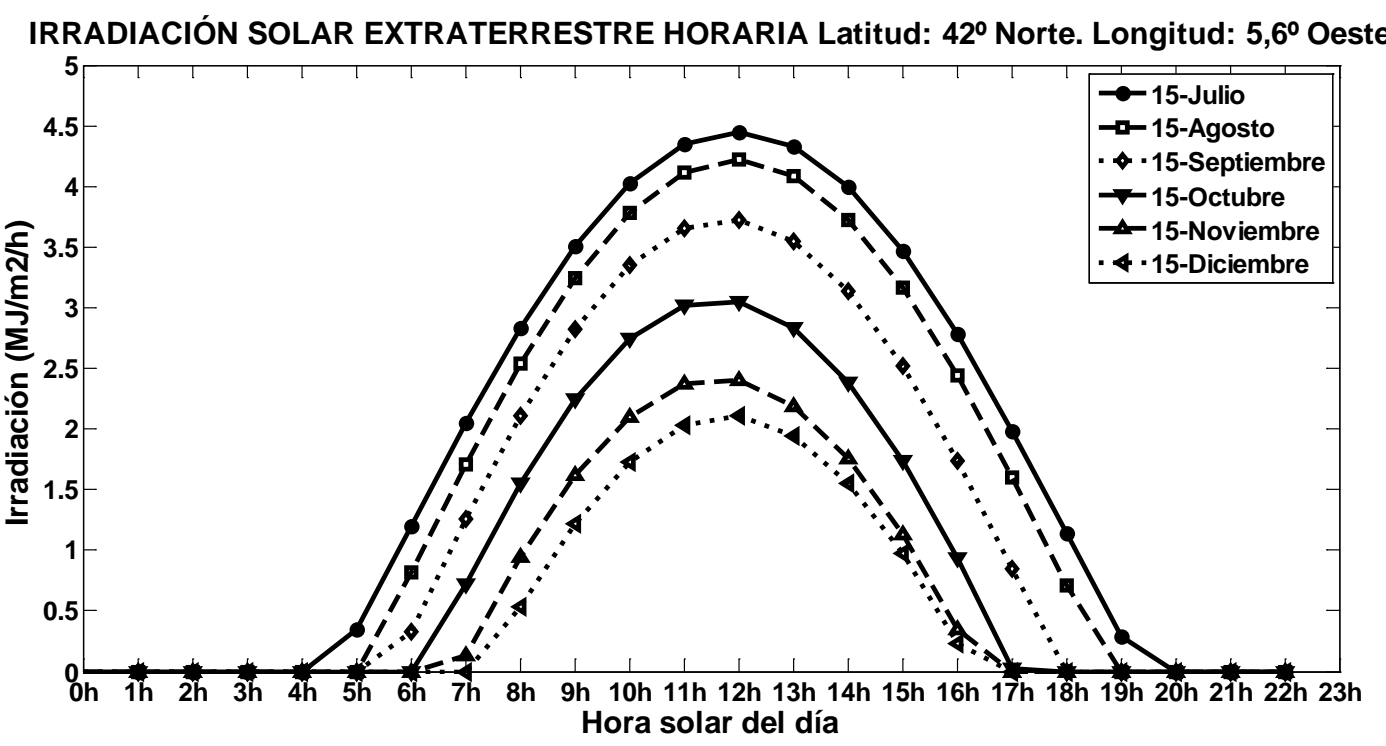

Fig. 4.5.3 Irradiación solar extraterrestre horaria calculada en la latitud $42^{\circ}$ Norte y la longitud $5,6^{\circ}$ Oeste para cada día 15 del mes de julio a diciembre 


\subsubsection{Resultado del modelado de la irradiación solar difusa horizontal}

Las distintas correlaciones propuestas para las fracciones difusas horarias (Apartado 2.3.1) se muestran en la gráfica (Fig. 4.5.4). Cada modelo, por lo general, propone tres relaciones para cada tipo de cielo, como (Iqbal, 1983) propone el índice de claridad diario para definir las condiciones del cielo tal que:

- Cielo claro para 0,7 $\leq \mathrm{k}_{\mathrm{t}}<0,9$.

- Cielo parcialmente nublado para $0,3 \leq \mathrm{k}_{\mathrm{t}}<0,7$.

- Cielo cubierto para $0 \leq \mathrm{k}_{\mathrm{t}}<0,3$.

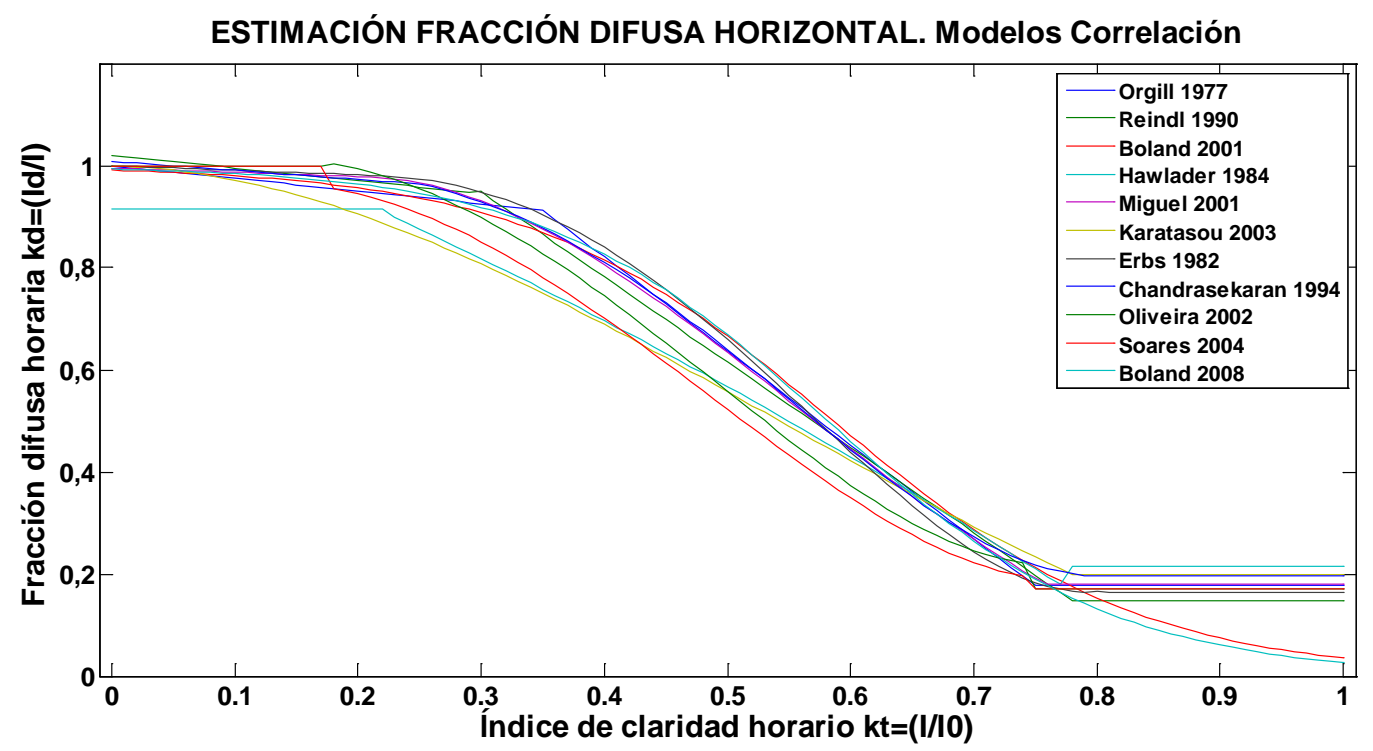

Fig. 4.5.4 Muestra distintas correlaciones de irradiación solar difusa sobre la horizontal propuestas en la literatura

Los resultados de la metodología presentada para la estimación de la irradiación solar difusa horaria respecto a la irradiación solar global horaria (Apartado 3.5.2), obtenidos de los datos registrados por la Agencia Estatal de Meteorología AEMET, en la estación de La Virgen del Camino (León) durante el año 2011, se muestran en la gráfica (Fig. 4.5.5). Se representa el modelo propuesto para su utilización, junto a los datos de la fracción difusa horaria respecto el índice de claridad horario, de los valores registrados en las ocho horas centrales del día de todo el año 2011.

Se puede apreciar tres zonas en la representación gráfica, correspondientes a las horas del día con el cielo cubierto donde se obtiene un índice $k_{d}$ máximo y un índice $k_{t}$ mínimo, otra zona correspondiente a las horas del día con cielo despejado que se caracteriza con un índice $k_{d}$ mínimo y un índice $k_{t}$ máximo, y una tercera zona intermedia que se corresponde con las horas del día parcialmente cubierto con unos índices $k_{d} y k_{t}$ inversamente variables el uno del otro según el grado de nubosidad del cielo. 
IRRADIACIÓN SOLAR DIFUSA HORIZONTAL

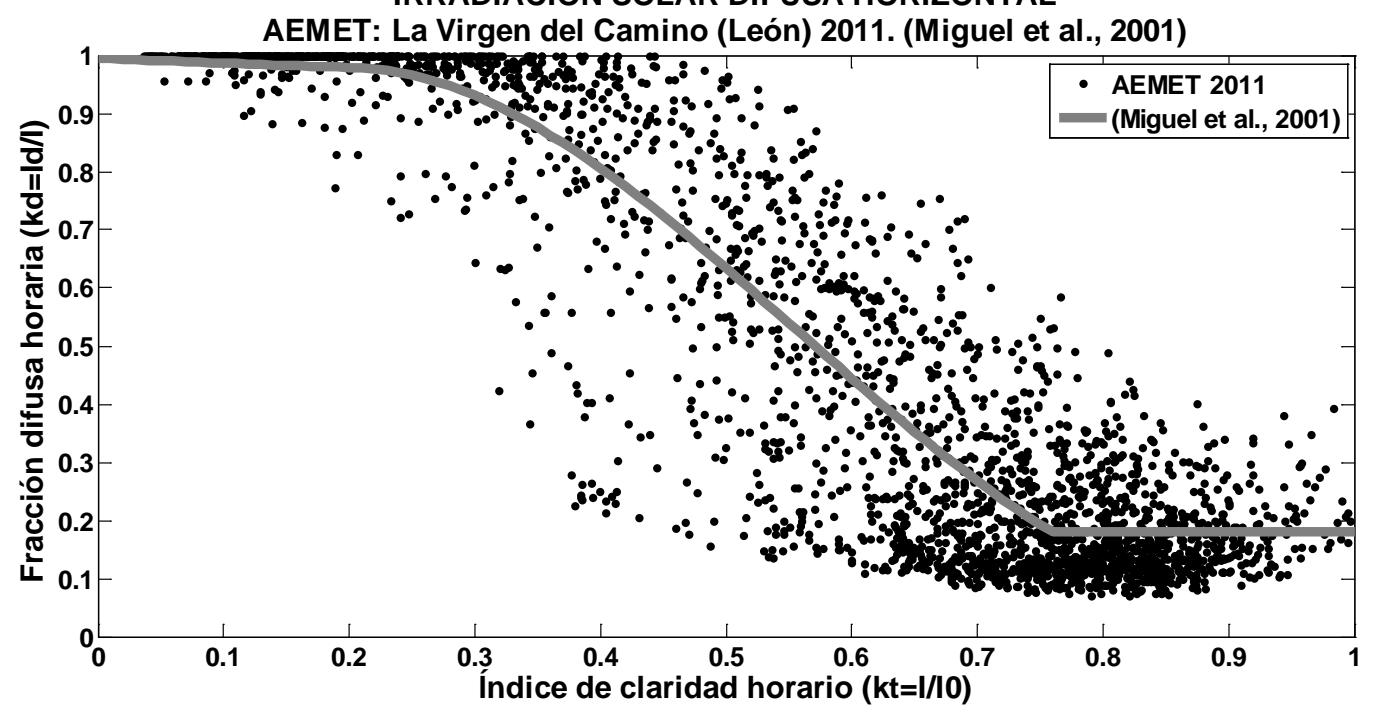

Fig. 4.5.5 Datos resultantes de la fracción difusa horaria respecto al índice de claridad horario de las ocho horas centrales del día del año 2011, registrados por AEMET en la estación de La Virgen del Camino (León) y el modelo propuesto de estimación de la irradiación solar difusa horizontal 


\subsubsection{Resultado del cálculo de la altura solar horaria en la latitud $42^{\circ}$ Norte y la longitud $5,6^{\circ}$ Oeste}

Los resultados de la metodología presentada para el cálculo de la altura solar horaria (Apartado 3.5.3), obtenidos para el día 15 de todos los meses del año en la latitud $42^{\circ}$ Norte y la longitud $5,6^{\circ}$ Oeste, se muestran en las gráficas (Fig. 4.5.6) y (Fig. 4.5.7), donde se puede apreciar la altura solar para cada hora del día, del día 15 de todos los meses del año, se observa la simetría de la altura solar a lo largo del día respecto al mediodía solar y el progresivo aumento de la altura solar desde el mes de diciembre hasta el mes de junio y el descenso de la altura solar desde el mes de junio hasta el mes de diciembre. Los resultados se validaron por comparación con los tabulados en la literatura (Duffie y Beckman, 2006) resultando un buen ajuste, sin considerar la aplicación de más estadísticos.

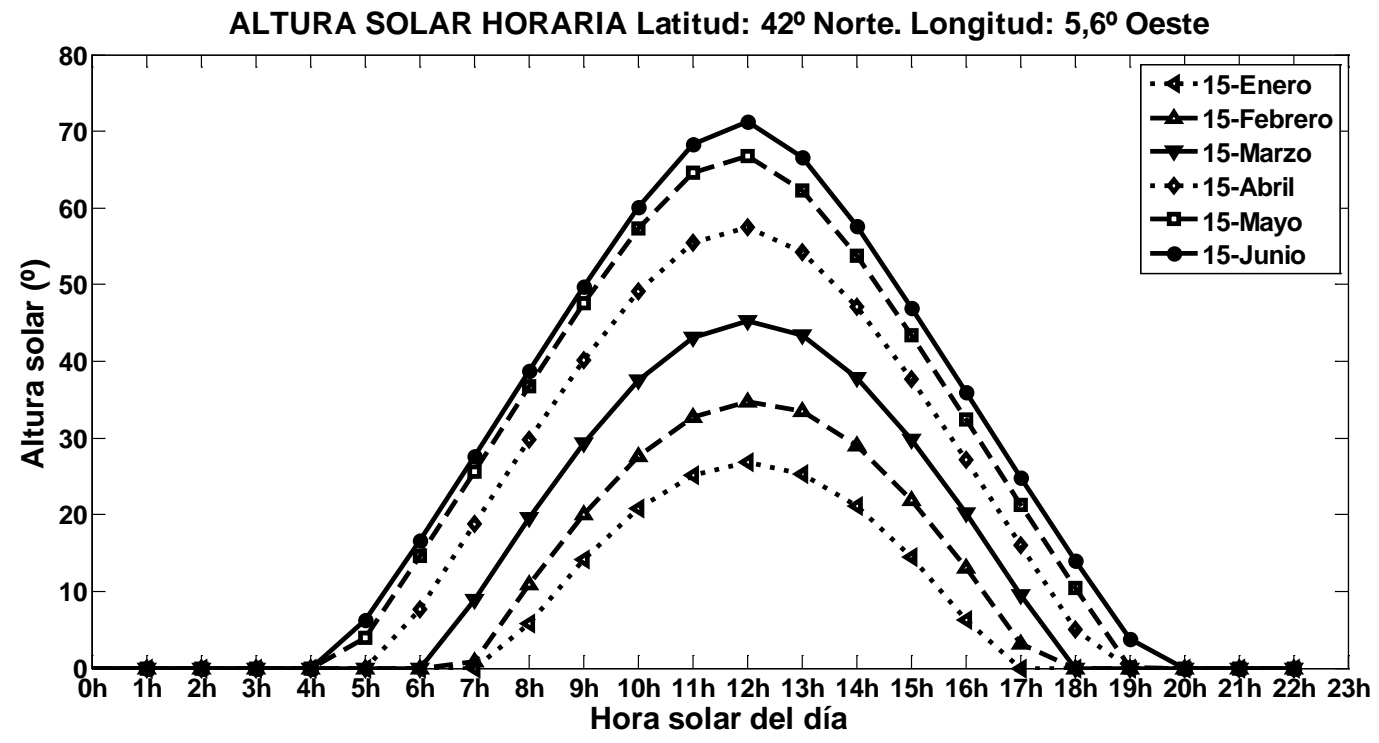

Fig. 4.5.6 Altura solar horaria calculada en la latitud $42^{\circ}$ Norte y la longitud $5,6^{\circ}$ Oeste, para cada día 15 del mes de enero a junio

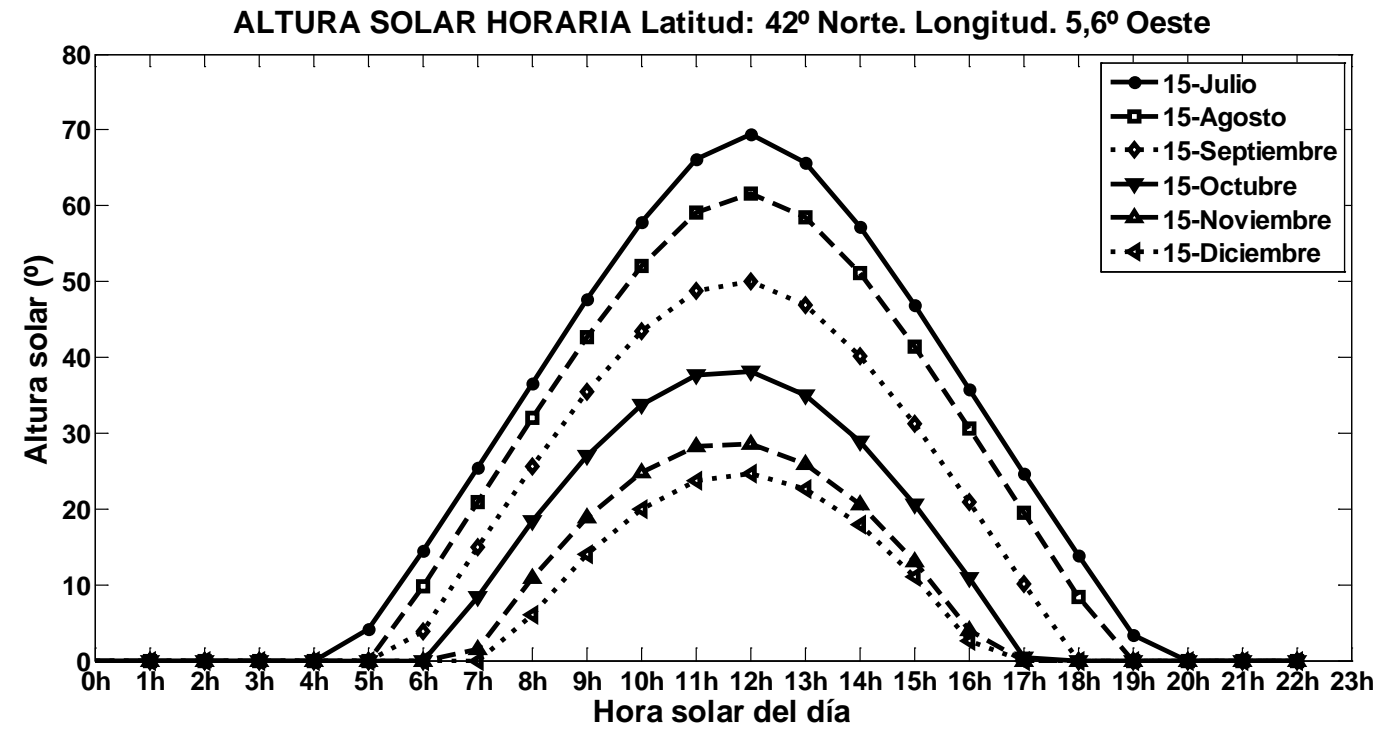

Fig. 4.5.7 Altura solar horaria calculada en la latitud $42^{\circ}$ Norte y la longitud 5, $6^{\circ}$ Oeste, para cada día 15 del mes de julio a diciembre 
Los valores máximos de la altura solar, que se dan al mediodía solar, y se muestran en la gráfica (Fig. 4.5.8), observándose esta variación a lo largo del año, se comprueba que en la última quincena del mes de junio se alcanza el máximo en la posición más alta del Sol y en la última quincena del mes de diciembre se produce el mínimo en la altura solar de todo el año.

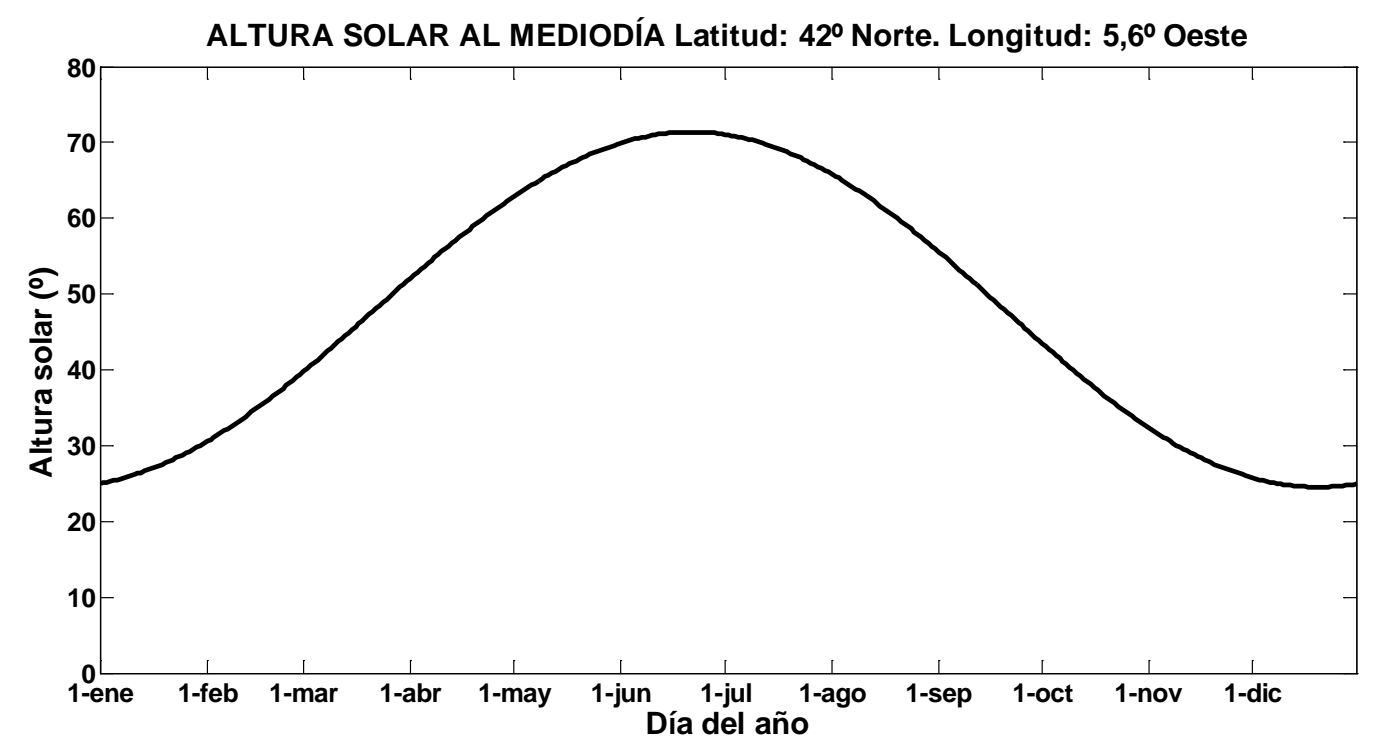

Fig. 4.5.8 Altura solar al mediodía solar calculada en la latitud $42^{\circ}$ Norte y la longitud $5,6^{\circ}$ Oeste, para todos los días del año

\subsubsection{Resultado del cálculo del ángulo de incidencia horario sobre un captador inclinado $45^{\circ}$ en la latitud $42^{\circ}$ y longitud $5,6^{\circ}$ Oeste}

Los resultados de la metodología presentada para el cálculo del ángulo de incidencia horario (Apartado 3.5.4), obtenidos en una superficie con una inclinación de $45^{\circ}$, para el día 15 de todos los meses del año en la latitud $42^{\circ}$ Norte y la longitud $5,6^{\circ}$ Oeste, se muestran en las gráficas (Fig. 4.5.9) y (Fig. 4.5.10), donde se puede apreciar la evolución del ángulo de incidencia para cada hora del día, del día 15 de todos los meses del año, se observa la simetría del ángulo de incidencia a lo largo del día respecto al mediodía solar donde se localiza el mínimo y el progresivo descenso del ángulo de incidencia desde el mes de diciembre hasta el mes de marzo, el aumento del ángulo de incidencia desde el mes de marzo hasta el mes de junio, el descenso del ángulo de incidencia desde el mes de junio hasta el mes de septiembre y el aumento del ángulo de incidencia desde el mes de septiembre hasta el mes de diciembre. Los resultados se validaron por comparación con los tabulados en la literatura (Bérriz y Álvarez, 2008) y (Duffie y Beckman, 2006) resultando un buen ajuste, sin considerar la aplicación de más estadísticos.

Los meses del año más favorecidos, con esta posición de la superficie inclinada a $45^{\circ}$, para la captación de la energía solar son febrero, marzo, abril, septiembre y octubre, al encontrarse la superficie inclinada en una posición más perpendicular a la trayectoria de los rayos solares en esas fechas. 


\section{ÁNGULO DE INCIDENCIA HORARIO}

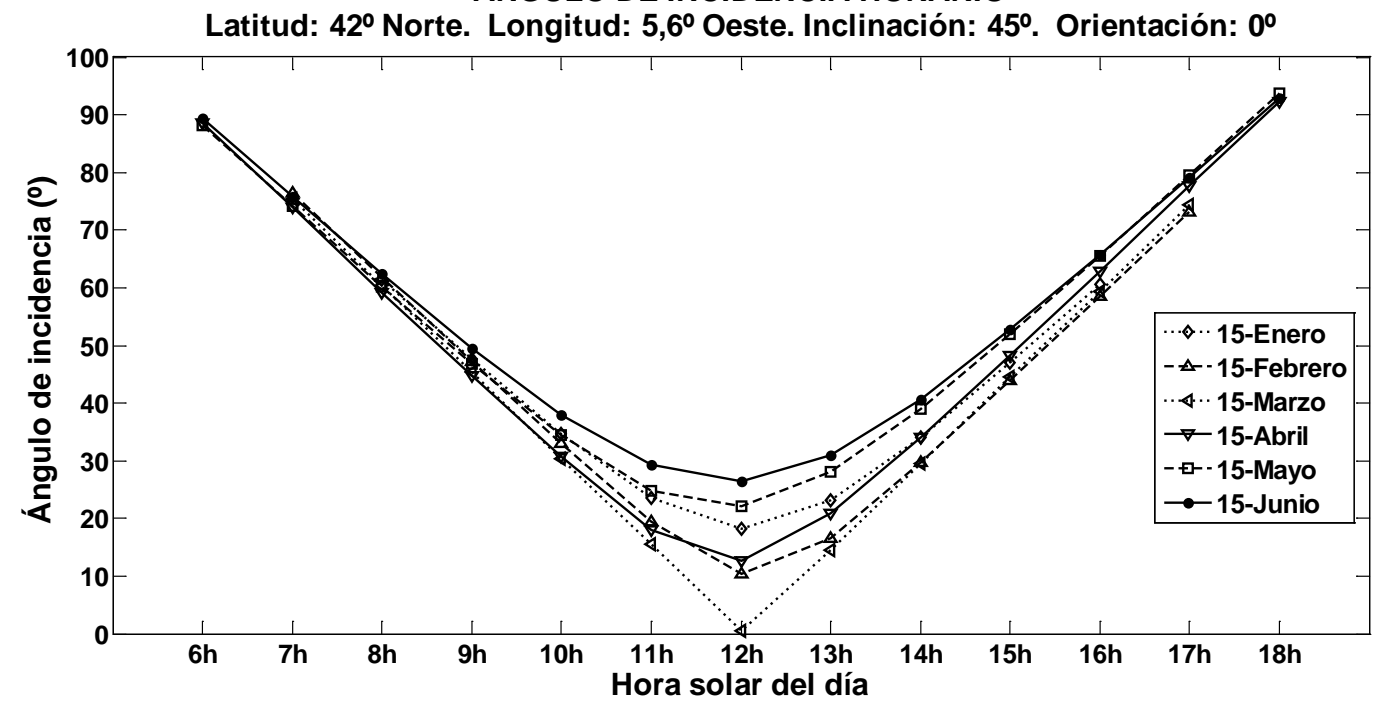

Fig. 4.5.9 Ángulo de incidencia horario calculado en la latitud $42^{\circ}$ Norte y la longitud $5,6^{\circ}$ Oeste, para cada día 15 del mes de enero a junio

ÁNGULO DE INCIDENCIA HORARIO

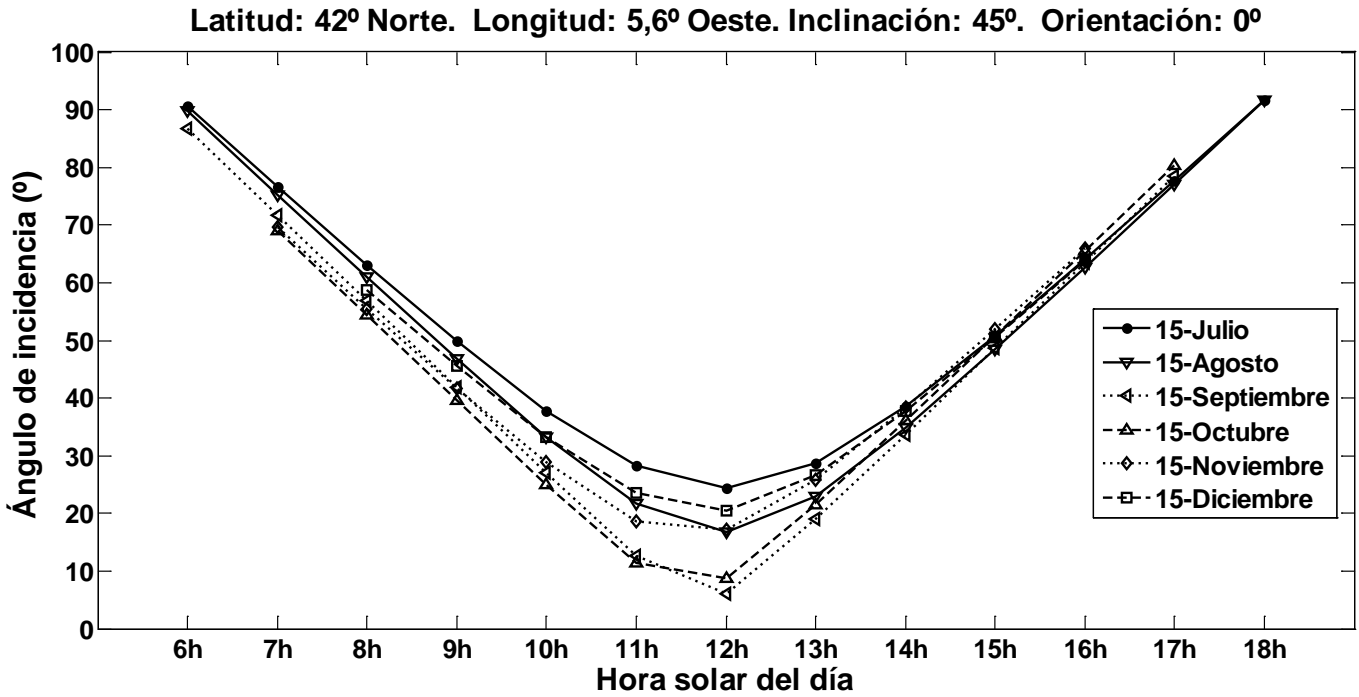

Fig. 4.5.10 Ángulo de incidencia horario calculado en la latitud $42^{\circ}$ Norte y la longitud $5,6^{\circ}$ Oeste, para cada día 15 del mes de julio a diciembre 
Los valores mínimos del ángulo de incidencia, que se dan al mediodía solar, para todos los días del año, y se muestran en la gráfica (Fig. 4.5.11), observándose esta variación a lo largo del año.

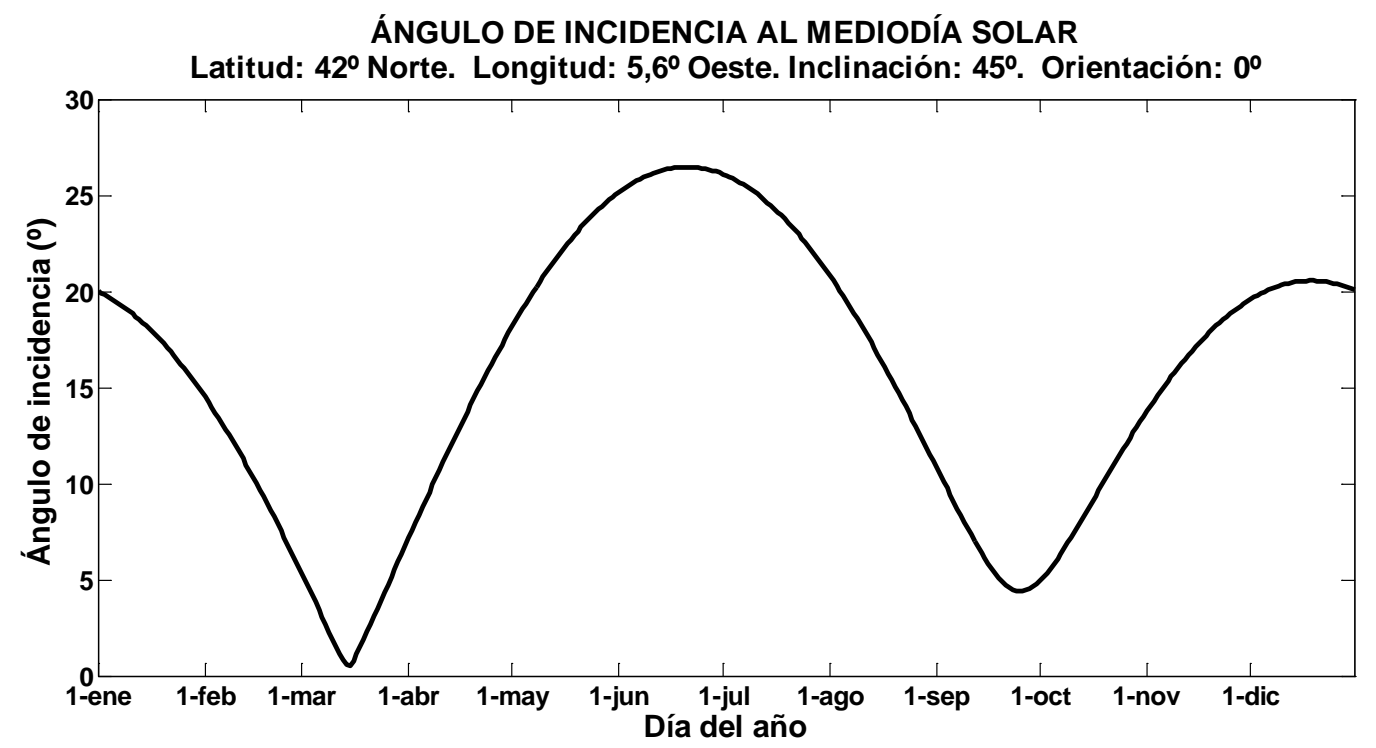

Fig. 4.5.11 Ángulo de incidencia al mediodía solar calculado en la latitud $42^{\circ}$ Norte y la longitud 5, $6^{\circ}$ Oeste, para todos los días del año

\subsubsection{Resultados obtenidos de la irradiación solar sobre el captador solar}

Los datos registrados de la irradiación solar global sobre la superficie horizontal durante el año 2011 en la estación meteorológica, situada en la localidad de Mansilla Mayor (León) perteneciente a la red SIAR, han sido utilizados para aplicar las metodologías descritas para la estimación del valor de la irradiación solar global sobre una superficie inclinada a $45^{\circ}$ y orientada hacia el ecuador, comparándose los resultados de los distintos métodos expuestos.

En la gráfica (Fig. 4.5.12) se representa los valores de la irradiación solar global diaria medida sobre la horizontal, junto a los cálculos realizados para la estimación de la irradiación solar global diaria sobre una superficie inclinada a $45^{\circ}$ y orientada al ecuador, mediante cuatro modelos que se describen a continuación.

\section{Modelo inclinado 1}

El modelo inclinado 1 es el método de CENSOLAR, probado (Apartado 4.2.1), el cual según sea la latitud, la inclinación y el mes del año proporciona un coeficiente para la obtención del valor de la irradiación solar global sobre el plano inclinado.

Los siguientes modelos utilizan la metodología descrita en los apartados anteriores, para el valor de la componente directa y del albedo de la irradiación solar, utilizando distintos modelos para el valor de la componente difusa, con los que se obtienen distintos resultados.

\section{Modelo inclinado 2}

El modelo inclinado 2 utiliza para la estimación de la componente difusa el modelo isotrópico de Liu y Jordan, presentado (Apartado 2.3.2). 


\section{Modelo inclinado 3}

El modelo inclinado 3 utiliza para la estimación de la componente difusa el modelo anisotrópico de Temps y Coulson, presentado (Apartado 2.3.2).

\section{Modelo inclinado 4}

El modelo inclinado 4 utiliza para la estimación de la componente difusa el modelo anisotrópico de Klucher, presentado (Apartado 2.3.2).

\section{Modelo inclinado 5}

El modelo inclinado 5 utiliza para la estimación de la componente difusa el modelo anisotrópico de Hay, presentado (Apartado 2.3.2).

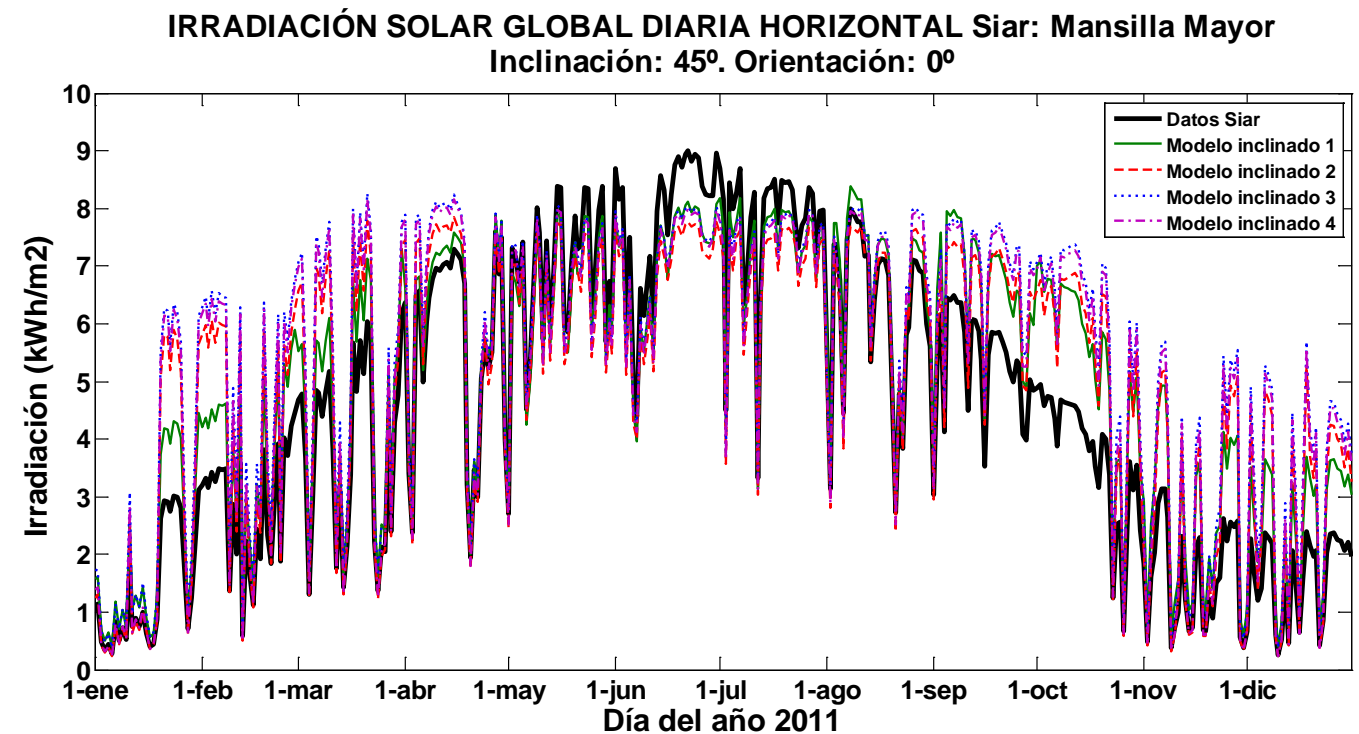

Fig. 4.5.12 Comparación de los valores diarios de irradiación solar global medidos sobre la horizontal y estimados sobre el plano inclinado a $45^{\circ}$ y orientado hacia el ecuador con cuatro modelos

Por último se aplica el módulo de conversión de los valores de la irradiación solar global horaria dado en unidades energéticas de $\left(\mathrm{MJ} / \mathrm{m}^{2}\right)$ sobre el plano inclinado a los valores horarios medios de irradiancia solar en unidades de potencia $\left(\mathrm{W} / \mathrm{m}^{2}\right)$ sobre el plano inclinado. 
En las gráficas (Fig. 4.5.13) y (Fig. 4.5.14), se representa la variación horaria de la irradiancia solar para un día del mes de abril y otro día de octubre respectivamente, se compara con la evolución de la irradiación solar global horizontal de la base de datos de la red SIAR situada en Mansilla Mayor (León), la irradiancia solar sobre el plano inclinado calculada con los cinco métodos de conversión y la irradiancia solar registrada por el piranómetro de la planta piloto.

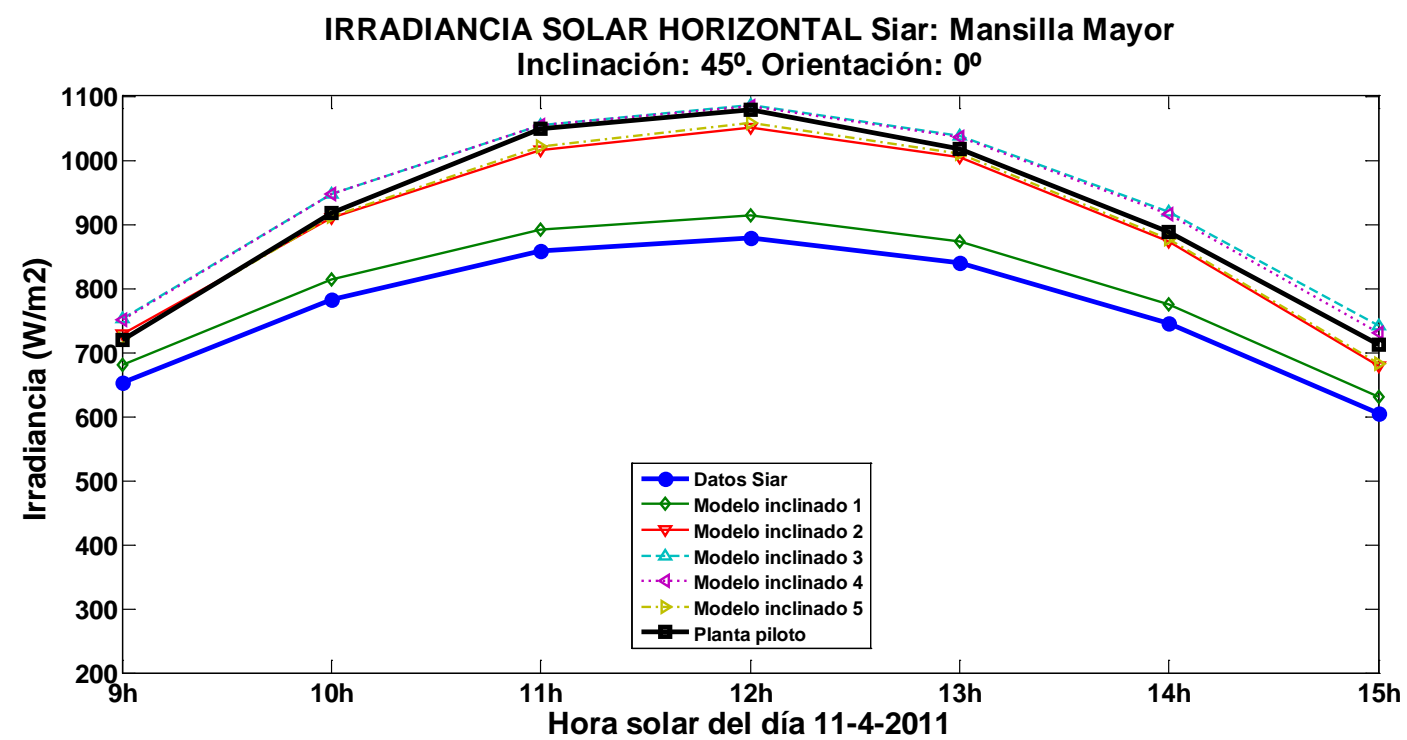

Fig. 4.5.13 Comparación de los valores horarios de irradiancia solar medidos sobre la horizontal SIAR en Mansilla Mayor (León), estimados sobre el plano inclinado a $45^{\circ}$ y orientación al ecuador, con cinco modelos y los registrados en la planta piloto para el día 11-4-2011

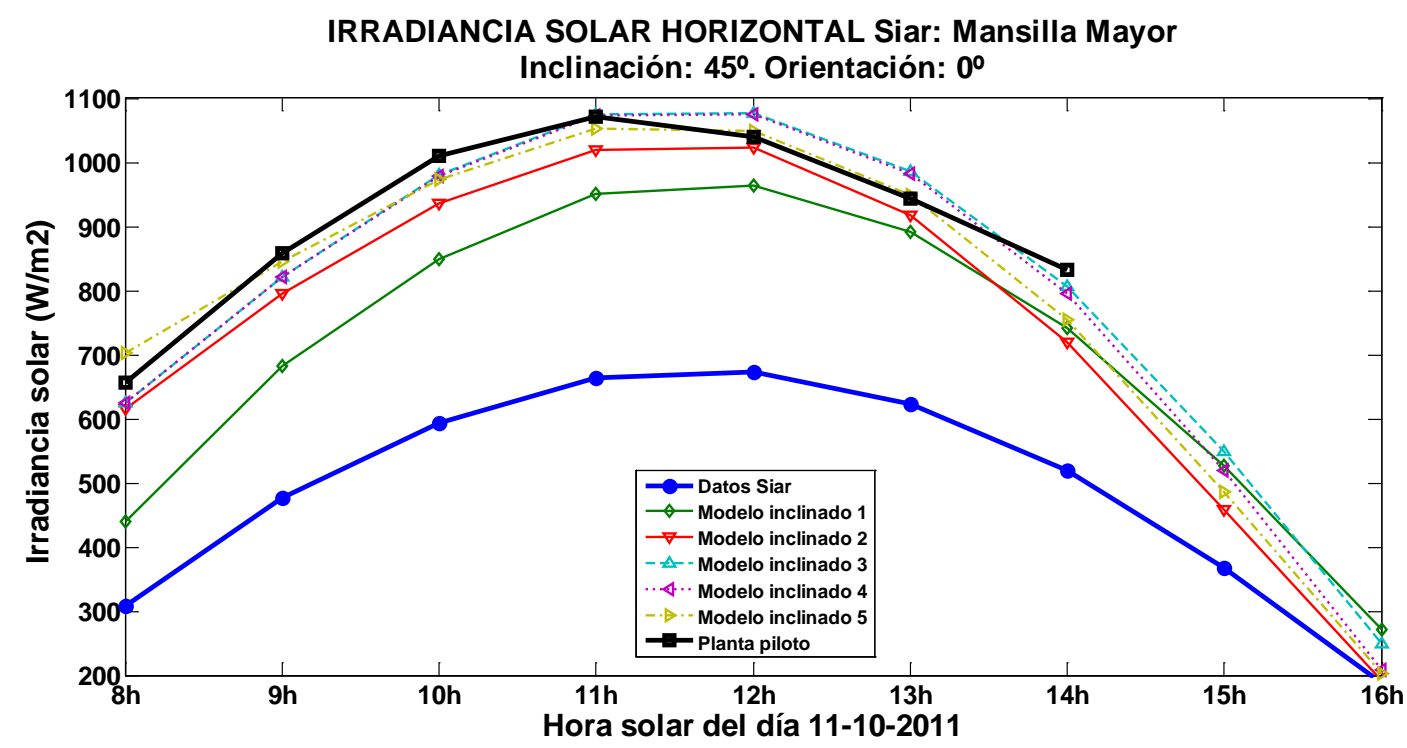

Fig. 4.5.14 Comparación de los valores horarios de irradiancia solar medidos sobre la horizontal SIAR en Mansilla Mayor (León), estimados sobre el plano inclinado a $45^{\circ}$ y orientación al ecuador, con cinco modelos y los registrados en la planta piloto para el día 11-10-2011 


\subsection{Modelado neural de los componentes del sistema solar térmico}

Los resultados de la metodología para el modelado de los componentes principales del sistema solar térmico, como son el captador solar, el intercambiador de calor y el depósito acumulador de agua caliente solar con redes neuronales artificiales, se presenta utilizando los datos registrados en la planta piloto que se describe (Apartado 3.1), y que se representan gráficamente (Anexo 2 Datos de la planta piloto).

\subsubsection{Resultado del modelado del captador solar con redes neuronales artificiales}

Los resultados de la metodología para el modelado del captador solar con redes neuronales artificiales, se presenta para tres caudales diferentes del fluido portador. Para la capa oculta se fueron probando distintos números de neuronas en el modelo (Fig. 3.6.1), calculando el valor de estadístico RMSE para la salida obtenida y poder seleccionar la arquitectura de la red neuronal artificial de mejores resultados.

Se representa el valor del estadístico RMSE obtenido con todas las redes neuronales artificiales creadas con distinto número de neuronas en la capa oculta, para predecir la temperatura de ida del captador solar (Fig. 4.6.1).

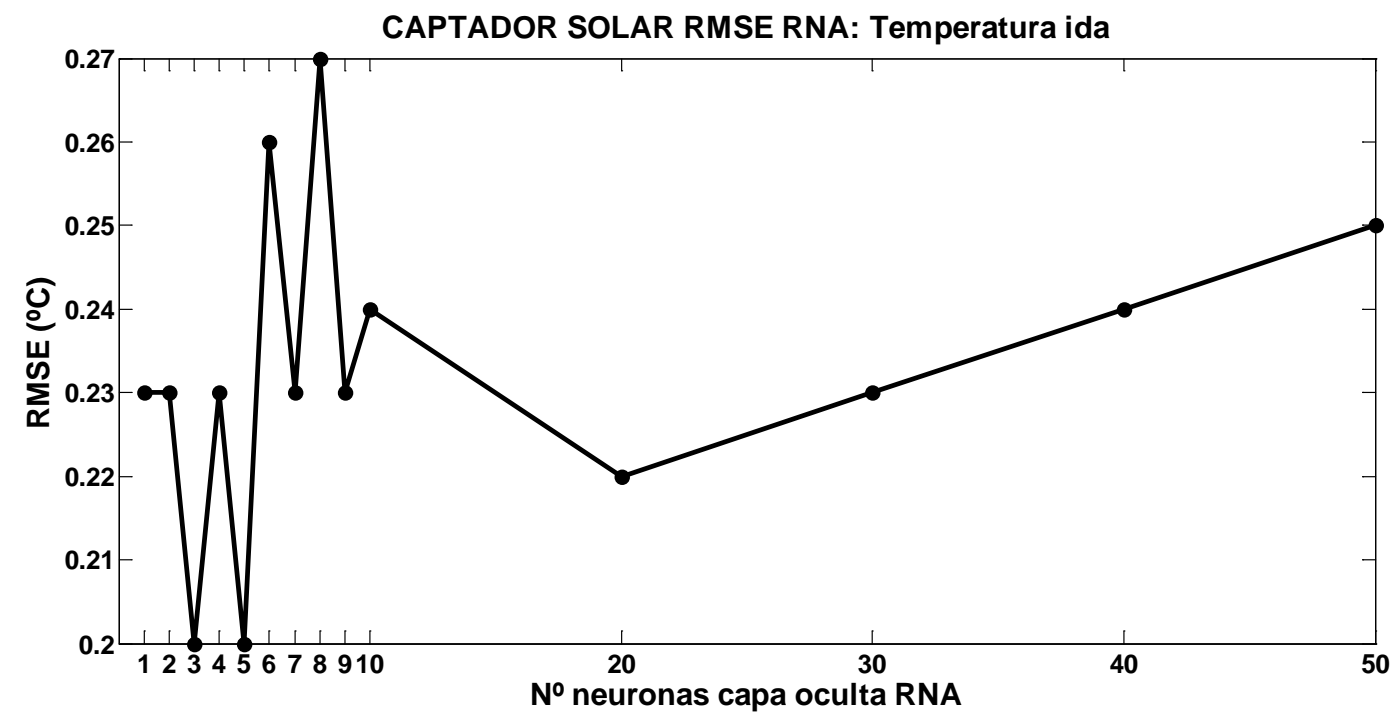

Fig. 4.6.1 Valores de RMSE obtenidos de la salida de las redes neuronales artificiales probadas con distintos números de neuronas en la capa oculta para el modelado del captador solar 
Se representa la simulación realizada del captador solar en el ensayo de la planta piloto del día 7-92011, realizado con un caudal del fluido en el captador de $2 \mathrm{l} / \mathrm{min}$, junto con los datos medidos y el error producido, $\mathrm{RMSE}=0,18{ }^{\circ} \mathrm{C}$, para cada intervalo de tiempo de un minuto del ensayo, con una red neuronal artificial de cinco neuronas en la capa oculta, gráfica (Fig. 4.6.2).

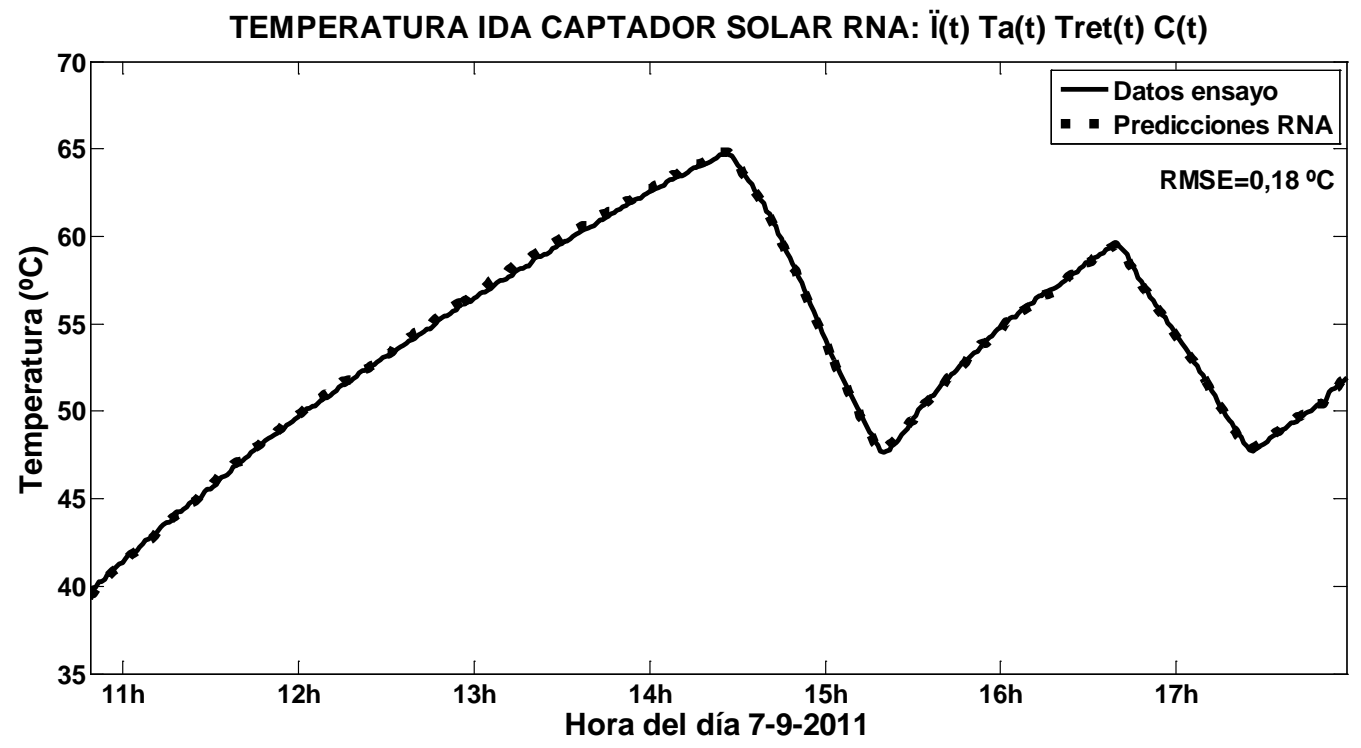

Fig. 4.6.2 Modelado RNA captador, datos medidos en el ensayo de la planta piloto el día 7-9-2011 y resultado de las predicciones

Se representa la simulación realizada del captador solar en el ensayo de la planta piloto del día 1-72011, realizado con un caudal del fluido en el captador de 1,6 l/min, junto con los datos medidos y el error producido, $\mathrm{RMSE}=0,20^{\circ} \mathrm{C}$, para cada intervalo de tiempo de un minuto del ensayo, con una red neuronal artificial de cinco neuronas en la capa oculta, gráfica (Fig. 4.6.3).

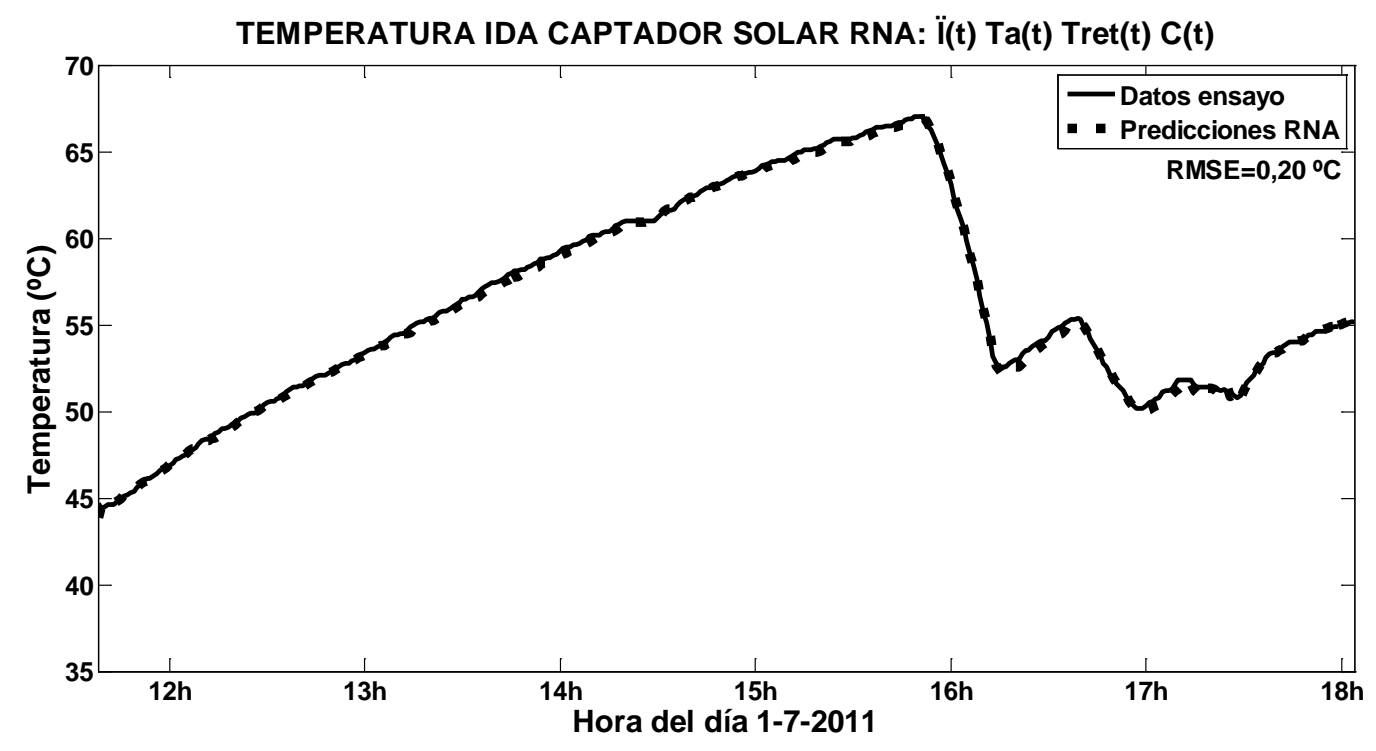

Fig. 4.6.3 Modelado RNA captador, datos medidos en el ensayo de la planta piloto el día 1-7-2011 y resultado de las predicciones 
Se representa la simulación realizada del captador solar en el ensayo de la planta piloto del día 4-102011, realizado con un caudal del fluido en el captador de $1 \mathrm{l} / \mathrm{min}$, junto con los datos medidos y el error producido, RMSE $=0,19{ }^{\circ} \mathrm{C}$, para cada intervalo de tiempo de un minuto del ensayo, con una red neuronal artificial de cinco neuronas en la capa oculta, gráfica (Fig. 4.6.4).

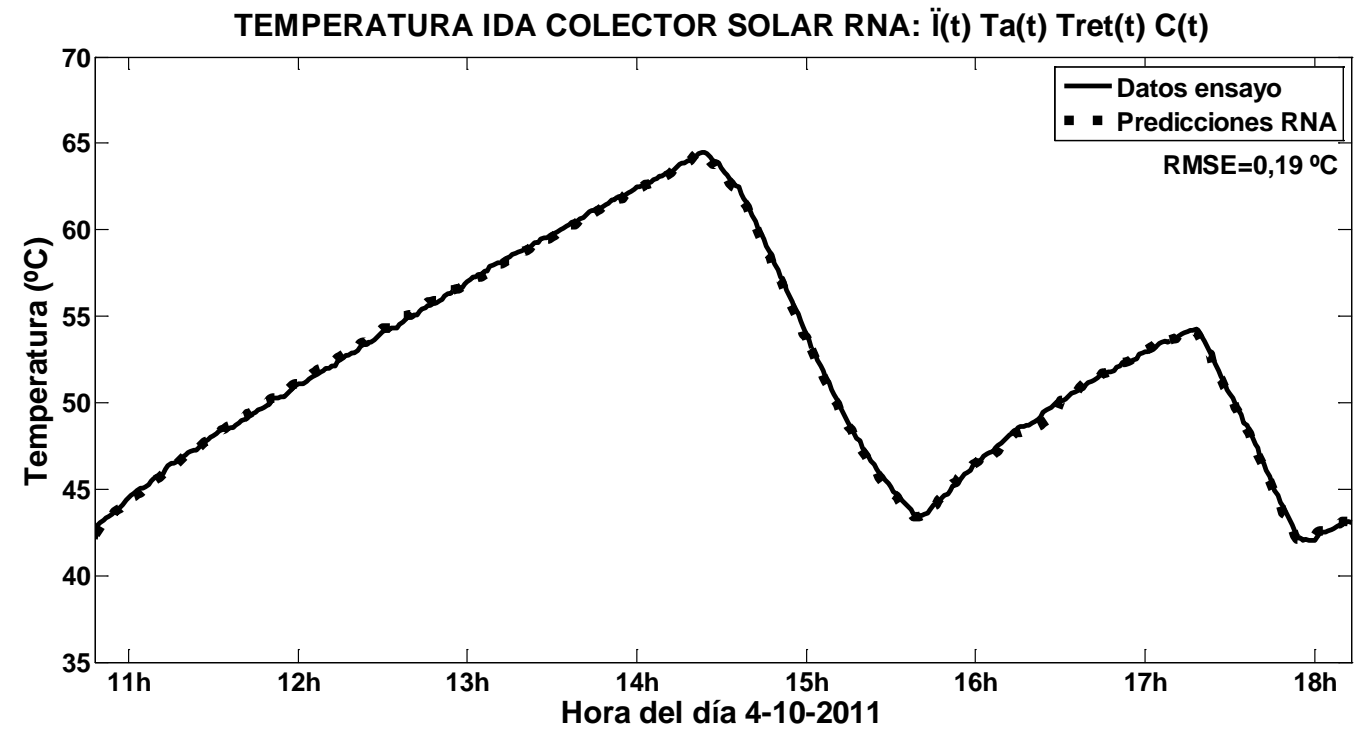

Fig. 4.6.4 Modelado RNA captador, datos medidos en el ensayo de la planta piloto el día 4-10-2011 y resultado de las predicciones 


\subsubsection{Resultado del modelado del intercambiador de calor con redes neuronales artificiales}

Los resultados de la metodología para el modelado del intercambiador de calor con redes neuronales artificiales, se presenta para tres caudales diferentes del fluido portador. Para la capa oculta se fueron probando distintos números de neuronas en el modelo (Fig. 3.6.2), calculando el valor del estadístico RMSE para la salida obtenida y poder seleccionar la arquitectura de la red neuronal artificial de mejores resultados.

Se representa el valor del estadístico RMSE obtenido con todas las redes neuronales artificiales creadas con distinto número de neuronas ocultas, para predecir la temperatura de retorno en el intercambiador de calor del fluido portador (Fig. 4.6.5).

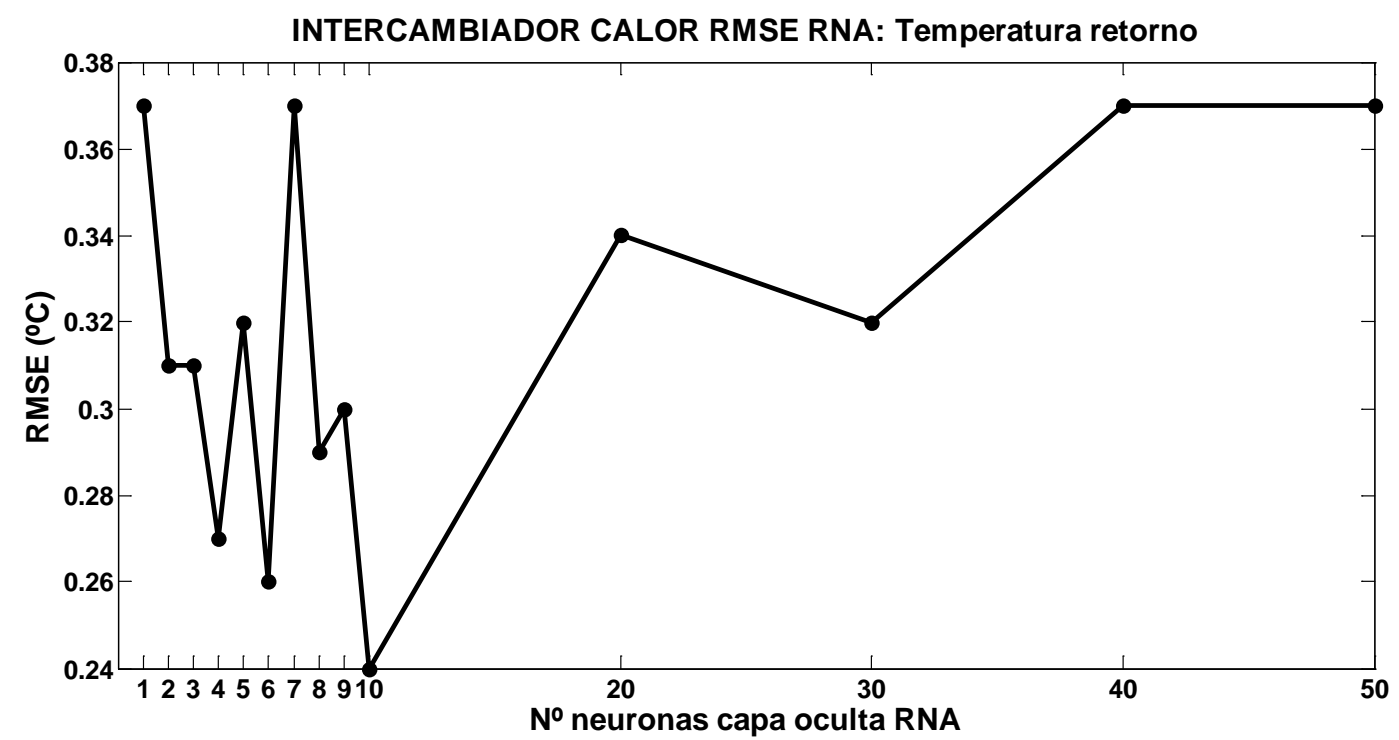

Fig. 4.6.5 Valores de RMSE obtenidos de la salida de las redes neuronales artificiales probadas con distintos números de neuronas en la capa oculta para el modelado del intercambiador de calor 
Se representa la simulación realizada del intercambiador de calor en el ensayo de la planta piloto del día 7-9-2011, realizado con un caudal del fluido portador de $2 \mathrm{l} / \mathrm{min}$, junto con los datos medidos y el error producido, RMSE $=0,17{ }^{\circ} \mathrm{C}$, para cada intervalo de tiempo de un minuto del ensayo, con una red neuronal artificial de 10 neuronas en la capa oculta, gráfica (Fig. 4.6.6).

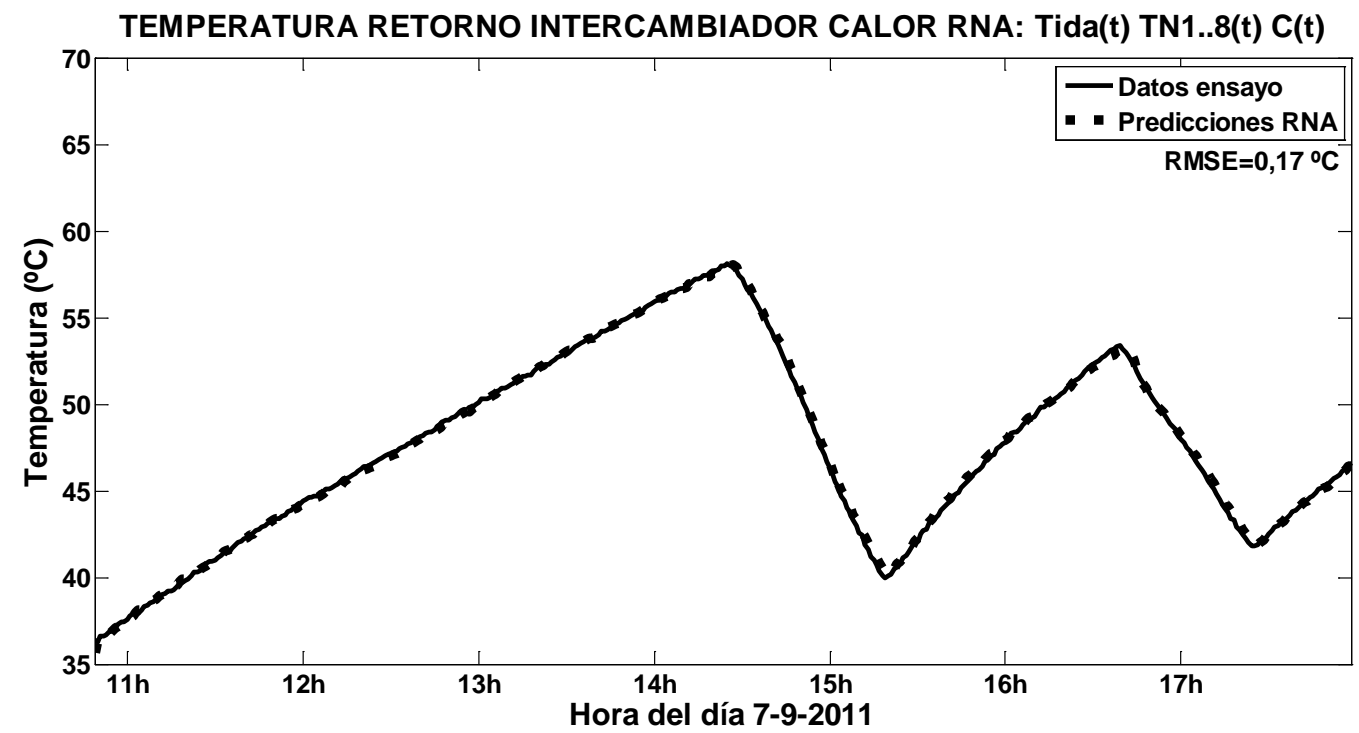

Fig. 4.6.6 Modelado RNA del intercambiador, datos medidos en el ensayo de la planta piloto el día 7-9-2011 con un caudal del fluido portador de $2 \mathrm{l} / \mathrm{min}$ y resultado de las predicciones

Se representa la simulación realizada del intercambiador de calor en el ensayo de la planta piloto del día 1-7-2011, realizado con un caudal del fluido portador de 1,6 l/min, junto con los datos medidos y el error producido, RMSE $=0,24{ }^{\circ} \mathrm{C}$, para cada intervalo de tiempo de un minuto del ensayo, con una red neuronal artificial de 10 neuronas en la capa oculta, gráfica (Fig. 4.6.7).

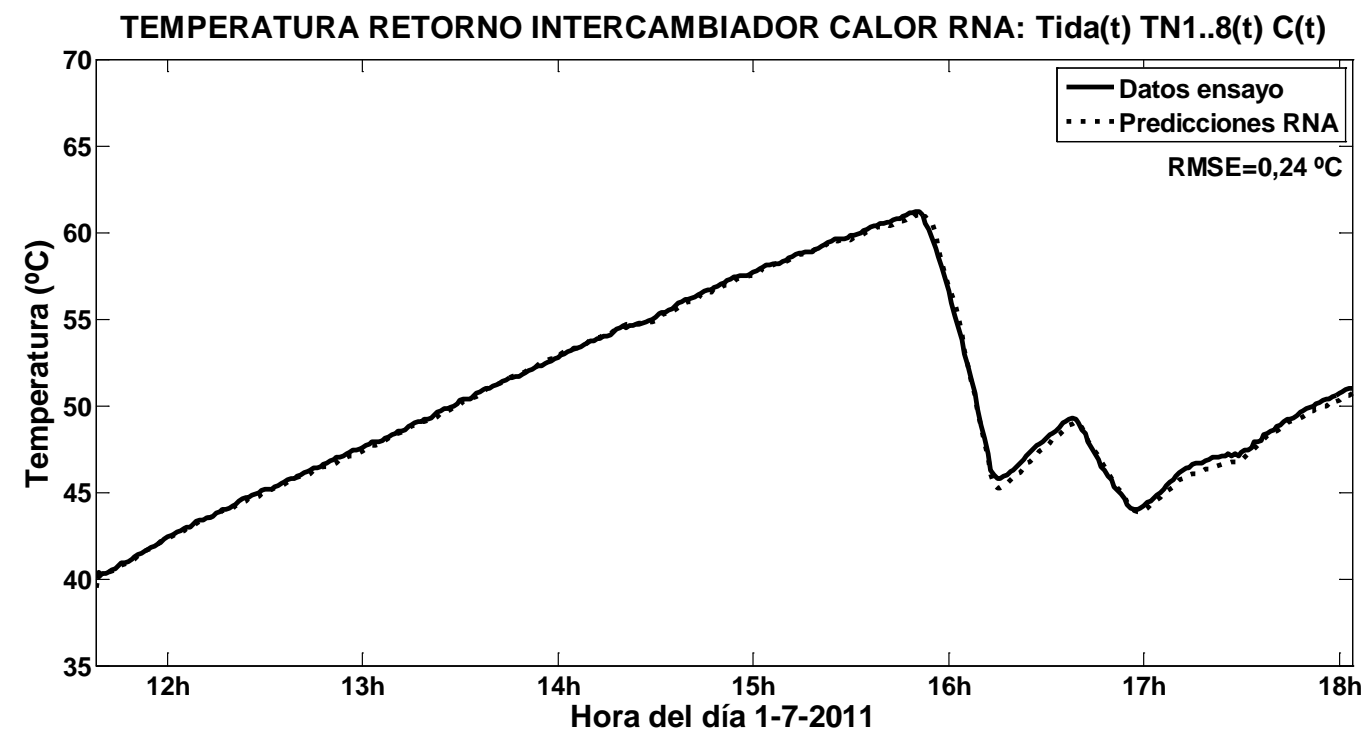

Fig. 4.6.7 Modelado RNA del intercambiador, datos medidos en el ensayo de la planta piloto el día 1-7-2011 con un caudal del fluido portador de $1,6 \mathrm{l} / \mathrm{min}$ y resultado de las predicciones 
Se representa la simulación realizada del intercambiador de calor en el ensayo de la planta piloto del día 21-9-2011, realizado con un caudal del fluido portador de $1 \mathrm{l} / \mathrm{min}$, junto con los datos medidos y el error producido, $\mathrm{RMSE}=0,46{ }^{\circ} \mathrm{C}$, para cada intervalo de tiempo de un minuto del ensayo, con una red neuronal artificial de 10 neuronas en la capa oculta, gráfica (Fig. 4.6.8).

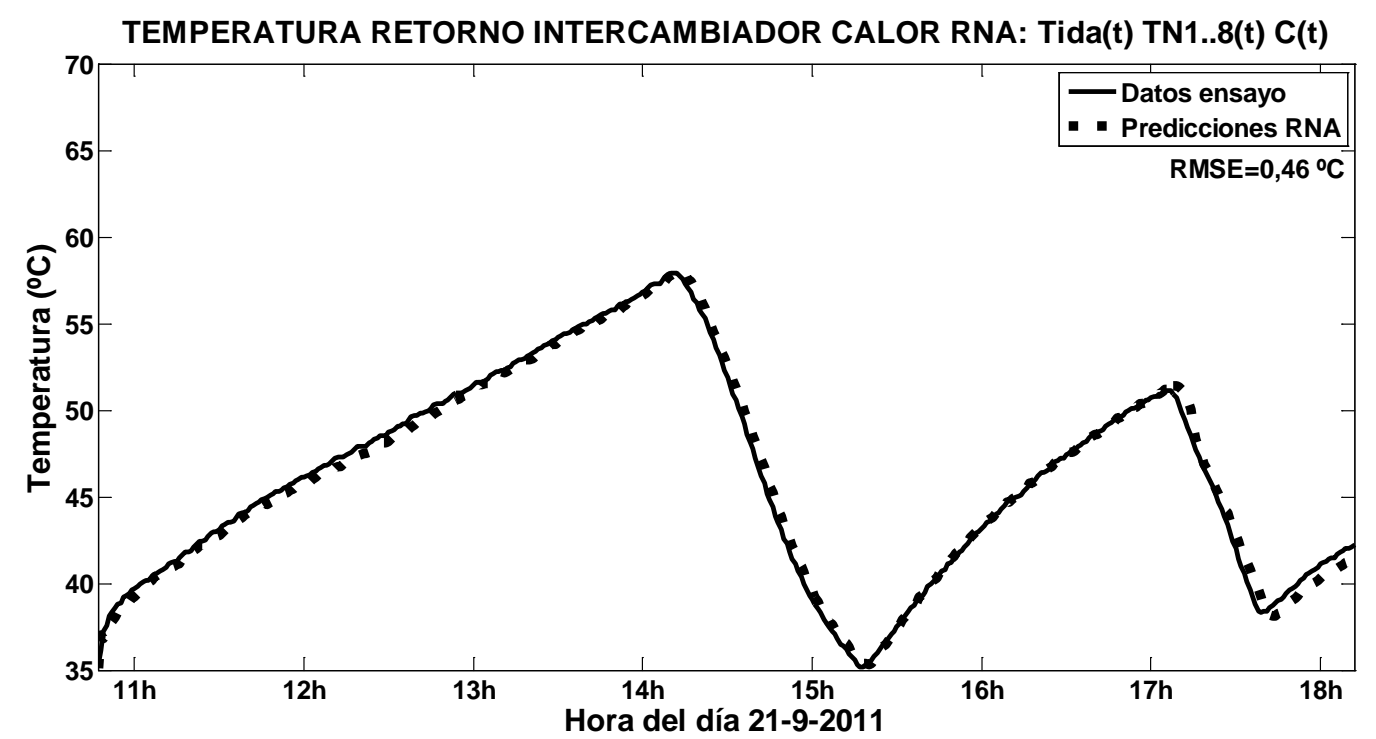

Fig. 4.6.8 Modelado RNA del intercambiador, datos medidos en el ensayo de la planta piloto el día 21-9-2011 con un caudal del fluido portador de $1 \mathrm{l} / \mathrm{min}$ y resultado de las predicciones 


\subsubsection{Resultado del modelado de la estratificación térmica del depósito acumulador de agua caliente con redes neuronales artificiales}

Los resultados de la metodología para el modelado de la estratificación térmica del depósito acumulador de agua caliente con redes neuronales artificiales, se presenta para los cuatro estados posibles de su funcionamiento:

1) El estado denominado SOL que corresponde al tiempo en que la irradiación solar es suficiente para que la bomba de impulsión esté en marcha y sin descarga de agua caliente solar.

2) El estado denominado SOL + ACS que corresponde al tiempo en que la irradiación solar es suficiente para que la bomba de impulsión esté en marcha y con descarga de agua caliente solar.

3) El estado denominado NOCHE que corresponde al tiempo en que la irradiación solar es insuficiente para que la bomba de impulsión esté en marcha y sin descarga de agua caliente solar.

4) El estado denominado NOCHE + ACS que corresponde al tiempo en que la irradiación solar es insuficiente para que la bomba de impulsión esté en marcha y con descarga de agua caliente solar. 


\section{1) Resultado de la estratificación térmica estado: SOL}

Se representa la simulación realizada para el día 6-10-2011, mediante la red neuronal artificial previamente entrenada con el modelo (Fig. 3.6.3) de 18 neuronas en la capa oculta, junto con los datos medidos y el error producido para cada minuto del día mientras que la planta piloto se encuentra en estado SOL, obteniéndose un $\mathrm{RMSE}=0,10^{\circ} \mathrm{C}$, en la gráfica (Fig. 4.6.9).

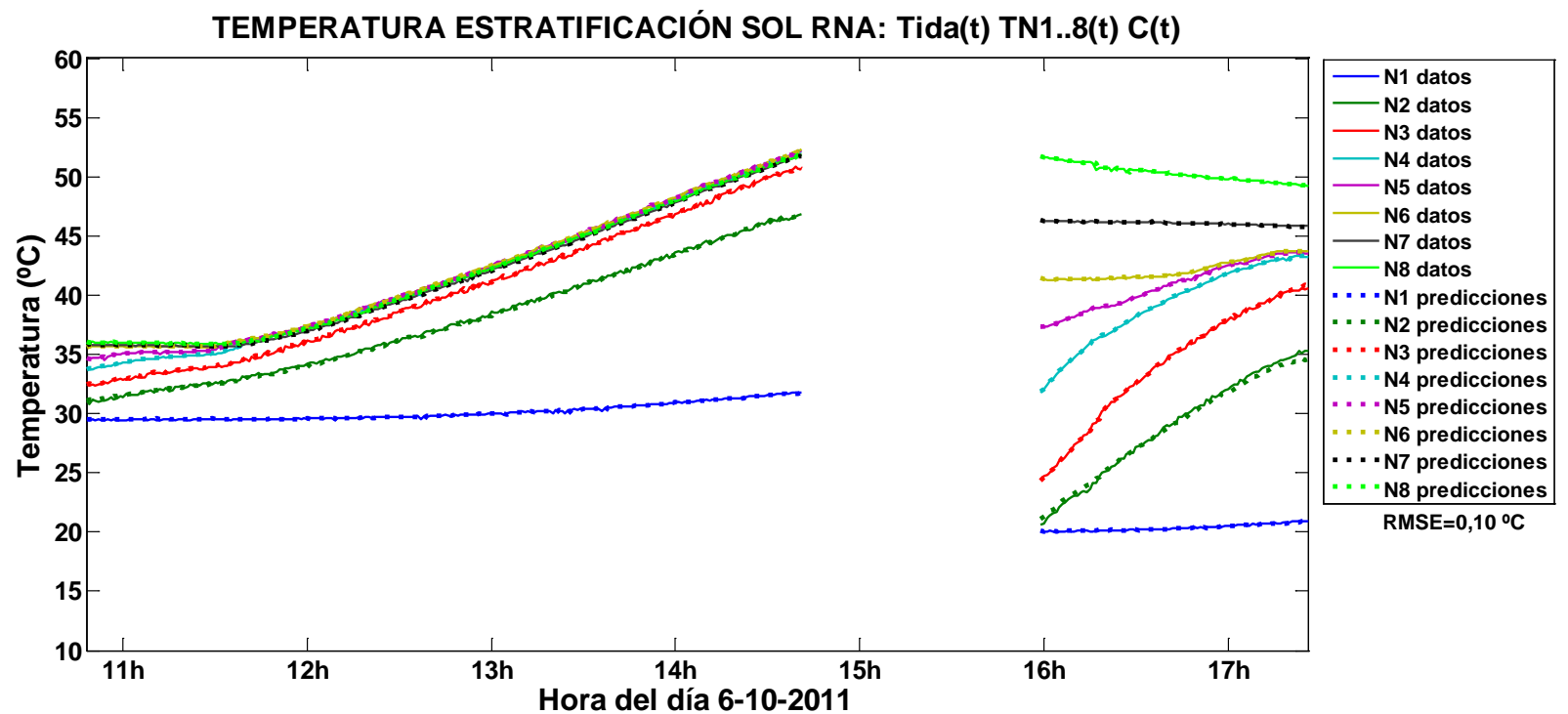

Fig. 4.6.9 Modelado RNA estratificación durante el periodo de insolación sin consumo de agua caliente solar, datos medidos en el ensayo de la planta piloto el día 6-10-2011 y resultado de las predicciones 


\section{2) Resultado de la estratificación térmica estado: SOL + ACS}

Se representa la simulación realizada para el día 6-10-2011, mediante la red neuronal artificial previamente entrenada con el modelo (Fig. 3.6.4) de 22 neuronas en la capa oculta, junto con los datos medidos y el error producido para cada minuto del día mientras que la planta piloto se encuentra en estado $\mathrm{SOL}+\mathrm{ACS}$, obteniéndose un $\mathrm{RMSE}=0,12{ }^{\circ} \mathrm{C}$, en la gráfica (Fig. 4.6.10).

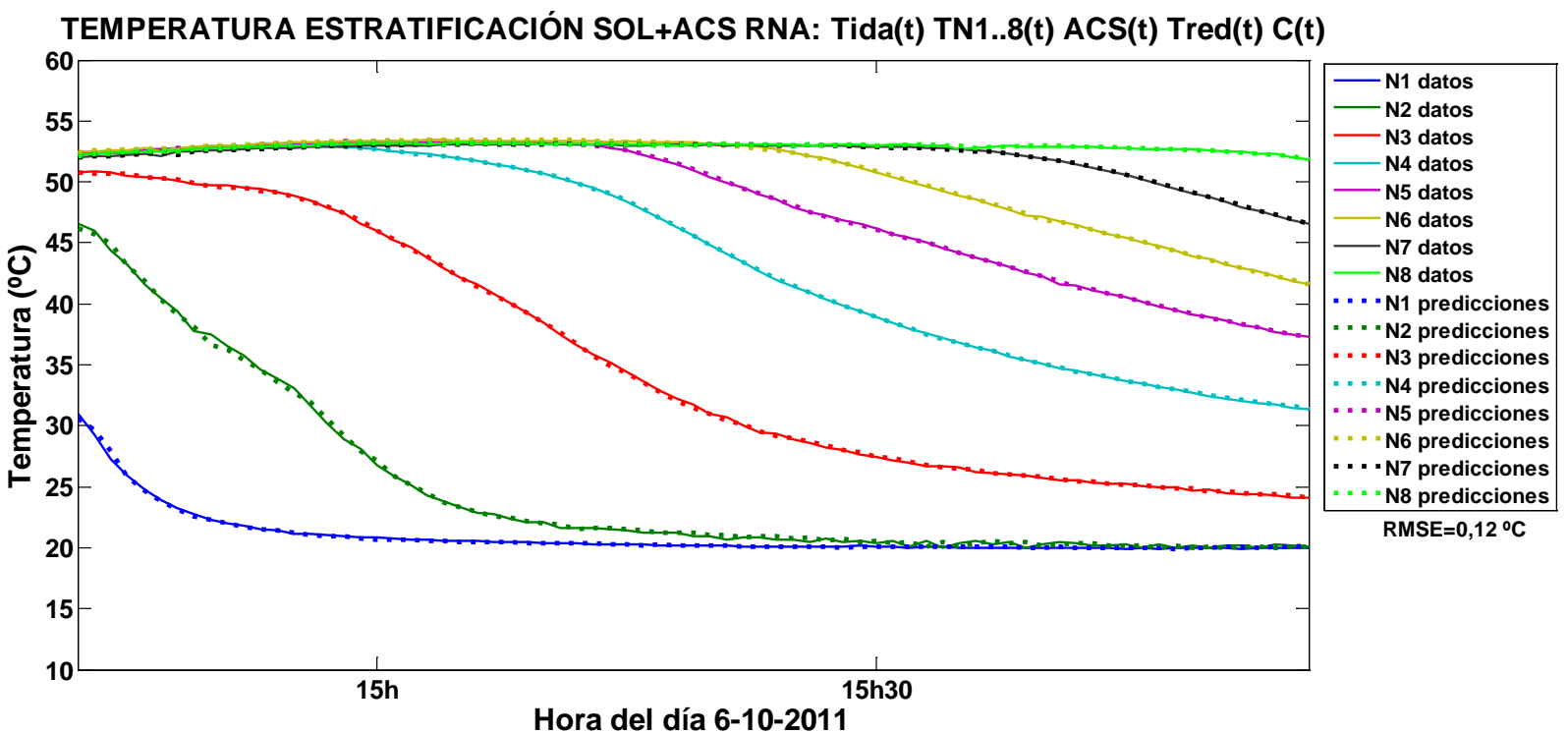

Fig. 4.6.10 Modelado RNA estratificación durante el periodo de insolación con consumo de agua caliente solar, datos medidos en el ensayo de la planta piloto el día 6-10-2011 y resultado de las predicciones 


\section{3) Resultado de la estratificación térmica estado: NOCHE}

Se representa la simulación realizada para los días $6,7,8,9$ y 10-10-2011, mediante la red neuronal artificial previamente entrenada con el modelo (Fig. 3.6.5) de 16 neuronas en la capa oculta, junto con los datos medidos y el error producido para cada diez minutos del día mientras que la planta piloto se encuentra en el interior del laboratorio, en el estado NOCHE, obteniéndose un RMSE $=0,07^{\circ} \mathrm{C}$, en la gráfica (Fig. 4.6.11).

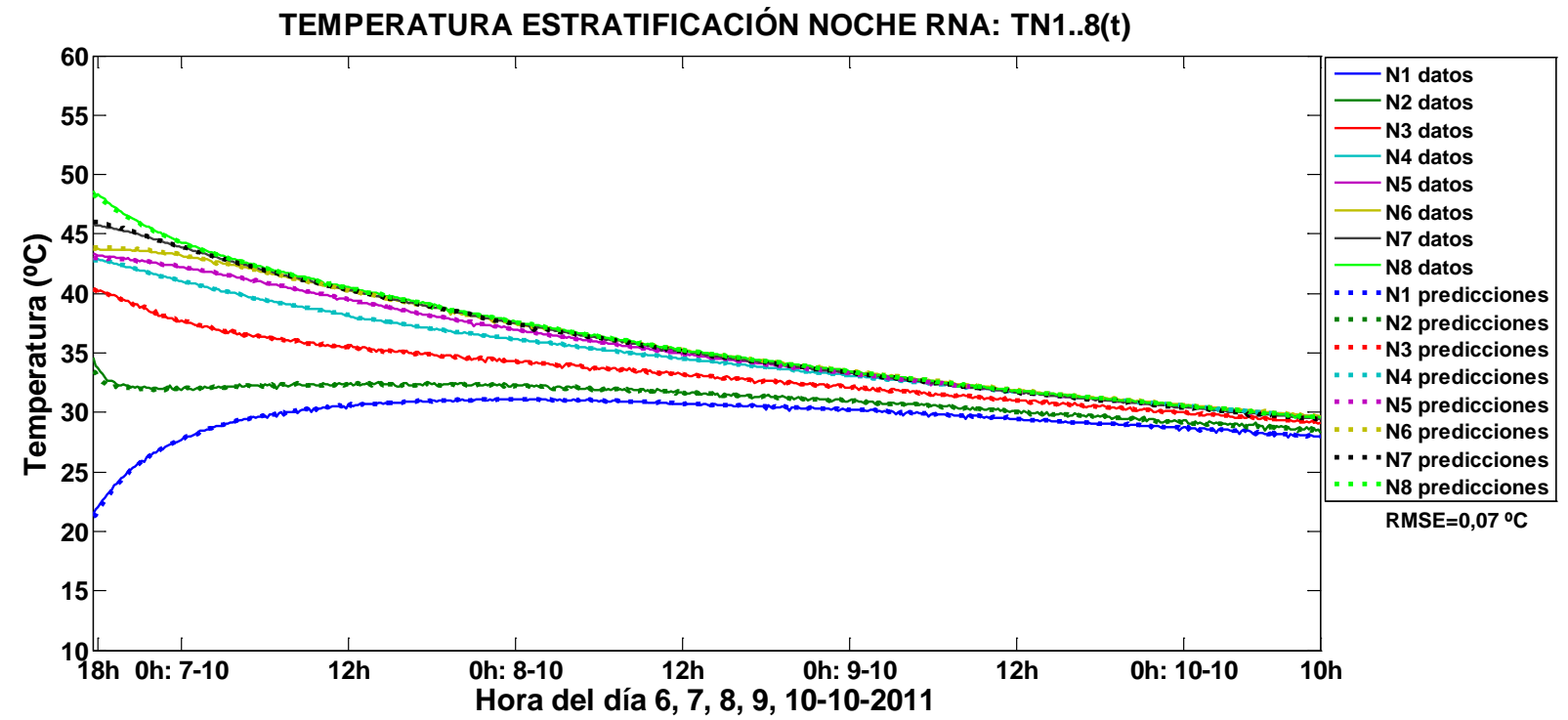

Fig. 4.6.11 Modelado RNA estratificación durante el periodo de noche o cielo nubado sin consumo de agua caliente solar, datos medidos en el ensayo de la planta piloto los días 6, 7, 8, 9 y 10-10-2011 y resultado de las predicciones

\section{Identificación curvas estratificación térmica estado: NOCHE}

Se ha conseguido identificar matemáticamente las curvas de la evolución térmica de cada capa del depósito mediante la suma de dos curvas exponenciales.

Por estratificación estática se conoce a la evolución de las temperaturas que se produce en el depósito, cuando la planta piloto se encuentra inactiva en el interior del laboratorio, que aquí equivale al estado denominado NOCHE de un sistema solar térmico cuando la radiación solar incidente sobre el captador es insuficiente para activar la bomba del circuito primario y además no se realiza descarga de agua caliente solar del depósito.

Los datos medidos en esta situación se registraron en los ensayos con un tiempo de muestreo de 10 minutos, al ser su evolución más lenta, desde el atardecer entre las $18 \mathrm{~h}$ y $19 \mathrm{~h}$ cuando la planta piloto es Ilevada al interior del laboratorio, hasta las $10 \mathrm{~h} \mathrm{u} 11 \mathrm{~h}$ del día siguiente en que la planta piloto se vuelve a trasladar al exterior del laboratorio para continuar los ensayos.

En algunos ensayos se registraron medidas durante varios días consecutivos, con la planta piloto en el interior del laboratorio, con objeto de observar la evolución de la estratificación durante un largo periodo de tiempo. 
Estos cambios en la temperatura de cada volumen se deben a dos causas: la transferencia de calor entre las capas y a las pérdidas del depósito con el exterior.

La primera intenta llegar a lo largo del tiempo a una temperatura de equilibrio, hasta conseguir la mezcla total del agua del depósito, con lo que las capas más altas que están a mayor temperatura pierden energía calorífica, que es cedida a las capas inferiores de temperaturas más bajas del depósito.

Esto origina una pérdida en la calidad de la energía que se puede extraer del tanque, desde su parte superior al llegar el agua al consumo a una temperatura menor.

La segunda se debe a la cesión de calor al exterior del depósito, que se encuentra a una temperatura inferior, a través del aislante térmico con el que el fabricante ha construido la envolvente del depósito.

En este punto se pensó, en buscar la ecuación que representa la evolución de la temperatura en cada capa, para la identificación de esta ecuación se supone en una primera instancia que existe una transferencia de calor entre las dos capas adyacentes y otra con el exterior del depósito, una representa la cesión de calor de la capa superior con la capa analizada con otra cesión de calor de ésta con su vecina inferior, con lo que tenemos en la capa objeto de estudio una ganancia de calor proveniente de la capa superior y una pérdida de calor hacia la capa inferior, la transferencia de calor con el exterior se debe a las pérdidas de las paredes de la capa estudiada.

Otra suposición utilizada proviene de la teoría de transferencia del calor, la cual nos dice que la velocidad de transferencia del calor aumenta al aumentar el gradiente o diferencial de temperaturas entre dos puntos, o sea que para una misma distancia la velocidad de transferencia de calor entre dos puntos aumenta si la diferencia de temperatura es mayor y disminuye en el caso de que la diferencia de temperaturas sea menor, todo esto hace pensar que la representación de estas tres transferencias de calor pueda conseguirse mediante curvas exponenciales, en este punto si se trabaja la ganancia y pérdida de calor de la capa estudiada respecto a la capa superior e inferior como una suma se puede pensar que la evolución de la temperatura de cada capa del tanque durante la noche se puede representar por medio de la suma de dos curvas exponenciales, $f(x)=a e^{b x}+c e^{d x}$ una de ellas debida a la ganancia-pérdida con las capas vecinas y otra debida a las pérdidas caloríficas de las paredes del depósito .

Para comprobar dicho pensamiento, se utilizan los datos recogidos de los ensayos realizados con la planta piloto durante la noche y la Toolbox de Matlab Curve Fitting, que nos ayuda a buscar el valor de los coeficientes $a, b, c$ y d de las dos curvas exponenciales de las que se espera puedan representar la evolución térmica durante la noche a partir de los datos registrados en los ensayos con la planta piloto, los resultados obtenidos reflejan un ajuste del $99 \%$ entre el modelo de las dos curvas exponenciales y los datos registrados en los experimentos.

Se representan los 97 registros de las medidas tomadas en la noche del día 4 al 5-7-2011 y el modelo de dos curvas exponenciales generado (Fig. 4.6.12) con los datos correspondientes a las 8 capas en las que se ha dividido el depósito, en la (Tabla 4.6.1) se identifican sus respectivas ecuaciones. 


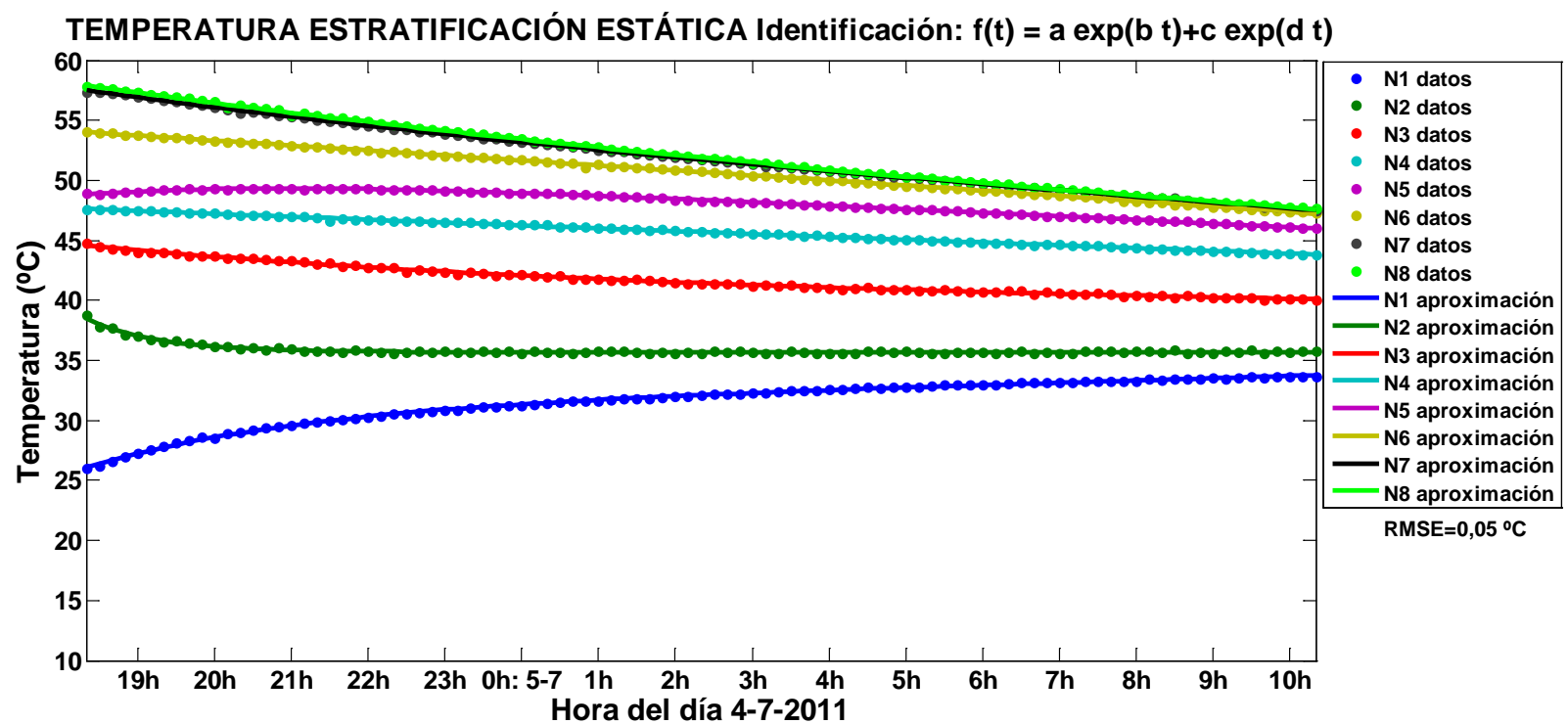

Fig. 4.6.12 Ensayo realizado en el interior del laboratorio del día 4 al 5-7-2011, se representan los datos registrados cada 10 minutos de la temperatura de estratificación del depósito, junto con la aproximación de una curva exponencial doble

Tabla 4.6.1 Ensayo realizado en el interior del laboratorio del día 4 al 5-7-2011, se representa la ecuación para cada capa del depósito

\begin{tabular}{|c|c|}
\hline Capa del depósito & Función identificativa de la evolución térmica estática \\
\hline N8 & $f(t)=49,27 e^{-0,0009809 t}+8,775 e^{-0,0117 t}$ \\
\hline N7 & $f(t)=55,06 e^{-0,001562 t}+2,618 e^{-0,02597 t}$ \\
\hline N6 & $f(t)=54,18 e^{-0,001237 t}-0,1016 e^{-0,02166 t}$ \\
\hline N5 & $f(t)=51,16 e^{-0,001093 t}-2,444 e^{-0,05953 t}$ \\
\hline N4 & $f(t)=47,68 e^{-0,0008671 t}-0,01 e^{-0,01 t}$ \\
\hline N3 & $f(t)=40,9 e^{-0,0002926 t}+3,783 e^{-0,02477 t}$ \\
\hline N2 & $f(t)=35,69 e^{0,000002052 t}+3,336 e^{-0,1775 t}$ \\
\hline N1 & $f(t)=31,02 e^{0,0008816 t}-5,269 e^{-0,0597 t}$ \\
\hline
\end{tabular}

Se dan algunas excepciones de curvas que se pueden representar con un solo término exponencial $f(x)=$ $a e^{b x} y$ estas se dan en las capas que se encuentran rodeadas de capas a la misma temperatura con lo cual la ganancia-pérdidas con las capas superior e inferior es cero. Y en el caso de que pasados unos días la mezcla del tanque se haya homogenizado y la variación de la temperatura solo responde a pérdidas en el tanque hacia el exterior, pudiendo representarse con una única exponencial.

Otra característica que se observa que cumplen las curvas de variación térmica de cada capa del depósito es que no se cortan, permaneciendo la capa superior a más temperatura que su inferior, solo se consiguen igualar en algunos casos en la parte superior cuando se ha captado gran cantidad de energía calorífica.

Ahora además de los datos de las mediciones de la evolución de la temperatura de cada capa del depósito en los ensayos durante la noche, se dispone de una ecuación matemática que las identifica. 


\section{4) Resultado de la estratificación térmica estado: NOCHE + ACS}

Se representa la simulación realizada para el día 9-3-2012, mediante la red neuronal artificial previamente entrenada con el modelo (Fig. 3.6.6) de 16 neuronas en la capa oculta, junto con los datos medidos y el error producido para cada minuto del día mientras que la planta piloto se encuentra en estado NOCHE + ACS, obteniéndose un RMSE $=0,12{ }^{\circ} \mathrm{C}$, en la gráfica (Fig. 4.6.13). En este ensayo para conseguir esta situación se colocó la planta piloto en una zona de sombra para evitar la incidencia de la radiación solar sobre el captador solar y se realizó una descarga de 150 litros de agua caliente solar.

Datos de entrada: Caudal de agua caliente solar $1,41 \mathrm{l} / \mathrm{min}$, y temperatura del agua de red $11,6^{\circ} \mathrm{C}$

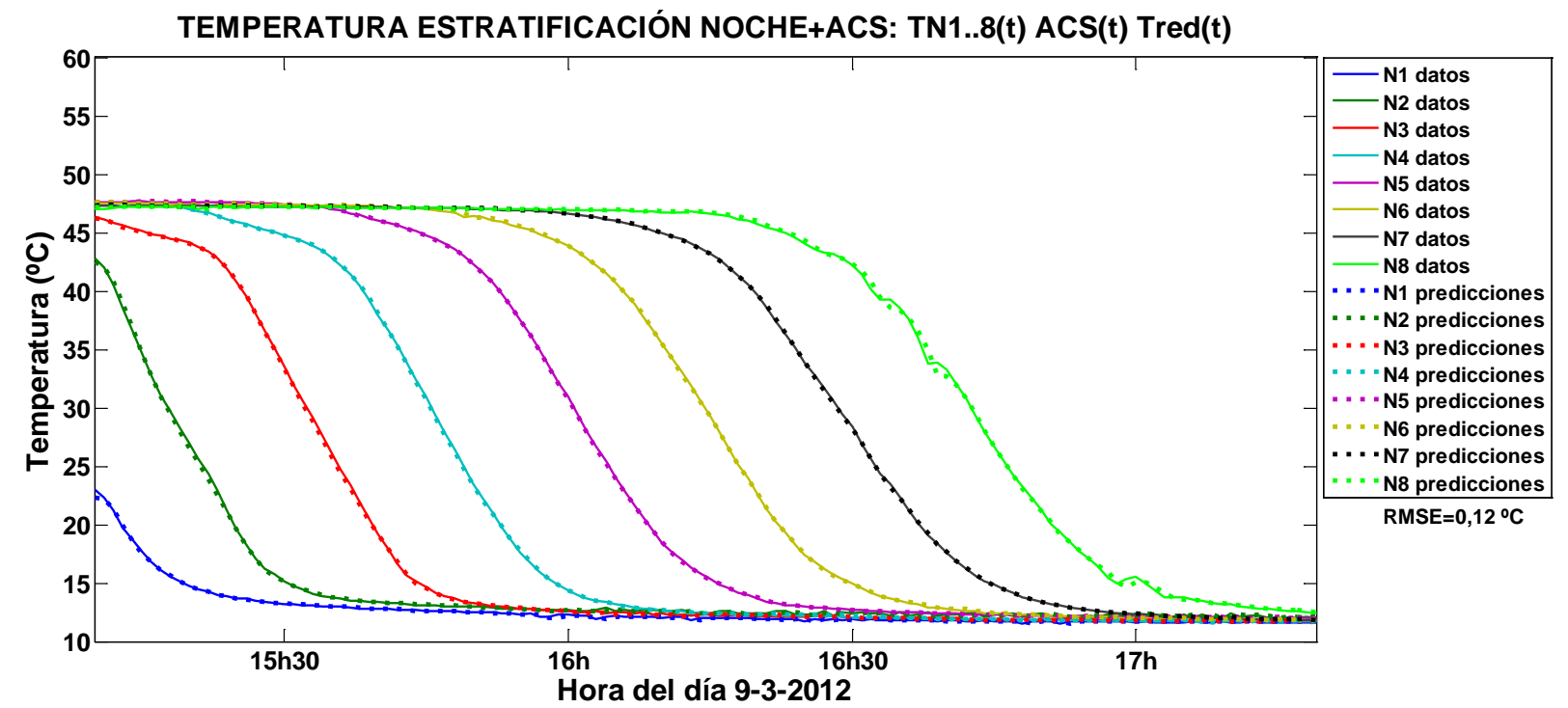

Fig. 4.6.13 Modelado RNA estratificación durante el periodo de noche o cielo nublado con consumo de agua caliente solar, datos medidos en el ensayo de la planta piloto el día 9-3-2012 y resultado de las predicciones 


\subsection{Simulación neural del sistema solar térmico}

Se presentan los resultados de las simulaciones del funcionamiento de un sistema solar térmico realizado con la metodología (Apartado 3.7), de varios ensayos junto con los datos medidos y registrados en la planta piloto, y el error cometido valorado mediante el estadístico RMSE, para validar su resultado. También se presentan los resultados de las simulaciones mensuales realizadas para el año 2002 y del 2004 al año 2012, con el objetivo de conocer el rendimiento anual del sistema solar térmico estudiado en este caso la planta piloto y compáralo con el resultado derivado del método f-chart, descrito (Apartado 3.2), el cual se utiliza como referencia en esta Tesis Doctoral. 


\subsubsection{Resultado de la simulación del sistema solar térmico el día 10-10-2011 en León}

Se presentan los resultados de la simulación del funcionamiento del sistema solar térmico de la planta piloto el día 10-10-2011 y la noche siguiente en León, con el modelo del (Apartado 3.7). Las entradas al modelo son cuatro:

- La irradiancia solar.

- La temperatura ambiente.

- El caudal del agua caliente solar descargada.

- La temperatura del agua de red.

Estos datos en escala de minuto se representan gráficamente en la (Fig. A.2.8).

Antes de comenzar la simulación se ajustan en el modelo neuronal del sistema solar térmico, las temperaturas de estratificación en el depósito acumulador a las $10 \mathrm{~h} 42$ y el caudal de funcionamiento de la bomba de impulsión.

La simulación diurna termina a las 18h22, con los resultados que se observan en la gráfica (Fig. 4.7.1), junto a los datos medidos en la planta piloto, con un $\mathrm{RMSE}=0,77{ }^{\circ} \mathrm{C}$ en las temperaturas de estratificación del depósito acumulador.

ENTRADAS MODELO RNA PLANTA PILOTO DÍA: 10-10-2011 (Fig. A.2.8)

Irradiancia solar

Caudal del agua caliente solar: 1,7 l/min
Temperatura ambiente

Temperatura del agua de red: $18,5^{\circ} \mathrm{C}$

SALIDA MODELO RNA PLANTA PILOTO DÍA: 10-10-2011 (Fig. A.2.8)

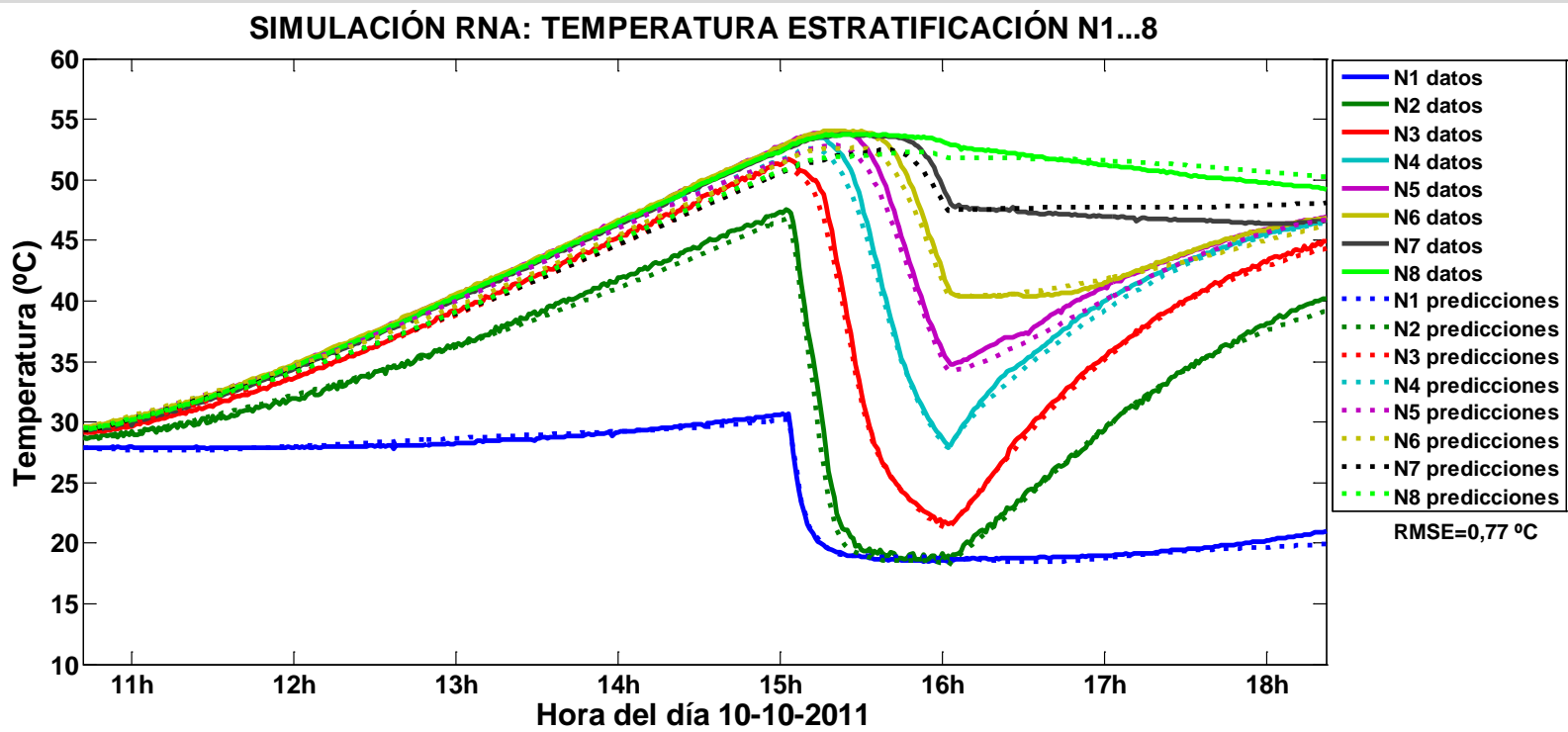

Fig. 4.7.1 Modelado RNA planta piloto con el caudal del circuito primario $1 \mathrm{l} / \mathrm{min}$, datos medidos en el ensayo del día 10-10-2011 y resultado de la simulación realizada 
La simulación nocturna comienza a las $18 \mathrm{~h} 30$, con la planta piloto en el interior del laboratorio, ajustándose en el modelo neuronal del sistema solar térmico las temperaturas de estratificación en el depósito acumulador, finalizando a las $10 \mathrm{~h} 19$ del día siguiente, con los resultados que se observan en la gráfica (Fig. 4.7.2), junto a los datos medidos en la planta piloto, con un RMSE $=0,13{ }^{\circ} \mathrm{C}$ en las temperaturas de estratificación del depósito acumulador.

\section{ENTRADAS MODELO RNA PLANTA PILOTO NOCHE: 10-10-2011 (Fig. A.2.8)}

Datos de la temperatura de estratificación N1..N8

en el estado inicial a las 18 h30 del día 10-10-2011

$\begin{array}{llllllll}\text { NODO 1 } & \text { NODO } 2 & \text { NODO } 3 & \text { NODO 4 } & \text { NODO } 5 & \text { NODO 6 } & \text { NODO 7 } & \text { NODO 8 } \\ 21,05^{\circ} \mathrm{C} & 39,81{ }^{\circ} \mathrm{C} & 44,90^{\circ} \mathrm{C} & 46,72{ }^{\circ} \mathrm{C} & 46,89{ }^{\circ} \mathrm{C} & 46,91{ }^{\circ} \mathrm{C} & 46,84{ }^{\circ} \mathrm{C} & 49,10^{\circ} \mathrm{C}\end{array}$

SALIDA MODELO RNA PLANTA PILOTO NOCHE: 10-10-2011 (Fig. A.2.8)

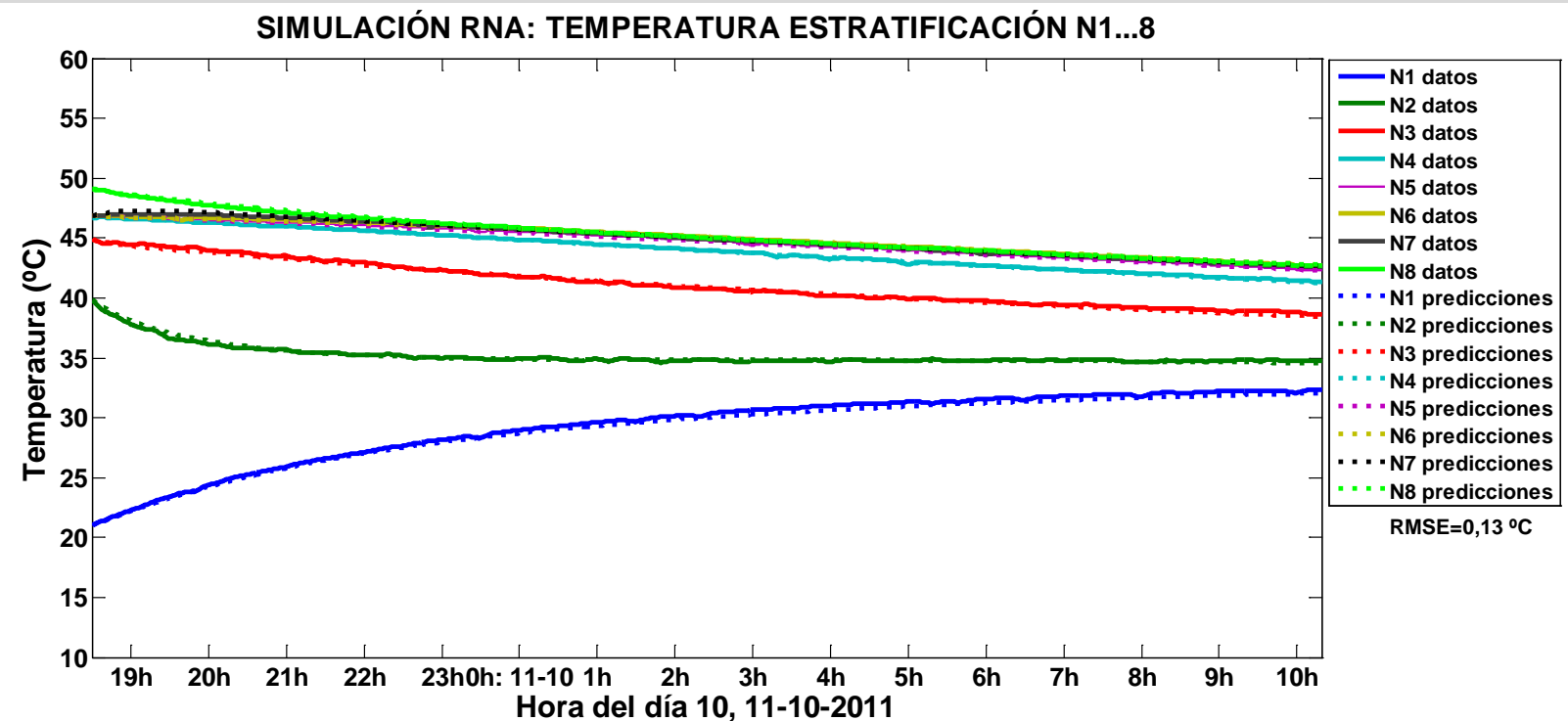

Fig. 4.7.2 Modelado RNA planta piloto durante el periodo de noche o cielo nubado sin consumo de agua caliente, datos medidos en el ensayo de la planta piloto los días 10 y 11-10-2011 y resultado de la simulación realizada 


\subsubsection{Resultado de la simulación del sistema solar térmico el día 28-11-2011 en León}

Se presentan los resultados de la simulación del funcionamiento del sistema solar térmico de la planta piloto el día 28-11-2011 y la noche siguiente en León, con el modelo del (Apartado 3.7). Las entradas al modelo son cuatro:

- La irradiancia solar.

- La temperatura ambiente.

- El caudal del agua caliente solar descargada.

- La temperatura del agua de red.

Estos datos en escala de minuto se representan gráficamente en la (Fig. A.2.10).

Antes de comenzar la simulación se ajustan en el modelo neuronal del sistema solar térmico, las temperaturas de estratificación en el depósito acumulador a las $10 \mathrm{~h} 32$ y el caudal de funcionamiento de la bomba de impulsión.

La simulación diurna termina a las $17 \mathrm{~h} 29$, con los resultados que se observan en la gráfica (Fig. 4.7.3), junto a los datos medidos en la planta piloto, con un RMSE $=0,69{ }^{\circ} \mathrm{C}$ en las temperaturas de estratificación del depósito acumulador.

\section{ENTRADAS MODELO RNA PLANTA PILOTO DÍA: 28-11-2011 (Fig. A.2.10)}

Irradiancia solar

Caudal del agua caliente solar: $1,5 \mathrm{l} / \mathrm{min}$
Temperatura ambiente

Temperatura del agua de red: $12,4^{\circ} \mathrm{C}$

\section{SALIDA MODELO RNA PLANTA PILOTO DÍA: 28-11-2011 (Fig. A.2.10)}

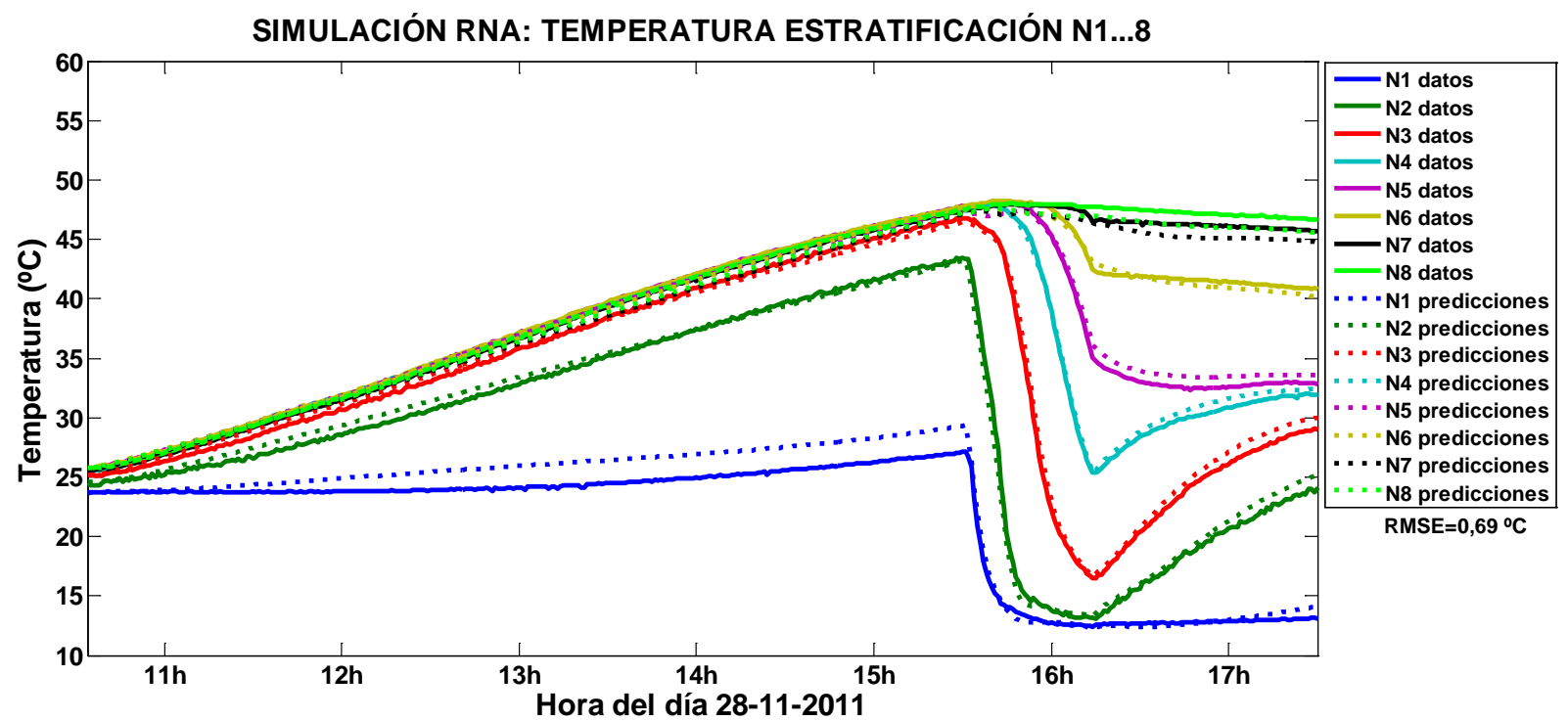

Fig. 4.7.3 Modelado RNA planta piloto con el caudal del circuito primario 1,6 l/min, datos medidos en el ensayo del día $28-11-2011$ y resultado de la simulación realizada 
La simulación nocturna comienza a las $17 \mathrm{~h} 40$, con la planta piloto en el interior del laboratorio, ajustándose en el modelo neuronal del sistema solar térmico las temperaturas de estratificación en el depósito acumulador, finalizando a las $10 \mathrm{~h} 20$ del día siguiente, con los resultados que se observan en la gráfica (Fig. 4.7.4), junto a los datos medidos en la planta piloto, con un RMSE $=0,41{ }^{\circ} \mathrm{C}$ en las temperaturas de estratificación del depósito acumulador.

ENTRADAS MODELO RNA PLANTA PILOTO NOCHE: 28-11-2011 (Fig. A.2.10)

Datos de la temperatura de estratificación N1..N8

en el estado inicial a las $17 \mathrm{~h} 40$ del día 28-11-2011

$\begin{array}{llllllll}\text { NODO } 1 & \text { NODO } 2 & \text { NODO 3 } & \text { NODO 4 } & \text { NODO } 5 & \text { NODO 6 } & \text { NODO 7 } & \text { NODO 8 } \\ 13,28^{\circ} \mathrm{C} & 23,88^{\circ} \mathrm{C} & 29,10^{\circ} \mathrm{C} & 31,68^{\circ} \mathrm{C} & 32,78^{\circ} \mathrm{C} & 40,45^{\circ} \mathrm{C} & 45,56^{\circ} \mathrm{C} & 46,53^{\circ} \mathrm{C}\end{array}$

SALIDA MODELO RNA PLANTA PILOTO NOCHE: 28-11-2011 (Fig. A.2.10)

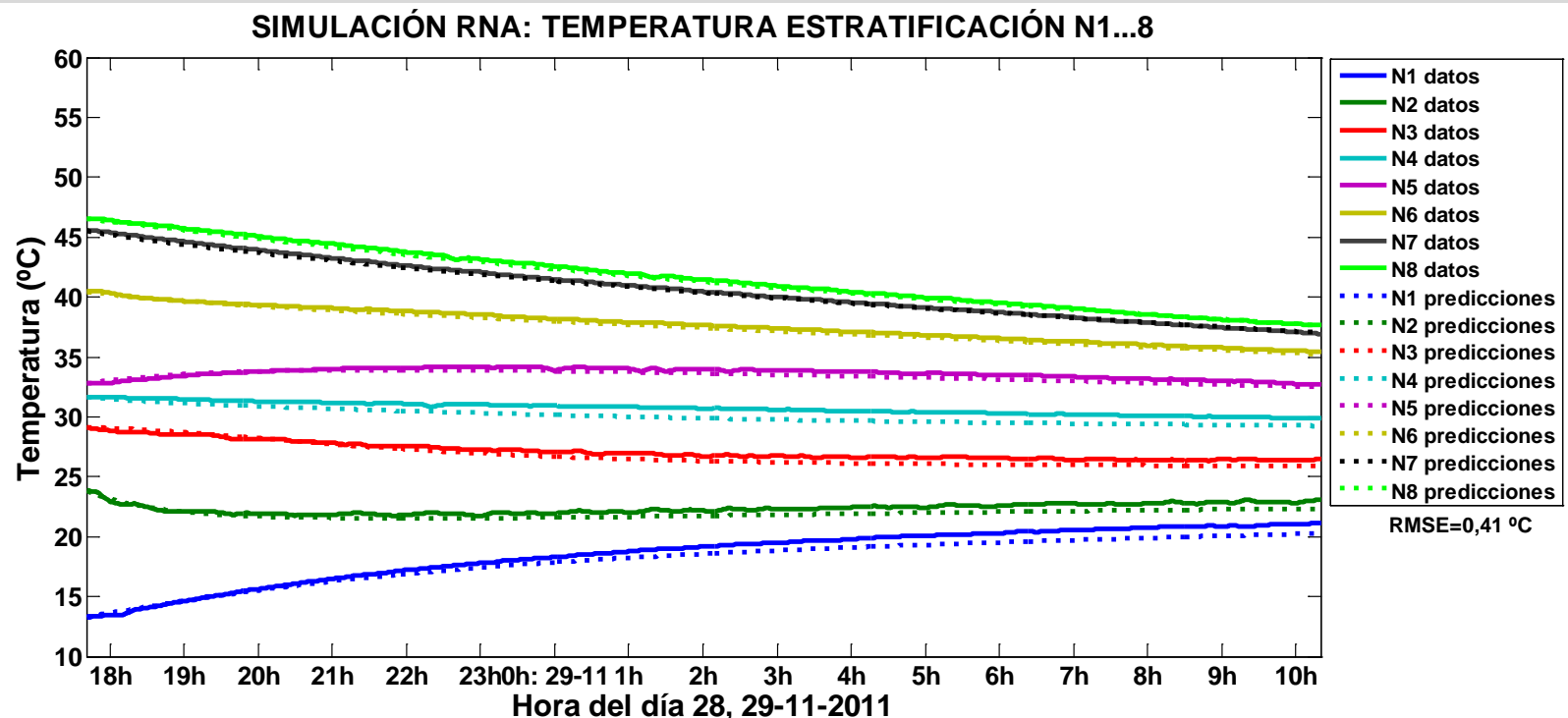

Fig. 4.7.4 Modelado RNA planta piloto durante el periodo de noche o cielo nubado sin consumo de agua caliente, datos medidos en el ensayo de la planta piloto los días 28 y 29-11-2011 y resultado de la simulación realizada 


\subsubsection{Resultado de la simulación del sistema solar térmico mensualmente durante diez años en León}

Se presentan los resultados del modelado en la simulación del funcionamiento del sistema solar térmico de la planta piloto, para cada mes, durante el año 2012 en León, con el modelo (Apartado 3.7). Las entradas al modelo son cuatro:

- La irradiancia solar.

- La temperatura ambiente.

- El caudal del agua caliente solar descargada.

- La temperatura del agua de red.

Estos datos en escala de minuto, son los datos de la irradiancia solar sobre el plano inclinado del captador solar y la temperatura ambiente aplicada la metodología (Apartado 3.5), el caudal del agua caliente solar se realiza con las estimaciones del consumo en un sistema solar térmico concreto en este caso de $75 \mathrm{l} /$ día a $50{ }^{\circ} \mathrm{C}$ distribuida con los porcentajes de uso doméstico (Mutch, 1974) y la temperatura del agua de red se estima a través de mediciones repartidas durante cada mes del año 2011 llevadas a cabo en la planta piloto, realizando un ajuste para el resto de días al no tener una variación importante.

Antes de comenzar la simulación se ajustan en el modelo neuronal del sistema solar térmico, las temperaturas de estratificación en el depósito acumulador a las 0h00 del día uno del mes y el caudal de funcionamiento de la bomba de impulsión.

La simulación termina a las $23 \mathrm{~h} 59$ del último día del mes, con los resultados que se observan en las gráficas (Fig. 4.7.5) ... (Fig. 4.7.16), correspondientes a los meses de enero a diciembre del año 2012 en las temperaturas de estratificación del depósito acumulador.

La validación del modelado del sistema solar térmico para ejecutar la simulación de su funcionamiento, se realizó mediante una comparación de los datos registrados en los numerosos ensayos realizados en la planta piloto durante un año (Anexo 2 Datos de los ensayos en la planta piloto), resultando desviaciones similares a las presentadas (Apartado 4.7.1) y (Apartado 4.7.2).

La simulación anual también se revisó visualmente día por día en busca de resultados anómalos o no coherentes con el nivel de irradiación solar diario de cada día del año 2012 (Fig. A.1.12), resultando que no se producen situaciones que hagan que el modelado neural propuesto (Apartado 3.7) no pueda ser utilizado para valorar el funcionamiento en un largo periodo de tiempo, ante cualquier estado que se produzca, ya sea en la climatología o en el funcionamiento del sistema solar térmico, considerando por ello que se puede dar por válido el modelo presentado para simular el funcionamiento de un sistema solar térmico.

Además en el próximo capítulo se analizarán los resultados de la simulación con respecto a los obtenidos con la aplicación del método f-chart en las mismas condiciones, resultando que también apoyan la validez de la simulación del modelo neural en un largo periodo de tiempo con respecto al método f-chart. 


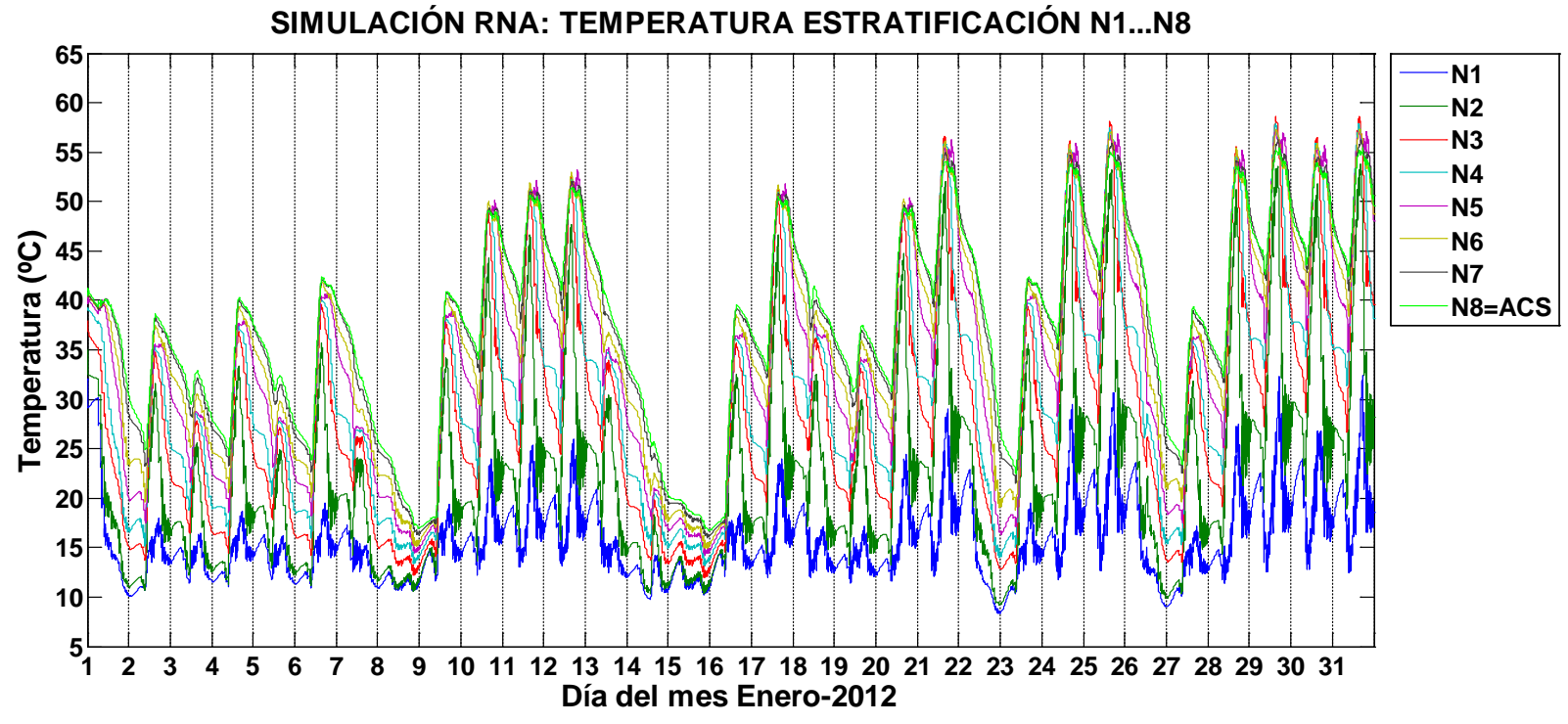

Fig. 4.7.5 Temperaturas de estratificación de la simulación con el modelo RNA de la planta piloto para el mes de enero-2012

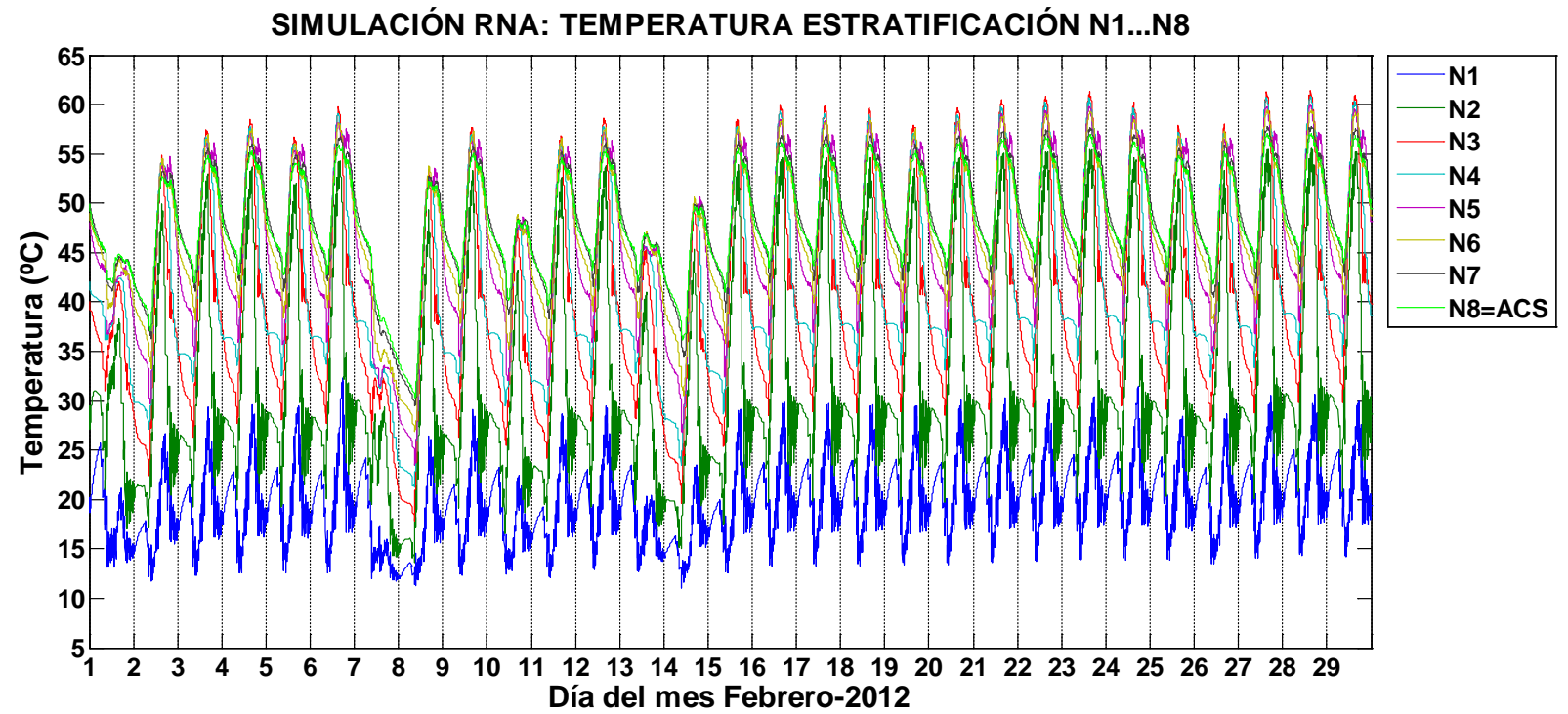

Fig. 4.7.6 Temperaturas de estratificación de la simulación con el modelo RNA de la planta piloto para el mes de febrero-2012 


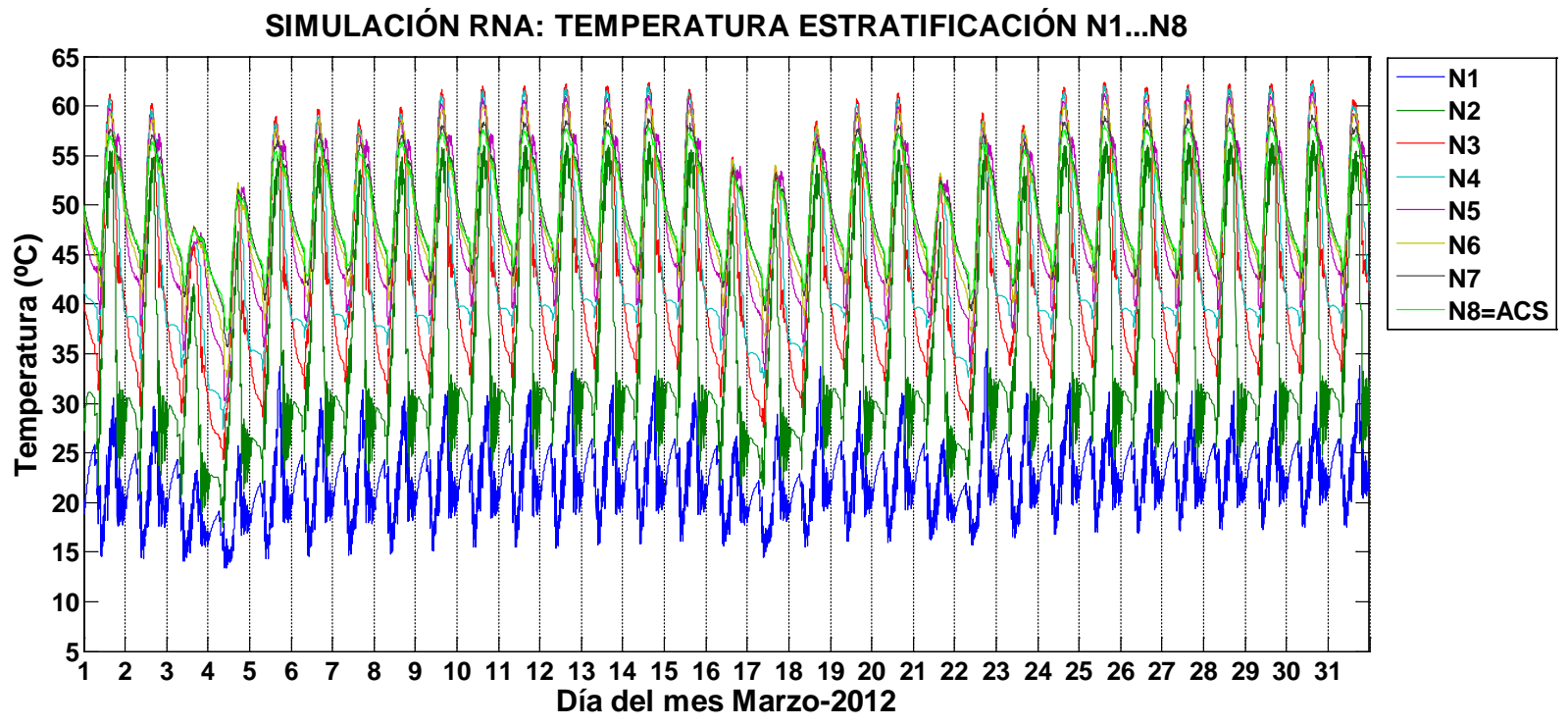

Fig. 4.7.7 Temperaturas de estratificación de la simulación con el modelo RNA de la planta piloto para el mes de marzo-2012

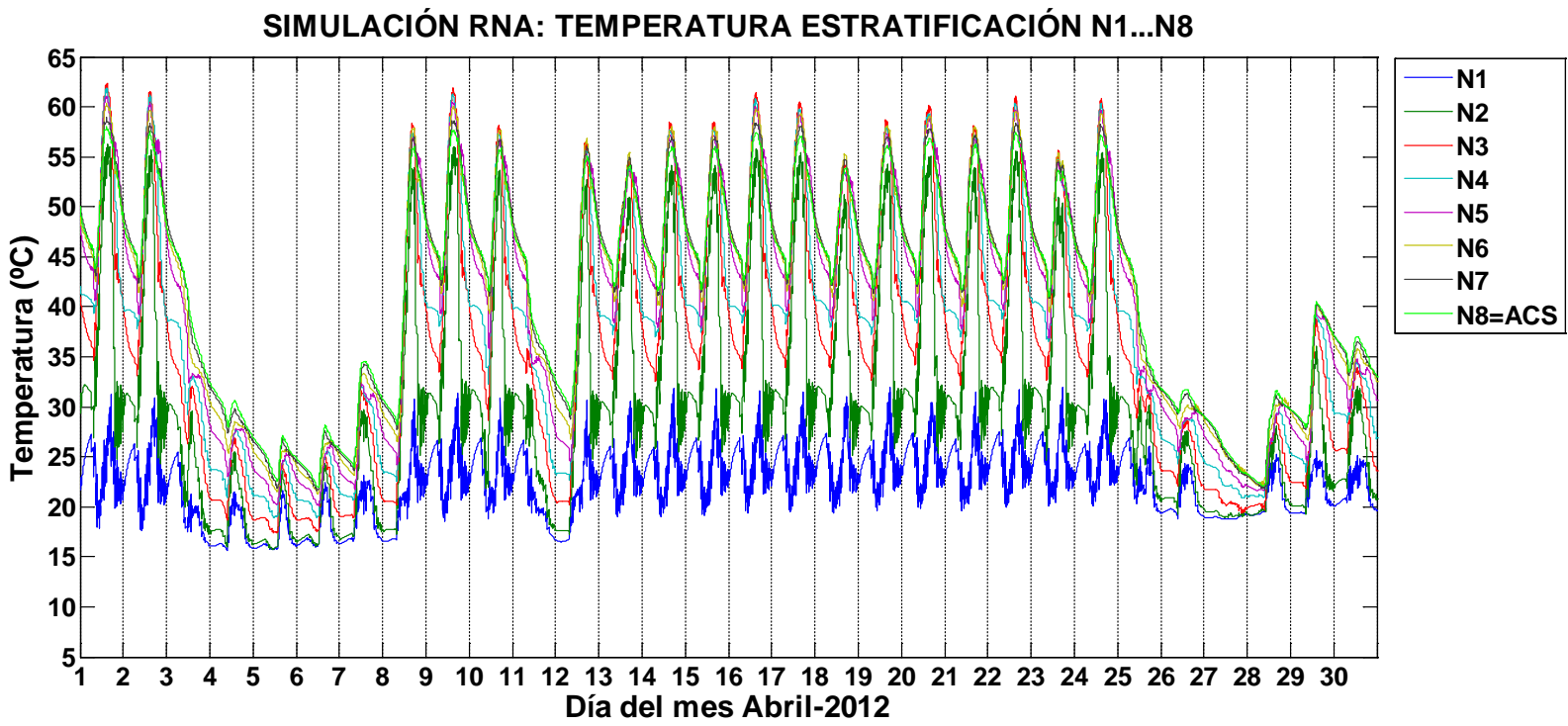

Fig. 4.7.8 Temperaturas de estratificación de la simulación con el modelo RNA de la planta piloto para el mes de abril-2012 


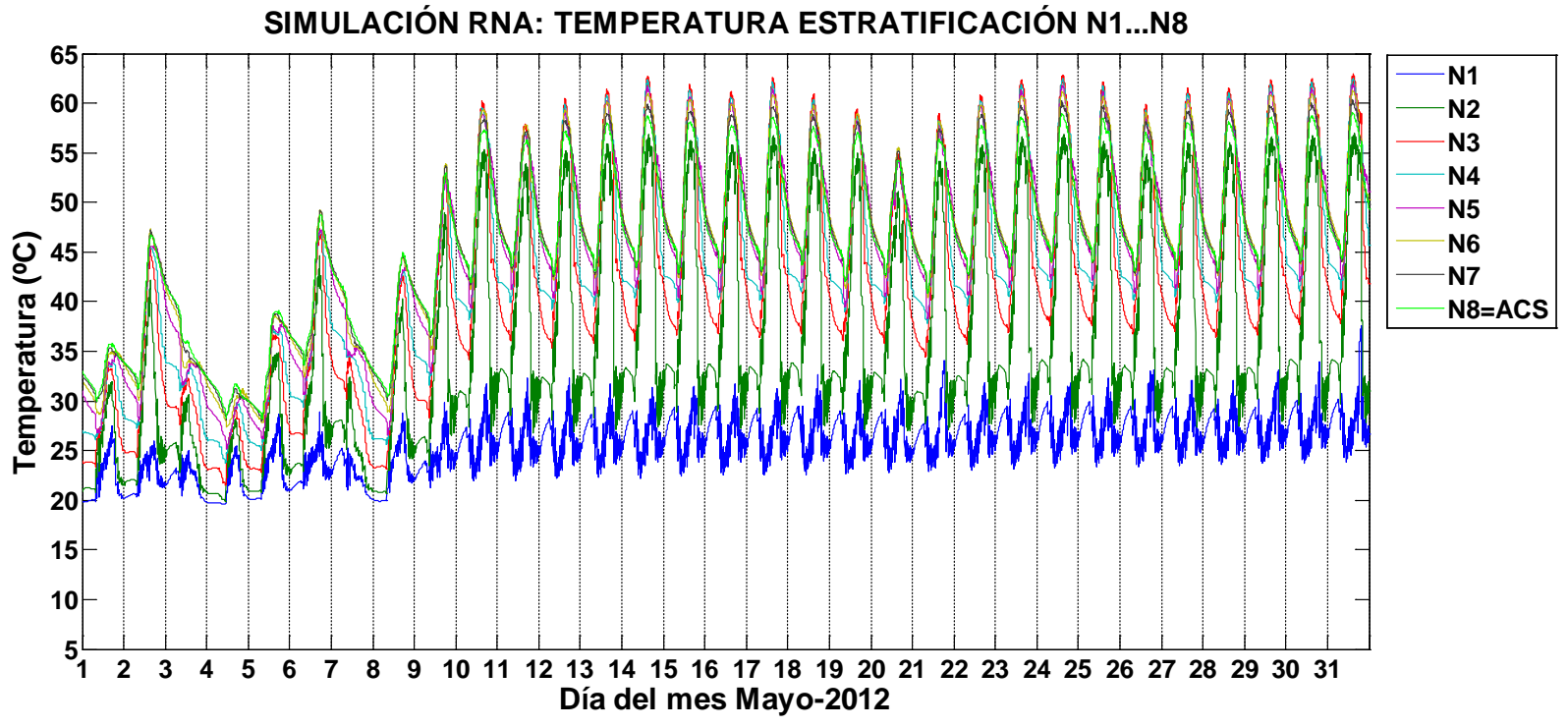

Fig. 4.7.9 Temperaturas de estratificación de la simulación con el modelo RNA de la planta piloto para el mes de mayo-2012

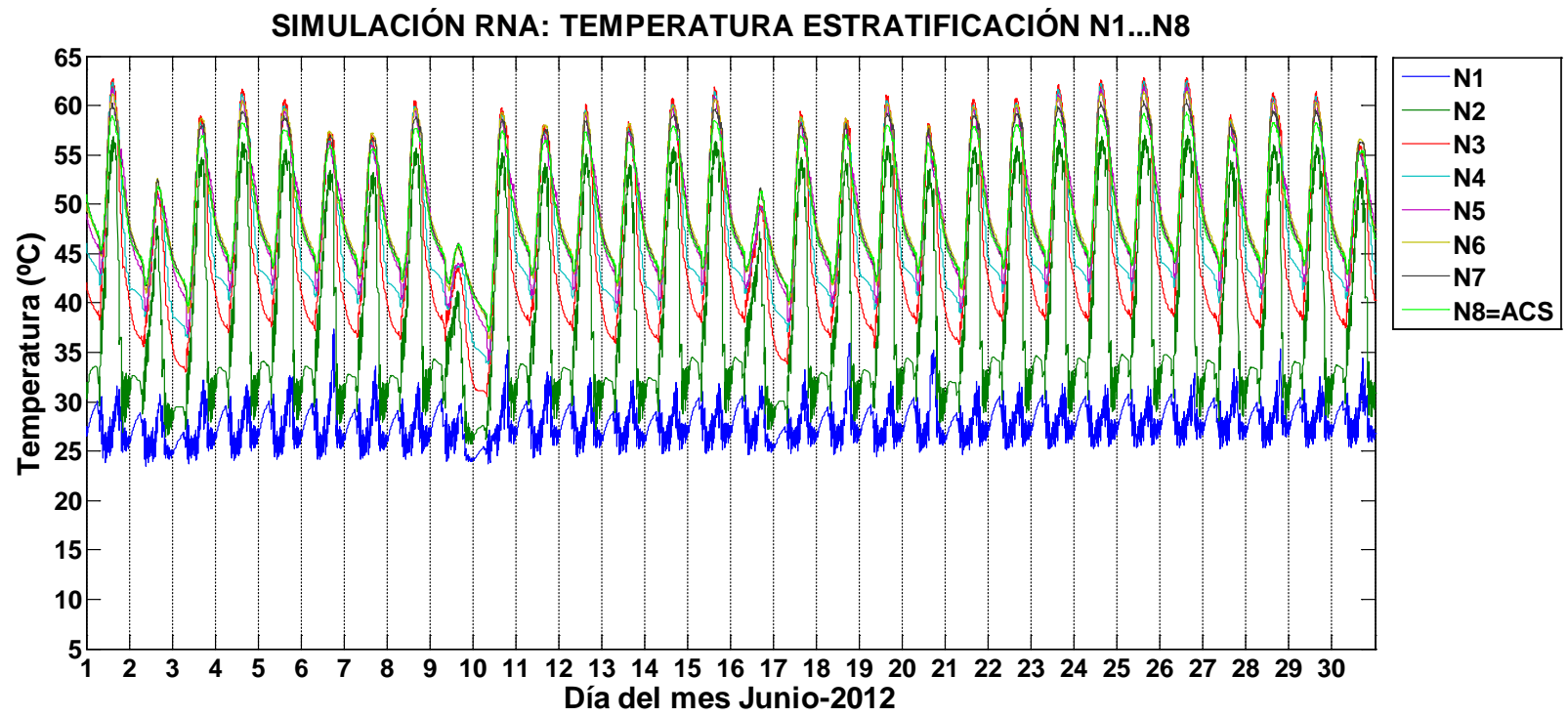

Fig. 4.7.10 Temperaturas de estratificación de la simulación con el modelo RNA de la planta piloto para el mes de junio-2012 


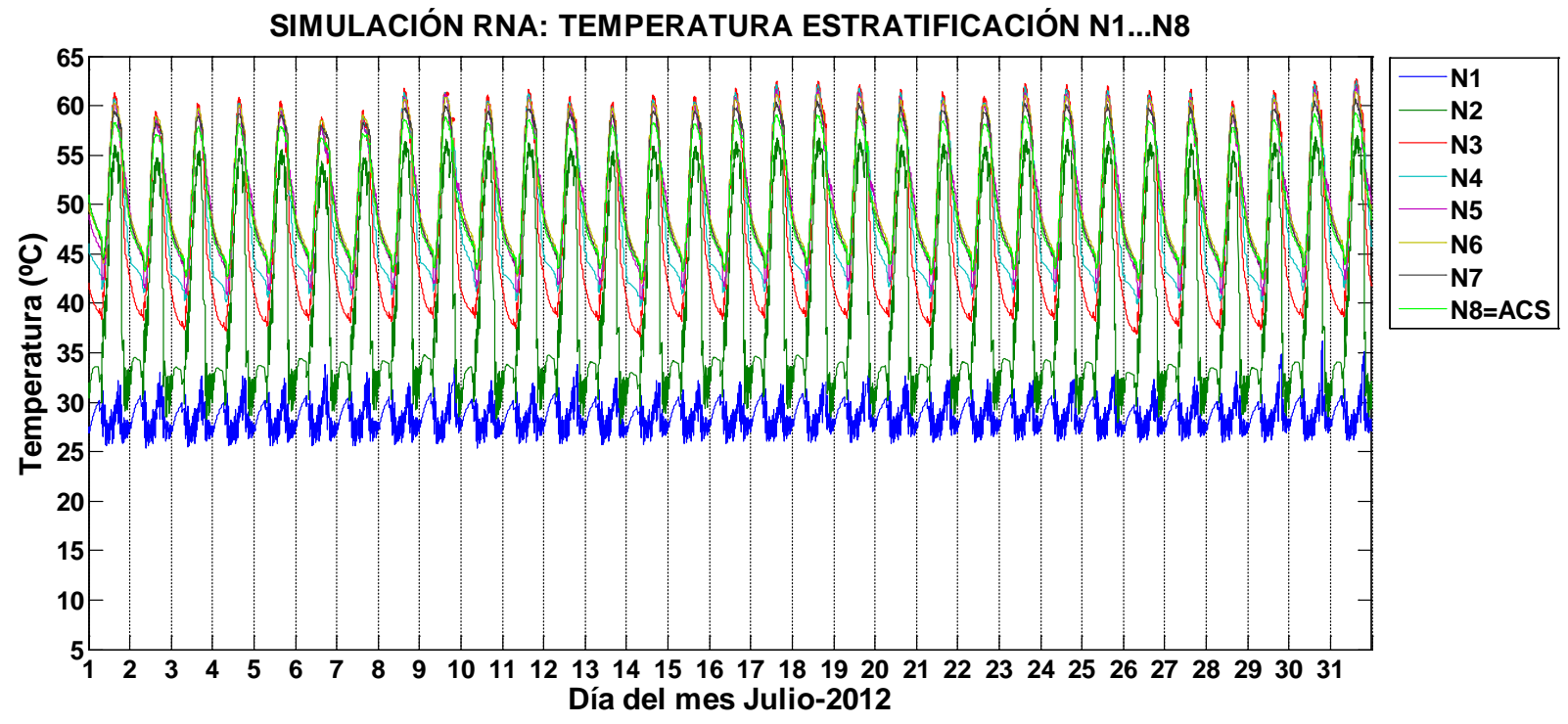

Fig. 4.7.11 Temperaturas de estratificación de la simulación con el modelo RNA de la planta piloto para el mes de julio-2012

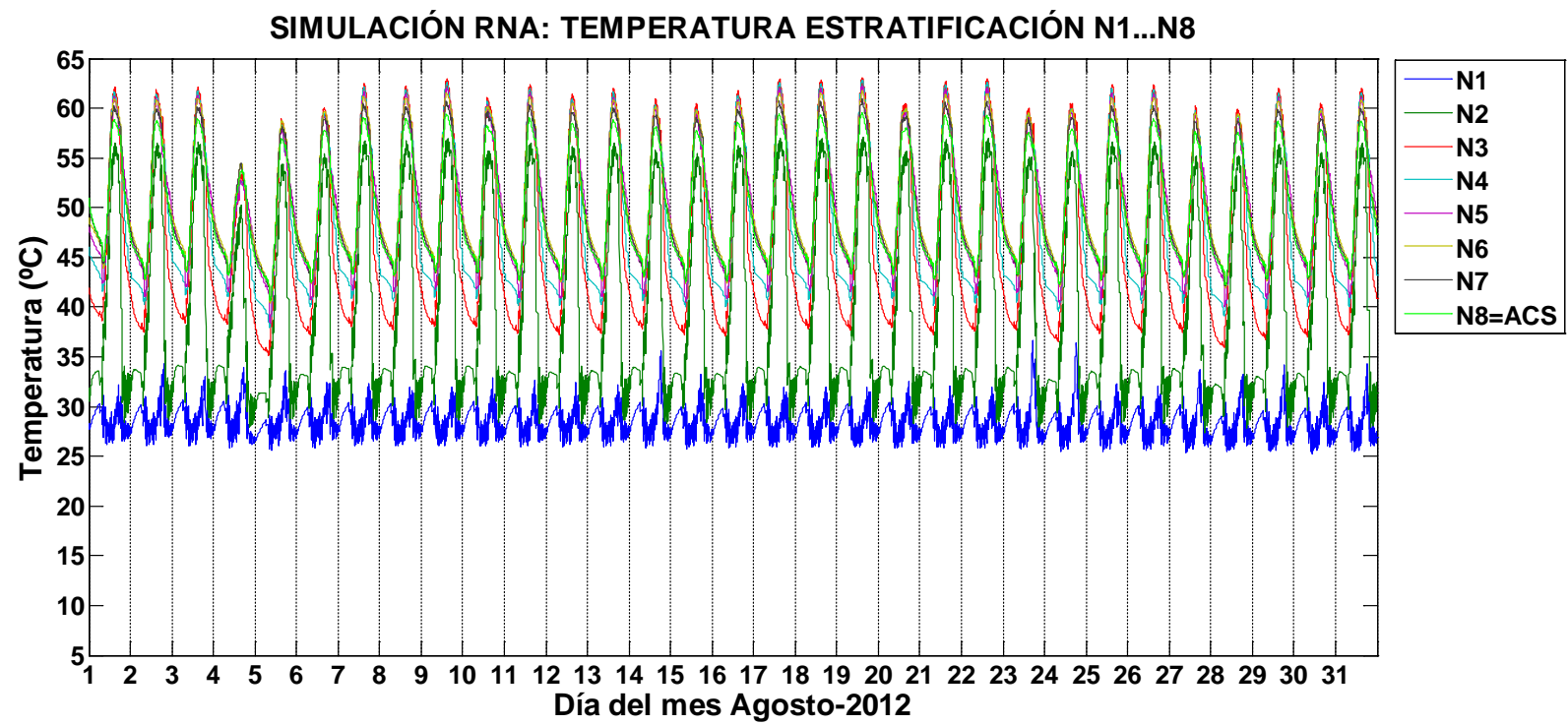

Fig. 4.7.12 Temperaturas de estratificación de la simulación con el modelo RNA de la planta piloto para el mes de agosto-2012 


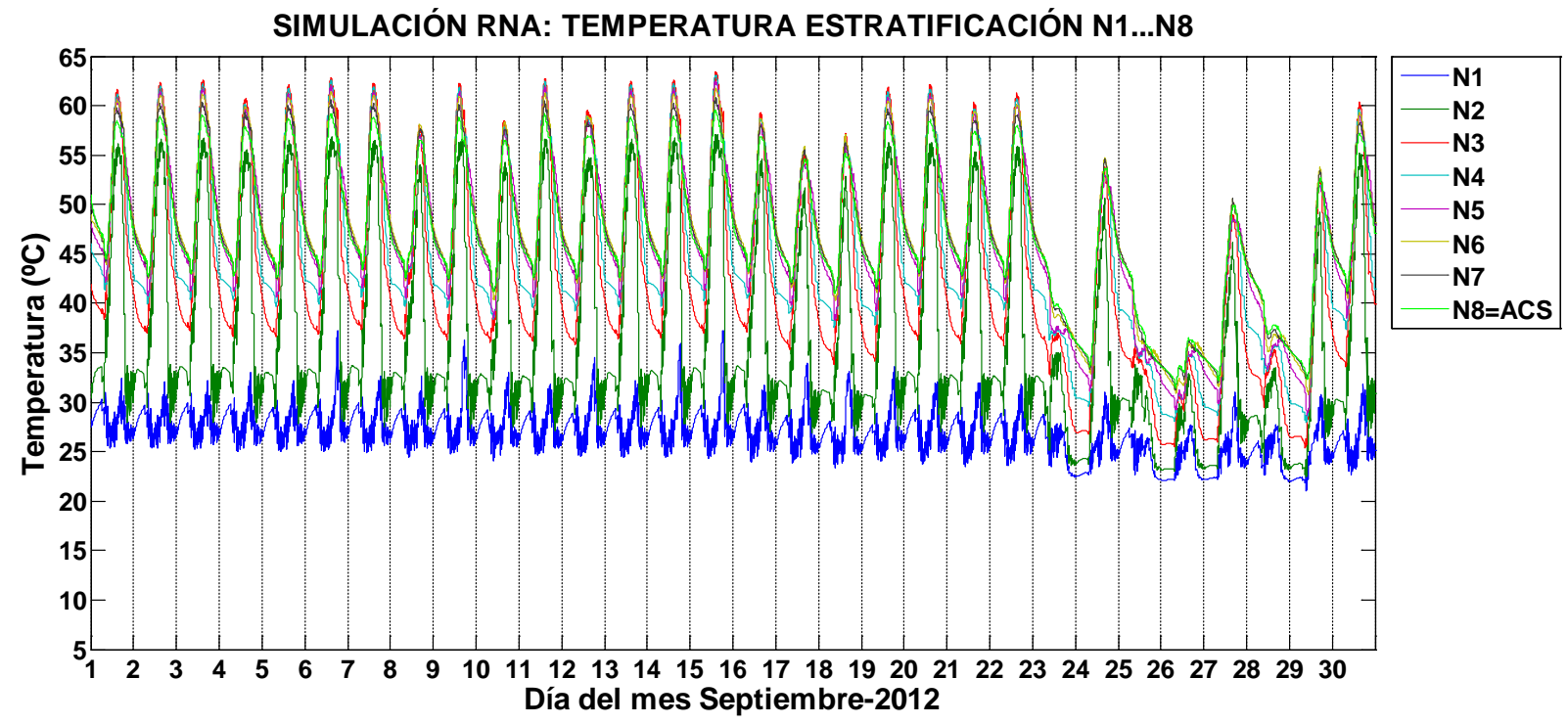

Fig. 4.7.13 Temperaturas de estratificación de la simulación con el modelo RNA de la planta piloto para el mes de septiembre-2012

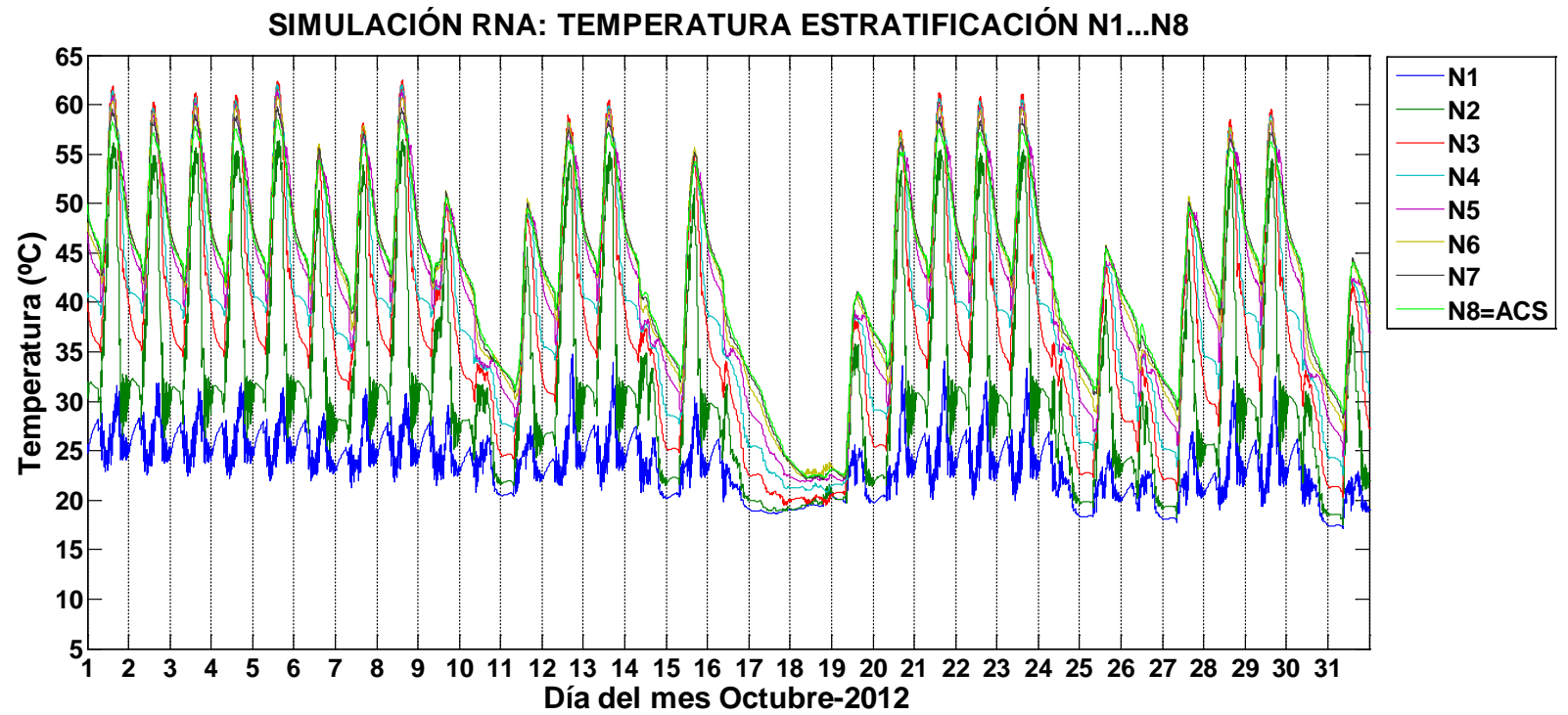

Fig. 4.7.14 Temperaturas de estratificación de la simulación con el modelo RNA de la planta piloto para el mes de octubre-2012 


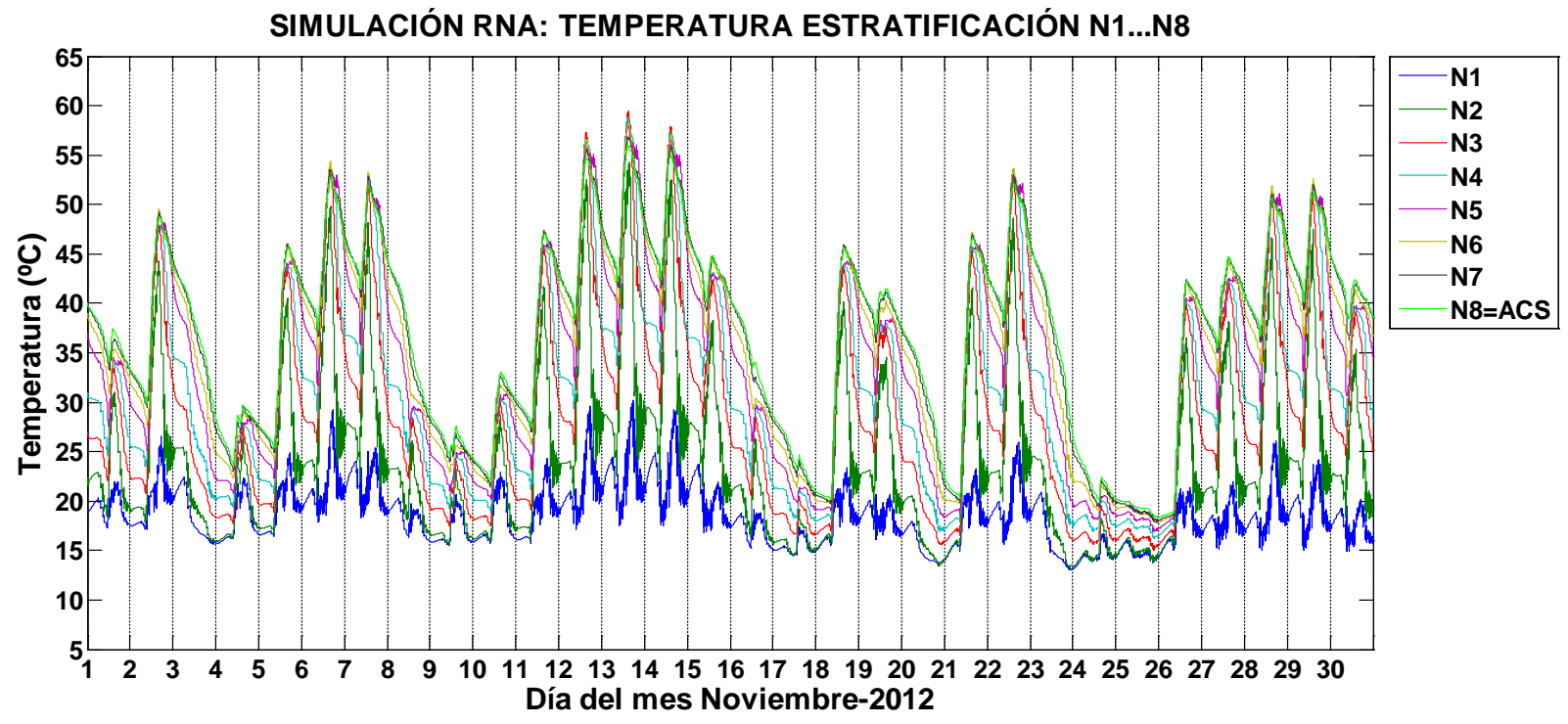

Fig. 4.7.15 Temperaturas de estratificación de la simulación con el modelo RNA de la planta piloto para el mes de noviembre-2012

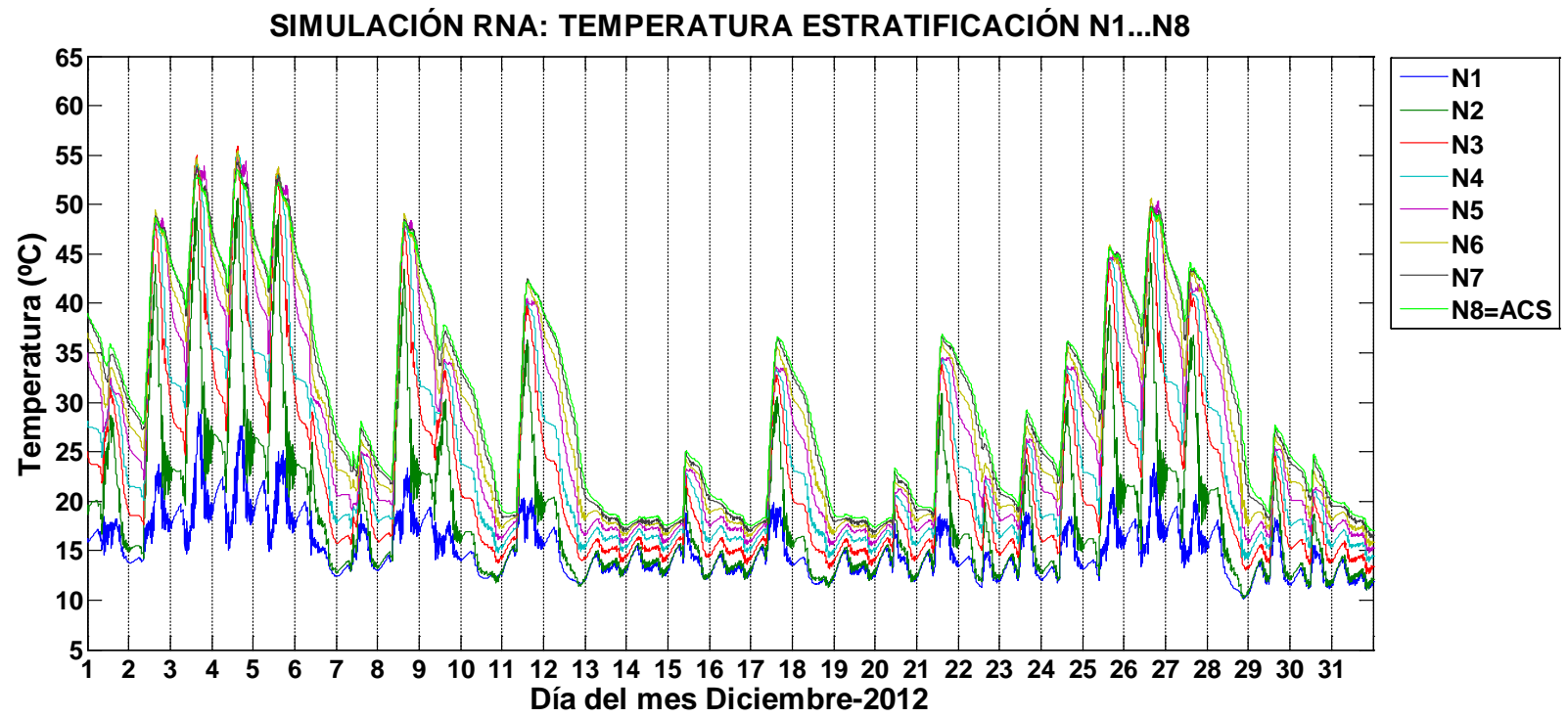

Fig. 4.7.16 Temperaturas de estratificación de la simulación con el modelo RNA de la planta piloto para el mes de diciembre-2012 
La simulación del funcionamiento del sistema solar térmico con el modelo neural propuesto también se ejecutó con datos de los años 2002, y del 2004 al año 2011, los resultados del rendimiento mensual para los 10 años en las condiciones establecidas anteriormente, contemplando el efecto de la estratificación térmica del agua en el depósito y utilizando el depósito mezclado con una temperatura homogénea se muestran para tres caudales del fluido portador por separado en las (Tablas 4.7.1), (Tablas 4.7.2) y (Tablas 4.7.3).

Los resultados del rendimiento mensual y anual aplicando la metodología del método f-chart, al mismo sistema solar térmico, en las condiciones establecidas para su aplicación se muestran en la (Tablas 4.7.4) con el captador solar ensayado a $2 \mathrm{l} / \mathrm{min}$ (Fig. 4.1.5.a), en la (Tablas 4.7.5) con el captador solar ensayado a $1,6 \mathrm{l} / \mathrm{min}$ (Fig. 4.1.5.b) y en la (Tablas 4.7.6) con el captador solar ensayado a $1 \mathrm{l} / \mathrm{min}$ de la (Fig. 4.1.5.c).

Los resultados del rendimiento anual obtenidos con la simulación del modelo neural, contemplando la estratificación térmica y utilizando el depósito mezclado a una temperatura homogénea, los resultados del método f-chart y la variación del porcentaje de irradiación solar global para cada año respecto a la base de datos climatológica de CENSOLAR se representan en la gráfica (Fig. 4.4.17), para su mejor comparación. 
Tabla 4.7.1 Rendimientos anuales y mensuales de la planta piloto simulados con RNA a un caudal de $2 \mathrm{l} / \mathrm{min}$

\begin{tabular}{|c|c|c|c|c|c|c|c|c|c|c|c|c|c|}
\hline \multicolumn{14}{|c|}{ RENDIMIENTOS SIMULACIÓN RNA 75 I/d a $50^{\circ} \mathrm{C}$ Caudal: 2 I/min } \\
\hline \multicolumn{2}{|c|}{ ESTRATIFICACIÓN } & \multicolumn{12}{|c|}{ Mensual (\%) } \\
\hline AÑO & Anual (\%) & ene & feb & mar & abr & may & jun & jul & ago & sep & oct & nov & dic \\
\hline 2002 & 77,06 & 47,27 & 77,42 & 79,26 & 90,22 & 89,01 & 93,46 & 99,98 & 96,20 & 87,70 & 72,60 & 49,02 & 43,06 \\
\hline 2004 & 84,68 & 61,88 & 82 & 82,30 & 94,16 & 90,39 & 102,34 & 99,37 & 92,97 & 100,38 & 73,70 & 65,06 & 69,54 \\
\hline 2005 & 86,82 & 63,12 & 89,37 & 92,74 & 85,65 & 94,51 & 103,54 & 103,66 & 103,32 & 99,5 & 69,19 & 68,09 & 69,73 \\
\hline 2006 & 83,47 & 69,25 & 86,68 & 78,84 & 96,08 & 99,76 & 99,21 & 102,50 & 97,38 & 88,98 & 69,50 & 52,20 & 61,69 \\
\hline 2007 & 85,78 & 49,21 & 68,80 & 88,66 & 91,64 & 91,99 & 94,62 & 102,45 & 100,47 & 97,86 & 90,32 & 89,27 & 63,50 \\
\hline 2008 & 85,81 & 61,13 & 80,21 & 96,71 & 85,48 & 85,53 & 99,63 & 103,22 & 102,65 & 94,98 & 87,46 & 65,21 & 64,48 \\
\hline 2009 & 85,65 & 48,19 & 86,16 & 97,81 & 92,97 & 98,79 & 95,78 & 103,23 & 102,04 & 102,58 & 87,03 & 60,64 & 52,99 \\
\hline 2010 & 82,82 & 55,79 & 69,33 & 79,94 & 93,22 & 90,97 & 90,91 & 106,08 & 104,27 & 93,13 & 84,08 & 75,40 & 50,20 \\
\hline 2011 & 84,40 & 46,73 & 79,59 & 79,87 & 92,98 & 99,37 & 102,1 & 102,03 & 98,46 & 100,88 & 93,77 & 56,05 & 60,99 \\
\hline 2012 & 86,41 & 70,74 & 97,42 & 101,20 & 76,59 & 90,73 & 100,40 & 104,62 & 103,44 & 93,50 & 81,08 & 64,78 & 50,09 \\
\hline Media & 84,29 & 57,33 & 81,70 & 87,73 & 89,90 & 93,11 & 98,20 & 102,71 & 100,12 & 95,95 & 80,87 & 64,57 & 58,63 \\
\hline \multicolumn{2}{|c|}{ MEZCLA } & \multicolumn{12}{|c|}{ Mensual (\%) } \\
\hline AÑO & Anual (\%) & ene & feb & mar & $a b r$ & may & jun & jul & ago & sep & oct & nov & dic \\
\hline 2002 & 61,06 & 32,50 & 58,93 & 62,50 & 73,44 & 72,64 & 77,43 & 83,37 & 79,71 & 71,61 & 56,25 & 34,59 & 29,98 \\
\hline 2004 & 67,75 & 44,32 & 63,37 & 65,36 & 77,29 & 74,25 & 85,88 & 82,67 & 76,97 & 83,49 & 57,38 & 49,08 & 51,31 \\
\hline 2005 & 70,20 & 47,46 & 70,70 & 74,63 & 68,93 & 78,09 & 87,14 & 87,03 & 86,49 & 82,91 & 56,43 & 51,25 & 51,73 \\
\hline 2006 & 66,90 & 51,31 & 67,78 & 61,44 & 79,14 & 83,31 & 83,17 & 85,89 & 81,08 & 73 & 54,39 & 38,05 & 44,56 \\
\hline 2007 & 69,05 & 34,51 & 50,62 & 70,94 & 74,63 & 75,78 & 78,56 & 86 & 83,71 & 81,45 & 73,82 & 71,38 & 46,48 \\
\hline 2008 & 68,79 & 44,05 & 61,02 & 79,28 & 69,03 & 69,32 & 83,18 & 86,46 & 86 & 78,38 & 69,90 & 49,16 & 47,18 \\
\hline 2009 & 69,18 & 33,14 & 68,52 & 80,42 & 75,78 & 82,47 & 79,86 & 86,67 & 85,39 & 85,77 & 70,31 & 44,75 & 37,42 \\
\hline 2010 & 66,26 & 40,71 & 51 & 62,33 & 76,26 & 75,01 & 75,65 & 89,53 & 87,71 & 76,64 & 67,09 & 56,89 & 35,57 \\
\hline 2011 & 68,08 & 34,53 & 60,89 & 62,77 & 76,49 & 82,98 & 85,77 & 85,62 & 81,97 & 84,10 & 76,90 & 40,82 & 43,94 \\
\hline 2012 & 69,62 & 52,09 & 77,89 & 83,79 & 61,09 & 75,15 & 83,89 & 88,09 & 86,69 & 77,09 & 64,87 & 47,72 & 35,18 \\
\hline Media & 67,69 & 41,46 & 63,07 & 70,35 & 73,21 & 76,90 & 82,05 & 86,13 & 83,57 & 79,44 & 64,73 & 48,37 & 42,34 \\
\hline
\end{tabular}


Tabla 4.7.2 Rendimientos anuales y mensuales de la planta piloto simulados con RNA a un caudal de 1,6 I/min

\begin{tabular}{|c|c|c|c|c|c|c|c|c|c|c|c|c|c|}
\hline \multicolumn{14}{|c|}{ RENDIMIENTOS SIMULACIÓN RNA 75 I/d a $50^{\circ} \mathrm{C}$ Caudal: 1,6 I/min } \\
\hline \multicolumn{2}{|c|}{ ESTRATIFICACIÓN } & \multicolumn{12}{|c|}{ Mensual (\%) } \\
\hline AÑO & Anual (\%) & ene & feb & mar & $a b r$ & may & jun & jul & ago & sep & oct & nov & dic \\
\hline 2002 & 76,74 & 46,45 & 77,06 & 78,71 & 89,59 & 88,82 & 93,75 & 100,24 & 96,36 & 87,79 & 71,96 & 48,15 & 42,44 \\
\hline 2004 & 84,27 & 61,02 & 81,16 & 81,74 & 93,61 & 90,19 & 102,59 & 99,65 & 93,24 & 100,52 & 72,94 & 64,37 & 68,14 \\
\hline 2005 & 86,46 & 62,55 & 88,90 & 92,05 & 85,11 & 94,42 & 103,74 & 103,88 & 103,52 & 99,58 & 68,80 & 67,03 & 68,60 \\
\hline 2006 & 83,11 & 68,15 & 86,09 & 78,20 & 95,87 & 99,70 & 99,60 & 102,80 & 97,53 & 89,06 & 69,07 & 51,61 & 60,08 \\
\hline 2007 & 85,50 & 48,32 & 68,12 & 88,09 & 91,23 & 91,91 & 94,75 & 102,68 & 100,64 & 97,93 & 90,18 & 88,96 & 62,56 \\
\hline 2008 & 85,44 & 60,46 & 79,79 & 96,43 & 85,08 & 85,33 & 99,72 & 103,39 & 102,80 & 95 & 87,10 & 63,87 & 63,36 \\
\hline 2009 & 85,29 & 46,94 & 85,48 & 97,52 & 92,44 & 98,72 & 96,04 & 103,45 & 102,25 & 102,63 & 86,78 & 59,74 & 51,90 \\
\hline 2010 & 82,39 & 54,70 & 68,38 & 79,34 & 92,87 & 90,76 & 91,21 & 106,33 & 104,45 & 93,23 & 83,82 & 73,96 & 48,98 \\
\hline 2011 & 84,14 & 46,45 & 79,26 & 79,39 & 92,72 & 99,38 & 102,22 & 102,19 & 98,81 & 100,98 & 93,55 & 55,25 & 59,55 \\
\hline 2012 & 85,78 & 69,49 & 96,98 & 100,87 & 76,42 & 90,55 & 100,55 & 104,80 & 103,62 & 93,51 & 80,76 & 63,35 & 49,28 \\
\hline Media & 83,91 & 56,45 & 81,12 & 87,23 & 89,49 & 92,98 & 98,42 & 102,94 & 100,32 & 96,02 & 80,50 & 63,63 & 57,49 \\
\hline \multicolumn{2}{|c|}{ MEZCLA } & \multicolumn{12}{|c|}{ Mensual (\%) } \\
\hline AÑO & Anual (\%) & ene & feb & mar & $a b r$ & may & jun & jul & ago & sep & oct & nov & dic \\
\hline 2002 & 60,75 & 31,81 & 58,55 & 61,99 & 72,81 & 72,42 & 77,66 & 83,58 & 79,83 & 71,65 & 55,66 & 33,88 & 29,45 \\
\hline 2004 & 67,35 & 43,56 & 62,50 & 64,83 & 76,73 & 74,03 & 86,10 & 82,90 & 77,18 & 83,59 & 56,69 & 48,53 & 50 \\
\hline 2005 & 69,86 & 46,93 & 70,18 & 73,96 & 68,41 & 77,98 & 87,30 & 87,22 & 86,66 & 82,95 & 56,08 & 50,30 & 50,72 \\
\hline 2006 & 66,56 & 50,33 & 67,17 & 60,84 & 78,90 & 83,22 & 83,50 & 86,15 & 81,20 & 73,06 & 53,98 & 37,52 & 43,14 \\
\hline 2007 & 68,76 & 33,72 & 49,97 & 70,34 & 74,19 & 75,67 & 78,65 & 86,20 & 83,83 & 81,49 & 73,66 & 71,04 & 45,63 \\
\hline 2008 & 68,44 & 43,49 & 60,58 & 78,93 & 68,64 & 69,10 & 83,24 & 86,59 & 86,11 & 78,37 & 69,54 & 47,94 & 46,20 \\
\hline 2009 & 68,86 & 32,14 & 67,88 & 80,09 & 75,26 & 82,37 & 80,08 & 86,85 & 85,56 & 85,79 & 70,05 & 43,97 & 36,50 \\
\hline 2010 & 65,86 & 39,81 & 50,11 & 61,71 & 75,92 & 74,81 & 75,90 & 89,75 & 87,85 & 76,69 & 66,82 & 55,61 & 34,56 \\
\hline 2011 & 67,84 & 34,25 & 60,53 & 62,30 & 76,23 & 82,96 & 85,88 & 85,82 & 82,25 & 84,16 & 76,69 & 40,12 & 42,70 \\
\hline 2012 & 69,05 & 50,88 & 77,43 & 83,40 & 60,91 & 74,98 & 84 & 88,23 & 86,82 & 77,07 & 64,55 & 46,43 & 34,51 \\
\hline Media & 67,33 & 40,69 & 62,49 & 69,84 & 72,80 & 76,75 & 82,23 & 86,33 & 83,73 & 79,48 & 64,37 & 47,53 & 41,34 \\
\hline
\end{tabular}


Tabla 4.7.3 Rendimientos anuales y mensuales de la planta piloto simulados con RNA a un caudal de $1 \mathrm{l} / \mathrm{min}$

\begin{tabular}{|c|c|c|c|c|c|c|c|c|c|c|c|c|c|}
\hline \multicolumn{14}{|c|}{ RENDIMIENTOS SIMULACIÓN RNA 75 I/d a $50{ }^{\circ} \mathrm{C}$ Caudal: 1 I/min } \\
\hline \multicolumn{2}{|c|}{ ESTRATIFICACIÓN } & \multicolumn{12}{|c|}{ Mensual (\%) } \\
\hline AÑO & Anual (\%) & ene & feb & mar & abr & may & jun & jul & ago & sep & oct & nov & dic \\
\hline 2002 & 76,46 & 46,70 & 76,96 & 78,51 & 89,30 & 88,73 & 93,23 & 99,44 & 95,79 & 87,70 & 71,57 & 47,88 & 42,23 \\
\hline 2004 & 83,91 & 60,26 & 80,9 & 81,59 & 94,87 & 90,09 & 101,89 & 98,88 & 92,91 & 99,85 & 72,29 & 64,20 & 67,21 \\
\hline 2005 & 86,01 & 62,32 & 88,94 & 91,34 & 84,97 & 94,04 & 102,92 & 103,04 & 102,88 & 99,11 & 68,46 & 66,49 & 68,26 \\
\hline 2006 & 82,70 & 67,7 & 86,14 & 78,06 & 95,43 & 99,22 & 99,06 & 101,91 & 97,1 & 88,9 & 68,72 & 51,2 & 59,46 \\
\hline 2007 & 85,12 & 48,26 & 67,83 & 87,89 & 90,75 & 91,37 & 94,29 & 102 & 99,75 & 97,61 & 90,32 & 88,78 & 62,02 \\
\hline 2008 & 85,02 & 60,30 & 79,64 & 96,20 & 85,15 & 85,23 & 98,92 & 102,49 & 102,07 & 94,50 & 86,78 & 63,54 & 62,87 \\
\hline 2009 & 84,96 & 47,03 & 85,47 & 97,39 & 92,30 & 98,29 & 95,70 & 102,73 & 101,59 & 102,22 & 86,37 & 59,47 & 51,43 \\
\hline 2010 & 82,11 & 54,78 & 68,44 & 79,19 & 92,43 & 90,70 & 91,08 & 105,60 & 103,74 & 92,99 & 83,67 & 73,34 & 48,82 \\
\hline 2011 & 83,67 & 46,53 & 79,36 & 79,35 & 92,25 & 98,80 & 100,78 & 101,50 & 98,26 & 100,47 & 93,26 & 54,81 & 58,77 \\
\hline 2012 & 85,37 & 69,19 & 96,78 & 100,47 & 76,61 & 90,39 & 99,84 & 104,04 & 102,94 & 93,17 & 80,41 & 62,57 & 48,95 \\
\hline Media & 83,53 & 56,31 & 81,05 & 87 & 89,41 & 92,69 & 97,77 & 102,16 & 99,70 & 95,65 & 80,19 & 63,23 & 57 \\
\hline \multicolumn{2}{|c|}{ MEZCLA } & \multicolumn{12}{|c|}{ Mensual (\%) } \\
\hline AÑO & Anual (\%) & ene & feb & mar & $a b r$ & may & jun & jul & ago & sep & oct & nov & dic \\
\hline 2002 & 60,40 & 31,90 & 58,35 & 61,69 & 72,43 & 72,23 & 77,04 & 82,75 & 79,23 & 71,45 & 55,25 & 33,55 & 29,20 \\
\hline 2004 & 66,83 & 42,89 & 62,10 & 64,59 & 76,47 & 73,81 & 85,34 & 82,11 & 76,76 & 82,90 & 56,02 & 48,32 & 49,13 \\
\hline 2005 & 69,36 & 46,66 & 70,14 & 73,25 & 68,16 & 77,51 & 86,43 & 86,35 & 85,98 & 82,44 & 55,70 & 49,75 & 50,33 \\
\hline 2006 & 66,09 & 49,89 & 67,11 & 60,60 & 78,38 & 82,66 & 82,89 & 85,23 & 80,69 & 72,81 & 53,58 & 37,09 & 42,54 \\
\hline 2007 & 68,30 & 33,55 & 49,60 & 70,08 & 73,63 & 75,08 & 78,11 & 85,44 & 82,94 & 81,11 & 73,35 & 70,82 & 45,12 \\
\hline 2008 & 67,99 & 43,27 & 60,31 & 78,64 & 68,60 & 68,92 & 82,37 & 85,64 & 85,35 & 77,88 & 69,19 & 47,53 & 45,66 \\
\hline 2009 & 68,47 & 32,14 & 67,78 & 79,91 & 75,03 & 81,86 & 79,59 & 86,05 & 84,88 & 85,34 & 69,60 & 43,68 & 36,03 \\
\hline 2010 & 65,52 & 39,80 & 50,03 & 61,50 & 75,41 & 74,65 & 75,65 & 88,95 & 87,11 & 76,38 & 66,62 & 55,01 & 34,32 \\
\hline 2011 & 67,34 & 34,24 & 60,47 & 62,16 & 75,68 & 82,29 & 84,80 & 85 & 81,67 & 83,62 & 76,34 & 39,69 & 41,97 \\
\hline 2012 & 68,60 & 50,50 & 77,20 & 82,95 & 60,97 & 74,69 & 83,22 & 87,42 & 86,12 & 76,66 & 64,18 & 45,73 & 34,18 \\
\hline Media & 66,89 & 40,48 & 62,31 & 69,54 & 72,48 & 76,37 & 81,54 & 85,49 & 83,07 & 79,06 & 63,98 & 47,12 & 40,85 \\
\hline
\end{tabular}


Tabla 4.7.4 Rendimiento anual y mensual de la planta piloto simulado con el método f-chart y el captador solar ensayado a $2 \mathrm{l} / \mathrm{min}$

\begin{tabular}{|c|c|c|c|c|c|c|c|c|c|c|c|c|}
\hline \multicolumn{13}{|c|}{ MÉTODO F-CHART Caudal: 2 l/min } \\
\hline Mes & ene & feb & mar & $a b r$ & may & jun & jul & ago & sep & oct & nov & dic \\
\hline $\operatorname{ACS}(1 / d)$ & 75 & 75 & 75 & 75 & 75 & 75 & 75 & 75 & 75 & 75 & 75 & 75 \\
\hline $\mathbf{N}$ & 31 & 28 & 31 & 30 & 31 & 30 & 31 & 31 & 30 & 31 & 30 & 31 \\
\hline$\overline{\mathbf{T}}_{\mathrm{ac}}\left({ }^{\circ} \mathrm{C}\right)$ & 50 & 50 & 50 & 50 & 50 & 50 & 50 & 50 & 50 & 50 & 50 & 50 \\
\hline$\overline{\mathbf{T}}_{\text {red }}\left({ }^{\circ} \mathrm{C}\right)$ & 4 & 5 & 7 & 9 & 10 & 11 & 12 & 11 & 10 & 9 & 7 & 4 \\
\hline L (MJ) & 447,79 & 395,67 & 418,59 & 386,25 & 389,39 & 367,40 & 369,92 & 379,65 & 376,83 & 399,12 & 405,09 & 447,79 \\
\hline $\mathbf{A}_{\mathrm{c}}\left(\mathrm{m}^{2}\right)$ & 1,85 & 1,85 & 1,85 & 1,85 & 1,85 & 1,85 & 1,85 & 1,85 & 1,85 & 1,85 & 1,85 & 1,85 \\
\hline$F_{R}(\tau \alpha)_{n}$ & 0,61 & 0,61 & 0,61 & 0,61 & 0,61 & 0,61 & 0,61 & 0,61 & 0,61 & 0,61 & 0,61 & 0,61 \\
\hline$\frac{(\overline{\tau \alpha})}{(\tau \alpha)_{n}}$ & 0,96 & 0,96 & 0,96 & 0,96 & 0,96 & 0,96 & 0,96 & 0,96 & 0,96 & 0,96 & 0,96 & 0,96 \\
\hline$\frac{\mathbf{F}_{\mathrm{R}}^{\prime}}{\mathbf{F}_{\mathbf{R}}}$ & 0,95 & 0,95 & 0,95 & 0,95 & 0,95 & 0,95 & 0,95 & 0,95 & 0,95 & 0,95 & 0,95 & 0,95 \\
\hline$\overline{\mathbf{H}}_{\boldsymbol{\beta} \boldsymbol{\gamma}}\left(\mathrm{MJ} / \mathrm{m}^{2}\right)$ & 8,29 & 11,48 & 16,28 & 17,88 & 18,33 & 19,89 & 22,74 & 21,94 & 21,15 & 14,87 & 10,99 & 7,39 \\
\hline$\overline{\mathbf{H}}\left(\mathrm{MJ} / \mathrm{m}^{2}\right)$ & 5,80 & 8,70 & 13,80 & 17,20 & 19,50 & 22,10 & 24,20 & 20,90 & 17,20 & 10,40 & 7 & 4,80 \\
\hline$\overline{\mathbf{R}}$ & 1,43 & 1,32 & 1,18 & 1,04 & 0,94 & 0,9 & 0,94 & 1,05 & 1,23 & 1,43 & 1,57 & 1,54 \\
\hline Y L (MJ) & 264,62 & 330,94 & 519,54 & 552,31 & 584,82 & 614,12 & 725,77 & 700,15 & 653,21 & 474,49 & 339,32 & 235,84 \\
\hline $\mathbf{F}_{\mathbf{R}} \mathbf{U}_{\mathbf{L}}$ & 4,2 & 4,2 & 4,2 & 4,2 & 4,2 & 4,2 & 4,2 & 4,2 & 4,2 & 4,2 & 4,2 & 4,2 \\
\hline$\overline{\mathbf{T}}_{\mathbf{a}}\left({ }^{\circ} \mathrm{C}\right)$ & 5 & 6 & 10 & 12 & 15 & 19 & 22 & 22 & 19 & 14 & 9 & 6 \\
\hline$K_{1}=\frac{X_{c}}{X}$ & 0,98 & 0,98 & 0,98 & 0,98 & 0,98 & 0,98 & 0,98 & 0,98 & 0,98 & 0,98 & 0,98 & 0,98 \\
\hline$K_{2}=\frac{X_{c}}{X}$ & 0,78 & 0,80 & 0,82 & 0,88 & 0,87 & 0,85 & 0,84 & 0,79 & 0,80 & 0,84 & 0,84 & 0,76 \\
\hline$X \mathrm{~L}(\mathrm{MJ})$ & 1443,3 & 1330,6 & 1442,9 & 1454,2 & 1442,5 & 1294,3 & 1277,3 & 1202,5 & 1221,9 & 1412,7 & 1439,9 & 1398,3 \\
\hline$Y$ & 0,59 & 0,84 & 1,24 & 1,43 & 1,50 & 1,67 & 1,96 & 1,84 & 1,73 & 1,19 & 0,84 & 0,53 \\
\hline$x$ & 3,22 & 3,36 & 3,45 & 3,76 & 3,70 & 3,52 & 3,45 & 3,17 & 3,24 & 3,54 & 3,55 & 3,12 \\
\hline$f$ & 0,40 & 0,57 & 0,81 & 0,90 & 0,94 & 1,01 & 1,11 & 1,07 & 1,03 & 0,78 & 0,57 & 0,35 \\
\hline $\mathbf{F}_{\text {anual }}$ & & & & & & 78 & $\%$ & & & & & \\
\hline
\end{tabular}


Tabla 4.7.5 Rendimiento anual y mensual de la planta piloto simulado con el método f-chart y el captador solar ensayado a 1,6 l/min

\begin{tabular}{|c|c|c|c|c|c|c|c|c|c|c|c|c|}
\hline \multicolumn{13}{|c|}{ MÉTODO F-CHART Caudal: 1,6 I/min } \\
\hline Mes & ene & feb & mar & $a b r$ & may & jun & jul & ago & sep & oct & nov & dic \\
\hline $\operatorname{ACS}(1 / d)$ & 75 & 75 & 75 & 75 & 75 & 75 & 75 & 75 & 75 & 75 & 75 & 75 \\
\hline N & 31 & 28 & 31 & 30 & 31 & 30 & 31 & 31 & 30 & 31 & 30 & 31 \\
\hline$\overline{\mathbf{T}}_{\mathrm{ac}}\left({ }^{\circ} \mathrm{C}\right)$ & 50 & 50 & 50 & 50 & 50 & 50 & 50 & 50 & 50 & 50 & 50 & 50 \\
\hline$\overline{\mathrm{T}}_{\text {red }}\left({ }^{\circ} \mathrm{C}\right)$ & 4 & 5 & 7 & 9 & 10 & 11 & 12 & 11 & 10 & 9 & 7 & 4 \\
\hline L (MJ) & 447,79 & 395,67 & 418,59 & 386,25 & 389,39 & 367,40 & 369,92 & 379,65 & 376,83 & 399,12 & 405,09 & 447,79 \\
\hline$A_{c}\left(m^{2}\right)$ & 1,85 & 1,85 & 1,85 & 1,85 & 1,85 & 1,85 & 1,85 & 1,85 & 1,85 & 1,85 & 1,85 & 1,85 \\
\hline$F_{R}(\tau \alpha)_{n}$ & 0,46 & 0,46 & 0,46 & 0,46 & 0,46 & 0,46 & 0,46 & 0,46 & 0,46 & 0,46 & 0,46 & 0,46 \\
\hline$\frac{(\overline{\tau \alpha})}{(\tau \boldsymbol{\alpha})_{\mathbf{n}}}$ & 0,96 & 0,96 & 0,96 & 0,96 & 0,96 & 0,96 & 0,96 & 0,96 & 0,96 & 0,96 & 0,96 & 0,96 \\
\hline$\frac{\mathbf{F}_{\mathrm{R}}^{\prime}}{\mathbf{F}_{\mathrm{R}}}$ & 0,95 & 0,95 & 0,95 & 0,95 & 0,95 & 0,95 & 0,95 & 0,95 & 0,95 & 0,95 & 0,95 & 0,95 \\
\hline $\begin{array}{c}\overline{\mathbf{H}}_{\beta \gamma} \\
\left(\mathrm{MJ} / \mathrm{m}^{2}\right)\end{array}$ & 8,29 & 11,48 & 16,28 & 17,88 & 18,33 & 19,89 & 22,74 & 21,94 & 21,15 & 14,87 & 10,99 & 7,39 \\
\hline$\overline{\mathbf{H}}\left(\mathrm{MJ} / \mathrm{m}^{2}\right)$ & 5,80 & 8,70 & 13,80 & 17,20 & 19,50 & 22,10 & 24,20 & 20,90 & 17,20 & 10,40 & 7 & 4,80 \\
\hline$\overline{\mathbf{R}}$ & 1,43 & 1,32 & 1,18 & 1,04 & 0,94 & 0,9 & 0,94 & 1,05 & 1,23 & 1,43 & 1,57 & 1,54 \\
\hline$Y L$ (MJ) & 199,54 & 249,56 & 391,78 & 416,49 & 441,01 & 463,10 & 547,30 & 527,98 & 492,58 & 357,81 & 255,88 & 177,84 \\
\hline$F_{R} U_{L}$ & 2,3 & 2,3 & 2,3 & 2,3 & 2,3 & 2,3 & 2,3 & 2,3 & 2,3 & 2,3 & 2,3 & 2,3 \\
\hline$\overline{\mathbf{T}}_{\mathrm{a}}\left({ }^{\circ} \mathrm{C}\right)$ & 5 & 6 & 10 & 12 & 15 & 19 & 22 & 22 & 19 & 14 & 9 & 6 \\
\hline$K_{1}=\frac{x_{c}}{X}$ & 0,98 & 0,98 & 0,98 & 0,98 & 0,98 & 0,98 & 0,98 & 0,98 & 0,98 & 0,98 & 0,98 & 0,98 \\
\hline$K_{2}=\frac{X_{c}}{X}$ & 0,78 & 0,80 & 0,82 & 0,88 & 0,87 & 0,85 & 0,84 & 0,79 & 0,80 & 0,84 & 0,84 & 0,76 \\
\hline$X \mathrm{~L}$ (MJ) & 790,38 & 728,66 & 790,17 & 796,33 & 789,96 & 708,78 & 699,49 & 658,51 & 669,12 & 773,61 & 788,52 & 765,75 \\
\hline$Y$ & 0,44 & 0,63 & 0,93 & 1,07 & 1,13 & 1,26 & 1,47 & 1,39 & 1,30 & 0,89 & 0,63 & 0,39 \\
\hline$x$ & 1,76 & 1,84 & 1,88 & 2,06 & 2,02 & 1,92 & 1,89 & 1,73 & 1,77 & 1,93 & 1,94 & 1,71 \\
\hline$f$ & 0,32 & 0,46 & 0,67 & 0,75 & 0,78 & 0,85 & 0,96 & 0,92 & 0,88 & 0,64 & 0,46 & 0,28 \\
\hline $\mathbf{F}_{\text {anual }}$ & & & & & & 65 & & & & & & \\
\hline
\end{tabular}


Tabla 4.7.6 Rendimiento anual y mensual de la planta piloto simulado con el método f-chart y el captador solar ensayado a $1 \mathrm{l} / \mathrm{min}$

\begin{tabular}{|c|c|c|c|c|c|c|c|c|c|c|c|c|}
\hline \multicolumn{13}{|c|}{ MÉTODO F-CHART Caudal: 1 I/min } \\
\hline Mes & ene & feb & mar & $a b r$ & may & jun & jul & ago & sep & oct & nov & dic \\
\hline $\operatorname{ACS}(1 / d)$ & 75 & 75 & 75 & 75 & 75 & 75 & 75 & 75 & 75 & 75 & 75 & 75 \\
\hline $\mathbf{N}$ & 31 & 28 & 31 & 30 & 31 & 30 & 31 & 31 & 30 & 31 & 30 & 31 \\
\hline$\overline{\mathbf{T}}_{\mathrm{ac}}\left({ }^{\circ} \mathrm{C}\right)$ & 50 & 50 & 50 & 50 & 50 & 50 & 50 & 50 & 50 & 50 & 50 & 50 \\
\hline$\overline{\mathbf{T}}_{\text {red }}\left({ }^{\circ} \mathrm{C}\right)$ & 4 & 5 & 7 & 9 & 10 & 11 & 12 & 11 & 10 & 9 & 7 & 4 \\
\hline $\mathbf{L}(\mathrm{MJ})$ & 447,79 & 395,67 & 418,59 & 386,25 & 389,39 & 367,40 & 369,92 & 379,65 & 376,83 & 399,12 & 405,09 & 447,79 \\
\hline $\mathbf{A}_{c}\left(\mathrm{~m}^{2}\right)$ & 1,85 & 1,85 & 1,85 & 1,85 & 1,85 & 1,85 & 1,85 & 1,85 & 1,85 & 1,85 & 1,85 & 1,85 \\
\hline$F_{R}(\tau \alpha)_{n}$ & 0,29 & 0,29 & 0,29 & 0,29 & 0,29 & 0,29 & 0,29 & 0,29 & 0,29 & 0,29 & 0,29 & 0,29 \\
\hline$\frac{(\overline{\tau \alpha})}{(\tau \alpha)_{n}}$ & 0,96 & 0,96 & 0,96 & 0,96 & 0,96 & 0,96 & 0,96 & 0,96 & 0,96 & 0,96 & 0,96 & 0,96 \\
\hline$\frac{\mathbf{F}_{\mathrm{R}}^{\prime}}{\overline{\mathbf{F}_{\mathrm{R}}}}$ & 0,95 & 0,95 & 0,95 & 0,95 & 0,95 & 0,95 & 0,95 & 0,95 & 0,95 & 0,95 & 0,95 & 0,95 \\
\hline $\begin{array}{c}\overline{\mathbf{H}}_{\boldsymbol{\beta} \boldsymbol{\gamma}} \\
\left(\mathrm{MJ} / \mathrm{m}^{2}\right) \\
\end{array}$ & 8,29 & 11,48 & 16,28 & 17,88 & 18,33 & 19,89 & 22,74 & 21,94 & 21,15 & 14,87 & 10,99 & 7,39 \\
\hline$\overline{\mathbf{H}}\left(\mathrm{MJ} / \mathrm{m}^{2}\right)$ & 5,80 & 8,70 & 13,80 & 17,20 & 19,50 & 22,10 & 24,20 & 20,90 & 17,20 & 10,40 & 7 & 4,80 \\
\hline$\overline{\mathbf{R}}$ & 1,43 & 1,32 & 1,18 & 1,04 & 0,94 & 0,9 & 0,94 & 1,05 & 1,23 & 1,43 & 1,57 & 1,54 \\
\hline $\mathbf{Y} L(\mathrm{MJ})$ & 125,80 & 157,33 & 246,99 & 262,57 & 278,03 & 291,96 & 345,04 & 332,86 & 310,54 & 225,58 & 161,32 & 112,12 \\
\hline $\mathbf{F}_{\mathbf{R}} \mathbf{U}_{\mathrm{L}}$ & 1,8 & 1,8 & 1,8 & 1,8 & 1,8 & 1,8 & 1,8 & 1,8 & 1,8 & 1,8 & 1,8 & 1,8 \\
\hline$\overline{\mathbf{T}}_{\mathrm{a}}\left({ }^{\circ} \mathrm{C}\right)$ & 5 & 6 & 10 & 12 & 15 & 19 & 22 & 22 & 19 & 14 & 9 & 6 \\
\hline$K_{1}=\frac{X_{c}}{X}$ & 0,98 & 0,98 & 0,98 & 0,98 & 0,98 & 0,98 & 0,98 & 0,98 & 0,98 & 0,98 & 0,98 & 0,98 \\
\hline$K_{2}=\frac{X_{c}}{X}$ & 0,78 & 0,80 & 0,82 & 0,88 & 0,87 & 0,85 & 0,84 & 0,79 & 0,80 & 0,84 & 0,84 & 0,76 \\
\hline$X \mathrm{~L}(\mathrm{MJ})$ & 618,56 & 570,26 & 618,40 & 623,22 & 618,23 & 554,70 & 547,43 & 515,36 & 523,66 & 605,44 & 617,11 & 599,29 \\
\hline$Y$ & 0,28 & 0,40 & 0,59 & 0,68 & 0,71 & 0,79 & 0,93 & 0,88 & 0,82 & 0,57 & 0,40 & 0,25 \\
\hline$x$ & 1,38 & 1,44 & 1,48 & 1,61 & 1,59 & 1,51 & 1,48 & 1,36 & 1,39 & 1,52 & 1,52 & 1,34 \\
\hline$f$ & 0,20 & 0,29 & 0,45 & 0,51 & 0,53 & 0,59 & 0,69 & 0,66 & 0,62 & 0,43 & 0,29 & 0,17 \\
\hline $\mathbf{F}_{\text {anual }}$ & & & & & & 4 & & & & & & \\
\hline
\end{tabular}




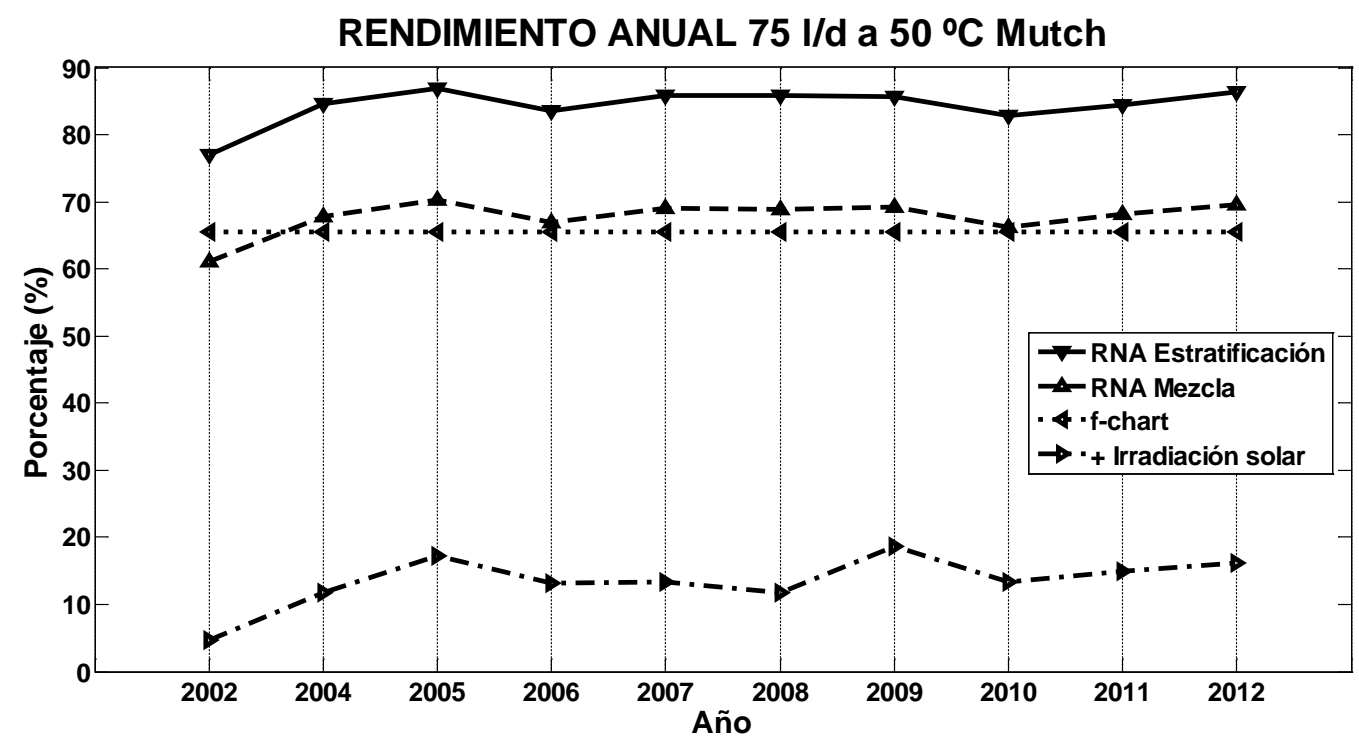

Fig. 4.7.17 Rendimiento anual de la planta piloto simulado con el modelo RNA y con el método f-chart 


\subsection{Optimización del rendimiento en los sistemas solares térmicos}

Para medir el resultado de la propuesta metodológica de optimización horaria (Apartado 3.8), se ha realizado el cálculo del rendimiento mediante simulaciones neurales del funcionamiento de la planta piloto para el año 2012 con diferentes distribuciones de consumo de agua caliente solar, partiendo de la dada por (Mutch, 1974) y siguiendo con una concentración del uso durante 12 horas diarias, hasta llegar a centrarse en el mediodía solar de las que se obtuvieron los resultados que se muestran en la (Tabla 4.8.1) y en la gráfica de la (Fig. 4.8.1).

Tabla 4.8.1 Rendimiento mensual y anual en el año 2012, obtenido de la simulación neural en la planta piloto para distintas distribuciones horarias de la carga ACS demandada de $75 \mathrm{l} / \mathrm{d}$ a $50{ }^{\circ} \mathrm{C}$

\begin{tabular}{|c|c|c|c|c|c|c|c|c|c|c|c|c|c|c|}
\hline & \multicolumn{14}{|c|}{ RENDIMIENTOS SIMULACIÓN RNA 2012 Caudal: 1,6 I/min } \\
\hline & \multicolumn{2}{|c|}{ ESTRATIFICACIÓN } & \multicolumn{12}{|c|}{ Mensual (\%) } \\
\hline & Hora solar & Anual (\%) & ene & feb & mar & abr & may & jun & jul & ago & sep & oct & nov & dic \\
\hline \multirow{13}{*}{ 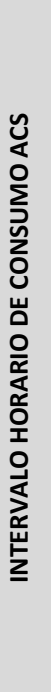 } & Mutch & 85,81 & 69,49 & 96,98 & 100,87 & 76,42 & 90,55 & 100,55 & 104,80 & 103,62 & 93,51 & 80,76 & 63,35 & 49,28 \\
\hline & $9 \mathrm{~h} \rightarrow 23 \mathrm{~h}$ & 91,04 & 71,69 & 100,23 & 105,29 & 80,72 & 92,49 & 110,60 & 114,52 & 113,80 & 99,79 & 84,80 & 66,67 & 52,25 \\
\hline & $11 \mathrm{~h} \rightarrow 23 \mathrm{~h}$ & 93,89 & 71,20 & 102 & 107,70 & 82,36 & 102,69 & 114,55 & 120,07 & 119,18 & 103,45 & 88,38 & 64,77 & 50,47 \\
\hline & $11 \mathrm{~h} \rightarrow 22 \mathrm{~h}$ & 94,63 & 71,77 & 102,58 & 108,23 & 83,24 & 103,21 & 115,40 & 121,78 & 119,95 & 104,07 & 89,44 & 65,26 & 50,80 \\
\hline & $11 \mathrm{~h} \rightarrow 21 \mathrm{~h}$ & 96,18 & 72,14 & 102,69 & 109,06 & 84,74 & 104,70 & 117,63 & 124,34 & 122,79 & 107,29 & 91,33 & 66,12 & 51,42 \\
\hline & $11 \mathrm{~h} \rightarrow 20 \mathrm{~h}$ & 97,88 & 73,47 & 103,56 & 110,60 & 86,24 & 105,89 & 119,51 & 126,66 & 125,48 & 109,75 & 93,98 & 67,19 & 52,28 \\
\hline & $11 \mathrm{~h} \rightarrow 19 \mathrm{~h}$ & 98,46 & 74,04 & 103,20 & 110,21 & 87,02 & 106,50 & 120,25 & 127,46 & 126,50 & 110,34 & 95,55 & 67,76 & 52,77 \\
\hline & $11 \mathrm{~h} \rightarrow 18 \mathrm{~h}$ & 98,80 & 74,29 & 102,91 & 110,21 & 87,93 & 107,04 & 120,67 & 127,84 & 127,19 & 110,53 & 95,76 & 68,10 & 53,15 \\
\hline & $11 \mathrm{~h} \rightarrow 17 \mathrm{~h}$ & 99,65 & 74,67 & 102,71 & 110,80 & 89,32 & 107,78 & 121,06 & 128,47 & 128,65 & 112,33 & 96,86 & 69,02 & 54,05 \\
\hline & $11 \mathrm{~h} \rightarrow 16 \mathrm{~h}$ & 101,05 & 75,84 & 103,71 & 112,44 & 91,24 & 108,89 & 121,75 & 129,59 & 130,28 & 114,24 & 99,52 & 70,10 & 54,91 \\
\hline & $11 \mathrm{~h} \rightarrow 15 \mathrm{~h}$ & 101,47 & 77,65 & 105,08 & 112,62 & 92,84 & 108,31 & 120,37 & 127,96 & 129,77 & 115,36 & 100,83 & 71,29 & 55,57 \\
\hline & $11 \mathrm{~h} \rightarrow 14 \mathrm{~h}$ & 102,47 & 79,93 & 106,61 & 113,90 & 93,80 & 109,24 & 120,61 & 128,46 & 130,08 & 115,77 & 101,23 & 72,73 & 57,38 \\
\hline & $12 h \rightarrow 13 h$ & 103,56 & 78,09 & 104,57 & 114,76 & 95,30 & 111,68 & 125,48 & 132,95 & 133,94 & 118,27 & 101,84 & 70,03 & 55,66 \\
\hline
\end{tabular}

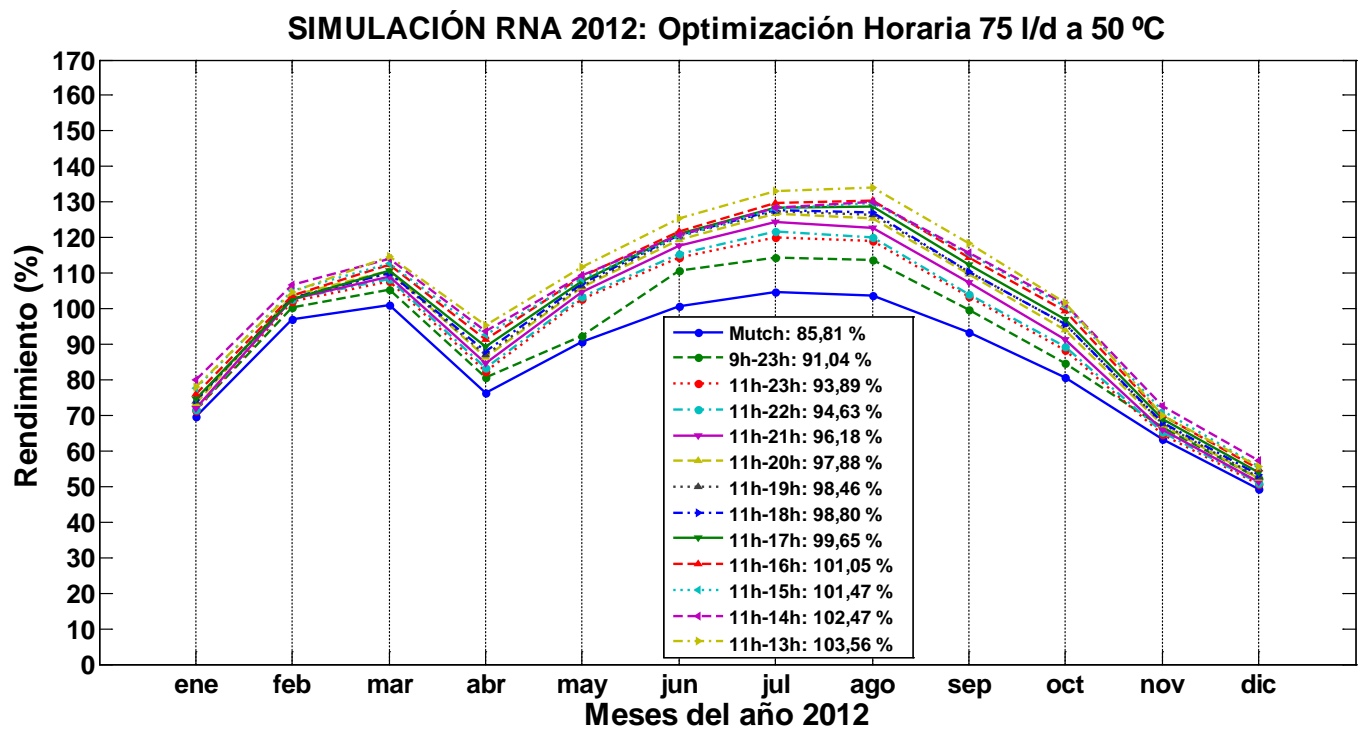

Fig. 4.8.1 Rendimiento mensual y anual en el año 2012, obtenido de la simulación neural en la planta piloto para distintas distribuciones horarias de la carga ACS demandada de $75 \mathrm{l} / \mathrm{d}$ a $50{ }^{\circ} \mathrm{C}$ 
Para medir el resultado de la propuesta metodológica de optimización diaria (Apartado 3.8), se ha realizado el cálculo del rendimiento mediante simulaciones del funcionamiento de la planta piloto para el año 2012 con diferentes cantidades en el volumen de descargas de agua caliente solar, según el nivel de irradiación solar diario alta, media y baja, pero con el mismo perfil horario (Mutch, 1974) para todas las simulaciones.

- La primera distribución de consumo fijo de $75 \mathrm{l} / \mathrm{d}$, utilizada como referencia.

- La segunda distribución con una descarga variable diaria para los días de alta irradiación solar > $20 \mathrm{MJ} / \mathrm{m}^{2} / \mathrm{d}$ de $100 \mathrm{l} / \mathrm{d}$, los días de media irradiación solar entre 20 y $10 \mathrm{MJ} / \mathrm{m}^{2} / \mathrm{d}$ de $75 \mathrm{l} / \mathrm{d}$ y los días de baja irradiación solar $<10 \mathrm{MJ} / \mathrm{m}^{2} / \mathrm{d}$ de $50 \mathrm{l} / \mathrm{d}$.

- La tercera distribución de consumo diario de agua caliente solar probada fue de aumentar más el consumo los días de alta irradiación solar $>20 \mathrm{MJ} / \mathrm{m}^{2} / \mathrm{d}$ a $125 \mathrm{l} / \mathrm{d}$.

Tabla 4.8.2 Rendimiento mensual y anual del año 2012, obtenido de la simulación neural en la planta piloto para distintas distribuciones diarias de la carga ACS demandada a $50^{\circ} \mathrm{C}$, según el nivel de irradiación solar

\begin{tabular}{|c|c|c|c|c|c|c|c|c|c|c|c|c|c|c|}
\hline & \multicolumn{14}{|c|}{ RENDIMIENTOS SIMULACIÓN RNA 2012 Caudal: 1,6 I/min } \\
\hline & \multicolumn{2}{|c|}{ ESTRATIFICACIÓN } & \multicolumn{12}{|c|}{ Mensual (\%) } \\
\hline & $\begin{array}{c}\text { Irradiación } \\
\mathrm{H}(\mathrm{MJ} / \mathrm{m} 2 / \mathrm{d}) \\
\rightarrow \\
\text { Consumo } \\
\text { (I/d) }\end{array}$ & $\begin{array}{c}\text { Anual } \\
\text { (\%) }\end{array}$ & ene & feb & mar & $a b r$ & may & jun & jul & ago & sep & oct & nov & dic \\
\hline \multirow{3}{*}{ 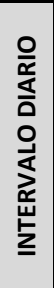 } & $\mathrm{H}>0 \rightarrow 75$ & 85,81 & 69,49 & 96,98 & 100,87 & 76,42 & 90,55 & 100,55 & 104,8 & 103,62 & 93,51 & 80,76 & 63,35 & 49,28 \\
\hline & $\begin{array}{c}H>20 \rightarrow 100 \\
10 \leq H \leq 20 \rightarrow 75 \\
H<10 \rightarrow 50\end{array}$ & 93,88 & 58,15 & 94,13 & 109,11 & 88,23 & 111,98 & 126,58 & 133,34 & 129,66 & 104,31 & 78,04 & 54 & 38,94 \\
\hline & $\begin{array}{c}H>20 \rightarrow 125 \\
10 \leq H \leq 20 \rightarrow 75 \\
H<10 \rightarrow 50\end{array}$ & 103,80 & 58,15 & 94,13 & 116,98 & 98,98 & 129,19 & 146,51 & 159,92 & 153,94 & 116,20 & 78,04 & 54 & 38,94 \\
\hline
\end{tabular}

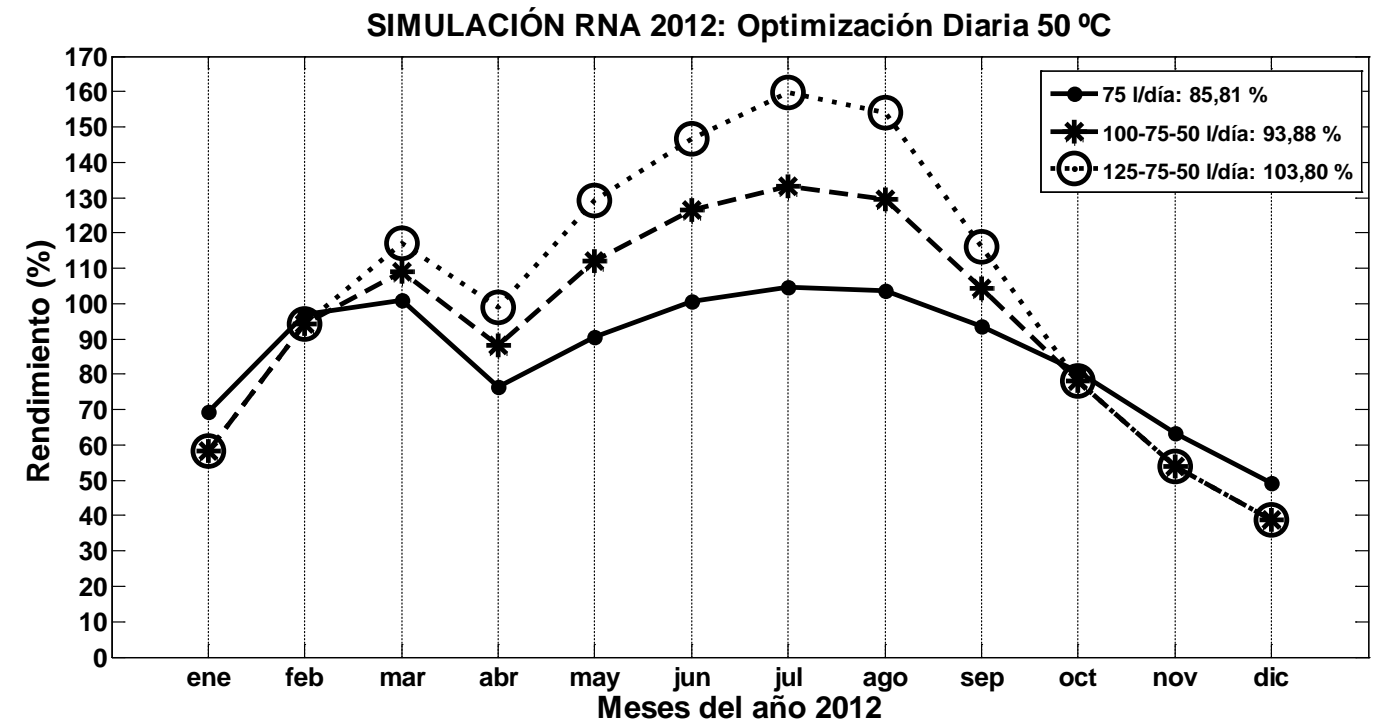

Fig. 4.8.2 Rendimiento mensual y anual del año 2012, obtenido de la simulación neural en la planta piloto para distintas distribuciones diarias de la carga ACS demandada a $50^{\circ} \mathrm{C}$, según el nivel de irradiación solar 


\section{Capítulo 5}

\section{ANÁLISIS Y DISCUSIÓN DE LOS RESULTADOS}

\subsection{Análisis de la predicción de variables ambientales}

5.2 Análisis de la estimación de irradiación solar sobre el plano inclinado

5.3 Análisis del modelado neural de los componentes del sistema solar térmico

5.4 Análisis sobre la simulación neural del sistema solar térmico

5.5 Análisis de la optimización del rendimiento mediante la distribución del consumo respecto a la energía solar disponible

Un sistema solar térmico, se puede comprender como un interface energético entre el sistema aire (variables ambientales) y el sistema agua (agua caliente solar para el consumo y almacenamiento). Un sistema, que mediante un intercambiador de calor (captador solar), absorbe la energía solar que se recibe desde el aire y la transfiere a un fluido portador, para su transporte a otro intercambiador de calor, que transfiere la energía solar al agua caliente destinada para el consumo.

El comportamiento del sistema solar térmico es función de las condiciones de funcionamiento específicas en cada instalación solar. El rendimiento característico del sistema depende de varios factores como (Diez, 2007):

- La localización del sistema solar térmico respecto a los valores de irradiación solar y temperatura ambiente de cada lugar.

- La evolución de las condiciones climáticas locales a lo largo del año.

- La inclinación y orientación con la que han sido instalados los captadores solares.

- La calidad con que han sido fabricados los componentes del sistema solar térmico.

- El diseño elegido para el dimensionado de los componentes en función del perfil de consumo y el nivel de temperatura demandado diariamente a lo largo del año y en periodos más cortos estacionales o semanales según la aplicación del sistema solar térmico.

En esta Tesis Doctoral, se realizó la simulación de un sistema solar térmico, a partir de los datos obtenidos de la irradiancia solar, la temperatura ambiente, la temperatura y el caudal del fluido portador en las entradas y salidas de los componentes del circuito primario, y las temperaturas de estratificación térmica del depósito acumulador durante su funcionamiento.

En lugar de utilizar las características técnicas de los componentes, suministrados habitualmente por los fabricantes, que después de su instalación y puesta en funcionamiento pueden variar, o no cubrir todos los intervalos de funcionamiento como estaba previsto, o ser aplicados inadecuadamente en los 
métodos de diseño de los sistemas solares térmicos, como el método f-chart en el caso del ensayo del captador solar y la estratificación térmica del agua caliente solar almacenada en el depósito acumulador.

También mediante una predicción a corto plazo de los valores de las variables ambientales, irradiancia solar y temperatura ambiente, en lugar de utilizar las bases de datos climatológicos medios que se pueden desviar de las condiciones acaecidas para cada año.

La simulación neural propuesta proporciona un conocimiento más real sobre la evolución del funcionamiento de un sistema solar térmico particular, extensible y aplicable a cualquier sistema solar térmico instalado. Proporcionando las variaciones de las temperaturas en cada componente, con las que estimar la energía suministrada por el sistema solar térmico. Adicionalmente la monitorización que se realiza al registrar los datos, puede ser utilizada para realizar el control del funcionamiento del sistema solar térmico, además de para corregir y prevenir posibles averías.

El método f-chart, utilizado como referencia en esta Tesis Doctoral, una vez revisado y analizado en profundidad tanto en su formulación teórica, como de forma práctica mediante diversos ensayos (Apartado 3.2) y (Apartado 4.1). Se detectaron una serie de debilidades en su discurso, que han sido utilizadas para proponer una optimización en el rendimiento de los sistemas solares térmicos, en concreto el método f-chart:

- No da la posibilidad de considerar los distintos niveles de irradiación solar diaria, está diseñado para ser utilizado con datos diarios medios mensuales de cada zona y de hecho se aplica así el método.

- No da la posibilidad de tener en cuenta la estratificación térmica del depósito acumulador, está diseñado con la temperatura de mezcla completa del agua caliente acumulada en el depósito.

- No tiene en consideración las pérdidas térmicas en las tuberías, ni tampoco en el depósito acumulador, está diseñado como adiabático.

- No valora la energía solar que se haya transformado en exceso para cubrir las necesidades energéticas, está diseñado para no considerar como parte de la carga de calentamiento el agua almacenada que supera la mínima aceptable.

- No considera los perfiles variables de consumo de agua caliente, está diseñado para una distribución de agua caliente demandada a lo largo del día como la indicada en (Mutch, 1974).

- No considera los diversos caudales del fluido portador que pueda haber en el circuito primario del sistema solar térmico, está diseñado para un caudal del fluido portador en el circuito primario de $0,015 \mathrm{l} /\left(\mathrm{s} \mathrm{m}^{2}\right)$ unidad de superficie captadora instalada.

Por otra parte, se ha detectado una tendencia en la comunidad científica internacional interesada en el conocimiento de estos sistemas solares térmicos, mediante la utilización de la técnica de las redes neuronales artificiales basada en la inteligencia computacional (inteligencia artificial de bajo nivel basada en los datos del funcionamiento) para el modelado de los componentes que se utilizan en los sistemas solares térmicos (Apartado 2.4), además también están siendo utilizadas las redes neuronales artificiales en el modelado y la predicción de la irradiación solar (Apartado 2.2.8).

En esta Tesis Doctoral, se ha conseguido ampliar los modelos presentados hasta la actualidad en la literatura para la predicción de las variables ambientales (Apartado 3.4) y el modelado de los componentes del sistema solar térmico (Apartado 3.6). Pero lo más importante, es que por primera vez 
se ha conseguido utilizar los modelos neurales conjuntamente para la simulación de todo el sistema solar térmico, mediante la metodología neural planteada (Apartado 3.7). Porque para ser una verdadera alternativa los modelos neurales de los componentes, también debe de ser posible utilizarlos en una simulación dinámica del funcionamiento real de los sistemas solares térmicos, junto con todos los componentes. (Fischer, 2012) simula un sistema solar doméstico incorporando un modelo neural del captador solar a la biblioteca TRNSYS pero no responde adecuadamente en algunas situaciones. La aproximación de la simulación neural, propuesta en esta Tesis Doctoral, a la realidad es muy alta, como se presentó (Apartado 4.7.3). Esta simulación puede estar alimentada por las predicciones de la irradiación solar realizadas el día anterior o por datos reales, lo que proporciona una idea de su funcionamiento más cercano a la realidad.

(Peuser et al., 2002) expone que las variaciones anuales de la irradiación solar y la temperatura ambiente en un lugar determinado se suelen mantener en un valor inferior al $10 \%$ respecto de los valores medios respectivos a largo plazo, lo que implica que la fracción solar pueda diferir en un $\pm 10 \%$ del promedio, para un año concreto, debido a las condiciones climáticas particulares, y solo ocasionalmente se observan desviaciones mayores.

Se ha comprobado en esta Tesis Doctoral que entre los años 2002 y 2012 en Mansilla Mayor (León), la irradiación solar anual entre el año con menor y mayor insolación, osciló en un 14 \% (Fig. 4.7.17), y que la cobertura solar proporcionada por el sistema solar térmico de la planta piloto construida (Apartado 3.1), aplicando el método f-chart con los valores reales de irradiación solar y temperatura ambiente correspondientes a los mismos años (Fig. 4.1.1), el rendimiento osciló en un $\mathbf{9 , 1} \%$ respecto al obtenido con los datos medios mensuales CENSOLAR y fluctuó en un 7,9 \% entre los años 2002 y 2012 . Por otra parte, el rendimiento obtenido de la simulación realizada con el modelo neural propuesto (Apartado 3.7), con los resultados obtenidos para el depósito estratificado y mezclado (Tabla 4.7.2) osciló en $\mathbf{9 , 7 2}$ \% con el depósito estratificado y fluctuó en 8,93 \% con el depósito mezclado entre los años 2002 y 2012.

También se ha observado que en años con un nivel mayor de irradiación solar anual, tienen un rendimiento menor, esto es debido a la distribución de la irradiación solar durante el año y teniendo en cuenta la temperatura del agua de la red que es más baja en invierno que en verano. Lo que ocasiona, que para alcanzar la misma cobertura solar en invierno respecto al verano a la temperatura de preparación, sea necesario un nivel mayor de irradiación solar en invierno, precisamente en la época de menor disponibilidad.

Los obstáculos tradicionales para la aplicación de los sistemas solares térmicos han sido el coste de los componentes y la baja eficiencia de conversión, pero actualmente están pasando a primer plano los problemas de intermitencia y fiabilidad (Kleissl, 2013), la precisión de los proyectos a corto y largo plazo han hecho que el campo de la predicción y la evaluación del recurso solar sea un soporte importante.

Se destaca que resulta conveniente favorecer la estratificación térmica del agua caliente solar en los depósitos acumuladores para que el funcionamiento del sistema solar térmico obtenga un mayor rendimiento (Apartado 2.4.3). (Silió et al., 2007) presenta una simulación dinámica implementada en el lenguaje de programación Matlab, contemplando el depósito acumulador mezclado y estratificado, de la que resulta una variación del rendimiento global del sistema solar térmico de entre 10 al $20 \%$ de aumento al utilizar el depósito estratificado, para distintos captadores solares y volumen de acumulación del agua caliente solar. El modelo matemático empleado en este caso es la simulación de la estratificación con el modelo multinodo para el depósito acumulador (Duffie y Beckman, 2006). 
También observa que el incremento es más elevado al aumentar el volumen de un depósito pequeño o mediano y prácticamente constante al aumentar el volumen en grandes depósitos.

Aquí el problema que se plantea es la medida de las temperaturas de la estratificación conseguida en un sistema solar térmico particular. (López et al., 2012) comprueba que el emplazamiento de la sonda de medida de la temperatura del agua en el depósito en su parte baja, como el que los depósitos tienen habitualmente equipados de fábrica (Lapesa, 2006), el cual está diseñado para su utilización en el control diferencial de temperatura respecto la salida del fluido portador del captador solar (Close, 1967) indicado en el (Apartado 4.1) no sirve para realizar una estimación de la energía almacenada en el depósito acumulador. Ya que puede inducir a resultados incongruentes en los cálculos del rendimiento, dependiendo de la altura en la que se mida y registre la temperatura cambiará el rendimiento estimado, porque su posición en otra altura distinta modificaría sustancialmente los resultados. Si se contempla la estratificación, los balances energéticos en el depósito se modifican, afectando al rendimiento conjunto de la instalación solar.

Solo con una medida de la temperatura de agua almacenada en la parte baja del depósito, no es posible conocer la energía total acumulada en el depósito. En esta Tesis Doctoral, se resuelve este problema con la introducción de una sonda que mide la distribución de temperaturas a lo largo de toda la altura del depósito acumulador (Fig. 3.1.2).

Los ensayos que los fabricantes y laboratorios de ensayo realizan actualmente a los captadores solares para obtener su ecuación característica bajo diversas condiciones de ensayo estándares (AENOR, 2006). Se realizan con una irradiancia solar, que incide perpendicularmente o con desviaciones no mayores de $20^{\circ}$ sobre la normal del captador solar, durante el mediodía de días despejados o utilizando simuladores solares en el interior. Con lo que el resultado obtenido no tiene en cuenta las variaciones de la transmitancia de la cubierta transparente $\tau$, y la absortancia de la placa $\alpha$, en otras direcciones en las que se reciba la irradiancia solar (Apartado 3.2.1).

Además, los ensayos se realizan considerando un modelo de cielo isotrópico, con un nivel de irradiación solar difusa inferior al $30 \%$ lo que corresponde a días con cielo claro. La velocidad del viento paralelo al absorbedor se considera de $3 \mathrm{~m} / \mathrm{s}$. Y el caudal del fluido portador durante el ensayo de $0,02 \mathrm{l} /\left(\mathrm{s} \mathrm{m}^{2}\right)$ de superficie de captador solar, con lo que no considera las variaciones del rendimiento en el captador solar al cambiar el caudal del fluido portador en el circuito primario del sistema solar térmico (AENOR, 2006).

Los coeficientes de la ecuación característica del captador solar que se aplican en el método f-chart, corresponde a un ensayo que se realiza en función de la temperatura de entrada del fluido portador al captador solar con un caudal de $0,015 \mathrm{l} /\left(\mathrm{s} \mathrm{m}^{2}\right)$ de superficie de captador solar (Apartado 3.2.2).

Se ha comprobado, que realizar el ensayo al mismo captador solar en función de otros parámetros como la temperatura media o de salida del fluido portador en el captador solar, hace variar el valor de los coeficientes de la ecuación característica de la forma en que se muestra en las (Fig. 4.1.3.a), (Fig. 4.1.3.b) y (Fig. 4.1.3.c) aumentando su valor al utilizar una temperatura mayor como la de salida del captador solar.

Se ha comprobado también, que realizar el ensayo al mismo captador solar utilizando distintos caudales del fluido portador, hace variar el valor de los coeficientes de la ecuación característica de la forma en 
que se muestra para varios ensayos del captador solar en las (Fig. 4.1.5.a), (Fig. 4.1.5.b) y (Fig. 4.1.5.c), y para un ensayo del captador solar en las (Fig. 4.1.6.a), (Fig. 4.1.6.b) y (Fig. 4.1.6.C), de manera muy notable, aumentando su valor al utilizar un caudal del fluido portador mayor (Diez y Falagán, 2013b).

Como consecuencia una aplicación de los coeficientes de la ecuación característica del captador solar en los métodos de diseño, obtenidos en otras condiciones de las prescritas en el método f-chart, ocasionarían grandes variaciones en la cobertura solar anual que puede proporcionar el sistema solar térmico, lo que se ha verificado (Tabla 4.7.4), (Tabla 4.7.5) y (Tabla 4.7.6).

Se ha comprobado que las variaciones en el caudal del fluido portador, no ocasionan variaciones significativas en el rendimiento total de un sistema solar térmico (Tabla 4.7.1), (Tabla 4.7.2) y (Tabla 4.7.3), debido al volumen de almacenamiento de agua caliente solar en el depósito acumulador como prescribe el método f-chart (Apartado 4.1).

En la ingeniería, es de gran interés el análisis de los datos obtenidos mediante el muestreo de señales en los sensores y prever su comportamiento futuro (Palit y Popovic, 2005). La atención se centró en los datos experimentales tomados de los sensores colocados en los sistemas solares térmicos. Y con el fin de tener en cuenta las condiciones más realistas, un intervalo de tiempo de un minuto fue elegido para la formación de las series de tiempo.

Se ha utilizado una técnica concreta como son las redes neuronales artificiales para resolver el problema de las series de tiempo, planteado en el marco teórico de la inteligencia computacional (Apartado 2.5). Para ser aplicado en otra área de conocimiento, que estudia los sistemas solares térmicos activos con fluido portador líquido, en base al conocimiento adquirido de su funcionamiento mediante los datos registrados, por la variación de la irradiancia solar incidente, caudal y temperatura del fluido portador, y del agua caliente solar estratificada que se almacena en el depósito acumulador.

Se resolvió un problema, como es la obtención de una adecuada simulación del funcionamiento del sistema solar térmico, a partir de la cual se puede conseguir una optimización de su rendimiento. Todo ello con la aplicación de una técnica para resolver un problema, que pertenece a un área de conocimiento concreta, con el conocimiento de otra área distinta.

El modelado del sistema solar térmico, que aquí se ha propuesto, solo necesita para su aplicación a una instalación solar térmica específica de una base de datos de la irradiancia solar, caudal y temperaturas del fluido portador y el agua caliente solar estratificada, representativa del intervalo de funcionamiento que se pretenda simular. Los puntos concretos a medir en la instalación solar son las entradas y las salidas de los componentes principales, con el objetivo de crear modelos black box de cada uno de ellos, y para el depósito acumulador la temperatura de varias capas en el eje longitudinal de la altura. Por lo que se considera exportable a cualquier tipo de sistema solar térmico construido.

El equipo utilizado para recoger estos datos es el habitual que se puede manejar para registrar este tipo de mediciones hacia un ordenador o equipos específicos, que se comercializan para realizar la monitorización de la instalación solar, obligada por la legislación en instalaciones de grandes dimensiones. La adquisición de datos en las instalaciones solares equipadas con sondas térmicas, de presión, de caudal, de irradiancia solar,... se registran en memorias programables y pueden utilizar para la comunicación con el exterior vía cable o antena: RS-232, Ethernet, Wi-Fi, ADSL, telefonía móvil o GSM. 
Estando homologados para su utilización y preparados en maletas portátiles para su fácil empleo (Systemtronic, 2010).

Los sensores de temperatura utilizados se colocan en sondas, que se instalan en los puntos a medir. El caso de la medida de la irradiancia solar en instalaciones pequeñas, debido al alto coste del sensor, puede no ser interesante económicamente. Entonces se dispone de dos alternativas: la primera son los piranómetros fotovoltaicos o su construcción a partir del sensor de infrarrojo que resulta más barato (Brooks, 2008) y la segunda son los métodos de estimación de la irradiación solar a partir de la registrada sobre la superficie horizontal (Apartado 3.5) en estaciones cercanas de los servicios climatológicos (Anexo 1 Datos climatológicos) o en la cada vez mayor red de estaciones de aficionados que ofrecen sus datos (Meteoclimatic, 2013) calificadas según su fiabilidad.

El modelo neural de captador solar necesitó datos de la irradiancia solar incidente, la temperatura ambiente que lo rodea, el caudal y temperatura del fluido portador de entrada y salida al captador solar (Apartado 3.6.1). Habitualmente, hay más de un captador solar en las instalaciones solares por lo que se realizará el modelado al campo de captación completo simultáneamente o en el caso de ser muy grande a los grupos de captadores solares instalados, registrando las medidas para cada conjunto de captadores solares de su caudal y temperatura del fluido portador en la entrada y salida del conjunto a configurar (Diez y Falagán, 2013a) y (Diez y Falagán, 2013b).

El modelo neural de intercambiador de calor necesitó para su ejecución de los caudales y temperaturas del fluido portador de entrada y salida, y las temperaturas del agua que rodea al serpentín sumergido en el agua caliente solar almacenada en el depósito acumulador en el caso del tipo interior (Apartado 3.6.2) mediante los sensores instalados en la sonda de medida de la estratificación térmica. En el caso de los intercambiadores de calor de tipo exterior es necesario el caudal y temperatura del agua caliente solar en el circuito secundario, de entrada y salida (Apartado 4.3.2) pudiéndose incluir en este caso la temperatura ambiente en el entorno del intercambiador de calor, si tuviera una variación importante.

El modelo neural de depósito acumulador de agua caliente solar necesitó para su realización de los datos de carga, descarga y los niveles de estratificación térmica (Apartado 3.6.3). La carga con las temperaturas y el caudal del fluido portador en el circuito primario de entrada y salida en el caso de utilizar un intercambiador de calor interior, o de las temperaturas y el caudal del agua caliente solar en el circuito secundario de entrada y salida en el caso de utilizar un intercambiador de calor de tipo exterior. La descarga con la temperatura y el caudal del agua caliente solar que sale del depósito con destino al consumo y la temperatura del agua de red que entra en el depósito. Los niveles de estratificación con las temperaturas registradas, para considerar su efecto. Pudiéndose incluir la temperatura ambiente en el entorno del depósito, si tuviera una variación importante.

El modelado de las tuberías, en esta Tesis Doctoral debido a su corta trayectoria y al estar aisladas térmicamente, no se ha tenido en cuenta, pero en instalaciones en las que su recorrido pueda generar pérdidas significativas pueden ser modeladas como otro componente del sistema solar térmico. Para ello se necesita de los datos de las temperaturas y el caudal en la entrada y salida del tramo considerado, tomados en los mismos sensores colocados en las entradas y salidas de los componentes a los que se acoplan las tuberías, sin tener que duplicarse los sensores instalados. Y para su mejor aproximación, de la temperatura ambiente del entorno de la tubería, si tuviera una variación importante, al igual que en el caso del depósito acumulador. 
Se ha observado durante la realización de las simulaciones con el modelo neural del sistema solar térmico, que introducir datos erróneos o falsos, por ejemplo en el valor inicial de la temperatura de las tuberías de ida y retorno al comienzo de la simulación, o en las capas de la estratificación térmica del agua caliente solar almacenada en el depósito acumulador. Que la red neuronal artificial reacciona rápidamente, posicionándose a valores reales de funcionamiento.

Se ha comprobado que el ajuste de los resultados obtenidos con los modelos neurales propuestos de los componentes modelados y los datos reales ha sido óptimo (Apartado 4.6).

- El captador solar (Apartado 4.6.1) obtuvo valores RMSE de $\mathbf{0 , 1 8}, \mathbf{0 , 1 9}$ y $\mathbf{0 , 2 0}{ }^{\circ} \mathbf{C}$ en la temperatura de salida del fluido portador con diferentes caudales.

- El intercambiador de calor (Apartado 4.6.2) obtuvo valores RMSE de $\mathbf{0 , 1 7}, \mathbf{0 , 2 4}$ y $\mathbf{0 , 4 6}{ }^{\circ} \mathbf{C}$ en la temperatura de salida del fluido portador con diferentes caudales.

- El depósito acumulador (Apartado 4.6.3) formado por cuatro modelos correspondientes a los diferentes estados de funcionamiento obtuvieron, en las temperaturas de estratificación:

- Estado SOL con carga y sin descarga un valor RMSE $=\mathbf{0 , 1 0}{ }^{\circ} \mathrm{C}$.

O Estado $\mathrm{SOL}+\mathrm{ACS}$ con carga y descarga un valor $\mathrm{RMSE}=\mathbf{0 , 1 2}{ }^{\circ} \mathrm{C}$.

- Estado NOCHE sin carga ni descarga un valor $\mathbf{R M S E}=\mathbf{0 , 0 7}{ }^{\circ} \mathrm{C}$.

o Estado NOCHE + ACS sin carga pero con descarga un valor $\mathrm{RMSE}=\mathbf{0 , 1 2}{ }^{\circ} \mathrm{C}$.

Las variables ambientales más influyentes en el funcionamiento de un sistema solar térmico, son la irradiancia solar y la temperatura ambiente, a la que está expuesto el captador solar. Estas variables cambian su valor de forma espacial y temporal, según el lugar y la climatología de cada momento.

Para la aplicación del método f-chart utilizado como referencia en esta Tesis Doctoral, las variables ambientales utilizadas se necesitan en forma de datos diarios medios mensuales de la zona concreta. Estos datos de los valores diarios medios de cada mes para cada provincia son utilizados frecuentemente por los técnicos e ingenieros solares (IDAE, 2009) en las tablas CENSOLAR.

Pero, se ha comprobado que estos datos diarios medios mensuales suelen estar por debajo de los datos reales (Fig. 4.7.17). La irradiación solar global horizontal de la estación SIAR en Mansilla Mayor (León) respecto a los datos medios de CENSOLAR fue:

- $\quad+4,75 \%$ en el año 2002 .

- $\quad+\mathbf{1 1}, \mathbf{8 1} \%$ en el año 2004 .

- $\quad+\mathbf{1 1 7 , 2 6} \%$ en el año 2005 .

- $\quad+\mathbf{1 3 , 2 2} \%$ en el año 2006 .

- $\quad+\mathbf{1 3}, \mathbf{3 0} \%$ en el año 2007 .

- $\quad+\mathbf{1 1 , 8 2} \%$ en el año 2008 .

- $\quad+\mathbf{1 8 , 7 4} \%$ en el año 2009.

- $\quad+13,36 \%$ en el año 2010 .

- $\quad+\mathbf{1 4 , 9 2} \%$ en el año 2011.

- $\quad+\mathbf{1 1 6 , 1 0 \%}$ en el año 2012 .

La utilización de estos datos reales en el método f-chart producen una variación en la cobertura solar anual de hasta el $\mathbf{9 , 1} \%$ en el año con mayor insolación respecto a los datos climatológicos medios CENSOLAR (Fig. 4.1.1). 
Para resolver esta situación en esta Tesis Doctoral, se ha propuesto realizar la predicción neural a corto plazo, diaria en este caso, de la evolución de las variables ambientales, irradiación solar y temperatura ambiente que van a tener lugar el día de mañana (Apartado 3.4). Estas predicciones pueden utilizarse en lugar de los datos reales o medios como base a la simulación del sistema solar térmico, mediante el modelado neural propuesto del sistema solar térmico (Apartado 3.7).

Se probaron diversas técnicas de predicción aplicadas en la literatura a las variables ambientales (Apartado 4.2) con los datos climatológicos correspondientes al año 2011 (Fig. A.1.11) y (Fig. A.1.22) que se mantuvieron a parte para un control independiente de los modelos de predicción. Es importante señalar que el mismo conjunto de datos se utilizó para las pruebas de rendimiento de todos los modelos de predicción.

- Los datos climáticos CENSOLAR (Apartado 4.2.1) obtuvo valores RMSE de $\mathbf{5 , 1 8} \mathbf{~ M J} / \mathrm{m}^{\mathbf{2}} / \mathbf{d}$ (Fig. 4.2.1) y $3,64^{\circ} \mathrm{C} / \mathrm{d}$ (Fig. 4.2.2).

- El modelado por correlación con la aplicación de la media móvil ponderada (Apartado 4.2.3) utilizando los coeficientes obtenidos de la autocorrelación parcial de las series de datos (Apartado 4.2.2) obtuvo valores:

o RMSE de 4,26 y $3,98 \mathrm{MJ} / \mathrm{m}^{2} / \mathrm{d}$ para 2 y 11 días de retardo (Fig. 4.2.7) y (Fig. 4.2.8).

o RMSE de 1,86 y $1,81{ }^{\circ} \mathrm{C} / \mathrm{d}$ para 2 y 5 días de retardo de la temperatura media (Fig. 4.2.10) y (Fig. 4.2.11).

o RMSE de 2,86 y $\mathbf{2 , 7 6}{ }^{\circ} \mathrm{C} / \mathrm{d}$ para 2 y 5 días de retardo de la temperatura máxima (Fig. 4.2.12) y (Fig. 4.2.13).

- RMSE de 2,52 y $2,53{ }^{\circ} \mathrm{C} / \mathrm{d}$ para 2 y 5 días de retardo de la temperatura mínima (Fig. 4.2.14) y (Fig. 4.2.15).

- La regresión lineal respecto a los valores del día anterior (Apartado 4.2.4) obtuvo valores RMSE de $\mathbf{4 , 2 4} \mathrm{MJ} / \mathrm{m}^{2} / \mathrm{d}$ (Fig. 4.2.18) y $\mathbf{1 , 8 5}{ }^{\circ} \mathrm{C} / \mathrm{d}$ (Fig. 4.2.20).

- Las series de Fourier (Apartado 4.2.5) con el primer armónico, obtuvo valores:

O $\quad$ RMSE $=4,27 \mathrm{MJ} / \mathrm{m}^{2} / \mathrm{d}$ (Fig. 4.2.22).

O $\quad$ RMSE $=\mathbf{2 , 6 6}{ }^{\circ} \mathrm{C} / \mathrm{d}$ para la temperatura media (Fig. 4.2.24).

O $\quad$ RMSE $=3,83^{\circ} \mathrm{C} / \mathrm{d}$ para la temperatura máxima (Fig. 4.2.26).

o $\quad$ RMSE $=3,37^{\circ} \mathrm{C} / \mathrm{d}$ para la temperatura mínima (Fig. 4.2.28).

- Las matrices de transición de Markov (Apartado 4.2.6) obtuvo un valor RMSE $=\mathbf{4 , 3 7} \mathbf{~ M J} / \mathrm{m}^{2} / \mathbf{d}$ (Fig. 4.2.29).

- El método ASHRAE para la estimación de los valores horarios a partir de la temperatura ambiente máxima y mínima (Apartado 4.2.7) obtuvo un valor $\mathrm{RMSE}=1,85^{\circ} \mathrm{C} / \mathrm{h}$ (Fig. 4.2.30).

En esta Tesis Doctoral se han desarrollado varios modelos de predicción de la irradiación solar y la temperatura ambiente, fiables, que pueden predecir el valor de las variables ambientales del día de mañana y su distribución a lo largo del día, para el uso en la simulación del funcionamiento del sistema solar térmico, en periodos de tiempo de un minuto, en función de los valores registrados de las variables ambientales del día o días anteriores sobre el que se realiza la predicción (Apartado 3.4). La técnica escogida son las redes neuronales artificiales de la inteligencia computacional aplicadas a las series de tiempo (Apartado 2.5), constituidas por la base de datos climatológicos registrados en la estación de SIAR en Mansilla Mayor (León) (Anexo 1 Datos climatológicos). 
Se ha creado un modelo de predicción de la distribución de las variables ambientales, útil en cualquier lugar del que se disponga una base de datos climatológicos y fácil de aplicar por personal no excesivamente especializado. El método consta de dos fases, la primera realiza una predicción del valor de mañana en función del valor registrado hoy, y la segunda realiza una estimación de la distribución durante el día de la predicción resultante anteriormente (Apartado 3.4).

Para la primera fase de predicción del valor diario del día de mañana.

Se proponen varias arquitecturas neurales en función de varias entradas (Apartado 3.4.1), como el valor de la irradiación solar global diaria.

- Con un día de retardo (Fig. 3.4.2) que obtuvo un valor RMSE = 4,26 MJ/m² $/ \mathbf{d}$ (Fig. 4.4.1).

- Con dos días de retardo (Fig. 3.4.3) que obtuvo un valor RMSE = 4,13 $\mathbf{~ M J} / \mathrm{m}^{2} / \mathrm{d}$ (Fig. 4.4.2).

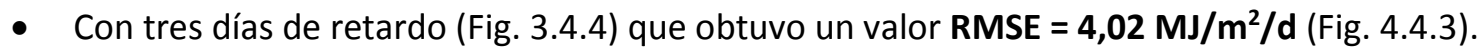

Añadiendo el día del año.

- Con un día de retardo (Fig. 3.4.5) que obtuvo un valor RMSE $=\mathbf{3}, \mathbf{8 0} \mathbf{~ M J} / \mathbf{m}^{2} / \mathbf{d}$ (Fig. 4.4.5).

- Con dos días de retardo (Fig. 3.4.6) que obtuvo un valor RMSE =3,85 MJ/m² $/ \mathbf{d}$ (Fig. 4.4.6).

- Con tres días de retardo (Fig. 3.4.7) que obtuvo un valor RMSE = 3,84 MJ/m²/d (Fig. 4.4.7).

Añadiendo el índice de claridad.

- Con un día de retardo (Fig. 3.4.8) que obtuvo un valor RMSE = $3,77 \mathbf{~ M J / m ²} / \mathbf{d}$ (Fig. 4.4.9).

Y añadiendo a este último el día del año (Fig. 3.4.9) que obtuvo un valor RMSE $=3,80 \mathrm{MJ} / \mathrm{m}^{2} / \mathbf{d}$ (Fig. 4.4.10).

También se proponen métodos alternativos para la predicción de la irradiación solar global diaria en el caso de no disponer en la instalación solar de un sensor para la medida de la irradiancia solar, a partir de los valores de la temperatura ambiente (Apartado 3.4.2).

- Con el valor de la temperatura media diaria con un día de retardo (Fig. 3.4.10) que obtuvo un valor RMSE = 6,13 MJ/m²/d (Fig. 4.4.12).

- Con el valor de la temperatura máxima y mínima diaria con un día de retardo (Fig. 3.4.11) que obtuvo un valor RMSE = 5,68 MJ/m²/d (Fig. 4.4.13).

- Con el valor de la temperatura media, máxima y mínima diaria con un día de retardo (Fig. 3.4.12) que obtuvo un valor $\mathrm{RMSE}=5,40 \mathrm{MJ} / \mathrm{m}^{2} / \mathrm{d}$ (Fig. 4.4.14).

Añadiendo el día del año.

- A la temperatura media con un día de retardo (Fig. 3.4.13) que obtuvo un valor RMSE $=\mathbf{4 , 2 8}$ $\mathrm{MJ} / \mathrm{m}^{2} / \mathrm{d}$ (Fig. 4.4.15).

- A la temperatura máxima y mínima con un día de retardo (Fig. 3.4.14) que obtuvo un valor RMSE = 3,92 MJ/m²/d (Fig. 4.4.16).

- A la temperatura media, máxima y mínima con un día de retardo (Fig. 3.4.15) que obtuvo un valor RMSE = 3,84 MJ $/ \mathrm{m}^{2} / \mathrm{d}$ (Fig. 4.4.17). 
En el caso de la predicción de la temperatura ambiente media, máxima y mínima diaria se proponen varias arquitecturas neurales respecto al valor de las temperaturas máxima, media, mínima diaria con un día de retardo y el día del año (Apartado 3.4.3).

- Con el valor de la temperatura media, máxima y mínima diaria con un día de retardo (Fig. 3.4.16) que obtuvo valores RMSE de $\mathbf{1 , 8}, \mathbf{2 , 8}$ y $\mathbf{2 , 2}{ }^{\circ} \mathrm{C} / \mathbf{d}$ respectivamente (Fig. 4.4.18).

- Añadiendo el día del año a la temperatura media, máxima y mínima con un día de retardo (Fig.

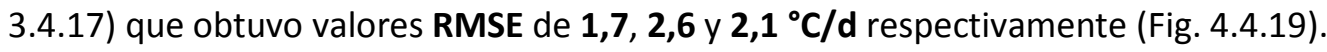

Y para la segunda fase de estimación de la distribución de los valores horarios.

Se proponen varias arquitecturas neurales en función de varias entradas como el valor de la predicción realizada anteriormente y el día del año para el caso de la irradiancia solar (Apartado 3.4.4).

- Se comprueba con los datos medidos la desviación resultado de los valores horarios (Fig. 3.4.18) que obtuvo un valor RMSE $=87 \mathrm{~W} / \mathrm{m}^{2} / \mathbf{h}$ (Fig. 4.4.20).

- Y añadiendo el día del año a la irradiación solar global diaria (Fig. 3.4.19) que obtuvo un valor RMSE $=51 \mathrm{~W} / \mathrm{m}^{2} / \mathrm{h}$ (Fig. 4.4.21).

Y para el caso de la estimación de la distribución de los valores horarios de la temperatura ambiente (Apartado 3.4.5).

- Se comprueba con los datos medidos la desviación resultado de los valores horarios (Fig. 3.4.20)

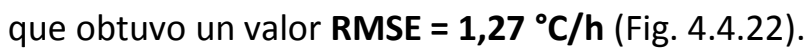

- Y añadiendo el día del año a la temperatura media, máxima y mínima diaria (Fig. 3.4.21) que obtuvo un valor $\mathrm{RMSE}=\mathbf{1 , 2 4}{ }^{\circ} \mathrm{C} / \mathrm{h}$ (Fig. 4.4.23).

Estos valores horarios se tratan mediante una interpolación para crear una distribución de la predicción de los valores que toman cada minuto las variables ambientales, irradiancia solar y temperatura ambiente, durante el día de mañana, para ser utilizados como entradas al modelo neural propuesto.

Se conoce que el aumento del caudal del fluido portador por el captador solar, repercute en un aumento del rendimiento que se obtiene del propio captador solar (Apartado 4.1). Pero también se conoce que el aumento del caudal del circuito primario, repercute en el depósito acumulador con temperaturas más bajas (Apartado 2.4.3). Los depósitos mezclados hacen una recirculación hacia el captador solar con una temperatura más alta, que un depósito estratificado en los cuales las temperaturas altas están en la parte superior y las temperaturas bajas se concentran en la parte inferior, desde donde retorna para el captador solar, con lo que se consigue un aumento del rendimiento en el captador solar. En la parte de arriba del depósito acumulador se descarga el agua caliente solar para el consumo a una temperatura más alta que en el mismo depósito acumulador en el caso de estar mezclado.

Por lo que, se recomienda la búsqueda del caudal más adecuado del fluido portador en cada sistema solar térmico particular, para obtener el máximo rendimiento del captador solar con la mínima pérdida en la estratificación del depósito acumulador debida principalmente a la mezcla turbulenta del agua ocasionada por los efectos del chorro de entrada en el depósito acumulador. 
Las redes neuronales artificiales necesitan para el entrenamiento de los datos representativos de todo el intervalo de funcionamiento que se pretenda modelar, tanto para los componentes del sistema solar térmico, como para la predicción de las variables ambientales.

Por lo que, se recomienda la implementación de una red neuronal artificial para cada estado, con el objetivo de poder modelar con más precisión cada conjunto de datos similares, procedentes de estados distintos de funcionamiento del componente, repartiéndose para cada modelo neural concreto de estado.

Como en el modelado de los componentes o la predicción de las variables ambientales se detectan, conjuntos o tramos con características similares, que se pueden agrupar, como se realizó en el modelado de la estratificación térmica del depósito acumulador (Apartado 3.6.3) al encontrar cuatro estados diferentes de funcionamiento, resultado de la combinación de las situaciones de carga y/o descarga: soleado, soleado con consumo, noche y noche con consumo.

Y para el caso de la predicción de las variables ambientales se recomienda, realizar una arquitectura neural para cada estación climática del año, ya que al tener características distintas, se puede modelar con más precisión cada estado por separado.

En el modelado del depósito acumulador, se recomienda tener en cuenta la temperatura ambiente en el caso de tener una variación notable, al influir directamente en las pérdidas térmicas hacia el exterior, si en la ubicación del depósito acumulador la temperatura ambiente se mantiene en un intervalo no muy grande, se podría no tener en consideración, como fue el caso de la planta piloto, al estar su influencia incrustada en los datos de la evolución de la estratificación térmica.

En la instalación de los sensores, que recogen los datos del funcionamiento en el sistema solar térmico, hay que seguir unas recomendaciones, que a continuación se exponen.

El piranómetro encargado de medir la irradiancia solar sobre el captador solar, se tiene que colocar junto a los componentes de captación y siempre sobre su mismo plano, con la misma inclinación y orientación en la que están instalados los captadores solares, para poder medir la misma irradiancia solar que llega a los captadores solares. Los sensores de temperatura se pueden colocar en vainas (Laughton, 2010) que quedan introducidas en el tramo de tubería que da entrada o salida al componente a modelar. También pueden ser adheridas en la parte superior exterior de la tubería y siempre cubiertas por un aislante térmico para no estar afectados por la temperatura ambiente (Martínez, 2010) con esta última opción se evita tener que hacer un corte en la tubería para instalar la vaina de la sonda.

Y en concreto, el sensor que mide las variaciones de temperatura del fluido portador en la salida del captador solar, tiene que introducirse dentro del absorbedor del propio captador solar, para evitar que se produzcan picos de temperatura en el arranque de la bomba de circulación, evitándose siempre colocar el sensor fuera del captador solar (Peuser et al., 2002) como se observó en los ensayos realizados con la planta piloto.

Los sensores de temperatura para la medida de la estratificación térmica en el depósito acumulador se colocan en una vaina, uniformemente distribuidos y con una separación entre 8 o $10 \mathrm{~cm}$, que se introduce por la salida para la descarga de agua caliente solar en la parte alta del depósito acumulador. Esta vaina debido a la longitud del depósito y condicionado por la posible altura del techo del lugar 
donde se encuentra el depósito puede que no lo permita, en este caso se consigue introducir en varios tramos que se van empalmando según se van introduciendo en el interior del depósito acumulador, o también hay la posibilidad de utilizar una vaina de material flexible. El cierre con la salida se realizará mediante una conexión de tubería de forma T de la cual, la salida hacia arriba se taponará con un racor soldado, por donde se introducirá la sonda, y la salida lateral de la conexión T se utilizará para el agua caliente solar, esta tubería debe continuar su trayectoria hacia abajo con el fin de evitar las pérdidas térmicas a causa de la circulación por convección natural dentro de las tuberías de conexión de salida del depósito, para evitar que cuando en este tramo de tubería el agua se enfríe, ésta se deslice a la parte alta del depósito, donde se almacena el agua caliente solar, con la consiguiente pérdida de energía (German Solar Energy Society, 2010).

El modelado del sistema solar térmico se ha propuesto desde la base de datos medidos y registrados en el propio sistema solar térmico. Una alternativa a los datos reales son los que se pueden generar con otros modelos para ser utilizados en el entrenamiento de las redes neuronales artificiales que simulan el funcionamiento de cada componente del sistema solar térmico.

Se ha comprobado que con una inclinación de $45^{\circ}$ del captador solar sobre la superficie horizontal, se da un aprovechamiento distinto según la época del año (Fig. 4.5.12) como sigue:

- Mayor en los meses de irradiación solar media (febrero, marzo, abril, septiembre, octubre y noviembre) debido a que la altura solar, produce un ángulo de incidencia sobre el captador solar menor que en otros meses.

- Para los meses de irradiación solar alta (mayo y agosto) la captación solar es casi la misma que sobre la horizontal.

- Y para los meses de irradiación solar muy alta (junio y julio) la captación solar es menor sobre el plano inclinado que en la horizontal, debido a la elevada altura solar.

Para el uso en el modelado de la planta piloto se ha optado por el modelo de paso de la irradiación solar difusa del cielo sobre la horizontal a la incidente sobre un plano inclinado, que utiliza las correcciones de Klucher para todo tipo de cielo (Apartado 2.3.2) por ser más preciso en esta Tesis Doctoral. Resultado de la comparación de las medidas registradas de la irradiancia solar sobre la horizontal y el plano inclinado, y de los resultados obtenidos con las correlaciones de Liu y Jordan, Temps y Coulson, Hay y los datos de las tablas CENSOLAR (Fig. 4.5.13) y (Fig. 4.5.14).

Resultando un nivel de la irradiación solar global para el año 2011 (Fig. 4.5.12) como sigue:

- El modelo que usa las correcciones de Klucher un valor de $1,93 \mathrm{MWh} / \mathrm{m}^{2} /$ año.

- El modelo que usa las correcciones de Temps y Coulson para cielo claro resulta un valor de 1,99 $\mathrm{MWh} / \mathrm{m}^{2} /$ año.

- El modelo que usa las correcciones de Hay resulta un valor de $1,86 \mathrm{MWh} / \mathrm{m}^{2} /$ año.

- El modelo que usa las correcciones de Liu y Jordan para cielo nuboso resulta un valor de $\mathbf{1 , 8 4}$ $\mathrm{MWh} / \mathrm{m}^{2} /$ año.

- El modelo de CENSOLAR que utiliza coeficientes mensuales resulta un valor de $\mathbf{1 , 8 4}$ $\mathrm{MWh} / \mathrm{m}^{2} /$ año.

Todos ellos respecto a una irradiación solar anual sobre la horizontal medida en el año 2011 de un valor de $1,67 \mathrm{MWh} / \mathrm{m}^{2} /$ año. 
Con lo que se obtiene utilizando las correcciones del modelo de Klucher para todo tipo de cielo un valor de $90 \mathrm{kWh} / \mathrm{m}^{2} /$ año, superior al modelo de coeficientes mensuales de CENSOLAR el cual suele subestimar el valor de la irradiación solar, utilizado en la (Tabla 4.7.5).

Se comprueba que los modelos anisotrópicos que estiman la irradiación solar difusa sobre el plano inclinado son más ajustados a las medidas efectuadas por el pirómetro de la planta piloto, con valores superiores que el modelo de coeficientes de CENSOLAR utilizado habitualmente en el diseño de sistemas solares térmicos (Fig. 4.5.13) y (Fig. 4.5.14).

Las predicciones resultantes de los modelos se evaluaron con diferentes pruebas estadísticas, para poder realizar una selección de los más apropiados, interpretación de los resultados y medida de su precisión para evaluar la efectividad del modelo en la predicción. Cada estadístico es apropiado para un determinado problema.

En el capítulo cuarto dedicado a los resultados y presentación de los datos, se han realizado gráficas en las que se representan los errores de las predicciones, que contribuyen a proporcionar una medida útil de hasta qué punto, las predicciones se ajustan a los datos. Así, los residuos muy grandes implican un mal ajuste, mientras que residuos pequeños implican un buen ajuste.

El estadístico, Root Mean Square Error RMSE, se utilizó para realizar una primera selección de los modelos predictivos. Con él encontramos el mejor modelo de predicción que presente el mínimo error, también se utiliza para comparar la precisión de diferentes modelos de predicción. Tiene la ventaja de que sus resultados están en las unidades originales de la información.

El estadístico, Coeficiente de Determinación $\mathbf{R}^{\mathbf{2}}$, se utilizó para describir una medida adecuada en el análisis de la bondad o ajuste del modelo. Indica la proporción de variación de la predicción que queda ajustada por el modelo con respecto a los datos. Toma valores entre $0-1$, un valor elevado se asocia a un buen ajuste y un valor pequeño a un mal ajuste.

El estadístico, Durbin-Watson DW, se utilizó para detectar la autocorrelación de primer orden. Toma valores entre 0-4, un valor elevado se asocia a una autocorrelación negativa, un valor pequeño a una positiva y un valor de 2 a la nula autocorrelación.

El estadístico, Mean Percentage Error MPE, se utilizó para una interpretación de los modelos predictivos. Sirve para ver el sesgo del error de la predicción. Un valor cercano a cero indica un buen resultado.

El estadístico, Forecast Accuracy FA, se utilizó para realizar una medida de la precisión para evaluar la efectividad de los modelos de predicción. Es uno de los estadísticos más utilizados a corto plazo, se recomienda su uso sin sobrepasar los tres periodos. Los errores absolutos penalizan en mayor medida los grandes errores. Un valor cercano a 1 indica un buen resultado.

El estadístico, Akaike Information Criterion AIC, se utilizó para seleccionar el mejor modelo dentro del conjunto de los mismos datos. Penaliza la complejidad del modelo tomando en cuenta el número de variables. Selecciona el modelo que presenta el valor menor. 


\subsection{Análisis de la predicción de variables ambientales}

En esta Tesis Doctoral se han comprobado diferentes modelos de predicción de las variables ambientales, expuestos en la literatura:

1) Datos climáticos CENSOLAR.

2) Media móvil ponderada con la autocorrelación parcial.

3) Regresión lineal.

4) Análisis de Fourier.

5) Análisis de Markov.

6) Método ASHRAE.

Utilizando la base de datos climatológicos SIAR en Mansilla Mayor (León). Los cuales obtuvieron la efectividad que seguidamente se analiza.

1) Tablas de CENSOLAR propuestas a escala provincial de irradiación solar y temperatura ambiente diurna

Elección: Se pueden utilizar dichas tablas para una buena aproximación, además de ser rápida y sencilla su aplicación.

Interpretación: Ajuste bueno. El modelo no tiene en cuenta las variaciones diarias para cada día del mes.

Precisión: Media.

Por lo que se observa de los resultados estadísticos evaluados para comprobar su efectividad (Tabla 5.1.1) y (Tabla 5.1.2).

Tabla 5.1.1 Efectividad de las tablas de irradiación solar CENSOLAR respecto a los datos de SIAR en Mansilla Mayor (León) para el año 2011

\begin{tabular}{|c|c|c|c|c|c|c|}
\hline \multicolumn{7}{|c|}{ Tablas CENSOLAR: Irradiación solar global diaria } \\
\hline & $\begin{array}{c}\text { RMSE } \\
\left(\mathbf{M J} / \mathbf{m}^{2} / \mathbf{d}\right)\end{array}$ & $\mathbf{R}^{\mathbf{2}}$ & $\mathbf{D W}$ & MPE & FA & AIC \\
\hline $\mathbf{H}(\mathbf{t})$ & 5,1829 & 0,6837 & 0,7092 & $-0,1342$ & 0,5286 & 5,2105 \\
\hline
\end{tabular}

Tabla 5.1.2 Efectividad de las tablas de temperatura ambiente diurna CENSOLAR respecto a los datos de SIAR en Mansilla Mayor (León) para el año 2011

\begin{tabular}{|c|c|c|c|c|c|c|}
\hline \multicolumn{7}{|c|}{ Tablas CENSOLAR: Temperatura media diurna diaria } \\
\hline & $\begin{array}{c}\mathbf{R M S E} \\
\left({ }^{\circ} \mathbf{C}\right)\end{array}$ & $\mathbf{R}^{\mathbf{2}}$ & $\mathbf{D W}$ & $\mathbf{M P E}$ & FA & AIC \\
\hline $\mathbf{T}_{\mathrm{a}}(\mathbf{t})$ & 3,6352 & 0,7505 & 0,4255 & $-0,1157$ & 0,6524 & 3,6546 \\
\hline
\end{tabular}


2) Media móvil ponderada por los coeficientes de autocorrelación parcial

Los resultados obtenidos de la autocorrelación parcial para un día de retardo en la irradiación solar global diaria fue de $\mathbf{0 , 8 7 4 7}$ (Tabla 4.2.1) y (Fig. 4.2.3), y para las temperaturas media, máxima y mínima

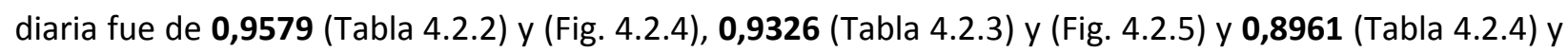
(Fig. 4.2.6) respectivamente.

Elección: Se pueden utilizar estas correlaciones para una buena predicción. Mejoran los resultados de las tablas CENSOLAR, al realizar una predicción diaria sobre los valores registrados en los días anteriores.

Interpretación: Ajuste bueno. La autocorrelación parcial más fuerte se produce con un día de retardo, disminuyendo drásticamente para los días siguientes. Los coeficientes de autocorrelación parcial cercanos a 1 confirman la persistencia de las variables ambientales de un día para el siguiente. Utilizar varios días de retardo mejora ligeramente las predicciones.

Precisión: Buena, sobre todo para las temperaturas al ser una variable continua. Mejor para las temperaturas medias que las extremas, al ser su variabilidad más alta para estas últimas.

Por lo que se observa de los resultados estadísticos evaluados para comprobar su efectividad (Tabla 5.1.3) y (Tabla 5.1.4).

Tabla 5.1.3 Efectividad de la predicción media móvil ponderada con los coeficientes de autocorrelación parcial de irradiación solar respecto a los datos de SIAR en Mansilla Mayor (León) para el año 2011

\begin{tabular}{|ccc|c|c|c|c|c|c|}
\hline \multicolumn{7}{|c|}{ Modelo Media Móvil Ponderada: Irradiación solar global diaria } \\
\hline Entradas & $\rightarrow$ & Salida & $\begin{array}{c}\text { RMSE } \\
\left(\mathbf{M J} / \mathbf{m}^{2} / \mathbf{d}\right)\end{array}$ & $\mathbf{R}^{\mathbf{2}}$ & DW & MPE & FA & AIC \\
\hline $\mathbf{H}(\mathbf{t}-\mathbf{1}), \mathbf{H}(\mathbf{t})$ & $\rightarrow$ & $\mathbf{H}(\mathbf{t}+\mathbf{1})$ & 4,2582 & 0,7865 & 2,0952 & $-0,1366$ & 0,6589 & 4,3048 \\
\hline $\mathbf{H}(\mathbf{t}-\mathbf{1 0}) \ldots \mathbf{H}(\mathbf{t})$ & $\rightarrow$ & $\mathbf{H}(\mathbf{t}+\mathbf{1})$ & 3,9810 & 0,8134 & 1,7265 & $-0,1682$ & 0,6493 & 4,2283 \\
\hline
\end{tabular}

Tabla 5.1.4 Efectividad de la predicción media móvil ponderada con los coeficientes de autocorrelación parcial de temperatura media, máxima y mínima respecto a los datos de SIAR en Mansilla Mayor (León) para el año 2011

\begin{tabular}{|c|c|c|c|c|c|c|c|c|}
\hline \multicolumn{9}{|c|}{ Modelo Media Móvil Ponderada: Temperatura media, máxima y mínima diaria } \\
\hline Entradas & $\rightarrow$ & Salida & $\begin{array}{l}\text { RMSE } \\
\left({ }^{\circ} \mathrm{C}\right)\end{array}$ & $\mathbf{R}^{2}$ & DW & MPE & FA & AIC \\
\hline$T_{\text {med }}(t-1), T_{\text {med }}(t)$ & $\rightarrow$ & $T_{\text {med }}(t+1)$ & 1,8628 & 0,9097 & 1,9296 & $-0,0463$ & 0,7534 & 1,7811 \\
\hline$T_{\text {med }}(t-4) \ldots T_{\text {med }}(t)$ & $\rightarrow$ & $T_{\text {med }}(t+1)$ & 1,8135 & 0,9144 & 1,5192 & $-0,0116$ & 0,7967 & 1,8636 \\
\hline$T_{\max }(t-1), T_{\max }(t)$ & $\rightarrow$ & $T_{\max }(t+1)$ & 2,8626 & 0,8610 & 1,8969 & $-0,0316$ & 0,8366 & 2,8941 \\
\hline$T_{\max }(t-4) \ldots T_{\max }(t)$ & $\rightarrow$ & $T_{\max }(t+1)$ & 2,7562 & 0,8711 & 1,6610 & $-0,0380$ & 0,8391 & 2,8324 \\
\hline$T_{\min }(t-1), T_{\min }(t)$ & $\rightarrow$ & $T_{\min }(t+1)$ & 2,5226 & 0,7740 & 1,8751 & 0,1455 & 0,7016 & 2,5458 \\
\hline$T_{\min }(t-4) \ldots T_{\min }(t)$ & $\rightarrow$ & $T_{\min }(t+1)$ & 2,5287 & 0,7729 & 1,4721 & 0,2502 & 0,7670 & 2,5970 \\
\hline
\end{tabular}


3) Regresión lineal utilizando como variable independiente la registrada el día sobre el que se realiza la predicción

Elección: Se puede utilizar esta regresión para una buena predicción.

Interpretación: Ajuste bueno, similar a la media móvil ponderada. Al utilizar la persistencia diaria de las variables ambientales.

Precisión: Buena, sobre todo para la temperatura.

Por lo que se observa de los resultados estadísticos evaluados para comprobar su efectividad (Tabla 5.1.5) y (Tabla 5.1.6).

Tabla 5.1.5 Efectividad de la predicción regresión lineal de irradiación solar respecto a los datos de SIAR en Mansilla Mayor (León) para el año 2011

\begin{tabular}{|ccc|c|c|c|c|c|c|}
\hline \multicolumn{8}{|c|}{ Modelo Regresión Lineal: Irradiación solar global diaria } \\
\hline Entradas & $\rightarrow$ & Salida & $\begin{array}{c}\text { RMSE } \\
\left(\mathbf{M J} / \mathbf{m}^{\mathbf{2}} / \mathbf{d}\right)\end{array}$ & $\mathbf{R}^{\mathbf{2}}$ & DW & MPE & FA & AIC \\
\hline $\mathbf{H}(\mathbf{t})$ & $\rightarrow$ & $\mathbf{H}(\mathbf{t}+\mathbf{1})$ & 4,2434 & 0,7880 & 2,2880 & $-0,2234$ & 0,6103 & 4,2666 \\
\hline
\end{tabular}

Tabla 5.1.6 Efectividad de la predicción regresión lineal de temperatura media diaria respecto a los datos de SIAR en Mansilla Mayor (León) para el año 2011

\begin{tabular}{|ccc|c|c|c|c|c|c|}
\hline \multicolumn{8}{|c|}{ Modelo Regresión Lineal: Temperatura media diaria } \\
\hline Entradas & $\rightarrow$ Salida & $\begin{array}{c}\text { RMSE } \\
\left({ }^{\circ} \mathbf{C}\right)\end{array}$ & $\mathbf{R}^{\mathbf{2}}$ & DW & MPE & FA & AIC \\
\hline $\mathbf{T}_{\text {med }}(\mathbf{t})$ & $\rightarrow \mathbf{T}_{\text {med }}(\mathbf{t}+\mathbf{1})$ & 1,8505 & 0,9109 & 1,7523 & $-0,0685$ & 0,7552 & 1,8580 \\
\hline
\end{tabular}


4) Función anual típica de Fourier del $1^{\circ}$ al $8^{\circ}$ armónico

Elección: Se pueden utilizar estas funciones anuales típicas de Fourier para una buena predicción.

Interpretación: Ajuste bueno, similar a la media móvil ponderada en la irradiación y empeora para las temperaturas. La utilización de más de un armónico no aporta mejora significativa.

Precisión: Media para la irradiación. Buena para las temperaturas.

Por lo que se observa de los resultados estadísticos evaluados para comprobar su efectividad (Tabla 5.1.7), (Tabla 5.1.8), (Tabla 5.1.9) y (Tabla 5.1.10).

Tabla 5.1.7 Efectividad de la predicción de la función anual típica de Fourier del $1^{\circ}$ al $8^{\circ}$ armónico de irradiación solar respecto a los datos de SIAR en Mansilla Mayor (León) para el año 2011

\begin{tabular}{|c|c|c|c|c|c|c|}
\hline \multicolumn{7}{|c|}{ Función anual típica de Fourier: Irradiación solar global diaria } \\
\hline $\mathbf{N}^{\circ}$ de armónicos & $\begin{array}{c}\text { RMSE } \\
\left(\mathbf{M J} / \mathbf{m}^{\mathbf{2}} / \mathbf{d}\right)\end{array}$ & $\mathbf{R}^{\mathbf{2}}$ & $\mathbf{D W}$ & $\mathbf{M P E}$ & FA & AIC \\
\hline $\mathbf{1}$ & 4,2747 & 0,7848 & 1,0439 & $-0,2692$ & 0,5294 & 4,2974 \\
\hline $\mathbf{2}$ & 4,2626 & 0,7861 & 1,0498 & $-0,2629$ & 0,5381 & 4,3086 \\
\hline $\mathbf{3}$ & 4,2675 & 0,7856 & 1,0474 & $-0,2617$ & 0,5388 & 4,3374 \\
\hline $\mathbf{4}$ & 4,2618 & 0,7861 & 1,0499 & $-0,2560$ & 0,5466 & 4,3562 \\
\hline $\mathbf{5}$ & 4,2465 & 0,7877 & 1,0575 & $-0,2580$ & 0,5439 & 4,3642 \\
\hline $\mathbf{6}$ & 4,2552 & 0,7868 & 1,0532 & $-0,2577$ & 0,5444 & 4,3971 \\
\hline $\mathbf{7}$ & 4,2537 & 0,7869 & 1,0539 & $-0,2547$ & 0,5490 & 4,4199 \\
\hline $\mathbf{8}$ & 4,2557 & 0,7867 & 1,0529 & $-0,2543$ & 0,5495 & 4,4463 \\
\hline
\end{tabular}

Tabla 5.1.8 Efectividad de la predicción de la función anual típica de Fourier del $1^{\circ}$ al $8^{\circ}$ armónico de temperatura media respecto a los datos de SIAR en Mansilla Mayor (León) para el año 2011

\begin{tabular}{|c|c|c|c|c|c|c|}
\hline \multicolumn{7}{|c|}{ Función anual típica de Fourier: Temperatura media diaria } \\
\hline $\mathbf{N}^{\circ}$ de armónicos & $\begin{array}{c}\mathbf{R M S E} \\
\left({ }^{\circ} \mathbf{C}\right)\end{array}$ & $\mathbf{R}^{\mathbf{2}}$ & $\mathbf{D W}$ & $\mathbf{M P E}$ & $\mathbf{F A}$ & AIC \\
\hline $\mathbf{1}$ & 2,6686 & 0,8148 & 0,4825 & 0,0266 & 0,7489 & 2,6815 \\
\hline $\mathbf{2}$ & 2,6780 & 0,8135 & 0,4794 & 0,0146 & 0,7295 & 2,7047 \\
\hline $\mathbf{3}$ & 2,7081 & 0,8093 & 0,4689 & 0,0163 & 0,7357 & 2,7507 \\
\hline $\mathbf{4}$ & 2,7035 & 0,8099 & 0,4703 & 0,0145 & 0,7324 & 2,7617 \\
\hline $\mathbf{5}$ & 2,6990 & 0,8105 & 0,4721 & 0,0178 & 0,7352 & 2,7712 \\
\hline $\mathbf{6}$ & 2,7067 & 0,8095 & 0,4696 & 0,0169 & 0,7337 & 2,7919 \\
\hline $\mathbf{7}$ & 2,7183 & 0,8078 & 0,4659 & 0,0190 & 0,7349 & 2,8210 \\
\hline $\mathbf{8}$ & 2,8287 & 0,7919 & 0,4320 & 0,0036 & 0,7145 & 2,9505 \\
\hline
\end{tabular}


Tabla 5.1.9 Efectividad de la predicción de la función anual típica de Fourier del $1^{\circ}$ al $8^{\circ}$ armónico de temperatura máxima respecto a los datos de SIAR en Mansilla Mayor (León) para el año 2011

\begin{tabular}{|c|c|c|c|c|c|c|}
\hline \multicolumn{7}{|c|}{ Función anual típica de Fourier: Temperatura máxima diaria } \\
\hline $\mathbf{N}^{\circ}$ de armónicos & $\begin{array}{c}\mathbf{R M S E} \\
\left({ }^{\circ} \mathbf{C}\right)\end{array}$ & $\mathbf{R}^{\mathbf{2}}$ & $\mathbf{D W}$ & $\mathbf{M P E}$ & FA & AIC \\
\hline $\mathbf{1}$ & 3,8353 & 0,7505 & 0,5492 & $-0,0106$ & 0,7969 & 3,8555 \\
\hline $\mathbf{2}$ & 3,7535 & 0,7610 & 0,5741 & $-0,0076$ & 0,7972 & 3,7916 \\
\hline $\mathbf{3}$ & 3,7463 & 0,7620 & 0,5760 & $-0,0072$ & 0,7974 & 3,8061 \\
\hline $\mathbf{4}$ & 3,7482 & 0,7617 & 0,5755 & $-0,0072$ & 0,7975 & 3,8289 \\
\hline $\mathbf{5}$ & 3,7520 & 0,7612 & 0,5744 & $-0,0110$ & 0,7969 & 3,8535 \\
\hline $\mathbf{6}$ & 3,7904 & 0,7563 & 0,5629 & $-0,0076$ & 0,7959 & 3,9152 \\
\hline $\mathbf{7}$ & 3,7583 & 0,7604 & 0,5717 & $-0,0075$ & 0,7956 & 3,9042 \\
\hline $\mathbf{8}$ & 3,8490 & 0,7487 & 0,5467 & $-0,0082$ & 0,7925 & 4,0183 \\
\hline
\end{tabular}

Tabla 5.1.10 Efectividad de la predicción de la función anual típica de Fourier del $1^{\circ}$ al $8^{\circ}$ armónico de temperatura mínima respecto a los datos de SIAR en Mansilla Mayor (León) para el año 2011

\begin{tabular}{|c|c|c|c|c|c|c|}
\hline \multicolumn{7}{|c|}{ Función anual típica de Fourier: Temperatura mínima diaria } \\
\hline $\mathbf{N}^{\circ}$ de armónicos & $\begin{array}{c}\mathbf{R M S E} \\
\left({ }^{\circ} \mathbf{C}\right)\end{array}$ & $\mathbf{R}^{\mathbf{2}}$ & $\mathbf{D W}$ & $\mathbf{M P E}$ & FA & AIC \\
\hline $\mathbf{1}$ & 3,3747 & 0,5955 & 0,5521 & 0,2576 & 0,6710 & 3,3930 \\
\hline $\mathbf{2}$ & 3,3414 & 0,6035 & 0,5630 & 0,2464 & 0,6733 & 3,3782 \\
\hline $\mathbf{3}$ & 3,3739 & 0,5957 & 0,5521 & 0,2649 & 0,6910 & 3,4296 \\
\hline $\mathbf{4}$ & 3,3942 & 0,5908 & 0,5460 & 0,2881 & 0,7062 & 3,4695 \\
\hline $\mathbf{5}$ & 3,3691 & 0,5969 & 0,5537 & 0,2933 & 0,7511 & 3,4626 \\
\hline $\mathbf{6}$ & 3,3714 & 0,5963 & 0,5530 & 0,2875 & 0,7441 & 3,4839 \\
\hline $\mathbf{7}$ & 3,3738 & 0,5957 & 0,5522 & 0,2652 & 0,7302 & 3,5053 \\
\hline $\mathbf{8}$ & 3,4049 & 0,5883 & 0,5425 & 0,2354 & 0,7002 & 3,5567 \\
\hline
\end{tabular}


5) Análisis de Markov realizado con una matriz de transición de 33 estados posibles de irradiación $\underline{\text { solar }}$

Elección: Se puede utilizar este análisis de Markov para una buena predicción.

Interpretación: Ajuste bueno, similar al análisis de Fourier. Se basa en las probabilidades de cambio de estado de un día para otro.

Precisión: Media, que mejora al análisis de Fourier.

Por lo que se observa de los resultados estadísticos evaluados para comprobar su efectividad (Tabla 5.1.11).

Tabla 5.1.11 Efectividad de la predicción del análisis de Markov con una matriz de transición de 33 estados de irradiación solar respecto a los datos de SIAR en Mansilla Mayor (León) para el año 2011

\begin{tabular}{|ccc|c|c|c|c|c|c|}
\hline \multicolumn{8}{|c|}{ Análisis de Markov: Irradiación solar global diaria } \\
\hline Entrada & $\rightarrow$ & Salida & $\begin{array}{c}\text { RMSE } \\
\left(\mathbf{M J} / \mathbf{m}^{2} / \mathbf{d}\right)\end{array}$ & $\mathbf{R}^{\mathbf{2}}$ & DW & MPE & FA & AIC \\
\hline$[\mathrm{H}(\mathbf{t})]$ & $\rightarrow$ & {$[\mathbf{H}(\mathbf{t}+\mathbf{1})]$} & 4,3653 & 0,7756 & 2,4099 & $-0,1525$ & 0,6497 & 4,3892 \\
\hline
\end{tabular}

6) Modelo de ASHRAE para la estimación de la temperatura media horaria a partir de los valores extremos diarios

Elección: Se puede utilizar este modelo de ASHRAE para una buena estimación.

Interpretación: Ajuste bueno. La temperatura se eleva durante la mañana hasta pasadas unas horas del mediodía solar, para continuar descendiendo hasta las horas del amanecer.

Precisión: Buena.

Por lo que se observa de los resultados estadísticos evaluados para comprobar su efectividad (Tabla 5.1.12).

Tabla 5.1.12 Efectividad de la estimación de la temperatura media horaria con el método ASHRAE respecto a los datos de SIAR en Mansilla Mayor (León) de los días 10 al 16-5-2011

\begin{tabular}{|ccc|c|c|c|c|c|c|}
\hline \multicolumn{8}{|c|}{ Modelo ASHRAE: Temperatura media horaria } \\
\hline Entradas & $\rightarrow$ & Salida & $\begin{array}{c}\mathbf{R M S E} \\
\left({ }^{\circ} \mathbf{C}\right)\end{array}$ & $\mathbf{R}^{\mathbf{2}}$ & DW & MPE & FA & AIC \\
\hline $\mathbf{T}_{\max }(\mathbf{t}), \mathbf{T}_{\min }(\mathbf{t})$ & $\rightarrow$ & $\mathbf{T}_{\text {med } 0 \mathrm{~h}}(\mathbf{t}) \ldots \mathbf{T}_{\text {med } 23 \mathrm{~h}}(\mathbf{t})$ & 2,3586 & 0,8460 & 0,2229 & 0,0948 & 0,8622 & 2,4151 \\
\hline
\end{tabular}


Se han ensayado los modelos neurales propuestos en esta Tesis Doctoral, para realizar la predicción de los valores del día de mañana de las variables ambientales, que más influyen en el funcionamiento de un sistema solar térmico como son la irradiación solar y la temperatura ambiente (Apartado 3.4).

La técnica escogida ha sido las redes neuronales artificiales de la inteligencia computacional, aplicadas sobre la base teórica de las series de tiempo, quedando formadas por la base de datos de los valores medidos y registrados de las variables a predecir. En este caso las series de tiempo están formadas por los valores de la irradiación solar y la temperatura ambiente, registrados por la estación de la red SIAR en Mansilla Mayor (León). Esta serie de datos temporales es utilizada en la predicción de las variables ambientales, mediante diversos tipos de arquitectura de redes neuronales artificiales que se han presentado.

Los modelos descritos han conseguido obtener unas buenas predicciones, con modelos muy simples que se pueden reproducir en otros lugares, por personal que no requiere una alta cualificación y con medios técnicos al alcance de cualquier economía. De esta manera se salvan varios obstáculos para que los modelos puedan ser universales.

Los requisitos para su desarrollo son una base de datos históricos de las variables ambientales propias de la zona, representativos de la climatología del lugar, que se pueden obtener de los servicios meteorológicos del país, de bases de datos internacionales, de las estimaciones de los satélites artificiales, o de las cada vez más estaciones meteorológicas de personas aficionadas que publican sus registros vía web. Otra posibilidad que se da en la literatura es la estimación de los datos de irradiación solar a partir de otras variables ambientales de las que existan registros, por ejemplo, la temperatura ambiente o tradicionalmente respecto de las horas de insolación.

Los requisitos técnicos son un programa informático para el desarrollo e implementación de las redes neuronales artificiales, en este caso se escogió Matlab por su gran difusión entre los técnicos e ingenieros, pudiéndose aplicar otro software comercial al efecto.

Los requisitos de personal serían los mismos que para cualquier otro desarrollo tecnológico concreto del que se espera poder extender su uso, el que la persona que vaya a desarrollar los modelos tenga unos mínimos conocimientos sobre el manejo de datos, las redes neuronales artificiales y la aplicación informática que se vaya a utilizar. Aquí la metodología para la predicción de las variables ambientales presentada, aporta las ventajas de ser fácilmente implementable por personal no excesivamente especializado y con un bajo coste.

Se realizó la presentación de los datos resultado de aplicar las metodologías propuestas, para realizar la predicción de los valores del día de mañana de las variables ambientales que más influyen en el funcionamiento de un sistema solar térmico como son la irradiación solar y la temperatura ambiente. Con la técnica escogida que ha sido las redes neuronales artificiales de la inteligencia computacional, aplicadas sobre la base teórica de las series de tiempo.

Esta metodología se ha validado con la base de datos de la red SIAR en la estación de Mansilla Mayor (León) del año 2011. El rendimiento de los modelos se ha revisado mediante gráficos comparando los datos reales y las predicciones obtenidas, calculando el error cometido para cada día del año 2011 y también mediante el estadístico RMSE. 
1) La primera serie de modelos neurales predice la irradiación solar global diaria del día de mañana a partir de la recibida hov, aver y antes de ayer

Elección: Se puede utilizar este modelo neural para una buena predicción.

Interpretación: Ajuste bueno, similar a los métodos probados de la literatura. El rendimiento del modelo aumenta, al considerar la irradiación solar global de más días de retardo, de forma parecida a la media móvil ponderada.

Precisión: Buena.

Por lo que se observa de los resultados estadísticos evaluados para comprobar su efectividad (Tabla 5.1.13).

Tabla 5.1.13 Efectividad de la predicción neural de irradiación solar mediante $\mathrm{H}(\mathrm{t}-2), \mathrm{H}(\mathrm{t}-1), \mathrm{H}(\mathrm{t})$ respecto a los datos de SIAR en Mansilla Mayor (León) para el año 2011

\begin{tabular}{|c|c|c|c|c|c|c|c|c|}
\hline \multicolumn{9}{|c|}{ Modelos Predicción RNA: Irradiación solar global diaria } \\
\hline Entradas & $\rightarrow$ & Salida & \begin{tabular}{c|} 
RMSE \\
$\left(\mathrm{MJ} / \mathrm{m}^{2} / \mathrm{d}\right)$
\end{tabular} & $\mathbf{R}^{2}$ & DW & MPE & FA & AIC \\
\hline$H(t)$ & $\rightarrow$ & $H(t+1)$ & 4,2609 & 0,7862 & 2,2632 & $-0,2523$ & 0,5884 & 4,2835 \\
\hline$H(t-1), H(t)$ & $\rightarrow$ & $H(t+1)$ & 4,1292 & 0,7988 & 1,9703 & $-0,2517$ & 0,5940 & 4,1733 \\
\hline$H(t-2), H(t-1), H(t)$ & $\rightarrow$ & $H(t+1)$ & 4,0204 & 0,8088 & 1,8543 & $-0,2507$ & 0,5938 & 4,0830 \\
\hline
\end{tabular}

2) La segunda serie de modelos neurales predice la irradiación solar global diaria del día de mañana a partir de la recibida hoy, ayer y antes de ayer, añadiendo a todos el día del año

Elección: Se puede utilizar este modelo neural para una buena predicción.

Interpretación: Ajuste bueno, mejor que la primera serie, mejora a los métodos probados de la literatura. El rendimiento del modelo en este caso no aumenta, al considerar la irradiación solar global de más días de retardo. Utilizar el día del año como predictor mejora el rendimiento del modelo, ya que introduce un parámetro que indica la época o estación del año en que se realiza la predicción, porque como se sabe la irradiación solar extraterrestre diaria varía estacionalmente en forma senoidal (Fig. 4.5.1).

Precisión: Buena.

Por lo que se observa de los resultados estadísticos evaluados para comprobar su efectividad (Tabla 5.1.14).

Tabla 5.1.14 Efectividad de la predicción neural de irradiación solar mediante $H(t-2), H(t-1), H(t), J(t)$ respecto a los datos de SIAR en Mansilla Mayor (León) para el año 2011

\begin{tabular}{|cc|c|c|c|c|c|c|}
\hline \multicolumn{7}{|c|}{ Modelos Predicción RNA: Irradiación solar global diaria } \\
\hline Entradas & $\rightarrow$ Salida & $\begin{array}{c}\text { RMSE } \\
\left(\mathbf{M J} / \mathbf{m}^{\mathbf{2}} / \mathbf{d}\right)\end{array}$ & $\mathbf{R}^{\mathbf{2}}$ & $\mathbf{D W}$ & $\mathbf{M P E}$ & FA & AIC \\
\hline $\mathbf{H}(\mathbf{t}), \mathbf{J}(\mathbf{t})$ & $\rightarrow \mathbf{H}(\mathbf{t}+\mathbf{1})$ & 3,8012 & 0,8299 & 1,9263 & $-0,2154$ & 0,6196 & 3,8427 \\
\hline $\mathbf{H}(\mathbf{t}-\mathbf{1}), \mathbf{H}(\mathbf{t}), \mathbf{J}(\mathbf{t})$ & $\rightarrow \mathbf{H}(\mathbf{t}+\mathbf{1})$ & 3,8467 & 0,8253 & 1,9061 & $-0,2232$ & 0,6160 & 3,9106 \\
\hline $\mathbf{H}(\mathbf{t}-\mathbf{2}), \mathbf{H}(\mathbf{t}-\mathbf{1}), \mathbf{H}(\mathbf{t}), \mathbf{J}(\mathbf{t}) \rightarrow \mathbf{H}(\mathbf{t}+\mathbf{1})$ & 3,8431 & 0,8253 & 1,8007 & $-0,2032$ & 0,6277 & 3,9261 \\
\hline
\end{tabular}


3) La tercera serie de modelos neurales predice la irradiación solar global diaria del día de mañana a partir de la recibida hoy, el índice de claridad y el día del año

Elección: Se puede utilizar este modelo neural para una buena predicción.

Interpretación: Ajuste bueno. El rendimiento del modelo mejora al considerar el índice de claridad. Pero utilizar el día del año o el índice de claridad como predictor tiene el mismo valor en el rendimiento del modelo, con lo que se decide por utilizar el día del año al ser un valor más sencillo de manejar que el índice de claridad y producir rendimientos similares.

Precisión: Buena.

Por lo que se observa de los resultados estadísticos evaluados para comprobar su efectividad (Tabla 5.1.15).

Tabla 5.1.15 Efectividad de la predicción neural de irradiación solar mediante $\mathrm{H}(\mathrm{t}), \mathrm{K}_{\mathrm{t}}(\mathrm{t})$, J(t) respecto a los datos de SIAR en Mansilla Mayor (León) para el año 2011

\begin{tabular}{|c|c|c|c|c|c|c|c|c|}
\hline \multicolumn{9}{|c|}{ Modelos Predicción RNA: Irradiación solar global diaria } \\
\hline Entradas & $\rightarrow$ & Salida & $\begin{array}{c}\text { RMSE } \\
\left(\mathrm{MJ} / \mathrm{m}^{2} / \mathrm{d}\right)\end{array}$ & $\mathbf{R}^{2}$ & DW & MPE & FA & AIC \\
\hline$H(t), K_{t}(t)$ & $\rightarrow$ & $H(t+1)$ & 3,7703 & 0,8326 & 1,9183 & $-0,2022$ & 0,6324 & 3,8118 \\
\hline$H(t), K_{t}(t), J(t)$ & $\rightarrow$ & $H(t+1)$ & 3,8043 & 0,8297 & 1,8716 & $-0,2273$ & 0,6098 & 3,8662 \\
\hline
\end{tabular}

4) La cuarta serie de modelos neurales predice la irradiación solar global diaria del día de mañana a partir de las temperaturas media, máxima y mínima diaria

Elección: Se puede utilizar este modelo neural para una moderada predicción.

Interpretación: Ajuste medio. El rendimiento del modelo mejora al considerar la temperatura media y las extremas. Evita la utilización del piranómetro.

Precisión: Baja.

Por lo que se observa de los resultados estadísticos evaluados para comprobar su efectividad (Tabla 5.1.16).

Tabla 5.1.16 Efectividad de la predicción neural de irradiación solar mediante $T_{\operatorname{med}}(t)$, $T_{\max }(t)$, $T_{\min }(t)$ respecto a los datos de SIAR en Mansilla Mayor (León) para el año 2011

\begin{tabular}{|cc|c|c|c|c|c|c|}
\hline \multicolumn{7}{|c|}{ Modelos Predicción RNA: Irradiación solar global diaria } \\
\hline Entradas & $\rightarrow$ Salida & $\begin{array}{c}\text { RMSE } \\
\left(\mathbf{M J} / \mathbf{m}^{\mathbf{2}} / \mathbf{d}\right)\end{array}$ & $\mathbf{R}^{\mathbf{2}}$ & $\mathbf{D W}$ & $\mathbf{M P E}$ & $\mathbf{F A}$ & AIC \\
\hline $\mathbf{T}_{\operatorname{med}}(\mathbf{t})$ & $\rightarrow \mathbf{H}(\mathbf{t}+\mathbf{1})$ & 6,1298 & 0,5576 & 0,6611 & $-0,5570$ & 0,2354 & 6,1516 \\
\hline $\mathbf{T}_{\max }(\mathbf{t}), \mathbf{T}_{\min }(\mathbf{t})$ & $\rightarrow \mathbf{H}(\mathbf{t}+\mathbf{1})$ & 5,6811 & 0,6200 & 0,8843 & $-0,4071$ & 0,3958 & 5,7372 \\
\hline $\mathbf{T}_{\text {med }}(\mathbf{t}), \mathbf{T}_{\max }(\mathbf{t}), \mathbf{T}_{\min }(\mathbf{t})$ & $\rightarrow \mathbf{H}(\mathbf{t}+\mathbf{1})$ & 5,3956 & 0,6572 & 1,2314 & $-0,3857$ & 0,4218 & 5,4772 \\
\hline
\end{tabular}


5) La quinta serie de modelos neurales predice la irradiación solar global diaria del día de mañana a partir de las temperaturas media, máxima y mínima diaria y el día del año

Elección: Se puede utilizar este modelo neural para una buena predicción.

Interpretación: Ajuste bueno. El rendimiento del modelo de la serie cuarta mejora notablemente al considerar el día del año. Evita la utilización del piranómetro.

Precisión: Media.

Por lo que se observa de los resultados estadísticos evaluados para comprobar su efectividad (Tabla 5.1.17).

Tabla 5.1.17 Efectividad de la predicción neural de irradiación solar mediante $T_{\operatorname{med}}(\mathrm{t}), \mathrm{T}_{\max }(\mathrm{t})$, $\mathrm{T}_{\min }(\mathrm{t})$, J(t) respecto a los datos de SIAR en Mansilla Mayor (León) para el año 2011

\begin{tabular}{|cc|c|c|c|c|c|c|}
\hline \multicolumn{7}{|c|}{ Modelos Predicción RNA: Irradiación solar global diaria } \\
\hline Entradas & $\rightarrow$ Salida & $\begin{array}{c}\text { RMSE } \\
\left(\mathbf{M J} / \mathbf{m}^{\mathbf{2}} / \mathbf{d}\right)\end{array}$ & $\mathbf{R}^{\mathbf{2}}$ & $\mathbf{D W}$ & $\mathbf{M P E}$ & FA & AIC \\
\hline $\mathbf{T}_{\text {med }}(\mathbf{t}), \mathbf{J}(\mathbf{t})$ & $\rightarrow \mathbf{H}(\mathbf{t}+\mathbf{1})$ & 4,2774 & 0,7846 & 1,0672 & $-0,2571$ & 0,5468 & 4,3240 \\
\hline $\mathbf{T}_{\text {max }}(\mathbf{t}), \mathbf{T}_{\min }(\mathbf{t}), \mathbf{J}(\mathbf{t})$ & $\rightarrow \mathbf{H}(\mathbf{t}+\mathbf{1})$ & 3,9229 & 0,8188 & 1,5685 & $-0,2256$ & 0,6082 & 3,9875 \\
\hline $\mathbf{T}_{\text {med }}(\mathbf{t}), \mathbf{T}_{\max }(\mathbf{t}), \mathbf{T}_{\min }(\mathbf{t}), \mathbf{J}(\mathbf{t})$ & $\rightarrow \mathbf{H}(\mathbf{t}+\mathbf{1})$ & 3,8383 & 0,8265 & 1,5223 & $-0,2155$ & 0,6206 & 3,9229 \\
\hline
\end{tabular}

6) La sexta serie de modelos neurales predice las temperaturas media, máxima y mínima del día de mañana a partir de las temperaturas media, máxima y mínima diaria y el día del año

Elección: Se puede utilizar este modelo neural para una buena predicción.

Interpretación: Ajuste bueno. Mejora a los métodos probados de la literatura.

Precisión: Buena.

Por lo que se observa de los resultados estadísticos evaluados para comprobar su efectividad (Tabla 5.1.18).

Tabla 5.1.18 Efectividad de la predicción neural de temperatura diaria mediante $T_{\operatorname{med}}(t)$, $T_{\max }(t)$, $T_{\min }(t)$, J(t) respecto a los datos de SIAR en Mansilla Mayor (León) para el año 2011

\begin{tabular}{|c|c|c|c|c|c|c|c|}
\hline \multicolumn{8}{|c|}{ Modelos Predicción RNA: Temperatura media, máxima y mínima diaria } \\
\hline Entradas & Salidas & $\begin{array}{l}\text { RMSE } \\
\left({ }^{\circ} \mathrm{C} / \mathrm{d}\right)\end{array}$ & $\mathbf{R}^{2}$ & DW & MPE & FA & AIC \\
\hline \multirow{3}{*}{$\begin{array}{c}T_{\text {med }}(t), T_{\text {max }}(t), \\
T_{\text {min }}(t)\end{array} \rightarrow$} & $T_{\text {med }}(t+1)$ & 1,7741 & 0,9181 & 1,8461 & $-0,0170$ & 0,7843 & 1,8021 \\
\hline & $T_{\max }(t+1)$ & 2,7537 & 0,8714 & 1,9245 & $-0,0390$ & 0,8410 & 2,7991 \\
\hline & $T_{\min }(t+1)$ & 2,1730 & 0,8393 & 1,6303 & 0,0390 & 0,6711 & 2,2180 \\
\hline \multirow{3}{*}{$\begin{array}{c}T_{\text {med }}(t), T_{\text {max }}(t), \\
T_{\text {min }}(t), J(t)\end{array} \rightarrow$} & $T_{\text {med }}(t+1)$ & 1,6756 & 0,9269 & 1,7168 & 0,0045 & 0,7772 & 1,7126 \\
\hline & $T_{\max }(t+1)$ & 2,5886 & 0,8863 & 1,7957 & $-0,0256$ & 0,8505 & 2,6456 \\
\hline & $T_{\min }(t+1)$ & 2,1261 & 0,8322 & 1,6176 & 0,1010 & 0,6507 & 2,1578 \\
\hline
\end{tabular}


7) La séptima serie de modelos neurales estima la irradiancia solar horaria a partir de la irradiación solar global diaria del mismo día

Elección: Se puede utilizar este modelo para una buena estimación.

Interpretación: Ajuste muy bueno. El rendimiento del modelo aumenta al considerar el día del año. Los errores más altos se producen con los cielos cubiertos cuando la bomba de impulsión está parada por no haber suficiente irradiación solar. El total de la irradiancia solar del día se ajusta al verdadero valor de la irradiación solar global diaria. El error en la estimación es en algunos tramos horarios pero no afectaría al total del día.

Precisión: Buena.

Por lo que se observa de los resultados estadísticos evaluados para comprobar su efectividad (Tabla 5.1.19).

Tabla 5.1.19 Efectividad de la predicción neural de irradiancia horaria mediante H(t), J(t) respecto a los datos de SIAR en Mansilla Mayor (León) para el año 2011

\begin{tabular}{|ccc|c|c|c|c|c|c|}
\hline \multicolumn{7}{|c|}{ Modelos Estimación RNA: Irradiancia solar global horaria } \\
\hline Entradas & $\rightarrow$ & Salidas & $\begin{array}{c}\text { RMSE } \\
\left(\mathbf{W} / \mathbf{m}^{2}\right)\end{array}$ & $\mathbf{R}^{\mathbf{2}}$ & DW & MPE & FA & AIC \\
\hline $\mathbf{H}(\mathbf{t})$ & $\rightarrow$ & $\mathbf{I}_{\text {oh }}(\mathbf{t}) \ldots \dot{I}_{23 \mathrm{~h}}(\mathbf{t})$ & 80,1897 & 0,9458 & 0,8613 & $-0,1421$ & 0,7464 & 55,0550 \\
\hline $\mathbf{H}(\mathbf{t}), \mathbf{J}(\mathbf{t})$ & $\rightarrow$ & $\dot{\mathbf{I}}_{\text {oh }}(\mathbf{t}) \ldots . . \dot{I}_{23 \mathrm{~h}}(\mathbf{t})$ & 75,5258 & 0,9519 & 0,8907 & $-0,1677$ & 0,7363 & 52,4809 \\
\hline
\end{tabular}

8) La octava serie de modelos neurales estima la temperatura media horaria a partir de la temperatura media, máxima y mínima y el día del año

Elección: Se puede utilizar este modelo para una buena estimación.

Interpretación: Ajuste muy bueno. El rendimiento del modelo no varía significativamente al considerar el día del año, esto puede ser debido a que la temperatura ambiente es una variable ambiental con una persistencia mayor que la irradiación solar.

Precisión: Buena.

Por lo que se observa de los resultados estadísticos evaluados para comprobar su efectividad (Tabla 5.1.20).

Tabla 5.1.20 Efectividad de la predicción neural de temperatura horaria mediante $T_{\operatorname{med}}(t)$, $T_{\max }(t)$, $T_{\min }(t)$, J(t) respecto a los datos de SIAR en Mansilla Mayor (León) para el año 2011

\begin{tabular}{|c|c|c|c|c|c|c|c|c|}
\hline \multicolumn{9}{|c|}{ Modelos Estimación RNA: Temperatura media horaria } \\
\hline Entradas & $\rightarrow$ & Salidas & $\begin{array}{c}\text { RMSE } \\
\left({ }^{\circ} \mathrm{C}\right)\end{array}$ & $\mathbf{R}^{2}$ & DW & MPE & FA & AIC \\
\hline $\begin{array}{c}T_{\text {med }}(t), T_{\max }(t), \\
T_{\min }(t)\end{array}$ & $\rightarrow$ & $T_{\text {med 0h }}(t) \ldots T_{\text {med 23h }}(t)$ & 1,2524 & 0,9565 & 0,4339 & $-0,0131$ & 0,9199 & 0,8766 \\
\hline $\begin{array}{c}T_{\text {med }}(t), T_{\max }(t), \\
T_{\min }(t), J(t)\end{array}$ & $\rightarrow$ & $T_{\text {med oh }}(t) \ldots T_{\text {med 23h }}(t)$ & 1,4173 & 0,9444 & 0,3695 & $-0,0008$ & 0,9081 & 1,0030 \\
\hline
\end{tabular}


Estas metodologías neurales están desarrolladas para crear una base de datos horarios, con la que poder simular el funcionamiento del modelo del sistema solar térmico. Primero se realiza la predicción del valor total de la irradiación solar global diaria y de la temperatura media, máxima y mínima diaria, y segundo se hace una estimación de los valores horarios, posteriormente se puede interpolar los datos a una escala de minuto, para poder realizar una simulación continua del sistema solar térmico que se ha modelado de una forma más realista.

Los resultados de la simulación para un año, debido al bajo sesgo del error de las predicciones de las metodologías planteadas, obtienen un valor de la irradiación solar global horizontal anual total muy parecido al medido y registrado. Se ha comprobado que el total anual de la irradiación solar global horizontal medida y registrada por la estación SIAR en Mansilla Mayor (León), es muy parecido al total anual resultante de las predicciones diarias con la metodología escogida. Con lo que al realizar la simulación del rendimiento sería el mismo al utilizar datos reales, que con las predicciones diarias.

Esta metodología neural para las predicciones de las variables ambientales puede ser mejorada incluyendo como predictores otras variables ambientales que indican cambios en la climatología como pueden ser la presión atmosférica, humedad relativa, nubosidad,... Otra forma de mejorar la metodología sería utilizando redes neuronales artificiales con mejores capacidades para ser utilizadas con las series de tiempo como las redes neuronales artificiales dinámicas. Pero en esta Tesis Doctoral se quiere dar una metodología que sea fácilmente aplicable tanto desde los datos climatológicos necesarios para el entrenamiento de las redes neuronales artificiales, que no necesiten muchas variables ambientales como entradas, que en algunos casos son de difícil disponibilidad, como desde el punto de vista del personal que vaya a implementar la metodología, que solo necesiten una pequeña base de conocimiento técnico sobre las redes neuronales artificiales. 


\subsection{Análisis de la estimación de irradiación solar sobre el plano inclinado}

Los datos de la irradiación solar necesarios para ejecutar una simulación de un sistema solar térmico son los incidentes sobre el plano inclinado de los captadores solares, pero normalmente los datos disponibles son los que recibe la superficie horizontal.

Existen diversos métodos que aplican coeficientes o software concreto que estima el valor de la irradiación solar sobre un plano inclinado, soliendo producir unos resultados moderados. Para el cálculo preciso del valor de la irradiación solar sobre un plano inclinado a partir de los datos registrados sobre la superficie horizontal, se debe tratar sus tres componentes por separado. Su cálculo no es directo:

- Irradiación solar directa del sol.

- Irradiación solar reflejada del suelo.

- Irradiación solar difusa del cielo.

Se ha propuesto en esta Tesis Doctoral, una metodología flexible y adaptable a diversos modelos. La dificultad que encuentra un ingeniero solar a la hora de realizar su cálculo es que, aunque existiendo numerosos modelos en la literatura, su aplicación conjunta es difícil de comprender, sino es por un experto.

El objetivo del (Apartado 3.5) ha sido dar una metodología clara y flexible de aplicación de todos los pasos a seguir, que en la literatura se encuentra muy bien desarrollada, pero es difícil encontrar un proceso claro para su aplicación conjunta. Y poder conseguir una estimación precisa de la irradiación solar incidente sobre los captadores solares de cada sistema solar térmico concreto a ensayar.

Una metodología para utilizar las redes neuronales artificiales de la inteligencia computacional que en esta Tesis Doctoral se proponen, se expone en el capítulo dedicado a las líneas de investigación, aplicada a la estimación de la irradiación solar global sobre el plano inclinado a partir de los datos medidos y registrados sobre la superficie horizontal. Que se plantea en el capítulo como futura línea de investigación, necesitaría las medidas de dos piranómetros, uno instalado horizontalmente y el otro instalado en el plano inclinado del captador solar, el entrenamiento de la red neuronal artificial se realizaría en la entrada con los datos tomados de la horizontal y en la salida con los datos tomados sobre el plano inclinado, con bajo, medio y alto nivel de irradiancia. Para que los datos del entrenamiento neural cubran todo el intervalo de la irradiancia solar, los datos pueden ser recogidos por ejemplo en un día despejado desde el amanecer con $0 \mathrm{~W} / \mathrm{m}^{2}$ hasta el mediodía solar cuando se dan valores máximos de $1100 \mathrm{~W} / \mathrm{m}^{2}$.

Se realizó la presentación de los datos (Apartado 4.5) resultado de aplicar las metodologías (Apartado 3.5) propuestas en la literatura (Apartado 2.3), para realizar la estimación de los valores de la irradiación solar global sobre el plano inclinado del captador solar, a partir de la irradiación solar global que incide sobre la superficie horizontal, habitualmente medida y registrada en las estaciones meteorológicas. Los cálculos de las variables necesarias en los distintos procedimientos se realizaron para las coordenadas geográficas de latitud $42^{\circ}$ Norte y longitud $5,6^{\circ}$ Oeste de la ciudad de León y un plano inclinado a $45^{\circ}$ sobre la horizontal orientado hacia el ecuador. 
De los resultados de la irradiación solar extraterrestre diaria (Apartado 4.5.1), se observa que para un año se alcanza el máximo en la última quincena del mes de junio con $\mathbf{4 1 , 9 1} \mathbf{M J} / \mathrm{m}^{2} / \mathrm{d}$ y el mínimo se da en la última quincena del mes de diciembre con $12,28 \mathrm{MJ} / \mathrm{m}^{2} / \mathrm{d}$ (Fig. 4.5.1). Se comprueba el componente estacional de la irradiación solar para esta latitud con un ascenso en la primera mitad del año y un descenso en la segunda mitad del año.

Como su cálculo es relativamente complejo, se propone para su uso habitual por parte de personal no especializado, una aproximación de Fourier con uno, dos y tres armónicos, con la que se obtiene un error del estadístico RMSE de $\mathbf{0 , 2 1 0}, \mathbf{0 , 0 4 8}$ y $\mathbf{0 , 0 0 9} \mathbf{~ M J} / \mathrm{m}^{\mathbf{2}} / \mathbf{d}$ respectivamente (Tabla 4.5.1). También se realiza otra aproximación con suma de funciones senos, con dos, tres y cuatro senos, con las que se obtiene un error del estadístico RMSE de $\mathbf{0 , 1 9 3 , 0 , 0 0 6}$ y $\mathbf{0 , 0 0 4} \mathbf{~ M J} / \mathrm{m}^{2} / \mathbf{d}$ respectivamente (Tabla 4.5.2). Estas aproximaciones que se realizan para la latitud $42^{\circ}$ Norte, se pueden proponer para otras latitudes con el objetivo de un uso más sencillo.

De los resultados del cálculo de la irradiación solar extraterrestre horaria (Apartado 4.5.1), obtenidos para el día 15 de cada mes del año. Se observa una simetría sobre el mediodía solar a lo largo de todo el día, así como el aumento de la irradiación solar desde el mes de diciembre hasta el mes de junio (Fig. 4.5.2) y un descenso desde el mes de junio hasta el mes de diciembre (Fig. 4.5.3).

El modelo de irradiación solar difusa horizontal escogido en el (Apartado 3.5.2), se compara con los índices de claridad y la fracción difusa horaria resultados de los datos registrados por la Agencia Estatal de Meteorología AEMET en la estación de La Virgen del Camino (León) durante las ocho horas centrales del día de todo el año 2011 (Fig. 4.5.5). Se observa un buen ajuste con el modelo utilizado que fue desarrollado por sus autores en zonas del Mediterráneo con la ecuación (Ec. 2.3.5). Hay que destacar que con los datos utilizados para la comparación en los días de cielo despejado, se observa que están por debajo del modelo, lo que quiere decir que la fracción difusa media en los días claros es menor que la del modelo, lo que indica una baja dispersión de la irradiación solar del cielo en los días despejados, cielo muy claro (Apartado 4.5.2).

De los resultados del cálculo de la altura solar horaria (Apartado 4.5.3), obtenidos para el día 15 de cada mes del año (Fig. 4.5.6) y (Fig. 4.5.7). Se observa una simetría sobre el mediodía solar en el que se da el máximo a lo largo de todo el día, así como el aumento de la altura solar desde el mes de diciembre hasta el mes de junio, que alcanza el valor máximo de $72^{\circ}$ y un descenso desde el mes de junio hasta el mes de diciembre, que alcanza el valor mínimo de $\mathbf{2 4 , 5 ^ { \circ }}$ (Fig. 4.5.8).

De los resultados en el cálculo del ángulo de incidencia de la irradiancia solar directa sobre el plano inclinado a $45^{\circ}$ y orientado hacia el ecuador (Apartado 4.5.4), obtenidos para el día 15 de cada mes del año (Fig. 4.5.9) y (Fig. 4.5.10). Se observa la simetría del ángulo de incidencia sobre el mediodía solar en el que se alcanza el mínimo a lo largo de todo el día, así como la disminución del ángulo de incidencia desde el mes de diciembre hasta el mes de marzo, que alcanza el valor mínimo de $\mathbf{0 , 5 ^ { \circ }}$ a continuación se da un aumento hasta el mes de junio que alcanza el valor máximo de $\mathbf{2 6 , 5 ^ { \circ }}$ seguido de una disminución hasta el mes de septiembre que alcanza un mínimo local de $4,5^{\circ}$ continuando con un aumento hasta el mes de diciembre que alcanza un máximo local de $20,5^{\circ}$ (Fig. 4.5.11).

El estudio de la variación del ángulo de incidencia es muy importante, ya que proporciona la época del año en que la captación de energía es máxima, según la inclinación y la orientación del captador solar. 
Este resultado si se compara con el perfil de necesidades energéticas anual que tenga cada sistema solar térmico particular, da la posibilidad de encontrar la época del año en que la captación solar es óptima.

Los resultados obtenidos de la metodología aplicada en la estimación del valor de la irradiación solar global sobre el captador solar de la planta piloto en base de tiempo diaria durante todo el año 2011 con diferentes métodos y combinaciones en el cálculo de la componente difusa del cielo de la irradiación solar (Apartado 4.5.5), que es en la que se ha encontrado mayores variaciones en los métodos revisados, se comparan entre sí y con los valores medidos sobre la superficie horizontal de la base de datos SIAR en la estación de Mansilla Mayor (León) y las medidas en la planta piloto (Fig. 4.5.12).

Se observa una mayor incidencia de la irradiación solar global sobre el captador solar en los meses en que la altura solar produce un ángulo de incidencia menor sobre el captador solar, respecto a la irradiación solar global sobre la superficie horizontal, disminuyendo en los meses con mayor ángulo de incidencia, incluso llegando a ser menor la irradiación incidente sobre el captador solar que sobre la horizontal en los meses de máximo ángulo de incidencia.

Para la comprobación del modelo más idóneo en la estimación de la irradiación solar global sobre el plano inclinado, se realizaron pruebas durante varios días de los cinco modelos y combinaciones de modelos, comparándose entre sí y con las medidas tomadas del piranómetro instalado en la planta piloto (Fig. 4.5.13) y (Fig. 4.5.14). Resultando que el modelo que utiliza las correcciones de Klucher es más adecuado, el modelo de Temps y Coulson también resulta adecuado, el modelo de Hay también es idóneo pero queda un poco por debajo de las mediciones del piranómetro, el modelo de Liu y Jordan subestima los valores de las mediciones al igual que el modelo de CENSOLAR que queda muy por debajo de las mediciones realizadas, siendo válido para dar una aproximación por su sencillez de uso.

El valor de la irradiación solar global que recibió el captador solar inclinado a $45^{\circ}$ y orientado hacia el ecuador en la ciudad de León, durante el año 2011 que tuvo sobre la horizontal 1,67 MWh/m²/año, son los siguientes:

- Con las correcciones de Klucher: $1,93 \mathrm{MWh} / \mathrm{m}^{2} / \mathbf{a n ̃ o}$.

- Con las correcciones de Temps y Coulson: $1,99 \mathrm{MWh} / \mathrm{m}^{2} / \mathrm{año}$.

- Con las correcciones de Hay: 1,86 MWh/m²/año.

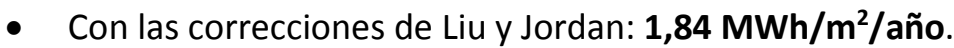

- Las tablas de CENSOLAR: 1,84 MWh/m²/año.

Con lo que se obtiene utilizando las correcciones del modelo de Klucher, para todo tipo de cielo, un valor de $90 \mathrm{kWh} / \mathrm{m}^{2} /$ año superior al modelo de coeficientes mensuales de CENSOLAR, el cual suele subestimar el valor de la irradiación solar. 


\subsection{Análisis del modelado neural de los componentes del sistema solar térmico}

La simulación del funcionamiento de un sistema solar térmico, pasa por un modelado preciso de los componentes que forman el propio sistema. En esta Tesis Doctoral se desarrolla una metodología basada en la técnica de las redes neuronales artificiales de la inteligencia computacional, aplicada a la base teórica de las series de tiempo (Apartado 3.6), realizando una predicción de la salida resultante de los componentes en el lapso de tiempo siguiente en función de los valores que se han escogido como entradas, a partir de una base de datos del funcionamiento de cada componente (Anexo 2 Datos de los ensayos en la planta piloto).

En este caso la serie de tiempo está formada por los valores registrados en el sistema solar térmico concreto a estudiar de la irradiancia solar, la temperatura ambiente, la temperatura del fluido portador en diferentes puntos del circuito primario y su caudal, la temperatura de estratificación del agua almacenada en el depósito acumulador, la temperatura del agua de red y su caudal.

Aquí aparece la primera ventaja de la metodología propuesta, al basarse en datos de temperaturas que son fácilmente medibles, mediante sensores colocados en el circuito del sistema solar térmico, el caudal fijado por la bomba de impulsión en el circuito primario y para el modelado del captador solar se hace necesario un piranómetro para la medida de la irradiancia solar. Actualmente en el mercado se comercializan piranómetros de silicio mucho más económicos que los de tipo termoeléctrico, el cual instalado junto al captador solar y en el mismo plano mide el valor de la irradiancia solar que recibe en cada momento.

Por lo que la metodología propuesta tiene la ventaja de no necesitar ningún dato de las características técnicas concretas del componente, que se suelen utilizar en otros modelos, facilitados por el fabricante o resultados derivados de ensayos en otros laboratorios. El modelado propuesto se puede llevar a cabo con los datos tomados del sistema solar térmico concreto, sin tener que depender de la documentación técnica, que en ocasiones puede no estar disponible, o darse el caso que por motivos de la instalación o envejecimiento hayan variado las características técnicas, tampoco es necesario hacer suposiciones de otros datos que no se conozcan, como el rendimiento del intercambiador de calor y la estratificación térmica del agua caliente solar en el depósito acumulador.

La metodología presentada para el modelado del captador solar (Apartado 3.6.1), el intercambiador de calor (Apartado 3.6.2) y la estratificación térmica en el depósito acumulador (Apartado 3.6.3) es ampliable a todos los componentes, como por ejemplo, los tramos de tuberías, que tradicionalmente se realiza el cálculo de sus pérdidas térmicas en base a características físicas de dimensiones y propiedades del aislante térmico instalado, facilitados por el respectivo fabricante, en este caso aplicando la metodología propuesta se puede modelar la tubería con datos de la temperatura y caudal del fluido portador en su entrada y salida.

La base de datos de las series temporales medidos y registrados en el sistema solar térmico, tiene que ser representativa de todos los estados por los que pasa a lo largo del periodo de funcionamiento que se pretende simular, para que el entrenamiento de las redes neuronales artificiales cubra todos los intervalos de funcionamiento del componente. Por ejemplo, en el modelado del captador solar la serie 
de datos para el entrenamiento de la red neuronal artificial debe de contener datos con alto, medio y bajo nivel de irradiancia solar, pero no descuidar los periodos de baja irradiancia como se comprobó en el ensayo según la norma EN 12975 (Fig. 4.3.1) y (Diez y Falagán, 2013b).

En el caso de que el caudal del fluido portador se cambie durante el funcionamiento, también se deberá monitorizar el sistema solar térmico con los distintos caudales, en caso contrario se puede eliminar la entrada del caudal en el modelo.

En el modelado del depósito acumulador se midieron y registraron datos con diferentes perfiles de temperaturas de estratificación térmica. En el caso de que el caudal del consumo de agua caliente fuera el mismo en todas las situaciones, también puede eliminarse como entrada al modelo. Para el caso de que se realice una simulación de un periodo corto, por ejemplo, un mes en el que la temperatura del agua de red no varía considerablemente, esta entrada al modelo también se puede eliminar.

La metodología presentada para el modelado neural de los componentes del sistema solar térmico aporta flexibilidad a la hora de ser aplicada en cada sistema particular, para ser adaptada a sus peculiaridades y también independencia, al no tener que depender de características técnicas que tienen que ser proporcionadas por el fabricante o un laboratorio de ensayos.

La presentación de datos resultado de aplicar las metodologías propuestas, para realizar el modelado de los componentes principales del sistema solar térmico: captador solar (Apartado 3.6.1), intercambiador de calor (Apartado 3.6.2) y depósito acumulador (Apartado 3.6.3), se han presentado junto a los datos medidos y registrados en la planta piloto, que se describe (Apartado 3.1), y que se representan gráficamente (Anexo 2 Datos de los ensayos en la planta piloto) para su validación.

Los resultados de la metodología propuesta para el modelado neural del captador solar (Apartado 4.6.1), con una red neuronal artificial para tres caudales diferentes del fluido portador $2,1,6$ y $1 \mathrm{l} / \mathrm{min}$, obtuvo un valor del estadístico RMSE de $\mathbf{0 , 1 8}, \mathbf{0 , 2 0}$ y $\mathbf{0 , 1 9}{ }^{\circ} \mathrm{C}$ respectivamente de los ensayos con la planta piloto correspondientes a los días 7-9-2011 (Fig. 4.6.2), 1-7-2011 (Fig. 4.6.3) y 4-10-2011 (Fig. 4.6.4). Por lo que puede ser elegido el modelo para su utilización. El ajuste del modelo es casi perfecto, el error de la predicción tiene un sesgo casi nulo y la precisión del modelo es óptima, por lo que se observa de los resultados estadísticos evaluados para comprobar su efectividad (Tabla 5.3.1).

Tabla 5.3.1 Efectividad del modelo neural del captador solar durante tres días de funcionamiento con distintos caudales del fluido portador

\begin{tabular}{|c|c|c|c|c|c|c|c|}
\hline \multicolumn{8}{|c|}{ Modelo RNA: Captador solar } \\
\hline $\begin{array}{c}\text { Entradas } \\
\mathbf{i}, \mathbf{T}_{\mathrm{a}}, \mathbf{T}_{\text {ret }}, \mathrm{C}(\mathbf{t})\end{array}$ & $\begin{array}{c}\text { Salida } \\
T_{\text {ida }}(t+1)\end{array}$ & $\begin{array}{l}\text { RMSE } \\
\left({ }^{\circ} \mathrm{C}\right)\end{array}$ & $\mathbf{R}^{2}$ & DW & MPE & FA & AIC \\
\hline $\begin{array}{c}7-9-2011 \\
10 h 49 . . .17 h 58\end{array}$ & $\mathrm{C}=2 \mathrm{l} / \mathrm{min}$ & 0,1780 & 0,9991 & 0,4361 & $-0,0010$ & 0,9972 & 0,1793 \\
\hline $\begin{array}{c}1-7-2011 \\
11 \mathrm{~h} 38 . . .18 \mathrm{~h} 04\end{array}$ & $\mathrm{C}=1,6 \mathrm{I} / \mathrm{min}$ & 0,2047 & 0,9988 & 0,3330 & 0,0022 & 0,9971 & 0,2045 \\
\hline $\begin{array}{c}4-10-2011 \\
10 h 48 . . .18 h 13\end{array}$ & $C=1 \mathrm{l} / \mathrm{min}$ & 0,1867 & 0,9991 & 0,3781 & 0,0009 & 0,9970 & 0,1896 \\
\hline
\end{tabular}

Se observa un resultado óptimo en todas las situaciones en las que puede estar funcionando el captador solar, ya sea con alta o baja irradiancia solar, con y sin descarga en el depósito y con distintos caudales 
del fluido portador. En el caso de que el captador solar funcione siempre a un mismo caudal del fluido portador, su entrada en el modelo se puede suprimir.

Por lo que se puede decir, que el modelo del captador solar basado en una red neuronal artificial, mejora a otros modelos en sus limitaciones de los rangos de la irradiancia solar y los caudales, siempre y cuando el entrenamiento de la red neuronal artificial se haya realizado con datos de todo el intervalo de funcionamiento. También se puede decir, que da un modelo actual de las características técnicas en que se encuentra, ya que estas pueden variar a causa, por ejemplo del envejecimiento del componente.

Los resultados de la metodología propuesta para el modelado neural del intercambiador de calor (Apartado 4.6.2), con una red neuronal artificial para tres caudales diferentes del fluido portador 2, 1,6 y $1 \mathrm{l} / \mathrm{min}$, obtuvo un valor del estadístico RMSE de $\mathbf{0 , 1 7}, \mathbf{0 , 2 4}$ y $\mathbf{0 , 4 6}{ }^{\circ} \mathrm{C}$ respectivamente de los ensayos con la planta piloto correspondientes a los días 7-9-2011 (Fig. 4.6.6), 1-7-2011 (Fig. 4.6.7) y 4-10-2011 (Fig. 4.6.8). Por lo que puede ser elegido el modelo para su utilización. El ajuste del modelo es casi perfecto, el error de la predicción tiene un sesgo casi nulo y la precisión del modelo es óptima, por lo que se observa de los resultados estadísticos evaluados para comprobar su efectividad (Tabla 5.3.2). El mayor valor de RMSE en el ensayo del día 4-10-2011 puede deberse a un error en la medición o de calibración al intervenir los ocho sensores de la estratificación térmica, o también en el manejo de datos al pasar por varios equipos en su tratamiento para su estudio, más que a un error en el modelo neural.

Tabla 5.3.2 Efectividad del modelo neural del intercambiador de calor durante tres días de funcionamiento con distintos caudales del fluido portador

\begin{tabular}{|c|c|c|c|c|c|c|c|}
\hline \multicolumn{8}{|c|}{ Modelo RNA: Intercambiador de calor } \\
\hline $\begin{array}{c}\text { Entradas } \\
T_{\text {ida, }} T_{N 1 . . N 8}, C(t)\end{array}$ & $\begin{array}{lc}\rightarrow & \text { Salida } \\
& \mathrm{T}_{\text {ret }}(\mathrm{t}+\mathbf{1}) \\
\end{array}$ & $\begin{array}{l}\text { RMSE } \\
\left({ }^{\circ} \mathrm{C}\right)\end{array}$ & $\mathbf{R}^{2}$ & DW & MPE & FA & AIC \\
\hline $\begin{array}{c}7-9-2011 \\
10 h 49 . . .17 h 58\end{array}$ & $C=2 \mathrm{l} / \mathrm{min}$ & 0,1747 & 0,9989 & 0,3255 & $-0,0008$ & 0,9971 & 0,1789 \\
\hline $\begin{array}{c}1-7-2011 \\
11 \mathrm{~h} 38 . . .18 \mathrm{~h} 04\end{array}$ & $C=1,6 \mathrm{I} / \mathrm{min}$ & 0,2442 & 0,9980 & 0,1973 & 0,0026 & 0,9961 & 0,2568 \\
\hline $\begin{array}{c}4-10-2011 \\
10 h 48 . . .18 h 13\end{array}$ & $C=1 \mathrm{I} / \mathrm{min}$ & 0,4647 & 0,9938 & 0,0902 & 0,0007 & 0,9918 & 0,4868 \\
\hline
\end{tabular}

Se observa un resultado óptimo en todas las situaciones en las que puede estar funcionando el intercambiador de calor, ya sea con alta o baja temperatura, con y sin descarga en el depósito y con distintos caudales del fluido portador. En el caso de que el intercambiador de calor funcione siempre a un mismo caudal del fluido portador, su entrada en el modelo se puede eliminar.

Por lo que se puede decir, que el modelo del intercambiador de calor basado en una red neuronal artificial, mejora a otros modelos en sus limitaciones de rangos de temperatura y caudales, siempre y cuando el entrenamiento de la red neuronal artificial se haya realizado con datos de todo el intervalo de funcionamiento. También se puede decir, como para el caso del captador solar al ser este otro intercambiador de calor, que da un modelo actual de las características técnicas en que se encuentra, por ejemplo del envejecimiento del componente.

Los resultados de la metodología propuesta para el modelado neural del depósito acumulador (Apartado 4.6.3), que tiene en cuenta la estratificación térmica del agua caliente solar para sus cuatro estados: SOL, SOL + ACS, NOCHE y NOCHE + ACS, obtuvo un valor del estadístico RMSE de $\mathbf{0 , 1 0 , 0 , 1 2}$, 
0,07 y $\mathbf{0 , 1 2}{ }^{\circ} \mathrm{C}$ respectivamente de los ensayos con la planta piloto correspondientes a los días 6-10-2011 (Fig. 4.6.9), 6-10-2011 (Fig. 4.6.10), 6...10-10-2011 (Fig. 4.6.11) y 9-3-2012 (Fig. 4.6.13). Por lo que pueden ser elegidos los modelos para su utilización. El ajuste de los modelos es casi perfecto, el error de la predicción tiene un sesgo casi nulo y la precisión de los modelos es óptima, por lo que se observa de los resultados estadísticos evaluados para comprobar su efectividad (Tabla 5.3.3), (Tabla 5.3.4), (Tabla 5.3.5) y (Tabla 5.3.6).

Tabla 5.3.3 Efectividad del modelo neural de la estratificación térmica durante el estado SOL durante el ensayo del día 6-10-2011

\begin{tabular}{|c|c|c|c|c|c|c|c|c|}
\hline \multicolumn{9}{|c|}{ Modelo RNA: Estratificación térmica SOL } \\
\hline $\begin{array}{c}\text { Entradas } \\
T_{\text {ida, }} T_{N 1 . . N 8}, C(t)\end{array}$ & $\rightarrow$ & $\begin{array}{c}\text { Salidas } \\
\mathrm{T}_{\mathrm{N1} . . \mathrm{N} 8}(\mathrm{t}+1)\end{array}$ & $\begin{array}{l}\text { RMSE } \\
\left({ }^{\circ} \mathrm{C}\right)\end{array}$ & $\mathbf{R}^{2}$ & DW & MPE & FA & AIC \\
\hline \multirow{3}{*}{ Ensayo: } & & N1 & 0,0635 & 0,9997 & 2,5788 & 0,0000 & 0,9983 & 0,0673 \\
\hline & & N2 & 0,2054 & 0,9988 & 1,0248 & 0,0010 & 0,9951 & 0,2170 \\
\hline & & N3 & 0,1485 & 0,9994 & 2,4667 & $-0,0012$ & 0,9967 & 0,1579 \\
\hline \multirow[t]{2}{*}{$6-10-2011$} & & N4 & 0,0601 & 0,9998 & 2,0282 & $-0,0007$ & 0,9989 & 0,0635 \\
\hline & & N5 & 0,0769 & 0,9997 & 2,6874 & 0,0002 & 0,9986 & 0,0817 \\
\hline \multirow{3}{*}{$\begin{array}{l}10 h 48 \ldots . .14 h 41 \\
15 h 59 . . .17 h 26\end{array}$} & & N6 & 0,0571 & 0,9998 & 2,5518 & 0,0000 & 0,9990 & 0,0596 \\
\hline & & N7 & 0,0504 & 0,9998 & 2,1572 & 0,0003 & 0,9990 & 0,0535 \\
\hline & & N8 & 0,0677 & 0,9998 & 2,6125 & 0,0001 & 0,9990 & 0,0719 \\
\hline
\end{tabular}

Tabla 5.3.4 Efectividad del modelo neural de la estratificación térmica durante el estado SOL + ACS durante el ensayo del día 6-10-2011

\begin{tabular}{|c|c|c|c|c|c|c|c|}
\hline \multicolumn{8}{|c|}{ Modelo RNA: Estratificación térmica SOL + ACS } \\
\hline $\begin{array}{c}\text { Entradas } \\
T_{\text {ida, }} T_{N 1 . . N 8}, A C S, T_{\text {red }}, C(t)\end{array}$ & $\rightarrow \quad \begin{array}{c}\text { Salidas } \\
\mathrm{T}_{\mathrm{N} 1 \ldots \mathrm{N} 8}(\mathrm{t}+1)\end{array}$ & $\begin{array}{l}\text { RMSE } \\
\left({ }^{\circ} \mathrm{C}\right)\end{array}$ & $\mathbf{R}^{2}$ & DW & MPE & FA & AIC \\
\hline \multirow{3}{*}{ Ensayo: } & N1 & 0,1217 & 0,9963 & 1,8048 & 0,0000 & 0,9968 & 0,1553 \\
\hline & N2 & 0,2484 & 0,9988 & 2,5124 & $-0,0010$ & 0,9921 & 0,3376 \\
\hline & N3 & 0,1280 & 0,9998 & 2,0337 & $-0,0003$ & 0,9967 & 0,1762 \\
\hline \multirow{2}{*}{$6-10-2011$} & N4 & 0,0551 & 0,9999 & 1,5467 & $-0,0005$ & 0,9989 & 0,0758 \\
\hline & N5 & 0,0803 & 0,9997 & 2,1187 & $-0,0003$ & 0,9987 & 0,1105 \\
\hline \multirow{3}{*}{$14 h 42 \ldots 15 h 58$} & N6 & 0,0804 & 0,9995 & 2,1518 & $-0,0002$ & 0,9988 & 0,1106 \\
\hline & N7 & 0,0696 & 0,9982 & 2,1382 & $-0,0002$ & 0,9980 & 0,0956 \\
\hline & N8 & 0,0644 & 0,9542 & 2,2478 & 0,0001 & 0,9990 & 0,0877 \\
\hline
\end{tabular}

Tabla 5.3.5 Efectividad del modelo neural de la estratificación térmica durante el estado NOCHE durante el ensayo de los días 6...10-10-2011

\begin{tabular}{|c|c|c|c|c|c|c|c|c|}
\hline \multicolumn{9}{|c|}{ Modelo RNA: Estratificación térmica NOCHE } \\
\hline $\begin{array}{l}\text { Entradas } \\
T_{\mathrm{N} 1 . . \mathrm{N} 8}(\mathrm{t})\end{array}$ & $\rightarrow$ & $\begin{array}{c}\text { Salidas } \\
T_{\mathrm{N1} \text {..N8 }}(t+1)\end{array}$ & $\begin{array}{l}\text { RMSE } \\
\left({ }^{\circ} \mathrm{C}\right)\end{array}$ & $\mathbf{R}^{2}$ & DW & MPE & FA & AIC \\
\hline \multirow{3}{*}{ Ensayo: } & & N1 & 0,0981 & 0,9962 & 2,5430 & 0,0000 & 0,9978 & 0,1008 \\
\hline & & N2 & 0,1427 & 0,9869 & 1,5997 & 0,0012 & 0,9968 & 0,1375 \\
\hline & & N3 & 0,0934 & 0,9988 & 2,8329 & 0,0002 & 0,9978 & 0,0961 \\
\hline \multirow{5}{*}{$\begin{array}{c}6-10-2011 \text { 17h58 } \\
\ldots \\
10-10-201110 h 00\end{array}$} & & N4 & 0,0391 & 0,9998 & 2,7654 & $-0,0001$ & 0,9991 & 0,0401 \\
\hline & & N5 & 0,0532 & 0,9998 & 1,9058 & 0,0000 & 0,9989 & 0,0525 \\
\hline & & N6 & 0,0514 & 0,9998 & 1,7080 & $-0,0002$ & 0,9990 & 0,0521 \\
\hline & & N7 & 0,0594 & 0,9998 & 1,8692 & $-0,0002$ & 0,9989 & 0,0603 \\
\hline & & N8 & 0,0653 & 0,9998 & 2,0061 & 0,0004 & 0,9988 & 0,0657 \\
\hline
\end{tabular}




\begin{tabular}{|c|c|c|c|c|c|c|c|c|}
\hline \multicolumn{9}{|c|}{ Modelo RNA: Estratificación térmica NOCHE + ACS } \\
\hline $\begin{array}{c}\text { Entradas } \\
\mathrm{T}_{\mathrm{N} 1 . . \mathrm{N} 8}, \mathrm{ACS}, \mathrm{T}_{\mathrm{red}}(\mathrm{t})\end{array}$ & $\rightarrow$ & $\begin{array}{c}\text { Salidas } \\
\mathrm{T}_{\mathrm{N} 1 . \mathrm{N} 8}(\mathrm{t}+1) \\
\end{array}$ & $\begin{array}{l}\text { RMSE } \\
\left({ }^{\circ} \mathrm{C}\right)\end{array}$ & $\mathbf{R}^{2}$ & DW & MPE & FA & AIC \\
\hline \multirow[b]{3}{*}{ Ensayo: } & & N1 & 0,1026 & 0,9973 & 2,4537 & $-0,0003$ & 0,9949 & 0,0965 \\
\hline & & N2 & 0,1702 & 0,9993 & 1,7001 & 0,0020 & 0,9908 & 0,1960 \\
\hline & & N3 & 0,1054 & 0,9999 & 1,1083 & 0,0021 & 0,9951 & 0,1220 \\
\hline \multirow{2}{*}{$9-3-2012$} & & N4 & 0,0800 & 0,9999 & 0,9432 & $-0,0013$ & 0,9964 & 0,0934 \\
\hline & & N5 & 0,0697 & 0,9999 & 1,4365 & 0,0000 & 0,9972 & 0,0813 \\
\hline \multirow{3}{*}{ 15h10...17h19 } & & N6 & 0,0844 & 0,9999 & 1,3947 & $-0,0014$ & 0,9973 & 0,0983 \\
\hline & & N7 & 0,0773 & 0,9999 & 1,1349 & $-0,0012$ & 0,9975 & 0,0902 \\
\hline & & N8 & 0,2286 & 0,9997 & 1,6400 & $-0,0010$ & 0,9955 & 0,2658 \\
\hline
\end{tabular}

Se observa un resultado óptimo en todos los estados que pueden darse en el depósito acumulador, ya sea con o sin carga y/o descarga. En el caso de que el circuito primario funcione siempre a un mismo caudal del fluido portador, su entrada en el modelo se puede suprimir. En el caso de que la temperatura del agua de red sea siempre la misma, su entrada también se puede suprimir.

Por lo que se puede decir, que los modelos para el funcionamiento del depósito acumulador basados en redes neuronales artificiales, mejoran otros modelos en el rango de sus limitaciones, siempre y cuando el entrenamiento de la red neuronal artificial se haya entrenado con datos de todo el intervalo de funcionamiento. También se puede decir, que elimina la necesidad del conocimiento de las complicadas ecuaciones que gobiernan el movimiento del fluido y del calor en los depósitos de acumulación, lo cual ha sido la principal causa de que siga utilizándose el modelo de mezcla del depósito para los diseños de sistemas solares térmicos, sin contemplar el beneficio de la estratificación térmica.

Durante la realización de la Tesis Doctoral, se ha conseguido identificar la función matemática que describe el enfriamiento del agua caliente solar en el depósito acumulador en el estado NOCHE sin carga y sin descarga (Apartado 4.6.3), que es el estado de la estratificación estática, que siendo el menos estudiado en la literatura, es el de mayor duración en los sistemas solares térmicos, mediante la suma de dos curvas exponenciales (Fig. 4.6.12) y (Tabla 4.6.1). Hallazgo inspirado en la ley de enfriamiento de Newton, entre las capas adyacentes en las que se ha dividido el depósito para su estudio y con el exterior del depósito (Diez et al., 2014).

Los resultados de la función doble exponencial propuesta para la identificación de la estatificación térmica estática en el depósito acumulador (Tabla 4.6.1), que tiene en cuenta la estratificación térmica del agua caliente solar para el estado NOCHE, obtuvo un valor del estadístico RMSE de $\mathbf{0 , 0 5}{ }^{\circ} \mathrm{C}$ respecto del ensayo con la planta piloto correspondiente al día 4 al 5-7-2011 (Fig. 4.6.12). Por lo que puede ser utilizada la función doble exponencial para la identificación de la evolución de las temperaturas durante la estratificación térmica estática en el depósito acumulador. El ajuste de las funciones es casi perfecto, el error de la identificación tiene un sesgo nulo y la precisión de las funciones es óptima, por lo que se observa de los resultados estadísticos evaluados para comprobar su efectividad (Tabla 5.3.7). 
Tabla 5.3.7 Efectividad de la identificación de la estratificación térmica ESTÁTICA durante el ensayo del día 4 al 5-7-2011

\begin{tabular}{|c|c|c|c|c|c|c|c|}
\hline \multicolumn{8}{|c|}{ Identificación doble exponencial: Estratificación térmica ESTÁTICA } \\
\hline \multicolumn{2}{|c|}{$f(t)=a e^{b t}+c e^{d t}$} & $\begin{array}{c}\text { RMSE } \\
\left({ }^{\circ} \mathrm{C}\right)\end{array}$ & $\mathbf{R}^{2}$ & DW & MPE & FA & AIC \\
\hline \multirow{3}{*}{ Ensayo: } & N1 & 0,0689 & 0,9987 & 0,6953 & 0,0000 & 0,9981 & 0,0811 \\
\hline & N2 & 0,0877 & 0,9684 & 2,2725 & $-0,0001$ & 0,997 & 0,0993 \\
\hline & N3 & 0,0782 & 0,9961 & 1,9382 & 0,0000 & 0,9985 & 0,0894 \\
\hline \multirow{5}{*}{$\begin{array}{c}4-7-2011 \text { 18h20 } \\
\ldots \\
5-7-2011 \text { 10h20 }\end{array}$} & N4 & 0,0438 & 0,9984 & 1,3989 & 0,0002 & 0,9992 & 0,0502 \\
\hline & N5 & 0,0358 & 0,9988 & 1,2944 & 0,0000 & 0,9994 & 0,0411 \\
\hline & N6 & 0,0412 & 0,9995 & 2,0127 & 0,0000 & 0,9993 & 0,0483 \\
\hline & N7 & 0,0452 & 0,9997 & 1,7022 & 0,0000 & 0,9993 & 0,0494 \\
\hline & N8 & 0,0490 & 0,9997 & 2,0712 & 0,0000 & 0,9993 & 0,0561 \\
\hline
\end{tabular}

Para la identificación de la función matemática que describe la evolución de las temperaturas en un sistema solar térmico en los otros estados con irradiación solar suficiente para su funcionamiento y la descarga de agua caliente solar. Se ha encontrado una aproximación a la función matemática conocida como serpentina de Newton, en la que una curva creciente de baja pendiente, concuerda con el periodo de carga, seguido de una recta decreciente de pendiente muy fuerte, que se corresponde con el periodo de descarga, para seguir con otra curva creciente de baja pendiente para un nuevo periodo de carga. Pero no se ha llegado todavía a un buen ajuste de sus coeficientes.

Los fenómenos transitorios también pueden ser objeto de estudio con esta metodología, pero en esta Tesis Doctoral no se han tenido en cuenta, ya que se dirige al rendimiento del sistema solar térmico a largo plazo, para ser comparado con los resultados del método f-chart. 


\subsection{Análisis sobre la simulación neural del sistema solar térmico}

Se ha desarrollado la metodología propuesta (Apartado 3.7) en esta Tesis Doctoral, para realizar la simulación del funcionamiento del sistema solar térmico, en este caso de la planta piloto descrita (Apartado 3.1). Para su implementación se utilizaron los modelos desarrollados de los componentes del sistema solar térmico (Apartado 3.6) mediante las redes neuronales artificiales de la inteligencia computacional, basados en datos medidos y registrados.

Estos modelos neurales se convierten en bloques funcionales de la plataforma Simulink del programa Matlab, de esta forma se transforman los modelos desarrollados de los componentes para su utilización, como otro bloque del programa Simulink para su programación visual. Los modelos son conectados entre sí, siguiendo la lógica del funcionamiento del sistema solar térmico planteado (Fig. 3.7.1).

El bloque funcional que representa el captador solar recibe como entradas los valores de la irradiancia solar y la temperatura ambiente generados con la metodología de predicción (Apartado 3.4), además de la temperatura y el caudal de retorno del fluido portador del circuito primario y se obtiene como salida la temperatura de ida del fluido portador.

El bloque funcional que representa el intercambiador de calor recibe como entradas la temperatura y caudal de ida del fluido portador, además de las temperaturas de estratificación térmica en el depósito acumulador y se obtiene a la salida la temperatura de retorno del fluido portador.

El bloque funcional que representa el depósito acumulador está formado por cuatro modelos independientes, que simulan el funcionamiento en sus estados posibles. Los cuatro modelos reciben como entradas las temperaturas de estratificación térmica, el modelo SOL recibe además la temperatura y caudal de ida, el modelo SOL + ACS recibe además la temperatura y caudal de ida, y la temperatura y caudal del agua de red, el modelo NOCHE no recibe ninguna más y el modelo NOCHE + ACS recibe además la temperatura y caudal del agua de red. De los cuatro modelos se obtiene la temperatura de estratificación del depósito acumulador en el siguiente lapso de tiempo.

Se utilizan varios bloques funcionales que representan conmutadores para obtener la salida del modelo correspondiente a la situación que se da en cada lapso de tiempo, con o sin carga y/o descarga en el depósito acumulador.

El bloque funcional utilizado para la realimentación de las temperaturas de estratificación, puede utilizase también para asignar los valores iniciales de las temperaturas en la simulación (Fig. 3.7.3).

El bloque funcional utilizado como marcha/paro de la bomba de impulsión, según el nivel de irradiancia solar que reciba el captador solar (Fig. 3.7.2), también se puede plantear para realizar un control por temperatura de consigna.

La presentación de datos resultado de aplicar las metodologías propuestas, para realizar la simulación del sistema solar térmico, se ha mostrado junto a los datos medidos y registrados en la planta piloto (Apartado 3.1) y que se representan gráficamente (Anexo 2 Datos de los ensayos en la planta piloto). 
Los resultados de la metodología propuesta para la simulación del sistema solar térmico (Apartado 3.7), mediante redes neuronales artificiales que utiliza como entradas el valor en cada minuto de tiempo:

- La irradiancia solar.

- La temperatura ambiente.

- El caudal de agua caliente solar consumida.

- La temperatura del agua de red que entra en el depósito acumulador.

Con el modelo propuesto (Fig. 3.7.1) se da la posibilidad de variar el caudal del fluido en la simulación, ofrece la variación de las temperaturas en las tuberías de ida y de retorno al captador solar y la evolución de las temperaturas de estratificación térmica en las ocho zonas en las que se ha dividido el depósito acumulador para su estudio.

Se ha observado el comportamiento robusto del modelado del sistema solar térmico durante diversas pruebas en la simulación ante datos erróneos, como por ejemplo al introducir datos iniciales en las tuberías de ida y retorno, o en el depósito acumulador que no corresponde a situaciones reales, ante esta situación el modelo neural del sistema solar térmico evoluciona en unos pocos minutos al estado natural correspondiente.

A este respecto, también se ha observado que las pequeñas desviaciones propias que se producen en una simulación tan larga como un día o un mes se van corrigiendo cuando se conmuta el estado de funcionamiento SOL, NOCHE y/o ACS durante la simulación con sus correspondientes modelos neurales concretos. Observándose una autocorrección al conectarse la neurona correspondiente al estado actual, por ejemplo (Fig. 4.7.3) donde la simulación de la evolución de la temperatura de la capa N1 tiene una desviación respecto a los datos reales, la cual se corrige al cambiar de estado y conectarse otro modelo neural del estado correspondiente.

El resultado de la simulación neural del sistema solar térmico realizado para el día 10-10-2011 (Apartado 4.7.1) ejecutado a un caudal del fluido portador de $1 \mathrm{l} / \mathrm{min}$ y comparado con los datos registrados del funcionamiento real, obtuvo durante el día un valor del estadístico RMSE $=\mathbf{0 , 7 7}{ }^{\circ} \mathrm{C}$ (Fig. 4.7.1) y durante la noche un valor del estadístico RMSE $=\mathbf{0 , 1 3}{ }^{\circ} \mathrm{C}$ (Fig. 4.7.2) en las temperaturas de estratificación térmica de las ocho capas del depósito acumulador. Por lo que la simulación puede ser considerada para su utilización. El ajuste del modelo es casi perfecto, el error de la predicción tiene un sesgo casi nulo y la precisión del modelo es óptima, por lo que se observa de los resultados estadísticos evaluados para comprobar su efectividad (Tabla 5.4.1) y (Tabla 5.4.2).

El mayor valor de RMSE en el ensayo de las capas superiores del depósito acumulador N7 y N8 en el día 10-10-2011 puede deberse a un error en la medición durante las descargas de agua caliente solar, que se realizaban manualmente y que algunas veces se hacían a un caudal distinto de la entrada del agua de red. Provocando vacíos en la parte alta del depósito acumulador y los consecuentes errores de medición en los sensores de la estratificación térmica, también pueden deberse a la calibración de los sensores que no estuviera realizada correctamente, más que a un error en el modelo neural. 
Tabla 5.4.1 Efectividad de la simulación neural en la estratificación térmica durante el estado SOL y SOL + ACS en el ensayo del día 10-10-2011

\begin{tabular}{|c|c|c|c|c|c|c|c|c|}
\hline \multicolumn{9}{|c|}{ Simulación RNA: Planta Piloto DÍA Y ACS } \\
\hline $\begin{array}{c}\text { Entradas } \\
\mathbf{i}, \mathbf{T}_{\mathrm{a}}, \mathrm{ACS}, \mathrm{T}_{\text {red }}(\mathrm{t})\end{array}$ & $\rightarrow$ & $\begin{array}{c}\text { Salidas } \\
T_{N 1 . N 8}(t+1)\end{array}$ & $\begin{array}{l}\text { RMSE } \\
\left({ }^{\circ} \mathrm{C}\right)\end{array}$ & $\mathbf{R}^{2}$ & DW & MPE & FA & AIC \\
\hline \multirow{3}{*}{ Ensayo: } & & N1 & 0,3074 & 0,9956 & 0,0463 & 0,0028 & 0,9893 & 0,3128 \\
\hline & & N2 & 0,6222 & 0,9935 & 0,1184 & 0,0094 & 0,9862 & 0,6330 \\
\hline & & N3 & 0,4753 & 0,9962 & 0,0652 & 0,0057 & 0,9901 & 0,4836 \\
\hline \multirow{2}{*}{$10-10-2011$} & & N4 & 0,5408 & 0,9940 & 0,0119 & 0,0082 & 0,9899 & 0,5503 \\
\hline & & N5 & 0,7284 & 0,9884 & 0,0075 & 0,0127 & 0,9861 & 0,7411 \\
\hline \multirow{3}{*}{$10 \mathrm{~h} 42 . . .18 \mathrm{~h} 22$} & & N6 & 0,8750 & 0,9831 & 0,0060 & 0,0131 & 0,9838 & 0,8903 \\
\hline & & N7 & 1,1802 & 0,9731 & 0,0028 & 0,0089 & 0,9779 & 1,2008 \\
\hline & & N8 & 1,0727 & 0,9818 & 0,0017 & 0,0133 & 0,9804 & 1,0915 \\
\hline
\end{tabular}

Tabla 5.4.2 Efectividad de la simulación neural en la estratificación térmica durante el estado NOCHE en el ensayo del día 10 al 11-10-2011

\begin{tabular}{|c|c|c|c|c|c|c|c|c|}
\hline \multicolumn{9}{|c|}{ Simulación RNA: Planta Piloto NOCHE } \\
\hline $\begin{array}{c}\text { Entradas } \\
\mathrm{i}, \mathrm{T}_{\mathrm{a}}, \mathrm{ACS}, \mathrm{T}_{\text {red }}(\mathrm{t})\end{array}$ & $\rightarrow$ & $\begin{array}{c}\text { Salidas } \\
T_{\mathrm{N} 1 . \mathrm{N} 8}(\mathrm{t}+1) \\
\end{array}$ & $\begin{array}{l}\text { RMSE } \\
\left({ }^{\circ} \mathrm{C}\right)\end{array}$ & $\mathbf{R}^{2}$ & DW & MPE & FA & AIC \\
\hline \multirow{3}{*}{ Ensayo: } & & N1 & 0,2666 & 0,9917 & 0,0021 & 0,0081 & 0,9918 & 0,2711 \\
\hline & & N2 & 0,1288 & 0,9775 & 0,0100 & $-0,0005$ & 0,9972 & 0,1310 \\
\hline & & N3 & 0,1548 & 0,9924 & 0,0064 & 0,0018 & 0,9968 & 0,1575 \\
\hline \multirow{5}{*}{$\begin{array}{c}10-10-2011 \text { 18h30 } \\
\ldots \\
11-10-2011 \text { 10h19 }\end{array}$} & & N4 & 0,0539 & 0,9988 & 0,0289 & 0,0002 & 0,9990 & 0,0548 \\
\hline & & N5 & 0,0736 & 0,9970 & 0,0151 & 0,0012 & 0,9985 & 0,0748 \\
\hline & & N6 & 0,0723 & 0,9968 & 0,0133 & 0,0002 & 0,9986 & 0,0736 \\
\hline & & N7 & 0,1091 & 0,9938 & 0,0070 & $-0,0015$ & 0,9984 & 0,1110 \\
\hline & & N8 & 0,0837 & 0,9975 & 0,0077 & $-0,0008$ & 0,9985 & 0,0851 \\
\hline
\end{tabular}

El resultado de la simulación neural del sistema solar térmico realizado para el día 28-11-2011 (Apartado 4.7.2) realizado a un caudal del fluido portador de $1,6 \mathrm{l} / \mathrm{min}$ y comparado con los datos registrados del funcionamiento real, obtuvo durante el día un valor del estadístico RMSE $=\mathbf{0 , 6 9}{ }^{\circ} \mathrm{C}$ (Fig. 4.7.3) y durante la noche un valor del estadístico RMSE $=\mathbf{0 , 4 1}{ }^{\circ} \mathrm{C}$ (Fig. 4.7.4) en las temperaturas de estratificación térmica de las ocho capas del depósito acumulador. Por lo que la simulación puede ser considerada para su utilización. El ajuste del modelo es casi perfecto, el error de la predicción tiene un sesgo casi nulo y la precisión del modelo es óptima, por lo que se observa de los resultados estadísticos evaluados para comprobar su efectividad (Tabla 5.4.3) y (Tabla 5.4.4).

El mayor valor de RMSE en el ensayo de la capa N1 del depósito acumulador en el día 28-11-2011 puede deberse a un error en la medición al estar desplazada la sonda de su posición, también puede deberse a la calibración del sensor que no estuviera realizada correctamente, o al posterior tratamiento de los datos ya que se recogían desde dos aparatos de medida distintos para posteriormente ser tratados en otro ordenador como en el caso anterior, más que a un error en el modelo neural. 
Tabla 5.4.3 Efectividad de la simulación neural en la estratificación térmica durante el estado SOL y SOL + ACS en el ensayo del día 28-11-2011

\begin{tabular}{|c|c|c|c|c|c|c|c|c|}
\hline \multicolumn{9}{|c|}{ Simulación RNA: Planta Piloto DÍA Y ACS } \\
\hline $\begin{array}{c}\text { Entradas } \\
\mathrm{i}, \mathrm{T}_{\mathrm{a}}, \mathrm{ACS}, \mathrm{T}_{\text {red }}(\mathrm{t})\end{array}$ & $\rightarrow$ & $\begin{array}{c}\text { Salidas } \\
T_{\mathrm{N} 1 . \mathrm{N} 8}(t+1)\end{array}$ & $\begin{array}{l}\text { RMSE } \\
\left({ }^{\circ} \mathrm{C}\right)\end{array}$ & $\mathbf{R}^{2}$ & DW & MPE & FA & AIC \\
\hline \multirow[b]{3}{*}{ Ensayo: } & & N1 & 1,3764 & 0,9307 & 0,0043 & $-0,0431$ & 0,9517 & 1,4030 \\
\hline & & N2 & 0,6177 & 0,9949 & 0,0756 & $-0,0110$ & 0,9805 & 0,6296 \\
\hline & & N3 & 0,5246 & 0,9960 & 0,0419 & $-0,0098$ & 0,9848 & 0,5348 \\
\hline \multirow{2}{*}{ 28-11-2011 } & & N4 & 0,3627 & 0,9973 & 0,0258 & $-0,0044$ & 0,9907 & 0,3697 \\
\hline & & N5 & 0,4897 & 0,9946 & 0,0204 & $-0,0017$ & 0,9900 & 0,4992 \\
\hline \multirow{3}{*}{$10 \mathrm{~h} 32 \ldots 17 \mathrm{~h} 29$} & & N6 & 0,3965 & 0,9964 & 0,0236 & 0,0064 & 0,9917 & 0,4042 \\
\hline & & N7 & 0,6237 & 0,9927 & 0,0062 & 0,0101 & 0,9871 & 0,6358 \\
\hline & & N8 & 0,6096 & 0,9933 & 0,0080 & 0,0102 & 0,9878 & 0,6214 \\
\hline
\end{tabular}

Tabla 5.4.4 Efectividad de la simulación neural en la estratificación térmica durante el estado NOCHE en el ensayo del día 28 al 29-10-2011

\begin{tabular}{|c|c|c|c|c|c|c|c|c|}
\hline \multicolumn{9}{|c|}{ Simulación RNA: Planta Piloto NOCHE } \\
\hline $\begin{array}{c}\text { Entradas } \\
\mathrm{i}, \mathrm{T}_{\mathrm{a}}, \mathrm{ACS}, \mathrm{T}_{\mathrm{red}}(\mathrm{t})\end{array}$ & $\rightarrow$ & $\begin{array}{c}\text { Salidas } \\
T_{\mathrm{N} 1 . . \mathrm{N} 8}(\mathrm{t}+1)\end{array}$ & $\begin{array}{l}\text { RMSE } \\
\left({ }^{\circ} \mathrm{C}\right)\end{array}$ & $\mathbf{R}^{2}$ & DW & MPE & FA & AIC \\
\hline \multirow{3}{*}{ Ensayo: } & & N1 & 0,5935 & 0,9260 & 0,0001 & 0,0256 & 0,9729 & 0,6031 \\
\hline & & N2 & 0,4559 & 0,8603 & 0,0007 & 0,0183 & 0,9811 & 0,4632 \\
\hline & & N3 & 0,4178 & 0,8805 & 0,0004 & 0,0125 & 0,9857 & 0,4246 \\
\hline \multirow{5}{*}{$\begin{array}{c}28-11-2011 \text { 17h40 } \\
\ldots \\
29-11-2011 \text { 10h20 }\end{array}$} & & N4 & 0,6841 & 0,9314 & 0,0000 & 0,0214 & 0,9785 & 0,6951 \\
\hline & & N5 & 0,2850 & 0,8411 & 0,0008 & 0,0068 & 0,9922 & 0,2896 \\
\hline & & N6 & 0,1961 & 0,9795 & 0,0003 & 0,0049 & 0,9950 & 0,1993 \\
\hline & & N7 & 0,1455 & 0,9964 & 0,0006 & 0,0025 & 0,9970 & 0,1479 \\
\hline & & N8 & 0,1675 & 0,9958 & 0,0015 & 0,0033 & 0,9965 & 0,1702 \\
\hline
\end{tabular}

La presentación de datos resultado de realizar la simulación del funcionamiento del sistema solar térmico utilizando las metodologías propuestas, para realizar el modelado, se ha presentado utilizando la base de datos climatológicos de la red SIAR, medidos y registrados en la estación de Mansilla Mayor (León), que se representan gráficamente (Anexo 1 Datos climatológicos).

Con la citada base de datos correspondiente a la irradiancia solar y la temperatura ambiente, el perfil de consumo diario de agua caliente solar con la distribución de porcentajes de uso doméstico (Mutch, 1974) en (Duffie y Beckman, 2006) que es el utilizado por el método f-chart (Apartado 3.2), y la temperatura del agua de red con la que entra en el depósito acumulador, que se realizó tomando medidas a lo largo de cada mes del año. Se generó la simulación del funcionamiento de todo el año 2012 (Apartado 4.7.3), que se representa gráficamente con la variación de las temperaturas de estratificación correspondientes a cada mes del año, enero-2012 (Fig. 4.7.5)... hasta diciembre-2012 (Fig. 4.7.16).

Además de la simulación del año 2012, se realizó la simulación de otros nueve años con los datos registrados en 2002, y de 2004 hasta el año 2011, los resultados obtenidos del rendimiento mensual y anual de estos diez años también se han presentado para los casos del funcionamiento del depósito acumulador a una temperatura de mezcla homogénea, como se realizó en el método f-chart, y el segundo caso teniendo en cuenta el efecto de la estratificación térmica en el agua caliente solar del depósito acumulador, para poder observar su variación en años con distinto nivel de irradiación solar 
con un caudal del fluido portador de $\mathbf{2} \mathrm{l} / \mathrm{min}$ (Tabla 4.7.1), de 1,6 I/min (Tabla 4.7.2) y de $1 \mathrm{l} / \mathrm{min}$ (Tabla 4.7.3).

Los resultados del rendimiento mensual y anual fueron también presentados, aplicando la metodología del método f-chart (Apartado 3.2), al mismo sistema solar térmico, en las condiciones establecidas para su aplicación.

- Con los coeficientes de la ecuación característica del captador solar (Fig. 4.1.5.a), resultado de los ensayos realizados con un caudal del fluido portador de $2 \mathrm{l} / \mathrm{min}$ (Tabla 4.7.4) resulta un rendimiento anual del $\mathbf{7 8 , 2 5} \%$.

- Con los coeficientes de la ecuación característica del captador solar (Fig. 4.1.5.b), resultado de los ensayos realizados con un caudal del fluido portador de 1,6 I/min (Tabla 4.7.5) resulta un rendimiento anual del $65,48 \%$.

- Con los coeficientes de la ecuación característica del captador solar (Fig. 4.1.5.c), resultado de los ensayos realizados con un caudal del fluido portador de $1 \mathrm{l} / \mathrm{min}$ (Tabla 4.7.6) resulta un rendimiento anual del $\mathbf{4 4 , 2 3} \%$.

De lo que se comprueba que la variación del rendimiento con el método f-chart es muy acusado, al aplicar la ecuación característica del captador solar ensayado con otro caudal de fluido portador con solución anticongelante distinto al fijado por el método de $0,015 \mathrm{l} /\left(\mathrm{s} \mathrm{m}^{2}\right)$ de superficie de captador solar.

Se realizó la comparación de los resultados obtenidos de la simulación neural y la variación de la irradiación solar anual (Fig. 4.7.17).

En esta Tesis Doctoral, la forma escogida para la validación de la metodología propuesta de simulación neural del sistema solar térmico es la comparación con un método aceptado:

- Se comparan los resultados obtenidos por los dos métodos.

- Si hay concordancia entre los dos métodos puede utilizarse.

- El método puede validarse también en diferentes instalaciones solares.

La validación de la simulación neural ejecutada con la metodología propuesta, se realizó en las mismas condiciones con las que se formuló el método f-chart, esto es:

- Un caudal del fluido portador de $0,015 \mathrm{l} /\left(\mathrm{s} \mathrm{m}^{2}\right)$ de superficie de captador solar, que en el sistema solar térmico de la planta piloto equivale a $1,6 \mathrm{l} / \mathrm{min}$, lo que en los ensayos realizados resulta una ecuación característica: $\eta=0,46-2,3\left(\frac{T_{e}-T_{a}}{i}\right)$ (Fig. 4.1.5.b).

- Además el modelo del depósito acumulador considera un almacenamiento a la temperatura de mezcla completa, por lo que no considera el efecto de la estratificación térmica del agua caliente solar.

- Otra consideración es que asume una distribución del agua caliente demandada diariamente dada por (Mutch, 1974) en (Duffie y Beckman, 2006) que representa los porcentajes horarios típicos de consumo doméstico, por lo que otros perfiles diarios de consumo o el cambio de volumen en cada día puede afectar al resultado del rendimiento.

Estas consideraciones se han tenido en cuenta al realizar la simulación neural, presentando el resultado de los rendimientos obtenidos durante 10 años (Tabla 4.7.2) del que se obtuvo una media en el rendimiento de $\mathbf{6 7 , 3 3} \%$ y aplicando el método f-chart con los datos medios climatológicos como es lo 
característico (Tabla 4.7.5) se obtuvo una media en el rendimiento del 65,48 \%. De lo que resulta una desviación entre el método considerado f-chart y la simulación neural propuesta para 10 años de un $1,85 \%$ por lo que se considera que la simulación neural propuesta se puede utilizar.

La validación en otras instalaciones, no se consideró necesario llevar a cabo, ya que la metodología del modelado de los componentes es la misma, solo cambia su tamaño o número de elementos y no se dan variables que puedan afectar al modelado neural, lo que hace prever que no haya desviaciones.

Con los resultados de la simulación neural del sistema solar térmico de la planta piloto, para los 10 años, que se ejecutó utilizando datos climatológicos reales y calculado su rendimiento con las temperaturas de las ocho capas en las que se dividió el depósito acumulador. Resultó que considerando el depósito estratificado térmicamente con la salida de agua caliente a la temperatura de la capa N8 en la posición más alta del depósito, un rendimiento medio anual sobre los 10 años de simulación neural de un 83,91 $\%$, lo que significa un $\mathbf{1 8 , 4 3} \%$ más que el método f-chart.

Se concluye que la metodología neural desarrollada en esta Tesis Doctoral, proporciona una forma de realizar la simulación de un sistema solar térmico, a partir de los datos de la irradiancia solar, las temperaturas y caudal del fluido portador en las tuberías y las temperaturas de estratificación térmica del depósito acumulador. Siendo innecesarios cualquier tipo de característica técnica de los componentes del sistema solar térmico. 


\subsection{Análisis de la optimización del rendimiento mediante la distribución del consumo respecto a la energía solar disponible}

Se analizan los resultados obtenidos al aplicar la simulación de la planta piloto a los dos tipos de optimización horaria y diaria propuestos en esta Tesis Doctoral.

\section{1) Optimización horaria}

Se ha observado que existe un determinado periodo para el cual la temperatura del agua caliente solar dispuesta para el consumo en el depósito acumulador es máxima. Que, por ejemplo, para un sistema solar térmico en las latitudes norte y orientado hacia el sur, en los días soleados se encuentra en la segunda o tercera hora pasado el mediodía solar, sobre las $15 \mathrm{~h}$ hora solar. Este punto se ha alcanzado después de un proceso de carga en la primera mitad del día, más dos o tres horas de la segunda mitad del día durante las cuales la irradiancia solar es todavía alta.

También, se ha encontrado del análisis realizado al método f-chart, el cual utiliza una distribución de consumo de agua caliente solar dada por (Mutch, 1974) en (Duffie y Beckman, 2006). Que el consumo doméstico se centra durante la mañana y la tarde-noche.

Los resultados obtenidos en esta Tesis Doctoral son un aumento progresivo en el rendimiento del sistema solar térmico, al realizar las descargas de agua caliente solar en los periodos de tiempo que coinciden con las temperaturas más altas en el depósito acumulador, pudiendo llegar a un rendimiento del $\mathbf{1 8} \%$ mayor que el obtenido con un perfil del tipo usado en el método f-chart.

\section{2) Optimización diaria}

Se ha observado que existe una variación de la energía solar disponible para cada día del año, limitada por la cubierta nubosa correspondiente, lo que provoca una variación diaria de la temperatura del agua caliente solar almacenada en el depósito acumulador en función de la irradiación solar incidente en los captadores solares.

Los resultados obtenidos en esta Tesis Doctoral son un aumento importante en el rendimiento del sistema solar térmico, al aumentar la descarga de agua caliente solar los días de alta irradiación solar y disminuir la descarga los días de baja irradiación solar, pudiendo llegar a un rendimiento del $\mathbf{1 8}$ \% mayor que el obtenido con un consumo diario fijo mensual del tipo usado en el método f-chart. 



\section{Capítulo 6}

\section{CONCLUSIONES}

En este capítulo se presentan de forma sintética las conclusiones generales de la Tesis Doctoral, respecto a los modelos y metodologías utilizados por primera vez, relacionándose con los objetivos planteados en un principio, y agrupándose las aportaciones más interesantes surgidas de la investigación realizada.

Se han estudiado los modelos de predicción de la irradiación solar y temperatura ambiente, los modelos de estratificación térmica, los modelos que definen los componentes principales del sistema solar térmico y la estimación de la irradiación solar sobre el plano inclinado. Y se ha visto que las condiciones habituales de los sistemas solares térmicos siempre han tenido como denominador común, el bajo rendimiento obtenido en la conversión de la energía solar y su aprovechamiento final. Además de que las investigaciones llevadas a cabo hasta el momento sobre la variabilidad del recurso solar a corto plazo, siguen sin aplicación práctica a estos sistemas. Por lo que, se ha afrontado el estudio del efecto de un uso inteligente del sistema solar térmico para mejorar el rendimiento, mediante una nueva metodología de simulación neural.

Las conclusiones más interesantes de los estudios de investigación se exponen a continuación. Utilizando como referencia de comparación el método f-chart, que se considera actualmente un procedimiento idóneo en el diseño de los sistemas solares térmicos, es aplicado al sistema solar térmico construido.

Conclusiones respecto al objetivo principal de optimizar el rendimiento, sea logrado que:

1. Al tener en cuenta el efecto de la estratificación térmica en el depósito acumulador, aumenta considerablemente el rendimiento, respecto al uso de una mezcla completa del mismo, $18 \%$.

2. Al realizar un consumo inteligente del agua caliente solar en las horas del día, cuando la temperatura del depósito acumulador es más alta, después del mediodía solar y durante la tarde, desplazando a esos periodos de tiempo los consumos más importantes, que se pueden realizar en una vivienda como el uso de los electrodomésticos, lavadora y lavavajillas, y los baños. En lugar de realizarlo en los periodos de tiempo cuando la temperatura del agua almacenada en el depósito es menor, la mañana y la noche. Se alcanza un rendimiento mayor que el obtenido con un perfil de consumo diario del tipo utilizado en el método f-chart, $18 \%$.

3. Al realizar un consumo inteligente del agua caliente solar, durante los días en que la irradiación solar es más alta, desplazando a esos días los consumos más importantes, que se pueden realizar en una vivienda como el uso de la lavadora, calefacción, climatización y piscina. Se logra un rendimiento mayor que el obtenido con un consumo fijo para cada día del mes como el tipo 
usado en el método f-chart, que no distingue entre el día con una alta o baja irradiación solar, $18 \%$.

Todo ello se puede aplicar en cualquier sistema solar térmico doméstico, adaptando los hábitos de consumo de agua caliente solar, en base a las predicciones de la irradiación solar diaria, utilizando la filosofía de aumentar el consumo los días de alta irradiación y reduciendo el consumo los días con previsiones de baja irradiación solar. En lugar de tener un consumo fijo diario, la adecuación del consumo a las previsiones de la irradiación solar consigue un rendimiento mayor del sistema solar térmico.

Por lo que, se puede proponer su aplicación para obtener una optimización importante en el rendimiento de los sistemas solares térmicos, teniendo en consideración que ante las distintas climatologías y hábitos de consumo de agua caliente como su distribución en el tiempo, horario y diario, pueden variarlo.

Conclusiones respecto a los objetivos específicos inicialmente propuestos:

1. Se han desarrollado nuevos modelos neurales destinados a la predicción a corto plazo de la irradiación solar y la temperatura ambiente en el lugar del sistema solar térmico, a partir de datos históricos de la zona concreta, mediante su uso en sencillas redes neuronales artificiales, durante un año, $R M S E=3,77 \mathrm{MJ} / \mathrm{m}^{2} / \mathrm{d}$ y $1,7^{\circ} \mathrm{C} / \mathrm{d}$.

2. Se ha conseguido realizar el modelado neural de la estratificación térmica del agua caliente solar almacenada en el depósito acumulador del sistema solar térmico, mediante cuatro redes neuronales artificiales, que simulan la evolución de las temperaturas en las ocho capas que se dividió el depósito acumulador utilizado. Una red neuronal artificial distinta para modelar cada uno de los cuatro estados posibles de funcionamiento: en el modo dinámico con carga, carga y descarga, descarga, y en el modo estático sin carga ni descarga, RMSE $=0,10{ }^{\circ} \mathrm{C}, 0,12{ }^{\circ} \mathrm{C}, 0,12{ }^{\circ} \mathrm{C}$ y $0,07^{\circ} \mathrm{C}$ respectivamente.

3. Se ha modelado el funcionamiento de los componentes principales del sistema solar térmico, captador solar, intercambiador de calor y depósito acumulador, a partir de datos medidos y registrados en su funcionamiento: irradiancia solar, temperaturas y caudales del fluido portador en sus entradas y salidas. Para ser tratados por las redes neuronales artificiales, RMSE $=0,19^{\circ} \mathrm{C}$, $0,29{ }^{\circ} \mathrm{C}$ y $0,10^{\circ} \mathrm{C}$ respectivamente.

4. Se ha conseguido, que todos los modelos neurales de los componentes principales actúen sincronizadamente, para poder simular el funcionamiento del sistema solar térmico específico. $Y$ aplicable a cualquier otro, para evaluar su rendimiento mediante las variaciones de temperaturas, $\mathrm{RMSE}=0,77^{\circ} \mathrm{C}$ día y $0,13^{\circ} \mathrm{C}$ noche.

5. Se ha realizado una revisión de los métodos necesarios para estimar el valor de la irradiación solar global incidente sobre el captador solar instalado con una inclinación y orientación determinada, a partir de la irradiación solar global horizontal que es la habitualmente medida y registrada en las estaciones meteorológicas. Y se ha propuesto una metodología clara y flexible en su aplicación, y adaptable a otros modelos, ya que en la literatura se encuentra muy bien desarrollada, pero su aplicación conjunta es difícil de emplear, sino es por un experto. 
En esta Tesis Doctoral se han conseguido varias aportaciones principales respecto al modelado y la optimización del rendimiento de los sistemas solares térmicos. En relación al modelado, se ha logrado realizar la simulación neural del funcionamiento de los sistemas solares térmicos, con una metodología nueva y flexible, que se puede adaptar a cualquier instalación solar. Y con respecto a la optimización del rendimiento, se ha encontrado la mejor manera de aumentarlo, mediante un uso inteligente de la energía solar, que puede ser aplicado por cualquier usuario de una instalación solar térmica doméstica.

Se resalta que todos los desarrollos presentados partieron después de haber detectado en la bibliografía una corriente científica computacional, aplicada a la resolución de un problema perteneciente a este campo de investigación de los sistemas solares, que plantea modelar los componentes que integran el sistema solar térmico mediante las redes neuronales artificiales, utilizando para su entrenamiento los datos del funcionamiento real organizados como una serie de tiempo. Consiguiendo una nueva metodología para la simulación neural de los sistemas solares térmicos, la cual funciona a partir de unas variables de entrada, ambientales y de consumo, que se indican a continuación.

Las variables de entrada, ambientales, al modelo desarrollado para la simulación en intervalos de tiempo de un minuto, irradiancia solar y temperatura ambiente, son los datos medidos y registrados a largo plazo o las predicciones realizadas a corto plazo con la misma técnica de las redes neuronales artificiales basada en el marco teórico de las series de tiempo. Después de haber sido estimado el valor de la irradiancia solar sobre el plano inclinado de los captadores solares mediante la metodología tradicional que se ha recopilado.

Las variables de entrada, de consumo, al modelo desarrollado para la simulación en intervalos de tiempo de un minuto, son los datos medidos y registrados de la temperatura del agua de red que entra en el depósito y el caudal del agua caliente solar estimado que sale del depósito.

Además durante el transcurso de los estudios de investigación, se han encontrado diversos hallazgos, que se considera interesante su exposición:

1. Se ha conseguido identificar matemáticamente la evolución de las temperaturas de estratificación en el modo estático de funcionamiento, mediante la suma de dos curvas exponenciales, inspirado en la ley de enfriamiento de Newton entre las capas adyacentes, superior e inferior a la estudiada.

2. Se ha descubierto un grave problema en la aplicación actual del método f-chart, al utilizar unos coeficientes de la ecuación característica del captador solar, resultado de ensayos realizados con un caudal del fluido portador distinto, para el que fue creado el método. Lo que produce notables desviaciones en la cobertura solar al aplicar el método f-chart.

3. Las variables medidas y registradas actualmente en los sistemas solares térmicos son útiles para el control, pero no sirven para un modelado energético como es el caso del depósito acumulador, que por lo general solo dispone de una sonda de temperatura en la parte baja del depósito destinada para actuar sobre el accionamiento de la bomba de circulación. La instalación de una sonda de estratificación como se propone en esta Tesis Doctoral, proporciona el conocimiento de la energía almacenada verdaderamente en el depósito acumulador respecto la temperatura del agua de red que entra en el depósito. 
4. Se han encontrado varias funciones que se aproximan a la variación de la irradiación solar extraterrestre diaria en función del número del día del año, para la latitud $42^{\circ}$ Norte, pudiéndose realizar para otras latitudes, mediante las series de Fourier o mediante sumas de funciones seno. Estas funciones de aproximación pueden facilitar el cálculo de la irradiación solar extraterrestre diaria en las aplicaciones de una forma más sencilla.

5. Se ha comprobado que la variación de las temperaturas en un sistema solar térmico es de una forma continua y estable, y que las variaciones más drásticas se dan en los cambios del estado de funcionamiento, como se ha encontrado al variar la carga, por ejemplo, cuando baja la insolación que hace parar la bomba de circulación, y al accionar la descarga cuando se realiza un consumo de agua caliente solar. De estas observaciones surgió la pensamiento de formular modelos diferentes para cada estado de funcionamiento de los componentes del sistema solar térmico, como se aplicó en la estratificación térmica del depósito acumulador, que conmuten para cada situación concreta del sistema solar térmico, logrando la mejor aproximación del modelado a la situación real de funcionamiento en lugar de un modelo concreto para todos los estados. 


\section{Capítulo 7}

\section{LÍNEAS FUTURAS DE INVESTIGACIÓN}

En este capítulo se proponen las líneas futuras de investigación, que pueden desarrollarse como continuación de los modelos, las metodologías y los resultados obtenidos de los estudios llevados a cabo en esta Tesis Doctoral.

Son diversas las líneas futuras de investigación, que pueden dar continuidad a los estudios de investigación expuestos en este documento.

Por una parte están las nuevas líneas de investigación que son una prolongación de los estudios llevados a cabo hasta la fecha en cada línea de actuación propuesta inicialmente, como son:

1. En la predicción de la irradiación solar global y la temperatura ambiente a corto plazo, se pretende trabajar en el desarrollo de nuevos modelos neurales, usando más variables ambientales explicativas como pueden ser la humedad, la presión atmosférica,... que contribuyan a detectar cambios en su evolución. El estudio por separado de los datos para cada estación del año que tengan características similares. La mejora del rendimiento de los modelos neurales también puede realizarse a partir de las predicciones de los servicios meteorológicos en lugar de utilizar únicamente los datos históricos registrados en la zona. Otra posibilidad de mejora en las predicciones puede ser la combinación de los modelos de predicción para el aumento de su rendimiento.

2. En el modelado de la estratificación térmica del depósito acumulador, se pretende identificar matemáticamente la variación de las temperaturas en los estados de carga y/o descarga, mediante la aproximación a la curva geométrica conocida como serpentina de Newton, ampliable a otros puntos del sistema solar térmico. Que junto a la identificación matemática del estado de enfriamiento mediante la suma de dos curvas exponenciales, se podría extender a un nuevo modelado de todo el sistema solar térmico.

3. En el modelado de los componentes del sistema solar térmico, se pretende estudiar cada estado de funcionamiento de los componentes por separado con sus respectivas redes neuronales artificiales, como se realizó para el caso de la estratificación térmica del depósito acumulador. Utilizar el modelado neural para simular los efectos transitorios, como pueden ser el enfriamiento y el calentamiento de las tuberías, y en el captador solar las maniobras de parada y arranque de la bomba de circulación, que se producen en el funcionamiento de los sistemas solares térmicos. Se realizaría por separado y se aplicaría en la metodología de modelado del sistema solar térmico, para conseguir que sea más completo. Facilitar los modelos neurales de los componentes por los propios fabricantes, con los datos de los ensayos de prueba que hayan obtenido. 
4. En la estimación de la irradiación solar incidente en el plano inclinado y orientado del captador solar, respecto de la recibida sobre la superficie horizontal, se pretende utilizar la metodología neural usando los datos medidos y registrados en varios días despejados con el piranómetro en las dos posiciones, horizontal e inclinado, para el entrenamiento del modelo neural, que utilice como entradas los valores de la irradiación solar sobre la horizontal y entregue a la salida el valor correspondiente al plano inclinado analizado. Esto evitaría los complejos cálculos necesarios para su estimación y completaría el modelado neural del sistema solar térmico.

5. En el marco teórico de las redes neuronales artificiales sobre el que se desarrollan las metodologías, se pretende ampliar aplicando otros tipos de redes neuronales artificiales a las utilizadas en esta Tesis Doctoral, como pueden ser las dinámicas, con las que se puedan lograr mejores resultados en la predicción de las series de tiempo por personal más cualificado. Utilizar en el modelado neural la metodología grey-box, además de usar los datos medidos y registrados del funcionamiento en el sistema solar térmico, se aplica el conocimiento físico de los componentes al modelado y de las variables ambientales para su predicción. Lo que puede hacer que la cantidad de datos necesarios para el entrenamiento de la red neuronal artificial sea menor y al mismo tiempo mejorar su rendimiento.

Reformular la metodología planteada para el modelado de una instalación solar térmica desarrollada $\mathrm{n}$ esta Tesis Doctoral, como un método de diseño para los sistemas solares térmicos, a partir de datos del funcionamiento de los componentes de otros modelos teóricos en lugar de los datos medidos en la instalación solar. Con la que se eliminen gastos de construcción de los prototipos, dando una idea más comprensible y conocimiento del funcionamiento, optimizar componentes, estimar la energía y conocer las variaciones de las temperaturas del sistema solar térmico respecto a las condiciones climatológicas.

Y por otra parte está la línea futura de investigación que se dirige al desarrollo de metodologías de predicción, modelado neural y optimización, similares a las propuestas en esta Tesis Doctoral y aplicadas en los sistemas solares térmicos, para extender su estudio a otros sistemas de energías renovables como son el fotovoltaico y el eólico. 


\section{Anexo 1}

\section{DATOS CLIMATOLÓGICOS}

\section{A.1.1 Estación meteorológica SIAR en Mansilla Mayor (León)}

\section{A.1.2 Datos de irradiación solar SIAR en Mansilla Mayor (León)}

\section{A.1.3 Datos de temperatura ambiente SIAR en Mansilla Mayor (León)}

\section{A.1.4 Datos de irradiación solar CENSOLAR en León}

\section{A.1.5 Datos de temperatura ambiente CENSOLAR en León}

En este anexo se presenta la estación meteorológica de la red SIAR situada en la localidad de Mansilla Mayor a $20 \mathrm{~km}$ al Sur de la ciudad de León y se representan gráficamente los datos climatológicos utilizados de su base de datos de la irradiación solar global horizontal y temperatura ambiente, utilizados en esta Tesis Doctoral para la simulación del funcionamiento del sistema solar térmico, modelado mediante redes neuronales artificiales y utilización de los modelos probados para la predicción de las variables.

También se representan gráficamente los datos CENSOLAR de irradiación solar que incide sobre la superficie horizontal en un día medio de cada mes en la provincia de León y la temperatura ambiente media durante las horas de sol, recomendados en el Pliego de Condiciones Técnicas de Instalaciones de Baja Temperatura (IDAE, 2009) para el cálculo y diseño de estos sistemas. 


\section{A.1.1 Estación meteorológica SIAR en Mansilla Mayor (León)}

Los datos climatológicos utilizados son recogidos por las estaciones de la red SIAR, que es un proyecto de la Dirección General de Desarrollo Rural del Ministerio de Medio Ambiente y Medio Rural y Marino. En Castilla y León esta información está gestionada por el servicio Inforiego de asesoramiento al regante desde el Instituto Tecnológico Agrario de Castilla y León ITACyL, que pretende fomentar el acceso del público a la información relativa de la meteorología en Castilla y León, además de facilitar a los regantes recomendaciones que sirvan para ahorrar agua en el riego, desde el sitio web: http://www.inforiego.org

La situación de las estaciones meteorológicas en Castilla y León, se muestra en el mapa (Fig. A.1.1). Las estaciones se componen de tres partes: fuente de alimentación, almacén de datos con comunicación al ordenador central y los sensores de temperatura, humedad relativa, precipitación, velocidad y dirección del viento, e irradiancia solar.

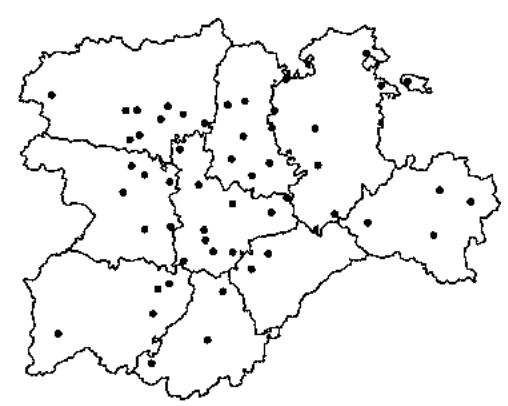

Fig. A.1.1 Situación de la red de estaciones meteorológicas del proyecto SIAR en Castilla y León

En este apartado se presenta la estación meteorológica de la red SIAR situada en la localidad de Mansilla Mayor (León) y se representan gráficamente los datos climatológicos utilizados de su base de datos de la irradiación solar global diaria horizontal y de la temperatura ambiente máxima, media y mínima diaria para cada año del 2002 al 2012, salvo el año 2003.

En lo que respecta a la variables ambientales, que en esta Tesis Doctoral se utilizan irradiación solar y temperatura ambiente, están tomadas con un piranómetro Skye SP1110 Campbell, que es una fotocélula de silicio sensible a la radiación entre 350-1100 nm, la medida de la temperatura se realiza mediante un sensor de temperatura Pt-1000 que se basa en la variación de la resistencia del platino con la temperatura. Estos cambios son detectados, linealizados y amplificados por un circuito electrónico situado en la sonda Vaisala HMP45C Campbell.

Los datos de irradiación solar global diaria horizontal, temperatura media diaria, temperatura máxima diaria y temperatura mínima diaria utilizados en esta Tesis Doctoral son los recogidos por la estación SIAR en Mansilla Mayor (León), durante 11 años del 2002 al 2012, que se puede ver en la fotografía (Fig. A.1.2).

Los datos de irradiancia solar y temperatura registrados y computados para cada media hora por la estación climatológica fueron recalculados para ser utilizados en un periodo de una hora. Antes de realizar un análisis detallado y la construcción de modelos, los datos utilizados fueron identificados, controlados y corregidos. Todos los datos tomados del sitio web fueron revisados visualmente, mediante gráficas, detectándose datos faltantes y valores sospechosos de ser erróneos muy aislados, 
para su corrección se compararon los datos con otras estaciones cercanas, por ejemplo Santas Martas, y se realizó una extrapolación para completar la base de datos.

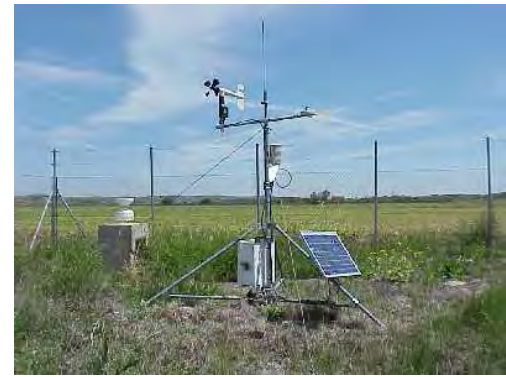

Fig. A.1.2 Imagen de la estación meteorológica SIAR situada en Mansilla Mayor (León). Hora Local GMT-21,725555

Se puede observar la presentación de los datos por el servicio Inforiego, en hojas de cálculo del programa informático Excel. (Tabla A.1.1) los datos absolutos registrados diariamente y (Tabla A.1.2) los datos calculados en base diaria. (Tabla A.1.3) se muestran los datos registrados cada media hora en la estación.

Tabla A.1.1 Datos absolutos diarios registrados en la estación SIAR de Mansilla Mayor (León)

Datos recogidos de la estación LE02 - Mansilla Mayor (León) Desde el día 01/03/2012 hasta el día 07/03/2012

\begin{tabular}{|c|c|c|c|c|c|c|c|c|c|c|c|c|}
\hline \multicolumn{13}{|c|}{ Datos absolutos registrados } \\
\hline Fecha & $\begin{array}{c}\text { Temperatura } \\
\text { media }\end{array}$ & $\begin{array}{l}\text { Temperatura } \\
\text { máxima }\end{array}$ & $\begin{array}{c}\text { Temperatura } \\
\text { mínima }\end{array}$ & $\begin{array}{c}\text { Humedad } \\
\text { media }\end{array}$ & $\begin{array}{l}\text { Humedad } \\
\text { máxima }\end{array}$ & $\begin{array}{l}\text { Humedad } \\
\text { mínima }\end{array}$ & $\begin{array}{l}\text { Velocidad } \\
\text { viento }\end{array}$ & $\begin{array}{l}\text { Dirección } \\
\text { viento }\end{array}$ & $\begin{array}{l}\text { Velocidad } \\
\text { máxima }\end{array}$ & $\begin{array}{l}\text { Dirección } \\
\text { Vel. Máx. }\end{array}$ & Irradiación & Precipitación \\
\hline $\mathrm{dd} / \mathrm{mm} / \mathbf{a a a a}$ & ${ }^{\circ} \mathrm{C}$ & ${ }^{\circ} \mathrm{C}$ & ${ }^{\circ} \mathrm{C}$ & $\%$ & $\%$ & $\%$ & $\mathrm{~m} / \mathrm{s}$ & ${ }^{\circ}\left(\mathrm{N}=0^{\circ}\right)$ & $\mathrm{m} / \mathrm{s}$ & ${ }^{\circ}\left(\mathrm{N}=0^{\circ}\right)$ & $\mathrm{MJ} / \mathrm{m}^{2}$ & $\mathrm{~mm}$ \\
\hline 01/03/2012 & 7.87 & 18.46 & -3.15 & 54.75 & 85.80 & 25.27 & 1.11 & 75.40 & 4.95 & 95.20 & 16.43 & 0.0 \\
\hline 02/03/2012 & 8.50 & 17.47 & 1.43 & 62.48 & 89.10 & 27.74 & 1.61 & 105.80 & 7.10 & 260.10 & 15.12 & 0.0 \\
\hline 03/03/2012 & 6.50 & 13.37 & -1.23 & 83.00 & 100.00 & 56.63 & 1.57 & 191.80 & 7.22 & 205.80 & 9.78 & 0.2 \\
\hline 04/03/2012 & 8.04 & 15.69 & -0.37 & 74.80 & 93.30 & 38.26 & 2.71 & 262.20 & 9.71 & 259.80 & 12.14 & 0.0 \\
\hline 05/03/2012 & 2.59 & 10.57 & -7.14 & 63.41 & 92.90 & 28.48 & 1.03 & 167.80 & 6.03 & 232.70 & 16.14 & 0.0 \\
\hline 06/03/2012 & 1.79 & 13.03 & -8.01 & 58.59 & 91.70 & 13.04 & 1.54 & 350.80 & 6.22 & 354.40 & 16.64 & 0.0 \\
\hline 07/03/2012 & 3.30 & 13.56 & -7.21 & 64.61 & 87.20 & 43.65 & 1.10 & 305.20 & 4.45 & 323.90 & 14.64 & 0.0 \\
\hline
\end{tabular}

Tabla A.1.2 Datos calculados en base diaria en la estación SIAR de Mansilla Mayor (León)

\begin{tabular}{|c|c|c|c|c|c|c|c|c|c|}
\hline \multicolumn{10}{|c|}{ Datos calculados } \\
\hline Fecha & $\begin{array}{c}\text { ETo } \\
\text { (P.MON.) }\end{array}$ & $\begin{array}{c}\text { Precipitación } \\
\text { Efectiva (P.MON.) }\end{array}$ & $\begin{array}{c}\text { Horas } \\
\text { insolación }\end{array}$ & $\begin{array}{c}\text { Velocidad } \\
\text { viento diurna }\end{array}$ & $\begin{array}{c}\text { Velocidad } \\
\text { viento nocturna }\end{array}$ & $\begin{array}{c}\text { Recorrido } \\
\text { viento }\end{array}$ & $\begin{array}{l}\text { Irradiación } \\
\text { neta }\end{array}$ & $\begin{array}{l}\text { Temperatura } \\
\text { media diurna }\end{array}$ & $\begin{array}{c}\text { Humedad } \\
\text { media diurna }\end{array}$ \\
\hline $\mathrm{dd} / \mathrm{mm} /$ aaaa & $\mathrm{mm}$ & $\mathrm{mm}$ & $\mathrm{h}$ & $\mathrm{m} / \mathrm{s}$ & $\mathrm{m} / \mathrm{s}$ & 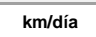 & $\mathrm{MJ} / \mathrm{m}^{2}$ & ${ }^{\circ} \mathrm{C}$ & $\%$ \\
\hline 01/03/2012 & 2.19 & 0.0 & 10.09 & 1.61 & 0.61 & 96.16 & 5.49 & 13.03 & 40.26 \\
\hline $02 / 03 / 2012$ & 2.40 & 0.0 & 9.49 & 2.37 & 0.85 & 139.10 & 5.49 & 12.04 & 48.73 \\
\hline 03/03/2012 & 1.46 & 0.0 & 8.87 & 2.18 & 0.95 & 135.39 & 4.81 & 8.76 & 75.25 \\
\hline 04/03/2012 & 2.41 & 0.0 & 9.06 & 4.02 & 1.40 & 234.23 & 5.24 & 10.65 & 65.13 \\
\hline 05/03/2012 & 1.68 & 0.0 & 9.96 & 1.34 & 0.73 & 89.16 & 6.07 & 5.85 & 49.37 \\
\hline 06/03/2012 & 2.27 & 0.0 & 10.37 & 2.21 & 0.87 & 133.06 & 5.87 & 5.73 & 50.65 \\
\hline $07 / 03 / 2012$ & 1.72 & 0.0 & 9.91 & 1.46 & 0.73 & 94.87 & 6.13 & 7.24 & 57.48 \\
\hline
\end{tabular}


Tabla A.1.3 Datos recogidos cada media hora en la estación SIAR de Mansilla Mayor (León)

Datos recogidos cada media hora en la estación LE02 - Mansilla Mayor (León) Desde el día 01/03/2012 hasta el día 01/03/2012

\begin{tabular}{|c|c|c|c|c|c|c|c|}
\hline \multicolumn{8}{|c|}{ Datos absolutos registrados } \\
\hline Fecha & Hora & $\begin{array}{c}\text { Temperatura } \\
\text { media }\end{array}$ & $\begin{array}{c}\text { Humedad } \\
\text { media }\end{array}$ & Irradiancia & $\begin{array}{l}\text { Velocidad } \\
\text { viento }\end{array}$ & $\begin{array}{l}\text { Dirección } \\
\text { viento }\end{array}$ & Precipitación \\
\hline $\mathrm{dd} / \mathrm{mm} / \mathrm{aaaa}$ & hh:mm & ${ }^{\circ} \mathrm{C}$ & $\%$ & $\mathrm{~W} / \mathrm{m}^{2}$ & $\mathrm{~m} / \mathrm{s}$ & ${ }^{\circ}\left(\mathrm{N}=0^{\circ}\right)$ & $\mathrm{mm}$ \\
\hline 01/03/2012 & $00: 30$ & 3,89 & 64,25 & 0,00 & 0,57 & 337,50 & 0,00 \\
\hline 01/03/2012 & 01:00 & 3,11 & 66,69 & 0,00 & 0,89 & 338,20 & 0,00 \\
\hline 01/03/2012 & 01:30 & 3,29 & 66,67 & 0,00 & 1,44 & 358,30 & 0,00 \\
\hline 01/03/2012 & 02:00 & 1,87 & 70,90 & 0,00 & 1,20 & 357,30 & 0,00 \\
\hline 01/03/2012 & 02:30 & 1,12 & 74,20 & 0,00 & 0,85 & 352,90 & 0,00 \\
\hline 01/03/2012 & 03:00 & 1,21 & 75,30 & 0,00 & 0,43 & 349,70 & 0,00 \\
\hline 01/03/2012 & 03:30 & 0,77 & 76,30 & 0,00 & 0,68 & 11,29 & 0,00 \\
\hline 01/03/2012 & 04:00 & $-0,03$ & 78,60 & 0,00 & 0,12 & 340,90 & 0,00 \\
\hline 01/03/2012 & 04:30 & $-0,50$ & 79,40 & 0,00 & 0,04 & 5,25 & 0,00 \\
\hline 01/03/2012 & 05:00 & $-1,09$ & 80,40 & 0,00 & 0,32 & 45,02 & 0,00 \\
\hline 01/03/2012 & 05:30 & $-1,40$ & 82,90 & 0,00 & 0,13 & 11,82 & 0,00 \\
\hline 01/03/2012 & 06:00 & $-2,02$ & 83,10 & 0,00 & 0,00 & 0,00 & 0,00 \\
\hline 01/03/2012 & 06:30 & $-2,24$ & 84,60 & 0,00 & 0,34 & 9,81 & 0,00 \\
\hline 01/03/2012 & 07:00 & $-2,51$ & 82,80 & 2,60 & 0,11 & 91,40 & 0,00 \\
\hline $01 / 03 / 2012$ & 07:30 & $-2,73$ & 84,60 & 31,99 & 0,48 & 33,20 & 0,00 \\
\hline 01/03/2012 & 08:00 & $-1,20$ & 82,90 & 105,20 & 0,58 & 31,44 & 0,00 \\
\hline 01/03/2012 & 08:30 & 1,93 & 75,10 & 194,30 & 0,30 & 139,30 & 0,00 \\
\hline 01/03/2012 & 09:00 & 4,79 & 65,37 & 295,20 & 0,63 & 73,90 & 0,00 \\
\hline 01/03/2012 & 09:30 & 7,15 & 56,83 & 380,20 & 0,48 & 221,40 & 0,00 \\
\hline 01/03/2012 & 10:00 & 9,98 & 48,94 & 423,30 & 0,44 & 17,30 & 0,00 \\
\hline $01 / 03 / 2012$ & $10: 30$ & 12,52 & 40,96 & 534,30 & 1,91 & 86,20 & 0,00 \\
\hline 01/03/2012 & 11:00 & 14,55 & 35,09 & 578,70 & 2,50 & 111,50 & 0,00 \\
\hline 01/03/2012 & $11: 30$ & 14,90 & 34,20 & 632,10 & 2,50 & 130,80 & 0,00 \\
\hline 01/03/2012 & 12:00 & 15,38 & 34,02 & 652,50 & 2,25 & 137,00 & 0,00 \\
\hline 01/03/2012 & $12: 30$ & 15,98 & 32,96 & 672,80 & 2,76 & 119,50 & 0,00 \\
\hline 01/03/2012 & $13: 00$ & 16,55 & 32,38 & 679,10 & 2,55 & 125,50 & 0,00 \\
\hline 01/03/2012 & $13: 30$ & 17,17 & 30,71 & 664,40 & 2,73 & 120,00 & 0,00 \\
\hline $01 / 03 / 2012$ & $14: 00$ & 17,72 & 28,69 & 639,50 & 2,35 & 134,00 & 0,00 \\
\hline 01/03/2012 & $14: 30$ & 17,89 & 27,81 & 594,50 & 2,14 & 132,60 & 0,00 \\
\hline 01/03/2012 & $15: 00$ & 18,31 & 27,45 & 535,90 & 1,87 & 128,60 & 0,00 \\
\hline $01 / 03 / 2012$ & $15: 30$ & 18,26 & 26,80 & 468,80 & 2,38 & 144,90 & 0,00 \\
\hline 01/03/2012 & $16: 00$ & 18,24 & 26,47 & 391,70 & 1,82 & 143,70 & 0,00 \\
\hline 01/03/2012 & $16: 30$ & 18,26 & 25,63 & 297,50 & 2,02 & 138,90 & 0,00 \\
\hline 01/03/2012 & 17:00 & 17,80 & 26,89 & 206,90 & 2,03 & 135,60 & 0,00 \\
\hline 01/03/2012 & 17:30 & 17,18 & 27,41 & 112,70 & 1,89 & 157,10 & 0,00 \\
\hline $01 / 03 / 2012$ & 18:00 & 16,10 & 27,67 & 32,54 & 1,30 & 167,90 & 0,00 \\
\hline $01 / 03 / 2012$ & $18: 30$ & 14,22 & 31,23 & 2,32 & 0,60 & 182,10 & 0,00 \\
\hline 01/03/2012 & 19:00 & 11,72 & 36,24 & 0,00 & 0,19 & 212,40 & 0,00 \\
\hline 01/03/2012 & 19:30 & 8,78 & 48,25 & 0,00 & 0,55 & 28,32 & 0,00 \\
\hline 01/03/2012 & $20: 00$ & 8,19 & 48,70 & 0,00 & 0,47 & 271,20 & 0,00 \\
\hline 01/03/2012 & $20: 30$ & 9,24 & 47,51 & 0,00 & 0,31 & 206,40 & 0,00 \\
\hline 01/03/2012 & 21:00 & 6,34 & 56,26 & 0,00 & 1,06 & 62,42 & 0,00 \\
\hline $01 / 03 / 2012$ & $21: 30$ & 5,14 & 62,52 & 0,00 & 0,57 & 63,66 & 0,00 \\
\hline 01/03/2012 & 22:00 & 4,55 & 65,86 & 0,00 & 0,53 & 358,80 & 0,00 \\
\hline 01/03/2012 & $22: 30$ & 4,35 & 65,88 & 0,00 & 0,75 & 350,40 & 0,00 \\
\hline 01/03/2012 & 23:00 & 4,66 & 66,72 & 0,00 & 1,75 & 58,90 & 0,00 \\
\hline 01/03/2012 & 23:30 & 4,97 & 64,26 & 0,00 & 0,59 & 31,55 & 0,00 \\
\hline 01/03/2012 & $24: 00$ & 3,46 & 69,39 & 0,00 & 1,01 & 313,10 & 0,00 \\
\hline
\end{tabular}




\section{A.1.2 Datos de irradiación solar SIAR en Mansilla Mayor (León)}

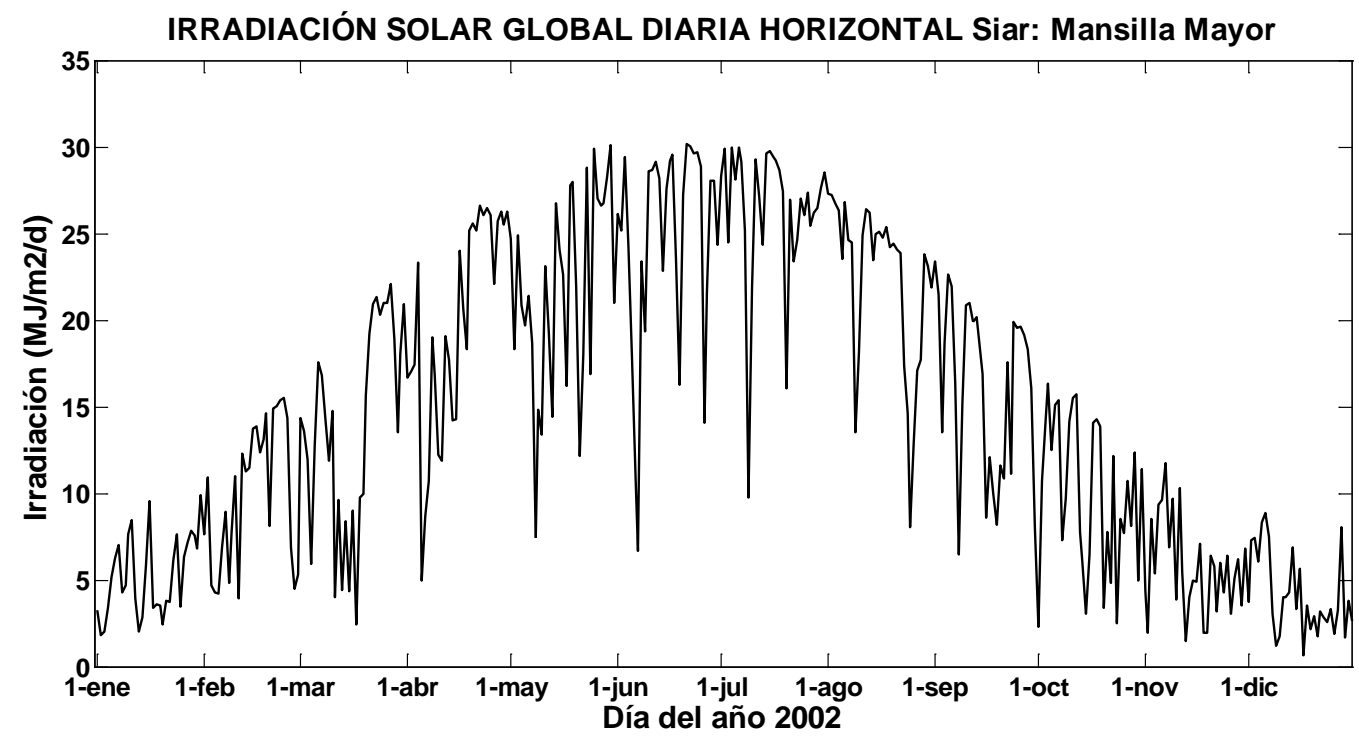

Fig. A.1.3 Datos de la irradiación solar global diaria horizontal de la estación SIAR en Mansilla Mayor (León) del año 2002

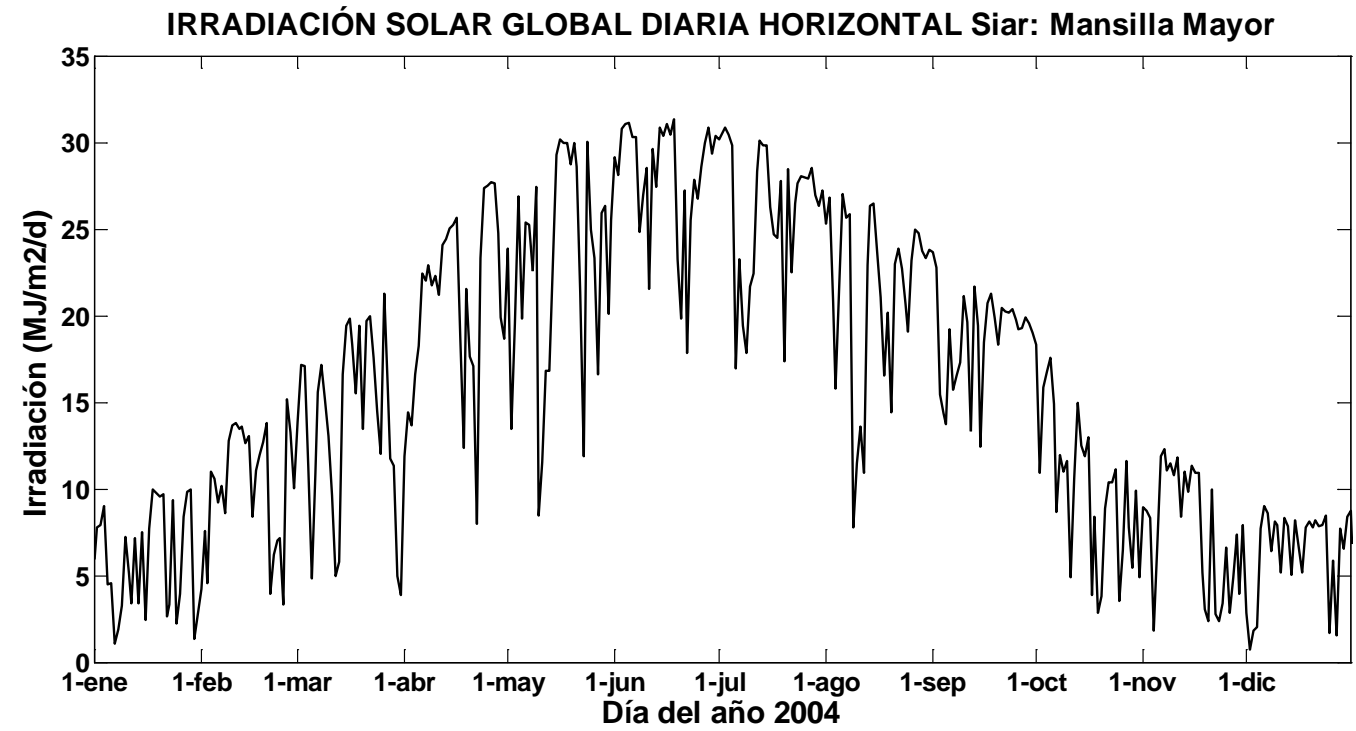

Fig. A.1.4 Datos de la irradiación solar global diaria horizontal de la estación SIAR en Mansilla Mayor (León) del año 2004 


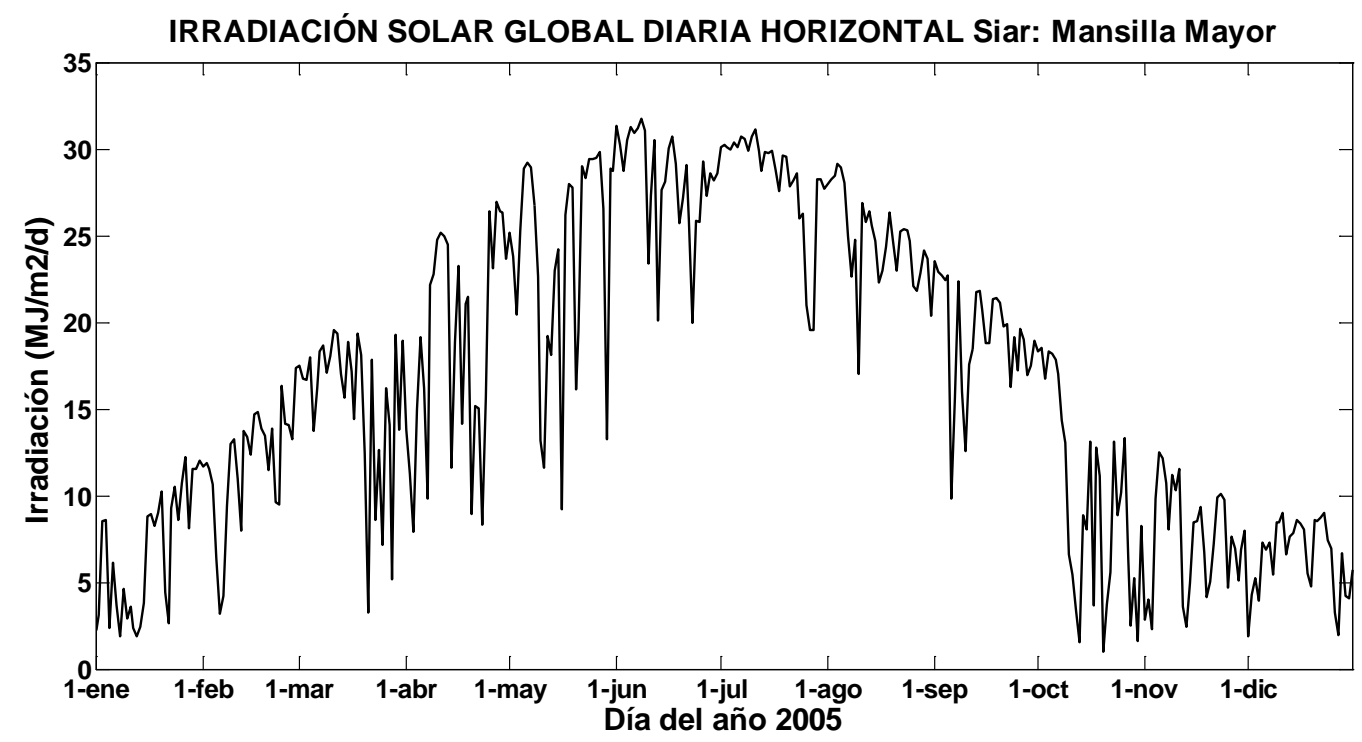

Fig. A.1.5 Datos de la irradiación solar global diaria horizontal de la estación SIAR en Mansilla Mayor (León) del año 2005

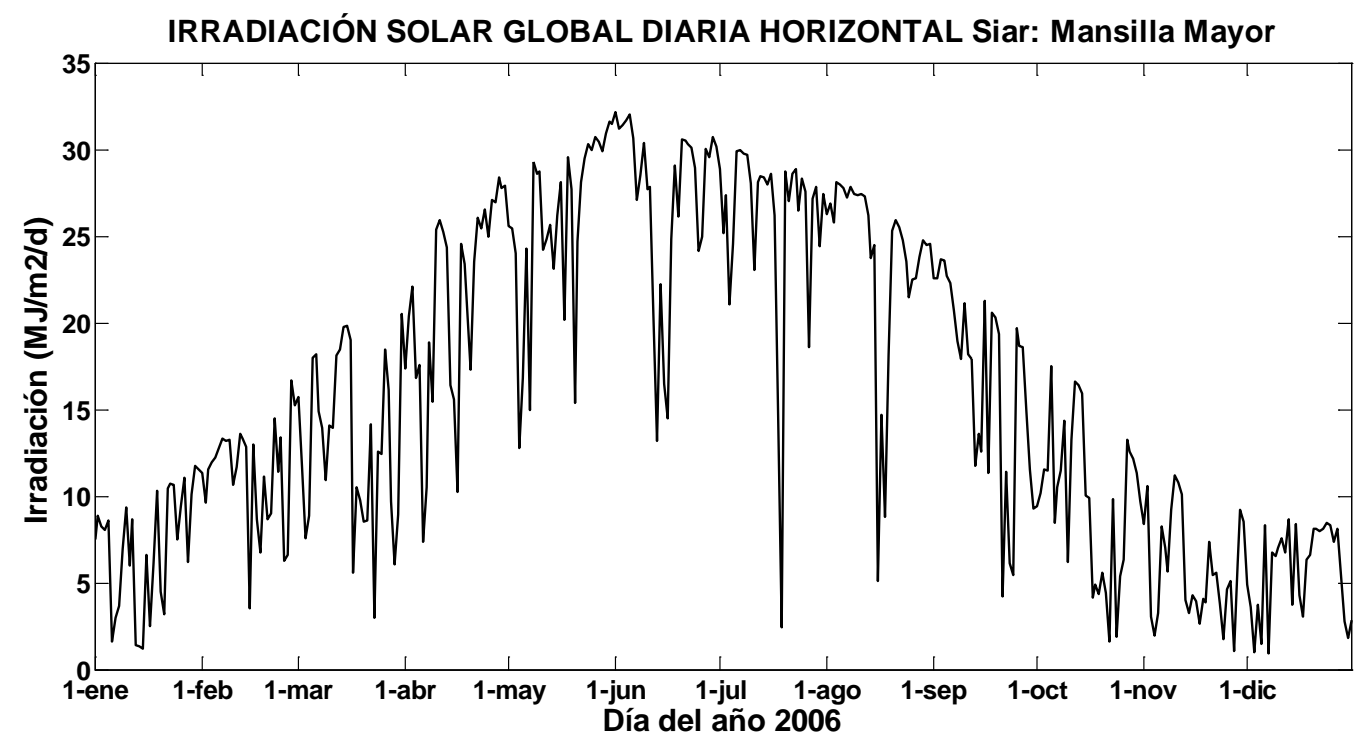

Fig. A.1.6 Datos de la irradiación solar global diaria horizontal de la estación SIAR en Mansilla Mayor (León) del año 2006 


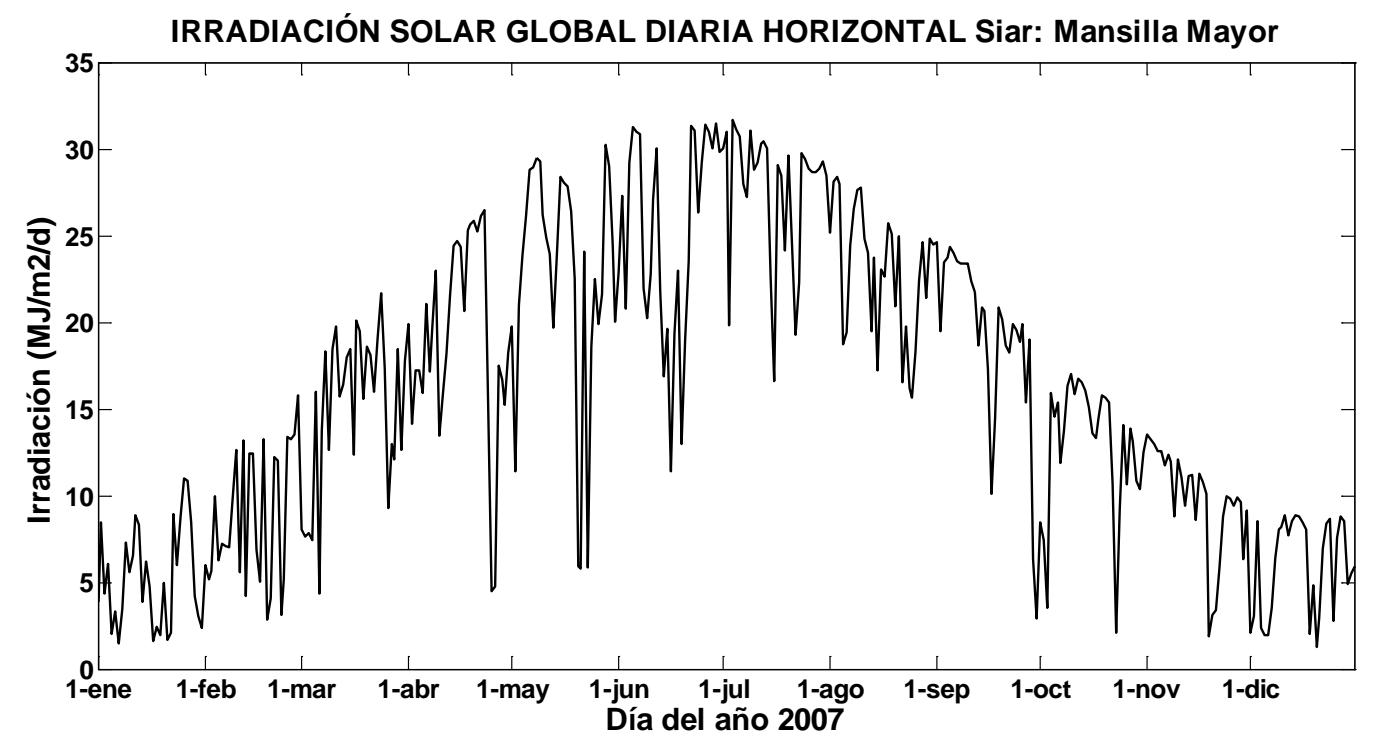

Fig. A.1.7 Datos de la irradiación solar global diaria horizontal de la estación SIAR en Mansilla Mayor (León) del año 2007

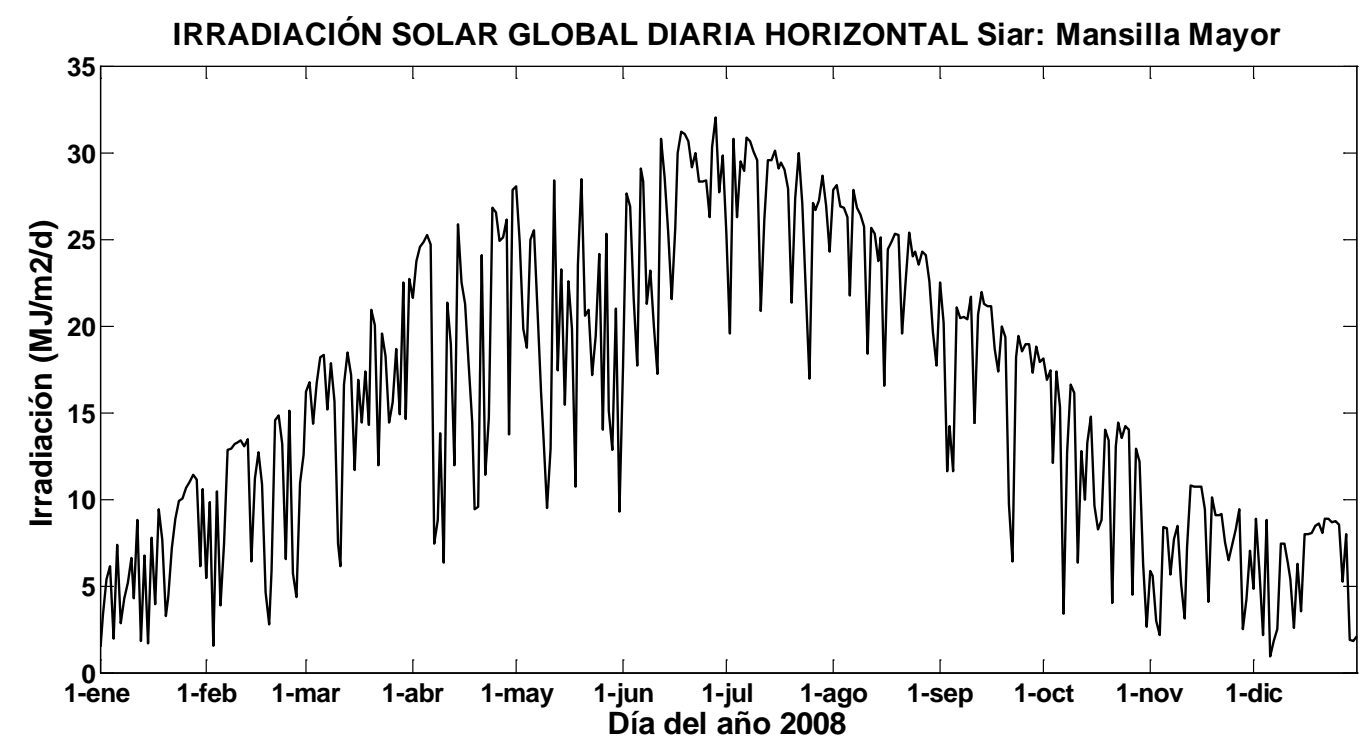

Fig. A.1.8 Datos de la irradiación solar global diaria horizontal de la estación SIAR en Mansilla Mayor (León) del año 2008 


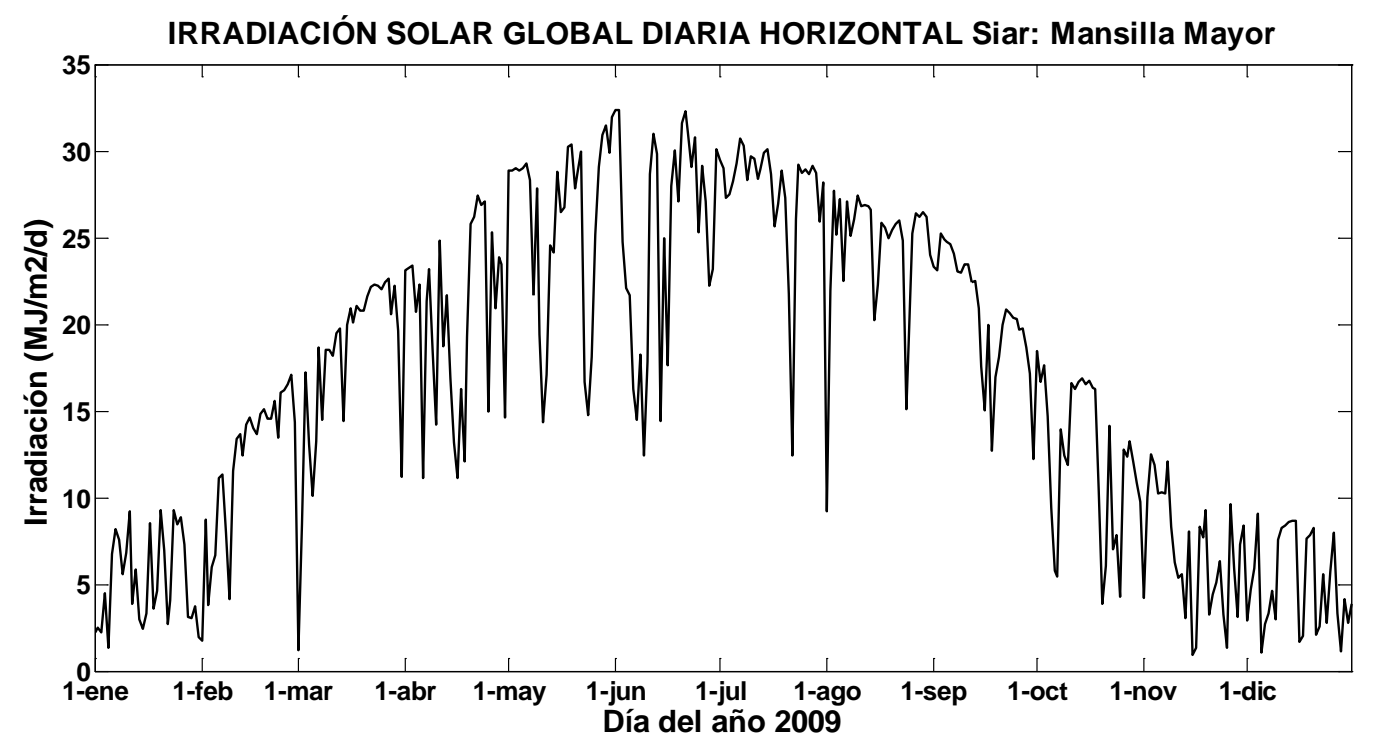

Fig. A.1.9 Datos de la irradiación solar global diaria horizontal de la estación SIAR en Mansilla Mayor (León) del año 2009

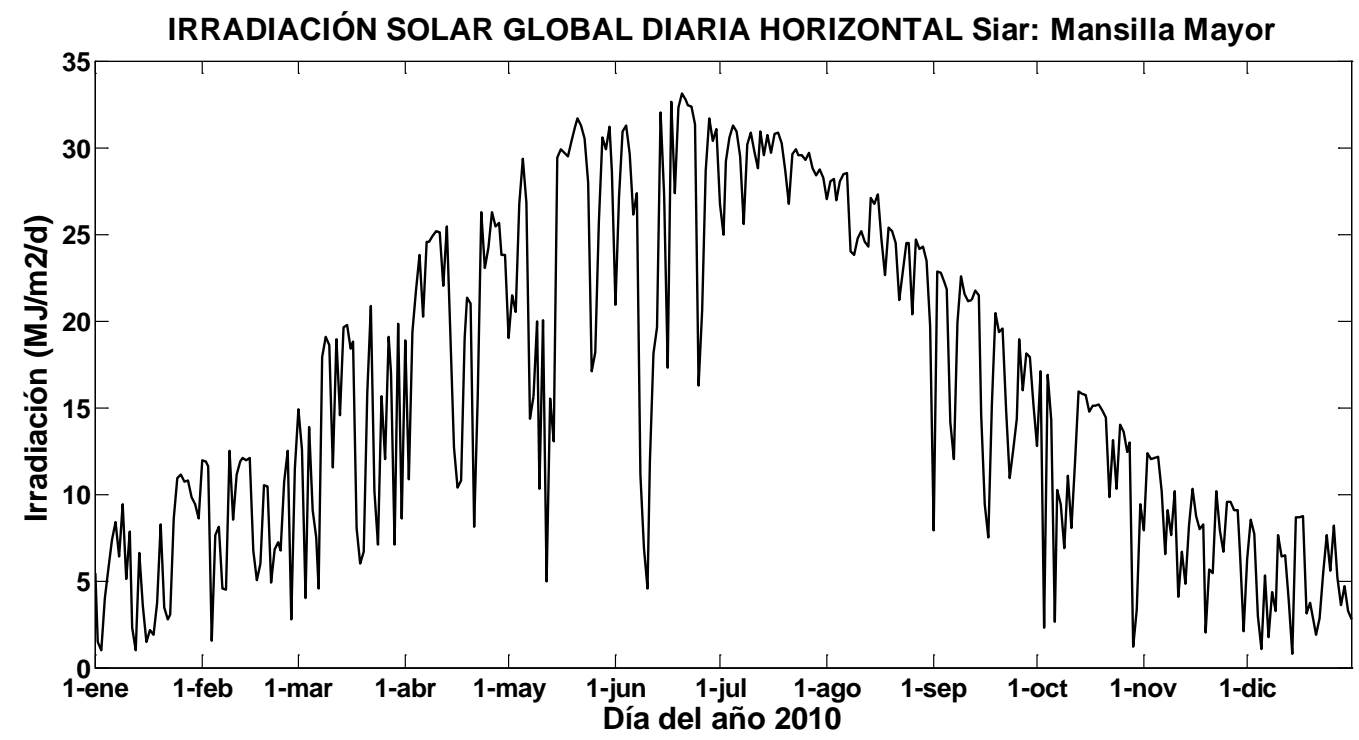

Fig. A.1.10 Datos de la irradiación solar global diaria horizontal de la estación SIAR en Mansilla Mayor (León) del año 2010 


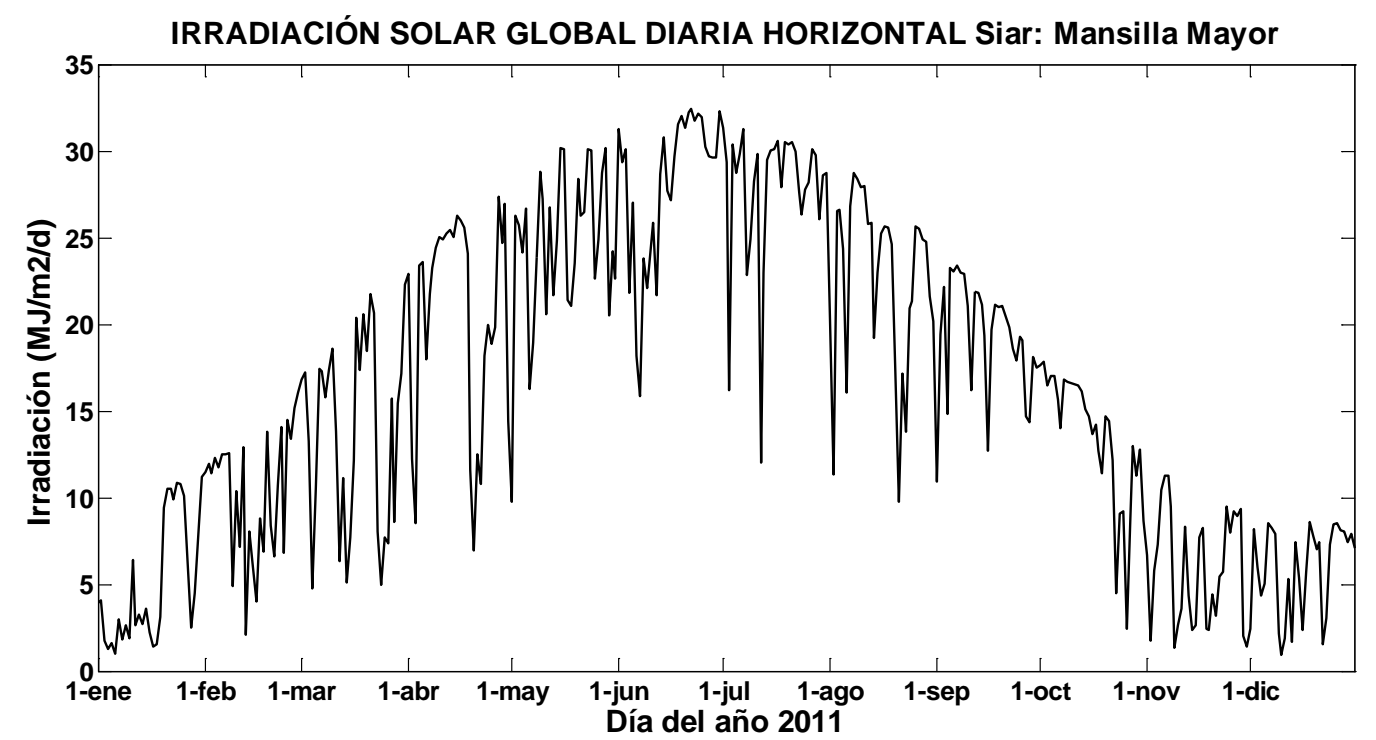

Fig. A.1.11 Datos de la irradiación solar global diaria horizontal de la estación SIAR en Mansilla Mayor (León) del año 2011

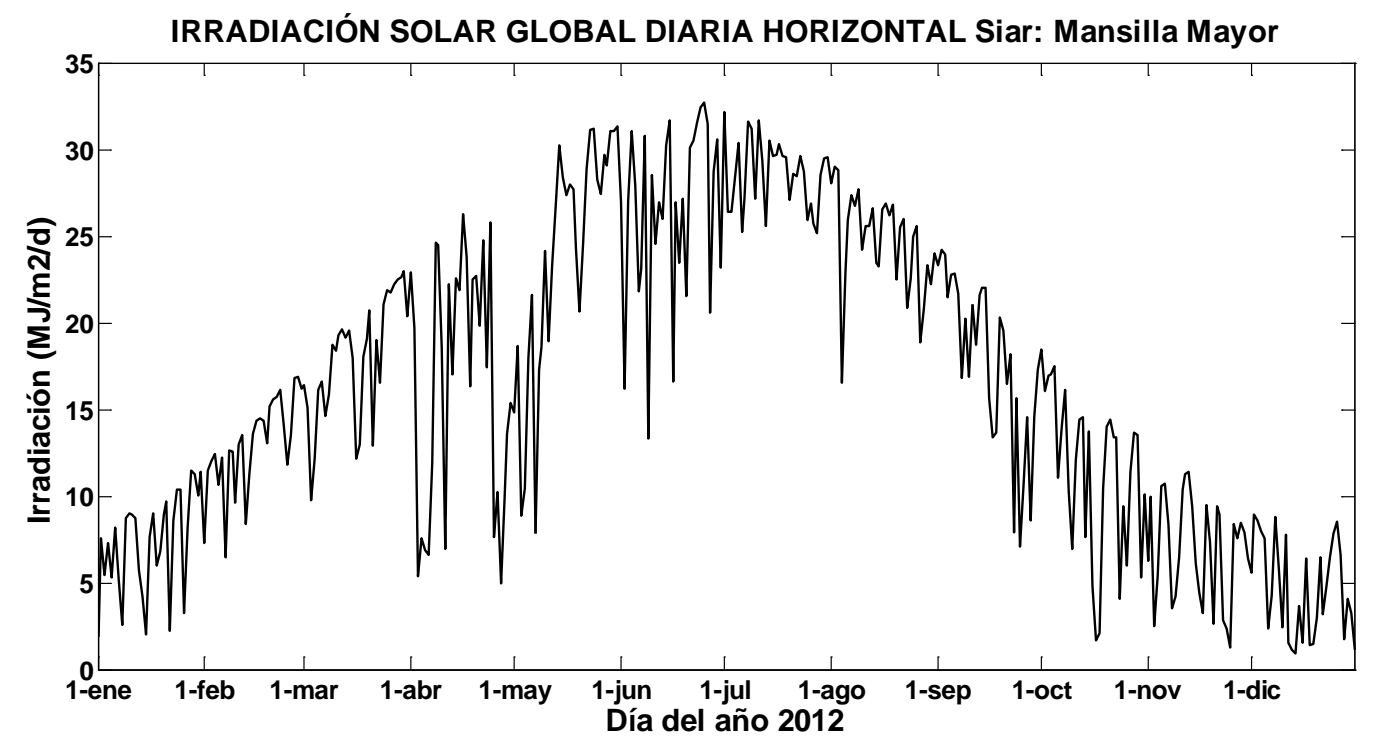

Fig. A.1.12 Datos de la irradiación solar global diaria horizontal de la estación SIAR en Mansilla Mayor (León) del año 2012 
La base de datos SIAR también dispone de los datos de irradiancia solar horizontal cada media hora.

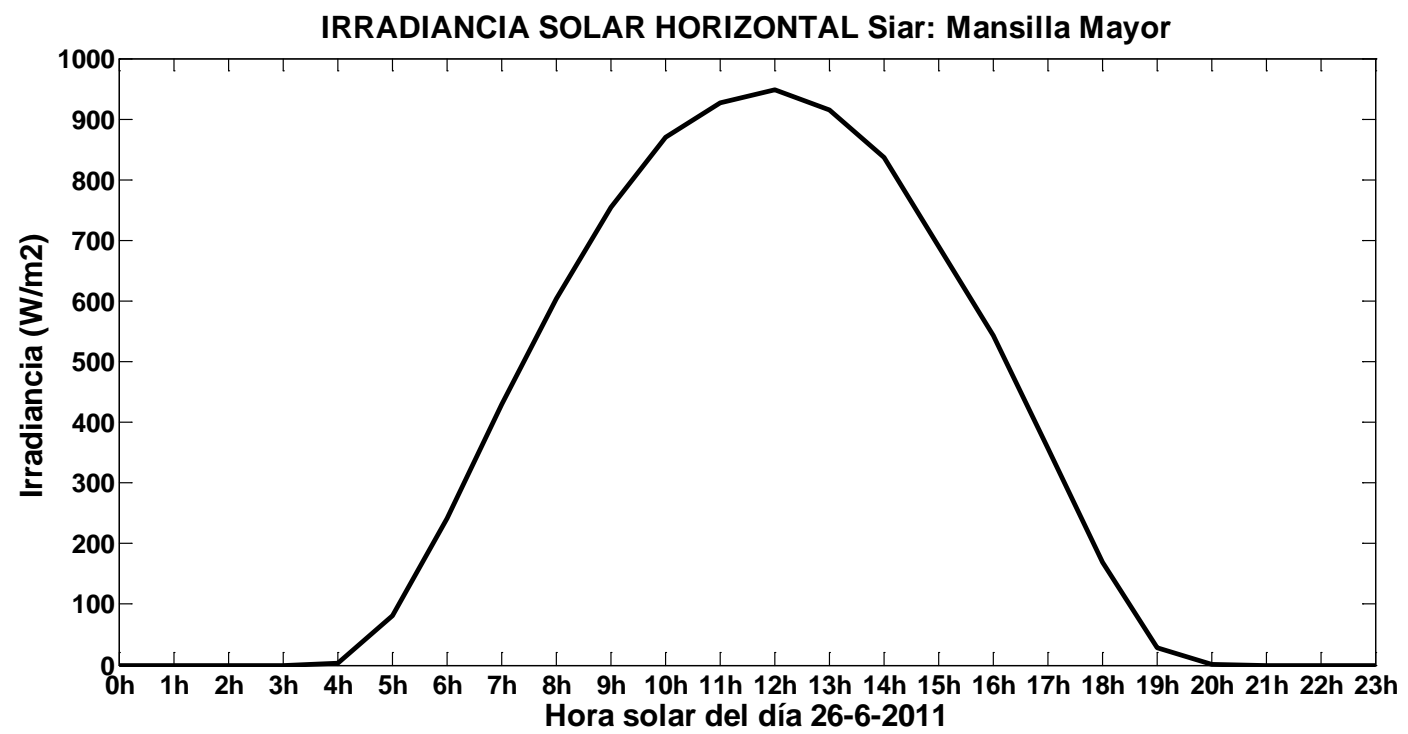

Fig. A.1.13 Datos de la irradiancia solar horizontal de la estación SIAR en Mansilla Mayor (León) del día 26-6-2011 


\section{A.1.3 Datos de temperatura ambiente SIAR en Mansilla Mayor (León)}

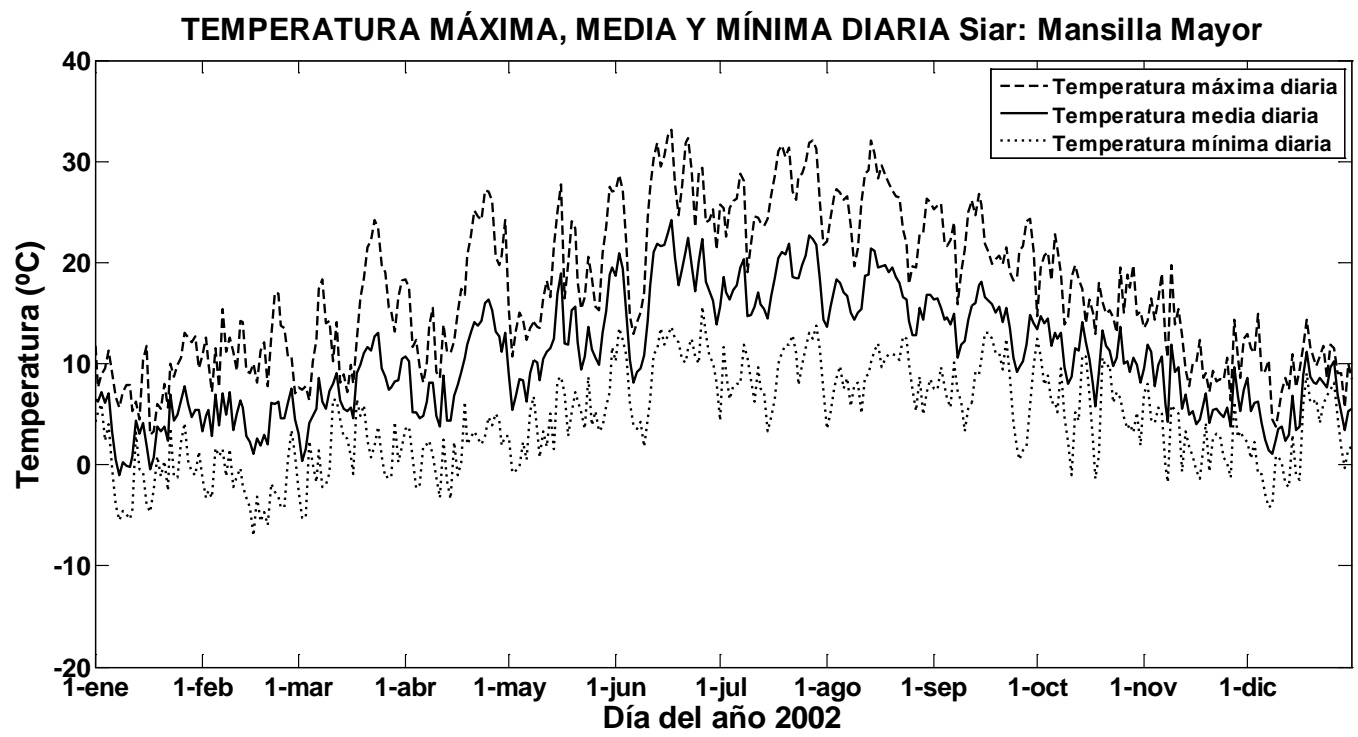

Fig. A.1.14 Datos de la temperatura máxima, media y mínima diaria de la estación SIAR en Mansilla Mayor (León) del año 2002

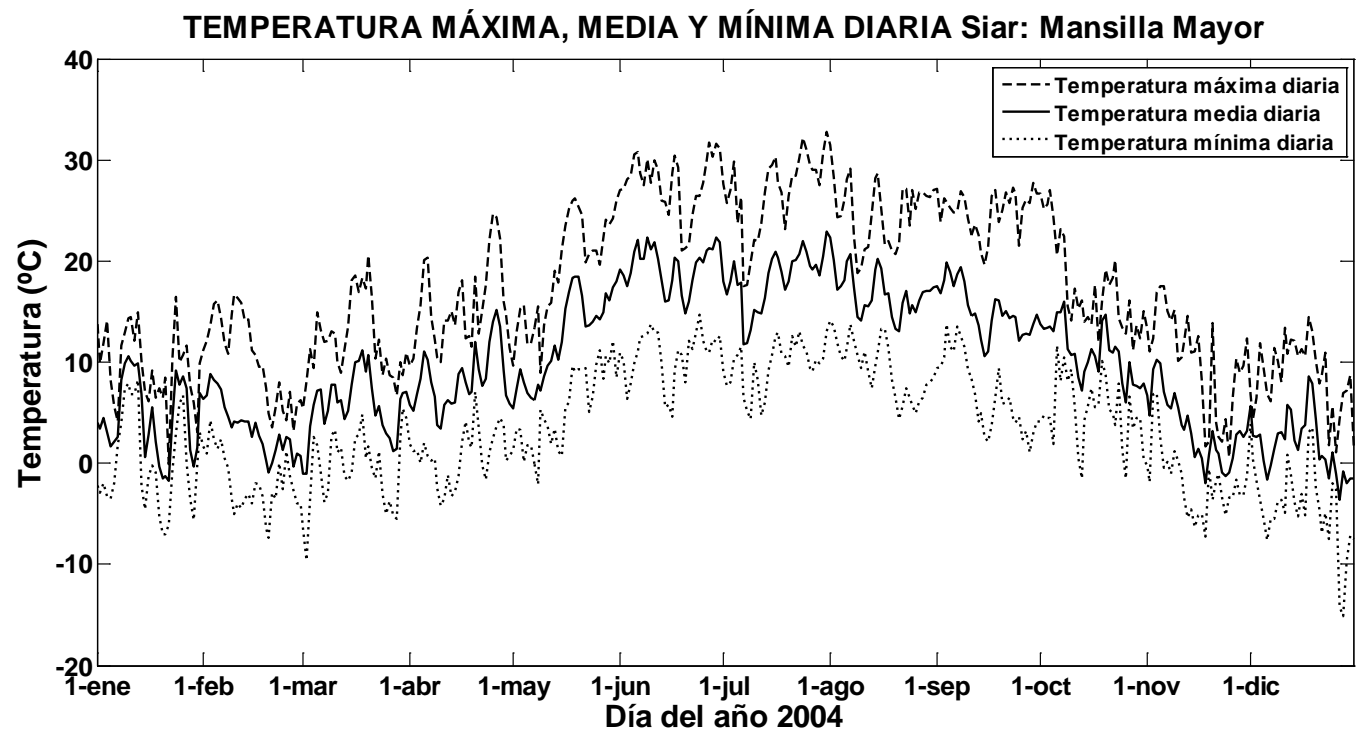

Fig. A.1.15 Datos de la temperatura máxima, media y mínima diaria de la estación SIAR en Mansilla Mayor (León) del año 2004 


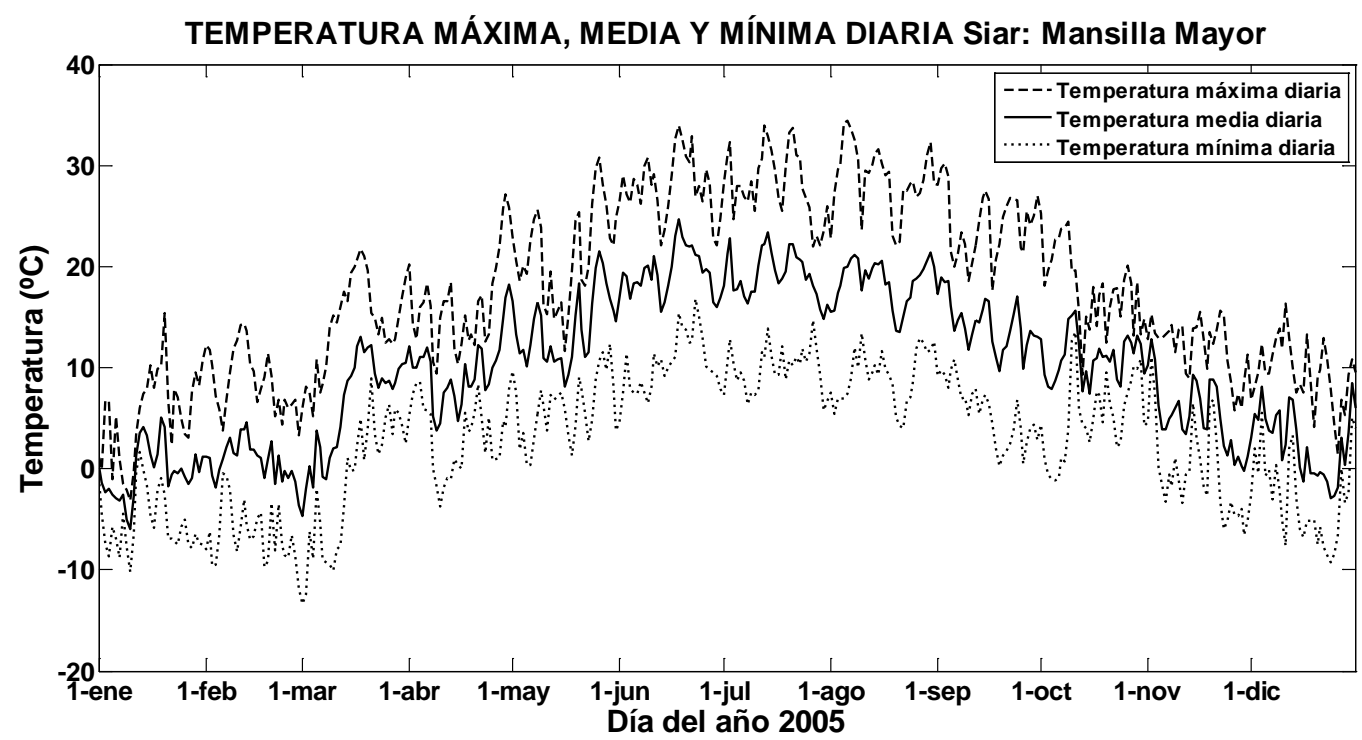

Fig. A.1.16 Datos de la temperatura máxima, media y mínima diaria de la estación SIAR en Mansilla Mayor (León) del año 2005

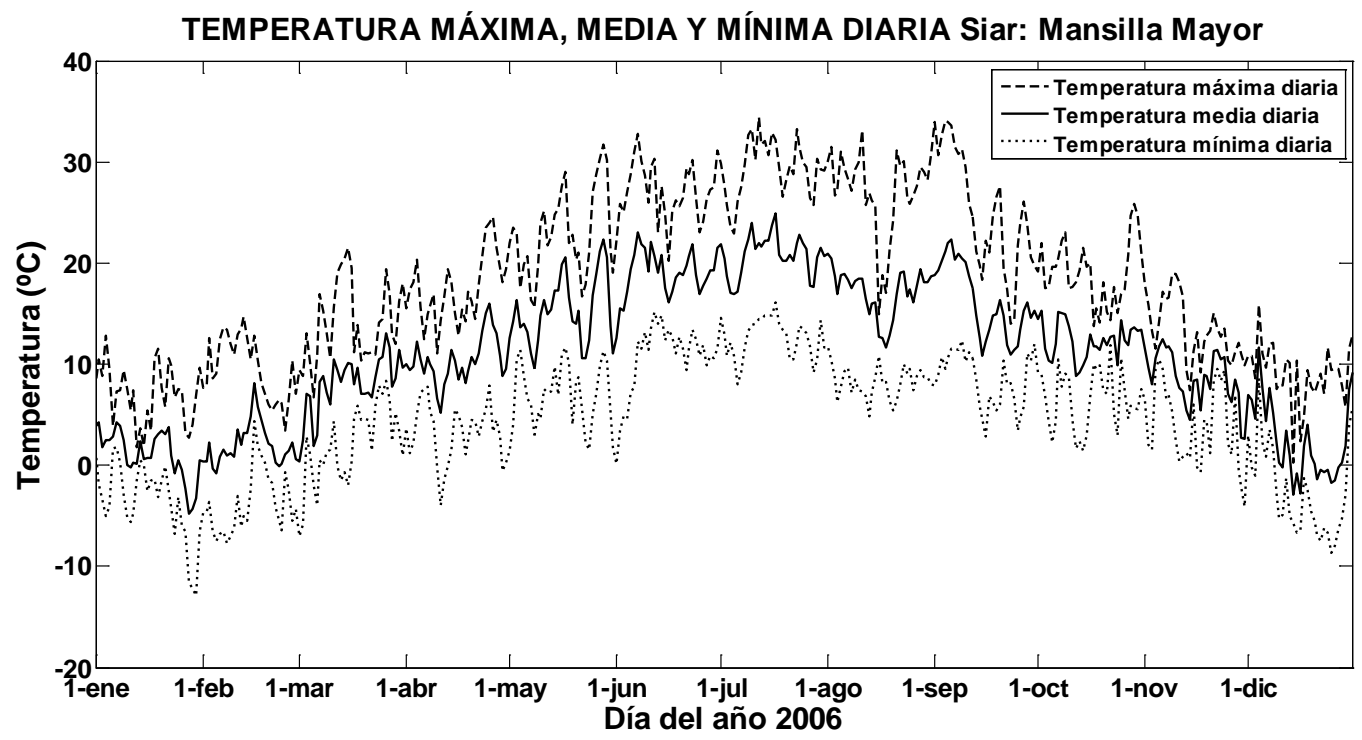

Fig. A.1.17 Datos de la temperatura máxima, media y mínima diaria de la estación SIAR en Mansilla Mayor (León) del año 2006 


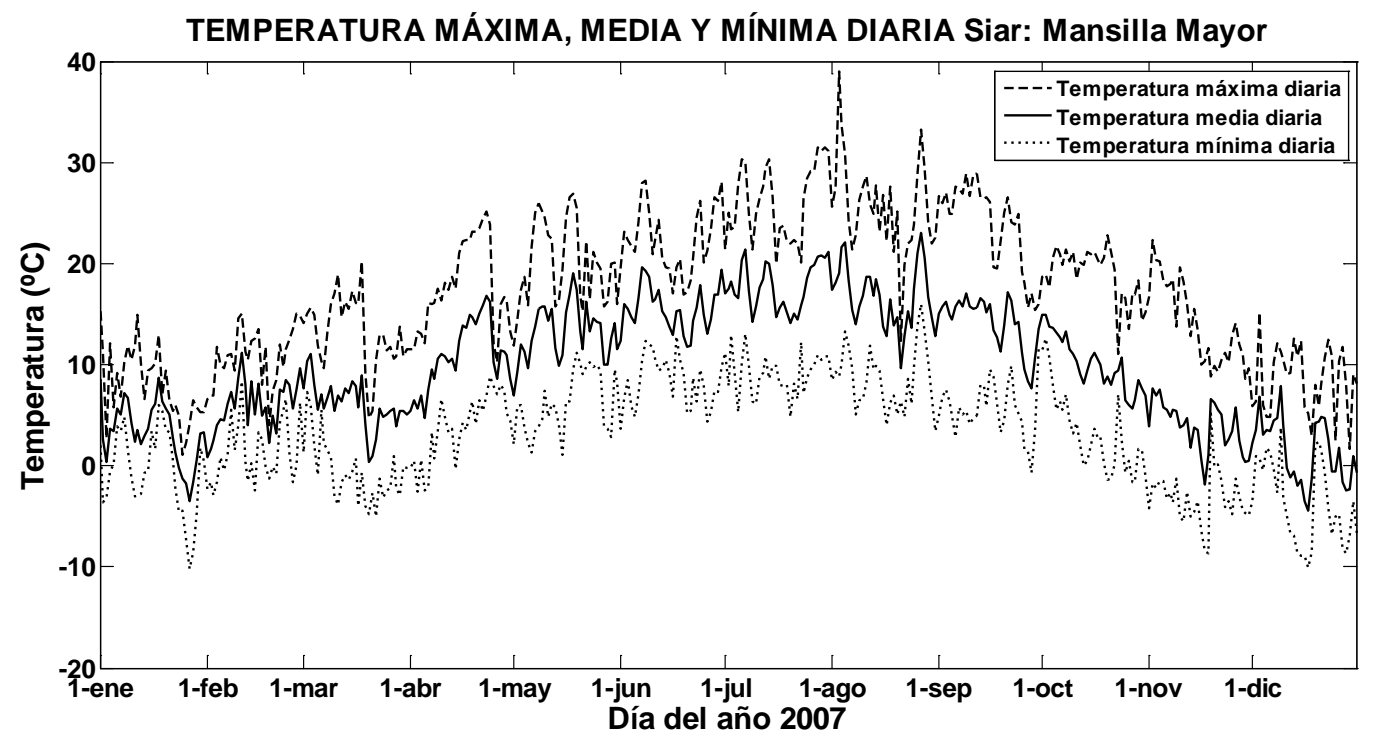

Fig. A.1.18 Datos de la temperatura máxima, media y mínima diaria de la estación SIAR en Mansilla Mayor (León) del año 2007

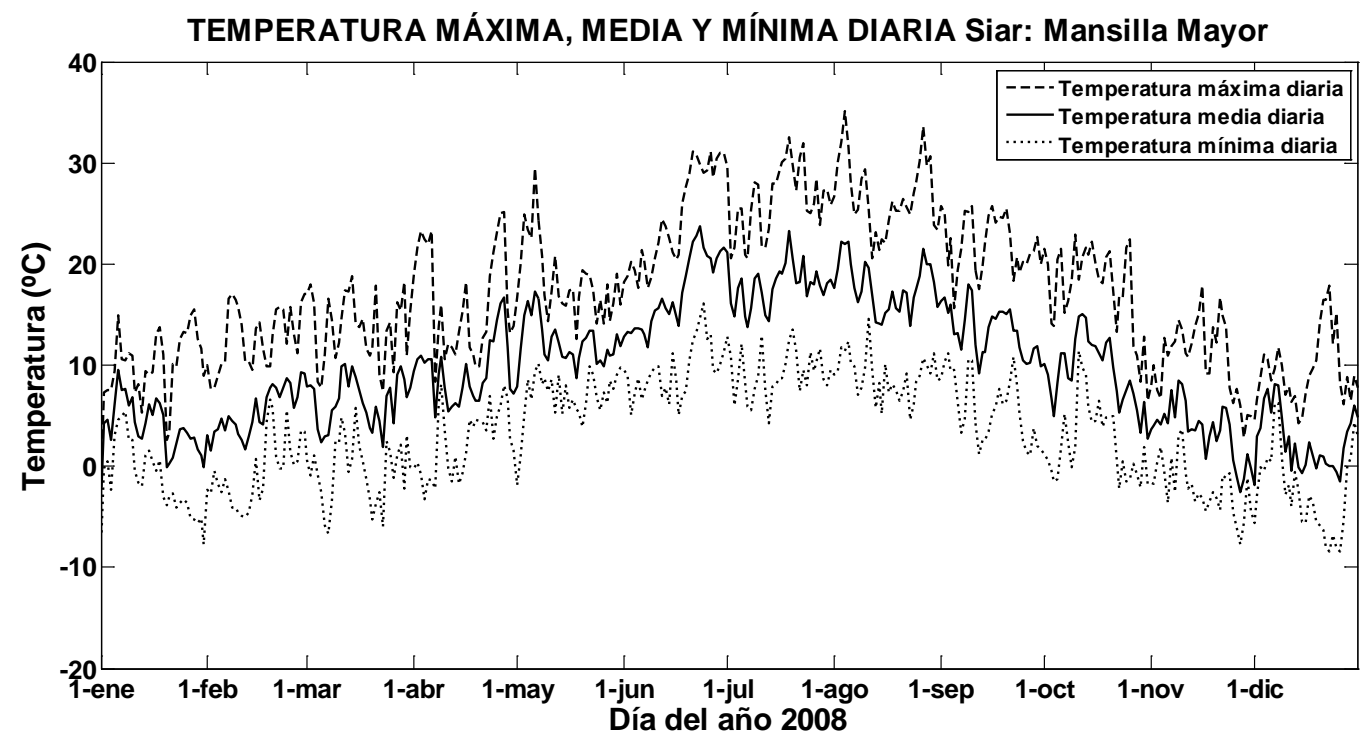

Fig. A.1.19 Datos de la temperatura máxima, media y mínima diaria de la estación SIAR en Mansilla Mayor (León) del año 2008 
TEMPERATURA MÁXIMA, MEDIA Y MÍNIMA DIARIA Siar: Mansilla Mayor

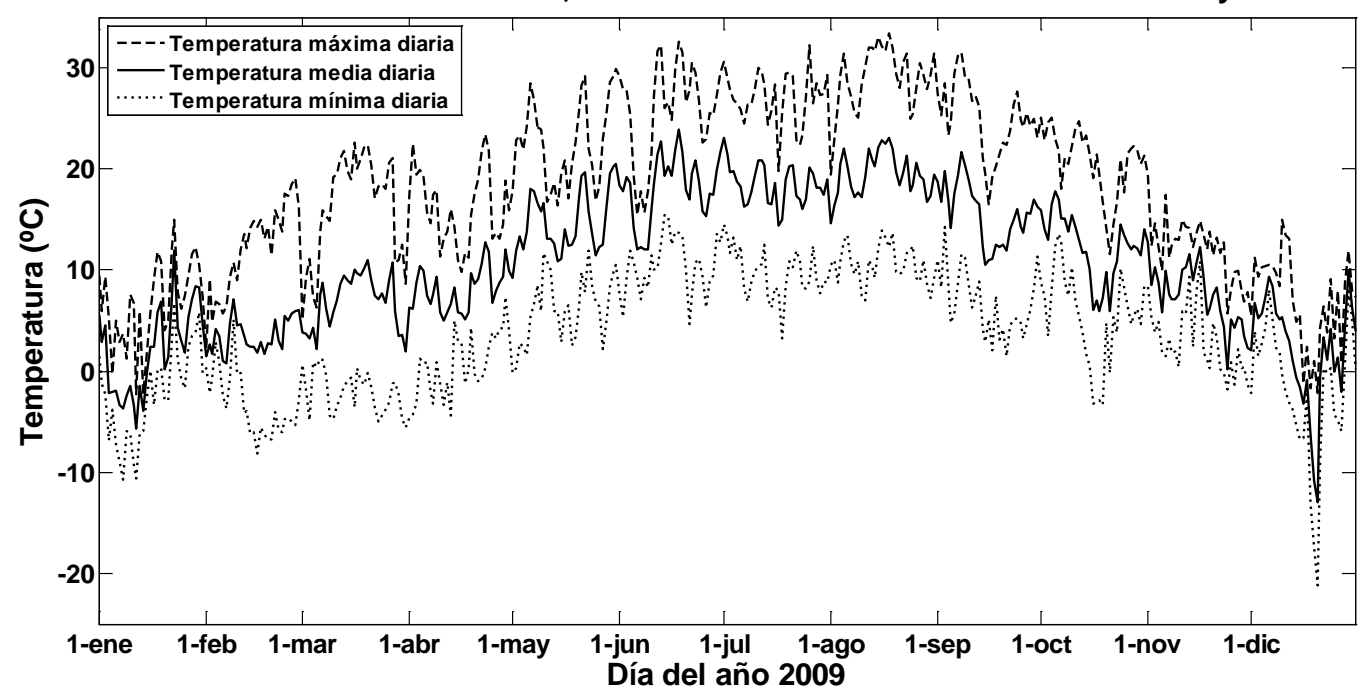

Fig. A.1.20 Datos de la temperatura máxima, media y mínima diaria de la estación SIAR en Mansilla Mayor (León) del año 2009

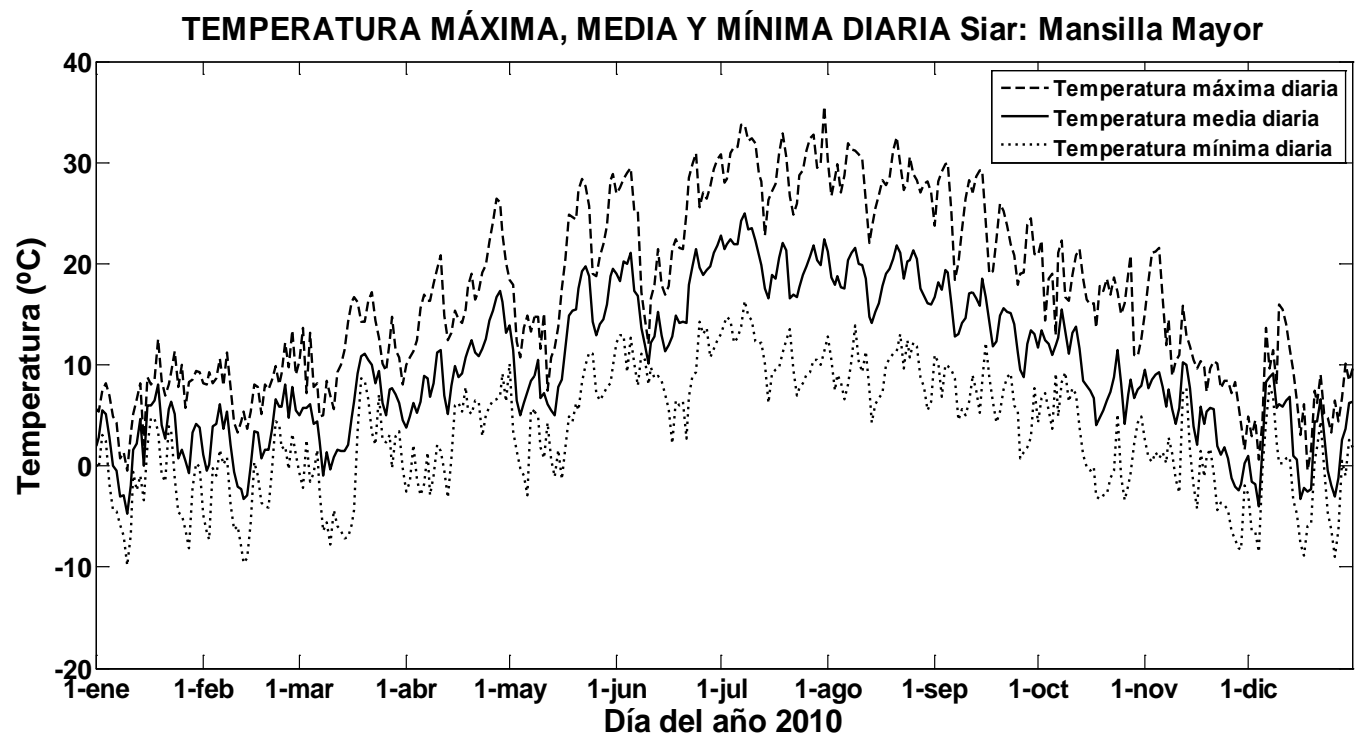

Fig. A.1.21 Datos de la temperatura máxima, media y mínima diaria de la estación SIAR en Mansilla Mayor (León) del año 2010 


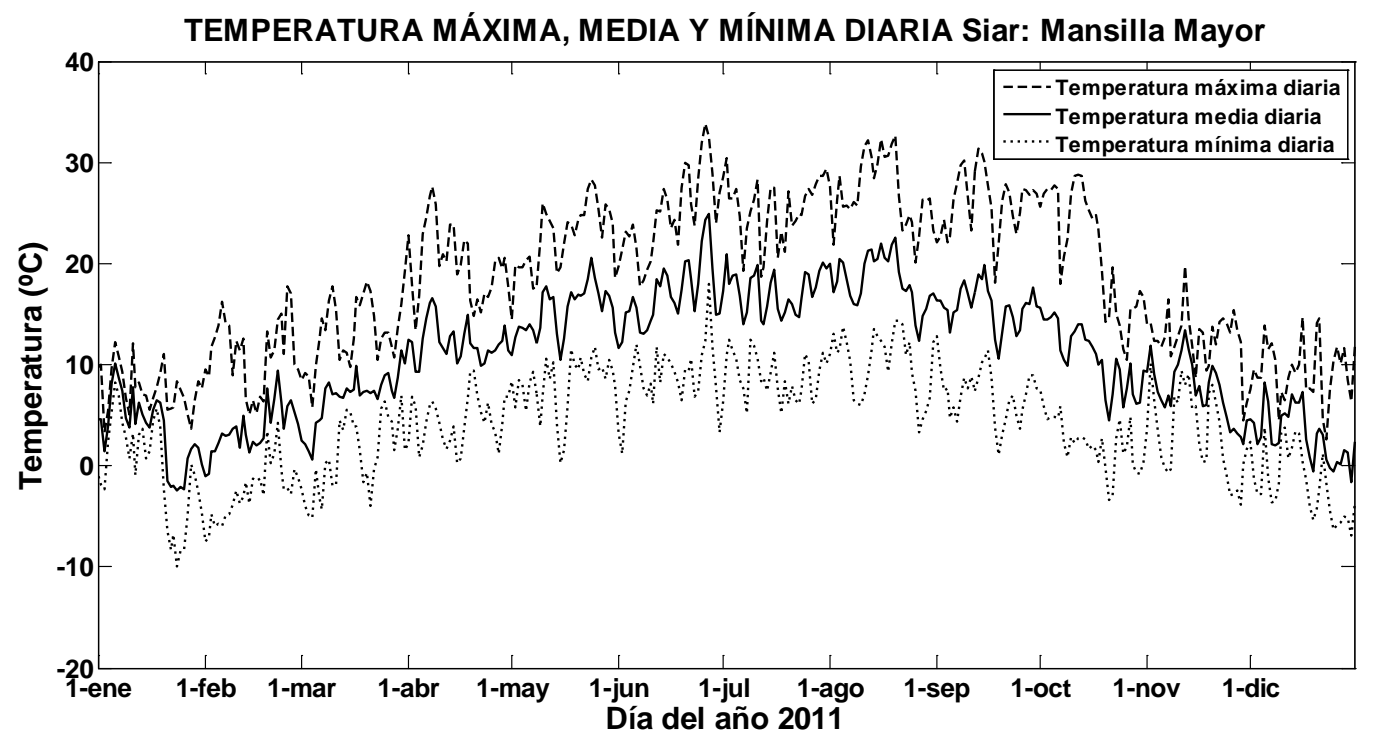

Fig. A.1.22 Datos de la temperatura máxima, media y mínima diaria de la estación SIAR en Mansilla Mayor (León) del año 2011

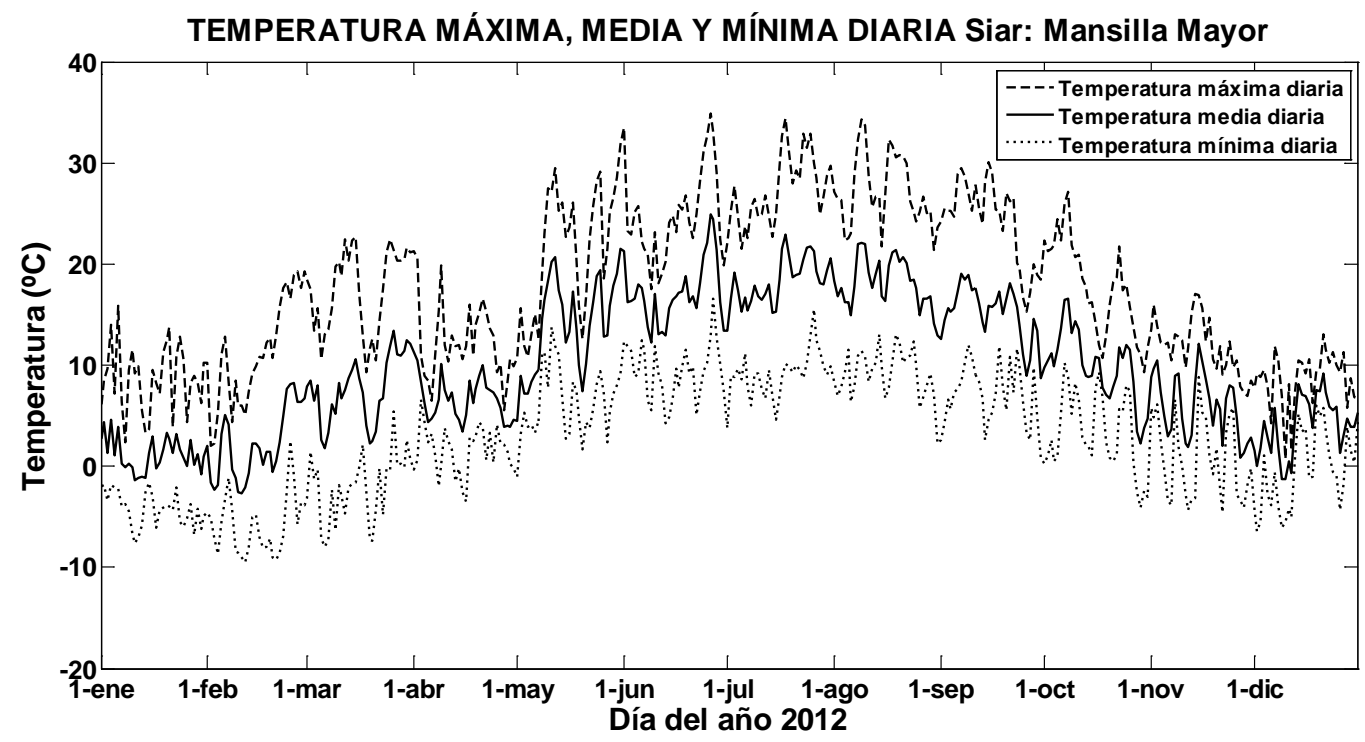

Fig. A.1.23 Datos de la temperatura máxima, media y mínima diaria de la estación SIAR en Mansilla Mayor (León) del año 2012 
La base de datos SIAR también dispone de los datos de temperatura ambiente media cada media hora.

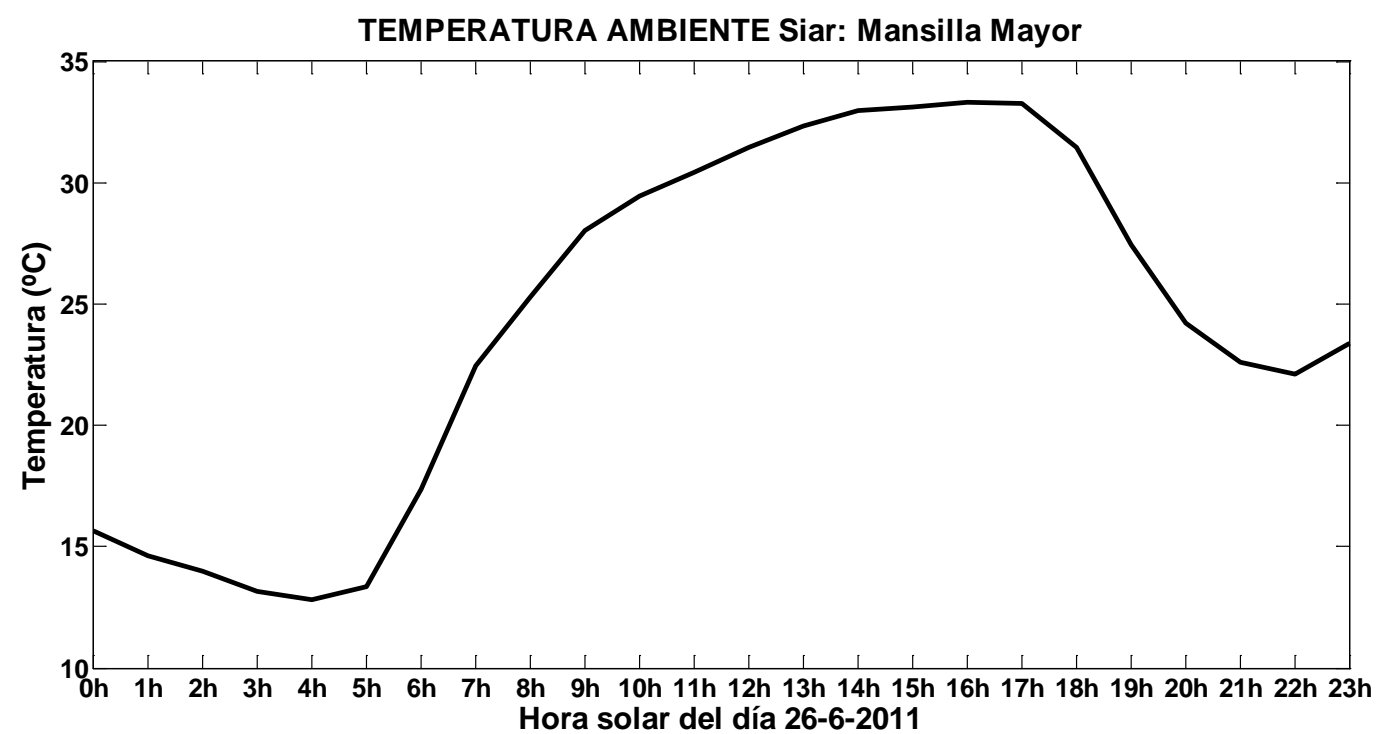

Fig. A.1.24 Datos de la temperatura ambiente media de la estación SIAR en Mansilla Mayor (León) del día 26-6-2011 


\section{A.1.4 Datos de irradiación solar CENSOLAR en León}

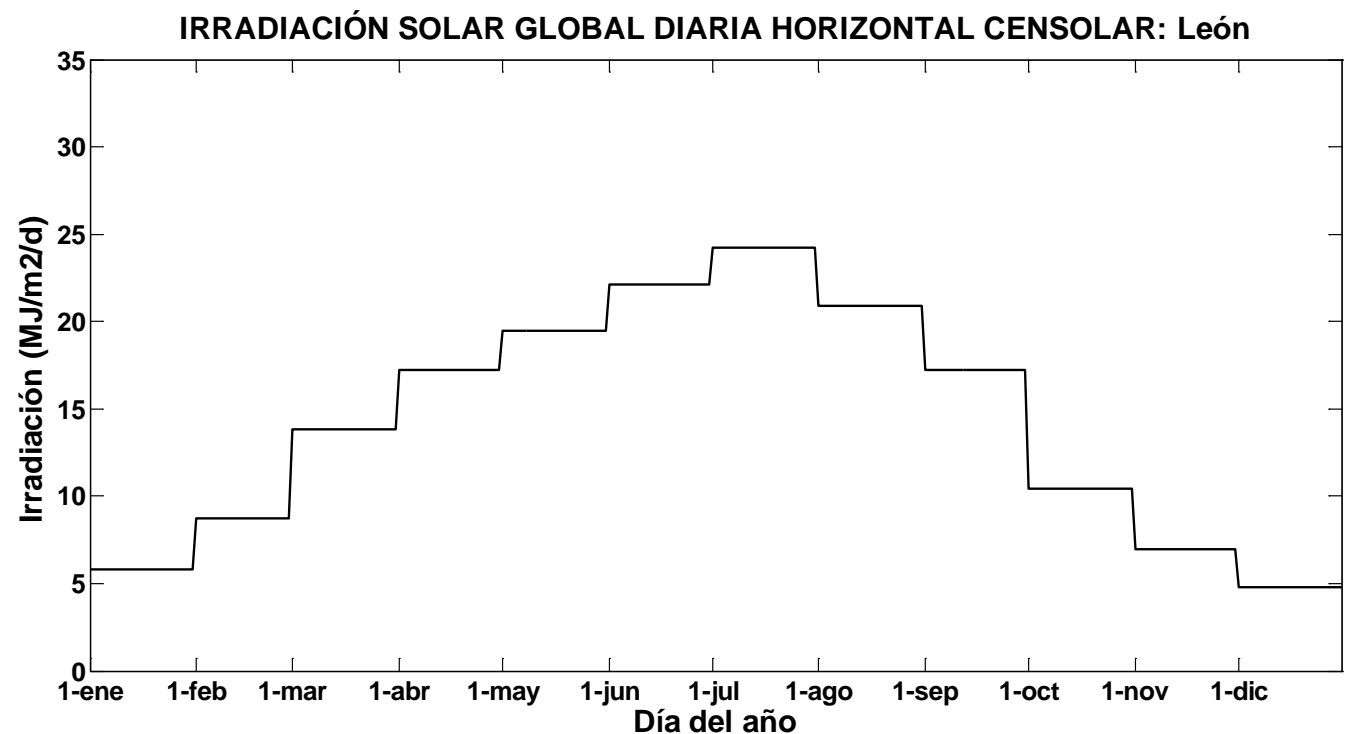

Fig. A.1.25 Datos de la irradiación solar global diaria horizontal CENSOLAR en la provincia de León

\section{A.1.5 Datos de temperatura ambiente CENSOLAR en León}

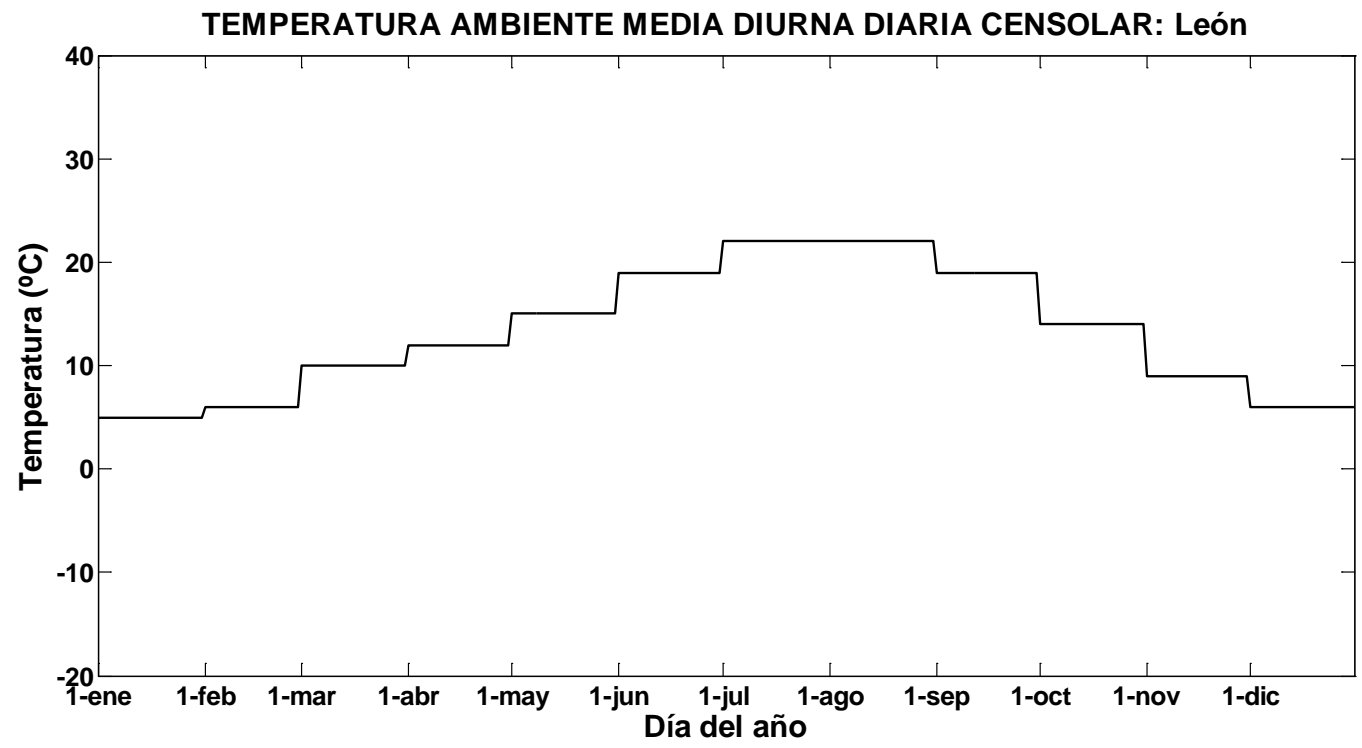

Fig. A.1.26 Datos de la temperatura ambiente media durante las horas de sol CENSOLAR en la provincia de León 



\section{Anexo 2}

\section{DATOS DE LOS ENSAYOS EN LA PLANTA PILOTO}

A.2.1 Datos del ensayo en la planta piloto del día: 1-7-2011

A.2.2 Datos del ensayo en la planta piloto del día: 4-7-2011

A.2.3 Datos del ensayo en la planta piloto del día: 29-8-2011

A.2.4 Datos del ensayo en la planta piloto del día: 7-9-2011

A.2.5 Datos del ensayo en la planta piloto del día: 21-9-2011

A.2.6 Datos del ensayo en la planta piloto del día: 4-10-2011

A.2.7 Datos del ensayo en la planta piloto del día: 6-10-2011

A.2.8 Datos del ensayo en la planta piloto del día: 10-10-2011

A.2.9 Datos del ensayo en la planta piloto del día: 7-11-2011

A.2.10 Datos del ensayo en la planta piloto del día: 28-11-2011

A.2.11 Datos del ensayo en la planta piloto del día: 9-3-2012

En este anexo se presentan los datos registrados relativos a la irradiancia solar incidente sobre el captador solar, la temperatura ambiente, la temperatura de ida y retorno del fluido portador al captador solar, las temperaturas de estratificación en 8 capas en las que se ha dividido el depósito acumulador, el caudal y temperatura del agua de red que entra en el depósito, la temperatura y volumen de agua caliente solar que se extrae del depósito y el caudal del fluido portador. Durante 11 ensayos diarios en la planta piloto de los múltiples realizados a lo largo del año 2011 y 2012, para la realización de esta Tesis Doctoral. 


\section{A.2.1 Datos del ensayo en la planta piloto del día: 1-7-2011}
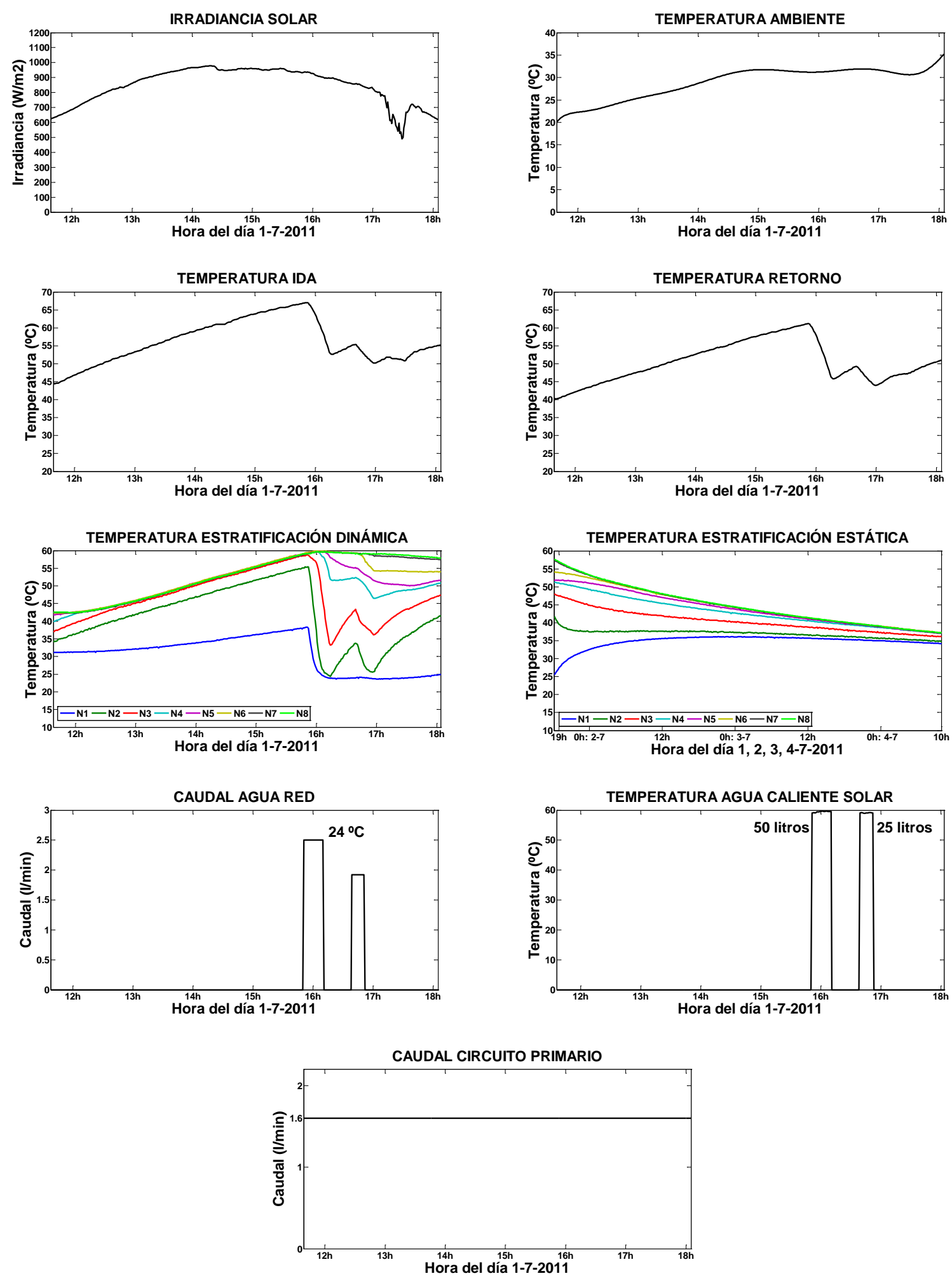

Fig. A.2.1 Datos registrados de la irradiancia solar, la temperatura ambiente, la temperatura de ida, la temperatura de retorno y las temperaturas de estratificación, el caudal del agua de red, la temperatura del agua caliente solar y el caudal del circuito primario en el ensayo de la planta piloto realizado el día 1-7-2011 


\section{A.2.2 Datos del ensayo en la planta piloto del día: 4-7-2011}
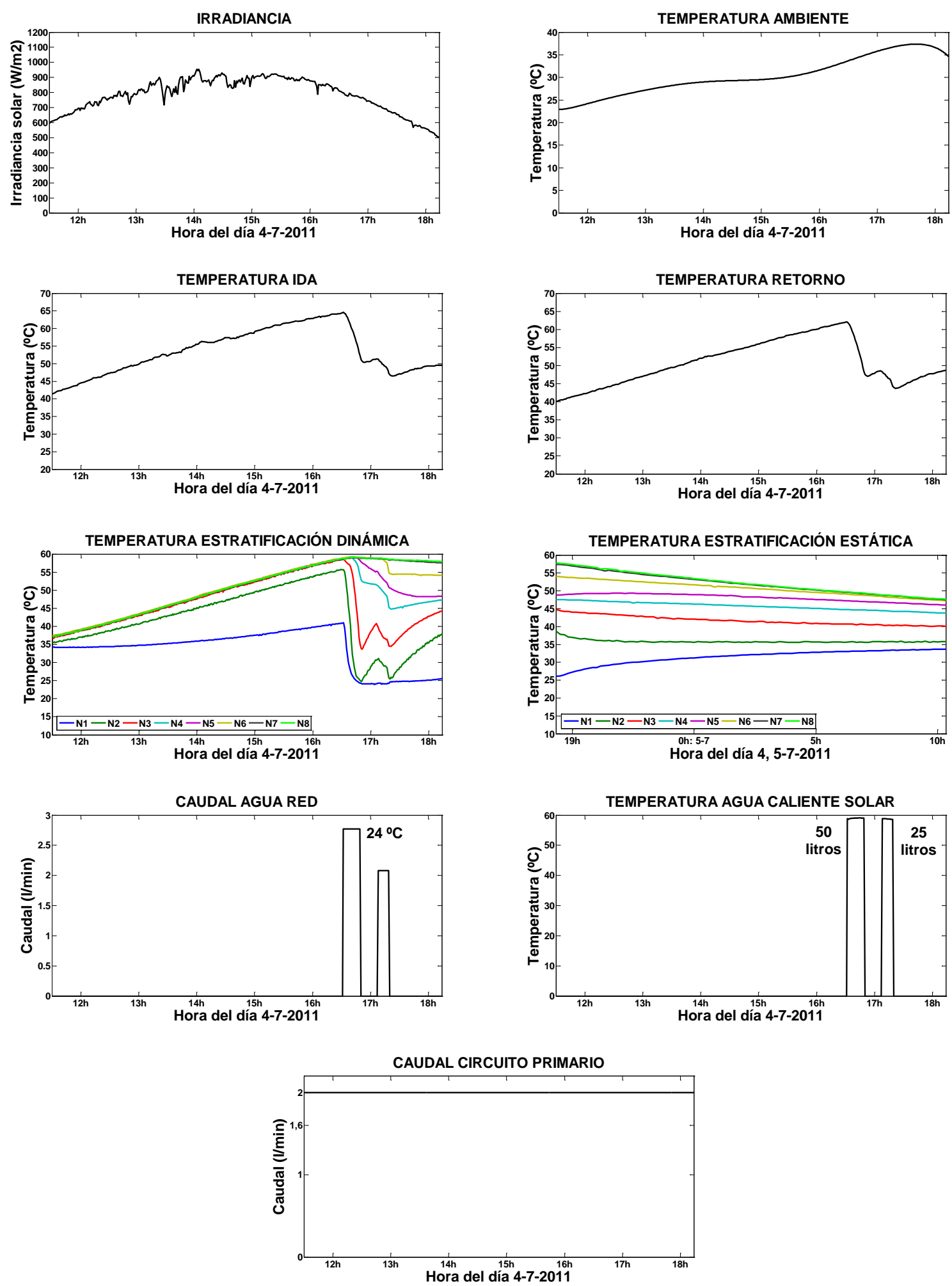

Fig. A.2.2 Datos registrados de la irradiancia solar, la temperatura ambiente, la temperatura de ida, la temperatura de retorno y las temperaturas de estratificación, el caudal del agua de red, la temperatura del agua caliente solar y el caudal del circuito primario en el ensayo de la planta piloto realizado el día 4-7-2011 


\section{A.2.3 Datos del ensayo en la planta piloto del día: 29-8-2011}
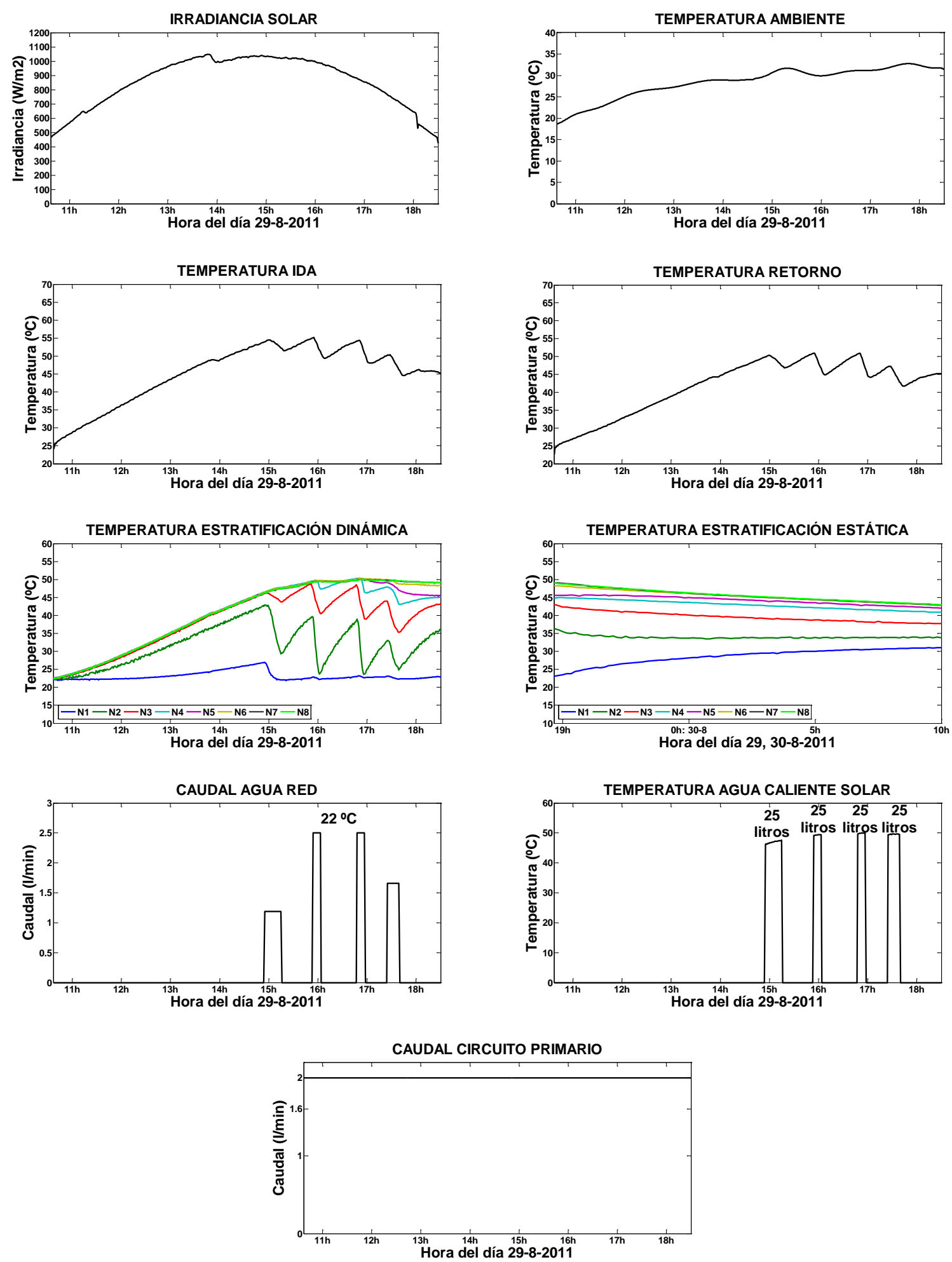

Fig. A.2.3 Datos registrados de la irradiancia solar, la temperatura ambiente, la temperatura de ida, la temperatura de retorno y las temperaturas de estratificación, el caudal del agua de red, la temperatura del agua caliente solar y el caudal del circuito primario en el ensayo de la planta piloto realizado el día 29-8-2011 


\section{A.2.4 Datos del ensayo en la planta piloto del día: 7-9-2011}
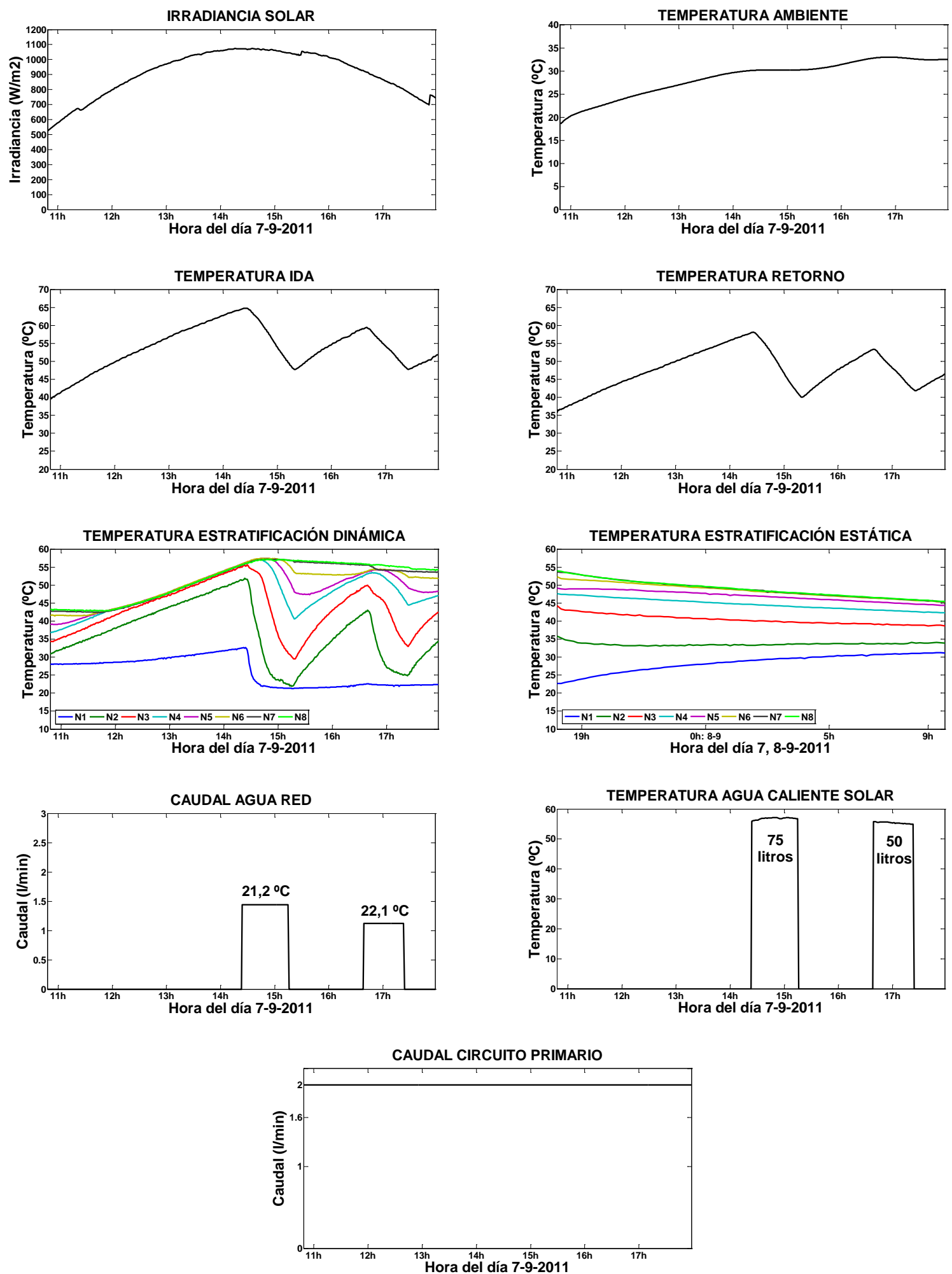

Fig. A.2.4 Datos registrados de la irradiancia solar, la temperatura ambiente, la temperatura de ida, la temperatura de retorno y las temperaturas de estratificación, el caudal del agua de red, la temperatura del agua caliente solar y el caudal del circuito primario en el ensayo de la planta piloto realizado el día 7-9-2011 


\section{A.2.5 Datos del ensayo en la planta piloto del día: 21-9-2011}
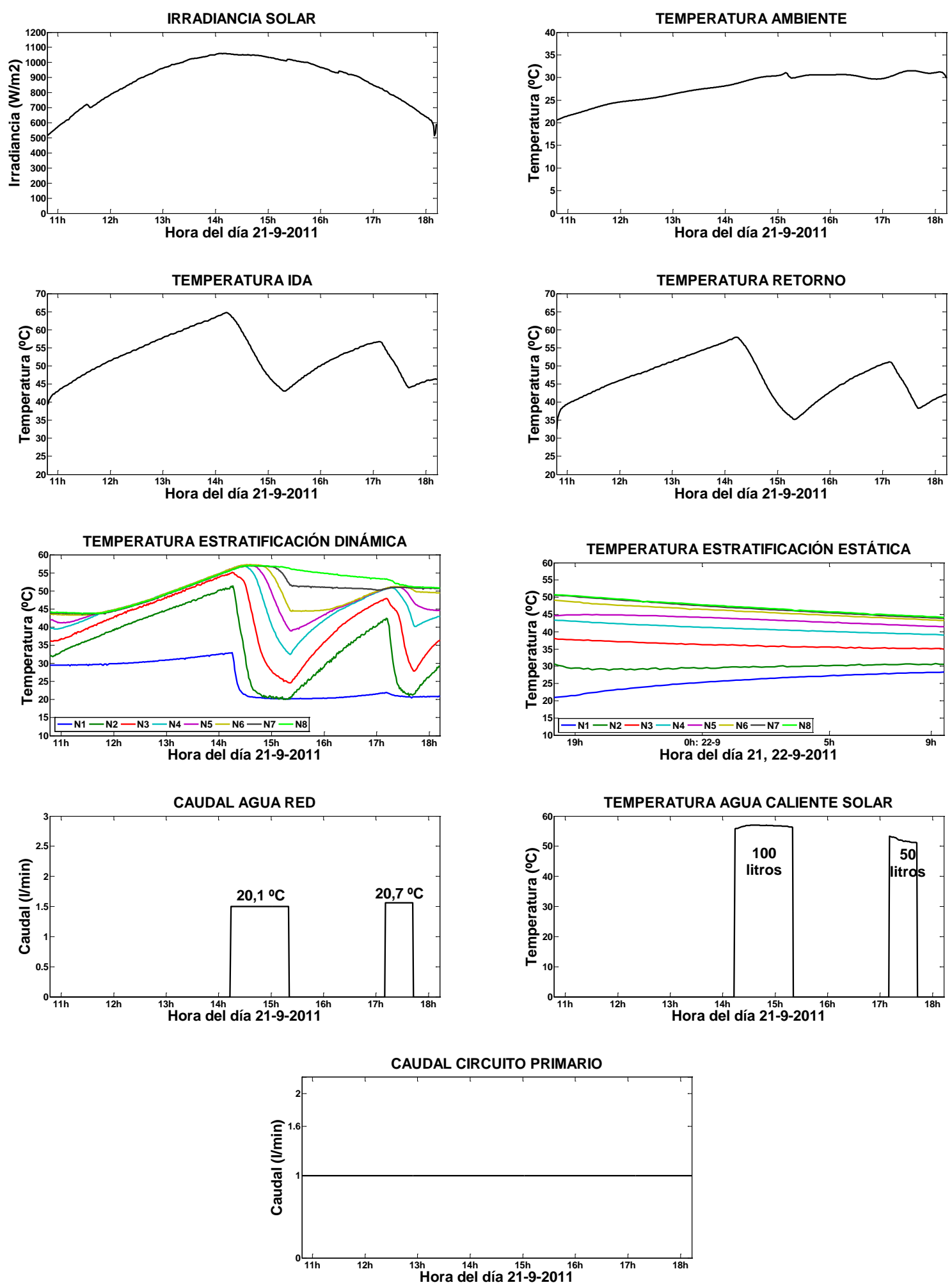

Fig. A.2.5 Datos registrados de la irradiancia solar, la temperatura ambiente, la temperatura de ida, la temperatura de retorno y las temperaturas de estratificación, el caudal del agua de red, la temperatura del agua caliente solar y el caudal del circuito primario en el ensayo de la planta piloto realizado el día 21-9-2011 


\section{A.2.6 Datos del ensayo en la planta piloto del día: 4-10-2011}
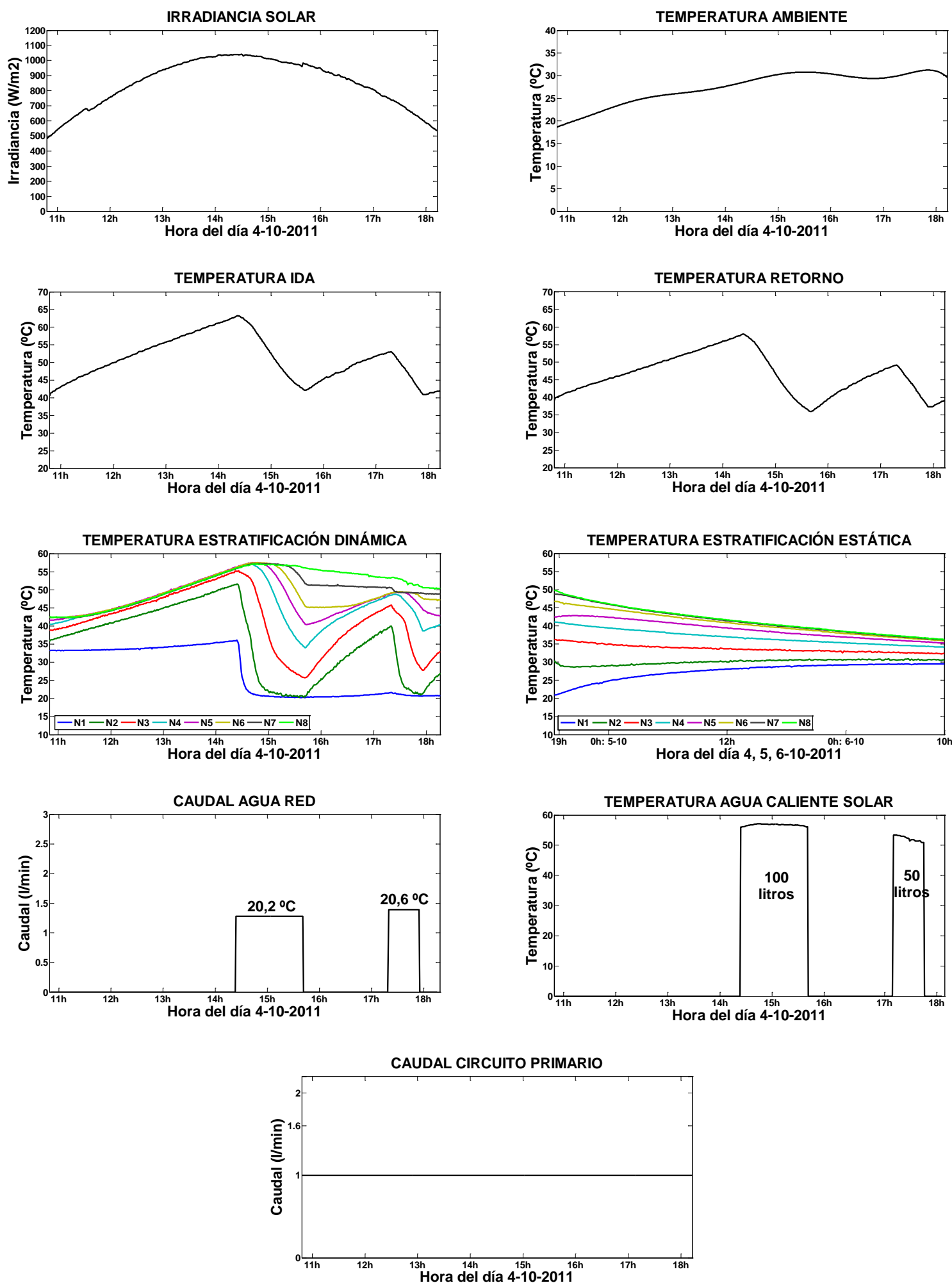

Fig. A.2.6 Datos registrados de la irradiancia solar, la temperatura ambiente, la temperatura de ida, la temperatura de retorno y las temperaturas de estratificación, el caudal del agua de red, la temperatura del agua caliente solar y el caudal del circuito primario en el ensayo de la planta piloto realizado el día 4-10-2011 


\section{A.2.7 Datos del ensayo en la planta piloto del día: 6-10-2011}
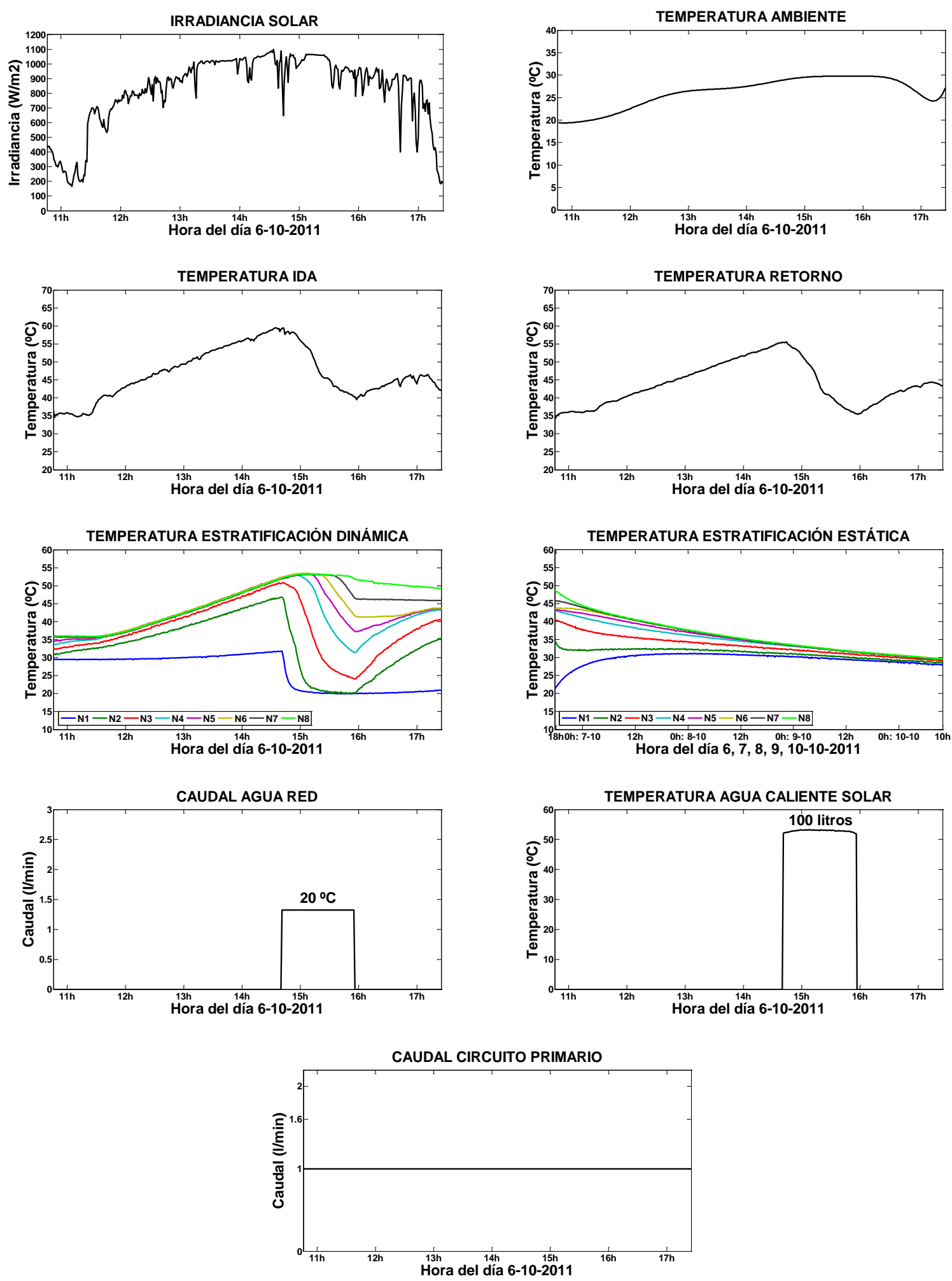

Fig. A.2.7 Datos registrados de la irradiancia solar, la temperatura ambiente, la temperatura de ida, la temperatura de retorno y las temperaturas de estratificación, el caudal del agua de red, la temperatura del agua caliente solar y el caudal del circuito primario en el ensayo de la planta piloto realizado el día 6-10-2011 


\section{A.2.8 Datos del ensayo en la planta piloto del día: 10-10-2011}
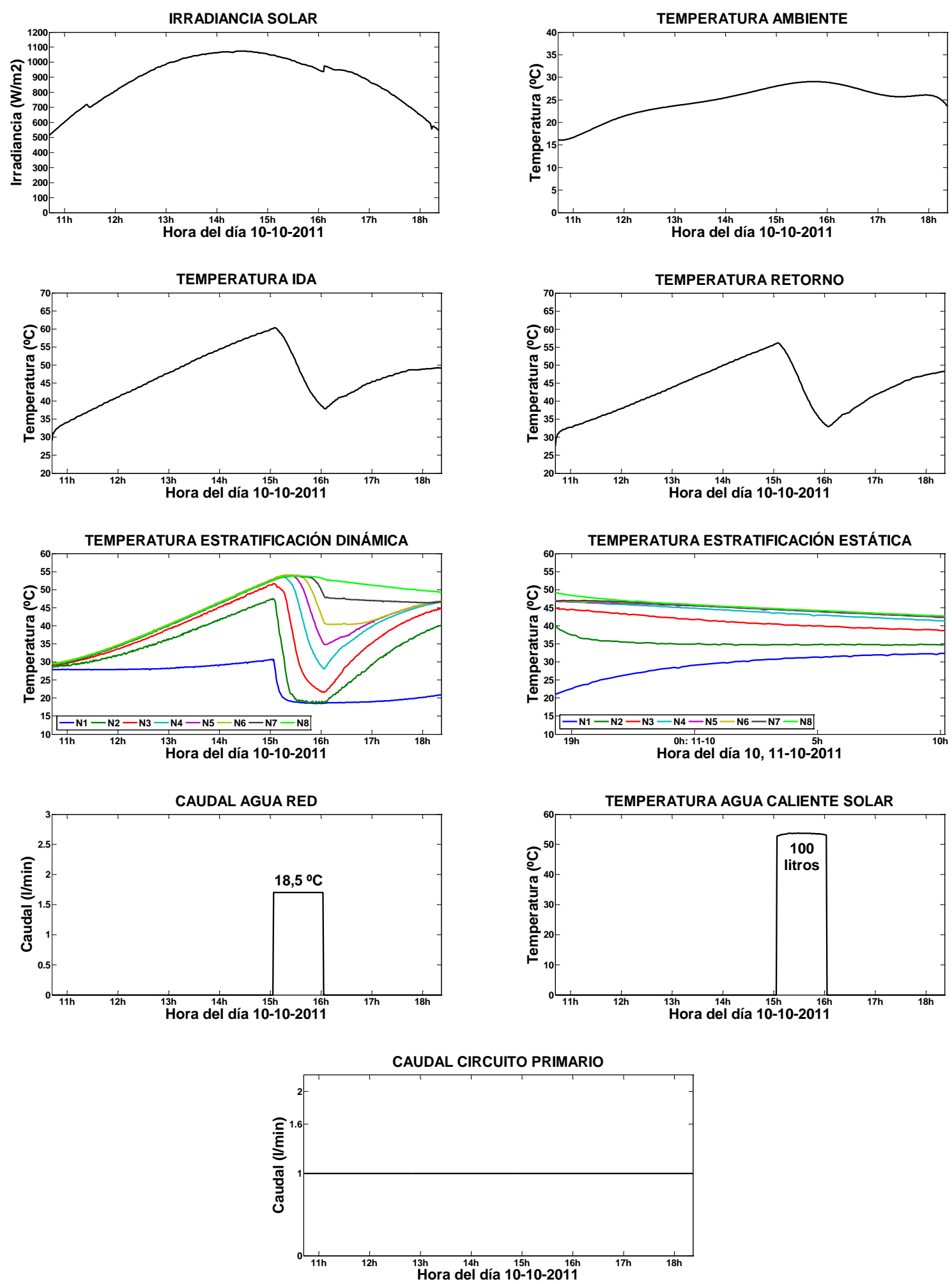

Fig. A.2.8 Datos registrados de la irradiancia solar, la temperatura ambiente, la temperatura de ida, la temperatura de retorno y las temperaturas de estratificación, el caudal del agua de red, la temperatura del agua caliente solar y el caudal del circuito primario en el ensayo de la planta piloto realizado el día 10-10-2011 


\section{A.2.9 Datos del ensayo en la planta piloto del día: 7-11-2011}
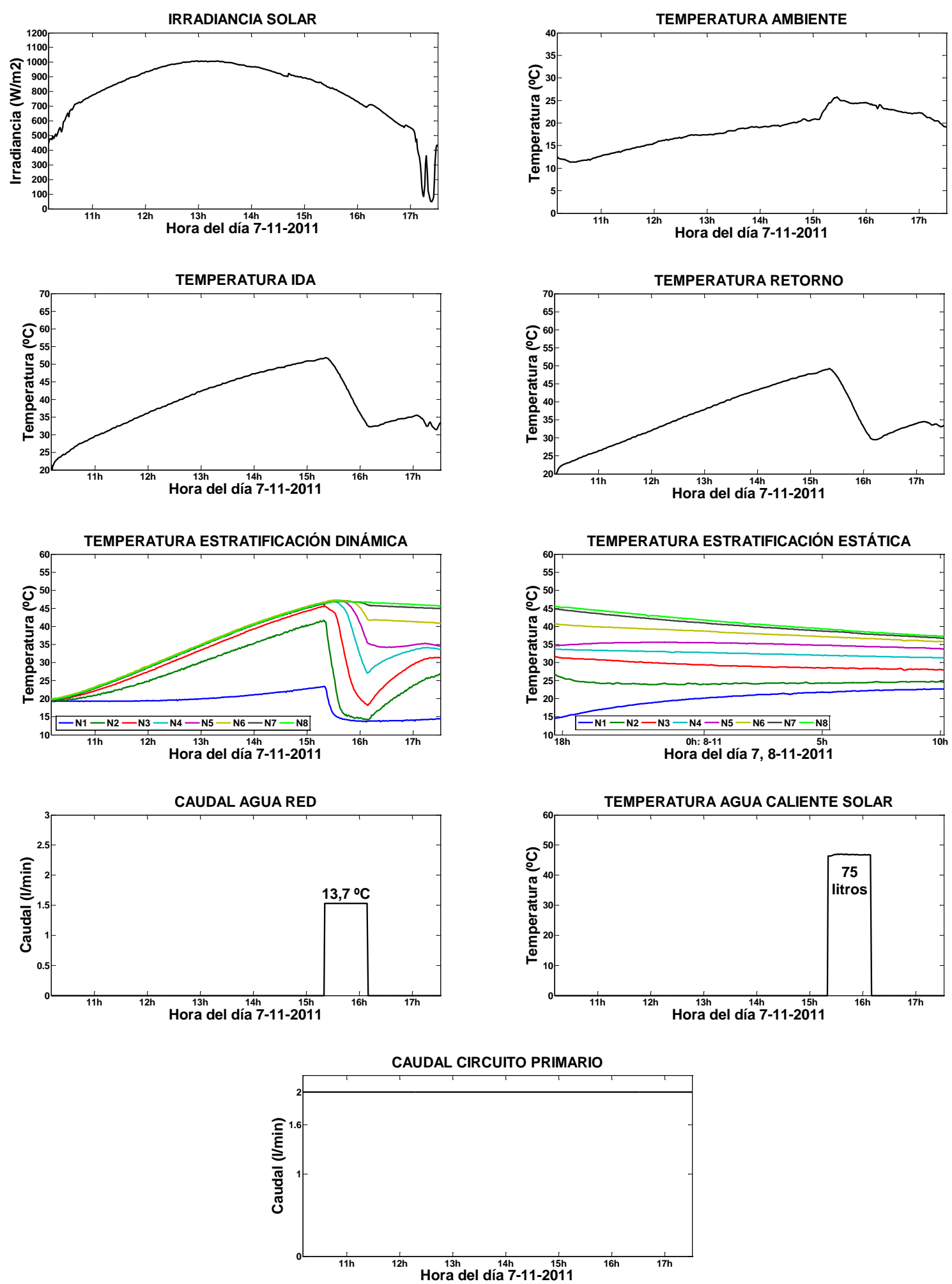

Fig. A.2.9 Datos registrados de la irradiancia solar, la temperatura ambiente, la temperatura de ida, la temperatura de retorno y las temperaturas de estratificación, el caudal del agua de red, la temperatura del agua caliente solar y el caudal del circuito primario en el ensayo de la planta piloto realizado el día 7-11-2011 


\section{A.2.10 Datos del ensayo en la planta piloto del día: 28-11-2011}
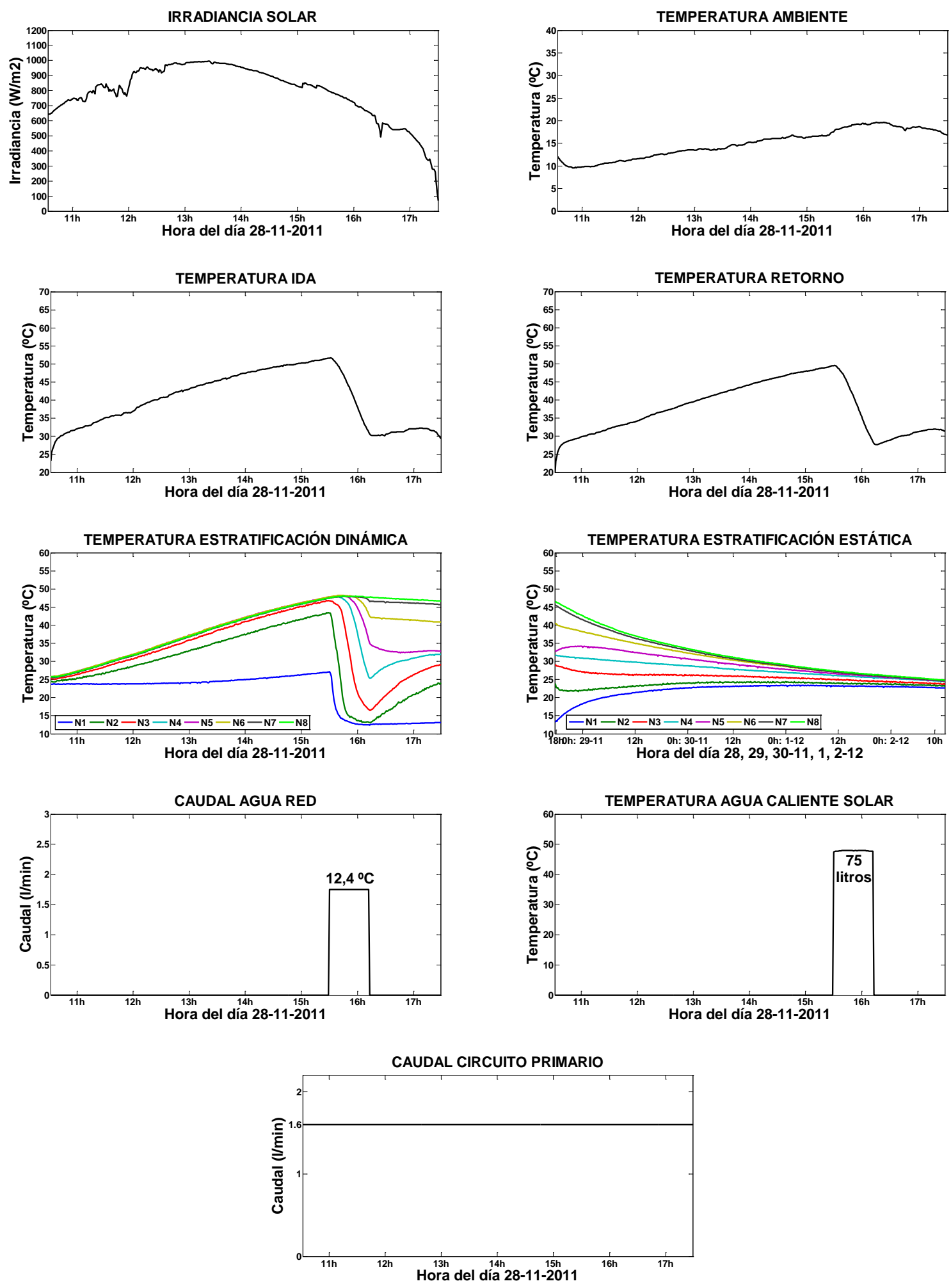

Fig. A.2.10 Datos registrados de la irradiancia solar, la temperatura ambiente, la temperatura de ida, la temperatura de retorno y las temperaturas de estratificación, el caudal del agua de red, la temperatura del agua caliente solar y el caudal del circuito primario en el ensayo de la planta piloto realizado el día 28-11-2011 


\section{A.2.11 Datos del ensayo en la planta piloto del día: 9-3-2012}
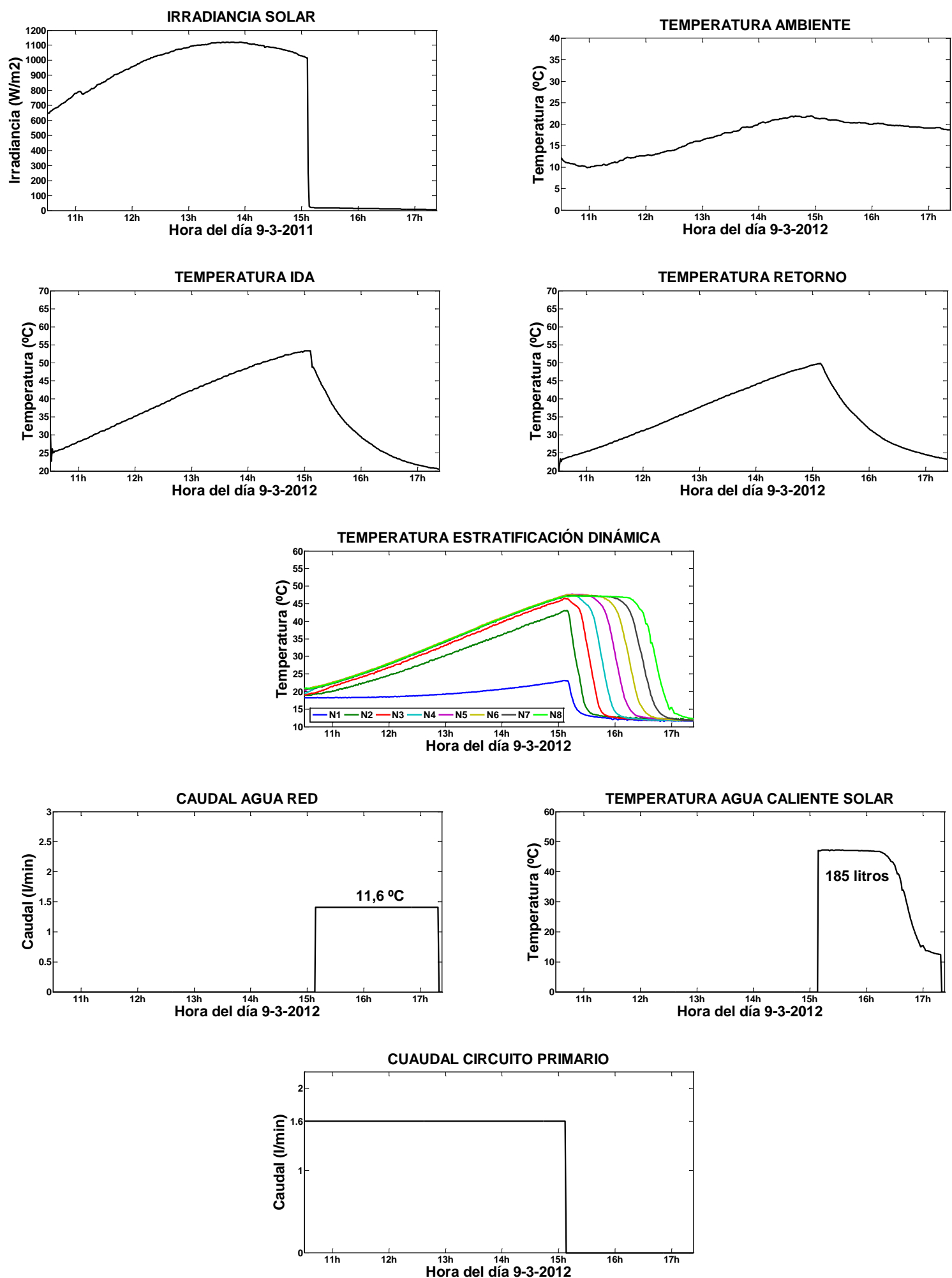

Fig. A.2.11 Datos registrados de la irradiancia solar, la temperatura ambiente, la temperatura de ida, la temperatura de retorno y las temperaturas de estratificación, el caudal del agua de red, la temperatura del agua caliente solar y el caudal del circuito primario en el ensayo de la planta piloto realizado el día 9-3-2012 


\section{Anexo 3}

\section{PUBLICACIONES}

Esta Tesis Doctoral ha generado hasta la fecha, varios artículos científicos. Los cuales se incorporan en este anexo.

Sistemas solares térmicos. Modelado del captador mediante redes neuronales artificiales (I) es el título del primer artículo publicado por la revista Era Solar en su Edición 176, Septiembre/Octubre 2013, Año XXXI, páginas 26 a 34 .

Sistemas solares térmicos. Modelado del captador mediante redes neuronales artificiales (II) es el título del segundo artículo publicado por la revista Era Solar en su Edición 177, Noviembre/Diciembre 2013, Año XXXI, páginas 42 a 54.

Prediction and identification of the evolution of solar-heated hot water temperature in a stratified tank in static mode using artificial neural networks es el título del artículo redactado por el autor de esta Tesis Doctoral que se encuentra en proceso de publicación. 



\section{SA A P PUBLICACIONES TÉCNICAS, S.L.}

Costa Rica, 32 - 28016 Madrid - España. Tlf. 913505885 - Fax. 913459313

Correo electrónico: sapt@erasolar.es - Web: www.erasolar.es

D. Vicente Fernández Bustos, Coordinador General de la revista Era Solar

Hace constar:

Que D. Francisco Javier Diez Morante, con DNI XXXXXXXXX, publico en la revista Era Solar №176 (Septiembre/Octubre 2013) y №177 (Noviembre/Diciembre 2013) el articulo "Modelado del colector. Sistemas solares térmicos mediante redes neuronales artificiales", del cual es autor.

La revista ERA SOLAR es una publicación técnica especializada en energía solar, que lleva en el mercado desde el año 1983. De aparición bimestral, cuenta con una tirada de 12.000 ejemplares y amplia difusión en España e Iberoamérica. En la revista se publican artículos técnicos, escritos por académicos, investigadores y profesionales de prestigio, sujetos a selección supervisada por un Comité Técnico. También se publican noticias del sector de la energía solar térmica y fotovoltaica, análisis de mercados, e información y avances técnicos sobre nuevos productos y desarrollos industriales. La revista ERA SOLAR es considerada como un referente de investigación e información técnica dentro del sector solar en los países de habla hispana.

Como indicios del interés académico de esta publicación, a continuación listamos las principales universidades que tienen suscrita nuestra revista:

- Biblioteca Universitaria Universidad de Huelva.

- Biblioteca Universitaria Universidad de Sevilla.

- Biblioteca Universitaria

Universidad Salesiana de Sarria.

- Departamento de Ing. Eléctrica

Escuela Universitaria Politécnica de Valladolid.

- Biblioteca

Escuela Universitaria de Ingeniería Técnica Industrial de Madrid.

- Biblioteca

Escuela Universitaria Politécnica de Gerona.

- Biblioteca

- Departamento de Ing. Eléctrica

Escuela Universitaria Politécnica de Zaragoza.

- Unidad de Física Aplicada

Universidad Politécnica de Valencia.

Universidad Politécnica de Valencia.

- Biblioteca Esc.Politécnica Superior

Universidad San Pablo CEU

- Biblioteca

Universidad de Extremadura.

- Departamento de Electricidad

Universidad de León.

- Biblioteca

Escuela de Ing. Industrial e Informática Universidad de León.

- Dep. Física General y de la Atmósfera Universidad de Salamanca.

- Biblioteca

Escuela Universitaria Politécnica de Valladolid.

- Departamento de Física

Universidad de Extremadura.

- Biblioteca

Centro Superior de Ciencias Agrarias Universidad de La Laguna.

- Biblioteca

- Dep. Termodinámica Aplicada

Escuela Politécnica Superior Universidad Miguel Hernández.

Universidad Politécnica de Valencia. 
- Biblioteca

- Biblioteca

- Biblioteca

- Biblioteca

- Biblioteca General/Hemeroteca

- Biblioteca

- Biblioteca

- Biblioteca

- Hemeroteca

- Biblioteca

- Biblioteca Universitaria

- Biblioteca

- Biblioteca

- Etc.
Universidad Pública de Navarra

Sede Iberoamericana de la Rábida Universidad Internacional Andalucía.

Escuela Tec.Sup. Ingeniería Industrial Universidad Politécnica de Cataluña.

Escuela Tec.Sup. Arquitectura Universidad del País Vasco.

Universidad de Castilla-La Mancha.

Escuela Técnica Superior Río Vena Universidad de Burgos.

Escuela Universitaria de Arquitectura Técnica de La Coruña.

Escuela Universitaria Politécnica de El Ferrol.

Universidad de Jaén.

Escuela Sup.Tec. Ingeniería Agraria Universidad de León.

Universidad de La Rioja.

UNED (Ingenierías).

Esc.Politécnica Superior Universidad Carlos III de Madrid.

A lo que hay que añadir una larga lista de centros de investigación públicos y privados, agencias autonómicas y locales de la energía, fundaciones, institutos de enseñanza, e investigadores y profesionales a título particular.

Algunos autores, adscritos a universidades y centros de investigación relevantes, que han publicado artículos técnicos en ERA SOLAR en los últimos años son:

- Eduardo Collado Fernández ETSIl de la UNED.

- Antonio Colmenar Santos ETSII de la UNED.

- Manuel-Alonso Castro Gil ETSII de la UNED.

- P.J. Pérez

Grupo I+DEA Universidad de Jaén.

- L. Hontoria

- G. Almonacid

Grupo I+DEA Universidad de Jaén.

- J. Aguilera

Grupo 1+DEA Universidad de Jaén.

Grupo I+DEA Universidad de Jaén.

- P.G. Vidal

- R. Pujol

Grupo 1+DEA Universidad de Jaén.

Departamento de Física Universidad de les Illes Balears.

- A. Moià

- V. Martínez

- Mikel Antón Arriazu

- Manuel Ibáñez Plana

Departamento de Física Universidad de les Illes Balears.

Departamento de Física Universidad de les Illes Balears.

Universitat de Lleida (Cretesos).

Universitat de Lleida (Cretesos).

- J. Cuenca

- Faustino Chenlo Romero

División de Energías Renovables CIEMAT.

División de Energías Renovables CIEMAT.

- Pedro G. Vicente Quiles

Grupo Ingeniería Energética Universidad Miguel Hernández de Elche.

- J.F. Guilló

- M. Lucas

- R. Lucas

- Juan Bisquert

- Miguel Alonso Abella

- Eduardo Lorenzo Piqueiras

- Antonio Luque López

- A. Carrillo Andrés

Grupo Ingeniería Energética Universidad Miguel Hernández de Elche.

Grupo Ingeniería Energética Universidad Miguel Hernández de Elche.

Grupo Ingeniería Energética Universidad Miguel Hernández de Elche.

Departamento de Física Aplicada Universidad Jaume I de Castelló.

División Energías Renovables CIEMAT.

Instituto de Energía Solar Universidad Politécnica de Madrid.

Instituto de Energía Solar Universidad Politécnica de Madrid.

Grupo Energética Universidad de Málaga.

- L. Jurado

Grupo Energética Universidad de Málaga.

- L. Druet

Grupo Energética Universidad de Málaga.

- F. Domínguez Muñoz

Grupo Energética Universidad de Málaga.

- J.M. Cejudo López

Grupo Energética Universidad de Málaga. 
- Valeriano Ruiz Hernández

- C. Monné

- S. Alonso

- J.M. Izquierdo

- F. Palacín

- Ángel A. Bayod Rujula

- Abel Ortego Bielsa

- Amaya Martinez Gracia

- Daniel Chemisana

- Joan Rosell

- Francisco Jarabo Friedrich
Catedratico de Termodinámica Universidad de Sevilla.

GITSE-I3A Universidad de Zaragoza.

GITSE-I3A Universidad de Zaragoza.

GITSE-I3A Universidad de Zaragoza.

Centro Nacional de Energías Renovables CENER.

Centro Investigación Recursos y Consumos Energéticos Universidad de Zaragoza.

Centro Investigación Recursos y Consumos Energéticos Universidad de Zaragoza.

Centro interés Recursos y Consumos Energéticos Universidad de Zaragoza.

Universidad de Lleida.

Universidad de Lleida.

Universidad de La Laguna.

La revista ERA SOLAR es portavoz en España de las siguientes asociaciones nacionales e internacionales:

- ASIF (Asociación de la Industria Fotovoltaica).

- ASIT (Asociación Solar de la Industria Térmica).

- EUROSOLAR (European Association for Renewable Energy).

- HELIOS (Asociación de Fabricantes, Importadores e Instaladores de Energía Solar).

- IEF (International Energy Foundation).

- PROTERMOSOLAR (Asociación Española de la Industria Solar Termoeléctrica).

- SEI (Solar Energy International).

- WCRE (World Council for Renewable Energy).

- AEF (Asociación Empresarial Fotovoltaica).

Principales premios recibidos por ERA SOLAR:

- European Solar Prize 2003.

- Premio Solar 2003.

- Premio Ricardo Carmona 2004.

- Premio Sol y Paz 2006.

Y para que así conste, firmo la presente en Madrid a 17 de septiembre de 2013

\section{S.A.P.T. PUBLICACIONES TÉCNICAS, S.L.}

Vicente Fernández Bustos

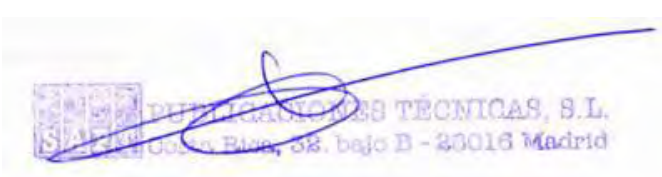




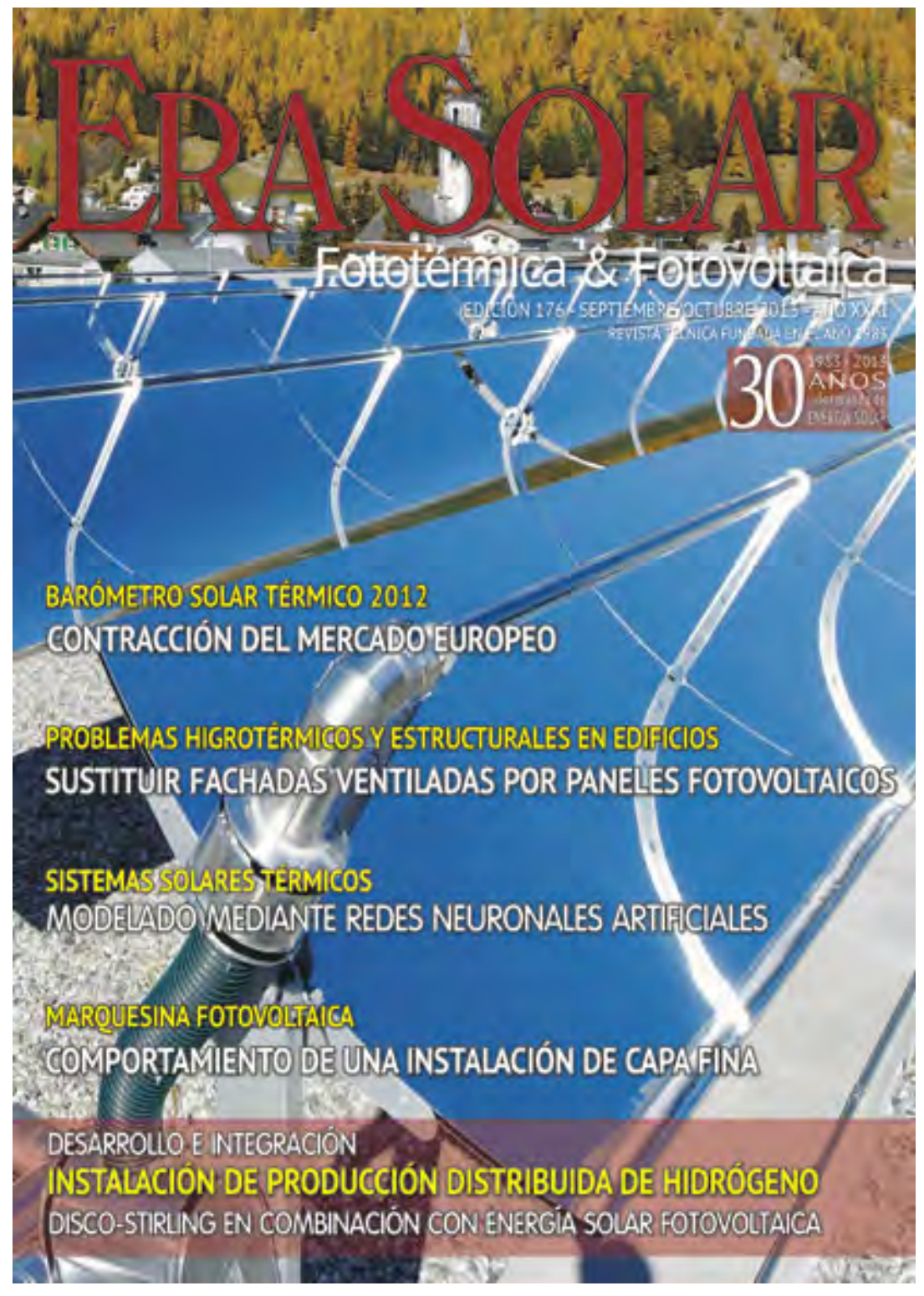



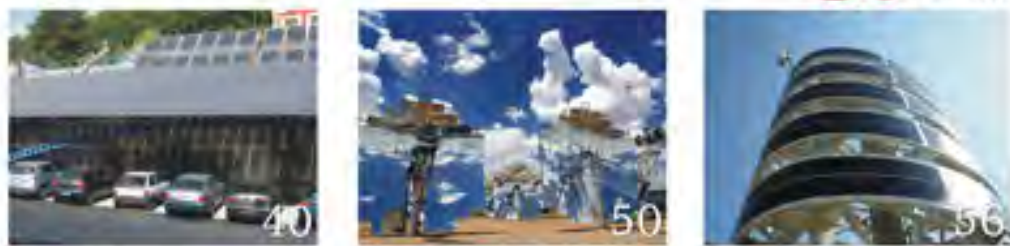

Somero

6 Barbmetro solar termico 2012.

Contracción del mercado europeo por cuarto año consecutivo.

20 Problemas higrotermicos y estructurales.

Sustitucion de una fachada ventilada convencional por una fotovoltaica,

26 Sistemas solares térmicos

Modelado del captador mediante redes neuronates artificiates (i).

40 Marquesina fotovoltaica

Análisis del comportamiento en operación real de una instalación de capa fina (a-Si)

46 Semana intemacional CSP

Tecrologias de concentración solar termoelectrica.

50 Instalación de producción distribuida de hidrógena. Desarrollo e integración de un sistema de Disco-Stirling en combinación con ener gia solar fotowoitaica.

56 Integración arquitectónica.

Conceptos innovadores basados en fotovolraica de capa fina.

62 Impulsando la energia solar térmica.

rowate

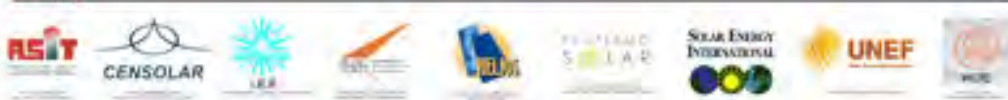




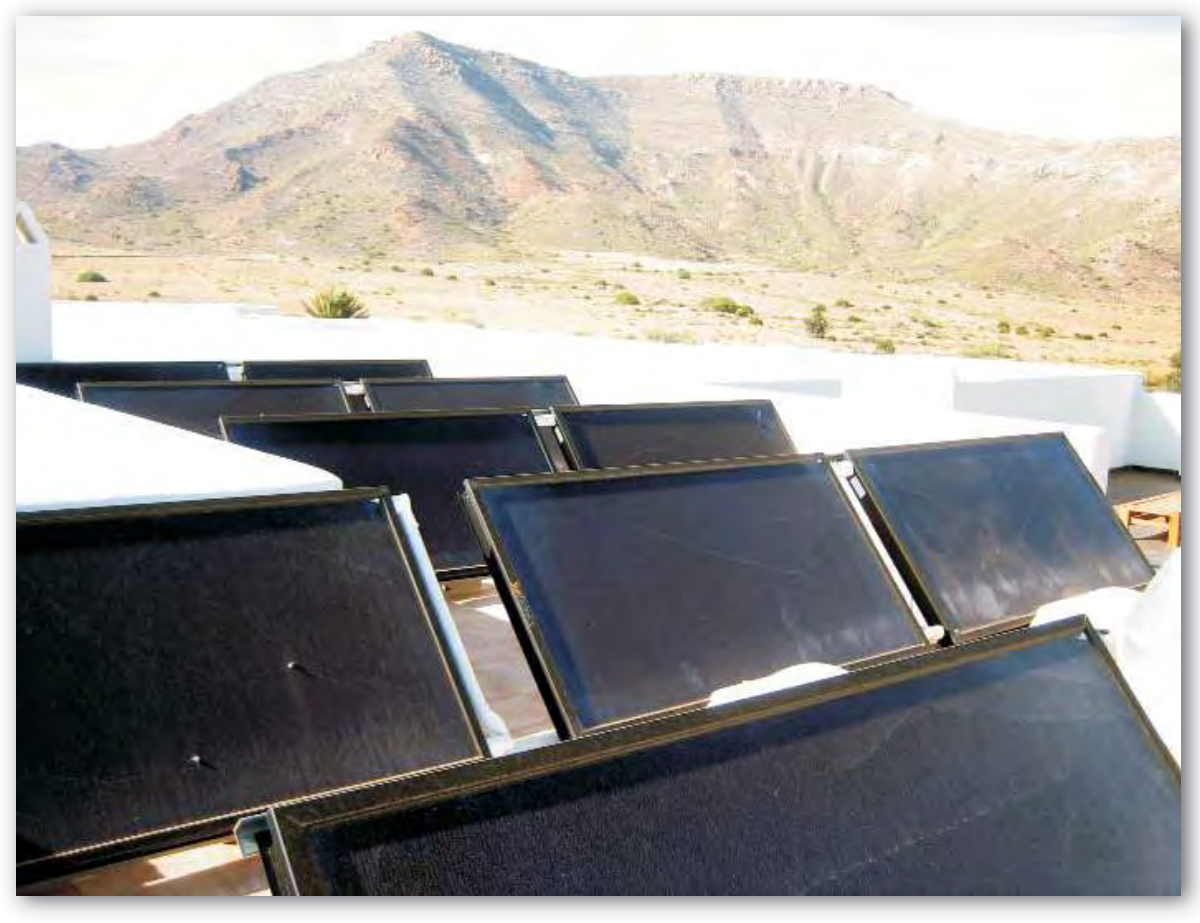

Modelado del captador

\section{Sistemas solares térmicos mediante redes neuronales artificiales (I)}

\section{F.J. Diez, J.L. Falagán}

En este estudio, se informa del análisis experimental en un captador solar de placa plana. El objetivo principal es el modelado de su funcionamiento en un sistema solar térmico, mediante la técnica de las redes neuronales artificiales de la inteligencia computacional.

El modelado se basa en los datos experimentales tomados sobre el captador solar proporcionado por el fabricante y equipado con un sistema de adquisición de datos apropiado.

El captador solar utilizado, el circuito primario del sistema solar térmico al que está acoplado, el sistema de adquisición de datos y la metodología teórica y experimental se detallan en este estudio.

El clásico modelo del captador solar de Hottel-Whillier-Bliss y el actual modelo de la norma europea EN 12975 se describen y se aplican a los datos registrados en los ensayos realizados al captador solar, con diferentes caudales del fluido portador, deduciendo su ecuación característica del rendimiento, y se comprueban las desviaciones que se producen al no tener en cuenta las especificaciones concretas de cada método.

El modelado del captador solar mediante una red neuronal artificial se describe y se presentan los resultados obtenidos, resultando ser un método preciso, flexible y fácil de aplicar a cualquier captador solar, ya instalado, y extensible al campo de captación completo, a partir de una muestra de datos característica de las condiciones de funcionamiento, que se pretenda simular y un software para implementar la red neuronal artificial.
El colector solar es el componente del sistema solar térmico que tiene la función de calentar el agua que fluye por su interior mediante la irradiación solar que recibe del Sol (Peuser et al., 2002). Podemos referirnos al captador solar como un intercambiador de calor entre la irradiación solar y la energía térmica del fluido portador, siendo el componente encargado de captar la irradiación solar en los sistemas solares térmicos. Esto se puede lograr, según la aplicación que se le vaya a dar al agua caliente, mediante cinco tipos de captadores solares.

El captador termosifónico, que funciona mediante convección natural y por lo tanto no requiere bomba de impulsión para el fluido portador. El captador de placa plana usado en instalaciones destinadas para el suministro de agua caliente sanitaria, calefacción solar y climatización de piscinas. El captador de vacío usado también en el mismo tipo de instalaciones que el captador de placa plana, pero cuando estos tienen dificultades de alcanzar la temperatura requerida. El captador de polipropileno usado en el calentamiento del agua para piscinas. Y el captador cilíndrico parabólico usado industrialmente en las centrales térmicas para obtener altas temperaturas en el fluido portador. En este trabajo, se trata con un captador de placa plana, por ser los más extendidos, pudiéndose aplicar la metodología a los otros tipos de captadores solares.

El captador solar de placa plana está formado por una o más cubiertas transparentes a la irradiación solar que producen el efecto invernadero, la placa o absorbedor donde se transfiere la energía calorífica al fluido portador que circula por su interior, el aislamiento térmico posterior y lateral para reducir las pérdidas de calor ha- 
cia el exterior y la carcasa para resguardar los elementos anteriores y colocar los soportes. Los demás componentes de un sistema solar térmico son del mismo tipo que los utilizados para la producción de agua caliente sanitaria en sistemas convencionales. Un extenso estudio sobre los captadores solares térmicos se encuentra en (Kalogirou, 2004) tipos, historia, análisis, rendimiento, modelado de sistemas solares térmicos, economía y aplicaciones.

El modelado de los captadores solares se realiza mediante ensayos experimentales y validando los modelos resultantes. En el diseño del modelo es necesario conocer las características del captador solar, también hay que tener claro el grado de complejidad que va a alcanzar y la precisión de los resultados. Los métodos unidimensionales logran una gran precisión en sus resultados, que es aumentada por los bidimensionales (Kazeminejad, 2002). Pero es necesario un acuerdo entre la simplicidad del modelo y su precisión. Los parámetros que repercuten en el rendimiento del captador solar se pueden clasificar como de diseño, operacionales y ambientales.
(Klein, 1978) utiliza el método utilizability desarrollado por (Whillier, 1953) y difundido por (Liu y Jordan, 1963). (Whillier, 1964) estudia la resistencia térmica de la unión entre los tubos de la parrilla y la placa del absorbedor. Aunque los efectos transitorios no se tienen en cuenta en los modelos estacionarios, respecto al tiempo de duración en un periodo diario su influencia es muy pequeña. También hay que tener en cuenta que la resolución temporal de los datos ambientales usualmente no supera una hora, por lo que un modelado muy complejo no tiene mucha utilidad. Por otra parte, la identificación experimental de las características ópticas y térmicas de un captador solar es importante para la normalización y certificación de captadores solares.

Una revisión de los modelos y ensayos de los captadores solares se encuentra en (Frid, 1990), además de una formulación para dos y tres nodos del captador solar. Otra revisión y clasificación de la literatura de los métodos de ensayo de los captadores solares se encuentra en (Amer et al., 1997). 
(El-Adawi, 2002) utiliza la técnica de la transformada de Fourier para resolver la difusión del calor en el absorbedor y estimar el rendimiento del captador.

Para la modelización de los captadores de placa plana, también existe software de diseño como la herramienta Kolektor de (Matuska et al., 2009), útil para la creación de prototipos virtuales y análisis de los parámetros que influyen en el rendimiento de los captadores solares utilizados en la edificación.

Los modelos de ensayos de los captadores solares se pueden clasificar en modelos de estado estacionario y modelos de prueba dinámicos.

El enfoque dinámico es un enfoque más preciso para el cálculo del rendimiento y diseño de los captadores de placa plana. El modelo dinámico de (Arinze et al., 1993) describe las temperaturas en el fluido portador, absorbedor y cubierta del captador solar con tres ecuaciones diferenciales, resolubles mediante series de Taylor y el método Runge-Kutta.

Por citar algunos están, el método de la función de transferencia de (Hou et al., 2004), (Wang, 2008) y (Xu, 2009) que se utiliza para obtener la temperatura de salida en el captador solar en condiciones estacionarias y dinámicas, que (Kong et al., 2012) lo mejora pudiendo estimar los parámetros de los captadores solares como el coeficiente de pérdida cero y el coeficiente de pérdida de calor. El método de la función respuesta de (Emery y Rogers, 1984) que se utiliza para ensayar captadores solares en modo transitorio. (Cruz-Peragon et al., 2012) presenta una metodología para validar un modelo de captador solar con una complejidad indeterminada caracterizada por coeficientes físicos y optimizar un modelo de diferencias finitas con bajo caudal.

En este estudio, se modela un captador solar mediante el clásico modelo de Hottel-Whillier-Bliss, el estandarizado modelo de la norma europea EN 12975-2:2006 y se propone utilizar las técnicas de la inteligencia computacional como son las redes neuronales artificiales para el modelado de los captadores solares como alternativa a los métodos utilizados habitualmente.

\section{EQUIPO EXPERIMENTAL}

El captador solar ensayado es de la marca Takama y modelo T3-Inox, está instalado con una inclinación de $45^{\circ}$ respecto a la superficie horizontal, formando parte de un sistema solar térmico que tiene una bomba de impulsión con tres velocidades para producir la circulación del fluido portador, un vaso de expansión para compensar
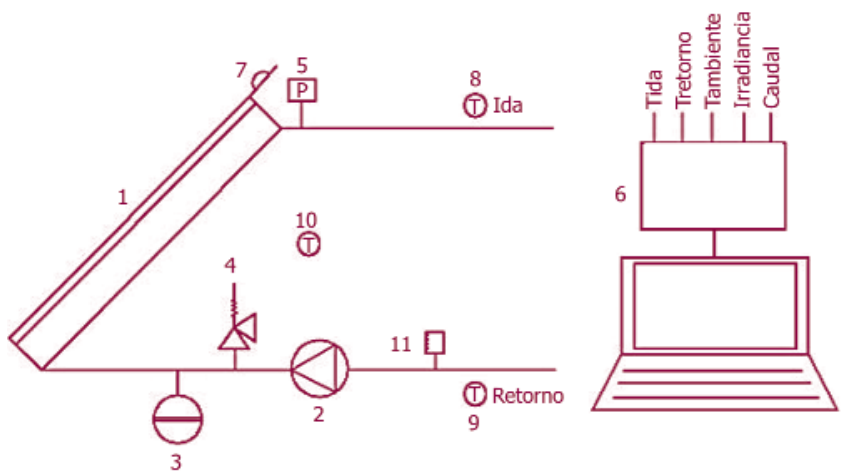

$$
\begin{array}{ll}
\text { 1.- Colector solar plano } & \text { 7.- Piranómetro } \\
\text { 2.- Bomba de impulsión } & \text { 8.- Sensor temperatura tubería ida } \\
\text { 3.- Vaso de expansión } & \text { 9.- Sensor temperatura tubería retorno } \\
\text { 4.- Válvula de seguridad } & \text { 10.- Sensor temperatura ambiente } \\
\text { 5.- Purgador } & \text { 11.- Sensor caudal }
\end{array}
$$$$
\text { 6.- Sistema de adquisición de datos }
$$

Figura 1.- Esquema del captador solar en el sistema solar térmico y el sistema de adquisición de datos.

los cambios de volumen del fluido portador ocasionados por la dilatación térmica, un purgador de aire automático que libera al exterior el aire del circuito primario y una válvula de seguridad para prevenir daños en la instalación y de operación. Esta es la parte de captación de la irradiación solar del sistema solar térmico, que está conectada a la parte de acumulación de la energía calorífica en un depósito de almacenamiento térmico de agua con un intercambiador interno de tipo serpentín.

La adquisición de datos del funcionamiento del captador solar se realiza con cinco sensores: Dos sondas de temperatura de la marca Danfoss y modelo ESMU.100, que tienen un sensor básico de resistencias de platino Pt 1000, la sonda de inmersión tiene una vaina en tubo de cobre, cuerpo de latón y cabeza de poliamida, instaladas en la salida y entrada del captador solar, para muestrear las temperaturas del fluido portador de ida y retorno, respectivamente. Otra sonda de temperatura ambiente, situada de forma que quede protegida de la insolación y del viento mediante un forro plástico y lámina de aluminio. Un piranómetro instalado sobre el mismo plano que el captador solar, para la medida de la irradiancia solar global, de la marca Delta Ohm y modelo LP PYRA 02 AC de primera clase, fabricado de acuerdo con la norma ISO 9060, siguiendo las recomendaciones del World Meteorological Organization WMO y calibrado individualmente usando como referencia el World Radiometric Reference WRR. Y un caudalímetro que registra el caudal con el que circula el fluido portador por el circuito primario del sistema solar térmico. Los valores muestreados mediante los sensores de las variables temperaturas de ida, retorno y ambiente, irradiancia solar y caudal, mediante una tarjeta de adquisi- 
ción de datos quedan registrados en un ordenador. En la figura 1 se muestra el esquema de conexión entre los componentes y el sistema de adquisición de datos.

El captador solar que se dispone a modelar se compone de una cubierta de vidrio templado Dura Solar prismático de $4 \mathrm{~mm}$ de espesor y bajo contenido en hierro. El captador tiene una parrilla de 8 tubos verticales tipo "Flat Pipe" de cobre de $10 \mathrm{~mm}$ de diámetro, soldados con cobre a 2 tubos horizontales de cobre de $18 \mathrm{~mm}$ de diámetro. La superficie de absorción está sometida a un proceso de estampación en el que se embuten semiesferas consiguiendo una estructura tridimensional, lo que aumenta la superficie de captación efectiva, dentro de las mismas medidas externas. Debido a que a lo largo de todo el día hay planos de superficie de absorción en los que la irradiancia solar incide perpendicularmente, el rendimiento diario es más elevado. La superficie absorbedora tiene unas dimensiones de $1.950 \times 950 \times 0,3 \mathrm{~mm}$, lo que da un área de absorbedor de $1,85 \mathrm{~m}^{2}$, fabricado en chapa de aluminio con 8 canales planos con 8.266 semiesferas embutidas que aumentan la superficie útil de absorción hasta 2,593 $\mathrm{m}^{2}$. En los canales planos van encajados los tubos "Flat Pipe" en contacto con pasta termoconductora formando un sólo cuerpo, soldados mediante resistencia eléctrica. La superficie absorbedora lleva un recubrimiento selectivo de alto rendimiento y eficacia sin cromo, a base de óxido de cobre negro, magnesio y silicio, con una absortividad $\alpha=0,94$ y una emisividad $\varepsilon=0,29$.

El aislamiento térmico es de espuma de poliisocianurato PIR de $20 \mathrm{~mm}$ de espesor, revestido por ambas caras con aluminio gofrado. La carcasa tiene unas dimensiones totales de $2.000 \times 1.000 \times 72 \mathrm{~mm}$, lo que da un área total de $2 \mathrm{~m}^{2}$ y unas dimensiones de apertura de $1.940 \mathrm{x}$ $942 \mathrm{~mm}$, con un área de apertura de $1,83 \mathrm{~m}^{2}$, es una caja de acero inoxidable AISI $304 \mathrm{~L}$ de $0,6 \mathrm{~mm}$ de espesor soldada y sellada con silicona termoresistente para su total estanqueidad. Lleva incorporados 4 anclajes para su fijación a la estructura con tolerancia suficiente para absorber las posibles dilataciones. La caja Ileva incorporados dos evaporadores anticondensación.

Las conexiones son cuatro salidas desnudas de tubo de $18 \mathrm{~mm}$ de diámetro con racords de unión rectos sin soldadura a prueba de dilatación. Las limitaciones de funcionamiento son de $150^{\circ} \mathrm{C}$ de máxima temperatura de operación, 7 bar de máxima presión de operación y de $25^{\circ}$ a $60^{\circ}$ de mínimo y máximo ángulo de inclinación. El peso del captador en vacío es de $39,3 \mathrm{~kg}$, pudiendo contener 1,2 litros de fluido portador.
TEORÍA

\section{Modelo captador solar Hottel-Whillier-Bliss}

El modelo de Hottel-Whillier-Bliss es el primero que definió matemáticamente el captador de placa plana con tubos paralelos, de forma unidimensional aleta-tubo, y que tiene en cuenta el efecto invernadero que se produce en el interior de la cubierta. La ecuación característica lineal que describe su funcionamiento, por su sencillez, se sigue utilizando en nuestros días. Este modelo supone que los procesos de transferencia de calor en el captador solar son constantes, sin tener en cuenta los fenómenos transitorios tratando su funcionamiento como una secuencia de estados estacionarios. En estado estacionario, la captación de energía útil es la diferencia entre la energía absorbida por la placa y la energía perdida debida a la diferencia de temperatura entre la placa y el ambiente.

El rendimiento del captador solar se puede valorar de dos formas, la primera llamada instantánea trata el rendimiento en un instante determinado de tiempo, el cual es dependiente de la climatología y los valores de las variables de funcionamiento que se dan en un instante determinado, y la segunda forma de valorar el rendimiento de un captador es a largo plazo en un periodo de tiempo de por ejemplo un año, en distintas condiciones de funcionamiento.

El rendimiento instantáneo de un captador solar en unas condiciones concretas de la climatología y funcionamiento se determina a partir de la energía absorbida y perdida (Hottel y Woertz, 1942), (Hottel y Whillier, 1955), (Bliss, 1959) y (Duffie y Beckman, 2006), que se determinan en los ensayos realizados a los captadores solares, en los que se mide el rendimiento en un intervalo de tiempo apropiado.

La energía útil del captador solar en un instante determinado en el tiempo resulta de la diferencia entre la energía absorbida y la perdida al exterior, por la ecuación:

$Q_{u}=F_{R} \cdot A \cdot\left[I \cdot(\tau \alpha)-U_{L} \cdot\left(T_{e}-T_{a}\right)\right]$

Donde, $\mathrm{Q}_{\mathrm{u}}$ es la potencia útil extraída del captador solar en (W), $F_{R}$ es el factor de eficiencia de extracción de calor del captador solar, A es el área del captador solar plano en $\left(\mathrm{m}^{2}\right)$, I es la irradiancia solar que incide sobre el captador solar por unidad de área en $\left(\mathrm{W} / \mathrm{m}^{2}\right)$, $\mathrm{T}$ es la transmitancia solar de la cubierta transparente, $\alpha$ es la absortancia de la placa del captador, $U_{L}$ es el coeficiente global de pérdidas de energía del captador solar en $\left(\mathrm{W} /\left({ }^{\circ} \mathrm{C} \cdot \mathrm{m}^{2}\right)\right), \mathrm{T}_{\mathrm{e}}$ es la temperatura de entrada del fluido portador al captador solar en $\left({ }^{\circ} \mathrm{C}\right), \mathrm{y}_{\mathrm{a}}$ es la temperatura ambiente en $\left({ }^{\circ} \mathrm{C}\right)$. 
La energía útil está dada también por la ecuación (2) sobre el fluido portador que circula en el captador solar.

$Q_{u}=A \cdot C \cdot c_{e} \cdot\left(T_{s}-T_{e}\right)$

Donde, C es el flujo másico del fluido portador por unidad de área del captador solar en $\left(\mathrm{kg} /\left(\mathrm{s}^{\cdot} \mathrm{m}^{2}\right)\right), \mathrm{c}_{\mathrm{e}}$ es el calor específico del fluido portador en $\left(\mathrm{J} /\left(\mathrm{kg} \cdot{ }^{\circ} \mathrm{C}\right)\right)$, y $\mathrm{T}_{\mathrm{s}}$ es la temperatura de salida del fluido portador en el captador solar en $\left({ }^{\circ} \mathrm{C}\right)$.

Los resultados de los ensayos del captador se ofrecen en términos de rendimiento $\eta$, como:

$\eta=\frac{Q_{u}}{I \cdot A}$

Los ensayos de los captadores solares se pueden realizar al aire libre durante los días claros entorno al mediodía solar, o en interiores utilizando un simulador solar. En ambos casos la irradiación solar difusa es de un valor mucho menor que la irradiación solar directa que incide sobre la superficie del captador solar que se recibe casi de forma normal. El producto de la transmitancia-absortancia resultante de los ensayos de los captadores solares se la supone que corresponde a la irradiación solar directa en incidencia normal que se escribe como $(\tau \alpha)_{n}$. Por lo que el rendimiento instantáneo del captador solar se puede expresar como:

$\eta=\frac{Q_{u}}{I \cdot A}=F_{R}(\tau \alpha)_{n}-F_{R} U_{L} \cdot\left(\frac{T_{e}-T_{a}}{I}\right)$

Si $U_{L}$ se asume que es constante, la representación gráfica del rendimiento respecto al término $\left(T_{\mathrm{e}}-\mathrm{T}_{\mathrm{a}}\right) / \mathrm{I}$ resulta una línea recta con una intersección con el eje de ordenadas en el valor $F_{R}(\tau \alpha)_{n}$ y una pendiente de $-F_{R} U_{L}$.

Los ensayos de los captadores se suelen representar gráficamente de esta forma. Los datos de los ensayos tienen una ligera dispersión sobre la línea recta que es debida a las fluctuaciones reales del valor de $U_{L}$ con la velocidad del viento y la temperatura, además de la influencia de los errores en las mediciones.

Esta es la forma apropiada para aplicar los valores $F_{R}(\tau \alpha)_{n}$ y $F_{R} U_{L}$ en el método "f-chart" para estimar el rendimiento a largo plazo de un sistema solar térmico.

El rendimiento del captador solar se ve afectado por las características técnicas de diseño propias de cada captador solar como el número de cubiertas, el material de la superficie absorbedora y el aislamiento térmico. El rendimiento también fluctúa en función de las variables propias del funcionamiento como las temperaturas y el caudal del fluido portador durante el trabajo del captador solar.
El rendimiento del captador solar a veces se representa en función de la temperatura media del captador o también respecto de la temperatura de salida del captador. Las representaciones gráficas de esta forma son muy similares a las gráficas de rendimiento respecto a la temperatura de entrada del captador solar sin embargo, la intersección con el eje de ordenadas y la pendiente de las rectas tiene una interpretación diferente. Introducir la referida a la temperatura media o de salida del captador en el método "f-chart" es un error que sobreestima la producción solar.

El caudal del fluido portador recomendado por el método "f-chart" para una mezcla 50-50 de etilenglicolagua es de 0,9 I/( $\left.\min \cdot \mathrm{m}^{2}\right)$ de captador solar.

En este trabajo, se comprueba en los ensayos realizados la variación en el rendimiento del captador solar que se produce al variar el caudal de circulación del fluido portador por el captador solar y también se calcula la ecuación característica respecto a las temperaturas de entrada, media y salida en el captador solar.

\section{Modelo captador solar EN 12975-2}

La norma europea EN 12975-2:2006 contiene varios modelos de captador uno es en forma cuasi-dinámica en condiciones transitorias elaborado por (Perers et al., 1991), (Perers, 1993) y (Perers, 1997), el cual añade al modelo de estado estacionario unos términos de corrección, que modelizan la dependencia de la irradiación solar directa y difusa, la velocidad del viento, la temperatura del cielo, los efectos del ángulo de incidencia y la capacidad térmica efectiva.

El modelado del rendimiento instantáneo se realiza mediante el cálculo de la energía útil del captador con:

$Q_{u}=m \cdot c_{e} \cdot\left(T_{s}-T_{e}\right)$

Donde, $m$ es el caudal másico del fluido portador. Utilizando el valor correspondiente del calor específico a la temperatura media del fluido portador. Si el caudal másico del fluido portador se obtiene de la medida del caudal volumétrico, entonces debe calcularse la densidad a la temperatura del fluido portador.

La irradiación solar recibida sobre el captador, no requiere el uso de una corrección del modificador del ángulo de incidencia, mientras este sea menor de $20^{\circ}$, en captadores solares de placa plana de una cubierta.

La energía solar disponible se calcula como A·I, con lo que la energía útil se puede escribir como:

$Q_{u}=A \cdot I \cdot \eta$ 
El rendimiento del captador solar se calcula en función del término denominado diferencia de temperatura reducida, utilizando la temperatura media en el captador solar:

$T_{m}=T_{e}+\frac{\left(T_{s}-T_{e}\right)}{2}$

La diferencia de temperatura reducida se expresa como:

$T_{m}^{*}=\frac{T_{m}-T_{a}}{I}$

El rendimiento instantáneo se calcula mediante el ajuste estadístico de curvas, usando el método de mínimos cuadrados para obtener la curva de rendimiento instantáneo de la ecuación:

$\eta=\eta_{0}-a_{1} \cdot\left(\frac{T_{m}-T_{a}}{I}\right)-a_{2} \cdot I \cdot\left(\frac{T_{m}-T_{a}}{I}\right)^{2}$

Donde, $\eta_{0}$ es la eficiencia óptica del captador solar siendo $\eta$ a $\left(\left(T_{m}-T_{a}\right) / I\right)=0, a_{1}$ es el coeficiente de pérdidas térmicas a $\left(T_{m}-T_{a}\right)=0$ en $\left(W /\left(m^{2} \cdot K\right)\right), a_{2}$ es el coeficiente de pérdidas térmicas dependiente de la temperatura en $\left(\mathrm{W} /\left(\mathrm{m}^{2} \cdot \mathrm{K}^{2}\right)\right), \mathrm{T}_{\mathrm{m}}$ es la temperatura media del fluido portador en $\left({ }^{\circ} \mathrm{C}\right), \mathrm{T}_{\mathrm{a}}$ es la temperatura del aire ambiente circundante en $\left({ }^{\circ} \mathrm{C}\right)$, y I es la irradiancia solar en el plano del captador solar en $\left(\mathrm{W} / \mathrm{m}^{2}\right)$.

\section{Modelo captador solar con redes neuronales artificiales}

Las redes neuronales artificiales son masivamente paralelas, los sistemas de procesamiento distribuido representan una tecnología de computación basada en la similitud con el sistema biológico humano para procesar la información. Las redes neuronales artificiales partieron de la idea original de la neurofisiología en (Hebb, 1949) sobre la estructura y el funcionamiento de un sistema neuronal biológico. Los principios fueron sentados por (McCulloch y Pitts, 1943) que utilizando la lógica formal, modelaron redes neuronales artificiales utilizando las neuronas a la manera de dispositivos binarios con umbrales fijos, conectados entre si por sinapsis. (Rosenblatt, 1958) amplió la idea de la computación neuronal al perceptron como elemento de una red computacional autorganizada capaz de aprender por la realimentación y por la adaptación estructural.

Los investigadores usan los diferentes tipos de red como posibles alternativas. (Amari y Maginu, 1988) con redes autorganizadas. (Grossberg, 1987) redes neuronales de resonancia. (Werbos, 1974) redes feedforward. (Kohonen, 1989) redes de memoria asociativa. (Hecht-Nielsen, $1987)$ redes counterpropagation. (Elman, 1990) redes recurrentes. (Broomhead y Lowe, 1988) redes de función de base radial. (Specht, 1988) redes probabilísticas.
Las redes más manejadas en la ingeniería son las redes multilayer perceptron MLP y las redes de base radial RBF. Fundamentado en las propiedades para el aprendizaje y la generalización a partir de los datos de las observaciones, las redes neuronales artificiales han sido ampliamente admitidas por los ingenieros y los investigadores como una herramienta para el procesamiento de los datos experimentales (Palit y Popovic, 2005). El uso práctico de las redes neuronales artificiales ha sido reconocido por propiedades tan distinguidas, como en los procesos de asignación no lineal entre un subconjunto de valores pasados de la serie de tiempo y los valores futuros de la serie de tiempo, la habilidad de encontrar las relaciones funcionales esenciales entre los datos, lo que es útil cuando las relaciones no son a priori conocidas o son muy difíciles de describir matemáticamente y/o cuando los datos de la observación están dañados por el ruido, la habilidad de la aproximación a una función universal que permite el modelado de funciones continuas arbitrarias no lineales en cualquier grado de exactitud, y la habilidad de aprendizaje y generalización a través de los ejemplos con el manejo de datos de una forma autoconfigurable. El software desarrollado en los últimos tiempos es de gran utilidad para solucionar los problemas mediante redes neuronales artificiales.

Las redes neuronales artificiales pertenecen a la clase de enfoques basados en datos, en lugar de enfoques basados en modelos para el análisis y los resultados dependen de los resultados disponibles o simulados (Chakraborty, 1992). Las relaciones entre las variables se construyen después de realizar un artificio que simula los datos considerados.

(Farkas y Géczy-Víg, 2003) utiliza para modelar los captadores solares un modelo basado en redes neuronales artificiales, se ofrece su utilidad cuando otros modelos presentan dificultades en su aplicación. Las variables de entrada son la irradiancia solar, la temperatura de entrada del fluido portador al captador y la temperatura del ambiente, la salida resulta ser la temperatura de salida del fluido portador del captador. El entrenamiento de la red neuronal artificial se realiza con datos medidos para las entradas del modelo y/o con simulados por el modelo Hottel-Whillier-Bliss para la salida.

(Kalogirou, 2006) muestra cómo utilizar los datos experimentales de los ensayos de rendimiento en los captadores solares, mediante redes neuronales artificiales para realizar la predicción de los parámetros del rendimiento, evitando ensayos prolongados. 
(Sözen, 2008) crea una ecuación cuyos coeficientes se calculan mediante una red neuronal artificial, para la determinación del rendimiento de un captador solar, a partir de los datos experimentales, utilizando como variables de entrada a la red neuronal artificial la fecha, la hora, la temperatura de la superficie, la irradiancia solar y los ángulos de declinación, el azimut y la inclinación. (Fischer et al., 2012) propone utilizar las redes neuronales artificiales como alternativa al método de la norma europea EN 12975-2 para el modelado de otros tipos de captadores al de placa plana, que no pueden realizarse con la misma precisión. El modelo de red neuronal artificial es de tipo no lineal autorregresivo con entradas exógenas NARX, tiene como variables de entrada la irradiancia solar directa y difusa, la diferencia de temperatura entre el fluido portador en la entrada del captador solar y el ambiente, y el caudal másico del fluido portador en el captador solar, la salida es la energía calorífica del fluido portador en la propia salida del captador solar.

\section{REFERENCIAS}

[1] Amari S, Maginu K. Statistical neurodynamics of associative memory. Neural Networks 1988;1(1):63-73.

[2] Amer EH, Nayak JK, Sharma GK. Transient test methods for flat-plate collectors: Review and experimental evaluation. Solar Energy 1997;60(5):229-43.

[3] Arinze EA, Schoenau GJ, Sokhansanj S, Adefila SS, Mumah SM. A dynamic performance simulation model of flat- plate solar collectors for a heat pump system. Energy Conversion and Management 1993;34(1):33-49.

[4] Bliss RW]. The derivations of several "Plate-efficiency factors" useful in the design of flat-plate solar heat collectors. Solar Energy 1959;3(4):55-64.

[5] Broomhead DS, Lowe D. Multivariable functional interpolation and adaptive networks. Complex Systems 1.988;2:321-55.

[6] Cener-Ciemat. Informe de ensayo de captador solar térmico T3-Inox Takama 30.0184.0-1. Sarriguren, Navarra; 2006.

[7] Chakraborty K, Mehrotra K, Mohan CK, Ranka S. Forecasting the behavior of multivariate time series using neural networks. Neural Networks 1992;5(6):961-70.

[8] Cruz-Peragon F, Palomar JM, Casanova PJ, Dorado MP, Manzano-Agugliaro F. Characterization of solar flat plate collectors. Renewable and Sustainable Energy Reviews 2012;16(3):1709-20.

[9] Demuth $H$, Beale M, Hagan M. Neural network toolbox. User's guide Matlab. The MathWorks 2010.

[10] Duffie JA, Beckman WA. Solar engineering of thermal processes. 3rd ed. New Jersey: Wiley; 2006. 
[11] El-Adawi MK. New approach to modelling a flat plate collector: the Fourier transform technique. Renewable Energy 2002;26(3):489-506.

[12] Elman JL. Finding structure in time. Cognitive Science 1990;14(2):179-211.

[13] Emery M, Rogers BA. On a solar collector thermal performance test method for use in variable conditions. Solar Energy 1984;33(2):117-23.

[14] EN 12975-2. EN 12975-2:2006. Thermal Solar Systems and Components - Solar Collectors - Part 2: Test Methods.

[15] Farkas I, Géczy-Víg P. Neural network modelling of flatplate solar collectors. Computers and Electronics in Agriculture 2003;40(1-3):87-102.

[16] Fischer S, Frey P, Drück H. A comparison between stateof-the-art and neural network modelling of solar collectors. Solar Energy 2012;86(11):3268-77.

[17] Frid SE. Multinode models and dynamic testing methods of solar collectors. Solar \& Wind Technology 1990;7(6):655-61.

[18] Grossberg S. Competitive learning: From interactive activation to adaptive resonance. Cognitive Science 1987;11(1):23-63.

[19] Hebb DO. The organisation of behaviour. New York: Wiley; 1949.

[20] Hecht-Nielsen R. Kolmogorov's mapping neural network existence theorem. Proceedings of the First International Conference on Neural Networks IEEE 1987;3:11-3.

[21] Hottel HC, Whillier A. Evaluation of flat plate collector performance. Transactions of the Conference on the Use of Solar Energy. Part I, vol. 2. University of Arizona Press 1955;:74-104. [22] Hottel HC, Woertz BB. Performance of flat-plate solar-heat collectors. Transactions of American Society of Mechanical Engineers 1942;64:91.

[23] Hou H, Wang Z, Wang R, Qi B. Transient test method for thermal performance of flat-plate solar collectors. Taiyangneng Xuebao/Acta Energiae Solaris Sinica 2004;25(3):310-4.

[24] Kalogirou SA. Prediction of flat-plate collector performance parameters using artificial neural networks. Solar Energy 2006;80(3):248-59.

[25] Kalogirou SA. Solar thermal collectors and applications. Progress in Energy and Combustion Science 2004;30(3):231-95.

[26] Kazeminejad $H$. Numerical analysis of two dimensional parallel flow flat-plate solar collector. Renewable Energy 2002;26(2):309-23.

[27] Klein SA. Calculation of flat-plate collector utilizability. Solar Energy 1978;21(5):393-402.

[28] Kohonen T. Self-organization and associative memory. Berlin; New York: Springer-Verlag; 1989.

[29] Kong W, Wang Z, Fan J, Bacher P, Perers B, Chen Z, et al. An improved dynamic test method for solar collectors. Solar Energy 2012;86(6):1838-48.

[30] Liu BYH, Jordan RC. The long-term average performance of flat-plate solar-energy collectors: With design data for the
U.S., its outlying possessions and Canada. Solar Energy 1963;7(2):53-74.

[31] Matuska T, Zmrhal, V, Metzger, J,. Detailed modeling of solar flat-plate collectors with design tool Kolektor 2.2. Eleventh International IBPSA Conference Building Simulation, Glasgow 2009:2289-96.

[32] McCulloch WS, Pitts W. A logical calculus of the ideas immanent in nervous activity. Bulletin of Mathematical Biophysics 1943;5:115-33.

[33] Palit AK, Popovic D. Computational intelligence in time series forecasting. Theory and engineering applications. London: Springer; 2005.

[34] Perers B. Dynamic method for solar collector array testing and evaluation with standard database and simulation programs. Solar Energy 1993;50(6):517-26.

[35] Perers B, Walletun $H$, et al. Dynamic Collector Models for 1 hr Time Step Derived From Measured Outdoor Data. Pergamon Press 1991.

[36] Perers B. An improved dynamic solar collector test method for determination of non-linear optical and thermal characteristics with multiple regression. Solar Energy 1997;59(4-6):163-78.

[37] Peuser FA, Remmers K, Schnauss M. Solar thermal systems: successful planning and construction. Berlin: Solarpraxis; 2002.

[38] Rosenblatt F. The Perceptron: A probabilistic model for information storage and organisation of the brain. Psychological Review 1958;65:386-408.

[39] Sözen A, Menlik T, Ünvar S. Determination of efficiency of flatplate solar collectors using neural network approach. Expert Systems with Applications 2008;35(4):1533-9.

[40] Specht DF. Probabilistic neural networks for classification, or associative memory. Proc. of IEEE Intern. Conf. on Neural Networks 1988;1:525-32.

[41] Wagner Solar. 400 preguntas. Resuelva sus dudas sobre la energía solar térmica. Era Solar 2009; 153: 58-62.

[42] Wang BW. Tesis: Solar Collector Thermal Performance Dynamic Test. Institute of Electrical Engineering, Chinese Academy of Sciences 2008.

[43] Werbos PJ. Tesis. Beyond regression: New tool for prediction and analysis in the behavioural sciences. Cambridge: Universidad de Harvard; 1974.

[44] Whillier A. Tesis: Solar energy collection and its utilization for house heating. MIT Massachusetts Institute of Technology 1953.

[45] Whillier A. Thermal resistance of the tube-plate bond in solar heat collectors. Solar Energy 1964;8(3):95-8.

[46] Xu L. Tesis: Research on Dynamic Test Method for Thermal Performance of Solar Collectors. Northeast University 2009. 


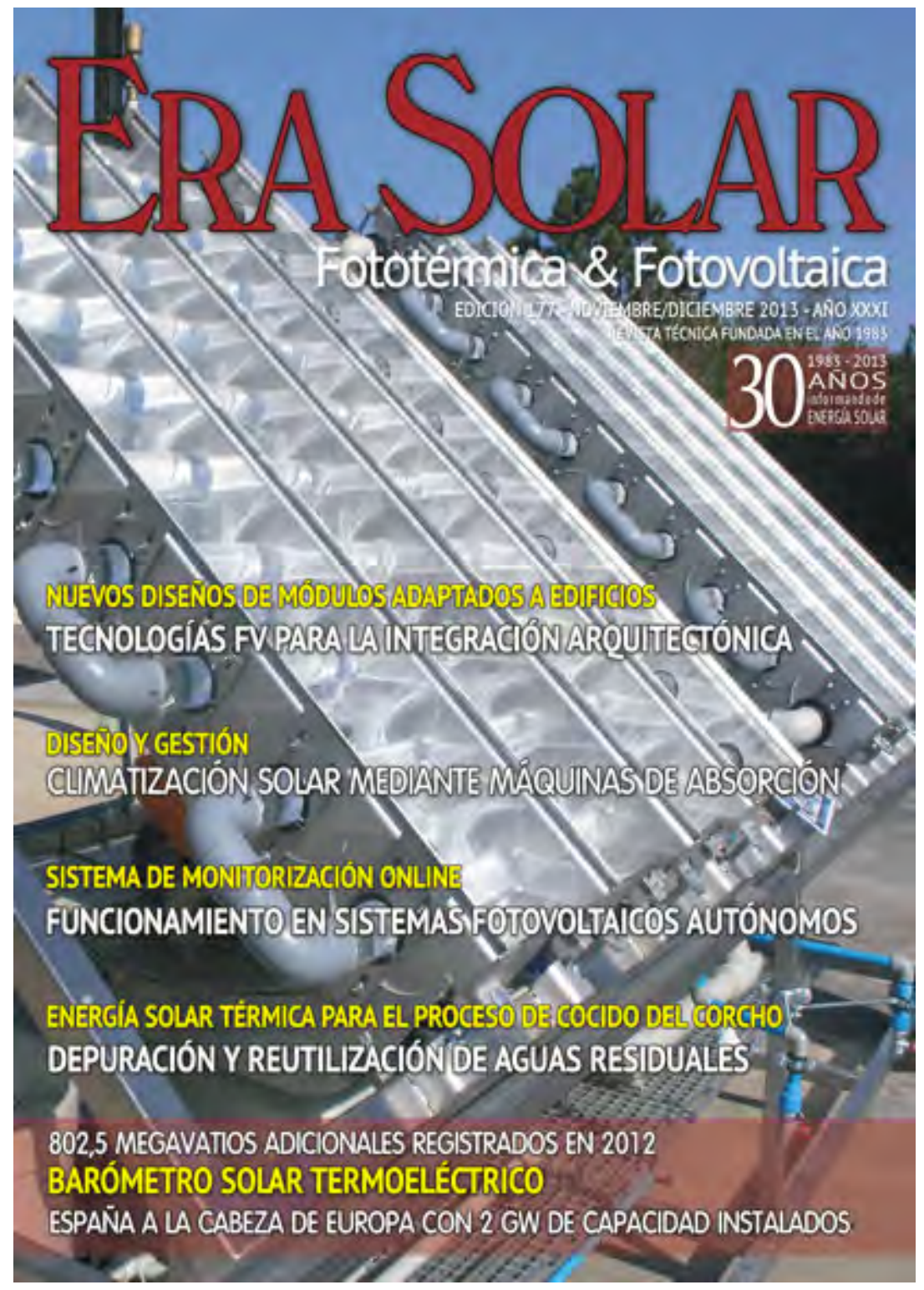



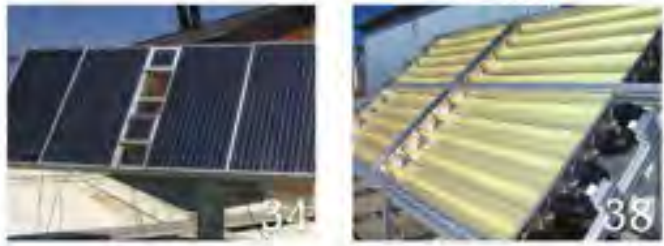

530 años, Una panorámica de la energia solar 1983/2013.

B. Nuevos diseños de módulos adaptados a edificios. Tecnologias fotovoitaicas para ta integración arquitectónica.

14 Actualización del DB-HE del Código Teeriça de la Edificación (CTE), Modificación del HES sobre "Contribucićn fotowaltaica minima de energia eléctricas.

18 Diseño y gestión. Instataciones de climatización solar mediante máquinas de absorción

26 Barometro solar termaeléctrico 2012. Esparia sigue a la cabeza de Europa con casi 2 Gigavatios de capacidad instalada

34 Sistema de monitorización online. Analisis del funcionamiento de sistemas fotovoltaicos autónomos.

38. Aprovechamiento de la energia solar termica. Depuración y retutilización de aguas residuales generadas durante el proceso de cocido del corcho.

42 Sistemas solares tèrmicos.

Modelado del captador mediante redes neuronales artificiales (ii).

56. El Gobierno apaga la luz al autoconsumo.

58 Autoconsumo: Verdades y falsedades.

60 Protocolo de Colaboración Aspencia Andaluza de la Energia (AAE) y ASIT. 


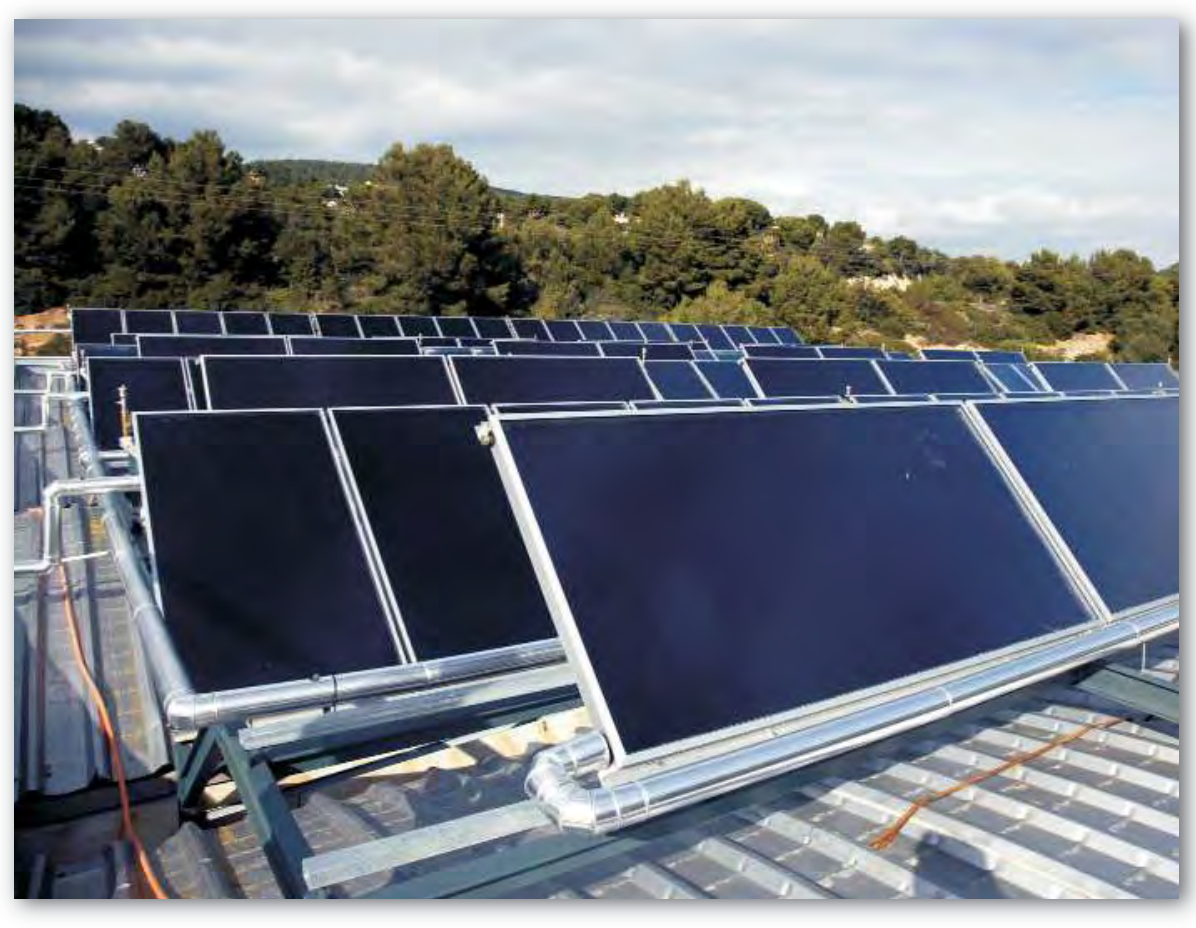

Sistemas solares térmicos

\section{Modelado del captador mediante redes neuronales artificiales (II)}

F.J. Diez, J.L. Falagán

La inteligencia computacional dispone de una herramienta que ofrece grandes posibilidades a la hora de ser aplicada en el modelado del funcionamiento de captadores solares, de forma flexible y abierta a modelos distintos: las redes neuronales artificiales. Aplicando dicha técnica derivada de la inteligencia artificial, investigadores del Departamento de Ingeniería Eléctrica y de Sistemas y Automática de la Universidad de León (España) han realizado un análisis experimental del modelado del funcionamiento de un sistema solar térmico de placa plana.

Como se indicaba en la primera parte de este artículo - publicado en la edición anterior de Era Solar, número 176 (Septiembre/Octubre 2013)- el trabajo de investigación detalla los distintos componentes utilizados en el proyecto tales como: el captador solar, el circuito primario del sistema solar térmico al que está acoplado, el sistema de adquisición de datos y la metodología teórica y experimental empleadas. Asimismo, se describe por un lado, la fórmula del clásico modelo del captador solar de Hottel-Whillier-Bliss y, por otro, el actual modelo de la norma europea EN 12975. Tras la aplicación de sendos modelos a los datos registrados en los ensayos realizados al captador solar utilizando diferentes caudales del fluido portador, se deduce la ecuación característica de su rendimiento, y se comprueban las desviaciones que se producen al no tener en cuenta las especificaciones concretas de cada método.

Los resultados obtenidos del modelado del captador solar mediante una red neuronal artificial resultan ser un método preciso, flexible y fácil de aplicar a cualquier captador solar, ya instalado. Asimismo, la metodología es extensible al campo de captación completo realizando el modelado de todos los captadores instalados en un sistema solar térmico.

\section{EXPERIMENTO Y ANÁLISIS}

Los experimentos contienen los periodos de calentamiento que comienzan sobre las 10 horas en un día soleado, con la bomba de impulsión del fluido portador siempre en funcionamiento en el circuito primario del sistema solar térmico. El depósito unos días está más caliente que otros, dependiendo del agua caliente solar consumida y de las condiciones climatológicas del día anterior.

A lo largo del día se procede a realizar descargas de agua caliente solar del depósito de entre 50 y 150 litros, a un caudal de entre 1 y 1,6 $\mathrm{I} / \mathrm{min}$. El ensayo diario termina sobre las 18 horas cuando el captador deja de recibir la insolación.

Durante el ensayo se van registrando cada dos segundos en el ordenador los valores de las variables medidas por los sensores en el captador solar de la irradiancia solar, la temperatura de entrada y salida del fluido portador y la temperatura ambiente.

Los ensayos diarios se repiten varios días con distinto caudal de la bomba de impulsión de 2, 1,6 y 1 l/min.

Los datos medidos cada dos segundos son promediados en un minuto, para ser utilizados en el modelado.

\section{Modelo captador solar}

Hottel-Whillier-Bliss

Del ensayo realizado al captador solar en el día 4-7-2011, con un caudal del fluido portador de 2 l/min, resulta una ecuación característica:

$$
\eta=0,64-5,4\left(\frac{T_{e}-T_{a}}{I}\right)
$$

También se calcularon las ecuaciones características para el captador solar respecto a las temperaturas de entrada, media y de salida con los datos registrados en el ensayo del día 29-8-2011, que se representan en la figura 2 , resultando: 
Respecto a la temperatura de entrada la ecuación característica:

$\eta=0,66-7,7\left(\frac{T_{e}-T_{a}}{I}\right)$

Respecto a la temperatura media:

$\eta=0,69-7,8\left(\frac{T_{m}-T_{a}}{I}\right)$

Respecto a la temperatura de salida:

$\eta=0,72-8,1\left(\frac{T_{s}-T_{a}}{I}\right)$

De lo que se observa, que los coeficientes de la recta, que simboliza la ecuación característica del captador solar, aumentan al utilizar la temperatura de salida respecto de la media, y esta respecto de la entrada al captador solar.
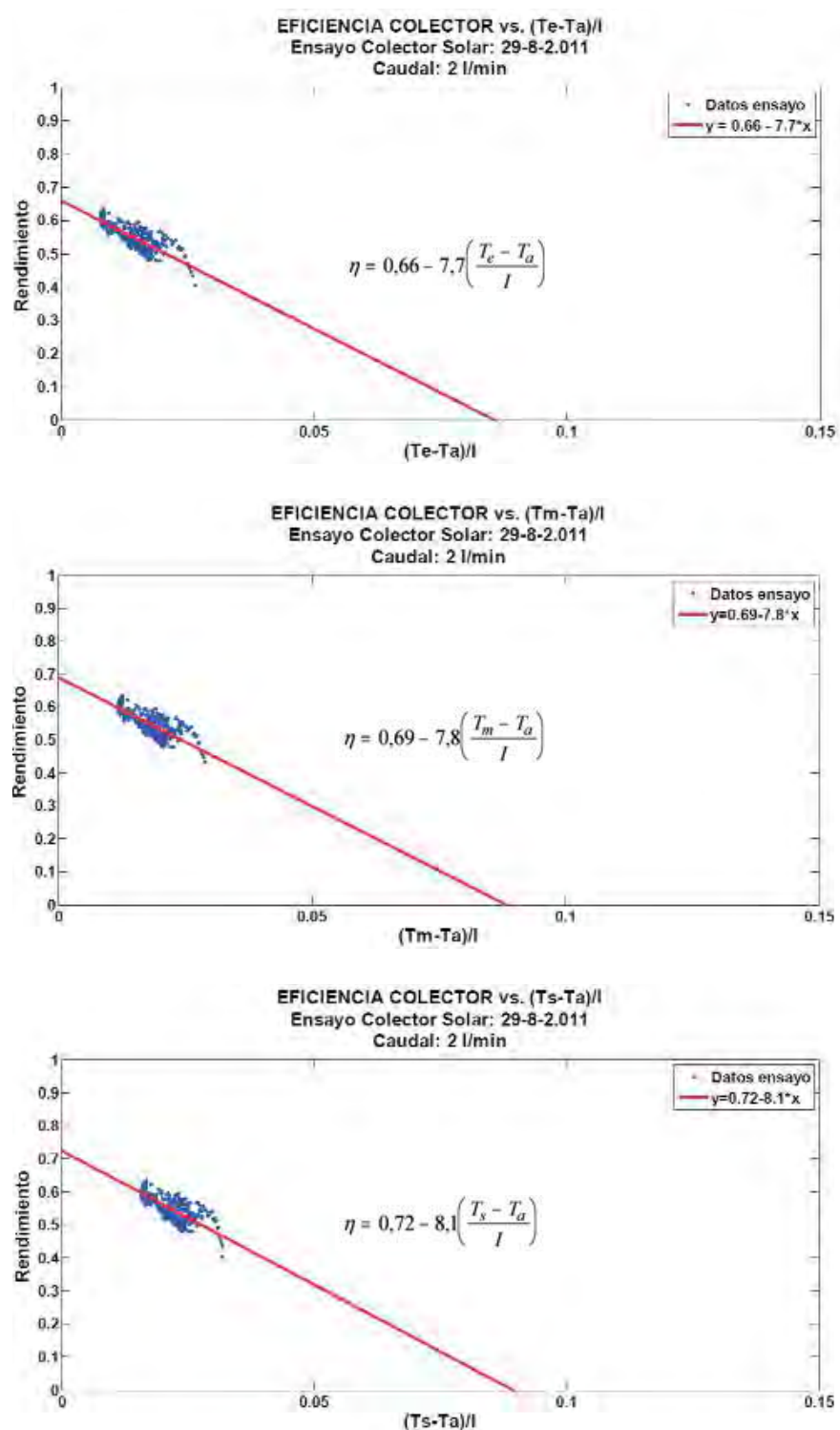

Figura 2.- Ecuación característica del captador solar resultado del ensayo en el día 29-8-2011, respecto a la temperatura de entrada, media y de salida. 


\section{Caudal en el captador solar}

El caudal recomendado en el captadorpor el método "fchart" para una mezcla (50-50, etilenglicol-agua) es de $0,015 \mathrm{l} /\left(\mathrm{s} \cdot \mathrm{m}^{2}\right)=0,9 \mathrm{l} /\left(\min \cdot \mathrm{m}^{2}\right)$, que en el captador solar con una superficie de 1,85 $\mathrm{m}^{2}$ corresponde a 1,665 (1/min). El método "f-chart" sólo tiene en cuenta el efecto del caudal a partir de la variación de $F_{R}$ (Wagner Solar, 2009).

Se realizaron distintos ensayos con el captador solar a lo largo de un año, utilizando tres caudales en el fluido portador de 2, 1,6 y $1 \mathrm{l} / \mathrm{min}$, el resultado del rendimiento del captador solar respecto de $\left(T_{-}-T_{a}\right) / I$ se muestra en la gráfica de la figura 3 , donde se pueden apreciar tres zonas distintas de funcionamiento del captador solar.

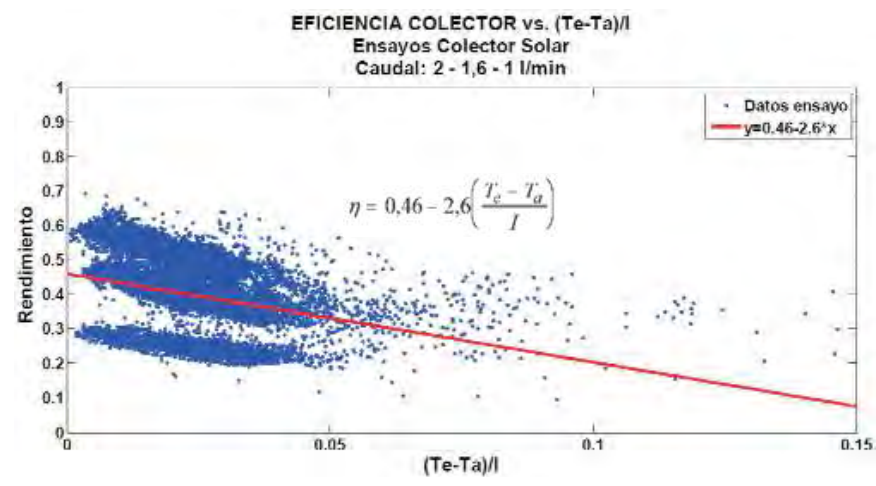

Figura 3.- Ensayos realizados con el captador solar al variar el caudal del fluido portador en 2, 1,6 y $1 \mathrm{l} / \mathrm{min}$ y la ecuación característica resultante.

Se crean tres zonas en el funcionamiento del captador solar, con tres concentraciones en la zona alta, intermedia y en la zona baja de rendimiento. Se atribuye su distribución a los distintos caudales de circulación del fluido portador, ya que al utilizar un caudal mayor conlleva un aumento del rendimiento del captador (al aumentar la velocidad de extracción de energía útil de la placa del captador solar).

Para comprobarlo, se separaron los ensayos realizados con el captador solar en tres grupos, correspondientes a los tres caudales de ensayo utilizados. Los resultados se muestran en las gráficas de la figura 4 con los datos de los ensayos de varios días. En estos ensayos se comprueba que cada caudal lleva al captador solar a una zona de funcionamiento determinada, con un rendimiento mayor con el caudal del fluido portador más alto. En la figura 5 se representa el ensayo para un sólo día con distintos caudales de fluido portador por el captador solar.

De los ensayos con el captador solar se observa que el caudal de fluido portador que circula por el captador solar, influye en los valores de los coeficientes $F_{R}(\tau \alpha)_{n}$ y $\mathrm{F}_{\mathrm{R}} \mathrm{U}_{\mathrm{L}}$ que corresponden con la intersección con el eje vertical y la pendiente respectivamente de la ecuación característica del captador solar.

El valor de $F_{R}(\tau \alpha)_{n}$ y el valor de $F_{R} U_{L}$ aumentan con el caudal del fluido portador en el captador solar.

\section{Modelo captador solar EN 12975-2}

La curva de eficiencia está basada en el área del absorbedor y la temperatura media: $800 \mathrm{~W} / \mathrm{m}^{2}$ de irradiancia solar media y $0,018 \mathrm{~kg} /\left(\mathrm{s}^{\cdot} \mathrm{m}^{2}\right)$ de caudal de agua como fluido portador en el captador solar según el laboratorio de ensayos (Cener-Ciemat, 2006). Siguiendo el método de ensayo descrito en la norma EN-12975, resulta la ecuación característica:

$$
\eta=0,693-4,972 \cdot\left(\frac{T_{m}-T a}{I}\right)-0,022 \cdot I \cdot\left(\frac{T_{m}-T_{a}}{I}\right)^{2}
$$
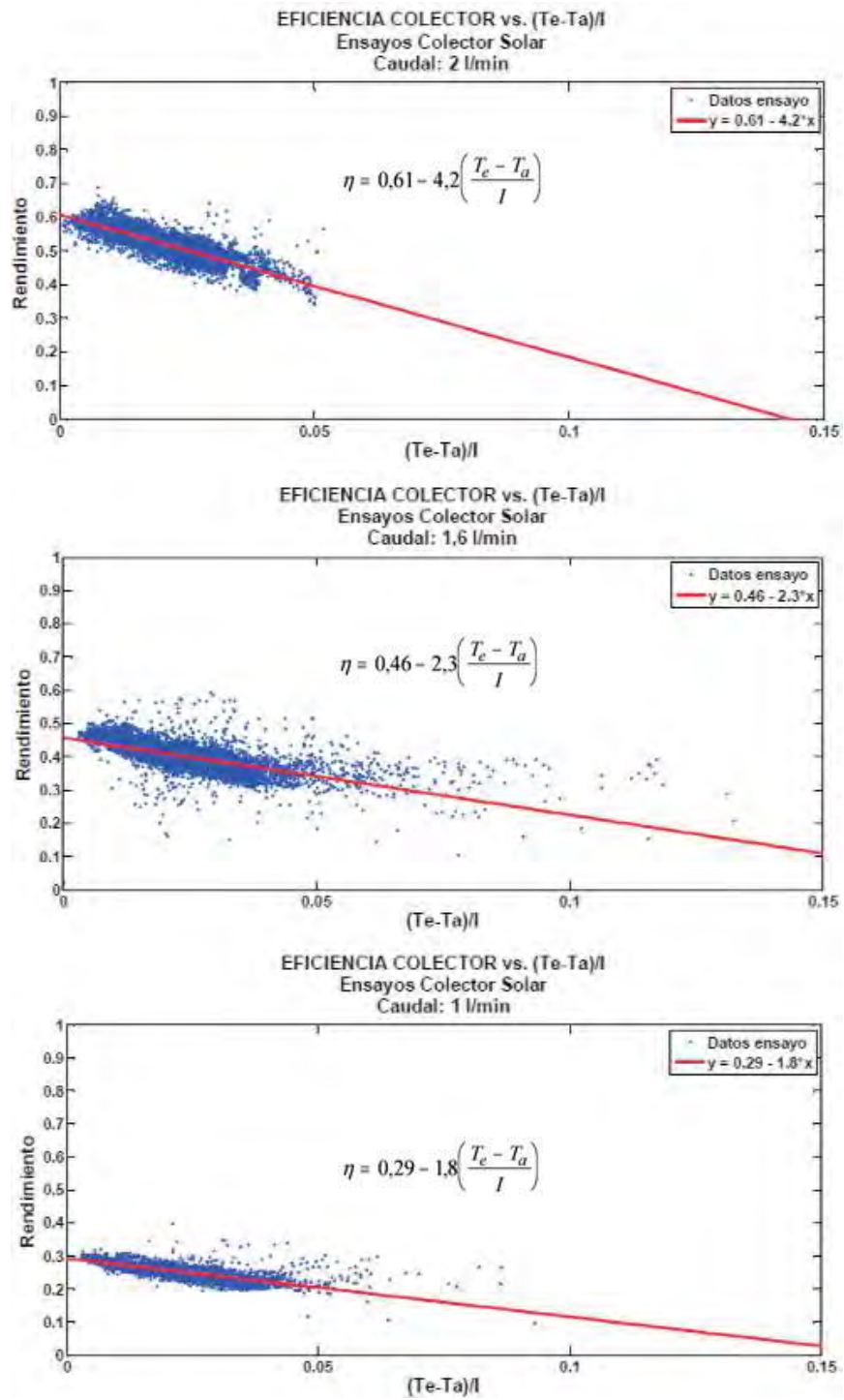

Figura 4.- Ensayos realizados con el captador solar separados según el caudal del fluido portador de 1, 1,6 y 2 l/min y ecuación característica resultante, en cada caso. 

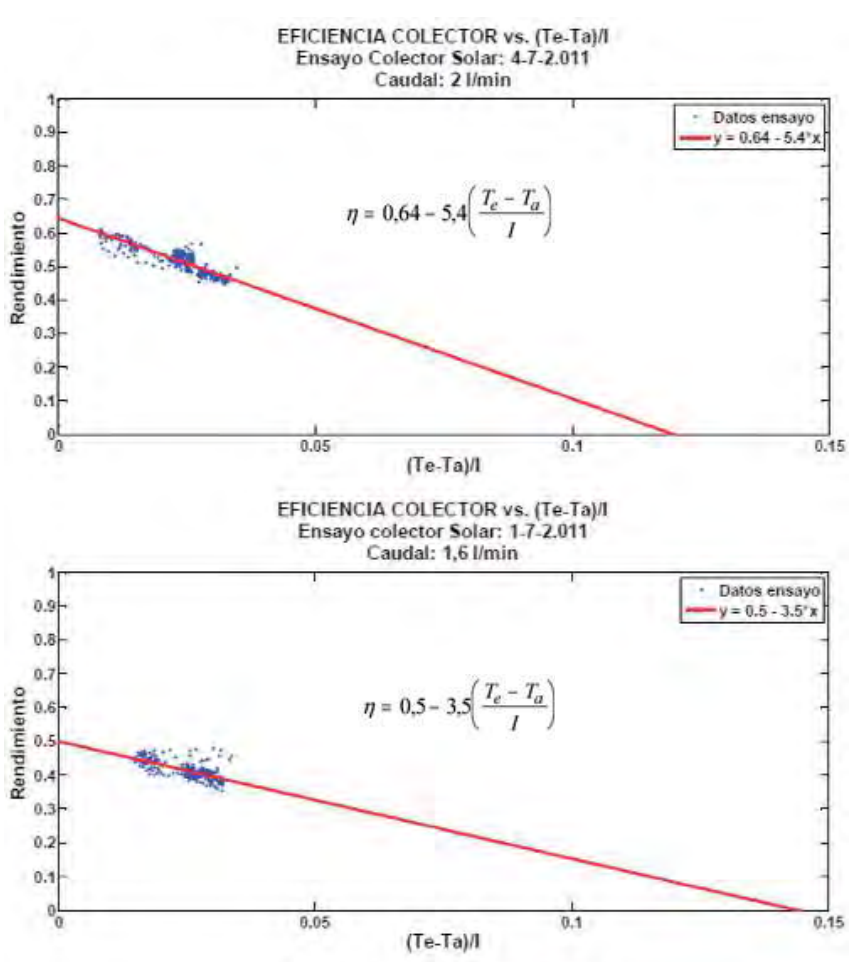

EFICACIA COLECTOR vs. (Te-Ta)// Ensayo Colector Solar: 21-9-2.011

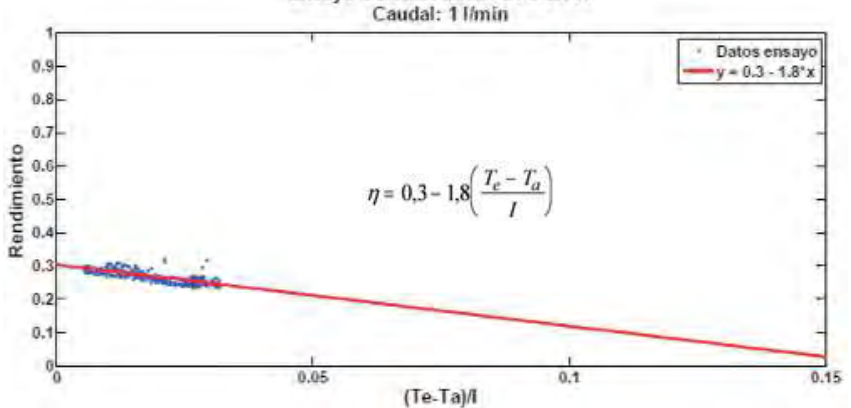

Figura 5.- Ecuación característica del captador solar resultado del ensayo al variar el caudal del fluido portador en 2, 1,6 y $1 \mathrm{l} / \mathrm{min}$.

En la figura 6 se representan los valores obtenidos en cada intervalo de tiempo de un minuto, con los datos registrados durante varios días de ensayos realizados con el captador solar, junto con la curva de eficiencia del laboratorio Cener (a $800 \mathrm{~W} / \mathrm{m}^{2}$ ).

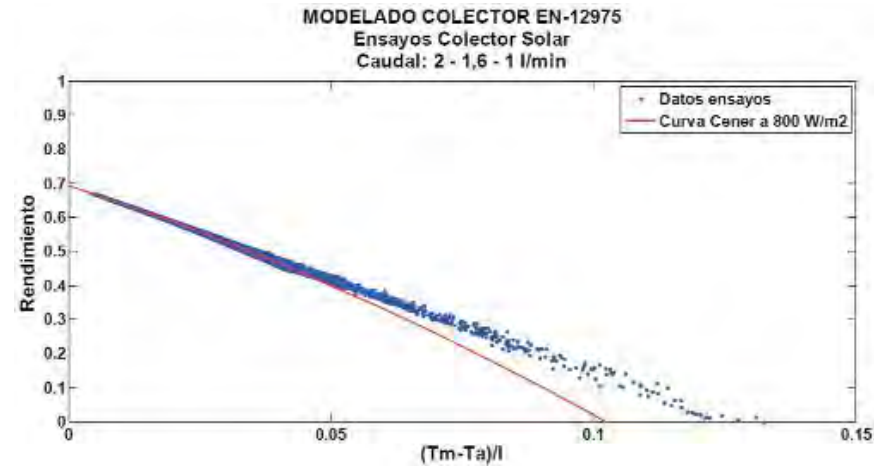

Figura 6.- Modelado del captador EN-12975, resultados obtenidos con los datos registrados cada minuto en los ensayos del captador solar, y curva del laboratorio Cener a $800 \mathrm{~W} / \mathrm{m}^{2}$ de irradiancia solar media.

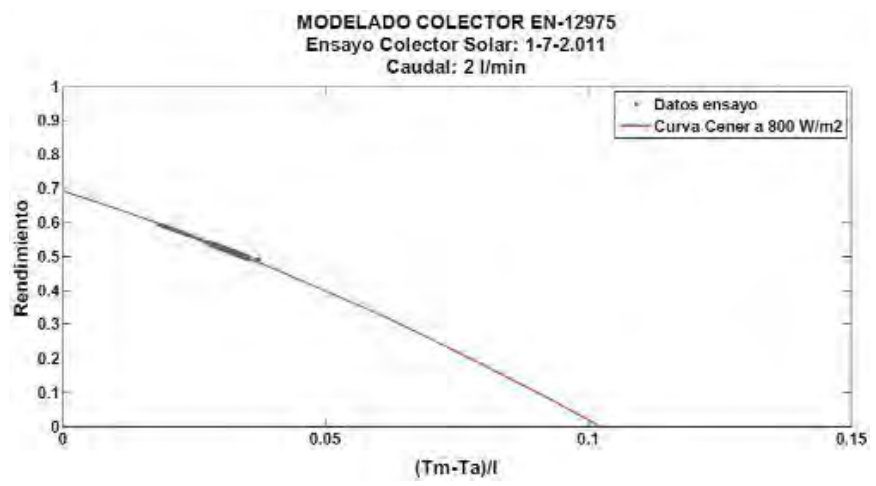

Figura 7.- Modelado del captador EN-12975, resultados obtenidos con los datos registrados cada minuto en el ensayo del captador.

Se observan desviaciones en la segunda mitad de la gráfica, debido a que esos puntos están con una irradiancia solar más alejada del valor de la irradiancia solar media con la que la curva fue realizada por el laboratorio, en la que irradiancia solar sobre el plano del captador solar siempre es mayor de $650 \mathrm{~W} / \mathrm{m}^{2}$. La curva del ensayo realizado por el laboratorio Cener se obtuvo para un caudal de agua de $0,018 \mathrm{~kg} /\left(\mathrm{s}^{\cdot} \mathrm{m}^{2}\right)$, que en el captador solar estudiado equivale a un caudal de agua de $2 \mathrm{l} / \mathrm{min}$. El ensayo realizado el día 1-7-2011, soleado y despejado, en el que los valores de irradiancia solar registrados estaban en torno a $800 \mathrm{~W} / \mathrm{m}^{2}$, fue más ajustado a la curva Cener, como se muestra en la gráfica de la figura 7.

\section{Modelado del captador solar por balance energético}

La curva de eficiencia " $h$ ", basada en el área del absorbedor y la temperatura se define como la relación de la energía que el captador solar ha conseguido absorber y la energía solar que incide sobre su superficie y recibe en el mismo intervalo de tiempo (3).

Para el caso de los ensayos realizados con el captador solar durante intervalos de tiempo de un minuto y teniendo en cuenta la equivalencia de $1 \mathrm{~kJ}=1.000 \mathrm{~W} \cdot \mathrm{s}$, resulta para su cálculo la ecuación:

$\eta=\frac{m \cdot c_{e} \cdot\left(T_{s}-T_{e}\right)}{I \cdot A \cdot 60 / 1.000}$

Donde, ' $m$ ' es el caudal másico del fluido portador en $(\mathrm{kg} / \mathrm{min}) ;$ ' $\mathrm{c}_{\mathrm{e}}$ ' es el calor especifico del fluido portador que para el caso del agua se toma 4,18 en $\left(\mathrm{kJ} /\left(\mathrm{kg} \cdot{ }^{\circ} \mathrm{C}\right)\right) ;{ }^{\prime} \mathrm{T}_{\mathrm{s}}$ ' es la temperatura de salida, $\mathrm{y}^{\prime} \mathrm{T}_{\mathrm{e}}$ ' es la temperatura de entrada del fluido portador al captador, ambas en $\left({ }^{\circ} \mathrm{C}\right)$.

Se comparan los resultados obtenidos mediante el balance energético realizado al captador en función del diferencial de la temperatura entre el fluido de la entrada y la salida del captador solar, junto con los valores 
obtenidos con el método de ensayo descrito en la norma EN 12975 función de la temperatura media del fluido en el captador, en las gráficas de las figura 8. Cada uno de los tres ensayos se realizó a un caudal del fluido portador distinto de 2, 1,6 y $1 \mathrm{l} / \mathrm{min}$, respectivamente.

Se observa la disminución del rendimiento del captador solar respecto la reducción en el caudal del fluido portador en el captador solar. La ecuación Cener a $800 \mathrm{~W} / \mathrm{m}^{2}$ está diseñada para un caudal de $2 \mathrm{l} / \mathrm{min}$, cuando se reduce el caudal en los ensayos este modelo no tiene en cuenta su efecto: de un $10 \%$ al utilizar el caudal de 1,6 $\mathrm{l} / \mathrm{min}$ y de un $25 \%$ al utilizar el caudal de $1 \mathrm{l} / \mathrm{min}$.

También se observa una variación en el rendimiento al variar las temperaturas de salida y de entrada al captador solar del fluido portador, coincidiendo con los con-
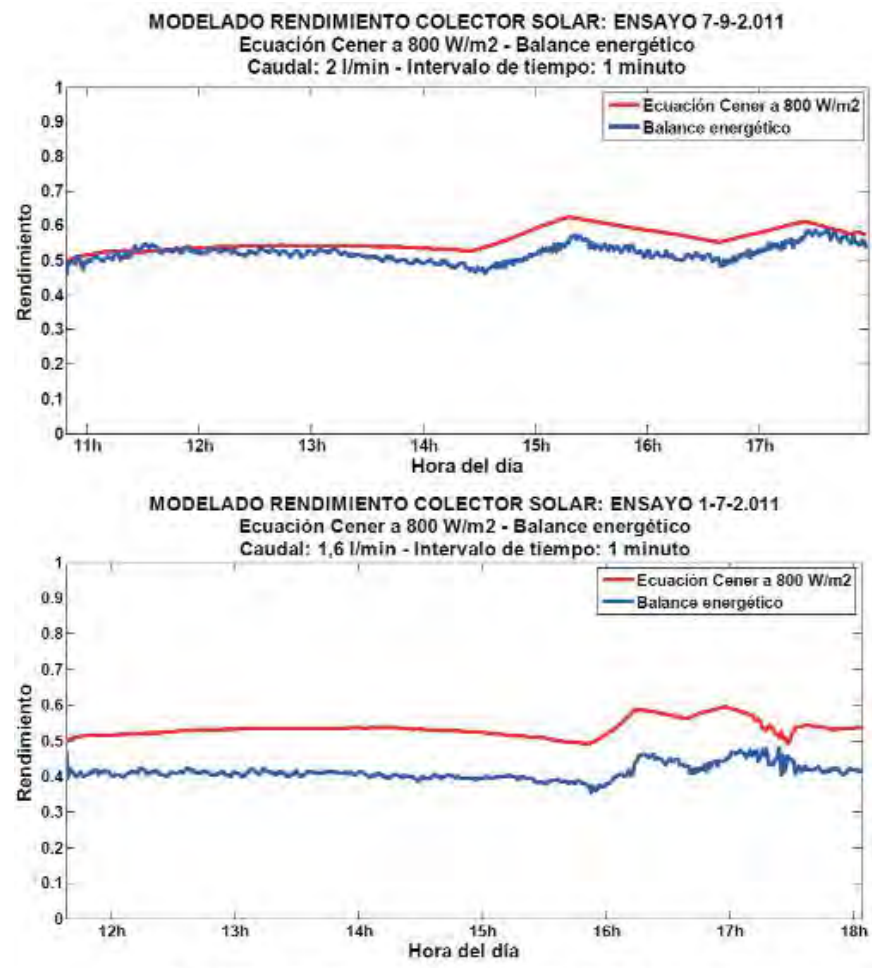

MODELADO RENDIMIENTO COLECTOR SOLAR: ENSAYO 21-9-2.011 Ecuación Cener a $800 \mathrm{~W} / \mathrm{m} 2$ - Balance energético

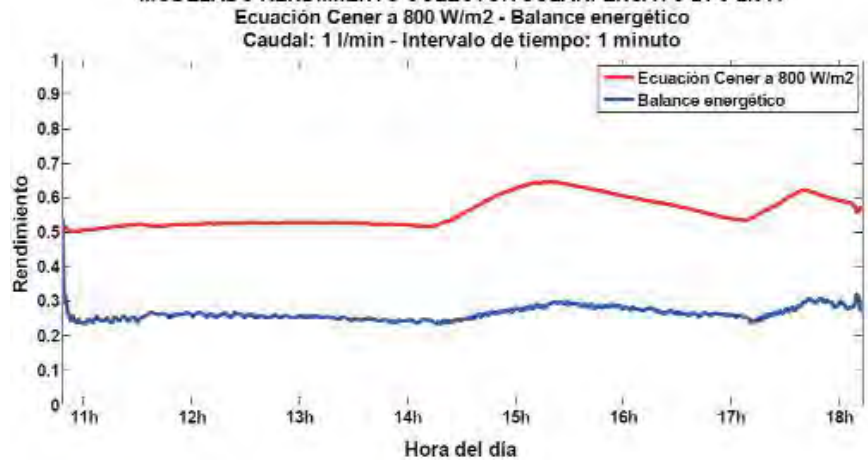

Figura 8.- Rendimiento instantáneo del captador solar de los datos registrados cada minuto con un caudal del fluido portador de 2, 1,6 y $1 \mathrm{l} / \mathrm{min}$, resultados obtenidos del balance energético y la ecuación Cener a $800 \mathrm{~W} / \mathrm{m}^{2}$ de irradiancia solar media a $2 \mathrm{l} / \mathrm{min}$.

\begin{tabular}{|c|c|}
\hline \multicolumn{2}{|c|}{$\begin{array}{l}\text { ARQUITECTURA DE LA RED NEURONAL EN EL MODELO DEL } \\
\text { CAPTADOR SOLAR }\end{array}$} \\
\hline $\begin{array}{l}\text { No de neuronas de las capas: } \\
\text { entrada-oculta-salida }\end{array}$ & $\begin{array}{l}\text { RMSE: } \\
\text { Temperatura de salida }\left({ }^{\circ} \mathrm{C}\right)\end{array}$ \\
\hline $4-1-1$ & 0,23 \\
\hline $4-2-1$ & 0,23 \\
\hline $4-3-1$ & 0,20 \\
\hline $4-4-1$ & 0,23 \\
\hline $4-5-1$ & 0,20 \\
\hline $4-6-1$ & 0,26 \\
\hline $4-7-1$ & 0,23 \\
\hline $4-8-1$ & 0,27 \\
\hline $4-9-1$ & 0,23 \\
\hline $4-10-1$ & 0,24 \\
\hline $4-20-1$ & 0,22 \\
\hline $4-30-1$ & 0,23 \\
\hline $4-40-1$ & 0,24 \\
\hline $4-50-1$ & 0,25 \\
\hline
\end{tabular}

Tabla 1.- Valores de RMSE obtenidos de salida de las RNA probadas con distintos números de neuronas en la capa oculta.

sumos de agua caliente solar desde el depósito acumulador y la correspondiente entrada de agua fría proveniente de la red. Esta bajada en la temperatura del fluido portador se transforma en un aumento en el rendimiento del captador solar.

\section{Modelo captador solar con redes neuronales artificiales}

En este trabajo, se propone realizar el modelado del captador solar mediante un modelo "black-box", implementado con tecnología de redes neuronales artificiales, utilizando para su realización los datos registrados en los ensayos de la irradiancia solar incidente sobre el captador solar, la temperatura ambiente del entorno del captador solar, la temperatura del fluido portador de entrada al captador solar y su caudal dado por la bomba de impulsión del circuito primario del sistema solar térmico, para obtener a la salida del modelo la temperatura del fluido portador en la salida del captador solar.

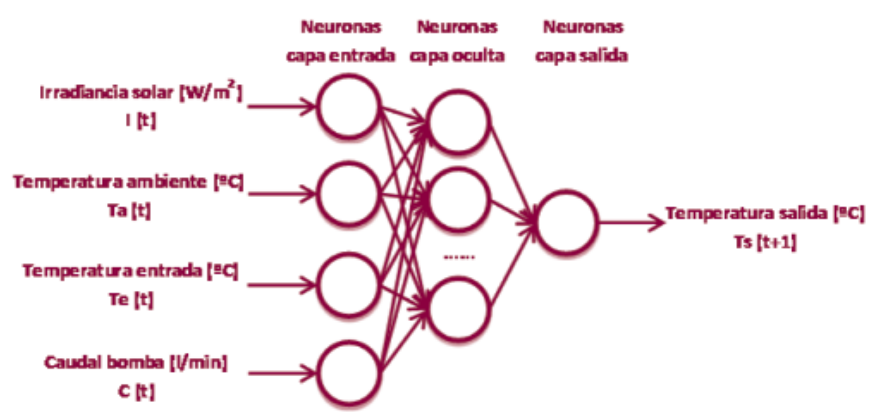

Figura 9.- Estructura de la RNA diseñada para la predicción de la temperatura de salida del captador, respecto de la irradiancia solar incidente, la temperatura ambiente, la temperatura de entrada del fluido portador y su caudal. 
La estructura de la red neuronal artificial diseñada para el modelado del comportamiento del captador solar tiene cuatro neuronas correspondientes a las variables de entrada: la irradiancia solar, la temperatura ambiente, la temperatura de entrada del fluido portador y su caudal. La capa de salida tiene una neurona, correspondiente a la temperatura de salida en el captador. Para la capa oculta se fueron probando distintos números de neuronas, calculando el valor RMSE para la salida obtenida y poder seleccionar la de mejores resultados. En la tabla 1 se muestra el valor de RMSE obtenido con las redes neuronales artificiales creadas con distinto número de neuronas en la capa oculta, para predecir la temperatura de salida en el captador solar.

La estructura de la red neuronal artificial diseñada para el modelado del comportamiento del captador solar se muestra en la figura 9, con la capa de entrada para cuatro neuronas correspondientes a: la irradiancia, la temperatura ambiente, la temperatura de entrada, y el caudal en el captador solar. La capa de salida tiene una neurona, correspondiente a la temperatura de salida del captador solar.

En este trabajo se escogió para la implementación de las redes neuronales artificiales "Neural Network Toolbox" de Matlab por la gran difusión que tiene el uso de este programa entre los ingenieros (Demuth et al., 2.010). A continuación se exponen las funciones que se utilizaron para ello.

Para la creación de la red neuronal se hace uso de la función 'newff' de la siguiente forma:

$>$ net $=$ newff $(x, y, h)$

Donde 'net' es la red feedforward backpropagation que resulta con la matriz de vectores de datos de entrada ' $x$ ', la matriz de vectores de datos de salida ' $y$ ', y el número escogido de neuronas de la capa oculta ' $h$ '. De esta forma queda determinado el tamaño de la capa de salida por la matriz ' $y$ ', las funciones de transferencia de las neuronas en la capa oculta como tangente sigmoidal hiperbólica 'tansig' y las neuronas de la capa de salida como lineal 'purelin'. También la función de entrenamiento de la red backpropagation Levenberg-Marquardt 'trainlm', la función de aprendizaje del sesgo y el momento del peso con gradiente descendente 'learngdm'; la función de rendimiento error medio cuadrado normalizado 'mse', las funciones de procesamiento de los elementos de la matriz de entrada como el procesado de datos para hacer las filas con datos desconocidos 'fixunknowns' y 'remconstantrows'; el procesado de matrices para hacer las filas con valores míni-

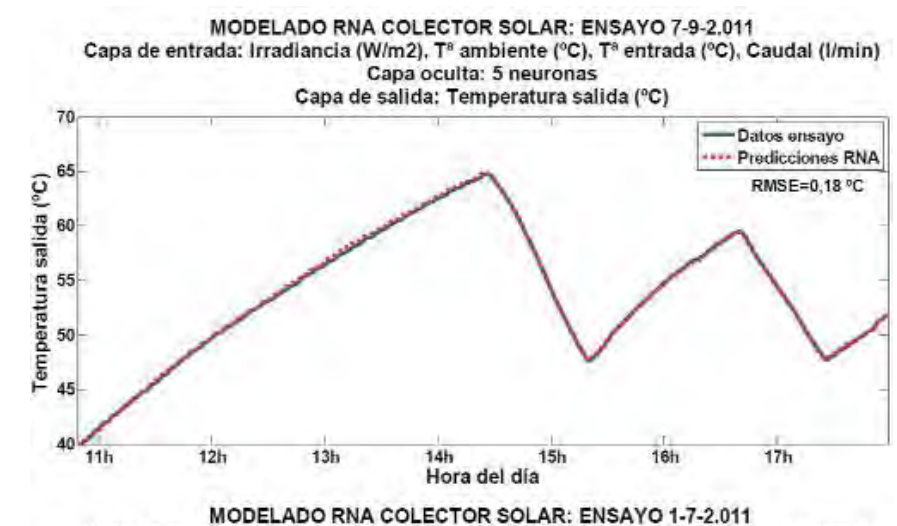

Capa de entrada: Irradiancia $(\mathrm{W} / \mathrm{m} 2), \mathrm{T}^{\mathrm{T}}$ ambiente $\left({ }^{\circ} \mathrm{C}\right), \mathrm{T}^{\mathrm{a}}$ entrada $\left({ }^{\circ} \mathrm{C}\right)$, Caudal $(\mathrm{l} / \mathrm{min})$ Capa oculta: 5 Neuronas

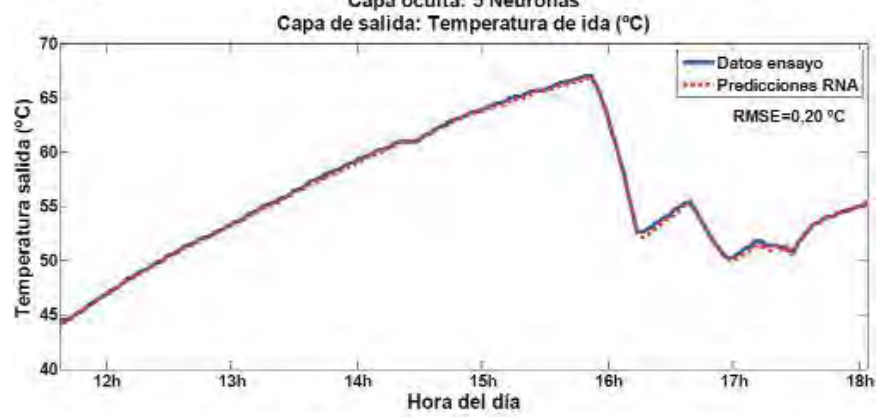

MODELADO RNA COLECTOR SOLAR: ENSAYO 4-10-2.011

Capa de entrada: Irradiancia $(\mathrm{W} / \mathrm{m} 2), \mathrm{T}^{\mathrm{T}}$ ambiente $\left({ }^{\circ} \mathrm{C}\right), \mathrm{T}^{\mathrm{a}}$ entrada $\left({ }^{\circ} \mathrm{C}\right)$, Caudal $(1 / \mathrm{min})$ Capa ocuita: 5 neuronas

Capa de salida: Temperatura salida $\left({ }^{\circ} \mathrm{C}\right)$

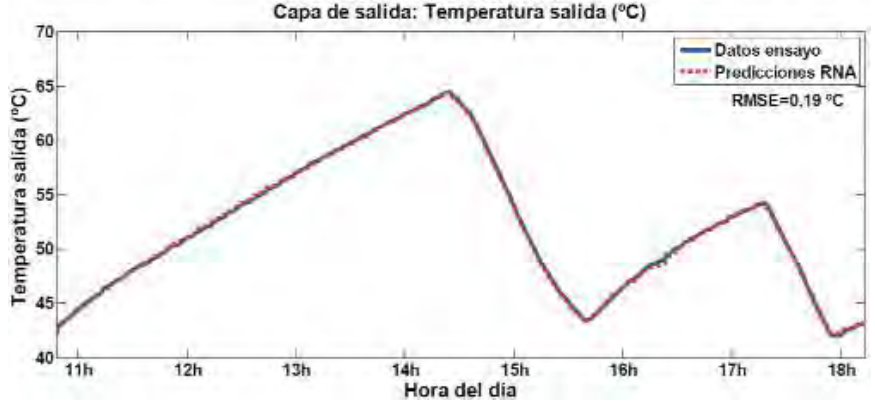

Figura 10.- Modelado RNA del captador solar, se representan Ios datos registrados cada minuto con un caudal del fluido portador de $2,1,6$ y $1 \mathrm{l} / \mathrm{min}$, y los resultados de las predicciones realizadas con la red neuronal artificial.

mos y máximos de [-1 1 - 'mapminmax', las funciones de procesamiento de los elementos de la matriz de salida 'removeconstantrows' y 'mapminmax'. Esta función retorna una red feedforward backpropagation de n-capas. Para el entrenamiento de la red neuronal se hace uso de la función 'train' de la siguiente forma:

$>$ net $=$ train (net, $x, y$ )

Donde 'net' es la red feedforward backpropagation que va a ser entrenada, que previamente ha sido creada, con la matriz de vectores de datos de entrada ' $x$ ' $y$ la matriz de vectores de datos de salida ' $y$ ', pudiéndose fijar las condiciones iniciales. Esta función retorna la red entrenada, graba el proceso de entrenamiento ('epoch' y rendimiento), dando las salidas de la red, los errores de la red, el estado final de la entrada y el estado final de las capas. 

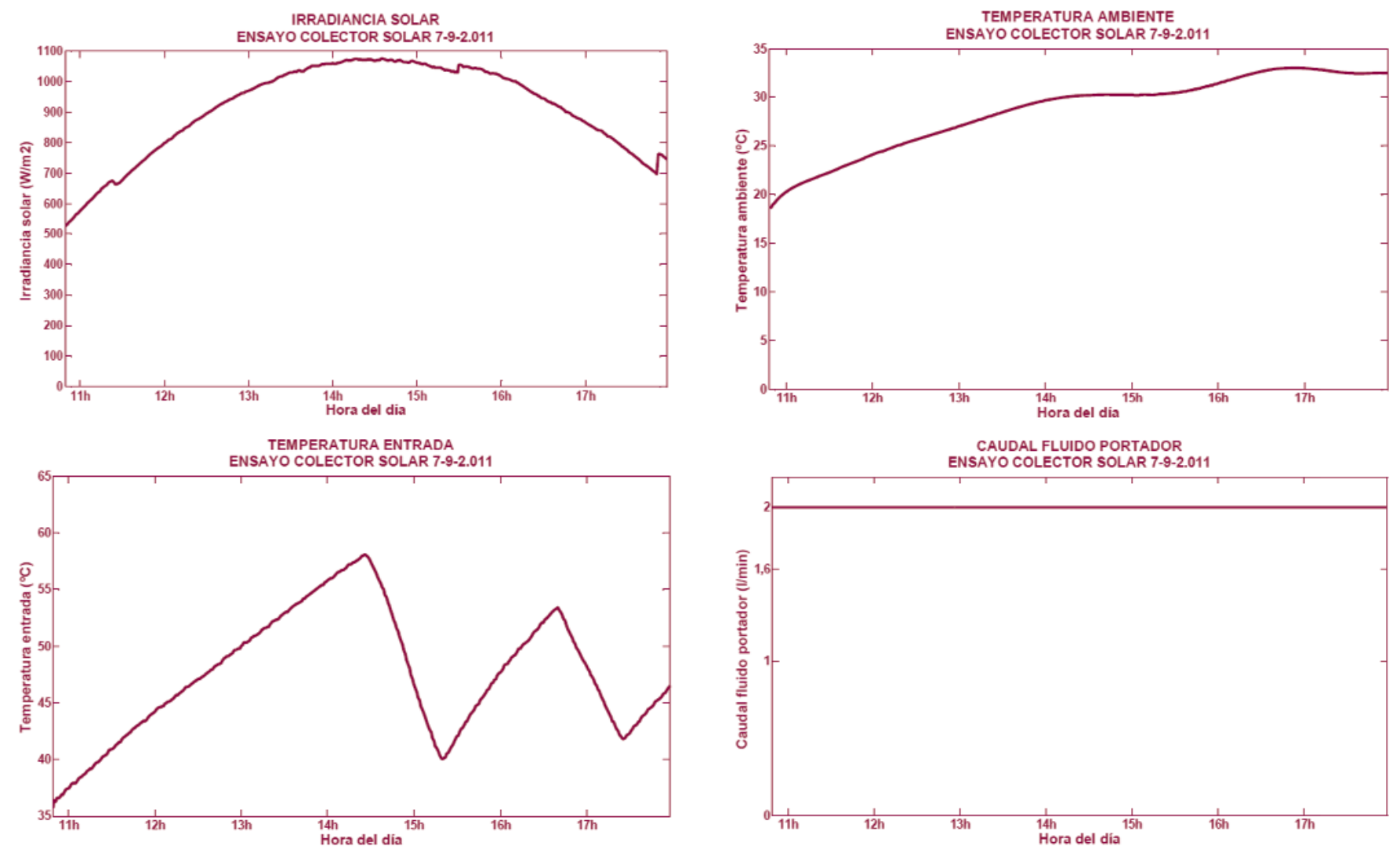

Figura 11.- Datos del ensayo en el captador solar registrados cada minuto el día 7-9-2011 de la irradiancia solar, la temperatura ambiente, la temperatura de retorno al captador solar y el caudal del fluido portador.

Para la simulación de la red neuronal artificial se hace uso de la función 'sim' de la siguiente forma:

$>$ ts $=\operatorname{sim}($ net, $t x)$

Donde 'ts' es el resultado de la simulación con la matriz de vectores de datos de entrada 'tx' en la red 'net' feedforward backpropagation previamente entrenada, pudiéndose fijar las condiciones iniciales. Esta función retorna las salidas de la red, el estado final de la entrada, el estado final de las capas, los errores de la red y el rendimiento de la red.

\section{RESULTADOS Y DISCUSIÓN}

El modelo neural de captador solar propuesto a partir de varias entradas que proporcionan el valor de la irradiancia solar, la temperatura ambiente, la temperatura de entrada y el caudal del fluido portador en el captador solar en un determinado instante, resulta a la salida del modelo el valor de la temperatura de salida del fluido portador del captador solar en el lapso de tiempo siguiente.

En las gráficas de la figura 10 se representa laa simulación realizada del captador solar para cada intervalo de tiempo de un minuto, con una red neuronal artificial de cinco neuronas en la capa oculta, junto con los datos medidos en el ensayo y el error producido mediante el estadístico RMSE. En el ensayo del día 7-9-2011, realizado con un caudal del fluido portador en el captador solar de $2 \mathrm{l} / \mathrm{min}$, se obtuvo un RMSE $=0,18^{\circ} \mathrm{C}$; en el ensayo del día 1-7-2011, realizado con un caudal del fluido portador en el captador solar de $1,6 \mathrm{l} / \mathrm{min}$, se obtuvo un RMSE $=0,20^{\circ} \mathrm{C}$; y en el ensayo del día 4-10-2011, realizado con un caudal del fluido portador en el captador solar de $1 \mathrm{l} / \mathrm{min}$, se obtuvo un RMSE $=0,19^{\circ} \mathrm{C}$.

Los datos registrados en los días de los ensayos y utilizados como entradas al modelo de red neuronal artificial, se representan gráficamente en las figuras 11,12 y 13 .

De la metodología propuesta para el modelado de un captador solar instalado, se puede decir que salva las situaciones de las condiciones específicas en las que otros modelos no se ajustan a las especificaciones del método correspondiente, como pueden ser los dos casos estudiados aquí, con la utilización de las diferentes temperaturas del captador solar, y cuando funcionan a un caudal distinto al del modelo escogido. La metodología neural puede cubrir todo el rango de la irradiancia solar con la base de datos de entrenamiento, además de no ser necesarias las características técnicas del captador solar que se utilice, pudiendo extenderse la metodología neural a cualquier tipo de capta- 

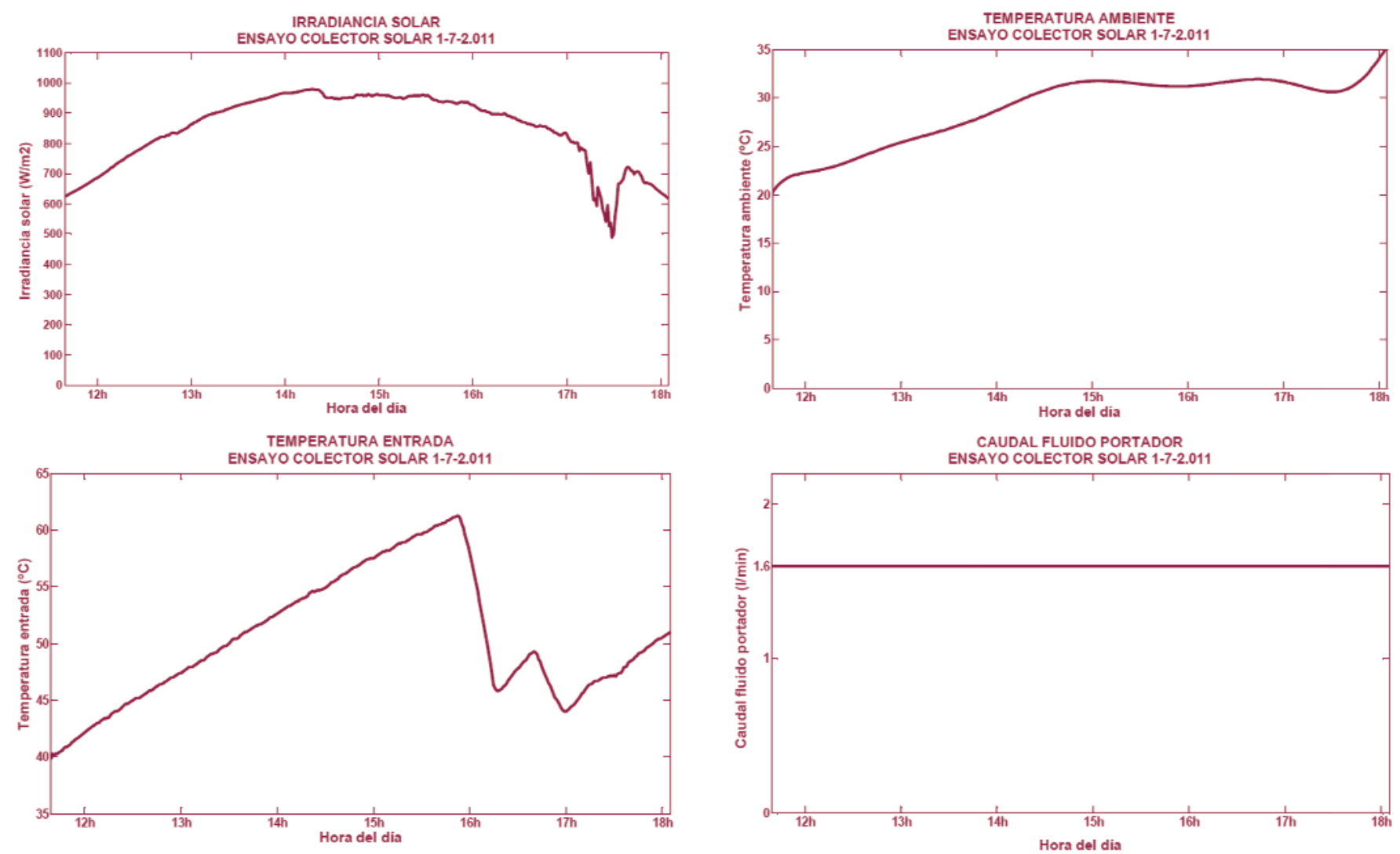

Figura 12.- Datos del ensayo en el captador solar registrados cada minuto el día 1-7-2011 de la irradiancia solar, la temperatura ambiente, la temperatura de retorno al captador solar y el caudal del fluido portador.

dor solar y al campo de captación completo de la instalación del sistema solar térmico.

La metodología neural es flexible ante otras entradas que puedan utilizarse en cada caso específico. Tan sólo se necesita un conocimiento del funcionamiento del captador solar que lo proporciona la base de datos registrada en el propio componente.

\section{CONCLUSIONES}

La inteligencia computacional -una rama de la inteligencia artificial que estudia los mecanismos adaptativos para permitir el comportamiento inteligente de sistemas complejos y cambiantes- dispone de una herramienta muy interesante para modelar el funcionamiento de los captadores solares de una forma flexible y abierta a diversos modelos. Esta herramienta son las redes neuronales artificiales.

La condición necesaria para su utilización es la de disponer de una base de datos representativa de todas las condiciones de funcionamiento, que se propongan reproducir. Estos datos del intervalo de funcionamiento sirven para el entrenamiento de la red neuronal artificial, con diferentes valores de la irradiancia solar, la temperatura ambiente, y de la temperatura, el caudal y el calor especifico del fluido portador utilizado. Según sea la variedad de los datos, así se podrá afrontar la simulación del funcionamiento del captador solar.

Otra condición se centra en la implementación de la red neuronal artificial, para lo cual es necesario varias pruebas, con distintas arquitecturas de red neuronal artificial hasta conseguir el grado de precisión que se pretenda alcanzar, esto depende de la experiencia y habilidad de la persona que realice esta tarea.

La metodología resulta interesante para ser aplicada a captadores solares, ya instalados, de los cuales se quiera obtener un modelo de su funcionamiento, y que por causas como el envejecimiento del captador solar, el tipo de instalación efectuado, o que simplemente el técnico no disponga de las características técnicas del captador solar concreto necesarias para la aplicación de otros métodos de modelado. Mediante una simple toma de datos del funcionamiento, se puede realizar un modelado del captador solar de una gran precisión, como se ha demostrado.

La misma metodología neural puede ser aplicada al campo de captación completo cuando el sistema solar térmico esté formado por más de un captador solar, realizando el modelado de todo el conjunto de captadores insta- 
DATOS DEL ENSAYO EN EL COLECTOR SOLAR EL DÍA 4-10-2.011

IRRADIANCIA SOLAR
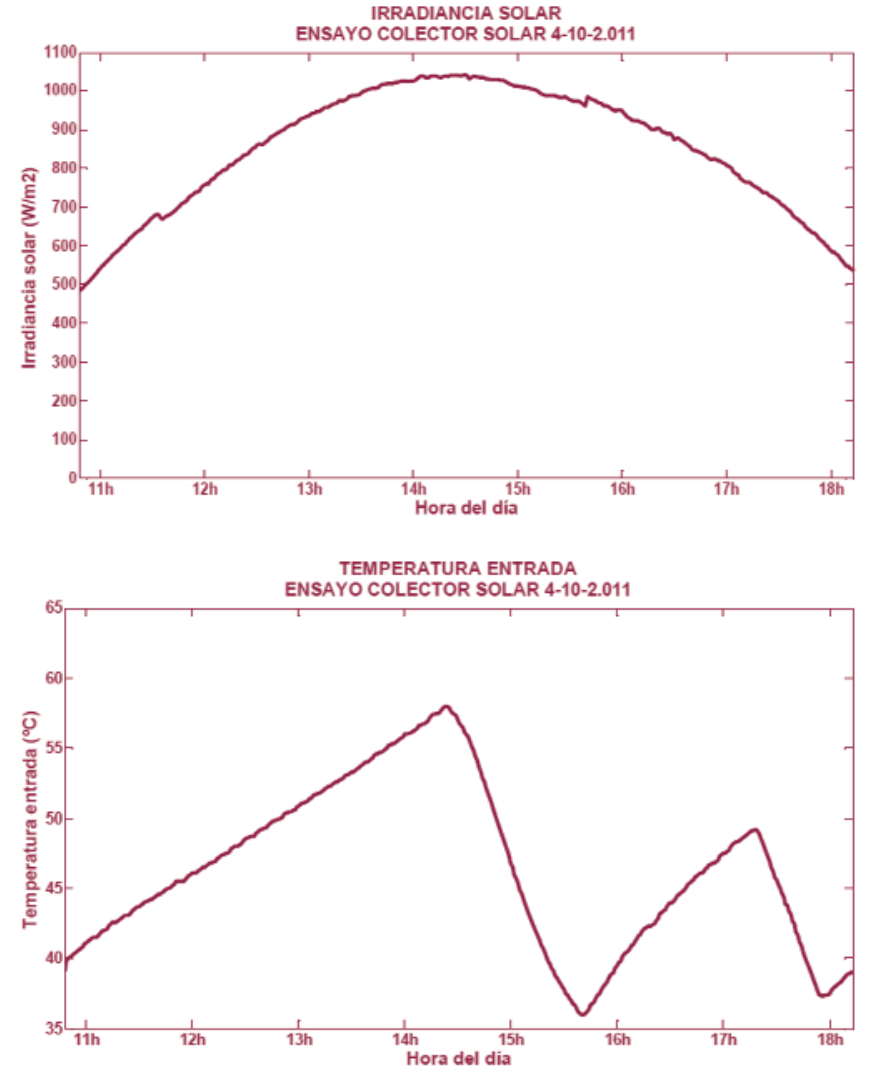

TEMPERATURA AMBIENTE ENSAYO COLECTOR SOLAR 4-10-2.011

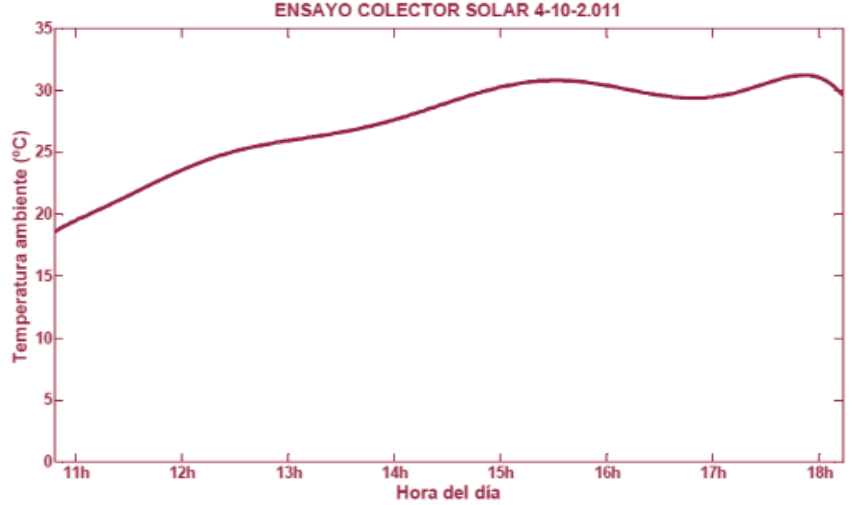

CAUDAL FLUIDO PORTADOR ENSAYO PLANTA PILOTO 4-10-2011

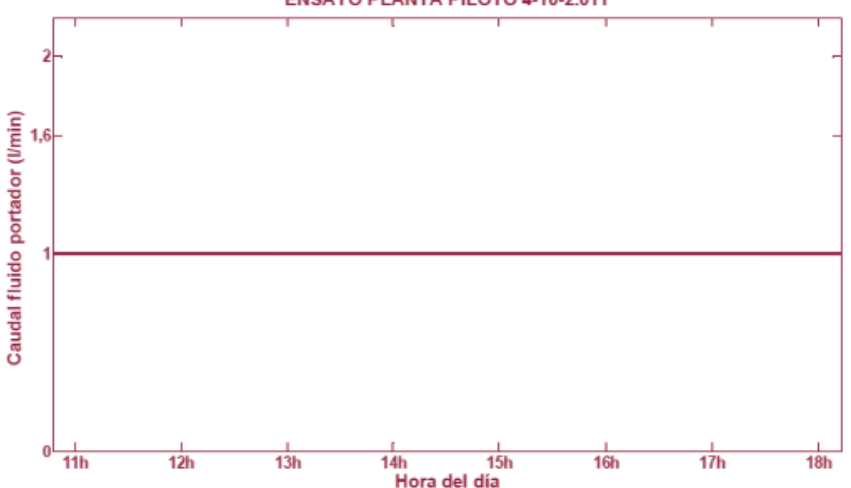

Figura 13.- Datos del ensayo en el captador solar registrados cada minuto el día 4-10-2011 de la irradiancia solar, la temperatura ambiente, la temperatura de retorno al captador solar y el caudal del fluido portador.

lados en un sistema solar térmico, siendo las temperaturas de salida y entrada en este caso las temperaturas de ida y retorno del fluido portador al campo de captadores solares, con lo que se modela todos los captadores solares en su funcionamiento conjunto, consiguiendo un modelado preciso de la instalación específica.

Otra posibilidad de aplicación de la metodología neural es el estudio de los fenómenos transitorios en el captador solar.

Por último hay que tener siempre en cuenta que el rendimiento de los captadores solares no es comparable entre distintos métodos.

\section{REFERENCIAS}

[1] Amari S, Maginu K. Statistical neurodynamics of associative memory. Neural Networks 1988;1(1):63-73.

[2] Amer EH, Nayak JK, Sharma GK. Transient test methods for flat-plate collectors: Review and experimental evaluation. Solar Energy 1997;60(5):229-43.

[3] Arinze EA, Schoenau G], Sokhansanj S, Adefila SS, Mumah SM. A dynamic performance simulation model of flat- plate solar collectors for a heat pump system. Energy Conversion and Management 1993;34(1):33-49.
[4] Bliss RWJ. The derivations of several "Plate-efficiency factors" useful in the design of flat-plate solar heat collectors. Solar Energy 1959;3(4):55-64.

[5] Broomhead DS, Lowe D. Multivariable functional interpolation and adaptive networks. Complex Systems 1.988;2:321-55.

[6] Cener-Ciemat. Informe de ensayo de captador solar térmico T3-Inox Takama 30.0184.0-1. Sarriguren, Navarra; 2006.

[7] Chakraborty K, Mehrotra K, Mohan CK, Ranka S. Forecasting the behavior of multivariate time series using neural networks. Neural Networks 1992;5(6):961-70.

[8] Cruz-Peragon F, Palomar JM, Casanova PJ, Dorado MP, Manzano-Agugliaro F. Characterization of solar flat plate collectors. Renewable and Sustainable Energy Reviews 2012;16(3):1709-20.

[9] Demuth $H$, Beale M, Hagan M. Neural network toolbox. User's guide Matlab. The MathWorks 2010.

[10] Duffie JA, Beckman WA. Solar engineering of thermal processes. 3rd ed. New Jersey: Wiley; 2006.

[11] El-Adawi MK. New approach to modelling a flat plate collector: the Fourier transform technique. Renewable Energy 2002;26(3):489-506.

[12] Elman JL. Finding structure in time. Cognitive Science 1990;14(2):179-211.

[13] Emery M, Rogers BA. On a solar collector thermal perform- 
ance test method for use in variable conditions. Solar Energy $1984 ; 33(2): 117-23$.

[14] EN 12975-2. EN 12975-2:2006. Thermal Solar Systems and Components - Solar Collectors - Part 2: Test Methods.

[15] Farkas I, Géczy-Víg P. Neural network modelling of flatplate solar collectors. Computers and Electronics in Agriculture 2003;40(1-3):87-102.

[16] Fischer S, Frey P, Drück H. A comparison between stateof-the-art and neural network modelling of solar collectors. Solar Energy 2012;86(11):3268-77.

[17] Frid SE. Multinode models and dynamic testing methods of solar collectors. Solar \& Wind Technology 1990;7(6):655-61.

[18] Grossberg S. Competitive learning: From interactive activation to adaptive resonance. Cognitive Science 1987;11(1):23-63.

[19] Hebb DO. The organisation of behaviour. New York: Wiley; 1949.

[20] Hecht-Nielsen R. Kolmogorov's mapping neural network existence theorem. Proceedings of the First International Conference on Neural Networks IEEE 1987;3:11-3.

[21] Hottel HC, Whillier A. Evaluation of flat plate collector performance. Transactions of the Conference on the Use of Solar Energy. Part I, vol. 2. University of Arizona Press 1955;:74-104. [22] Hottel HC, Woertz BB. Performance of flat-plate solar-heat collectors. Transactions of American Society of Mechanical Engineers $1942 ; 64: 91$.

[23] Hou H, Wang Z, Wang R, Qi B. Transient test method for thermal performance of flat-plate solar collectors. Taiyangneng Xuebao/Acta Energiae Solaris Sinica 2004;25(3):310-4.

[24] Kalogirou SA. Prediction of flat-plate collector performance parameters using artificial neural networks. Solar Energy 2006;80(3):248-59.

[25] Kalogirou SA. Solar thermal collectors and applications. Progress in Energy and Combustion Science 2004;30(3):231-95.

[26] Kazeminejad H. Numerical analysis of two dimensional parallel flow flat-plate solar collector. Renewable Energy 2002;26(2):309-23.

[27] Klein SA. Calculation of flat-plate collector utilizability. Solar Energy 1978;21(5):393-402.

[28] Kohonen T. Self-organization and associative memory. Berlin; New York: Springer-Verlag; 1989.

[29] Kong W, Wang Z, Fan J, Bacher P, Perers B, Chen Z, et al. An improved dynamic test method for solar collectors. Solar Energy 2012;86(6):1838-48.

[30] Liu BYH, Jordan RC. The long-term average performance of flat-plate solar-energy collectors: With design data for the U.S., its outlying possessions and Canada. Solar Energy 1963;7(2):53-74.

[31] Matuska T, Zmrhal, V, Metzger, J,. Detailed modeling of so-
Iar flat-plate collectors with design tool Kolektor 2.2. Eleventh International IBPSA Conference Building Simulation, Glasgow 2009:2289-96.

[32] McCulloch WS, Pitts W. A logical calculus of the ideas immanent in nervous activity. Bulletin of Mathematical Biophysics 1943;5:115-33.

[33] Palit AK, Popovic D. Computational intelligence in time series forecasting. Theory and engineering applications. London: Springer; 2005.

[34] Perers B. Dynamic method for solar collector array testing and evaluation with standard database and simulation programs. Solar Energy 1993;50(6):517-26.

[35] Perers B, Walletun $H$, et al. Dynamic Collector Models for 1 hr Time Step Derived From Measured Outdoor Data. Pergamon Press 1991.

[36] Perers B. An improved dynamic solar collector test method for determination of non-linear optical and thermal characteristics with multiple regression. Solar Energy 1997;59(4-6):163-78.

[37] Peuser FA, Remmers K, Schnauss M. Solar thermal systems: successful planning and construction. Berlin: Solarpraxis; 2002.

[38] Rosenblatt F. The Perceptron: A probabilistic model for information storage and organisation of the brain. Psychological Review 1958;65:386-408.

[39] Sözen A, Menlik T, Ünvar S. Determination of efficiency of flatplate solar collectors using neural network approach. Expert Systems with Applications 2008;35(4):1533-9.

[40] Specht DF. Probabilistic neural networks for classification, or associative memory. Proc. of IEEE Intern. Conf. on Neural Networks 1988;1:525-32.

[41] Wagner Solar. 400 preguntas. Resuelva sus dudas sobre la energía solar térmica. Era Solar 2009; 153: 58-62.

[42] Wang BW. Tesis: Solar Collector Thermal Performance Dynamic Test. Institute of Electrical Engineering, Chinese Academy of Sciences 2008.

[43] Werbos PJ. Tesis. Beyond regression: New tool for prediction and analysis in the behavioural sciences. Cambridge: Universidad de Harvard; 1974.

[44] Whillier A. Tesis: Solar energy collection and its utilization for house heating. MIT Massachusetts Institute of Technology 1953.

[45] Whillier A. Thermal resistance of the tube-plate bond in solar heat collectors. Solar Energy 1964;8(3):95-8.

[46] Xu L. Tesis: Research on Dynamic Test Method for Thermal Performance of Solar Collectors. Northeast University 2009. 



\title{
PREDICTION AND IDENTIFICATION OF THE EVOLUTION OF SOLAR-HEATED HOT WATER TEMPERATURE IN A STRATIFIED TANK IN STATIC MODE USING ARTIFICIAL NEURAL NETWORKS
}

\begin{abstract}
The main objectives of the analysis were to predict the evolution of thermal behaviour in the storage tank during static mode using artificial neural networks, and to identify said evolution using geometric curves. The analysis was based on experimental data obtained for a storage tank provided by the manufacturer and equipped with an appropriate data acquisition system. A description is given of the storage tank, the solar heating system of which it formed a part, the data acquisition system and the theoretical and experimental methodology. Prediction of thermal evolution was based solely on the initial temperature profile using artificial neural networks, while identification of thermal evolution was performed using the sum of two natural exponential functions based on the number $e$, when the water tank was not in use, this being the operational mode of longest duration in a solar thermal system. The results of analyses of thermal stratification using different initial water temperature profiles are reported and discussed. Stratification proved to be the main factor in the cooling process, since although ambient temperature is also a determining factor, in this case it played a lesser role because the tank's location inside the laboratory meant that it remained almost constant.
\end{abstract}

Keywords Solar hot water tank; thermal stratification; artificial neural networks; natural exponential functions

\section{Nomenclature}

\begin{tabular}{|c|c|c|c|}
\hline $\mathrm{a}$ & indicates the initial temperature value & MA & moving average \\
\hline ANN & artificial neural network & MBE & mean bias error \\
\hline AR & autoregressive & $\mathrm{n}$ & number of values \\
\hline ARMA & autoregressive-moving-average & N1...N8 & tank layers $1 \ldots 8$ \\
\hline $\mathrm{b}$ & temperature evolution trend & Pt & platinum \\
\hline C & adjusts the initial temperature value & $\mathrm{q}$ & time interval \\
\hline $\mathrm{C}$ & centigrade & $\mathrm{R}^{2}$ & coefficient of determination \\
\hline $\mathrm{cm}$ & centimetres & $\mathrm{t}$ & time \\
\hline d & adjusts temperature evolution & $\mathrm{T}$ & temperature $\left({ }^{\circ} \mathrm{C}\right)$ \\
\hline DIN & Deutsches Institut für Normung & $\mathrm{T}_{\mathrm{a}}$ & ambient temperature $\left({ }^{\circ} \mathrm{C}\right)$ \\
\hline f & function & $\mathrm{T}_{\mathrm{i}}$ & initial temperature $\left({ }^{\circ} \mathrm{C}\right)$ \\
\hline h & hours & $\mathrm{T}_{\mathrm{f}}$ & final temperature $\left({ }^{\circ} \mathrm{C}\right)$ \\
\hline $\mathrm{k}$ & cooling constant & RMSE & root mean square error \\
\hline $\mathrm{L}$ & litres & $\mathrm{X}$ & variable \\
\hline $\mathrm{m}$ & metres & $\wedge$ & prediction \\
\hline $\min$ & minutes & $\circ$ & degrees \\
\hline
\end{tabular}

\section{INTRODUCTION}

Solar thermal systems incorporate storage tanks because supply and demand may not coincide in time, since unlike fuels used in conventional systems, solar radiation is not always available. Even in the case of air conditioning based on solar cooling systems, an application which usually coincides with maximum levels of solar radiation, demand may also occur after sunset in hot weather.

Thermal storage tanks store the excess solar energy accumulated on sunny days for use on cloudy days or during the night, thus making it possible to separate demand for hot water from production of the same and creating more efficient solar thermal systems through helping to reduce consumption of the additional energy necessary to cover envisaged energy needs. Therefore, hot water storage tanks improve the performance of solar thermal systems.

There are many different kinds of hot water storage systems, Dinçer and Rosen [5], with tanks of various types and sizes where thermal energy is accumulated as either sensible or latent heat. In the first, the temperature varies when heat is added or removed. In the second, the temperature remains constant throughout the phase transition. For medium and low temperature systems, sensible heat is accumulated in PREDICTION AND IDENTIFICATION OF THE EVOLUTION OF SOLAR-HEATED HOT WATER TEMPERATURE IN A STRATIFIED TANK IN STATIC MODE USING ARTIFICIAL NEURAL NETWORKS 
liquid form for domestic, commercial and industrial applications, where energy demand can vary on a daily, weekly or seasonal basis. This demand can be met by solar energy through the use of hot water storage tanks, which enable solar thermal systems to operate synergistically. Water is the most commonly used storage medium due to its high volumetric heat capacity and low cost, and it acts as the heat transport fluid in the primary and secondary circuits of solar thermal systems, into which it is easily integrated.

The static operating mode of a hot water storage tank refers to its thermal behaviour when the stored water is not being used, in other words, when no water is flowing either into or out of the tank. In contrast, the dynamic operating mode refers to its thermal behaviour when the heat in the tank is used, for example, when loading or discharge occurs. Most of the studies which have been conducted have focused on the dynamic operating mode, Fernández-Seara et al. [10]. Gopalakrishnan and Srinivasa Murthy [14] dealt with dynamic discharge mode of operation of hot water storage tanks, with a numerical study of transient, two-dimensional, mixed convective heat transfer and flow characteristics in stratified hot water storage tanks.

Oliveski et al. [29] examined cooling from a homogeneous temperature in vertical cylindrical tanks subjected to internal natural convection. In their analysis of thermal stratification in static mode, FernándezSeara et al. [9] showed that this primarily depends on the initial temperature profile of the water. Han et al. [17] evaluated the energy and exergy efficiency of thermal stratification during the cooling process.

Jaluria and Gupta [20] carried out an experimental study of heat loss in a stratified tank. Time-dependant temperature profiles were measured for various initial temperature distributions and ambient conditions. An initially isothermal tank was thermally stratified by means of discharges and the influx of hot water into the upper part. The decrease in stratification over time due to the transfer of heat to the environment and to the water volume was studied experimentally for different initial conditions and heat losses. Initial temperature distribution was found to have a strong influence on the subsequent loss of stratification.

Haller et al. [15] reviewed two different methods proposed in the literature for characterising thermal stratification in tanks from a theoretical perspective. Specifically, they focused on the methods used to determine the tank's capacity to promote and maintain stratification during loading, storage and discharge, and represented this capacity with a single numerical value for stratification efficiency in a determined experiment or under determined environmental conditions. Haller et al. [16] presented a method for calculating the stratification efficiency of tanks based on the second law of thermodynamics, conducting a theoretical and experimental study of the influence of heat loss.

Géczy-Víg and Farkas [13] proposed an artificial neural network model for modelling temperatures in the layers of a solar thermal system tank. The model was based on measurements of a hot water solar thermal system. Temperature distribution in the tank was vertically divided into eight equal parts using measurements taken every minute and averaged over five minutes of global solar irradiation, ambient temperature, mass flow of the heat transport fluid in the primary circuit, demand for solar-heated hot water and tank layer temperatures in the preceding time interval. The artificial neural network model consisted of two parts which described the periods with and without hot water demand. The models thus constructed gave acceptable results during the training period, with a mean variation of $0.22^{\circ} \mathrm{C}$ during training and $0.26^{\circ} \mathrm{C}$ during validation. Ameri Siahoui et al. [1] studied thermal stratification in an underground cold water reservoir analytically and also using artificial neural networks.

Oshchepkov and Frid [30] carried out the numerical simulation of the thermal stratification process in the storage tanks of an integrated collector-storage solar water heater of various shapes. Oshchepkov et al. [31] simulated the process of rapid hot water displacement from the inclined tank of an accumulative solar water heater, studied the thermocline dissipation pattern, and determined the effect on the degree of stratification of the flow rate, the angle of installation of the tank and the relative position of intake and outtake pipes. 
This article presents the development of a model for simulating temperatures in a solar heated water storage tank in static mode, at short intervals and for long periods of time, from the initial temperature profile. The model is based on time series prediction theory, using data obtained from temperature measurements recorded during operation and applying ANN. This study is complemented by another in which the dynamic operating mode of the tank was simulated using the same ANN approach but with different inputs, in order to model a complete tank. These models have been combined to provide a detailed simulation of a complete thermal system based on the same ANN approach, without applying any technical feature of the components. Further details will be reported in forthcoming articles.

This approach differs from classical methods in its ease of application, since only a representative database of temperatures during operation is required, obtained by installing a probe along the height of the tank under study.

Although classical three-dimensional and two-dimensional models are suitable for design, they are characterised by the need for extensive calculations and the use of specific software, and are not appropriate for simulation. Classical one-dimensional models require empirical parameters obtained from experimental analysis, which are difficult to measure; consequently, the validity of the results depends on the accuracy of experimental coefficients. The tank mix method does not provide a description of stratification.

\section{EXPERIMENTAL EQUIPMENT}

A 150 L capacity Lapesa CV-150-M1S hot water storage tank was used with this solar thermal system, installed in a vertical position. It was equipped with an internal serpentine heat exchanger for thermal exchange with the solar thermal system's primary circuit heat transport fluid. The solar thermal system consisted of a flat plate solar thermal collector (T3-Inox Takama), installed at 45 degrees to the horizontal plane. The absorber measured $1.85 \mathrm{~m}^{2}$, with eight Flat Pipe type vertical tubes welded to two horizontal tubes, a circulating pump, an expansion tank, an air bleeder and a safety valve. Fig. 1 shows a diagram of the experimental set up.

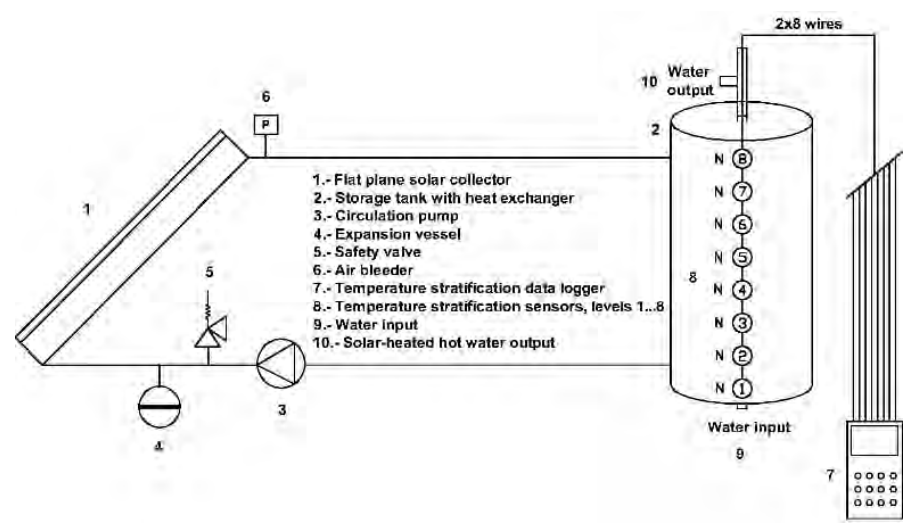

Fig. 1. Diagram of the solar thermal system and tank, with the data collection system.

The storage tank consisted of a vertical cylindrical body with Klopper type caps, manufactured in vitrified steel in accordance with the standard DIN 4753. Height and diameter were 864 and $480 \mathrm{~mm}$, respectively, with a consequent tank aspect ratio, or slenderness, of 1.8. The tank was thermally insulated with injection molded polyurethane foam. The cylinder surface was $40 \mathrm{~mm}$ thick, while cap thickness varied depending on the geometry of the cap. The exterior finish was a detachable white padded jacket and polyvinyl chloride caps.

The tank was equipped with a data collection system based on a Daq PRO 5300 Fourier Systems data logger. Temperature distribution in the water inside the tank was measured using eight Pt 100 platinum 
resistor temperature sensors, sited at regular intervals along the height of the tank, $10.8 \mathrm{~cm}$ apart. The sensors inserted into the domestic hot water outlet in the upper tank cover via a T-joint pipe were sited along the height of the tank. The measuring probe consisted of the temperature sensors, which were glued with silicon to small aluminium plates, the sensor cables and a wire used to provide the probe with consistency and prevent it from floating, encased in heat shrink tubing into which a copper or brass sheath could also be inserted.

Calibration of the data collection system was tested to correct temperature measurement errors by recording values for the eight sensors comprising the probe every minute for seven hours, with the probe placed outside the tank. The reference temperature used for calibration was recorded with a 309 Center data logger, which incorporates a dedicated measuring probe. Calibration of the eight sensor probes was conducted by calculating the difference in temperature between the reference temperature and the temperature recorded for each of the eight sensors at one minute intervals. The resulting differences were averaged for each sensor to obtain a correction factor for each of them.

\section{THEORY}

\subsection{TIME SERIES}

A time series is an ordered sequence of values recorded for a variable observed at uniform time intervals, forming a discrete data group, $\mathrm{x}_{1}, \mathrm{X}_{2}, \ldots, \mathrm{X}_{\mathrm{n}}$. This sequence of values was obtained from the sensors installed in the solar-heated hot water storage tank by means of sampling the continuous temperature signals in the eight layers into which the tank had been divided for the purposes of this study.

Analysis of a time series entails definition, classification, description and construction of a model on the basis of the data recorded for the series, and prediction of future values, Box and Jenkins [2]. There are several methods for modelling and predicting the future elements of a time series, such as exponential smoothing, regression analysis and models reflecting the implied properties of dynamic operation. The most advanced methods involve computational intelligence techniques.

Time series are analysed statistically in order to study the relationships between the observed data for the phenomena and the parameters involved. The observed processes are time-dependent, with time being the only parameter, hence the name time series.

They form input-output models, with a transfer function that forms the time series. Prediction of the future values of a time series on the basis of past values is performed using models. There are two basic forms of time series statistics; deterministic models, represented by functions of the type $\mathrm{x}_{\mathrm{t}}=\mathrm{f}(\mathrm{t})$ or $\mathrm{x}_{\mathrm{t}}=\mathrm{f}\left(\mathrm{x}_{\mathrm{t}-1}, \mathrm{x}_{\mathrm{t}-2}, \ldots\right)$, and stochastic models, represented as functions of random variables.

Time series models can be constructed using regression analysis, which is based on combinations of variables to estimate and predict the values of a variable on the basis of other variables belonging to a time series. The most frequently used models are autoregressive (AR) models, moving average (MA) models and autoregressive-moving-average (ARMA) models.

The future values of a time series for a set of observed data $\mathrm{x}_{1}, \mathrm{x}_{2}, \ldots, \mathrm{x}_{\mathrm{n}}$ can be predicted in two ways: the future values $x_{n+1}, x_{n+2}, \ldots$ can be estimated, or the prediction can be staggered over various future time intervals, $\mathrm{x}_{\mathrm{n}+\mathrm{q}}$, calculating $n$ where $q$ is the time interval used for the estimation.

In this study, artificial neural networks were employed due to their capacity for learning and generalising from the observed data. Artificial neural networks are widely accepted among engineers and researchers as a technique for processing experimental data, and their use implies significant advantages for nonlinear 
mapping between groups of past elements from time series and groups of future time series elements. For example, they are capable of finding basic functional relationships between data when these relationships are not known, the data contain a high level of noise and it is difficult to create a mathematical relationship which describes them. Furthermore, nonlinear function modelling can approximate a function with varying degrees of accuracy. Lastly, artificial neural networks are also capable of generalising and learning from examples, through self-configurable data processing, Palit and Popovic [32].

\subsection{CURVE FITTING}

Curve fitting is based on locating a function which contains a series of data points. The function may be a polynomial, a nonlinear function or a linear combination of known functions. The function selected to fit a curve has a number of unknown coefficients. The method for calculating these coefficients is based on minimisation of the differences between the function chosen and the data values and is known as the least squares method, fully described in the Gauss-Markov theorem, Kay [23].

Curve fitting is used to interpret the experimental data. The results are described best when a function that fits the data is located. This is the aim of mathematical modelling, to identify functions which describe system operation. These functions can be of two kinds, empirical or theoretical, the latter being based on a physical theory.

Empirical modelling attempts to identify a function which fits the system data, independently of whether this function has a physical effect on what is happening in the system. Consequently, it can be used for calibration, prediction or simulation. The same data can similarly be interpreted using different functions, although it is always advisable to choose those with fewest parameters. The most commonly used empirical models are different degree polynomial models. When selecting a function, it is important to verify that the type of curve that predicts the function matches the qualitative behaviour of the experimental data. In this study, the natural exponential function was used, which is based on the number e, Maor [26].

The next step is to fit the selected function to the experimental data. This procedure consists in locating the values that best fit the function to the data, fitting the function to the data, varying parameter values but not the data, which do not change, and fitting the curve. Normally, the least squares criterion is applied, which consists in obtaining the parameter values that minimise the sum of squared residuals, where residuals are the vertical distances of the data values to the fitted curve. Lastly, different criteria can be used to determine goodness of fit, such as the coefficient of determination $\left(\mathrm{R}^{2}\right)$, the mean bias error (MBE), or the root mean square error (RMSE), Makridakis et al. [25].

\subsection{HEAT TRANSFER}

Isaac Newton observed that when removed from the heat source, an iron block cooled more quickly if it had been heated to red-hot than if it had been heated to a temperature close to room temperature. These observations gave rise to what is today known as Newton's law of cooling, Davidzon [3], which states that the temperature of a hot body cools exponentially over time to the temperature of the surrounding medium.

Heat transfer is related to hot and cold bodies and sources and recipients, and has its own mechanisms, namely conduction, convection and radiation, which each have their own particular properties. An element at a different temperature to its surroundings will eventually reach a final temperature equal to its surroundings. A relatively hot element cools as it warms its surroundings while a cold element heats up when as it cools its surroundings. The rate of heat loss, whether caused by conduction, convection or radiation, is proportional to the temperature difference between the temperature of the element in question and that of its surroundings, Incropera et al. [19]. This law is also valid for heating. If an object is cooler 
than its surroundings, the rate of heat gain is again proportional to the difference or gradient between the two temperatures. Newton's law of cooling is described mathematically by the expression (1):

$$
d T / d t=-k\left(T-T_{a}\right) \text {. }
$$

Where $d T / d t$ is the rate of cooling, $k$ is the cooling rate constant, $T$ is the temperature of the body studied at a given instant and $T_{a}$ is the ambient temperature surrounding the body. If the body is cooled from an initial temperature $T_{i}$, to a final temperature $T_{f}$, the expression (1) can be written as (2):

$$
\mathrm{T}=\mathrm{T}_{\mathrm{f}}+\left(\mathrm{T}_{\mathrm{i}}-\mathrm{T}_{\mathrm{f}}\right) \mathrm{e}^{-\mathrm{kt}} \text {. }
$$

The exponential function describes and identifies the progress of the process; thus, variation in a given time interval is proportional to the initial value, with time being the independent variable.

\section{EXPERIMENT AND ANALYSIS}

Experiments included heating and cooling periods, the latter being analysed in static operating mode. The heating period began at dawn on sunny days, with the water at a medium or low temperature depending on how much of the solar-heated hot water had been consumed the previous day and on the previous day's weather. At approximately solar noon, between 50 and $150 \mathrm{~L}$ of solar-heated hot water was discharged at a rate of 1 to $1.6 \mathrm{~L} / \mathrm{min}$. Once the discharge was completed, the solar thermal system remained exposed to sunlight until sunset. The volume of solar-heated hot water discharged each day was varied in order to induce different temperature profiles inside the tank at the end of each daily heating period.

Static stratification provides information about the evolution of temperatures inside the tank when a solar thermal system is inactive, which in this study corresponded to the state when incident sunlight on the collector was insufficient to activate the primary circuit pump and no solar-heated hot water was discharged from the tank.

Since evolution is slower in static state than under dynamic operating conditions, for these assays values were measured at 10 minute intervals, from dusk - between $18 \mathrm{~h}$ and $19 \mathrm{~h}$ - when the solar collector stopped receiving sunlight, until $10 \mathrm{~h}$ or $11 \mathrm{~h}$ the following day, when the pump began to re-circulate the heat transport fluid in the tank's heat exchanger. For some assays, measurements were taken for several consecutive days when the solar thermal system was inactive in order to observe the evolution of stratification over a longer period of time. The ambient temperature around the tank during experiments was $20^{\circ} \mathrm{C} \pm 20 \%$.

The results for identification and prediction were compared with the measurements taken using the root mean square error (RMSE) (3), which provides information about the model's predictive capacity by highlighting large deviations in the estimations with respect to the measurements recorded.

$$
\operatorname{RMSE}=\sqrt{\frac{\sum_{\mathrm{i}=1}^{\mathrm{n}}\left(\mathrm{x}_{\mathrm{i}, \mathrm{data}}-\hat{\mathrm{x}}_{\mathrm{i}, \text { predictions }}\right)^{2}}{\mathrm{n}}} .
$$

\subsection{PREDICTION}

Artificial neural networks consist of simple elements which operate in parallel, and their conception was inspired in the biological nervous system. As in nature, network operation is largely determined by the connections between elements.

In this study, the initial stratified temperature profiles for the eight layers into which the tank had been divided were used to predict the evolution of temperatures in static operating mode, when the tank was neither being loaded or discharged. It would have been possible to use another indicator, such as the ambient 
temperature, but this option was ruled out in this study because the tank was located inside a laboratory with a fairly constant temperature. However, it would be necessary to include ambient temperature if this varied greatly in the location where the tank was installed, in order to obtain better model output results.

Eight input and eight output parameters were used in this study to train the artificial neural network. The input parameters consisted of the eight temperatures recorded at a given time for the eight tank layers, while the output parameters consisted of the same eight temperatures of the eight tank layers, but recorded ten minutes later than the input parameters.

Artificial neural networks have been applied extensively in many fields. Most applications use a feedforward neural network with the backpropagation learning algorithm. There are many variations of the classic backpropagation and other learning algorithms, Haykin [18]. The main advantage of feedforward neural networks is that they do not require an algorithm to solve the problems posed, as is the case with classical programming, since the strategy used is learning from example, like humans, Mellit et al. [28]. Another advantage is that they possess the innate ability to generalise. This means that they can be used to determine and solve assays which are similar but not identical to those used for training.

The data obtained from solar thermal systems are especially noisy, and are thus particularly suitable for processing with computational intelligence techniques. A data set is necessary, preferably of an experimental nature, showing the previous evolution of a solar thermal system so that the chosen artificial neural network can be trained to learn the dependence of outputs on inputs.

A solar thermal system can be modelled with good accuracy to achieve the desired objectives. In practice however, it may be difficult to model some of the situations that occur during the actual operation of the systems exactly, since some of the problems that arise in real systems, such as poor thermal insulation of the tanks, are not easy to model. In addition, solar thermal system simulation programmes are only concerned with the thermal behaviour of the processes; however, mechanical and hydraulic factors also influence the thermal performance of solar thermal systems. An exception to this is the use of intelligent systems, which process data from real systems, where possible faults are included in the data used for model training, Kalogirou [21].

To apply artificial neural networks, the data sets obtained from measurements taken during assays were divided into three different groups: training, validation and test. The training data set was used during the initial phase to determine the relationships between stratification temperatures in each layer. The validation data set was employed with a stop criterion in order to avoid overfitting during training and improve the ability to generalise for data which did not form part of this set. When generating a simulated set of stratification temperatures from previous values, a test data set was used to evaluate model performance.

Evolution of stratification temperatures in the tank was determined for 10 minute intervals using the artificial neural network, and output feedback was interpolated to obtain predictions for 1 minute intervals.

The architecture of the artificial neural network Table 1 consisted of 8 inputs, 16 neurons in the hidden layer and 8 outputs, as shown in Fig. 2.

Table 1. ANN Architecture for modelling a tank in static mode

\begin{tabular}{c|c}
\hline & Modelling static stratification temperatures at 10 minute intervals \\
\hline Layers & Artificial neural network architecture \\
\hline Input & (8 neurons) Temperatures $\left({ }^{\circ} \mathrm{C}\right): \mathrm{N}_{1}, \mathrm{~N}_{2}, \ldots, \mathrm{N}_{8}(\mathrm{t})$ \\
Hidden & $(16$ neurons $)$ \\
Output & $\left(8\right.$ neurons) Temperatures $\left({ }^{\circ} \mathrm{C}\right): \mathrm{N}_{1}, \mathrm{~N}_{2}, \ldots, \mathrm{N}_{8}(\mathrm{t}+10)$ at 10 minutes \\
\hline
\end{tabular}




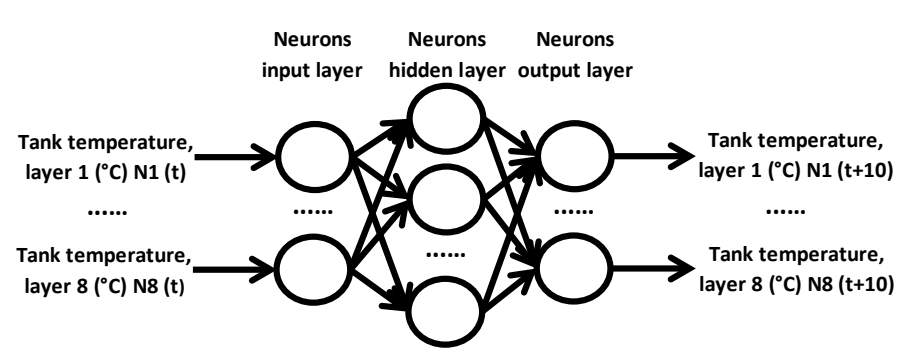

Fig. 2. Structure of the ANN designed for the prediction of stratification temperatures at 10 minute intervals.

The Matlab Neural Toolbox was used to implement the neural networks used in this study, selected on the basis of the widespread use of this program among engineers and researchers, Demuth et al. [4]. The feedforward backpropagation network used was derived from use of the 'newff' function based on the input parameters of the data input and output vector matrices, allocating the number of neurons in the hidden layer. The other parameters were assigned by default, selecting a hyperbolic tangent sigmoid for the transfer function of the neurons in the hidden layer, a linear function for the output layer and the LevenbergMarquardt algorithm for the training function, and data matrix processing was set to generate rows with minimum and maximum values in the range [-1 1]. The artificial neural network was trained using the function 'train', and the simulation was run using the function 'sim'.

\subsection{IDENTIFICATION}

The thermal evolution of each layer in the tank was mathematically determined from the sum of the two exponential curves. Temperature changes in each layer were due to two processes: heat transfer between the layers and heat loss from the tank to the exterior.

The first process is the result of a trend over time towards an equilibrium temperature through complete mixing of the water in the tank. Thus, the upper tank layers at a higher temperature lost heat energy, which was transferred to the lower tank layers at a lower temperature. This generated a loss in the quality of the energy which could be extracted from the upper part of the tank, since the water reached the point of consumption at a lower temperature. The second process is due to the transfer of heat from the tank to the cooler exterior, via the thermal insulation used by the manufacturer to construct the tank jacket.

As regards identification of the function which represents the evolution of the temperature in each layer, it was assumed that a heat transfer would occur between the two layers adjacent to the layer studied and also from the tank to the exterior. In the first case, the layer above would cede heat to the layer analysed and the layer below would receive heat from this latter; thus, the layer studied would gain heat from the layer above and lose heat to the layer below, in accordance with the multi-node model, Duffie and Beckman [8], Kleinbach et al. [24]. In the second case, heat would be transferred from the tank to the exterior as a result of heat loss through the walls of the layer studied.

A second assumption was derived from heat transfer theory, which states that the heat transfer rate will increase as the temperature differential or gradient between two point's increases. In other words, for the same distance, the greater the temperature difference, the higher the heat transfer rate between two points, and conversely, the lower the temperature difference, the lower the transfer rate. This suggests that these three heat transfers could be represented by exponential curves, using the sum of the heat gain and loss of the studied layer with respect to the layers immediately above and below. Thus, the second assumption was that the temperature evolution of each layer in the tank at night or during cloudy days when no solar-heated hot water had been discharged could be represented by the sum of two exponential curves, $f(t)=a e^{b t}+c e^{d t}$, 
one corresponding to heat gain and loss with respect to the adjacent layers and the other corresponding to heat loss from the tank walls.

The aim of this model was to find a function that fitted the system data.

\section{RESULTS AND DISCUSSION}

The results presented were obtained from experimental data.

\subsection{PREDICTION}

With the previously trained artificial neural network, assays were performed on the 6th, 7th, 8th, 9th and 10th of October 2011, as shown in Fig. 3. From the measured data and error obtained at ten minute intervals each day, during which the tank, located within the laboratory and was in static mode, a RMSE value of $0.07^{\circ} \mathrm{C}$ was obtained.

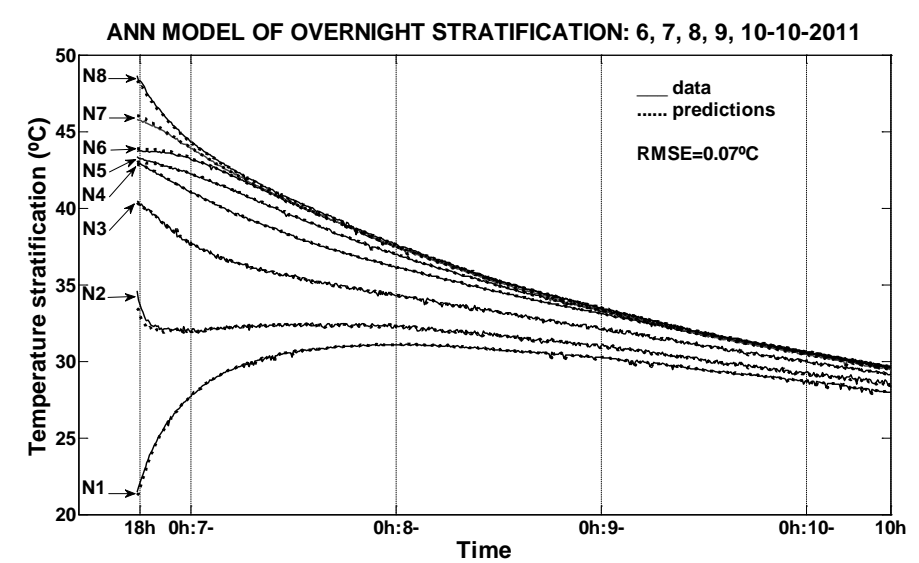

Fig. 3. Measurements obtained on the 6th, 7th, 8th, 9th and 10th of October 2011 and results of predictions made in the ANN test.

The artificial neural network model of the storage tank in static mode without sunlight and without solarheated hot water consumption was trained using data obtained every ten minutes. Thus, the output was the prediction of the evolution of stratification for that period of time. In order to obtain a prediction for a time lapse of one minute, the output was interpolated by dividing the difference between input and output values by ten and subtracting the result from the input value. The design, implemented in a visual programming environment using Matlab Simulink model or system tool, Karris [22], is shown in Fig. 4. 


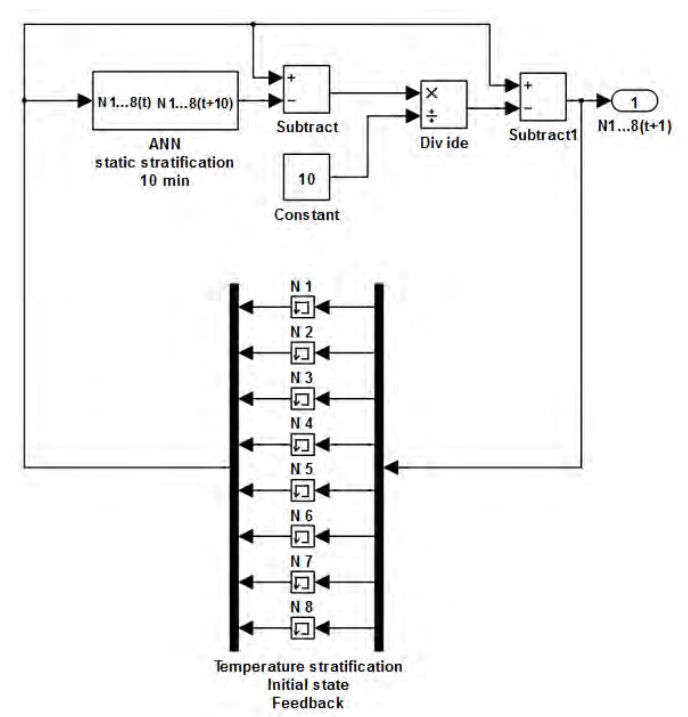

Fig. 4. Static operating mode stratification prediction model.

When the static operating mode commenced, the model generated temperature evolution data over time from the initial storage tank stratification temperature profiles, showing good agreement with the measurements.

The data obtained in the assay performed on the night of the 10th to 11th of October 2011 were compared with the predictions of the model created. Model inputs consisted of tank temperatures at 18.30 on the 10th of October 2011, given in Table 2. Model output for the tank in static mode from 18.30 on 10th of October 2011 until 10.20 on the 11 th October 2011 presented a RMSE $=0.13^{\circ} \mathrm{C}$ compared to the measurements taken Fig. 5.

Table 2. Stratification temperature profiles in the tank at 18.30 on the 10th of October 2011

\begin{tabular}{c|c|c|c|c|c|c|c}
\hline \multicolumn{6}{c}{ Inputs for the ANN model of tank stratification in static mode at 18.30 on the 10th of October 2011} \\
\hline Layer 1 & Layer 2 & Layer 3 & Layer 4 & Layer 5 & Layer 6 & Layer 7 & Layer 8 \\
\hline $21.05^{\circ} \mathrm{C}$ & $39.81^{\circ} \mathrm{C}$ & $44.90^{\circ} \mathrm{C}$ & $46.72^{\circ} \mathrm{C}$ & $46.89^{\circ} \mathrm{C}$ & $46.91^{\circ} \mathrm{C}$ & $46.84^{\circ} \mathrm{C}$ & $49.10^{\circ} \mathrm{C}$ \\
\hline
\end{tabular}

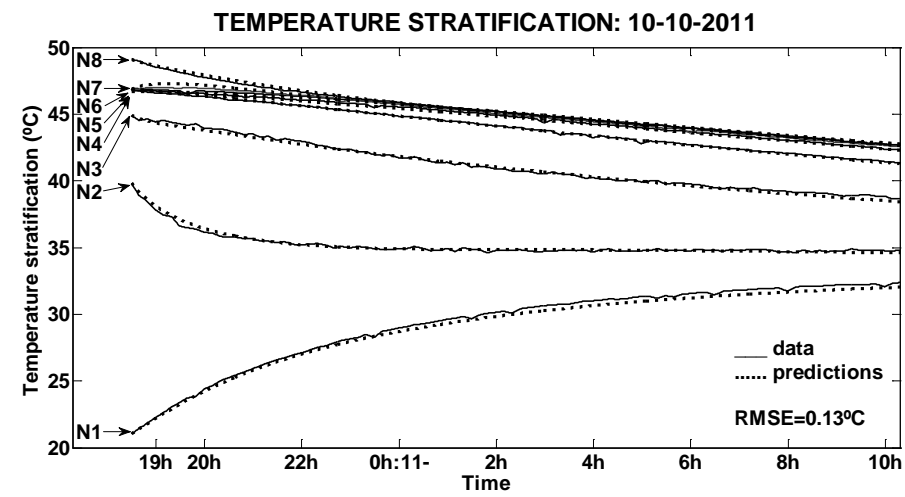

Fig. 5. Measurements obtained on the night of the 10th to 11th of October 2011 and results of predictions made at one minute intervals with the prediction model.

The data obtained in the assay performed on the night of the 28th to 29th of November 2011 were compared with the predictions of the model created. Model inputs consisted of tank temperatures at 17.40 on the 28th of November 2011, given in Table 3. Model output for the tank in static mode from 17.40 on the 28th of November 2011 until 10.20 on the 29th of November 2011 presented a RMSE $=0.41^{\circ} \mathrm{C}$ compared to the 
measurements taken Fig. 6. This assay gave the worst results of all those conducted. It should be noted that although the thermocline was very high and the tank temperature profile was continuous, prediction deviations did not exceed $0.8^{\circ} \mathrm{C}$ in the layer presenting highest deviation after 16 hours of simulation, which could also be attributed decalibration of the sensor.

Table 3. Stratification temperature profiles in the tank at 17.40 on the 28th of November 2011

\begin{tabular}{c|c|c|c|c|c|c|c}
\hline \multicolumn{6}{c}{ Inputs for the ANN model of tank stratification in static mode at 17.40 on the 28th of November 2011} \\
\hline Layer 1 & Layer 2 & Layer 3 & Layer 4 & Layer 5 & Layer 6 & Layer 7 & Layer 8 \\
\hline $13.28^{\circ} \mathrm{C}$ & $23.88^{\circ} \mathrm{C}$ & $29.10^{\circ} \mathrm{C}$ & $31.68^{\circ} \mathrm{C}$ & $32.78^{\circ} \mathrm{C}$ & $40.45^{\circ} \mathrm{C}$ & $45.56^{\circ} \mathrm{C}$ & $46.53^{\circ} \mathrm{C}$ \\
\hline
\end{tabular}

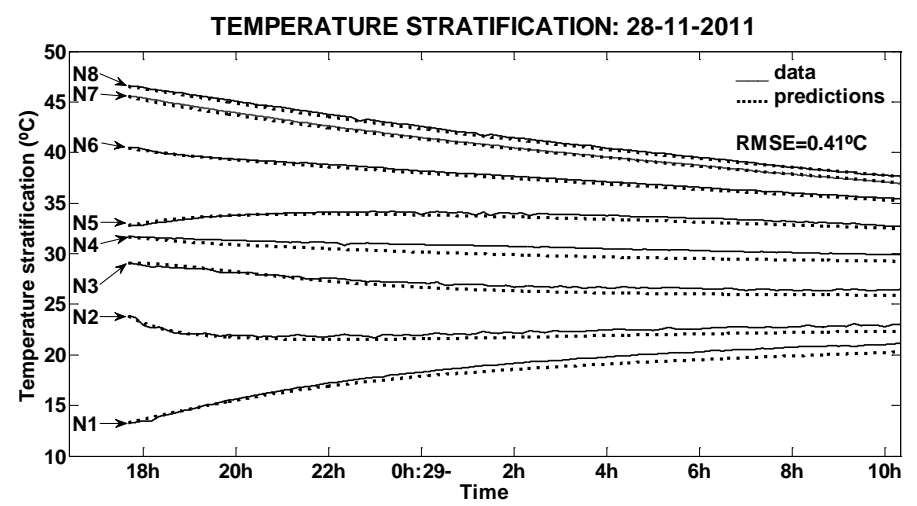

Fig. 6. Measurements obtained on the night of the 28th to 29th of November 2011 and results of predictions made at one minute intervals with the prediction model.

The validity range for applying ANNs is determined by the representativeness of the data set used for training and the capacity for generalising to data outside of that set. In this case, no deviations were found.

\subsection{IDENTIFICATION}

Curves were fitted using the data obtained from solar thermal system assays conducted during static operating mode and processed with the Matlab Curve Fitting Toolbox MathWorks [27]. This software was employed to find the values of the coefficients $a, b, c$ and $d$ of the two exponential curves used to represent overnight thermal evolution, $\mathrm{f}(\mathrm{t})=\mathrm{a} \mathrm{e}^{\mathrm{b} t}+\mathrm{c} \mathrm{e}^{\mathrm{dt}}$, using data recorded in the storage tank assays.

' $a$ ' indicates proximity to the initial temperature values, always (+). ' $b$ ' indicates the general trend of the temperature to decrease if it is (-), or to increase if it is $(+)$. ' $c$ ' adjusts the initial value of ' $a$ ', $(+)$ or (-) as appropriate. ' $d$ ' adjusts the general trend to decrease (-). It holds that ' $a+c$ ' is the initial temperature value. ' $c$ ' and above all ' $a$ ' indicate the initial temperature value. ' $d$ ' and above all ' $b$ ' indicate the trend of the temperature to increase if it is $(+)$ and decrease if it is (-); the higher the values, the more rapid the trend.

The results showed a good fit between the model of the two exponential curves and the data recorded in experiments. Fig. 7 shows the 97 measurements recorded on the night of the 4th to 5th of July 2011, while Table 4 gives the functions of the two exponential curves generated from the data for the 8 layers into which the deposit was divided, resulting in a $\mathrm{RMSE}=0.05^{\circ} \mathrm{C}$ compared to measurements. 


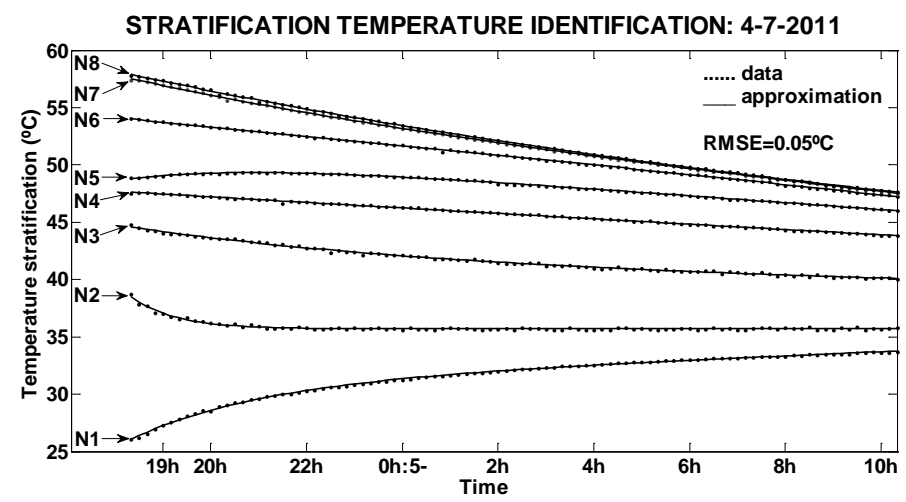

Fig. 7. Measurements obtained on the night of the 4th to 5th of July 2011, together with the approximation of a double exponential curve for each tank layer.

Table 4. Functions resulting from fitting the data obtained from the assay conducted on the 4th of July 2011

\begin{tabular}{c|l|c}
\hline Tank layer & \multicolumn{1}{|c}{ Functions corresponding to the assay conducted on the 4th to 5th of July } & RMSE, ${ }^{\circ} \mathrm{C}$ \\
\hline Layer 8 & $\mathrm{f}(\mathrm{t})=49.27 \mathrm{e}^{-0.0009809 \mathrm{t}+8.775 \mathrm{e}^{-0.0117 t}}$ & 0.05 \\
Layer 7 & $\mathrm{f}(\mathrm{t})=55.06 \mathrm{e}^{-0.001562 \mathrm{t}}+2.618 \mathrm{e}^{-0.02597 \mathrm{t}}$ & 0.04 \\
Layer 6 & $\mathrm{f}(\mathrm{t})=54.18 \mathrm{e}^{-0.001237 \mathrm{t}}-0.1016 \mathrm{e}^{-0.02166 \mathrm{t}}$ & 0.04 \\
Layer 5 & $\mathrm{f}(\mathrm{t})=51.16 \mathrm{e}^{-0.001093 \mathrm{t}}-2.444 \mathrm{e}^{-0.05953 \mathrm{t}}$ & 0.03 \\
Layer 4 & $\mathrm{f}(\mathrm{t})=47.68 \mathrm{e}^{-0.0008671 \mathrm{t}}-0.01 \mathrm{e}^{-0.01 \mathrm{t}}$ & 0.04 \\
Layer 3 & $\mathrm{f}(\mathrm{t})=40.90 \mathrm{e}^{-0.0002926 \mathrm{t}}+3.783 \mathrm{e}^{-0.02477 \mathrm{t}}$ & 0.08 \\
Layer 2 & $\mathrm{f}(\mathrm{t})=35.69 \mathrm{e}^{0.000002052 \mathrm{t}}+3.336 \mathrm{e}^{-0.1775 \mathrm{t}}$ & 0.08 \\
Layer 1 & $\mathrm{f}(\mathrm{t})=31.02 \mathrm{e}^{0.0008816 \mathrm{t}}-5.269 \mathrm{e}^{-0.0597 \mathrm{t}}$ & 0.07 \\
\hline
\end{tabular}

Some exceptions to the curves were obtained which can be represented by a single exponential term $f(t)=a$ $\mathrm{e}^{\mathrm{b} t}$. These occurred in layers which were surrounded by others at the same temperature and thus heat gain and loss with respect to layers above and below was zero. Although a single exponential curve could be used to represent the case where tank layers had become homogenised after a few days and temperature variations corresponded solely to heat loss from tank to the exterior, the most accurate representation would always be achieved with the sum of two exponential curves.

Another feature observed which fulfilled the temperature variation curves of each tank layer is that they do not cut or cross; the upper layer usually remained hotter than the layer below, and only in some cases did the layer below achieve the same temperature as that above, e.g. when a large amount of heat energy had been captured.

Thus, in addition to obtaining data on the temperature evolution of each tank layer during overnight assays, a mathematical function has been developed to identify these temperatures, which will be of use in the control and simulation of a solar thermal system.

\section{CONCLUSIONS}

An experimental study was conducted in static operating mode of a $150 \mathrm{~L}$ capacity solar thermal system hot water storage tank. Water in the lower part of the tank was found to heat up at the start of the cooling process. An analysis of stratification revealed that this depended mainly on initial temperature profiles. Therefore, the cooling process depended on initial heat levels and thus on prior loading and/or discharge. The influence of ambient temperature on cooling was not explored in this study, since it remained relatively constant in the laboratory where the assays were conducted. However, it remains an option for consideration, and could be used as another ANN input. 
The novelty of this method resides in the possibility it presents of using a data set obtained from the operation of a specific tank to create an ANN-based model capable of predicting the evolution of layer temperatures on the basis of the initial static operating mode temperature profile, when there is insufficient sunlight to activate the primary circuit pump and no solar-heated hot water has been discharged, which is the most common state in a solar thermal system, arising mainly at night and on cloudy days. Clearly, the model obtained is only applicable to the tank used for data collection; in contrast, the proposed methodology can be generalised.

It has also been possible to determine the way in which water temperatures in the tank change over time in static operating mode, from the sum of two natural exponential curves based on the number e and deduced from theories about heat transfer inspired by Newton's law of cooling.

Most studies on thermal stratification have addressed the dynamic operating mode, with loading and discharge. However, the proposed model is capable of determining the temperature of solar-heated hot water after a set period of time on cloudy days or at night, when no hot water has been consumed. The model can be applied to the simulation, control or monitoring of solar thermal systems, and can be extended to any tank storing sensible heat. To date, heat loss from a tank has been calculated on the basis of the mean temperature of the water in the tank and the technical characteristics and dimensions of the thermal insulation used, or by more elaborate methods such as the computation of fluid dynamics, which is difficult for non-specialist personnel to apply to facilities. In contrast, the model proposed here is capable of accurately determining the evolution of temperatures in a tank using a method which is simple and easy to apply.

This model forms part of a study aimed at simulating the dynamic operation of solar thermal systems using ANN. The neural model of the solar collector is shown, Diez and Falagán [6] [7], a previous study, Garcia et al. [11]. The authors have evaluated the sources of alternative energy for greenhouse, García et al. [12] and performed the analysis of the life cycle for a solar thermal system, Rey et al. [33].

\section{REFERENCES}

1. Ameri Siahoui, H.R., Dehghani, A.R., Razavi, M. and Khani, M.R., Investigation of thermal stratification in cisterns using analytical and artificial neural networks methods, Energy Convers. Manage., 2011, vol, 52, no. 1, pp. 505-511.

2. Box, G.E.P. and Jenkins, G.M., Time series analysis: forecasting and control, San Francisco CA: Holden-Day, 1976.

3. Davidzon, M.I., Newton's law of cooling and its interpretation, Int. J. Heat Mass Transfer, 2012, vol. 55, no. 21-22, pp. 5397-5402.

4. Demuth, H., Beale, M. and Hagan, M., Neural network toolbox. User's guide Matlab, Natick MA: The MathWorks Inc., 2010.

5. Dinçer, I. and Rosen, M.A., Thermal energy storage: systems and applications, Chichester: Wiley, 2011.

6. Diez, F.J. and Falagán, J.L., Sistemas solares térmicos: modelado del captador mediante redes neuronales artificiales (I), Era Solar, 2013, vol. 176, no. 5, pp. 26-34.

7. Diez, F.J. and Falagán, J.L., Sistemas solares térmicos: modelado del captador mediante redes neuronales artificiales (II), Era Solar, 2013, vol. 177, no. 6, pp. 42-54.

8. Duffie, J.A. and Beckman, W.A., Solar engineering of thermal processes, New Jersey: Wiley, 2006.

9. Fernández-Seara, J., Uhía, F.J. and Sieres, J., Experimental analysis of a domestic electric hot water storage tank. Part I: static mode of operation, Appl. Therm. Eng., 2007, vol. 27, no. 1, pp. 129-136.

10. Fernández-Seara, J., Uhía, F.J. and Sieres J., Experimental analysis of a domestic electric hot water storage tank. Part II: dynamic mode of operation, Appl. Therm. Eng., 2007, vol. 27, no. 1, pp. 137-144. 
11. García, J.L., de la Plaza, S., Durán, J.M., Navas, L.M., Benavente, R.M. and Luna, L., Instalación de colectores solares para su evaluación en aplicaciones agrícolas y agroalimentarias, Era Solar, 1996, vol. 76, no. 6, pp. 1819.

12. García, J.L., de la Plaza, S., Navas, L.M., Benavente, R.M. and Luna, L., Evaluation of the feasibility of alternative energy sources for greenhouse heating, J. Agr. Eng. Res., 1998, vol. 69, no. 2, pp. 107-114.

13. Géczy-Víg, P. and Farkas, I., Neural network modelling of thermal stratification in a solar DHW storage, Solar Energy, 2010, vol. 84, no. 5, pp. 801-806.

14. Gopalakrishnan, N. and Srinivasa Murthy, S., Mixed convective flow and thermal stratification in hot water storage tanks during discharging mode, Appl. Solar Energy, 2009, vol. 45, no. 4, pp. 254-261.

15. Haller, M.Y., Cruickshank, C.A., Streicher, W., Harrison, S.J., Andersen, E. and Furbo, S., Methods to determine stratification efficiency of thermal energy storage processes - Review and theoretical comparison, Solar Energy, 2009, vol. 83, no. 10, pp. 1847-1860.

16. Haller, M.Y., Yazdanshenas, E., Andersen, E., Bales, C., Streicher, W. and Furbo, S., A method to determine stratification efficiency of thermal energy storage processes independently from storage heat losses, Solar Energy, 2010, vol. 84, no. 6, pp. 997-1007.

17. Han, Y.M., Wang, R.Z. and Dai, Y.J., Thermal stratification within the water tank, Renew. Sustainable Energy Rev., 2009, vol. 13, no. 5, pp. 1014-1026.

18. Haykin, S.S., Neural networks: a comprehensive foundation, Upper Saddle River NJ: Prentice Hall, 1999.

19. Incropera, F.P., DeWitt, D.P., Bergman, T.L. and Lavine, A.S., Fundamentals of heat and mass transfer, New York: Wiley, 2010.

20. Jaluria, Y. and Gupta, S.K., Decay of thermal stratification in a water body for solar energy storage, Solar Energy, 1982, vol. 28, no. 2, pp. 137-143.

21. Kalogirou, S., Solar energy engineering: processes and systems, Burlington MA: Elsevier/Academic Press, 2009.

22. Karris, S.T., Introduction to Simulink with engineering applications, Fremont CA: Orchard Publications, 2006.

23. Kay, S.M., Fundamentals of statistical signal processing: estimation theory, vol. 1, Englewood Cliffs NJ: Prentice Hall, 1993.

24. Kleinbach, E.M., Beckman, W.A. and Klein, S.A., Performance study of one-dimensional models for stratified thermal storage tanks, Solar Energy, 1993, vol. 50, no. 2, pp. 155-166.

25. Makridakis, S.G., Wheelwright, S.C. and Hyndman, R.J., Forecasting: methods and applications, New York: Wiley, 1998.

26. Maor, E., $e$ : the story of a number, Princeton NJ: Princeton University Press, 1994

27. MathWorks, Curve fitting toolbox: for use with MATLAB, Natick MA: The MathWorks Inc., 2006.

28. Mellit, A., Eleuch, H., Benghanem, M., Elaoun, C. and Pavan, A.M., An adaptive model for predicting of global, direct and diffuse hourly solar irradiance, Energy Convers. Manage., 2010, vol. 51, no. 4, pp. 771-782.

29. Oliveski, R.D.C., Krenzinger, A. and Vielmo, H.A., Cooling of cylindrical vertical tanks submitted to natural internal convection, Int. J. Heat Mass Transfer, 2003, vol. 46, no. 11, pp. 2015-2026.

30. Oshchepkov, M.Yu. and Frid, S.E., Thermal stratification in storage tanks of integrated collector storage solar water heaters, Appl. Solar Energy, 2015, vol. 51, no. 1, pp. 74-82.

31. Oshchepkov, M.Yu., Frid, S.E. and Kolobaev, M.A., Stratification in a solar tank accumulator during rapid displacement of hot water, Appl. Solar Energy, 2015, vol. 51, no. 3, pp. 177-182.

32. Palit, A.K. and Popovic, D., Computational intelligence in time series forecasting: theory and engineering applications, London: Springer, 2005.

33. Rey, J., Velasco, E., Martín, J., Navas, L.M. and Hernández, S., Life cycle analysis of a thermal solar installation at a rural house in Valladolid (Spain), Environ. Eng. Sci., 2008, vol. 25, no. 5, pp. 713-724. 


\section{BIBLIOGRAFÍA}

Abdoly MA, Rapp D. 1982. Theoretical and experimental studies of stratified thermocline storage of hot water. Energy Conversion and Management, 22(3): 275-285.

Adams DE, Davidson JH. Tank stratification with a flexible manifold. 1993. Proceedings of the American Solar Energy Society Annual Conference, Washington DC, April 22-28: 277-281.

AENOR. Sistemas solares térmicos y componentes. Captadores solares. Parte 2: Métodos de ensayo. UNE-EN 12975-2: 2006.

Aitkenhead MJ, McDonald AJS, Dawson JJ, Couper G, Smart RP, Billett M, Hope D, Palmer S. 2003. A novel method for training neural networks for time-series prediction in environmental systems. Ecological Modelling, 162(1-2): 87-95.

Ajona JI, Gordon JM. 1987. An analytic model for the long-term performance of solar air heating systems. Solar Energy, 38(1): 45-53.

Al-Alawi SM, Al-Hinai HA. 1998. An ANN-based approach for predicting global radiation in locations with no direct measurement instrumentation. Renewable Energy, 14(1-4): 199-204.

Al-Hamdani N, Al-Riahi M, Tahir K. 1989. Estimation of the diffuse fraction of daily and monthly average global radiation for Fudhaliyah, Baghdad (Iraq). Solar Energy, 42(1): 81-85.

Alam S, Kaushik SC, Garg SN. 2009. Assessment of diffuse solar energy under general sky condition using artificial neural network. Applied Energy, 86(4): 554-564.

Alizadeh S. 1999. An experimental and numerical study of thermal stratification in a horizontal cylindrical solar storage tank. Solar Energy, 66(6): 409-421.

Allen RG. 2006. Evapotranspiración del cultivo: Guías para la determinación de los requerimientos de agua de los cultivos. Organización de las Naciones Unidas para la Agricultura y la Alimentación FAO, Roma.

Al-Marafie AMR. 1987. Stratification behaviour in a chilled water storage tank. International Journal of Refrigeration, 10(6): 364-366.

Almonacid F, Rus C, Pérez-Higueras P, Hontoria L. 2011. Calculation of the energy provided by a PV generator. Comparative study: Conventional methods vs. artificial neural networks. Energy, 36(1): 375384. 
Alnaser WE. 1989. Empirical correlation for total and diffuse radiation in Bahrain. Energy, 14(7): 409414.

Al-Sadah FH, Ragab FM, Arshad MK. 1990. Hourly solar radiation over Bahrain. Energy, 15(5): 395-402.

Altuntop N, Arslan M, Ozceyhan V, Kanoglu M. 2005. Effect of obstacles on thermal stratification in hot water storage tanks. Applied Thermal Engineering, 25(14-15): 2285-2298.

Amari S, Maginu K. 1988. Statistical neurodynamics of associative memory. Neural Networks 1(1): 63-73.

Amato U, Andretta A, Bartoli B, Coluzzi B, Cuomo V, Fontana F, Serio C. 1986. Markov processes and Fourier analysis as a tool to describe and simulate daily solar irradiance. Solar Energy, 37(3): 179-194.

Amer EH, Nayak JK, Sharma GK. 1997. Transient test methods for flat-plate collectors: Review and experimental evaluation. Solar Energy, 60(5): 229-243.

Andersen E, Furbo S, Fan J. 2007. Multilayer fabric stratification pipes for solar tanks. Solar Energy, 81(10): 1219-1226.

Ångström A. 1924. Solar and terrestrial radiation. Quarterly Journal of the Royal Meteorological Society, 4: 121-126.

Arahal MR, Cirre CM, Berenguel M. 2008. Serial grey-box model of a stratified thermal tank for hierarchical control of a solar plant. Solar Energy, 82(5): 441-451.

Argiriou A, Lykoudis S, Kontoyiannidis S, Balaras CA, Asimakopoulos D, Petrakis M, Kassomenos P. 1999. Comparison of methodologies for tmy generation using 20 years data for Athens, Greece. Solar Energy, 66(1): 33-45.

Arinze EA, Schoenau GJ, Sokhansanj S, Adefila SS, Mumah SM. 1993. A dynamic performance simulation model of flat-plate solar collectors for a heat pump system. Energy Conversion and Management, 34(1): 33-49.

Armacell Iberia SL. 2006. Catálogo técnico HT/Armaflex S. Palafrugell, Girona.

ASHRAE. 1997. Handbook of fundamentals. American Society of Heating, Refrigerating and AirConditioning Engineers, Atlanta, GA.

Atia DM, Fahmy FH, Ahmed NM, Dorrah HT. 2010. Optimal sizing of solar water heating system based on genetic algorithm for aquaculture system. $14^{\text {th }}$ International Middle East Power Systems Conference MEPCON'10, Cairo University, ID 244: 590-595.

Azadeh A, Maghsoudi A, Sohrabkhani S. 2009. An integrated artificial neural networks approach for predicting global radiation. Energy Conversion and Management, 50(6): 1497-1505.

Bahnfleth WP, Song J. 2005. Constant flow rate charging characteristics of a full-scale stratified chilled water storage tank with double-ring slotted pipe diffusers. Applied Thermal Engineering, 25(17-18): 3067-3082. 
Balcomb JD, McFarland RD. 1978. Simple empirical method for estimating the performance of a passive solar heated building of the thermal storage wall type. $2^{\text {nd }}$ National Passive Solar Conference, University of California, LA-UR-78-1159.

Baldasano JM, Clar J, Berna A. 1988. Fourier analysis of daily solar radiation data in Spain. Solar Energy, 41(4): 327-333.

Barley CD, Winn CB. 1978. Optimal sizing of solar collectors by the method of relative areas. Solar Energy, 21(4): 279-289.

Bates JM, Granger CWJ. 1969. The combination of forecasts. Operation Research Quart 20: 692-695.

Batlles FJ, Rubio MA, Tovar J, Olmo FJ, Alados-Arboledas L. 2000. Empirical modeling of hourly direct irradiance by means of hourly global irradiance. Energy, 25(7): 675-688.

Baum EB, Haussler D. 1989. What size net gives valid generalization? Neural Computation, 1: 151-160.

Beckman WA, Klein SA, Duffie JA. 1977. Solar heating design by the f-chart method. Wiley, New York, NY.

Behrang MA, Assareh E, Ghanbarzadeh A, Noghrehabadi AR. 2010. The potential of different artificial neural network (ANN) techniques in daily global solar radiation modeling based on meteorological data. Solar Energy, 84(8): 1468-1480.

Bendt P, Collares-Pereira M, Rabl A. 1981. The frequency distribution of daily insolation values. Solar Energy, 27(1): 1-5.

Benghanem M, Mellit A, Alamri SN. 2009. ANN-based modelling and estimation of daily global solar radiation data: A case study. Energy Conversion and Management, 50(7): 1644-1655.

Benrod F, Bock JE. 1934. A time analysis of sunshine. Transactions of the American Illumination Engineering Society, 34: 200-218.

Benson RB, Paris MV, Sherry JE, Justus CG. 1984. Estimation of daily and monthly direct, diffuse and global solar radiation from sunshine duration measurements. Solar Energy, 32(4): 523-535.

Berkel J. 1996. Mixing in thermally stratified energy stores. Solar Energy, 58(4-6): 203-211.

Berkel J, Rindt CCM, van Steenhoven AA. 1999. Modelling of two-layer stratified stores. Solar Energy, 67(1-3): 65-78.

Bérriz L, Álvarez M. 2008. Manual para el cálculo y diseño de calentadores solares. Cubasolar, La Habana.

Beyer HG, Costanzo C, Heinemann D. 1996. Modifications of the Heliosat procedure for irradiance estimates from satellite images. Solar Energy, 56(3): 207-212.

Bezdek JC. 1992. On the relationship between neural networks, pattern recognition and intelligence. International Journal of Approximate Reasoning, 6(2): 85-107. 
Biga AJ, Rosa R. 1981. Statistical behaviour of solar irradiation over consecutive days. Solar Energy, 27(2): 149-157.

Bilbao J, Miguel A, Franco J, Ayuso A. 2004. Test reference year generation and evaluation methods in the continental Mediterranean area. Journal of Applied Meteorology, 43(2): 390-400.

Bird R, Hulstrom R. 1983. Review, evaluation, and improvement of direct irradiance models. Journal of Solar Energy Engineering, 103: 182-192.

Bliss RWJ. 1959. The derivations of several "Plate-efficiency factors" useful in the design of flat-plate solar heat collectors. Solar Energy, 3(4): 55-64.

Bloisi F, Catalanotti S, Cuomo V, De Stefano S, Vicari L. 1980. Heat storage and solar system performance. Applied Energy, 7(1-3): 19-29.

BOE. Resolución de 18 de diciembre de 2006 de la Secretaría de Industria del Departamento de Innovación, Universidades y Empresa, de conformidad del producto fabricado por Takama SL, con contraseña GPS-8130: Paneles solares, publicado en BOE núm. 20, martes 23 enero 2007, pag. 3286.

Boileau E. 1983. Use of some simple statistical models in solar meteorology. Solar Energy, 30(4): 333339.

Boland J, Scott L, Luther M. 2001. Modelling the diffuse fraction of global solar radiation on a horizontal surface. Environmetrics, 12(2): 103-116.

Boland J, Ridley B, Brown B. 2008. Models of diffuse solar radiation. Renewable Energy, 33(4): 575-584.

Bouhdjar A, Harhad A. 2002. Numerical analysis of transient mixed convection flow in storage tank: Influence of fluid properties and aspect ratios on stratification. Renewable Energy, 25(4): 555-567.

Brinkworth BJ. 1977. Autocorrelation and stochastic modelling of insolation sequences. Solar Energy, 19(4): 343-347.

Bristow KL, Campbell GS. 1984. On the relationship between incoming solar radiation and daily maximum and minimum temperature. Agricultural and Forest Meteorology, 31(2): 159-166.

Brooks DR. 2008. Bringing the sun down to earth: Designing inexpensive instruments for monitoring the atmosphere. Springer, New York, NY.

Broomhead DS, Lowe D. 1988. Multivariable functional interpolation and adaptive networks. Complex Systems, 2: 321-355.

Bruno R. 1978. A correction procedure for separating direct and diffuse insolation on a horizontal surface. Solar Energy, 20(1): 97-100.

Buckles WE, Klein SA. 1980. Analysis of solar domestic hot water heaters. Solar Energy, 25(5): 417-424.

Bugler JW. 1977. The determination of hourly insolation on an inclined plane using a diffuse irradiance model based on hourly measured global horizontal insolation. Solar Energy, 19(5): 477-491. 
Bulut H. 2003. Generation of typical solar radiation data for Istanbul, Turkey. International Journal of Energy Research, 27(9): 847-855.

Bulut H. 2004. Typical solar radiation year for southeastern Anatolia. Renewable Energy, 29(9): 14771488.

Cabelli A. 1977. Storage tanks-A numerical experiment. Solar Energy, 19(1): 45-54.

Caleffi Spa. 2006. Catálogo técnico purgadores automáticos de aire. Fontaneto d'Agogna, Piamonte.

Camacho EF, Berenguel M, Rubio FR, Martínez D. 2012. Control of solar energy systems. Springer, New York, NY.

Camps J, Soler MR. 1992. Estimation of diffuse solar irradiance on a horizontal surface for cloudless days-A new approach. Solar Energy, 49(1): 53-63.

Cano D, Monget JM, Albuisson M, Guillard H, Regas N, Wald L. 1986. A method for the determination of the global solar radiation from meteorological satellite data. Solar Energy, 37(1): 31-39.

Cao S, Cao J. 2005. Forecast of solar irradiance using recurrent neural networks combined with wavelet analysis. Applied Thermal Engineering, 25(2-3): 161-172.

Cao JC, Cao SH. 2006. Study of forecasting solar irradiance using neural networks with preprocessing sample data by wavelet analysis. Energy, 31(15): 3435-3445.

Cao J, Lin X. 2008a. Application of the diagonal recurrent wavelet neural network to solar irradiation forecast assisted with fuzzy technique. Engineering Applications of Artificial Intelligence, 21(8): 12551263.

Cao J, Lin X. 2008b. Study of hourly and daily solar irradiation forecast using diagonal recurrent wavelet neural networks. Energy Conversion and Management, 49(6): 1396-1406.

Carter C. 1994. Few-day solar radiation cycles and their use in building simulation. Solar Energy, 53(5): 461-465.

CENER-CIEMAT. 2006. Informe de ensayo de captador solar. Rendimiento anexo 6 del captador solar térmico T3-inox Takama SL. Sarriguren, Navarra.

CENER-CIEMAT. 2006. Informe de ensayo de captador solar. Resumen del informe de ensayo de rendimiento anexo 7 del captador solar térmico T3-inox Takama SL. Sarriguren, Navarra.

Chakraborty K, Mehrotra K, Mohan CK, Ranka S. 1992. Forecasting the behavior of multivariate time series using neural networks. Neural Networks, 5(6): 961-970.

Chan ALS, Chow TT, Fong SKF, Lin JZ. 2006. Generation of a typical meteorological year for Hong Kong. Energy Conversion and Management, 47(1): 87-96.

Chandrasekaran J, Kumar S. 1994. Hourly diffuse fraction correlation at a tropical location. Solar Energy, 53(6): 505-510. 
Chang K, Minardi A. 1980. An optimization formulation for solar heating systems. Solar Energy, 24(1): 99-103.

Chauvin Y, Rumelhart DE. 1994. Backpropagation: Theory, architectures, and applications. Lawrence Erlbaum Associates, Hillsdale, NJ.

Choudhury NKD. 1963. Solar radiation at New Delhi. Solar Energy, 7(2): 44-52.

Chow TT, Chan ALS, Fong KF, Lin Z. 2006. Some perceptions on typical weather year-from the observations of Hong Kong and Macau. Solar Energy, 80(4): 459-467.

Close DJ. 1967. A design approach for solar processes. Solar Energy, 11(2): 112-122.

Coffari E. 1977. The sun and the celestial vault, cap 2. En: Solar energy engineering. Sayigh AAM ed, Academic Press, New York, NY.

Collares-Pereira M, Rabl A. 1979. The average distribution of solar radiation-correlations between diffuse and hemispherical and between daily and hourly insolation values. Solar Energy, 22(2): 155-164.

Cònsul R, Rodríguez I, Pérez-Segarra CD, Soria M. 2004. Virtual prototyping of storage tanks by means of three-dimensional CFD and heat transfer numerical simulations. Solar Energy, 77(2): 179-191.

Coronas A, Baldasano JM. 1984. Fourier analysis of meteorological data to obtain a typical annual time function. Solar Energy, 32(4): 479-488.

Cristofari C, Notton G, Poggi P, Louche A. 2003. Influence of the flow rate and the tank stratification degree on the performances of a solar flat-plate collector. International Journal of Thermal Sciences, 42(5): 455-469.

Cruickshank CA. 2009. Evaluation of a stratified multi-tank thermal storage for solar heating applications. Tesis Doctoral, Queen's University.

Cruz-Peragon F, Palomar JM, Casanova PJ, Dorado MP, Manzano-Agugliaro F. 2012. Characterization of solar flat plate collectors. Renewable and Sustainable Energy Reviews, 16(3): 1709-1720.

Csordas GF, Brunger AP, Hollands KGT, Lightstone MF. 1992. Plume entrainment effects in solar domestic hot water systems employing variable-flow-rate control strategies. Solar Energy, 49(6): 497505.

Cuadros F, López-Rodríguez F, Segador C, Marcos A. 2007. A simple procedure to size active solar heating schemes for low-energy building design. Energy and Buildings, 39(1): 96-104.

Cybenko G. 1989. Approximation by superpositions of a sigmoidal function. Mathematical Control Signals Systems, 2: 303-314.

Czeplak G, Noia M, Ratto CF. 1991. An assessment of a statistical method to estimate solar irradiance at the earth's surface from geostationary satellite data. Renewable Energy, 1(5-6): 737-743.

Dahm J, Bales C, Lorenz K, Dalenbäck J-O. 1998. Evaluation of storage configurations with internal heat exchangers. Solar Energy, 62(6): 407-417. 
Danfoss SA. 2006. Catálogo técnico sondas de temperatura. San Sebastián de los Reyes, Madrid.

Dedieu G, Deschamps P, Kerr Y. 1987. Satellite estimation of solar irradiance at the surface of the earth and surface albedo using a physical model applied to METEOSAT data. Journal of Climate and Applied Meteorology, 26: 79-87.

Delta Ohm SRL. 2006. Catálogo técnico piranómetro LP PYRA 02. Padova, Véneto.

Demuth H, Beale M, Hagan M. 2010. Neural network toolbox: User's guide Matlab. The MathWorks, Natick, MA.

Diabaté L, Demarcq H, Michaud-Regas N, Wald L. 1988. Estimating incident solar radiation at the surface from images of the earth transmitted by geostationary satellites: The Heliosat Project. International Journal of Solar Energy, 5: 261-278.

Diabaté L, Moussu G, Wald L. 1989. Description of an operational tool for determining global solar radiation at ground using geostationary satellite images. Solar Energy, 42(3): 201-207.

Díaz G. 2000. Simulation and control of heat exchangers using artificial neural networks. Tesis Doctoral, University of Notre Dame.

Díaz G, Sen M, Yang KT, McClain RL. 2001. Dynamic prediction and control of heat exchangers using artificial neural networks. International Journal of Heat and Mass Transfer, 44(9): 1671-1679.

Diez FJ. 2007. Optimización de sistemas solares térmicos. Trabajo de Investigación Doctoral, Departamento de Ingeniería Eléctrica, y de Sistemas y Automática, Universidad de León.

Diez FJ, Falagán JL. 2013a. Sistemas solares térmicos. Modelado del captador mediante redes neuronales artificiales (I). Era Solar, 176: 26-34.

Diez FJ, Falagán JL. 2013b. Sistemas solares térmicos. Modelado del captador mediante redes neuronales artificiales (II). Era Solar, 177: 42-54.

Diez FJ, Navas LM, Martínez A. 2014. Prediction and identification of the evolution of solar-heated hot water temperature in a stratified tank in static mode using artificial neural networks. (En proceso de publicación).

Dinçer I, Dilmaç S, Ture IE, Edin M. 1996. A simple technique for estimating solar radiation parameters and its application for Gebze. Energy Conversion and Management, 37(2): 183-198.

Dinçer I, Rosen MA. 2011. Thermal energy storage: Systems and applications, $2^{\text {nd }}$ ed. Wiley, Chichester, West Sussex.

Domínguez F, Ruzafa J, Carrillo A, Cejudo JM. 2008. Análisis de la validez del método f-chart para el cálculo de la contribución solar en instalaciones comunitarias de ACS. XIV Congreso Ibérico y IX Congreso Iberoamericano de Energía Solar CIES, Vigo, 17-21 Junio: 425-430.

Dorvlo ASS, Jervase JA, Al-Lawati A. 2002. Solar radiation estimation using artificial neural networks. Applied Energy, 71(4): 307-319. 
Drew MS, Selvage RBG. 1979. Correspondence between solar load ratio method for passive water wall systems and f-chart performance estimates. Solar Energy, 23(4): 327-331.

Dudzik S. 2011. Investigations of a heat exchanger using infrared thermography and artificial neural networks. Sensors and Actuators A: Physical, 166(1): 149-156.

Duffie JA, Beckman WA. 2006. Solar engineering of thermal processes, $3^{\text {rd }}$ ed. Wiley, Hoboken, NJ.

Eberhard R, Simpson P, Dobbins R. 1995. Computational intelligence PC tools. Academic Press, Boston, MA.

Ebrahimpour A, Maerefat M. 2010. A method for generation of typical meteorological year. Energy Conversion and Management, 51(3): 410-417.

El-Adawi MK. 2002. New approach to modelling a flat plate collector: The Fourier transform technique. Renewable Energy, 26(3): 489-506.

Elman JL. 1990. Finding structure in time. Cognitive Science, 14(2): 179-211.

El-Metwally M. 2004. Simple new methods to estimate global solar radiation based on meteorological data in Egypt. Atmospheric Research, 69(3-4): 217-239.

Elminir HK. 2007. Experimental and theoretical investigation of diffuse solar radiation: Data and models quality tested for Egyptian sites. Energy, 32(1): 73-82.

Elminir HK, Azzam YA, Younes FI. 2007. Prediction of hourly and daily diffuse fraction using neural network, as compared to linear regression models. Energy, 32(8): 1513-1523.

El-Sebaii AA, Al-Hazmi FS, Al-Ghamdi AA, Yaghmour SJ. 2010. Global, direct and diffuse solar radiation on horizontal and tilted surfaces in Jeddah, Saudi Arabia. Applied Energy, 87(2): 568-576.

Emery M, Rogers BA. 1984. On a solar collector thermal performance test method for use in variable conditions. Solar Energy, 33(2): 117-123.

Engels JD, Pollock SM, Clark JA. 1981. Observations on the statistical nature of terrestrial irradiation. Solar Energy, 26(1): 91-92.

Erbs DG, Klein SA, Duffie JA. 1982. Estimation of the diffuse radiation fraction for hourly, daily and monthly-average global radiation. Solar Energy, 28(4): 293-302.

Ertekin C, Yaldiz O. 1999. Estimation of monthly average daily global radiation on horizontal surface for Antalya (Turkey). Renewable Energy, 17(1): 95-102.

ESRA. 2000. European solar radiation atlas, $4^{\text {th }}$ ed. Commission of the European Communities, Ecole des mines de Paris.

Evseev EG, Kudish Al. 2009. The assessment of different models to predict the global solar radiation on a surface tilted to the south. Solar Energy, 83(3): 377-388.

Exell RHB. 1981. A mathematical model for solar radiation in South-East Asia (Thailand). Solar Energy, 26(2): 161-168. 
Exell R. 1984. Mapping solar radiation by meteorological satellite. Renewable Energy Review Journal, $6(1)$.

Fanney AH, Klein SA. 1988. Thermal performance comparisons for solar hot water systems subjected to various collector and heat exchanger flow rates. Solar Energy, 40(1): 1-11.

Farkas I, Géczy-Víg P. 2003. Neural network modelling of flat-plate solar collectors. Computers and Electronics in Agriculture, 40(1-3): 87-102.

Fernández-Seara J, Uhía FJ, Sieres J. 2007a. Experimental analysis of a domestic electric hot water storage tank. Part I: Static mode of operation. Applied Thermal Engineering, 27(1): 129-136.

Fernández-Seara J, Uhía FJ, Sieres J. 2007b. Experimental analysis of a domestic electric hot water storage tank. Part II: Dynamic mode of operation. Applied Thermal Engineering, 27(1): 137-144.

Ferrante P, La Gennusa M, Nicolosi S, Scaccianoce G, Sorrentino G. 2008. Comparison of methodologies for test reference year (TRY) generation for Mediterranean sites. 25 ${ }^{\text {th }}$ Passive and Low Energy Architecture International Conference PLEA, Dublin, October 22-24: 320.

Ferreiro R. 2012. Improving heat exchanger supervision using neural networks and rule based techniques. Expert Systems with Applications, 39(3): 3012-3021.

Festa R, Ratto CF. 1993. Proposal of a numerical procedure to select reference years. Solar Energy, 50(1): 9-17.

Feuermann D, Gordon JM, Zarmi Y. 1985. A typical meteorological day (TMD) approach for predicting the long-term performance of solar energy systems. Solar Energy, 35(1): 63-69.

Feuermann D, Zemel A. 1992. Validation of models for global irradiance on inclined planes. Solar Energy, 48(1): 59-66.

Finkelstein JM, Schafer RE. 1971. Improved goodness-of-fit test. Biometrika, 58(3): 641-645.

Fischer LS, van Koppen CWJ, Mennink BD. 1975. The thermodynamics and some practical aspects of thermally stratified heat storage in water. Report WPS3.75.11.R247, Eindhoven University of Technology, The Netherlands.

Fischer S, Frey P, Drück H. 2012. A comparison between state-of-the-art and neural network modelling of solar collectors. Solar Energy, 86(11): 3268-3277.

Fogel DB. 1991. An information criterion for optimal neural network selection. Transactions on Neural Networks, IEEE, 2: 490-497.

Fogel DB. 1995. Review of computational intelligence: Imitating life. Transactions on Neural Networks, IEEE, 6(6): 1562-1565.

Fourier Systems. 2006. Catálogo técnico DaqPRO 5300. Atlanta, GA.

Frid SE. 1990. Multinode models and dynamic testing methods of solar collectors. Solar \& Wind Technology, 7(6): 655-661. 
Gansler RA, Klein SA, Beckman WA. 1994. Assessment of the accuracy of generated meteorological data for use in solar energy simulation studies. Solar Energy, 53(3): 279-287.

Gantner M. 2000. Dynamische simulation thermischer solaranlagen. Tesis Doctoral, Hochschule für Technik Rapperswil, Suiza.

Garcia RF. 2012. Improving heat exchanger supervision using neural networks and rule based techniques. Expert Systems with Applications, 39(3): 3012-3021.

Gardner MW, Dorling SR. 1998. Artificial neural networks (the multilayer perceptron)-a review of applications in the atmospheric sciences. Atmospheric Environment, 32(14-15): 2627-2636.

Gautier C, Diak G, Masse S. 1980. A simple physical model to estimate incident solar radiation at the surface from GOES satellite data. Journal of Applied Meteorology, 19(8): 1005-1012.

Gazela M, Mathioulakis E. 2001. A new method for typical weather data selection to evaluate long-term performance of solar energy systems. Solar Energy, 70(4): 339-348.

Géczy-Víg P, Farkas I. 2010. Neural network modelling of thermal stratification in a solar DHW storage. Solar Energy, 84(5): 801-806.

German Solar Energy Society. 2010. Planning and installing solar thermal systems: A guide for installers, architects and engineers, $2^{\text {nd }}$ ed, Earthscan, London.

Ghaddar NK, Al-Marafie AM, Al-Kandari A. 1989. Numerical simulation of stratification behaviour in thermal storage tanks. Applied Energy, 32(3): 225-239.

Gómez V, Casanovas A. 2003. Fuzzy modeling of solar irradiance on inclined surfaces. Solar Energy, 75(4): 307-315.

Gopinathan KK. 1989. Diffuse irradiation contours for southern Africa. Solar \& Wind Technology, 6(3): 265-273.

Gordon JM, Reddy TA. 1988a. Time series analysis of daily horizontal solar radiation. Solar Energy, 41(3): 215-226.

Gordon JM, Reddy TA. 1988b. Time series analysis of hourly global horizontal solar radiation. Solar Energy, 41(5): 423-429.

Grossberg S. 1987. Competitive learning: From interactive activation to adaptive resonance. Cognitive Science, 11(1): 23-63.

Guemene E, Njomo D, Fouda E, Simo A. 2010. On the reliability of HELIOSAT method: A comparison with experimental data. Solar Energy, 84(6): 1047-1058.

Guerrero A. 2006. El método f-chart. Era Solar, 132: 88-94.

Gueymard CA. 2003a. Direct solar transmittance and irradiance predictions with broadband models. Part I: Detailed theoretical performance assessment. Solar Energy 74(5): 355-379. 
Gueymard CA. 2003b. Direct solar transmittance and irradiance predictions with broadband models. Part II: Validation with high-quality measurements. Solar Energy, 74(5): 381-395.

Gueymard CA, Myers DR. 2007. Performance assessment of routine solar radiation measurements for improved solar resource and radiative modeling. Proceedings Solar Conference, American Solar Energy Society ASES, Cleveland, $\mathrm{OH}$.

Gueymard CA. 2008. REST2: High-performance solar radiation model for cloudless-sky irradiance, illuminance, and photosynthetically active radiation - validation with a benchmark dataset. Solar Energy, 82(3): 272-285.

Gueymard CA, Myers DR. 2008. Validation and ranking methodologies for solar radiation models. En: Badescu V. Modeling solar radiation at the earth's surface. Springer, Berlin.

Haar TV, Raschke E, Bandeen W, Pasternak M. 1973. Measurements of solar energy reflected by the earth and atmosphere from meteorological satellites. Solar Energy, 14(2): 175-184.

Haberl JS, Cho S. 2004. Literature review of uncertainty of analysis methods (F-chart program). Texas Commission on Environmental Quality, ESL-TR-04/08-04, Texas A\&M University.

Hahne E, Chen Y. 1998. Numerical study of flow and heat transfer characteristics in hot water stores. Solar Energy, 64(1-3): 9-18.

Hall IJ, Prairie RR, Anderson HE, Boes EC. 1978. Generation of a typical meteorological year. Sandia Laboratories, SAND-78-1096C, CONF-780639-1, Albuquerque, NM.

Haller MY, Cruickshank CA, Streicher W, Harrison SJ, Andersen E, Furbo S. 2009. Methods to determine stratification efficiency of thermal energy storage processes - review and theoretical comparison. Solar Energy, 83(10): 1847-1860.

Haller MY, Yazdanshenas E, Andersen E, Bales C, Streicher W, Furbo S. 2010. A method to determine stratification efficiency of thermal energy storage processes independently from storage heat losses. Solar Energy, 84(6): 997-1007.

Hammer A, Heinemann D, Lorenz E, Lückehe B. 1999. Short-term forecasting of solar radiation: A statistical approach using satellite data. Solar Energy, 67(1-3): 139-150.

Han YM, Wang RZ, Dai YJ. 2009. Thermal stratification within the water tank. Renewable and Sustainable Energy Reviews, 13(5): 1014-1026.

Happ H, Lin W, Raschke E, Rieland M, Stuhlmann R. 1989. Solar radiation atlas of Africa. Total and diffuse fluxes at ground level measured by geostationary satellites. Personal Communication Sent.

Harald PG, Kamastra M. 1997. Evolving artificial neural networks to combine the financial forecasts. Transactions on Evolutionary Computation, IEEE, 1(1): 40-51.

Hargreaves GH, Samani ZA. 1982. Estimating potential evapotranspiration. Journal of Irrigation and Drainage Engineering, ASCE, 108(IR3): 223-230. 
Hargreaves GL, Hargreaves GH, Riley P. 1985. Irrigation water requirement for the Senegal River Basin. Journal of Irrigation and Drainage Engineering, ASCE, (111): 265-275.

Hariharan K, Badrinarayana K, Srinivasa Murthy S, Krishna Murthy MV. 1991. Temperature stratification in hot-water storage tanks. Energy, 16(7): 977-982.

Hawas MM, Abou-Zeid MR. 1983. A general chart for sizing the collectors of solar heating systems. Energy Conversion and Management, 23(3): 135-140.

Hawlader MNA. 1984. Diffuse, global and extraterrestrial solar radiation for Singapore. International Journal of Ambient Energy, 5: 31-38.

Hay JE. 1976. A revised method for determining the direct and diffuse components of the total shortwave radiation. Atmosphere, 14(4): 278-287.

Hay JE. 1979. Calculation of monthly mean solar radiation for horizontal and inclined surfaces. Solar Energy, 23(4): 301-307.

Hay JE, Davies JA. 1980. Calculation of the solar radiation incident on an inclined surface. Proceedings First Canadian Solar Radiation Data Workshop, Toronto, Ontario: 59-72.

Hebb DO. 1949. The organization of behavior. Wiley, New York, NY.

Hecht-Nielsen R. 1987. Kolmogorov's mapping neural network existence theorem. Proceedings of the First International Conference on Neural Networks, IEEE, 3: 11-13.

Hecht-Nielsen R. 1988. Applications of counterpropagation networks. Neural Networks, 1(2): 131-139.

Heywood H. 1966. The computation of solar radiation intensities part 2-solar radiation on inclined surfaces. Solar Energy, 10(1): 46-52.

Hill T, O'Connor M, Remus W. 1996. Neural network models for time series forecasts. Management Science, 42(7): 1082-1092.

Hirunlabh J, Sarachitti R, Namprakai P. 1997. Estimating solar radiation at the earth's surface from satellite data. Thammasat International Journal of Science and Technology, 1: 69-79.

Hocaoğlu FO, Gerek ÖN, Kurban M. 2008. Hourly solar radiation forecasting using optimal coefficient 2D linear filters and feed-forward neural networks. Solar Energy, 82(8): 714-726.

Hollands KGT, Lightstone MF. 1989. A review of low-flow, stratified-tank solar water heating systems. Solar Energy, 43(2): 97-105.

Hontoria L. 2001. Generación de series sintéticas de radiación solar combinando herramientas estadísticas y redes neuronales. Tesis Doctoral, Universidad de Jaén.

Hontoria L, Aguilera J, Zufiria P. 2002. Generation of hourly irradiation synthetic series using the neural network multilayer perceptron. Solar Energy, 72(5): 441-446.

Hontoria L, Aguilera J, Zufiria P. 2005. An application of the multilayer perceptron: Solar radiation maps in Spain. Solar Energy, 79(5): 523-530. 
Hottel HC, Woertz BB. 1942. Performance of flat-plate solar-heat collectors. Transactions of American Society of Mechanical Engineers, 64: 91-104.

Hottel HC, Whillier A. 1955. Evaluation of flat plate collector performance. Transactions of the Conference on the Use of Solar Energy, University of Arizona Press, 1(2): 74-104.

Hottel HC. 1976. A simple model for estimating the transmittance of direct solar radiation through clear atmospheres. Solar Energy, 18(2): 129-134.

Hou H, Wang Z, Wang R, Qi B. 2004. Transient test method for thermal performance of flat-plate solar collectors. Taiyangneng Xuebao/Acta Energiae Solaris Sinica, 25(3): 310-314.

Hu MJC. 1964. Application of the ADALINE system to weather forecasting. Master Tesis, Stanford Electronics Laboratories, Technical Report 6775- 1, Stanford University.

Ibaiondo SA. 2006. Catálogo técnico vasos de expansión. Mungía.

Ibáñez M, Rosell JR, Rosell JI. 2005. Tecnología solar. Mundi-Prensa, Madrid.

IDAE. 2009. Pliego de condiciones técnicas de instalaciones de baja temperatura. Instalaciones de energía solar térmica. Instituto para la Diversificación y Ahorro de la Energía, Madrid.

Ineichen P, Perez R. 1999. Derivative of cloud index from geostationary satellites and application to the production of solar irradiance and daylight illuminance data. Theoretical Applications of Climatology, 64: 119-130.

Ineichen P, Perez R. 2002. A new air mass independent formulation for the Linke turbidity coefficient. Solar Energy, 73(3): 151-157.

Iqbal M. 1978a. Estimation of the monthly average of the diffuse component of total insolation on a horizontal surface. Solar Energy, 20(1): 101-105.

Iqbal M. 1978b. Hourly vs daily method of computing insolation on inclined surfaces. Solar Energy, 21(6): 485-489.

Iqbal M. 1979a. A study of Canadian diffuse and total solar radiation data-I monthly average daily horizontal radiation. Solar Energy, 22(1): 81-86.

lqbal M. 1979b. A study of Canadian diffuse and total solar radiation data-II monthly average hourly horizontal radiation. Solar Energy, 22(1): 87-90.

lqbal M. 1980. Prediction of hourly diffuse solar radiation from measured hourly global radiation on a horizontal surface. Solar Energy, 24(5): 491-503.

Iqbal M. 1983. An introduction to solar radiation. Academic Press, Toronto, Ontario.

Iqdour R, Zeroual A. 2007. The multi-layered perceptrons neural networks for the prediction of daily solar radiation. International Journal of Information and Communication Engineering, 3(1): 24-29. 
Islamoglu Y. 2003. A new approach for the prediction of the heat transfer rate of the wire-on-tube type heat exchanger-use of an artificial neural network model. Applied Thermal Engineering, 23(2): 243249.

Ismail KAR, Leal JFB, Zanardi MA. 1997. Models of liquid storage tanks. Energy, 22(8): 805-815.

Jack MW, Wrobel J. 2009. Thermodynamic optimization of a stratified thermal storage device. Applied Thermal Engineering, 29(11-12): 2344-2349.

Jacovides CP, Tymvios FS, Assimakopoulos VD, Kaltsounides NA. 2006. Comparative study of various correlations in estimating hourly diffuse fraction of global solar radiation. Renewable Energy, 31(15): 2492-2504.

Jaluria Y, O'Mara BT. 1989. Thermal field in a water body for solar energy storage and extraction due to a buoyant two-dimensional surface water jet. Solar Energy, 43(3): 129-138.

Jaluria Y, Gupta SK. 1982. Decay of thermal stratification in a water body for solar energy storage. Solar Energy, 28(2): 137-143.

Janjai S, Laksanaboonsong J, Nunez M, Thongsathitya A. 2005. Development of a method for generating operational solar radiation maps from satellite data for a tropical environment. Solar Energy, 78(6): 739751.

Jiménez Jl, Castro Y. 1982. Solar radiation on sloping surfaces with different orientations in Granada, Spain. Solar Energy, 28(3): 257-262.

Jiménez JI, Llebot JE, Casas-Vázquez J. 1977. Solar and diffuse radiation at Barcelona. Solar Energy, 19(6): 775-776.

Johannes K, Fraisse G, Achard G, Rusaouën G. 2005. Comparison of solar water tank storage modelling solutions. Solar Energy, 79(2): 216-218.

Jordan U, Vajen K. 2001. Influence of the DHW load profile on the fractional energy savings: A case study of a solar combi-system with TRNSYS simulations. Solar Energy, 69(Supplement 1-6): 197-208.

Jordan U, Furbo S. 2005. Thermal stratification in small solar domestic storage tanks caused by drawoffs. Solar Energy, 78(2): 291-300.

Kalogirou SA. 2003. Generation of typical meteorological year (TMY-2) for Nicosia, Cyprus. Renewable Energy, 28(15): 2317-2334.

Kalogirou SA. 2004. Solar thermal collectors and applications. Progress in Energy and Combustion Science, 30(3): 231-295.

Kalogirou SA. 2006. Prediction of flat-plate collector performance parameters using artificial neural networks. Solar Energy, 80(3): 248-259.

Kalogirou SA. 2009. Solar energy engineering: Processes and systems. Elsevier/Academic Press, Burlington, MA.

Kandari AM. 1990. Thermal stratification in hot storage-tanks. Applied Energy, 35(4): 299-315. 
Karatasou S, Santamouris M, Geros V. 2003. Analysis of experimental data on diffuse solar radiation in Athens, Greece, for building applications. International Journal of Sustainable Energy, 23(1-2): 1-11.

Kasten F, Czeplak G. 1980. Solar and terrestrial radiation dependent on the amount and type of cloud. Solar Energy, 24(2): 177-189.

Kays WM, London AL. 1984. Compact heat exchangers. McGraw-Hill, New York, NY.

Kazeminejad H. 2002. Numerical analysis of two dimensional parallel flow flat-plate solar collector. Renewable Energy, 26(2): 309-323.

Kemmoku Y, Orita S, Nakagawa S, Sakakibara T. 1999. Daily insolation forecasting using a multi-stage neural network. Solar Energy, 66(3): 193-199.

Kenjo L, Inard C, Caccavelli D. 2007. Experimental and numerical study of thermal stratification in a mantle tank of a solar domestic hot water system. Applied Thermal Engineering, 27(11-12): 1986-1995.

Khorasani K, Weng W. 1994. Structure adaptation in feedforward neural networks. Proceeding International Conference on Neural Networks, IEEE, 3: 1403-1408.

Klein SA, Cooper PI, Freeman TL, Beekman DM, Beckman WA, Duffie JA. 1975. A method of simulation of solar processes and its application. Solar Energy, 17(1): 29-37.

Klein SA. 1976. A design procedure for solar heating systems. Tesis Doctoral, University of WisconsinMadison.

Klein SA, Beckman WA, Duffie JA. 1976. A design procedure for solar heating systems. Solar Energy, 18(2): 113-127.

Klein SA. 1977. Calculation of monthly average insolation on tilted surfaces. Solar Energy, 19(4): 325329.

Klein SA, Beckman WA, Duffie JA. 1977. A design procedure for solar air heating systems. Solar Energy, 19(5): 509-512.

Klein SA. 1978. Calculation of flat-plate collector utilizability. Solar Energy, 21(5): 393-402.

Kleinbach EM, Beckman WA, Klein SA. 1993. Performance study of one-dimensional models for stratified thermal storage tanks. Solar Energy, 50(2): 155-166.

Kleissl J. 2013. Solar energy forecasting and resource assessment, $1^{\text {st }}$ ed. Elsevier/Academic Press, Oxford.

Klucher TM. 1979. Evaluation of models to predict insolation on tilted surfaces. Solar Energy, 23(2): 111114.

Knudsen S, Furbo S. 2004. Thermal stratification in vertical mantle heat-exchangers with application to solar domestic hot-water systems. Applied Energy, 78(3): 257-272.

Kohonen T. 1989. Self-organization and associative memory. Springer-Verlag, New York, NY. 
Kondratyev KJ, Manolova MP. 1960. The radiation balance of slopes. Solar Energy, 4(1): 14-19.

Kondratyev KY. 1969. Radiation in the atmosphere. Academic Press, New York, NY.

Kong W, Wang Z, Fan J, Bacher P, Perers B, Chen Z, Furbo S. 2012. An improved dynamic test method for solar collectors. Solar Energy, 86(6): 1838-1848.

Kreith F. 1978. Review of solar heating design by the F-chart method. Solar Energy, 20(5): 439-440.

Kurita T. 1990. A method to determine the number of hidden units of three-layered neural networks by information criteria. Transactions of Institute of Electronics, Information and Communication Engineers, J73-D-II-11: 1872-1878.

Lalot S, Pálsson H. 2010. Detection of fouling in a cross-flow heat exchanger using a neural network based technique. International Journal of Thermal Sciences, 49(4): 675-679.

Lapedes A, Farber R. 1988. Nonlinear signal processing using neural networks: Prediction and system modelling. Technical Report LA-UR-87-2662, Los Alamos, NM.

Lapesa Grupo Empresarial SL. 2006. Catálogo técnico serie coral vitro. Zaragoza.

Laughton C. 2010. Solar domestic water heating: The earthscan expert handbook for planning, design and installation, $1^{\text {st }}$ ed, Earthscan, London.

Lavan Z, Thompson J. 1977. Experimental study of thermally stratified hot water storage tanks. Solar Energy, 19(5): 519-524.

Lecoeuche S, Lalot S, Desmet B. 2005. Modelling a non-stationary single tube heat exchanger using multiple coupled local neural networks. International Communications in Heat and Mass Transfer, 32(7): 913-922.

Lefèvre M, Wald L, Diabaté L. 2007. Using reduced data sets ISCCP-B2 from the Meteosat satellites to assess surface solar irradiance. Solar Energy, 81(2): 240-253.

Lek S, Guégan JF. 1999. Artificial neural networks as a tool in ecological modelling, an introduction. Ecological Modelling, 120(2-3): 65-73.

Linacre E. 1992. Climate data and resources: A reference and guide. Routledge, London.

Lippmann RP. 1987. An introduction to computing with neural nets. ASSP Magazine, IEEE, April: 4-22.

Liu BYH, Jordan RC. 1960. The interrelationship and characteristic distribution of direct, diffuse and total solar radiation. Solar Energy, 4(3): 1-19.

Liu BYH, Jordan RC. 1961. Daily insolation on surfaces tilted towards the equator. ASHRAE Journal, 3: 5359.

Liu BYH, Jordan RC. 1962. Daily insolation on surfaces tilted toward the equator. Transactions ASHRAE: 526-541. 
Liu BYH, Jordan RC. 1963. The long-term average performance of flat-plate solar-energy collectors: With design data for the U.S., its outlying possessions and Canada. Solar Energy, 7(2): 53-74.

Ljung L. 1987. System identification theory for the user. Prentice-Hall, Englewood Cliffs, NJ.

Loehrke RI, Holzer JC, Gari HN, Sharp MK. 1979. Stratification enhancement in liquid thermal storage tanks. Journal of Energy, 3: 129-130.

López F, Segador C, Encinas D, Cosme JM, Cuadros L. Valencia. 2012. Monitorización de parámetros de funcionamiento de una instalación solar térmica para una residencia universitaria. XVI Congreso Internacional de Ingeniería de Proyectos, Valencia, 11-13 Julio: 1304-1315.

López G, Batlles FJ, Tovar-Pescador J. 2005. Selection of input parameters to model direct solar irradiance by using artificial neural networks. Energy, 30(9): 1675-1684.

Loutzenhiser PG, Manz H, Felsmann C, Strachan PA, Frank T, Maxwell GM. 2007. Empirical validation of models to compute solar irradiance on inclined surfaces for building energy simulation. Solar Energy, 81(2): 254-267.

Lund PD. 1988. Effect of storage thermal behavior in seasonal storage solar heating systems. Solar Energy, 40(3): 249-258.

Ma CCY, Iqbal M. 1983. Statistical comparison of models for estimating solar radiation on inclined surfaces. Solar Energy, 31(3): 313-317.

Ma CCY, Iqbal M. 1984. Statistical comparison of solar radiation correlations monthly average global and diffuse radiation on horizontal surfaces. Solar Energy, 33(2): 143-148.

Madhlopa A, Mgawi R, Taulo J. 2006. Experimental study of temperature stratification in an integrated collector-storage solar water heater with two horizontal tanks. Solar Energy, 80(8): 989-1002.

Mahmoud E. 1984. Accuracy in forecasting: A survey. Journal of Forecasting, 3: 139-159.

Mandurino C. 2009. I dati meteorologici per applicazioni energetiche e ambientali. Tesis Doctoral, Università di Bologna.

Marks RJ. 1993. Intelligence: Computational versus artificial. Transactions on Neural Networks, IEEE, 4(5): 737-739.

Martín J. 2003. El tiempo y el clima. Rubes, Barcelona.

Martín L, Zarzalejo LF, Polo J, Navarro A, Marchante R, Cony M. 2010. Prediction of global solar irradiance based on time series analysis: Application to solar thermal power plants energy production planning. Solar Energy, 84(10): 1772-1781.

Martínez MA. 2010. Aportaciones a la instrumentación electrónica en la optimización de sistemas basados en energía solar. Tesis Doctoral, Universidad de Huelva.

Martins FR, Pereira EB, Abreu SL. 2007. Satellite-derived solar resource maps for Brazil under SWERA project. Solar Energy, 81(4): 517-528. 
Mather DW, Hollands KGT, Wright JL. 2002. Single- and multi-tank energy storage for solar heating systems: Fundamentals. Solar Energy, 73(1): 3-13.

Matuska T, Zmrhal V, Metzger J. 2009. Detailed modeling of solar flat-plate collectors with design tool kolektor 2.2. $11^{\text {th }}$ International IBPSA, Conference Building Simulation, Glasgow, Scotland, July 27-30: 2289-2296.

Mavros P, Belessiotis V, Haralambopoulos D. 1994. Stratified energy storage vessels: Characterization of performance and modeling of mixing behavior. Solar Energy, 52(4): 327-336.

McCulloch WS, Pitts W. 1943. A logical calculus of the ideas immanent in nervous activity. Bulletin of Mathematical Biophysics, 5: 115-133.

McNees SK. 1985. Which forecast should you use? New England Economic Review, July/August: 36-42.

Mellit A, Benghanem M, Arab AH, Guessoum A. 2005. A simplified model for generating sequences of global solar radiation data for isolated sites: Using artificial neural network and a library of Markov transition matrices approach. Solar Energy, 79(5): 469-482.

Mellit A, Benghanem M, Kalogirou SA. 2006. An adaptive wavelet-network model for forecasting daily total solar-radiation. Applied Energy, 83(7): 705-722.

Mellit A. 2008. Artificial intelligence technique for modelling and forecasting of solar radiation data: A review. International Journal of Artificial Intelligence and Soft Computing, 1(1): 52-76.

Mellit A, Kalogirou SA, Shaari S, Salhi H, Hadj Arab A. 2008. Methodology for predicting sequences of mean monthly clearness index and daily solar radiation data in remote areas: Application for sizing a stand-alone PV system. Renewable Energy, 33(7): 1570-1590.

Mellit A, Eleuch H, Benghanem M, Elaoun C, Pavan AM. 2010. An adaptive model for predicting of global, direct and diffuse hourly solar irradiance. Energy Conversion and Management, 51(4): 771-782.

Mellit A, Pavan AM. 2010. A 24-h forecast of solar irradiance using artificial neural network: Application for performance prediction of a grid-connected PV plant at Trieste, Italy. Solar Energy, 84(5): 807-821.

Meteoclimatic. Sitio web: http://www.meteoclimatic.com.

Miguel A, Bilbao J, Aguiar R, Kambezidis H, Negro E. 2001. Diffuse solar irradiation model evaluation in the North Mediterranean Belt area. Solar Energy, 70(2): 143-153.

Miguel A, Bilbao J. 2005. Test reference year generation from meteorological and simulated solar radiation data. Solar Energy, 78(6): 695-703.

Mihalakakou G, Santamouris M, Asimakopoulos DN. 2000. The total solar radiation time series simulation in Athens, using neural networks. Theoretical and Applied Climatology, 66(3): 185-197.

Minsky ML, Papert S. 1988. Perceptrons: An introduction to computational geometry. MIT Press, Cambridge, MA. 
Moghaddamnia A, Remesan R, Kashani MH, Mohammadi M, Han D, Piri J. 2009. Comparison of LLR, MLP, Elman, NNARX and ANFIS Models-with a case study in solar radiation estimation. Journal of Atmospheric and Solar-Terrestrial Physics, 71(8-9): 975-982.

Mohandes M, Rehman S, Halawani TO. 1998. Estimation of global solar radiation using artificial neural networks. Renewable Energy, 14(1-4): 179-184.

Mohandes M, Balghonaim A, Kassas M, Rehman S, Halawani TO. 2000. Use of radial basis functions for estimating monthly mean daily solar radiation. Solar Energy, 68(2): 161-168.

Mora L. 1994. Caracterización y generación de series de exposición horaria de radiación global. Tesis Doctoral. Universidad Complutense de Madrid.

Mora L, Sidrach de Cardona M. 1997. Characterization and simulation of hourly exposure series of global radiation. Solar Energy, 60(5): 257-270.

Mora L, Sidrach M. 1998. Multiplicative ARMA models to generate hourly series of global irradiation. Solar Energy, 63(5): 283-291.

Moriarty WW. 1991. Estimation of diffuse from measured global solar radiation. Solar Energy, 47(2): 7582.

Morrison GL, Nasr A, Behnia M, Rosengarten G. 1998. Analysis of horizontal mantle heat exchangers in solar water heating systems. Solar Energy, 64(1-3): 19-31.

Mosalam MA, Tadros MTY. 1994. Typical solar radiation year for Egypt. Renewable Energy, 4(4): 387393.

Moser W, Rachke E. 1984. Incident solar radiation over Europe from METEOSAT data. Journal of Climate and Applied Meteorology, 23: 166-170.

Moser W, Raschke E. 1983. Mapping of global radiation and of cloudiness from METEOSAT image data. Theory and ground truth comparisons. Meteorologische Rundschau, 36: 33-41.

Mubiru J. 2008. Predicting total solar irradiation values using artificial neural networks. Renewable Energy, 33(10): 2329-2332.

Mueller RW, Dagestad KF, Ineichen P, Schroedter-Homscheidt M, Cros S, Dumortier D, Kuhlemann R, Olseth JA, Piernavieja G, Reise C, et al. 2004. Rethinking satellite-based solar irradiance modelling: The SOLIS clear-sky module. Remote Sensing of Environment, 91(2): 160-174.

Muneer T, Munawwar S. 2006. Potential for improvement in estimation of solar diffuse irradiance. Energy Conversion and Management, 47(1): 68-86.

Muneer T, Gueymard C, Kambezidis H. 2004. Solar radiation and daylight models, $2^{\text {nd }}$ ed. Elsevier/Butterworth-Heinemann, Amsterdam.

Murthy SS, Nelson JEB, Rao TLS. 1992. Effect of wall conductivity on thermal stratification. Solar Energy, 49(4): 273-277. 
Mustacchi C, Cena V, Rocchi M. 1979. Stochastic simulation of hourly global radiation sequences. Solar Energy, 23(1): 47-51.

Mutch JJ. 1974. Residential water heating: Fuel conservation, economics and public policy. R-1498-NSF, Santa Mónica, CA.

Nelson JEB, Balakrishnan AR, Murthy SS. 1998. Transient analysis of energy storage in a thermally stratified water tank. International Journal of Energy Research, 22(10): 867-883.

Nelson JEB, Balakrishnan AR, Srinivasa S. 1999a. Parametric studies on thermally stratified chilled water storage systems. Applied Thermal Engineering, 19(1): 89-115.

Nelson JEB, Balakrishnan AR, Srinivasa S. 1999b. Experiments on stratified chilled-water tanks: Expériences menées avec des reservoirs d'accumulation d'eau glacée à stratification. International Journal of Refrigeration, 22(3): 216-234.

Noia M, Ratto CF, Festa R. 1993a. Solar irradiance estimation from geostationary satellite data: I. Statistical models. Solar Energy, 51(6): 449-456.

Noia M, Ratto CF, Festa R. 1993b. Solar irradiance estimation from geostationary satellite data: II. Physical models. Solar Energy, 51(6): 457-465.

Norris DJ. 1966. Solar radiation on inclined surfaces. Solar Energy, 10(2): 72-76.

Nunez M. 1993. The development of a satellite-based insolation model for the tropical western Pacific Ocean. International Journal of Climatology, 13(6): 607-627.

Oladiran MT. 1994. Total solar radiation received at various collector inclinations. Applied Energy, 48(2): 149-161.

Oliveira AP, Escobedo JF, Machado AJ, Soares J. 2002. Correlation models of diffuse solar-radiation applied to the city of São Paulo, Brazil. Applied Energy, 71(1): 59-73.

Oliveira KA, Vannucci Á, da Silva EC. 2000. Using artificial neural networks to forecast chaotic time series. Physica A: Statistical Mechanics and its Applications, 284(1-4): 393-404.

Oliveski RDC, Krenzinger A, Vielmo HA. 2003. Cooling of cylindrical vertical tanks submitted to natural internal convection. International Journal of Heat and Mass Transfer, 46(11): 2015-2026.

Oppel FJ, Ghajar AJ, Moretti PM. 1986. Computer simulation of stratified heat storage. Applied Energy, 23(3): 205-224.

Orgill JF, Hollands KGT. 1977. Correlation equation for hourly diffuse radiation on a horizontal surface. Solar Energy, 19(4): 357-359.

Pacheco-Vega A. 2002. Simulation of compact heat exchangers using global regression and soft computing. Tesis Doctoral, University of Notre Dame.

Pacheco-Vega A, Sen M, Yang KT. 2003. Simultaneous determination of in- and over-tube heat transfer correlations in heat exchangers by global regression. International Journal of Heat and Mass Transfer, 46(6): 1029-1040. 
Padovan A, Del Col D. 2010. Measurement and modeling of solar irradiance components on horizontal and tilted planes. Solar Energy, 84(12): 2068-2084.

Page JK. 1964. The estimation of monthly mean values of daily total short-wave radiation of vertical and inclined surfaces from sunshine records for latitudes $40^{\circ} \mathrm{N}-40^{\circ} \mathrm{S}$. Proceedings of the United Nations, Conference on New Sources of Energy, 4: 378.

Palit AK, Popovic D. 2005. Computational intelligence in time series forecasting: Theory and engineering applications. Springer, London.

Panthalookaran V, Heidemann W, Müller-Steinhagen H. 2007. A new method of characterization for stratified thermal energy stores. Solar Energy, 81(8): 1043-1054.

Paoli C, Voyant C, Muselli M, Nivet M. 2010. Forecasting of preprocessed daily solar radiation time series using neural networks. Solar Energy, 84(12): 2146-2160.

Parker BD. 1985. Learning logic. MIT, Cambridge, MA.

Pattanasethanon S, Lertsatitthanakorn C, Atthajariyakul S, Soponronnarit S. 2008. An accuracy assessment of an empirical sine model, a novel sine model and an artificial neural network model for forecasting illuminance/irradiance on horizontal plane of all sky types at Mahasarakham, Thailand. Energy Conversion and Management, 49(8): 1999-2005.

Paulescu M. 2008. Solar radiation via air temperature data. En: Badescu V. Modeling solar radiation at the earth's surface. Springer, Berlin.

Peng $\mathrm{H}$, Ling X. 2008. Optimal design approach for the plate-fin heat exchangers using neural networks cooperated with genetic algorithms. Applied Thermal Engineering, 28(5-6): 642-650.

Peng H, Ling X. 2009. Neural networks analysis of thermal characteristics on plate-fin heat exchangers with limited experimental data. Applied Thermal Engineering, 29(11-12): 2251-2256.

Pereira EB, Martins FR, Abreu SL, Couto P, Stuhlmann R, Colle S. 2000. Effects of burning of biomass on satellite estimations of solar irradiation in Brazil. Solar Energy, 68(1): 91-107.

Perez R, Seals R, Ineichen P, Stewart R, Menicucci D. 1987. A new simplified version of the Perez diffuse irradiance model for tilted surfaces. Solar Energy, 39(3): 221-231.

Perez R, Ineichen P, Seals R, Michalsky J, Stewart R. 1990. Modeling daylight availability and irradiance components from direct and global irradiance. Solar Energy, 44(5): 271-289.

Perez R, Seals R, Zelenka A. 1997. Comparing satellite remote sensing and ground network measurements for the production of site/time specific irradiance data. Solar Energy, 60(2): 89-96.

Perez R, Ineichen P, Moore K, Kmiecik M, Chain C, George R, Vignola F. 2002. A new operational model for satellite-derived irradiances: Description and validation. Solar Energy, 73(5): 307-317.

Perez R, Ineichen P, Kmiecik M, Moore K, Renne D, George R. 2004. Producing satellite-derived irradiances in complex arid terrain. Solar Energy, 77(4): 367-371. 
Peuser FA, Remmers K, Schnauss M. 2002. Solar thermal systems: Successful planning and construction. Solarpraxis, Berlin.

Phillips WF. 1981. Effects of stratification on the performance of solar air heating systems. Solar Energy, 26(2): 175-180.

Phillips WF, Dave RN. 1982. Effects of stratification on the performance of liquid-based solar heating systems. Solar Energy, 29(2): 111-120.

Pinker R, Laszlo I. 1995. Modelling surface solar irradiance for satellite applications on a global scale. Journal of Applied Meteorology, 31: 194-211.

Pissimanis D, Karras G, Notaridou V, Gavra K. 1988. The generation of a "typical meteorological year" for the city of Athens. Solar Energy, 40(5): 405-411.

Polo J. 2008. Solar radiation derived from satellite images. En: Badescu V. Modeling solar radiation at the earth's surface. Springer, Berlin.

POLYSUN. 2008. Manual programa. Vela Solaris, Winterthur, Zúrich.

Popovic D, Bhatkar VP. 1994. Methods and tools for applied artificial intelligence. Marcel Dekker Inc, New York, NY.

Posadillo R, López R. 2009. Hourly distributions of the diffuse fraction of global solar irradiation in Córdoba (Spain). Energy Conversion and Management, 50(2): 223-231.

Posadillo R, López R. 2010. The generation of hourly diffuse irradiation: A model from the analysis of the fluctuation of global irradiance series. Energy Conversion and Management, 51(4): 627-635.

Prescott JA. 1940. Evaporation from a water surface in relation to solar radiation. Transactions of the Royal Society of South Australia, 64: 114-125.

Radhakrishnan VR, Ramasamy M, Zabiri H, Do Thanh V, Tahir NM, Mukhtar H, Hamdi MR, Ramli N. 2007. Heat exchanger fouling model and preventive maintenance scheduling tool. Applied Thermal Engineering, 27(17-18): 2791-2802.

Ragab FM, Som AK. 1991. Correlation between estimated and measured hourly and daily solar fluxes over Bahrain. Applied Energy, 40(2): 83-99.

Rahimikhoob A. 2010. Estimating global solar radiation using artificial neural network and air temperature data in a semi-arid environment. Renewable Energy, 35(9): 2131-2135.

Rahman IA, Dewsbury J. 2007. Selection of typical weather data (test reference years) for Subang, Malaysia. Building and Environment, 42(10): 3636-3641.

Reddy KS, Ranjan M. 2003. Solar resource estimation using artificial neural networks and comparison with other correlation models. Energy Conversion and Management, 44(15): 2519-2530.

Reindl DT, Beckman WA, Duffie JA. 1990a. Diffuse fraction correlations. Solar Energy, 45(1): 1-7. 
Reindl DT, Beckman WA, Duffie JA. 1990b. Evaluation of hourly tilted surface radiation models. Solar Energy, 45(1): 9-17.

Remund J, Salvisberg E, Kunz S. 1998. On the generation of hourly shortwave radiation data on tilted surfaces. Solar Energy, 62(5): 331-344.

Ridley B, Boland J, Lauret P. 2010. Modelling of diffuse solar fraction with multiple predictors. Renewable Energy, 35(2): 478-483.

Rigollier C, Bauer O, Wald L. 2000. On the clear sky model of the ESRA - European Solar Radiation Atlas - with respect to the heliosat method. Solar Energy, 68(1): 33-48.

Rigollier C, Lefèvre M, Wald L. 2004. The method Heliosat-2 for deriving shortwave solar radiation from satellite images. Solar Energy, 77(2): 159-169.

Robinson R. 1966. Solar radiation. Elseiver, New York, NY.

Rodríguez C. 2000. Análisis de series temporales. La Muralla, Madrid.

Rodríguez-Hidalgo MC, Rodríguez-Aumente PA, Lecuona A, Gutiérrez-Urueta GL, Ventas R. 2011a. Flat plate thermal solar collector efficiency: Transient behavior under working conditions. Part II: Model application and design contributions. Applied Thermal Engineering, 31(14-15): 2385-2393.

Rodríguez-Hidalgo MC, Rodríguez-Aumente PA, Lecuona A, Gutiérrez-Urueta GL, Ventas R. 2011b. Flat plate thermal solar collector efficiency: Transient behavior under working conditions. Part I: Model description and experimental validation. Applied Thermal Engineering, 31(14-15): 2394-2404.

Roetzel W, Xuan Y. 1999. Dynamic behaviour of heat exchangers. Wit Press, Boston, MA.

Rojas D, Beermann J, Klein SA, Reindl DT. 2008. Thermal performance testing of flat-plate collectors. Solar Energy, 82(8): 746-757.

Rosen MA. 2001. The exergy of stratified thermal energy storages. Solar Energy, 71(3): 173-185.

Rosen MA, Tang R, Dincer I. 2004. Effect of stratification on energy and exergy capacities in thermal storage systems. International Journal of Energy Research, 28: 177-193.

Rosenblatt F. 1958. The perceptron: A probabilistic model for information storage and organization in the brain. Psychological Review, 65: 386-408.

Rosenblatt F. 1962. Principles of neurodynamics: Perceptrons and the theory of brain mechanisms. Spartan Books, Washington DC.

Ruffing SM, Venayagamoorthy GK. 2009. Short to medium range time series prediction of solar irradiance using an echo state network. $15^{\text {th }}$ International Conference on Intelligent System Applications to Power Systems ISAP'09, Curitiba, Brazil, November 8-12: 1-6.

Ruíz MM. 2004. Aplicación de la dinámica de fluidos computacional al control de las mermas de vino en naves de crianza climatizadas. Tesis Doctoral, Universidad de La Rioja. 
Ruíz-Arias JA, Alsamamra H, Tovar-Pescador J, Pozo-Vázquez D. 2010. Proposal of a regressive model for the hourly diffuse solar radiation under all sky conditions. Energy Conversion and Management, 51(5): 881-893.

Rumelhart DE, McClelland JL. 1986. Parallel distributed processing: Explorations in the microstructure of cognition. MIT Press, Cambridge, MA.

Said SAM, Kadry HM. 1994. Generation of representative weather-Year data for Saudi Arabia. Applied Energy, 48(2): 131-136.

Santabàrbara JM, Calbó J, Baldasano JM, Esteve J, Mitjà A. 1996. Month-to-month variation of global solar radiation in Catalonia (Spain). International Journal of Climatology, 16(6): 711-721.

Schillings C, Mannstein H, Meyer R. 2004a. Operational method for deriving high resolution direct normal irradiance from satellite data. Solar Energy, 76(4): 475-484.

Schillings C, Meyer R, Mannstein H. 2004b. Validation of a method for deriving high resolution direct normal irradiance from satellite data and application for the Arabian Peninsula. Solar Energy, 76(4): 485497.

Schmetz J. 1989. Towards a surface radiation climatology: Retrieval of downward irradiances from satellites. Atmospheric Research, 23(3-4): 287-321.

Seme S, Štumberger G, Pihler J. 2009. Predicting daily distribution of solar irradiation by neural networks. International Conference on Renewable Energies and Power Quality ICREPQ'09, Valencia, April 15-17: 275.

Sen Z. 1998. Fuzzy algorithm for estimation of solar irradiation from sunshine duration. Solar Energy, 63(1): 39-49.

Sen M, Yang KT. 2000. 4.24 Applications of artificial neural networks and genetic algorithms in thermal engineering. En: Kreith F. The CRC handbook of thermal engineering. CRC Press, Boca Raton, FL.

Sfeir AA. 1980. A stochastic model for predicting solar system performance. Solar Energy, 25(2): 149154.

Sfeir AA. 1981. Solar radiation in Lebanon. Solar Energy, 26(6): 497-502.

Sfetsos A, Coonick AH. 2000. Univariate and multivariate forecasting of hourly solar radiation with artificial intelligence techniques. Solar Energy, 68(2): 169-178.

Shah A, Kaushik SC, Garg SN. 2009. Assessment of diffuse solar energy under general sky condition using artificial neural network. Applied Energy, 86(4): 554-564.

Shah LJ. 1999. Investigation and modeling of thermal conditions in low flow SDHW systems. Tesis Doctoral, Report R-034, Department of Buildings and Energy, Technical University of Denmark.

Shah L, Furbo S. 2003. Entrance effects in solar storage tanks. Solar Energy, 75(4): 337-348.

Sharda R, Patil RB. 1990. Neural networks as forecasting experts: An empirical test. Proceedings of the International Joint Conference on Neural Networks, IJCNN: 491-494. 
Shi S, Liu B. 1993. Nonlinear combination of forecasts with neural networks. Proceedings of International Joint Conference on Neural Networks, IJCNN: 952-962.

Shin M, Kim H, Jang D, Lee S, Lee $Y$, Yoon H. 2004. Numerical and experimental study on the design of a stratified thermal storage system. Applied Thermal Engineering, 24(1): 17-27.

Silió DS, Renedo JCE, Castañera VH. 2007. Eficiencia en instalaciones fototérmicas de colectores planos: Influencia del grado de estratificación en el tanque acumulador. Era Solar, 139: 18-21.

Siqueira AN, Tiba C, Fraidenraich N. 2010. Generation of daily solar irradiation by means of artificial neural networks. Renewable Energy, 35(11): 2406-2414.

Skaggs RH, Baker DG, Ljungkull JE. 1982. The influence of persistence and variability on the required solar radiation record length. Solar Energy, 28(4): 281-287.

Skeiker K. 2004. Generation of a typical meteorological year for Damascus zone using the FilkensteinSchafer statistical method. Energy Conversion and Management, 45(1): 99-112.

Skeiker K. 2006. Correlation of global solar radiation with common geographical and meteorological parameters for Damascus province, Syria. Energy Conversion and Management, 47(4): 331-345.

Skeiker K. 2007. Comparison of methodologies for TMY generation using 10 years data for Damascus, Syria. Energy Conversion and Management, 48(7): 2090-2102.

Skeiker K, Ghani BA. 2008. Advanced software tool for the creation of a typical meteorological year. Energy Conversion and Management, 49(10): 2581-2587.

Skeiker K. 2009. Optimum tilt angle and orientation for solar collectors in Syria. Energy Conversion and Management, 50(9): 2439-2448.

Skeiker K, Ghani BA. 2009. A software tool for the creation of a typical meteorological year. Renewable Energy, 34(3): 544-554.

Soares J, Oliveira AP, Božnar MZ, Mlakar P, Escobedo JF, Machado AJ. 2004. Modeling hourly diffuse solar-radiation in the city of São Paulo using a neural-network technique. Applied Energy, 79(2): 201214.

Sorapipatana C, Exell RHB. 1989. Mesoscale mapping of daily insolation over Southest Asia from satellite data. Solar \& Wind Technology, 6(1): 59-69.

Sorapipatana C, Exell RH, Borel D. 1988. A bispectral method for determining global solar radiation from meteorological satellite data. Solar \& Wind Technology, 5(3): 321-327.

Sözen A, Arcaklioglu E, Özalp M. 2004. Estimation of solar potential in turkey by artificial neural networks using meteorological and geographical data. Energy Conversion and Management, 45(18-19): 3033-3052.

Sözen A, Menlik T, Ünvar S. 2008. Determination of efficiency of flat-plate solar collectors using neural network approach. Expert Systems with Applications, 35(4): 1533-1539. 
Specht DF. 1988. Probabilistic neural networks for classification, or associative memory. Proceedings of International Conference on Neural Networks, IEEE 1: 525-532.

Srivastava SK, Gaur A, Singh OP, Tiwari RN. 1995. Comparison of methods for estimating daily and hourly diffuse solar radiation. Applied Energy, 51(2): 119-123.

Stanhill G. 1966. Diffuse sky and cloud radiation in Israel. Solar Energy, 10(2): 96-101.

Stone M. 1977. An asymptotic equivalence of choice of model by cross-validation and Akaike's criterion cross validation. Journal of the Royal Statistical Society, B36: 44-47.

Supit I, van Kappel RR. 1998. A simple method to estimate global radiation. Solar Energy, 63(3): 147-160.

Systemtronic SL. 2010. Catálogo técnico: Maleta test para supervisión de instalaciones de energía solar térmica. Castelldefels, Barcelona.

Takama SL. 2006. Catálogo técnico colector solar Takama T3-inox. Lleida.

Tang Z, Almeida C, Fishwick PA. 1991. Time series forecasting using neural networks vs. Box-Jenkins methodology. Simulation, 57(5): 303-310.

Tan CK, Ward J, Wilcox SJ, Payne R. 2009. Artificial neural network modelling of the thermal performance of a compact heat exchanger. Applied Thermal Engineering, 29(17-18): 3609-3617.

Tarpley J. 1979. Estimating incident solar radiation at the surface from geostationary satellite data. Journal of Applied Meteorology 18: 1172-1181.

Temps RC, Coulson KL. 1977. Solar radiation incident upon slopes of different orientations. Solar Energy, 19(2): 179-184.

Torres JL, de Blas M, García A, de Francisco A. 2010. Comparative study of various models in estimating hourly diffuse solar irradiance. Renewable Energy, 35(6): 1325-1332.

TRNSYS. 2013. TRNSYS 17: A TRaNsient SYstem simulation program. University of Wisconsin-Madison.

Tsilingiris PT. 1996. Solar water-heating design-A new simplified dynamic approach. Solar Energy, 57(1): 19-28.

Tuller SE. 1976. The relationship between diffuse, total and extra terrestrial solar radiation. Solar Energy, 18(3): 259-263.

Tymvios FS, Jacovides CP, Michaelides SC, Scouteli C. 2005. Comparative study of Ångström's and artificial neural networks' methodologies in estimating global solar radiation. Solar Energy, 78(6): 752762.

Vasičkaninová A, Bakošová M, Mészáros A, Klemeš JJ. 2011. Neural network predictive control of a heat exchanger. Applied Thermal Engineering, 31(13): 2094-2100.

Vergara L, Garcia R, Figueiras AR, Casar J, Casajus FJ. 1985. Automatic modelling and simulation of daily global solar radiation series. Solar Energy, 35(6): 483-489. 
Vignola F, Harlan P, Perez R, Kmiecik M. 2007. Analysis of satellite derived beam and global solar radiation data. Solar Energy, 81(6): 768-772.

Villiers J, Barnard E,. 1992. Backpropagation neural nets with one and two hidden layers. Transactions on Neural Networks, IEEE: 136-141.

Wagner S. 2009. 400 preguntas: Resuelva sus dudas sobre energía solar térmica. Era Solar, 153: 58-72.

Wald L, Albuisson M, Best C, Delamare C, Gaboardi E, Hammer A, Heinemann D, Kift R. 2002. SoDa: A project for the integration and exploitation of networked solar radiation databases. Environmental Communication in the Information Society, Viena.

Wald L, Albuisson M, Best C, Delamare C, Dumortier D, Gaboardi E, Hammer A. 2004. SoDa: A web service on solar radiation. Eurosun Congress, International Solar Energy Society ISES, Freiburg, June 2024.

Wang BW. 2008. Solar collector thermal performance dynamic test. Tesis Doctoral, Institute of Electrical Engineering, Chinese Academy of Sciences.

WATSUN. 1996. Manual programa. Natural Resources Canada, Canada.

Watts Industries Ibérica SA. 2006. Catálogo técnico válvulas de seguridad. Rubí, Barcelona.

Werbos PJ. 1974. Beyond regression: New tool for prediction and analysis in the behavioural sciences. Tesis Doctoral, Harvard University.

Werbos PJ. 1989. Backpropagation and neural control: A review and prospectus. Proceedings International Joint Conference of Neural Networks, IJCNN, 1: 209-216.

Werbos PJ. 1990. Backpropagation through time: What it does and how to do it. Proceedings of IEEE, 78(10): 1550-1560.

Whillier A. 1953. Solar energy collection and its utilization for house heating. Tesis Doctoral, Department of Mechanical Engineering, Massachusetts Institute of Technology.

Whillier A. 1964. Thermal resistance of the tube-plate bond in solar heat collectors. Solar Energy, 8(3): 95-98.

Whitten KW, Gailey KD. 1987. Química general, $2^{\text {nd }}$ ed. Interamericana, México.

Widrow B, Hoff ME. 1960. Adaptive switching circuits. En: Anderson J, Rosenfeld E. Neurocomputing. MIT Press, Cambridge, MA.

Wilks DS. 2006. Statistical methods in the atmospheric sciences. International geophysics, vol $91,2^{\text {nd }}$ ed. Elsevier Science \& Technology, Amsterdam.

Wilo Ibérica SA. 2006. Catálogo técnico serie star-RS classic. Alcalá de Henares, Madrid.

Winkler R, Makridakis S. 1983. The combination of forecasts. Journal of the Royal Statistical Society, Series A: 150-157. 
Winter F. 1975. Heat exchanger penalties in double-loop solar water heating systems. Solar Energy, 17(6): 335-337.

Wolf D, Sembira AN, Kudish Al. 1984. Dynamic simulation and parametric sensitivity studies on a central solar domestic hot water system. Energy, 9(2): 169-181.

Wong LT, Chow WK. 2001. Solar radiation model. Applied Energy, 69(3): 191-224.

Wyser K, O'Hirok W, Gautier C, Jones C. 2002. Remote sensing of surface solar irradiance with corrections for 3-D cloud effects. Remote Sensing of Environment, 80(2): 272-84.

Xie GN, Wang QW, Zeng M, Luo LQ. 2007. Heat transfer analysis for shell-and-tube heat exchangers with experimental data by artificial neural networks approach. Applied Thermal Engineering, 27(5-6): 10961104.

Xu L. 2009. Research on dynamic test method for thermal performance of solar collectors. Master Tesis Northeast University.

Yang L, Lam J, Liu J. 2007. Analysis of typical meteorological years in different climates of china. Energy Conversion and Management, 48(2): 654-668.

Yang L, Lam J, Liu J, Tsang CL. 2008. Building energy simulation using multi-years and typical meteorological years in different climates. Energy Conversion and Management, 49(1): 113-124.

Yee CK, Lai FC. 2001. Effects of a porous manifold on thermal stratification in a liquid storage tank. Solar Energy, 71(4): 241-254.

Yoo H, Pak E. 1993. Theoretical model of the charging process for stratified thermal storage tanks. Solar Energy, 51(6): 513-519.

Yoo H, Kim C, Kim CW. 1999. Approximate analytical solutions for stratified thermal storage under variable inlet temperature. Solar Energy, 66(1): 47-56.

Zarzalejo LF, Ramirez L, Polo J. 2005. Artificial intelligence techniques applied to hourly global irradiance estimation from satellite-derived cloud index. Energy, 30(9): 1685-1697.

Zelenka A, Perez R, Seals R, Renne D. 1999. Effective accuracy of satellite-derived hourly irradiances. Theoretical and Applied Climatology, 62(3-4): 199-207.

Zelenka A. 1986. Satellite versus ground observation based model for global irradiation. INTERSOL 85, Proceedings of the Ninth Biennial Congress of the International Solar Energy Society, Montreal, June 2329: 2513-2517.

Zervas PL, Sarimveis H, Palyvos JA, Markatos NCG. 2008. Prediction of daily global solar irradiance on horizontal surfaces based on neural-network techniques. Renewable Energy, 33(8): 1796-1803.

Zurigat YH, Ghajar AJ, Moretti PM. 1988. Stratified thermal storage tank inlet mixing characterization. Applied Energy, 30(2): 99-111. 